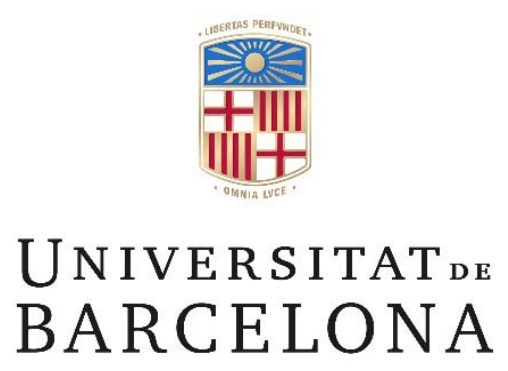

\title{
Lexicon of the Phrygian Inscriptions
}

\author{
Bartomeu Obrador Cursach
}

ADVERTIMENT. La consulta d'aquesta tesi queda condicionada a l'acceptació de les següents condicions d'ús: La difusió d'aquesta tesi per mitjà del servei TDX (www.tdx.cat) i a través del Dipòsit Digital de la UB (diposit.ub.edu) ha estat autoritzada pels titulars dels drets de propietat intel-lectual únicament per a usos privats emmarcats en activitats d'investigació i docència. No s'autoritza la seva reproducció amb finalitats de lucre ni la seva difusió i posada a disposició des d'un lloc aliè al servei TDX ni al Dipòsit Digital de la UB. No s'autoritza la presentació del seu contingut en una finestra o marc aliè a TDX o al Dipòsit Digital de la UB (framing). Aquesta reserva de drets afecta tant al resum de presentació de la tesi com als seus continguts. En la utilització o cita de parts de la tesi és obligat indicar el nom de la persona autora.

ADVERTENCIA. La consulta de esta tesis queda condicionada a la aceptación de las siguientes condiciones de uso: La difusión de esta tesis por medio del servicio TDR (www.tdx.cat) y a través del Repositorio Digital de la UB (diposit.ub.edu) ha sido autorizada por los titulares de los derechos de propiedad intelectual únicamente para usos privados enmarcados en actividades de investigación y docencia. No se autoriza su reproducción con finalidades de lucro ni su difusión y puesta a disposición desde un sitio ajeno al servicio TDR o al Repositorio Digital de la UB. No se autoriza la presentación de su contenido en una ventana o marco ajeno a TDR o al Repositorio Digital de la UB (framing). Esta reserva de derechos afecta tanto al resumen de presentación de la tesis como a sus contenidos. En la utilización o cita de partes de la tesis es obligado indicar el nombre de la persona autora.

WARNING. On having consulted this thesis you're accepting the following use conditions: Spreading this thesis by the TDX (www.tdx.cat) service and by the UB Digital Repository (diposit.ub.edu) has been authorized by the titular of the intellectual property rights only for private uses placed in investigation and teaching activities. Reproduction with lucrative aims is not authorized nor its spreading and availability from a site foreign to the TDX service or to the UB Digital Repository. Introducing its content in a window or frame foreign to the TDX service or to the UB Digital Repository is not authorized (framing). Those rights affect to the presentation summary of the thesis as well as to its contents. In the using or citation of parts of the thesis it's obliged to indicate the name of the author. 


\title{
Lexicon of the Phrygian Inscriptions
}

\author{
Bartomeu Obrador Cursach
}

Doctoral dissertation supervised and advised by

Prof. Dr. Ignasi-Xavier Adiego Lajara

in

Linguistic, Literary and Cultural Studies,

Cultures and Languages of the Ancient World and Their Lasting Presence

University of Barcelona, Faculty of Philology
Department of Classical, Romance and Semitic Philology

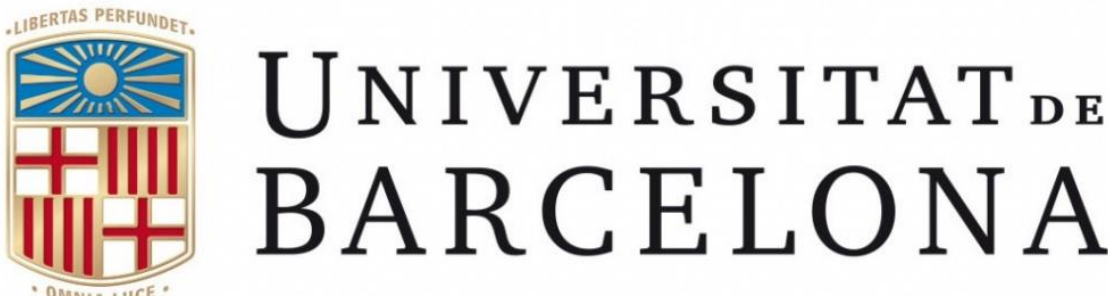

2018 

Als meus pares, Tomeu i Eulàlia, com a penyora de gratitud $i$ afecte pels capvespres de lectura als terrats. 



\begin{abstract}
Phrygian is a fragmentary Indo-European language recorded in inscriptions found mainly in central Anatolia, dated to between ca. $800 \mathrm{BC}$ and the $3^{\text {rd }}$ century AD. The main objective of this dissertation is to provide a comprehensive analysis of all the Phrygian words attested in these Phrygian inscriptions, using a dictionary structure. The result is an overview of the preserved Phrygian lexicon. Although the Phrygian texts are classified as belonging to one of three stages on the basis of chronology, linguistic features, script and contents (old Phrygian, Middle Phrygian and New Phrygian), the whole lexicon has been compiled in a single dictionary. Before dealing with the main objective, a catalogue of all the known Phrygian inscriptions was created. Although the Old Phrygian inscriptions were collected by Brixhe and Lejeune (with Brixhe's supplements), other inscriptions not considered in their corpus have been included here. An editio maior of the all New Phrygian inscriptions is still lacking and a complete catalogue was needed. Our work on the Phrygian language therefore began with the compilation of this catalogue. The middle stage of Phrygian is essentially attested by a single large epitaph, well edited by Brixhe. Consequently, this dissertation also offers a catalogue of the Phrygian inscriptions on which the study of the lexicon is based. Also addressed are the value of some letters of the Phrygian alphabet, used in the first stage of the language, and the segmentation of the inscriptions which employ scriptio continua. Once these preliminary problems have been dealt with, each segmented word is analysed, under one lemma when multiple forms are attested. Together with morphological analysis and examination of context, prior studies are corroborated by the current knowledge of Phrygian, when possible. Information from other fields such as Ancient Greek, the Anatolian languages and general IndoEuropean studies is also considered. Indeed, the comparative method is essential in this work, although context is constantly consulted in order to avoid purely etymological speculations. Innovative, personal contributions are often given, although many words remain unexplained because of the fragmentation of the inscriptions and the noteworthy abundance of hapax. After the detailed study of each word, a short grammar is built on the basis of the lexicon; this chapter is offered as an updated introduction to the Phrygian language.
\end{abstract}


El frigi és una llengua indoeuropea fragmentària documentada per inscripcions trobades al centre d'Anatòlia des d'aproximadament el 800 a.C. fins al s. III d.C. L'objectiu d'aquesta tesi doctoral és oferir una anàlisi completa de tots els mots documentats en aquestes inscripcions en forma de diccionari per a tenir una visió de conjunt del que s'ha preservat de la llengua frígia. Malgrat la divisió dels textos frigis en tres estadis prou diferenciats (paleofrigi, frigi mitjà i neofrigi) tant pel que fa a llur cronologia, trets lingüístics, com l'escriptura emprada i els continguts dels texts, tot el material ha estat distribuitt en un únic diccionari. Abans de procedir a aquest estudi, però, s'ha confeccionat un recopilació de totes les inscripcions conegudes. Si bé en el cas del paleofrigi aquest a feina fou feta de forma exemplar per Brixhe i Lejeune (i els suplements posteriors de Brixhe), s'han incorporat algunes altes inscripcions. Per altra banda, la situació de les inscripcions neofrígies era més precària per la manca d'un corpus actualitzat, motiu pel qual començàrem la nostra intervenció en aquest punt. L'estadi intermedi consisteix bàsicament en un llarg epitafi ben editat per Brixhe. El resultat és un catàleg crític de les inscripcions frígies (ofert a la mateixa tesi) que serveix de base per a l'estudi lexicogràfic. Altres dificultats prèvies encarades són el valor d'algunes lletres de l'alfabet frigi, emprat en el primer estadi de la llengua, i la segmentació de les mateixes inscripcions en què es fa ús de la scriptio continua. Una vegada considerades aquestes qüestions prèvies, s'ha procedit a analitzar cada un dels segments, agrupats sota un mateix lemma en cas de tenir vàries formes d'un mateix mot. Juntament amb una anàlisi morfològica i contextual $i$, sempre que sigui possible, es consideren les anàlisis anteriors confrontant-les amb el coneixement actual del frigi, el grec antic, l'anatolística i la indoeuropeística en general. El mètode històric comparatiu és essencial en aquesta tasca, si bé el context és constantment considerat per a evitar especulacions purament etimològiques. Sovint, aquest lèxic ofereix noves interpretacions pròpies, encara que per mor de la fragmentació i els hàpax són molts els mots dels quals ben poca cosa es pot dir. Després d'un estudi detallat de cada mot, s'ofereix també un buidatge de les dades que se'n poden extreure en forma de petita gramàtica frígia que serveix com a introducció actualitzada a aquesta llengua. 


\section{Table of Contents}

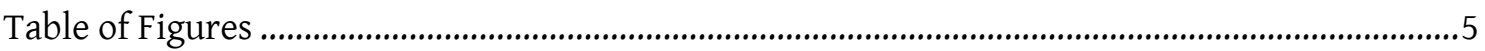

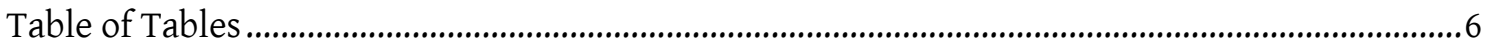

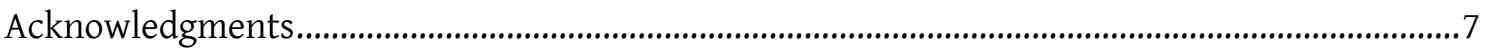

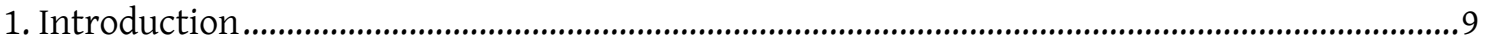

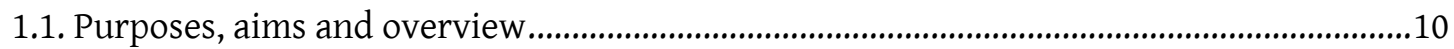

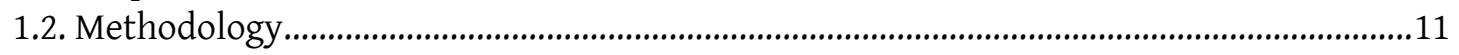

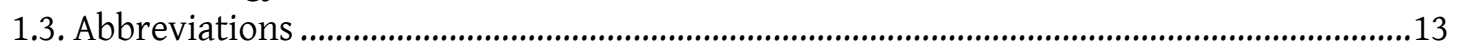

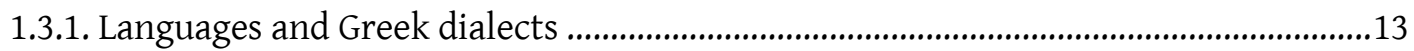

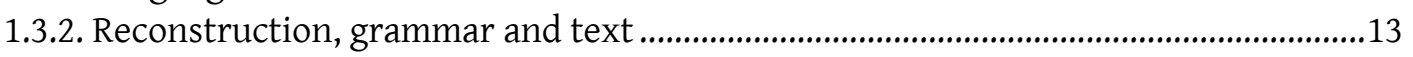

1.3.3. Greek and Latin Authors and works ..........................................................................14

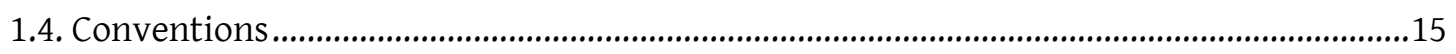

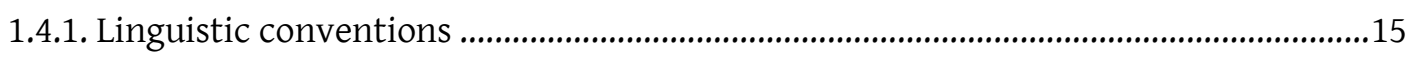

1.4.2. Epigraphical conventions ...............................................................................................15

2. Direct sources for the Phrygian language: the epigraphical subcorpora ..................................17

2.1. The Old Phrygian subcorpus ...............................................................................................18

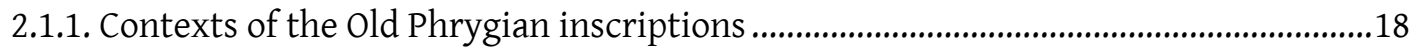

2.1.2. Old Phrygian writing materials ....................................................................................2

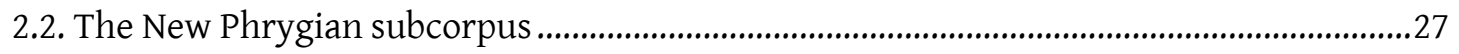

3. The scripts used to note the Phrygian language.....................................................................

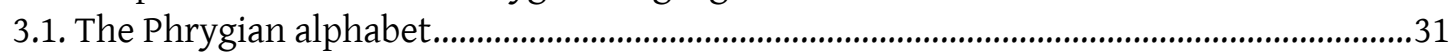

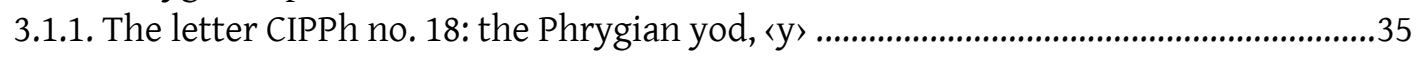

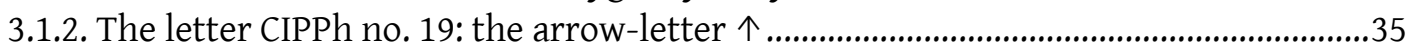

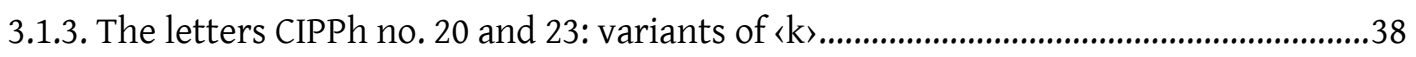

3.1.4. The letter CIPPh no. 21: the unparalleled Phrygian "qof" .............................................4

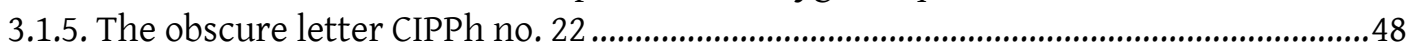

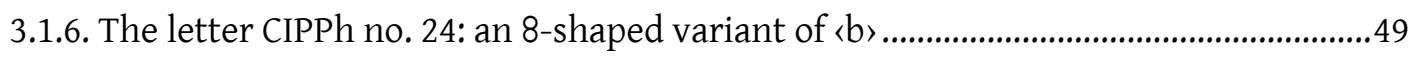

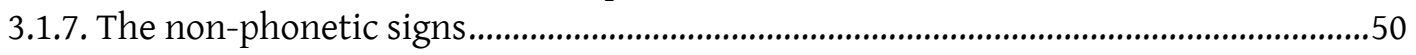

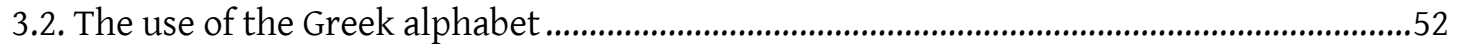

3.2.1. MPhr-01, the first Phrygian inscription in Greek alphabet.........................................52

3.2.2. The Greek alphabet of the New Phrygian inscriptions .................................................54

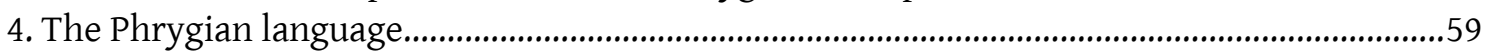

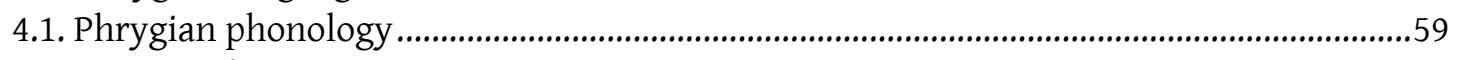

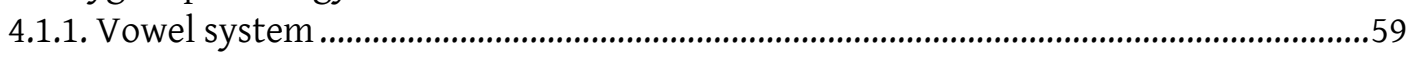

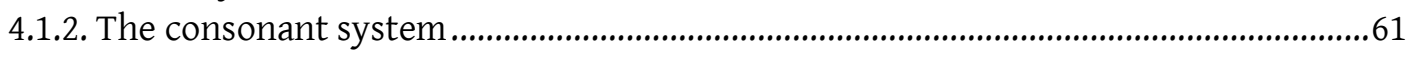

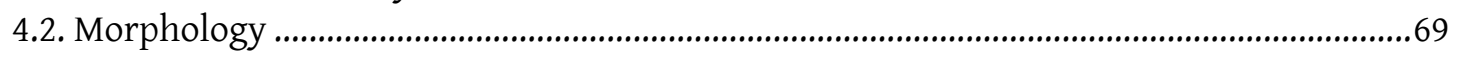

4.2.1. Nominal and Pronominal Morphology ......................................................................69

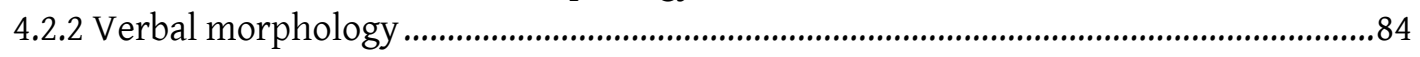

4.2.3. Prepositions, preverbs, conjunctions and particles ....................................................... 91

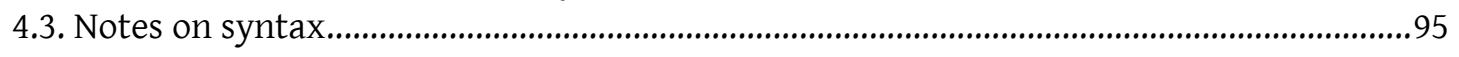

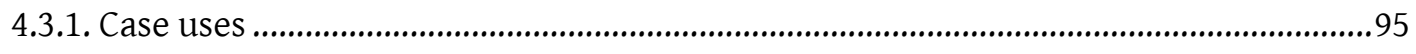

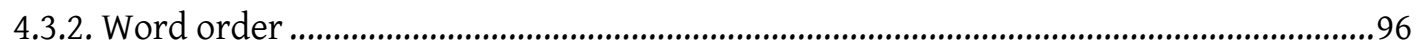

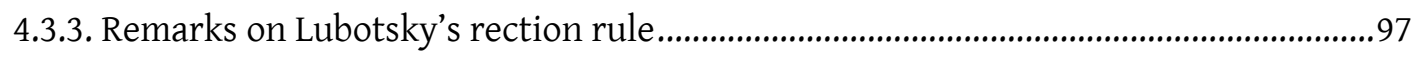

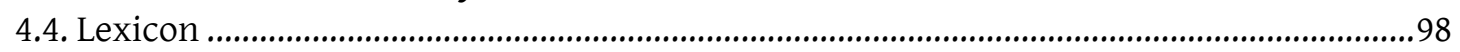

4.5. The place of Phrygian in the Indo-European language family............................................101

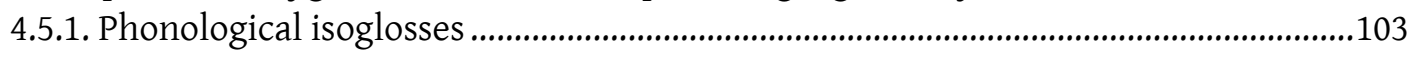

4.5.2. Morphological isoglosses .........................................................................................103 


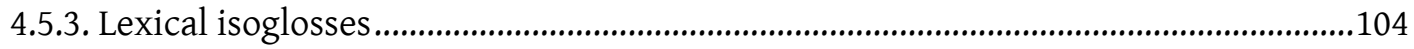

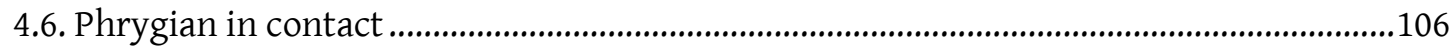

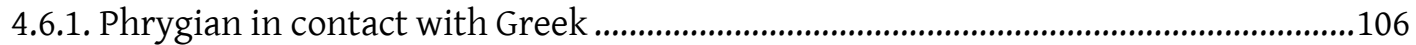

4.6.2. Phrygian in contact with the Anatolian languages .................................................115

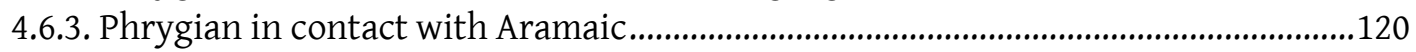

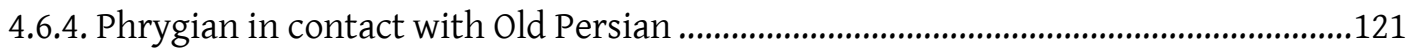

4.6.5. Phrygian in contact with Elamite ............................................................................123

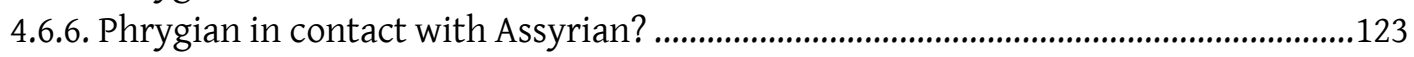

4.6.7. Phrygian in contact with Galatian.............................................................................123

4.6.8. Phrygian in contact with Latin ..............................................................................123

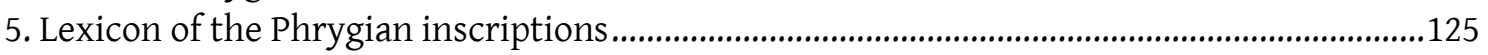

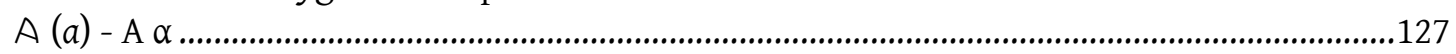

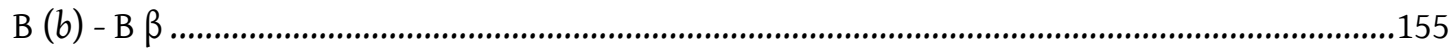

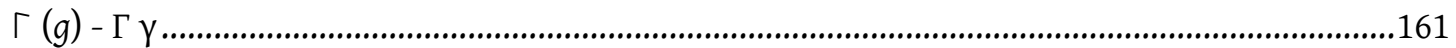

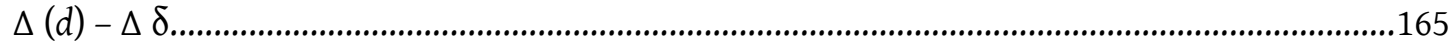

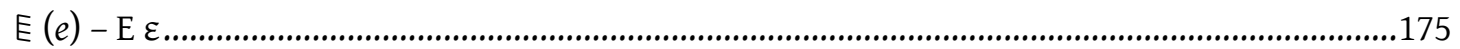

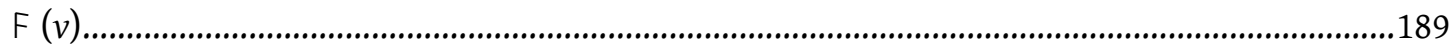

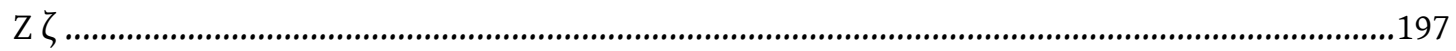

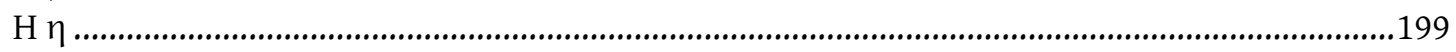

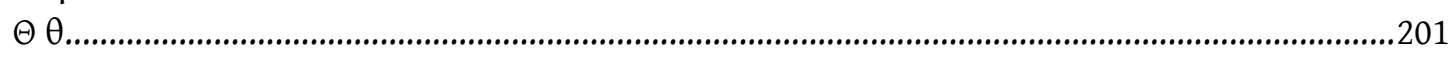

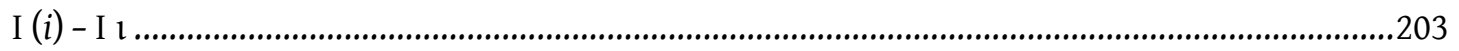

$\mathrm{K}(\mathrm{k})-\mathrm{K}$ K

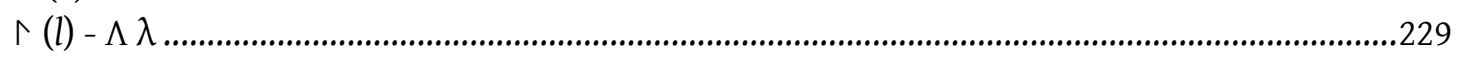

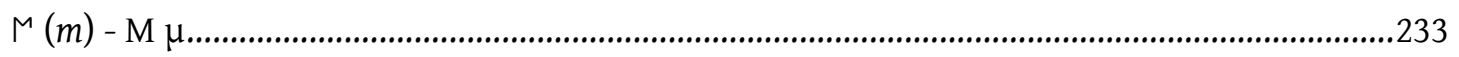

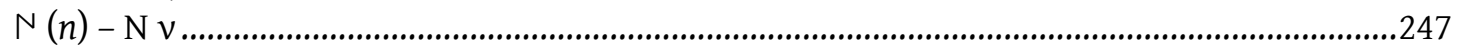

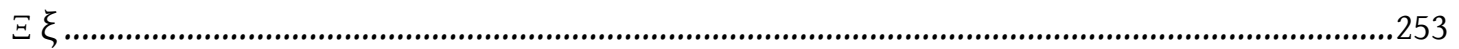

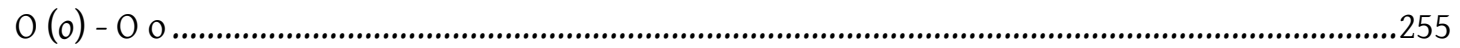

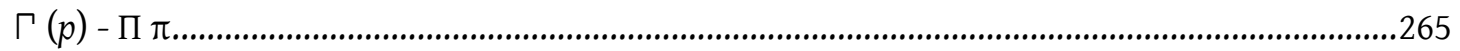

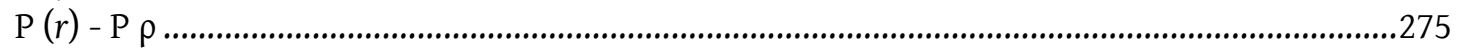

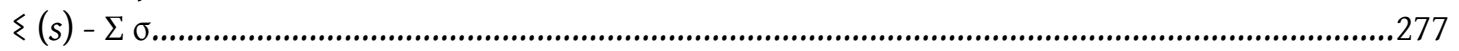

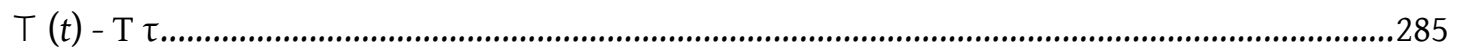

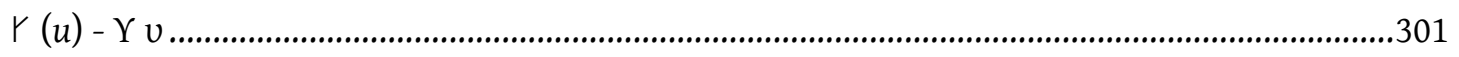

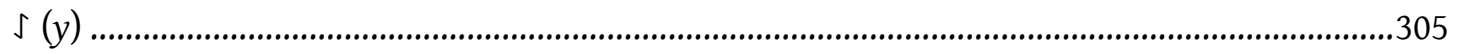

$\psi_{1}$

个

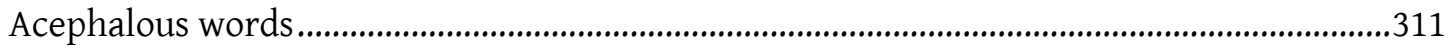

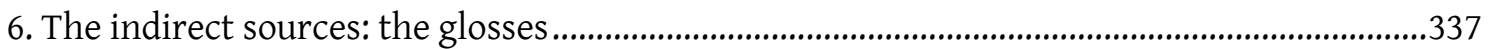

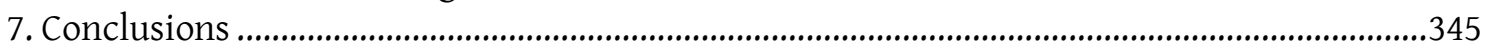

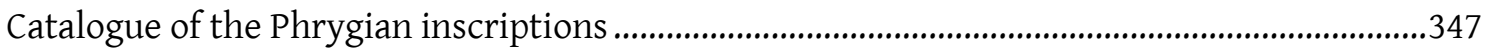

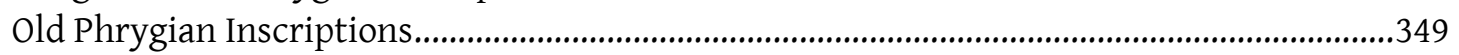

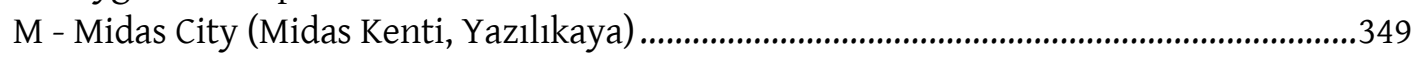

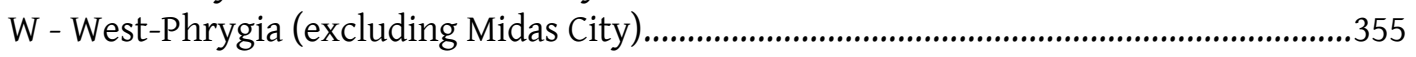

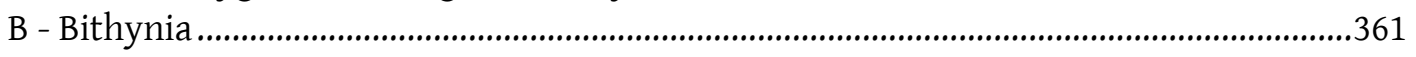

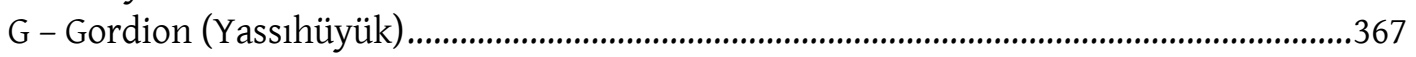

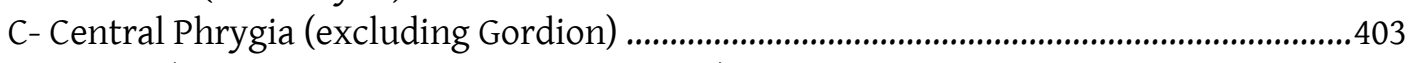

P - Pteria (Alacahöyük, Pazarlı and Boğazkale) .....................................................................404

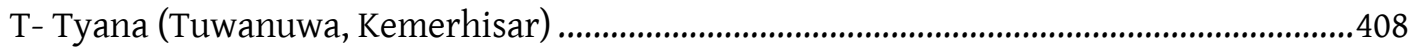

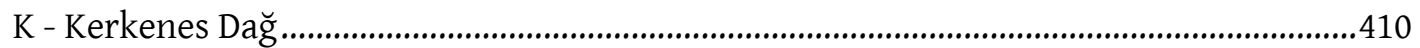

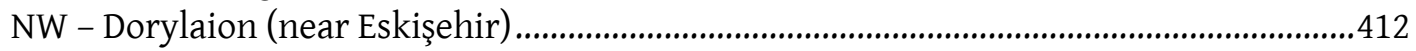

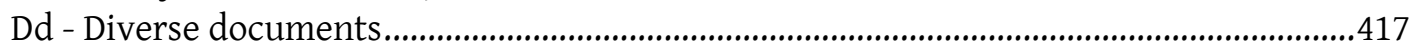

HP - Dispersed inscriptions found outside Phrygia .............................................................418 


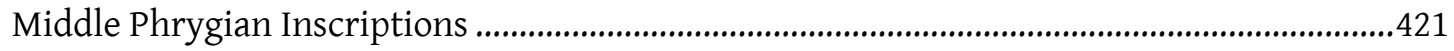

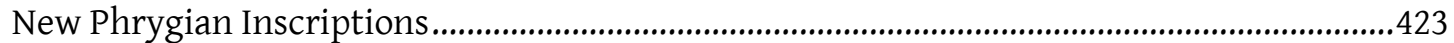

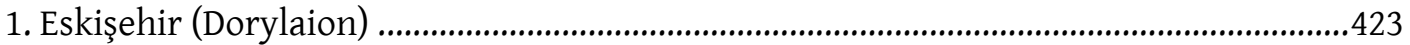

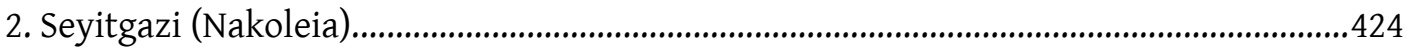

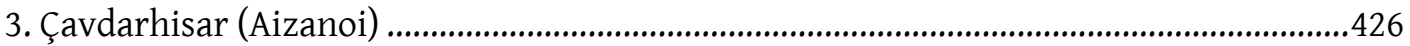

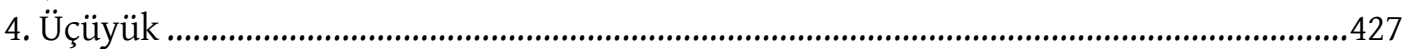

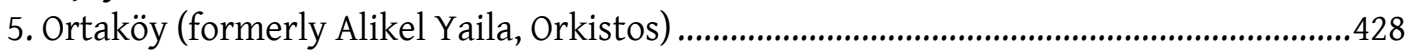

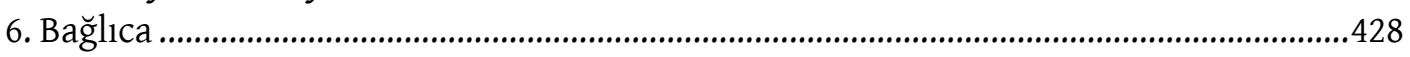

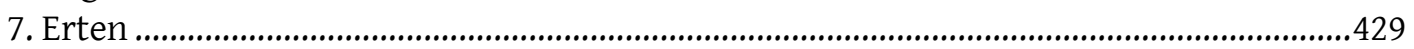

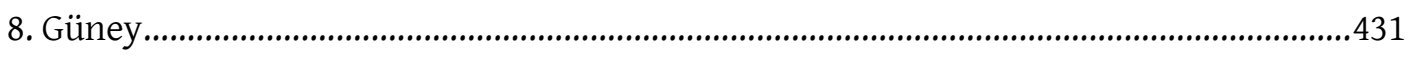

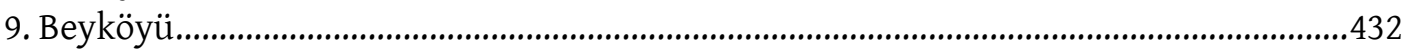

10. Gökçeyayla (formerly Orhaniye and Kilise, near Malos)................................................432

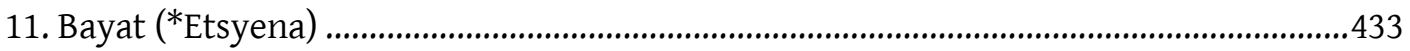

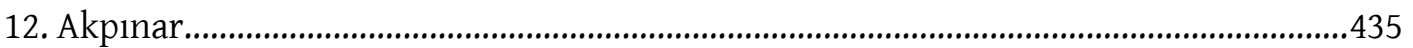

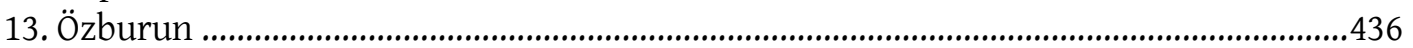

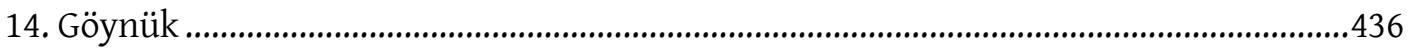

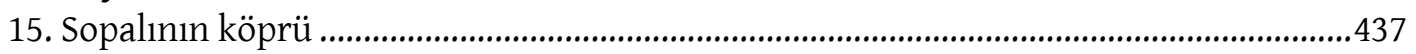

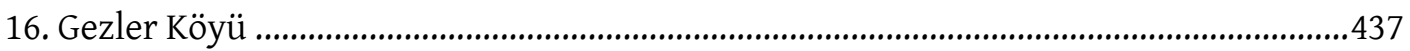

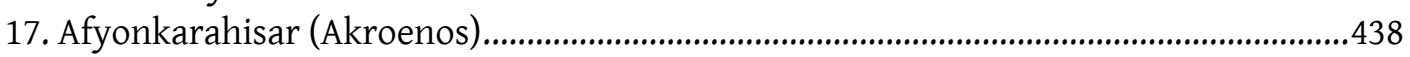

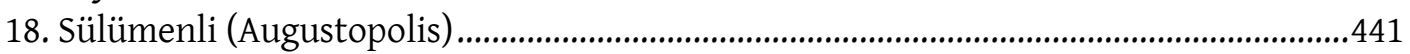

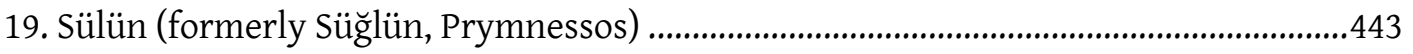

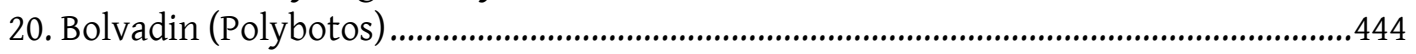

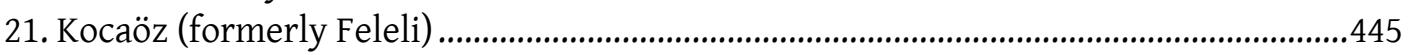

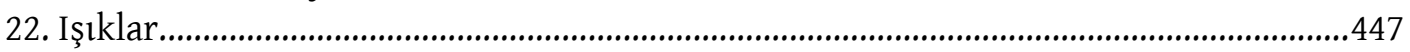

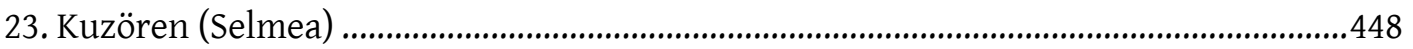

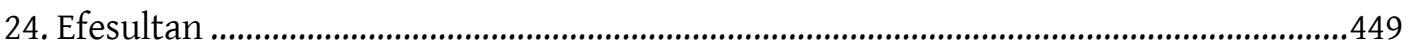

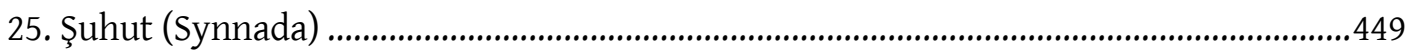

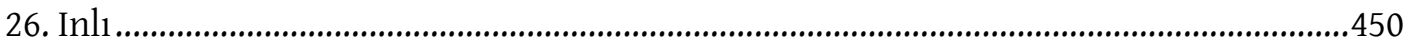

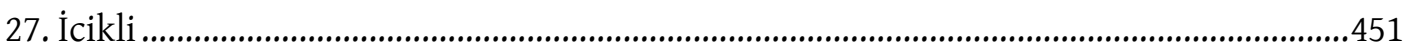

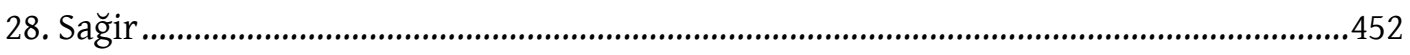

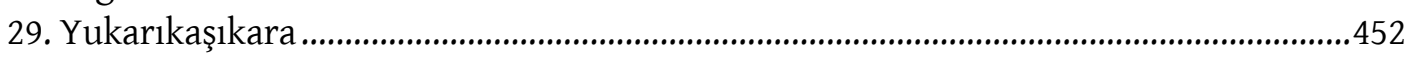

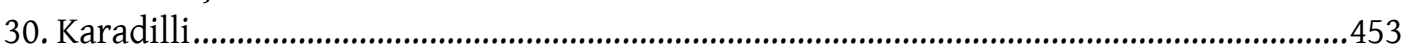

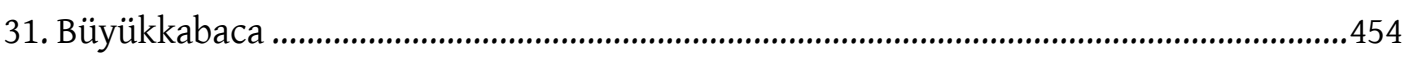

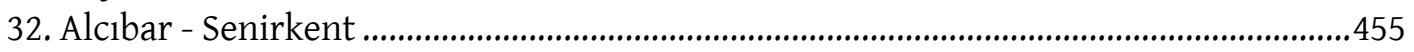

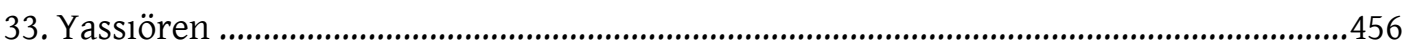

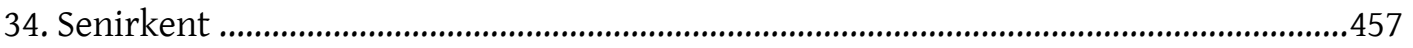

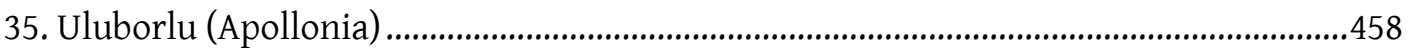

36. Şarkıkaraağaç (Tetrapolis) ............................................................................................458

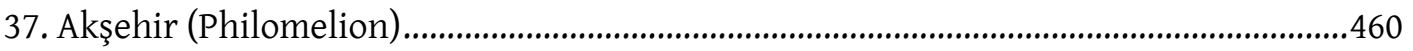

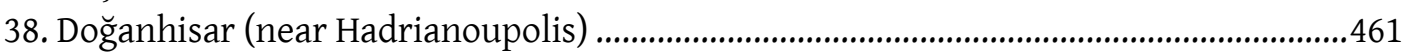

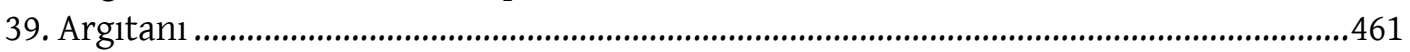

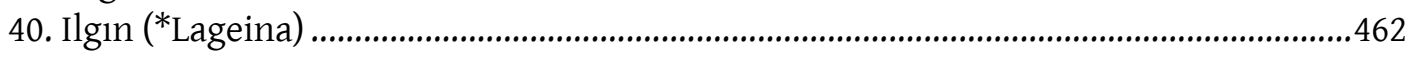

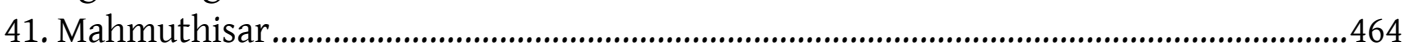

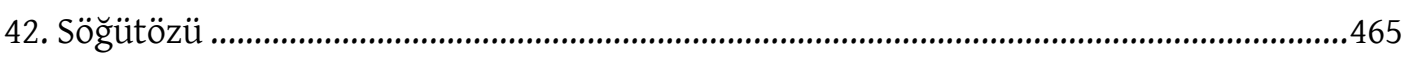

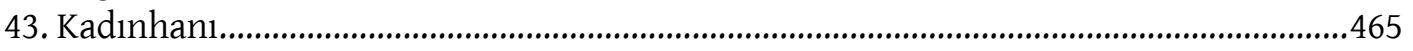

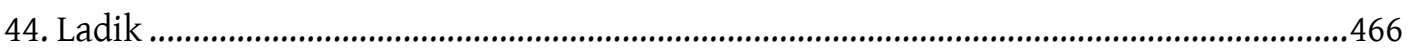

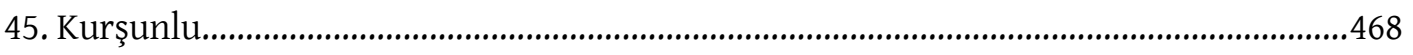

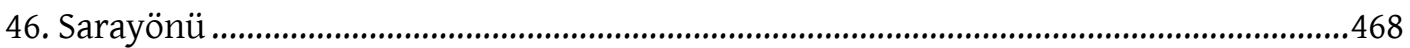

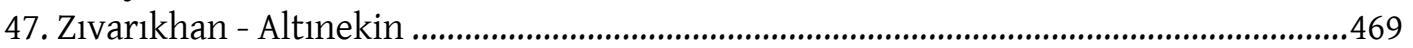

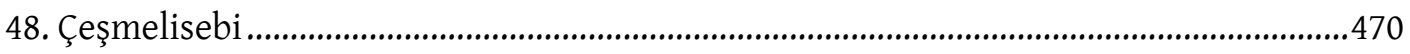

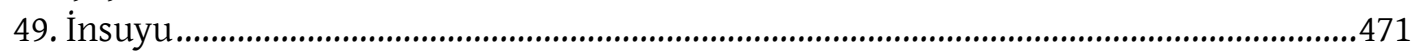




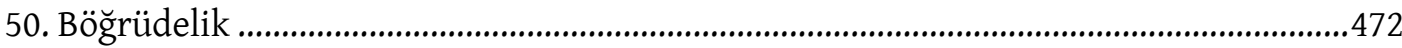

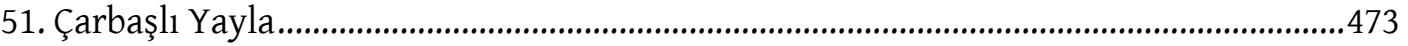

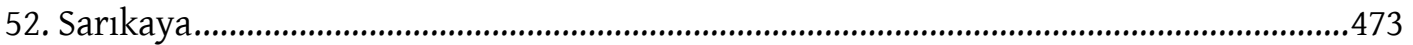

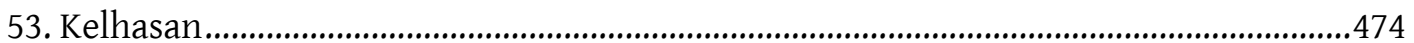

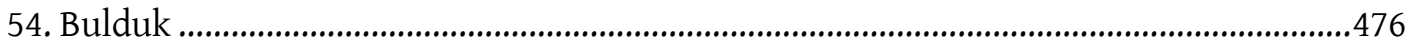

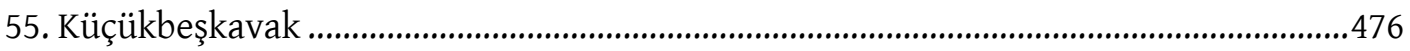

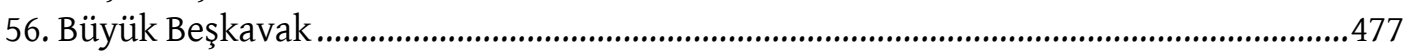

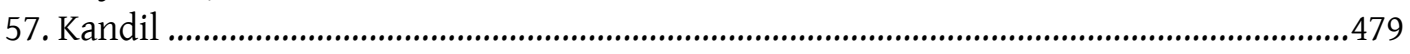

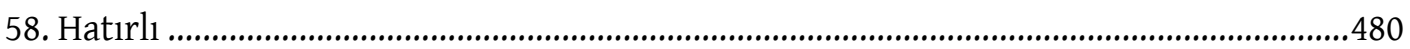

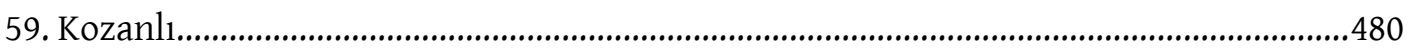

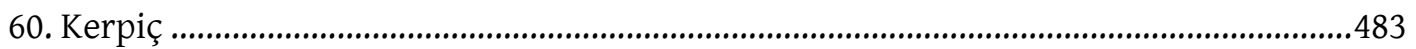

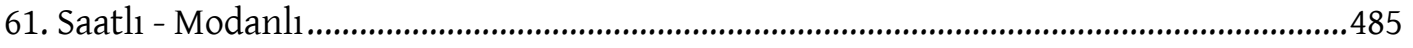

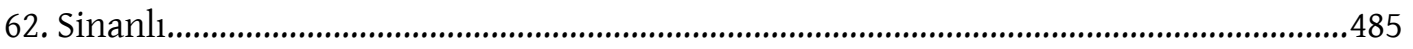

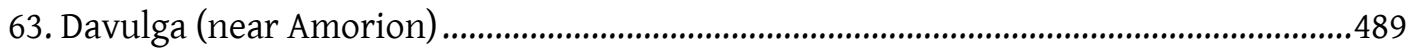

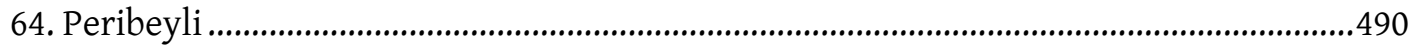

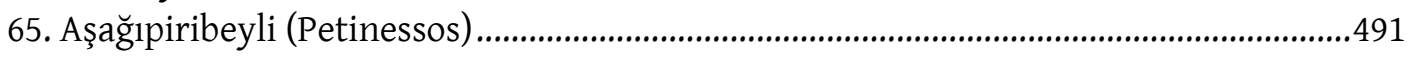

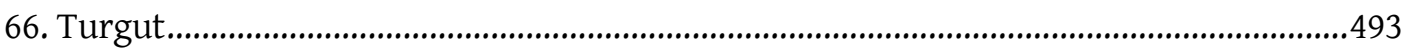

Appendix: Greek inscriptions enumerated in the traditional list of New Phrygian

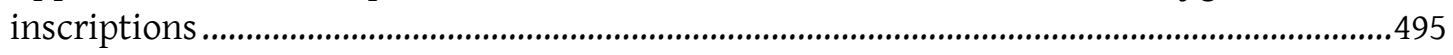

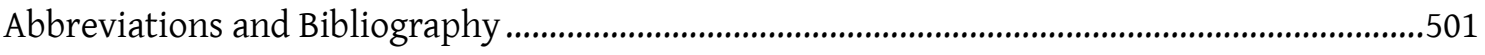

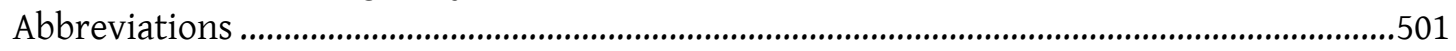

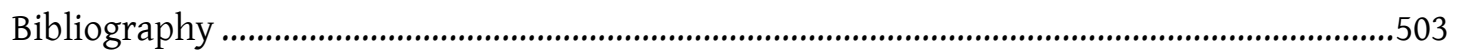

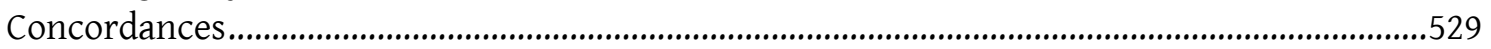

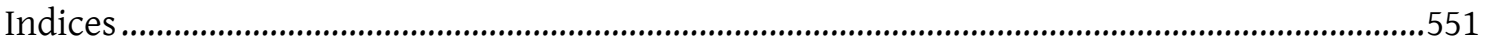

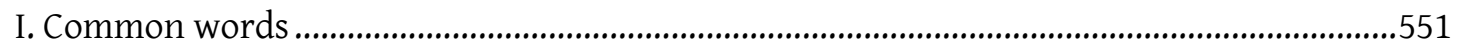

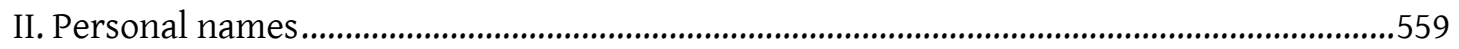

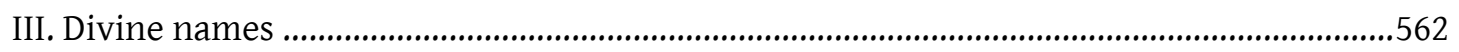

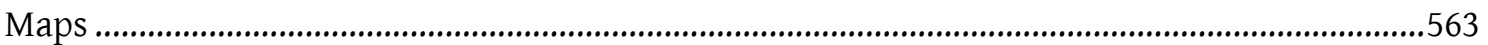




\section{Table of Figures}

Fig. 1 Door-stele from Prymnessos (modern Sülün) containing the New Phrygian text 19.1

(96; Kelp 2013, 80 Fig. 4.10).

Fig. 2 Photograph of G-145 (Young 1969, pl. 70 no. 72) .................................................................39

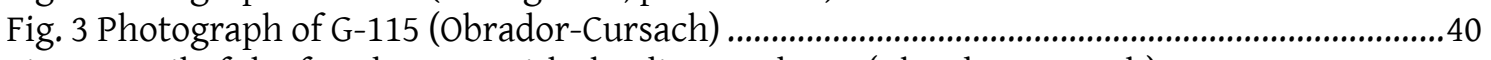

Fig. 4 Detail of the façade W-01 with the discussed text (Obrador-Cursach) .................................41

Fig. 5 Weight with the Phrygian inscription G-249 (CIPPh I, 195 and II, CVI no. 3-4) .....................42

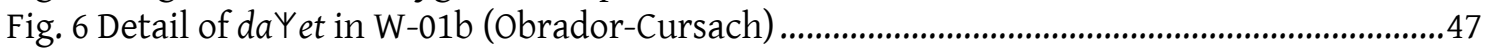

Fig. 7 Drawing of G-106 according to CIPPh (I, 101).......................................................................4

Fig. 8 Photograph of G-106 published by Young (1969, pl. 68 no. 32) ..............................................49

Fig. 9 Drawing of G-244 according to CIPPh (I, 192).........................................................................4

Fig. 10 G-346, K-01V and K-01VI+VIIa (Liebhart \& Brixhe 2009, 155-156 and Brixhe \& Summers 2006, 121-122) . .51

Fig. 11 Capacity signs found on Gordion pithoi with Phrygian graffiti, drawings by R. S. Young (1969). 52

Fig. 12 Old Phrygian inscription Dd-102 (Musées d'art et d'histoire, Ville de Genève, inv. no.

023469 @ Musées d'art et d'histoire, Ville de Genève, photographer: Monique Delley) 119 


\section{Table of Tables}

Table 1 Gordion (Yassihöyük) chronology according to Rose \& Darbyshire..................................20

Table 2 The old Phrygian inscriptions according to writing material ..........................................26

Table 3 Comparison between the Old and the New Phrygian subcorpora .....................................29

Table 4 Comparison of the Phoenician abjad, Classical Greek and Phrygian alphabets...............33

Table 5 Chart of Phrygian letters according to CIPPh I, 280 .............................................................

Table 6 Suggested classification of the Phrygian letters ...................................................................34

Table 7 Contexts and occurrences of $\uparrow$.............................................................................................

Table 8 The Phoenician letter gīml and its reflections in other alphabets as hypothetically

suggested here ..........................................................................................................................3

Table 9 Comparison between W-01b and the common NPhr. apodosis.........................................41

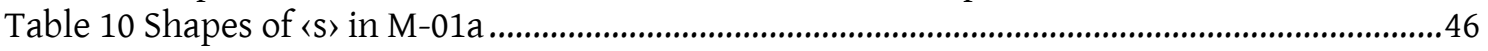

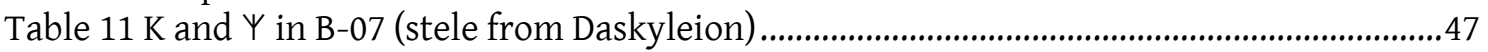

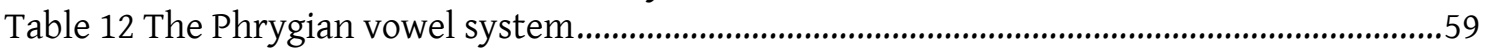

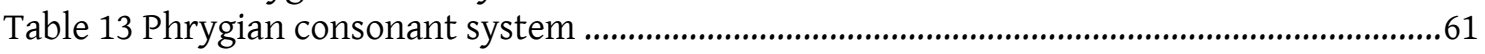

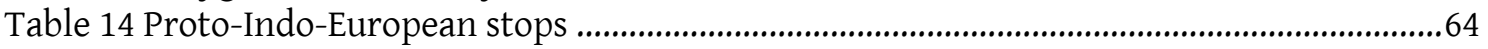

Table 15 Phrygian developments of the PIE velars.................................................................66

Table 16 The Phrygian treatment of PIE laryngeals ....................................................................68

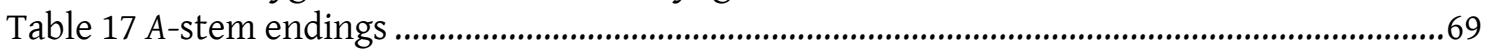

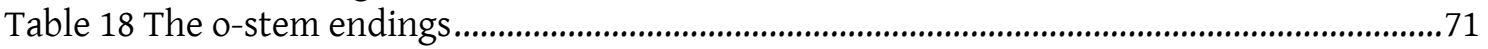

Table 19 C-stem endings .............................................................................................................

Table 20 Possible inflection of the personal name Manes...............................................................

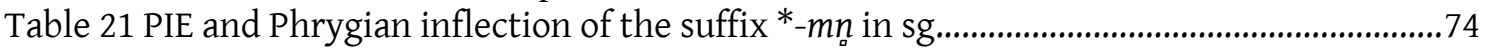

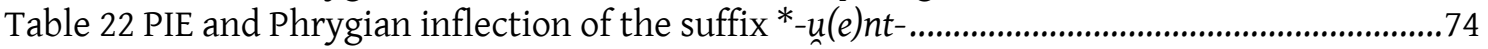

Table 23 *-tèr inflection in PIE and Phrygian .....................................................................................76

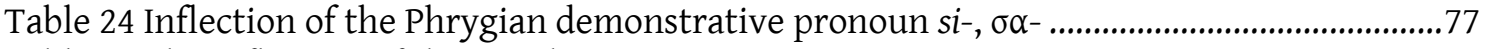

Table 25 The inflection of the anaphoric pronun tos ...................................................................79

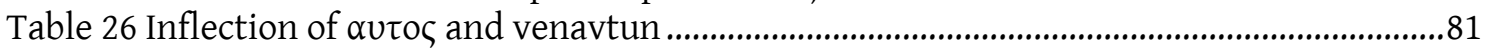

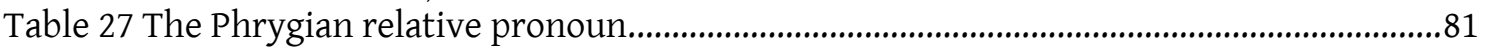

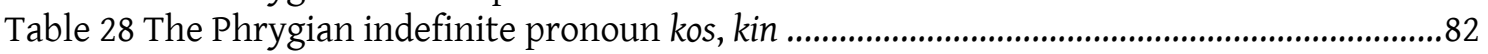

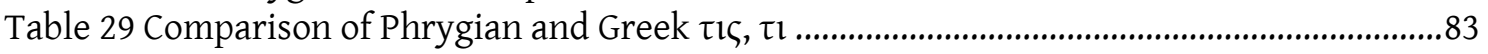

Table 30 Inflection of the Phrygian possessive pronoun...................................................................83

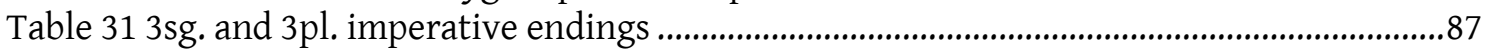

Table 32 Summary of the identified Phrygian prepositions and preverb ......................................93

Table 33 Classification of the lemmata considered in the Lexicon of the Phrygian Inscriptions

.100

Table 34 Comparison of Phrygian features with Greek, Armenian, Albanian and Indo-Iranian

Table 35 Equivalences between the Phrygian and Greek texts of B-05.

Table 36 Classification of the glosses regarding their relationship with Phrygian......................344 


\section{Acknowledgments}

Writing this PhD dissertation has taken more than four-and-a-half years, from September 2012 to October 2017. During this long period, I have been assisted and accompanied by many people to whom I wish to offer my thanks publicly. First of all, I want to thank my whole family, and especially my parents, who encouraged me to go on in many difficult moments. I reserve special gratitude for Ixiar Iturzaeta Goikoetxea, who accompanied me (and endured stoically) throughout most of the time I spent in Barcelona: eskerrik asko bidai guzti honetan nire alboan izateagatik.

Also, I must thank the friends and colleagues who helped me in the task of gathering all the relevant publications: Julia Abajo San Martín, Alicia Calvo Panera, Henning Haselmann, Eva Llabrés Llambies, Carlos Molina Valero and Josep Querol Donat. I reserve special thanks for Diego Corral Varela, who not only assisted me in this work but also gave generously of his time in responding to my endless consultations and mapping the corpus: tibi qui haec omnia passus es gratias maxumas ago.

I am indebted to Peter Cottee for his revision of my English. Needless to say, all the possible errors are my own responsibility. I am also grateful to the following scholars, who were solicitous in answering my questions and requests: Alexandru Avram, Scott Branting, Lorenzo d'Alfonso, José Virgilio García Trabazo, Hermann Genz, Annelies Hämmig, Alwin Kloekhorst, Alexander Lubotsky, Julián Méndez Dosuna, Alan Nussbaum, Blanca María Prósper, Marijana Ricl, Marco Antonio Santamaría Álvarez, Simon Zsolt, Ilya Yakubovich and José Ángel Zamora. I must stress the help offered during these years by $\mathrm{M}^{\mathrm{a}} \mathrm{Paz}$ de Hoz García-Bellido, who also introduced me to Greek epigraphy and the Phrygian world.

In addition, I want to thank both Mariona Vernet Pons and Elena Martínez Rodríguez, who helped and accompanied me during the research project. I am also grateful to the members of the IPOA, especially Adelina Millet Albà and Lluís Feliu Mateu, for their assistance. Thanks are also due to Ernest Marcos Hierro, who, despite the frenetic activity of his charges, always found time to help me.

I cannot conclude this list without expressing particular gratitude to Ignasi-Xavier Adiego Lajara, who supervised this work. His deep knowledge of Indo-European linguistics and his active research into fragmentary languages over the last decades have filled many gaps in my knowledge, the fruit of my inexperience.

Finally, I must add that, against the backdrop of such a severe financial crisis, writing this dissertation would have been impossible without the doctoral research scholarship granted by the Spanish Ministry of Economy, Industry, and Competitiveness (BES-2013-062696) for my work as part of the research project "Los 'dialectos lúvicos' del grupo anatolio indoeuropeo: aproximaciones genéticas y areales” (FFI2012-32672). 



\section{Introduction}

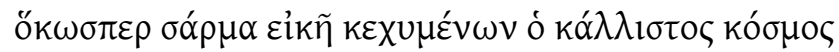

(Heraclitus B 124)

Phrygian is a fragmentary ancient language and much of its corpus remains unexplained, despite the efforts of scholars over the last century. The language is still being deciphered, and new inscriptions and interpretations appear in scientific journals year after year. It is a fact that many difficulties and limitations complicate our understanding of the Phrygian texts, yet it is no less true that Phrygian is edifying in many respects, particularly for the linguistic new information it provides and the historical implications of the texts. This explains why the critical study of Phrygian is increasing among scholars. Mallory and Adams $(2006,37)$, for example, are explicitly aware of its value, as they state in their introduction to Proto-Indo-European: "of all the minor languages, Phrygian has probably the greatest claim to consideration".

Nonetheless, only a handful of people are working on Phrygian with full scientific rigour. The explanation for this scenario can be found in the lack of works that provide an introduction to or comprehensive up-to-date study of the Phrygian language. We have excellent editions of the Old Phrygian inscriptions by Brixhe and Lejeune (CIPPh and Brixhe's supplements), but an editio maior of the all New Phrygian inscriptions is still lacking. Some Phrygian lexica exist, but they offer arbitrary interpretations ${ }^{1}$ or new discoveries in historical phonology invalidate a significant part of them. Indeed, ad hoc interpretations are found elsewhere in many lexical approaches to Phrygian. Finally, there is the successful updated grammatical overview of the Phrygian language by Ligorio and Lubotsky (2013), but it is a concise work whose findings are to be applied to the whole corpus.

Therefore, dealing with Phrygian is a near-Sisyphean task: great effort and poor results. Although frustration is always a factor when working with fragmentary languages, Phrygian offers many possibilities that other ancient corpora do not. Its corpus is not closed and many ongoing digs, such as in Kerkenes Dağ, are promising with regard to the appearance of new texts. The context of such texts is more extensively and more effectively studied. From a historical and archaeological point of view, Central Anatolia during the Iron Age is not as obscure as it was and, with specific regard to language and culture, knowledge of the surrounding Anatolian languages and the contents of their preserved inscriptions has increased considerably in the last decades. In addition, the study of the influence of "local cultures" (as Hellenists refer to this phenomenon) on Greek epigraphy in Anatolia also provides useful information that must be considered when analysing a Phrygian inscription.

Unfortunately, leaving aside some significant exceptions, Anatolists and Hellenists ignored the Phrygian question because Phrygian does not belong to the Anatolian branch of Indo-European languages and it is not Greek, although they have much to say on this matter. Indeed, Phrygian texts must be studied in the cultural context of Iron Age and Roman Anatolia and from a comparative Indo-European perspective combined with internal reconstruction. In any case, this information related to the Phrygian world - but not always considered - is relevant in the decipherment of this language.

\footnotetext{
${ }^{1}$ See, e.g., Martin West's criticism $(2003,78)$ of Orel's book on Phrygian (1997a): "nearly all of this seems to be as arbitrary and ad hoc as much of the exegetical material in Orel's useful but unsatisfactory work". Orel also published a Phrygian vocabulary in the journal Orpheus (1997b) but this work will be not considered here because it mainly reproduces the vocabulary offered in his book.
} 


\subsection{Purposes, aims and overview}

The main objective of this dissertation is to provide a comprehensive analysis of all the Phrygian words attested in the Phrygian inscriptions. As addressed in $\S 4.6 .1 .5$ and $\S 6$, there are some words transmitted in Greek sources, although their filiation is not always clear and the indirect transmission affects their quality as a source. Therefore, the lexicon contained in the inscriptions must be the basis of any approach to Phrygian, while borrowings and glosses in Greek must be studied in the light of the epigraphic material.

As has been said, this PhD dissertation is intended to fill what some scholars have identified as an important gap in Phrygian studies. Indeed, I agree with Woodhouse, for instance, that this kind of work was needed in our field: "[t]he situation of Phrygian is very similar to that of Lydian. If anyone is looking for a PhD / Kandidat project, I think there is probably room for a book like Gusmani's Lydisches Wörterbuch that would contain not the biased conclusions of one scholar but an annotated compendium of whatever useful interpretations have been advanced for each interpreted word that has been divined in the corpus or corpora" $(2009,176)$. This first objective is the core of this dissertation and corresponds to chapter $\S 5$.

I must acknowledge the usefulness of Gusmanis' Lydisches Wörterbuch (1964) and Neumann's Glossar des Lykischen (2007) as models for building the Phrygian lexicon. However, the lexical tradition of the former Department of Latin Philology and Indo-European Linguistics at the University of Barcelona has provided me with useful examples of how to deal with fragmentary languages. ${ }^{2}$ Moreover, my dissertation is not the first analysis of this subject to be defended at this university: ten years ago Morante Mediavilla wrote about the history of Phrygian studies (2007) in an unpublished work where she gives a useful and detailed study of the first approaches to this language.

Nevertheless, before attempting to list all the Phrygian terms preserved in the inscriptions I have had to compile all the known Phrygian inscriptions. This is the key secondary objective of the dissertation. As has been said above, most of the Old Phrygian inscriptions were gathered and well edited in the Brixhe and Lejeune corpus (CIPPh) with Brixhe's supplements (2002a and 2004a). However, some findings were not included. The situation of the New Phrygian inscriptions is more precarious: no critical edition of the whole corpus was published. I endeavoured to remedy this with my master's dissertation (2013), but since I was unable to corroborate all of the data of the preserved inscription (not the most, by the way), I produced what can be best described as a catalogue, containing critical remarks on the texts. This academic work, with many corrections and additions, forms the basis of the one presented and used here. The full catalogue of the Phrygian inscriptions is given at the end of the dissertation.

Another secondary objective is to present an overview of the Phrygian language as gleaned from the Phrygian inscriptions. This is intended to join together the available data and to identify the ad hoc explanations that are inconsistent with the main evidence. The outcome is essentially an overview of the Phrygian language ( $\$ 4)$ based on the lexicon. During the writing of this dissertation, this exercise proved as useful means of improving the different entries in the lexicon. Finally, in my analysis of the Phrygian lexicon I considered it interesting to devote some pages to the glosses, with the exception of the onomastic ones (§6). The main objective of this chapter is to show how our knowledge of the epigraphical lexicon can be used to corroborate the filiation of each entry and their connection with directly transmitted words.

Finally, I conclude the dissertation with indexes of terms from the other languages used here and epigraphical correspondences, in order to make the work easier to use both for scholars accustomed to previous studies in the literature and for those from other fields who

\footnotetext{
${ }^{2}$ I refer to works such as Adiego study of Carian (2007) and the dissertations of Velaza (1991) and Moncunill (2007) on Iberian, among others.
} 
have an interest in Phrygian. Indeed, this dissertation aims to be a useful tool for anyone wishing to dicover what Phrygian linguistic materials exist and what we know about these materials.

\subsection{Methodology}

The basis of this study is the epigraphical corpus, because the inscriptions provide a guaranteed source of Phrygian material. Nevertheless, the necessary first step is to "use a correctly-edited and judicious corpus of inscriptions". ${ }^{3}$ For the OPhr. subcorpus I used as a reference Brixhe and Lejeune's CIPPh and its supplements, but I also considered some inscriptions not gathered before (mainly edited by Brixhe himself). The criteria for considering those inscriptions not included in CIPPh as Phrygian are as follows: the script must be the Phrygian alphabet, the features of the linguistic material they contain must be consistent with our knowledge of Phrygian, and their contexts must be chronologically defensible as Phrygian. In any case, instances that cannot be fully confirmed are duly noted in the catalogue of inscriptions ( $\$ 7)$. I followed the enumeration of the OPhr. inscriptions provided in the CIPPh and supplements. The only exception is MPhr-01 (W-11), which is not classed here as an OPhr. text because of its exceptional features (a Phrygian text written in the Greek script in the early Hellenistic period). Inscriptions written in Phrygian script are given in transliteration, while those written in the Greek alphabet are given in standardised classical Greek form, although particularities in the shape of the letters are indicated when known.

Because of the similarity between the Phrygian and Greek scripts and the occurrences of words in both the OPhr. and NPhr. subcorpora, the value of most of the Phrygian letters is known. However, some letters lack a direct counterpart or are used in a different way. Such cases are dealt with in chapter $\S 3.1$, where I discuss the status of the sign and the assigned phonetic value through the contexts in which they appear. Although I deviate from the traditional interpretation of CIPPh letters no. 20 and 23, which I consider mere variants of $\langle\mathrm{k}\rangle, \mathrm{I}$ did not transliterate them in order to show where these discussed letters appear.

As has been said, NPhr. is more problematic because a judicious corpus of inscriptions is lacking (see also $\S 2.2$ ). I have had to work with my own catalogue. New findings are excellently edited by Brixhe and Lubotsky in collaboration with other scholars but most of the inscriptions are only known through copies. Unfortunately, I was unable to see for myself the preserved impression of the NPhr. inscription 11.2 (18). Since the traditional numbering of this corpus is defective (Brixhe 1999, 286), I renumbered the inscriptions according to the place where they appeared, starting from North-West Phrygia. Nevertheless, I also provide the old numbering in order to facilitate the use of this work.

All inscriptions considered in the catalogue are introduced by number and with a brief description based on prior editions. After the inscription itself, I have added a critical apparatus with the most relevant alternative readings. While the insertion of this apparatus is not frequent in Old Phrygian, since the CIPPh improved on previous editions, for New Phrygian I chose to be more exhaustive due to the lack of a prior critical corpus.

Another matter that must be considered before working with the Phrygian lexicon is determining the segmentation of the texts, since scriptio continua occurs elsewhere in the Phrygian corpus. Indeed, establishing word boundaries is a difficult task in a language that has not been fully deciphered. I followed the CIPPh method and Lubotsky's reference work on B-01 (1993b). When a sequence does not occur more than once, the segmentation is based on morphological and orthographic reasoning. However, sometimes the data to detect a boundary are lacking.

\footnotetext{
${ }^{3}$ I take the formulation of this basic criterion from Valério 2016, 32, which is, in turn, mainly based on Pope 1999 and Duhoux, Palaima and Bennett 1989.
} 
The lexicon in chapter $\S 5$ is based on the suggested segmentation. I grouped the various attested forms of the same word in a single entry to avoid redundancy. However, "calling lemmata" with the all forms are also given in order to redirect the reader to the place where the word is analysed. Note that many calling lemmata are preceded by a crux to indicate that the segmentation is no longer deemed valid, despite being commonly found in prior works. In the case of nouns, adjectives and pronouns, the sg.nom. is the preferred lemma form. However, very often the sg.nom. is lacking, in which case the most frequent form is chosen as the lemma.

Unfortunately, we do not know the original order of the Phrygian alphabet. Nevertheless, since some words written in Phrygian script also occur in Greek script and must be studied together, I preferred to merge the lexicon of all corpora following the common Greek order. Of course, the result is an artificial order of the lemmata, as follows:

$\begin{array}{cccccc}a / \alpha & v / F & l / \lambda & p / \pi & \chi & \vee \psi \\ b / \beta & \zeta & m / \mu & r / \rho & \psi & \phi^{?} \\ g / \gamma & \eta & n / v & t / \tau & \omega & 7^{?} \\ d / \delta & \theta & \xi & u / v & y & . \\ e / \varepsilon & k / \kappa & 0 / 0 & \varphi & \uparrow \mathrm{T} \Phi & \end{array}$

Note that although I consider $V$ and $\Psi$ to be variants of $\langle\mathrm{k}\rangle$ and $\uparrow$, and $T$ and $\Phi$ can be equated to Greek $\zeta$, I have preserved the traditional position of these letters in this lexicon to reflect what appears in the inscriptions.

Each lemma is followed by the word class, given in brackets (noun, adjective verb, conjunction, preposition, PN, etc.), and the suggested meaning, if it is known. In each entry, I first give the variants of the word according to the subcorpus to which they belong, in the given alphabetical order. A morphological analysis is also provided for each variant, when known. After this, the class, the context(s) and the origin of the word are discussed. Since purely etymological approaches are essentially speculative if they are not corroborated by the context of the inscriptions, the discussion of each word takes into account the available linguistic, historical and material evidence for each word. With regard to etymology, ad hoc interpretations are avoided in the light of the general knowledge of the language presented in chapter $\S 4$. At the end of each entry I have attached a list of references in which the word is discussed. Generally, the oldest references (prior to Haas and Lejeune) are omitted. However, they are considered if they have been corroborated recently or remain the sole reference for a particular word. Works by Ramsay and Calder are commonly listed because of their significance.

Since Phrygian is an ancient Indo-European language, the comparative method and the historical reconstruction are fundamental to its analysis. For this reason, I used constantly updated Indo-European lexica. With regard to Proto-Indo-European forms, verbal roots are quoted according LIV ${ }^{2}$, nouns NIL and particles LIPP. Pokorny's IEW is also quoted. In general, I only provide Greek, Latin and Sanskrit forms in order to avoid large lists of cognates, although other languages are often considered. In any case, Greek is the most useful comparative language, so Greek etymological dictionaries (basically $E D G$ and $D E L G$ ) are fundamental to this work.

Finally, the Anatolian corpora are frequently considered. Indeed, the information contained in the Anatolian corpora and the Greek and Aramaic inscriptions from Anatolia often provide suitable parallels for the cultural context of the Phrygian inscriptions. Even calques are found in many formulae. Although word-for-word bilinguals are lacking, some themes are found elsewhere in Anatolia from the Iron Age to the Roman imperial period. When the theme of an inscription is identified because some words of a sentence are known, these parallels, in combination with internal reconstruction, can shed light on unclear words. This method, which 
is used in other fragmentary ancient languages (such as Italic languages and Etruscan), ${ }^{4}$ is especially productive for curses and funerary formulae.

\subsection{Abbreviations}

\subsubsection{Languages and Greek dialects}

Aeol. Aeolic

Alb. Albanian

Arc.-Cypr. Arcado-Cyprian

Arm. Classical Armenian

Att. Attic

Av. Avestan

CLuw. Cuneiform Luwian

cret. Cretan

Cypr. Cyprian

Dor. Doric

El. Elean

Etr. Etruscan

Gaul. Gaulish

Gm. Germanic

Go. Gothic

Gr. Greek

Hitt. Hittite

HLuw. Hieroglyphic Luwian

IE Indo-European

IIr. Indo-Iranian

Ion. Ionic

Lacon. Laconian

Lat. Latin

Lesb. Lesbian

Luw. Luwian

Lyc. Lycian

$\begin{array}{ll}\text { Lyd. } & \text { Lydian } \\ \text { MBret. } & \text { Middle Breton } \\ \text { MHG } & \text { Middle High German } \\ \text { MoE } & \text { Modern English } \\ \text { MPhr. } & \text { Middle Phrygian } \\ \text { Myc. } & \text { Mycenaean } \\ \text { NPhr. } & \text { New Phrygian } \\ \text { OCS } & \text { Old Chuch Slavonic } \\ \text { OHG } & \text { Old High German } \\ \text { OE } & \text { Old English } \\ \text { OIr. } & \text { Old Irish } \\ \text { ON } & \text { Old Norse } \\ \text { OP } & \text { Old Persian } \\ \text { OPhr. } & \text { Old Phrygian } \\ \text { PA } & \text { Proto-Anatolian } \\ \text { Pamph. } & \text { Pamphylian } \\ \text { PGm. } & \text { Proto-Germanic } \\ \text { Phr. } & \text { Phrygian } \\ \text { PIE } & \text { Proto-Indo-Eropean } \\ \text { Russ. } & \text { Russian } \\ \text { Skt. } & \text { Sanskrit } \\ \text { Thess. } & \text { Thessalian } \\ \text { ToA } & \text { Tocharian A } \\ \text { ToAB } & \text { Tocharian A and B } \\ \text { ToB } & \text { Tocharian B } \\ & \end{array}$

\subsubsection{Reconstruction, grammar and text}

$\begin{array}{llll}\text { abl. } & \text { ablative } & \text { e.g. } & \text { for example } \\ \text { acc. } & \text { accusative } & \text { EN } & \text { ethnonym } \\ \text { act. } & \text { active } & \text { encl. } & \text { enclitic } \\ \text { AD } & \text { anno domini } & \text { fem. } & \text { feminine } \\ \text { adj. } & \text { adjective } & \text { fn. } & \text { footnote } \\ \text { adv. } & \text { adverb } & \text { fthc. } & \text { forthcoming } \\ \text { aor. } & \text { aorist } & \text { fut. } & \text { future } \\ \text { athem. } & \text { athematic } & \text { gen. } & \text { genitive } \\ \text { BC } & \text { before Christ } & \text { H } & \text { any PIE laryngeal } \\ \text { c. } & \text { century } & \text { id. } & \text { idem } \\ \text { ca. } & \text { circa } & \text { ind. } & \text { indicative } \\ \text { cf. } & \text { compare } & \text { ins. } & \text { instrumental } \\ \text { conj. } & \text { conjunction } & \text { ipv. } & \text { imperative } \\ \text { dat. } & \text { dative } & \text { loc. } & \text { Locative } \\ \text { DN } & \text { divine name } & \text { LP } & \text { Late Phrygian period } \\ \text { DO } & \text { direct object } & \text { MP } & \text { Middle Phrygian period }\end{array}$

${ }^{4}$ See a brief explanation of this method (developed by Olzscha and Pallottino) in Agostiniani 1982, 38-39, who obtained very successful results. 


$\begin{array}{ll}\text { masc. } & \text { masculine } \\ \text { med. } & \text { middle } \\ \text { n. } & \text { neuter } \\ \text { neg. } & \text { negative } \\ \text { nom. } & \text { nominative } \\ \text { obl. } & \text { oblique } \\ \text { opt. } & \text { optative } \\ \text { p. } & \text { page } \\ \text { p.c. } & \text { personal communication } \\ \text { pcl. } & \text { particle } \\ \text { perf. } & \text { perfect } \\ \text { pers. } & \text { personal } \\ \text { pl. } & \text { Plural } \\ \text { PN } & \text { personal name } \\ \text { poss. } & \text { possessive }\end{array}$

\subsubsection{Greek and Latin Authors and works}

A

$\begin{array}{ll} & \text { Aeschylus } \\ \text { Pers. } & \text { Persae } \\ \text { Supp. } & \text { Supplices }\end{array}$

Alcm. Alcman

AP Anthologia Graeca

Arist. Aristoteles

Ar.Byz. Aristophanes Byzantius

Arn. Arnobius

Cic. Cicero

Leg. De Legibus

Clem. Al. Clemens Alexandrinus

Strom. Stromateis

Cons. VII Constantinus VII

D.S. Diodorus Siculus

EM Etymologicum Magnum

Erot. Erotianus

Eur. Euripides

Ba. Bacchae

Eust. Eustathius

Ad Il. Commentarii ad Homeri Iliadem

H. Hesychius

Hippon. Hipponax

Hdt. Herodotus

Il. Iliad

Iuu. Juvenalis

Sat. Satirae

Liv. Titus Livius ppp. passive past participle

pres. present

prep. preposition

prev. preverb

pron. pronoun

pass. passive

ptc. participle

rel. relative

subj. subjunctive

sg. singular

s.u. subuoce

them. thematic

uel sim. or similarly

voc. vocative
Plin. C. Plinius Secundus (major)

HN Historia Naturalis

Ps.-Plu. Plutarchus

Fluv. De Fluuiis

Od. Odyssey

Orph. Fr. Orphica Fragmenta

Ov. Ovidius

Fast. Fasti

Met. Metamorphoses

Paus. Pausanias

Philyll. Philyllius

Pi. Pindarus

N. Nemean

Plato Plato

Cra. Cratylus

S. Sophocles

Fr. Fragmenta

oC Oedipus Coloneus

Socr.Sch. Socrates Scholasticus

HE Historia eclesiastica.

St.Byz. Stephanus Byzantius

Str. Strabo

Th. Thucydides

Verg. P. Vergilius Maro

Aen. Aeneis

$\mathrm{X}$ Xenophon

HG Historia Graeca (Hellenica) 


\subsection{Conventions}

\subsubsection{Linguistic conventions}

$>\quad$ becomes by regular phonological development

$<\quad$ reflects by regular phonological development

(?) meaning uncertain

* X a reconstructed item of a proto-stage

〈X〉 spelled with the symbol X

/X/ the phoneme X

$Y=X \quad$ clitic elemen

Y-X morphological segmentation of a word: prefixes, suffixes, endings, etc.

\# $\quad$ word final

\subsubsection{Epigraphical conventions}

$<\alpha \beta>\quad$ Characters erroneously omitted by the engraver. Restored or corrected by the editor.

$[\alpha \beta] \quad$ Letters missing from the original text due to lacuna. Restored by the editor.

[.] A lacuna or gap in the inscription, not restored by the editor, extent known. Each dot counts as one estimated letter.

[ ] A lacuna or gap in the inscription, not restored by the editor, extent known but difficult to calculate a number of letters lost.

[---] A lacuna or gap in the inscription, not restored by the editor (extent unknown).

[-?-] Unknown if a lacuna or gap must be suggested to the inscription.

$\{\alpha \beta\} \quad$ Letters in the text considered erroneous and superfluous by the editor.

$\llbracket \alpha \beta \rrbracket \quad$ Deleted letters by the engraver and legible.

$\alpha(\beta) \quad$ Abbreviation in the text, expanded by the editor.

$\alpha \beta \quad$ Characters damaged or otherwise unclear in the text, ambiguous outside of their context.

$\alpha^{2} \beta^{?} \quad$ A very dubious reading.

... Traces of letters on the surface, insufficient for restoration by the editor.

$\alpha \mid \beta \quad$ Line feed or, when the text is read in more than one face, the corner.

uac. Space left empty (uacat) on the stone. In OPhr. context it is not given in italics.

$\alpha \cdot \beta \quad$ Use of interpunctions, the number of dots used is the same in the inscription $(\cdot,:,:,:)$.

$\alpha \beta \quad$ Word boundary considered by the editor. When in the inscription spaces are used for that purpose it is specified.

$\alpha \beta \quad$ Ligature of letters.

$\alpha \beta \quad$ Letters corrected by the editor.

$\leftarrow \quad$ Sinistroverse line. Unless otherwise noted, the following lines are also sinistroverse.

$\rightarrow \quad$ Dextroverse line. Unless otherwise noted, the writing is supposed to be dextroverse. This sign is only used after sinistroverse mark. Unless otherwise noted, the following lines are also dextroverse.

$\rightarrow \quad$ Arrow incised.

se Hedera.

$\Psi$ Cross. 



\section{Direct sources for the Phrygian language: the epigraphical subcorpora}

Traditionally, the Phrygian epigraphical material is divided into two separate subcorpora: Old Phrygian (or Paleo-Phrygian) and New Phrygian (or Neo-Phrygian). ${ }^{5}$ There are several reasons for this division. The two kinds of inscriptions attest to different stages of the Phr. language, they are written in two different alphabets, the materials themselves are highly dissimilar, and even the locations of the findings differ.

The Old Phrygian subcorpus as considered here (see the Catalogue) consists of 395 inscriptions of many different typologies found across a huge area and dated between ca. 800 and $330 \mathrm{BC}$. At the start of this period Phrygia was an independent region (though it is unclear if such a political organisation ever existed as one unified state) but it fell under the Lydian Hegemony (beginning at some point toward the end of the $7^{\text {th }}$ c. BC) $)^{6}$ until the period of Persian rule, which lasted two centuries (ca. 540-330 BC). ${ }^{7}$ Although CIPPh and its supplements (Brixhe 2002a and 2004a) contain most of the known OPhr. inscriptions, some entries consist of nonverbal graffiti. For this reason, W-103, G-208, NW-101a, NW-107 and NW-115 are excluded from the present compilation. By contrast, other Phr. inscriptions not included in CIPPh (nor in the supplements) are considered here. In any case, most were also edited by Brixhe (sometimes in collaboration with other scholars), ${ }^{8}$ so their consideration as Phr. is endorsed by the main authority in this field. Texts not considered by Brixhe are restricted to three seals ${ }^{9}$, two graffiti from Kerkenes Da $\breve{g}^{10}$ and one isolated graffito on an orthostat. ${ }^{11}$ In addition, an unpublished text on a block stone is included. ${ }^{12}$ Because of the importance and influence of CIPPh and its supplements, its enumeration is followed in this dissertation, with only the non-verbal entries omitted. Then, texts not hitherto included are added to this enumeration. On it, CIPPh divided the material into epigraphical areas denoted by the initial of the given name, thus: $\mathrm{M}$ - of Midas City, W- of West Phrygia, B- of Bithynia, G- of Gordion, C- of Central Phrygia, P- of Pteria, ${ }^{13} \mathrm{~T}$ - of Tyana, NW- of North West Phrygia (Dorylaion), Dd- of Divers Documents and HP- of hors de Phrygie. A new area is added here: K- of Kerkenes Dağ. It must be added that most of the OPhr. inscriptions are preserved in museums or, when monumental, in situ. ${ }^{14}$

\footnotetext{
${ }^{5}$ The terms Paleo- and Neo-Phrygian were mostly used in the earliest works devoted to Phrygian (see, e.g., Ramsay 1905), while Old-Phrygian and New-Phrygian are now more common (especially after the publication of Lubotsky's papers). On the formation of the Phrygian corpus and the first approach to the language, see the exhaustive research by Morante Mediavilla 2010.

${ }^{6}$ Details of this Lydian period are mainly lost, see Payne and Wintjes 2016, 31-37.

${ }^{7}$ A very useful and up-to-date comprehensive overview of Phrygian history between 900 BC and 100 AD is provided by Thonemann 2013, who expands on the classic overview of Phrygian in the Iron Age by Barnett 1967.

${ }^{8}$ W-11 in Brixhe \& Sivas 2002. M-11, M-101, W-13 and W-102 in Brixhe \& Sivas 2003. W-12, W-101 in Bilgen, Brixhe \& Coşkun 2011. G-346 in Liebhart \& Brixhe 2009. NW-120 - NW-139 in Brixhe \& Sivas 2009. K-01, K-101, K-102, K-103 and K-104 in Brixhe \& Summers 2006. HP-02 and HP-115 in Brixhe \& Keles 2011. B-08 in Brixhe \& Vottéro 2016.

${ }^{9}$ G-347 (first published by Körte \& Körte 1904), P-108 (Bittle \& Güterbock 1935, 79-80) and HP-116 (Boehmer \& Güterbock 1987, 86). Genz $(2009,310)$ claimed that these seals contain a Phr. text, although no reading is available.

${ }^{10} \mathrm{~K}-102, \mathrm{~K}-103$ and $\mathrm{K}-104$, which have been published in the bulletin of the on-going dig, Kerkenes News, and on the website of the archaeological project (with good photographs).

${ }^{11}$ HP-01 (Börker-Klähn 1994).

${ }^{12} \mathrm{NW}-01$. Although I was able to view them in November 2015 at Eskişehir Museum, I cannot provide a good reading of the few letters that are legible.

${ }^{13}$ Although it is not a good identification, see $\$ 2.1 .1$.

${ }^{14}$ Lost inscriptions are B-04, P-01, P-101, T-01 and T-02.
} 
The New Phrygian subcorpus is greatly restricted in space and time: entries are dated to between the $1^{\text {st }}$ and $3^{\text {rd }} \mathrm{c}$. BC and appear only in the western part of ancient Phrygia. ${ }^{15}$ The subcorpus consists of 117 funerary inscriptions, most of them curses against desecrators added after a Greek epitaph. Two other differences with respect to the OPhr. corpus are that for the NPhr. inscriptions the Greek alphabet was used and most have been lost, so they are only known through the testimony of the first compilers. ${ }^{16}$ These inscriptions form a very consistent and homogenous subcorpus, very different to the one found in OPhr. The traditional numbering of the inscriptions consists of a number assigned to mark the time of discovery, following Ramsay's first collections. ${ }^{17}$ Here, however, the inscriptions are arranged according to the place in which they were found and each city has a number, which is followed by a second number for each inscription. ${ }^{18}$

A third stage of the Phr. Language, Middle Phrygian (MPhr), is sometimes also considered. It is represented by a single inscription found in Dokimeion (MPhr-01 = W-11), a Phr. epitaph consisting of six hexametric verses (Lubotsky 2017) written in eight lines. It is dated to the end of the $4^{\text {th }} \mathrm{c}$. BC or the beginning of the $3^{\text {rd }} \mathrm{c}$. BC, close in time to the Macedonian conquest, and can be considered the first Phr. text written in the Greek alphabet. Its phraseology has some echoes of the OPhr. epitaph B-07 but it anticipates phonetic and spelling features found in the NPhr. subcorpus (see 3.2.1. for more details). Because of its exceptionality, in the present collection it has been removed from the OPhr. list and classed as the sole example of the MPhr. subcorpus. Some graffiti from Gordion are ambiguous in terms of alphabet and could perhaps be added to this subcorpus. This is the case, e.g., of G-226 (found in a layer dated to the $4^{\text {th }}$ or $3^{\text {rd }}$ c. BC), G-244 ( $3^{\text {rd }}$ C. BC) and G-158 (ca. $200 \mathrm{BC}$ ). However, their language is also ambiguous, since the Phr. filiation is not conclusive. Despite these problems, their position in CIPPh is followed here, in the hope that new studies will shed light on this question.

\subsection{The Old Phrygian subcorpus 2.1.1. Contexts of the Old Phrygian inscriptions}

The OPhr. inscriptions are found across a huge area of central Anatolia (Map 1 and 2). Although there are isolated findings (e.g. the bronze bowls found in the Tumulus D of Bayındır, East Lycia), most of the inscriptions are found between the cities of Dorylaion (Eskişehir) and Kerkenes Dağ (likely the old Pteria). During the Iron Age, this vast territory would have

\footnotetext{
${ }^{15}$ Note that Dorylaion (Eskişehir) is the sole site where both old and New Phrygian inscriptions have been found (NW-inscriptions and NPhr. 1.1 and 1.2, respectively).

${ }^{16}$ Only 14 inscriptions are preserved in known places: 1.2 (98), 2.2 (130), 3.1 (97), 6.1 (88), 12.1 (121), 16.1 (116), 17.5 (91), 17.6 (119), 19.2 (129), 20.2 (128), 22.2 (118), 25.1 (115), 25.2 (126) and 33.3 (127).

${ }^{17}$ Ramsay 1887 and 1905. He gathered some inscriptions found before (by Hamilton 1842 and Seetzen, in CIG III). After these collections, Calder, who accompanied Ramsay on some epigraphical expeditions, added most of the known NPhr. inscriptions in three papers entitled "Corpus Inscriptionum NeoPhrygiarum", 1911, 1913 and 1926, and in different volumes of MAMA (I, IV, V, VI, VII and VIII). Since the late-1970s, Brixhe (with some collaboration) has published more inscriptions: Brixhe 1978, Brixhe \& Waelkens 1981, Brixhe \& Neumann 1985, Brixhe \& Drew-Bear 1997, Brixhe and Drew-Bear 2010 (considered not NPhr. but Hellenistic). Other scholars have also published new inscriptions: LamingerPascher 1984, Mitchell 1993 and Drew-Bear, Lubotsky \& Üyümez 2008. See Ligorio \& Lubotsky 2013, 182 for the continuation of the traditional enumeration.

${ }^{18}$ A similar attempt to catalogue was first suggested by Morante Mediavilla in her unpublished PhD dissertation (2007), where she labelled each inscription with the name of the place where it was found followed by a number (one can find this system in the HLuw. corpus). Nevertheless, the labels were not applied systematically to the whole Phrygian corpus because this was not the author's intention. I also used the same system given here in my master's dissertation (2013), although the enumeration has since been revised.
} 
included the most important Phrygian cities: Midas City (Yazılıkaya), Gordion (Yassıhüyük), Karahüyük, Hattuša (Boğazkale, formerly Boğazköy, the Hittite capital) and Alacahöyük.

Gordion is by far the most important site, with 259 inscriptions $-65.6 \%$ of the whole OPhr. subcorpus - found in this city to date (labelled with G-). This city was the seat of a Phrygian royal house and is often considered "the Phrygian capital" (e.g. Rose 2012, 1), as Greek sources report. Its relevance in the Anatolian Iron Age plateau is a matter of record. However, it is still debated whether Gordion was indeed the capital of a unified Phrygia (i.e. the capital of the entire "kingdom of Phrygia" by Rose and Darbyshire 2011,2) or the capital of one of several Phrygian chiefdoms. The difficulties of the traditional view of Gordion as "the Phrygian capital" are excellently summarised by Genz (2011, 360-361):

"the archaeological evidence does not unanimously support the idea of a unified Phrygian kingdom encompassing most parts of Central Anatolia with Gordion as its capital. While Gordion from at least the 9th century onwards was clearly a centre of supra-regional importance, several elements necessary for viewing it as the capital of an empire-like polity seem to be lacking. So far no evidence for any kind of administrative system involving the use of seals and writing has come to light in Gordion. Furthermore, while the richly equipped tumulus burials testify to the fact that persons of a high social rank were buried there, it has to be pointed out that similar tombs - although generally less well investigated - have been found at several other sites in Central Anatolia, for instance at Ankara, Kaynarca and Tatarl. This rather seems to indicate the existence of several independent political entities - best termed chiefdoms - in Central Anatolia during the Middle Iron Age and the earlier part of the Late Iron Age. Thus the picture emerging from the archaeological record resembles rather Early Iron Age societies from Europe such as the Hallstatt culture than contemporaneous Near Eastern states such as Assyria or Urartu. A similar political organisation in fact is attested for Tabal, where Assyrian sources recorded as many as 24 kings ruling simultaneously".

In any case, Gordion has a special status in Iron Age and Phrygian studies because its citadel mound, tumuli and surrounding area provided an extraordinary wealth of information about central Anatolia in this period. Since the Körte brothers' excavations in the early $20^{\text {th }} \mathrm{c}$., Gordion has been considered "one of the most important sites in the Near East because of its chronology" (Rose \& Darbyshire 2011, 2). Indeed, given the unique preservation of the city's stratigraphy and the possibility of dating its phases not only relatively but also absolutely (using modern techniques such as dendrochonology and radiocarbon dating ${ }^{19}$, see Table 1), Gordion is used by archaeologists as the basis for chronologies of less well-known sites. The city provides a record of periods of construction and destruction that can be connected to historical facts known through literary sources.

Although information is available for a period covering five millennia (from the Early Bronze Age to the present day), it is the Gordion Iron Age ( $1^{\text {st }}$ millennium $\left.B C\right)$ that is most useful for the study of central Anatolia. More important, however, for the study of the history of the alphabet is that Gordion is the location in which the oldest alphabetical inscriptions appear. The context of the first Phr. inscriptions (G-03, G-104, G-237 and G-249, according to Brixhe 2004b, 276-278) is the Destruction Level, a layer in the Cidadel Mound (the palatial area of the city), which attests a great fire. It was first considered evidence of the Kimmerian invasion (710$709 \mathrm{BC}$ ) by Young ${ }^{20}$, but following a re-examination and reevaluation of the material lead by

\footnotetext{
${ }^{19}$ On dendrochronology applied to Gordion, see Kuniholm and Newton $2011.0 n{ }^{14} \mathrm{C}$ results, see Manning and Kromer 2011.

${ }^{20}$ Young $(1981,272)$ connected the archaeological evidence to the information provided by Str. 1.3.21: oi

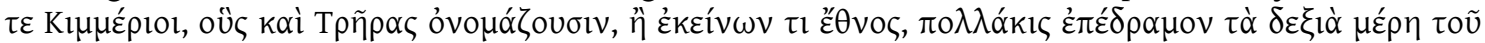

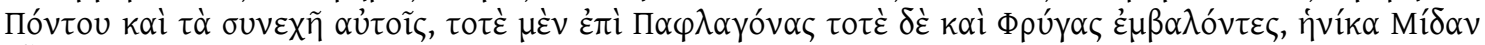

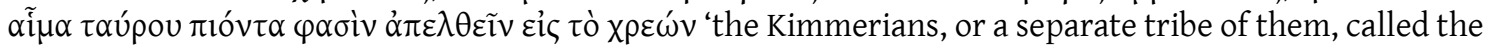


DeVries, this layer must now be considered the consequence of an accidental burning dated ca. $800 \mathrm{BC}$ (see § 3.1). The reevaluation of this dating, and that of the Tumulus MM (the "Midas Mound"), had a bearing on our understanding of the whole Gordion site and, by extension, of those whose chronologies were based on the original datings.

Table 1 Gordion (Yassihöyü̈) Chronology according to Rose and Darbyshire (2011, 2).

\begin{tabular}{|c|c|c|c|}
\hline YHSS Phase & Period Name & Approximate Dates & Cultural Affiliation \\
\hline 0 & Modern & 1920 s & Turkish \\
\hline 1 & Medieval & $10^{\text {th }}-15^{\text {th }}$ centuries AD & Unknown/Selcuk \\
\hline 2 & Roman & $1^{\text {st }}$ century BCE $-4^{\text {th }}$ century AD & Roman \\
\hline 3A & Late Hellenistic & $260(?)-100 \mathrm{BC}$ & Galatian \\
\hline 3B & Early Hellenistic & $330-260(?) \mathrm{BC}$ & Phrygian/Greek \\
\hline 4 & Late Phrygian & $540-330 \mathrm{BC}$ & Phrygian/Persian \\
\hline 5 & Middle Phrygian & $800-540 \mathrm{BC}$ & Phrygian \\
\hline $6 \mathrm{~A}-\mathrm{B}$ & Early Phrygian & $900-800 \mathrm{BC}$ & Phrygian \\
\hline 7 & Early Iron Age & $1100-900 \mathrm{BC}$ & Phrygian \\
\hline $9-8$ & Late Bronze Age & $1400-1200 \mathrm{BC}$ & Hittite \\
\hline 10 & Middle Bronze Age & $1600-1400 \mathrm{BC}$ & Hittite \\
\hline
\end{tabular}

Despite the reevaluation and our good knowledge of Gordion, most of the inscriptions remain undated or are, at best, only classifiable to one of the two major periods which provide epigraphical material: Middle Phrygian (MP), dated between the reconstruction after the destruction level (c. $800 \mathrm{BC}$ ) and the conquest of the Persians (540 BC), including the Lydian hegemony, or Late Phrygian (LP), which corresponds to the Achaemenid period (540-330). The reason for such a relative dating is that most of the epigraphical material was found in fillings containing a mixture of broken artefacts from several periods or artefacts reused in a new building (as is the case of many stone inscriptions). Unfortunately, sherds without clear filiation (leaving aside the kind of paste) are all too common in this scenario and do not provide much information. Moreover, surface inscriptions are found that have no known context (e.g. G-09) or clear origin (G-10). Of course, some inscriptions appeared in clearer contexts associated with buildings or areas, such as the Middle Phrygian megara or other buildings (see Map 3 for their locations), in particular the Citadel Mound, the core of Gordion with the most sumptuous buildings, where digging has been more extensive and more inscriptions have been found.

Tumulus MM is also a very important site with regard to chronology. It is the largest tumulus of the 151 standing mainly in the northwest of the city and was not looted when Young opened it in 1957. Young thought that the tomb was dated to 725-718 BC, although today it is known that it was closed ca. 740 BC (Kuniholm \& Newton 2011, 92-94). So, the valuable material found inside, corresponding to a funerary banquet, can be perfectly dated. Inscriptions were found on jars (G-109), silver and bronze bowls (G-105, G-106, G-107 and G-108), and also on a beam (G-346). This is a useful finding, since it allows us to date similar objects found in other less well-known tumuli (see, e.g., the Ikiztepe Tumulus, Lydia, or Tumulus D from Bayındır, East Lycia). All of these inscriptions contain PNs. Other areas of Gordion in which inscriptions appeared are the Küçük Höyük (a sector preserved because it was buried by a Persian assault ram, see DeVries 2011, 17), the surrounding wall, the Lower Town (which has not been dug), and the house under Tumulus $\mathrm{E}$ (dated to before the $6^{\text {th }} \mathrm{C}$. BC, when the tumulus was built on it).

Karahüyük, an artificial mound (tepe) located between Hacituğrul and Yenidoğan, is not far from Gordion (20 km to the northeast). It was inhabited since the Bronze Age. The

Treres, have frequently overrun the countries to the right of the Euxine and those adjacent to them, bursting now into Paphlagonia, now into Phrygia, as they did when, according to report, Midas came to his death by drinking bull's blood.' 
inscriptions found there, grouped under the label C- in CIPPh (I, 215-222), are engraved on a fragment of stone (C-01) and a fragment of a plate (C-101), a handle (C-102) and a kind of lekythos (C-103). No datings are available for these materials.

A second important site where many OPhr. inscriptions (labelled $\mathrm{M}-$ ) were found is Midas City (in Turkish Yazılıkaya, 'inscribed rock', also Midas Kale, 'Midas' Fortress'). ${ }^{21}$ This is the most impressive Phrygian site, since it is a mountain fortress where many cultic monuments devoted to the Mother-Goddess Matar were built during the MP period, although

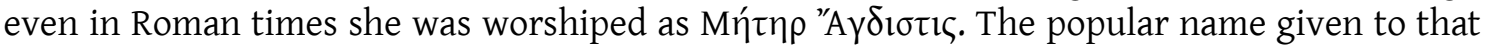
site, Midas City, is a modern creation taken from the main façade, devoted to Midas (M-01a). ${ }^{22}$ Indeed, in the city 16 inscriptions incised on cut-rock monuments ("altars", idols and façades) were found, as well as one graffito on a sherd (M-101). These monuments are dated to the MP period (mostly in the first half of the $6^{\text {th }} \mathrm{c}$. BC, although some are a little earlier). Façades are the most typical Phrygian monument and can be found in many parts of West Phrygia (especially the Highlands).

Another important site is Dorylaion (Karacahisar, a höyük near Eskişehir), located to the North-West of Phrygia, an ancient city where 28 graffiti incised on sherds (few containing more than a letter) and one stone inscription have been found. All these inscriptions (the NWgroup) are dated to the LP period (540-330 BC). ${ }^{23}$

Under the label P-, derived from Pteria, CIPPh (I, 223-251) grouped inscriptions from four sites: Alacahöyük, Kalehisar, Pazarlı and Boğazköy. Brixhe and Lejeune (in CIPPh I, 224) considered that Alacahöyük corresponds to Pteria, an important capital of Cappadocia under the Assyrian Empire, finally conquered and destroyed by the Lydian king Croessus who defeated Cyrus the Great in 547 BC, according to Hdt. 1.76. Although this identification is far from confirmed and Kerkenes Dağ is a more likely candidate ${ }^{24}$ the Assyrian influence seems to be attested in the patronymic kanutieivais, containing the Assyrian PN Kanutî (see § 4.6.6). The inscriptions found in this area were engraved on block stones (P-01, P-02, P-04), a slab (P-03), a sculpture of a lion (P-05) $)^{25}$ and a rock-cut altar (P-06) and contain similar series to PN. All of them are tentatively dated to the MP period but their archaeological context is unknown and some of the blocks were reused in the building of modern houses. The old Hittite capital, Hattuša (Boğazkale, formerly Boğazköy), was also occupied by Phrygians, as were many former Hittite cities and settlements. This city yielded seven graffiti on sherds dated to the MP period, corresponding to the period Büyükkale Ic-a. ${ }^{26}$ The third site in this area is Pazarl (about $29 \mathrm{~km}$ $\mathrm{NE}$ of Alacahöyük), where a Late Iron Age fortification is located. ${ }^{27}$ The sole inscription from this site (P-101) is a graffito incised on the bottom of a pot dated to the $7^{\text {th }} \mathrm{C} . \mathrm{BC}$ (according to Bossert 1942, 289).

The most promising site for forthcoming research is Kerkenes Dağ, a fortress located to the North of Cappadocia. The site was built ex nouo and inhabited for only a short period in the first half of the $6^{\text {th }}$ c. BC. Nevertheless, it is the largest city in Central Anatolia and has been

\footnotetext{
${ }^{21}$ For a detailed overview of the site, see Berndt 2002, although the chronology of the rock-cut monuments used here is provided by Berndt-Ersöz 2006.

${ }^{22}$ This site is very likely to be the mountain Agdus attested by Arn., Adversus Nationes 5.5.1. Note that the epithet of the local Mother-Goddess worshipped there must derive from this oronym. I will deal with this question in a future study.

${ }^{23}$ All these inscriptions were published by Brixhe 2004a, 3-24.

${ }^{24}$ Note, however, that neither city is located near Sinop on the Black Sea, as Herodotus reports.

${ }^{25}$ This sculpture is dated to the Imperial Hittite period, although the inscription is clearly a later Phrygian addition. See Summers \& Özen 2012, 516-518.

${ }^{26}$ The Phrygian inscriptions at this site were first published Neumann 1975, 81-82. On the comparison between the chronology of Gordion and Boğazkale, see Genz 2009, 311 and 2011, 334.

${ }^{27}$ The site was occupied before, since there are also considerable Chalcolithic and Hittite remains. Nevertheless, the Phrygian period is the most important one. The depiction of Phrygian soldiers on terracotta is the most famous finding. See Koşay 1941, Åkerström 1966, 167-89 and Genz 2011, 34.
} 
identified with Pteria by Summers (see 1997, see also Brixhe \& Summers 2006, 93-111, Draycott \& Summers 2008, 4 and Genz 2011, 343). The city, which had many buildings including megara and was defended by a wall with seven gates, was an ambitious project. At one of these, the Cappadocian Gate, a broken stela was found containing a monumental inscription (K-01), as well as two graffiti on sherds (K-103 and K-104), while two further graffiti were found in the palatial complex (K-101 and K-102). Although no more inscriptions have been discovered to date ${ }^{28}$ new findings are expected.

OPhr. inscriptions are not only found in the area traditionally considered to be occupied by Phrygians. Daskyleion (modern Ergili), the seat of the Hellespontic Phrygia satrapy (OP tayaiy drayahy $\bar{a}$ 'those (peoples) that (are) in the sea' DB 1.15), ${ }^{29}$ is also an important site for Phrygian epigraphy during the Achaemenid Period (= LP). This multicultural city provides inscriptions written in Old Babylonian, Old Persian, ${ }^{30}$ Aramaic, ${ }^{31}$ Greek $^{32}$ and Phrygian. Phrygian inscriptions are found on funerary stelae (B-06 and B-07), Attic pottery (B-101, B-102 and B-103), northwestern Anatolian amphorae (B-104, B-105 and B-106), a Mysian plate (B-107) and an unclassified pottery artefact (B-108). Note that these materials are not related to the Phrygian tradition and Daskyleion is the sole location where Old Phrygian epitaphs have been found.

In the territory of Bithynia we know of five isolated inscriptions engraved on rock. When possible, they have been dated to the Achaemenid period (= LP). B-01 and B-08 are large inscriptions on rock associated with the cult of the Mother-Goddess (in B-01 the niche was also engraved). ${ }^{33}$ B-02 is a Greco-Persian funerary stele found near Afşarıvvel. B-03 and B-04 are inscriptions engraved on stone blocks without a clear function. The first was found at Firanlar, while B-04 was found at Üyücek. Both are undated. Finally, B-05 is a large Greco-Persian stele found at Vezirhan and dated to the $5^{\text {th }} \mathrm{C}$. BC. It contains a bilingual text with a lex sacra. It is the largest Phrygian text, while the Greek part is a short summary of the contents.

Other findings are even more isolated. A large stone slab was found in the centre of Kocagür, perhaps the ancient Pitya (14 km from the ancient Parion, in Bithynia). However, its context is unknown (Brixhe \& Keleş 2011). An undated clay spindle (HP-101, Dinç \& Innocente 1999) appeared in a höyük at Çamönü (ancient Karasonya), in northern Lydia (Gusmani 1988) and, also from Lydia, a silver cup (HP-102) was found by clandestine diggers in the main tumulus of Ikiztepe. This last object is similar to the ones found in Gordion Tumulus MM and in Tumulus D at Bayındır, East Lycia, where silver cauldrons (HP-103 and HP-104), a silver ladle (HP-105), a silver bowl (HP-106) and bronze bowls (HP-107, HP-108, HP-109, HP-110, HP-111, HP-112 and HP-113) were discovered (Varinlioğlu 1992). These objects are dated to the mid- $8^{\text {th }} \mathrm{c} . \mathrm{BC}$, close in time to the main Gordion tumulus, and were very likely gifts between sovereign allies from Bayındır.

Moving to the east, the most relevant site is Tyana (Luw. Tuwanuwa) in Tabal, the heartland of Luwian-speaking territory. In this city fragments of three stelae (T-01, T-02 and T03) have been found, very likely related to Midas' campaigns against Sargon II (final quarter of the $8^{\text {th }}$ c. BC). Also in a Neo-Hittite State, an undated Phrygian PN was incised on an orthostat

\footnotetext{
${ }^{28}$ Scott Branting, p.c. $19 / 09 / 2017$.

${ }^{29}$ See Schmitt 1972. Greek sources are Hdt. 3.120.2 and Th. 1.129.1.

${ }^{30}$ Both languages are only found in bullae with impressions of stamp and cylinder seals. Aramaic and Greek are also found in such artefacts, on which see Balkan 1959.

${ }^{31}$ Ten bullae (Balkan 1959, 128 and Lemaire 2000, II.4 no. 1-4) and two well-known Aramaic funerary stelae (see, e.g., Dupont-Sommer 1966, Lipiński 1975a, 150-153, Altheim-Stielh \& Cremer 1985 and Lemaire 2000, II.1 and II.2).

${ }^{32}$ After the Macedonian conquest, the site was Hellenised; however, before this only a single bulla is written in Greek (Balkan 1959, 128 = DS 144 in Kaptan 2002). The text may be read as ['A $\tau^{\prime}$ '] $\mu \alpha \varsigma$ according to Kaptan (2002 I, 173 and 2013, 31 fn. 18).

${ }^{33}$ On the B-01 monument see CIPPh I, 62 and Berndt-Ersöz 2006, 239-240 (with exhaustive references). On B-08, a recent finding, see Brixhe \& Vottéro 2016.
} 
from Karkemiš which contains an earlier HLuw. inscription (850 BC).$^{34}$ In addition, a seal-stamp of Neo-Assyrian style appeared at Nemrud Dağ (Boehmer \& Güterbock 1987, 86) 35 and a stone bowl was found in Alişar Höyük (Cappadocia, Brixhe \& Summers 2006, 134). Finally, the most interesting text found outside Phrygia is the clay tablet in the Persepolis Fortification Archive, and dated to the end of the $6^{\text {th }} \mathrm{C}$. BC or the first half of the $5^{\text {th }} \mathrm{c}$. BC. This extraordinary piece must of course be related to the Achaemenid administration (Brixhe 2004a, 118-126).

\subsubsection{Old Phrygian writing materials}

Old Phrygian has been identified on four kinds of materials: pottery, stone, metal and wood (see Table 2). Pottery is by far the most attested material, accounting for almost $77 \%$ of the subcorpus: 304 of the 395 known OPhr. inscriptions were found on pottery. Unfortunately, many of these inscriptions (125) were found on unclassifiable sherds ${ }^{36}$ that do not provide useful information about either the form or function of the original piece. Those pots that have been classified are objects for daily life, especially for containing food and drinks (water and beer), and are mostly of local facture: 54 cups ${ }^{37} 27$ pithoi, ${ }^{38} 24$ bowls, ${ }^{39} 17$ pots, ${ }^{40} 16$ vessels, ${ }^{41} 11$ jugs, ${ }^{42} 3$ jars, 3 saucers, 3 North-west Anatolian amphorae, 3 plates, 2 jugs, 1 dinos, 1 marmite, 1 oenochoe, 1 tile, 1 mortar and 1 clay spindle. ${ }^{43}$ In Bithynia and once in Gordion, Phrygian inscriptions were also incised on Attic importations: 3 Attic cups (B-101, B-102 and B-340), 1 Attic plate (G-341) and 1 Attic kantharos (B-103). To this list, a Cyprian cup found in Gordion can also be added (G-102).

Most of these graffiti on vessels were incised after firing and may be interpreted as owner's marks. Note that graffiti consisting of PNs (complete or abbreviated) are abundant in this category of materials. Even the numerous graffiti consisting of a sole letter can be interpreted as the owner's first initial. However, there remains a degree of ambiguity, and the use of these letters as a mark without linguistic referent cannot be ruled out. Indeed,

\footnotetext{
${ }^{34}$ The text was identified by Börker-Klähn 1994. This scholar also considered some graffiti from Hamath, however they are less clearly Phrygian and, worse still, some of the shapes of the "letters" are unparalleled in the Phrygian corpus.

${ }^{35}$ This inscription was recently claimed as Phrygian by Genz 2009, 310, although no reading is provided. ${ }^{36}$ M-101, W-101, W-102, G-111, G-112, G-120, G-144, G-154, G-155, G-157, G-159, 163, G-164, G-168, G-179, G-180, G-182, G-184, G-185, G-186, G-187, G-189bis, G-192, G-196, G-197, G-201, G-206, G-207, G-209, G-217, G-218, G-220, G-221, G-222, G-223, G-232, G-233, G-235, G-236, G-240, G-247, G-251, G-252, G-253, G-255, G256, G-258, G-259, G-263, G-264, G-267, G-268, G-270, G-273, G-275, G-280, G-281, G-286, G-287, G-290, G291, G-292, G-294, G-298, G-299, G-300, G-303, G-305, G-306, G-307, G-308, G-309, G-311, G-312, G-313, G314, G-315, G-316, G-317, G-318, G-320, G-322, G-324, G-325, G-327, G-328, G-329, G-330, G-332, G-333, G334, G-335, G-343, G-344, C-102, P-102, P-103, P-105, P-106, P-107, K-103, NW-103, NW-104, NW-105, NW111, NW-112, NW-113, NW-114, NW-116, NW-119, NW-120, NW-121, NW-122, NW-123, NW-124, NW-125, NW-127, NW-128, NW-129, NW-133, NW-134, NW-135, NW-136, NW-137 and NW-139.

${ }^{37}$ G-135, G-141, G-146, G-156, G-158, G-160, G-161, G-162, G-167, G-169, G-172, G-173, G-181, G-183, G-188, G-210, G-210, G-215, G-216, G-227, G-228, G-234, G-244, G-248, G-254, G-257, G-265, G-269, G-272, G-277, G278, G-282, G-285, G-289, G-295, G-297, G-304, G-319, G-336, G-337, G-339, G-345, P-104, NW-106, NW-108, NW-109, NW-110, NW-117, NW-118, NW-126, NW-130, NW-131, NW-132 and NW-138.

${ }^{38}$ G-116, G-117, G-122, G-126, G-143, G-147, G-150, G-151, G-152, G-171, G-174, G-191, G-193, G-200, G-204, G-219, G-230, G-231, G-237, G-238, G-239, G-271, G-283, G-301, G-302, G-323 and G-326.

${ }^{39}$ B-108, G-104, G-115, G-118, G-119, G-121, G-133, G-142, G-153, G-165, G-194, G-195, G-202, G-203, G-205, G-208, G-241, 242, G-243, G-246, G-276, G-293, K-101, NW-102 and HP-115.

${ }^{40}$ G-101, G-103, G-113, G-114, G-123, G-125, G-128, G-132, G-140, G-148, G-149, G-175, G-189, G-214, G-288, $\mathrm{P}-101$ and $\mathrm{K}-105$.

${ }^{41}$ G-124, G-127, G-130, G-137, G-166, G-170, G-176, G-177, G-190, G-198, G-211, G-229, G-260, G-262, G-274 and G-279.

${ }^{42}$ G-131, G-134, G-139, G-145, G-199, G-250, G-284, G-310, G-338, G-342 and K-102.

43 Dinos: G-138. Jars: G-109, G-226 and G-296. Saucers: G-213, G-225 and G-261. North-west Anatolian amphorae: B-104, B-05 and B-106. Jugs: G-110 and G-129. Plates: G-266, C-101 and B-107 (Mysian). Marmite: G-224. Oenochoe: G-331. Tile: G-321. Mortar: G-245. Clay spindle: HP-101.
} 
commercial marks are also known in this collection, among which "capacity marks" are the clearest (see § 3.1.7.3). Only two examples of "verbal" graffiti incised before firing are found: $\mathrm{W}-101$ and $\mathrm{K}-104 .{ }^{44}$ of course, being incised before firing implies that the inscriptions were made in the potter's workshop. There are certain reasons why a potter marks their products: to identify the potter or his establishment or to denote the potential capacity of the pot, its function or the place in which it should be stored. However, for the two examples considered here the reason is unknown. In any case, W-101 bears only a single letter 〈p〉, which seems to be a PN abbreviation expanded after firing as p?asakas, while K-104 consists only of a possible letter «n〉 and a non-verbal mark cannot be ruled out.

Leaving aside this common material, there are two special artefacts made of clay. The first is a terracotta disc found in Dorylaion, NW-101, with an obscure inscription. Its function and significance are unclear. ${ }^{45}$ The second is a clay tablet, HP-114, found in the Persepolis Fortress Archive among Elamite artefacts. Because there are no parallels for such material in Phrygia and the place where it was found, this clay tablet must be related to the Persian administration. Indeed, although it is broken and difficult to read, it appears to be a list of workers and people like those found in Elamite in the same archive.

The second most productive material is stone, on which 72 inscriptions were found. As is the case of pottery, there is a rich typology of stone inscriptions. Cult façades, associated with the Mother-Goddess, are the most representative form of Phrygian rock-cut monument, on which ten inscriptions were engraved: M-01a, M-01-b, M-05, W-01a, W-01b, W-01c, W-02, W-03, W-05a and W-06 (perhaps also M-11). Sometimes, the façades have a niche where inscriptions were also engraved: M-01c, M-01d, M-01e, M-01f and W-05b. Although there is a niche with an inscription in a step-monument, W-04, other niches with inscriptions are independent: W-07 and B-01 (B-08 was found near this inscription).

Rock-cut step-monuments, sometimes considered altars because of the presence of iconic idols, are another kind of monument with OPhr. inscriptions: M-02, M-03, M-04, M-06, W-11 and P-06. Nevertheless, Phrygian inscriptions were also engraved on unworked rocks. Of these, three are on sole lone rocks, W-08, W-09 and W-10, while the others are on the walls of larger rock formations: M-07, M-08 and W-13.

As can be seen, all of the above inscriptions were found basically in Midas City and West Phrygia. Bithynia, Gordion and East Phrygia provide ten inscriptions on worked blocks of stone: B-03, B-04, G-03, G-04, G-11, P-01, P-02, P-04, NW-01 and HP-01. Five stone slabs with inscriptions were also found in Gordion and East Phrygia: G-01, G-02, C-01, P-03 and HP-02. Two small stone idols with inscriptions were found in Gordion: G-136, a falcon-shaped idol, and G-178, anthropomorphic. Text on a large statue was only found in Alacahöyük (near the ancient capital of the Hittites, Hattuša), on an unfinished statue of a lion (P-05). Stelae have only been found on the periphery of Phrygia. Indeed, four stelae (of the Greco-Persian type) have been found in Bithynia, B-02, B-05, B-06 and B-07, as well as fragments of three stelae of Assyrian-type in Tyana, T-01, T-02 and T-03, and one in Kerkenes Dağ, K-01. Unfortunately, eight inscriptions are preserved on stone fragments whose original shapes and typologies are unknown: M-09, M10, W-12, G-05, G-06, G-07, G-08, G-09 and G-10.

Small artefacts containing inscriptions have also been found. There are two seals made of (semi-)precious gemstones, Dd-101 (Chalcedony) and Dd-103 (Agate), an alabaster weight (G249 , reused as a loomweight in Gordion) and a mortar, G-164bis.

\footnotetext{
${ }^{44}$ This is not a surprising account when compared to Roller's compilation of non-verbal marks from Gordion (1987a, 1-7): of 560 marks, only 24 were incised before firing. There are also 16 examples of stamps, but these contain no letters, only triskeles, tetraskeles, ingo-shaped or asterisk marks.

${ }^{45}$ In the same city, another disc was found with non-verbal inscriptions (NW-101a, omitted from this dissertation). This disc is older than the first one. On both pieces, see Brixhe 2002a, 3-11, who suggests some possibilities.
} 
There are seventeen metal artefacts with a Phrygian inscription, pertaining to funerary banquets inside tumuli (Gordion MM, Ikiztepe and Bayındır). The most abundant are bronze bowls: G-105, G-106, G-107, G-108, HP-108, HP-109, HP-110, HP-111, HP-112 and HP-113. There are also three silver bowls (Dd-102, HP-106 and HP-107), two silver cauldrons (HP-103 and HP104), a silver cup (HP-102) and a silver ladle (HP-105). While most of the inscriptions were made by scratching the artefacts, on the bowls G-105, G-106 and G-107 they were made by smearing beeswax.

Finally, a list of names was found engraved on a wooden beam from Tumulus MM in Gordion. It is the sole example of a Phrygian inscription preserved on wood. There is no evidence for the use of perishable materials (papyrus, parchment) as writing supports for Phrygian, but it is a strong possibility, because the kind of epigraphic supports found to date are typically those used only marginally in other, better attested Near Eastern languages. 
Table 2 The Old Phrygian inscriptions according to writing material

\begin{tabular}{|c|c|c|c|}
\hline Material & Typology & No. of OPhr. inscriptions & Total \\
\hline \multirow{12}{*}{ Stone } & Façades & 10 & \multirow{12}{*}{74} \\
\hline & Stone blocks & 10 & \\
\hline & Niches & 9 & \\
\hline & Rock walls & 7 & \\
\hline & Stelae & 8 & \\
\hline & "Altars" & 6 & \\
\hline & Slabs & 5 & \\
\hline & Statues & 3 & \\
\hline & Seal & 5 & \\
\hline & Mortar & 1 & \\
\hline & Weight & 1 & \\
\hline & Undet. frag. & 9 & \\
\hline \multirow{25}{*}{ Pottery } & Unind. Sherds & 125 & \multirow{25}{*}{303} \\
\hline & Cups & 53 & \\
\hline & Pithoi & 27 & \\
\hline & Bowls & 24 & \\
\hline & Pots & 18 & \\
\hline & Vessels & 16 & \\
\hline & Jugs & 1 & \\
\hline & Attic cups & 3 & \\
\hline & NW Anat. Amph. & 3 & \\
\hline & Jar & 3 & \\
\hline & Saucers & 3 & \\
\hline & Jugs & 13 & \\
\hline & Plates & 2 & \\
\hline & Marmites & 1 & \\
\hline & Oenochoe & 1 & \\
\hline & Lekythos & 1 & \\
\hline & Tile & 1 & \\
\hline & Attic plate & 1 & \\
\hline & Attic kantharos & 1 & \\
\hline & Cyprian cup & 1 & \\
\hline & Mysian plate & 1 & \\
\hline & Mortar & 1 & \\
\hline & Terracotta disc & 1 & \\
\hline & Clay spindle & 1 & \\
\hline & Clay tablet & 1 & \\
\hline \multirow{7}{*}{ Metal } & Bronze bowls & 10 & \multirow{7}{*}{17} \\
\hline & Silver bowls & 3 & \\
\hline & Silver cauldron & 2 & \\
\hline & Silver cup & 1 & \\
\hline & Silver ladle & 1 & \\
\hline & Bronze & 10 & \\
\hline & Silver & 7 & \\
\hline Wood & Beam & 1 & 1 \\
\hline \multicolumn{3}{|c|}{ Total Old Phrygian inscripions } & 395 \\
\hline
\end{tabular}




\subsection{The New Phrygian subcorpus}

As stated above, the New Phrygian subcorpus consists of 117 New Phrygian (NPhr. ${ }^{46}$ inscriptions dated to between the end of the $1^{\text {st }}$ and the middle of the $3^{\text {rd }} \mathrm{c} . \mathrm{BC}$, found in a far more restricted area than the OPhr. subcorpus (Map 4 and 5), "bounded by Eskişehir-Dorylaion, Kütahya-Kotiaion, the lake of Eğridir, Laodikeia Katakekaumene and the northern point of Lake Tatta (Tuz Gölü)" (Brixhe 2013, 60). Note that a sizeable part of ancient Phrygia was occupied by the Galatians (including Gordion, see Mitchell 1993, 13-20) and a deep Hellenisation left its mark on many important cities. In any case, the whole NPhr. subcorpus consists of funerary texts on stone, mostly the local limestone. Although the number of inscriptions is considerable, the material itself is largely redundant, since few inscriptions contain more than a formulaic curse. Indeed, most of the New Phrygian texts follow an epitaph in Greek, although this disposition is reversed in two inscriptions $(13.1=122$ and $58.1=72)$, where the Phrygian curse is followed by a Greek epitaph. The most common text resembles the following standardisation:

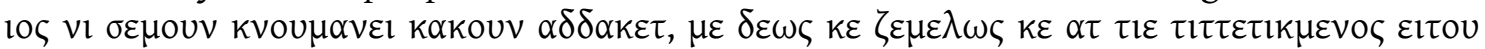
'whoever does harm to this tomb, let him be accursed by Zeus in the sight of gods and men'.

NPhr. curses have parallels in the contemporaneous Greek inscriptions but the most striking parallel is the continuity of the Luw. phraseology (Lubotsky 1998, 420; see § 4.6.2.2). How the Iron Age phraseology could have survived until Roman times is unknown, because texts containing these formulae are not attested in earlier periods. Indeed, OPhr. curses are different to those found in NPhr.

Only twelve of the inscriptions contain other kinds of texts, although these are always related to the epitaphs. ${ }^{47}$ By the time of NPhr., the process of language replacement in Phrygia seems to be complete in the major cities, since most of the NPhr. inscriptions are restricted to villages and towns. However, Greek borrowings and calques are found elsewhere in the Phrygian inscriptions, so even outside the cities this process of change can be perceived. In any case, the last possible evidence for Phr. as a living language is provided by Socr.Sch. Hist. Eccl.

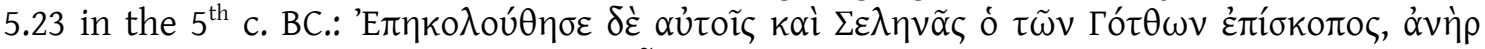

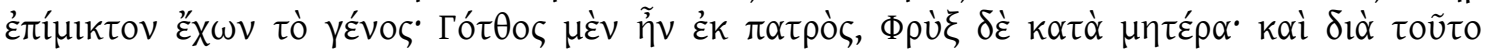

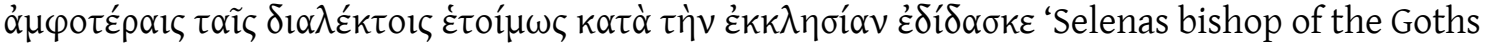
adopted the views of this party, a man of mixed descent; he was a Goth by his father's side, but by his mother's a Phrygian, by which means he taught in the church with great readiness in both these languages.'

As has been said, all of the monuments that bear New Phrygian inscriptions are funerary, mainly of the door-stele type, on which 33 inscriptions have been found. ${ }^{48}$ This is perhaps the most characteristic form of Phrygian monument in Roman times (see an example in Fig. 1). Despite attempts to link it to the OPhr. cult façades, the stone representation of a door as part of a funerary monument (tumulus or rock-cut chamber) is first attested in Lydia in the $6^{\text {th }}-4^{\text {th }}$ C. BC (Rooselvelt 2006, 66). ${ }^{49}$ Whatever their significance for the people who made them, Kelp is right when linking the use of NPhr. to the "distinctive local forms of grave monuments"

\footnotetext{
${ }^{46}$ Or 116 if 11.1 (17) and 11.3 (74) are considered to be the same inscription, as in Haas 1966 (Friedrich 1932, 138 fn. 74) and Lubotsky (in TITUS). Nevertheless, Brixhe 1999, 286 argued that they are two different inscriptions.

${ }^{47}$ The NPhr. inscriptions 1.1 (48), 1.2 (98), 2.1 (15), 2.2 (130), 11.2 (18), 16.1 (116), 17.1 (116, the largest NPhr. inscription), 22.1 (9), 37.2 (30), 40.3 (31), 43.1 (69) and 56.2 (58).

${ }^{48} 3.1$ (97), 7.2 (111), 10.1 (112), 10.2 (113), 11.3 (17), 12.1 (121), 13.1 (122), 14.1 (73), 15.1 (120), 17.4 (90), 17.5 (91), 17.6 (119), 19.1 (96), 21.1 (42), 21.2 (43), 22.1 (9), 25.1 (115), 26.2 (38), 37.2 (30), 43.1 (69), 45.1 (65), 51.1 (80), 53.1 (76), 56.1 (57), 56.2 (58), 57.1 (78), 59.4 (106), 62.1 (32), 62.2 (33), 62.3 (34), $62.4(35), 62.5$ (36) and $65.1(20)$.

${ }^{49}$ The Archaic and Hellenistic filiation of some examples was defended by Waelkens 1986, who gathered and studied all the known examples of this phenomenon, examining their rich typology, original workshops and distribution. See also Lochman 2003 and Kelp 2013 and 2015.
} 
and pointing out that "[t]he more urban an area and richer the purchasers, the more similar their grave monuments appear to the well-established funerary repertoire of the metropoleis of Asia Minor; no Neo-Phrygian curses appear on wealthy urban monuments [...] [g]rave-types with a door façade and the Neo-Phrygian inscriptions tended to occur in recently or partially urbanized regions" (2013, 92-93). Although the funerary function of the door-stelae is clear and their chronology is well established, monuments with NPhr. inscriptions did not appear in situ (with one exception) and only one of all the known examples of door-stelae has been found in its archaeological context: grave T1073 at Amorium (Kelp 2013, 76-77). In the light of this discovery, Ramsay's words about NPhr. 18.3 (6) are particularly interesting. Although he did not record what kind of monument it was, he described a finding that is consistent with our knowledge of funerary practices in Roman Phrygia and the grave found at Amorium: "beside Surmeneh, on one of the circle of stones ( $\chi \rho \eta \pi i$ ) which surrounded a small tumulus. There seem to have been in this neighbourhood many small tumuli, built all in the same way with a low circular wall enclosing and holding together a mound of earth" (Ramsay 1887, 389).

Fig. 1 Door-stele from Prymnessos (modern Sülün) containing the New Phrygian text 19.1 (96; Kelp 2013, 80 Fig. 4.10)

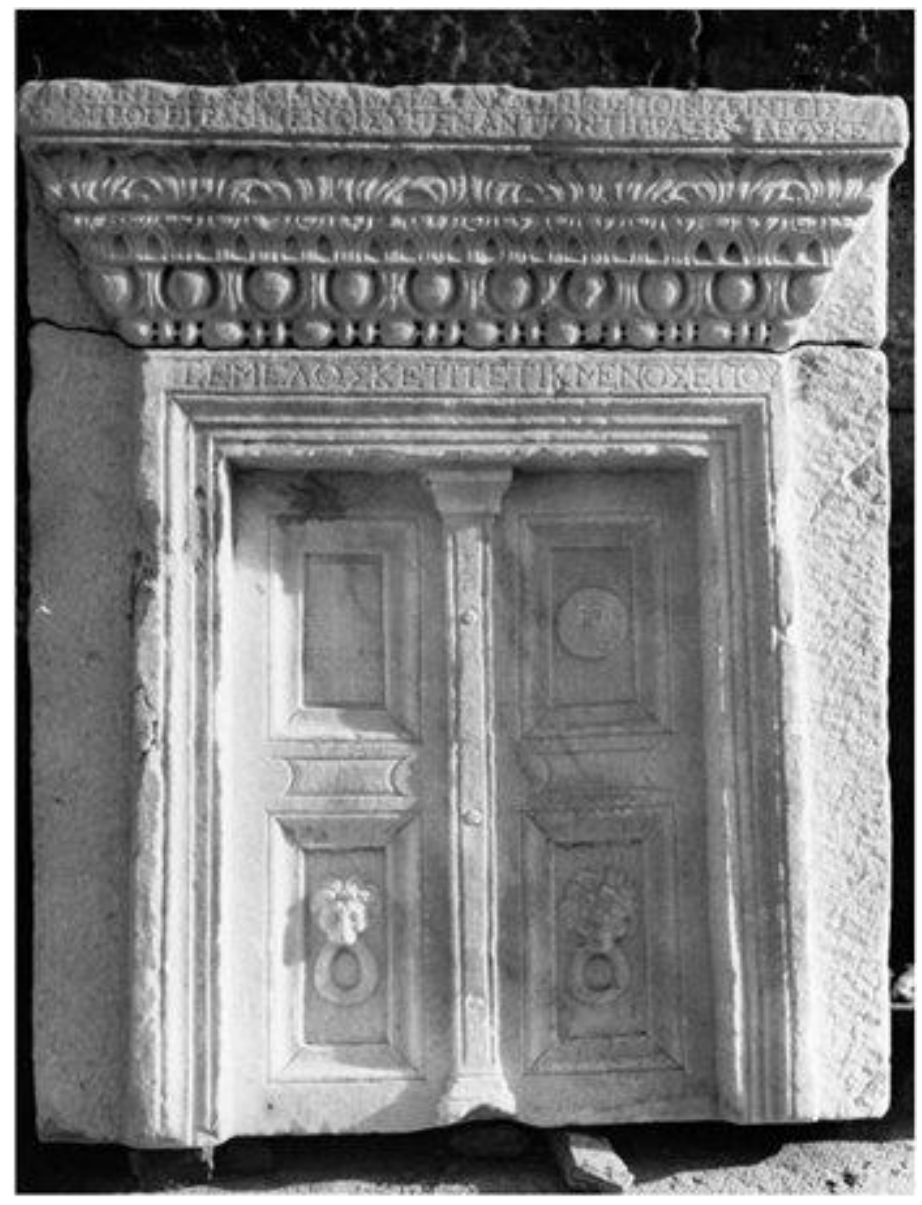

Another kind of funerary monument containing NPhr. inscriptions is the pediment stele (14 examples are recorded) ${ }^{50}$ which normally consists of a relief representing two columns supporting a triangular pediment (perhaps a representation of a temple). In the central space, the deceased and his family may be depicted, ${ }^{51}$ while the pediment is commonly reserved for a

501.2 (98), 16.1, 20.2 (128), 22.1 (9), 29.1 (114), 31.1 (29), 33.3 (127), 46.1 (53), 48.1 (81), 55.1 (56), 59.1 (107), 59.3 (79), 60.2 (60) and 62.6 (105). In some instances, however, it remains unclear if they were part of a door-stele.

${ }^{51}$ See, e.g., 20.2 (128) in the good photograph provided by Drew-Bear, Lubotsky and Üyümez 2008, 113. 
lion $(46.1=53)$ or an eagle $(33.3=127)$, apotropaic symbols of the Mother-Goddess and Zeus Bronton respectively. These elements are also common in door-stelae, while the depiction of people is only found in their pediment instead of these animals are not found. Other kind of monuments are bomoi 'altars' (6 examples), ${ }^{52}$ round pillars (4 examples) ${ }^{53}$ and even shapeless stone $(44.1=61)$.

None of these inscriptions contains any dating. Nevertheless, the typology of these monuments, as well as the palaeography, is coherent with the "flourishing high Imperial period of the second and third centuries AD" (as stated in Kelp 2013, 71). Moreover, some of the

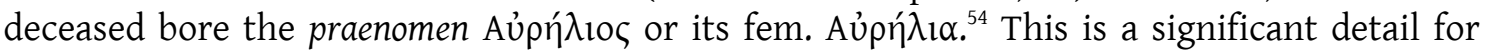
dating the inscriptions as it provides a terminus post quem. Indeed, this name was adopted by many people in the Empire after the emperor Caracalla, officially Marcus Aurelius Severus Antoninus Augustus, who extended the citizenship through the Constitutio Antoniniana in the year $212 \mathrm{BC}$.

Since most of the NPhr. inscriptions have been lost and are known only through old copies (only 19 are preserved), ${ }^{55}$ it is difficult to know whether inconsistences in the spelling were originally engraved on the stone or if they are a modern copyist's mistake. As seen in $\S 3.2$, spelling mistakes and hesitations are found elsewhere, but there also readings that must be considered a confusion of the copy. In contrast to the OPhr. subcorpus, one cannot corroborate the old readings, particularly in inscriptions with many hapaxes. A comparison of different examples of formulae also points - cautiously - to copyist's mistakes.

Table 3 Comparison between the Old and the New Phrygian subcorpora

\begin{tabular}{|c|c|c|}
\hline Feature & Old Phrygian & New Phrygian \\
\hline Number of inscriptions & 395 & 117 \\
\hline Dating & ca. $800-330 \mathrm{BC}$ & Late $1^{\text {st }}-3^{\text {rd }} \mathrm{C}$. AD \\
\hline Alphabet & Phrygian & Greek \\
\hline Writing material & Varied & Stone \\
\hline Contents & Varied & Funerary \\
\hline Area & Huge & Restricted \\
\hline Archaeological context & Mainly yes & Never \\
\hline Preserved & Mainly yes & Mainly no \\
\hline
\end{tabular}

\footnotetext{
${ }^{52} 2.2$ (130, a very big one), 8.1 (86), 17.1 (4b), 28.1 (71), 33.1 (28) and 52.1 (75). Despite the term, they were used as a prayer and vow to the deceased as well as to the divinities, see de Hoz 2017.

${ }^{53} 44.2$ (70), 49.1 (110), 58.1 (72) and 64.1 (82).

${ }^{54}$ In the NPhr. Subcorpus it appears in 5.1 (19), 6.1 (88), 50.2 (55) and 65.3 (21). The fem. form only appears in 65.3 (21). It is common to find it abbreviated.

${ }^{55}$ Preserved inscriptions are 2.2 (130), 3.1 (97), 6.1 (88), 7.2 (111), 10.1 (112), 10.2 (113), 12.1 (121), 16.1 (116), 17.6 (119), 19.2 (129), 20.2 (128), 22.2 (118), 25.1 (115), 25.2 (126), 29.1 (114), 31.1 (29), 33.3 (127), 63.1 (123) and 65.4 (124),
} 



\section{The scripts used to note the Phrygian language 3.1. The Phrygian alphabet}

The Phrygian language appears for the first time at the beginning of the $8^{\text {th }} \mathrm{c} . \mathrm{BC}$ (or in the last years of the $9^{\text {th }}$ ), recorded in a local alphabetic script written on stone blocks and sherds from Gordion. The archaeological context of these first inscriptions (G-03, G-104, G-237 and G249 , according to Brixhe 2004b, 276-278) corresponds to the reconstruction of the Gordion citadel after the "Destruction Level" dated to ca. 800 BC. This disaster, perhaps a great fire, was first considered a consequence of the Kymmerian invasion, which indeed took place a century after (ca. $700 \mathrm{BC}$ as recorded in the Neo-Assyrian documentation and some Greek traditions). However, recent revisions of the site gave a new chronology for Middle Phrygian Gordion (after 800-540s BC, see Rose and Darbyshire 2011), thus ruling out this initial hypothesis. The alphabet then, arrives in the Phrygian capital alongside many elements borrowed from south-east Anatolia (the Neo-Hittite, or Syro-Hittite states). Indeed, the architecture of Gordion from the $9^{\text {th }}$ C. BC, the sculptural remains, much of the pottery and many prestigious have their origins in the Neo-Hittite states (Sams \& Voigt 2011, 155-156). Far from dulling Gordion's splendour, the city's reconstruction was even more ambitious than the original architectural project and became the prelude to the "supraregional political and cultural importance" of the Phrygian state(s) (van Dongen 2014, 707) under the reign of Midas (late $8^{\text {th }}-$ early the $7^{\text {th }} \mathrm{c} . \mathrm{BC}$ ).

On the basis of the context of the first inscriptions, the Phrygians appear to have adopted the alphabet in the late $9^{\text {th }} \mathrm{c}$. or early $8^{\text {th }} \mathrm{C} . \mathrm{BC}$, through contact with south-east Anatolia (Cilicia or Tyanide milieux). This is both chronologically and geographically consistent with scholarly conclusions regarding the Greek alphabet. The subject is too complex to be addressed fully here, but it should be noted that in the last two decades the Greek presence in Cilicia has provided a very suitable context in which the Greeks might have adapted the Phoenician abjad to their language, despite the lack of local Greek inscriptions. ${ }^{56}$ Indeed, the western route of arrival of the alphabet to Gordion is hardly defensible because the Greek presence there is restricted to imports (mainly pottery of Corinthian and eastern Greek origin), which appear only from the late $8^{\text {th }} \mathrm{c}$. onwards ${ }^{57}$ Consequently, the Greek influence is detectable only from a period in which the Phrygians were already using their alphabet, when the Greek alphabet is found for the first time.

Although the first Phrygian inscriptions are some decades older than the Greek ones, Brixhe (2004b, 284-285) is right to warn against converting the "traditional Hellenocentrism" (according to which the Phrygian alphabet is derived from the (Proto-)Greek alphabet) into "Phrygocentrism". His thoughts on this issue are in agreement with Sass (2005, 133-152), who from a (very necessary) Semitic perspective established that the Phrygians and the Greeks adopted their alphabets from a "monumental Semitic model" (Phoenician or Aramaean) dated “ca. 750 BCE or slightly [sic] earlier" ("maximum of ca. 75 years-to around 825 BCE”, Sass 2005,

\footnotetext{
${ }^{56}$ See Yakubovich 2015, 48-50 for an attempt to explain this fact from a sociolinguistic point of view. In his monumental and influential work, Jeffery 1961, 10-12 suggested that the place of the adoption may have been on the Cilician-Syrian border. Nevertheless, it is not the only location considered by scholars: Boeotian Thebes, Euboia, Crete and even Cyprus (Woodard 1997 and 2014) have all been posited. However, most of these proposals only consider Greek evidence and assume that Phrygian is derived from Greek. Note that new findings of the earliest Greek inscriptions in Methone and Eretria still date the first inscriptions to the second half of the $8^{\text {th }} \mathrm{C}$. BC (Papadopoulos 2016). Janko 2015 raised the date of the inscription from Osteria dell'Osa (ancient Gabii, near Rome) to c. 825 at the latest and used it as evidence for an earlier Greek adoption of the alphabet. However, this piece is difficult to date and harder still to assign to one language or alphabetic tradition.

${ }^{57}$ See DeVries 2005 and Genz 2011, 359, who follows Sams 1979, 8-10; DeVries 1990, 390; 1997; DeVries in Voigt et alii 1997, 19-21. The presence of Greek imports at other sites is still less relevant.
} 
150-151). Given that the Greek and the Phrygian alphabets share their core letters, he also concludes that the Phoenician (or Aramean) abjad was adopted at the same time and it later passed from Greek to Phrygian or, as the chronology implies, from Phrygian to Greek, although the possibility remains that both derived together from a West Semitic abjad (as Brixhe 2004b, 284-285 suggests). Indeed, although the Phrygian inscriptions are older and the presence of Phrygian is attested in Tyana (albeit at the end of the $8^{\text {th }} \mathrm{c} . \mathrm{BC}$ ), the Greek alphabet preserves some of the Phoenician (or Aramean) letters not found in the Phrygian alphabet (e.g. $\otimes>\Theta$, compare Table 5$).^{58}$ Consequently, the seniority of the Greek or the Phrygian alphabet remains unresolved. In addition, any discussion of the matter must consider the other Anatolian alphabets, which are traditionally assumed to be derived from the Greek, although the details of such relationships are not clear. ${ }^{59}$

The Phrygian alphabet was used interruptedly until around the time of the Macedonian conquest of Anatolia (333 BC), when Phrygian speakers began to use the Greek alphabet to write their language. Graffiti from Gordion recorded in CIPPh are claimed to have been written in the Greek alphabet prior to the arrival of Alexander the Great, however the difference between the Greek and Phrygian alphabets at this stage it not always clear (Brixhe 2004a, 7 illustrates this with G-153, G-158 and G-167). Leaving aside the older Phrygian funerary stele written in Greek (MPhr-01 = Brixhe's 2004a no. W-11), in Gordion the documentation from the Hellenistic levels shows "the decline of both Phrygian script and language" in favour of Greek as a consequence of "probable shifts of population during the late fourth and third century B.C." (and the later emergence of Galatian names after the middle of the $3^{\text {rd }} \mathrm{C} . \mathrm{BC}$, Roller 1987b, 103-104).

The commonly used catalogue of Phrygian letters was given by CIPPh (280), which identifies 24 letters (see Table 5). However, this table must be reconsidered because some signs are known to be variants of other letters (no. 23 of no. 20 and, very likely, no. 24 of no. 2 , according to Morante Mediavilla 2000, 40) and new variants have appeared since the

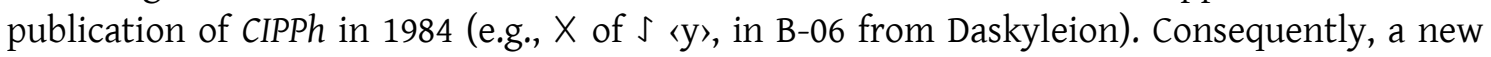
classification of the Phrygian letters is suggested in Table 6, similar to the one given by Ligorio and Lubotsky $(2013,181)$. While the core letters and the yod largely follow the information given in the successive works of Brixhe and Lejeune, the remaining letters (CIPPh no. 19-24, which the authors refer to as "lettres rares", herein 19-22) will be reanalysed in the following pages.

\footnotetext{
${ }^{58}$ Note that this is the only aspirated letter which is consistent in all Greek archaic alphabets. It is not considered a new incorporation in texts where the letters representing aspirated and double sounds are said to be borrowed after the first adoptions. On this question, see Willi 2013.

${ }^{59}$ For the Lydian alphabet, see Payne \& Wintjes 2016, 76: "Lydian is recorded in a local, 26-letter alphabetic script. It may have been derived from an eastern Greek alphabet, the exact relationship between both unknown". On the Lycian alphabet, Melchert 2008, 47 (following Carruba 1978): "Lycian is written in an alphabet derived from or closely related to that of Greek. The details of the relationship remain unclear". On the problematic origin of the Carian alphabet see Adiego 2007, 230-233.
} 
Table 4 Comparison of the Phoenician abjad, Classical Greek and Phrygian alphabets (excluding CIPPh no. 21-22)

\begin{tabular}{|c|c|c|c|c|c|c|c|}
\hline Phoenician & Trans. & Phoneme & Phrygian & Trans. & Phoneme & Greek & Phoneme \\
\hline$k$ & $?$ & /2/ & $A$ & $a$ & /a//a:/ & $\mathrm{A} \alpha$ & /a//a:/ \\
\hline 4 & $b$ & $/ \mathrm{b} /$ & B 8 & $b$ & /b/ & $\mathrm{B} \beta$ & /b/ \\
\hline 1 & $g$ & /g/ & $\Gamma$ & $g$ & lg/ & $\Gamma \gamma$ & /g/ \\
\hline$\Delta$ & $d$ & $/ \mathrm{d} /$ & $\Delta \wedge$ & $d$ & /d/ & $\Delta \delta$ & $/ \mathrm{d} /$ \\
\hline$\exists$ & $h$ & $/ \mathrm{h} /$ & $E E$ & $e$ & /e/ /e:/ & $\mathrm{E} \varepsilon$ & /e/ \\
\hline \multirow{2}{*}{$Y$} & \multirow{2}{*}{$w$} & \multirow{2}{*}{ /w/ } & $\mathrm{F}$ & $v$ & /w/ & $\mathrm{FF}_{\mathrm{F}}$ & $/ \mathrm{w} /$ \\
\hline & & & $r$ & $u$ & /u/ /ui/ & YU & $/ \mathrm{u} /$ \\
\hline$I$ & $z$ & $/ \mathrm{z} /$ & - & - & - & $\mathrm{z} \zeta$ & /zd/ /dz/ \\
\hline 目 & $h$ & $/ \mathrm{h} /$ & - & - & - & $\mathrm{H \eta}$ & / $\varepsilon: /$ \\
\hline$\otimes$ & $t$ & $/ \mathrm{t}^{\mathrm{f}} /$ & - & - & - & $\Theta \theta$ & $/ \mathrm{t}^{\mathrm{h}} /$ \\
\hline \multirow{2}{*}{$\exists$} & \multirow{2}{*}{$y$} & \multirow{2}{*}{$/ \mathrm{j} /$} & 5 & $y$ & /j/ & \multirow{2}{*}{ I 1} & \multirow{2}{*}{ /i/ /i:/ } \\
\hline & & & I & $i$ & /i/ /i:/ & & \\
\hline \multirow{2}{*}{$y$} & \multirow{2}{*}{$k$} & \multirow{2}{*}{$/ \mathrm{k} /$} & \multirow{2}{*}{$K \Psi \vee$} & \multirow{2}{*}{$k \Psi V$} & \multirow{2}{*}{$/ \mathrm{k} /$} & $\mathrm{K} \mathrm{K}$ & $/ \mathrm{k} /$ \\
\hline & & & & & & $\Psi \psi ?$ & /ps/ or /ks/ \\
\hline$L$ & 1 & $/ 1 /$ & $r$ & $l$ & $/ 1 /$ & $\Lambda \lambda$ & $/ 1 /$ \\
\hline$m$ & $m$ & $/ \mathrm{m} /$ & $M$ & $m$ & $/ \mathrm{m} /$ & $\mathrm{M} \mu$ & $/ \mathrm{m} /$ \\
\hline$\eta$ & $n$ & $/ \mathrm{n} /$ & $N$ & $n$ & $/ \mathrm{n} /$ & $\mathrm{Nv}$ & $/ \mathrm{n} /$ \\
\hline$\mp$ & $s$ & $/ \mathrm{s} /$ & - & - & - & $\Xi \xi$ & $/ \mathrm{ks} /$ \\
\hline \multirow{2}{*}{0} & \multirow{2}{*}{ S } & \multirow{2}{*}{$/ \varsigma /$} & \multirow{2}{*}{ O } & \multirow{2}{*}{0} & \multirow{2}{*}{ /o//o:/ } & Oo & /o/ \\
\hline & & & & & & $\Omega \omega$ & /0:/ \\
\hline 2 & $p$ & $/ \mathrm{p} /$ & $\Gamma$ & $p$ & $/ \mathrm{p} /$ & $\Pi \pi$ & $/ \mathrm{p} /$ \\
\hline$r$ & $\underline{s}$ & $/ \mathrm{s}^{\mathrm{s}} /$ & - & - & - & $M \mu$ & /s/ \\
\hline \multirow{2}{*}{$\Phi$} & \multirow[b]{2}{*}{$q$} & \multirow{2}{*}{ /q/ } & \multirow{2}{*}{-} & \multirow{2}{*}{ - } & \multirow{2}{*}{-} & $Q_{Q}$ & $/ \mathrm{k} /$ \\
\hline & & & & & & $\Phi \varphi$ & $/ \mathrm{p}^{\mathrm{h}} /$ \\
\hline 4 & $r$ & $/ \mathrm{r} /$ & $P$ & $r$ & $/ \mathrm{r} /$ & $\mathrm{P} \rho$ & $/ \mathrm{r} /$ \\
\hline$W$ & $\check{s}$ & $/ S /$ & $\varepsilon$ & $s$ & /s/ & $\Sigma \sigma \varsigma$ & $/ \mathrm{s} /$ \\
\hline$x$ & $t$ & $/ \mathrm{t} /$ & $T$ & $t$ & $/ \mathrm{t} /$ & $\mathrm{T} \tau$ & $/ \mathrm{t} /$ \\
\hline- & - & - & $\uparrow \Phi$ & $\uparrow$ & /z/ [zd]? & T, T & $/ \mathrm{ts} / ?$ \\
\hline
\end{tabular}

Before dealing with the less clear letters, some generalities of the Old Phrygian texts are in order. Although Phrygian seems to have five vowels $(/ \mathrm{a} /, / \mathrm{e} /, / \mathrm{i} /, / \mathrm{o} /, / \mathrm{u} /)$ that contrast in length with a further five (/a:/, /e:/, /i:/, /o:/, /u:/, although the existence of /e:/ is controversial and not all vowels have been identified), the Phrygian alphabet has only five

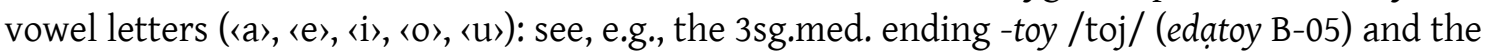
thematic sg.dat. ending -oy /o:j/ (surgastoy Dd-102). In OPhr. inscriptions, repetitions of the same vowel are rarely used within words (M-06 deiatiteea.?) and very often their presence is good evidence for a word boundary when spaces or interpunctions are not used to mark word boundaries and texts employs scriptio continua. However, in the inscriptions without yod the sequence (ii) occurs within the same word (T-03aI $a \uparrow$ iiai) to represent /ij/ or /ji/. Geminates are not marked by the Phrygian alphabet, although they are known to be pronounced, e.g, $3 \mathrm{pl}$.

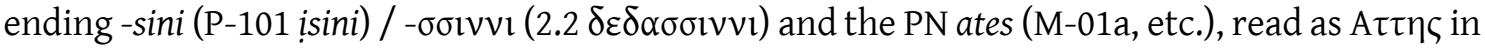

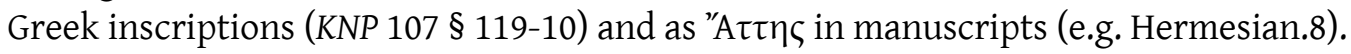


Table 5 Chart of Phrygian letters according to CIPPh I, 280

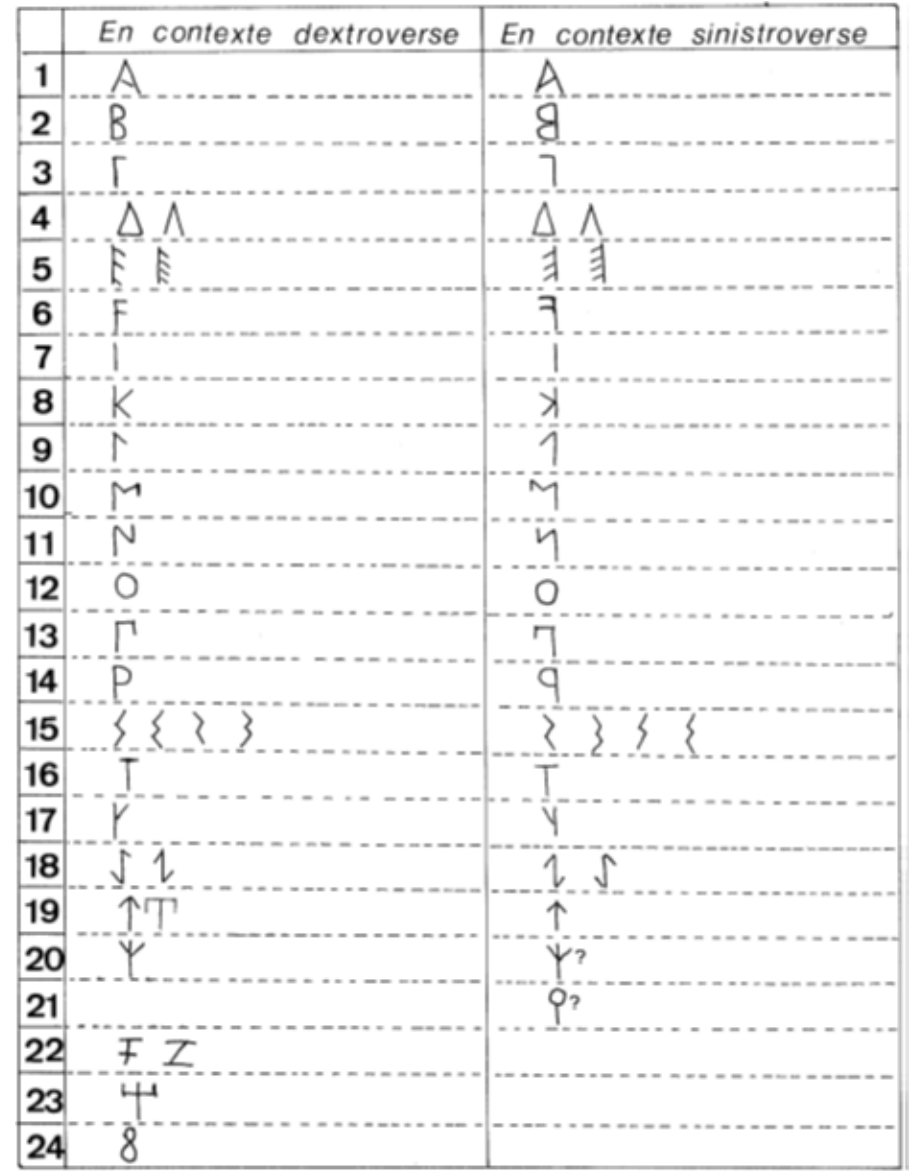

Table 6 Suggested classification of the Phrygian letters

\begin{tabular}{|c|c|c|c|c|}
\hline No. & Dextroverse & Sinistroverse & Transcription & Phoneme \\
\hline 1 & $A$ & 4 & $a$ & /a/ /a:/ \\
\hline 2 & B 8 & 88 & $b$ & $/ \mathrm{b} /$ \\
\hline 3 & $\Gamma$ & 7 & $g$ & /g/ \\
\hline 4 & $\Delta \wedge$ & $\wedge \Delta$ & $d$ & /d/ \\
\hline 5 & $E E$ & 羽 & $e$ & /e//e:/ \\
\hline 6 & $F$ & 7 & $v$ & $/ \mathrm{w} /$ \\
\hline 7 & 1 & 1 & $i$ & /i//i:/ \\
\hline 8 & KYV & त्र $Y \vee$ & $k \Psi \vee \Psi$ & $/ \mathrm{k} /$ \\
\hline 9 & $r$ & 1 & 1 & $/ 1 /$ \\
\hline 10 & $M$ & $M$ & $m$ & $/ \mathrm{m} /$ \\
\hline 11 & $N$ & 4 & $n$ & $/ \mathrm{n} /$ \\
\hline 12 & O & 0 & 0 & /o/ /o:/ \\
\hline 13 & $\Gamma$ & 7 & $p$ & $/ \mathrm{p} /$ \\
\hline 14 & $P$ & 9 & $r$ & $/ \mathrm{r} /$ \\
\hline 15 & $s \leqslant \varepsilon \xi$ & 23 & $s$ & $/ \mathrm{s} /$ \\
\hline 16 & $T$ & $\mathrm{~T}$ & $t$ & $/ \mathrm{t} /$ \\
\hline 17 & $r$ & $y$ & $u$ & $/ \mathrm{u} / \mathrm{u} / \mathrm{s}$ \\
\hline 18 & $5 x$ & 25 & $y$ & /j/ \\
\hline 19 & 个Ф斤T & $\uparrow$ & $\uparrow \Phi T$ & $/ \mathrm{z} /[\mathrm{zd}] ?$ \\
\hline
\end{tabular}


Another feature of the Phrygian alphabet is that most inscriptions are written sinistroverse. However, at least 66 inscriptions are dextroverse and boustrophedon occurs in 18 texts. Finally, it must be added that Phrygian employs scriptio continua in many instances, though the use of interpunctions or spaces is not unusual (see § 3.1.7.1).

\subsubsection{The letter CIPPh no. 18: the Phrygian yod, 〈y〉}

The identification of the Phrygian yod is one of the most important contributions to the decipherment of Phrygian by Michel Lejeune (1969a, 30-38). Since his analysis, it has been universally accepted that CIPPh no. 18 represents the consonantal allophone [j] of /i/. According to his work, this letter appears in the following contexts:

a) At the beginning of a word before a vowel (never before $i$ ): e.g. yos (passim).

b) Between vowels (other than $i$ ): e.g. areyastin (W-01b).

c) Between a consonant and vowel: e.g. kuryaneyon (W-01c).

d) Optionally between $i$ and another vowel (other than $i$ ): compare, e.g., kuliya[---] (G-101), $k \uparrow$ iyanaveyos (M-02) or tiyes (M-04) with kadiun (G-103) or $k$ Piyanaveyos (M-01b).

e) In final diphthongs: tedatoy (W-01a), materey (W-01b), avtay...

f) Following the vowel $-i$ at the end of a word followed by an initial vowel: tuave|niy $\vdots$ ae (M-01f), materey eveteksete? $y(\mathrm{~W}-01 \mathrm{~b})$, niy art (B-05)... One example is found before a consonant: dedasitiy tubetiv (B-05).

g) this final yod is often found (especially in Bithynian text) after the vowel -e before an initial vowel or consonant (not considered by Lejeune), especially with the copulative conj. ke(y) 'and' in text from Bithynia (but not exclusively): key venavtun (W-01b), key estat (B-05), key iverais (B-05)... This position is not to be confused with the athem. sg.dat. ending -ey $<$ PIE *-ei.

However, as Lejeune noticed, this sound is not always marked with this letter, since commonly the yod is not found in the second element of non-final diphthongs: see, e.g., memevais (M-02), proitavos (M-01b and M-02) or esait (W-01b, esai $=\mathrm{t})$. This said, even here some exceptions are found: e.g. eymiva? $k^{?} i^{?}[---]$ (G-178).

A surprising fact, also considered by Lejeune, is that this letter does not appear in Phrygian texts before the $6^{\text {th }} \mathrm{c}$. BC (pace Brixhe 2004b, 281-284). During the two first centuries of Phrygian writing [j] is represented by 〈ì: e.g. a $\uparrow$ iiai (T-03aI), [---] $i$ : avtoi (T-03b, last quarter of the $8^{\text {th }} \mathrm{c} . \mathrm{BC}$ ), agaritoi petes adoikavoi (G-02)... Even in later inscriptions the use of the Phrygian yod was not at all widespread: e.g. midai lavagtaei vanaktei (M-01a, second quarter of the $6^{\text {th }} \mathrm{C}$. $\mathrm{BC}$ ) and estatoi avun (G-144, $5^{\text {th }} \mathrm{C}$. BC).$^{60}$ In any case, $<\mathrm{y}$ seems to be derived from the Phoenician(Aramaic) yod, as well as the Phrygian iota (see Brixhe 2004a, 29), although it remains unclear if it was an internal development or the result of the Semitic influence.

\subsubsection{The letter CIPPh no. 19: the arrow-letter $\uparrow$}

The arrow-letter ( $\uparrow, \Phi, \Upsilon$ and $T)$ is attested 23 times in 18 in 23 Phrygian inscriptions, from early texts of the $8^{\text {th }}$ C. BC, e.g., Gordion Tumulus MM (some years before $740 \mathrm{BC}$ ) or Tyana stele(s) (730-712 BC), to the end of the Hellenistic period:

\footnotetext{
${ }^{60}$ With regard to [w], a similar hesitation is found in three inscriptions where this allophone is represented by $\langle\mathrm{u}\rangle$ instead of the most common 〈V〉. Compare M-01c m? onokaua, M-01f tuave|niy and W-11 [.]'][.?]agaua with M-01dI tvemes, M-01a lavagtaei and M-04 akinanogavan.
} 
1. G-105 si个idos akor (incised on a bronze bowl found inside Tumulus MM, before $740 \mathrm{BC}$ ).

2. G-203 $\uparrow \mid . X$ (fragment of the bottom of a bowl from the $4^{\text {th }} \mathrm{C} . \mathrm{BC}$ ).

3. $\mathrm{G}-225 \uparrow \mid a$ (on the bottom of a saucer from the $4^{\text {th }}$ or $3^{\text {rd }} \mathrm{c} . \mathrm{BC}$ ).

4. G-275 Ti (incised on a sherd from the $4^{\text {th }}$ or the beginning of the $3^{\text {rd }} \mathrm{C} . \mathrm{BC}$ ).

5. G-346 si iidos (incised on a beam of Tumulus MM, Gordion, before $740 \mathrm{BC}$ ).

6. $\mathrm{M}-01 \mathrm{~b}$ baba $\vdots$ memevais $\vdots$ proitavos $\vdots k$ Qiyanaveyos $\vdots$ si=keneman $\vdots$ edaes 'Baba Memevais the proitavos, the $k$ Фiyanaveyos, made this niche' (on Midas Façade dated to 575-550 BC, although the inscription is a later addition).

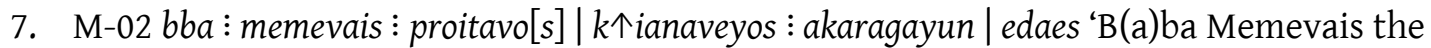
proitavos, the $k \uparrow$ ianaveyos, made this akaragayun' (on a vertical side of an outcrop of rock near other monuments of Midas City, contemporaneous to M-01b).

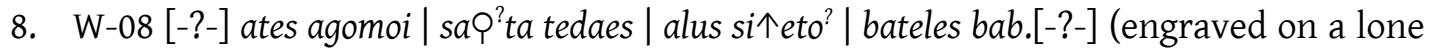
rock at Çepni).

9. W-09 si个eto ae | alus (engraved on a lone rock at Çepni).

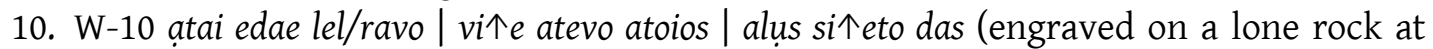
Çepni);

11. B-04 ... $a^{?} m^{?}$ ? $p^{?}$ tov? $a \uparrow i y \cdot a^{?} e^{?}$ lavoy $・$ ue ... (undated marble block only viewed in 1926 on the wall of a house in Üyücek, a fragment).

12. B-05 tiv $\dagger<s>$ imun inmeney asenan daket torvetun $\uparrow$ iray ayniy oy $\mid$ tubnuv nevos, me deritoy kovis ke abretoy nun oy nev<otan> | yos isekosos 个emeney dupratoy, veban ituv (fragment of the imprecative part of the Vezirhan stele, $\left.5^{\text {th }} \mathrm{c} . \mathrm{BC}\right)$.

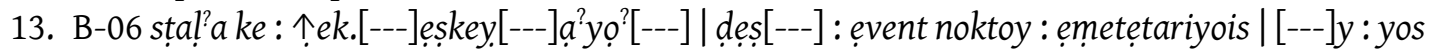
tumoy: $\uparrow e k m a t i n \mid[---] a t o n k e y e n$ (funerary stele from Daskyleion, perhaps from the first half of the $6^{\text {th }} \mathrm{c} . \mathrm{BC}$ ).

14. T-02b [---]|[---]tumida $\vdots$ memeuis $:[---] \mid[---] a \vdots$ tesa $n \vdots a \uparrow$ ion $\vdots v[---] \mid[---]$ oitumen $\vdots$ mida $[-$ $--] \mid[---] n \vdots a$ 个ios $\vdots$ mi[---] $\mid[---] n$ ! batan $\vdots e .[---]$ and $C \vdots^{?} e a .[---]|[---] . n a|[---]|[---]|[---] \uparrow \mid$ [---] (fragments of a stele from Tyana, late $8^{\text {th }} \mathrm{C} . \mathrm{BC}$ ).

15. T-03aI a iiai $\vdots$ polodrẹ|tes $\vdots$ poreti $\vdots$ ọtu|[---] and T-03bII | [---]sn|a[---]|[---]ed|eia[---] | [--] ${ }^{?} r \uparrow e \mid s \vdots \operatorname{ar}[---]$ (fragments of a stele from Tyana, late $8^{\text {th }}$ c. BC).

16. NW-139 $a \uparrow[i / e$.$] (fragment of the bottom of a pot from Dorylaion, 550-330 BC).$

17. HP-109 $a \uparrow s e s$ (on a bronze bowl found in the Tumulus D of Bayındır, east Lycia, middle of the $\left.8^{\text {th }} \mathrm{c} . \mathrm{BC}\right)$.

18. HP-110 si idos (on a bronze bowl found in Tumulus D at Bayındır, east Lycia, middle of the $8^{\text {th }}$ c. BC).

On its nature, Brixhe $(1982,229-239)$ equated the arrow-letter to the Ionian sampi, T, and the Lydian 〈c〉 (perhaps /dz/ or /tz/, see Melchert 2004, 603 and Gérard 2005, 58-59) and considered it a palatalised consonant arising in contact with front vowels (/e/ and /i/). This explanation fits well with the occurrences of the discussed letter (Table 7, only in HP-109 a ses is the letter not followed by a front vowel, see Brixhe (2004a, 115), who considered 〈 $\uparrow$ s a redundant representation of $/ \mathrm{ts} /$ ). However, he also suggested that it stands for a voiceless affricate /ts/ rendering the palatalisation of PIE * $k$ (even in Brixhe 2008, 74), perhaps written in NPhr. as $\sigma(\sigma)$, although these proposals are more disputable. 
Table 7 Contexts and occurrences of $\uparrow$

\begin{tabular}{|c|c|}
\hline Contexts & Occurrences \\
\hline /\#_e & 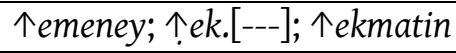 \\
\hline /\#_i & 个irạy \\
\hline /a_i & $a \uparrow$ ion, $a \uparrow i o s, a \uparrow i i a i$ \\
\hline /a_s & $a \uparrow s e s$ \\
\hline /i_e & 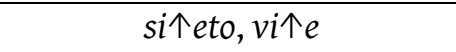 \\
\hline /i_i & si个idos \\
\hline$/ \mathrm{k}_{-} \mathrm{i}$ & $k \uparrow$ ianaveyos, $k$ Фiyanaveyos \\
\hline$/ r_{-} e$ & {$[---] \rho^{?} r \uparrow e \mid s$} \\
\hline Unclear & $a \uparrow[---],[---] \uparrow \mid[---]$ \\
\hline
\end{tabular}

Some facts must be considered to reveal the sound represented by the arrow-letter. Firstly, words with this letter remain unclear but there is no reason to consider that $\langle\uparrow\rangle$ renders a development of $/ \mathrm{k} /$. The suggested etymology "*se:(i)k- ("tender, presenter ..., cf. grec ík $\omega$,

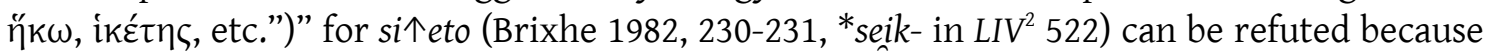

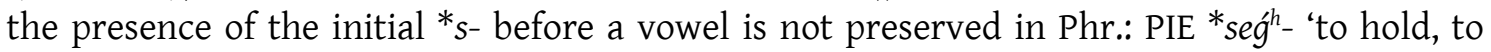

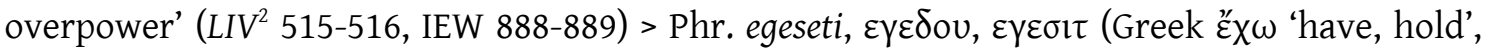
Sanskrit sáhate 'overwhelm, defeat'). ${ }^{61}$ Moreover, the only likely etymology for a word with the

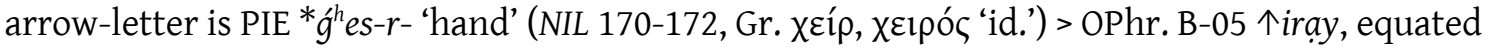

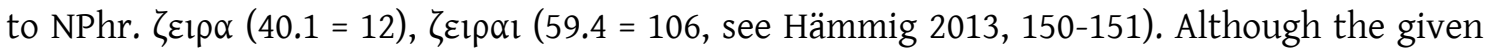
etymology (and the meaning of the word) are open to discussion, the comparison between OPhr. $\uparrow$ iray and NPhr. $\zeta \varepsilon l p \alpha l$ is strong enough to consider that OPhr. $\langle\uparrow\rangle$ appears as $\langle\zeta\rangle$ in NPhr. texts. It implies that $\langle\uparrow\rangle$ represents a voiced consonant (perhaps a voiced alveo-palatal affricate or palato-alveolar affricate), since the Greek 〈ל〉 stands for /zd/ or /dz/. The realisation of this Greek letter is difficult to determine and seems to be slightly different in each period and area, and it cannot be ruled out that another change, perhaps through the influence of Greek, was undergone by the sound represented by $\langle\uparrow\rangle$ between OPhr. and NPhr. documentation. In any case, in such a scenario, the etymology * $g^{h} e s-r$ - 'hand' > OPhr. iray remains valid because a similar development is attested in Phrygian: PIE * $d^{(h)}$ g $^{h} e-m$ - 'ground' (NIL 86-99, IEW 414-416) ${ }^{62}>$

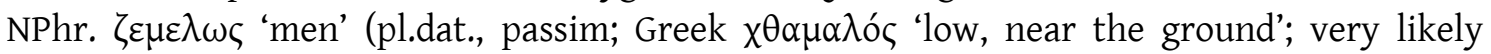
$\zeta \varepsilon \mu \varepsilon \lambda \omega \varsigma$ has the simplification * $d^{(h)} \dot{g}^{h} e-m->{ }^{*} \dot{g}^{h} e-m$ - found in Greek $\chi \alpha \mu \alpha$ ' 'to the earth, on the earth', $\chi \alpha \mu \eta \lambda$ ó 'low, lowered' and Lat. humus 'ground, earth'). Also, H. $\zeta 128$ seems to fit with

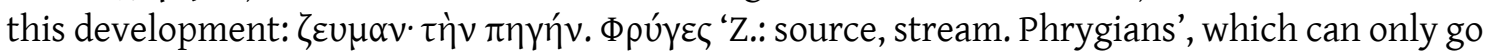

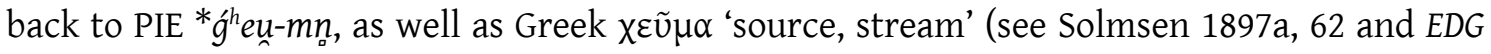
1629).

In the light of the little information available, 〈 $\uparrow$ may represent a secondary palatalisation of PIE * $\dot{g}^{h}$ - before front vowels (/e/ and /i/). However, in many examples PIE * $\dot{g}^{h_{-}}$ is represented by ' $g$ 〉 and ' $\gamma$ 〉 in OPhr. and NPhr., respectively: PIE *seg' - 'to hold, to overpower'

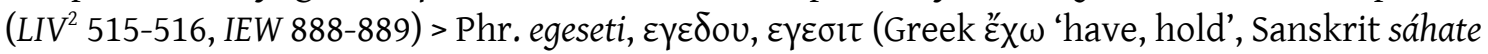
'overwhelm, defeat') and PIE * ${ }^{h}$ er $(H)$ - 'desire, enjoy' (LIV ${ }^{2}$ 176-177, IEW 440-441) > NPhr. $\gamma \varepsilon-\gamma \alpha \rho \imath \tau-\mu \varepsilon v o \zeta$ 'cursed, devoted'. In Phrygian the PIE palatal series merged with the plain velar series (as centum languages) and the aspirate became a voiced stop. So, PIE ${ }^{*} \dot{g}^{h}$ is expected to

\footnotetext{
${ }^{61}$ The only possible exception is found in the demonstrative pron. $\sigma \alpha, \sigma l, \sigma \varepsilon \mu o u v . .$. However, although it has been suggested that the $s$ - goes back to the pronominal PIE theme *to- / so-, Ligorio \& Lubotsky 2013, 185 recently suggested that it is inherited from the PIE demonstrative *ki- (see § 4.2.1.2.1), and this possibility is preferred here.

${ }^{62}$ The reconstruction $d^{h}{ }^{h}-m$ - is argued by Kloekhorst 2014 .
} 
become /g/ as well as PIE * $g^{h}$. Compare PIE * seg ${ }^{h}$ - > OPhr. egeseti and PIE * $g^{h}$ rei $(H)$ - 'strike' (LIV 203 , IEW 457) $>\gamma \varepsilon \gamma \rho \varepsilon i \mu \varepsilon v \alpha \nu(53.1=76,60.1=59$, etc. $)$.

Therefore, we must assume the following steps: PIE $* \dot{g}^{h}>{ }^{*} g^{h}>$ Phr. $g$-, parallel to PIE $* g^{h}$ $>$ Phr. $g$-. In addition, in some words a secondary shift $\left.{ }^{*} g\right\rangle\langle\uparrow\rangle\langle\langle\zeta\rangle$ occurs before front vowels. Nevertheless, this is not a consistent notation since it is common to find $\langle g\rangle$ and $\langle\gamma\rangle$ followed or preceded by front vowels, as we have seen. The same is true of words without a clear origin: OPhr. perbastidages (HP-101), saragis (PN, B-108 and M-101), lagineios (PN, G-110), [-?-]agipeia (G135), [---]ṃ?agi.[---] (G-240), [l'] agineia (PN, G-276), egertoy (W-01c), olgiavos (G-150 a), iyungidas

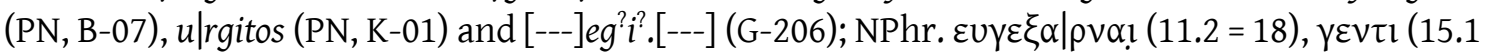

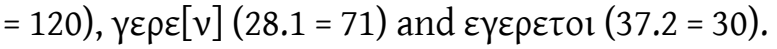

Consequently, in Phrygian some words with ${ }^{*} g^{h}>g$ show this palatalisation and some do not. $\langle\uparrow\rangle$ may represent a fricative allophone [z] or palatal $\left[\mathrm{g}^{\mathrm{j}}\right],[\mathrm{zd}],[\mathrm{dz}]^{63}$ or $\left.[\mathrm{d}]\right]$ of $/ \mathrm{g} / \mathrm{hot}$ always indicated in writing. Finally, it is tempting to consider the Phrygian arrow-letter as derived from the Phoenician giml, as well as the Phrygian gamma, by the addition of a stroke in order to make a new symmetric letter (see Table 8). However, this is a mere hypothesis and prior proposals cannot be refuted. ${ }^{64}$

Table 8 The Phoenician letter giml and its reflections in other alphabets as hypothetically suggested here

\begin{tabular}{|c|c|c|c|c|}
\hline Phoenician & Phrygian & Greek & Lydian & Lycian \\
\hline \multirow{2}{*}{1} & $\Gamma / \mathrm{g} /$ & $\Gamma / \mathrm{g} /$ & $\jmath[\mathrm{g}]$ & $\mathrm{r} / \mathrm{g} /$ \\
\cline { 2 - 5 } & $\uparrow / \mathrm{z} /,[\mathrm{dz}, \mathrm{zd}] ?$ & $\mathrm{~T} / \mathrm{ts} / ?$ & $\uparrow / \mathrm{dz} / ?$ & $\uparrow / \mathrm{c} /$ \\
\hline
\end{tabular}

Another possible origin for the Phrygian arrow-letter in Phrygia is the Phoenician șade $\langle\boldsymbol{\langle}\rangle$. Although the earliest Phrygian texts have the arrow-shape of this letter, the Vezirhan stele has an unusual shape, 4 , which recalls the old shape of the Phoenician letter as found, e.g., in the inscription from Karatepe, $r$. However, Karatepe and Vezirhan inscriptions belong to different periods: the Phoenician inscription is dated to the $8^{\text {th }} \mathrm{c} . \mathrm{BC}$, the Phrygian one to the $5^{\text {th }}$ c. BC. So, accepting this equation would imply that the "original" form of the letter was preserved in a peripherical location like Vezirhan, although the oldest Phr. inscription has the arrow-shape.

\subsubsection{The letters CIPPh no. 20 and 23: variants of $\langle k\rangle$}

The Old Phrygian letter CIPPh no. 20 occurs 23 times in 21 different inscriptions from Gordion (11), Dorylaion (8) and Daskyleion (B-07) and on the Areyastin monument (W-01, near Midas City). However, ten of these occurrences are graffiti in which the letter does not appear in a text but as a (owner's) mark. The earliest instances of this letter can be dated to the beginning of the $8^{\text {th }}$ c. BC (immediately after the Gordion Destruction Level, G-249 and, as a mark, in G-278), while most occurrences date to the period between the beginning of the Achaemenid period (550 BC) and the Macedonian conquest of Anatolia (330 BC), except G-324 (perhaps from the Hellenistic or Roman period). Regarding its shape, three variants are

\footnotetext{
${ }^{63}$ As Ligorio \& Lubotsky 2013, 185 preferred.

${ }^{64}$ Brixhe 1982, 226-227 considered that Greek sampi was derived from șade, $\mu$, or, better, from taw, X. Since it is an open question, both possibilities remain feasible. Symmetry is a common feature of the new letters developed in the Anatolian alphabets (Adiego fthc. a).
} 
attested: $\Psi$ (9 occurrences, W-01b, B-07, G-115, G-145, G-224, G-278, G-294, G-306 and G-339), V (9 ocurrences, G-249, G-322, G-324, NW-101, NW-105, NW-112, NW-119, NW-121 and NW-121 ) and 4 (G-112, NW-128 and NW-135).

After Lejeune (1978), who refuted prior equations with the different values of the Greek psi, $\psi$, it is commonly considered that this letter represents the stop + fricative sequence $/ \mathrm{ks} /$, like the Greek xi, $\xi$. However, this explanation is not at all compatible with the Phr. documentation, as I will try to show, following Lejeune's argumentation step by step. His analysis began with the misspelling found in G-145, a graffito incised after firing on "a flat strap handle of a gray ware jug, excellently black-polished" (Young 1969, 289), dated to the $5^{\text {th }} \mathrm{C} . \mathrm{BC}$ (Fig. 2):

Fig. 2 Photograph of G-145 (Young 1969, pl. 70 no. 72)

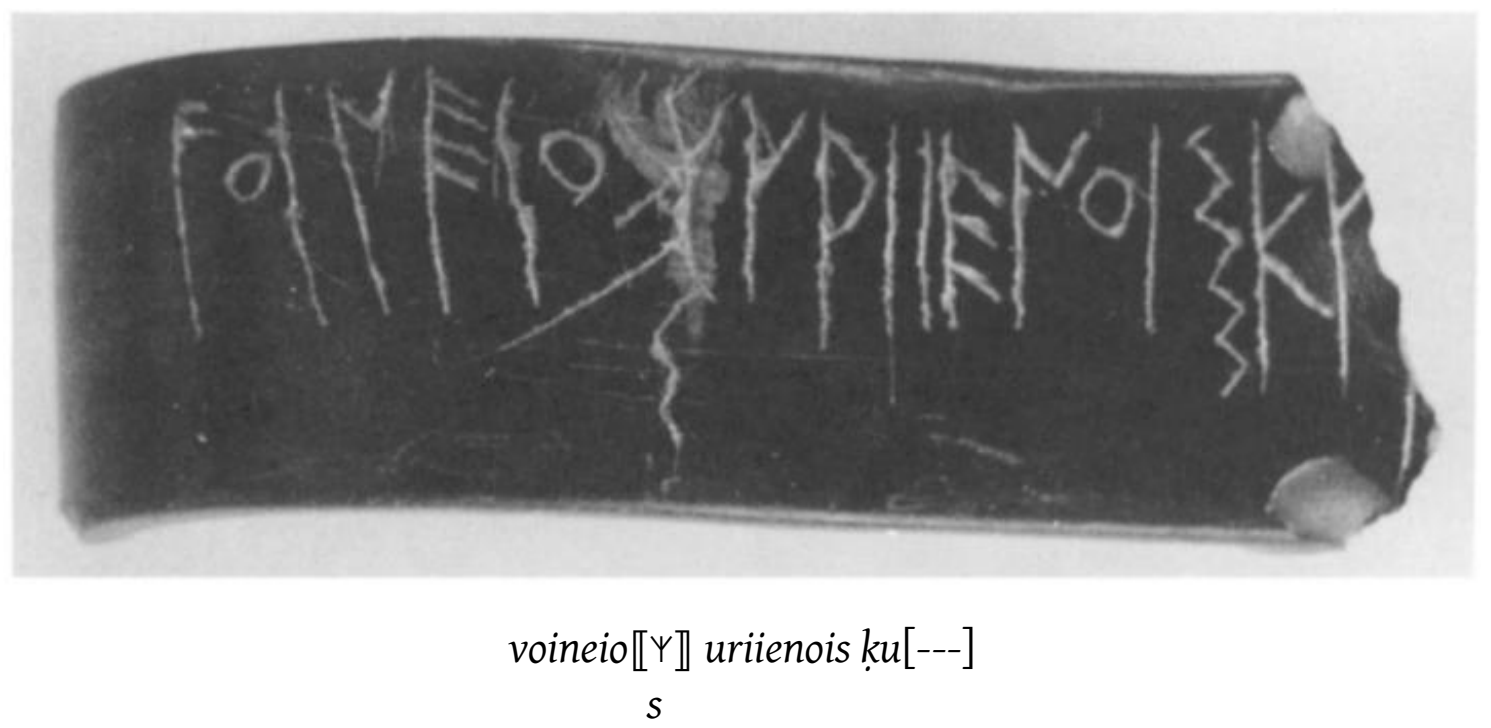

As can be seen, the engraver first wrote voineio $Y$ and, later, incised the 〈S〉 under the letter $\langle\Psi\rangle$, after scratching it. In the light of this example, Lejeune $(1978,786)$ considered that the sound represented by this letter must be similar to that of $\langle\mathrm{S}\rangle$. Then he suggested that it could stand for "une articulation consonantique complexe à composante sifflante" related to /s/ similar to /ss/, /ts/, /ks/ or /ps/, adducing the common hesitation in Greek between $\xi u ́ v$ and oúv. Either way, as he admits, the text of G-145 is far from being clear: voneios can be considered a PN derived from voines, a well attested PN from Gordion (G-129, G-286; voine in G228), but uriienois and $\mathrm{ku}[---]$ remain unclear.

Adiego, on the other hand, has recently suggested (p.c.) that if one examines carefully the photograph of this text given by CIPPh, the presence of $\llbracket Y \rrbracket$ is not as clear as has been said. According to his proposal, the engraver wrote $\langle\mathrm{o} \mathrm{u}\rangle$ and, after realising that he should have written 〈osu〉, tried to insert an 〈s〉 betwen the two vowels. However, there was not space enough and the result is not satisfactory. He then wrote the $\langle\mathrm{s}\rangle$ under the position that it was supposed to occupy and scratched the previous attempt because the result was confusing. Finally, he added another 〈s〉. Although this proposal must be confirmed or rejected by reading the physical object rather than the photograph, it shows that this error does not provide a valid basis to determine the nature of the letter $\langle\Psi\rangle$, because even the reading is unclear.

Secondly, Lejeune (1978, 785-786) adduced the graffito G-115, incised (also after firing) on the "base of a gray-ware bowl with finely black-polished surfaces" (Young 1969, 271) and dated to the $6^{\text {th }} \mathrm{c} . \mathrm{BC}$ : 
Fig. 3 Photograph of G-115 (Obrador-Cursach)

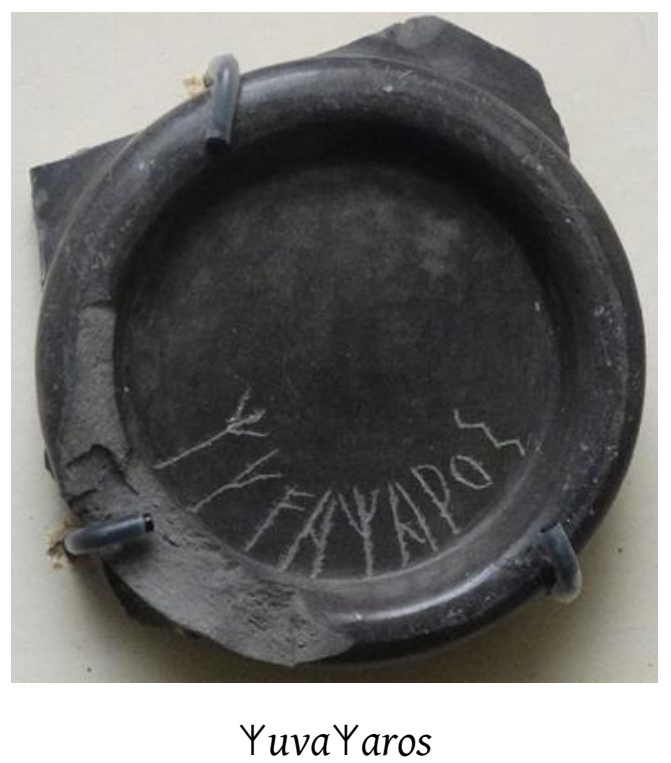

Haas (1976, 80-82) identified it as the PN (also borne by a Median king) attested in OP as ${ }^{h}$ Uvaxšatara- (Behistun inscription), in New Assyrian as ${ }^{\mathrm{m}} U$-ak-sa-tar (TCL 03, 5372 1. 42), ${ }^{\mathrm{m}} U k$-sa$\operatorname{tar}$ (ABL 645), in New and Late Babylonian as ${ }^{\mathrm{m}}{ }^{U}$-ma-ku-iš-tar or ${ }^{\mathrm{m}} U$-ma-kiš-tar, in Elamite as $M a-$ ki-iš-tur-ri and Ma-ak-iš-tar-ra (Beshitun inscription, note that in Elamite the sign ME/PI often

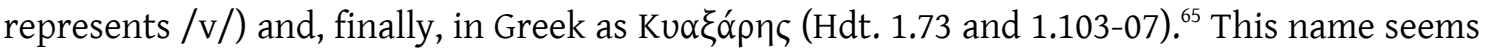
to go back to a Median form ${ }^{*}$ Uvaxštra and following this likely interpretation for the Phrygian graffito, Lejeune considered that the Phrygian rendering follows the OP form with the common OP simplification of the Median cluster -xštr- $\rangle-x \check{s}-$. Here, he argued that the second $\langle\Psi\rangle$ of Yuva Yaros stands for the OP 〈Xš〉 and Greek $\langle\xi\rangle$ and, consequently, that Phr. $\langle\Psi\rangle$ represents a cluster $/ \mathrm{ks} /$, parallel to the Greek form. According to him, it fits with the misspelling found in G-145. Finally, for the first $\langle\Psi\rangle$, he suggested a regressive assimilation from the second $\langle\Psi\rangle$ to the initial /h-/ of this Persian PN, promoted because it is not a non-Phrygian phoneme. So, he reads Yuva Yaros as /ksuwaksaros/. In addition, G-224c, a graffito incised on a marmite (from the $4^{\text {th }}$ C. BC, published after Lejeune's work) is very likely an abbreviation of this PN (CIPPh I, 180-181): Yuv.

Following this interpretation, Lejeune also considered the verb daYet of the imprecative protasis W-01b (see Fig. 4), read on a cult façade devoted to the Mother-Goddess (near Midas City, dated ca. 550 BC according to Berndt-Ersöz 2006, 238):

yos esait : materey $\vdots$ eveteksete $e^{?} y \vdots$ ovevin $\vdots$ onoman $\vdots$ da Yet $\vdots$

\footnotetext{
${ }^{65}$ Lyc. waxsser (M 237; see Schmitt 1982, 27 and Neumann 2007, 423) cannot be considered in this list after Konuk 2016, 20-27, who read it as waxssepddimi, a PN also attested in Xanthos Stele (44a,49, perhaps Carian in origin, Adiego fthc. b). Regarding wexssere (also read in coins, M 132, M 133, M 207 and M 236), one can consider that waxsse- and wexsse- are the outcome of a Luwic theme (Adiego p.c. 16/02/2018).
} 
Fig. 4 Detail of the façade W-01 with the discussed text (Obrador-Cursach)

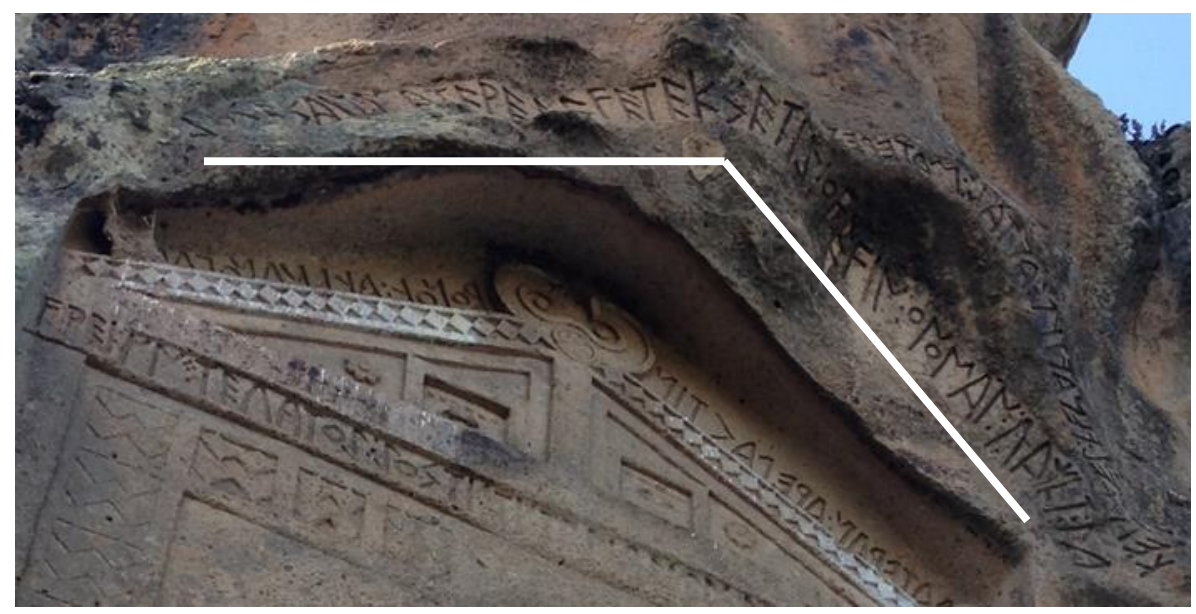

In the light of his analysis of the previous occurrences of $\langle\Psi\rangle$, he considered da $\Psi$ et a clear form of the verb edaes (3sg.ind.aor.act.) / $\alpha \delta \delta \alpha \kappa \varepsilon \tau$ (3sg.pres.act.) < PIE $* d^{h} e_{1^{-}}$'to put, to do', a sigmatic form (subj. or fut.) similar to Lat. faxō regarding to faciō / fēcī. In addition, since 〈ks〉 is also attested in the same sentence, he adduced that the difference between the sequence $/ \mathrm{ks} /$ found in eveteksete $y$ and in da $\mathrm{Y}$ et is that the first word contains a morpheme boundary between the two sounds: ev-e-tek-s-e-tey.

However, a verbal sequence -s-et (suffix and ending) is never attached to a consonant verbal theme (the interpretation of anivay eti depends on daYet, see below) and it is easier to consider daYet a spelling variant of OPhr. B-05 daket and the NPhr. ( $\alpha \delta) \delta \alpha \kappa \varepsilon \tau$ (3sg.pres.act.). Indeed, this sentence is a clear imprecative protasis, "who(ever) puts his own name in this Mother Eveteksetey...', and is the same syntactic sequence as the common New Phrygian protasis

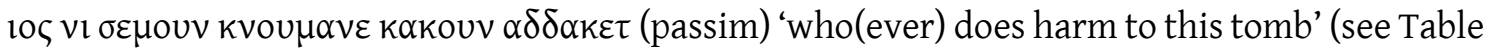
9). It is also similar to the OPhr. protasis tiv $\dagger<s>i m u n$ inmeney asenan daket 'whoever puts/does asenan in/to this monument' (B-05, Vezirhan stele, following Hämmig's 2013 analysis). On the other hand, one could argue that there is a protasis with a similar verbal form, P-04 a. ios ni akenan egeseti, but the ending - $t i$ of this verb instead of - $t$ shows that egeseti is not the same as da Yet, and note that there is a vowel between the root eg- (< PIE *seg' - 'hold') and -s-eti (NPhr. $\varepsilon \gamma \varepsilon \sigma(\tau)$.

Table 9 Comparison between $\mathrm{W}-01 \mathrm{~b}$ and the common NPhr. apodosis

\begin{tabular}{|c|c|c|c|c|c|}
\hline W-01b & yos & esai $=t$ & $\begin{array}{c}\text { materey } \\
\text { eveteksetey }\end{array}$ & $\begin{array}{l}\text { ovevin } \\
\text { onoman }\end{array}$ & daYet \\
\hline $\begin{array}{l}\text { Morphological } \\
\text { analysis }\end{array}$ & $\begin{array}{l}\text { rel. pron. in } \\
\text { sg.nom.masc. }\end{array}$ & $\begin{array}{l}\text { demonstrative } \\
\text { pronoun in } \\
\text { sg.dat. (+ pcl.) }\end{array}$ & $\begin{array}{l}\text { noun (+ adj. } \\
\text { in sg.dat.) }\end{array}$ & $\begin{array}{l}\text { (poss. pron } \\
+ \text { ) noun in } \\
\text { sg.acc. }\end{array}$ & $\begin{array}{l}3 \mathrm{sg} . \\
\text { verb }\end{array}$ \\
\hline $\begin{array}{c}\text { OPhr. B-05, } \\
\text { syntactical } \\
\text { parallel }\end{array}$ & tiv $\dagger(=$ yos $)$ & $<s>$ imun & inmeney & asenạn & dạket \\
\hline $\begin{array}{c}\text { NPhr. syntactical } \\
\text { parallel }\end{array}$ & $\operatorname{los}(v i)$ & $\sigma \varepsilon \mu o u v$ & 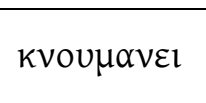 & kakouv & $\alpha \delta \delta \alpha \kappa \varepsilon \tau$ \\
\hline
\end{tabular}

Therefore, this is the first context in which Lejeune's suggestion is questionable, although the arguments given here to refute it are not conclusive. Nevertheless, there is a 
disregarded inscription which could be the key to this question: G-249. It is a short text incised on the bottom of an unfinished alabaster weight, according to the first editors (CIPPh I, 195196):

\section{seVelt|ias}

Fig. 5 Weight with the Phrygian inscription G-249 (CIPPh I, 195 and II, CVI no. 3-4)
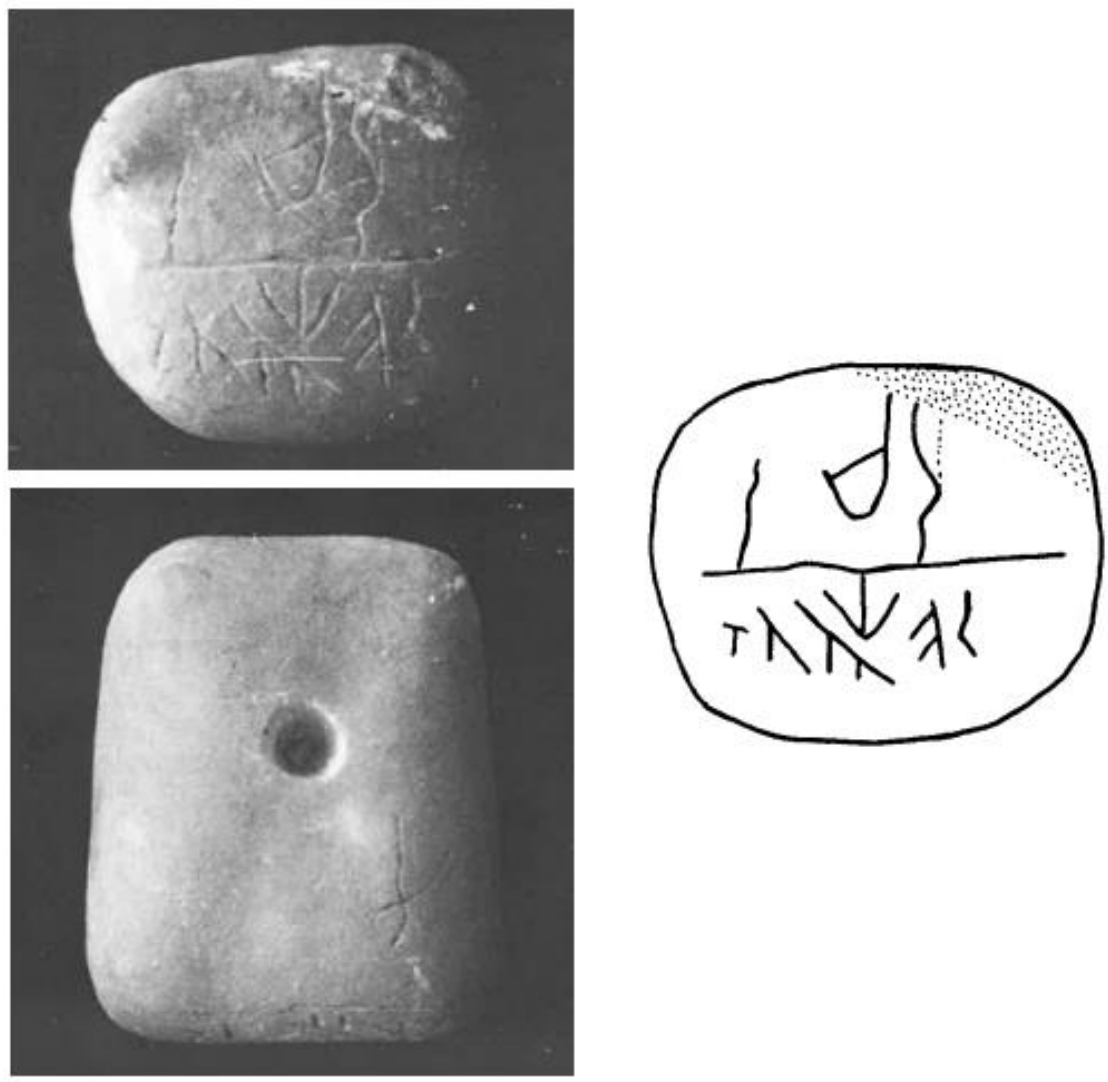

It is difficult to date this artefact because it was found in a layer of the $6^{\text {th }} \mathrm{c}$. BC with many objects dated to the $8^{\text {th }} \mathrm{c}$. BC. Despite the ambiguous context (a layer in the postdestruction level in building (C) 3 ), the editors considered it "archaïque" and, more recently, Brixhe $(2002 a, 26$ and $2004 b, 276)$ reconsidered that it may be dated to the beginning of the $8^{\text {th }}$ c. BC, following the reconsideration of Gordion chronology by DeVries and Voigt (see § 3.1). In this case, it would be the oldest occurrence of $\langle V\rangle$. Note that this shape is the common one of the Phoenician kāp before the $8^{\text {th }}$ c. BC (see, e.g., the Schrifttafel given by Friedrich and Röllig 1970).

The reading of this inscription is not easy, but the experienced editors made an excellent job. Indeed, not only is the text established by the editors is the only defensible intepretation, it is also supported by new arguments. Since the artefact where G-249 was incised is a weight (modified to serve as loom weight, as the unfinished central hole and the archaeological context show), ${ }^{66}$ it can be considered that the inscription refers to the unit of measurement. Indeed, the first part, seVel, fits perfectly as a borrowing of the well-known West

\footnotetext{
${ }^{66}$ On the large number of loom weights from this level and on textile production at Gordion, see DeVries 1990, 387 (who counts 509 weights in the main room of CC 3) and Burke 2005, 75-78. Note that this alabaster weight differs considerably from the more common "doughnut" type (most "made of sun-dried clay" from the banks of the Sakarya River" according to Burke 2005, 75).
} 


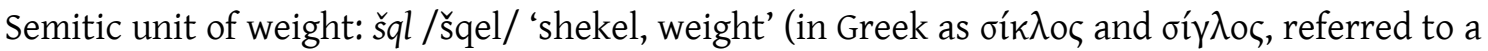
weight or coin, also in Lyc. as sixla-, see Neumann 2007, 324-325). It is a common epigraph incised on weights from Old Aramaic and Imperial/Official Aramaic periods. See, for example, the typical Old Aramaic inscription on weights: e.g. šql ḥmt 'Shekel of Hamath', šql șydn 'Shekel of Sidon', šql qrqr 'Shekel of Qarqar' (see Riis \& Buhl 1990, 65-66 and Deutsch \& Millard 2014), all of them contemporaneous to the Phrygian one. Therefore, the word se $V e l$ provides an explicit occurrence against the interpretation $/ \mathrm{ks} /$ for the letter $\langle\mathrm{V}\rangle$.

According to the given parallels, the rest of the inscription, $t$ ias, may be a toponym in sg.gen., however an ethnic in sg.nom. cannot be ruled out in the light of New Phrygian 1.1 (48)

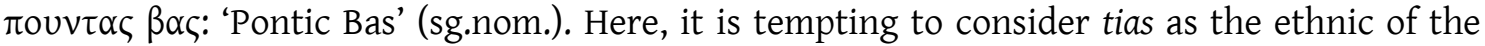
Bithynian city Tícıov, Tíoৎ, Tńıv (KON 618-619 § 1337), named after Ti- (the Phrygian Zeus)

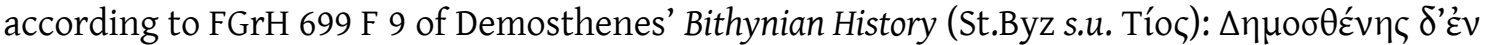

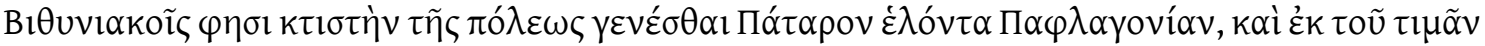

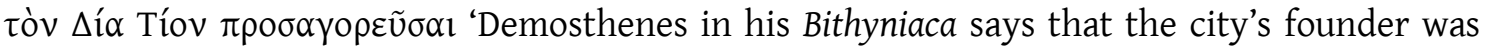
Pataros, who conquered Paphlagonia, and that he called it Tios after Zeus worship'. Nevertheless, other unrecorded cities could be also named after this central Phrygian god and the suggested identification is a mere possibility.

Before giving an alternative interpretation for the representation of the letter $\langle\Psi\rangle, \mathrm{I}$ prefer to further explore the other occurrences of this letter. However, only the verb anivayeti (B-07) provides some information. This 3sg. verb occurs in a Greco-Persian grave stele dated to between 500 and $475 \mathrm{BC}$ and found in Daskyleion (seat of the Persian satrapy of Hellespontic Phrygia). My reading, below, is based on the one given by Brixhe (2004a, 85), with some differences in the segmentation:

[.]gat: $s=$ manes iyungidas manitos apelev porniyoy esț[..]

[..] es va knais manuka odeketoy meros ke manes is yos tiv[.]

$[$.$] n ke devun k$ umnotan ordoineten me kos anivay eti s=manin

The stele has a relief representing a banquet scene with a couple reclined on a couch and surrounded by attendants. ${ }^{67}$ It very likely represents Manes (1. 1, 2 and 3) and his wife Manukka (va knais manuka 1. 2). Although the text is not at all clear, the second part of the last line can be reconsidered. According to Brixhe $(2002,85)$, the sequence may be read as mekos anivay eti $(i)$ s manin, where mekos is a variant of mekas (erroneously considered a noun referring to the tomb) or, as he preferred, an unknown word in pl.dat., (i)s a preposition (the loss of its vowel is explained by its position after anivay eti) and manin the acc. of the PN manes. However, he cannot give clear sense to this part of the inscription and mekos has no parallels.

Considering that $m e$ has recently been identified as the prohibitive pcl. PIE * meh (simultaneously Hämmig fthc. a and Obrador-Cursach fthc.a), B-07 me ... anivayeti can be interpreted in the light of the New Phrygian curses against violators, where $\mu \varepsilon+$ subjunctive

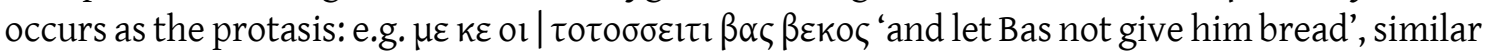
to $86 \beta \alpha[\varsigma] \mid$ tor $\beta \varepsilon \kappa o \varsigma \mu \varepsilon \beta \varepsilon \rho \varepsilon[\tau]$ 'let Bas not bring bread to him' (following Hämmig's likely interpretation). Moreover, this new segmentation of B-07 shows a subject of the verb: the indefinite pron. kos (sg.nom.masc., inherited from PIE ${ }^{*} k^{u} 0-$ ). This pron. is found four times in

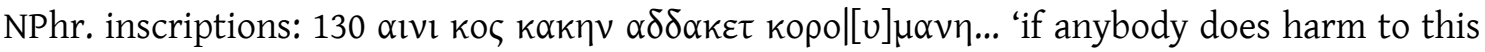

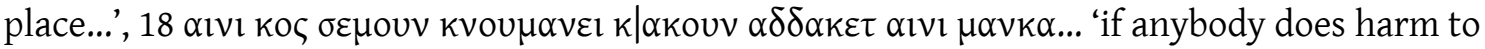

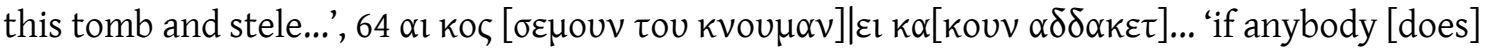

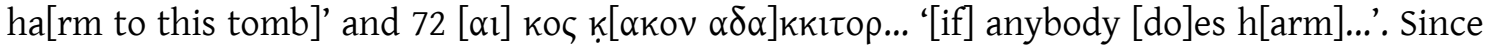

${ }^{67}$ On the significance of this motif see Baughan 2013, 233-266. 
this inscription uses spaces to mark the word boundaries, the lack of a space between me and kos suggests that me is a clitic word as well as its Greek parallel $\mu$ '. Finally, the lone $s$ is the same clitic form of the demonstrative pron. found in M-01d s=materan (midas s=materan tvemes eneparkes? 'Midas engraved this Matar tvemes', a text from the same period as B-07). Consequently, me kos anivay eti s=manin means something like 'let nobody anivayeti Manes'.

Despite the above analysis, the verb anivayeti remains the only misunderstood word of this short sentence. Nevertheless, a similar funerary stele with an Aramaic inscription found in the same city, Daskyleion, can be the key to clarifying the meaning of the Phrygian verb. According to Lipiński (1975a, 151), the Aramaic epitaph reads as follows:

$$
\begin{aligned}
& \text { Plh șlmh zy Plnp br ?šy- } \\
& \text { hw \bd lnpšh hwmytk } \\
& \text { bl wnbw zy ?rḥ? znh } \\
& \text { yhwh Sdh ?yš ?l ySml }
\end{aligned}
$$

'These are the images, which Elnāp, son of Ashyā|hū, has made for his tomb. I adjure thee | by Bēl and Nabû! May the man, who along this way | will be going, do no harm! ${ }^{68}$

In the light of the last line of the text, me kos anivayeti s=manin can be considered to mean 'let nobody harm Manes'. But does anivay eti have any relation with harm? Here, a very suitable etymology can be proposed. If we consider an(i)- a preverb (as Brixhe 2004a, 84 does), ${ }^{69}$ we have a verbal root vay- which fits as inherited from PIE *ueh ${ }_{2} g-$ / *ueh ${ }_{2}$ g $^{-}$'break' (LIV 664 -

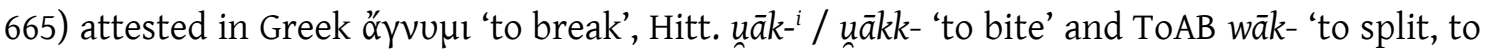
burst'. Of course, this development assumes the shift ${ }^{*}{ }_{-}-{ }^{*}{ }^{*} \dot{g}_{-}>-k$ - found in mekas 'big' (<

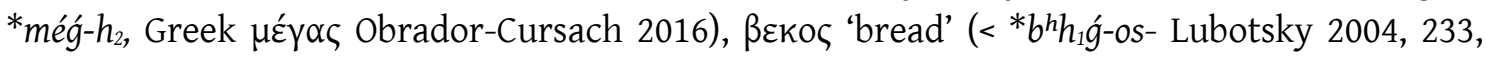

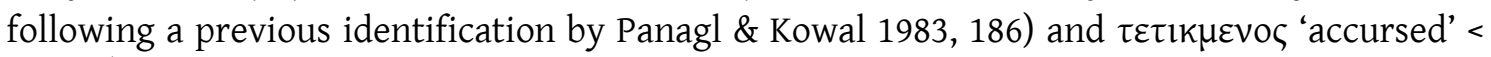
*de-diḱk-mh no- (Greek $\delta 1 \alpha-\delta ı \alpha \alpha ́ \zeta \omega$ 'judge', $\kappa \alpha \tau \alpha-\delta ı \kappa \alpha ́ \zeta \omega$ 'condemn'). Thus, there is another $\langle y\rangle$ related somehow to $/ \mathrm{k} /$.

Moreover, it can be suggested as a working hypothesis that, in the light of the Aramaic rel. clause in the same position, zy ?rḥ? znh | yhwh $\{d h$ ?yš $2 l y\{m l$ 'who along this way | will be going, do no harm!', the rel. clause read before this little sentence, yos tiv[.]|[?]n ke devun $k$ umnotan ordoineten me kos anivayeti s=manin, is related to kos, the subject of the sentence. Note also the presence of the DNs bl wnbw 'Bēl and Nabû' in the Aramaic text, the occurrence of the word devun 'god(s)' (sg.acc. or pl.gen?) and the tentative presence of the Phrygian Zeus in $\operatorname{tiv}[] \mid.\left[.{ }^{?}\right] n$ (first suggested by Lubotsky 2004, 230). So, both inscriptions are very similar in their formulation.

Following the analysis of this letter, the remaining occurrences must be considered to confirm that they do not provide valuable information. Certainly, the form deVeti seems to be related somehow to daY et (a zero-grade form of the PIE root * $d^{h}(e) h_{1^{-}}$'to put, to do'?). ${ }^{70}$ It was read by Brixhe (2002a, 6-7) on a small terracotta disc found on the surface of the ancient Dorylaion (Şarhöyük, near Eskişehir), without a clear archaeological context. The nature of this

\footnotetext{
${ }^{68}$ Other translations of the last sentence are 'let no one do harm (to my tomb)' (Cross 1966, 8-9), 'que personne ne (lui) fasse de mal!' (Lemaire 2000, II.1).

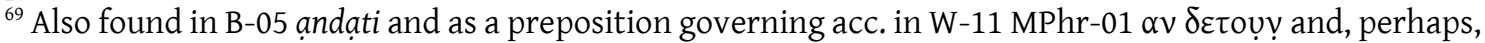
in $40.3 \alpha v \mid \mu a v k \alpha v$. Since its origin is to be found in the PIE adverb * $h_{2} e n$ - 'on, onto' (see e.g. Greek $\alpha$ vó 'up, upwards, along', Avestan ana 'upwards, along'), I must admit that the presence of the vowel $i$ in B-07 an-i- is a mystery to me.

${ }^{70}$ The alternative given by Brixhe (2002a, 6-7), a form related to PIE *dek- 'take, perceive' (LIV 109-112,

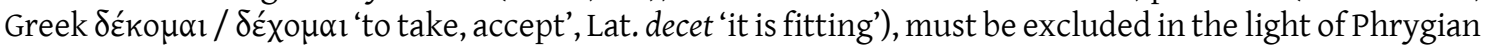
Lautverschiebung suggested by Lubotsky (2004).
} 
inscription remains unclear according to its editor (a seal?), and even the text, displayed on both faces, is a pile of minuscule strokes that are difficult to read (especially face B). The whole text was edited by Brixhe (2002a, 4-10) as follows:

$$
\begin{array}{lll}
\text { Face A I } & \text { deVeti } \\
\text { A II } & \text { toTiatiei } \\
\text { Face } & \text { B } & \text { as- } \\
& & \text { na isnou }
\end{array}
$$

After de eti, the remaining words are even more obscure. The form toTi (with the rare letter no. 19, a variant of $\uparrow$ ) is tentatively suggested to be the object of the verb (a sg.acc. of an unknown $i$-stem neuter noun) and the collation a tiei seems to correspond to NPhr. $\alpha(\tau) \mathrm{Tl}(\eta)$ 'by Zeus' (see Lubotsky 1997, 126 fn. 23 and Lubotsky 2004, 230). The two words of face B are even less clear: isnou is equated to NPhr. 87 lovou (verb of an imprecative apodosis without clear meaning) and the hapax as $n a$ is suggested to be the subject of the verb (a neuter plural).

Also unclear are $\mathrm{G}-112$, a graffito from the $6^{\text {th }} \mathrm{c}$. BC with the sequence $e \Psi t a[---]$, perhaps

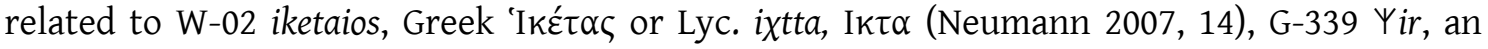
unparalleled graffito dated to 550-330 BC, G-306 [---]Yọ[---] or [---]ọ Y---] (5 $\left.{ }^{\text {th }} \mathrm{C} . \mathrm{BC}\right)$ and NW-135 miye[-?-]oЧ $(550-330 \mathrm{BC})$. In the other occurrences of this letter, it appears as a simple mark: $\Psi$ in G-294 ( $4^{\text {th }}$ C. BC), ${ }^{71} \vee$ in G-322 (560-550 BC), G-324 (Hellenistic or Roman period?), NW-105, NW-112, NW-119, NW-121 (all from Dorylaion and dated to 550-330 BC), VV in NW-121 (550 $330 \mathrm{BC})$ and $\Psi$ in NW-128 (550-330 BC).

Leaving aside the marks, the contexts in which it occurs can be established as follows:

a) Initial position (3 occurrences), G-115 Yuva Yaros, its possible abbreviation G-224 Yuv and G-339 Yir;

b) Between vowels (5 occurrences), W-01b daYet, B-07 anivayeti, G-115 Yuva Yaros, seVel G-249 and NW-101 deVeti twice between $a$ and $e$, twice between $e$ and $e$, once between $a$ and $a$;

c) Beween a vowel and a consonant (1 occurence), $e$ $\Psi$ ta [---];

d) Unknown (3 occurrences): G-145 voineio $\llbracket Y \rrbracket s$, G-306 [---]Yọ[---] or [---]ọ Y[---] and NW135 miye[-?-]oफI ;

Moreover, in 4 of these 12 instances (or 9 instances, leaving aside point (d)) it is found in borrowed words: G-115 Yuva Yaros, Yuv and seVel and in 6 of these 12 instances (9 leaving aside point (d)) it is in contact with front vowels (/e/ and /i/). In YuvaYaros it is the Phrygian rendering of the Persian - $x \check{s}^{-}$, while in seVel the Aramaic /q/ (̌́qel) $)^{72}$ and in daY et (=B-05 dạket, NPhr. $(\alpha \delta) \delta \alpha k \varepsilon \tau)$ and anivayeti it goes back to PIE $*_{-k-}\left({ }^{*} d^{h} e h_{1}-k\right.$ - and $*_{n}^{*} h_{2} k_{-}$, respectively), perhaps also in deVeti if related to da $Y$ et.

According to the available information, one can consider three possibilities:

1. $\langle\Psi\rangle$ represents a palatalised allophone of $/ \mathrm{k} /$ in contact with front vowels ([kj], [ts] or [t]]): Yir (G-339), da Yet (W-01b), anivayeti (B-07), deVeti (NW-101) and eYta[---]. The suggested palatalisation was sufficient to be identified by the engravers, who developed a variant of the kaph / kappa. Later this letter was used to represent the foreign sounds

\footnotetext{
${ }^{71}$ We can add to this list $\Psi$ in G-278 (dated to between the $8^{\text {th }}$ and the $7^{\text {th }} \mathrm{c}$. BC according to Brixhe 2004a, 38-40), however, although there is a small amount of text ([-?-]? [.] $\left.] a i^{?} \quad u^{?}\right)$, this suggested letter appears near to non-verbal marks and is very likely not to be a proper grapheme. As has been said above, the certain instances of this letter appear in the $6^{\text {th }} \mathrm{c}$. BC.

${ }^{72}$ This uvular sound /q/ is supposed to merge with the Phrygian velar sound /k/, as occurs in Greek

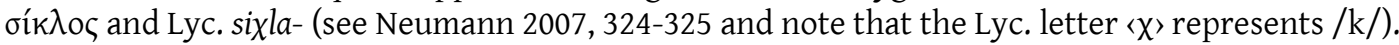


of huvaxšatara- > Yuva Yaros. The Lycian alphabet can be adduced as a parallel of the

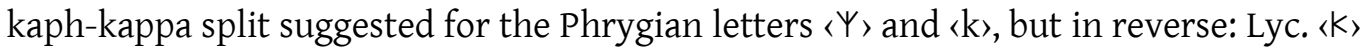
(transcribed as $\langle k\rangle$ ) stands for $/ \mathrm{c} /$ and $V($ transcribed as $\langle\chi\rangle)$ for $/ \mathrm{k} /$.

2. $\langle\Psi\rangle$ represents a fricative allophone $[\mathrm{x}]$ of $/ \mathrm{k} /$ in intervocalic position, a shift similar to *népot-s > nevos (B-05, as Hämmig 2013 identified). In such a case, the use of this letter fits with ${ }^{h}$ Uvaxšatara- $>$ Yuva $\Psi$ aros, since / $\mathrm{h} /$ could have been heard as / $\mathrm{x} /$ by the Phr. speakers and - $x \check{s}$ - could have been simplified to /x/. Again, this shift only occurred in some places and was not consistently represented.

3. $\langle\Psi\rangle$ and $\langle\mathrm{k}\rangle$ are two shapes of the same letter $\langle\mathrm{k}\rangle$, since da $Y$ et $(\mathrm{W}-01 \mathrm{~b})$ is the same verbal form of daket (B-05) / ( $\alpha \delta) \delta \alpha k \varepsilon \tau$ (passim). If this is the case, Phrygian Yuva Yaros renders

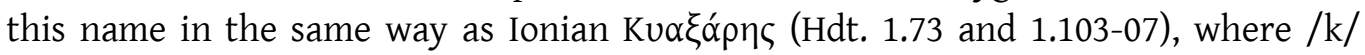
renders Persian $/ \mathrm{x} /$ and $/ \mathrm{h} /{ }^{73}$ and the cluster $-k_{s}->$ was simplified in $-k$ - in Phrygian

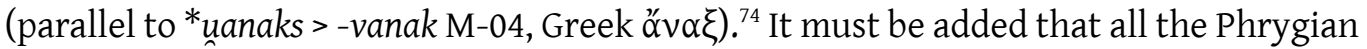
shapes related to «k» are found in Semitic inscriptions of the same period for kāp.

A problem shared by the two first possibilities is that the verb daYet never again appears with a letter other than 〈k〉 in OPhr. and 〈 $($ 〉 in NPhr.: daket (B-05) / ( $\alpha \delta) \delta \alpha \kappa \varepsilon \tau$ (passim). Especially in the case of the second possibility, the lack of a NPhr. variant ${ }^{* * \delta \alpha \chi \varepsilon \tau}$ is significant and the spelling of the Greek borrowing $\chi \omega ́ \rho \rho \varsigma$, , -ov > kopov $(27.1=92)$ does not make sense, since Classical Greek $/ \mathrm{k}^{\mathrm{h}} /$ was pronounced as / $\mathrm{x}$ / by the New Phrygian times. Of course, it could be adduced that this shift occurred only in some some variants of Phrygian which were not precedents of the NPhr. stage. However, there is no evidence for such a conclusion. Moreoever, the first possibility may be refuted because in the same $\mathrm{W}-01 \mathrm{~b},<\mathrm{k}>$ occurs in contact with a front vowel, eveteksete? $y$, lakedo and key.

The third possibility could be rejected because in $\mathrm{W}-01 \mathrm{~b}$ and B-07 the two shapes occur in the same inscription with «k〉. However, this is not a valid argument because it is not unusual to find two or even more different shapes of one letter in the same inscription. See, e.g., the famous inscription M-01a (from the $6^{\text {th }} \mathrm{c}$. BC, as well as W-01b), where 〈s〉 has several shapes (Table 10):

Table 10 Shapes of $\langle$ s〉 in M-01a

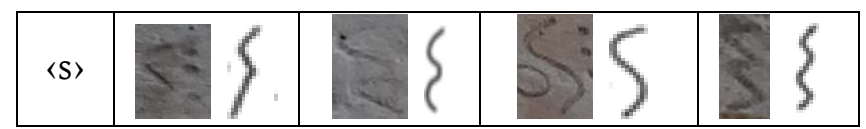

Turning back to the letter $\langle\Psi\rangle$, it seems also to be found in B-07 knais. Brixhe (2004a, 74), if we consider that the breach at this position of the stele hides a stroke of this letter. However, the shape is clearly different to the other $\langle\mathrm{k}\rangle$ of the stele and similar to $\langle\psi\rangle$, and detailed examination of the photo provided by Brixhe suggests that the consonant complete (albeit eroded). Observe in Table 11 that not all the vertical strokes of the «k are as apparent as drawn by Brixhe (especially $4,1.2$ ):

\footnotetext{
${ }^{73}$ Since Phrygian and Ionian are psilotic, the rendering of $/ \mathrm{h} /$ is not expected. Consequently, one must assume an anticipatory assimilation between /h/ and /x/ in this PN: *huvaxšatara- > *xuvaxsara- (with the assimilation and syncope *-šatara- > *-šara-) > Ion. Kuałá pns / Phr. Yuva Yaros.

${ }^{74}$ From of $s e \bigvee e l<$ Aramaic šqel we know that this Semitic sibiliant was rendered as /s/ in Phrygian, as

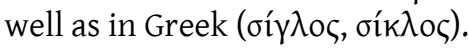


Table $11 \mathrm{~K}$ and $\Psi$ in B-07 (stele from Daskyleion) according to the photo and copy by Brixhe (2004a, 74-75)

\begin{tabular}{|c|c|c|c|}
\hline Occurrence & Photo & Copy & Word \\
\hline $1(1.2)$ & & & knais \\
\hline $2(1.2)$ & & & manuka \\
\hline $3(1.2)$ & & & odeketoy \\
\hline $4(1.2)$ & & & ke \\
\hline $5(1.3)$ & & & ke \\
\hline $6(1.3)$ & & & kos \\
\hline $7(1.3)$ & & & anivareti \\
\hline
\end{tabular}

Indeed, by the time the alphabet had been adapted to the Phrygian language, the Phoenician-Aramaic variant $\psi$ was commonly used (e.g., the Kulamuwa stele, dated ca. 830 BC). Consequently, there is good reason to consider that $\psi$ is a mere graphic variant of $\langle\mathrm{k}\rangle$ rather than a representation of /ks/ or other sounds. Nevertheless, in this dissertation I will represent the variants of the letter in the words where they appear, since the question requires further research. Finally, the coexistence of various shapes must be addressed. The scenario suggested here may show interferences of cursive writing in monumental inscriptions; the same evolution is found in Phoenician and Aramaic inscriptions. Note that $\Psi$ is significantly more common in graffiti on sherds than in stone inscriptions, since in the latter context this shape only occurs twice: da Yet (W-01b) and anivaYeti (B-07). At least in W-01b, the use of $\Psi$ instead of $\mathrm{K}$ seems to be conditioned by the lack of space at the end of the line (see Fig. 6) but the same can be adduced for B-07, where the letters are slightly bigger and spaced further apart at the beginning than at the end of the inscription.

Fig. 6 Detail of daY et in W-01b (Obrador-Cursach)

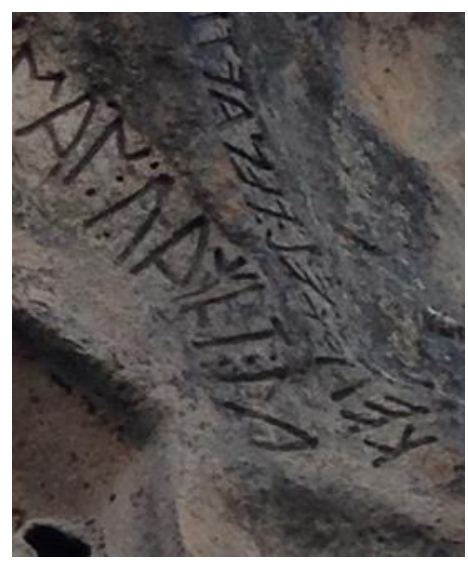




\subsubsection{The letter CIPPh no. 21: the unparalleled Phrygian "qof"}

The letter CIPPh no. 21 is a hapax found only in the rock inscription W-08 (undated):

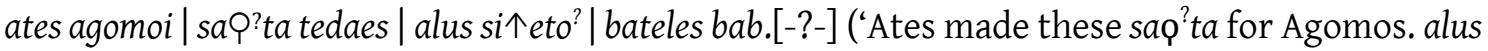
si个eto?. Bateles Baba?...'). Although it has been sometimes equated to the Semitic qof and Greek

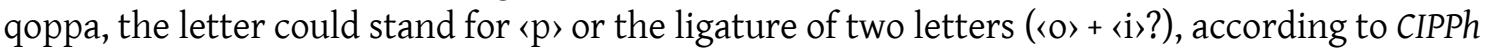
(I, 53 see also Brixhe \& Drew-Bear 1982, 69 and 72). In any case, it is never found elsewhere in the Phrygian corpus and the reading is not certain enough for it to be deemed a proper letter. Indeed, the vertical stroke seems deliberate, but the circular part is more tentative. So, as CIPPh assumes, its existence is unclear.

\subsubsection{The obscure letter CIPPh no. 22}

Before the identification of the Phrygian yod by Lejeune (1969a), the letter CIPPh no. 18 was considered similar to Greek Z $\zeta$. However, when the yod was identified, the letter CIPPh no. 22 was suggested to be the counterpart of this Greek letter (see Lejeune 1969a, 39, Lejeune 1970, 58 and 60, Brixhe 1982, 240-241 and Morante Mediavilla 2000, 185-196). However, both of the claimed occurrences of this letter are far from clearly read texts and belong to very different periods of Gordion's history. In G-106 ufd (see Fig. 7 and Fig. 8) the whole inscription ("scratched on a smear of beeswax beside one handle" of a bronze bowl of the MM Tumulus, Young 1969, 262 no. 32, dated before 740 BC) has no parallels and does not refer to any known sequence. Brixhe $(1982,240)$ considered it an abbreviation of a PN, however this PN is unknown. Very probably, his motivation is that two of the three letters are consonants and the other inscriptions found in MM are PNs. In any case, the first letter has a strange shape for a $\langle\mathrm{u}\rangle$ and perhaps the claimed 7 is the shape of another letter. As a working hypothesis, one could suggest a three-stroke $\langle\mathrm{s}\rangle$, similar to the one found in M-01d. However, the two letters are not at all equal, and whatever this inscription contains it remains unclear, as does the reading of the second letter. It is true that a reading usd would fit the NPhr. sequence $v \sigma \delta-(22.1=9)$, but it is also problematic. ${ }^{75}$

\section{Fig. 7 Drawing of G-106 according to CIPPh (I, 101)}

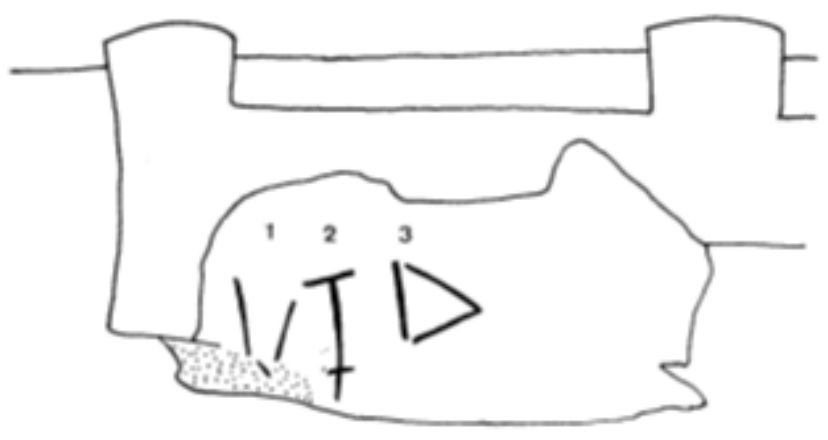

\footnotetext{
${ }^{75}$ In addition, a Phoenician (or Aramaic) reading of G-106 can be ruled out because the letters would be too schematic. Moreover, neither a root nor personal name $D-Z-W$ is attested in the West Semitic branch and this sequence does not fit anything known in Anatolia. I want to thank José Ángel Zamora for his observations on ruling out this possibility (p.c. 19/07/2017).
} 


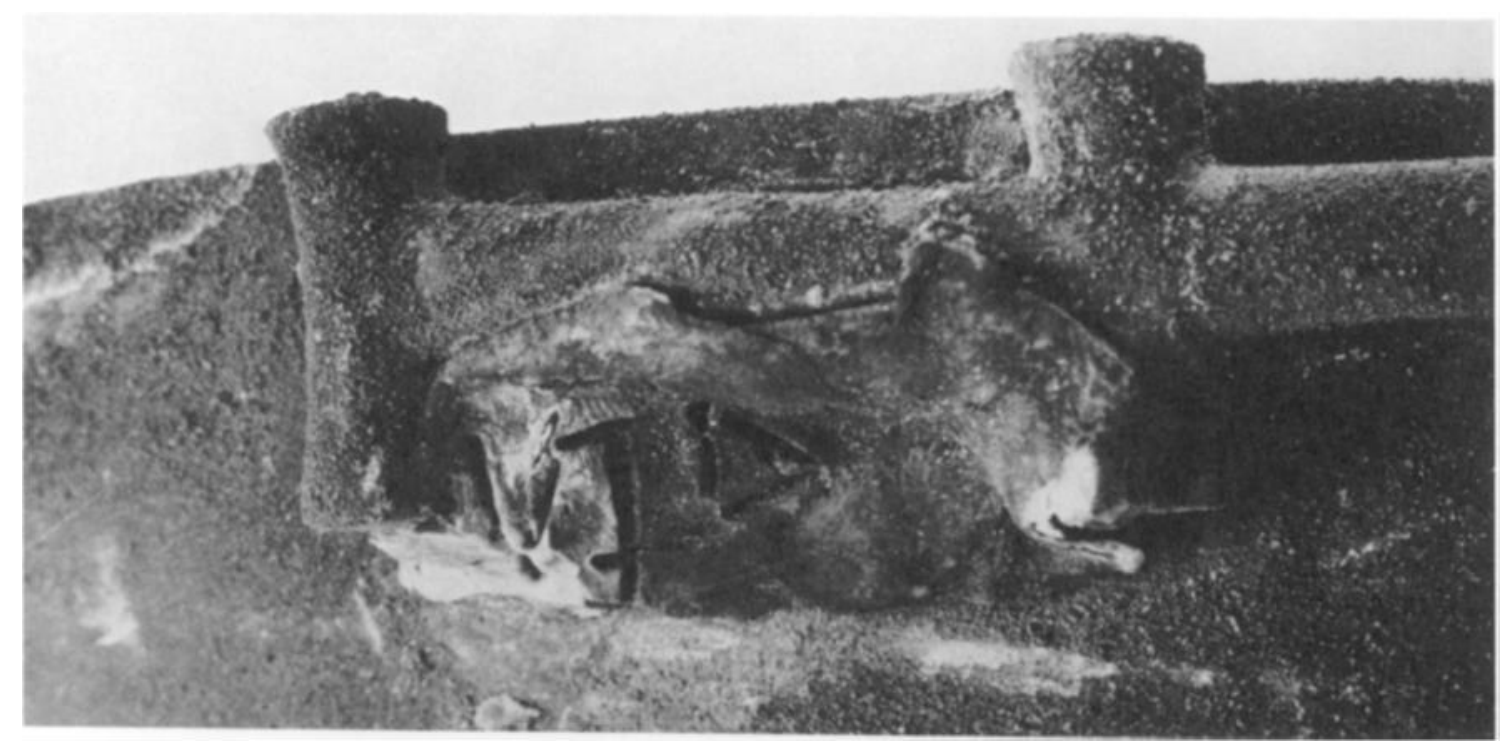

The second claimed inscription is G-244, a graffito incised on a sherd (fragment of a cup from the $3^{\text {rd }}$ C. BC, Fig. 9): [-?-]me? $\mathrm{Ti}[-$-?-] (according to CIPPh, 191). It was suggested to be an abbreviated PN by Brixhe $(1982,241)$. However, since it is dated to the $3^{\text {rd }} \mathrm{c}$. BC, it seems most likely to be a Greek inscription (as is more common in Hellenistic Gordion). Moreover, the incised letters are highly simplified compared to other text Phrygian graffiti, especially the letter «e without the central stroke. Therefore, G-244 could be read in Greek as [-?-]MEZI[-?-]. As can be seen, the two inscriptions claimed to attest such a letter are particularly difficult to read, so the existence of the Old Phrygian letter CIPPh no. 22 is hardly defensible.

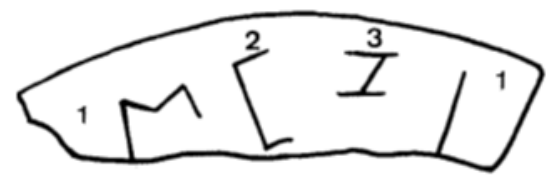

\subsubsection{The letter CIPPh no. 24: an 8-shaped variant of 〈b〉}

The 8-shaped letter CIPPh no. 24 is only found in three obscure inscriptions, which lack clear significance because they are full of hapax:

1. P-101 (incised on the bottom of a cup from $7^{\text {th }}$ c. BC) aini $\mid$ dasp ula isini (conj. + noun + verb);

2. P-106 (on a sherd, $7^{\text {th }}$ or $6^{\text {th }}$ C. BC) [---].ti : makio?taTi8i :.[---] (?);

3. W-08 (inscribed on a rock, undated) ates agomoi $\mid$ sa $\varphi^{?}$ ta tedaes $\mid$ alus si $\uparrow$ eto? $\mid$ 8ateles 8a8.[-?-] ('Ates made these sa९'ta for Agomos. alus si个eto?. Bateles Baba?...'). 
Although a similar letter is found in the Lydian (and the Etruscan) alphabet as $/ \mathrm{f} / \mathrm{f}^{76}$ Brixhe (in Brixhe \& Drew-Bear 1982, 78; see also CIPPh I, 54) considered it a variant of 〈b〉 written with one stroke. Indeed, by analysing its positions he concluded that it was a consonant (in P101 it is found after a vowel and before a consonant, in P-106 between vowels, in W-08 at the beginning of two words and before vowels). His proposal is very likely since the letter never occurs in a text where the common $\langle b\rangle$ is used, hence it does not suggest a possible new sound for the Phrygian language (never found again in either OPhr. or NPhr.) and, finally, the common PN baba(s) can be read in W-08. Following Brixhe's analysis, in this dissertation this 8 -shaped letter is transliterated as $b$.

\subsubsection{The non-phonetic signs 3.1.7.1. Interpunctions and spaces}

Usually, OPhr. inscriptions are written in scriptio continua and word boundaries are not marked. Nevertheless, in some inscriptions, interpunctions are used to separate words. These signs may consist of one or several dots in vertical disposition. In monumental inscriptions, this sign consists of three (:) or four (:) dots: three dots in M-02, M-06, M-10, W-01, W-02, G-01a, G10, P-06, T-01 and T-02 and four in M-01f, M-04 and K-01. Sometimes, interpunctions of three and four dots coexist in the same inscriptions: M-01a, M-01b, W-07, G-02 and T-03 (T-03aI only has :, while the other fragments have :). These two types of interpuntions are also found in graffiti on pottery, but less commonly: G-125 and P-107 have !, G-136 has : and P-106 has both types. Only one inscription, B-04, has the single dot. Interpunctions consisting of two dots (:) are used in the funerary inscription from Daskyleion (B-07), in the graffito B-108 and the seal Dd-103.

Spaces to separate words are less common. They are only found in the monumental inscriptions B-01 and B-05 and some graffiti on sherds, G-109. Interpunction and spaces share a common feature: clitics are not separated from the stressed words. See, e.g., M-01b :sikeneman: for si=keneman and B-01 sibevdos for si=bevdos.

\subsubsection{The "determinative" () before PNs}

In three instances ${ }^{77}$ an upper semi-circular sign appears before PNs: 'urunis (G-346), 'uva (K-01V) and 'masa urgitos (K-01VI+VIIa, where the inverse sign appears). The case of G-346, a beam from Gordion MM Tumulus (closed between 743 and $741 \mathrm{BC}$ ), is striking because this sign is not used in the other three PNs incised on the same beam. In any case, there is a significant space between 'urunis and the other PNs and perhaps for some reason this name has a special status, also marked by the use of the symbol '. After rejecting a reading 〈k〉 or 〈g for this sign, Brixhe (in Liebhart \& Brixhe 2009, 151-152) concluded that it must be a non-phonetic sign, used in the same way as the determinatives in the cuneiform and hieroglyphic scripts. Then, according to him, with this sign, Phrygians tried to imitate the cuneiform use of the sign I (transliterated as ${ }^{1}$ or $^{\mathrm{m}}$ ), which is put before male personal names in cuneiform scripts. ${ }^{78}$

\footnotetext{
${ }^{76}$ A similar letter is also found in Carian (doubtfully mentioned by Brixhe): Masson no. 33(+34) 8 and $\mathrm{X}$, transcribed as $\gamma$ (see Adiego 2007, 20 and 21).

${ }^{77} \mathrm{~A}$ fourth testimony is also found in K-01V. However, the following word is lost.

${ }^{78}$ Perhaps, HLuw. also has a "personal maker", the sign no. *380 (see Payne 2010, 6-7 and 2017, 224).
} 


\section{G-346}
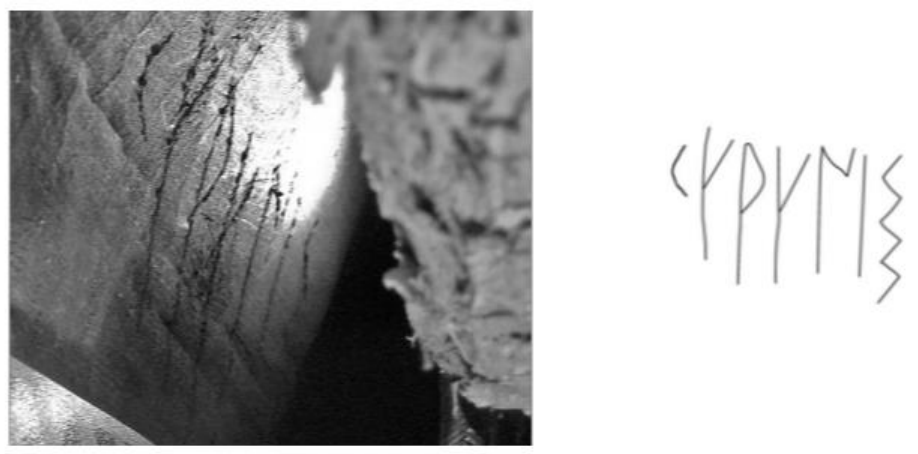

\section{$\mathrm{K}-01 \mathrm{~V}$}
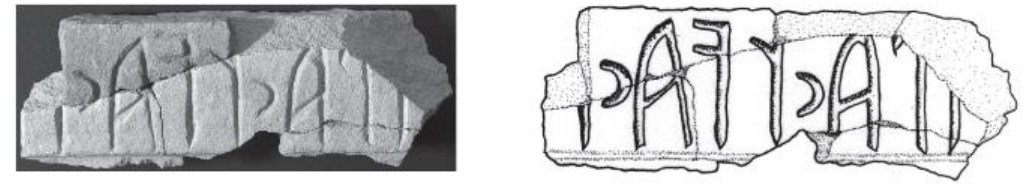

\section{K-01VI+VIIa}
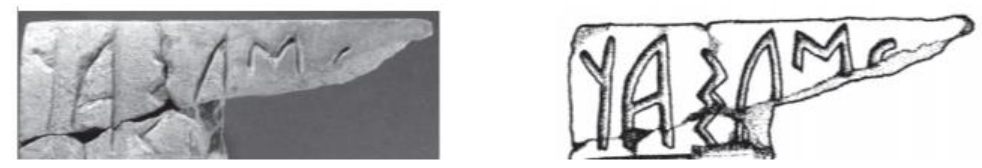

\subsubsection{Capacity marks}

Three pithoi from Gordion with grafitti also bear metrological marks (Fig. 11), which are also found on other vessels (manly pithoi) from the same city with non-verbal marks. ${ }^{79}$ It is unclear whether they refer to the potential or actual volume of the vessel or even the weight of its contents. Roller $(1987 a, 60)$ provides a very likely interpretation for their use: "because they were incised after firing [with one partial exception: 3b-29], the marks were probably first placed on the containers to record the volume or weight of the vessel's contents. Once incised, however, the marks became permanent and stood as a record of the potential capacity of the empty vessel."

These "capacity marks" consist of compass-drawn circles, half-circles or straight stroke. G-116 has four cicles and its capacity is 95.04 litres, so each circle has been considered to represent ca. 23.76 litres $.^{80} \mathrm{G}-117$ is estimated to contain 132 litres and the metrological marks consists of five circles (ca. 118.8 litres), one half-circle (ca. 11.88 litres) and one straight stroke,

\footnotetext{
${ }^{79}$ See the in-depth Roller 1987a, 60-68, section 3b, with 40 occurrences of this system used "only on vessels of local manufacture". Regarding the dating of the objects, note that the book is previous to the recent revision.

${ }^{80}$ These estimations are based on Young 1969, 272 and fn. 43. Edwards 1963, $46-47$ considered that it represents approximately 25 liters, while Roller, more conservatively, speaks about 20-28 liters.
} 
which must represent ca. 1.32 litres. Finally, G-150 has three circles (ca. 71.25 litres), but it is too fragmentary to corroborate its capacity.

Nevertheless, there are three gray-ware jugs from the same city which do not fit this theory. They are too small to contain the litres represented on them according to the previous analysis. So, Roller $(1987 \mathrm{a}, 62)$ considered that "the circle unit could have referred to two different units of measure altogether, perhaps a large and a small unit of grain, or perhaps the distinction between a wet and dry measure". In any case, a Greek numeral system is not used by the inhabitants of Gordion until the Hellenistic period, when the Ionic numeral system is found on several pithoi. Previous occurrences of Greek acrophonic numerals only appear on vases imported into the city.

Fig. 11 Capacity signs found on Gordion pithoi with Phrygian graffiti, drawings by R. S. Young (1969).

G-116

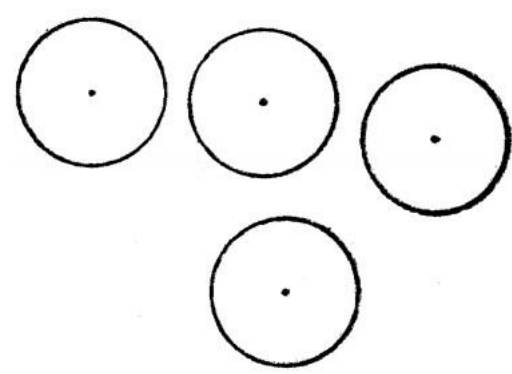

G-117

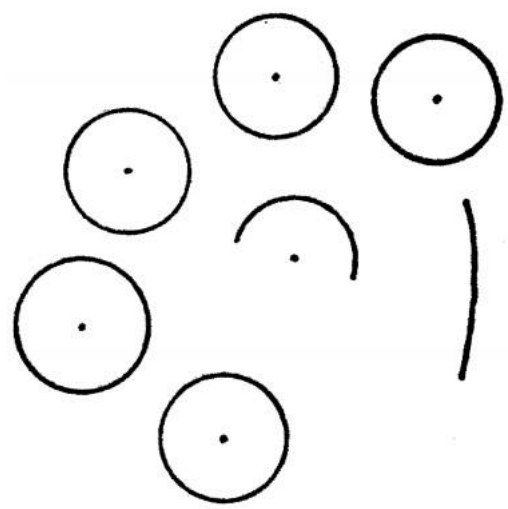

G-150

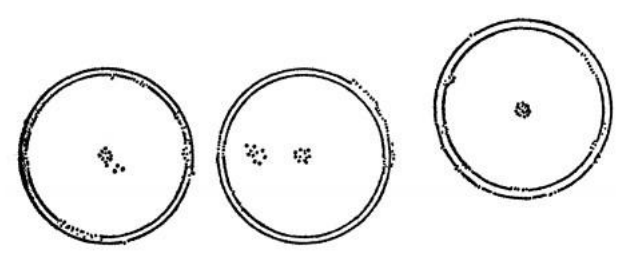

\subsection{The use of the Greek alphabet}

\subsubsection{MPhr-01, the first Phrygian inscription in Greek alphabet}

The use of the Phrygian alphabet had disappeared by the time of the Macedonian conquest led by Alexander the Great (mid 330s BC), perhaps in "the period immediately preceding" it, as Brixhe $(2008,70)$ established. After this critical event, all Phrygian inscriptions are written in Greek script. However, only one clear text has been found from the period between the Macedonian conquest and the Roman Imperial era (the NPhr. inscriptions). ${ }^{81}$ This

\footnotetext{
${ }^{81}$ As has been said, some OPhr. may be written in Greek script. Brixhe and Drew-Bear (2010) considered that NPhr. 20.2 (129, from Prymnessos) was also a Hellenistic inscription (perhaps from the $2^{\text {nd }} c$. BC). However, since there is no good reason for such a consideration beyond the "style" of the letters, it should preferably be classed as another NPhr. inscription (the second one found in Prymnessos, $19.1=$ 96), as in Ligorio and Lubotsky $(2013,182)$. Indeed, the only significant feature of its letters is the presence of apices at the extremes, which is shared with the Imperial inscriptions. See also Bru (2017, 227-228),
} 
single inscription (MPhr-01 = Brixhe's 2004a W-11) was engraved on a funerary stele discovered near Dokimeion, "the earliest colonial settlement [...] founded as a Greek polis in the last years of the fourth c. BC by a certain Domikos" (Thonemann 2013, 17). Despite the excellent edition and analysis given by Brixhe (2004a, 7-26), the content of the inscription remains obscure. However, the language is clearly Phrygian, in the light of some intelligible sequences (the clearest is $1.1 \mu \alpha v \kappa \alpha \mu \varepsilon \kappa \alpha \zeta \sigma \alpha \varsigma$ 'this big stele', see Obrador-Cursach 2016, 183-184) and the maintenance of some obscure terms found on other Phrygian funerary stelae (e.g., compare B071.8 ouviol $\tau$ with B-07 umnotan). What seems clear is that the stele was erected by a man called

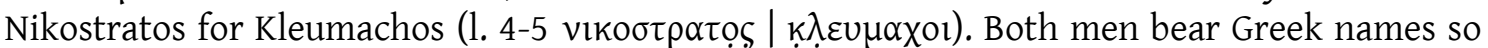
they are considered to belong to "a Phrygian elite family adopting Greek cultural practices (the practice of erecting inscribed funerary stelai, Greek names, the Greek alphabet, the Greek language), ${ }^{82}$ with a Greek family adopting Phrygian cultural practices (the Phrygian language, a Phrygian 'baby-name'), or with a culturally hybrid family formed by intermarriage between settlers and natives" (Thonemann 2013, 17-19). ${ }^{83}$

This inscription is so significant that Brixhe considered an intermediate stage between OPhr. and NPhr.: Middle-Phrygian (MPhr.). Indeed, the phraseology of the text seems related to the OPhr. text, but the script is the same used in the NPhr. inscriptions. The epitaph reads as follows:

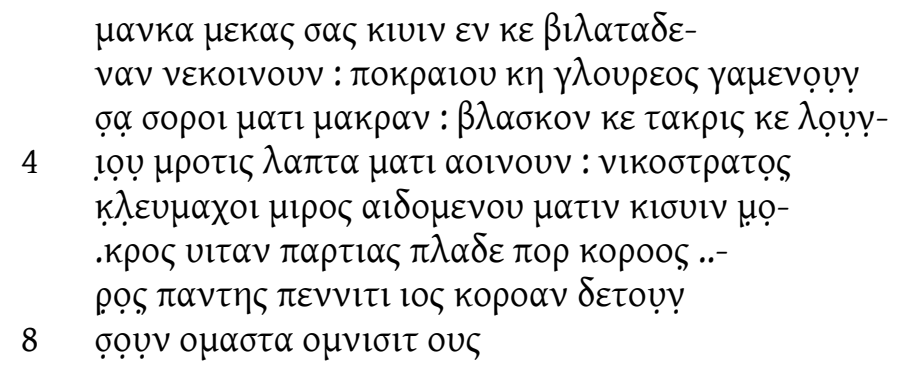

Some particularities of this inscription must be considered before moving to the NPhr. text. First, the lack of waw or digamma is supplied by the use of upsilon: $1.1 \mathrm{klviv}, 1.5 \mathrm{kiviv}$ and

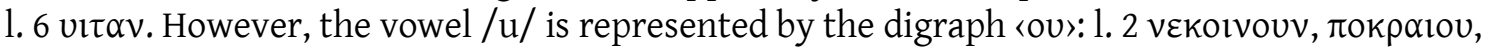

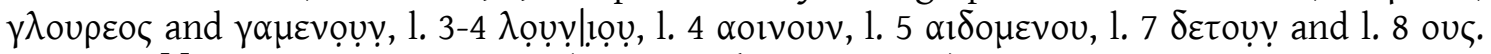
Likewise, [j] is marked by iota: 1. 10 (OPhr. yos / ios, NPhr. 10૬). Another feature is the use of eta, $\eta$, for /e/ instead of a long vowel (as happens in some NPhr. inscriptions): see $1.2 \mathrm{k} \eta<$ PIE * $k^{u} \cdot e$ 'and' (= $1.3 \mathrm{\kappa}, \mathrm{OPhr}$. $k e(y)$ and NPhr. $\kappa \varepsilon / \kappa \eta)$ and the athem. pl.nom. ending of $\pi \alpha \nu \tau \eta \zeta<$ PIE

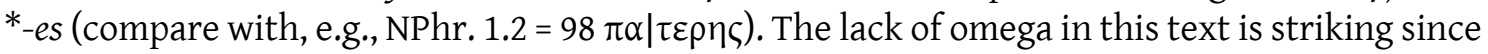
it is expected in the o-stem sg.dat. k $\lambda \varepsilon v \mu \alpha \chi 01$ (OPhr. Dd-102 surgastoy, NPhr. $11.2=18 \lambda \varepsilon v \kappa l \omega l$, $37.2=30 \alpha v \tau \omega$, although the common NPhr. ending is $-\mathrm{ov}, 65.3=21$ and $65.4=124$ oopov, $27.1=$ 92 kopov). The presence of the Greek letter chi, $\chi$, is unparalleled in the whole Phrygian corpus. Nevertheless, this oddity is unsurprising in PNs borrowed from Greek such as K $\lambda \varepsilon$ có $\alpha \chi 0 \varsigma$ / $\mathrm{K} \lambda \varepsilon u ́ \mu \alpha \chi \circ \varsigma$. Finally, there is one possible example of geminates in $\pi \varepsilon v v i \tau \imath$ (pace Brixhe 2004a, 13).

\footnotetext{
who suggested that it is perhaps from the $1^{\text {st }} \mathrm{c}$. BC rather than $3^{\text {rd }}$ or $2^{\text {nd }} \mathrm{c}$. BC. Moreover, although incomplete, the content of the inscription is the common NPhr. imprecation against violators.

${ }^{82}$ Brixhe $(2013,59)$ and Bru $(2017,227)$ preferred this possibility.

${ }^{83}$ On the Greek language and the "Phrygian 'baby-name", another stele found alongside MPhr-01 has the epitaph of Nikostratos' daughter, according to the Turkish translation of the text given by Drew-Bear (1985, 259 "Nikostratos'un k1z1, Theophilos'un karısı Tatis") and the English translation by Thoneman (2013, 18 "Tatis, daughter of Nikostratos, wife of Theophilos"). This girl bears a typical Anatolian Lallname, which contrasts with the Greek names borne by her father and her husband.
} 


\subsubsection{The Greek alphabet of the New Phrygian inscriptions}

After MPhr-01, Phrygian is not seen again until Roman Imperial times, in a very homogeneous group of inscriptions dated to between the end of the $1^{\text {st }}$ and the end of the $3^{\text {rd }} \mathrm{c}$. AD: the New Phrygian subcorpus. The script used at this stage is very similar to that of Greek monumental inscriptions from Hellenistic and Roman times. However, the reading of these texts is not always as easy as one could expect. Leaving aside the significant fact that this alphabet was not designed for the Phrygian language, the changes of Greek phonology (itacism, disappearance of the length contrast, loss of word-end consonants and geminates, etc.) affected the manner in which Phrygian was written (see § 3.2.2.1) and there are many hesitations in the spelling of the words: e.g. $\alpha \delta \delta \alpha \kappa \varepsilon \tau$ (passim) $\sim \alpha \delta \alpha \kappa \varepsilon \tau(3.1=97,7.1=99,7.2=111$, etc.), $\sigma \varepsilon \mu o u v$ (passim) $\sim \sigma \varepsilon \mu o v(3.1=97,7.1=99,10.1=112$, etc. $) \sim \sigma \varepsilon \mu \mathrm{Iv}(53.1=76,59.1=107$ and $61.1=100)$ and $10 \varsigma$ (passim) $\sim \operatorname{\varepsilon lo\zeta }(40.1=12) \sim 1 \varsigma(17.1=4 \mathrm{~b}, 12.1=121$, etc. $)$. Moreover, the lack of spaces between the words (the so-called scriptio continua) or interpunctions in most cases also complicates the segmentation and interpretation of the texts.

Nevertheless, the main problem with this subcorpus is that many of the NPhr. inscriptions are now lost and the readings given by the old copies (riddled with mistakes) cannot be corroborated. As Brixhe $(1999,293-295)$ showed ${ }^{84}$ one of the most common mistakes in the reading of the inscriptions is the confusion of the round letters. Indeed, by Imperial times it is common to find epsilon and sigma as $€$ and $C$ (the so-called lunate epsilon and sigma), ${ }^{85}$ which is why in many copies of the first known inscriptions they are confused, also with $O, \Phi$ and even $\Theta$. Since most of the Phrygian texts are reiterative formulae, many of these mistakes can be deteced. Taking one example given by Brixhe $(1999,293)$, according to CIG 3880 in the NPhr. inscription 17.1 (4 bis) there is an unparalleled sequence O€MON which must be read as the common pron. $\sigma \varepsilon \mu o u v$. In the lost inscriptions, it is impossible to corroborate if these mistakes were originally on the stone. In any case, mistakes like this are also common in contemporaneous Greek inscriptions: see, e.g., $\Lambda$ OIПЄIC for $\Lambda$ OIחOIC in IG II ${ }^{2} 1028$ (1.13). ${ }^{86}$ The same can be said of the quadratic epsilon and sigma. Moreover, the angular letters $(\Delta, \Lambda, \mathrm{A}$ and M) present similar problems: see, e.g., 43.1 (69) l. 1, EINEAM or EINEMA? There are two instances

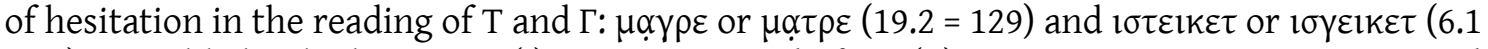
$=88$ ). Very likely, the letter iota (I) appears instead of tau (T) in two inscriptions. As suggested here, $\pi \varepsilon 1 \varepsilon \varsigma(40.1=12)$ may be read as $\pi \varepsilon \tau \epsilon \varepsilon \zeta$ and the relative pron. $10 \varsigma$ seems to introduce an apodosis in $33.1(28)$, where $\tau$ o is expected (see, e.g., $18.3=6$ ) ${ }^{87}$ In these examples, it remains unknown whether we are dealing with a copyist's misreading, an eroded letter or a mistake by the engraver, who could have forgotten to engrave the horizontal stroke.

Finally, engravers' mistakes seem to occur very often (Brixhe 1999, 296) ${ }^{88}$ however in many instances is difficult to detect them in non-formulaic texts, and even in the case of the many lost inscriptions one cannot rule out errors made by modern copyists. A clear example of

\footnotetext{
${ }^{84}$ In this excellent paper, "Prolégomènes au Corpus Néo-Phrygien", he dealt with the main issues of this chapter, giving a very detailed and useful account. Here I follow his approach, although some alternative interpretations will be added.

${ }^{85}$ The classical and the rectangular shapes of these letters are also found in the New Phrygian inscriptions.

${ }^{86}$ This example is taken from McLean 2014, 15, where these kinds of mistakes are introduced with some references.

${ }^{87}$ The only possible 10 introducing an apodosis is found in 15.1 (120). However, it occurs as 15 and while in the protasis it is well spelled (pace Brixhe \& Drew-Bear 1997, 89), one wonders if it is the ending of the preceding $\tau \varepsilon \alpha \mu \alpha$. This noun also appears as $\tau 1 \alpha \mu \alpha, \tau \varepsilon \alpha \mu \alpha \varsigma$ and $\tau 1 \alpha \mu \alpha \varsigma$. Although it would be morphologically unexpected, similar variants are found for $\mu \alpha \nu \kappa \alpha: \mu \alpha \nu \kappa \alpha 1, \mu \alpha \nu \kappa \alpha \nu$ and $\mu \alpha \nu \kappa \eta \varsigma$.

${ }^{88}$ Note also that Brixhe $(1999,296$ fn. 22) considers the possibility that the engravers were not Phrygian speakers.
} 
an engraver's mistake on a preserved stele is $\alpha \delta \alpha \kappa \tau \varepsilon(33.3=127)$ for $\alpha \delta \alpha \kappa \varepsilon \tau$ (passim, see DrewBear, Lubotsky \& Üyümez 2008, 111).

\subsubsection{The representation of the consonants}

The main difference between the consonants of the Phrygian alphabet and those of the Greek alphabet from the Imperial period is that the New Phrygian inscriptions show a tendency

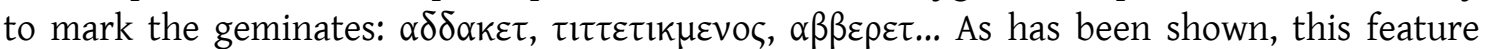
seems to be found in MPhr-01 (see $\S 3.2 .1$ ). However, by the times of these inscriptions, geminates had been simplified in Greek (Brixhe 1987a, 31-33), and the same appears to have occurred with Phrygian texts. Indeed, although 54 of the $117 \mathrm{NPhr}$. inscriptions (46.15\%) ${ }^{89}$ have geminates, $20(17.10 \%)^{90}$ do not and $17(14.53 \%)^{91}$ show hesitation. The remaining 26 inscriptions $(22.22 \%)^{92}$ do not provide information relevant to this issue. In such a scenario, the presence of hypercorrect geminates is not strange: e.g. $k v o u \mu \mid \mu \alpha v \varepsilon l(38.1=44)$ and $k v[o v] \mid \mu \mu \alpha v \varepsilon l(46.1=53)$

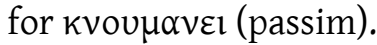

The lack of the Greek letter chi (as has been said, $\chi$ is only attested in MPhr-01) and the few attestations of the other two letters which represent the aspirated stops are remarkable. This is accounted for by the fact that the Phrygian phonemic repertory does not contain this kind of sound, and their occurrences are very limited. The letter theta $\left(\theta, / \mathrm{t}^{\mathrm{h}} />/ \theta /\right)$ appears three times in the whole NPhr. corpus: $\theta \alpha \lambda \alpha \mu \varepsilon 1$ 18.1 (4), $\alpha \delta 1 \theta \rho \varepsilon \rho \alpha \kappa ~ 40.3$ (31) and $\theta \imath \tau[\tau] \varepsilon \tau \iota k \mu \varepsilon v o ̣[\zeta] 45.1$ (65). The first word, $\theta \alpha \lambda \alpha \mu \varepsilon l$, is a clear borrowing from Greek $\theta \alpha \lambda \alpha$ an and justifies the use of this letter, however $\theta 1 \tau[\tau] \varepsilon \tau 1 \kappa \mu \varepsilon v o ̣[\zeta]$ must be a hypercorrection of the

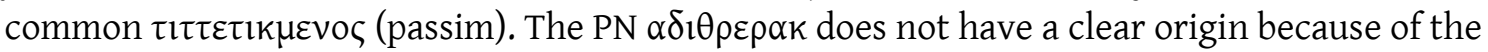
lack of parallels, and cannot be analysed. The letter phi $\left(\varphi, / \mathrm{p}^{\mathrm{h}} />/ \varphi /\right)$ is only found in the

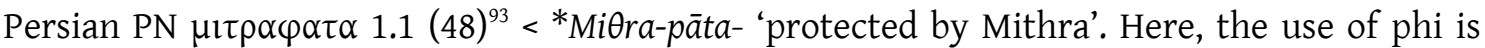
unexpected and is very likely a common hypercorrection. Indeed, the lack of these kinds of stops in Phrygian affected the Greek spoken in Phrygian, since misspellings related to chi, phi

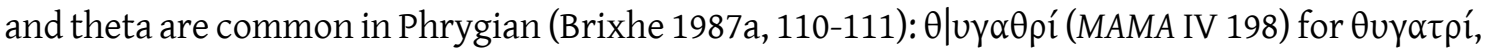

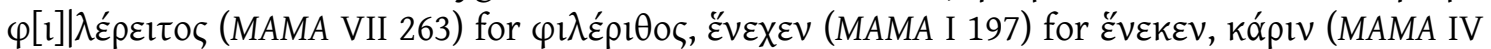

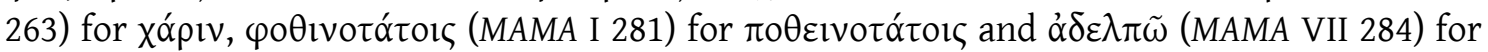
$\dot{\alpha} \delta \varepsilon \lambda \varphi \tilde{\omega}$.

On the other hand, the Phrygian consonantism has two approximants that are lost in contemporary Greek: the velar [w] and the palatal [j]. Because there were no specific letters for these sounds, other Greek letters and digraphs were reused to represent the Phrygian

\footnotetext{
${ }^{89}$ No. 1.1 (48), 2.2 (130), 4.1 (2), 6.1 (88), 8.1 (86), 10.2 (113), 11.2 (18), 12.1 (121), 14.1 (73), 15.1 (120), Afyonkarahisar.2 (3), Afyonkarahisar.3 (7), 17.5 (90), 17.4 (91), 18.6 (129), 18.3 (6), 20.3 (62), 21.1 (42), 21.2 (43), 24.1 (40), 25.2 (126), 28.1 (71), 29.1 (114), 30.1 (39), 31.1 (29), 35.1 (25), 36.1 (26), 38.1 (10), 39.1 (11), 40.1 (12), 40.2 (13), 41.1 (45), 42.1 (101), 45.1 (65), 46.1 (53), 49.3 (85), 50.1 (54), 50.2 (55), 51.1 (80), 52.1 (75), 53.1 (76), 53.2 (77), 54.1 (108), 55.1 (56), 56.1 (57), 59.2 (47), 59.3 (79), 60.1 (59), 62.1 (32), 62.2 (33), $62.3(34)$, $62.4(35), 63.1(123)$ and $65.4(124)$.

${ }^{90}$ No. 3.1 (97), 7.2 (111), 7.3 (14), 9.1 (87), 19.1 (4), 18.2 (5), 19.1 (96), 26.2 (38), 27.1 (92), 30.2 (68), 32.1 (93), 33.1 (28), 33.3 (127), 34.1 (37), 40.4 (102), 61.1 (100), 62.5 (35), $62.6(105), 65.1(20)$ and $66.1(103)$.

${ }^{91}$ No. 7.1 (99), 10.1 (112), 17.6 (119), 20.1 (63), 20.2 (128), 22.2 (118), 25.1 (115), 36.3 (94), 43.1 (69), 44.1 (61), 44.3 (67), 47.1 (51), 57.1 (75), 58.1 (72), 59.4 (106), 64.1 (81) and 65.3 (21).

${ }^{92}$ No. 1.2 (98), 2.1 (15), 5.1 (19), 11.1 (17), 11.3 (17), 17.1 (4b), 13.1 (122), 16.1 (116), 22.1 (9), 23.1 (89), 26.1 (8), 33.2 (95), 37.2 (27), 37.2 (30), 38.1 (44), 40.3 (31), 44.2 (70), 48.1 (81), $48.2(84), 49.1(110), 53.3$ (109), 56.2 (58), 56.3 (64), 59.1 (107), $60.2(60)$ and $65.2(104)$.

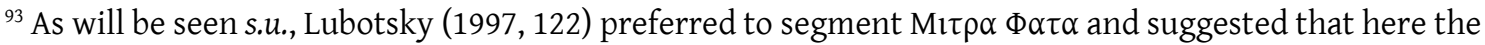
Iranian god MiӨra is qualified with an (unparalleled) ethnic $\Phi \alpha \tau \alpha$, in the light of the other two DNs that follow this sequence in NPhr. 48.
} 
consonants. In the case of [j], it was commonly spelled with a simple iota 〈 1$\rangle: 10 \varsigma$ (passim, OPhr.

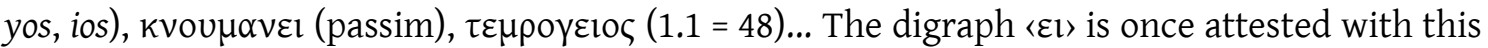
function as consequence of Greek itacism: $\varepsilon 10 \varsigma(40.1=12)$ lo $($ passim). It must be added that it is also common to find « $\mathrm{l}$ ) for /jo/, also explained by the Greek simplification /jo/ > /i/ in final position (and sometimes in the middle of the word, according to Brixhe 1987a, 49-50 and 1999, 299-300): the clearest example in Phrygia $15(17.1=4 \mathrm{~b}, 12.1=121,15.1=120,16.1=116$ and 18.2 = 5) for $10 \zeta$ (passim). The form $\tau \varepsilon \tau \iota 0 \mid \kappa \mu \varepsilon v o \zeta ~(22.2=118)$ for $\tau \varepsilon \tau \iota \kappa \mu \varepsilon v o \zeta$ is a hypercorrection arising from this shift. The velar approximant $[\mathrm{w}]$ is commonly represented by the digraph (ov):

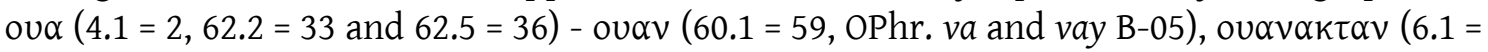

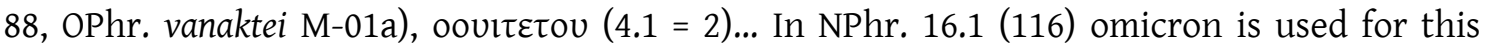

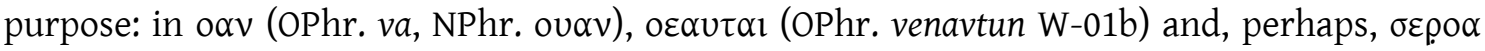
19.2 (129, unclear if related to OPhr. servas G-130).

The letter sigma $\langle\sigma\rangle$ ordinarily represents a consonant/s/. It appears in many positions, including consonant clusters: at the beginning of a word followed by a vowel ( $\sigma \varepsilon \mu o u v$ passim) and consonant $(\sigma \kappa \varepsilon \lambda \varepsilon \delta \rho i \alpha 144.3=67)$, between vowels $(\varepsilon \gamma \varepsilon \sigma l \tau 56.2=58)$, between a vowel and a

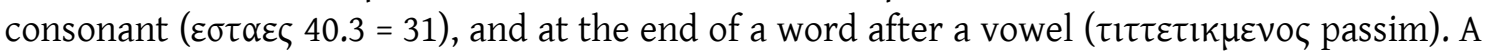

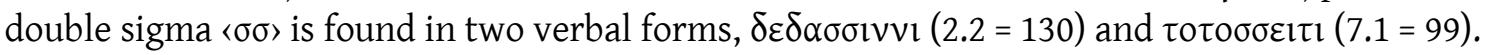
It is unknown if $\langle\sigma \sigma\rangle$ denotes a sound other than $/ \mathrm{s} / .{ }^{94} \mathrm{In}$ both occurrences of $-\sigma \sigma$ - it is preceded by an etymological long vowel. In OPhr. a single 〈S〉 represents the same form, as evident in dedasitiy (B-05, also ịsini in G-289), although the OPhr. alphabet avoids the repetition of a letter

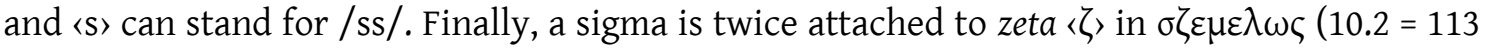
and $30.1=39$ ), a variant of the common $\zeta \varepsilon \mu \varepsilon \lambda \omega \varsigma$ (passim). This spelling, considered redundant, is well attested in Greek inscriptions elsewhere (mainly from Hellenistic times) and in Phrygia (MAMA IV $219 \dot{\varepsilon} \lambda \pi i ́ \sigma \zeta o v \tau \imath$ for $\dot{\varepsilon} \lambda \pi i ́ \zeta o v \tau \imath$, Brixhe 1987a, 46 and 1999, 297).

The remaining letters $\beta, \delta, \gamma, \pi, \tau$ and $\kappa$ represent the voiced and voiceless stops $/ b /$, $/ \mathrm{d} /, / \mathrm{g} /, / \mathrm{p} /, \mathrm{t} /$ and $/ \mathrm{k} /$, respectively. Although Greek stops become fricative in the inner position (except following a nasal), there is no reason to consider this shift in Phrygian (Brixhe 1999, 297-298). It is possible that $\gamma$ represents an allophone [y] before a consonant (as in Greek before $\kappa, \gamma, \chi$ and $\xi)$, but the only possible example is $\varepsilon \gamma \delta \alpha \varepsilon \varsigma\left(11.2=18\right.$, if $\left.\varepsilon \gamma^{-}<\varepsilon \nu^{-}\right)$, a word that remains unclear, although it appears to be a verb..$^{95}$

\subsubsection{The representation of vowels}

The representation of the Phrygian vowels is more strongly influenced by Greek phonetic shifts than consonantism because they seem to also affect the Phrygian language. This said, the formulaic character of the NPhr. curses tends to show a conservative spelling, although shifts are attested elsewhere. In such a scenario, the NPhr. inscriptions show many hesitations and hypercorrections in the notation of the vowels. There are two significant changes: the itacism (also known as iotacism) and the loss of the vowel-length contrast (see $\S$ 4.1.1).

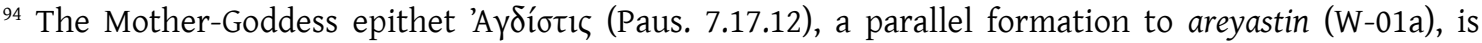
derived from the oronym Agdus (Arn., Adversus Nationes 5.5.1). In Greek inscriptions contemporary to the

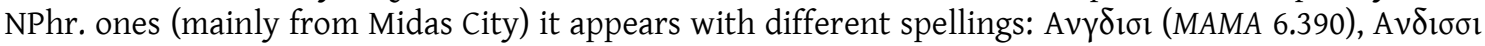
(MAMA 6.391), $A \vee \delta \xi_{1}$ (MAMA 6.395), etc. In the light of these spellings Gusmani (1959a, 205) considered that -st-before /i/ was pronounced /stz/ (sic.) or /š/. Indeed, we cannot ignore that $\langle\sigma \sigma\rangle$ is used in other Anatolian areas to represent a sound other than /s/. This is the case of Carian PNs arliš and uśo $\lambda$, found

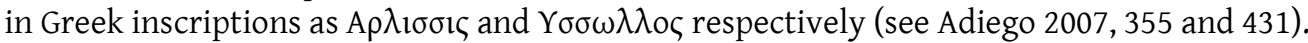

${ }^{95}$ Even less clear is $\alpha \rho \gamma \mu \varepsilon v \alpha[?]$ ] 16.1 (116).
} 
As a result of the first shift, there are many hesitations between $1, \varepsilon l, \eta$ and even $v$ :

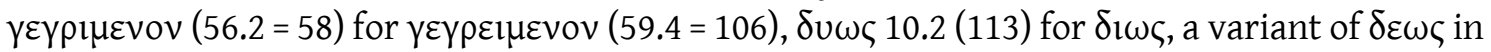

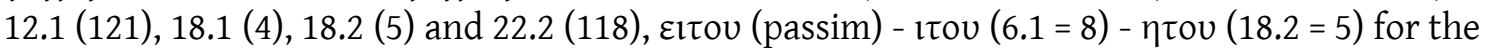

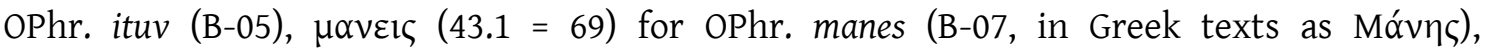

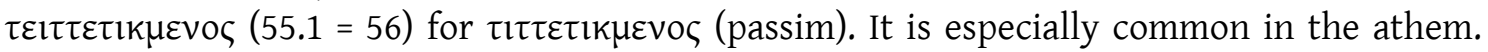
sg.dat. ending (PIE *-ein): compare $\kappa v o u \mu \alpha v \varepsilon l$ (passim), $\kappa v o u \mu \alpha v \varepsilon$ (passim), $\kappa v o u \mu \alpha v i(6.1=88$, $8.1=86$, etc. $)$ and $k v o u \mu \alpha v \eta(29.1=114)$ or $\tau 1 \varepsilon$ (passim) $\tau l(9.1=87,38.1=44,39.1=11$, etc. $)$ and $\tau$ in $(8.1=86,18.3=6,20.3=62)$. The hesitation occurs even in the same text: $\alpha$ ivi ove $\beta \alpha v$

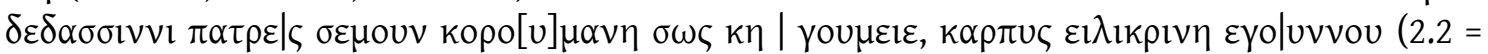
130). According to Lubotsky $(1997,126, \mathrm{fn} .23)$, the GN $\tau 1 \varepsilon-\tau 1-\tau \imath \eta$ shows a tendency towards the following distribution: "Tin only occurs before consonants $(6,39,62,65,86,114),{ }^{96} \mathrm{~T} 1$ only

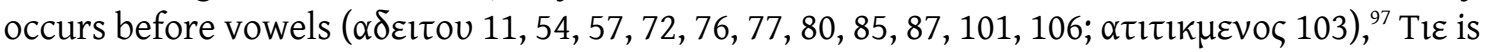
found in both positions, but the instances before a vowel are rare (only $5 x$ out of $15: 12,45,56$,

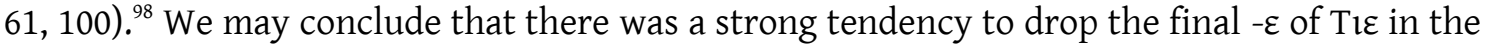

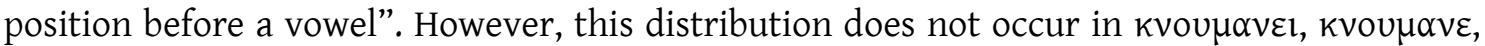
$\kappa v o u \mu \alpha v 1$ and $\kappa v o u \mu \alpha v \eta$. Brixhe $(2008,75$, see also Brixhe $1990,78-79)$ considers the final $-\varepsilon$ "an inverse spelling related to the interchangeability, in final position, of $e$ and $i$ ".

The letter eta 〈 $\eta$ ' has special status (see Brixhe 1999, 301-303), since it is found to represent three different sounds: /e/, /i/ and [j]. However, the possible personal name in sg.nom. $\alpha \delta \varepsilon v \pi \mid \alpha \tau n \varsigma$ (69), which seems to be Iranian in origin but adapted to Greek, ${ }^{99}$ is the only occurrence that provides a possible example of eta used for the Greek classical sound /ع:/.

In any case, it clearly represents /e/ in many occurrences: e.g. $\pi \alpha \tau \varepsilon \rho \eta \varsigma$ 'parents' (1.2 =

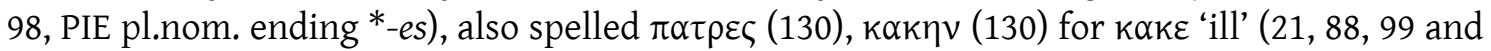
124) or $k \eta$ 'and' (130) for $k \varepsilon$ (passim, OPhr. ke(y)). This use already appears in MPhr-01 (W-11), where $k \eta$ and $\pi \alpha v \tau \eta \varsigma$ '?' (very likely an athematic pl.nom.) occur. For this last text, Brixhe $(2004 a, 17)$ suggests that the Macedonians introduced the Greek alphabet in Phrygia and these spellings are a result of the "même aperture pour * ${ }^{*}$ : et pour * $e$ " in Macedonian.${ }^{100}$ Nevertheless, this hypothesis may be refuted for a number of reasons. In view of the bilingual inscription from Vezirhan (B-05), the Greek alphabet was introduced in Phrygian before the arrival of the Macedonians, which invalidates the first assumption of Brixhe's proposal. Moreover, worse still, if the Dodona oracular tablet No. $2493 \mathrm{~A}$ is indeed written in Macedonian, ${ }^{101}$ it contains a good example of $\eta$ representing / $\varepsilon_{:} /$and not /e:/ in a Macedonian context (Méndez Dosuna 2012, 144).

When analysing the use of eta for /e/ in Greek inscriptions from Anatolia, Brixhe (1987, 49) considers it to be the result of hypercorrections that occurred at school, where the ancient sound of this letter was still taught. This explanation is possible, although when this spelling occurs in Pontus, it is thought to be evidence of the preservation of the sound /e/ from / $:$ :/, as also occurs in the new Greek dialect from that region (Brixhe 1987a, 110). Although schooling may have resulted in such spelling, the diffusion of education in rural Phrygia is "enormously controversial" (de Hoz 2006, 139, with references) and is not the only possible explanation. In

\footnotetext{
${ }_{96} 18.3,30.1,20.3,45.1,8.1$ and 29.1 , respectively.

${ }_{97} 39.1,50.1,56.1,56.1,58.1,53.1,53.2,51.1,49.3,9.1,59.4$ and 66.1, respectively.

${ }^{98} 40.1,2.1,41.1,55.1,44.1$ and 31.1 respectively. After Lubotsky's paper it also appeared in 15.1 (120), 25.1 (115), 25.2 (126), 33.1 (127),63.1 (123).

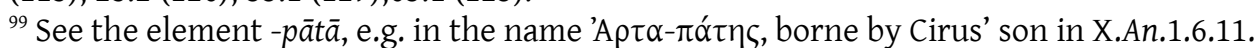

${ }^{100}$ See also Brixhe 1999, 302.

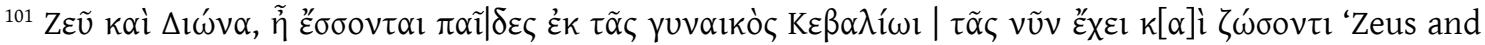
Diona, shall Kebalios have children from the wife he has now, and shall they survive?' (Méndez Dosuna 2012, 144).
} 
Phrygian, PIE ${ }^{*} \bar{e}$ and ${ }^{*} e h_{1}>{ }^{*} \bar{e}$ merged with /a:/. As a result, it is likely that there was no phoneme /e:/ in this language (Ligorio \& Lubotsky 2013, 183). In such a scenario, the lack of a Phrygian counterpart for the Greek sound traditionally represented by eta may have given rise to such spelling, not only in Phrygian, but also in Greek inscriptions from Phrygia.

In any case, the letter eta also represents [j] after or before the vowel (if not also in the athematic sg.dat. ending, see § 4.2.1.1.3): $\alpha v \tau \alpha \eta$ (30, OPhr. avtay W-01b), $\mu \alpha \iota \mu \alpha \rho \eta \alpha v(31)$ and $\delta \varepsilon \kappa \mu o u \tau \alpha \eta \zeta(31) \sim \delta \varepsilon \kappa \mu o u \tau \alpha ı \zeta(9)$. This use is clearly a consequence of Greek itacism, since it is not attested in $\mathrm{W}-12$ ( $4^{\text {th }}$ century BC).

The second significant issue is the loss of the vowel-length contrast (Brixhe 1987a, 46-

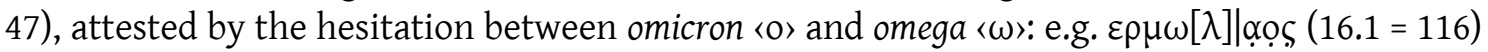
for Greek 'Epuó $\lambda \alpha o \varsigma$ or $\delta \varepsilon \circ \varsigma(17.3=7$ and $18.3=6$ ) for $\delta \varepsilon \omega \varsigma$ (passim).

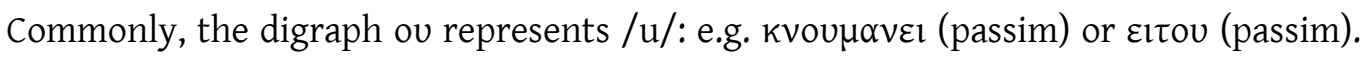
On rare occasions this sound is represented by upsilon $\langle v\rangle$ : $\sigma \varepsilon \mu v v$ and $k \alpha k v v(20.3=62)$. The hesitation between ov and o shows the neutralisation between $/ \mathrm{u} /$ and $/ \mathrm{o} /$ before the nasal $/ \mathrm{n} /$ (Brixhe 1999, 306): $\sigma \varepsilon \mu \mathrm{ov}(3.1=97,7.1=99,10.1=112)$ and $\operatorname{k\alpha kov}(10.1=112,14.1=73,15.1=$ 120 , etc.). On the other hand, the hesitation ov $\sim$, found in $\sigma \varepsilon \mu \mathrm{vv}(53.1=76,59.1=107$ and 61.1

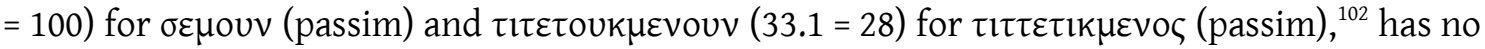
phonetic motivation according to Brixhe (1999, 307-308): "on a vu que OY pouvait être occasionnellement relayé par $Y$; or $Y$, dans le système grec, est une des notations de /i/, cf. d'ailleurs $\delta \omega \omega \varsigma$ (113 [= 10.2]) pour $\delta \varepsilon \omega \varsigma / \delta \imath \omega \varsigma$ (où, en hiatus, $\varepsilon / \imath$ vaut [j]; avec la médiation implicite de $Y$, OY (en finale, O et OY) pourra être remplacé par I".

102 Brixhe 1999, 307 also adds $\tau 1(22.1=9,30.1=39,35.1=25,44.3=67$ and $66.1=103)$, however it must be ruled out since it is also found in OPhr. as ti (B-05). 


\section{The Phrygian language \\ 4.1. Phrygian phonology \\ 4.1.1. Vowel system}

Since the Phrygian alphabet does not represent the contrast between short and long vowels, a description of the OPhr. vowel system must consider the PIE origin of the morphemes and the NPhr. subcorpus, even though at this stage the vowels are problematic due to the influence of the coetaneous development of Greek vowel system, as well as the inner Phrygian evolution. Indeed, the loss of the length contrast in Roman times is particularly problematic. In addition, the spelling of Phrygian words in Greek sources is useful, especially for PNs. However, if one disregards the onomastic material and the glosses (with unclear filiations), few words

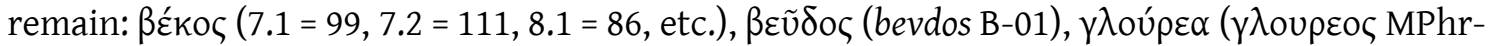
01 ), etc. Despite these difficulties and the limitations posed by a fragmentary language, OPhr. is considered to have 5 short vowels contrasting with 4 (or 5) long vowels, while NPhr. seems to have merged both series, as had occurred in Greek by this time (see Table 12, showing the syntheses of Brixhe 1983, 115-117 and Ligorio \& Lubotsky 2013, 182-184):

Table 12 The Phrygian vowel system

\begin{tabular}{|c|c|c|c|c|c|c|}
\cline { 2 - 7 } \multicolumn{1}{c|}{} & \multicolumn{3}{c|}{ Old Phrygian } & \multicolumn{3}{c|}{ New Phrygian } \\
\cline { 2 - 7 } \multicolumn{1}{c|}{} & Front & Central & Back & Front & Central & Back \\
\hline Close & /i//i:/ & & /u//u:/ & $/ \mathrm{i} /$ & & $/ \mathrm{u} /$ \\
\hline Mid & /e/ & & $/ \mathrm{o} / / \mathrm{o} / /$ & $/ \mathrm{e} /$ & & $/ \mathrm{o} /$ \\
\hline Open & & /a/ /a:/ & & & $/ \mathrm{a} /$ & \\
\hline
\end{tabular}

/a/ is the result of the outcome of ${ }^{*} h_{2}$ (PIE ${ }^{*} h_{2} n \bar{e} r>$ NPhr. $\left.\alpha v \alpha \rho\right)$ and the vocalisation ${ }^{*} n$ (neuters in ${ }^{*}-m_{n}>-$ man) and the development of the sequence ${ }^{*} h_{2} e^{-}\left({ }^{*} h_{2} e d>0 \mathrm{Ohr}\right.$. ad B-05, NPhr. $\alpha \delta 7.3=99$ ).

/a:/ goes back to PIE ${ }^{*} e h_{2}$ and ${ }^{*} e^{\text {; , either an original PIE }} *^{*}$ : or derived from ${ }^{*} e h_{1}$ (as has been seen): PIE * méh ${ }_{2} t e \bar{r}>$ OPhr. matar (W-04, W-06 and B-01; also in NPhr. $\mu \alpha \tau \alpha \rho 11.2=18$ ).

/e/ follows the PIE vowel ${ }^{*} e$, see PIE ${ }^{*} b^{h} e r->(\alpha \beta) \beta \varepsilon \rho \varepsilon \tau\left(18.3=6,29.1=114\right.$, etc.), PIE * $k^{u} e$, OPhr. ke (passim), key (B-05). It is also the result of the vocalisation of PIE ${ }^{*} h_{1}$ : PIE

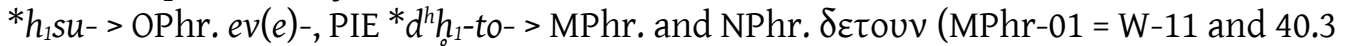
$=31)$ and NPhr. Sctov $(16.1=116)$. There are many hesitations between $\langle\mathrm{e}\rangle$ and $\langle\mathrm{i}\rangle$ in Phrygian: see akenanogavos (M-01a and W-01a) akinanogavan $(\mathrm{M}-04)$ or $\delta \varepsilon \omega \varsigma$ (3.1 = $97,10.1=112,17.6=119$, etc. $) \sim \delta 1 \omega \varsigma(12.1=121,18.1=4,18.2=5$, etc. $)$. Although it has been unanimously considered a phonetic hesitation between /e/ and /i/, the two given analyses are very different: Brixhe $(2008,75)$ identifies neutralisation of the contrast of /e/ and /i/ in hiatus (as in $\delta \varepsilon \omega \varsigma$ passim $\delta 1 \omega \varsigma 12.1=121$, etc.), while Ligorio and Lubotsky $(2013,187)$ prefer to speak about a pretonic neutralisation. The second explanation is better because it accounts for all occurrences of such a hesitation. ${ }^{103}$

/e:/ is a problematic vowel, since according to the communis opinio all PIE ${ }^{*} \bar{e}$ and ${ }^{*} e h_{1}$ became /a: in Phrygian. Certainly, it is a well attested shift: PIE * méh 2 têr > OPhr. matar (W-04, W-06 and B-01; also in NPhr. $\mu \alpha \tau \alpha \rho 11.2=18)$, *pērk'- > OPhr. eneparkes (G-125

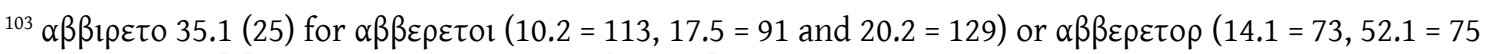

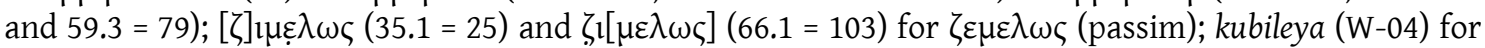

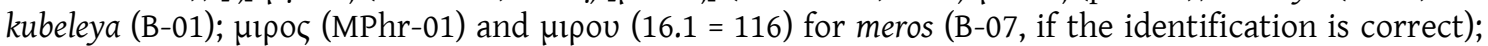
olpouv $(35.1=25)$ for $\sigma \varepsilon \mu o u v($ passim); $\tau \varepsilon \alpha \mu \alpha(15.1=120)$, $\tau \varepsilon \alpha \mu \alpha \varsigma(7.3=14,10.1=112,21.2=43$ and $25.1=$ $115)$ for $\tau_{1} \alpha \mu \alpha(11.2=18)$ and $\tau \iota \alpha \mu \alpha \varsigma(9.1=87)$. This neutralisation very likely occurs also in niptiyan (B$05,<$ PIE $\left.*_{n e p t-i h^{-}}\right)$and $\uparrow$ irạy $(\mathrm{B}-05), \zeta \varepsilon 1 \rho \alpha(40.1=12)$ and $\zeta \varepsilon 1 \rho \alpha 1(59.4=106)$, if it goes back to $*^{h} e^{h}$ - $r-($ NIL 170-172). 


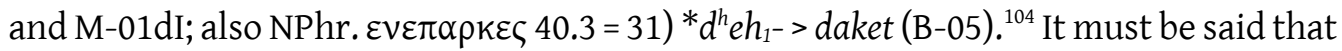
Brixhe $(1990,70-71$, and still in 2008, 75) considered that in Phrygian a secondary /e:/ appeared as a monophthongisation of * ei and this phenomenon resulted in a merging of the inherited /e:/ with /a:/. However, Lubotsky $(1998,415)$ rejected this possibility, showing the preservation of -ei in OPhr., and established that only in NPhr. final position was this diphthong "prone to monophthongisation".

/i/ goes back to PIE *i and ${ }^{*}$ : iman (M-06, G-136, G-210, etc.), areyastin (W-01a), aini (P-101), ayniy (B-05), kin (B-01), etc. In NPhr. it remains unchanged: $\alpha \mathfrak{l v l}(2.2=130,3.1=97$, etc.), $\operatorname{klv}(61.1=100)$, etc.

/e:/ has not been identified, although it is assumed, in the light of other pairs of vowels.

/o/ continues the PIE *o, e.g.: PIE *ios > OPhr. yos, ios, NPhr. 10, the thematic sg.nom. ending -os, the middle verbal ending *-toi $>$-toy, etc. It is also is the result of the outcome of $* h_{3}$ and, very likely, $r: * d h_{3}$-ti- (NIL 61) > totin (M-01f), PIE * pr $>$ por (W-05 b), NPhr. $\operatorname{\pi oup}(6.1=88)$. However, the PIE *o merged with $/ \mathrm{u} /$ at least in nasal context, see the thematic acc.sg. ending PIE *-om > OPhr. -un, avtun (W-01b), bagun (G-136), etc.,

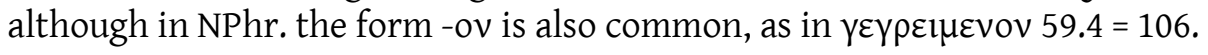

/o:/ renders the PIE ${ }^{*} \bar{o}$, however this sound very likely became / $\overline{\mathrm{u}} /$ because in the 3 sg.med. endings the historical spelling 〈O〉, 〈uv occurs once and in NPhr. it is always spelled with ov: compare lakedo (W-01b) or si eto (W-08, W-09 and W-10, if it is a verb) with ituv (B-05) / NPhr. eıtov (passim, ıtov 6.1 = 8) and, very likely, tubnuv (B-05). ${ }^{105}$ As has been seen, the hesitation between $/ \mathrm{o}(:) /$ and $/ \mathrm{u}(\mathrm{:}) /$ is commonly found and Brixhe $(2008,75)$ explains it - at least for NPhr. - as "a neutralisation of the contrast [...] /o/ /u/ (in favour of the high vowel) in absolute-final position" parallel to /e/ /i/. This assumption seems to be supported by the presence of a rare digraph in two OPhr. examples: the variants of the same $u$-stem $\mathrm{PN}$ vasus $(\mathrm{P}-05) \sim$ vasous $(\mathrm{P}-03$, with an unparalleled digraph in the whole OPhr. corpus) and the verb in 3pl.impv.act. isnou (NW-101 a) found in NPhr. as lovou $(9.1=87)$. However, the hesitation between /o/ /u/ is also attested in inner position: kakoioi (G-02 c) and kakuioi (P-04 b).

$/ \mathrm{u} /$ is inherited from PIE * $u$ and is also developed from *o in some positions: e.g. vasus (P$05, u$-stem sg.nom.), surgastoy (Dd-102) or $v \psi \circ \delta \alpha v(2.1=15$ and $16.1=116<$ PIE *upsod ${ }^{h} n$ ).

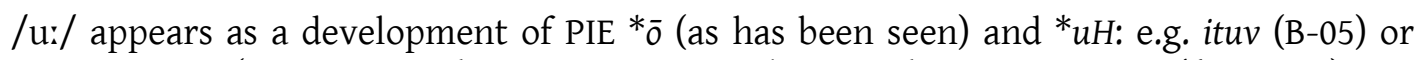

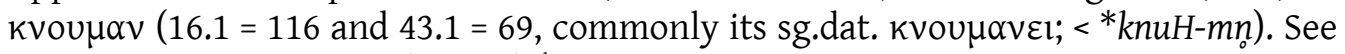

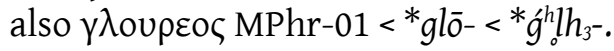

Phrygian also has the following diphthongs:

/aj/ in OPhr. aini (P-101), ayniy (B-01 and B-05), $\alpha \mathrm{lvl}(2.2=130,3.1=97$, etc.). The PIE origin of this diphthong is the PIE sequence ${ }^{*} h_{2}$ ei. In light of the preservation of the long diphthong /o:j/, /aij/ very likely occurred at least in OPhr.: midai (B-05), atai (W-10) avtay $(\mathrm{W}-01 \mathrm{~b}), \alpha v \tau \alpha \eta(37.2=30),(\mathrm{oc}) \alpha v \tau \alpha \mathrm{l} 16.1=116), \mu \alpha \nu \kappa \alpha \mathrm{l}(4.1=2,17.2=3$, etc.), etc. It is found in the $a$-stem sg.dat. ending and goes back to PIE *-eh 2 ei. Very likely in NPhr. /aij/ merged with /aj/. Its second element in final position commonly drops in NPhr. final position: see $\sigma \alpha(17.5=91,21.1=42$, etc. $)$ for $\sigma \alpha \mathrm{l}(43.1=69,62.4=35$, etc. $)$ or $\mu \alpha v k \alpha$ $(3.1=97,11.2=18$, etc. $)$ for $\mu \alpha v \kappa \alpha l(4.1=2,17.2=3$, etc. $)$.

/ej/ in materey (M-01e and W-01b), ibey (B-01 and B-05), inmeney (B-05), 个emeney (B-05), etc. $\mathrm{PIE}^{*}{ }_{\mathrm{e}} i$ is preserved in Phrygian until NPhr. Times, as has been stated above.

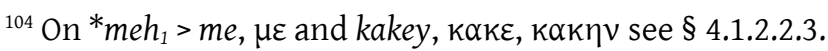

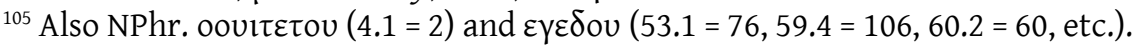


/oj/commonly found in the 3sg.med. ending: abretoy (B-05), $\alpha \beta \beta \varepsilon \rho \varepsilon \tau o r ~(10.2=113,17.5=91$ and $19.2=129$ ), edatoy (B-05), tedatoy (W-01a), etc. It follows the PIE *oi. Note that in OPhr. it is spelled in the same way as the thematic sg.dat. ending -oi $<$ PIE ${ }^{*}-\bar{o} i$.

/o:j/ is inherited from PIE ${ }^{*} \bar{o} i$, and is commonly found in the OPhr. thematic sg.dat. -oy, -oi in tadoy (G-136), surgastoy (Dd-102), davoi (M-06 and B-05), etc. Despite the lack of omega,

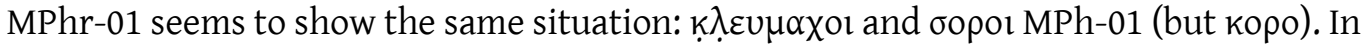
NPhr. this diphthong resulted in /o:/ and finally merged with /u:/ in absolute final position: oopov $(65.3=21$ and $65.4=124)$ and kopov $(27.1=92)$ but $\alpha v \tau \omega(37.2=30)$ and $\lambda_{\varepsilon \cup \kappa l \omega l}(11.2=18)$. However, ${ }^{*}{ }_{\alpha} i$ in the thematic pl.dat. ending *- ois lost its second

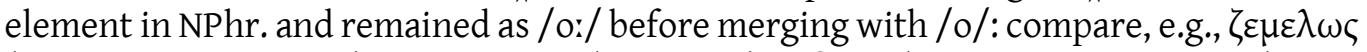
$(3.1=97,14.1=73$, etc. $)$ with $\zeta \varepsilon \mu \varepsilon \lambda$ o $(20.2=128)$ or $\delta \varepsilon \omega \varsigma(3.1=97,10.1=112$, etc. $)$ with $\delta \operatorname{\varepsilon os}(17.3=7$ and $18.3=6 ; \delta 10 \varsigma 30.1=39)$.

/aw/ is the outcome of the PIE sequence ${ }^{*} h_{2} e u$ and is preserved in all stages of the Phrygian language: PIE * he eu-to-, OPhr. avtay (W-01b), avtoi (T-03b), NPhr. $\alpha v \tau \alpha \eta$ and $\alpha v \tau \omega(37.2$ $=30)$, $\alpha \cup \tau o v(2.2=130)$ and $\alpha \cup \tau o \zeta ~(58.1=72,62.2=33$ and $62.5=35)$.

/ew/, inherited from PIE ${ }^{*} e u$ and the drop of intervocalic *-s-: PIE ${ }^{*} b^{h} e u d^{h}$-os- OPhr. bevdos (B-01) and ${ }^{*} h_{1} s u->e v(e)-(B-01)$. The form apelev (B-07) remains unclear.

/ow/?, the existence of this diphthong in Phrygian is unknown since the only possible occurrence is the obscure sequence [-?-].eivanouș[-?-] (G-250), however it rather shows the neutralisation between $/ \mathrm{o} / \sim / \mathrm{u} /$ as in vasous (P-03). Less probable occurrences are otekonov (B-01) and isnou (NW-101), where 〈ov perhaps represents /o:/ or /u:/ in a similar way to 〈uv in ituv (B-05).

In this overview it must also be noted that in two instances an epenthetic vowel $i$ arises between two contiguous consonants: $\kappa i v o[v] \mid \mu \alpha(22.1=9)$ for $\kappa v o u \mu \alpha v(16.1=116$ and $43.1=69)$ and in its gen. $k<v>$ ouplvo $(18.2=5)$. On the other hand, in two instances syncope worked: $\pi \alpha \mid \tau \varepsilon \rho \eta \varsigma(1.2=48)>\pi \alpha \tau \rho \varepsilon \varsigma(2.2=130)$ and in abretoy B-05, if it is accepted to be the same verbal form found in NPhr. as $\alpha \beta \beta \varepsilon \rho \varepsilon \tau o l ~(10.2=113,17.5=91$ and $19.2=129$, see Brixhe 2004a, 62). Moreover, apocopated forms of the conj. $k e(y) / \kappa \varepsilon$ and twice of $\alpha \mathrm{lv}$ before a vowel are not

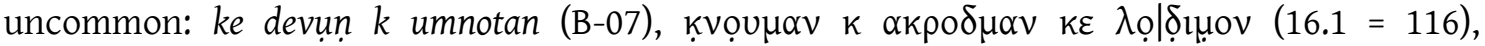

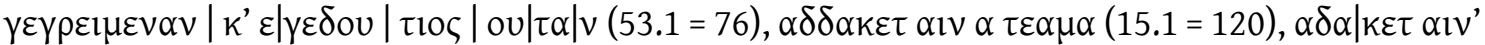

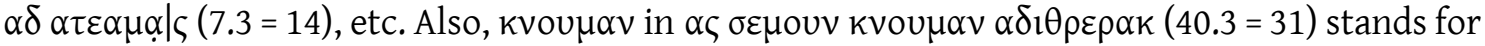

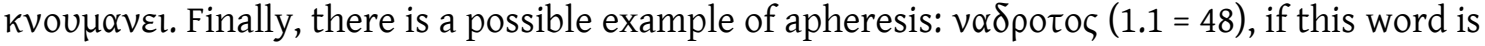
a borrowing from Greek ơvó́v $\delta \omega \tau o \zeta$, -ov 'impotent, husbandless’ (see Lubotsky 1997, 122).

\subsubsection{The consonant system}

Although not all sounds are clear, details of which are discussed on the following pages, the Phrygian consonant system can be classified as follows (see Table 13):

Table 13 Phrygian consonant system

\begin{tabular}{|c|c|c|c|c|c|c|}
\hline & & & Labial & $\begin{array}{c}\text { Dental or } \\
\text { Alveolar }\end{array}$ & Palatal & Velar \\
\hline \multirow{4}{*}{ Obstruent } & \multirow{2}{*}{ Stop } & Voiceless & $p\langle p, \pi\rangle$ & $t\langle\mathrm{t}, \tau\rangle$ & & $k\langle\mathrm{k}, \mathrm{k}\rangle$ \\
\hline & & Voiced & $b\langle b, \beta\rangle$ & $d\langle d, \delta\rangle$ & & $g\langle g, \gamma\rangle$ \\
\hline & \multirow{2}{*}{ Fricative } & Voiceless & & $s\langle\mathrm{~S}, \sigma\rangle$ & & \\
\hline & & Voiced & & $z ?\langle\uparrow, \zeta\rangle$ & & \\
\hline \multirow{3}{*}{ Sonorant } & \multicolumn{2}{|c|}{ Nasal } & $m\langle\mathrm{~m}, \mu\rangle$ & $n\langle\mathrm{n}, \mathrm{v}\rangle$ & & \\
\hline & \multicolumn{2}{|c|}{ Approximant } & $w\langle\mathrm{~V}, \mathrm{v}, \mathrm{ov}, \mathrm{O}\rangle$ & $l \ll 1, \lambda\rangle$ & $j\langle i, y, l\rangle$ & \\
\hline & \multicolumn{2}{|c|}{ Vibrant } & & $r\langle r, \rho\rangle$ & & \\
\hline
\end{tabular}




\subsubsection{Sonorants}

4.1.2.1.1. Nasals

Phrygian /m/ goes back to PIE *m: *méh 18), ${ }^{*}-m h_{1}$ no- $>\tau \imath \tau \tau \varepsilon \tau 1 \kappa \mu \varepsilon v o \varsigma$ (passim), ${ }^{*} d^{(h)}{ }^{\prime}{ }^{h} e m->\zeta \varepsilon \mu-\varepsilon \lambda \omega \varsigma$ (passim), etc. The PIE C-stem sg.acc. ending *-m shows that it is vocalised as *-am, although after the final ${ }^{*}-m$ became $-n$ in Phr. (as occurs in Gr.): ${ }^{*} m_{\text {é }}$ terma > materan (M-01dI and W-01a), ${ }^{*} d h_{3}$-ti-m (NIL 61) > totin (M-01f), ${ }^{*} h_{2} e$ uto- $m>$ venavtun $(\mathrm{W}-01 \mathrm{~b}) / \alpha u \tau o v(2.2=130)$, etc.

Phrygian preserved the PIE ${ }^{*} n$ in most positions: see, e.g., ${ }^{*}$ népot- > nevos (B-05), ${ }^{*} k^{2} n h_{1^{-}}$

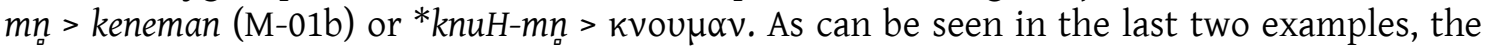
vocalisation of $*_{n}$-at least in final position - is -an. There is a position in which it seems to disappear: ${ }^{*}-V n s>-V i s$. It was suggested by Brixhe ${ }^{106}$ for the sg.nom. kanutieivaijs (P-03) and memevais (M-02) in light of the sg.gen. kanutii? evanos ${ }^{?}(\mathrm{P}-02)$. On the basis of this last form, he considered the shift sg.nom *-ans $>$ ais, and assumed that this also occurred in the pl.acc. ending *-ns / -C-ñs as in brataterạis (B-04) < *braterans < PIE * $b^{h}$ réh ${ }_{2}$ terñs. Although this analysis is accepted here, the contexts of the possible pl.acc. remain obscure: B-01 yos tivo [t]a spereta ayni kin te[l]emi | [..] toyo[.]is [.]erktẹvoys ekey da[b]ati..., B-04 [e?]lakes s? braterais patriyiọi is? $k(e) . .$. B-05 nidus ad kaliyay karatu panato ando popostois klaniv kelmis ke umnișet evradus dạkerais key iverais..., B-06 des [---] : ẹvent noktoy : emetetetariyois |[---]y..., G-145 voineios uriienois ku[---], G-239 mekais[-?-], 16.1

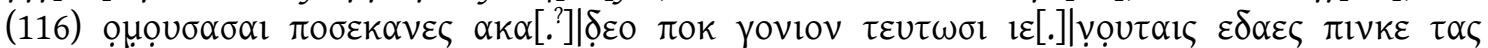

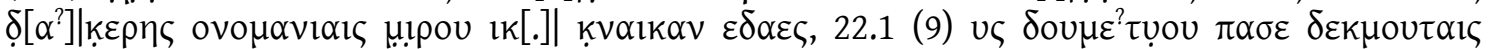

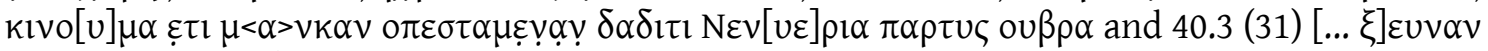

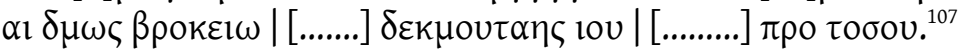

In addition, the shift *-ons > -ois does not fit Brixhe and Lejeune's (CIPPh I, 231) interpretation of P-02, a complete text on a stone block: sest bugnos va|sos kanutii? evanos?. The form ses=t can be the pl.acc. of the demonstrative pron. with the pcl. $t$ in agreement with bugnos, an o-stem pl.acc. The other two words are considered the sg.gen. of a PN and a title (here a patronymic, see $\S 4$.2.1.1.5.2) found in another text from the P epigraphic area. Then, we have a sequence in sg.acc. followed by a sequence in sg.gen, which does not make clear sense, and it is unknown why both cases are used here. Orel (1997a, 291-292) analysed sest as $s=e s t$, a sequence of the pcl. + the 3sg.ind.pres. of the copulative verb * $h_{1}$ es- 'to be' ( $L^{2} V^{2} 241-242$, IEW 340-341, with secondary ending) and bugnos "nom. sg. Masc. o-stem. A proper name of unknown origin". Consequently, he translated P-02 as 'This is Bugnos, keeper of the cultic object'. Leaving aside his interpretation of kanutiievanos (as he reads this title), his interpretation is attractive, since the presence of similar enunciates is also found on other blocks: P-03 vasous iman mekas kanutieivaịs devọs ke mekạs 'Vasus Iman the great son of Kanutî and the great god' and P-05 vasus kanutiẹ[---] 'Vasus the son of Kanutî'. ${ }^{108}$

Nevertheless, the preservation of -st in est is not expected in the light of the aor. ending $*_{-e-s-t}>-e s$ (edaes, eneparkes, etc.) and, worse still, this verbal form seems to be attested in Phr. as is according to Brixhe (2004a, 82), although the context of this last form remains unclear. Moreover, the considered PN bugnos remains unparalleled. It is tempting to interpret it in the light of the Persian name Baga- (in the patronymic Bagāna-) found in Aramaic texts as bgn

\footnotetext{
${ }^{106}$ First in Brixhe 1990, 65-67, but still in 2004a, 41-42. He is followed by Ligorio \& Lubotsky 2013, 187. In Lesbian Greek a secondary diphthong appears after the simplification of ${ }^{*}{ }_{-} n s-$ in word-medial and final

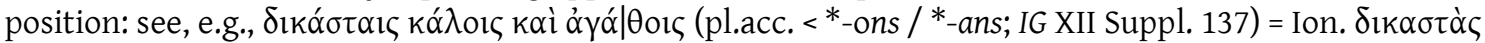

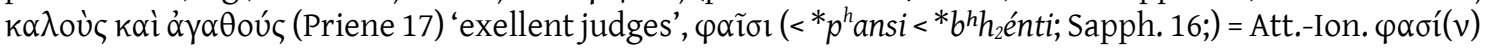
'they say' or $\mu$ oĩ $\sigma \alpha$ (Sapph. 84) = Att. $\mu$ oṽ $\sigma \alpha$ 'muse'.

${ }^{107}$ In any case, note that the preposition $\alpha \varsigma(7.1=99,7.3=14$, etc. $)$ does not fit this analysis, if it goes back to * $h_{1} n s$ (expected to yield *ais) or *hens (*eis?), as Lubotsky (1988, 24 fn. 13, also 1989a, 84) and Brixhe (1997, 50-53) suggested.

${ }^{108}$ In that case, these blocks could be used as pedestals for reliefs or statues.
} 
(according to Naveh's 1979, 186 interpretation of the Ber-sheva ostraca no. 34, 43 and 46; see also Tavernier 2007, 136), but baga- 'god' was very likely borrowed in Phrygian as bagun (G-136).

A third possibility for P-02 is to consider ses the sg.nom.masc. of the demonstrative pron. in agreement with bugnos (an o-stem sg.nom.): ses=t bugnos valsos kanutii? evanos " this (is) Bugnos, the son of Vasos the kanutievais'. This would imply that in ses=t a hesitation occurs between e and $i$ (see also its sg.dat. <s>imun / $\sigma \varepsilon \mu o u v$ ) and the pcl. $=t$ appears attached (see esai=t $\mathrm{W}-01 \mathrm{~b})$. In that case, it shows a levelling of the vowel from the oblique cases.

The shift *-Vns > -Vis in Phr. is a fact in the light of the suffix -evais, -evanos (see $\S$ 4.2.1.1.5.2). However, most of the possible occurrences of this shift are obscure, as are their contexts.

\subsection{The semiconsonants /w/ and / j/}

The semivowel /w/, represented by $\langle\mathrm{v}\rangle$ (in a few examples $\langle\mathrm{u}\rangle$ ) and $\mathrm{v}$, ov and o, follows

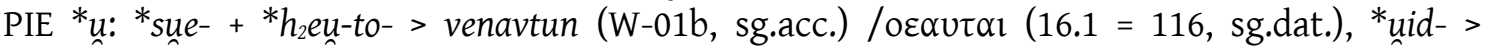

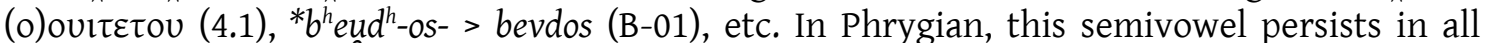
periods and positions with the sole exception of * uo $_{0}>0$ : *diu-os $>\tau 10 \zeta(53.1=76,54.1=108$, etc.). In two OPhr. words, $-v$ - appears as a hiatus-filling glide (Ligorio \& Lubotsky 2013, 186): ${ }^{*}$ toso > *toho $>$ tovo (P-01) and * $d^{h} h_{1}$ sos $>*$ dehos $>$ devos (P-03, also in devun B-07, not in NPhr. $\delta \varepsilon \omega \varsigma$, pl.dat.).

$/ \mathrm{j} /$, represented by $\langle\mathrm{i}\rangle$ or $\langle\mathrm{y}\rangle$ and $\mathrm{l}$, goes back to PIE $*_{i}$ and is preserved in most positions: ${ }^{*}$ Hios > yos, ios / 10 ( (passim), *-eio- > kuryaneyon (W-01c), *-ei > materey (M-01e and W-01b), etc. However, in NPhr. it drops when following long vowels: ${ }^{*}-\bar{i} i>\mathrm{OPhr}$. /o:j/ in dav-oi (M-07 and B-

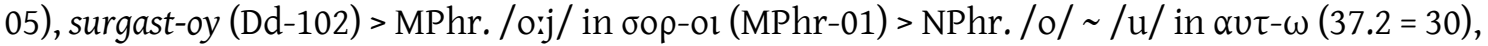

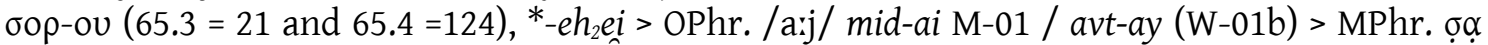
(MPhr-01, sg.dat. $)>$ NPhr. $/ a /$ in $\sigma \alpha(17.5=91,21.1=42$, etc. $), \mu \alpha v \kappa \alpha(3.1=97,11.2=18$, etc. $)$. Nevertheless, etymological spellings are commonly found: $\lambda \varepsilon v \kappa l \omega l(11.2=18),-a i>\sigma \alpha \mathrm{l}(43.1=$

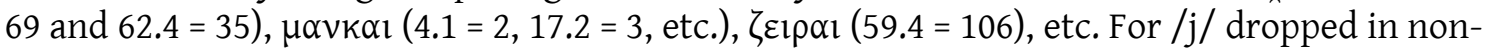
absolute final position, see ${ }^{*}-\bar{\alpha} i s>\delta \varepsilon \omega \varsigma$ (passim) and $\zeta \varepsilon \mu \varepsilon \lambda \omega \varsigma$ (passim). In OPhr., it appears in

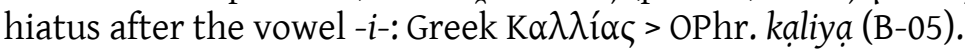

\subsection{The approximant /1/}

The approximant /1/ renders the PIE *l: see *sleh $g^{u}$ - > lakedo (W-01b) and*-elo- > $\varepsilon \mu \varepsilon \lambda \omega \varsigma$ (passim). There are no clear examples of $* l$, leaving aside $\gamma \lambda$ oupeos (MPhr-01), where its development is influenced by laryngeal ${ }^{*} g_{0}^{h} l h_{3^{-}}$(Greek $\left.\chi \lambda \omega \rho o ́ s\right)$.

\subsection{The vibrant $/ \mathrm{r} /$}

The Phrygian vibrant / $\mathrm{r}$ / goes back to PIE ${ }^{*} r{ }^{*}{ }^{h}$ er- > $\alpha \beta \beta \varepsilon \rho \varepsilon \tau(18.3=6,29.1=114$, etc.), ${ }^{*} p h_{2} t r->\pi \alpha \mid \tau \varepsilon \rho \eta \zeta(1.2=48) / \pi \alpha \tau \rho \varepsilon \zeta 2.2(130)$, etc. As in PIE, this sound is extremely unusual at the beginning of a word: rig?aru $(\mathrm{G}-222), \rho \varepsilon \mid \kappa \tau \varepsilon o l ~(47.1=51), \rho 1 \delta ı \imath ~(16.1=116)$, etc. (see Table

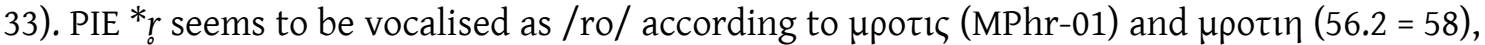
but as /or/ in final position in light of por $(\mathrm{W}-05 \mathrm{~b})$ ? / $\pi$ oup $(6.1=88)$, if both forms go back to PIE *pr. There are two examples of the simplification $(-) \mathrm{Cr}->(-) r-:$ *ureǵ- ? > vrekun (W-01a) > rekun $(\mathrm{M}-06)$ and $* d^{h}$ reguh -ro- > $\tau 1 \delta \rho \varepsilon \gamma \rho o u v(62.2=33)>\tau 1 \delta \rho \varepsilon \rho o u v(53.1=76)$. There is also a

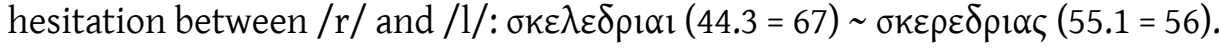




\subsubsection{Obstruents}

\subsection{Aspirant /s/}

PIE *s disappears in initial position before a vowel: e.g. PIE *seg ${ }^{h}$ - > OPhr. egeseti (P-04a), NPhr. $\varepsilon \gamma \varepsilon \delta o v ~(53.1=76,59.4=106$, etc.) and $\varepsilon \gamma \varepsilon \sigma i \tau(56.2=58)$. The Pron. $\sigma \alpha(1), \sigma \varepsilon \mu o u v$ (passim) can be considered an exception to this rule if it goes back to PIE *se/o-, however it is better

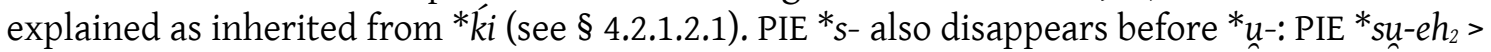
OPhr. va- (B-07 and B-05), NPhr. ovo- $(4.1=2,16.1=116$, etc.) and PIE *sue- > ve- OPhr. venavtun

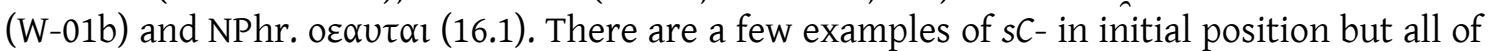
them are suggested to be borrowings: spereta $(\mathrm{B}-01)$, stal ${ }^{2} a(B-06)$ and $\sigma \kappa \varepsilon \lambda \varepsilon \delta \rho l \alpha l(44.3=67)$ /

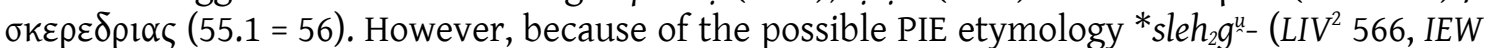
958, Greek $\lambda \alpha \mu \beta \alpha ́ v \omega)$ of OPhr. lakedo (W-01b), it can be tentatively assumed that PIE ${ }^{*}{ }^{-}$also dropped before a consonant other than $/ \mathrm{w} /{ }^{109}$

In intervocalic position PIE *-s- also disappears, as can be seen in the well attested word for 'god': PIE * $d^{h} h_{1} s_{-}$> NPhr. $\delta \varepsilon \omega \varsigma$ (pl.dat., passim, Greek $\left.\theta \varepsilon o ́ \varsigma\right)$. However, it is preserved in contact with a consonant at least in mid-word position: PIE * steh $_{1}$ ( LIV $^{2}$ 590-592, IEW 1004-1008) $>$ NPhr. $\varepsilon \sigma \tau \alpha \varepsilon \varsigma 40.3$ (31). An exception to this is considered by Lubotsky (1993a, $130 \mathrm{fn} .3$, still in

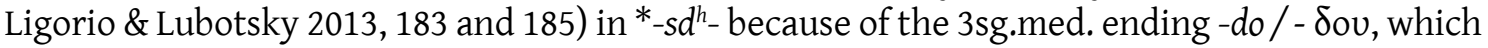
he equated to Greek $-\sigma \theta \omega$. Lejeune $(1969 b, 296)$ also considered for the form $\sigma \varepsilon \mu o u v$ (sg.dat.) a simplification of ${ }^{*} s e-s m-$ (here analysed as ${ }^{*} k e-$ ).

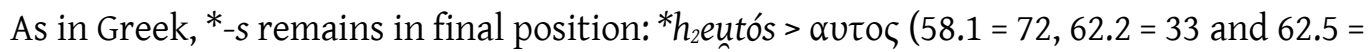
35), ${ }^{*} h_{1}-d^{h} e_{1}-e s-t>$ edaes (M-01a, M-01b, etc.), *népots > nevos (B-05). However, there is one example in which *-s drops in final position after -k-: compare -vanak $<*_{-} k$-s (in modrovanak, M04) with Greek ö $v \alpha \xi$.

\subsection{Stops}

The Phrygian language has two series of stops: three voiced stops, /b/, /d/ and /g/, contrast with the voiceless ones, /p/, / $/$ and / k/. Phrygian, then, greatly simplified the system of stops commonly reconstructed for the PIE (Table 14).

Table 14 Proto-Indo-European stops

\begin{tabular}{|c|c|c|c|}
\cline { 2 - 4 } \multicolumn{1}{c|}{} & Voiceless & Voiced & Aspirated \\
\hline Dentals & ${ }^{*} t$ & ${ }^{*} d$ & ${ }^{*} d^{h}$ \\
\hline Labials & ${ }^{*} p$ & $\left({ }^{*} b\right)$ & ${ }^{*} b^{h}$ \\
\hline Velars & ${ }^{*} k$ & ${ }^{*} g$ & ${ }^{*} g^{h}$ \\
\hline Palatovelars & ${ }^{*} k$ & ${ }^{*} g$ & ${ }^{*} \dot{g}^{h}$ \\
\hline Labialised velars & ${ }^{*} k^{u}$ & ${ }^{*} g^{u}$ & ${ }^{*} g^{u h}$ \\
\hline
\end{tabular}

First of all, Phrygian, as centum language ${ }^{110}$ merged the PIE palatovelar series with the plain velars, PIE $* k^{*},{ }^{\prime},{ }^{*} \dot{g}^{h}>* k,{ }^{*} g,{ }^{*} g^{h}$. Indeed, the Phr. outcome of this series is the same as the

\footnotetext{
${ }^{109}$ With regard to $s C$ - in Greek inscriptions from Anatolia (mainly from Roman Imperial times), Phrygia is notable for providing the most occurrences of vocalic prosthesis according to Brixhe (1987a, 115-116). Thumb $(1901,145)$ suggested that this feature could be attributed to the Phrygian substrate. Bubenik (1989, 242 and 279), partially following Thumb's proposal, considering it "a feature of the provincial substandard of the Hellenistic Koine as spoken by the middle and low classes in several regions of Asia Minor (most notably Phrygia)". However, as he admits, there are few inscriptions related to this issue containing information about the social scale of their promotors.

${ }^{110}$ This is a classical discussion in the history of Phrygian studies. Many scholars, especially in the period prior to the publication of Lejeune's works, considered that Phrygian belongs to the satzm group of PIE languages (on this, see Morante Mediavilla 2007, 543-559). Recently, while Brixhe considered that there
} 
plain velars (see Table 15, on some satom-like results see below). Secondly, it is widely known that the PIE aspirated stops became voiced: ${ }^{*} b^{h},{ }^{*} d^{h}, g^{h}>/ b /, / d /, / g /$. See, e.g., PIE ${ }^{*} b^{h}$ er- >

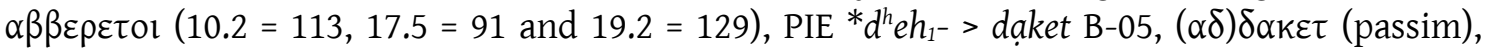
$* g^{h}$ rei $(H)->\gamma \varepsilon \gamma \rho \varepsilon l \mu \varepsilon v \alpha v(53.1=76,60.1=59$, etc.). Although some scholars question whether the Grasmann Law worked in Phrygian (e.g. Brixhe 2004a, 52 and Gorbachov 2008, 94-95), the noun ${ }^{*} b^{h}$ eud ${ }^{h}$-os- > bevdos clearly shows that it did not affect Phrygian (B-01, identified by Lubotsky 2008). Then, following Ligorio and Lubotsky (2013, 187 and 191) tedatoy (W-01a; tedat[---] B-05), the only example suggested to show this dissimilation more easily interpreted as bearing a preverb $t$ - before the common form edatoy (B-05; act. counterpart edaes M-01a, M-01b, etc.). Despite Brixhe's reticence (still in 2008, 74), ${ }^{111}$ Lubotsky (2004) showed that in parallel with this shift the PIE voiced stops became voiceless in Phrygian and postulated the Phrygian Lautverschiebung in the light of developments such as the following: *diēm, *diuos, *diuei > $\tau 1 \alpha v$,

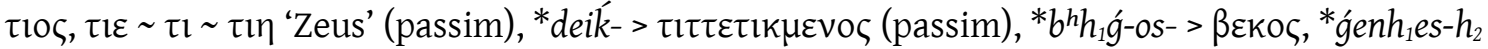
$>\kappa \varepsilon v \alpha$, etc. Even more examples that confirm his proposal have been identified since the publication of his paper: *doru- > torvetun (B-05; Hämmig 2013, 150, fn. 52, also in Ligorio \& Lubotsky 2013, 185), *ped- > petes (G-02, Kloekhorst, 2015), *méǵ- $h_{2}>$ mekas (M-05, G-111, etc.,

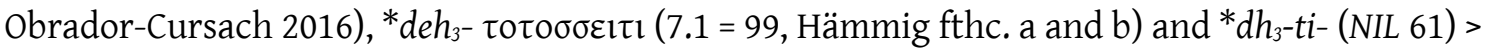
totin (M-01f, Ligorio 2016).

The plain voiceless stops seem to remain unchanged in most instances: ${ }^{*}$ méh ${ }_{2} t \bar{e} r>$ matar

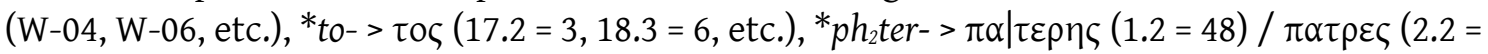

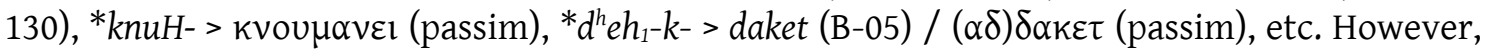
Hämmig (2013) has identified an example of intervocalic * $p>-v-:$ *népot- > nevos, nevotạn (B-05). As she noticed, this shift occurs only in this context, since in the same inscription she also identified its derived noun ${ }^{*}$ nept-ih $2_{2^{-}}>$niptiyan, niptiyay (B-05). The only clear example of *-VpV-

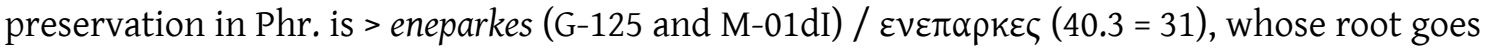
back to *perk- (as suggested Lejeune 1969b, 291-194). Consequently, it is unknown whether in Phrygian the shift * $V p V->-V v V$ - was a general phenomenon and the preservation in eneparkes due to paradigmatic levelling from forms without augment or whether $*-V p V->-V v V$ - was in fact a local shift, since it is only identified in a Vezirhan stele (B-05).

As can be seen, in Phr. there is no Lautverschiebung in the way that this concept is used in IE studies. Voiceless stops remained as so in all positions, excluding the invervocalic example of nevos (B-05). As such, stricto sensu it would be preferable to refer to a Phrygian devoicing and deaspiration.

\footnotetext{
was no clear information from which to conclude that Phrygian was a centum or satom (Brixhe 1983, 131), Lubotsky $(1989 b, 148-149 ; 1998,416)$ assumed that Phrygian shows centum developments.

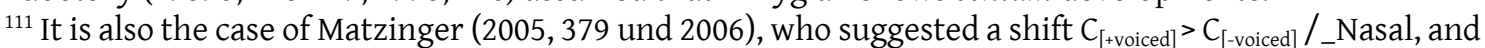
Woodhouse (2006), who suggested many contexts where the PIE voiced stops become voiceless in Phrygian. Nevertheless, although some of Woodhouse's new etymologies are possible, his general theory - that the shift occurred because of the presence of $/ \mathrm{n} /, / \mathrm{m} /, / \mathrm{w} /,{ }^{*} / \mathrm{b}^{h} /{ }^{*} / \mathrm{d}^{\mathrm{h}} /$ and perhaps $/ \mathrm{l} /$ in the same word - is not a satisfactory alternative to the more straightforward explanation given by Lubotsky. It is very likely that this is why his proposal remains unconsidered by other scholars. The aspirates and sonorants suggested by Woodhouse to be the cause of the shift do not constitute a natural class as regards this effect, it has no parallels and words identified after his paper do not fit his view: PIE *ped- > petes (G02, Kloekhorst, 2015) and *dh ${ }_{3}$-ti- (NIL 61) > totin (M-01f, Ligorio 2016).
} 
Table 15 Phrygian developments of the PIE velars

\begin{tabular}{|c|c|c|c|c|}
\hline PIE & oPhr. & OPhr. examples & NPhr. & NPhr. examples \\
\hline$* \dot{g}$ & $k$ & mekas $\left(<*\right.$ méǵ- $\left.h_{2}\right)$ & K & 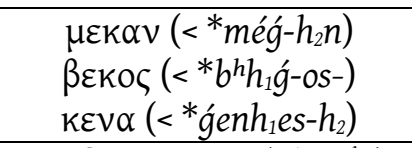 \\
\hline \multirow[t]{2}{*}{$* \dot{g}^{h}$} & $g$ & $\begin{array}{c}\text { egeseti }\left(<^{*} \text { seǵ }^{h}-\right) \\
\text { agarițoi }\left(<* \dot{g}^{h} \text { er }(H)-\right)\end{array}$ & $\gamma$ & $\begin{array}{c}\varepsilon \gamma \varepsilon \delta \circ v, \varepsilon \gamma \varepsilon \sigma i \tau\left(<^{*} \operatorname{seg}^{h}-\right) \\
\gamma \varepsilon \gamma \alpha \rho ı \tau \mu \varepsilon \cos \left(<^{*} g^{h} \operatorname{er}(H)-\right)\end{array}$ \\
\hline & $\uparrow$ & $\uparrow$ iray $\left(<*^{\prime} \dot{g}^{h} e s-r-\right)$ & $\zeta$ & $\zeta \varepsilon 1 \rho \alpha l\left(<{ }^{*} g^{h} e s-r-\right)$ \\
\hline$* g$ & - & - & - & - \\
\hline${ }^{*} g^{h}$ & - & - & $\gamma$ & 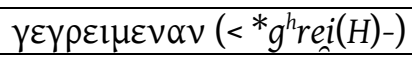 \\
\hline$* g^{u}$ & $k$ & $\begin{array}{l}\text { knays }\left(<*{ }^{*} g^{w}{ }^{2} h_{2^{-}}\right) \\
\text {lakedo }\left(<^{*} \text { sleh }_{2} g^{u}-\right)\end{array}$ & $\kappa$ & $\kappa v \alpha I K \alpha \nu\left(<{ }^{*} g^{w} n e h_{2^{-}}\right)$ \\
\hline$*^{\text {uh }}$ & - & - & $\gamma$ & $\tau 1 \delta \rho \varepsilon \gamma \rho o u v\left(<^{*} d^{h}{ }^{\prime} g^{\text {uh }}-r o-\right)$ \\
\hline$* k_{k}^{\prime}$ & - & - & $\kappa$ & $\tau \varepsilon \tau \iota k \mu \varepsilon \vee O \zeta\left(<* d i k^{\prime}\right)$ \\
\hline$*_{k}$ & $k$ & $\operatorname{daket}\left(<{ }^{*} d^{h} h_{1}-k-\right)$ & K & $(\alpha \delta) \delta \alpha \kappa \varepsilon \tau\left(<* d^{h} e h_{1}-k-\right)$ \\
\hline$* k^{u}$ & $k$ & $\begin{array}{c}k e, k e y\left(<* k^{u} e\right) \\
\operatorname{kos}, \operatorname{kin}\left(*^{u}{ }^{u}-/ *^{*} k^{u}{ }^{-}-\right)\end{array}$ & К & $\begin{array}{c}\kappa \varepsilon, \operatorname{\kappa \eta }\left(<* k^{u} e\right) \\
\operatorname{\kappa oc}, \operatorname{klv}\left({ }^{*} k^{u} 0-/{ }^{*} k^{u} i-\right)\end{array}$ \\
\hline
\end{tabular}

Lastly, Phrygian merged the PIE labialised velars, ${ }^{*} k^{u},{ }^{*} g^{u},{ }^{*} g^{u h}$, with the plain ones: ${ }^{*} k^{u} e$ $>$ ke (B-04, B-05, etc.), $k \varepsilon$ (passim), ${ }^{*} k^{u}{ }^{u}-{ }^{*}{ }^{*} k^{u} i->\operatorname{kos}(\mathrm{B}-07) / \operatorname{ko\zeta }(2.2=130,11.2=18$, etc.), kin (B$01) / \kappa v v(61.1=100),{ }^{*} g^{u}(e) n-h_{2^{-}}>$knays (HP-114), knais (B-07), etc. Although this shift confers a satom-look to the Phrygian language, it can only be explained as a secondary shift in the light of the previous confusion of palatovelars with regard to Latin and in Tocharian under some contexts (Pinault 2008, 445-447). In such a scenario, three forms show satom-like developments in Phrygian, which can also be considered secondary:

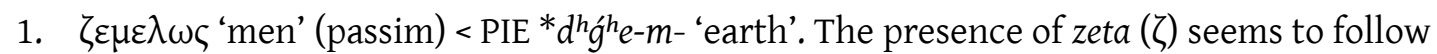
the PIE palatal * ${ }^{h}$, however in the light of what has been said it is more easily explained as representing a secondary palatalisation before the front vowel $e:{ }^{*} d^{h} g^{h} e-m->*(d) g e-$ $m->*(d)$ ǵe-m- $>\zeta \varepsilon \mu-$.

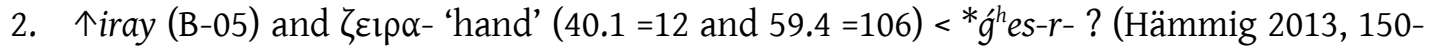
151). If the etymology and the equation of the OPhr. and NPhr. forms are accepted, we also have a similar context of $\zeta \varepsilon \mu \varepsilon \lambda \omega \varsigma:{ }^{*} \dot{g}^{h} e^{->}{ }^{*} g e^{-}>\uparrow i-/ \zeta \varepsilon \varepsilon-$.

3. The pron. $\sigma \varepsilon \mu o u v / \sigma \alpha$. Lejeune $(1969 b, 296)$ preferred to classify it as inherited from PIE * so- / to- (with split paradigm in Phrygian, see to $17.2=3,18.3=6$, etc.), however an etymology $* k i$ - is not ruled out by Ligorio and Lubotsky $(2013,185$, see also Hämmig 2013, $140 \mathrm{fn}$. 31). If this second possibility is preferred (as it is here), the front vowel can again be considered as causing the shift (subsequently spreading to the whole paradigm).

As can be seen, these examples of possible satom treatment occur before front vowels ${ }^{112}$ and can easily be considered secondary in the light of examples such as *még- $h_{2}>$ mekas. On the basis of the above considerations, the Phrygian system of stops can be defined as follows:

${ }^{112}$ Brixhe 1982, Brixhe 1994, 172 and Matzinger 2005, 380. 
/b/ is inherited from PIE $* b^{h}:{ }^{*} b^{h} e u d^{h}-o s^{-}>$bevdos $(\mathrm{B}-01),{ }^{*} b^{h} e r->\alpha \beta \beta \varepsilon \rho \varepsilon \tau(18.3=6,29.1=114$, etc.).

/d/ is the outcome of PIE * $d^{h}: * d^{h} e h_{1^{-}}>$edaes (M-01a, M-01b, etc.) / $\varepsilon \delta \alpha \varepsilon \zeta ~(16.1=116),{ }^{*} d^{h} h_{1^{-}}$ $s-0->\delta \varepsilon \omega \varsigma$ (passim), ${ }^{*} u p s o d^{h} n>v \psi o \delta \alpha v(2.1=15)$, etc.

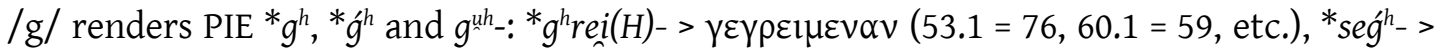
egeseti $\left(\mathrm{P}-04\right.$ a) $/ \varepsilon \gamma \varepsilon \delta$ ov $(53.1=76,59.4=106$, etc. $), \varepsilon \gamma \varepsilon \sigma 1 \tau(56.2=58),{ }^{*} d^{\text {h }}$ reg ${ }^{\text {uh }}$-ro- $>$ $\tau \imath \delta \rho \varepsilon \gamma \rho o u v(62.2=33)^{113} \ldots$

$/ p /$ follows the PIE ${ }^{*} p$, with remains in Phrygian (with the sole exception of * népots > nevos

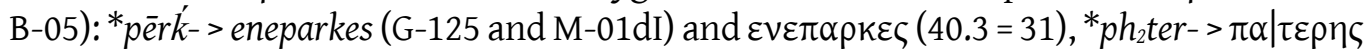
$(1.2=48), \pi \alpha \tau \rho \varepsilon \varsigma(2.2=130)$. The discussed PIE stop *b is expected to become * $p$ in Phr., however we have no evidence for the development of $* b$.

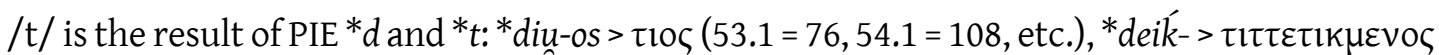
(passim), ${ }^{*} m^{m e ́}{ }_{2} t e \bar{r}>$ matar $(\mathrm{W}-04, \mathrm{~W}-06, \mathrm{~B}-01) / \mu \alpha \tau \alpha \rho(11.2=18), \pi \alpha \tau \rho \varepsilon \zeta(2.2=130)$,

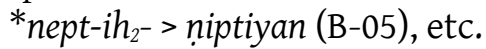

/k/ goes back to PIE *'́, * $g^{u},{ }^{*} k^{\prime},{ }^{*} k$ and ${ }^{*} k^{u}:{ }^{*}$ méǵ- $h_{2}>$ mekas (M-05, G-111, etc., sg.nom.) / $\mu \varepsilon k \alpha \varsigma$ (MPhr-01, sg.nom.) / $\mu \varepsilon \kappa \mid \alpha v\left(2.2=130\right.$, sg.acc.), ${ }^{*}$ sleh $_{2} g^{u}->$ lakedo $(\mathrm{W}-01 \mathrm{~b}),{ }^{*} \mathrm{~g}^{w}{ }^{w} \mathrm{eh}_{2^{-}}>$knais

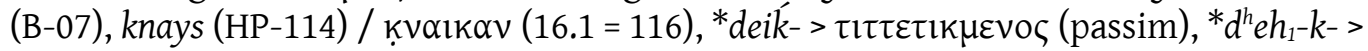

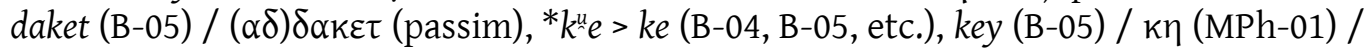

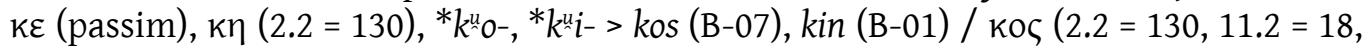
etc.), $\mathrm{kIV}(61.1=100)$. PIE ${ }^{*} \mathrm{~g}$ is expected to become $/ \mathrm{k} /$ in Phrygian (as well as ${ }^{*} g$ ), however evidence for ${ }^{*} g$ in Phrygian is lacking.

Finally, it must be added that stops drop in some clusters. This is the case of PIE *-t-s > *-s: see *népots $>$ nevos $(\mathrm{B}-05)$ and $\beta \alpha \varsigma(1.1=48,7.1=99$, etc.), in the light of its sg.acc. batan (T02) $/ \beta \alpha \tau \alpha v(20.2=128,62.2=33,62.5=35)$. Also $*_{\text {-st }}>{ }^{*}$-s can be considered in the light of the 3sg.aor. ending: ${ }^{*} h_{1}-d^{h} e h_{1}-e-s t>$ edaes (M-01a, M-01b, etc.).

\subsection{Reflexes of the Proto-Indo-European Laryngeals}

The three commonly reconstructed laryngeals for PIE disappeared in Phrygian. However, their presence is known through their reflexes and the comparison between other PIE languages. Moreover, as happens in Greek, Phrygian has different reflexes for each laryngeal, which they vocalise and "colour" in three different ways:

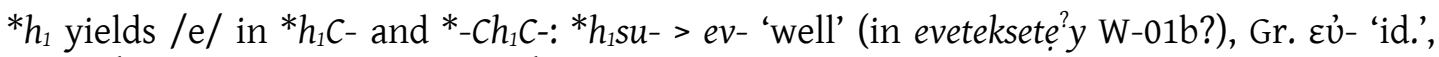

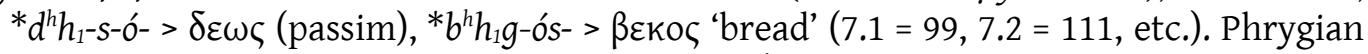
merged *-Vh $1^{-}$with $* \bar{e}$ and it became /a:/: e.g. * $d^{h} e_{1^{-}}>$daket (B-05), ( $\left.\alpha \delta\right) \delta \alpha \kappa \varepsilon \tau$ (passim). As has been said, there are two examples of ${ }^{*}-e h_{1} \#>-e / \varepsilon$ : the prohibitive pcl. ${ }^{*} m e h_{1}>$ $m e$ (B-05 and B-07) / $\mu \varepsilon$ and the adverb kakey (B-05) / $\kappa \alpha \kappa \varepsilon(6.1=88,7.1=99$, etc.). There are two hypothetical explanations for this unexpected result: in an early prehistoric stage of the language the laryngeal dropped in final position $\left(*_{-} h_{1} \#>*_{-} \breve{e}\right)$ or the shift $*_{\bar{e}}>\bar{a}$ only worked on stressed position. However, neither is conclusive: more examples of such dropping are lacking and our knowledge of the nature and position of the Phrygian stress is insufficient. In any case, before $*_{e}$ the laryngeal ${ }^{*} h_{1}$ - disappears without any reflex in Phrygian: ${ }^{*} h_{1} e$ - (the verbal augment) > e- in, e.g., edaes (M-01a, M02, etc.) and ${ }^{*} h_{1} i_{-}>\operatorname{ituv}(\mathrm{B}-05)$.

\footnotetext{
${ }^{113}$ According to Jokl 1927, 143 (followed by Neumann 1979, 824, Matzinger 2005, 384 and EDG 542), the

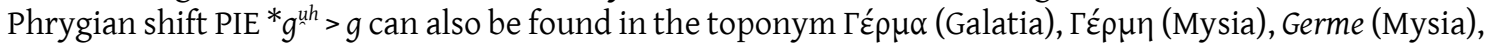

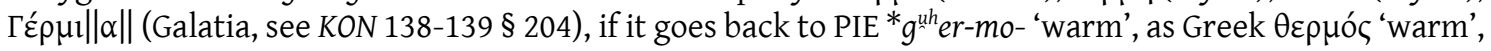
Arm. jerm 'id.' and Alb. zjarm, zjarr 'heat'.
} 


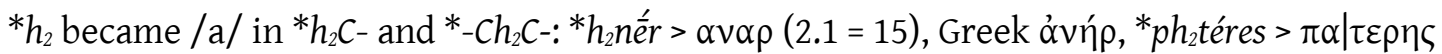
$(1.2=48), \pi \alpha \tau \rho \varepsilon \zeta(2.2=130),{ }^{*}$ meǵ- $h_{2}-(s)>$ mekas $(\mathrm{M}-05, \mathrm{G}-111$, etc. $) / \mu \varepsilon \kappa \alpha v(2.2=130$, sg.acc.), etc. Phrygian renders PIE *eh ${ }_{2}$ as /a:/: ${ }^{*}$ éh $_{2}$ tèr > matar (W-04, W-06, B-01) / $\mu \alpha \tau \alpha \rho(11.2=18),{ }^{*}$ steh $_{2^{-}}>$eștaes $(\mathrm{M}-11) / \varepsilon \sigma \tau \alpha \varepsilon \varsigma(40.3=31)$, etc. Before vowel ${ }^{*} e$ the

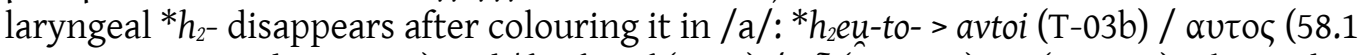
$=72,62.2=33$ and $62.5=35)$ and $* h_{2} e d>a d(B-05) / \alpha \delta(\hat{7} .3=99), \alpha \tau$ (passim). The sg.dat. ending provides the occurrence of this laryngeal in intervocalic position: -eh $e_{2} i$ > /aj/ $a i,-a y /-\alpha(\mathrm{l})$.

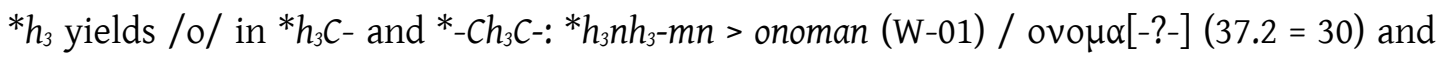

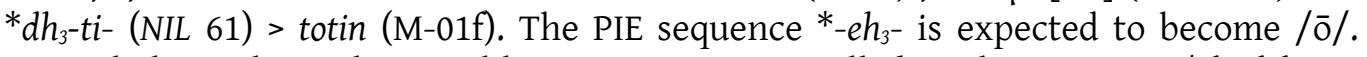
Nevertheless, the only possible occurrence is spelled with omicron: ${ }^{*} d e-d e h_{3^{-}}>$

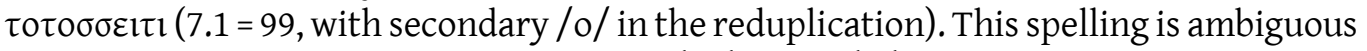
since Phrygian and Greek had merged /o:/ with /o/ by the times of the NPhr.

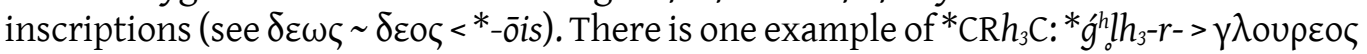
(MPhr-01). Here, the outcome is expected to be /o:/, however this vowel commonly shifts to /u:/ in Phrygian.

In addition, there are two Phrygian words with unspecified laryngeals which I would

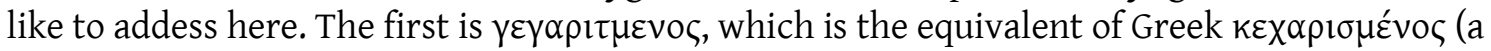

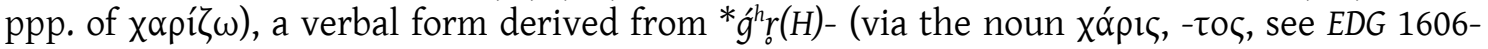
1607). ${ }^{114}$ In the Phrygian form ${ }^{*} h_{1}$ or ${ }^{*} h_{2}$ seems to have worked here because it is the only explanation for the vocalisation of $*_{0}>\alpha \rho$, differently to ${ }^{*} g_{0}^{h} l h_{3}-r->\gamma \lambda$ oupeos (MPhr-01). In the light of these forms one can consider that the following treatments (also attested in Greek) occurred in Phrygian:

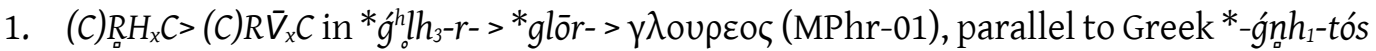

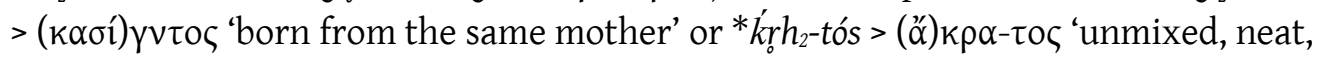
pure'.

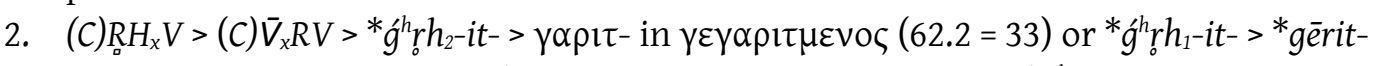

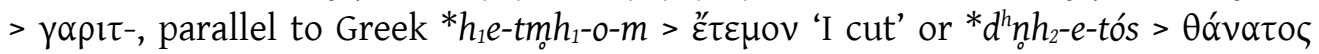
'death'. Also, the related adj. agarițoi 'devoted' (G-02 a, pl.nom. identified by

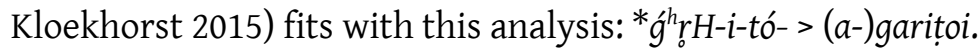

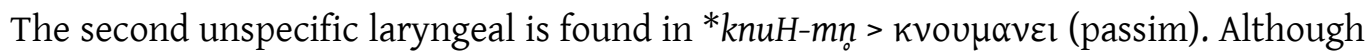
its root is also found in Greek $k v \mathfrak{u} \omega$ 'to dig', there is no evidence suggesting that laryngeal should be preferred in its reconstruction. Then, the laryngeal is only known for the Greek form, which suggests that the Phrygian form also had a long / $\mathrm{u}$ :/, at least before merging of / $\mathrm{u}$ :/with $/ \mathrm{u} /$.

In the light of the above, the PIE laryngeals result in Phrygian as follows:

Table 16 The Phrygian treatment of PIE laryngeals

\begin{tabular}{|c|c|c|c|c|c|c|c|c|}
\cline { 2 - 9 } \multicolumn{1}{c|}{} & ${ }^{*} \mathrm{HC}-$ & ${ }^{*}-\mathrm{CHC}-$ & ${ }^{*}-\mathrm{He}-$ & ${ }^{*}-e H e-$ & ${ }^{*}-e H-$ & ${ }^{*}-\mathrm{uH}-$ & ${ }^{*} \mathrm{CRHC}$ & ${ }^{*} \mathrm{CRHV}$ \\
\hline${ }^{*} h_{1}$ & $e C-$ & $-\mathrm{CeC}-$ & $-e-$ & - & $-\bar{a}-(-\bar{e}-)$ & - & - & - \\
\hline${ }^{*} h_{2}$ & $a C-$ & $-C a C-$ & $-a-$ & $-\bar{a}-$ & $-\bar{a}-$ & - & - & - \\
\hline${ }^{*} h_{3}$ & $o C-$ & $-C o C-$ & - & - & $-\bar{o}-?$ & - & ${ }^{*} C R \bar{o} C$ & - \\
\hline${ }^{*} H$ & - & - & - & - & - & $-\bar{u}-$ & - & $C \bar{V}_{x} R V$ \\
\hline
\end{tabular}

${ }^{114}$ The common vocalisation of ${ }^{*} r$ in Att.- Ion. is $\alpha \rho$. Then, a form ${ }^{*}{ }^{h} r$ - is expected to yiel $\chi a ̆ \rho-$. 


\subsection{Morphology}

\subsubsection{Nominal and Pronominal Morphology}

Phrygian nouns, adjective and pronouns have three genders (masculine, feminine and neuter), two numbers (singular and plural) and four cases (nominative, accusative, genitive and dative) ${ }^{115}$ These categories are expressed by the inflection of the words, although the gender of a word is often unclear because no specific endings are used and the agreement with an adjective or pron. is lacking in the preserved texts. In the case of nouns (and adjectives, although their inflection is even less documented), three basic types of nominal inflection are commonly established on the basis of the endings used for each type (although these are not the only distinguishing features): $a$-stem, $o$-stem and consonant stems ( $C$-stems, including $i-$ and $u$-stem).

\subsubsection{Nouns and adjectives}

\subsection{The $a$-stems}

In most instances, the Phrygian $\bar{a}$-stem inflection goes back to PIE ${ }^{*}-e_{2}$ and is followed by fem. and masc. nouns (especially personal names), fem. adj. and pronouns. The attested endings are shown in the table below:

Table 17 A-stem endings

\begin{tabular}{|l|c|c|c|c|c|c|}
\cline { 2 - 7 } \multicolumn{1}{c|}{} & \multicolumn{3}{c|}{ Singular } & \multicolumn{3}{c|}{ Plural } \\
\cline { 2 - 7 } \multicolumn{1}{c|}{} & OPhr. & MPhr. & NPhr. & OPhr. & MPhr. & NPhr. \\
\hline Nominative & $-a /-a s$ & $-\alpha /-$ & $-\alpha /-\alpha \varsigma$ & - & - & $-\alpha /-\alpha \varsigma ?$ \\
\hline Accusative & $-a n$ & $-\alpha v ?$ & $-\alpha \nu$ & - & - & $-\alpha 1 \varsigma,-\alpha \eta \varsigma ?$ \\
\hline Genitive & $-a s$ & - & $-\alpha \varsigma$ & - & - & - \\
\hline Dative & $-a i,-a y$ & $-\alpha$ & $-\alpha 1 /-\alpha$ & - & - & $-\alpha \varsigma$ \\
\hline
\end{tabular}

The sg.nom. ending $-a /-\alpha$ renders the PIE $*_{-}-h_{2}$. It is found in fem. nouns and adj.: kubeleya (B-01), kubileya (W-04), $\lambda \alpha \pi \tau \alpha$ (MPhr-01), $\mu \alpha v \kappa \alpha$ (MPhr-01), etc. It is also found in masculine personal names: ata (G-107, G-118, etc.), baba (M-01b and G-121), kaliya (B-05), $\mu ı \tau \rho \alpha \varphi \alpha \tau \alpha(1.1=48), \mu 1 \delta \alpha \kappa \alpha \varsigma(11.2=18)$, etc. There is an alternative ending -as for masculine PN, but even in those cases - $-\varnothing$ occurs: compare atas (G-128 and Dd-101), atatas (M-01c and HP01), midas (M-01d I, G-137 and HP-102) with baba (M-01b and G-121). This hesitation between forms with and without -s (also found in the other vowel stems, with the sole exception of the o-stem) is explained by Brixhe (1983, 128; 1993, 340 and 2004a, 51) as the result of Anatolian substratum / adstratum, since the Anatolian language does not have the contrast between masc. and fem. genre.

The PIE ending *-eh $2 m$ yields the sg.acc. -an / -a(v): akinanogavan (M-04), niptiyan (B-05), $\mu \alpha v \kappa \alpha v(2.1=15,11.2=18$, etc. $), \gamma \varepsilon \gamma \rho \varepsilon l \mu \varepsilon v \alpha \nu(53.1=76,60.1=59$, etc.)... There is not a clear occurrence in MPhr-01, since the obscure word $\beta_{\imath} \lambda \alpha \tau \alpha \delta \varepsilon \mid v \alpha \nu$ could be a $n$-stem (see imenan, an $<*-m)$.

The only clear noun in sg.gen. is oukvoouiac $(6.1=88)$, a fem. personal name. On masc. names in -as, Brixhe argued that there is a sg.gen. in -avo. However, the only example, leravo or lelavo (W-10), remains obscure (even its sg.nom. is unknown) and this assumption is made in the light of the o-stem -vo and the e-stem atevo (W-10), the possible gen. of the masculine PN ates (M-01a, W-08, etc.).

\footnotetext{
${ }^{115}$ It remains unknown whether Phrygian had a voc. case because of the nature of the texts.
} 
The sg.dat. -ai, -ay / $-\alpha /-\alpha \mathrm{l},-\alpha$ is the result of PIE *-eh ${ }^{*}$ i: atai (W-10), midai (M-01a), niptiyay (B-05), $\mu \alpha v \kappa \alpha l(4.1=2,17.2=3$, etc.), etc. It is common in NPhr. that the second element of the diphthong drops: $\mu \alpha v \kappa \alpha(3.1=97,11.2=18$, etc.). This simplification seems to have happened already in MPhr. in the light of $\sigma \alpha$ oopor (instead of $\sigma \alpha 1 \sigma o \rho o l)$. Often, this

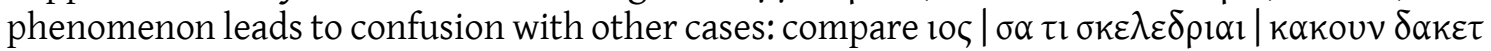

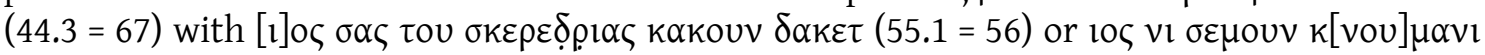

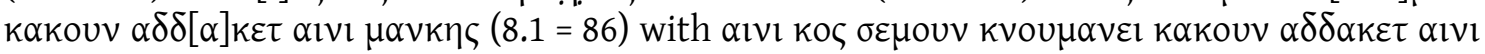
$\mu \alpha \nu \kappa \alpha(11.2=18)$. The spellings $\mu[\alpha \nu \kappa] \varepsilon(17.5=91)$ and $\mu \alpha \nu \kappa \eta \varsigma$ are very likely to have been influenced by Greek monophthongation $\alpha \mathrm{l}>\varepsilon$.

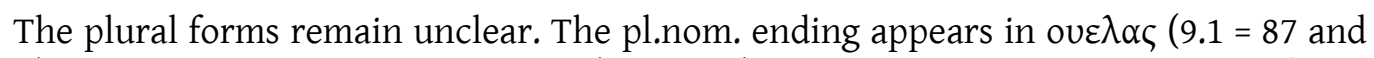
$15.1=120)$ according to Ligorio and Lubotsky $(2013,189)$, who consider that it goes back to * sueleh ${ }_{2}$-es. Nevertheless, Hämmig (fthc. a and b) has recently suggested another segmentation for both ocurrences (considered verbs) which, if accepted, invalidates this analysis: ove $\lambda \alpha \sigma k \varepsilon \tau o v$ $(9.1=87)$ and ove $\lambda \alpha \sigma k o v v o v(15.1=120)$. More likely, in NPhr. $40.1(12)$ the forms $\zeta \varepsilon 1 \rho \alpha$ and $\tau \iota \tau \tau \varepsilon \tau 1 k \mu \varepsilon v \alpha$ are in pl.nom. Perhaps, the simplification $-\alpha l>-\alpha$ occurred here, as in the sg.dat. If this is the case, the plural is an innovation shared with Greek, which built a pl.nom. - $\alpha$ l after the $o$-stem counterpart -ol. The pl.acc. ending - $\alpha 1 \zeta,-\alpha \eta \varsigma$, which goes back to PIE ${ }^{*}-e h_{2} n s$, is only

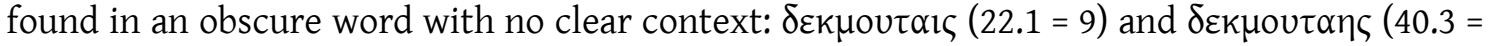

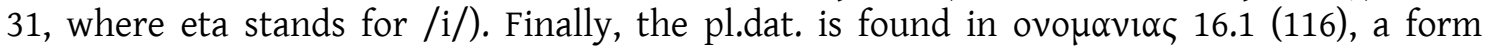
governed by the preposition $\mu \varepsilon$.

There are at least two secondary a-stems in Phrygian. The noun vrekun (W-01a) appears once as a feminine vrekan (B-05). In both instances, it can designate a relief of the goddess and perhaps it is the reason of the the stem and gender shift (see Matzinger 2005, 389). The PIE word for 'hand' was originally a C-stem PIE * g'hes-r- 'id.' (NIL 170-172, preserved in Hitt. keššar 'id.', Gr.

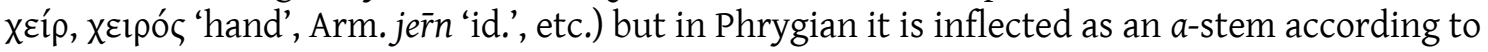
its sg.dat. 个iray $(\mathrm{B}-05) / \zeta \varepsilon i \rho \alpha \mathrm{l}(59.4=106)$. A parallel process occurred in the Alb. cognate dorë 'id.' (*der- $\bar{a}<* d \bar{e} r-<$ PIE $\left.{ }^{\prime} g^{h} e s-r-\right)$, but this is a general phenomenon in this language (Demiraj 1997, 140 with references).

The fem. forms of the adj. and pronouns follows this inflection. See, e.g., the fem. poss., sg.nom. $v a(B-07) /$ ova $(4.1=2,62.2=33$ and $62.5=36)$, sg.acc. oov $(16.1=116)-$ ovav $(60.1=59)$ and sg.dat. vay (B-05). In addition, the form kraniyas (B-05, read before as kraniyap) is considered in this dissertation a fem.sg.gen. adj. in agreement with the goddess artimitoș. Also, the forms

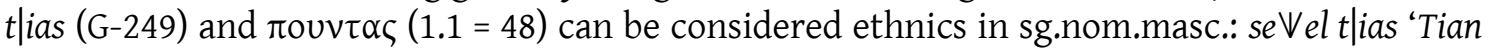

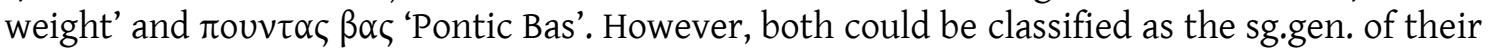
toponyms.

Finally, the adj. mekas 'big, great' < PIE * meǵ- $h_{2}$ was inflected in a similar way to $\bar{a}$-stems, although it has some peculiarities. Its sg.nom. mekas (M-05, G-111, etc.) / $\mu \varepsilon \kappa \alpha \varsigma$ (MPhr-01) has an ending -as (as in the Greek masc. $\mu \varepsilon \gamma_{\gamma} \breve{\alpha} \varsigma$ ) and it is used for both masc. and fem. (ObradorCursach 2016, 183-184): compare devọ ke mekas 'and the great god' (sg.nom.masc., P-03) and apelan mekas 'the great Apelan' (sg.nom.masc., M-05) with $\mu \alpha v \kappa \alpha \mu \varepsilon \kappa \alpha \varsigma$ $\sigma \alpha \varsigma$ 'this big stele' (sg.nom.masc., MPhr-01). Other cases are sg.acc. $\mu \varepsilon k \mid \alpha v(2.2=130)$ and sg.dat. $\mu \varepsilon k \alpha(35.1=25)$. The forms mekais (G-239, perhaps pl.acc., although a pl.dat. cannot be ruled out) and meka[---] (B-05) remain unclear.

\subsection{The o-stems}

The Phrygian thematic inflection, the o-stems, is inherited from its PIE equivalent. This inflection is followed by masculine and neuter nouns, adj. and pronouns, although there is at least one o-stem fem. noun ( $\sigma 0 \rho \circ 1 / \sigma o \rho o v)$. Their endings are as follows: 
Table 18 The o-stem endings

\begin{tabular}{|c|c|c|c|c|c|c|c|c|c|c|c|c|}
\hline & \multicolumn{6}{|c|}{ Singular } & \multicolumn{6}{|c|}{ Plural } \\
\hline & \multicolumn{2}{|c|}{ OPhr. } & \multicolumn{2}{|c|}{ MPhr. } & \multicolumn{2}{|c|}{ NPhr. } & \multicolumn{2}{|c|}{ OPhr. } & \multicolumn{2}{|c|}{ MPhr. } & \multicolumn{2}{|c|}{ NPhr. } \\
\hline & M-F & Neut. & M-F & Neut. & M-F & Neut. & M-F & Neut. & $\mathrm{M}-\mathrm{F}$ & Neut. & M-F & Neut. \\
\hline Nom. & $-0 S$ & \multirow[b]{2}{*}{-un } & $-O S$ & \multirow[b]{2}{*}{ - } & $-0 S$ & \multirow[b]{2}{*}{-ouv } & $-o i$ & \multirow[b]{2}{*}{$-a$} & - & \multirow[b]{2}{*}{ - } & -01 & \multirow[b]{2}{*}{$-\alpha$} \\
\hline Acc. & -un & & -OUV & & $\begin{array}{l}\text {-OUV } \\
\text {-ov }\end{array}$ & & -oys? & & - & & - & \\
\hline Gen. & \multicolumn{2}{|c|}{-ovo? } & \multicolumn{2}{|c|}{-00} & \multicolumn{2}{|c|}{$-0 v,-\omega$} & \multicolumn{2}{|c|}{ - } & \multicolumn{2}{|c|}{ - } & \multicolumn{2}{|c|}{-OUV } \\
\hline Dat. & \multicolumn{2}{|c|}{$-o i,-o y$} & \multicolumn{2}{|c|}{-01} & \multicolumn{2}{|c|}{$-0 v,-\omega,-\omega l$} & \multicolumn{2}{|c|}{ - } & \multicolumn{2}{|c|}{ - } & \multicolumn{2}{|c|}{$-\omega \varsigma$} \\
\hline
\end{tabular}

The PIE masc.sg.nom. ending *-o-s yields the Phrygian -os / -oc / -oc: akenanogavos (M-

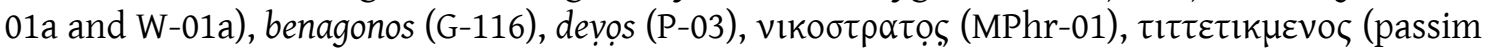
in NPhr.), etc.

The masc.sg.nom. ending -un / -ouv / -ouv, -ov goes back to PIE *-o-m: akaragayun (M-

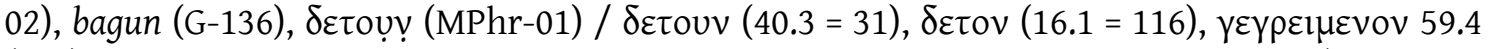
(106), etc. The same ending is used for the neut.sg.nom.-acc. of nouns and adjectives (but not in the pronominal inflection): vrekun (W-01a) and $\tau 1 \delta \rho \varepsilon \gamma \rho o u v(62.2=33), \tau 1 \delta \rho \varepsilon \rho o u v(53.1=76)$.

The OPhr. sg.gen. ending is suggested to be -ovo in the light of $[t]$ ovo (G-02 c, see Ligorio \& Lubotsky 2013, 189). Perhaps, some forms in -o such as kavarmoyo (B-01, B-05), a clear o-stem. as its sg.acc. kavarmoyun (B-01) shows. In any case, this ending appears in MPhr. and NPhr. as ov: $\alpha 1 \delta$ op $\varepsilon$ vov (MPhr-01), $\delta \alpha \delta$ ov $(11.2=18)$, $\alpha \rho \gamma o v(1.2=98$ and $37.2=30)$, etc. The adj. fem. $\alpha \omega \rho \omega$ $(6.1=88)$, borrowed from Greek ów $\omega \rho$ o , shows a spelling variant of the 0 -stem sg.gen. since it agrees with ovevaouiaৎ $(6.1=88)$. Following Ligorio and Lubotsky $(2013,189)$, the Phrygian thematic sg.gen. ending goes back to ${ }^{*}-0 s 0>{ }^{*}-0.0$, with an antihiatic $-v$-in the suggested OPhr. form. In MPhr. and NPhr., this ending $*_{0.0}>*_{-\bar{o}}>-$ ov merged with the sg.dat. -ou. The thematic sg.gen. ending * -osyo has not been identified in Phrygian. This absence can be considered surprising, since it is found in Skt. -asya, Gr. -olo and Arm. -oy (also in Faliscan -osio, Lat. Lapis Satricanus -osio and Lepontic-oiso). ${ }^{116}$ However, if indeed it is an archaism and not an innovation, it could simply have been lost in Phrygian.

The sg.dat. ending, -oi, -oy / -or, -o? / -ov, - $\omega$, follows the PIE *-oit. This diphthong is preserved in OPhr.: adoikavoi (G-02a), davoi (M-06 and B-05), imroy (B-01), etc. However, in NPhr. its second element dropped and the resulting /o:/ merged with / $\mathrm{u} /:$ oopov $(65.3=21$ and $65.4=$ $124)$ and kopov $(27.1=92)$. There are also few spellings with omega, e.g. $\alpha v \tau \omega(37.2=30)$, and one example of the old form, $\lambda \varepsilon v \kappa i \omega 1 \quad(11.2=18)$. In MPhr. the forms $k \lambda \varepsilon v \mu \alpha \chi 01$ and бopol (MPhr-01) show the same situation as the OPhr.

Phrygian has the thematic masc.pl.nom. ending -oi / -ol: agaritoi (G-02, Kloekhorst 2015, 110 and 116$)$ and $\tau \imath \tau \tau \varepsilon \tau 1 k \mu \varepsilon v o l ~(28.1=71)$. This ending, parallel e.g. to Greek -ol or Lat. $-\bar{l}(<-\bar{e}<$ $-e i<-0 i)$, is borrowed from the pronominal inflection.

The possible masc.pl.acc. ending -oys is the result of PIE *-ons, and is suggested to occur in kțevoys 'properties (?)' (B-01) and patriyiois 'relatives (?)' (B-04, see and Ligorio \& Lubotsky 2013 , 189). Note, however, that the contexts of both occurrences remain unclear. The PIE

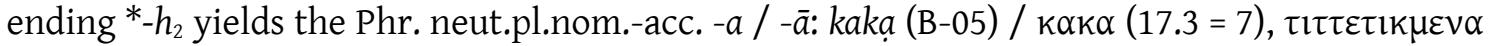
$(40.1=12)$ and $\mu \mu \nu \rho \alpha(35.1=25)$. Recently, the pl.gn. ending -ovv has been identified by Ligorio

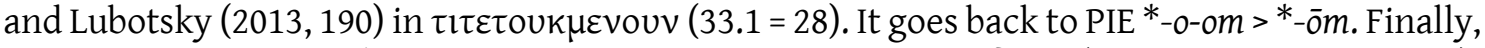
the PIE pl.dat. ending *-ois is clearly attested in NPhr. as $-\omega \varsigma$ : $\delta \varepsilon \omega \varsigma(3.1=97,10.1=112$, etc.), $\zeta \varepsilon \mu \varepsilon \lambda \omega \varsigma(3.1=97,14.1=73$, etc. $)$.

${ }^{116}$ On the Luwian outcome of -osyo see Yakubovich 2008. 
Finally, it must be said that in Phrygian at least one old fem. $a$-stem become a masc. 0 stem: outav $(53.1=76,54.1=108$, etc. $)$ and outov $(59.4=106)$. Both forms share the same

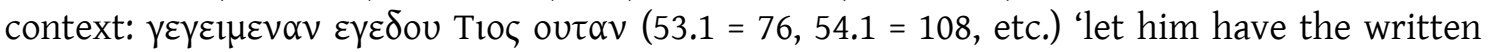

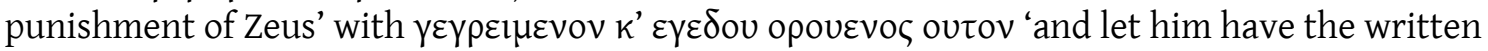
curse of the Keeper' $(59.4=106)$.

\subsection{The C-stems}

The C-stem encompasses the consonant stems, $t-, d-, k-, n-, m-r$-, $l$ - and $s$-stems, as well as the $i$-stems and $u$-stems. They share the same endings:

Table 19 C-stem endings

\begin{tabular}{|c|c|c|c|c|c|c|c|c|c|c|c|c|}
\hline & \multicolumn{6}{|c|}{ Singular } & \multicolumn{6}{|c|}{ Plural } \\
\hline & \multicolumn{2}{|c|}{ OPhr. } & \multicolumn{2}{|c|}{ MPhr. } & \multicolumn{2}{|c|}{ NPhr. } & \multicolumn{2}{|c|}{ OPhr. } & \multicolumn{2}{|c|}{ MPhr. } & \multicolumn{2}{|c|}{ NPhr. } \\
\hline & M-F & Neut. & M-F & Neut. & M-F & Neut. & M-F & Neut. & $\mathrm{M}-\mathrm{F}$ & Neut. & M-F & Neut. \\
\hline Nom. & $\begin{array}{c}-s /- \\
\varnothing\end{array}$ & \multirow{2}{*}{$-\varnothing$} & $-\varsigma$ & \multirow{2}{*}{ - } & $-\varsigma$ & \multirow{2}{*}{$-\varnothing$} & -es & \multirow{2}{*}{$-a$} & $-\eta \varsigma$ & \multirow{2}{*}{ - } & $\begin{array}{l}-\varepsilon \zeta \\
-\eta \zeta\end{array}$ & \multirow{2}{*}{$-\alpha$} \\
\hline Acc. & $\begin{array}{l}-n \\
-a n\end{array}$ & & $\begin{array}{l}-v \\
-\end{array}$ & & $\begin{array}{l}-v \\
-\alpha \nu\end{array}$ & & -ais? & & - & & - & \\
\hline Gen. & \multicolumn{2}{|c|}{$-o s$} & \multicolumn{2}{|c|}{-} & \multicolumn{2}{|c|}{$-0 S$} & \multicolumn{2}{|c|}{ - } & \multicolumn{2}{|c|}{ - } & \multicolumn{2}{|c|}{ - } \\
\hline Dat. & \multicolumn{2}{|c|}{$-e i,-e y$} & \multicolumn{2}{|c|}{-} & \multicolumn{2}{|c|}{$-\varepsilon l,-\varepsilon,-l,-\eta$} & \multicolumn{2}{|c|}{ - } & \multicolumn{2}{|c|}{ - } & \multicolumn{2}{|c|}{ - } \\
\hline
\end{tabular}

The masc. and fem. sg.nom. ending is -s, inherited from PIE *-s: Țuvatis (G-133), Alus (W-

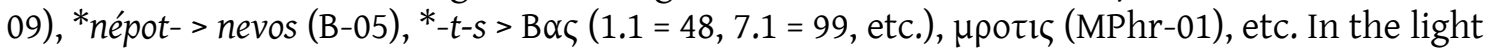
of modrovanak (M-04), it seems that after - $k$, the ending dropped. On the other hand, in the $r-, l_{-}$ and $n$-stems this ending does not occur, instead the nominative almost always shows a lengthened grade of the suffix (with the sifht ${ }^{*} \bar{e}>a$ ): matar (W-04, W-06 and B-01) / $\mu \alpha \tau \alpha \rho(11.2$ $=18), \operatorname{seVel}(\mathrm{G}-249$, a borrowing), iman (M-06, G-136, etc.), kuryaneyon $(\mathrm{W}-01 \mathrm{c})$, opovav $(1.1=48)$, $\alpha v \alpha \rho(2.1=15)$, etc.

PIE - $m$ /- $m$ yields the masc.-fem. sg.acc. ending $-n$ (after vowel) / -an (after consonant): areyastin (W-01a), imenan (B-05), materan (M-01dI and $\mathrm{W}-01 \mathrm{a})$, nevotan (B-05), Batan (T-02b) /

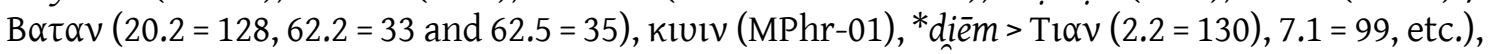

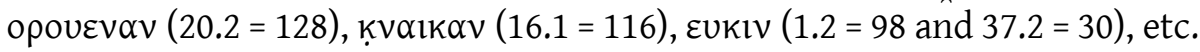

Neuters do not bear any ending in the sg.nom.-acc.: * $b^{h} e u d^{h}$-os- > bevdos (B-01, s-tem),

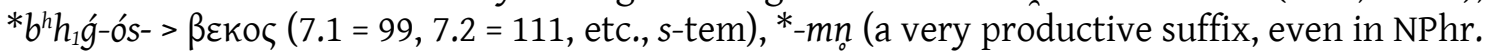

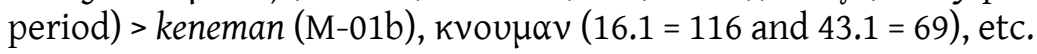

Phrygian generalised the PIE ending *-os for the C-stem sg.gen.: vasos (<*uasuos; P-02), kanutii 'evanos ' (P-02), urgitos (K-01 VI-VII a2), $\tau 10 \zeta(53.1=76,54.1=108$, etc.), opovevo 59.4 (106), $\kappa<v>$ ouplvo $(18.2=5)$, etc. According to artimitos $(B-05)$, Brixhe (2004a, 55-56) considered that

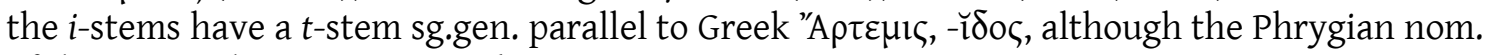
of this DN in Phr. is not attested.

Sg.dat. -ei, -ey / - - $1,-\varepsilon,-1,-\eta$ preserves the PIE ending *-ei, although in NPhr. this shows a simplification of this diphthong: materey (M-01e and $\mathrm{W}-01 \mathrm{~b})$, inmeney (B-05), $\uparrow$ emeney (B-05),

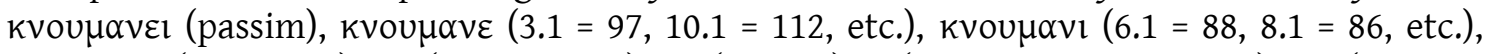

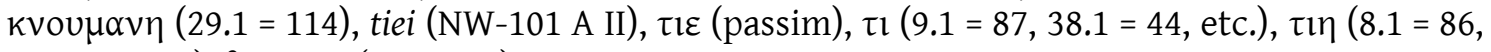
$18.3=6$, etc. $), \beta \rho \alpha \tau \varepsilon \rho \varepsilon(40.3=31)$, etc.

PIE pl.nom. ending *-es is preserved in Phrygian. Note that in NPhr. $\langle\eta\rangle$ represents /e/ (and /i/) instead of the classical / $\varepsilon: /$ : petes $(\mathrm{G}-02) / \pi \varepsilon \tau \varepsilon \zeta(40.1=12)$ ?, m?akeres $(\mathrm{HP}-114), \pi \alpha \nu \tau \eta \varsigma$ 
(MPhr-01), $\pi \alpha \tau \rho \varepsilon \varsigma(2.2=130), \pi \alpha \tau \varepsilon \rho \eta \varsigma(1.2=48)$, etc. The pl.acc. is not well attested, but it seems to go back to *-ns: buraterais (B-04), dakerais (B-05) ?, Finally, the neut.pl.nom.-acc. -a / -a goes

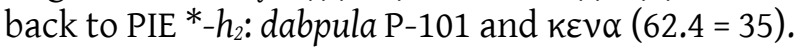

\subsection{Personal names in -es}

In the Phrygian corpus there are some PN with the nom. ending -es: manes (B-07; NPhr.

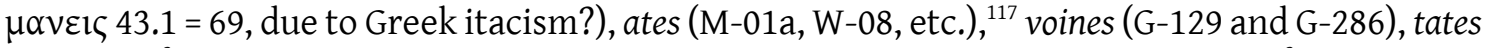
(G-122; $[t]$ ?ates $\mathrm{G}-148$ ?), tiyes (M-04), eies (G-108) and the more obscure geies or t? eies (G-125), p'erbastidages (HP-101), bateles (W-08), garies or paries $(\mathrm{G}-224 \mathrm{~b}), \alpha \delta \varepsilon v \pi \mid \alpha \tau \underline{\eta} \mathrm{h}(43.1=69)$. Two instances show a variant without $-s$, a hesitation found in all vowel stems PN: voine (G-228) and

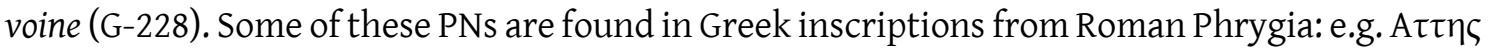

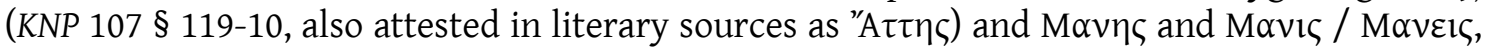

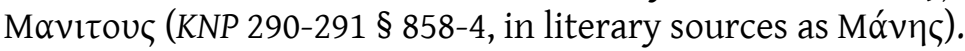

Their origin, as that of most PN attested in Phrygian and Greek texts from Phrygia, may be sought in the Anatolian languages, since some of them are PNS (including typical Lallnamen) that occur in Anatolian corpora: e.g. manes occurs in Lyd. as maneś (see Gusmani 1964,163) and in Carian as mane (see Adiego 2007, 381) and ates appears in the Lyd. poss. adj. ateliś 'of Ates' (Gusmani 1964, 69). Exceptions are $\alpha \delta \varepsilon v \pi \mid \alpha \tau n \varsigma$ and perbastidages (HP-101). ${ }^{118}$ Despite their abundance, they appear mostly in nom. and their inflection is not well attested. Leaving aside the forms atevo and $\alpha \delta \varepsilon \mid v<\pi>\alpha \tau \omega(43.1=69)$, only Manes seems to have more than this case:

Table 20 Possible inflection of the personal name Manes

\begin{tabular}{|c|c|}
\hline Nom. & $\begin{array}{c}\text { manes (B-07) } \\
\text { mane (Dd-103) }\end{array}$ \\
\hline Acc. & manin (B-07) \\
\hline Gen. & manitos (B-07) \\
\hline Dat. & - \\
\hline
\end{tabular}

In the light of Table 20, it seems that the PN in -es follow the $i$-stem inflection (with the inclusion of a - $t$ - in the $i$-stem sg.gen., as Brixhe 2004, 44 suggested). However, atevo (W-10) has been interpreted as the gen. of ates by Brixhe $(1983,124)$, with the same ending -vo found in the possible $a$-stem leravo or lelavo (W-10) and the pron. $[t]$ ovo (G-02 c). Also, contradictory to the suggested inflection of manes is the o-stem dat. $\alpha \delta \varepsilon \mid v<\pi>\alpha \tau \omega(43.1=69)$, if indeed it is the dat. of $\alpha \delta \varepsilon v \pi \mid \alpha \tau n \varsigma(43.1=69)$. Perhaps this hesitant inflection is due to the foreign origin of such PNs.

\subsection{Nominal and adjectival suffixes}

\subsection{1. - man, - $\mu l v o s$}

The suffix -man, inherited from PIE * ${ }^{-m n}$, is well attested in the Phrygian corpus. As in PIE, it derives neuter action nouns or result nouns from verbs: see *kenh ${ }_{1}$ - 'to dig' > keneman 'niche' (M-01b, Ligorio \& Lubotsky 2013, 189 and 192-193) or *knuH- 'scratch, dig' > kvou- $\mu \alpha v$. However, it is found in other constructions: PIE * $h_{3} n h_{3}-m n_{0}$ 'name' > onoman (W-01b, Greek óvo $\mu \alpha$ ). Secondary formations are also found, since this suffix spread to other nouns, even borrowings in NPhr. times: ${ }^{*} g^{w} o l(H)-t e h_{2^{-}}>$ko $\lambda \tau \alpha \mu \alpha v \varepsilon l(11.2=18$, if the etymology is right) and

${ }^{117}$ HP-103, HP-104, HP-105, HP-106, HP-107, HP-108. Perhaps also in [-?-]ates (G-123); [-?-]ateș?[-?-] (G-124) and [-?-]ates (G-148).

${ }^{118}$ On it see Brixhe 2004a, 105. 


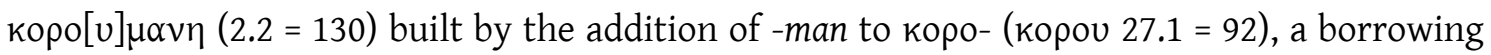
from Greek $\chi \omega ́$ pos, -ov. All of these nouns occur only in singular.

The PIE proterodynamic inflection of the nouns derived by this suffix seems to be

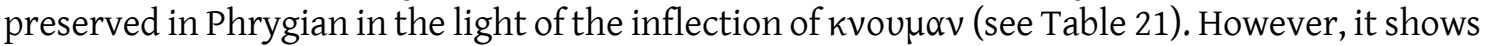
some particularities: the sg.gen. $k<v>0 v-\mu \mathrm{lv}$-o $\zeta$ has the common rising $e>i$ in the suffix and the sg.dat. forms $\kappa v o v-\mu \alpha v-\varepsilon l, \kappa o \lambda \tau \alpha-\mu \alpha v-\varepsilon l$ and $\kappa о \rho \circ[v]-\mu \alpha v-\eta$ has a levelling in the suffix vowel from the sg.nom (instead of the expected ${ }^{*}-\mu \varepsilon v-\varepsilon \mathrm{l}$ ).

Table 21 PIE and Phrygian inflection of the suffix ${ }^{*}-m_{a}$ in $s g$.

\begin{tabular}{|c|c|c|c|c|}
\hline & PIE & \multicolumn{3}{|c|}{ Phrygian } \\
\hline Nom.-Acc. & $*_{-m \eta}$ & onoman & keneman & $\kappa v o u \mu \alpha \nu$ \\
\hline Gen. & *-mén-s & - & - & $k<v>0 u \mu l v o \zeta$ \\
\hline Dat. & *-mén-ei & - & - & 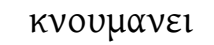 \\
\hline
\end{tabular}

\subsection{2. -evais, -evanos}

The suffix -evais /-evanos appears in adj. which occur in onomastic sequences and its origin may be found in the $\varnothing$-grade of PIE poss. suffix *-uent- (see Anatolian place names in wanda). While the sg.nom. is clear, ${ }^{*}$-unt-s $\left(>{ }^{*}\right.$-vants $>*^{*}$-vans $>$-vais), the sg.gen., which occurs in kanutii'evanos (P-02), is less straightforward. Ligorio \& Lubotsky $(2013,186)$ considered its

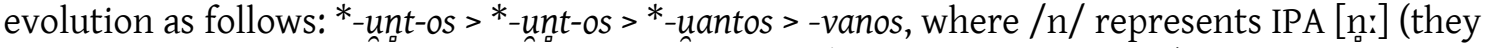

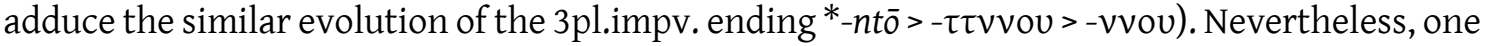
cannot rule out a simple levelling from the nom. *-van- to the gen. in Proto-Phrygian (instead of the expected gen. ${ }^{*}$-vant-os). The vowel $-e$-found before this suffix in all Phrygian instances may be a resegmentation in names with this vowel. The suffix -evais /-evanos has been considered to form titles (1988a, 175) or ethnics (Brixhe 2004a, 77-78). However, they are most easily explained as patronymics because two of the three occurrences can be analysed as derived from PN: arkia- in arkiaevais (M-01a) is very likely the Greek PN 'Apxías and mem(e)- in memevais (M-01b and M-02) looks like a common Anatolian Lallname (see, e.g., KPN $309 \S 895$

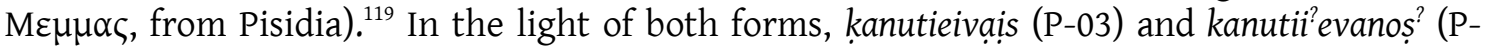
$02)^{120}$ can also be considered a patronymic. Although kanuti- does not occur elsewhere in Anatolia, a man called Kanutî appears as witness in a Neo-Assyrian judicial ruling dated after 626 BC (Fales \& Jakob-Rost 1991, 132-133 no. 66) and the area where Phrygian P-inscriptions were found was under Neo-Assyrian control. Consequently, this name is very likely to have an Assyrian origin.

Table 22 PIE and Phrygian inflection of the suffix *un(e)nt-

\begin{tabular}{|c|c|c|c|c|}
\hline & PIE & \multicolumn{3}{|c|}{ Phrygian } \\
\hline Nom. & *-unt & kanutieivạis & arkiaevais & memevais \\
\hline Gen. & *-unt-os & kanutii?evanoṣ? & - & - \\
\hline
\end{tabular}

\footnotetext{
${ }^{119}$ The sg.nom. memeuis (T-02) is a clear variant of memevais which shows the common Luw. contraction $*_{w a}>u$ (on this, see Rieken 2001). Since the loss of - $a$ - in such position remains unexplained an engraver's mistake is highly possible. Note also the historical consequences of this interpretation. If M-01a ates arkiaevais is to be understood as 'Attēs the son of Arkias', its identification with the Lydian Atys the son of Croesus (as suggested by Berndt-Ersöz 2006, 130) is not longer possible.

${ }^{120}$ A third occurrence is found in kanutie [---] (P-05), but its ending is lost. Note that all occurrences of kanuti- come from the same area.
} 


\subsection{3. -eyo/a-}

The suffix -eyo/a-, which goes back to PIE *-eic- $\left(\right.$ fem. $^{*}$-eieh ${ }_{2}$-), derives adjectives from nouns and creates fem. PNs from masc. These adjectives follow the o-stem inflection for the masc. and neuter and the $a$-stem inflection for the feminine. The list of instances is as follows: mireyun (sg.acc., B-05, very likely derived from meros B-07 / $\mu 1$ o fem. PN derived from iman, imen-os M-06, G-136, etc.), kubeleya (B-01) kubileya (W-04, DN), $k \uparrow$ ianaveyos (M-01b and M-02, title), lagineios (G-110, PN) and perhaps [l?] agineia (G-276, its fem.?), voineios (G-145, PN derived from voines G-129, G-286), [-?-]agipeia (G-135, if derived from

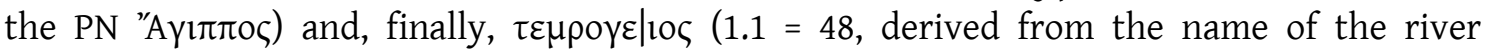
Thymbris).

\subsection{4. -yo/a-}

As well as -eyo/a-, the suffix -yo/a- (<PIE *-io-) creates thematic adjectives from nouns. It seems to be attested in patriyio 'is" 'relatives' (B-04) and, perhaps, in porniyoy (B-07).

\subsection{5. -iya}

The Phrygian suffix -iya-, inherited from PIE ${ }^{*}-i h_{2}$, occurs twice in the Phrygian corpus: in the noun niptiya 'daughter' (B-05) < *nept-ih ${ }_{2}$ (identified by Hämmig 2013, pace Simon 2014) and in the adj. kraniyas 'of the source' (sg.gen., B-05, formerly read as kraniyap). Note that the syllabicity of this suffix in Phrygian is explained by Siever's Law, since $-i h_{2}>-i y h_{2}$ happens following heavy syllables: ${ }^{*}$ nept-ih $h_{2} *_{n e p t-i y h_{2}}>$ niptiyă. Very likely, the adj. kraniyas is formed

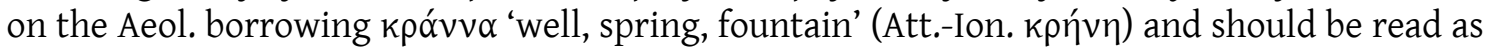
/kranniyas $/{ }^{121}$

\subsection{6. -elo-}

The suffix -elo-, which goes back to PIE *-elo-, is found in $\zeta \varepsilon \mu \varepsilon \lambda \omega \varsigma$ 'men' (pl.dat., $3.1=97$, $14.1=73$, etc.): * $d^{(h)} \dot{g}^{h} e m-e l o->* \dot{g}^{h} e m-e l o->* \zeta \varepsilon \mu-\varepsilon \lambda o-$.

\subsection{7. - مo-}

At least the word $\tau 1 \delta \rho \varepsilon \gamma \rho \circ u v(62.2=33$, also $[\tau 1 \delta \rho] \varepsilon \gamma \rho \circ \mid u v 54.1=108$ and $\tau 1 \delta \rho \varepsilon \rho \circ u v 53.1$ $=76$ ), derived from PIE * ${ }^{h}{ }^{h}$ reg ${ }^{u h}$ - 'to feed', ${ }^{122}$ shows the survival of the PIE suffix -ró-s in Phr. It derives adjectives.

\subsection{8. - tar}

The PIE suffix *-tr-is commonly found in kindship terms: *méh 04, W-06 and B-01; sg.acc. materan M-01d I and W-01a and sg.dat. materey M-01e, W-01b), ${ }^{*}$ ph ${ }_{2}$ téres > $\pi \alpha \tau \varepsilon \rho \eta \varsigma$ (pl.nom., $1.2=48$; also $\pi \alpha \tau \rho \varepsilon \varsigma 2.2=130$ ) and ${ }^{*} b^{h}{ }^{h}{ }^{2} h_{2}$ trey > $\beta \rho \alpha \tau \varepsilon \rho \varepsilon$ (sg.dat. with levelling in the suffix, $40.3=31$, pl.acc. braterais B-04).

In addition, since PIE *-têr is known to create agent nouns from verbal roots, one is tempted to consider that m'akeres 'kind of worker'? (pl.nom., HP-114) and dạkerạn '?' (sg.acc., B-

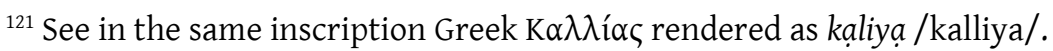

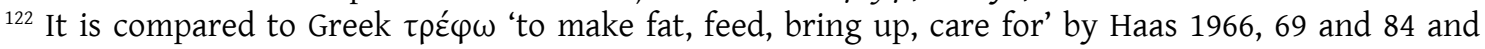
Lubotsky 2004, 235-236.
} 
05, other forms sg.nom. pl.acc. dạkerais B-05, pl.nom. $\delta[\alpha] \mid \kappa \varepsilon \rho \eta \varsigma ~ 16.1=116$, its sg.nom. can be daker B-05 or / and $\delta \alpha k \alpha \rho 11.2=18)$ contain this suffix: ${ }^{*}$ meh $_{2}$ ǵ-ter-es $>{ }^{*}$ makteres $>$ m?akeres (perhaps /makkeres/) and ${ }^{*} d^{h}$ h $_{1}-k$-ter-m $>*$ dakteram $>$ dakeran. As can be seen, this analysis assumes an assimilation *-kt- $>-k k$-. Although this analysis is preferable to accepting an unparalleled suffix **-er/-er-, both examples are unclear words and this working hypothesis remains open.

Table 23 *-tèr inflection in PIE and Phrygian

\begin{tabular}{|c|c|c|c|c|c|c|}
\hline & PIE & \multicolumn{5}{|c|}{ Phrygian } \\
\hline Sg.nom. & *-tèr & matar & - & - & - & 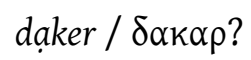 \\
\hline Sg.acc. & *-ter-m & materan & - & - & - & dạkerạn \\
\hline Sg.dat. & *-tr-eni & materey & - & $\beta \rho \alpha \tau \varepsilon \rho \varepsilon$ & - & - \\
\hline Pl.nom. & *-ter-es & - & $\begin{array}{c}\pi \alpha \tau \varepsilon \rho \eta \varsigma \\
\pi \alpha \tau \rho \varepsilon \varsigma\end{array}$ & - & m?akeres & $\delta[\alpha] \mid \kappa \varepsilon \rho \eta \varsigma$ \\
\hline Pl.acc. & *-ter-ngs & - & & buraterais & - & dạkeraịs \\
\hline
\end{tabular}

\subsection{9. -av-os?}

Two words show a Phrygian suffix -avos: akenanogavos (M-01a, W-01a), proitavos (M-01b and M-02). ${ }^{123}$ The first word is attested by the forms akenanogavos (M-01a, W-01a) and akinanogavan $(\mathrm{M}-04) .{ }^{124}$ On the one hand, both forms are considered to contain a suffix *-av-os

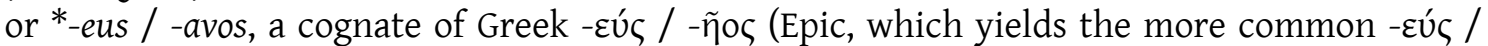
$-\varepsilon(\omega \varsigma) .{ }^{125}$ Indeed, akenanogavos is assumed by some scholars to be a kind of patronymic form in

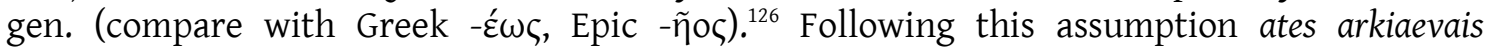
akenanogavos may be translated as "Attes (the son) of Arkias (the grandson) of akenanog- ${ }^{127}$ and bonok akenanogavọ (M-01a) as 'Bonok the son of Akenanog-'. Even the form akinanogavan (M04) can be explained as the sg.acc. of akenanogavos: ${ }^{*} m_{0}>{ }^{*}$-an (compare with Greek - $\varepsilon \bar{\alpha}$, Epic $-\tilde{\eta} \breve{\alpha} /-\varepsilon \tilde{\alpha})$. However, the context is less clear than that one of the gen. forms and this analysis implies a levelling ${ }^{*}-a v$-from the sg.gen. Moreover, there is not an independent source for a PN akenanog- in Phr. Moreover, since the first element of this word is a clear Phrygian noun and PN names derived from Phr. nouns are unknown, it is hardly defensible to classify akenanogavos as a genuine Phr. PN.

Lubotsky (1988, 12, see also Ligorio \& Lubotsky 2013, 188 and 192), Janda (1997), Orel (1997a, 10-11 and 412) and other scholars considered akenanogavos a title of ates and bonok, a thematic sg.nom., referring to a kind of priest. In this case, ates arkiaevais akenanogavos may be translated 'Attes the son of Arkias the akenanogavos' (M-01a, W-01a). Then, as Lubotsky suggested $(1988,12)$, akinanogavan (M-04) can only be the fem. form in sg.acc. (said of the Mother-Goddess, to whom the monument is devoted). The interpretation of akenanogavos as a title is favoured by the context: these words (including proitavos) are found on great cultic

\footnotetext{
${ }^{123}$ Despite the identical ending, the form oskavos (B-05 1.8) cannot be related to them because of the imprecative context of this word.

${ }^{124} \mathrm{~A}$ fourth form is found in M-09, aken? ano[---].

${ }^{125}$ Hajnal 2005, 200 suggested a link between the two suffixes and considered them patronymics in sg.gen. The origin of the Greek suffix is still discussed and there are scholars who consider it a borrowing from an unknown language. This is the case of Meissner (2016), who also provides an interesting approach to the history of the analysis of this suffix. Unfortunately, Phrygian does not provide information relevant to its origin.

${ }^{126}$ It is suggested and defended in Gusmani \& Polat 1999b, 156 fn. 61, Innocente 1997, 40, especially, Brixhe 2004a, 60 and 78 and Hajnal 2005, 200.

${ }^{127}$ A strong parallel for such a genealogical sequence is B-07 manes iyungidas manitos 'Manes (the son) of Iyungida (the grandson) of Manes'.
} 
monuments very likely promoted by the rulers or administrators of the area. So, the promotor's official titles can be expected to appear on this kind of public monument.

However, a problem remains: what is the origin of -ogav-? Indeed, akenan is found as a noun in P-04a, so akenanogavos is clearly a compound. The sole attempt to interpret -ogav-was given by Orel 1997a, 10-11 and 412 (= 1997b, 42), who considered a form -anog- (compared to

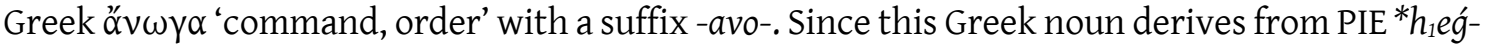
'to say' (see EDG 110-111), the equation can no longer be defended because of the Lautverschiebung. In my opinion, -ogav- can be equated to Greek oxev́c 'anything used for holding or fastening', which derived from *sog ${ }^{h}$, the o-grade variant of the root *seg ${ }^{h^{-}}$'to hold' (LIV ${ }^{2}$ 515-516, IEW 888-889). ${ }^{128}$ Then, it is easy to consider that from *sog' ${ }^{h}-\bar{e} u-$, as found in sg.gen.

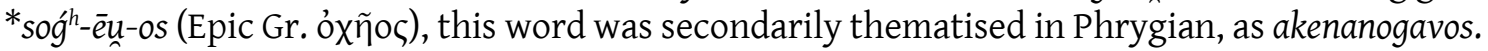
Note that both occurences of the title akenanogavos very likely appear in agreement in sg.gen. with ates (M-01a) and bonok (W-01a). The result of this analysis is a title related to the cultic monuments with the meaning 'the holder/keeper of the akenan, vel. sim.'.

The second word containing -av-os is less clear because proitavos (M-01b and M-02) does not have a clear etymological analysis and its interpretation depends on the meaning assigned to akenanogavos. In any case, its position is the same as akenanogavos, after a PN followed by a patronymic: baba memevais proitavos $k$ Фiyanaveyos... 'Baba the son of Meme, the proitavos, the proitavos, the $k$ Фiyanaveyos $(\mathrm{M}-01 \mathrm{~b}){ }^{129}$

\subsubsection{Pronouns}

The pronouns follow, with some peculiarities, the o-stem inflections for the masc. and neuter and $a$-stems for the fem. However, some pronouns have endings with $-i$ - in the masc. and neuter sg.nom. and sg.acc.

\subsection{Demonstrative pronoun}

Table 24 Inflection of the Phrygian demonstrative pronoun si-, $\sigma \alpha-$

\begin{tabular}{|c|c|c|c|c|c|c|}
\hline & \multicolumn{3}{|c|}{ Singular } & \multicolumn{3}{|c|}{ Plural } \\
\hline & Masculine & Neuter & Feminine & Masculine & Neuter & Feminine \\
\hline Nom. & ses? & \multirow[b]{2}{*}{ si } & $\sigma \alpha \varsigma !$ & - & \multirow[b]{2}{*}{ - } & - \\
\hline Acc. & $\begin{array}{c}\sin \\
\sigma \varepsilon \mu \text { ouv! }\end{array}$ & & $\varepsilon \sigma^{?} \alpha \nu ?$ & ses? & & - \\
\hline Gen. & \multicolumn{2}{|l|}{ 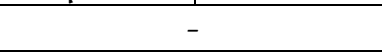 } & $\sigma \alpha \varsigma !$ & \multicolumn{2}{|c|}{ - } & - \\
\hline Dat. & \multicolumn{2}{|c|}{$\begin{array}{c}<s>i m u n, \sigma \varepsilon \mu o v v, \sigma \varepsilon \mu o v, \\
\sigma \varepsilon \mu v v, \sigma \varepsilon \mu l v, \sigma \varepsilon \mu o v, \\
\sigma l \mu o v v\end{array}$} & $\begin{array}{l}\text { esai, } \sigma \alpha 1, \\
\sigma \alpha, \sigma \alpha v ! \\
\quad \sigma \alpha \varsigma !\end{array}$ & \multirow{2}{*}{\multicolumn{2}{|c|}{ - }} & - \\
\hline Particle & \multicolumn{4}{|c|}{$S$} & & \\
\hline
\end{tabular}

This demonstrative has generally been considered the result of the split of the PIE * so-

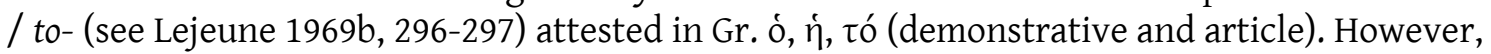
Ligorio and Lubotsky $(2013,185)$ have recently suggested the possibility of tracing it back to PIE * ki- 'this', a demonstrative found in Hitt. kāš, kī, CLuw. $z \bar{a} s, z \bar{a}$ (HLuw. za(-a)-sa, za(-a)), OCS s, Lith.

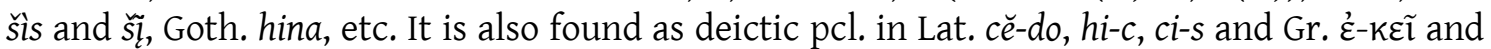

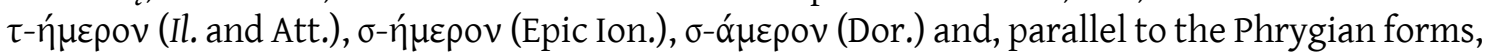

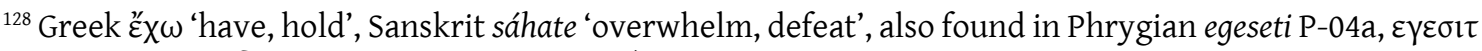
$56.2=58$ and $\varepsilon \gamma \varepsilon \delta$ ou $53.1=76,59.4=106$, etc.).

${ }^{129} \mathrm{M}-02$ contains the same titulature: bba memevais proitavos $k \Phi$ iyanaveyos...
} 


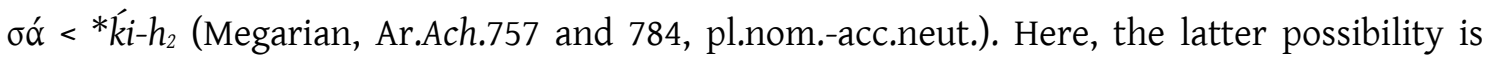
preferred because it avoids the irregularity implied by the preservation of PIE ${ }^{*} s$ - in this position and shows a consistent inflection with $-i$ - in the masc. and neut., inherited from PIE *kí(d). ${ }^{130}$

The OPhr. sg.acc.masc. form sin (B-05) appears in agreement with a masc. noun in its sole occurrence: sin=t imenan (B-05). Morphologically, it can be traced back to PIE *ki-m. On the other hand, in NPhr. the masc.-neut.sg.dat. form is used as sg.acc., since it agrees with a neuter

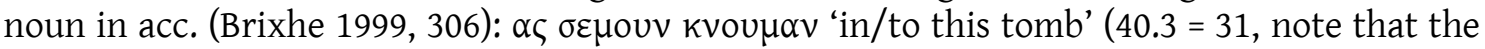
case is governed by the preposition).

The OPhr. sg.nom.-acc. si goes back to PIE * ki and occurs twice in agreement with neuter nouns: si bevdos (B-01) 'this statue' and si keneman (M-01b). Perhaps it is also found in G-11 b (with not clear agreement), however this text remains obscure: sit kraroy veao | dis.

The NPhr. masc.-neut.sg.dat. $\sigma \varepsilon \mu o u v$ is well attested (with many spelling variants $\sigma \varepsilon \mu o v, \sigma \varepsilon \mu \nu v, \sigma \varepsilon \mu \nu v, \sigma \varepsilon \mu \circ v$,), although its origins are not at all clear. It is commonly found in

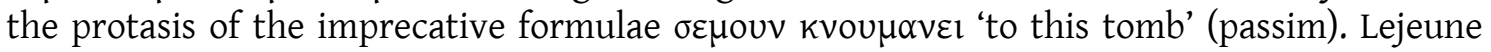
(1969b, 296) considered an element suffix -sm-added to the pron. (he reconstructed *se-sm-), while Ligorio and Lubotsky $(2013,190)$ preferred a sg.dat. form *-smōi followed by an unclear $-n$ (compared with Greek ny ephelkystikon). Although the spelling is aberrant in this part of the inscription, the OPhr. form <s>imun (B-05) was identified by Hämmig $(2013,149)$ as the precedent of the NPhr. $\sigma \varepsilon \mu o u v$ and it clearly agrees with a neuter noun in sg.dat.: †iv $\dagger<s>i m u n$ inmeney asenan daket... (instead of the expected yos *simun...). In any case, if indeed $\sigma \varepsilon \mu o u v$ and $<s>i m u n$ go back to ${ }^{*}$-smōi the change ${ }^{*}$-ōi > / $\mathrm{u}$ / must have occurred in OPhr. times, although no clear examples have been found at this stage. It is easier to consider it as coming from ${ }^{*}-s m \bar{o}-$ followed by a postposition *- $n$, as happens in Sabellic languages (see Untermann 2000, 223-225). In this case, we are dealing with a frozen abl. In addition, $<s>i m u n$ shows that the NPhr. vowel in $\sigma \varepsilon$ - very likely goes back to an original ${ }^{*} s i-{ }^{131}$

The fem. forms have more occurrences, although they are never found in OPhr. The pron. in this gender is inflected following the a-stem nouns. However, the sole occurrence of

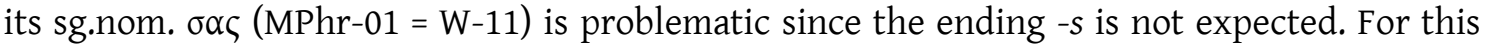

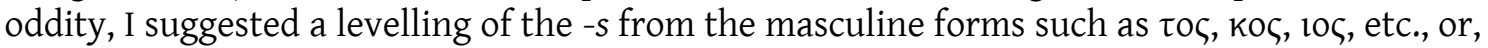
in the light of the sequence where it is read ( $\mu \alpha v \kappa \alpha \mu \varepsilon \kappa \alpha \varsigma \sigma \alpha \varsigma)$ 'this big stele', a mere dittography (Obrador-Cursach 2016, 183-184).

The expected sg.acc. form is $\sigma \alpha v$, however its sole occurrence is used as sg.dat. in

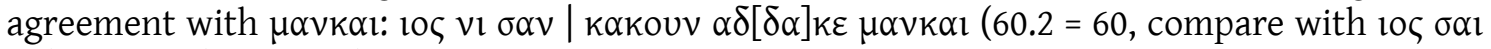
$\kappa \alpha|\kappa o v \alpha \delta \delta \alpha| \kappa \varepsilon \tau \mu \alpha \nu \kappa \mid \alpha 143.1=69)$. This usage is explained as a misspelling because both the final $-n$ and $-i$ (after long vowel) dropped in NPhr. times and, as a consequence, the spelling of both cases was confused. There is a possible occurrence of the fem.sg.acc.: $\varepsilon-\sigma^{?} \alpha v(40.3=31)$. Its identification was a suggestion by Neumann $(1986,81 \mathrm{a}$, instead of $\varepsilon 1 \alpha v$ read in Calder's copy of this text) also considered by Ligorio and Lubotsky $(2013,190)$ and makes the sequence

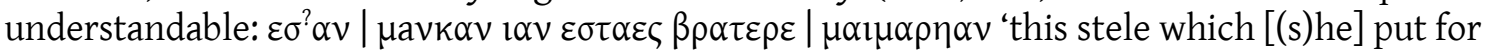
the brother as monument'.

\footnotetext{
${ }^{130}$ On the inflection of these pronouns in the Anatolian branch and their repercussion on the reconstruction of their PIE ancestors see Kloekhorst 2012, whom I follow here. Kloekhorst also analyses the forms with * ${ }^{\prime} o^{-}$, which seems to have coexisted with * $k^{\prime}$ - already in PIE, and suggests a substantival value for PIE * $k^{\prime} i$ - and adjectival value for * ${ }^{k o ́}-$, a parallel differentiation sometimes suggested for ${ }^{*} k^{u} i$ - and ${ }^{*} k^{u}$ o- (e.g. Beekes 1995, 203 and Meier-Brügger 2002, 231).

${ }^{131}$ The form oupouv $(35.1=25)$ cannot be used as valid evidence here because the text has non-

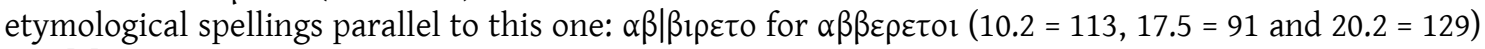
and $[\zeta] \mu \varepsilon \varepsilon \bar{\lambda} \omega \varsigma$ for $\zeta \varepsilon \mu \varepsilon \lambda \omega \varsigma(3.1=97,14.1=73$, etc.).
} 
The two clear occurrences of the sg.gen.fem. form $\sigma \alpha \varsigma$ (< PIE -eh $2 e s)$ are used as sg.dat.:

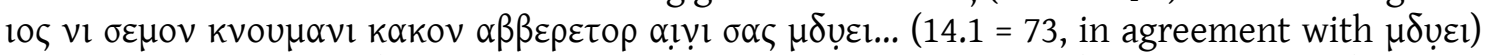

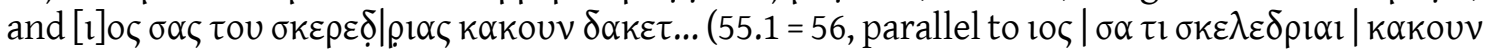
$\delta \alpha k \varepsilon \tau 44.3=67)$. There is a possible occurrence of $\sigma \alpha \varsigma$ in agreement with a sg.gen. noun,

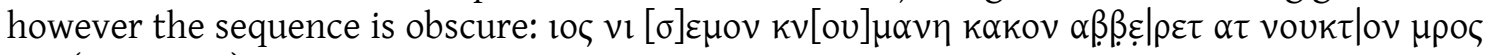

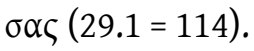

The sg.dat.fem. occurs in $e$-sai (W-01b) and $\sigma \alpha \mathrm{l}\left(43.1=69\right.$ and $62.4=35<$ PIE ${ }^{*}$-eh $h_{2} e$ ) $)$ : esai $=t$

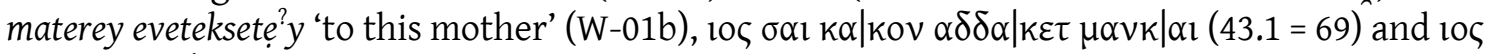
$v l \sigma \alpha l k \alpha k o \mid v v \alpha \delta \delta \alpha \kappa \varepsilon \mu \mu \alpha v \kappa \alpha l(62.4=35)$ 'who does harm to this stele'. In NPhr. it is more commonly found as $\sigma \alpha(17.5=91,21.1=42$, etc. $), \sigma \alpha v(60.2=60)$ or $\sigma \alpha \varsigma(14.1=73$ and $55.1=56)$, because of the drop of the final $-i$ and the confusion with other cases: e.g. $10 \varsigma v 1 \sigma \alpha$ tov $\mu \alpha v k \alpha$ k $\alpha$ Kouv $\alpha \delta \mid \delta \alpha \kappa \varepsilon \tau$ 'whoever does harm to this stele' $(64.1=81)$.

There are two unclear forms, sest $(\mathrm{P}-02)$ and $\sigma \omega \varsigma(2.2=130)$. As has been seen before, the interpretation of sest bugnos (P-02) as a sequence in pl.nom. or pl.acc. contradicts the other occurrences of the o-stem pl.nom. ending. A possible alternative is to consider the pron. ses as sg.nom. with hesitation between e and $i$ (see sg.dat. <s>imun / $\sigma \varepsilon \mu o u v$ ) and the pcl. =t attached. In that case, ses=t bugnos valsos kanutii? evanos?' could mean 'this (is) Bugnos, the son of Vasos the grandson of Kanutî̀. The NPhr. form $\sigma \omega \varsigma(2.2=130)$ was suggested to be a pl.dat. by Avram

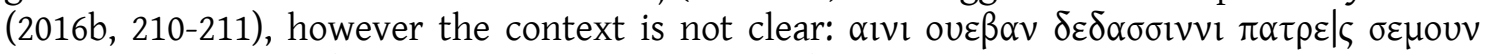

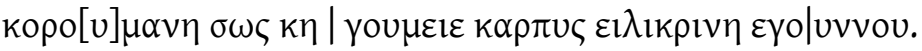

Two forms are compounds bearing the demonstrative element ${ }^{*} h_{1} e / 0_{-}>e-:$ esai $(\mathrm{W}-01 \mathrm{~b})$ and perhaps $\varepsilon \sigma^{2} \alpha v(40.3=31)$. Also, the clitic form $t$ is attached to some forms of this pronoun: esai=t (W-01b) and sin=t (B-05). ${ }^{132}$ This reinforces the demonstrative, according to Brixhe (1978b, 21).

Finally, there is a clitic pcl. derived from this pronoun: $s=$. Parallel to $t=$ (from the

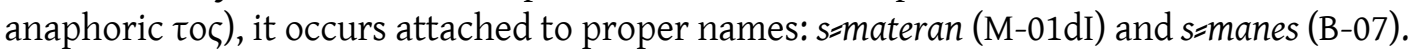

\subsection{Anaphoric pronouns}

4.2.1.2.2.1. The anaphoric pronoun $\tau$ \%

Table 25 The inflection of the anaphoric pronun $\tau$,

\begin{tabular}{|c|c|c|c|c|c|c|}
\hline & \multicolumn{3}{|c|}{ Singular } & \multicolumn{3}{|c|}{ Plural } \\
\hline & Masculine & Neuter & Feminine & Masculine & Neuter & Feminine \\
\hline Nom. & $\tau \circ \zeta$ & \multirow[b]{2}{*}{ - } & - & - & \multirow{2}{*}[t]{$a ?$} & - \\
\hline Acc. & - & & $\tan , \tau \alpha \nu$ & - & & - \\
\hline Gen. & \multicolumn{2}{|c|}{ tovo } & - & \multicolumn{2}{|c|}{-} & - \\
\hline Dat. & \multicolumn{2}{|c|}{ tov } & $\tau \alpha 1, \tau \alpha$ & \multirow{2}{*}{\multicolumn{2}{|c|}{$\tau$}} & - \\
\hline Particle & \multicolumn{4}{|c|}{$t, t i, \tau \mathrm{\tau l}, \tau \mathrm{\tau} \mathrm{U}, \tau \mathrm{\tau}$} & & \\
\hline
\end{tabular}

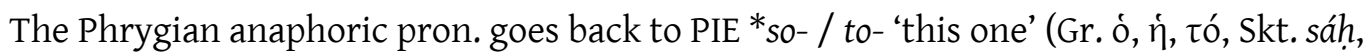
$s \vec{a}$, tát, Go. sa, sō, pata, etc.) and shows the generalisation of the forms with $t$ - to the whole paradigm in the light of the sg.nom.masc. $\tau$. $(17.2=3,18.3=6$, etc.). This form is always used

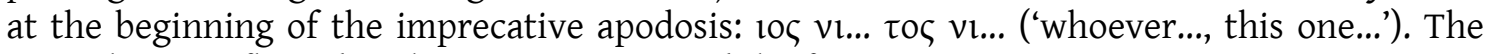
masculine is inflected as the o-stem nouns and the fem. as $a$-stem nouns.

According to Ligorio and Lubotsky $(2013,190)$, the sg.gen. form tovo (G-02 c) goes back to PIE * toso > to.o (see o-stem sg.gen.), with antihiatic $-v$-. The neut.pl.acc. ta is not clear, since

\footnotetext{
${ }^{132}$ Unclear remains sit, perhaps silt (G-11 b).
} 
its only occurs in an obscure text and its $t$ - is a restitution by Lubotsky (1993b, 94): B-01 yos tivo [t] a speretạ ayni kin te[l]ẹmi...

The fem. sg.acc. $\tan (\mathrm{W}-01 \mathrm{c}) / \tau \alpha \nu(2.1=15,11.2=18$, etc. $)$ show the expected ending PIE $*_{-}$eh ${ }_{2} m>-a m$. As happens in NPhr. a-stem inflection, the sg.dat. (< PIE $\left.*_{-}-h_{2} e i\right)$ appears with and without the original final $-i: \tau \alpha \mathrm{l}(11.2=18$ and $16.1=116), \tau \alpha(4.1=2$ and $11.2=18)$.

The remaining forms are variants of a clitic pcl. The basic form $t$ is attached to the demonstrative pron. in esai $=t(\mathrm{~W}-01 \mathrm{~b})$ and sin=t (B-05). The forms with vowel seem to be frozen cases. Indeed, $t i(\mathrm{~B}-05) / \tau l(30.1=39,35.1=25$, etc.) looks like the sg.nom.-acc.neuter (see si), while $\tau$ ou $(9.1=87,25.1=115$, etc. ; with the spelling variant $\tau 0,15.1=120,17.6=119$ and $37.2=$ 27) the sg.dat.masc.-neut. (<*-öi, sg.gen.). Both variants of this pcl. commonly appear between

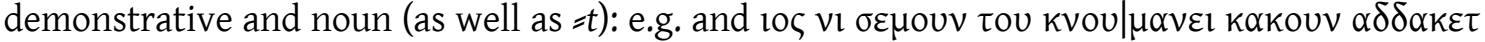

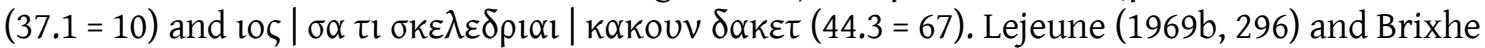

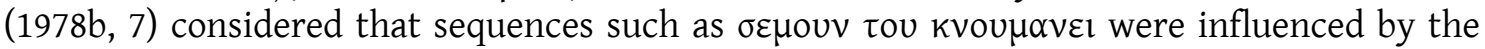

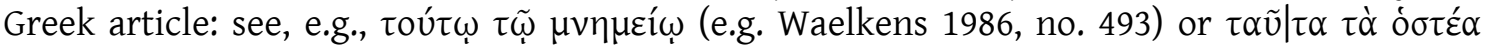
(Mendel 1909, no. 102 = SEG 6.343 and 30.1494). Its true that $\tau$ ov in 37.1 (10) could be considered

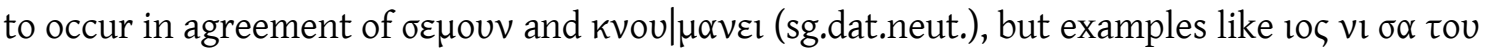

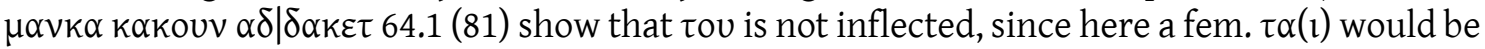

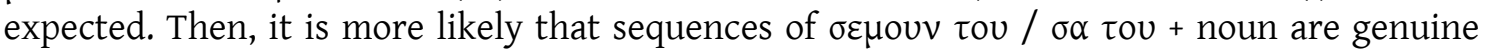
Phrygian structures in the light of OPhr. esai=t materey (W-01b) and sin=t imenan (B-05).

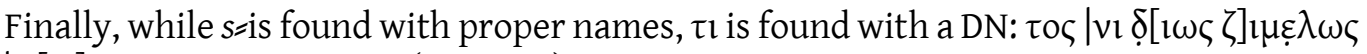

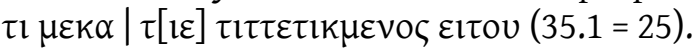

\subsection{The anaphoric pronoun io- / o-}

This anaphoric pronoun (mostly read in imprecative apodoses) appears in two variants: or $(1.1=48,7.1=99,17.3=7,18.1=4,40.1=12,50.2=55,53.1=76,62.2=33$ and $62.4=35)$ and 101

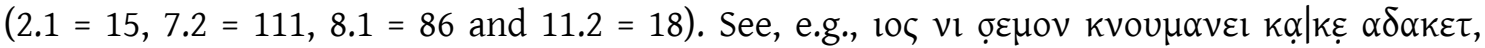

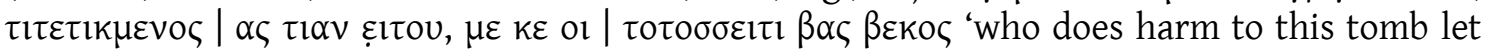
become accursed by Zeus and let Bas not give bread to him' $(7.1=99)$ and $10 \varsigma \alpha \delta \alpha \kappa \varepsilon \tau, \beta \alpha \varsigma$ 101 $\beta \varepsilon \kappa o \varsigma ~ \mu \varepsilon \beta \varepsilon \rho \varepsilon \tau$ [---] 'who does [harm to this monument], let Bas not produce bread to him' (7.2

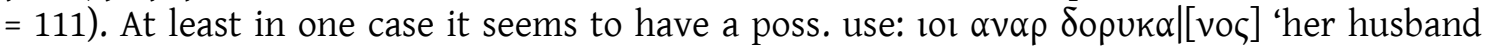
Doryka[nos]' $(2.1=15)$.

The existence of these variants has been explained in two different ways. Brixhe (Brixhe 1997, 66) and Hämmig (fthc. a and b) considered that 101 was the stressed variant of this pronoun, while or the clitic one. This interpretation compares them to Greek $\dot{\varepsilon}$ oi (Homer) / oi and considers that their origin is the PIE form *seu-oi. On the other hand, Lubotsky $(1997,126$ and Ligorio \& Lubotsky 2013, 190) showed that 101 ol are contextual variants: 101 appears after a consonant and or after a vowel. According to him, the original form was 101 which may go back to the PIE pron. ${ }^{*} h_{1} e(i)-/{ }^{*} h_{1} i-$, also attested in Lat. is, ea, id. It seems to appear in OPhr. text, always as oy (B-01 1. 6, B-05 1. 9, l. 11 and l. 12), however its contexts remain obscure: B-01 ... [..] toyo[.]is [.] erktẹvoys ekey da [b]ati | opito [k]ey oy evẹmẹmesmeneya anato (.')... B-05 1. 9 yos niy art sin=t imenan kaka oskavos kakey | kạn dedasitiy tubetiv oy kevos deraliv mekạs key | koyis abretoy..., B-05 1. 11-12 tiv imun inmeney asenan daket torvetun $\uparrow$ iray ayniy oy $\mid$ tubnuv nevos, me deritoy kovis ke abretoy nun oy nev<otan>... 
4.2.1.2.3. The emphatic adjective and anaphorical pronoun $\alpha u \tau o \varsigma$ and its derived reflexives

Table 26 Inflection of $\alpha v \tau$ c and venavtun

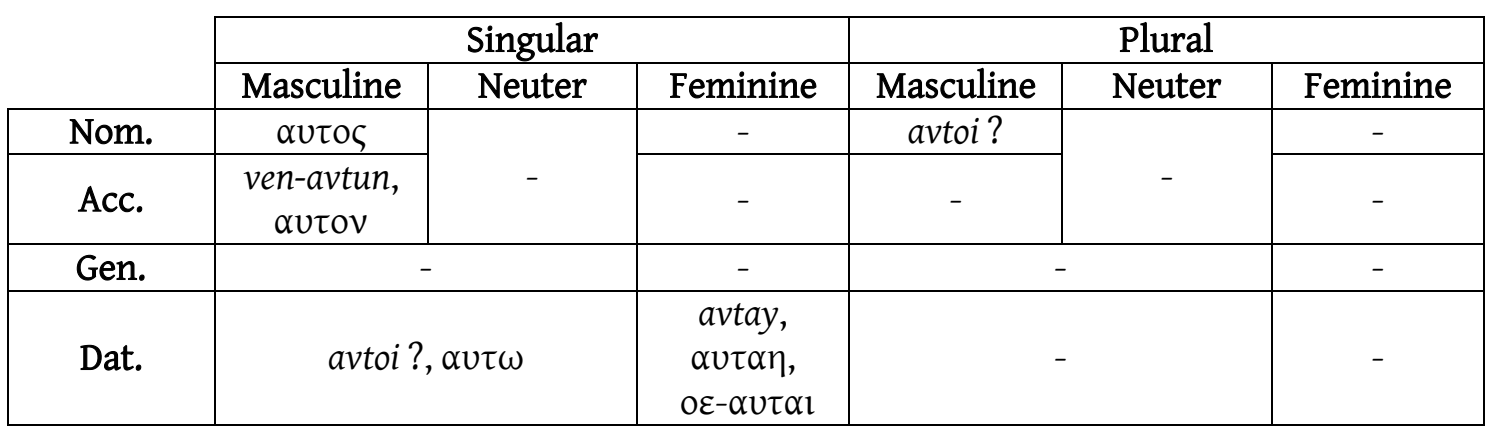

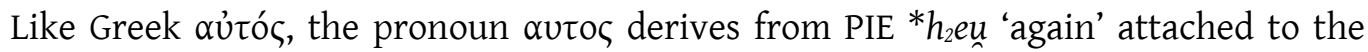
anaphoric pron. *to- 'that' (see EDG 173 on the Greek form). Since this pron. is found in the first Phrygian texts (T-03b) and has a regular phonetic development, there is no reason to consider it a Greek borrowing. The masculine form inflects like the o-stems, while the fem. like the $a$ stems.

The sg.nom.masc. $(58.1=72,62.2=33$ and $62.5=35)$, which goes back to PIE * $h_{2}$ eu -tó-s,

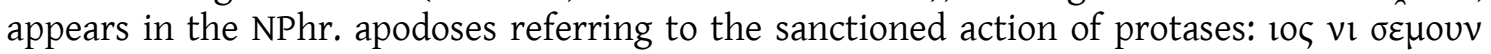

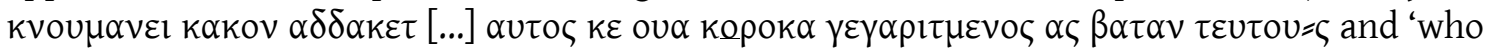

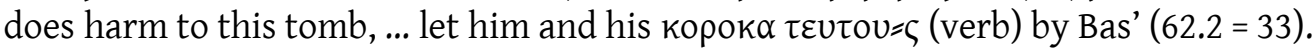

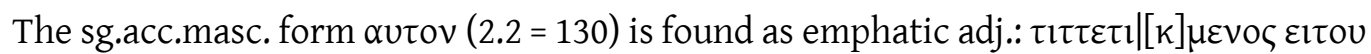
$\varepsilon 1 \kappa \alpha \delta \alpha \nu \tau o v \mu \varepsilon \kappa \mid \alpha \nu \tau \imath \alpha v$ 'let him become accursed by the same great Zeus'.

The NPhr. sg.dat.masc. $\alpha \cup \tau \omega\left(<{ }^{*}-\overline{0} i\right)$ is found in a damaged context: [............] ove $\beta \alpha v$

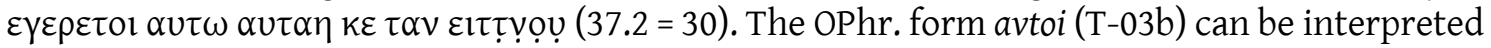
as sg.dat., however a pl.nom.masc. $\left(<*_{-o i}\right)$ cannot be ruled out since the context is not clear: [---]ọi $\vdots$ avtoi $\vdots$ eptuve[---]|[---]itan mẹ|[---]p̣pis $i$ : [---]..

The sg.dat. fem. form is avtay $(\mathrm{W}-01 \mathrm{~b}) / \alpha v \tau \alpha \eta(37.2=30)$, which goes back to $* h_{2} e u-t-e h_{2}-e i$. The OPhr. form is found as an emphatic adjective: yos esai=t materey eveteksete? ${ }^{?} y$ ovevin onoman daY et, lakedo key venavtun avtay materey "who puts his own name in this Matar Eveteksetey, let him be taken by the same Matar' (W-01b). The NPhr. $\alpha u \tau \alpha \eta(37.2=30)$ is found in the same obscure context as $\alpha u \tau \omega$.

The reflexive pron. is derived from $\alpha \cup \tau o \zeta$ and is parallel to Greek $\dot{\varepsilon} \alpha u \tau o \tilde{v}, \tilde{\eta} \varsigma$, ov 'of himself, herself, itself'. Both the Greek and the Phrygian forms are built with the PIE reflexive pron. *sue attested in Lat. se, Greek है (Lesb. FE), Sanskrit sva-, etc. (see EDG 365, it is also found in the poss. pronoun). The sg.acc. masc. venavtun ( $\mathrm{W}-01 \mathrm{~b})$ shows an acc. $-n$ added to * sue $>v e$

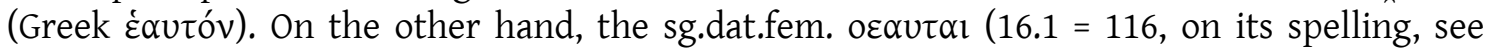
$\S 3.2 .2 .1)$ is a regular form identical to Greek $\dot{\varepsilon} \alpha \nu \tau \tilde{n}$.

\subsection{The relative pronoun yos}

Table 27 The Phrygian relative pronoun

\begin{tabular}{|c|c|c|}
\cline { 2 - 3 } \multicolumn{1}{c|}{} & \multicolumn{2}{c|}{ Singular } \\
\cline { 2 - 3 } \multicolumn{1}{c|}{} & Masculine & Feminine \\
\hline Nom. & $i o s$, yos, $10 \varsigma, \mathrm{l} \varsigma$ & - \\
\hline Acc. & ıov? & $1 \alpha \mathrm{V}$ \\
\hline
\end{tabular}


The Phrygian relative pronoun is found elsewhere in the Phrygian corpus, but few forms are attested, mainly the masc.sg.nom (with many spelling variants) at the beginning of curses. The origin of this pron. must be found in PIE *Hi-o- and it is a cognate of Greek ö and Skt. yás, yâa, yád (*hinió- in LIPP II, 312-315). The masculine forms are inflected following the o-stem nouns. The masc.sg.nom. is /jos/, commonly spelled as ios (G-02b, P-04a, P-04b, P-06), yos (B-01, B-05, B-06, B-07, W-01a, W-01b) and 10 (MPhr-01, passim in NPhr.). Less frequent spelling variants are tiv $\dagger$ (B-05, an engraver's mistake for yos according to Hämmig 2013, 149), Elo $(40.1=12$, influenced by Greek itacism $)$ and $ı$ $(17.1=4 \mathrm{~b}, 12.1=121,15.1=120,16.1=116$, $18.2=5$, explained by the simplification of $-10^{-}>-1-$ in Greek inscriptions from Roman Phrygia). ${ }^{133}$ Similarly to the Lat. indefinite pron. quisquis, quaequae, quidquis “whoever, whatever, everyone who', there is one occurrence of the reduplication of this Phrygian pronoun: yosyos (B-03). The text in which it is read remains too obscure to know whether it is an indefinite pron. like the Lat. parallel. Perhaps $1 \sigma \circ \zeta(34.1=37)$, found in the common position of $10 \varsigma(\mathrm{vl})$ (at the begining of the curses), goes back to this reduplication with a consonant simplification -sy- > $-\sigma-$

The masc.sg.acc. $10 v(56.2=58)$ has one likely attestation: $\mu$ ov $\alpha \nu \mu \rho \circ \tau i \eta ~ 10 v \varepsilon \gamma \varepsilon \sigma ı \mid \tau$ $\gamma \varepsilon|\gamma \rho 1| \mu \varepsilon|v o| v$ 'only for the death whom it has written'. However, my interpretation of this text is not at all conclusive. I prefer it to other possible interpretations because the noun $\mu$ potın can

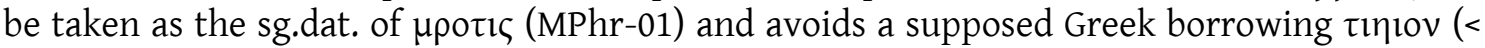

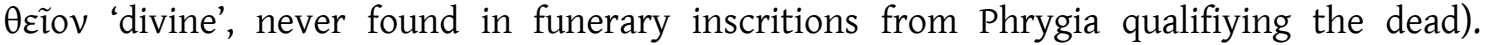
Nevertheless, it is not easy to explain the incongruence in the agreement of the fem.sg. $\mu$ ovav

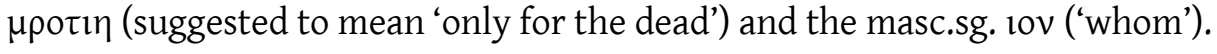

Finally, the fem.sg.acc. form $1 \alpha v$ is only attested once: $\varepsilon \sigma^{?} \alpha v \mid \mu a v \kappa \alpha v 1 \alpha v \varepsilon \sigma \tau \alpha \alpha \varepsilon \varsigma \beta \rho \alpha \tau \varepsilon \rho \varepsilon$ $\mid \mu \alpha \iota \mu \alpha \rho \eta \alpha v$ 'this stele which [(s)he] put for the brother as memorial' (40.3 =31).

4.2.1.2.5. Indefinite pronouns

4.2.1.2.5.1. The indefinite pronoun kos, kin

Table 28 The Phrygian indefinite pronoun kos, kin

\begin{tabular}{|c|c|c|}
\cline { 2 - 3 } \multicolumn{1}{c|}{} & \multicolumn{2}{c|}{ Singular } \\
\cline { 2 - 3 } \multicolumn{1}{c|}{} & Masculine & Neuter \\
\hline Nom. & kos, KO & \multirow{2}{*}{ kin, kıv } \\
\hline Acc. & - & \\
\hline
\end{tabular}

Phrygian inherited from PIE ${ }^{*} k^{u} 0-{ }^{*} *^{u} i$ - the indefinite pronoun $k o s, k i n$, found in other languages as Greek $\tau ı \varsigma, \tau \imath$, Lat. quis, quid, and Hitt. kuiš, kuit. The masc.sg.nom. kos (B-07), koৎ $(2.2=130,11.2=18,56.3=64$ and $58.1=72)$ shows an o-stem inflection, while the neuter nom.acc. has a common form in - $i$ - with the ending * ${ }_{-} m$, instead of ${ }^{*} d$ (Lat. quid) or $-\varnothing$ (as the demonstrative si). Then, $k i n / k I v$ is a parallel form to Sanskrit kim < PIE * $k^{u} i-m$ (see Ligorio and Lubotsky $(2013,183)$.

Following a first proposal by Hämmig (2013, $143 \mathrm{fn}$. 36), the OPhr. form kos B-07 is found with the prohibitive pcl. me (< PIE * meh ${ }_{1}$ ) and the resultant form mekos may mean 'nobody, no

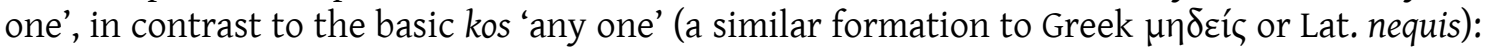
mekos anivayeti s=manin 'let nobody harm Manes' (B-07). In NPhr., ko also, appears in the

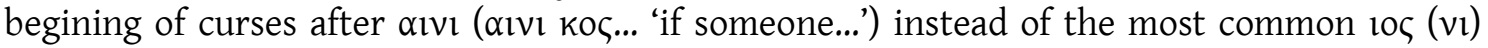

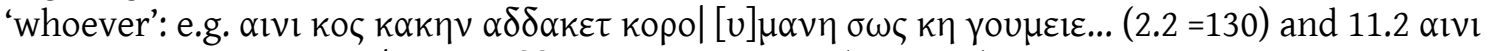

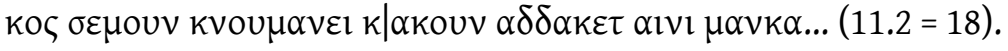

${ }^{133}$ On this phenomenon, see Brixhe 1987a, 50-51. 


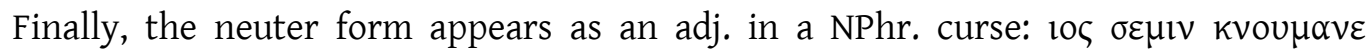

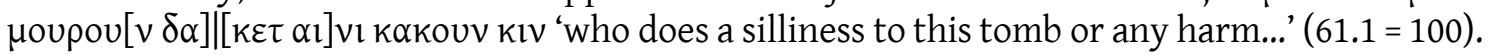
The OPhr. occurrence is in an obscure context: yos tivo [t] a spereta ayni kin te[l]emi... (B-01).

\subsection{The indefinite pronoun $\tau \iota \varsigma, \tau l$, a Greek borrowing}

Table 29 Comparison of Phrygian and Greek $\tau \iota \varsigma, \tau l$

\begin{tabular}{|c|c|c|c|c|}
\hline & \multicolumn{2}{|c|}{ Phrygian } & \multicolumn{2}{|c|}{ Greek } \\
\hline & Masculine & Neuter & Masc.-Fem. & Neuter \\
\hline Nom. & $\tau l \varsigma$ & \multirow{2}{*}{$\tau l$} & $\tau 1 \zeta$ & \multirow{2}{*}{$\tau 1$} \\
\hline Acc. & - & & 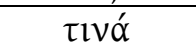 & \\
\hline
\end{tabular}

In its sole occurrence, $\tau 1(30.1=39)$, the sg.acc.neut. in agreement with kakouv, it appears as an indefinite adj. instead of kin / kıv: compare lo $v i \sigma[\varepsilon \mu] \circ v \tau[o v] \kappa v o v \mid \mu \alpha v[\varepsilon]$

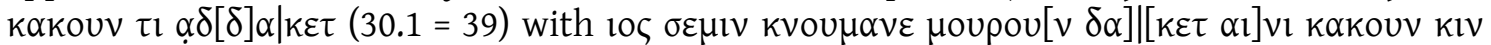

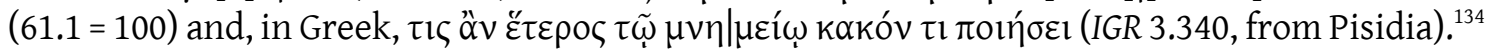

The sg.nom.masc. form $\tau 1 \varsigma(28.1=71)$ occurs once, introducing the protasis of a curse,

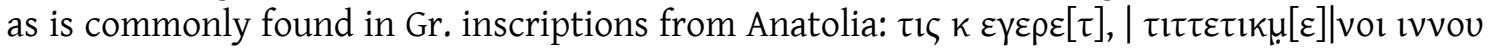
'and whoever $\varepsilon \gamma \varepsilon \rho \varepsilon[\tau]$, let them become accursed' ${ }^{135}$. In Greek curses from Anatolia $\tau 1 \zeta$ often occurs as a relative pronoun instead of the classical relatives (Brixhe 1987a, 84). ${ }^{136}$ Compare, e.g., two inscriptions from Appia containing the north Phrygian curse formula 'whoever lays a

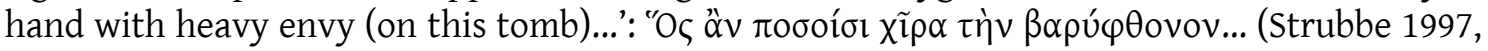

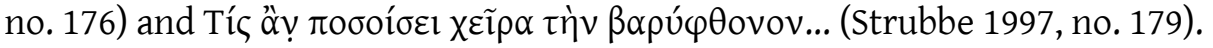

Since in both occurences this pron. appears in the same position as its Gr. Counterparts, and phonetically PIE * $k^{u} i$ - became $k i$ - in Phr., the forms $\tau \imath \varsigma$, $\tau l$ must be considered a Gr. borrowing.

\subsection{The possessive pronoun}

Table 30 Inflection of the Phrygian possessive pronoun

\begin{tabular}{|c|c|c|c|}
\hline & \multicolumn{3}{|c|}{ Singular } \\
\hline & Masculine & Neuter & Feminine \\
\hline Nom. & - & \multirow{2}{*}{ ove-vin } & $v a, o v \alpha$ \\
\hline Acc. & - & & $o v \alpha v, o \alpha v$ \\
\hline Gen. & \multicolumn{2}{|c|}{-} & - \\
\hline Dat. & \multicolumn{2}{|c|}{-} & vay \\
\hline
\end{tabular}

PIE * su-e/o- yields the Phrygian possessive pronoun (parallel to Greek ö, , its'), which only occurs in singular. The fem. forms follow the $a$-stem inflection: sg.nom.fem. ${ }^{*}$ su-eh $_{2}>v a(\mathrm{~B}-07) /$ ov $\alpha(4.1=2,62.2=33$ and $62.5=36)$, sg.acc.fem. ovov $(60.1=59$, spelling variant oov 16.1 = 116), * sun-eh $_{2} e_{\Lambda}$ > vay (B-05). E.g. va knais manuka 'his wife Manukka' (B-07). The

\footnotetext{
${ }^{134}$ An equivalent structure is found in Synnada, a Phrygian city where NPhr. occur: ôs ầ $\mid \delta \dot{\varepsilon} \alpha u ̉ \tau \tilde{\omega}$

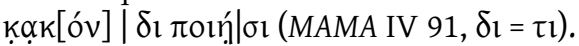

${ }^{135}$ The restitution of the verb in singular is suggested because of the agreement with $\tau 1 \zeta$, despite the fact that the apodosis has a verb in plural.

${ }^{136}$ The first occurrence of Gr. $\tau 1 \zeta$ as a relative is commonly said to be S.OC 48, although this phenomenon is found elsewhere in postclassical Greek. See more classical occurrences in Probert 2015, $49 \mathrm{fn}$. 65. See Muraoka 2015, 92-93 for this use in the Septuagint. On this use in other IE languages, see Luján 2009.
} 
neuter form is only found in the compound ove-vin (W-01b). Although ove- is unclear, Lubotsky $(1988,20$, also in Ligorio \& Lubotsky 2013,193$)$ suggested very convincingly that -vin is the poss. in sg.acc.: ovevin onoman 'his own name' (W-01b). Consequently, -vin is easily explained as inherited from PIE ${ }^{*}$ su- with the same neuter ending found, e.g., in the indefinite pron. kin, kIv.

\subsubsection{Verbal morphology}

Due to the nature of the Phrygian texts, which are mainly monumental inscriptions and short graffiti, most of the Phrygian forms are inflected in 3sg. and 3pl. It seems likely that other persons are attested in Phrygian, however such forms remain obscure. Even the analysis of the clearer verbs is difficult, and many conflictive details have yet to be explained. Therefore, our knowledge of the Phrygian verb is precarious and fragmentary. A very illustrative problem is the strange use of the primary and secondary set of endings. Despite the difficulties, as far as we know the Phrygian verb had at least three tenses (present, aor. and perfect), two voices (active and middle-passive) and four moods (indicative, subjunctive, opt. and ipv.). ${ }^{137}$

\subsubsection{Present}

\subsection{Indicative}

Verbal forms in present indicative are not common and most are obscure, as are the contexs in which they appear. However, they are recognisable because they have the expected primary ending. OPhr. deVeti (NW-101) is claimed to be the 3sg.act.ind.act. inherited from PIE ${ }^{*} d^{h} e h_{1}-k$ - If this is the case, it shows a $\varnothing$-grade in the root $\left(* d^{h} h_{1}-k-e-t i\right)$, while $e$-grade is expected here. Note that OPhr. andati (B-05), also claimed to go back to *dh ${ }^{2} h_{1}-t i$ (without ${ }^{*}-k-$ ), shows this vocalisation (if this etymology is accepted). The form $[\alpha] \beta \varepsilon \rho \varepsilon \tau$ ı 'brings' $(66.1=103)$ seems a clear 3sg.ind.pres.act. It may go back to PIE ${ }^{*} b^{h} e r-e-t i$, although it occurs in an imprecative protasis ${ }^{138}$ where $\alpha \delta \delta \alpha \kappa \varepsilon \tau$ or $\alpha \beta \beta \varepsilon \rho \varepsilon \tau$ is expected. Other claimed 3sg.act. forms are dabati (B-01 and B-08), $\delta \alpha \delta ı \imath ~(22.1=9$, verb?), poreti $(\mathrm{T}-03 \mathrm{aI})$, pı $\delta \imath \imath \mathrm{l}(16.1=116)$ and. OPhr. tubetiv $(\mathrm{B}-05)$ should be added to this list, despite the spelling of the ending (see Hämmig 2013, 143, who suggested a subjuntive form).

Neumann $(1997,22)$ and Brixhe $(2004,59)$ suggested that atikraiu (Brixhe) / atikvaiu (Neumann) is a verb in 1sg.ind.pres.act. ('I say'), where PIE $*_{-} \bar{o}$ raised to - $\bar{u}$. However, theetymology of this word is unknown. On the other hand, verbs in the 1sg.ind.pres.pass. are claimed to be attested in dakor (K-01, Brixhe 2004, 52, who found it to be inherited from ${ }^{*} d^{h} e h_{1}-k$-) and akor (G-105). ${ }^{139}$ Nevertheless, the context of dakor is extremely fragmentary and $\mathrm{G}-105$ is too short to corroborate it.

\footnotetext{
${ }^{137}$ A similar verbal system was considered by Haas 1966, 226-228. The most comprehensive study on this aspect of the Phrygian language is that of Sowa 2007a $(=2008,87-117)$. His analysis provides a useful compilation of the Phr. verbs and illustrates the main problems with the current analysis of the Phr. verbal system. More recently, Ligorio and Lubotsky 2013, 191-192 have offered an updated overview of the most important forms.

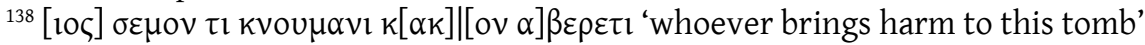

${ }^{139}$ Wrongly segmented as si i ido sakor before the graffiti on a beam of MM-Tumulus (G-346) were found and $s i \uparrow i d o s$ was read among other PNs.
} 
4.2.2.1.2. Subjuntive

4.2.2.1.1.1. $(\alpha \delta) \delta \alpha \kappa \varepsilon \tau$ and $(\alpha \beta) \beta \varepsilon \rho \varepsilon \tau$, subjunctives?

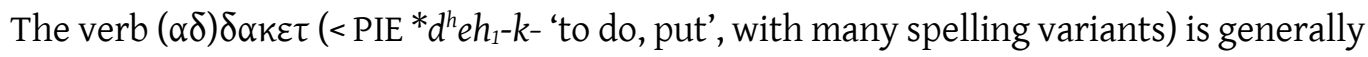

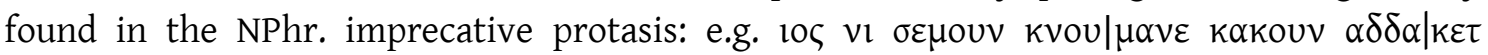
'whoever does harm to this tomb' $(20.2=128)$. It also appears two OPhr. protases: yos esai=t materey eveteksete? $y$ ovevin onoman daY et 'who puts his own name to this Mother E.' (W-01b) and tiv $\dagger<\mathrm{s}>$ imun inmeney asenan daket 'whoever puts/does asenan in/to this monument' (B-05). In some inscriptions $(18.3=6,29.1=114,39.1=11$ ? and $40.2=12)$ it is replaced by the verb $\alpha \beta \beta \varepsilon \rho \varepsilon \tau$

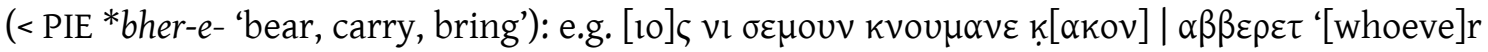
brings harm to this tomb' $(18.3=6)$. Even the passive forms of both verbs are used in the same position with the same meaning: $\alpha \delta \delta \alpha \kappa \varepsilon \tau o \rho(24.1=40$ and $12.1=121$, spelling variants in $20.1=$ 63 and $58.1=72)$ and $\alpha \beta \beta \varepsilon \rho \varepsilon \tau o l ~(10.2=113,17.5=91$ and $19.2=129) \sim \alpha \beta \beta \varepsilon \rho \varepsilon \tau o \rho(14.1=73,52.1$

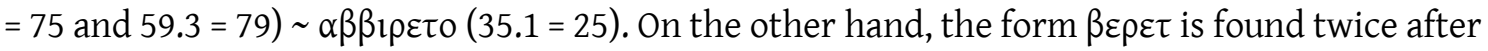
the prohibitive pcl. $\mu \varepsilon(7.2=111$ and $8.1=86): \beta \alpha \varsigma$ 101 $\beta \varepsilon \kappa o \varsigma ~ \mu \varepsilon \beta \varepsilon \rho \varepsilon \tau(7.2=111)$ and $\beta \alpha[\varsigma] \mid 101$ $\beta \varepsilon \kappa \circ \varsigma \mu \varepsilon \beta \varepsilon \rho \varepsilon[\tau](8.1=86)$. Also, the OPhr. abretoy (B-05), which looks like a syncopated form of NPhr. $\alpha \beta \beta \varepsilon \rho \varepsilon \tau o l$, it is found in an imprecative apodosis introduced by the prohibitive pcl.: $m e$ deritoy kovis ke abretoy nun oy nev<otan>. The verb deritoy is obscure (Hämmig 2013, 143), however it can be considered a passive form of an unknown verb in the light of abretoy. Finally, the obscure NPhr. verb $\beta \rho \varepsilon I \tau(29.1=114)$ can be added to the list of this kind of verbal form, since it has the secondary ending - $t$ and occurs in an imprecative protasis: $10 \varsigma \kappa \varepsilon \beta \rho \varepsilon \imath \tau \pi \varepsilon \rho \beta \varepsilon \delta \alpha \nu$ ' and whoever $\beta p \varepsilon i \tau$ the sepulture'.

Although a conclusive explanation is lacking (Ligorio \& Lubotsk 2013, 191), these verbs are considered subjunctive in some papers (see Brixhe 1979a and 2004, 52). ${ }^{140}$ While this hypothesis may be defensible in the light of their contexts, the lack of $-\bar{e}->-a$ - in the suffix of the thematic verb ( $\alpha \beta) \beta \varepsilon \rho \varepsilon \tau$ ( ${ }^{* *}$ berat is never found) shows that they are not subjuntive forms or that they are an inner Phrygian formation. By contrast, $(\alpha \delta) \delta \alpha \kappa \varepsilon \tau$ and $(\alpha \beta) \beta \varepsilon \rho \varepsilon \tau$ are considered injunctive forms by Haas $(1966,227)$ and Orel $(1997 a, 399-400$, who preferred the term "imperfect", see also Sowa 2007a, 82-84) because of the lack of augment, the present stem and the use of the secondary ending - $t$. However, a past form is not expected in the position where $(\alpha \delta) \delta \alpha \kappa \varepsilon \tau$ and $(\alpha \beta) \beta \varepsilon \rho \varepsilon \tau$ occur. In any case, each possibility requires better explanation.

Another unsolved problem is the co-occurrence of the middle endings - $\tau$ o $\rho$ with -toy / - $\tau$ ol (Ligorio \& Lubotsky 2013, 191). It is very likely that -toy is the oldest ending, since - $\tau$ o $\rho$ is not found in OPhr. Perhaps the form with $-r$ spread from the 1sg.mid. ending, but it remains unclear.

\subsection{Reduplied subjunctives with -se- $\sim$-si-}

During the last Phrygian Conference, Hämmig (fthc. $a$ and $b$ ) identified some verbal forms as containing a suffix -se $(t)->-s i(t)$ - and considered them a "sort of 'subjunctive' (called "Subjunctive II" in comparison with the other subjunctive $\alpha \delta \delta \alpha \kappa \varepsilon \tau$ and $\alpha \beta \beta \varepsilon \rho \varepsilon \tau)$ " with primary (IIa) or secondary endings (IIb): eveteksetiy (W-01b, sic), egeseti (P-04a), dedasitiy (B-05), anivay eti

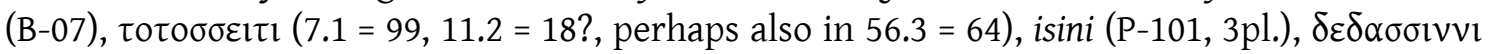

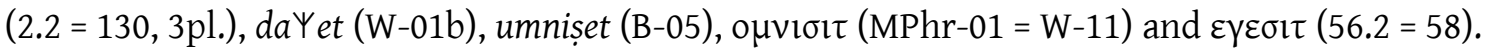
As can been seen, she considered that the letter $\langle y\rangle$ in anivayeti (B-07) and daYet (W-01b) represents a sibilant sound (follow Lejeune's analysis), and these verbs also have the suffix $s e(t)->-s i(t)$-. However, since I ruled out this interpretation for $\langle\Psi\rangle$, these forms can be omitted

${ }^{140} \mathrm{LIV}^{2} 76$ considered it a present without further information. 
from this list: da Yet (W-01b) is a graphic variant of daket $(\mathrm{B}-05=\mathrm{NPhr} .(\alpha \delta) \delta \alpha \kappa \varepsilon \tau)$ and $y$ in aniva yeti may also represent $/ \mathrm{k} /$ (the last root consonant of this verb). Another form I omit is eveteksetiy (W-01b), read as eveteksetey and considered an epithet of Matar (not a verb) by most scholars (also in this dissertation). On the other hand, kesiti (B-01) and ot.[....] seti could be added to this list, although they are even more obscure words.

Leaving aside the omitted and unclear forms, the remaining verbs have the spelling

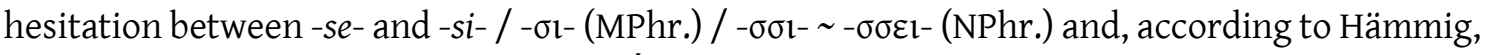
all these forms contain the PIE sufix *-ské/ó-. Consequently, the spelling with -se- (also spelled as - $Y e-$, according to Hämmig) represents an older stage, since forms with -si-show a raising of the vowel /e/. From a phonetic point of view, the assibilation of ${ }^{*}$-ski- is defensible in the light of * $k i->s i, \sin$ (the demonstrative pronoun). However, it is not expected before ${ }^{*} e$ and the suffix *-ski- seems to have been preserved in podaskai? (G-02, see Kloekhorst 2015, 117). Therefore, the origin of this suffix remains unclear and the comparison with the sigmatic fut. tense given by prior papers cannot be ruled out. ${ }^{141}$ What seems clear from Hämmig's assumption is the subjective nature of these forms, since they are mainly used where this mood is expected:

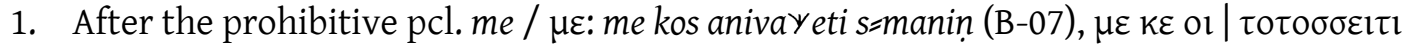

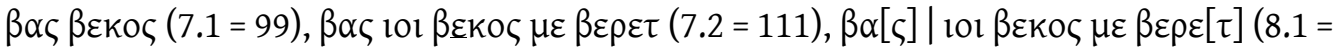

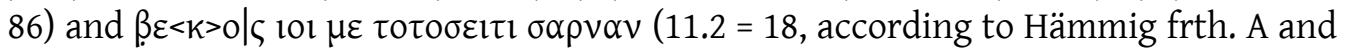
b).

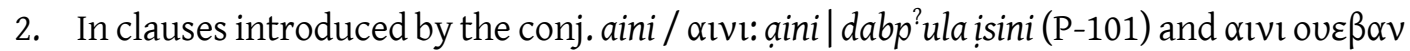

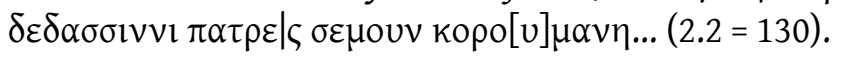

3. In imprecative protases where forms such as daket are commonly used: ios ni akenan egeseti (P-04) and yos niy ạrt sin=t imenạn kạkạ oskạvos kạkey | kạn dedạsitiy (B-05).

As happens elsewhere in Phrygian, the distribution of the primary and secondary sets of endings remains unclear. Some forms with primary ending show a reduplication but it is not known whether these forms have reduplicated the first consonant in $e$-grade or the whole root. Indeed, dedasitiy (B-05) and $\delta \varepsilon \delta \alpha \sigma \sigma \mathrm{lvvl}(2.2=130)$, which must go back to *deh ${ }_{1}^{-}$'to put, tu do'

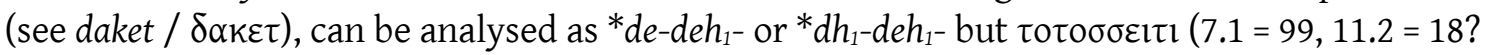
and perhaps $56.3=64$ ), which derives from PIE * deh $3^{-}$'to give' (see Hämmig fthc. a and b), disproves the first possibility and shows a full reduplication $* d h_{3}-d e h_{3^{-}}$. Nevertheless, one cannot rule out a possible secondary vowel in the reduplication of $\tau 0-\tau 0-\sigma \sigma \varepsilon l-\tau 1$. In any case, such reduplications seem to be a Phrygian inner formation, since they do not fit any kind of reduplicated present reconstructed for the PIE.

\subsection{Optative}

There is only one form clearly identified as optative: kakoioi (G-02c), with a phonetic variant kakuioi (P-04 b). This verb is a denominative verb in *oio derived from kakouv (equivalent to Greek kaków 'maltreat, distress'). The Phrygian 3sg. ending -oi is the same found in Greek -ol. Both kakoioi and kakuioi are used in imprecative protasis: ios oporokitis.? | kakoioi tovo (G-02c) and ios ervotsati kakuioi... (P-04b).

\footnotetext{
${ }^{141}$ Even Sowa 2007, 84-85 considered them verbs in fut.
} 


\subsection{Imperative}

The 3sg. and 3pl. imperative is well attested in imprecative apodoses. As expected, the ipv. has its own set of endings inherited from PIE:

Table 31 ssg. and 3pl. imperative endings

\begin{tabular}{|c|c|c|c|}
\cline { 2 - 4 } \multicolumn{1}{c|}{} & \multicolumn{2}{c|}{ Singular } & Plural \\
\cline { 2 - 4 } \multicolumn{1}{c|}{} & Active & Middle & Active \\
\hline PIE & $\begin{array}{c}*-t u \\
*_{-t o ̄ d}\end{array}$ & $*_{-s d^{h} \bar{o}}$ & $\begin{array}{c}*_{-n t u} \\
*_{-n t o ̄ d}\end{array}$ \\
\hline OPhr. & $\begin{array}{c}-t o \\
-t u v\end{array}$ & $-d o$ & $\begin{array}{c}-n o u \\
-n u v\end{array}$ \\
\hline NPhr. & $-\tau o v$ & $-\delta o v$ & $-v o v$ \\
& $-\tau v$ & $-\tau \tau v o v$ \\
\hline
\end{tabular}

PIE *-tō yields the 3sg.act. ending, parallel to Greek $-\tau \omega$. It occurs in some verbs, although it is more commonly attested in the verb $i$ - 'to come, become' ( $<$ PIE * $\left.h_{1} e i-\right)$ by far:

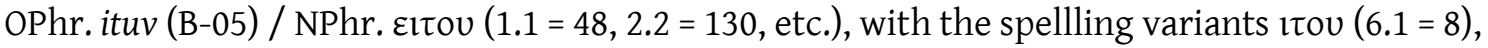

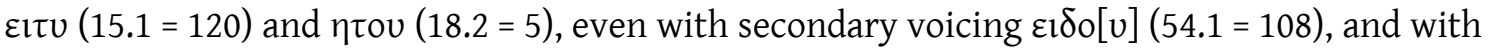
preverb $\alpha \delta \varepsilon i \tau$ ov $(9.1=87,38.1=44$, etc.). The other occurrences of this form are si eto $(\mathrm{W}-08$,

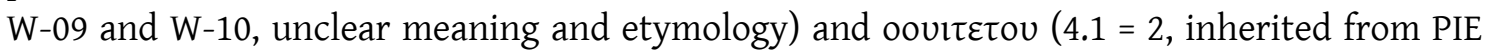
*uid-).

Its passive counterpart is -do / - $\delta$ ov, which goes back to PIE ${ }^{*}-s d^{h} \bar{o}$, also found in Greek $-\sigma \theta \omega$ (according to Lubotsky). It is found in the common NPhr. verb ${ }^{*}$ seg $^{h}->\varepsilon \gamma \varepsilon \delta$ ov (53.1 = 76, $59.4=106$, etc., Greek $\left.\varepsilon_{\chi} \dot{\varepsilon} \sigma \theta \omega\right)$ and in OPhr. lakedo (W-01b, very likely inherited from PIE $*_{\text {sleh }} g^{u-}$-).

The $3 p l$. is only attested in active. Its ending shows a metathesis in the consonants: *-

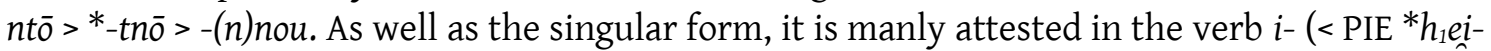

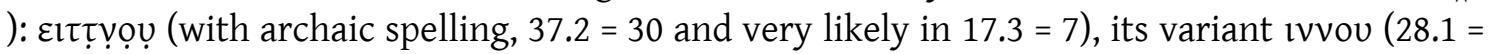
$71),<>>$ v ov $62.4(35)$ and, with preverb, $\alpha \delta \varepsilon 1 \tau \tau \vee$ ov $(40.1=12)$. Other forms are the verb isnou (NW-101 a), also in NPhr. as 10 vov $(9.1=87$, with the unusual variant $1 \sigma \mathrm{v} 1 \mathrm{o}[\mathrm{v}] 21.1=42)$, and tubnuv (B-05).

\subsubsection{Aorist}

Leaving aside its ending, the 3sg.aors.ind.act. edaes (M-01b, M-02, etc.) / $\varepsilon \delta \alpha \varepsilon \varsigma(16.1=$ 116) shows the common features of this tense. The Phr. aor. attach the so-called augment ${ }^{*} h_{1} e^{-}$ $>e-/ \varepsilon$ - to the verbs in aor., this feature is shared with Greek, Armenian and the IIr. branch. The root shows the $e$-grade or the lengthened grade: ${ }^{*} h_{1} e-d^{h} e h_{1}{ }^{-}{ }^{*} e d \bar{e}->e d a-(G r e e k ~ \varepsilon-\theta \eta-\kappa \varepsilon)$. The same can be said of $\varepsilon \sigma \tau \alpha \varepsilon \zeta(40.3=31$, perhaps also in estaẹs $\mathrm{M}-11)$, which goes back to $* h_{1} e-s t e h_{2^{-}}$

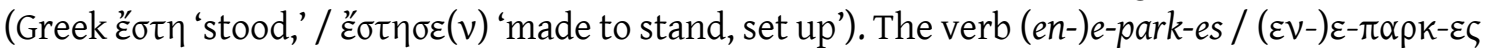
$(40.3=31)$ has been considered to have lengthened grade, ${ }^{*} h_{1} e-p e r r k-$, to explain the vowel $a$ in 
the root (see Lejeune 1969b, 291-194). ${ }^{142}$ The lengthened grade also seems to occur in $(\pi \circ \sigma) \varepsilon \kappa \alpha v \varepsilon \varsigma$ 'to dig'? $(16.1=116)$ too: ${ }^{*} h_{1} e-k e \bar{n} h_{1^{-}}>\varepsilon-\kappa \alpha v \varepsilon-$. In the light of these verbs, one cannot rule out a possible lengthened grade in edaes and $\varepsilon \sigma \tau \alpha \varepsilon \varsigma\left({ }^{*} h_{1} e-d^{h} \bar{e} h_{1^{-}}\right.$and ${ }^{*} h_{1} e-s t e \bar{h} h_{2^{-}}$?). Perhaps the form e? lakes (B-04) may be added to this list, if it is related to lakedo (W-01, perhaps also in B-03) and inherited from PIE *sleh $g_{2}^{u}$ - (LIV ${ }^{2}$ 566, IEW 958): *he-leh ${ }_{2} g^{u}-$ or $h_{1} e-l e h_{2} g^{u}-$ ?

The form $\varepsilon \gamma \delta \alpha \varepsilon \varsigma(11.2=18)$ is even less clear (Ligorio \& Lubotksy 2013, 191). Although it looks like an aor. $\varepsilon-\gamma \delta \alpha-\varepsilon \varsigma(11.2=18)$, it occurs in an imprecative apodosis where a verb in pres. is expected. The only attempt to explain this verb is made by Gorbachov $(2005,201)$, who equated it to Greek $\varphi \theta^{\prime}(v) \omega$ 'to decline, decay, perish' (also casual 'cause to decay or pine away, consume, destroy') and, consequently, considered that it goes back to PIE * $d^{\text {h }} g^{\text {uh }} e$ ei- ' $^{-}$to disappear'

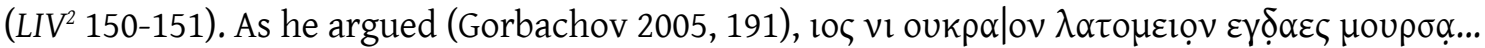
may mean 'whosoever... has destroyed? [the] Stone?". If he is right, $\varepsilon-\gamma \delta \alpha-\varepsilon \zeta$ is to be analysed as ${ }^{*} h_{1} e-d^{h} g^{\text {uh }} \bar{e} i->{ }^{*} e d g \bar{a} i->\varepsilon \gamma \delta \alpha-$ (with the loss of $-i$ after long vowel, see $\delta \varepsilon \omega \varsigma$ ).

The remaining forms lack clear context and and a grounded explanation. The form $\varepsilon v \alpha \rho \kappa \varepsilon(16.1=116)$ may perhaps be read as $\varepsilon v \alpha \rho \kappa \varepsilon<\zeta>$ (with engraver's mistakes, see $\kappa v \alpha 1 k 0<\zeta>$ in the same inscription). Brixhe and Neumann (1985, 173-174) interpreted it as $\varepsilon-v \alpha \rho k-\varepsilon(<\zeta>)$. The alternative they suggested, $\varepsilon v-\alpha \rho k-\varepsilon(<\varsigma>)$ (with a preverb), is less likely because of the lack

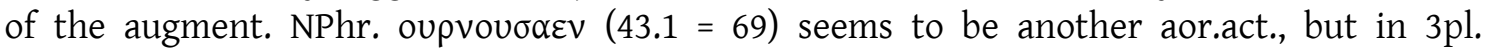
Nevertheless, the lack of augment and the obscure text (even its segmentation remains unclear)

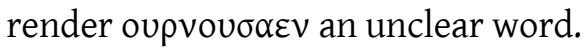

The origin of the forms in -aes is problematic, as Gorbachov showed (2005,193-195). The only consensus that has been reached is that the ending $-s$ is the simplification of the sigmatic form followed by the expected ending $*_{-} t:{ }^{*}-s-t>-s$ (see the same phonetic process in nevos, nevotan and $\beta \alpha \varsigma, \beta \alpha \tau \alpha v)$. According to Gorbachov $(2005,208-2012)$, -es is the outcome of the attachment of the suffix -s- (with a transitive value, see Jasanoff 2003, 43-44 and 194) to the thematic aor. ( ${ }^{*}-e / o-$, analysing $\varepsilon v \varepsilon \pi \alpha \rho \kappa \varepsilon \zeta$ as $\left.(\varepsilon v-) \varepsilon-\pi \alpha \rho \kappa-\varepsilon-\varsigma\right)$ and the aorist-stem wih ${ }^{*} h_{1}$ as the last consonant, like ${ }^{*} h_{1} e-k e \bar{e} h_{1^{-}}>\varepsilon-\kappa \alpha v \varepsilon-\varsigma$. Both kinds of aor. yield a form ${ }^{*}$-es- $t>e s$ which spread to other verbs such as edaes and $\varepsilon \sigma \tau \alpha \varepsilon \varsigma$. He considered this process parallel to the Slavic aor. suffix -ox-. In addition, he took the OPhr. estat (B-05) to be the inherited asigmatic aor. ${ }^{*} h_{1} e^{-}$ steh $_{2}-t$, in contrast with the new formation $\varepsilon \sigma \tau \alpha \varepsilon \varsigma .{ }^{143}$ On the other hand, Lubotsky $(1988,17-18)$ and Sowa (2007a, 78-79) have suggested a sequence ${ }^{*}-s-e-s-t$ with an intervocalic loss of the first $*_{-s-}{ }^{*} h_{1} e-d^{h} e_{h} h_{1} s-e-s-t>*_{e-d a-h-e s}>$ edaes. However, this suggestion renders the form redundant and does not explain the origin of the second $-s-$.

With regard to the passive aor., the 3sg. form adds the ending -toy to the root: edatoy (B-

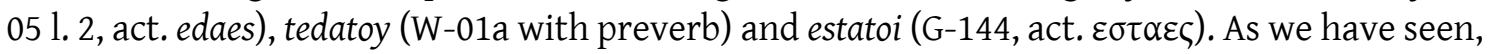
these verbs are ambiguous in terms of the grade of the root (lengthened or $e$-grade?), however there is not a general grade for all passive aor. and they very likely follow one of the active

\footnotetext{
${ }^{142}$ On the other hand, Gorbachov (2005, who made the first attempt to explain the Phrygian aor. in -aes) operated with a $\varnothing$-grade ${ }^{*} h_{1} e-p r k$ - for this form. However, this assumption is phonetically impossible since

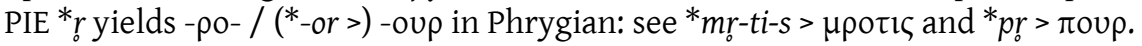

${ }^{143}$ Moreover, he suggested that NPhr. $\alpha \sigma \tau \alpha \tau(17.5=91)$ was a variant of estat $(B-05)$, with the same spelling of the augment found in $\alpha \chi \alpha v \varepsilon \zeta$. However, $\alpha \sigma \tau \alpha \tau$ is here read as $\alpha \sigma \tau \alpha_{l} !$ because it is in a clear imprecative protasis where this verb and this form are not expected and it is very likely the fem. of the possible adj.

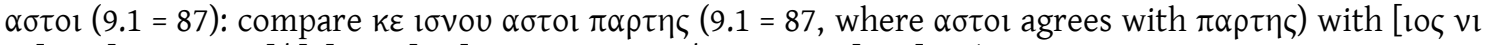

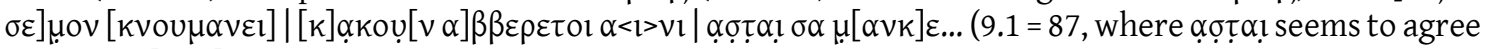
with $\sigma \alpha \mu[\alpha v \kappa] \varepsilon)$. Finally, it must be said that Gorbachov (2005) ignored Brixhe's "Prolégomènes au corpus néo-phrygien" (1999) and considered as a Phrygian verb the word $\alpha \chi \alpha v \varepsilon \varsigma$, which indeed is the

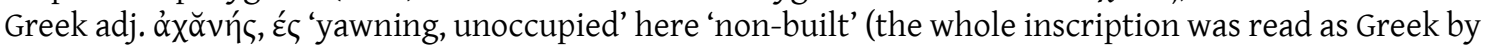
Brixhe and was excluded from the Phrygian corpus).
} 
forms. Indeed, ektetoy (B-01) is considered to be inherited from PIE *tkeh ${ }_{1-}^{-}$'rule, gain, acquire' (LIV 618-619, IEW 1057-1058, see Ligorio \& Lubotsky 2013, 191), with the metathesis in the root found in Greek $\kappa \tau \alpha$ ó $\mu_{\alpha 1}$ 'to acquire, win' (in perfect. 'possess'). Consequently, the form ektetoy can only go back to the root in ø-grade. Another possible 3sg.ind.aor.med. is epaktoy (B-01), although its meaning and etymology remain unknown. Finally, the form egertoy in W-01c is

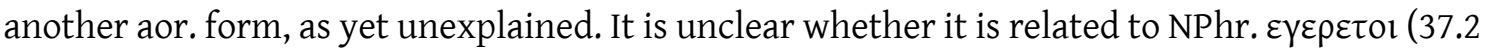
$=30)$ and $(\varepsilon)^{2} \gamma \varepsilon \rho \varepsilon[v](28.1=71)$.

\subsubsection{Perfect}

The only clear personal form of the perfect tense is $\delta \alpha \kappa \alpha \rho \varepsilon v(1.2=98)$, 3pl.ind.act of

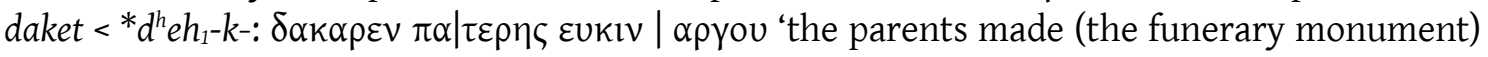
as a vow' ${ }^{144}$ In any case, $\delta \alpha \kappa \alpha \rho \varepsilon v$ is a particular form since it does not show the syllable reduplication (attested in non-personal ptc.s of other verbs) and the ø-grade expected in this plural form has been replaced by an e-grade, perhaps as a levelling from the present and aor. forms. Even the ending presents problematic features. It seems that the old ending -ēr- was recharacterised by the addition of the 3pl. ending $-\varepsilon v<*-e-n t$. As can be seen, the perfect $\delta \alpha k \alpha \rho \varepsilon v$ is a Phrygian new formation, as occurs with the equivalent forms in other languages such as Greek $\tau \varepsilon \theta \eta \dot{n} \kappa \bar{\alpha} \sigma \mathrm{l}(v)$ or Lat. fecēre fecērunt.

The form $\delta \alpha \kappa \alpha \rho(11.2=18)$ is considered by Orel $(1997 a, 400)$ and Sowa $(2007 a, 85)$ the singular form of $\delta \alpha \kappa \alpha \rho \varepsilon v$. According to them, it implies that this form levelled its ending from the plural -êr or, less likely, ${ }_{-r}-r>-\alpha \rho$ (see * $\left.p r>\pi \circ \rho \rho\right)$. On the other hand, $\delta \alpha \kappa \alpha \rho$ could be the

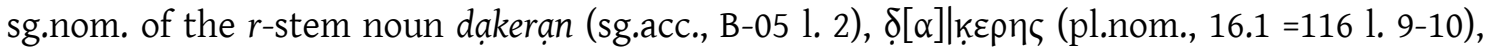
dakeraị (pl.acc., B-05 1. 7). Although dạker (B-05 l. 5) has been suggested to be its sg.nom., a form with $-\bar{e} r>-\bar{a} r$ is expected in the light of other $r$-stem nouns (see, e.g., matar). The context is ambiguous. It is possible to consider that $\mu 1 \delta \alpha \kappa \alpha \varsigma \delta \alpha \delta$ ov $\lambda \varepsilon v \kappa i \omega l \delta \alpha \kappa \alpha \rho$ means 'Midakas the son of Dad- made (it) for Leukios'. However, $\delta \alpha \kappa \alpha \rho$ is followed by a sg.nom. PN and is not far from

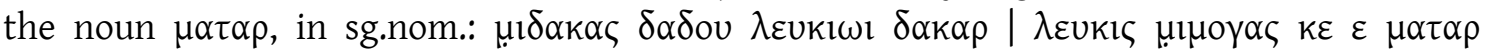

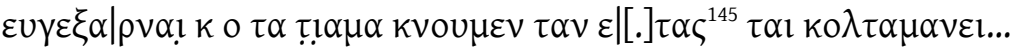

Lubotsky (1988, 17-18 and in Ligorio \& Lubotsky 2013, 192) considered that aey (W-01a, B-01 1. 8) was a perfect form of the copulative verb * $h_{1} e s$ - 'to be' (LIV 241-242, IEW 340-341): * $h_{1} e^{2}$ $h_{1} s-e->{ }^{*} \bar{e} s e->{ }^{*} \bar{a} h e->$ aey (with a secondary $-i$ ). It is built similarly to the Vedic äsa 'has been'. According to Lubotsky, who considered the rel. clause in W-01a where this form is read to be an imprecative protasis, yos tutut ...a.m.noy akenanogavos aey (W-01a) could mean 'whoever ... may become an akenanogavos (later, here or vel. sim.)'. Nevertheless, there is no apodosis and the preferred interpretation is that of a non-imprecative rel. clause: 'Bonok the akenanogavos, who was akenanogavos ...'. The context of aey in B-01 remains unclear and does not provide useful information to corroborate or refute Lubotsky's analysis. However, since key is a graphic variant of ke, aey cannot be ruled out as a variant of the pcl. ae.

The remaining verbs considered to be perfect forms are even more obscure. Lubotsky $(1997,123-124)$ also considered the form $\varepsilon v-\sigma \tau \alpha \rho v \alpha(1.1=48)$ to be the perfect of estatoi and $\varepsilon \sigma \tau \alpha \varepsilon \varsigma$ 'he put' (3.sg.aor.ind. mid. and act. respectively), which goes to * ${ }^{*}$ steh $_{2}$ ' 'to stand (up)' (LIV 590-592, IEW 1004-1008). Regarding its ending, he considered the presence of * $r$ (as in $\delta \alpha \kappa \alpha \rho \varepsilon v$ )

\footnotetext{
${ }^{144}$ Note that the aor. edaes / $\varepsilon \delta \alpha \varepsilon \zeta$ is commonly used for this purpose. Sowa $(2007,86)$ suggested that Phrygian shows the same process as Greek, where the aor. gradually took the function of the act. perfect. Here, I follow his analysis of $\delta \alpha \kappa \alpha \rho \varepsilon v$, see also Ligorio \& Lubotsky 2013, 192.

${ }^{145}$ I suggest reading $\varepsilon \mid[.] \tau \alpha \zeta$ as $\varepsilon \mid[\sigma] \tau \alpha<\varepsilon>\varsigma$ 'he put' (the lacking epsilon is explained by the rectangular shape of this letter and the following one, see § 3.2.2).
} 
followed by the 3pl.mid. ending -ntai, with the assimilation *-nt- $>{ }^{*}-n n$ - simplified in $-n$ - and the loss of the final $-i$. Although $\varepsilon v \sigma \tau \alpha \rho v \alpha$ fits the context as verb, ${ }^{146}$ the details are not clear. Note, e.g., that the 3sg.mid. ending occurs as -toi and -tor, but never as -tai (see Sowa 2007a, 77 and 2008, 97).

Finally, Brixhe (2004a, 41) considered that anerneuey (B-04) can be a verb in 3sg. perf.ind.act. (if not an athem. noun, as he also suggested), as well as (etit)evtevey (B-01). However, both forms occur in texts that have not been clearly read or interpreted.

Leaving aside the above forms, the perfect is commonly attested in ppp. (see § 4.2.2.4.). Since most cases show the expected syllable reduplication, we can conclude that it was a common feature of the Phr. perfect.

\subsubsection{Non-finite forms}

The only clearly identified non-finite form in Phrygian is the passive past ptc., which commonly occurs in imprecative curses. The occurrences of this ptc. show a reduplication with $e$-grade, $\varnothing$-grade in the root and the suffix $-m h_{1} n o$ - (cognate to Greek $\left.-\mu \varepsilon v o-\right)$, so they are inflected like an adj.: masc. and neuter forms follow the o-stem inflection while the fem. the $a$ stem. The reduplicated forms are: $\gamma \varepsilon \gamma \alpha \rho \imath \tau \mu \varepsilon v o \varsigma$ 'devoted to, cursed' $(62.2=33$, very likely in $59.3=79$ and $62.5=36$, with preverb in $\tau 1 \gamma \gamma \varepsilon \gamma \alpha \rho \imath \tau \mu \varepsilon v o \zeta 6.1=88), \gamma \varepsilon \gamma \rho \varepsilon ı \mu \varepsilon v \alpha v$ 'written' (53.1 =

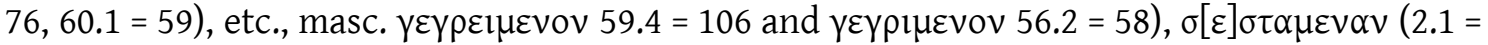
15), (o $) \varepsilon \sigma \tau \alpha \mu \varepsilon v \alpha \nu(22.1=9)$ and, the most common by far, $(\tau \imath \tau) \tau \varepsilon \tau \iota k \mu \varepsilon v o \zeta ~(2.2=130,4.1=2$, with many spelling variants). ${ }^{147}$ For instance, this last form goes back to PIE *de-dik-mh ${ }_{1}$ no-s. There are some obscure forms which are suggested to be ptc.s because they have the suffix -

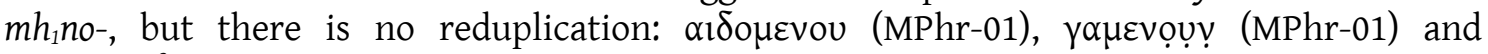
$\alpha \rho \gamma \mu \varepsilon v \alpha\left[{ }^{?}\right](16.1=116)$.

Hämmig $(2013,150)$ has suggested, very convincingly, that torvetun (B-05) is a present ptc. in *-ōn of a denominative verb derived from the noun *doru- 'tree, wood' (similar to Greek

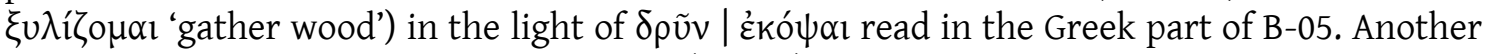
present ptc. seems to be kuryaneyon 'ruler' (W-01c), also of a denominative verb derived from *kor-io- 'war, army'. However, it has been considered a Myc. borrowing by Ligorio and Lubotsky

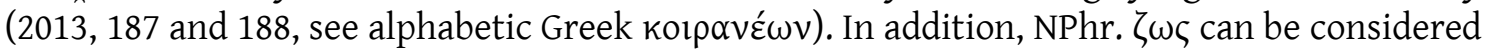
a Greek borrowing (very likely from Hellenistic or even Roman times, see $§$ 4.6.1.3) from $\zeta \omega \varsigma \varsigma$ 'alive, living' (< PIE * $g^{u} i h_{3}$-uno-s, Lat. uiuus).

Other forms are less clear. The obscure word oskavos (B-05) was suggested to be a masc.sg.nom. perfect ptc. in *-uno- and to mean 'to intend' by Hämmig (2013, 147-148). Recently, a similar analysis has been suggested for isekosos (B-05) by Simon (2015, 17-18). According to him, this form shows a ptc. in pl.acc. and goes back to *en-sek ${ }^{u}-u \bar{o} s^{-}$, and means something like 'contents (of the inscription)'. Nevertheless, both interpretations have some difficulties. For example, oskavos has no etymological explanation and for isekosos it is unclear why we have isekosos instead of *isekos and why the pl.acc. ending *-ons does not yield -ois, as would be expected. Moreover, the identification suggested by Simon (2015) between the last line of B-05 (where isekosos occurs) and the Gr. text from the same stele is hard to corroborate (see s.u.).

Finally, it should be noted that there are some adjectives derived from verbs by adding

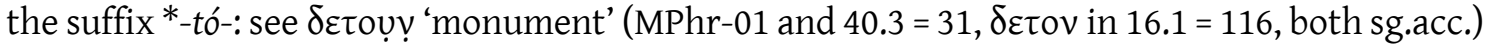

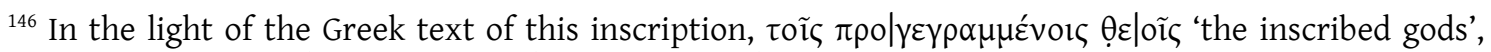

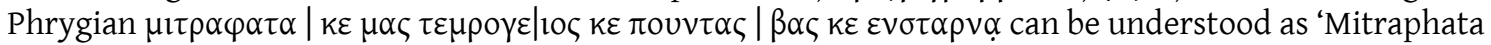
and Mas Tymbrian and the Pontic Bas were assigned'.

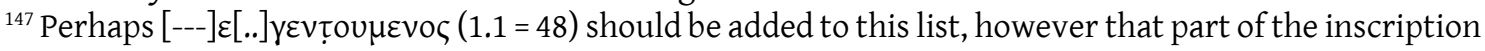

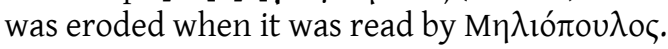


inherited from * $d^{h} h_{1}$-tó-, (parallel to Greek $\theta \varepsilon \tau o ́ \varsigma$, , , óv 'placed set'). In addition, forms with the fem. of this suffix have been identified (Brixhe 2004, 24 and Sowa 2007a, 91), although the words remain unclear: bilata (MPhr-01), lapta (MPhr-01) and omasta (MPhr-01).

\subsubsection{Prepositions, preverbs, conjunctions and particles 4.2.3.1. Prepositions and preverbs}

In the Phrygian corpus, some prepositions have been identified. Sometimes, they are also used as preverbs. The most frequent preposition is $\alpha \tau$ 'to, at, by' (passim), with the voiced variant ad (B-05) / $\alpha \delta(7.3=99)$. The first spelling is expected after the Laurverschiebung, since it is the outcome of PIE * $h_{2}$ ed (LIPP, II 8-9). However, assimilations happened in this form and the resultant geminates are commonly simplified: $\alpha \tau \tau l$ (42.1) $>\alpha \tau l$ (9.1). The preposition always

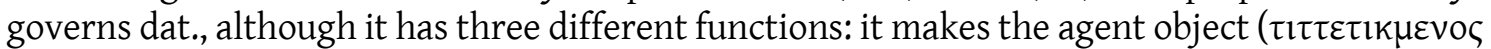

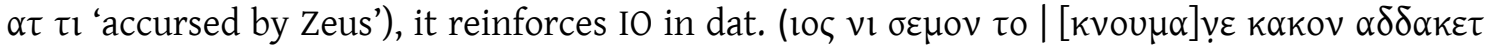

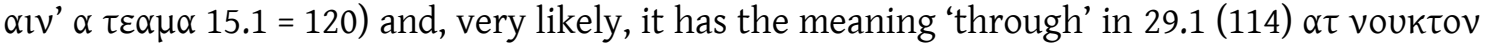
$\mu \rho \circ \varsigma \sigma \alpha \varsigma$ 'through a blow? to this mros'. In any case, it is commonly found as a preverb in *adberet $>\alpha \beta \beta \varepsilon \rho \varepsilon \tau\left(18.3=6,29.1=114\right.$, etc.) or $\alpha \delta \delta \alpha \kappa \varepsilon \tau$ (passim) ${ }^{148}$ It may even occur in the formation of the adj. a-garitoi 'devoted' (G-02), according to Kloekhorst $(2015,10)$.

The preposition $\alpha \varsigma$ 'in, at, by' $(7.1=99,7.3=14$, etc.), with the variant a $a(B-01) / \alpha(62.5$ $=36),{ }^{149}$ shares an origin with $a d / \alpha \delta$. Indeed, LIPP (II, 10 and 226) classifies it as the rendering of a PIE form * $h_{2} e d-s .{ }^{150}$ It also shares at least ${ }^{151}$ the agentive function in $\alpha \varsigma \beta \alpha \tau \alpha v(20.2=128)>$ ${ }^{*} \alpha \beta \beta \alpha \tau \alpha v>\alpha \beta \alpha \tau \alpha v$ 'by Bat' $(62.5=36)$, however it governs acc. Only in $\alpha \varsigma \alpha v \alpha v \kappa \alpha l(62.4=35)$ does a dat. occur after it, although orthographic confusion in this $a$-stem cannot be ruled out (see $\S$ 4.2.1.1.1).

The third most common preposition is $\mu \varepsilon$ 'before, in the sight of, among', which renders PIE *me- (LIPP II, 494). It is always found governing dat. in the formula $\mu \varepsilon \delta \varepsilon \omega \varsigma$ $\kappa \varepsilon \zeta \varepsilon \mu \varepsilon \lambda \omega \varsigma \kappa \varepsilon$ 'in the sight of gods and men'. Its meaning is assured by Luw. and Gr. parallels (see § 4.6.2.2). Traditionally, it has been considered also a preverb in $\mu \varepsilon \beta \varepsilon \rho \varepsilon \tau$, but in such position $\mu \varepsilon$ must be considered the prohibitive pcl. (see $\$ 4.2 .3 .2$ ).

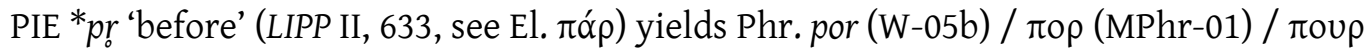

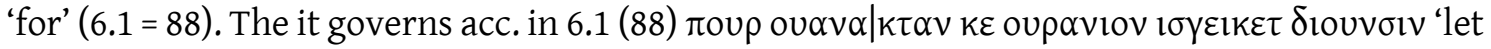
him be responsible before the heavenly lord Dionisos'. However, in MPhr-01, perhaps governs gen., זop kopoo . $^{152}$ The OPhr. occurrence is ambigous.

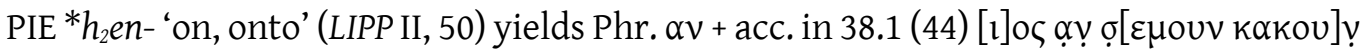

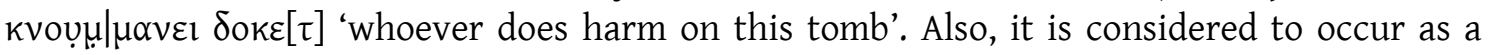
preverb in anivayeti (B-07) and, perhaps, in anerneuey B-04.

The preposition $\varepsilon v($ MPhr-01 and $16.1=116)$ only occurs in two obscure sequences followed by acc. However, this form, inherited from PIE * $h_{1}$ en 'in' (LIPP II, 221-222) clearly

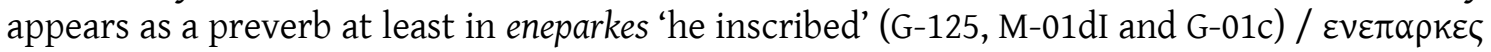
$40.3(31)$.

The PIE adverb *per 'before, forth, in front of' seems to yield the possible Phr. preposition $p^{?}$ er $(\mathrm{HP}-101) / \pi \varepsilon \rho(29.1=114)$. Although the occurrence of this pcl. as a preposition

\footnotetext{
${ }^{148}$ The resulting geminates are often simplified: $\alpha \beta \varepsilon \rho \varepsilon \tau 1 ~ 66.1$ (103) and $\alpha \delta \alpha \kappa \varepsilon \tau ~ 3.1$ (97), 7.1 (99), etc.

${ }^{149} \mathrm{Here}$, another assimilation followed by a simplification must have operated.

${ }^{150}$ Very likely, this final addition can be equated to $-\varsigma$ in Greek $\varepsilon \dot{\varepsilon} \zeta / \dot{\varepsilon} \zeta<^{*} e n-s$ or Lat. ab-s, see also $1 \sigma \tau^{2} \varepsilon 1 k \varepsilon \tau$ $(6.1=88)$.

${ }^{151}$ Other occurrences are still obscure or problematic.

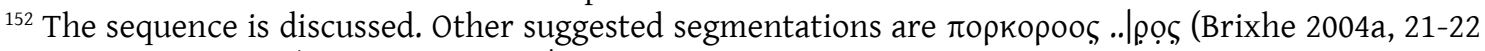

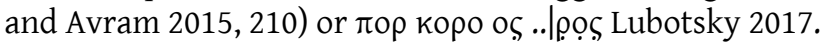




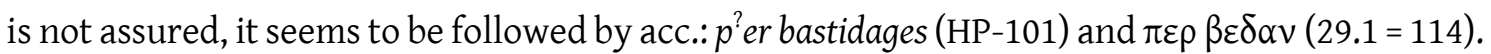
However, the meaning of these two words is unclear and composed forms cannot be ruled out.

The form $p^{\text {? os }}(\mathrm{B}-05) / \pi 0 k$ (16.1 = 116, with assimilation) is considered to be the outcome of the PIE adverb *pos 'after' (LIPP II, 628). However, both occurrences happen in obscure texts. In B-05 it appears in a strange position between acc. and the conj. key: panta vebras adun p?os key

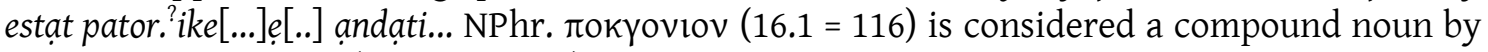
Brixhe and Neumann $(1985,176-177)$, but one cannot rule out a preposition + acc. IoK yoviov. In any case, the existence of pos in Phrygian is confirmed by its occurrence as a preverb in

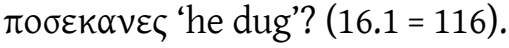

A preposition o seems to occur in the sequence o $\tau \alpha$ ț $1 \alpha \mu \alpha(11.2=18)$, where the case of the following noun is ambiguous (acc. $-a n>-\alpha$ or dat. $-a y>\alpha$ ?). Although this sequence is not

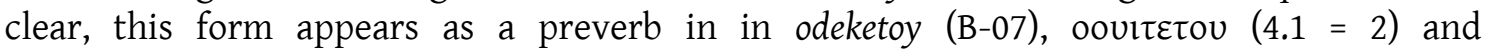

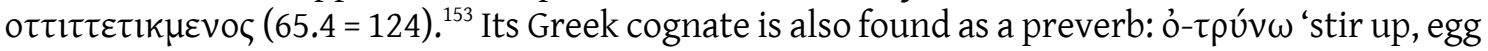
on, encourage'. Phr. o may go back to PIE * $h_{2}$ (LIPP II, 323-324).

Gorbachov $(2009,96-98)$ identified the Phr. outcome of PIE noun * $h_{2} e r-t-$ used, as well as Lith. arti 'about, near, beside', in OPhr. art (B-05; see also LIPP II, 290). The Greek version of B-05 makes it very likely: compare sin=t imenan in an imprecative apodosis: yos niy art sin=t imenan

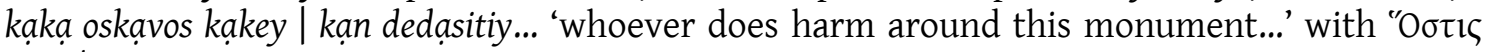

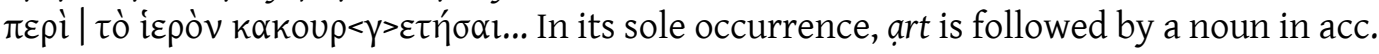

There are also some preverbs which never occur as prepositions, such as Phr. *tis- 'a part'. Lubotsky $(2004,235)$ equated it to Greek $\delta 1 \alpha-$ 'in two, a part, through', derived from PIE *dis 'in two, a part' (LIPP II 145-147; see DEG 327). The Lat. preverb dis- 'away, apart' is another good cognate (de Vann 2008, 171-172). The last sibilant of *tis- always appears assimilated to

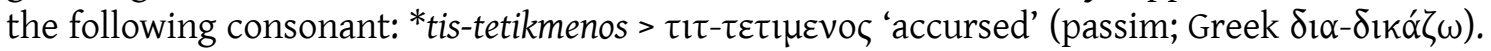

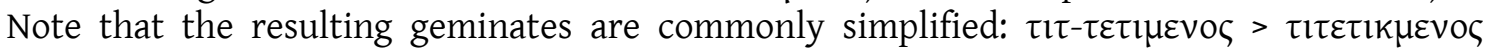
(passim). It also occurs in an adj.: *dis-dregro- $>{ }^{*} \tau 1 \delta \delta \rho \varepsilon \gamma \rho \circ o u v>\tau 1 \delta \rho \varepsilon \gamma \rho o u v$ 'unenjoyable, innutribile' $(53.1=76$ and $62.2=33)$.

An interesting preverb is found in o $\pi \varepsilon \sigma \tau \alpha \mu \varepsilon v \alpha \nu(22.1=9)$, where the form o $\pi$ - seems to go back to PIE * $h_{1}$ opi 'close upon, at, behind' (LIPP II 251), ${ }_{154}^{15}$ as well as Greek ö $\pi l-\sigma \theta \varepsilon v$ '(from) behind, at the back, after(wards)' and Lat. ob. Phr. on- is never found as a preposition. Orel (1997a, 315 and 428) equated ep- in eptuve[---] T-03b to Greek ż $\pi$ ' 'upon', a form which follows the e-grade of the same PIE element: ${ }^{*} h_{1} e p i$. However, this word remains unexplained.

A marginal preverb is $t$-, found only in tedatoy (W-01a; compare with edatoy B-05) ${ }^{155}$ The lack of further information and the shortness of this pcl. complicate research into its origin. As a working hypothesis, it can be considered the outcome of PIE *de 'to' (LIPP II 148), found in the Greek directive postposition $-\delta \varepsilon$ and Lat. in-de 'thence'.

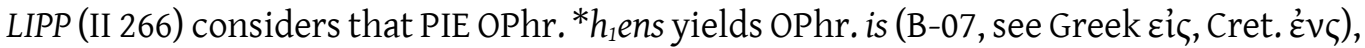
a form also found as a preverb in $1 \sigma \tau^{?} \varepsilon 1 k \varepsilon \tau(6.1=88)$. Nevertheless, the OPhr. cannot be a preposition, since it is preceded and followed by names in nom. The analysis of the NPhr. preverb still stands, but the form has reading problems that hinder its analysis.

Finally, it must be added that Brixhe (2004a, 58) considered ando (B-05) to be a preposition followed by an acc. noun in pl.acc.: popostois. The origin for such a preposition is found in PIE adverb * $h_{1}(e) n d o(m)$ 'inside' (LIPP II 159), attested e.g. in Greek हैv $\delta$ ov 'id.'. However,

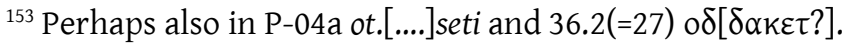

154 See also Ligorio \& Lubotsky 2013, 192 A second example could be found in oporokitis.? However, this word remains unexplained.

${ }^{155}$ See this analysis, without explanation, in Ligorio \& Lubotsky 2013, 187.
} 
the outcome of the laryngeal in Phr. is unexpected and this part of the inscription remains obscure, so the context is of no assistance.

Table 32 Summary of the identified Phrygian prepositions and preverb (dubious in grey)

\begin{tabular}{|c|c|c|c|c|}
\hline PIE & Phrygian & Case & preverb & Cognates (e.g.) \\
\hline$* d e,{ }^{*}$ do & - & - & t-edatoy & Greek $-\delta \varepsilon$ \\
\hline$* h_{1}$ en & $\varepsilon v$ & acc.? & en-eparkes & Greek غ̇v \\
\hline$* h_{1}$ opi & - & - & $o \pi-\varepsilon \sigma \tau \alpha \mu \varepsilon \nu \alpha \nu$ & Greek ö $\pi \mathrm{l}-\sigma \theta \varepsilon v$ \\
\hline${ }^{*} h_{2}$ ed & $\alpha \tau, \alpha \delta, \alpha$ & dat. & $\alpha \delta-\delta \alpha \kappa \varepsilon \tau$ & Lat. ad \\
\hline$* h_{2} e d-s$ & $\alpha \varsigma, \alpha \alpha \varsigma, \alpha$ & acc. / (dat.)? & - & Lesb. $\alpha ́ \sigma-\varphi l$ \\
\hline$* h_{2} e n-$ & $\alpha v$ & acc. & an-ivaYeti & Greek ỏv $v(\alpha)$ \\
\hline$* h_{1}$ en-s & - & - & $1 \sigma-\tau^{?} \varepsilon 1 K \varepsilon \tau$ & 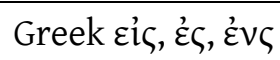 \\
\hline$* h_{2} e r-t-$ & art & acc. & - & Greek ớ $\rho \tau-1$ \\
\hline$* h_{2} \mathrm{O}$ & 0 & acc. or dat.? & 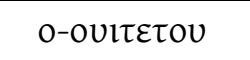 & Greek ỏ- $\tau \rho u ́ v \omega$ \\
\hline$*_{m e-}$ & $\mu \varepsilon$ & dat. & - & Greek $\mu \varepsilon-\tau \alpha ́$ \\
\hline *pos & p?os, $\pi$ ok & acc.? & $\pi O \sigma-\varepsilon K \alpha \nu \varepsilon \zeta$ & Arc.-Сypr. $\pi \circ \varsigma$ \\
\hline *per & per, $\pi \varepsilon \rho$ & acc. & - & Greek $\pi \varepsilon \rho i ́ ~$ \\
\hline *pr & 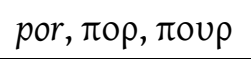 & acc. / (gen.)? & - & El. $\pi \alpha ́ \rho$ \\
\hline *dis & - & - & $\tau ı \tau-\tau \varepsilon \tau \iota k \mu \varepsilon \vee O \zeta$ & 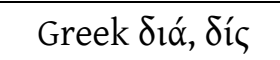 \\
\hline
\end{tabular}

\subsubsection{Adverbs}

Few adverbs have been identified and most of them are problematic. ${ }^{156}$ Indeed, only $v \psi \circ \delta \alpha v$ 'above, on the top' $(2.1=15$ and $16.1=116)$ has a well explained meaning and etymology. Lubotsky (1993a) equated it to the Greek adverb v́ ó$\varepsilon v$ ' from on high, from above', which goes back to *up-s- 'above' (LIPP II, 833). Regarding the divergence of endings, the Phrygian adverb is the outcome of the PIE pcl. ${ }^{*}-d^{h} n$ instead of ${ }^{*}-d^{h} e(+n)$ and must be a cognate of Greek $-\theta \alpha$ (Lejeune 1939, 357), found in adverbs of some Greek dialects such as $\pi \rho$ ó $\theta \alpha \alpha$ 'before' (Dor. and Aeol. for $\pi \rho o ́ \sigma \theta \varepsilon-v)$ or ö $\pi \_\theta \alpha$ 'behind, at the back' (Aeol. and Dor. for ö $\pi l \sigma \theta \varepsilon$ ), although not in

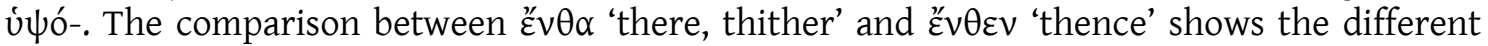
meaning of the two particles (Lejeune 1939, 386 and Lubotsky 1993a, 132): ${ }^{*}-d^{h} n>-\delta \alpha /-\theta \alpha$ has a loc. meaning while ${ }^{*}-d^{\text {h }} e>-\theta \varepsilon-v$ an abl. one.

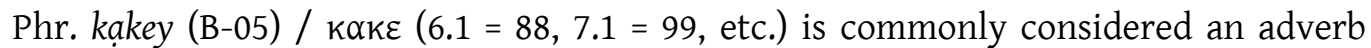

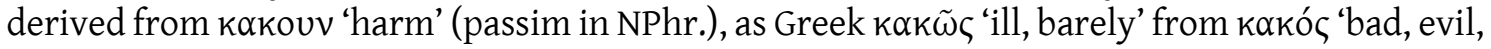
ill'. Since kakouv is clearly an o-stem, its derived adverb in -e has a good parallel in Latin, where adverbs derived from a thematic form take an ending $-\bar{e}$ (or - $\breve{e}$ after Iambic shortening): maximus 'greatest' > maxime 'especially, very much'. Its origin is the PIE sg.instr. ending *-eh (perhaps $^{-}$ also attested in InIr. sg.inst. $-\bar{a}$, if it does not go back to ${ }^{*}-o h_{1}$ ). Phr. $-e(y) /-\varepsilon$ is unlikely to have another origin. There is, however, a phonetic problem, since ${ }^{*}-e h_{1}$ is expected to yield $-\bar{a}$. As has been seen in $\S 4.1 .2 .2 .3$, the same problem is found in the prohibitive pcl. ${ }^{*} m e h_{1}>m e$ (B-05 and B-07) $/ \mu \varepsilon(7.1=99,7.2=111$, etc. $)$.

Other possible adverbs are even less clear. Bayun and Orel (1988a, 188, considered likely

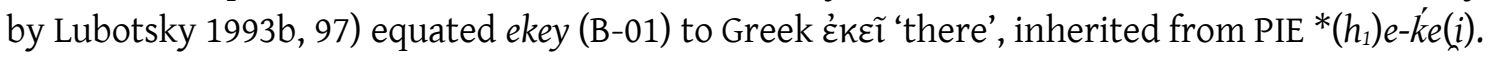

${ }^{156}$ This is only an overview. See s.u. the extensive discussion of each form. 
However, the context does not corroborate this possibility. NPhr. $\varepsilon \rho \alpha(62.5=36)$ is equated to

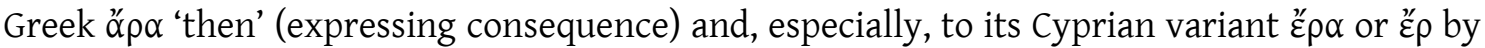
Brixhe (Brixhe 1997, 62, see also LIPP II, 289). The context favours the meaning 'then' for this Phr. word ${ }^{157}$ but the Greek forms are problematic, since they show a hesitation between $* h_{2}(e) r$ and ${ }^{*} h_{1}(e) r$ (EDG 121, LIPP II 289). Hämmig $(2013,148)$ suggested that kan (B-05) / $\kappa \alpha v ~(20.3=62$ and $46.1=53$ ) is an adverb derived from the pron. ${ }^{*} k^{u} \cdot e / o$ - (attested in Phrygian as koc) with the meaning 'somehow' parallel to Lat. quam 'as, than' and Armenian k'an 'id.'.

Recently, Hämmig (fthc. a) and Obrador (frthc. a) identified the Phr. outcome of the PIE prohibitive *meh ' not' (LIPP II 511-512). The context and a comparison of the formulae in which it appears with analogous formulae in Greek inscriptions from Anatolia shows that it is the best explanation for this pcl., previously considered a preverb (since $\mu \varepsilon^{1}$ is a clear preposition). However, there is a phonetic problem in the evolution of ${ }^{*} m e h_{1}>m e / \mu \varepsilon$, since ${ }^{\dagger} m \bar{a}$ would be the expected outcome (see § 4.1.1).

A similar problem is found in $v=k \varepsilon$ 'neither, nor' $(4.1=2)$, where $v$ - is considered the Phrygian equivalent of Greek oü $(\kappa)$ 'no' in the compound oü $\tau \varepsilon$ 'neither, not'. Nevertheless, the Greek form is commonly derived from PIE * $h_{2}$ oin- $k^{u} \cdot i d$, as well as Arm. oc 'id.' and Alb. as 'id.' (see EDG 1123, Martirosyan 2010, 531 and 2013, 91, with references). If the Phrygian form is indeed related to ${ }^{*} h_{2}$ oiu-, one may assume an unexpected phonetic erosion of $*_{i}$. However, a Greek influence cannot be ruled out here: it is striking that the same loss is found in $\gamma$ 入oupeos (MPhr$01)<{ }^{*} g_{0}^{h} l h_{3}$-eio-. This interpretation also has a syntactical problem, since the prohibitive pcl. $\mu \varepsilon$ is expected in this context. In any case, NPhr. $v=k \varepsilon$ was previously considered a graphic variant of the dative pron. (1)or 'to him' by Heubeck $(1958,22-3)$ and Brixhe $(1997,49,67)$ and the outcome of PIE * $h_{2} u-k^{u} e$ 'but also' (LIPP II 338), but such interpretations are not at all consistent with the context.

\subsubsection{Conjunctions}

The most attested Phrygian conjunction is the copulative ke(y) 'and' (B-04, B-05, B-07, etc.) / $\kappa \varepsilon$ (passim), which clearly goes back to PIE * $k^{u} \cdot e^{e}$ 'id.' (LIPP II 690-691). It may appear with some particles. Indeed, $\alpha \kappa k \varepsilon$ 'and' $(53.1=76$ and $62.2=33)$ could be a parallel of Lat. atque 'id.' and $v=k \varepsilon$ to Greek oü $\tau \varepsilon$ 'neither, not'. It is always attached after the second of two joined elements (sentences or words): $\delta \varepsilon \omega \varsigma \zeta \varepsilon \mu \varepsilon \lambda \omega \varsigma \kappa \varepsilon(24.1=40)$ with. However, it is commonly found after all the joined elements: $\mu \varepsilon \delta \varepsilon \omega \varsigma \kappa \varepsilon \zeta \varepsilon \mu \varepsilon \lambda \omega \varsigma \kappa \varepsilon$ in the sight of gods and men $(3.1=97)$. Prepositions and the pron. ( 1 )or are not considered a word in this rule, so the conj. is placed

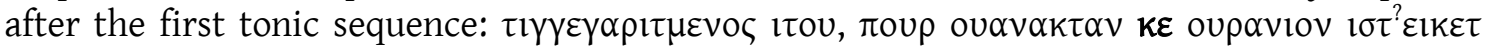
Siouvolv (joining two apodoses). In 1.1 (48) the ethnic and the DNs are treated as the same

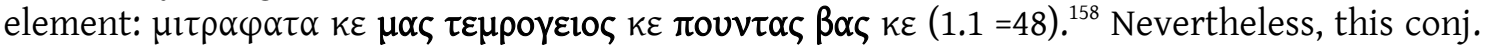

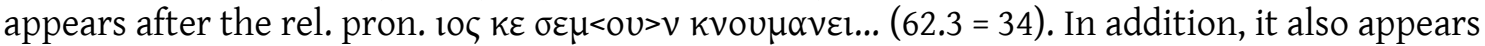
attached to neg. particles building the neg. conjunctions $\mu \varepsilon=k \varepsilon(7.2=111)$ and $v \leqslant k \varepsilon(4.1=2)$, perfect parallels of Greek $\mu \tilde{\eta} \tau \varepsilon$ 'and not' and oú $\tau \varepsilon$ 'and not' respectively.

The NPhr. hapax $\tau \varepsilon(43.1=69)$ is problematic because, if it is indeed the same copulative conj. $\tau \varepsilon$, it shows the Classical Greek treatment of the labiovelar and may perhaps be considered a borrowing. However, the context is not clear enough to rule out other segmentations. Also

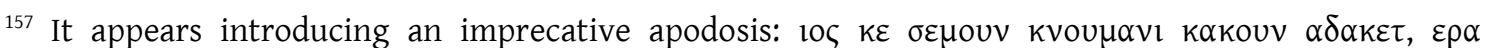

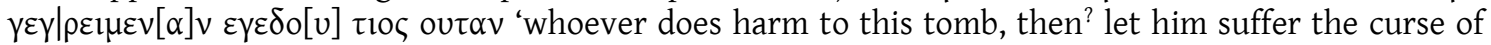
Zeus'.

${ }^{158}$ For more details on these rules, see Brixhe 1978, 1-2; 1997, 59-60, Lubotsky 1989b, 150-151; 1997, 122 and Woodhouse 2007, 189-191.
} 
unclear is the OPhr. eti (B-03) / $\varepsilon \tau 1(11.2=18$ and $\varepsilon \tau 122.1=9)$, perhaps related to PIE * $h_{1}$ eti (LIPP II, 260-261).

Finally, the conj. ay (B-03 and G-01a), ai (P-06) / $\alpha \mathrm{l}(40.3=31$ and $56.3=64)$ 'if, for' is mainly found followed by the pcl. ni(y) in aini (P-101), ayniy (B-01 and B-05) / alvi (passim).

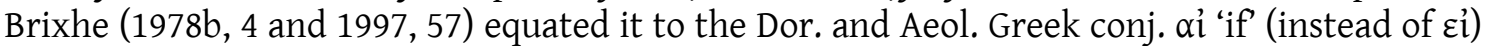
and considered both forms the old loc. of the PIE demonstrative-anaphoric pron. ${ }^{*}$ /o(contrary to EDG 379), also LIPP (II 348), where these forms are considered to be inherited from PIE *éh ${ }_{2}$ i.

\subsection{Notes on syntax}

\subsubsection{Case uses}

In the Phrygian corpus four nominal cases are attested: nominative, accusative, genitive and datative. Although it is impossible to compile a list of all the uses of each case in Phrygian because of the contextual limitations, they have the same functions found in the other Indo-European languages.

\subsubsection{Nominative}

The nominative is the case of the subject: baba ... si-keneman edaes 'Baba ... made this niche' (M-01b). It is also the case of the predicate noun and the adj. in agreement with it: ates arkiaevais akenanogavos ... edaes 'Attes the son of Arkia(s), the akenanogavos, made (it)...' (M-01),

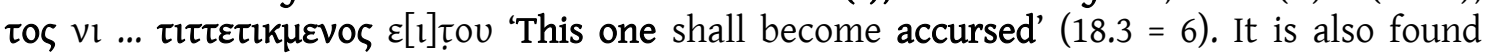
independently in inscriptions containing only a PN: Yuva Yaros (G-115). Finally, in HP-114, a clay tablet from Persepolis, it is used for listing items as a nominative of rubric. ${ }^{159}$ The noun knays 'woman', for example, occurs once in singular and once in plural, although both are preceded by a number higher than one: 30 ? knays ... $40^{\text {? }}$ knayke? [s] ' 30 woman [sic], ... 40 women'. Even the name of the month dating the same tablet (although the day and the year are lost) seems to be in sg.nom.: anamaka.

\subsubsection{Accusative}

The accusative is the case of the direct object: midas $s=$ materan ... eneparkes? 'Midas engraved this Matar' (M-01d I), ove $\beta \alpha v \delta \varepsilon \delta \alpha \sigma \sigma l v v l \pi \alpha \tau \rho \varepsilon \varsigma$ 'the parents put the tomb' $(2.2=130)$. In addition, Avram $(2016,122-123)$ considered a directive function of the acc. in veban ituv (B05), interpreted as 'may he go in the grave' (i.e. 'may he die'). Although it is a strong possibility, the protasis of this imprecative apodosis is still problematic and more studies are needed of this line of the Vezirhan stele. Finally, this case is governed by some prepositions (see 4.4.1.): e.g. $\alpha \varsigma$ $\beta \alpha \tau \alpha v$ 'by Bat' $(20.2=128)$.

\subsubsection{Genitive}

The genitive is not well attested in Phrygian and often occurs in obscure contexts, where it is only identified because of the morphology of the word. This is the case of artimitos kraniyas 'of Artemis she-one of the spring' (B-05) and $\kappa v \alpha 1 \kappa o<\varsigma>\varepsilon \kappa \alpha \tau \eta \alpha \varsigma$ '(his) wife Hekataias' $(16.1=116)$. In any case, Phr. ben. is found in the common adnominal function, limiting the

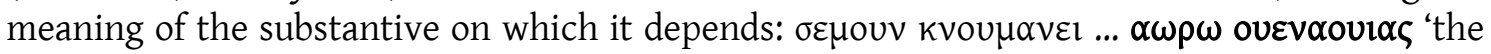

\footnotetext{
${ }^{159} \mathrm{It}$ is a very common feature in this kind of text, independently of the language. On a Myc. parallel, see Jiménez Delgado 2013. However, the influence of Achaemenid scribal practices on Aramaic and Elamite cannot be overlooked if one considers the context of this Phrygian text.
} 


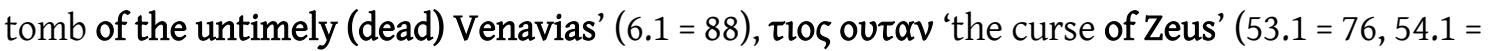
108 , etc.). Note that in the first example the gen. is found after the governing noun, while in the second the gen. precedes it.

As occurs in Greek and Lat., it is also found to indicate patronymics: ${ }^{160}$ bugnos vasos kanutii' evanoș? 'Bugnos (the son) of Vasus (the grand-son) of Kanutî̀ (P-02), s=manes iyungidas manitos manitos 'Manes Iyungidas (the son of) Manes' (B-07). A very interesting use is attested in

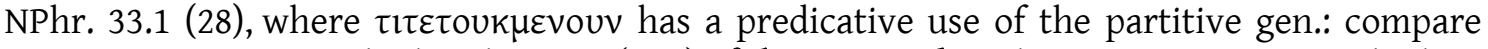

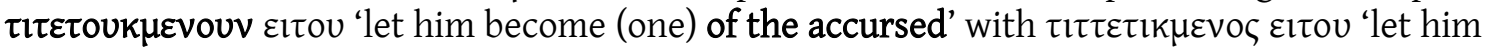
become accursed' (passim) ${ }^{161}$ Finally, it perhaps occurs after the preposition $\pi$ o $\rho$ once, if the suggested segmentation is correct (see 4.4.1.): $\pi$ op kopoos 'for the boy' (MPhr-01).

\subsubsection{Dative}

Commonly, the dative marks the indirect object of a verb: ates ... midai ... edaes 'Attes ...

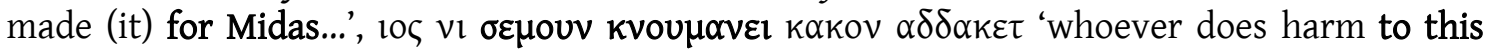
tomb...' $(62.2=33)$. A loc. function seems to be attested in some contexts: ${ }^{162}$ yos esai-t materey eveteksete 'y ovevin onoman daYet 'whoever puts his own name in this Mother eveteksete? ' $^{\prime}$ ' (W-

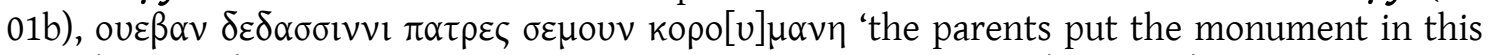
plot' $(2.2=130)$. Finally, dative is governed by some prepositions (see 4.4.1.): $\tau \imath \tau \tau \varepsilon \tau 1 k \mu \varepsilon v o \zeta \alpha \tau$ $\tau \imath(\varepsilon / \eta)$ 'accursed by Zeus' (passim), $\mu \varepsilon \delta \varepsilon \omega \varsigma$ $\kappa \varepsilon \zeta \varepsilon \mu \varepsilon \lambda \omega \varsigma \kappa \varepsilon$ 'in the sight of gods and men' (passim). These formulae haves variants without the preposition, which may indicate that the dative indeed has an agentive and locative meaning.

\subsubsection{Word order}

Phrygian is a subject-object-verb (SOV) language: ataniyen kuryaneyon (S) tan (DO)

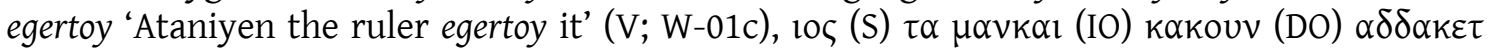
'whoever does harm to this stele' ( $\mathrm{V} ; 4.1=2)$. Nevertheless, the order is not always respected. Sometimes, DO clearly precedes the subject: sint imenan kaliya ti tedat [oy] 'this shrine, Kallias made it' (B-05). There are even clear examples of VS order in texts without metric: $\delta \alpha \kappa \alpha \rho \varepsilon v$

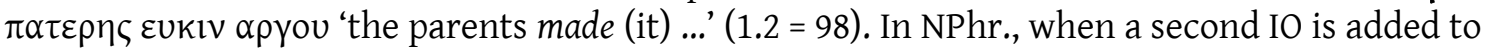

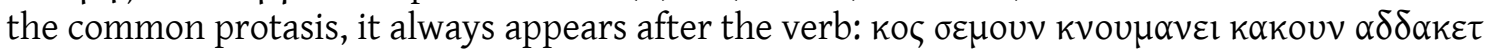
$\alpha \imath v \imath \mu \alpha v \kappa \alpha$ 'that one who does harm to this tomb or to the stele' $(11.2=18)$.

Phrygian, then, does not present great surprises in its word order. ${ }^{163}$ As is expected in this kind of language, Phrygian has prepositions instead of pospositions. Only one possible postposition is found but its context is not clear (see 4.4.1). The few examples of clear gen. show both positions, before and after the governing noun (see 4.3.3). The adj., however, commonly follows the noun: apelan mekas 'Apelan the great' (M-05), artimitos kraniygs 'Artemis she-one of the spring' (B-05), vasous iman mekas | kanutieivaịs | devọs ke mekas 'Vasus Iman the great, the son of Kanutî, and the great god' (P-03) materey eveteksete? $y$ (W-01b), matar kubeleya 'Mother of the (mountain) Kybelon' (B-01), $\mu \alpha v \kappa \alpha \mu \varepsilon \kappa \alpha \varsigma \sigma \alpha \varsigma$ (MPhr-01 = W-11), etc. The counterexamples can be considered emphatic: agaritoi petes 'devoted feet' (G-02, according to Kloekhorst 2015), $\alpha \omega \rho \omega$

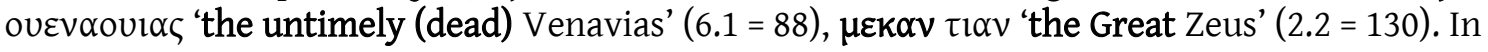

\footnotetext{
${ }^{160}$ Note, however, that adjectival patronymics also occur in the OPhr. Corpus: e.g. arkiaevais (M-01a).

${ }^{161}$ The pl.gen. form was identified by Ligorio \& Lubotsky 2013, 190. Regarding this function, compare with

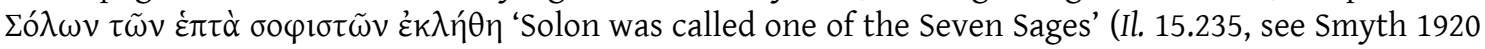
$\S 1304)$.

${ }^{162}$ The syncretism between dat. and loc. is found in Greek. However, the Greek athem. sg.dat. endings $(-1)$ go back to the PIE loc. ending $\left(*_{-}^{*}\right)$, while Phrygian presererved the genuine PIE ending $\left({ }^{*}-e y\right)$. So, there is no morphological trace of this syncretism in Phrygian.

${ }^{163}$ The features described here fit the universals suggested for the order of meaningful elements by Greenberg 1966. Of course, they are also shered with many ancient Indo-European languages.
} 


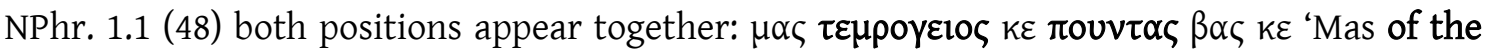
Tymbris and the Pontic Bas'. In addition, pronouns in their adjectival function almost always

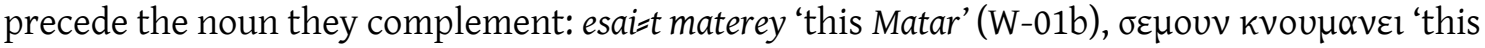
tomb' (passim). The exceptions are very few and restricted to two occurences of the indefinite

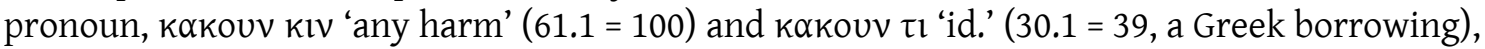
and the sequence $\mu \alpha v \kappa \alpha \mu \varepsilon \kappa \alpha \varsigma \sigma \alpha \varsigma$ 'this big stele' (MPhr-01 =W-11), which perhaps is a metrical consequence.

\subsubsection{Remarks on Lubotsky's rection rule}

Lubotsky (1997, 116 fn. 20) $)^{164}$ noticed that if "several members are conjoined by $\kappa \varepsilon$, the number and gender of the first member determines the rection". Indeed, this rule apparently

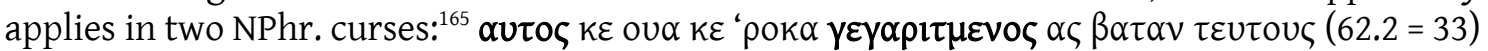

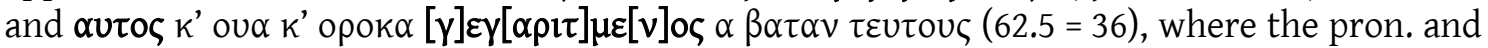

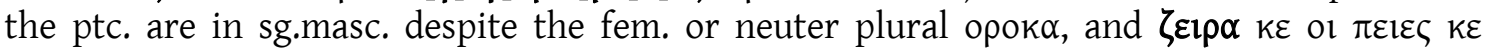
$\tau \imath \tau \tau \varepsilon \tau \iota k \mu \varepsilon v \alpha \alpha \tau \tau \imath \varepsilon \alpha \delta \varepsilon ı \tau \tau v o v ~(40.1=12)$, where the first noun and the ptc. are ambiguous (fem. sg.nom. or neuter pl.nom.-acc.?) despite the fem. or masc.pl.masc. $\pi \varepsilon 1 \varepsilon \zeta$.

Nevertheless, some remarks are in order. In 40.1 (12) the ptc. cannot be classified as a fem.sg. because the verb $\alpha \delta \varepsilon i \tau \tau v o v$ is in plural. Both words must agree in number, as can be

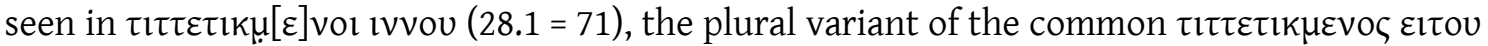
'let him be accursed' (passim). Then, if this word were a hapax it would be a neuter pl.nom.-acc. However, we know that this word is an a-stem because the sg.dat. is attested both in OPhr. and

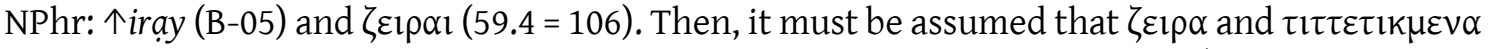
are pl.nom. with the drop of the second element of the diphthong: - $\alpha \mathrm{l}>-\alpha$ (Woodhouse 2007,

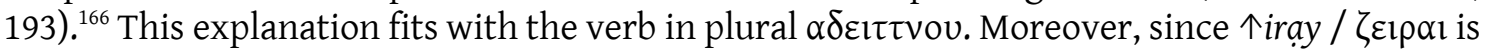
assumed to mean 'hand', the obscure word $\pi \varepsilon l \varepsilon \zeta$ is easly explained as an engraver's (if not

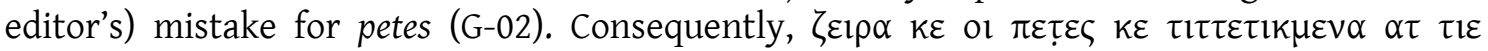
$\alpha \delta \varepsilon \imath \tau \tau$ ov can be translated as 'let (his) hands and his feet become accursed by Zeus'. ${ }^{167}$

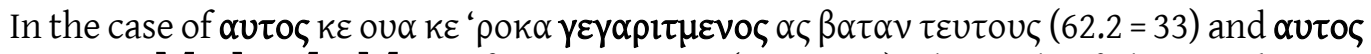

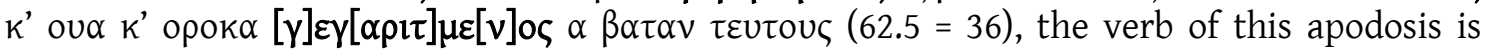
lacking. In Obrador-Cursach $(2017,308-309)$, the verb is hypothetically identified in $\tau \varepsilon v \tau o u=\varsigma$.

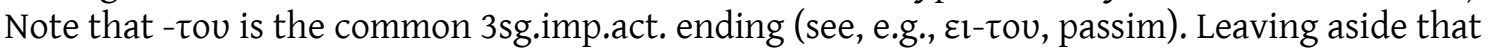
the stem of the verb remains unexplained (if inherited, $\tau \varepsilon v$ - goes back to PIE *teu- or *deu-), the suggested $\mathrm{pcl} .=\zeta$ seems to be unparalleled. However, we find an interesting parallel at the end

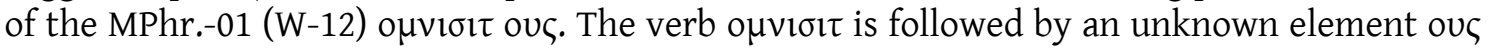
which is very likely the same $=\zeta$ found in the NPhr. inscriptions with crasis. Then, the verb again agrees in singular with the pron. and the subject. Nevertheless, a problem remains in ovo $k$ ' opoka. The first copulative conj. $k(\varepsilon)$ 'and' must join "this second apodosis to the first" and a second $\kappa(\varepsilon)$ is expected not after the clitic poss. ova but after opoka. Then, the correct

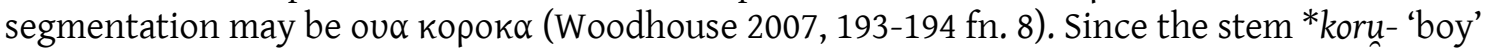
seems to occur in MPhr. kopoav (Lubotsky 2017, 430-431), Woodhouse's suggestion of dealing with a derivative of this stem is now more likely. ${ }^{168}$ Considering that кopok $\alpha$ is not joined to $\alpha \cup \tau o \zeta$ through any conj., one can assume that this noun is in neuter pl.nom.-acc. and the DO object of the verb $\tau \varepsilon \cup \tau o v$. Although identifying the verb will be the key to corroborating this

\footnotetext{
${ }^{164}$ The term "Lubotsky's rule" appears for the first time in Woodhouse 2007, 193. Although from a syntax point of view his paper is very interesting, I differ here from most of the lexical interpretations.

${ }^{165}$ I give here the common segmentation of these texts, not the one suggested in this dissertation.

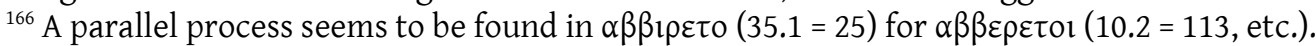

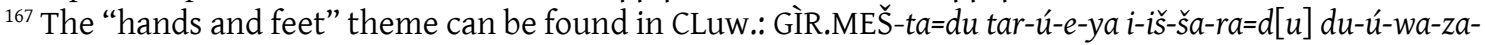
an ti-ya-am-mi-in du-ú-pí-t[a] (KUB 35.102+103 III 12-13).

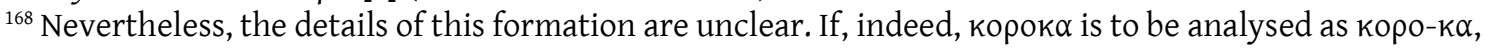
the suffix can be equated to $\mu \alpha \nu$ - $\alpha \alpha$ (a clear fem.sg.).
} 
hypothesis, the formula may be similar to those found in contemporaneous Greek imprecations from Phrygia referring to the children of the desecrator: see, e.g, the north Phrygian ó $\rho \varphi \alpha v \alpha$

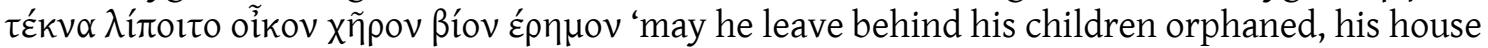
deserted, an empty life' (the east Phrygian curse formula, see Strubbe 1997, Appendix 2; it

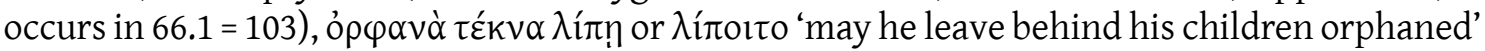

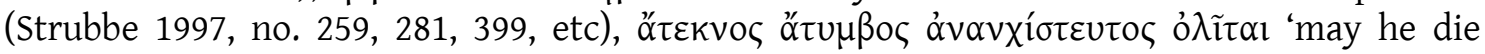

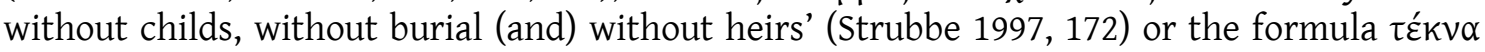

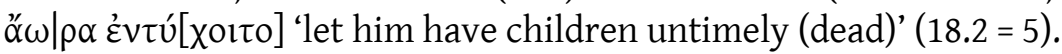

\subsection{Lexicon}

Most Phrygian words remain unexplained. This fact is illustrated by the detailed study presented in the main chapter of this work ( $\$ 5$, see also Table 33). Nevertheless, when identified, most of the basic lexicon is inherited, although there are many examples of borrowings, mainly from Greek in the NPhr. subcorpus (see $\S$ 4.6.1.3), but also from the Anatolian languages (\$ 4.6.2).

The available Phrygian lexicon, then, is almost exclusively restricted to onomastics (especially in graffiti, see Table 33), nouns referring to the monuments on which inscriptions appear, and verbs related to their construction. Indeed, at least 125 different PNs are attested in the Phrygian epigraphical corpus. Most of these PNs are Anatolian in origin: $k w a / i-l i-i(a)$, ku-li-i(a) (see Oreshko 2013a, 361) > kuliyas (G-127), ${ }^{\mathrm{m} U r a w a n n i}>$ urunis (G-346), etc. Lallnamen are especially common in Anatolia and the same tendency is found in Phrygian: atas (G-128), baba (M-01b, G-121), mama (G-173), etc. Greek and Persian PNs also appear: e.g. *mokuos (Myc.

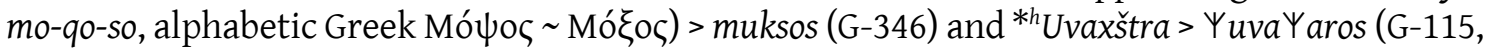

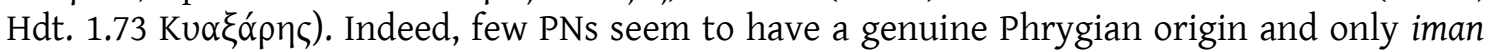
(M-06, G-136, G-210, etc.) can be confidently asserted. ${ }^{169}$

The Phrygian gods are also well paralleled in other Anatolian corpora, although the names of the main couple are properly Phrygian: matar 'Mother' (kubeleya B-01, areyasti- W-01a, etc.), ti- 'Zeus' (NPhr. passim) or $\beta \alpha \varsigma$ 'The shining one' (an epiclesis of Zeus, 1.1 = 48, 7.1 = 99,

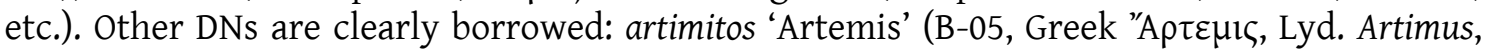
Lyc. Ertẽmi, its source remains unknown), mas 'Men' (very likely the Moon-God in $1.1=48$, a masculinisation of Persian $\mathrm{Ma})$ and $\delta$ rouvolv 'Dionysos' $(6.1=88) .{ }^{170}$

Toponyms only occur in derived words, mainly ethnics: e.g. $\tau \varepsilon \mu \rho о \gamma \varepsilon 10 \varsigma$ 'of the

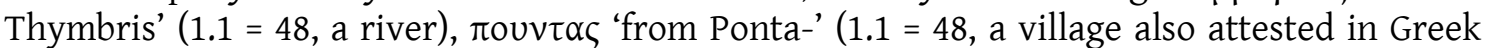
inscriptions, modern Gemiç) and kubeleya 'from Kybelon' (B-01, a mountain). The compound noun modrovanak 'sovereign of Modra/-oi' (M-04) contains the name of a city (found also in Str. 12.7 and Cons. VII, De Thematibus 4.28).

With regard to nouns, the Phrygian corpus attests many words referring to (parts of) the monuments or objects on which texts were engraved. In the case of the cult façades (their name in Phr. is unknown), the niche containing a relief of the Mother-Goddess is called keneman in M-01 and the relief itself seems to be vrekun. This noun appears in a W-01a, a façade that bore a large representation of the goddess, in M-06 its phonetic variant rekun designates the socalled 'Phrygian-idol' (a schematic representation in a step-cut monument) and, finally, in B05, a stele with a relief of a goddess (among others), the fem. vrekan seems to designate the representation: vrekan vitaran artimitoș kraniyas 'the vitaran idol of Artemis Kraniyas'. In once case the DN is used instead of this vrekun. Thus, in M-01b, matar 'Mother(-Goddess)' clearly refers to the representation: midas s=materan tvemes eneparkes? 'Midas engraved this MotherGoddess tvemes'. In B-01, bevdos refers to a lost statue in a triangular niche (Lubotsky 2008). In

\footnotetext{
${ }^{169}$ Nevertheless, there are many PNs only found in the OPhr. corpus without clear origin.

${ }^{170}$ I leave this question for a more detailed study in the future.
} 
the Vezirhan stele (B-05), iman clearly means 'shrine', since it is translated as ípóv in the short accompanying Greek text.

Funerary stelae appear in the Late Phrygian period (which corresponds to Achaemenid times). While in the first occurrence of an inscribed funerary stele the name given to it is a Greek borrowing stal? $a$ (B-06), from Hellenistic times they are consistently called $\mu \alpha v \kappa \alpha$ 'stele' (MPhr-01, NPhr. $3.1=97,11.2=18$, etc.), a Phr. word. There are at least three ways to refer to the whole (funerary) monument: $k v o u \mu \alpha v$ (NPhr. passim), veban (B-05) / oue $\beta \alpha v(1.1=48,2.2=$ 130 , etc.), equated to $\mu \nu \eta \mu \varepsilon \tilde{i}$ v 'monument, tomb' in 1.1. (48), and $\lambda \alpha \tau o \mu \varepsilon 10 v$, a Greek borrowing. Finally, there are several words that denote individual parts of tombs, although their specific referent is difficult to identify without a bilingual inscription. Indeed, the clearest examples of these words are borrowings from Greek: $\theta \alpha \lambda \alpha \mu \varepsilon l(18.1=4)$ 'funerary chamber',

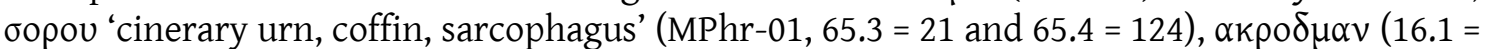
116) 'roof, top of the stele, pediment'?

Funerary inscriptions also attest another important semantic field: kinship. Several words have been identified: $\mu \alpha \tau \alpha \rho$ 'mother' $(11.2=18)$, knais 'woman, wife' (B-07), $\alpha v \alpha \rho$ 'man husband' $(2.1=15)$, $\pi \alpha \tau \varepsilon \rho \eta \varsigma(1.2=48) \sim \pi \alpha \tau \rho \varepsilon \varsigma(2.2=130)$ 'parents', patriyio 'is? 'relatives' (B-04), $\beta \rho \alpha \tau \varepsilon \rho \varepsilon$ 'brother' $(40.3=31)$, nevos 'son' or 'male-descendant' (B-05) and niptiya- 'daughter' or 'female-descendent' (B-05).

The attested verbs are divided into two main groups according to their meaning: verbs referring to the construction of the monuments and verbs referring to the curses. The first group contains verbs suchs as edaes 'he made, put' (M-01a, M-02, etc., compare with Greek

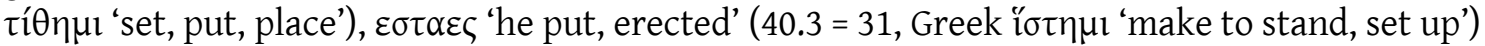
and their derivatives. In the second group, we find verbs of the imprecative protasis, $\alpha \delta \delta \alpha \kappa \varepsilon \tau$

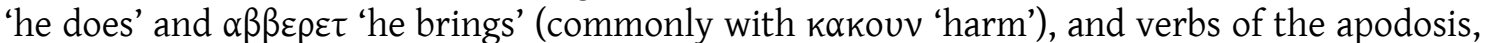

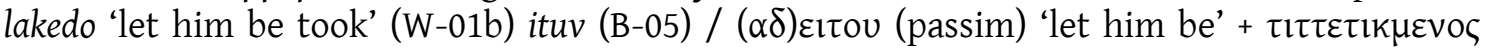

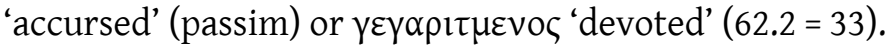


Table 33 Classification of the lemmata considered in the Lexicon of the Phrygian Inscriptions

\begin{tabular}{|c|c|c|c|c|c|c|c|c|c|c|c|c|c|c|c|c|c|c|c|c|c|c|c|c|}
\hline Categ. & $a-\alpha$ & $b-\beta$ & $g-\gamma$ & $d-\delta$ & $e \varepsilon$ & $v-f$ & $\uparrow-\zeta$ & $\eta$ & $\theta$ & $i-1$ & $k \Psi-k$ & $l-\lambda$ & $m-\mu$ & $n-v$ & $\xi$ & $0-0$ & $p-\pi$ & $r-\rho$ & $s-s$ & $t-\tau$ & $u-v$ & $y$ & ac. & Total \\
\hline PN & 32 & 5 & 3 & 8 & 5 & 4 & & & & 8 & 8 & 2 & 16 & 5 & 1 & 1 & 2 & 1 & 5 & 10 & 4 & & 3 & 123 \\
\hline PN? & 5 & 6 & & 6 & 6 & 1 & 1 & & & 3 & 6 & 3 & 4 & & & & 0 & 1 & 1 & 6 & 5 & & 26 & 80 \\
\hline $\mathrm{DN}$ & 1 & 1 & & 1 & & & & & & & & & 1 & & & & & & 2 & 1 & & & & 7 \\
\hline Noun & 9 & 4 & 2 & 6 & 3 & 4 & 3 & & 1 & 2 & 12 & 2 & 13 & 3 & & 6 & 5 & 1 & 7 & 5 & & & 1 & 89 \\
\hline Noun? & 2 & & & 1 & 4 & & 1 & & & 1 & & 2 & 1 & & & 3 & 6 & & 2 & 6 & & & 4 & 33 \\
\hline Adj. & 4 & & 1 & 1 & 5 & & 1 & & & 1 & 3 & 1 & 3 & 2 & & 3 & 2 & & & 3 & 1 & & & 31 \\
\hline Adj.? & 1 & & & & & & & & & & 1 & & 1 & & & & 2 & & & & & & 1 & 6 \\
\hline Pron. & 1 & & & & & 2 & & & & 2 & 2 & & & & & 1 & & & 1 & 2 & & 1 & & 12 \\
\hline Verb & 3 & & 2 & 2 & 8 & & & & & 4 & 1 & 1 & & & & 2 & 2 & 1 & & 5 & 1 & & & 32 \\
\hline Verb? & 6 & & & & 8 & 2 & & & & 1 & 2 & & & & & 3 & 2 & & 1 & & 1 & & 1 & 27 \\
\hline Prep. & 4 & & & 1 & 1 & & & & & & & & 1 & & & 1 & 1 & & & & & & & 9 \\
\hline Prep.? & 1 & & & & & & & & & & & & & & & & & & & & & & & 1 \\
\hline Conj. & 3 & & & & 1 & & & & & & 1 & & & & & & & & & & & & & 5 \\
\hline AdvPar. & & & & & 2 & & & & & & & & 1 & 2 & & 1 & & & & & 2 & & & 8 \\
\hline Adv.? & & & & & & & & & & & 1 & & & & & & & & & & & & & 1 \\
\hline Num. & & & & & & & & & & & & & & & & 1 & & & & & & & & 1 \\
\hline Mark & 1 & & & 1 & 1 & 1 & 1 & & & & 2 & & 1 & 2 & & & & & 1 & 1 & 1 & 1 & 2 & 16 \\
\hline Unkn. & 24 & 5 & 3 & 9 & 11 & 7 & & 1 & & 13 & 5 & 1 & 10 & 10 & & 16 & 16 & & 7 & 14 & 2 & 5 & 143 & 302 \\
\hline Total & 97 & 21 & 11 & 36 & 55 & 21 & 7 & 1 & 1 & 35 & 44 & 12 & 52 & 24 & 1 & 38 & 38 & 4 & 27 & 53 & 17 & 7 & 181 & 783 \\
\hline
\end{tabular}




\subsection{The place of Phrygian in the Indo-European language family}

Scholars have long debated the exact position of Phrygian in the Indo-European language family. Although this position is not a closed question because of the fragmentary nature of our current knowledge, Phrygian has many important features which show that it is somehow related to Greek and Armenian. Thracian, Macedonian and Albanian are often considered as being close to Phrygian, but the relationship is too problematic for them to be useful sources for comparison. ${ }^{171}$ Greek and Armenian are often postulated to derive from a common proto-language (Greco-Armenian). Although this assumption is based only on similarities between Proto-Greek and Proto-Armenian, which are not sufficient evidence to hypothesise a discrete Proto-Greco-Armenian, the relations between the two proto-languages "may have been intense" (Martirosyan 2013, 86). In any case, the similarities are such that the exact position of Phrygian is difficult to determine, a fact that is apparent in the history of Phrygian studies.

Indeed, between the $19^{\text {th }}$ and the first half of the $20^{\text {th }}$ C. BC Phrygian was mostly considered a satam language (a feature once considered important to establishing the position of a language) and, especially after Alf Torp's study, closer to Armenian (and Thracian), ${ }^{172}$ whereas it is now commonly considered to be closer to Greek. However, both those who favoured a Greek proximity for Phrygian ${ }^{173}$ and those who preferred the Armenian way ${ }^{174}$ adduced historiographic sources rather than linguistic ones, before the publications of Lejeune, Haas and Brixhe, simply because very few Phrygian inscriptions had been discovered until the end of the $19^{\text {th }}$ and the beginning of the $20^{\text {th }} \mathrm{C}^{175}$

Brixhe (1968), Neumann (1988) and, through an accurate analysis, Matzinger (2005) showed the inconsistency of the Phrygo-Armenian assumption and argued that Phrygian was a language closely related to Greek. Note, however, that these authors did not consider the Phrygian Lautverschiebung as proposed by Lubotsky (2004). This has been a significant boost to Phrygian studies over in the last decade, although it is not great value for elucidating the language's position. In any case, the question of its origin is complex, and Armenian is often cited as the language closest to Phrygian in modern publications. Recently, Hämmig (fthc. a and b) has claimed that most of the arguments for Phrygian's closer proximity to Greek are superfluous. She is certainly right to state that more in-depth studies are needed. Nevertheless, she also tried to show that Phrygian is closer to Armenian, and this position is not better defended than the others. Her argument is twofold: ${ }^{176}$

${ }^{171}$ The Thracian corpus is too short to give an overview of this language and Macedonian is better explained as a Greek dialect than a proper language (see Méndez Dosuna 2012). Albanian is attested as late as $14^{\text {th }} \mathrm{c}$. and shows many particularities that hinder the comparison with earlier languages. On the relationship with PIE see Klingenschmitt 1994 and, for a detailed discussion on Albanian historical phonology, see Demiraj 1997, 41-67.

${ }^{172}$ The relationship with Thracian is still considered by Brixhe (2006). However, I do not consider the possibility here because Thracian is a poorly attested language and such a relationship is ultimately based on Str. 7.1.25 (see also 7.3.2, 10.3.16 and 12.3.20), who considered that Phrygians were in origin a Thracian

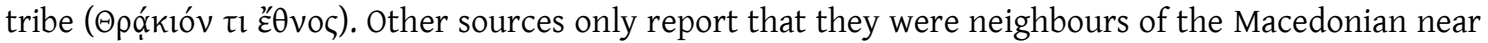

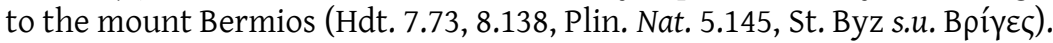

${ }^{173}$ W. C. Moriz Schmidt $(1869,133-141)$, Fick $(1873,409-417)$ and Ramsay $(1887,381)$.

${ }^{174}$ Mordtmann (1862), Gosche (1864, 84-86) and Torp (1894, 3-8) were the most important supporters of the Phrygo-Armenian relation in the beginning of the Phrygian studies.

${ }^{175}$ On this issue, one must consult the PhD dissertation by Morante Mediavilla defended in 2007 (unfortunately unpublished), which provides an exhaustive overview of Phrygian studies up to the publication of Ramsay's works.

${ }^{176}$ Of course, Hdt. 7.73 is also considered an ancient authority considering that Phrygians and Armenians

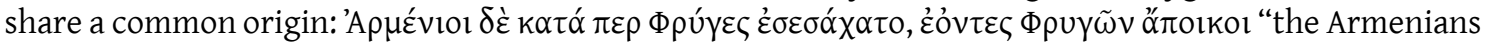
were armed just like the Phrygians, being settlers from the Phrygians". Also Eudoxus of Cnidus, as quoted

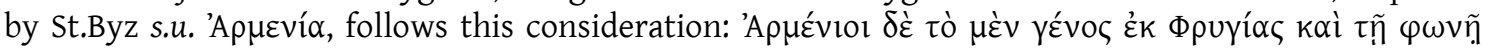


1. The Phrygian shift ${ }^{*} p>\langle\mathrm{V}\rangle / \mathrm{V}_{-} \mathrm{V}$ is similar to Armenian ${ }^{*} p>w / V_{-} \mathrm{V}$ (Hämmig 2013, 136-137).

2. The suffix *-ske/o- became a subjunctive marker in both languages and it yielded -ic'in Armenian and $-s / \Psi$ - in Phrygian. Perhaps, also aor. in -es goes back to a form derived through the same suffix, ${ }^{*}$-esket, although it is still less clear.

In my opinion, these two isoglosses (the first phonetic, the second morphological) do not prove that Phrygian has a closer position to Armenian. Of course, Phrygian is only fragmentarily attested and we ignore most of the features of this language. Therefore, the relevance of each feature must be judged not on the basis of quantity but on its quality. Nevertheless, the first feature has only been identified in one word, *nepots > nevos (Hämmig 2013), and one cannot rule out a local shift restricted to Bithynia. To complicate the matter further, unlike the PIE voiced and aspirated stops, the voiceless stops preserved their original articulation. Only in B-05 and only for this word does such a shift occur. Consequently, it may be considered a recent shift (if not a local feature). ${ }^{177}$ Indeed, the whole Phrygian Lautverschiebung can be compared to the Armenian stop shift. However, the only shift ${ }^{178}$ which is well attested in both Phrygian and Armenian is the devoicing of the PIE voiced stop series and it is not a strong evidence to postulate a common development, since it is found in many languages (e.g. in PGm. and To.).

Regarding to the second feature, it is neither an evidence for her hyphothesis. The interpretion of $\langle\Psi\rangle$ as representing something related to a sibilant is refuted here (see $\S 3.1 .3$ ), which rules out the possibility that forms with this letter contain the development of the suffix *-ske/o. In addition, it is possible that such suffix appears as -sk-in three instances: podaskai? (G-

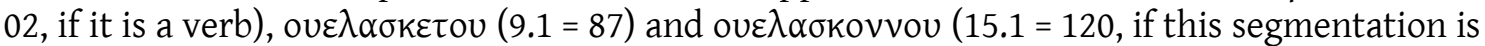
right, as also Hämmig, f.c., suggested). However, these forms are not clear enough to be used here. In any case, forms with $-s^{-} /-(\sigma) \sigma$ - between vowels (which she equated to $\langle\psi\rangle$ ) can be explained as a reintroduction similar to the one happened in the Greek sigmatic aor. and fut. In

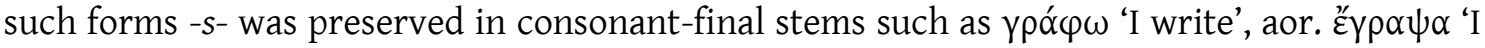
wrote' and later restored in verbs where it was lost (Chantraine 1984, 177 or Duhoux 2000, 377).

In the light of the available data, it is preferable to consider that Phrygian is closer to Greek than it is to Armenian. This tentative conclusion is based on some relevant features of the Phrygian language shared between Phrygian and Greek which are discussed on the following pages (summarised in Table 34). Furthermore, if Phrygian were not so-poorly attested perhaps we could reconstruct a Proto-Greco-Phrygian stage of both languages. Indeed, it is not only that Phrygian and Greek share a relatively large number of isoglosses and innovations, but also that not a single relevant isogloss restricted to Phrygian and Armenian is found. Then, I agree with Matzinger (2005, 377, despite the Lautverschiebung question) when he says "dass die Annahme einer besonderen Nähe zwischen Phrygisch und Armenish von Seiten der Sprachwissenschaft nicht zu stützen ist." Unfortunately, the Phr. verb has not been well studied and could be at the centre of this discussion in future work. Moreover, new findings could provide more features with which to corroborate or reject this statement. Therefore, the conclusion given here cannot be considered definitive.

$\pi 0 \lambda \lambda \grave{\alpha} \varphi \rho v \gamma i ́ \zeta o v \sigma r$ 'the Armenians are native of Phrygia and their tongue resembles very much the Phrygian one.' In any case, we do not have much information about the Armenian Language until the $5^{\text {th }}$ c. BC.

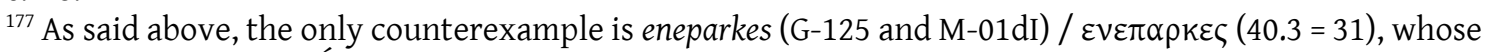
root goes back to *perk- (as suggested Lejeune 1969b, 291-194), but the stop was very likely preserved in forms without augment and was perhaps preserved after these forms.

${ }^{178}$ The shift PIE voiced aspirate stops > Armenian voiced stops, which is general in Phrygian, is still problematic for Armenian. See Clackson 2008, 127-130, who suggests that the letters transliterated as voiced stops can represent voiced aspirate stops. 


\subsubsection{Phonological isoglosses}

1. As has been argued in $\S 4.1 .2 .2 .2$, Phrygian belongs to the centum group of IE languages. Together with Greek, Celtic, Italic, Germanic, Hittite and Tocharian, Phrygian merged the old palatovelars with plain velars in a first step. However, as happened in Tocharian and the Romance languages, Phrygian subsequently also merged the old labiovelar with the plain velar (the etymological and the resulting ones), and in contact with palatal vowels (/e/ and /i/) some consonants became palatalised. These two secondary processes lend Phrygian the guise of a satom language.

2. In the attested positions, Phrygian shows the same reflexes as the old PIE laryngeals found in Greek, including the so-called "prothetic vowel" (see $\S 4.1 .2 .2 .3$ ). This feature is also shared with Armenian (Martirosyan 2010, 714-716, also 2013, 89).

3. The PIE sibilant /s/ is lost at the beginning of a word and in intervocalic position. Phrygian, as well as Greek, Armenian and Albanian, has lost the sibilant/s/ at the beginning of the word and in intervocalic position. Note, however, that this feature is also shared with Lycian, so it is not a very significative for our question. ${ }^{179}$

4. The PIE suffix ${ }^{*}-i h_{2}$ yields -iya in OPhr. niptiya (B-05), a development also found in

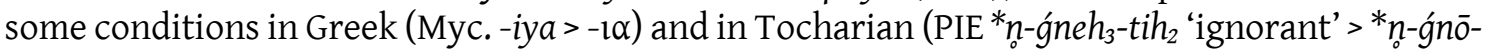
tyH > PTo. āknätsā > ToB aknātsa, cf. Latin ignōtus 'unacquainted with a thing, ignorant of'). In

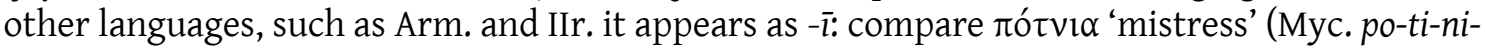
ja) < * potnih 2 with Ved. pátn̄̄ 'mistress, godess', Y.Av. paقnī- and Old Lith. vieš-patni 'housewife'.

\subsubsection{Morphological isoglosses}

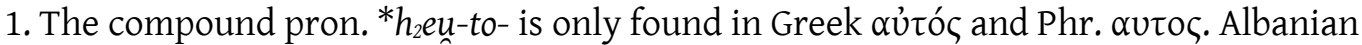
has an adverb derived from the zero-grade of this formation: * $h_{2} u-t o$ - > hut 'in vain' (compare with Greek $\alpha$ ú $\tau \omega \varsigma$ 'in this very manner, even so, in vain', Demiraj 1997, 59). A similar formation is Alb. aý 'this, he' < *he $h_{2}$-so- (Demiraj 1997, 70 and Matzinger 2005, 384).

2. Phrygian seem to share with Greek the existence of a suffix *-eú- /-ēu-: Gr. -عúc / $\varepsilon \varepsilon^{\prime} \omega$ (Epic -ño)), Phr. -avos (thematised). As happens in Greek, the Phrygian forms with this suffix are titles whose origin is not always clear: akenan-ogavos ('the holder of the akenan'? M-

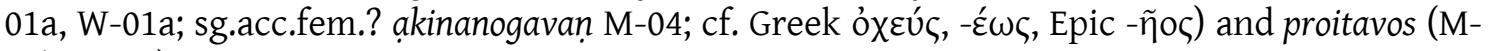
01b, M-02).

3. Phrygian shares the e-augment with Greek, Arm. and IIr.: compare 3sg.aor. PIE * $\left(h_{1}\right) e^{-}$ $d^{h} e_{1}-t$ '(s)he put', OPhr. e-da-es, Greek 'z- $\theta \eta-k \alpha$, Armenian $e-d$ and Skt. á-dhā-t. This is a very significant morphological isogloss, according to Martirosyan $(2013,90)$.

3. Phrygian perfect participles are built through the PIE suffix *-mh ${ }_{1}$ no-, as well as Greek $\left(-\mu \varepsilon v o \varsigma_{-}\right)$. The exact form is also found in ToA -mām, ToB -mane and Prakrit -mina- (slightly different to Skt. -a-māna-, Av. - $a-m n a-)$ and frozen in some Lat. words such as alumnus ( ${ }^{*} h_{2} a l-o-$ $\left.m h_{1} n^{-}\right)$or fēmina $\left(<{ }^{*} d^{h} h_{1}-m h_{1} n a h_{2}-\right)$.

4. Despite the phonetic problems discussed in $\S 4.1 .2 .2 .3$, the prohibitive pcl. ${ }^{*} m e h_{1}$ is found in Phrygian as $m e$ / $\mu \varepsilon$, as well as in Arm. $m i$, Skt. $m \vec{a}$, Av. $m \bar{a}$, Gr. $\mu$, Alb. mo and ToAB $m \bar{a}$ (also used for simple negation 'no' in To.).

5. Phrygian pcl. ni(y) / vi is also found in Pamph. kaí vi + imperv. (Pamph. 3, see Brixhe 1976, 131-132), although its use in both languages is different.

${ }_{179}$ Gusmani 1959b, 13-14 considered that Phrygian and Lycian where in contact when this sound disappeared. However, it is not necessary since this loss takes place in many unrelated languages. 
6. In the light of $v \psi \circ \delta \alpha v$ 'above, on the top', Phrygian also has a loc. pcl. *-d ${ }^{h}$ n attested in some Greek dialects as $-\theta \alpha$ (e.g. Aeol. $\pi \rho o ́ \sigma-\theta \alpha$ ‘before’).

7. A Greek innovation shared with Phrygian is found in the sg.nom. of PIE *méǵh ${ }_{2}$ ' 'big', where both languages added the ending -s: compare OPhr. mekas and Greek $\mu$ ź $\gamma \propto \zeta$ with Skt. máhi and Arm. mec.

8. In the Phr. corpus two denominative verbs are found: kakoioi (G-02c, also kakuioi P04b; see Lejeune 1969b, 299) and kuryaneyon (W-01c). The first is a verb in -o-yo- derived from an o-stem noun, kako-, while the second is in -e-yo-, derived from an o-stem noun, although only attested in Greek koípavo , -ov. In both cases one cannot rule out an early Greek borrowing dated to Myc. times. However, there is no phonetic reason to rule them out as Phrygian cognates of the Greek forms.

\subsubsection{Lexical isoglosses}

4.5.3.1. A derived noun $* b^{h} o h_{2}-t-/{ }^{*} b^{h} e h_{2}-t$ - from the PIE verbal root $* b^{h} e h_{2^{-}}$'to shine' (LIV² 68-69, IEW 104-105) has been largely considered to yield in Greek $\varphi \tilde{\omega} \varsigma, \varphi \omega \tau$ tó $\varsigma$ 'man, mortal, hero' (Peters 1993, 101-108 and Vijūnas 2009, 72-76, following a previous suggestion by Brugmann \& Delbrück 1906, 536; NIL 7). Recently, such a formation has been claimed for the Phrygian DN $\beta \alpha \varsigma$ (see Obrador-Cursach 2017).

4.5.3.2. The formation * $\left(h_{1}\right)$ en-mén- (LIPP II, 234) derived from *men 'stand fast, remain'

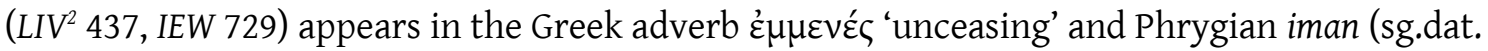
inmeney, B-05) according to Vine (2010). It is also found in OIr. ainmne 'patience'.

4.5.3.3. Although the root * ğ $^{h} h_{3^{-}}$' 'green, yellow' is found in Greek $\chi \lambda \omega p o ́ \varsigma$ 'greenishyellow, pale green', in Lat. helus, (h)olus 'green plants, vegetables, cabbage', in Skt. hari- 'fallow, greenish' (used in compounds), etc., the formation * ${ }^{h} l_{0} h_{3}$-ró- is only found in Greek $\chi \lambda \omega \rho o ́ s$ and Phrygian $\gamma$ 入oupeos 'golden' (MPhr-01 1. 2 identified by Brixhe 2004a, 17 through the Hesychius

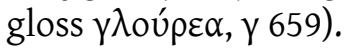

4.5.3.4. Here, OPhr. keneman 'cavity, niche' (M-01b) is suggested to derive from *ken-e/o'empty', a form found in Gr. *ken(e)-uó- 'empty, idle' (Att. kEvós, Ion. keıvós, Epic and Dor. KEveó() and Armenian sin, sn-oy 'empty'. ${ }^{180}$ Previously, keneman was considered to derive from * $k h_{1^{-}}$, attested in Sanskrit khánati 'to dig' (Lubotsky 1988, 15 and Ligorio \& Lubotsky 2013, 189 and 192-193), but this root is not found out of IIr.

4.5.3.5. The PIE verb *sleh $g^{u}$ - 'take hold of, grasp' (LIV² 566, IEW 958) was only attested in Greek $\lambda \alpha \beta \varepsilon \tilde{i v}$ 'id.' until Lubotsky $(2004,234-235)$ equated to Phrygian lakedo (W-01b).

4.5.3.6. The stem koru- (perhaps derived from * kerh ${ }_{3}$ ' 'grow' LIV² 329, IEW 577) is a Greek

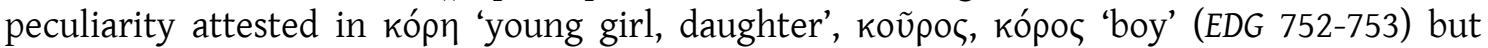
recently it has also been identified in MPhr. kopo- (MPhr-01, Lubotsky 2017). A borrowing in the prehistory of the both languages cannot be altogether ruled out.

${ }^{180}$ EDG 672, Clackson 1994, 138-139 and Martirosyan 2010, 575 and 2013, 116. 
Table 34 Comparison of Phrygian features with Greek, Armenian, Albanian and Indo-Iranian (grey files indicate that a borrowing cannot be totally ruled out)

\begin{tabular}{|c|c|c|c|c|c|}
\hline & Phrygian feature & Greek & Armenian & Albanian & Indo-Iranian \\
\hline \multirow{4}{*}{ 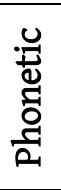 } & "prothetic vowels" & + & + & $?$ & - \\
\hline & Loss of $/ \mathrm{s} /$ & + & + & + & - \\
\hline & Centum treatment & + & - & - & - \\
\hline & $*_{-i h_{2}}>-i y a$ & + & - & + & - \\
\hline \multirow{10}{*}{ 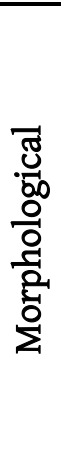 } & $e$-augment & + & + & + & + \\
\hline & $*_{-}$eu- / *-eu- & + & - & - & - \\
\hline & $*_{-}-d^{h} n$ & + & - & - & - \\
\hline & ${ }^{*} h_{2}$ eu-to- & + & - & + & - \\
\hline & ${ }^{*}$ méǵh $_{2}-s$ & + & - & - & - \\
\hline & ${ }^{*} m_{e} h_{1}$ & + & + & + & + \\
\hline & *-mhino- & + & - & - & - \\
\hline & $n i(y) / v i$ & + & - & - & - \\
\hline & verbs in -o-yo- & + & - & - & - \\
\hline & verbs in $-e-y o-$ & + & - & - & - \\
\hline \multirow{6}{*}{ 胥 } & $* b^{h} \mathrm{oh}_{2}-t-/{ }^{*} b^{h} e h_{2}-t-$ & + & - & - & - \\
\hline & $*\left(h_{1}\right)$ en-mén- & + & - & - & - \\
\hline & ${ }^{*} g_{0}^{h} l h_{3}-r o ́-$ & + & - & - & - \\
\hline & ken- & + & + & - & - \\
\hline & $*^{*}$ sleh $_{2} g^{u}-$ & + & - & - & - \\
\hline & ${ }^{*}$ koru- & + & - & - & - \\
\hline
\end{tabular}




\subsection{Phrygian in contact}

Because Phrygian was spoken in central Anatolia and was surrounded by many languages, as well as several ruling peoples, it came into contact with several languages, mainly Greek and some Anatolian tongues (Hittite, Luwian, Lydian and Lycian), but also with Assyrian, Aramaic, Old Persian, Elamite, Galatian and Latin. In this chapter, this contact will be considered language by language.

\subsubsection{Phrygian in contact with Greek}

Leaving aside prehistoric contacts between Greek and Phrygian, which are difficult to ascertain, Greek is present to a varying degree in the whole history of the Phrygian language, from the adaptation of the alphabet to the time of the NPhr. inscriptions. This presence is manifested in bilingual inscriptions, loanwords, onomastics and even in the use of Greek verse patterns in Phrygian. The relationship between Greek and Phrygian was not unidirectional, since a Phrygian influence can be perceived in borrowings into Greek and in the language of the Greek inscriptions from Phrygia. ${ }^{181}$

\subsubsection{Greco-Phrygian bilingual inscriptions}

All Phrygian bilingual inscriptions are Greco-Phrygian, with the sole exception of an Aramaic-Phrygian graffito on a sherd (G-157). The oldest Greco-Phrygian inscription (B-05) appeared in Vezirhan, Bithynia. It is engraved on a Greco-Persian stele and consists of 13 long lines of Phrygian text and 7 shorter lines of Greek under a relief depicting a goddess, a banquet and a hunting scene. Because of the great difference between the length of the two texts, it is clear that they are not word-for-word translations. Indeed, it is assumed that the Phrygian text was the original while the Greek was added sometime later as a summary of the Phrygian. Moreover, this addition is shown by the position of the Greek text, which was engraved in the empty space of the stele in two parts, one (1.1-5) above the Phrygian text and the other below (1. 6-7). The clearest correspondences between the content of the two texts can be seen in Table $35:^{182}$

Table 35 Equivalences between the Phrygian and Greek texts of B-05

\begin{tabular}{|c|c|c|c|}
\hline \multicolumn{2}{|r|}{ Phrygian text } & \multicolumn{2}{|r|}{ Greek text } \\
\hline L. 1 & $\begin{array}{l}\text { sin=t imenan kaliya ti tedat [...] } \\
\text { 'this monument Kallias erect[ed]' }\end{array}$ & L. $1-3$ & 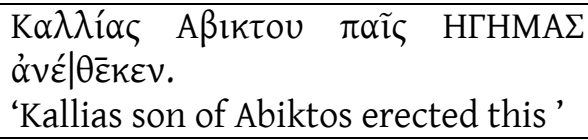 \\
\hline L. $8-9$ & $\begin{array}{l}\text { yos niy art sin=t imenan kaka oskavos } \\
\text { kakey| kan dedasitiy tubetiv } \\
\text { 'whoever does harm around this } \\
\text { monument...' }\end{array}$ & L. $3-4$ & 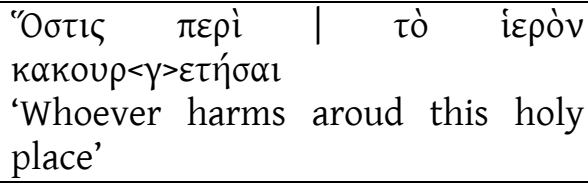 \\
\hline L. 11 & $\begin{array}{l}\text { torvetun } \text { 个iray } \\
\text { 'cutting by his hand'? }\end{array}$ & L. $4-5$ & 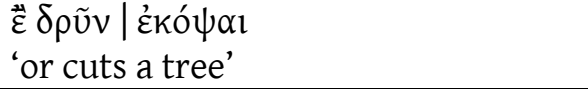 \\
\hline
\end{tabular}

The difference between this text and the other bilingual inscriptions is that it contains similar information, although the Greek text is a summary of the Phrygian. Note, however, that

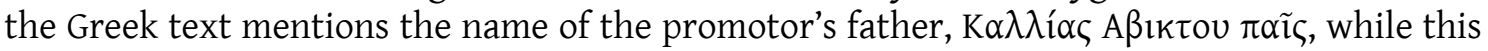
information is not found in the Phrygian version, where only kaliya is mentioned. Simon (2015)

\footnotetext{
${ }^{181}$ This chapter is based on Obrador Cursach fthc. c. On the relationship between Phrygian and Greek, see Neumann 1988.

${ }^{182}$ For a deeper analysis of this important monument see Hämmig 2013, followed here.
} 
also equated the last Phrygian line, yos isekosos 个emeney dupratoy veban ituv, to the conclusive

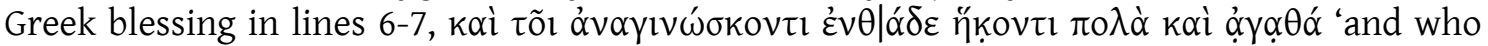
coming here reads it, many and good things to him'. Although Simon defends his hypothesis with an etymological analysis of each word, based on a good knowledge of Phrygian historical phonetics, the occurrence of veban in the NPhr. inscription 2.2. (130, firstly edited by Avram 2015) invalidates the equation of the two texts, since in NPhr. this word clearly refers to the

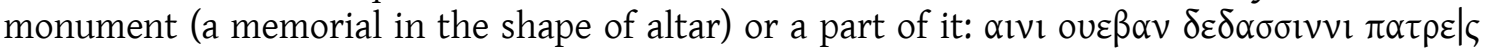

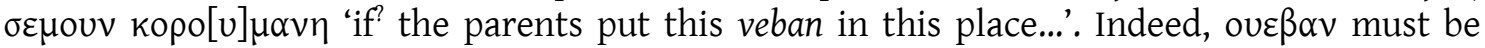
equated to $\mu v \eta \mu$ ó $u v$ vov 'memorial' in the Greek part of this NPhr. inscription (Face A).

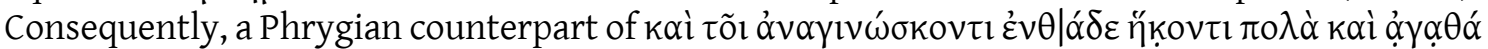
seems to be lacking. In any case, despite the excellent analysis given by Hämmig (2013) of lines 8-13 (the imprecative part of the text), most of this large inscription remains obscure.

The Vezirhan stele is the only Greco-Phrygian bilingual inscription in the whole OPhr. subcorpus. By Roman times, however, most NPhr. inscriptions are bilingual, although commonly the epitaph proper is written in Greek, while the Phrygian is restricted to a formulaic curse, usually in a secondary position. ${ }^{183}$ So, both parts of these funerary texts are independent clauses and the Phrygian curses were added systematically as a formula. ${ }^{184}$ Only five texts of the 63 bilingual inscriptions from Roman times show a real connexion between the Greek and the Phrygian texts:

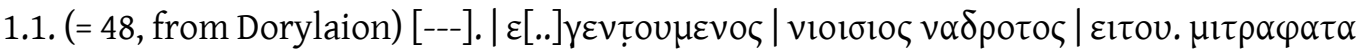

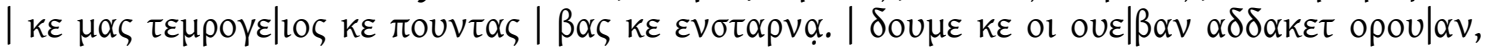

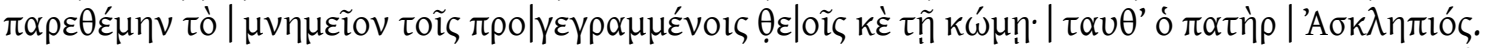

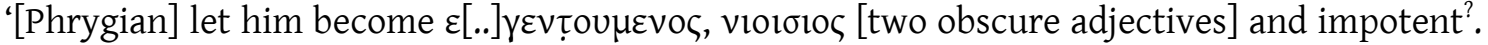
Mitrapata and Mas Timbrogic and Bas Pontic were appointed. And for (the care of) the religious community the 'father' has put his (tomb)stone. [Greek] The father Asklepios put this memorial under the protection of the gods written above and the community'. ${ }^{185}$

1.2. (98 = MAMA V Lists I no. 182.89, from Dorylaion) K $\lambda \omega \delta i ́ \alpha \mid$ Го

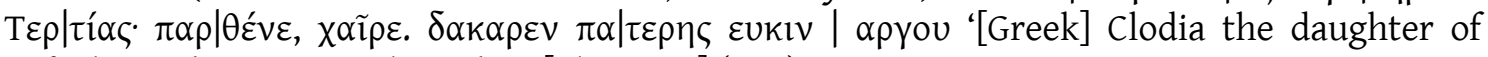
Sofocles and Tertias. Hail maiden! [Phrygian] (Her) parents set it up as a vow'.

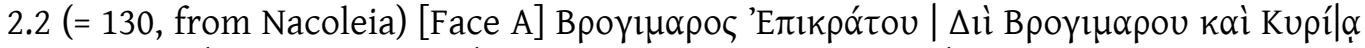

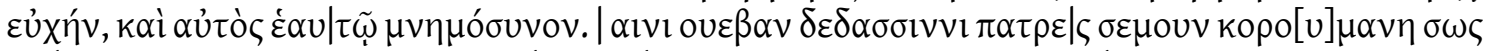

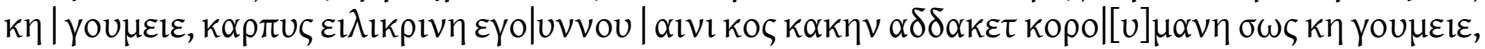

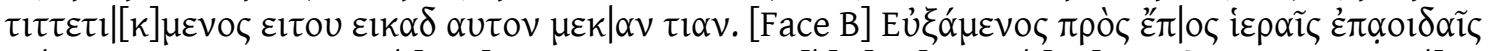

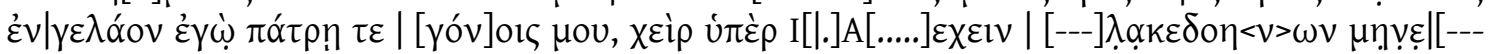

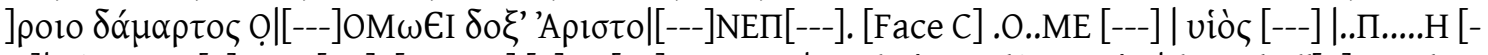

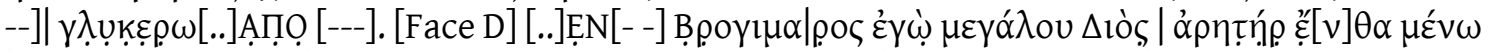
| ípoĩ of the Greek text, 1. 1-4:] '[Greek A:] Brogimaros (son) of Epikrates (dedicates) to Zeus of Brogimaros and to Kyria (his wife) a prayer; and he (dedicates) also the tomb for himself'. [Phrygian] If? the parents put this tomb in this place, ... If anybody does harm to this place and

\footnotetext{
${ }^{183}$ Only in two inscriptions, 14.1 (122) and 59.1 (72), does the Phrygian formula precede the Greek epitaph. ${ }^{184}$ This is the disposition of texts in 3.1 (97), 4.1 (2), 7.2 (111), 7.3 (14), 10.1 (112), 14.1 (73), 17.1 (4bis), 17.4 (90), 17.6 (119), 18.1 (4), 20.2 (128), 21.1 (42), 21.2 (43), 23.1 (89), 25.1 (115), 25.2 (126), 27.1 (92), 30.1 (39), 30.2 (68), 31.1 (125), 33.1 (28), 33.3 (127), 34.1 (37), 37.1 (10), 40.1 (12), 44.1 (61), 44.3 (67), 46.1 (53), 47.1 (51), 48.1 (81), 48.2 (84), 48.3 (85), 50.1 (54), 50.2 (55), 53.1 (76), 53.3 (109), 55.1 (56), 56.1 (57), 57.1 (78), 59.1 (107), 59.2 (47), 59.3 (79), 60.2 (60), 62.1 (32), 62.2 (33), 62.3 (34), 62.4 (35), 62.5 (36), 63.1 (123), 64.1 (82), 65.1 (20), 65.3 (21) and 65.4 (124). It must be added than in 58 the Greek epitaph is followed by a nonimprecative Phrygian text, but with an exhortation against burying someone else in the tomb. Note also that many of the inscriptions consisting of a Phrygian curse very likely originally followed a Greek text, which was lost as these funerary monuments deteriorated.

${ }^{185}$ This tentative translation is based mainly on the analysis of this inscription by Lubotsky (1997). Here, 'father' seems to be used as a priest title.
} 
..., let him become accursed by the great Zeus. [Greek B] Praying for this purpose with sacred incantations I enjoyed my tribe and my children... [Greek D] I Brogimaros the priest of the great Zeus stay here among my sacred offspring....

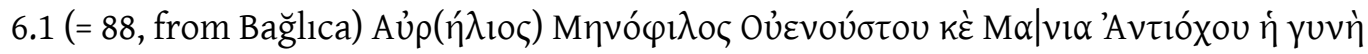

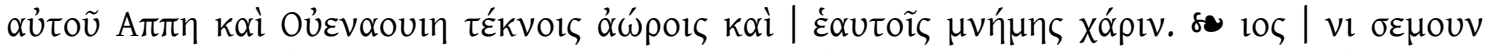

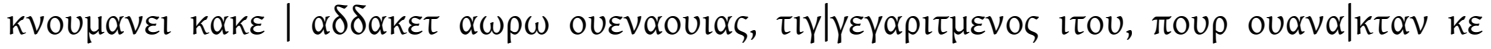

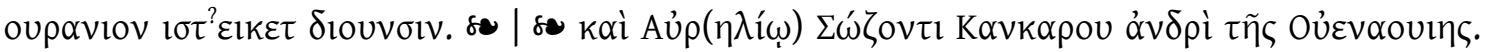
'[Greek] Aurelios Menophilos the son of Venustos and his wife Mania the daughter of Antiochus for Appe and Venavia, their children who died prematurely, in memoriam. [Phrygian] Whoever does harm to this tomb of the prematurely dead Venavia, let him become accursed and he will be responsible towards the heavenly king Dionysos. ${ }^{187}$ [Greek] and for Aurelio Sozo de son of Kankaros, Venavias' husband.'

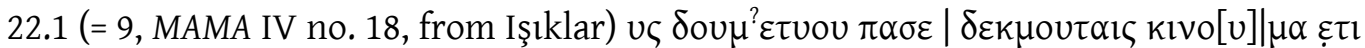

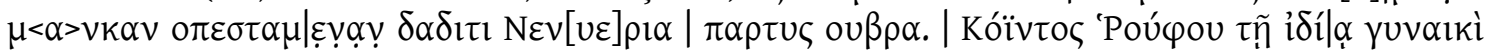

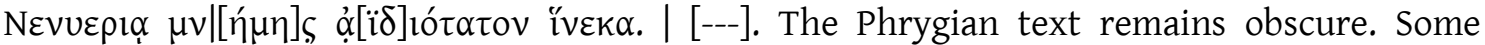

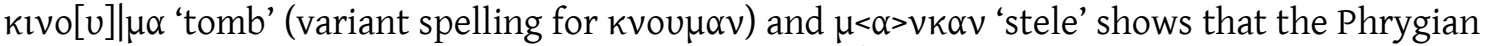

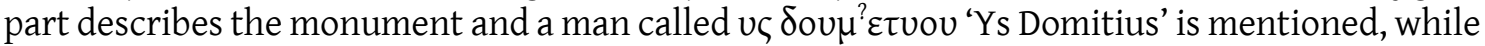

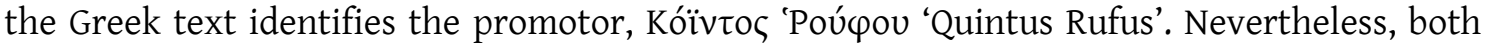
texts show that the monument was made for a girl called Nevvepla.

In three inscriptions after the Greek epitaph a Phrygian curse is followed by another different one in Greek. The text of 56.3 (= 64, from Beşkavak) was not well preserved when copied by Ramsay and Calder (1911, 210-211), but this disposition of the languages is clear. The other two inscriptions are the following:

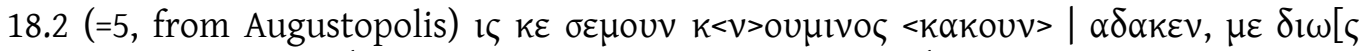

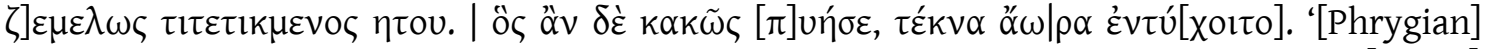
Whoever does <harm> to this tomb, let him be accursed in the sight of gods and men. [Greek] Whoever does harms, let his children die prematurely',

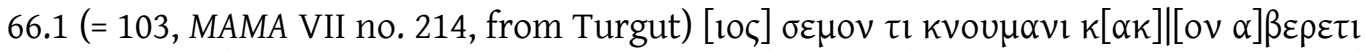

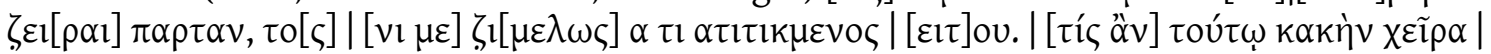

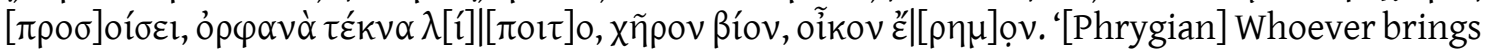
harm to this tomb by his hand ПAPTAN, let him be accursed by Zeus in the sight of men. [Greek] Whoever lays a wicked hand on this tomb, may he leave orphaned children, a widow's life for his wife, and a deserted house ${ }^{188}$

Finally, more interesting from the perspective of the bilingual parallelism is the inscription 19.1 (= 96, MAMA VI no. 382, from Prymnessos) ${ }^{189}$ which consists of a single curse

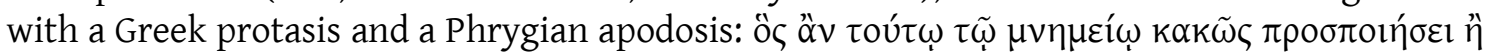

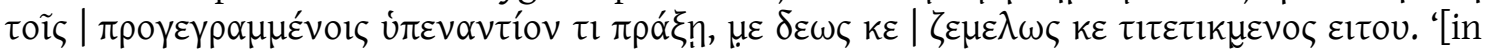
Greek] who damages this monument or contravenes the foregoing injunctions, [in Phrygian] let him be accursed in the sight of gods and men'.

\subsubsection{The Phrygian imprecative formulae also found in Greek inscriptions from Anatolia}

An important source of evidence of Greco-Phrygian contact is the use of shared imprecative formulae, although there are some particularities in each language. Curses are

\footnotetext{
${ }^{186}$ Tentative translation based on Avram 2015, with the remark of Obrador-Cursach 2016 and de Hoz 2017.

${ }^{187}$ Translation of the last apodosis by Lubotsky 2004, 235.

${ }^{188}$ On this last Greek formula, see Strubbe 1997, 291-292, with many parallels in east Phrygia.

${ }^{189}$ Brixhe 2002b, 252 considered this inscription to be irrefutable proof that Phrygian was understood.
} 
commonly attached to epitaphs in Anatolia in order to preserve the funerary monument against desecrators. There are hundreds of such texts written in Greek, mostly dated to the $3^{\text {rd }}$ c. AD, so they were contemporaneous to the NPhr. inscriptions. Curses were so popular that they even survived the expansion of Christianity. ${ }^{190}$ Although new inscription have been found, Strubbe (1997) provided a very useful corpus of the Greek curses which contains an excellent analysis. By compiling and classifying all of the different formulae attested in Greek inscriptions, he created a priceless source of information that can be compared with the Phrygian inscriptions.

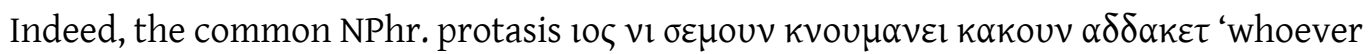

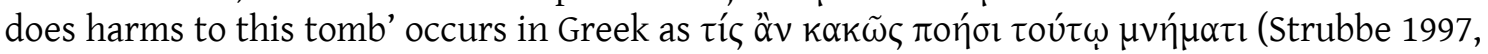
no. 193, from Appia-Soa). However, the most common variant of this north Phrygian curse

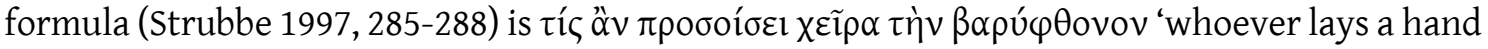
with heavy envy (on this tomb)'. The presence of the hand is also found once in the NPhr.

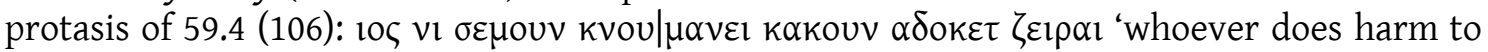
this tomb with the hand'. They are not word-for-word versions of the same text, but both the Greek and Phrygian inscriptions contain the same idea and it is possible that the variants are affected by the metrics of the Greek imprecations.

Phrygian formulae of apodoses are also found in Greek epitaphs. According to Hämmig (f.c., followed by Obrador-Cursach 2017), $\beta \alpha \varsigma, 101 \beta \varepsilon \kappa o \varsigma ~ \mu \varepsilon \beta \varepsilon \rho \varepsilon \tau$ 'let Bas not produce bread (=

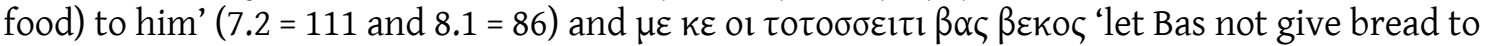

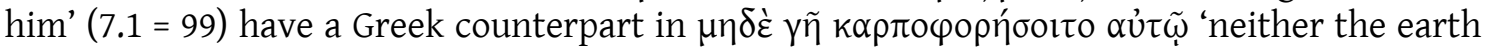

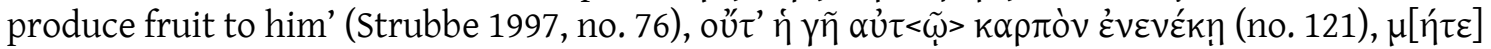

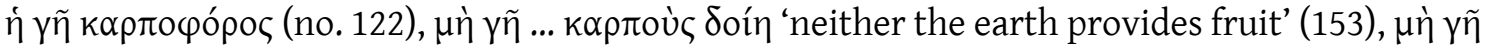

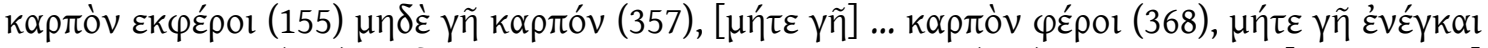

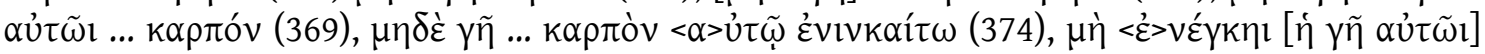

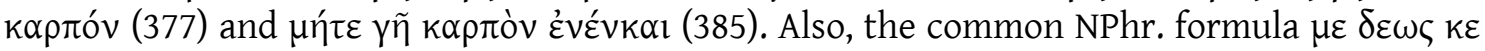

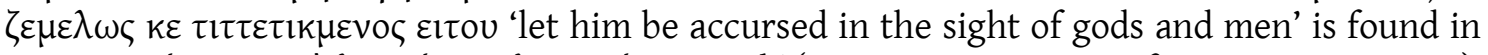

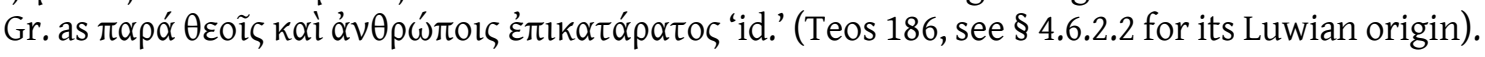

\subsubsection{Greek borrowings in Phrygian}

It is not always easy to decide if a Phrygian word is shared with or borrowed from Greek. Only when a phonetic rule or morphological feature restricted to Greek occurs can one be completely sure that a word is a loanword and not an inheritance. This issue is illustrated in the classic discussion of Midas' titles in the inscription W-01a: lavagtaei and vanaktei. Are they shared with Greek or early borrowings into Phrygian? Because of the Phrygian Lautverschiebung, lavagtaei can now be considered a Greek borrowing, but vanakt- (sg.nom. vanak M-04 and sg.acc.

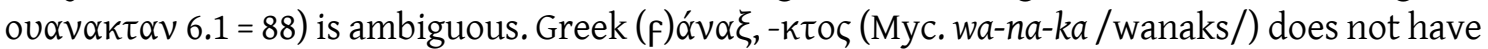
a clear origin and is commonly considered a "substrate word" (EDG 98-99). Perhaps Greek shares this substrate with Phrygian, but in the light of lavagtaei, it is likely that it was also borrowed from Greek. ${ }^{191} \mathrm{~A}$ similar case is kuryaneyon, W-01c, also a title. According to Ligorio and Lubotsky $(2013,187)$, it is a Myc. loanword (borrowed before the metathesis * kori- > kolp- and the loss of

\footnotetext{
${ }^{190}$ See, e.g., the reliquary of the martyr Trophimos in (SEG 6.343, 30.1494, see Guarducci 1978, 390-392):

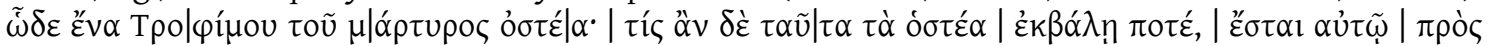
$\tau[\dot{o}<v>] \theta \varepsilon o ́ \mid v$ 'here within are (the) bones of the martyr Trophimos; if anyone, at any time, should throw out these bones, that person shall be answerable to God' (translation by Tabbernee 1997, no. 35).

${ }^{191}$ Brixhe in several papers (Brixhe 1990, 73-75; Brixhe 1993, 340-341; Brixhe 1994, 176-177; Brixhe 2002b, 257) considered that Phrygian vanakt- and Greek óv $\alpha \xi$, - $\kappa \tau \circ \zeta$ are cognates and, consequently, represent proof of the relationship between the two languages. However, as can be seen, this relationship is not so clear and does no constitute a valid argument with which to establish the position of Phrygian. Recently, Petrakis 2016, 104-105 also argued that the Phrygian word is borrowed from Greek.
} 


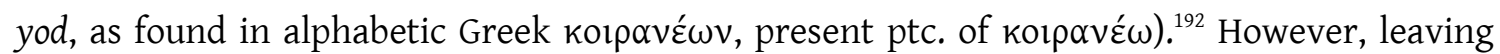
aside the fact that one title is borrowed (lavagtaei), there is no phonetic or morphological reason to rule out the possibility that Phrygian kuryaneyon is a cognate of Greek korpavé $\omega v$, since Phrygian kury- fits as inherited from PIE * kori- and there are deverbative Phrygian verbs at least in -oy-, as kakoioi (from kakouv) shows.

Aside from these titles, there are two probable Greek borrowings in the OPhr. inscriptions. The first is stal? $a$ (B-06), considered here a borrowing from Aeol. $\sigma \tau \alpha \dot{\alpha} \lambda \lambda \alpha$ 'stele' (better than Dor. $\sigma \tau \alpha \dot{\lambda} \lambda \alpha$, suggested by Vassileva 1995, 28-29). However, the context is obscure so this identification cannot be more than a possibility. The second is kraniyas (B-05, sg.gen.), an epithet of Artemis suggested to be derived from Aeol. kpóvva 'spring, fountain' (Att.-Ion.

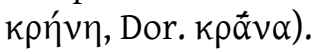

Clear Greek loanwords are more frequent in the NPhr. corpus (some are also found in MPhr.) and most of them refer to parts of the funerary monuments, as can be seen in the following list:

$\alpha \kappa \rho \circ \delta \mu \alpha \nu(16.1=116)$, despite not being found in Greek, it seems a clear Greek formation parallel to $\mu \varepsilon \sigma o ́-\delta \mu \eta$ 'crossbeam' (Brixhe \& Neumann 1985, 172), built with the element ök ${ }^{\circ} \varsigma$ 'at the farthest point or end, topmost' and $-\delta \mu \eta$ - 'house' (derived from $\delta \varepsilon \dot{\mu} \mu \omega$ 'build').

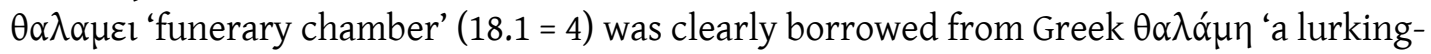
place, den, hole cave' (Brixhe 1978b, 5).

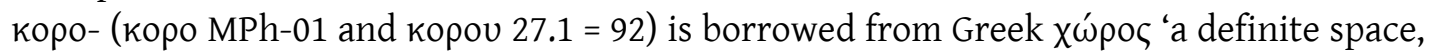
piece of ground, place' and in Phrygian may refer to the space devoted to the tomb. It also appears in a derived noun: $\mathrm{ko \rho o}[\mathrm{v}] \mu \alpha v \eta(2.2=130$, with the suffix -man).

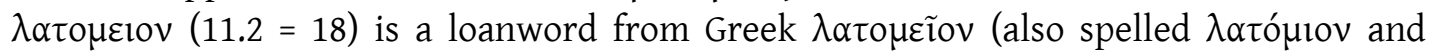
$\lambda \alpha \tau o \mu$ í) 'stone-quarry' (following Woodhouse 2006, 182), used with the meaning 'grave' at least in inscriptions from Perinthos (e.g., IG II 13218 or CIG 2032, see Robert 1974, 238-239).

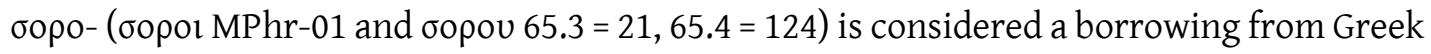
бopós -ov 'cinerary urn' by Brixhe (Brixhe 2002b, 258); it must be noted that in Anatolia this word is used for 'sarcophagus' (Kubińska 1968, 32-35).

In addition to these kinds of terms, we also find six more borrowings:

$\alpha v \alpha v \kappa \alpha 1(62.4=35)$ is very likely the Greek noun óvóp $\gamma \kappa \eta$ 'force, constraint, necessity'.

$\alpha \omega \rho \omega(6.1=88)$ is a clear borrowing from Greek o' $\omega \rho \circ$, , -ov 'untimely, unseasonable' (this interpretation is corroborated by the Greek part of the inscription).

Eyouvvou $(2.2=130)$ was identified by Avram $(2015,211)$ as a borrowing from Greek है $\gamma \gamma o v o v$ 'descendant' (it also appears in the Greek text of this inscription).

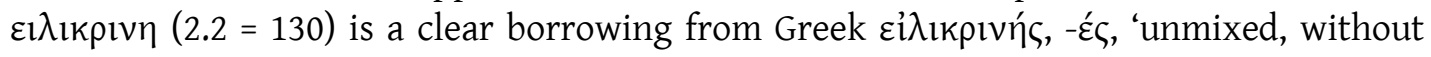
alloy, pure' (also found in the Greek part of the inscription, see Avram 2015, 14-15).

$\zeta \omega \varsigma(43.1=69)$ is the less clear loanword, but it seems to be borrowed from the Greek $\zeta \omega \varsigma$ 'alive, living'.

$\tau \iota \varsigma(28.1=71)$ and $\tau \imath(30.1=39)$ is the Greek indefinite pron. $\tau \iota \varsigma, \tau l$ 'any one, anything' used instead of the Phrygian cognate ki-. This grammatical borrowing, only found in NPhr., shows how intense the relationship between Greek and Phrygian was in Roman times. As can be seen, Greek o-stems are rendered as their etymological counterpart in Phrygian. However, Greek nouns in - $n \varsigma$ appear as Phrygian $a$-stems. It remains unclear whether this is a phonetic adaptation or if these words were early borrowings from the Aeol. dialect,

${ }^{192}$ On the other hand, Brixhe (in Brixhe \& Summers 2006, 128) interpreted it as a noun in sg.acc. without explaining either its meaning or its origin. 
which preserved the original sound of the old $a$-stems. The second option seems preferable

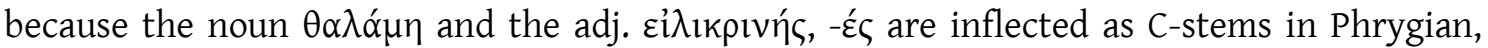

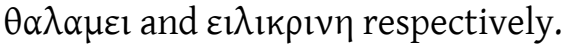

\subsubsection{Greek personal names in Phrygian}

Several Greek PNs are found in Phr. inscriptions from all stages of the language: 5 in OPhr., 2 in the MPhr. inscription MPhr-01 and 4 in NPhr. This is the list of the identified and possible Greek PNs in the Phrygian corpus:

arkia- (M-01a) was found under the patronymic form arkiaevais and is very likely borrowed from Greek 'Apxíac.

$\delta \circ \rho \cup k \alpha[v \circ \zeta](2.1=15)$, despite damage to the inscription at the end of the word, is restored in the light of two Greek inscriptions (Hierapolis I p and MAMA I 308, where $\triangle$ opvkovos and its dat. $\triangle \mathrm{o} \rho \mathrm{v} \alpha \mathrm{v} \omega \mathrm{l}$ occur, see KPN $152 \S 302-1)$.

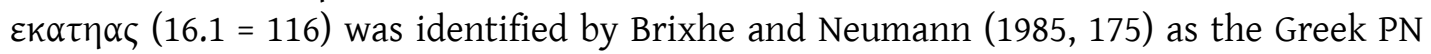

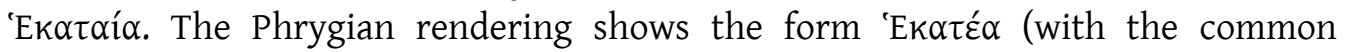
monophthongation) found in some Greek inscriptions such as IK Laodikeia am Lykos 116 (from Phrygia) or Erythrai 152 (from Ionia).

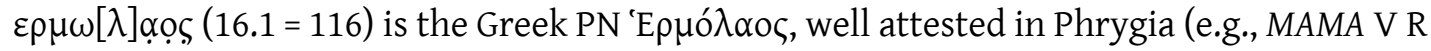
2), as well as the whole of Anatolia.

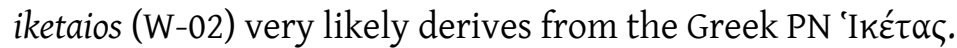

kaliya (dat. kaliyay, B-05) corresponds to K $\alpha \lambda \lambda i \alpha_{\varsigma}$ in the Greek part of this bilingual inscription.

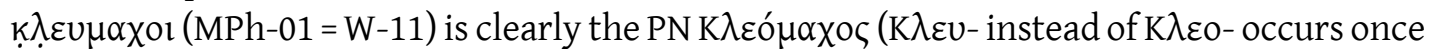
in the Greek inscription from Caria IK Rhod. Peraia 302, but it is more frequent in Central Greece and the Aegean Islands).

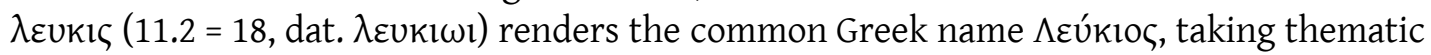
inflection despite the nom. form (with the shift $-10->-1^{-}$also found in Greek inscriptions from Phrygia).

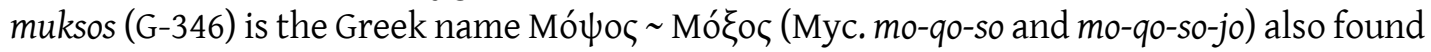
in HLuw. Muksasa- (the bilingual KARATEPE I \$21) and Phoenician mpš (in the same inscription).

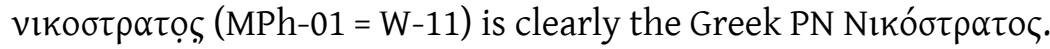

pser'keyoy (Dd-101, if it is not read as pseu?keyoy) can be equated to Greek $\Sigma \pi \varepsilon \rho x \varepsilon 1 o ́ s$, a PN found in Roman Caria (Tralles 83, the form $\Sigma \pi \varepsilon \rho x u ́ \lambda \varepsilon 10 \varsigma$ is attested in Ephesos and Smyrna and $\Sigma \pi \varepsilon \rho x i \varsigma$ in Thessalia).

The DN Siouvolv $(6.1=88)$ can be added to the list of Greek onomastics in Phrygian, since it is clearly related to $\Delta$ lóv $\bar{v} \sigma o \zeta$. However, its spelling is problematic, as it seems to show a syncope $\delta$ ióv $\bar{v} \sigma_{-}>* \delta 10 v \sigma->\delta 10 u v-$ and the thematic ending spelled with -1- instead of the common -ov- seen in $\sigma \varepsilon \mu l v$ (53.1 = 76 and $61.1=100$ ) for $\sigma \varepsilon \mu o u v$ (see Lubotsky 1989b, 153, against Brixhe 1999, 308, who did not rule out a "théonyme autochtone").

\subsubsection{Phrygian borrowings in Greek}

There are many Phrygian words in Ancient Greek works. However, most of them are names (anthroponyms, DNs and toponyms), mere glosses in lexica or are identified as Phrygian, 
not Greek. Consequently, only a few words can be considered true borrowings in Greek. ${ }^{193}$ Some of these are clear because the words occur in the Phr. epigraphic corpora. This is the case of $\beta \varepsilon \tilde{\varepsilon} \delta$ o ' 'woman's dress, statue', a borrowing from OPhr. bevdos 'statue' (B-05, see Lubotsky 2008)

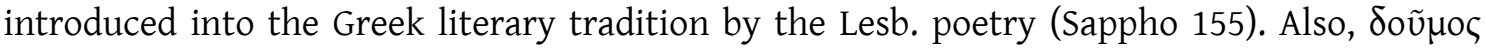
'cultic association' is a Phrygian borrowing attested as duman (B-01, sg.acc.) and $\delta$ oṽ $\mu \varepsilon(1.1=48$, sg.dat.). The Greek form is attested for the first time in Hipponax 40.2 and occurs in the work of other poets, however it is mainly documented in Greek inscriptions (see Polito 2004). Another Phrygian word in Greek literature is $\gamma \lambda$ oupó, , -ov 'gold', used by Besantinus in his famous Bomos calligram (AP 15.25,7). The first Phrygian inscription written in the Greek

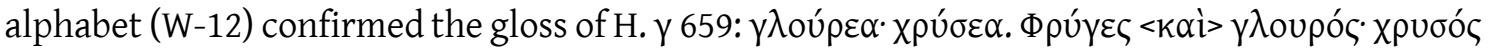
'g.: 'golden things. Phrygians. Also g.: gold'. Indeed, the Phrygian word $\gamma \lambda$ oupro $\varsigma$ is a cognate of

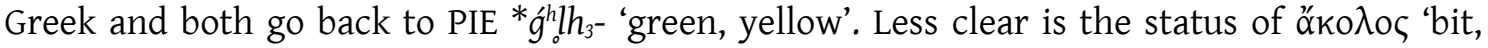

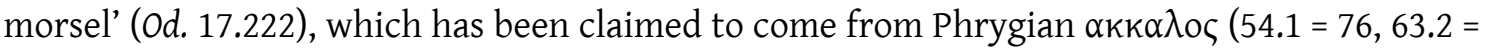
33 and $55.1=108, \alpha \kappa \alpha \lambda \alpha 4.1=2$ ). Its etymon is unclear. However, I have suggested a borrowing from Assyrian akalu 'bread'. In anycase, if both words share the same origin, the Greek form can only be explained as showing a vocalic dissimilation $a_{-} a>a_{-} 0$.

Words which are not attested in the Phrygian inscriptions or in glosses are hard to

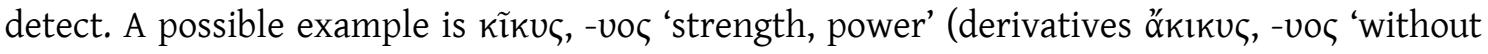

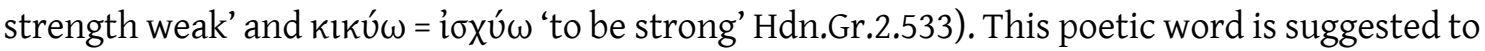
be (non-IE) pre-Greek by Beekes (EDG 697), however Mihaylova (2016, 321, following Van Windekens 1956, 239-242) assumes that "it continues ${ }^{*} g^{w} i h_{3} g^{(w)} u$ - from the IE root ${ }^{*}{ }^{w} i e h_{3^{-}}$'to live, life' (IEW 467-469, LIV 215), cf. with the same enlargement as Latv. dziga 'live' and the Gm. formations *kwikwaz 'alive': OE cwic, OIcel. kvikr, kykr, Germ. keck 'bold', etc. vs. Goth. qius 'alive' < * $g^{w} h_{3}$ uo-". As she observes (Mihaylova 2016, 313 fn. 14, following Müller 2007, 116-117), PGmc. *kwikwaz is one of the core examples of Cowgill's Law (at least ${ }^{*} h_{3}$ became $k$ between a sonorant and $w$ ), while Goth. qius is considered the resoult of a dissimilatory loss of the second stop. Nevertheless, languages of other branches show the velar enlargement of the root (Latv. dziga 'live', Lat. uigeō 'to be lively, be vigorous' or the perf. uīxi from uiuō 'to live'). Although none of the many lexica and grammars that gloss this word provides its origin - it is, in any case, nonGreek and with a very restricted use in poetry (Od., Homeric Hymns, some Aeschylus' fragments, Theocritus, etc.) - a Phr. origin can be defended. Indeed, the development ${ }^{*} g^{w} i h_{3} g^{(w)} u->$ kĩkv is expected in this language according to Lubotsky's Lautverschiebung and our analysis of the labiovelars. The path of the borrowing from Phrygian to Greek can be found in the Etymologicum

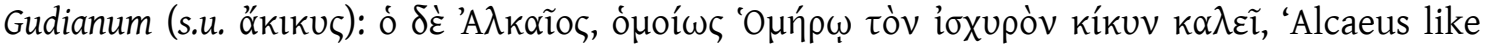
Homer calls a strong man kíkus'. Although the poem(s) where Alcaeus used the word kĩkuৎ is (are) lost, this testimony establishes a parallel with the borrowing identified by Lubotsky (2008) of $\beta \varepsilon \tilde{v} \delta$ o 'woman's dress, statue', taken from OPhr. bevdos 'statue' (B-05) and introduced into the Greek literary tradition by the Lesb. poetry (Sappho 155). Unfortunately, kĩkטৎ never occurs in the Phrygian corpus and this strong possibility cannot be corroborated. It is true that the OPhr. PN kikos G-284 can be taken as its derivative (<*kikuos, gen.), but one cannot rule out a Greek origin for this name in the light of Kíkos or Kíkкoৎ (see Brixhe 2002a, 45).

Finally, some remarks must be devoted to $\beta \varepsilon ́ v(v)$ os 'society of the faithful'. This noun and its derivatives $\beta \varepsilon ́ v(v) 10 \varsigma$ (ad. said of Zeus, also as a PN Bevios in NPhr. no. 66.1 = 103 and

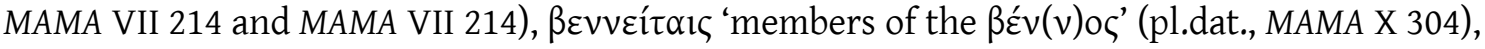
$\beta \varepsilon v v \alpha$ ó $\rho>x \eta v$ 'head of the $\beta \varepsilon \varepsilon^{\prime}(v)$ oc' (sg.acc. IK Iznik 1206) and $\beta \varepsilon v v \varepsilon v \varepsilon$ 'celebrate the cult of the $\beta \varepsilon ́ v(v) o \zeta^{\prime}$ (3sg. MAMA I 390) occur in inscriptions from northwest of Phrygia, also from Lydia,

${ }^{193}$ Although PN are not considered here, glosses are studied in $§ 6$. 
Bitynia, Galatia and Pisidia. ${ }^{194}$ It is commonly accepted that it is a Phrygian word related somehow to OPhr. benagonos (G-116). Indeed, leaving aside this OPhr. word, ${ }^{195} \beta \varepsilon ́ v(v)$ os has been analysed in several ways but a satisfactory explanation of its origin is still lacking.

It was first considered a Galatian word by Cavedoni in the light of benna, a Gallic word found in Festus 32.14 and glossed in Gloss. Lat. 4.132: Benna lingua Gallica genus uehiculi apellatur, unde uocantur combennones eadem benna sedentes 'In the Gallic language a sort of vehicle is said benna, so people sitting in a benna are called combennones'. This interpretation was followed by Deecked $(1882,385)$, who suggested that $\beta \varepsilon ́ v(v)$ lo was a Greek transcription of Bennius, a PN considered Illyrian but derived from the Celtic word. Ramsay, in his influential works (1887, 511-512; 1888, 367 and 1895, 157, 183 and 188), followed the Celtic explanation, considering $\beta \varepsilon ́ v(v)$ loc to mean 'he who stands on a car'. However, this explanation is not congruent with the area in which the text was found or the representations of this god.

Neumann $(1961,44)$ suggested a Pisidian origin, despite the lack of arguments, but this was never subsequently taken up. A second relevant interpretation was suggested by Haas $(1966,160)$, who considered $\beta \varepsilon$ vo o a noun with the meaning 'fertility offering' in the light of the context in which kaproí 'fruits' also appears (see, e.g., MAMA I 390). Following this proposal, Şahın $(1978,786-790)$ considered that the epithet Bév $(v)$ los was related to Zeus as the god of fertility and weather. The semantic of $\beta \dot{\varepsilon} v v$ - considered by this argument fits the rural context of Roman Phrygia, but the authors did not explain the origin of the word.

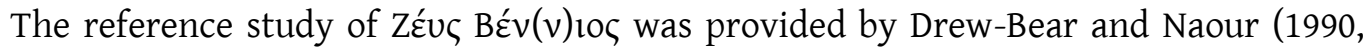
1987-1988), who gathered all the occurrences of $\beta \varepsilon ́ v(v)$ os and its derived words. According to them and Schwabl (1999), $\beta \varepsilon ́ v v$ - is a Phrygian term (because it occurs mainly in Phrygia) derived from a PIE root *bend- 'federation, association' 196 and the meaning of $\beta \varepsilon ́ v o \zeta$ is simply 'cult association'. Nevertheless, the PIE root must be * $b^{h} e n d^{h}-$ 'to tie' (LIV ${ }^{2} 75$, IEW 127). If indeed this is the etymology and it is a Phrygian word, the evolution of the cluster (PIE ${ }^{*}-n d^{h}->$ ) ${ }^{*} n d->-v v$ can be related to the 3pl. ending, where ${ }^{*}$-nt- occurs in NPhr. as $\langle\tau \tau \nu v\rangle$ and $\langle\nu v\rangle$ (see $\S 4.2 .2 .1 .4$ ).

Without considering the etymological problem, Eckhardt $(2016,165)$ suggests that the first meaning of Bźvvos in Phrygian was 'festival' or 'festive gathering', a word used "to designate cult communities, without a clear distinction between the participants of the feast and the feast itself". However, in Roman times "some inhabitants of northern Phrygia adapted their indigenous terminology to match new social structures" and the word then was used for

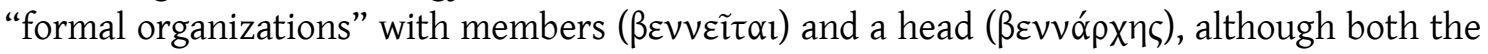
original and the new meanings coexisted.

Recently, a new etymological possibility has been suggested by Opfermann $(2017,72 \mathrm{fn}$. 89). In his study of the PIE root * $g^{u} e n-$ 'fruitful; fertility', he considers that the expletive verb

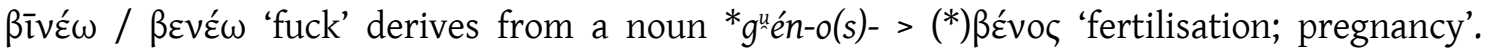
Consequently, $\beta \varepsilon v \varepsilon \varepsilon \omega$ may go back to * $g^{u} e n-e ́(s)-i$ e/o- 'fertilise' > $\beta \varepsilon v \varepsilon ́ \omega$ 'fuck' (improving a first identification by de Lamberterie 1991). Although a noun (*)ßévoৎ is reconstructed in the light of its derived verb, in an annotation he considers that this is the debated ßźvvo and, if it is the case, it may be a Thess. word introduced to Pisidia via the colony of Antioch. Note that in this city, a Magnesian colony, ßźvvoऽ occurs with the meaning 'fruit'. Indeed, the development

\footnotetext{
${ }^{194}$ On the occurrences and interpretations see Şahin 1978, 778-790, Drew-Bear and Naour 1990, 1987-1988 no. 19, Schwabl 1999 and Eckhardt 2016, 163-165.

${ }^{195}$ See Lubotsky 2004, 232 for a possible analysis.

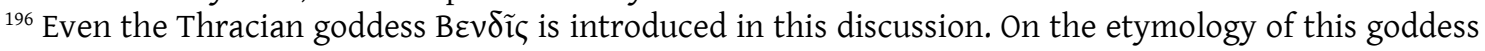
see Oreshko 2013a, 86-87, who considers that the Thracian DN perhaps means 'archer'.
} 
${ }^{*} g^{u} e n->\beta \varepsilon ́ v-$ is only possible in Aeol. However, the word could come from Aeolis instead of Thessaly.

To sum up, two of the given interpretations of ßźvvo are still defensible: it goes back to * $b^{h} e n d^{h}$ - 'to tie' and means 'cultic association' (Drew-Bear and Naour, Schwabl and Eckhardt) or it goes back to * $g^{u} e n$ - 'fruitful, fertility' and is a borrowing from Greek (*)Bévos with the meaning 'fruit' (Haas, Şahın and Opfermann). The first possibility does not explain the occurrence in the inscription from Pisidia, while the second does not take into account the geminated forms. ${ }^{197}$

\subsubsection{The Aeolic roll in the Greco-Phrygian contacts}

Greek o-stems remained as o-stems in Phrygian, while the old Greek $a$-stems with the Attic-Ionian shift $\bar{\alpha}>\eta$ were inflected as consonant-stems in Phrygian in the light of $\theta \alpha \lambda \alpha \mu^{\prime} \eta>$ $\theta \alpha \lambda \alpha \mu \varepsilon l$ (4, sg.dat.). ${ }^{198}$ On the basis of this example, we know that the Phrygian $a$-stem loanwords cannot be borrowed from Ionian, Attic or Koine and must instead come from a dialect which does not have the shift $\bar{\alpha}>\eta$. From a phonetic and geographical point of view, Aeolic stands as the most likely origin for these borrowings. Indeed, the Aeol. dialect retained the original $\bar{a}$ in all positions. Then, $\alpha v \alpha v \kappa \alpha l$ (35, sg.dat.) can be considered a borrowing from Aeol. óvó $\gamma \kappa \alpha$ (Alcaeus 75,6, 249,9 and 298,2) and stal? $a$ (B-06) from $\sigma \tau \alpha^{\prime} \lambda \lambda \alpha$ (in inscriptions from Aeolis and Lesbos). ${ }^{199}$ Even Artemis' epithet kraniyas (B-05, sg.gen.) is very likely derived from

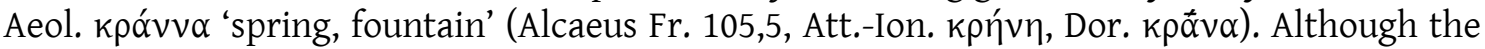

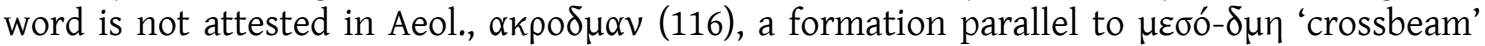
(Brixhe \& Neumann 1985, 172), may be considered a likely Aeol. formation.

The contact with Phrygian is corroborated by the presence of at least one Phrygian word in Lesb. poetry. Indeed, Sappho is responsible of the diffusion of Phr. bevdos (B-05) and perhaps Alcaeus is the origin of the poetic use of the conflictive word kĩkuc. In the light of this evidence, we must assume that a linguistic interaction took place in early historical times between Phrygia and Aeolia. Even Lesb. poetry seems to show this phenomenon, although since many texts were lost it is impossible to determine its scale.

In such a scenario, one wonders if the Phrygian shift *-ans >-ais, *-ons >-ois, also found in Aeol., is an areal feature which occurred at the same time in NW Anatolia at an uncertain proto-historical moment. Indeed, we know that in Lesbian it cannot be an old feature because it is not shared with Tessalian or Boeotian. Consequently, it is possible that the shift occurred in the historical territory of the Aeolians in contact with Phrygian.

Such a relationship between Aeolic and Phrygian is more likely when one considers the alleged Phrygian influence on Greek music, a discipline closely related to poetry. In Greek

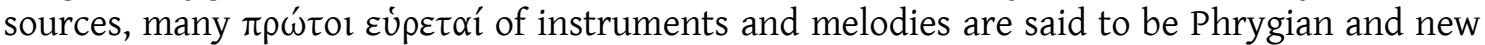
findings from Gordion (instruments such auloi and lyres, as well as depictions in figures and paitings) attest the strong relationship between Phrygians and music:

"These finds make it clear that over three centuries before Midas of Akragas won the aulos competition at Delphi or Euripides' bacchants played Phrygian cymbals for Dionysos, the Phrygian court had vibrant musical accompaniment, and percussion instruments had been incorporated into

\footnotetext{
${ }^{197}$ In addition, if indeed * $g^{u} e n$ - 'fruitful, fertility' is the origin of $\beta \varepsilon ́ v v o \varsigma$, a Galatian word cannot be ruled out. Note that * $g^{u} e n h_{2}$ 'woman' yields *bena in Proto-Celtic, OIr. bé 'id.', OW ben 'id.', Gaul. bnanom 'id.' (pl.gen.), PNs Bano[na] and Banonias (sg.gen., see Matasovič 2009, 61). As far as I know, however, a form * guén-o(s)- is unattested.

${ }^{198}$ Note also that personal names in -es in Phrygian have hesitant inflection, see § 4.2.1.1.4.

${ }^{199}$ Vassileva 1995, 28-29 considered a borrowing from Dor., but there is no evidence for contacts between this branch of dialects and Phrygian.
} 
Phrygian ritual. These finds support the primacy of Phrygia in invention myths by showing that two distinguishing musical instruments had already crystallized by the end of the ninth century, when Greeks began to learn and appropriate major technologies of the Near East, most notably the Phoenician alphabet." (Holzman 2016, 541)

Nevertheless, the most interesting and evident connection is provided by the two sources which report that Midas married a princess from Kyme called Hermodike (Aristotle frag. 611, 37, Rose) or Demodike (Julius Pollux, Onomasticon 9.83).

\subsubsection{Phrygian in contact with the Anatolian languages 4.6.2.1. Contacts between Hittite and Phrygian?}

Since Phrygians settled in the central highlands of Anatolia, a territory occupied by the Hittite Empire until its collapse (ca. $1175 \mathrm{BC}$ ), the Hitt. language has been considered the origin of some Phrygian words and personal names. However, the status of Hitt. in the last century of the empire is disputed ${ }^{200}$ and it may already have been a dead language by the time the Phrygians entered Anatolian history. In any case, there is a gap of five centuries between the last Hittite texts and the first Phrygian inscriptions. Moreover, the only evidence of Hittite we have in Phrygian is two possible but problematic loanwords (other proposals are rejected in this dissertation) and some onomastic material. In the light of these few examples, and given the doubts about when Hittite died and Phrygian arrived in central Anatolia, it remains unclear whether Hittite and Phrygian were ever in contact or if these possible Hittite words were in fact transmitted via other languages influenced by Hittite.

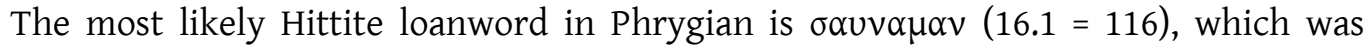
suggested to be a borrowing from Hitt. šāmă̄na- 'foundation(s); foundation deposit' by Lubotsky (1993a, 132, followed by Gorbachov 2009, 106 fn. 32). This meaning fits the context in which $\sigma \alpha v v \alpha \mu \alpha v$ occurs, a sequence of several nouns in the sg.acc. referring to different parts of the monument. However, there are two problems with this proposal: the shift $\check{s} \bar{a}->\sigma \alpha v-$ and the metathesis of its sonorants. Consequently, though it is a good working hypothesis it remains unclear.

Another noun suggested to have the same origin is ploria in ploriata[---] (G-132), which Orel (1997a, 453) considered a loanword from Hittite ${ }^{\text {DUG }}$ pulluriya 'vessel' (see e.g. CTH 476 § 22, 95). This meaning is possible because the inscription was incised on a fragment of a pitcher. Nevertheless, the segmentation of the graffito is unclear and so, by extension, is its interpretation.

In addition, Böker-Klähn (2000, 90, also Berndt-Ersöz 2006, 72-74) considered OPhr. sikeneman (M-01b) a loanword from "Syrian" sikkanum 'sacred stone, baetilo?' via Hitt. sikkanu 'id.'. However, this Phrygian sequence is better explained as si keneman 'this niche' as Lubotsky suggested (see 1988, 15 and Ligorio \& Lubotsky 2013, 189 and 192-193). Indeed, the inscription $\mathrm{M}-01 \mathrm{~b}$ very likely refers to the addition of a niche to the Midas' façade.

The remaining material is onomastic. The Phrygian dynastic name Midas (M-01d-I, G137 , etc.) is commonly equated to Mita, the name of a king of Pahhuwa found in CTH $146\left(16^{\text {th }}\right.$ $15^{\text {th }}$ c. BC). Following Burke $(2001,257)$, Berndt-Ersöz $(2015,112)$ has recently claimed that this name "can most certainly be derived from the Hittite word mita-". Because the adj. mit $(t) a-$, mitimeans 'red' in this language, she suggests a connection between such this most significant colour in the Anatolian religious tradition and the Phrygian royal family. She also suggests that the Greek noun $\mu$ í $\tau$ ऽ 'thread of the warp' is related to Hitt. mit $(t) a-$. However, the histories of the Hittite and Greek words are difficult to follow (see Kloekhorst 2008, 583 and EDG 958-959, respectively) and the spelling of the dental is not consistent. Therefore, the origin of this name

${ }^{200}$ On this question see, e.g., Melchert 2005 and van de Hout 2006. 
remains unclear and, considering how short it is, we cannot rule out that the similarity is a mere coincidence. A second royal name can be added to the discussion, since here Urgi- (in the patronymic gen. urgitos K-01 VI-VII a2) is suggested to follow the first part of the Hurrian name Urhi-Tešub ‘Teshub is truth' (vel. sim.) borne by Mursili III.

Other Phrygian PNs suggested to have Hittite origins are: aiay (G-319), equated to Aya(LNH 23 § 3, see Brixhe 2002a, 75-76), alis (NW-102) and ali- (LNH 27-28 § 33-36, see Brixhe 2002a, 12) ${ }^{201}$ In addition, surgastoy (Dd-102), also found in Lyd. as śrkaśtus, was suggested to be derived from the Hitt. adj. šarku- / šargaun- 'eminent, illustrious, powerful' by Gusmani (1980-1981, 2127; see also Beekes 2003, 19 fn. 21 with some remarks). However, this is a problematic issue (see $\S 4.6 .2 .3)$.

Finally, the discussion must take in the name of the Phrygian capital, Gordion. The name never occurs in the Phrygian corpus, appearing only in the Greek sources (Plb.l.c., Str. 12.5.3, 8.9, Plu.Alex. 18, Arr. An. 1.29.3, 2.3.1, etc). However, it is a productive Phrygian term in polionyms since some cities in Phrygia or surrounding areas are named after it: Manegordo

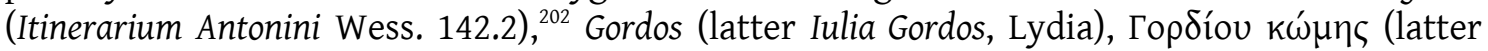

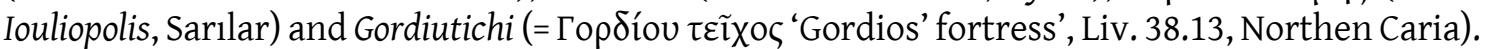
The etymology of this word is often considered to be the PIE word * $g^{h}(\mathrm{o}) r d h-o^{-}$, attested in Skt. grhá- 'house', Goth. gards 'house', Lith. gar̃das 'fence, enclosure, stall', ocs gradı 'wall, town, garden', Alb. gardh 'hedge, fence', etc.). The form has also been compared to New Hittite gurta'town, citadel, acropolis', a word considered a Luw. borrowing (Kloekhorst 2008, 465). Because there is no evidence for the presence of Phrygians in central Anatolia in the last period of the Hittite Empire, a Phrygian borrowing to Hittite is unlikely.

According to Simon $(2016,196-197)$, gurta- is highly unlikely to go back to * $g^{h} r d^{h}$-ó- or * $g^{h}$ or-tó- and he suggested a ptc. of PIE * $k^{u} \cdot e r-$ ' $(a b)$ schneiden, schnitzen' (LIV $\left.{ }^{2}, 391\right)$ : * $k^{u} r$-tó- > gurta-. Then, the origin of Luw. gurta- is inherited. In a recent paper (2017), he considers that Gordion is not related to Luw. gurta- but from a PN *Gordi- (borne by the father of Midas according to Hdt. 1.14 and St.Byz.). Then, the main city of the Phrygians was perhaps named

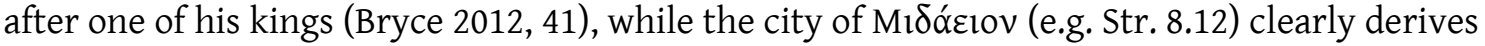
from Midas. In addition, according to Simon (2017b), the PN attested in Luw. as Kurtis (e.g. BOHÇA 1.1) and in Neo-Assyrian as Gurdîs is a borrowing from the Phrygian Gordi-, as well as

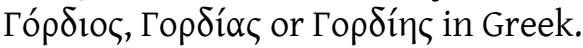

\subsubsection{Contacts with Luwian and Luwic languages}

Luwian is the Anatolian language that provided the greatest number of clear borrowings in Phrygian, including PNs, nouns and even one imprecative formula. This is not a surprising fact. At the beginning of Phrygian history ( $9^{\text {th }}$ and $\left.8^{\text {th }} \mathrm{C} . \mathrm{BC}\right)$, Gordion had an architectural style and many objects that were related to the Neo-Hittite states, where Luw. was a prestigious language. Even Phrygian stelae were found in Tuwanuwa / Tyana, the capital of Tabal. So, the contacts between Phrygians and Luwians were intense.

In the Phrygian corpus, the clearest element is the Phrygian calque of a Luw. imprecative apodosis, found elsewhere in NPhr. inscriptions. The HLuw. text, KARKAMIŠ A 3, line 4, reads as follows: wa/i-sá- | DEUS-na-za | CAPUT-tá-za-ha|zi-na-na| (DEUS)TONITRUS-tá-tí-i | (LOQUI)tatara/i-ia-mi-sa i-zi-ia-ru 'and let him be made accursed by Tarhunzas among gods and

\footnotetext{
${ }^{201}$ The PN masa (K-01 VI-VII a2) is also attested in Hittite sources as ${ }^{\mathrm{m}}$ Masa (LNH 115 § 770, see also ${ }^{* \mathrm{~m}}$ masamuwa LHN 115 § 771). However, this PN may be Luw. See § 4.6.1.2.

${ }^{202}$ Like many other toponyms, Manegordo appears in Itinerarium Burdigalense Wess. 575.2 as mansio Malogordis, a clear deformation (see, e.g., Wess. 575.1 mansio Mnizos instead os Minizo). I follow Cuntz's editon of both Itineraria $(1990=1929)$.
} 


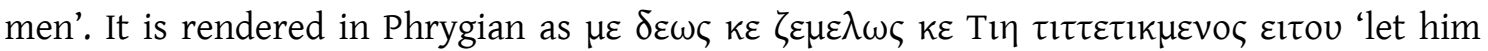
become accursed by Zeus in the sight of gods and men'. ${ }^{203}$

Phonetically, there is a very interesting common Luw. contraction *wa $>u$ (Rieken 2001) memeuis (T-02b) for memevais (M-01b and M-02) on one of the stelae from Tuwanuwa / Tyana. ${ }^{204}$ See also ${ }^{\mathrm{m}}$ Urawanni > urunis (G-346). In Phrygian, there are three nouns borrowed from an unclear Luwic dialect. The first is imroy (B-01, o-stem sg.dat.), a loanword from Luwic *imro-, a form attested in Luw. im(ma)ra/i- 'open country' found in HLuw. i-mára/i 'open country' and CLuw. $\operatorname{im}(m a) r a / i-$ 'open country' (attested in the gen.adj.-stem im(ma)rassa/i-), also in the

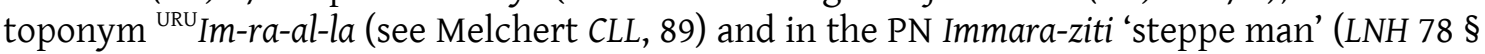
$450)$. Adiego $(2011,327)$ argued that it also occurs in Lyc. and Carian PNs under the forms ipre(rendered in Greek as $\iota \mu \beta \rho-$ ) and mpara-. The second borrowing is $\tau 1 \alpha \mu \alpha-$ '(burial) plot'? (with

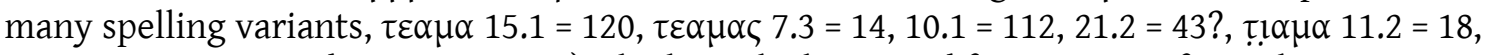
$\tau \varepsilon \alpha \mu \alpha \varsigma 25.1=115$ and $\tau 1 \alpha \mu \alpha \varsigma 9.1=87$ ) which can be borrowed from a Luwic form close to CLuw. tiiiamm(i)- 'earth' ( ${ }^{*}$ dǵémo-< PIE*dǵhem-) (firstly proposed by Orel 1997a, 463). In any case, note that in imro- and $\tau \imath \alpha \mu \alpha-$ there is no trace of the Luw. $i$-mutation. A third borrowing could be Luw. gurta- 'city', attested in some Phrygian polionyms, discussed above (§ 4.6.2.1).

The origin of the noun outav 'punishment, word, spell'? $(53.1=76,54.1=108$, etc.) is less clear. Bayun and Orel $(1989,32)$ considered it a borrowing from Hitt. uttar / uddan- (n.) 'word, speech' or CLuw. utar / utn- 'word, spell'. Although this is very likely, the word derives from PIE *ueth $2^{-}$'to say' (LIV 694-695, see Kloekhorst 2008, 932-933) and one cannot rule out the possibility that it is an inherited Phrygian word derived from the PIE oblique form *uth

Finally, the onomastic material is relatively abundant but sometimes ambiguous. The clearest Luw. PNs in the Phrygian corpus are: țuvatis (G-133, see Innocente 1997, 325) equated to Tuwattis (a dynastic PN from Tabal, see Weeden 2010), kuliyas (G-127, also in G-101) to HLuw. ku-li-i(a) /kuliia/ (read in the Suratkaya graffito no. 5 according to Oreshko 2013a, 361, simplification of Kwa/i-li-i(a) /kwaliya/, also found in Cappadocia as Ku-li-a LNH 97 § 612) and urunis (G-346) ${ }^{\mathrm{m}}$ Urawanni (an ethnic in origin, see Melchert 2013, 37). The PN Vasus (P-02, P-03 and P-05) is the hypocoristic of a Luwian PN such as Wasurunti(ya)- (MALATYA 1) or Wasusarma(TOPADA § 2, LNH 207 § 1514). OPhr. mamutas G-229 (bis) has been considered to be Anatolian (Brixhe 2013, 58). Although the first element $m a$ - is unclear, the second element -mutas seems to follow the Luwic form *muwata- 'might, potency', which is very common in Anatolian

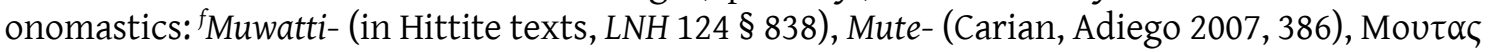
(found in Greek inscriptions from Cilicia and Phrygia, KPN 339 § 989-2; see also Melchert 2013, 34 ), etc. In that case, note that the $i$-mutation is lacking from the Phrygian form. An exact parallel is found in Mauotn (from Lycia, Cau 2003), although there are some variants, including

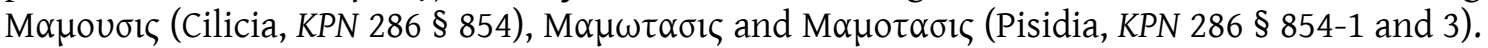

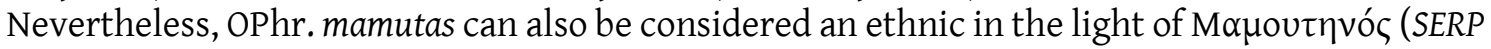

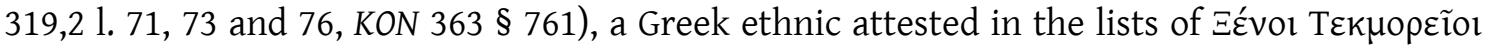

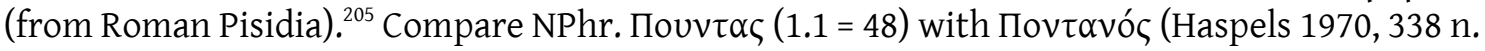
105), the ethnic of a village near Nacoleia.

The PN masa (K-01 VI-VII a2) occurs in Hittite as ${ }^{\mathrm{m}}$ Masa (LNH 115 § 770, see also *m masa-

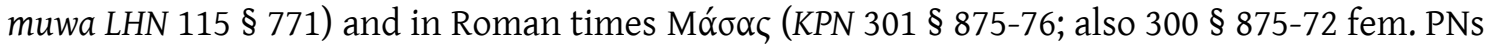
derived from it) occurs in Pisidia/Southern Phrygia, Lycia, Galatia and, recently, in Cicilia (see Laflı 2017, 166). It is very likely derived from the Luwic word massan- 'god', attested in CLuw.

\footnotetext{
${ }^{203}$ The first to propose the relationship between the two curses was Lubotsky 1997, 420. A Greek

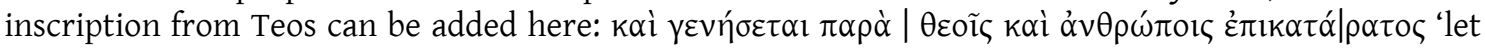
him become accursed in the sight of gods and men' (Strubbe 1997, no. 32).

${ }^{204}$ At this point, I want to thank Adiego for sharing with me the identification of the shift in this Phrygian word (in p.c. 05/10/2017).

${ }^{205}$ On these inscriptions see Blanco-Pérez 2016. Note that many Phrygian men are listed.
} 
mašša(i)-, HLuw. DEUS-n(i)- (= /massan(i)-/?), Lyc. mahan(a)- and, perhaps, Carian msn- in the PN msnord- (on it see Adiego 2007, 385). ${ }^{206}$

The PN alus (G-204, W-08 - W-10) may be added to this list, since it seems to be the Hitt. Al(l)uwa- (LNH 28 § 39) with the common Luw. contraction -uwa- >-u- (see Rieken 2001). This name also occurs in Lyd. as alus (49,2, see Gusmani 1964, 56, also in the Greek inscription from

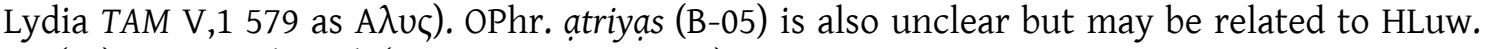
atri(ya)- 'personal, soul' (ALEPPO 6 \& 3 COR-i-sa).

An interesting fem. PN is ovevooutas, which occurs in the bilingual inscription no. 6.1

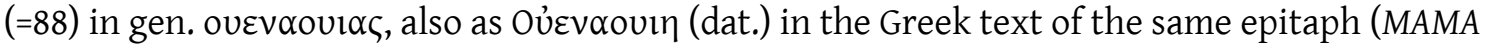
I, 216-217 no. 413) and other Greek inscriptions from Phrygia (KPN 396 § 1153): Ovevavia (nom., MAMA I 393, near Midas City, MAMA V 243, from Nacoleia, MAMA I 234, from Laodikeia Katakekaumene) and Ovevavin (MAMA VIII 100, also from Laodikeia). Following Dressler (1964), it can be analysed as a fem. Luw. PN -wiya ${ }^{207}$ Nevertheless, the first element wena- remains unclear. Laroche $(1966,640$, also Brixhe 2013,67$)$ related it to the Hitt. PNs in Wanni and HLuw. wani- 'stele', although this last word is indeed wanid- (CHLI s.u.) and must be rejected. Phrygian oucva- may follow the HLuw. PN Wana- (wa/i-na-sa SCRIBA-la-sá 'Wanas (was) the scribe' in KARABURUN \$14) and -wiya >-oula is only used to make the fem. form, if it "came to be perceived in some dialectal communities as a suffix of female onomastics, pure and simple", as Yakubovich cautiously suggested (2013, 107-108).

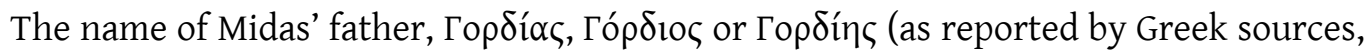
see 4.7.2.1.), can be added to this list. It is very likely the same PN found in Luw. Kurtis and the origin of the name of the Phrygian capital, Gordion. Finally, the Mother-Goddess epithet areyastin (W-01a) seems to be somehow related to CLuw. ari(ia)- 'raise; check, restrain', a cognate of Hitt. $\operatorname{ara}_{\bar{a}}^{i}$-, ari- 'id.' and Lyc. erije- 'raise, levy' (see CLL 27 and Kloekhorst 2008, 200). Note that, because of this etymology, the Phrygian form could be derived from an oronym and many epithets of Matar derived from such names. Perhaps a Sidetic name can be added to this list, if it is accepted that Phrygian si idos (G-105, HP-110 and G-346) is indeed the Sidetic PN śdi s (S6) with a metathesis in the Phr. renderering: *sidi os > si $\uparrow$ idos (Schürr 2017, 4 fn. 13). However, this interpretation cannot be proved (see also Nikolaev 2017, fn. 23).

Finally, Brixhe $(1983,128 ; 1994,176$ and 2008, 79) claimed that the hesitation between the masc.nom. of the PN with and without $-s$ in Phrygian PNs (also attested in a Greek inscription from Phrygia, see Brixhe 1987a, 78-79) also illustrates the Anatolian influence on Phrygian. Indeed, the distinction between masc. and fem. does not occur in Anatolian but in Phrygian, as well as in Greek, an $a$-stem masc. is expected to have an -s ending in the nominative and $-\varnothing$ in fem.: compare the masc. PN midas (M-01d I, G-137 and HP-102) with the fem. [l?]agineia (G-276). Nevertheless, masc. PNs without -s are commonly found (baba M-01b and G-121), even in other stems: compare voines (G-129 and G-286) with voine (G-228) and manes (B-07) with mane (Dd-103).

\subsubsection{Contacts with Lydian}

The Lydians were the Phrygians's neighbours to the east and, between 650 and 540 a.C. they ruled over Phrygia. Because of this, some Phrygian words and some PNs clearly have a Lydian origin. The two Lyd. borrowings I propose here in fact remain unclear, although they fit their context. The first is OPhr. asenan (B-05, from Vezirhan, an area strongly influenced by Lydian culture), which I suggest comes from Lyd. asinas '(part of a) grave' (Sardes no. 4). Then,

\footnotetext{
${ }^{206}$ Note that this word "can be used as an argument for the dialectology of the Anatolian language branch" (Kloekhorst 2008, 764), since it is not found in other Anatolian languages. Indeed, PIE *diēuyields Hitt. šiuna(na)-, Palaic tiuna- and Lyd. ciw-, all with the meaning 'god'.

${ }^{207}$ On this, see Yakubovich 2013, 94-95, who argued that originally names in -wiya (normally following deities, toponyms and other first members) meant ' $\mathrm{X}$ sent (her)'.
} 
Phrygian tiv $\dagger<s>$ imun inmeney asenan daket (B-05) could be translated as 'whoever puts a tomb in this shrine...'. The second, which is even less clear, is $\mu \rho \circ(\varsigma)(29.1=114)$ and/or $\mu \delta v \varepsilon l(14.1=$ 3, both from western Phrygian), which could be borrowed from mru- 'stele' (Sardes no. 2, 12, etc.). If we accept this proposal, the protasis $10 \varsigma$ vi $[\sigma] \varepsilon \mu o v \kappa v[o v] \mu \alpha v \eta \kappa \alpha \kappa o v \alpha \beta \beta \varepsilon \mid \rho \varepsilon \tau \alpha \tau$

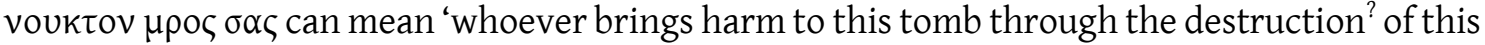
stele'. In addition, OPhr. tesan (T-02b) was suggested to be a borrowing from Lyd. taśẽv (No. 40, from Pergamon) by as Orel (1997a, 310 and 461), although this possibility remains unclear.

One may wonder whether Phrygian PNs in -es shared with Lyd. in fact originated in Lydian: compare manes (B-07) with Lyd. manes (see Gusmani 1964, 163) and ates (M-01a, W-08, etc.) with the poss. adj. atelis 'of Ates' (Gusmani 1964, 69). Another shared PN is OPhr. alus (W08, W-09 and W-10) = Lyd. alus (49,2, see Gusmani 1964, 56), which could be borrowed from Luw. (see $\S 4$ 4.6.2.3).

Fig. 12 Old Phrygian inscription Dd-102 (Musées d'art et d'histoire, Ville de Genève, inv. no. 023469 @ Musées d'art et d'histoire, Ville de Genève, photographer: Monique Delley)

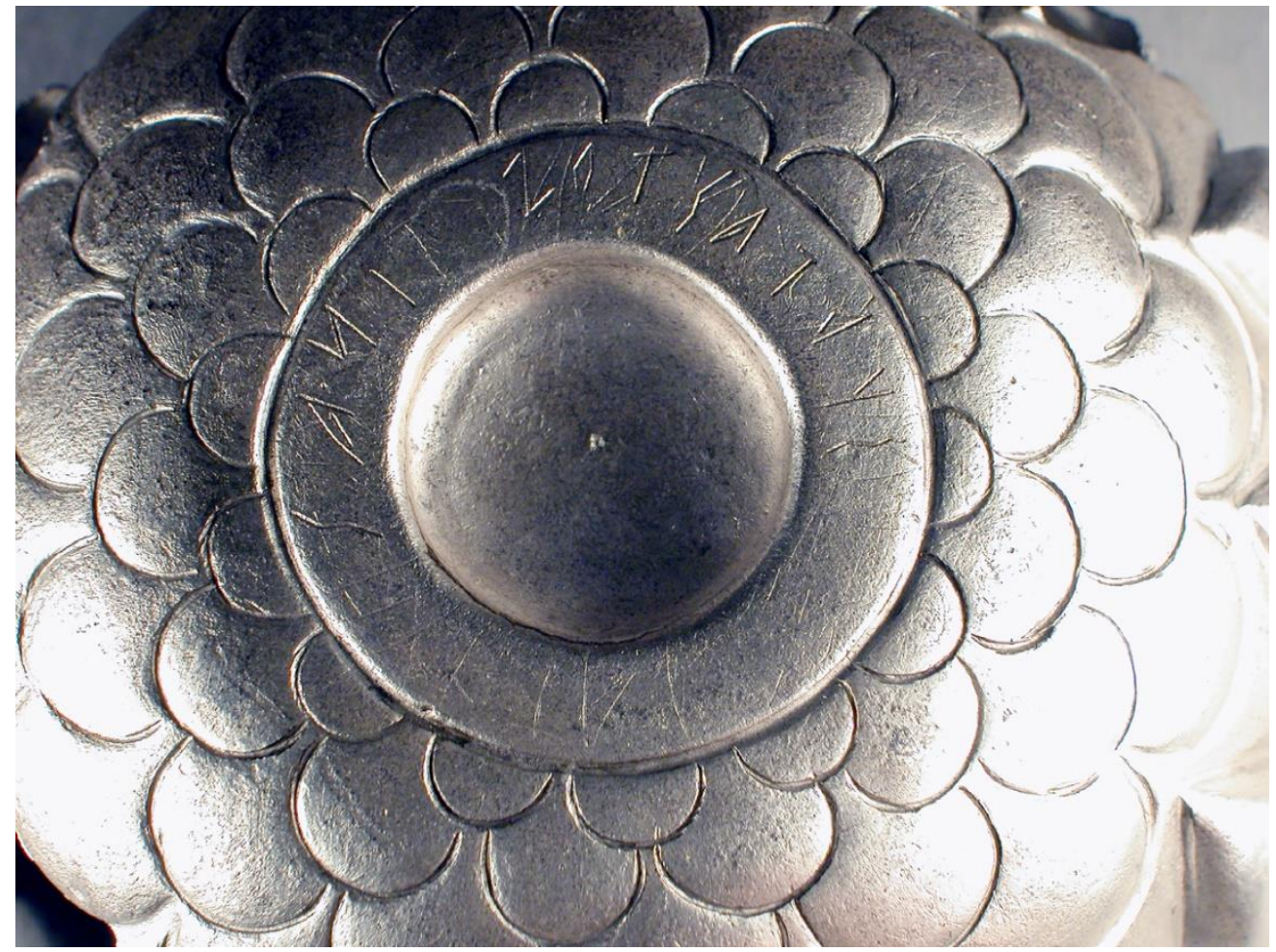

Finally, we must add to this list the form surgastoy (Dd-102), corresponding to Lyd. śrkaśtus, which occurs in inscription no. 11: śariśtros $\lambda$ śrkaśtus katowaliś sulos 'Surgastos the son? of Kadoas for Śariśtros'. The Lyd. form is considered a PN (Gusmani 1964, 199 and eDIANA, s.u.) and seems to be derived from an Anatolian adj. somehow related to Hitt. šarku- / šargau'eminent, illustrious, powerful' (Gusmani 1980-1981, 21-27, see also Beekes 2003, 19 fn. 21 with some remarks). However, it is unclear whether Phrygian surgastoy (Dd-102) refers to a man or to a god. ${ }^{208}$ Avram $(2016 \mathrm{~b}, 73-74)$ considered that the bowl on which this name in dat. was engraved (Fig. 12) is an offering to a god called surgasto- because it appears in Greek inscriptions as an epithet of Zeus: Zzù $\Sigma u \rho \gamma \alpha ́ \sigma \tau \eta \varsigma$ or $\Sigma v \rho \gamma \alpha \sigma \tau \varepsilon 10 \varsigma$ (on several coins dated to Imperial Roman times from Tion, modern Filyos, Bithynia, Head 1911, 518) and $\Delta i \mathrm{\Sigma} v \rho \gamma \alpha \sigma \tau \omega$ (SEG 48.984, from

${ }^{208}$ Avram $(2016 b, 74)$ also suggests that it appears in OPhr. G-113 [---]a? stoipitave[---], which he restores as [Surg]astoi, and G-164 [-?-].astoy, tentatively restored by as [Surg]astoy. As well as $\Sigma \alpha \rho v \varepsilon v \delta \eta v o \zeta$, another epiklesis of Zeus derived from a Phrygian word, the presence of this epithet in Dacia is explained as “introduced by colonists from Asia Minor after 106 AD" (Avram 2016b, 77). 
Apulum, Dacia Superior) ${ }^{209}$ One inscription from Hadrianopolis (Pontus-Bithynia) also reports

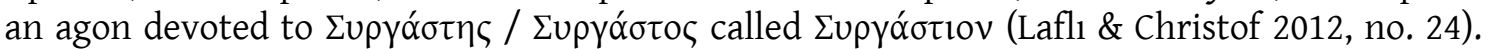
Finally, this DN occurs in a Lat. inscription as Surgasteo (CIL V 4206, from Brixia, Italy) and is very likely the origin of the name Sergestus found in Verg. Aen. (said to be the origin of the Sergian family) ${ }^{210}$ It is not clear whether this name is a Phrygian formation derived from an Anatolian word or if it is in fact Lydian. As far as we know, the first possibility is preferable, because the suffix -st- is a common feature of Phrygian DNs and PNs from the Phrygian cultural area that seem to be derived from Anatolian names. The DNs are areyastin (epithet of Matar in W-01a) and "A $\mathrm{\delta} \delta 1 \sigma \tau 1 \varsigma$ (epithet of the Mother-Goddess in a Greek inscription from Phrygia, also in Arn. Adu. Nat. 5, 5-6, Paus. 7, 17, 9-12, Str.12.5.3 and Hesychius $\alpha$ 404), while of the PNs we can consider M $\alpha \mu \alpha \sigma \tau \alpha$ (KPN 286 § 852-1, from Lycaonia), M $\alpha \mu \alpha \sigma \tau 1 \varsigma$ (KPN 286 § 852-2, from Pisidia),

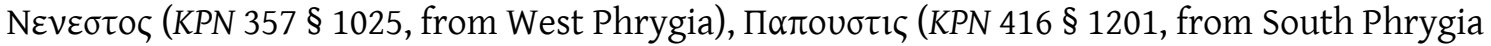

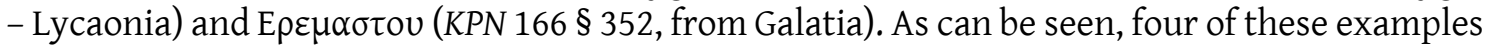

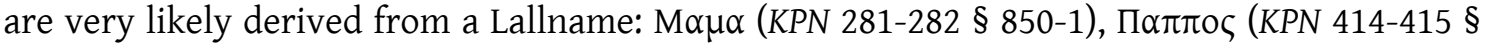

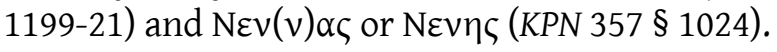

\subsubsection{Phrygian in contact with Aramaic}

Despite the importance of Aramaic in Neo-Hittite states and in the Achaemenid administration, in prior publications on Phrygian the relationship between Aramaic and Phrygian has been restricted to the bilingual graffito from Gordion G-157 ( $4^{\text {th }}$ C. BC, unfortunately), a sherd with few letters. ${ }^{211}$ However, the Aramaic influence on Phrygian is attested from the first OPhr. inscriptions, as G-249 (ca. $800 \mathrm{BC}$ ) shows, to the end of the Achaemenid period. Moreover, although Phoenician has been considered the origin of the Greek and Phrygian alphabets, Aramaic cannot be ruled out as a possible source, since the Phoenician and Aramaic alphabets were indistinct until the $8^{\text {th }}$ c. BC. In any case, Aramaic inscriptions (both monumental and quotidian) are found elsewhere in Anatolia and Phrygia is no exception, although Daskyleion, the satrapal seat of Hellespontic Phrygia, shows the strongest coexistence of Phrygian and Aramaic.

The only Aramaic borrowing attested in Phrygian is the term seVel 'weight, a shekel'

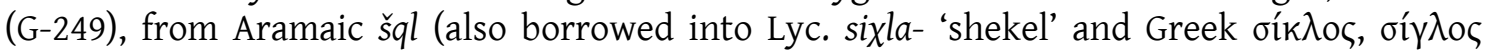
'weight, shekel'). It appears on a weight similar to those commonly found in Aramaic states, on which the unit of weight is incised (see Deutsch \& Millard 2014). Moreover, the Phrygian PN saragis (B-108, from Daskyleion, and M-101) is very likely to be found in an Aramaic Bulla from the satrapal seat as SGRY (Balkan 1959, no. 30, pl. XXXIVb and Lemaire 2000, II.4 no. 3).

Nevertheless, it is in the phraseology of the monuments that Aramaic seems to have had the greatest influence on Phrygian. As has been argued above, B-07 is a funerary stele with parallels in another Aramaic inscription from the same city, Daskyleion: compare me kos aniva Y eti s=manin, which is interpreted here as 'let nobody harm Manes' (see § 3.1.3), with ?l

\footnotetext{
${ }^{209}$ Note also that Mordtmann 1878, 292 considered that this divinity is the same found as $\theta \varepsilon \tilde{\omega}$ $\Sigma o u \rho \varepsilon \gamma \varepsilon \theta \eta$

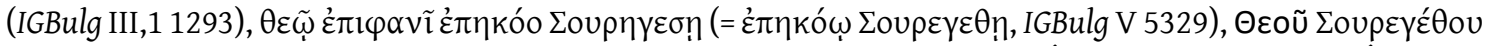

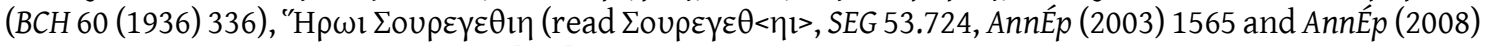

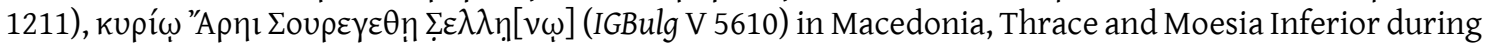
Roman Imperial times. However, such an identification is hard to substantiate: in these inscriptions it is

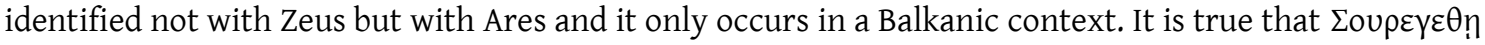
is very similar to surgastoy and perhaps both names are etymologically related. In any case, it is not a Phrygian issue.

${ }^{210}$ See Beekes 2003, 19-20 and 47, who also suggests that Lyd. srkastus can be the origin of the Etr. PN sekśtalus (TLE 713).

${ }^{211}$ See CIPPh I, 141 and 80 (with a reference to an unpublished Aramaic graffito from Gordion, inv. no. 9370) and Sowa 2015, 178.
} 
$y$ \ml 'do no harm!' (Lipińsky 1975a, 151). ${ }^{212}$ Both the Phrygian and the Aramaic sentences conclude their monuments. So, here, similar prohibitions replace the most common curses.

More Aramaic echoes can be found in an imprecative apodosis, W-01b, read on a façade devoted to the Mother-Goddess (see the details in the chapter devoted to Phrygian curses): lakedo key venavtun avtay materey 'and let him be taken by the same Mother'. Assuming Lubotsky's analysis of lakedo $(2004,234)$, the text is very similar to Aramaic curses such as wybSh lh śhr wšmš 'may Śēhr and Šamš search for him!' (inscription from Keseçek Köyü, Cilicia). Note that the verb ybSh means "“"to search for, "to look for" somebody, also in order to punish or to kill him" (Lipińsky 1975a, 150). Indeed, the Aramaic influence on this text could explain two oddities of this Phrygian apodosis: the unexpected presence of the copulative conj. key and the uncommon word order. The key 'and' can be equated to the Semitic "waw-apodosis". According to Pat-El $(2012,47-48)$, this term is "used for one of the functions of the Semitic coordinators ${ }^{*} w a$ or $*_{p a}$ when it introduces the apodosis of a conditional clause or when it introduces a matrix sentence after a subordinated clause, mostly a temporal clause." This is exactly what we have in both the Phrygian inscription $\mathrm{W}-01 \mathrm{~b}$ and the Aramaic inscription from Keseçek Köyü: lakedo key venavtun avtay materey 'let him be taken by the same Mother' is preceded by the subordinated clause yos esai=t materey eveteksete? $y$ ovevin onoman daYet 'whoever puts his own name to this Mother Evetkesetey' and wybSh lh śhr wšmš 'may Śēhr and Šamš search form him!' by wmn byš $\mid y$ Sbd Sm ptkr znh 'and whoever injury does to this figure' (trad. Lipińsky 1975a, 150). Moreover, the verb is commonly found at the end of the sentence. So, the unexpected word order of $\mathrm{W}-01 \mathrm{~b}$ is also explained as an Aramaic calque, in the light of the comparison with the inscription adduced here. It remains to be explained why the writer preferred venavtun (sg.acc.) to, e.g., avtos (sg.nom.). Indeed, this pron. clearly refers to the violator mentioned in the protasis, who is also the subject of the apodosis.

The beginning of MPhr-01 ( $=\mathrm{W}-11$, dated to the second half of the $\left.4^{\text {th }} \mathrm{c} . \mathrm{BC}\right)$ also shows a peculiar word order in which the demonstrative pronoun follows the noun (and the adj.). Indeed, the other occurrences of demonstrative pron. in agreement with a noun always precede

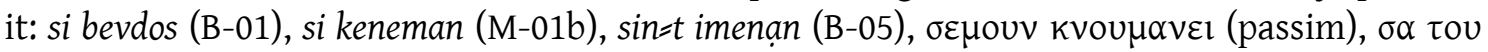
$\mu \alpha v \kappa \alpha(64.1=81)$... So, MPhr-01 has a particularly exceptional sequence. Given this scenario, it would seem to be another Aramaic calque in the light of šmh? znh 'this funerary stele' (lit. 'funerary stele this') found at the beginning of three contemporaneous Aramaic funerary inscriptions from Cilicia (Yukari Bozkuyu, Göller-near Bostanlar-and Kumkulluk). ${ }^{213}$ Indeed, Old and Official Aramaic, as well as most of the Semitic languages, tend to place the attributive demonstrative pronouns after the noun they modify (Pat-El 2012, 95).

Consequently, although Aramaic has not been considered in Phrygian studies, its influence on Phrygian was very strong, especially in the Achaemenid period. What is more, Aramaic influenced Phrygian not only at the lexical level but also at the syntactical level, at least in formulae borrowed from the Aramaic tradition.

\subsubsection{Phrygian in contact with Old Persian}

Old Persian influence on Phrygian is basically restricted to onomastics, as is the case with Lyc., although there are two possible PN borrowed into Phrygian. The first one is bagun (G-136), which has been suggested by Lubotsky $(2004,231)$ to be a loanword from OP baga'god'. ${ }^{214}$ Although the inscription containing this word is broken, a second borrowing is likely.

\footnotetext{
${ }^{212}$ Other translations: 'let no one do harm (to my tomb)' (Cross 1966, 8-9) or 'que personne ne (lui) fasse de mal!' (Lemaire 2000, II.1).

${ }^{213}$ On these, see Lemaire 1994 and 2000, V.10-12. There is another inscription from Cilicia (Ayvalik, near Aigeai) with the phrase šmh? znh, but it occurs in the 1.5 (see Lemaire 2004).

${ }^{214}$ A second possibility given by the same scholar is merely etymological: an inherited word from PIE PIE ${ }^{*} b^{h} e_{2} g^{h}$-u- 'lower arm, elbow' (e.g. Greek $\pi \tilde{\eta} \chi u \varsigma$ 'forearm, arm' or Skt. bāhú- 'lower arm, arm, foreleg of an animal'). Although it fits phonetically, the meaning is not expected in the context. On the other hand,
} 
Indeed, the word mago? [---], B-108 saragis:? mago? [---] (dated to between the late $6^{\text {th }}$ and early $5^{\text {th }}$ c. BC), is very likely to be the well-known priest title magus, borrowed from OP maguš (also

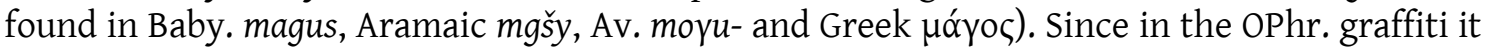
follows a PN in nom., one can easily restore its o-stem sg.nom. ending: mago? [s].

PNs of Persian origin are more common than nouns, but not all are clear. The possible Old Persian PNs in the Phrygian corpus are as follows:

asakas (G-150c): This name was suggested to have an Iranian origin by Lejeune (1970, 74, also by Orel 1997a, 194 and 416), and Schmitt $(1982,35)$ considered this possibility without being at all convinced. If both are right, this PN is derived from OP *asa- 'horse' with the hypocoristic suffix -ka- and also occurs in Elamite as Áš-šá-ka $a_{4}$ (Tavernier 2007, 118).

manuka (B-07): This name was considered a noun by Brixhe (2004a, 81), however in the light of its position after the phrase va knais 'his wife' it is very likely a PN. In that case, Manukka can be considered the same PN found in the administrative clay tablets from Persepolis (on this PN, see Mayrhofer 1973, 189 s.u.).

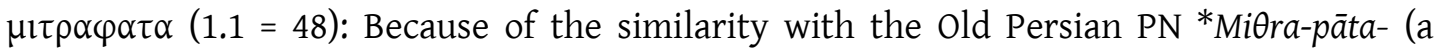
theofortic with the meaning 'protected by Mithra'), documented in Lyc. as milrapata

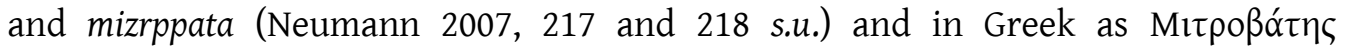

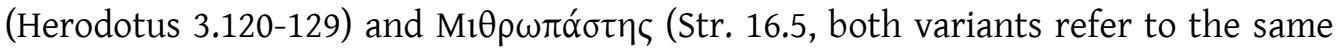
satrap of Hellespontic Phrygia), its identification is obvious (first proposed by Kretschmer 1898, 363, this identification is commonly accepted, pace Lubotsky 1997, 122). The confusion between letters for voiceless aspirated and voiceless plain stops in Phrygian and Greek from Phrygia is inconsequential.

Yuva Yaros (G-115, abbreviated as Yuv in G-224, § 3.1.3): This Phrygian form renders a Median PN via OP *h Uvaxštra, also found in in Akkadian as ${ }^{\mathrm{m}} U$-ak-sa-tar, ${ }^{\mathrm{m}} U k$-sa-tar and ${ }^{\mathrm{m}}{ }^{\mathrm{U}}$-maku-iš-tar, in Elamite as Ma-ki-iš-tur-ri and Ma-ak-iš-tar-ra (Schmitt 1982, 27) and finally in Greek through Herodotus 1.73, 1.103-07 as Kuaḱápns (borne by the son of the Median king Phraortes). This interpretation was first proposed by Kretschmer (in Prott 1898, 363, see also Schmitt 1982, 34-35, Tavernier 2007, 466-467).

Less clear are the following three PNs, also claimed to be of Persian origin:

$\alpha \delta \varepsilon v \pi \alpha \tau \eta \Lambda, \alpha \delta \varepsilon \nu<\pi>\alpha \tau \omega(43.1=69)$ : The reading is problematic and $\alpha \delta \varepsilon v \pi \mid \alpha \tau n \varsigma$ was formerly read as $A \lambda \varepsilon v \pi \alpha \tau \eta \varsigma$, while $\alpha \delta \varepsilon \mid v<\pi>\alpha \tau \omega$ as $A|\rho \varepsilon o \pi \alpha \delta \varepsilon| v \alpha \tau \omega$ (see Hämmig fthc. a). In any case, the element $-\pi \mid \alpha \tau n$ s probably has an Iranian origin, borrowed via the Greek language, since it can be equated to - pāta $\bar{a}$, like $\mu \imath \tau \rho \alpha \varphi \alpha \tau \alpha(1.1=48)$.

aspẹ[---] (P-102): Brixhe and Lejeune (CIPPh I, 145) equated this sequence to the Median word aspa- 'horse' and suggested that it is a PN of Iranian origin.

p'erbastidages (HP-101): Dinç and Innocente (1999, 69-71 also in Vassileva 2015, 94) considered it a PN with a Thracian or "Persianised Thracian" origin (whatever this means). However, Brixhe (2004a, 103-106) preferred to consider it a preposition $p^{\text {? }}$ er followed by a PN bastidages, without clear origin. As can be seen, this word(s) remain(s) obscure.

While in Greek the common masculine Old Iranian PNs in - $a$ became "either Greek stems in - $\eta \varsigma$ or Greek stems in -o (the genetically corresponding type)" (Tucker 2001, 776), in Phrygian the clear cases of these PN are rendered in either $a$-stems or o-stems: compare *MiOra-

Lejeune (1969b, 293, followed by CIPPh I, 125 and Sowa 2008, 28) considered it to be inherited from PIE ${ }^{*} b^{h} e_{2} g o-$ with the meaning 'present'. However, this can no longer be substantiated from a phonetic perspective: PIE ${ }^{*} g$ yields $k$ in Phrygian. 


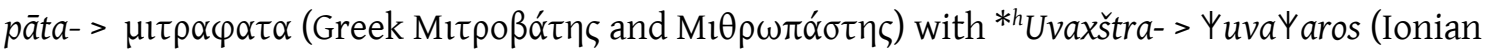

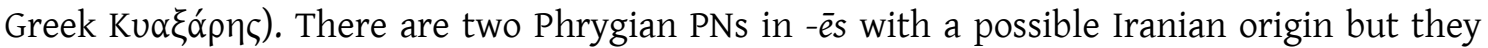

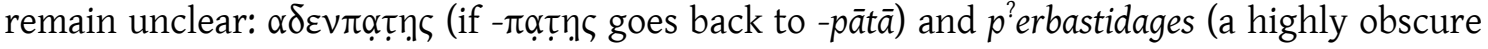
word).

\subsubsection{Phrygian in contact with Elamite}

The attested Phrygian contacts with Elamite and Phrygian are restricted to the Phrygian clay tablet found in Persepolis among thousands of Elamite tablets from the end of the $6^{\text {th }} \mathrm{c}$. BC and the first half of the $5^{\text {th }} \mathrm{c}$. BC. This Phrygian text, HP-114, has the Elamite month name anamaka, borrowed into the Persian calendar (Schmitt 2003, 27-29, Brixhe 2004a, 125 and Tavernier 2007, 39 and 83-84). The administrative nature of this text explains this loanword.

\subsubsection{Phrygian in contact with Assyrian?}

Leaving aside the PN kanutî (see $\S 4.2 .1 .1 .5 .2$ ), there is only a Phrygian word that could be borrowed from Assyrian: $\alpha \kappa \kappa \alpha \lambda \circ \varsigma(53.1=76,54.1=108$ and $62.2=33$, pl. $\alpha \kappa \alpha \lambda \alpha 4.1=2)$. It is

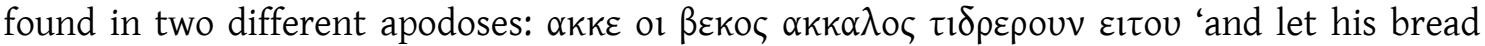

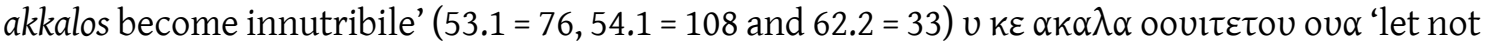
him found his loaf?' $(4.1=2)$. In this case, it is possibly a borrowing from the Assyrian akalu 'bread, food'. Perhaps $\beta \varepsilon \kappa o \varsigma ~ \alpha \kappa \kappa \alpha \lambda$ o refers to a specific kind of bread while in $v \kappa \varepsilon \alpha \kappa \alpha \lambda \alpha$

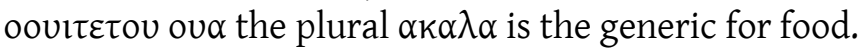

\subsubsection{Phrygian in contact with Galatian}

The Celtic tribes known as Galatians occupied the west part of ancient Phrygia in the $4^{\text {th }}$ c. BC, introducing a new language to the linguistic map of Anatolia. Nevertheless, Galatians did not produce inscriptions in this language, thus our knowledge of Galatian is restricted to PNs, toponyms and some glosses (see Freeman 2001). Despite the fact that Galatian is so poorly attested, the identification of Phrygian $\tau \varepsilon \cup \tau o u \varsigma ~(62.2=33$ and $62.5=36)$ as a Galatian borrowing (Brixhe \& Neumann 1985, 177, Bayun \& Orel 1988b, 156, Orel 1997a, 253 and 461 and Ligorio \& Lubotsky 2013, 194) must be refuted, since the ethnics Ambitoutus (established near Gordion according to Plin. HN 5.146) and Toutobodiaci (associated with Tectosages according to the same source) show that the word *teut- (borrowed from an unknown European language by some IE western branches, see Beekes 1998, 461-465) becomes tout- in Galatian. The only identified Galatian elements in inscriptions containing New Phrygian texts are the PNs B $\omega \delta$ op 15 , read in the Greek part of NPhr. no. $62.3(=34)^{215}$ and equated to Gaul. Borodix (CIL 11.867, see Freeman

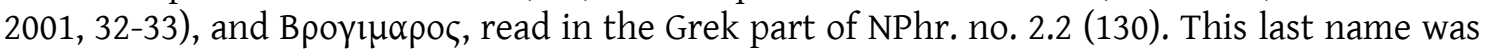
identified by Avram $(2015,205-206)$, the first editor of the inscription, and is also found in Gaul. Brogimaros. It is a compound of brogi- 'territory, region' and maros- 'great' (see Matasović 2009, 258 and 280). The most interesting feature of the altar that Brogimaros built in Nacoleia is that the first text incised on it was Greek, while the two Phrygian clauses, as well as three more Greek texts, were added after his death.

\subsubsection{Phrygian in contact with Latin}

The Latin influence on Phrygian is essentially restricted to a small number of PNs in the Greek part of NPhr. inscriptions such as Aủpri $\lambda$ ıos, very common after the Constitutio Antoniniana issued by Caracalla (officially Marcus Aurelius Severus Antoninus Augustus), a useful

${ }^{215}$ Its nominative B $\omega \delta$ op 15 occurs in another Greek epitaph (MAMA VII 335) from the same city, Sinanl (Brixhe 2013,63). A variant spelling of this PN is read on a gravestone from the late Ptolemaic cemetery

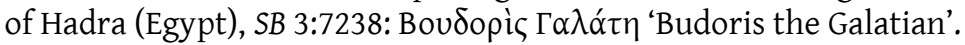




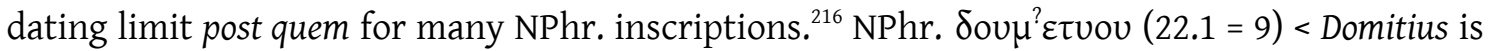
the sole Lat. PN found in a NPhr. text. In addition, Neumann $(1986,80-81)$ suggested that $\mu \alpha \iota \mu \alpha \rho \eta \alpha \nu(40.3=31)$, read as /memarian/, renders Lat. memoria with the same meaning found

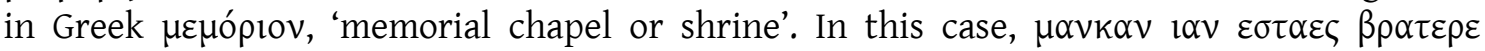
$\mu \alpha \iota \mu \alpha \rho \eta \alpha$ means 'stele which (he) erected for (his) brother as memorial'. Nevertheless, the most common opinion holds that this word is an adj. parallel to Greek $\mu \alpha \rho \mu \alpha$ ó $\rho$ o,$\alpha$, ov 'flashing, gleaming, of marble', although the spelling difference ( $\left.\mu \alpha \rho-/ \mu \alpha l^{-}\right)$is not accounted for. Following this view, $\mu \alpha v \kappa \alpha v i \alpha v \varepsilon \sigma \tau \alpha \varepsilon \zeta \beta \rho \alpha \tau \varepsilon \rho \varepsilon \mu \alpha \iota \mu \alpha \rho \eta \alpha v$ means 'stele of marble which (he) erected for (his) brother'. With regard to onomastics, the Phrygian PN davo- (dat. davoi in M-06 and B-05) is found in Latin sources as Dauus (bore by slaves), as well as in Greek as $\Delta \tilde{\alpha}$ (f)oc. Finally, it should be noted that the Phrygian Mother-Goddess is found in Latin as Cybele, but it is clearly an adaptation of the Greek rendering Kußź $\lambda \eta$.

${ }^{216}$ See Ramsay 1883, 30 and McLean 2014,114-117. 
5. Lexicon of the Phrygian inscriptions 



\section{$\mathrm{A}(a)-\mathrm{A} \alpha$}

$a^{1}$ (mark)

OPhr. a G-225, G-311

a[-?-] G-317, G-327, G-334, NW-108?

Single letter incised on potsherds. In G-225, $\uparrow$ also appears as an isolated letter, and G-327 has another undetermined sign. This letter in G-317, G-327, G-334 and NW-108 was perhaps followed by another that has not been conserved due to the fragmentation of the support. NW-108 could be read as $d[-?-]$.

CIPPh I, 161; Brixhe 1997, 42-49 and 50-52; Brixhe 2002a, 17 and 69.

$a^{2}$ see $a d$.

$a^{3}$ and $\alpha \alpha \zeta$ see as.

[-?-]ab, [-?-]abạ, [-?-]abas see babas.

$\alpha \beta \beta \varepsilon \rho \varepsilon \tau$ (verb) 'bear, produce'

OPhr. 3sg.sub.pres.med. abretoy B-05 1.10

NPhr. 3sg.sub.pres.act. $\quad \alpha \beta \beta \varepsilon \rho \varepsilon \tau 18.3$ (6), 29.1 (114), 39.1? (11), 40.2 (12)

3sg.sub..pres.med. $\alpha \beta \beta \varepsilon \rho \varepsilon \tau$ rol 10.2 (113), 17.5 (91), 19.2 (129)

3sg.sub.pres.med. $\alpha \beta \beta \varepsilon \rho \varepsilon \tau о \rho ~ 14.1$ (73), 52.1 (75), 59.3 (79)

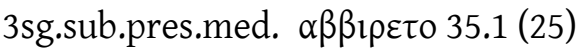

3sg.sub.pres.act.? $\alpha \beta \varepsilon \rho \varepsilon \tau 1 ~ 66.1(103)$

3sg.sub.pres.act. $\quad \beta \varepsilon \rho \varepsilon \tau 7.2(111), 8.1$ (86)

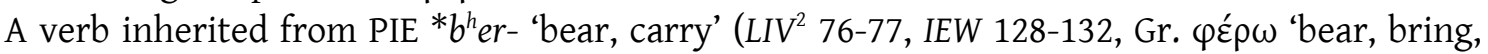
produce', Skt. bhárati 'bear, carry', Lat. fero 'id.'). In most instances it takes the preverb $\alpha \delta$ (with assimilation of its stop, as well as $\alpha \delta \delta \alpha \kappa \varepsilon \tau$; on the verbal formation, see LIPP II, 14, with parallels) and usually is found in imprecative protases in the same position as the more common verb

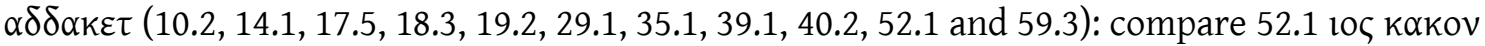

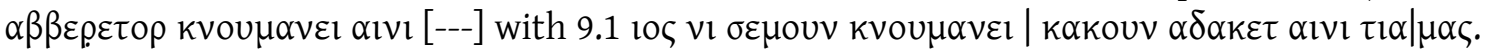
Even the NPhr. middle forms are found in the same position as the active form: e.g., $14.1105 \mathrm{vl}$

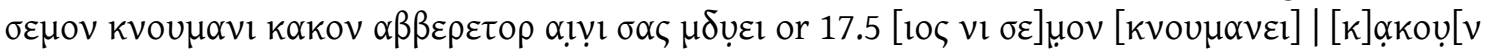

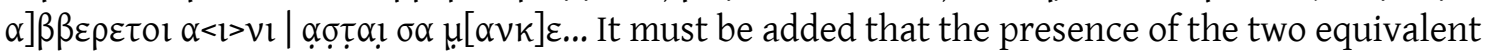

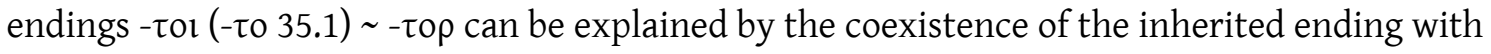
a secondary formation in the light of OPhr. abretoy B-05 (with syncope, see Brixhe 2004a, 62). This OPhr. occurrence is found in an apodosis: B-05 mekas key | kovis abretoy nun ibey nevotan niptiyan sirun mireyun. In the two occurrences of this verb without a preverb, its meaning is 'bring, produce, cause' (also found in Gr.): $7.2 \beta \alpha \varsigma$ lor $\beta \varepsilon \kappa o \varsigma \mu \varepsilon \varepsilon \varepsilon \rho \varepsilon \tau$ and $8.1 \beta \alpha[\varsigma]$ | $101 \beta \varepsilon \kappa \circ \varsigma \mu \varepsilon$ $\beta \varepsilon \rho \varepsilon[\tau]$ 'let Bas not bring bread to him'. In this instance, the formula is equivalent to $99 \mu \varepsilon \kappa \varepsilon$ or

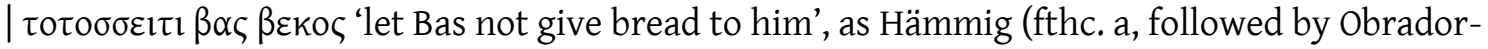
Cursach 2017, 309) identified in the light of Gr. parallels (§ 4.6.1.2).

Neumann 1988, 9; Neumann 1997, 22; Orel 1997a, 420; Brixhe 2004a, 62; Sowa 2007a, 74-77; Gorbachov 2008, 101-102; Sowa 2008, 104-106; Brixhe \& Drew-Bear 2010, 164-165; Hämmig 2013, 144; Ligorio \& Lubotsky 2013, 183, 187 and 191; Simon 2015, 21-22; LIPP II, 14; Obrador-Cursach 2017, 309; Hämmig fthc. $a$ and b.

$\alpha \beta \beta \varepsilon \rho \varepsilon \tau o l, \alpha \beta \beta \varepsilon \rho \varepsilon \tau o \rho, \alpha \beta \beta 1 \rho \varepsilon \tau 0, \alpha \beta \varepsilon \rho \varepsilon \tau, \alpha \beta \beta \varepsilon \rho \varepsilon \tau$ and abretoy see $\alpha \beta \beta \varepsilon \rho \varepsilon \tau$. 
abs (PN)

OPhr. abs G-166

Complete graffito incised on the neck of a vase. CIPPh $(\mathrm{I}, 147)$ equated to the PN abas (KPN 43-44 $\S 1-3$ ) and considered that the loss of the last vowel could be a consequence of the stress, adducing the variant bba (M-04) instead of the common baba (M-01b).

CIPPh I, 147.

agarițoi (adj.) ‘devoted’

OPhr. pl.nom. agarițoi G-02 a

This o-stem adjective agrees with the noun petes in the votive inscription where it occurs: agaritoi petes adoikavoi... According to Kloekhorst $(2015,116)$, it can be considered a deverbative adj. derived from the same verbal root attested in the participle $\gamma \varepsilon-\gamma \alpha \rho ı \tau-\mu \varepsilon v o \zeta$ 'cursed, devoted', which goes back to PIE * $g^{h} r H$ - 'desire, enjoy' (LIV 176-177, IEW 440-441). Regarding its beginning, he also considered ad- a preverb assimilated to the following velar stop. Following this interpretation, this word means 'devoted', which is highly expected in a votive text of this kind. Before Kloekhorst's analysis, it was misread as agartioi and considered a PN in sg.dat. which agreed with adoikavoi. Woudheinzen $(2008,183$ § 5) equated it to Gr. áxóplotos 'ungracious, unpleasant'. Although this Gr. adj. shares its PIE root with agaritoi, it is not an equivalent formation and even its meaning does not fit in this context.

CIPPh I, 87; Bayun \& Orel 1988a, 191; Lubotsky 1989b, 152; Woudhuizen 2008-2009, 183 §5; Kloekhorst 2015, 110 and 116.

${ }^{\dagger}$ agarțioi see agarițoi.

agipeia (PN)

OPhr. sg.nom. [-?-]agipeia G-135

Graffito incised on a fragment of a cup handle. Although more letters could precede the preserved text, it is very likely complete. Consequently, Neumann $(1988,7)$ suggested that agipeia was derived from "Aүıाто ऽ by adding the suffix -eia- and that it means 'the daughter of

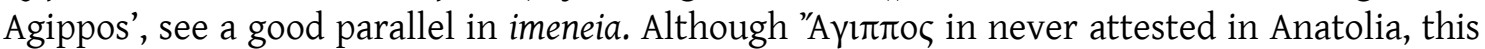
could be a good explanation. On the other hand, Orel $(1997 a, 185)$ read it as [l]agineia in the light of lagineios (G-110) and [l]]agineia (G-276). Nevertheless, this possibility was previously ruled out by CIPPh (I, 124).

Brixhe 1983, 127; CIPPh I, 124; Diakonoff \& Neroznak 1985, 90; Neumann 1988, 7; Innocente 1997, 39; Neumann 1997, 27 fn. 11.

${ }^{\dagger}$ aglavọy see ae and lavọy.

agomoi (PN)

OPhr. sg.dat. agomoi W-08

The inscription in which this word appears was engraved on a lone rock. The context is clear enough to conclude that, despite the lack of parallels, agomoi is a thematic PN: [-?-] ates agomoi

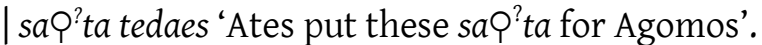

Brixhe \& Drew-Bear 1982, 70; Brixhe 1983, 115; CIPPh I, 53; Bayun \& Orel 1988a, 185.

ad (preposition) 'to, at, by'

OPhr. a NW-101 a II

ad B-05

NPhr. $\quad \alpha 9.1(87), 17.3(7), 66.1(103)$

$\alpha \delta 7.3(99)$ 
$\alpha \tau 8.1$ (86), 18.3 (6), 20.3 (62), 29.1 (114), 30.1 (39), 36.3 (94), 39.1 (11), 40.1 (12), 41.1 (45), 42.1 (101), 44.1 (61), 44.3 (67), 45.1 (65), 47.1 (51), 49.3 (85), 50.1 (54), 51.1 (80), 53.1 (76), 53.2 (77), 54.1 (108), 55.1 (56), 56.1 (57), 58.1 (72), 59.4 (106)

Preposition inherited from PIE * $h_{2}$ ed (LIPP II, 8), also attested, e.g., in Lat. ad, Oscan adpúd, Go. at and OIr. ad. It governs dat. (ad kaliyay B-05) and is commonly attested by the DN $\tau l^{-}$'Zeus' in the

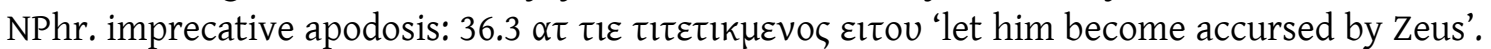
Because of the simplification of the $a$-stem inflection (see $\S$ 4.2.1.1.1.), it gives the impression of appearing in other cases: e.g. $\alpha \tau \varepsilon \alpha \mu \alpha \varsigma$ (10.1). However, it is once attested with sg.acc.: $10 \varsigma \mathrm{vl}$

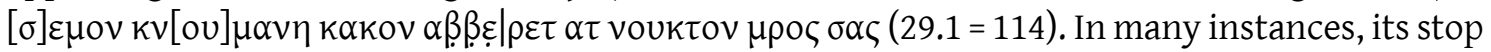
assimilates to the following one and the consequent geminates are often simplified in NPhr., $\alpha \tau$ $\tau \mathrm{l}(42.1)>\alpha \tau \mathrm{l}$ (9.1), while in OPhr. the script does not represent them: a tiei (= NPhr. $\alpha \tau \tau i \eta)$ /attiej/ (NW-101). Phr. ad is also a common preverb (with assimilation and often with simplification of the geminates): $\alpha \delta \delta \alpha \kappa \varepsilon \tau, \alpha \delta \alpha \kappa \varepsilon \tau, \alpha \beta \beta \varepsilon \rho \varepsilon \tau, \alpha \beta \varepsilon \rho \varepsilon \tau, \alpha \tau \varepsilon \tau \iota \kappa \mu \varepsilon v o \zeta . .$. According to Kloekhorst $(2015,10)$, it is very likely attested in the adj. a-garitoi 'devoted' (G-02a).

Brixhe 1997, 42-49; Ligorio \& Lubotsky 2013, 183; Kloekhorst 2016, 116; LIPP II, 8.

\section{$\alpha \delta \alpha \kappa \varepsilon v, \alpha \delta \alpha \kappa \varepsilon \tau, \alpha \delta \alpha \kappa \kappa i \tau o \rho, \alpha \delta \delta \alpha \kappa \varepsilon \kappa, \alpha \delta \delta \alpha \kappa \varepsilon \mu$ and $\alpha \delta \alpha \kappa \varepsilon v$ see $\alpha \delta \delta \alpha \kappa \varepsilon \tau$.}

$\alpha \delta \delta \alpha \kappa \varepsilon \tau$ (verb) 'do, put'

OPhr. 3sg.ind.pres.act. dạket B-05 l. 11; da Yet W-01b

1sg.ind.pres.med.? dakor K-01 VI-VII a2?

3sg.subj.pres.act. dedasitiy B-05

3sg.subj.pres.act.? deVeti NW-101 A I

3sg.ind.aor.act. edaes M-01a, M-01b, M-02, B-01, W-08; ẹdaes K-01 VI-VII b; ẹdaẹ[s] M-01f; edaẹ [s] P-04 c; ed[a]es W-02; [e]daes W-05 b

3sg.ind.aor.med. edatoy B-05 1.2

3sg. med. odeketoy B-07

3sg.ind.aor.med. tedatoy W-01a; tedat[oy] B-05 l.1?

NPhr. 3sg.ind.pres.act. $\quad \alpha \delta \alpha \mid \kappa \varepsilon 47.1(51)$,

3sg.ind.pres.act. $\quad \alpha \delta \alpha \kappa \varepsilon v 18.2(5) ;[\alpha \delta(\delta) \alpha \kappa] \varepsilon v 17.3(7)$ ?

3sg.ind.pres.act. $\quad \alpha \delta \alpha \kappa \varepsilon \tau ~ 3.1(97), 7.1$ (99), 7.2 (111), 7.3 (14), 9.1 (87), 10.1 (112), 18.1

(4), 25.1 (115), 32.1 (93), 33.1 (28), 36.3 (94), 40.4 (102), 44.1 (61),

62.5 (36), 62.6 (105), $65.1(20), 65.3(21) ; \alpha \delta \alpha \kappa \varepsilon[\tau] 30.2$ (68);

$\alpha \delta \sigma_{\alpha}<\varepsilon \tau>33.3(127) ; \alpha \delta \alpha \mid[\kappa] \varepsilon \tau 62.6(105)$

3sg.ind.pres.med.

$[\alpha \delta \alpha] \kappa \kappa \iota \tau о \rho ~ 58.1(72)$

3sg.ind.pres.act. $\quad \alpha \delta \delta \alpha \kappa \varepsilon \kappa 62.1(32)$

3sg.ind.pres.act. $\quad \alpha \delta \delta \alpha \kappa \varepsilon \mu 62.4(35)$

3sg.ind.pres.act. $\quad \alpha \delta \delta \alpha \kappa \varepsilon \tau 1.1(48), 2.2(130), 4.1$ (2), 6.1 (88), $11.2(17), 15.1(120), 17.2$

(3), 17.4 (90), 20.2 (128), 20.3 (62), 21.2 (43), 22.2 (118), 25.2 (126),

37.1 (10), 43.1 (69), 53.1 (76), 53.2 (77), 56.1 (57), 59.2 (47), 59.3

(79), 60.1 (59), 62.2 (33), 62.3 (34), 63.1 (123), 64.1 (81), 65.4 (124);

$\alpha \delta \delta[\alpha] \mid \kappa \varepsilon \tau \quad 8.1(86) ;<\alpha \delta \delta \alpha \kappa>\varepsilon<\tau>5.1(19) ? ;[\alpha \delta] \delta[\alpha \kappa \varepsilon \tau] 13.1$

(122)?; $\alpha \delta[\delta] \alpha \mid \kappa \varepsilon \tau ~ 30.1$ (39); $\alpha \delta \delta \alpha \kappa \mid[\varepsilon \tau] 31.1(29) ;[\alpha] \delta \delta \alpha \kappa \varepsilon \tau 41.1$

(45), 51.1 (82); $\alpha \delta[(\delta) \alpha \kappa \varepsilon \tau] 42.1$ (101)?; $\alpha \delta[[\delta \alpha \kappa \varepsilon] \tau$. 45.1 (65);

$\alpha \delta \delta \alpha \kappa[\varepsilon \tau] 50.2 ; \alpha \delta[\delta] \alpha \kappa \varepsilon \tau 57.1$ (78)

3sg.ind.pres.act.

$[\alpha] \mid \delta \delta \alpha \kappa \varepsilon \tau \tau 46.1(53)$

3sg.ind.pres.med.

3sg.ind.pres.med.

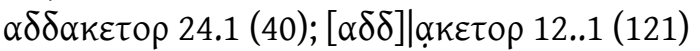

3sg.ind.pres.act.

$\alpha \delta \delta \alpha \mid \kappa \varepsilon \tau \tau \rho \rho \rho 20.1(63)$

3pl.ind.perf.act.

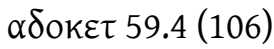

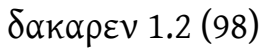




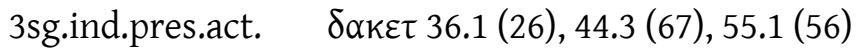

3pl.subj.pres.act. $\quad \delta \varepsilon \delta \alpha \sigma \sigma i v v ı 2.2(130)$

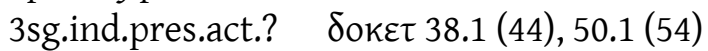

3sg.ind.aor.act. $\quad \varepsilon \delta \alpha \varepsilon \varsigma 16.1(116) 1.9$ and 1.11

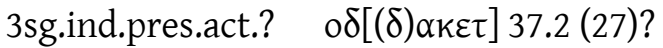

A verb inherited from PIE * $d^{h} e_{1-}$ 'to do, put, place' (LIV ${ }^{2} 136-140$, IEW 235-239), Lat. faciō 'to do', Gr. $\tau i ́ \theta \eta \mu \mathrm{r}$ 'to set, put, make', Sk. dádhāti 'id.', etc. Unlike the aor., the Phr. present forms show the same disputed element - $k$ - found in Italic *fac- (Berenguer \& Luján 2005 and de Vaan 2008, 198-199) and the Gr. aor. $\varepsilon^{\prime} \emptyset \eta \kappa \alpha$ and perfect $\tau \dot{\varepsilon} \theta \eta \kappa \alpha$. The most attested form is 3sg.ind.pres.act. $\alpha \delta \delta \alpha \kappa \varepsilon \tau$, with the preverb $\alpha \delta$-, attested in the common NPhr. protasis: e.g. 62.2 lo $v 1$ $\sigma \varepsilon \mu o u v$

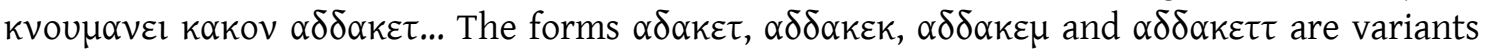
with simplification of the geminates ( $\alpha \delta \alpha \kappa \varepsilon \tau)$, hypercorrections ( $\alpha \delta \delta \alpha \kappa \varepsilon \tau \tau)$ and consequences

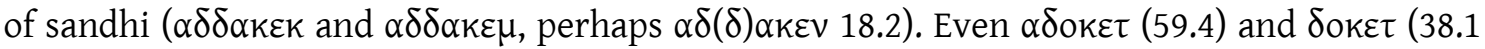
and 50.1) can be considered an Eastern phonetic variant because they are found in the same

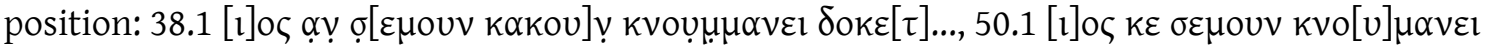

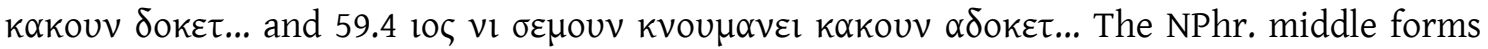

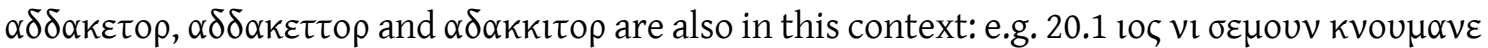

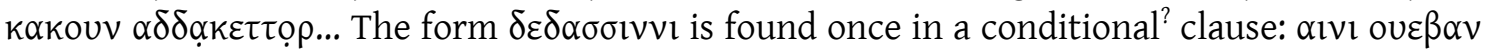

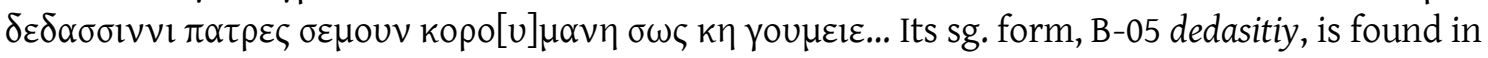
a protasis yos niy art sin=t imenạn kaka oskavos kakey kạn dedasitiy.... (see Hämmig fthc. a, pace Avram 2015, 209 who considered it a perfect form). Both $\delta \varepsilon \delta \alpha \sigma \sigma l v v 1$ and dedasitiy probably go

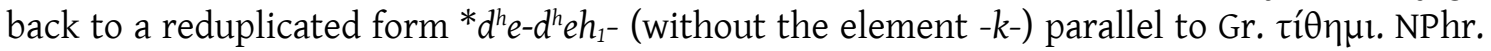

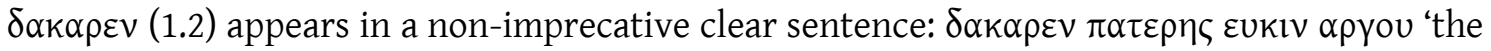
parents put it in memory?". The most common OPhr. form is eades, also found in NPhr. $16.1 \varepsilon \delta \alpha \varepsilon \zeta$, an aor. used in monuments: e.g. M-01a ates arkiaevais akenanogavos midai lavagtaei vanaktei edaes. Its middle form, edatoy, occurs in similar contexts: W-01a materan areyastin bonok akenanogavos | vrekun tedatoy (with the preverb $t$-, LIPP II, 772). W-01b da Yet was considered a sigmatic form by Lejeune $(1978,788)$, however since it occurs in a clear apodosis it is more easily explained as being the same form daket / $(\alpha \delta) \delta \alpha \kappa \varepsilon \tau$ (see $\S 3.1 .3$.): compare W-01b yos esai=t materey eveteksete? $\mathrm{y}$

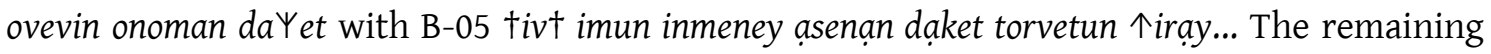
forms are less clear. The OPhr. form odeketoy B-07 appears in a funerary stele in the part devoted to the circunstances of the monument: ... va knais manuka odeketoy... The verb can be analysed as 3sg.ind.pres.med. o(d)-dek-e-toy of the verb * $d^{h} e h_{1}-k$ - 'to do', with the preverb o- (< PIE ${ }^{*} h_{2} \mathrm{O}$, LIPP II, 323-324). This interpretation is given by Gusmani (in Gusmani \& Polat 1999b, 158) and followed "sans doute" by Brixhe (2004a, 80). However, if the sentence means "his wife Manukka made it', the expected form is edatoy (as in B-05) and it remains unexplained why the verb occurs in present, as Simon $(2015,24)$ observes, and why it has zero-grade in the root. However, the alternative, an aor. verb od-e-ket-toy implies an unparalled root without clear origin and meaning. OPhr. deVeti (NW-101 A I) seems to be 3sg.subj.pres.act. Brixhe (2002a, 6-7) also

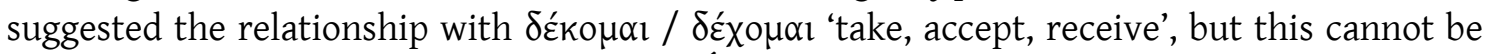
substantiated because it goes back to PIE * dek- 'take, perceive' (LIV $109-112$, IEW 189-190) and a voiced stop is not expected in Phrygian. In any case, it occurs in an unclear context: NW-101 de deVeti toTi a tiei. Finally, Brixhe (in Brixhe \& Summers 2006, 125-126) suggested that dakor (K-01) was the 1sg.ind.pres.med. form, although the damage to the inscription is such that this conclusion cannot be confidently drawn: ... | eniyẹ[---] | [---].pa ' uva (..---] | [---]' mạsa u|rgitos dakor s=vebrạ[---] | tataniyen? ẹdaes | [---]le.[---].

Haas 1966, 24 \& 112; Lejeune 1978, 788; Bayun \& Orel 1988a, 188; Bayun \& Orel 1988b, 134; Lubotsky 1988, 22 fn. 11; Orel 1997a, 409 and 422; Gusmani \& Polat 1999b, 158; Brixhe 2002a, 6-7; Brixhe 2004a, 52 and 80-81; Berenguer \& Luján 2005, 202; Gorbachov 2005; Brixhe \& Summers 2006, 125-126; Sowa 2007a, 74-77; Sowa 2008, 98-104; de Vaan 2008, 198-199; Simon 2015, 24; Avram 2015, 209. 
$\alpha \delta \delta \alpha \kappa \varepsilon \tau \tau, \alpha \delta \delta \alpha \kappa \varepsilon \tau o \rho$ and $\alpha \delta \delta \alpha \kappa \varepsilon \tau \tau$.

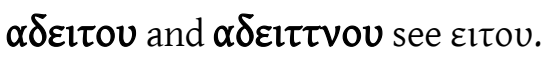

\section{$\alpha \delta \varepsilon v \pi \alpha \underline{T} \underline{\underline{T}} \zeta(\mathrm{PN})$}

NPhr. sg.nom.? $\alpha \delta \varepsilon v \pi \mid \alpha$ ț̣ 43.1 (69) 1. 4-5

sg.dat.? $\quad \alpha \delta \varepsilon \mid v<\pi>\alpha \tau \omega 43.1$ (69) $1.9-10$

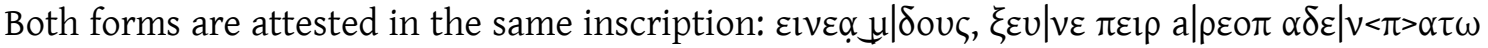

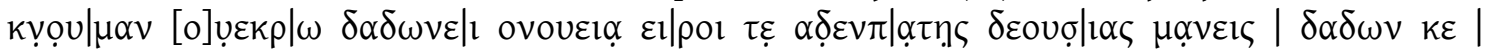

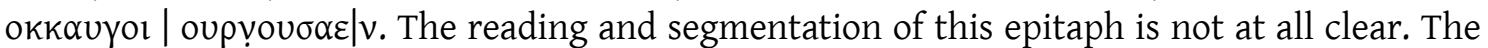
identification of $\alpha \delta \varepsilon \mid v<\pi>\alpha \tau \omega$ was suggested by Hämmig (fthc. a) in the light of $\alpha \delta \varepsilon v \pi \mid \alpha \tau \underline{\text { th }}$. Since the PN $\delta \alpha \delta \omega v$ also occurs in sg.nom. and sg.dat. in the same inscription, this identification is very likely, despite assuming the engraver's mistake with pi. The element $-\pi \mid \alpha+n, n$ s probably shows an Iranian origin, since it can be equated to -pātā, like $\mu \iota \tau \rho \alpha \varphi \alpha \tau \alpha(1.1=48)$. The form

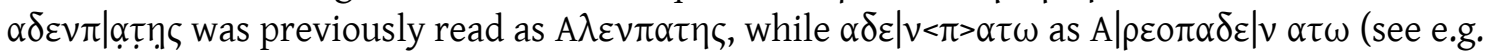
Haas 1966, 107-108).

Haas 1966, 107-108; Hämmig fthc. a.

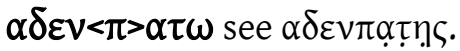

adi..[---] (PN?)

OPhr. adi..[---] B-01

This occurs at the begining of a large inscription describing a niche devoted to the MotherGoddess: si bevdos adi..[..] | kavarmoyo imroy edaes etovesniyo 'Adi..[..] made this statue for this field...'.The only possible subject of this sentence is adi..[---], meaning that it is very likely a PN, despite being mainly lost.

Lubotsky 2008.

\section{$\alpha \delta \imath \theta \rho \varepsilon \rho \alpha \kappa(\mathrm{PN})$}

NPhr. sg.nom. $\alpha \delta i \theta \rho \varepsilon \rho \alpha \kappa ~ 40.3$ (31)

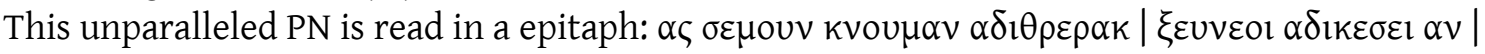
$\mu a v \kappa \alpha v i \alpha v \varepsilon \sigma \tau \alpha \varepsilon \varsigma \beta \rho \alpha \tau \varepsilon \rho \varepsilon \mid \mu \alpha \iota \mu \alpha \rho \eta \alpha v$. Its ending has been explained as an assimilation of an original $-s$ to the adjacent velar. However, it is not necessary since there are other PNs in Phr. ending with $-k$ such as bonok. In that case, the expected nom. ending -s drops after this stop, as modrovanak shows. The use of theta in this name perhaps suggests a non-Phrygian origin, since in the whole Phr. corpus it is only found in the Gr. loanword $\theta \alpha \lambda \alpha \mu \varepsilon$. However, we cannot rule

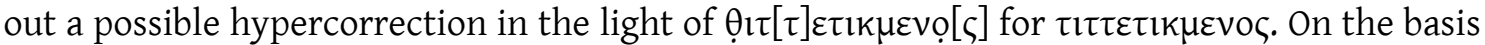
of this reasoning, Neumann $(1986,82)$ equated it to the Cilician name $\Sigma \alpha \rho 1 \delta \eta \rho \alpha \varsigma$ (KPN $456 \S$ 1376), although in order to identify the elements of this PN he also suggested the presence of

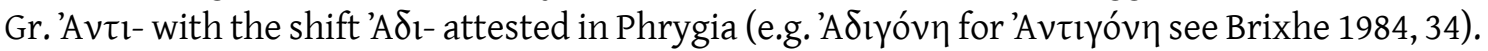
Alternatively, Orel (1997a, 332 and 41) equated - $\theta \rho \varepsilon \rho \alpha \kappa$ to Gr. $\theta \rho \varepsilon ́ \psi ı \varsigma$ 'nourishing'. Kowal 1984b, 181; Neumann 1986a, 82; Orel 1997a, 332 and 410; Brixhe 1999, 298-299.

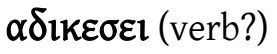

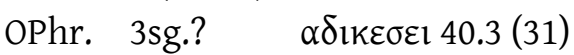

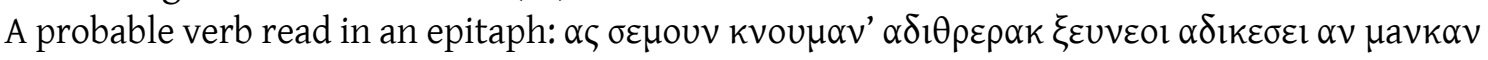
$\iota \alpha v \varepsilon \sigma \tau \alpha \varepsilon \varsigma \beta \beta \rho \tau \varepsilon \rho \varepsilon \mu \alpha \iota \mu \alpha \rho \eta \alpha v$. This sequence has been segmented in several alternative ways,

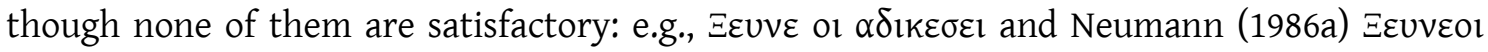
$(\varepsilon) \delta$ ikع $\varepsilon(\sigma) \alpha \nu$ (Brixhe \& Neumann 1985, 169). Although its ending is problematic (why not $-t(i)$ ?), the probable verb seems to take the preverb $\alpha \delta$-. Woudhuizen $(2008-2009,183)$ read it as 


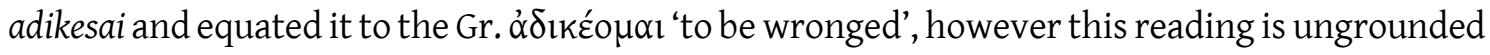
and the equation is phonetically unexpected.

Brixhe \& Neumann 1985, 169; Neumann 1986a; Lubotsky 1993a, 183; Woudhuizen 2008-2009, 183.

[a]doikaṿ[---] and adoikavoi see [a]doikavos.

adoikavos (PN)

OPhr. sg.dat. adoikavoi G-02 a

sg.nom. [a]doikavos G-146

[a]doikav?[---] G-153

This o-stem word is attested in two graffiti incised on pottery, G-146 [---].....--- a]doikavos and G-153 [--- a]doikav? [---], and on a votive slab: agaritoi petes adoikavoi... This last text has recently been interpreted by Kloekhorst $(2015,116)$ as '(these) feet (are) devoted to Adoikavos'. According to this interpretation, adoikavo- is a clear proper name, very likely of a divinity, as Woudhuizen considered $(2008-2009,197)$. However, such a god is not attested elsewhere and a PN can be considered if the dat. adoikavoi in G-02 a is understood as an agent: 'feet devoted by Adoikavos'. Although the beginning of this PN in G-02 can indeed be considered the preposition $a d-$, since the other occurences are not clear about this question (a form ad + doikavoi cannot be excluded), the expression of the agentive dat. without preposition is well attested: see, e.g., 4.1

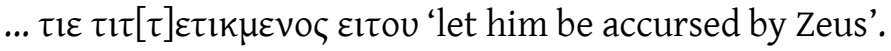

Lubotsky 1988, 12; Neuman 1988, 13; Bayun \& Orel 1988a, 191; Brixhe 1993, 333; Neumann 1997, 23; Orel 1997a, 159 and 410; Woudhuizen 2008-2009, 197; Ligorio \& Lubotsky 2013, 189; Kloekhorst 2015, 114-116.

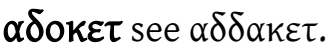

adun (noun)

OPhr. adun B-05 1.4

An unparalleled word read in the non-imprecative part of the stele of Vezirhan: ... panta vebras adun $p^{\text {? }}$ os key estat pator. ike[...] [...] andati... Because of its ending, it can be considered a masc. ostem noun in sg.acc., a sg.nom.-acc.neuter or even a pl.gen.

Brixhe 2004a, 56-57.

$a e(?)$

OPhr. ae M-01f

ae $\mathrm{W}-09$

$a^{?} e^{?} \mathrm{~B}-04$

The three contexts in which this unexplained word occurs remain unclear: M-01f [.?].as tuave|niy

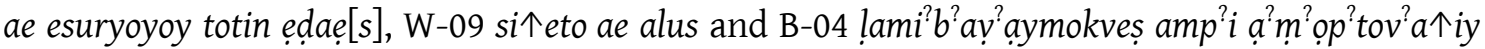
$a^{?} e^{?}$ lavoy ue edaviy p? is? anerneuey... Following a first suggestion by CIPPh (I, 17, 54), Brixhe (2004, 41) considered it a preposition. However, this is not probable in the light of W-09, where it occurs after a verb and followed by a noun, very likely in sg.nom. He also considered it to be a spelling variant of a aey.

Haas 1969, 73-78; Brixhe \& Drew-Bear 1982, 80-81; Brixhe 1983, 117; CIPPh I, 17, 54; Brixhe 1990, 70-71; Brixhe 2004a, $32-42$.

aeiketio[.] (?)

OPhr. aeiketio[.'] P-06

It occurs in an eroded inscription engraved on an altar: [-?-]a'kiti?...s ai ios aeiketio[.?] ivi..se.[.']n?. Since ios revails that the yod is not used in this inscription, a segmentation aei ketio[.?] is also defensible, in which case aei is a graphic variant of aey.

CIPPh I, 243. 
aey (verb?)

OPhr. 3sg.perf.? aey W-01a, B-01 1.8

It appears in obscure contexts on two cultic monuments: W-01a yos tutut ...a.m.noy akenanogavos aey (an imprecative protasis?) and B-01 ... kavarmoyun matar otekonov (.?) kesiti oyvos aey apaktneni pakray evkobeyan epaktoy... It can be also attested in P-06 as aei, although the segmentation is unclear (as are the reading and the context): ios aeiketio [.?] ivi..se.[.?]n?. Although many interpretations have been suggested, none is conclusive. Perhaps the most elaborated one is that of Lubotsky $(1988,17-18$ and later still in Ligorio \& Lubotsky 2013,192), who considered it a 3sg.perf. reduplicated form inherited from the PIE verb * $h_{1}$ es- 'to be' (LIV $241-242$, IEW 340341): ${ }^{*} h_{1} e s-h_{1}-e-i$ (with a secondary $-i$ ). According to Lubotskey, then, it makes sense in W-01, where this protasis translated as 'whoever ... may become an akenanogavos' can be equated to a well-attested imprecative formula in Anatolia and Syria 'whoever becomes king after me...' (see e.g. HLuw. KARKAMIŠ A2 + $3 \S 18-19)$. By contrast, Brixhe $(1990,72)$ considered it a sg.dat. pronoun inherited from PIE $*_{e} / o-$ and suggested that ae is a variant of aey. This tentative hypothesis can be supported by ke key, although the contexts of ae are also obscure. Woudheizen' proposal (2008-2009, $183 \S 4)$ must be refuted: he equated aey and even ay to the

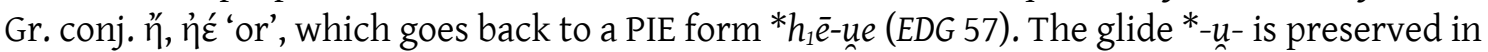
such a position in Phr. In any case, in W-01a and B-01 a conjungion is hardly defensible.

Haas 1969, 73-78; Brixhe \& Drew-Bear 1982, 80-81; Brixhe 1983, 117; CIPPh I, 17, $38-39$ and 54; Lubotksy 1988, 17-18; Brixhe 1990, 70-71; Brixhe 2004a, 32-42; Sowa 2007a, 86; Woudhuizen 2008-2009, 183; Ligorio \& Lubotsky 2013, 192.

avara[.] (?)

OPhr. avara[.?] M-04

Read in an inscription engraved on an altar: akinanogavan tiyes modrovanak avara[.?.]. Because it occurs in the last position of the sentence, a verb is expected (Witczak 1992-1993, 265). However, there is no basis to consider avara[.'] a verb (see CIPPh I, 23). Bayun and Orel (1988a, 180 ), after an ungrounded reading [k]avara[n], considered it a PN in agreement with akinanogavan. Ligorio and Lubotsky $(2013,192)$, on the other hand, tentatively translated it as 'exalted' (as an attribute of akinanogavan), without any argumentation. In any case, this word remains unclear.

CIPPh I, 23; Bayun \& Orel 1988a, 180; Witczak 1992-1993, 265; Orel 1997aa, 27; Berndt-Ersöz 2006, 75; Ligorio \& Lubotsky $2013,192$.

avie[---] (?)

OPhr. avie[---] M-01d II

Read in a badly preserved graffito from the central niche of the Midas façade: matera[---] avie[---]... Although it is a very short sequence, Bayun and Orel (1988a, 178, also in Bayun \& Orel $1988 b, 135-136)$ considered it a verb related to the even more fragmented B-03 ao[---] and translated it as 'permit, allow'. Going one step further, Blažek $(2005,21)$ classed it as a verb in 3sg.aor.act. 'e-eui-es-s (sic) with the meaning 'be favourable'. Nevertheless, these interpretations are clearly ungrounded.

CIPPh I, 14; Bayun \& Orel 1988a, 178; Bayun \& Orel 1988b, 135-136; Blažek 2005, 21.

[-?-]ạșịi (?)

OPhr. [-?-]avsịi G-283

Unparalleled graffito incised on a fragment of a pithos. Perhaps, it is a PN.

Brixhe 2002a, 43-44.

avtay and avtoi see $\alpha u \tau o \varsigma$. 
avun (?)

OPhr. sg.acc. avun G-144

This obscure word was incised on the bottom of a bowl or cup after a probable verb: estatoi avun. Its ending -un is ambiguous: it could be a a thematic or $u$-stem masc.sg.acc., a thematic sg.nom.acc. neuter, a masc. sg.nom. in *-ōn or even a pl.gen. Bayun and Orel $(1988 \mathrm{a}, 197)$ suggested a possible relation with the PN aoa (G-269). On the other hand, Orel (1997a, 190 and 417) translated it as 'vessel', considering that it refers to the bowl or cup on which it was incised, although no etymology was identified.

Bayun \& Orel 1988a, 197; Orel 1997a, 190 and 417.

ai see ay.

aiasay (PN)

OPhr. dat.sg. aiasay HP-102

The inscrition HP-102, engraved on a silver cup, has a clear structure: midas aiasay ma[---]un 'Midas (gave') this ma [---]un to Aiasa'. It is very likely a variant of aiay. Orel (1997a, 135-136 and 415) read it as arosay and interpreted it differently. However, since his reading is ungrounded, such an interpretation cannot be considered.

Gusmani 1988; Orel 1997a, 135-137 and 415; Brixhe 2004a, 106-108.

aiay $(\mathrm{PN})$

OPhr. sg.dat. aiay G-319

Read on a sherd from Hellenistic times, it is an $a$-stem PN, very likely a variant of aiasay. Note that both PNs share the spelling ai- where ay-is expected. Regarding its origin, Brixhe (2002, 75-76) suggested that it is the Hitt. PN Aya- (LNH 23 § 3$)$.

Gusmani 1988; Brixhe 2002, 75-76; Brixhe 2004a, 108.

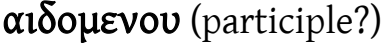

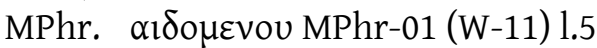

It appears in an obscure sentence on a large funerary stele after two Gr. PNs and one unclear

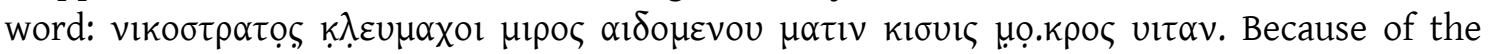
presence of $-\mu \varepsilon v o-\left(<*-m h_{1} n o-?\right)$, it seems to be a ppp. in. Regarding its ending, Brixhe (2004a, 20) considered it a sg.acc.masc. or sg.nom.-acc.neut. whose ending $-n$ dropped. However, a sg.gen. or even a sg.dat. cannot be ruled out. On its root, he also suggested, e.g., the PIE ${ }^{*} h_{2} e i d^{h}$ 'kindle, burn' ( $L I V^{2} 259$, IEW 11-12), attested in Gr. aî $\theta \omega$ 'id.', Lat. aedes 'dwelling, temple, shrine' and Sk. inddhe 'to light, set on fire'), or * $h_{2} e i s d$ - 'to be in awe, to worship' (LIV'260-261, IEW 11-

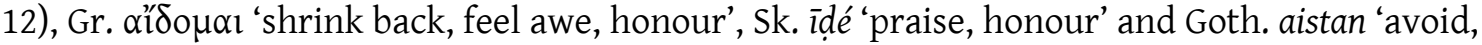
pay attention. However, the similarity of $\alpha_{1} \delta \alpha_{\mu \varepsilon v o v}$ with the ppp. of the last Gr. Verb,

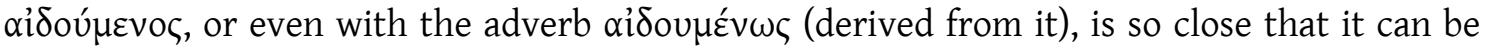
considered a Gr. borrowing. In any case, it remains unclear. Indeed, Phr. $\alpha 1 \delta$ o $\mu \varepsilon v o v$ cannot be inherited from ${ }^{*} h_{2} e i s d$ - because the preservation of the stop as voiced is not expected. Brixhe 2004a, 7-26; Sowa 2007a, 90; Sowa 2008, 114-115; Ligorio \& Lubotsky 2013, 192; Simon 2014a, 145.

${ }^{\dagger} \alpha \mathbf{L} \alpha \boldsymbol{v}$ ay and $k \alpha v$.

alv see ayniy. 
$\operatorname{ain}^{2}[---](?)$

OPhr. ain?[---] G-289

Read on a sherd, a reading aim[---] is not ruled out by Brixhe (2002a, 50), but the parallels with aini give the more probable reading ain[---]. In this case, it could be the conj. aini, which occurs once on another pottery fragment: P-101 aini | dabp'ula isini. However, since in G-209 only a fragment of the inscription remains, it can be also considered a PN Avv $\propto$, attested in Pisidia, or one of its variants (see KPN $49 \S 24$ ).

Brixhe 2002a, 49-50.

ạini and $\alpha \mathfrak{l v \imath}$ see ayniy.

$a k(\mathrm{PN})$

OPhr. ak B-105

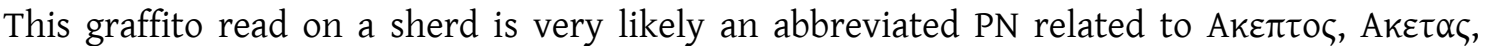

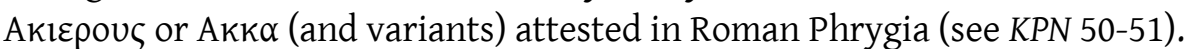

Bakir \& Gusmani 1993, 139; Brixhe 1996, 141-142; Brixhe 2004a, 89-90.

$\alpha \kappa \alpha\left[{ }^{?}\right] \delta_{\varepsilon o}(?)$

NPhr. $\left.\quad \alpha \kappa \alpha\left[{ }^{?}\right]\right] \mid \delta \varepsilon_{0} 16.1(116) 1.7-8$

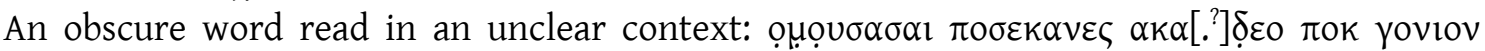

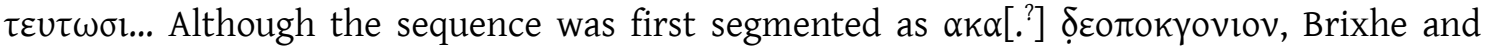
Neumann $(1985,176)$ ruled out any relationship with $\alpha \kappa \kappa \alpha \lambda$ os and $\alpha \kappa \alpha \lambda \alpha$ because there is not enough space for the restoration $\alpha \kappa \alpha[\lambda \alpha]$ and its context is very different.

Brixhe \& Neumann 1985, 176.

$\alpha \kappa \alpha \lambda \alpha$ see $\alpha \kappa k \alpha \lambda$ os.

$\alpha \kappa \alpha \lambda \alpha \varsigma(\mathrm{PN})$

NPhr. sg.gen.? $\alpha \kappa \alpha \lambda \alpha \varsigma 37.2(30)$

It has often been considered to be related to $\alpha \kappa \kappa \alpha \lambda$ os and $\alpha \kappa \alpha \lambda \alpha$. However, it does not fit the inflection, and their contexts are very different. While $\alpha \kappa k \alpha \lambda{ }_{0} \varsigma$ and $\alpha \kappa \alpha \lambda \alpha$ appear in imprecative apodoses, $\alpha \kappa \alpha \lambda \alpha \varsigma$ is found in a non-imprecative part of an epitaph, as the formula

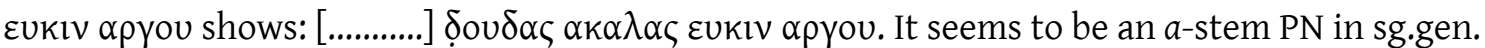

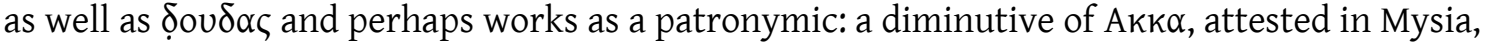
West-Phrygia, Galatia, Isauria and Lycia (KPN 51 § 36-1)? However, the text is damaged, making this difficult to corroborate.

Haas 1966, 67, 85, 223-224; Neumann 1971; Brixhe 1979a, 191-192; Panagl \& Kowal 1983, 187; Brixhe \& Neumann 1985, 176; Orel 1997a, 411; Lubotsky 2004, 236.

akaragayun (noun) 'altar'?

OPhr. sg.acc. akaragayun $\mathrm{M}-02$

Because of its position in the inscription, it is very likely a noun which works as the direct object: bba memevais proitavo[s] kiianaveyos akaragayun edaes. Moreover, although the etymology is unclear, since this inscription refers to the altar on which it was engraved, it very likely refers to this monument itself: 'B(a)ba ... set up this akaragayun'. By contrast, Ligorio and Lubotsky $(2013,187)$ preferred to consider it a part of the monument. On its origin, Varinlioğlu $(1991,35)$ suggested a compound noun whose components are related to Gr. ókpo- 'highest or farthest point' and yóïos 'on land, earthy' or youniios 'sprung from Gaia' with the meaning 'the hight place which has sprung from earth, the hill-top terrace'. Broadly following her interpretation, Orel (1997a, 23 and 411) considered that the first element is the word attested

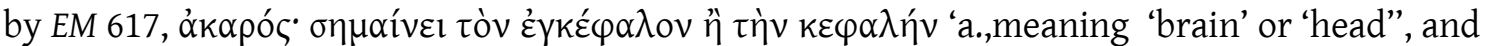


suggested that the first meaning of akaragayun was 'earth head' or 'earth mound', referring to the 'altar'. However, such an interpretation is highly speculative, as is the suggestion of Woudhuizen $(2008-2009,194)$, who equated it to Gr. દ̇ $\sigma \chi \alpha$ ó $\rho$ 'hearth, house, sacrificing hearth'. Finally, the proposal of Diakonoff and Neroznak (1985, 62 and 114), who translated it as 'sarcophagum', does not fit with the context and the phonetic equivalence is not defensible. CIPPh I, 19; Diakonoff \& Neroznak 1985, 62 and 114; Lubotsky 1988, 23; Bayun \& Orel 1988a, 179; Varinlioğlu 1991, 35; Lubotsky 1993b, 96 fn. 2; Orel 1997a, 23 and 411; Woudhuizen 2008-2009, 194; Ligorio \& Lubotsky 2013, 187 and 189.

\section{aka.[---] (PN)}

OPhr. aka.[---] G-160

Read on a sherd, this graffito is very likely a PN. The remaining strokes of the last letter could be accidental, so Orel's $(1997,198)$ reading akau [---] is a mere possibility. It is possibly related

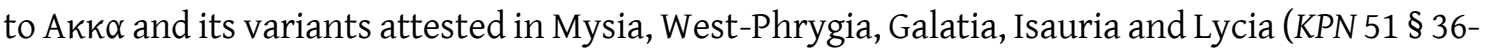
1).

CIPPh I, 143; Orel 1997a, 198.

$\alpha \kappa \varepsilon$ see $\alpha$ $\kappa \varepsilon$.

\section{akenan (noun)}

OPhr. sg.acc. akenan P-04a

sg.gen. akenas ${ }^{?} \mathrm{~W}-07$

This word is found in two different contexts. The first, W-07, is a very damaged text read on a cultic niche engraved on a rock: [---]t] ] [ ] ] [ [ ] ẹsagas ! akenạs [---]. Here, akenas seems to be qualified by esagas. On the other hand, the inscription P-04a is more legible and shows the word in an imprecative protasis, although its meaning is unclear: otuvoi vetei etlnaie ios ni akenan egeseti o? ? $^{?}$ irterkọ...]. tekmor ot.[....]seti vebru. Its origin remains unconfirmed, although Bayun and Orel (1988a, 184 and Orel 1997a, 46 and 411) suggested a borrowing from Lyc. ecãnẽ with the dual interpretation 'tombstone'. However, since the context of W-07 is not related to funerary monuments, such a word is not expected. Perhaps their alternative, a noun derived from the PIE root * $h_{2} e k$ - 'sharp' (LIV 261 , IEW 18-22), is more probable since it can mean 'stone, rock'. Although the pattern of the Phrygian akena- is not a morphological fit for the examples they give, Skt. aśani 'sharp point' and Gr. ókóvn 'whetstone, hone', a formation *h $h_{2} e k$-en- (NIL 287-300) attested in Av. asan- 'stone' is very suitable for both occurrences of this word, if we accept a secondary $a$-stem (as in $\uparrow$ iray). The title akenanogavos derives from this noun.

Kretschmer 1899, 360; Sayce 1927, 29 and 32; Bayun \& Orel 1988a, 184; Lubotsky 1988, 12-13; Varinlioğlu 1991, 35; Orel 1997a, 46 and 411; Brixhe 2008, 78; Ligorio \& Lubotsky 2013, 193.

akenạs see ạkenan.

akenanogavos (title) 'the holder of the akenan'?

OPhr. sg.nom.masc.? akenanogavos M-01a; akenanogavoș W-01a

sg.acc.fem.? akinanogavan M-04

aken? ano[---] M-09?

This word appears in monuments related to the cult of Matar: M-01a (a façade) ates arkiaevais akenanogavos midai lavagtaei vanaktei edaes W-01a (a façade) bonok akenanogavọ materan areyastin vrekun tedatoy and M-04 (step-cut altar) akinanogavan tiyes modrovanak avara [.']. The fourth possible occurrence is in M-09, a badly preserved inscription on an undetermined architectural element: [---] aken?ano[---]. On the one hand, since akenanogavos follows a PN in M-01a and W01a, Gusmani and Polat (1999b, 156 fn. 61), Innocente (1997, 40) and, in particular, Brixhe (2004a, 60 and 78) argued that it was a patronymic in sg.gen. derived from a PN in *-êu- parallel to Gr. 


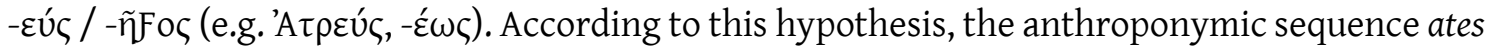
arkiaevais akenanogavos can be equated to B-07 manesiyungidas manitos 'Manes (the son) of Iyung(the grandson) of Manes'. On the other hand, Lubotsky (1988, 12), Janda (1997, 271-272), Orel (1997a, 10-11 and 412) and other scholars considered akenanogavos a title in sg.nom. of ates and bonok a reference to a kind of priest. Even more problematic is the form akinanogavan, which seems to be a sg.acc. and precedes the PN tiyes. Leaving aside the pretonic hesitation akenanakinan- (see $\S 4.1 .1$ ), the presence of this acc. is only addressed by Lubotsky $(1988,12)$, who suggested that it is the fem. of akenanogavos applied to the Mother-Goddess (to whom the step monument of M-04 is devoted). He also considered it derived from the noun akenan, although (o)gav-is not explained (against Orel 1997a, 10-11 and 412). In § 4.2.1.1.5.9, Phr. -ogav-is equated to Gr. oxev́c 'anything used for holding or fastening', which derives from * ${ }^{\text {sog }}{ }^{h}$, the o-grade variant of the root *segh- 'to hold' (LIV ${ }^{2}$ 515-516, IEW 888-889), and it is considered a thematisation after oblique cases like the sg.gen. * sog' ${ }^{h}$-ên-os (Epic Gr. oxỹoc). An alternative to the patronymic and title theories is given by Wittke $(2004,203)$ who suggests the possibility of an ethnic. However, such a toponym never occurs, so it is impossible to corroborate her suggestion, and the beginning akenan- supports the interpretation as a title.

Lubotsky 1988, 12; Varinlioğlu 1991, 35; Witczak 1992-1993, 265; Innocente 1997, 40; Janda 1997, 271-272; Vassileva 1997, 269; Orel 1997a, 10-11 and 412; Gusmani \& Polat 1999b, 156 fn. 61; Lancellotti 2002, 37, fn. 117; Brixhe 2004a, 60 and 78; Wittke 2004, 203; Woudhuizen 2008-2009, 168 § 60, 194; Woodhouse 2009, 170; Ligorio \& Lubotsky 2013, 188 and 192; Oreshko 2013b, 87-89.

ạken?ano[---] and ạkinanogavaṇ see akenanogavos.

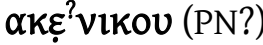

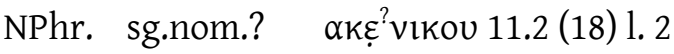

The third letter of this word is very unclear, however the epsilon suggested by Orel (1997a, 8081) fits well, more so if it is related to akenan. Nevertheless, the segmentation that he

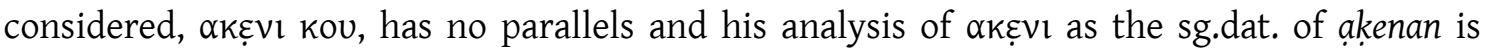
impossible because the shift $-\bar{a} i>-i$ is ad hoc. The context is not at all clear, however since it follows a probable PN it can be considered a PN in sg.gen. working as a patronymic (as

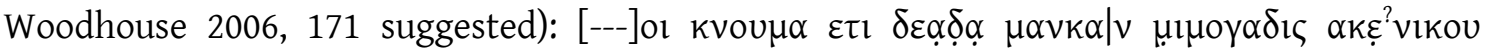

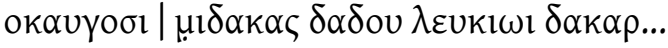

Orel 1997a, 80-81 and 411; Woodhouse 2006, 171.

\section{akio[---] (?)}

OPhr. akio[---] M-03

It appears in a damaged text engraved on an altar: [---] abas iman akio[---]. Since it follows a PN it can be considered a patronymic or a title. By contrast, Bayun and Orel (1988a, 179 and Orel 1997a, 24-25 and 412) suggested the restoration akio[i], considering it a dat. of a PN related to PNs such as the Hitt. Akiya- (LNH 24-25 § 15) and Aknৎ, Akkıৎ, attested in Gr. inscriptions from Mysia (KPN $51 \S 33$ and 36-1). In any case, as CIPPh (I, 21) considered, the lack of parallels means that no proposal can be made with absolute certainty.

CIPPh I, 20-21; Bayun \& Orel 1988a, 179; Orel 1997a, 24-25 and 412.

$\alpha \kappa \kappa \alpha \lambda$ os (noun or adjective?)

OPhr. pl.nom-acc.neut. $\quad \alpha k \alpha \lambda \alpha 4.1$ (2) sg.nom-acc.neut. $\alpha \kappa \kappa \alpha \lambda$ os 53.1 (76), 62.2 (33); $\alpha \kappa \kappa \alpha \lambda$ ọ $[\varsigma] 54.1$ (108)

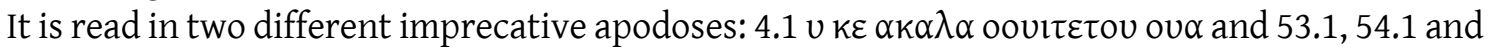

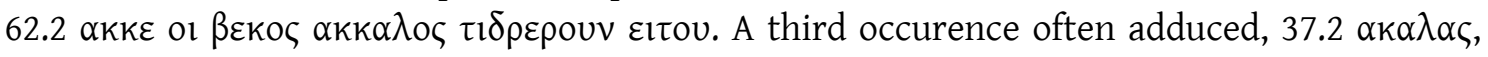
seems to be a PN not related to $\alpha \kappa \kappa \alpha \lambda$ oc. This word is clearly neuter, as the possessive ovo and he adj. $\tau 1 \delta \rho \varepsilon \rho o u v$ reveal. The origin and meaning of this noun remain unclear, despite several 
proposals (see Brixhe 1979a, 191). Haas (1966, 67, also p. 85 and 223-224, followed by Woudhuizen 2008-2009, 183 § 9), suggested that it was the Phrygian noun for 'water' (related

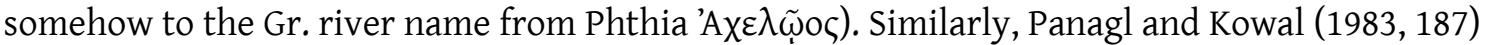
considered it an adj. derived from a noun * $\alpha \kappa \alpha$ - 'water' by the suffix -lo- with the meaning 'wet',

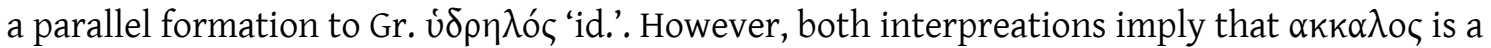
cognate of the Lat. aqua, Go. aho and OHG aha, and such a word is now considered a borrowing into these western IE branches from an unknown European language (Beekes 1998, 459-460). On the other hand, Orel (1997a, 411) considered it an adj. *ad-kalos with the meaning 'good, fine,

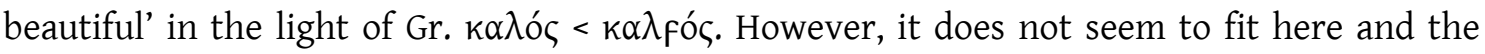
prehistory of this Gr. adj. is also unclear (see EDG 626-627). Finally, Brixhe and Neumann (1985, 176) and Lubotsky $(2004,236)$ considered that $\alpha \kappa k \alpha \lambda$ os is a noun in apposition to $\beta \varepsilon \kappa o \varsigma$, although no etymology or meaning is given. Following this last interpretation, we may consider the working hypothesis that $\alpha k \kappa \alpha \lambda \circ \zeta$ is a borrowing from the Assyrian noun akalu 'bread, food', thus in $\beta \varepsilon \kappa o \zeta ~ \alpha \kappa \kappa \alpha \lambda$ os it perhaps refers to a specific kind of bread while in $4.1 v \kappa \varepsilon \alpha \kappa \alpha \lambda \alpha$

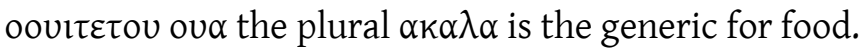

Haas 1966, 67, 85, 223-224; Neumann 1971; Brixhe 1979a, 191-192; Panagl \& Kowal 1983, 187; Brixhe \& Neumann 1985, 176; Orel 1997a, 411; Brixhe 1999, 296; Lubotsky 2004, 236.

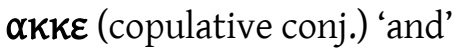

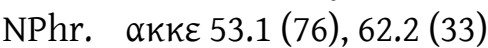

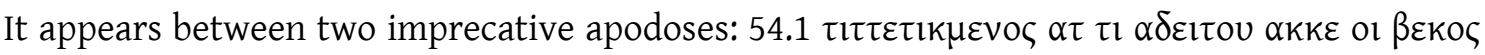

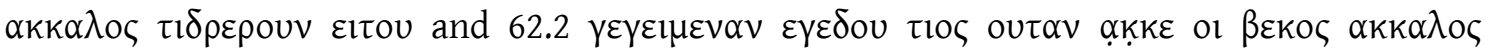
$\tau \imath \delta \rho \varepsilon \gamma \rho o u v \varepsilon \varepsilon \tau o u$. While the second part of $\alpha \kappa-\kappa \varepsilon$ clearly corresponds to the common inherited PIE copulative conj. ${ }^{*} k^{u} \cdot e>k e, k \varepsilon$, the interpretation of the first element is not unanimous. Haas $(1966,96)$ and Brixhe (1978b, 2, see also LIPP II, 11) suggested that this formation is parallel to Lat. atque, so $\alpha$ k- goes back to PIE * $h_{2}$ ed 'near, at' with assimilation of its stop before $k \varepsilon$. On the other hand, Lubotsky (1989b, 150, followed by Brixhe 1997, 49) preferred to consider that $\alpha \mathrm{k}$ works as the preposition (as the common $\alpha \delta \sim \alpha \tau$ ) governing the following sg.dat. pronoun ol. It may also be attested with a simplification of the geminates in the apodosis of 17.3 (7): $\delta \varepsilon \circ \varsigma \kappa \varepsilon$ $\zeta \varepsilon \mu[\varepsilon \lambda \omega \varsigma \kappa \varepsilon] \mid[---] \alpha \kappa \varepsilon$ ol $\varepsilon ı \rho 1 \alpha \tau \imath \varepsilon \tau \imath \tau \tau[\varepsilon \mid \tau \imath k \mu \varepsilon v o l \varepsilon l \tau \tau]$ vov. However, since the inscription was already damaged when it was copied, other possibilities cannot be ruled out, for example, [---] $\mathrm{\alpha} \kappa$, the ending of a word followed by the the simple conj.

Haas 1966, 96; Brixhe 1978b, 2; Lubotsky 1989b, 150; Brixhe 1997, 49; Poccetti 2012, 322; LIPP II, 11.

ako (PN)

OPhr. ako G-237

Graffito incised on a fragment of a pithos. Although it is too short to reach any conclusion, it is perhaps related to the masculine PN Akn read in a Gr. from Mysia (KPN $51 \S 33$ ).

CIPPh I, 188.

akor (noun?)

OPhr. akor G-105

Incised on a bronze bowl after a PN: si iidos akor. The old segmentation si iido sakor (Bayun and Orel 1988a, 193 and Orel 1997a, 169 and 456) is not defensible, since si $\uparrow$ idos appears in two other inscriptions. Brixhe $(2004 a, 116)$ suggested that it is a verb in 1sg.pres.ind.pass., while Lubotsky (Lubotsky 1988, 21; Lubotsky 1989b, 152) proposed a neuter noun in sg.nom.-acc. On the other hand, it cannot be ruled out that si个idos akor are two PNs. In any case, no parallel is attested elsewhere.

Lubotsky 1988, 21; Lubotsky 1989b, 152; Brixhe 2004a, 116. 


\section{$\alpha \kappa p o \delta \mu \alpha v$ (noun)}

NPhr. sg.acc. $\quad \alpha k \rho \circ \delta \mu \alpha v 16.1(116) 1.3$

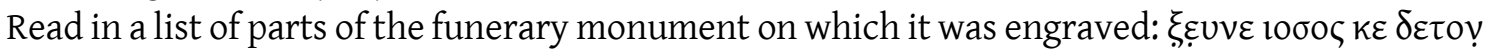

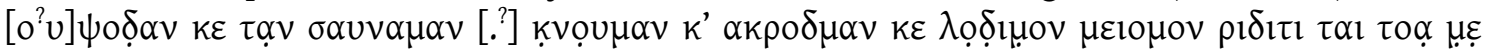
oy ${ }_{0} \mu \alpha v 1 \alpha \varsigma \varepsilon v \alpha \rho \kappa \varepsilon \varepsilon \rho \mu \omega[\lambda] \mid \alpha \cos _{\zeta} \kappa v \alpha 1 \kappa o<\varsigma>\varepsilon \kappa \alpha \tau \eta \alpha \varsigma$. Although it is never attested in Gr., it is very

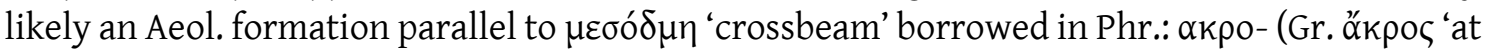
the farthest point or end, topmost,') and $-\delta \mu \alpha-(G r .-\delta \mu \eta$-'house', derived from $\delta \varepsilon \dot{\varepsilon} \mu \omega$ 'build'). Brixhe \& Neumann 1985, 172; Neumann 1988, 21-22; Lubotsky 1993, 128; Orel 1997a, 128 and 412; Lubotsky 2004, 233 fn. 14.

\section{aladis (PN)}

OPhr. sg.nom. aladis G-109

Although this graffito incised on a jar is unparalleled, it has been considered an $i$-stem PN. It is followed by the obscure sequence url.

Brixhe 1983, 127; CIPPh I, 103; Orel 1997a, 412; Brixhe 2008, 79; Liebhart \& Brixhe 2009, 150.

$\alpha \lambda \varepsilon v \pi \alpha \tau \eta \zeta$ see $\alpha \delta \varepsilon v \pi \alpha \underline{T} \underline{\eta} \zeta$.

alis (PN)

OPhr. sg.nom. alis NW-102

Incised on the bottom of a bowl with two other (less readable) graffiti. Brixhe (2002a, 12) considered it an Anatolian PN that he equated to the Hitt. names in ali- (LNH 345).

Brixhe 2002a, 12.

alu see alus.

$\operatorname{alus}(\mathrm{PN})$

OPhr. sg.nom. alus W-08, W-09; alus W-10 sg.nom.? alu G-204

It appears in a formula attested in three inscriptions on rock from West Phrygia: W-08 alus

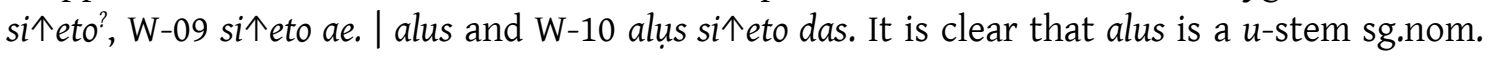
which works, perhaps as the subject of si个eto, if it is a verb in impv. Very probably alus is a PN attested in Lyd. alus $(49,2$, see Gusmani 1964, 56) and in the Gr. inscription from Lydia as A $\lambda$ us (TAM V,1 579), perhaps related to Hitt. Al(l)uwa- (LNH 28 § 39, with the common contraction ${ }^{*} w a>u$, see Rieken 2001). In addition, G-204 alu, read on a fragment of a pithos, seems to be a variant of this PN without the sg.nom. ending $-s$ (if not an abbreviation of another PN), but unfortunately its context is even less comprehensible: [---]da alu $m s$ [-?-]. In any case, the formula alus si $\uparrow$ eto remains obscure and other interpretations have been given, although they are not very probable. Bayun and Orel $(1989,32$, see also Sowa 2008, 80) considered that this word means 'priest' (although Lyd. alus is not commonly commonly considered a PN, still in

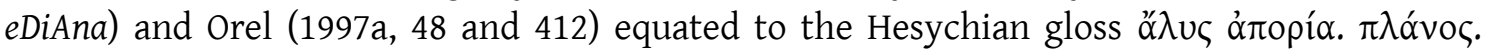

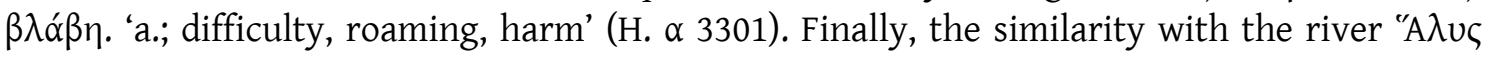
(modern-day Kizılırmak) was also considered by Brixhe and Drew-Bear (1978, 73-75).

Brixhe \& Drew-Bear 1978, 73-75; CIPPh I, $52-53$ and 168; Bayun \& Orel (1989, 32); Orel 1997a, 412; Sowa 2008, 80; Ligorio \& Lubotsky 2013, 188.

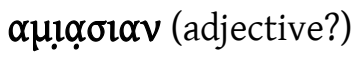

NPhr. sg.acc.fem. $\alpha \mu ! \mid \alpha \sigma \iota \alpha v 2.1$ (15)

Since this word follows the fem. noun $\mu \alpha v \kappa \alpha \nu, \alpha \mu l \alpha \sigma \alpha \alpha v$ seems to qualify it: $\xi \varepsilon v v \eta \tau \alpha \nu \varepsilon 1 \xi \alpha$

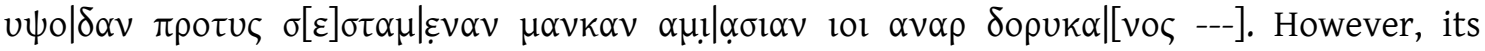
meaning remains unknown. Another possibility was given by Orel (1997a, 78 and 413), who 
considered that $\alpha \mu \mathrm{u} \mid \alpha_{\varsigma}$ was the PN attested in Gr. inscriptions from Lydia, Caria, Mysia and

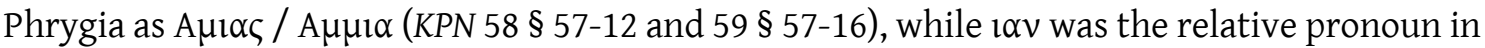
sg.acc.fem.

Haas 1966, 106; Orel 1997a, 78 and 413; Lubotsky 1993a, 127-134.

\section{$\operatorname{amos}(\mathrm{PN})$}

OPhr. sg.nom. amos C-102; amos G-313

Thematic Lallname attested in two sherds. It is very likely to be the same PN that occurs as A $\mu \omega \omega$ ऽ in a Gr. inscription from Philomelion (Phrygia, MAMA 7.202, KPN 65 § 57-32).

CIPPh I, 221-222; Orel 1997a, 288-289 and 413; Brixhe 2002a, 71.

$\alpha v^{1}$ (prepostion)

NPhr. $\quad \alpha \vee 40.3(31)$

Attested in two different contexts, an obscure curse and a descriptive part of a NPhr. epitaph:

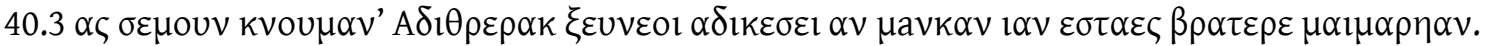
It precedes the nouns in sg.acc. $\mu a v \kappa \alpha v$, so it seems to be a preposition governing acc. Very likely it is also attested as a preverb in anerneuey (B-04) and anivayeti (B-07). Brixhe (2004a, 23) considered that it is also attested in MPhr-01, but the new segmentation suggested by Lubotsky (2017) rules out this possibility. Its origin must be found in the PIE adverb * $h_{2} e n$ - 'on, onto' (LIPP II, 50; e.g. Gk ơvó 'up, upwards, along', Av. ana 'upwards, along').

Brixhe 2004a, 23; LIPP II, 50.

$\alpha v^{2} ?$ (particle?)

NPhr. $\quad \alpha \underline{̣} 38.1(44)$

According to Woudhuizen $(2008-209,183 \S 11)$, an is the modal particle also attested in Gr. as óv. However, since he does not mention the texts in which it is attested, it is difficult to know where his reading is from. Indeed, there is only one possible attestation: 38.1 [1] os $\alpha \underline{\sigma} \sigma[\varepsilon \mu o u v$

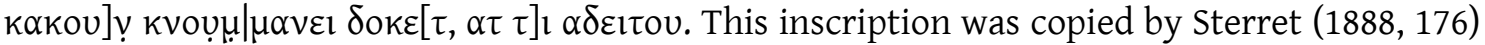
and published with a correction by Anderson $(1898,118)$. Although it is now lost, it seems clear that the inscription was very badly damaged when it was read by Sterret. Consequently, the existence of this form is difficult to substantiate.

Woudhuizen 2008-209, 183 § 11.

anamaka (noun) tenth month of the Persian calendar

OPhr. sg.nom. anamaka HP-114

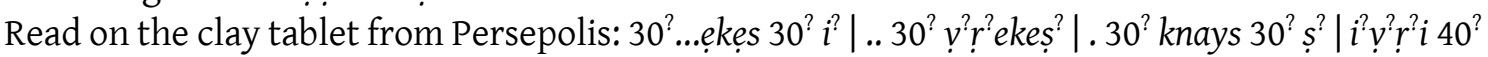

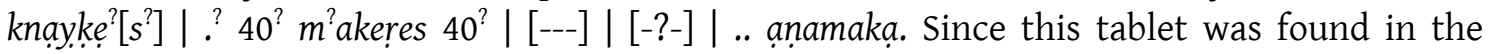
Fortification Archive among many Elamite administrative documents, it is clear that Phrygian anamaka is the $10^{\text {th }}$ month of the Persian calendar, Anämaka- (which corresponds to the Akkadian Tebêtu, December-January). Consequently, this is a Persian borrowing, also attested in the Elamite texts as Hanāmakaš (Poebel 1938, 130). According to Schmitt (2003, 27-29), who rejected the common etymology näman- 'name', *an-äma-ka- means "nichts Rohes habend" or "kein (rohes) Fleish als Speise habend" o "kein Fleisch zum Opfer habend" (followed by Tavernier 2007, 39 who translated it as "having no raw meat for sacrifice or having no raw meat for food"). On its Phryg. ending, it appears in nom., like the other words in the tablet, and can therefore be considered a nom. of rubric.

Haas 1966, 176; Diakonoff \& Neronak 1985, 92; Orel 1997a, 365 and 413; Schmitt 2003, 27-29; Brixhe 2004a, 125; Tavernier 2007, 39 and 83-84. 
$\alpha v \alpha v K \alpha \mathbf{l}$ (noun) 'force, constraint, necessity'

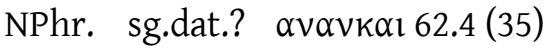

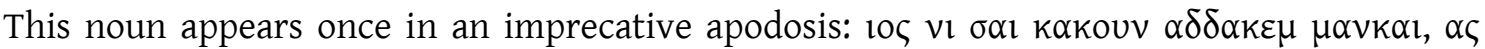
$\alpha v \alpha v \kappa \alpha 1$ ol $\pi \alpha v \tau \alpha \kappa \varepsilon v \alpha<<>v v o v$. It is very likely a borrowing from the Gr. noun $\alpha v \alpha$ '́ $\gamma \kappa \eta$ 'force, constraint, necessity' (on its unclear etymology see EDG 97). Its ending is the common $a$-stem sg.dat. However, according to Brixhe (1997, 51-52), the preposition $\alpha$ s governs acc., and it can perhaps be considered that here the ending was confused (like elsewhere in such a inflection, see the pronoun $\sigma \alpha, \sigma \alpha l, \sigma \alpha v)$. Since $\alpha v \alpha$ ó $\gamma \kappa \eta$ is never attested in Gr. imprecative apodoses from Anatolia (indeed, this word only appears in a protasis of Strubbe 1997, no. 39, from Lydia), there are no parallels through which to interpret the Phrygian sentence. Nevertheless, its meaning could be something like 'let his whole offspring become into necessity'.

Orel 1997a, 255 and 413; Brixhe 1997, 51-52; Lubotsky 2004, 234; EDG 97.

$\alpha v \alpha \rho$ (noun) 'man, husban'

NPhr. sg.nom. $\alpha v \alpha \rho 2.1$ (15)

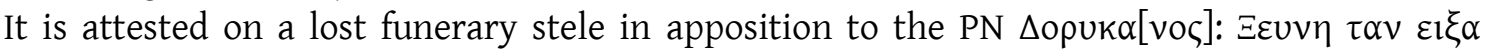
$v \psi \circ \delta \alpha v \pi \rho \circ \tau, \zeta \sigma[\varepsilon] \sigma \tau \alpha \mu \varepsilon v \alpha v \mu \alpha v \kappa \alpha v \alpha \mu 1 \alpha \sigma 1 \alpha v 101 \alpha v \alpha \rho \Delta o \rho v \kappa \alpha[v \circ \zeta---]$. The $r$-stem noun $\alpha v \alpha \rho$ is clearly inherited from the PIE noun *h $h_{2}$ ér 'man' (NIL 332-335, IEW 765) attested in Gr. ơvń 'id.', Skt. nä 'id.', Lat. Nerō (PN with the suffix *-ōn; see also Oscan niir and South Picene pl. gen. nerum 'id.').

Orel 1997a, 78 and 413; Matzinger 2005, 377 and 378; Ligorio \& Lubotsky 2013, 186 and 188.

anato (?)

OPhr. anato B-01 1.6

An unknown word read in a cultic inscription: ... opito [k]ey oy evemẹmesmeneya anato $\left(.^{?}\right)$ | kavarmoyun matar otekonov $\left(.^{?}\right) \mid$ kesiti... CIPPh $(\mathrm{I}, 66)$ argued that some strokes remain after anato which could be read as $y$ or $t$. Following this observation, Bayun and Orel (1988a, 188, also Orel 1997a, 144 and 413) considered that anatoy was a borrowing from the Gr. óv $\bar{\alpha} \tau o \varsigma^{\prime}$ 'unharmed, immune from punishment' in sg.dat. Nevertheless, Lubotsky $(1993 \mathrm{~b}, 94)$ considered "not very probable" the presence of this letter. Its ending in -o is also attested in 1.2 of the same inscription: kavarmoyo imroy edaes etovesniyo.

CIPPh I, 66; Bayun \& Orel 1988a, 188; Lubotsky 1993b, 94; Orel 1997a, 144 and 413.

andati (verb?)

OPhr. 3sg.? andati B-05 1.4

The ending suggests that this is a verb, however its context is damaged and unclear: panta vebras adun pos key estat pator.?ike[...]e[..] andati vạy niptiyạy dạker karatu... Since an- can be considered a preverb, it perhaps goes back to the PIE verbal root * $d^{h} e h_{1}{ }^{-}$'to do' (see $\left.\alpha \delta \delta \alpha \kappa \varepsilon \tau\right)$.

Brixhe 2004a, 57; Sowa 2007a, 74.

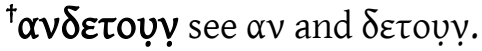

ando (preposition?)

OPhr. ando B-05 1.6

Read in a obscure part of this large inscription: ... nidus ad kaliyay karatu panato ando popostois klaniv | kelmis ke umnișet evradus dạerais key iverais [..] ... Brixhe (2004a, 58) after rejecting Neumann's segmentation andop opostois $(1997,22)$, read it as a single word andopopostois. Nevertheless, a first part ando can be related to the PIE adverb * $h_{1} n d o(m)$ 'inside', attested in Gr.

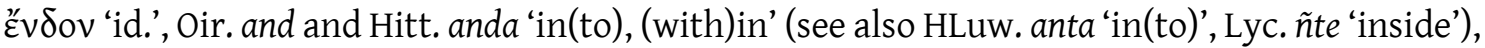
although the details of its vocalisation do not fit at all with the Phr. form. Since it is very likely followed by a noun in acc., ando seems to be a preposition. 
${ }^{\dagger}$ andopopostois see ando and popostois.

ạnerneuey (verb)

OPhr. 3sg. perfect.ind.? anerneuey B-04

Read in a lost inscription. Its context remains obscure: $a^{?} m^{?}{ }^{?} p^{?}$ tov? $a \uparrow i y \cdot a^{?} e^{?}$ lavoy $\cdot$ ue | edaviy $p^{?} i s^{?} \cdot$ anerneuey $\mid y^{?}$ a. oe $e^{?}$ ap.earvi $s^{?} \cdot ?$ bato ?ante... Although Brixhe $(2004 \mathrm{a}, 41)$ considered it a noun in sg.dat. or a verb in $3 \mathrm{sg}$., the latter option is the most probable in the light of (etit)evtevey. In that case, its beginning is very likely the preverb an-, also attested in anivayeti (B-07), and, as a

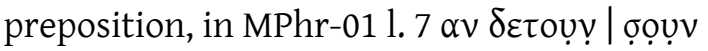

Brixhe 2004a, 41.

aniva'y eti (verb) 'to harm'

OPhr. 3sg.prest.sub.act. anivayeti B-07

A verb found in the last sentence of an epitaph from Daskyleion: me kos anivay eti s=manin 'let nobody harm Manes' (see the whole disccusion and parallels in \$ 3.1.3). This Phrygian verb may go back to the PIE root *ueh ${ }_{2}$ - / *ueh ǵ $^{-}$'break' (LIV 664-665), also attested in Gr. ópvvul 'to break', Hitt. una $k^{-}{ }^{i} / u_{n} \bar{a} k k_{-}$'to bite' and ToAB wāk- 'to split, to burst'. It seems to have the preverb an-, also attested as a preposition in NPhr. $\alpha v(40.3=31$, already identified by Brixhe 2004a, 84). However, the - $i$ - between the preverb and the verb remains unexplained.

Gusmani \& Polat 1999, 159; Brixhe 2004a, 84; Sowa 2007a, 84; Sowa 2008, 107; Hammig fthc. b.

aoa (PN)

OPhr. sg.nom. aoa G-269

Following CIPPh (I, 208), this word incised on a small cup is very likely a PN related to the fem. Aova, attested in a Gr. inscription from Isauria (KPN 111 § 125-1). On the other hand, Bayun and Orel (1988a, 197) equated it to avum, read in G-144.

CIPPh I, 208; Bayun \& Orel 1988a, 197.

aolvouv (verb?)

MPhr. 3pl.? aolvouv MPhr-01 (W-11) l. 4

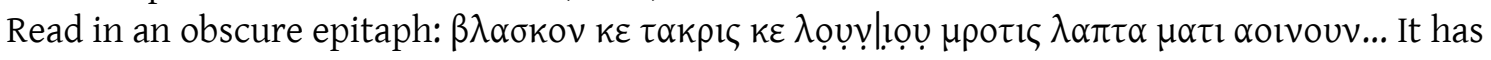
been considered a verb by Brixhe (2004a, 20) on the basis of its position in the sentence and its ending -ouv, very likely $3 \mathrm{pl}$. ( $<$ PIE $\left.{ }^{*}-n t\right)$. He also suggested that it is a past form, despite the lack of augment (perhaps lost in contact with the initial $\alpha-$ ). However, a pl.gen. cannot be ruled out. Either way, it remains unclear.

Brixhe 2004a, 16 and 20.

$\operatorname{ap}(\mathrm{PN})$

OPhr. ap G-162

Although it could be read as sinistroverse and considered a complete PN ( $p a$ is attested in G258, see also П $\alpha$ in the Gr. inscriptions from Isauria and Cilicia, KPN 419 § 1213-1) or an abbreviated PN, CIPPh $(\mathrm{I}, 145)$ preferred the dextroverse reading because of the strokes of 〈p In that case, it is an abbreviation of one of the many Phrygian PNs with this beginning (KPN 70$74 \S 66)$.

CIPPh I, 145; Bayun \& Orel 1988a, 199. 


\section{apaktneni (?)}

OPhr. apaktneni $\mathrm{B}-01 \mathrm{l} .8$

An obscure word read in the conclusive sentence of an inscription engraved on a cult-niche: oyvos aey apaktneni | pakray evkobeyan epaktoy. Orel (1997a, 145 and 414) considered apaktane a verb in 3pl.opt. derived from the PIE verbal root * $h_{2} e g$ - 'drive' (LIV $255-256$, IEW 4-5), attested in Gr. 'ó $\gamma \omega$ 'lead, carry, fetch, bring' and Skr. ájati 'to drive, propel, cast', with a preverb ap(unattested in Phr.). Following his suggestion, it may be translated as 'bring away, take away'. However, this interpretation is ungrounded and it has not been followed in the literature. As a phonetic note, Lubotsky $(1997,121$, also in Ligorio \& Lubotsky 2013, 186) considered that $\langle\mathrm{tn}\rangle$ is the Phrygian notation of [n:] (geminated voiceless nasal).

Bayun \& Orel 1988a, 198; Orel 1997a, 145 and 414; Ligorio \& Lubotsky 2013, 186.

ape (PN)

OPhr. ape G-336

It could be considered an abbreviated PN in the light of apel, apelan and apelev. However, according to Brixhe $(2002 \mathrm{a}, 90)$, it can be also considered a complete PN, since the Lallnamen $A \pi(\pi) \propto \varsigma$ and $A \pi(\pi) \eta \varsigma$ are found in the Gr. inscriptions from Phrygia (see KPN 70-74 § 66). In this case, ape is an $e$-stem PN in nom.sg. without the ending -s. Roller 1987a, 21, $n^{\circ} 2 A-73$ and 39, $n^{\circ}$ 2B-27; Brixhe 2002a, 89-90.

$\operatorname{apel}(\mathrm{PN})$

OPhr. apel G-342

Abbreviated PN incised on a sherd. Very likely related to apelan and apelev.

Brixhe 2002a, 96.

apelan (PN)

OPhr. apelan $\mathrm{M}-05$

Because of its position in an inscription on a rock-cut pediment, it is very likely a PN in sg.nom (similar to iman, imenos), qualified by the adj. mekas: apelan mekas tevano[---]. It is perhaps related to ape, apel and apelev, but it clearly appears to be the same Gr. PN found across the whole of Anatolia as 'A $A \varepsilon \lambda \lambda \alpha(\varsigma)$. It is very likely related in some way to the Gr. DN 'A $\pi$ '́ $\lambda \lambda \omega v$, especially to variants such as Dor. 'A $\pi \dot{\varepsilon} \lambda \lambda \omega v$ and Pamph. 'A $\pi \dot{\varepsilon} \lambda \bar{o} v \alpha$ (Brixhe 1976, no. 3).

CIPPh I, 25; Burkert 1985, 144-145; Diakonoff \& Neroznak 1985, 93; Bayun \& Orel 1988a, 180; CIPPh I, 24-25; Orel 1997a, 27 and 414; Brixhe 2002, 89-90, 96; Berndt-Ersöz 2006, 78; Woodhouse 2006, 161; Woudhuizen 2008-2009, $183 \S 17$.

\section{apelev (PN?)}

OPhr. apelev B-07

It is read in an anthroponymic sequence on a funerary stele: s=manes iyungidas manitos apelev porniyoy est[..]][..] es va knais manuka odeketoy... It is very likely related to ape, apel and apelan, found in contexts where PNs are also expected, and to the the Gr. PN 'A $\pi \varepsilon \lambda \lambda \alpha(\varsigma)$ (well attested in Anatolia, see apelan). Since apelev follows the sg.gen. manitos, it could be also a gen. However, its ending recalls the spelling -iv found in B-05: tubetiv (a verb in 3sg.) and deraliv (?).

Brixhe 2004a, 79.

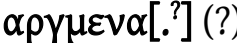

NPhr. $\quad \alpha \rho \gamma \mu \varepsilon v \alpha\left[{ }^{?}\right] 16.1(116)$

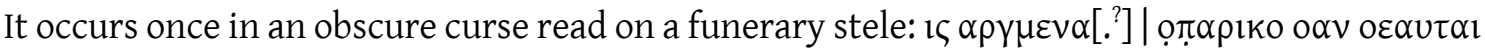

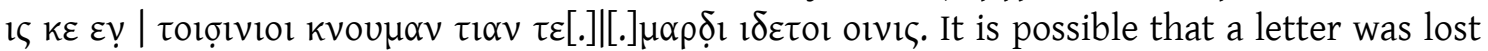
after the final letter, although very little space was available on the support. Consequently, its ending is not clear. It could be an $a$-stem fem. noun, but a participle with the suffix ${ }^{*}-m h_{1} n o-$ cannot be ruled out. Brixhe and Neumann $(1985,180)$ suggested a possible relation with apyov 
(1.2 and 37.2) and $\varepsilon \vee \propto \rho \kappa \varepsilon$ (also in 16.1) or even with arkiaevais, with a secondary voiced stop developed in this context (in the light of Gr. $\delta$ ó $\mu \alpha$ and $\pi \alpha \rho \alpha ́ \delta \varepsilon l \gamma \mu \alpha)$ ). In any case, the word remains unexplained.

Brixhe \& Neumann 1985, 180; Orel 1997a, 133 and 415; Liborio \& Lubotsky 2013, 192.

apyou (noun used as posposition?) 'on account of, for the sake of'?

NPhr. sg.gen.? apyou 1.2 (98), 37.2 (30)

In both inscriptions where this word is attested, it follows عukIv, considered a Gr. borrowing

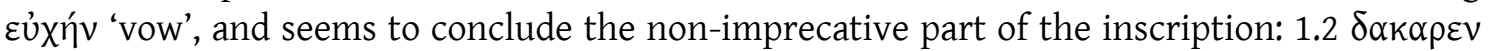

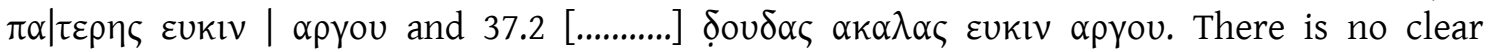
identification of its origin. While Haas $(1966,111)$ equated it to Gr. $\alpha \dot{\lambda} \varphi \eta$ ' 'produce, gain' (<PIE

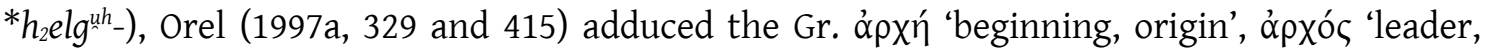
chief,' and other derivatives of 'óp $\omega \omega$ 'be first, begin, rule' (with an unclear etymology, see EDG 145 and DELG 119-121). However, none of these proposals fits well as a funerary formula. Following Ligorio and Lubotsky $(2013,189)$, its ending seems to be a thematic sg.gen. (although a sg.dat. cannot be ruled out), so it is very likely a noun. The same authors also interpreted the meaning of this word as 'because of, as a' (similarly to Haas 1966,111), which is very suitable in this context. Indeed, it appears to be a thematic noun used as postposition similar to the Lat. gen. + gratia / causa 'on account of, for the sake of'.

Haas 1966, 111; Brixhe 1993, 341; Brixhe 1999, 298; Brixhe 2002b, 258; Orel 1997a, 329 and 415; Ligorio \& Lubotsky 2013, 189.

arẹe. $[---](?)$

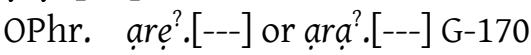

Bayun and Orel $(1988 \mathrm{a}, 182)$ read it in the light of areyastin. However, the context is completely different and the reading of G-170, a graffito incised on a sherd, is not clear enough for any conclusion to be reached.

CIPPh I, 149; Bayun \& Orel 1988a, 182 and 200.

$\alpha \rho \varepsilon o \pi \alpha \delta \varepsilon$ see $\alpha \delta \varepsilon v \pi \alpha \tau \eta \zeta$.

areyastin (epithet) 'from (the mountain) Areya'

OPhr. sg.acc. areyastin $\mathrm{W}-01 \mathrm{a}$

It follows the DN materan, in agreement with it: bonok akenanogavọ materan areyastin vrekun tedatoy... According to Berndt-Ersöz (2006, 84, also Yakubovich 2007, 143), its origin is to be found in the Luw. *ariyatt( $($ ) - 'elevation, mountain', a derivative of ari(ia)- 'raise; check, restrain', (Hitt. arāi-, ari- 'id.', Lyc. erije- 'raise, levy', CLL 27, Kloekhorst 2008, 200). However, the presence of -st-, also found in other Phrygian DNs (see, e.g., A $\delta \delta 1 \sigma \tau l \varsigma)$, means that areyasti- cannot be considered a direct borrowing from the Luw. *ariyatt( $(i)$-. Very probably, this $i$-stem epithet is a Phr. formation derived from a pre-Phrygian oronym (very likely Luwic), as is commonly

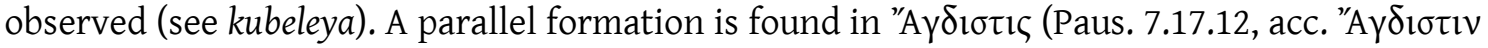
Str. 10.3.12 and Paus. 7.17.10), derived from the oronym Agdus (Arn., Adversus Nationes 5.5.1). Lubotksy 1988, 11; Orel 1997a, 36 and 414; Berndt-Ersöz 2006, 84; Yakubovich 2007, 143.

arkiaevais (patronymic) 'Son of Arkias'

OPhr. sg.nom. arkiaevais M-01a

Its sole attestation agrees with the PN ates in sg.nom.: ates arkiaevais akenanogavos midai lavagtaei vanaktei edaes. It has been considered a title, 'chief, official', an ethnic or a patronymic. The first proposal was given by Bayun and Orel $(1988 \mathrm{a}, 175)$ in the light of the other words with the same ending: memevais and kanutievais. They also equated it to Gr. ópxń. Since in arkia-there is a voiceless stop, this origin is only defensible if we assume a Gr. borrowing in Phrygian. However, 
the Gr. itacism is not expected so early. The ethnic interpretation (not ruled out by Brixhe 2014a, 78) is not very convincing because of the lack of a fitting toponym. Indeed, the best interpretation is to assume that it is a patronymic derived from the Gr. name 'Apxíac borrowed in Phrygian as arkia-. On its ending, Brixhe (2004a, 77-78) suggested that it shows the shift *evans > -evais, parallel to the sg.acc. ending ${ }^{*}$-an-s $>$-ais. According to him, ${ }^{*}$-ev-an-s are two suffixal sequences in which the second element is equated to Gr. $-\bar{\alpha} v /-\bar{\alpha} v o \zeta$ (see, e.g., "E $\lambda \lambda \eta \nu$ /

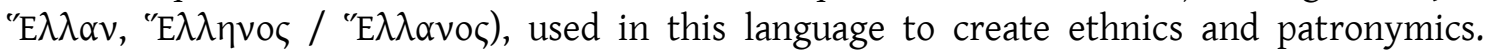
Recently, Ligorio and Lubotsky $(2013,189)$ considered that Phr. -evais is an ancient t-stem suffix: ${ }^{*}$-unts $>{ }^{*}$-uans $>{ }^{*}$-uais (see $§$ 4.2.1.1.5.2).

Huxley 1959, 86; Haas 1966, 189; CIPPh I, 8; Bayun \& Orel 1988a, 175; Brixhe 1991, 43; Innocente 1997, 40; Orel 1997a, 10; Brixhe 2002c, 60; Brixhe 2004a, 77-78; Ligorio \& Lubotsky 2013, 187, 189.

armam see arma.a.

$\operatorname{arma.a}(\mathrm{PN})$

OPhr. armam or arma.a G-277

The last letter of this complete graffito incised on the bottom of a vase is difficult to read. Brixhe (2002a, 37) prefers the reading arma.a, without ruling out armam. In any case, it seems to be a PN, perhaps abbreviated. On its origin, without ruling out the possibility that it could be a Phrygian PN (unattested elsewhere), Brixhe also suggested that it contains the Anatolian DN

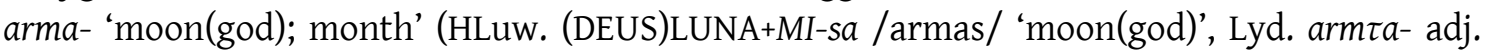
'belonging to Arma (?)' Lyc. armma- 'moon'), found in theophoric names such as Hitt. ${ }^{\mathrm{m}} \mathrm{Ar}-\mathrm{ma}$ -

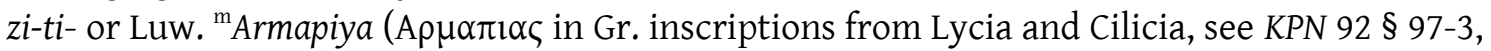
once as E $\rho \mu \alpha \pi \imath \alpha \zeta$ in Lycia, KPN 169-170 § 355-20, see also Adiego 2007, 331) and ${ }^{\mathrm{f}}$ Arma-wiya (LNH $40 \S 140)$.

Brixhe 2002a, 37-38; Brixhe 2004a, 51.

$\operatorname{aros}(\mathrm{PN})$

OPhr. sg.nom. aros W-12

Read on a stone fragment with other two PNs: sitoros aros | ispas. Since sitoros and ispas seems to be PNs, aros would appear to be another PN, despite the lack of parallels.

Bilgen, Brixhe \& Coşkun 2011, 148

art (preposition) 'around'

OPhr. art B-05 1.8

According to Gorbachov $(2008,96-98)$, who rejected Neumann's $(1997,23)$ first equation of this word with Gr. "o $\rho(\alpha)$, see also the Lith. adverb artì 'nearby; nearly, almost'. It is a preposition inherited from the PIE noun * $h_{2}$ er-t- 'fitting' (LIPP II, 290) attested in the Lat. noun ars, artis 'art, skill', in the Arm. adverb ard 'just now' and in the Gr. óp $p$ ' 'just, exactly' but also in the Lithuanian adverb artì 'nearby; nearly, almost', which developed prepositional usages: 'about, near, beside'. So, a similar meaning can be given to Phrygian art followed by the sg.acc. sin=t imenan in an imprecative apodosis: yos niy art sin=t imenan kaka oskavos kakey | kan dedasitiy... 'whoever does harm around this monument...'. It fits well with the Gr. protasis of the same stele:

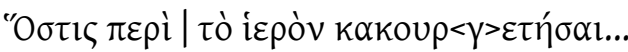

Neumann 1997, 23; Brixhe 2004a, 59; Gorbachov 2008, 96-98; Hämmig 2013, 146: LIPP II, 290.

$\operatorname{artimitos}(\mathrm{DN})$ Artemis

OPhr. sg.gen. artimitos B-05 1.3

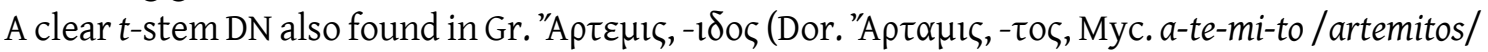
sg.gen., see EDG 142), Lyd. artimus (Gusmani 1964, 63-64; 1980, 34-35; 1986, 126) and Lyc. ertẽmi 
(Neumann 2007, 72). Its origin remains unclear (EDG 142). In the Phrygian text it agrees with the adj. kraniyạs (an epithet): vrekan vitạan artimitoṣ kraniyas [---] 'the relief' of Artemis Kraniyas'. Neumann 1997, 20-21; Gusmani \& Polat 1999b, 155-156; Brixhe 2004a, 55-56; Brixhe 2006, 40; Gorbachov 2008, 98.

$\operatorname{ar}[---](?)$

OPhr. $\operatorname{ar}[---] \mathrm{T}-03$ a II

Beginning of a unknown word in a fragment on a severly damaged stele: [---]sn|a[---] | [---]ed|eia[---]ọ? $r \uparrow e \mid s \vdots \operatorname{ar}[---]$.

Brixhe 2004a, 97.

as (preposition) 'in, at, by'

OPhr. a B-01 1.3

NPhr. $\quad \alpha \varsigma 7.1$ (99), 7.3 (14), 20.2 (128), 40.3 (31), 46.1 (53), 62.2 (33), 62.4 (35)

$\alpha 62.5(36)$

A clear preposition governing acc.: e.g. B-01 1. 3 matar kubeleya ibey a duman ektetoy... 7.1

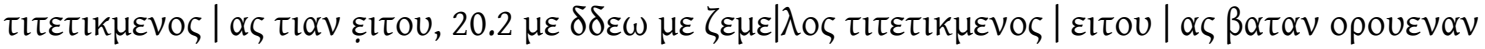
$\kappa \varepsilon$ and $40.3 \alpha \varsigma$ $\sigma \varepsilon \mu o u v \kappa v o u \mu \alpha v \alpha \delta 1 \theta \rho \varepsilon \rho \alpha \kappa$. Its final sibilant sometimes assimilates to the following letter and the resulting geminates are simplified: $\alpha \varsigma \beta \alpha \tau \alpha \nu$ (20.2) $>{ }^{*} \alpha \beta \beta \alpha \tau \alpha \nu>\alpha$ $\beta \alpha \tau \alpha v$ (62.5). In one case it is found with dat.: $62.4 \alpha \varsigma \alpha v \alpha v k \alpha 1$ ol $\pi \alpha v \tau \alpha \kappa \varepsilon v \alpha \mid<l>v v 0 v$. However, it can be considered the common hesitation between $-\alpha,-\alpha \nu$ and $-\alpha$ l attested in NPhr. $\alpha$-stem. Brixhe (2004a, 62) considered that it is also found in B-05 1. 11, but Hämmig 2013 preferred the segmentation asenan. The preposition $\alpha$ c has two functions: it expresses a position in the space,

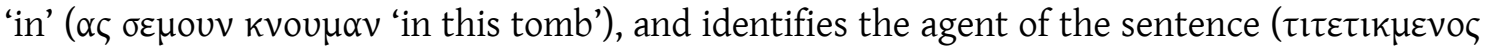

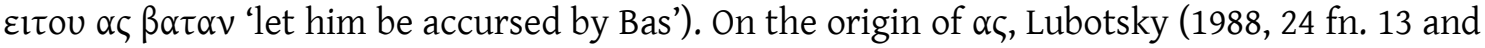
1989a, 84 fn. 31) and Brixhe (1997, 52 as a working hypothesis, see also LIPP II, 226) considered it the Phr. outcome of the PIE preposition ${ }^{*} h_{1}$ ens with a compensatory lengthening: ${ }^{*} h_{1}$ ens $>{ }^{*} \bar{e} s$ $>$ as. Nevertheless, since this lengthening is not identified elsewhere in Phrygian, it is easier to accept Heubeck's analysis (1958, 20 and 1987, 79, see also LIPP II, 10), which classifies this preposition as a variant of ${ }^{*} h_{2} e d($ see $\alpha \delta):{ }^{*} h_{2} e d-s>\alpha \varsigma$ (on the drop of the dentals before $-s$, see *nepots > nevos).

Heubeck 1958, 20; Haas 1966, 119; Heubeck 1987, 79; Lubotsky 1988, 24 fn. 13; Lubotsky 1989a, 84 fn. 31; Brixhe 1997, 50-53; Brixhe 2004a, 62; LIPP II, 10 and 226.

\section{$\operatorname{asakas}(\mathrm{PN})$}

OPhr. sg.nom. asakas G-150 c

An $a$-stem PN incised on a pithos with other independent graffiti: capacity marks, the PN olgiavos (G-150 a) and some unreadable strokes (G-150 b). Perhaps it is related to [-?-]p? asakas W-101. Its origin is possibly Iranian according to Lejeune $(1970,74)$ and Orel $(1997,194$ and 416). Schmitt $(1982,35)$ also considers this possibility, although he is far from convinced. If this identification is correct, the word goes back to OP *asa- 'horse' with the hypocoristic suffix -ka-, a form attested in Elamite Áššśá-ka

CIPPh I, 137; Diakonoff \& Neroznak 1985, 93; Lubotsky 1988, 19; Bayun \& Orel 1988a, 194; Orel 1997a, 194 and 416; Tavernier 2007, 118; Bilgen, Brixhe \& Coşkun 2011, 145.

$\alpha \sigma \gamma(?)$

NPhr. $\alpha \sigma \gamma 47.1(51)$

Unparalleled sequence read after a damaged but clear NPhr. curse: [10ৎ $\sigma \varepsilon \mu]$ ov $\rho \varepsilon \mid \kappa \tau \varepsilon o v$

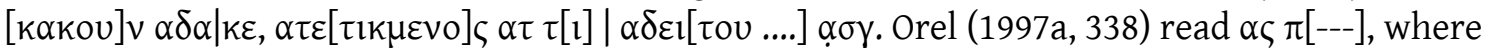
the first element is a preposition. Despite the fact that a word boundary is not expected after a gamma (the inscription is lost so we cannot know whether the text continued), Orel's interpretation of $\alpha \sigma \pi$ is far from certain. 
asenạn (noun) 'harm, damage' or 'grave'?

OPhr. sg.acc. asenan B-05 l. 11

Because of its position in an imprecative protasis (the object of the verb daket), Hämmig (2013, 147-149, followed by Simon 2014a, 141-142) suggested that its meaning is similar to kakouv

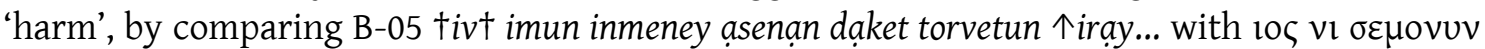

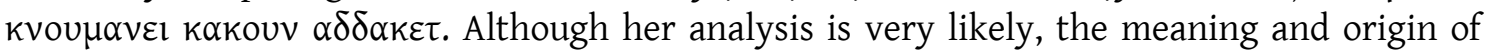
asenan remain unexplained. Brixhe $(2004 \mathrm{a}, 62)$, on the other hand, suggested that as enan is the preposition followed by a pronoun inherited from PIE * $h_{1}$ eno- (in sg.ac.fem.) and equated this

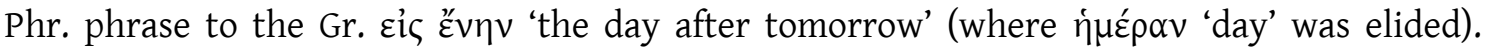
However, this interpretation does not fit with the imprecative context. Due to the Lyd. influence on Hellespontine Phrygia, a possible solution is to consider asenan a borrowing from the Lyd. noun asinas '(part of the) grave' (no. 4, formerly transcribed as aśina-, see Gusmani 1964, 67). According to this suggestion, †iv $\dagger<s>i m u n$ inmeney asenan dạket... means 'whoever puts a grave in this shrine...'.

Neumann 1997, 18; Brixhe 2004a, 62; Hämmig 2013, 147-149; Simon 2014a, 141-142.

ask[---] (?)

OPhr. ask|[---] G-01b

Read in a severly damaged inscription on a stone block: [ ]ita.[ ]țerkeya ask|[---]. It is the beginning of a unknown word. Orel's restoration lava[get]as voykay (1997a, 198) is ungrounded.

CIPPh I, 84; Orel 1997a, 158.

\section{așkịịdoṣ (PN)}

OPhr. ask ’ịados or așựịdoṣ G-161

Graffito incised on the broken bottom of a cup. Although it looks like a PN, its ending could be a thematic sg.nom. -os or a d-stem sg.gen. Because the bottom of the letters has been lost, it is impossible to know if the third letter was $k$ or $u$. Despite the fact that Bayun and Orel (1988a,

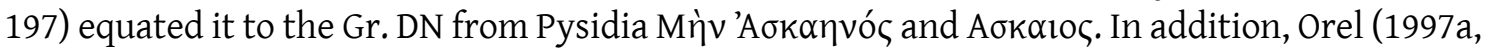
198) compared it to the Thracian Aбkı $\rho \alpha \sigma ı \zeta$, these names are not a good fit with the Phrygian occurrence. Consequently, this PN remains unparalleled.

CIPPh I, 144; Bayun \& Orel 1988a, 197; Orel 1997a, 198.

asna (noun?)

OPhr. as/na NW-101 b

Read on the obscure terracotta disc from Dorylaion: deVeti $\mid$ to Ti a tiei $\mid$ as $\mid$ na isnou. According to Brixhe (2002a, 10), it seems to be a noun in pl.nom.-acc., which here works as the subject of the verb isnou in the light of its ending $-a$. However, its meaning and etymology remain unknown. Brixhe 2002a, 10.

aspẹ[---] (PN)

Olphr. aspẹ[---] P-102

Broken graffito read on handle dated to the $7^{\text {th }} \mathrm{c} . \mathrm{BC}$ : [---]ia aspẹ[---]. This graffito seems to be a bimember PN, where aspẹ[---] is the second element. On its origin, CIPPh (I, 145) suggested that it was Iranian. Indeed, it could be a PN derived from the Median word for 'horse', aspa-. By contrast, Orel $(1997 \mathrm{a}, 303)$ considered that there was no basis to defend this origin and equated aspẹ[---] to the Lat. verb sperno 'sever, separate, remove' and Gr. óotaípw 'pant, gasp, struggle', considering it an imperfect. However, his interpretation is ungrounded.

CIPPh I, 145; Orel 1997a, 303. 
$\alpha \underline{\sigma} \tau \underline{\alpha} \mathbf{l}$ (pronoun or adj.?)

NPhr. sg.dat.fem. $\quad \alpha$ ợ

pl.nom.masc. $\quad \alpha \sigma \tau 019.1(87)$

In the last imprecative apodosis of 9.1, the only certain occurrence of this word, it agrees in

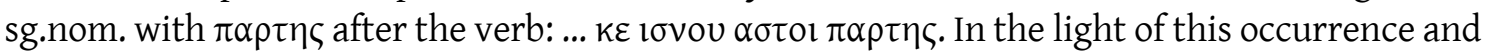
early reading, the second word of this form can be identified in the protasis of 17.5: [105 $\mathrm{vl}$

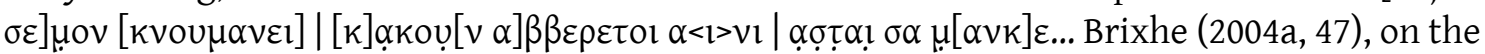
other hand, read it as $\alpha \sigma \tau \tau \alpha \tau$ and considered a verb inherited from the PIE root *steh ${ }^{-}$'stand, erect' (LIV $2590-592$, IEW 1004-1008). However, only a pronoun is expected here. According to this review, it is a word which agrees in sg.dat.fem. with $\sigma \alpha \mu[\alpha \nu \kappa] \varepsilon$.

Brixhe 2004a, 47.

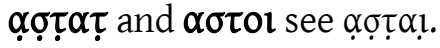

assu?[---] (?)

OPhr. assư ?---] or [---] $u^{?}$ ssa G-213 c

Fragmented inscription on a sherd, where an isolated $n$ and a gammadion cross were also incised. Despite the fact that even the direction of the reading is unclear, the presence of two $s$ is a good evidence for a word boundary. However, the inscription remains unparalleled. CIPPh I, 174 .

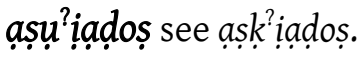

as[---] (PN?)

OPhr. as[---] G-187

Broken graffito read on sherd. It is very likely the beginning of a unknown PN.

CIPPh I, 159 .

$\alpha \tau$ (preposition) ‘to, at, by’ see $\alpha \delta$.

ata $(\mathrm{PN})$

OPhr. sg.nom. ata G-107, G-118, G-224a, G-234, HP-111

sg.dat. atai $\mathrm{W}-10$

sg.nom. atas G-128; atas Dd-101; [-?-]atas G-119, G-221

An $a$-stem PN whose nom. is attested both with and without the ending $-s$. It is a clear Anatolioan Lallname found elsewhere in Anatolia but especially in Gr. inscriptions from Phrygia as $A \tau(\tau) \propto \varsigma$ (see KPN 105-106 § 119). In Phrygian, its nom. is often found as the whole text on pottery. Indeed, only two texts are longer: Dd-101 pser'keyoy atas and G-221 (where it could originally be the variant [t]atas, as well as in G-119) [-?-]a.iy[-?-]| [-?-]ke?no?[-?-]| [-?-]atas | [-?]aratap? $a[-?-] \mid[-?-]$ obata? $m ?$ ?.[-?-]. Its dat. is found once in a dedication on a rock: atai edae lel/ravo | vi 个e atevo atoios...

CIPPh I, 55, 102-103, 110-111, 180 and 186; Lubotsky 1988, 23; Bayun \& Orel 1988a, 183; Brixhe 1991, 43; Brixhe 1996, 134; Janda 1997, 276; Brixhe 2004a, 51; Berndt-Ersöz 2006, 80; Brixhe \& Summers 2006, 127-128; Draycott \& Summers 2008, 73.

atai see ata.

ataniyen $(\mathrm{PN})$

OPhr. sg.nom. ataniyen $\mathrm{W}-01 \mathrm{c}$

PN parallel to tataniyen. It agrees with kuryaneyon in the inscription where it is read: ataniyen: kuryaneyon : taln egertoy. Recently, Brixhe (in Brixhe \& Summers 2006, 128) suggested the 
segmentation ata niyen by considering ata as the common Lallname. He also compared niyen with Gr. velóৎ/veóৎ 'fallow-land' as a working hypothesis. The problem here is the presence of the interpunction. Consequently, we must assume either that we are dealing with an error or that this word is an encl. one (very improbable if it were the direct object in sg.acc.). Also, the presence of kuryaneyon, a nominative singular which agrees with this anthroponym, would be very strange after the direct object. Therefore, it must be concluded that we have an unappealing sg.nom. in -en.

Brixhe \& Summers 2006, 128.

atas see ata.

$\operatorname{atatas}(\mathrm{PN})$

OPhr. sg.nom. atatas M-01c, HP-01

A clear masculine $a$-stem PN, variant of ata(s). In M-01c it agrees with m? onokaua: mater.. atatas m? onokaua. In the inscription HP-01, published by Borker-Klähn (1994), atatas appears isolated in an orthostrat from Karkamiš where a previous monumental HLuw. inscription was engraved (KARKAMIŠ A29p).

CIPPh I, 12; Diakonoff \& Neroznak 1985, 95; Bayun \& Orel 1988a, 178; Borker-Klähn 1994; Bernd-Ersöz 2006, 74, 85.

$\alpha \tau \varepsilon \alpha \mu \alpha$ and $\alpha \tau \varepsilon \alpha \mu \alpha \varsigma$ see $\tau \varepsilon \alpha \mu \alpha$.

atevo see ates.

ates (PN)

OPhr. sg.nom. ates M-01a, W-08, HP-103, HP-104, HP-105, HP-106, HP-107, HP-108; [-?-]ates G-123; [-?-]ates?[-?-] G-124?; [-?-]ates G-148?

sg.gen.? atevo $\mathrm{W}-10$

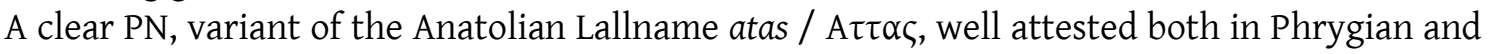

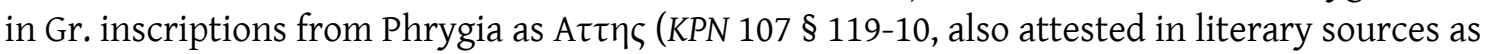

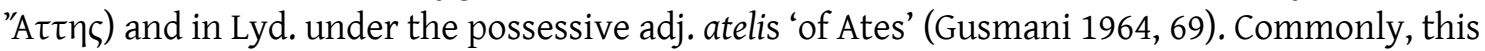
Phrygian name appears incised alone on instrumenta (metal bowls and pottery), but it is also attested as the subject of monumental inscriptions on rock: M-01a ates arkiaevais akenanogavos midai lavagtaei vanaktei edaes and W-08 [-?-] ates agomoi sa 9 ?ta tedaes. In some instances, it is not clear whether the name is ates or its variant tates because of damage to the inscription (W-08, G-123, G-124 and G-418). The form atevo W-10 looks like the gen. of this PN: atai edae lel/ravo | vi $\uparrow$ atevo atoios... However, this would imply that here -uo- has not been simplied to -o-, as is expected.

Neumann 1986a, 83; Varinlioğlu 1992; Vassileva 1997, 268; Orel 1997a, 417; Lancellotti 2002, 32-40; Brixhe 2004a, 77, 110; Brixhe 2006, 43; Ligorio \& Lubotsky 2013, 189.

$\alpha \tau \varepsilon \tau \iota k \mu \varepsilon v o \zeta$ see $\tau ו \tau \tau \varepsilon \tau \imath k \mu \varepsilon v o \zeta$.

$\alpha \tau 1 \alpha \mu \alpha$ see $\tau \varepsilon \alpha \mu \alpha$.

atikv?ạiu see ạtikr?ạiu.

atikr'ạiu (verb?) 'to say'?

OPhr. 1sg.pres.ind.act.? atikr?aiu or atikv?ạiu B-05 1.8

This word was considered a verb by Neumann (1997, 22, nuanced by Brixhe 2004a, 59 but still in LIPP II, 93), who also suggested that it was a 1sg.pres.ind.act. because of its ending $-u(<$ PIE 
*-ō). He also considered its beginning, ati-, a preverb, but the possible parallels have been already ruled out. Since its etymology has not been identified, this proposal is based on the position of the word. Indeed, it is read at the end of a clear sentence followed by the first imprecation of this inscription: kelmis ke umnișet evradus dakerais key iverais [..] | atikraiu... Even the reading is not at all clear. Neumann read atikv?aiu, while Brixhe proposed atikr?aiu. Moreover, Brixhe compared this sentence with the Gr. inscription MAMA IV 282 found in the

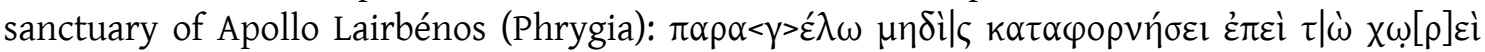
'A $\pi[o ́ \lambda] \lambda \omega$ yos $\mid \Lambda \varepsilon \imath \mu \eta$ [voṽ] 'I presage: nobody upon the earth will despise Apollo'. However, this part of B-05 is far from being understood, so both the word and the whole sentence remain unclear.

Neumann 1997, 22; Brixhe 2004a, 59; Sowa 2007a, 74; Sowa 2008, 93.

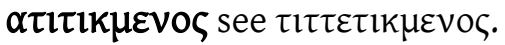

atoios (PN)

OPhr. sg.nom. atoios $\mathrm{W}-10$

A thematic PN, very likely a variant of ates / atas with the suffix -io-. It is the subject of the sentence in which it is read: atai edae lel/ravo | vi $\uparrow$ e atevo atoios, | alus si $\uparrow$ eto das.

Brixhe 1983, 124; Diakonoff and Neroznak 1985, 94; Vassileva 1997, 268; Wittke 2004, 305.

atriygas (PN)

OPhr. sg.nom. atriyas B-05 1.2

Although it seems clear that this word is a PN and the subject of the sentence in which it is read,

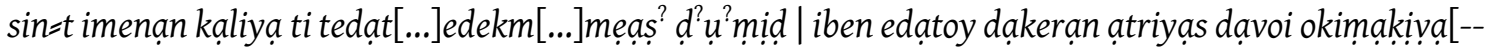
-]..., it remains unparalleled and, to complicate matters further, it is not found in the Gr. summary of this long inscription. On its origin, Brixhe (2004a, 55) suggested as a working

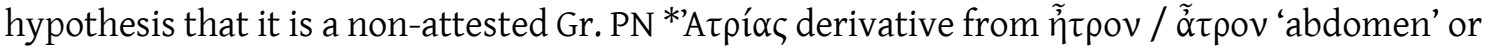

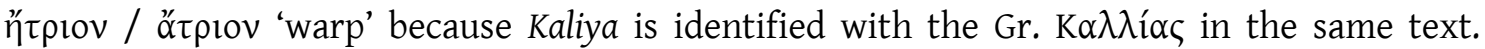
Nevertheless, there is another Gr. explanation for this PN, according to which it was borrowed

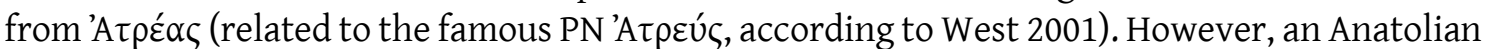
formation cannot be ruled out in the light of the HLuw. atri(ya)- 'personal, soul' (ALEPPO 6 § 3 COR-i-sa) and the city Atriya (attested in the Hitt. text CTH 181, the Tawagalawa letter dated to around $1250 \mathrm{BC}$ ).

Brixhe 2004a, 55.

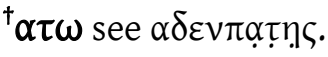

$\alpha u \tau \alpha \eta$ and $\alpha u \tau o v$ see $\alpha u \tau o \zeta$.

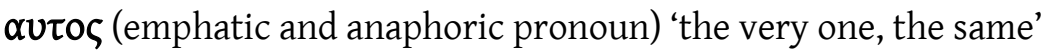

OPhr. sg.dat.fem. avtay W-01b

sg.dat.masc. or

pl.nom.masc. avtoi T-03b

NPhr. sg.dat.fem. $\quad \alpha \cup \tau \alpha \eta 37.2(30)$

sg.acc.masc. $\quad \alpha u \tau o v 2.2(130)$

sg.nom.masc. $\quad \alpha u \tau$ o $58.1(72), 62.2(33), 62.5$ (35)

sg.dat.masc. $\quad \alpha \cup \tau \omega 37.2(30)$

This pronoun is used in two different ways, emphatic and anaphoric. The first is attested in curses where the god previously quoted in the same inscription is again mentioned as keeper of the monument: $\mathrm{W}-01 \mathrm{~b}$ yos esai=t materey eveteksete ${ }^{?} y$ ovevin onoman da Yet, lakedo key venavtun 


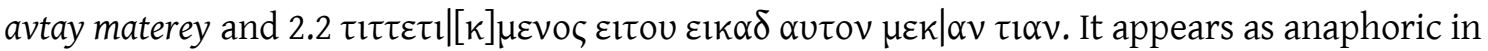
the apodoses, in correlation with the protases, where the desecration is mentioned: $58.1,[\alpha 1]$

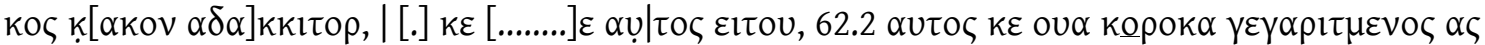

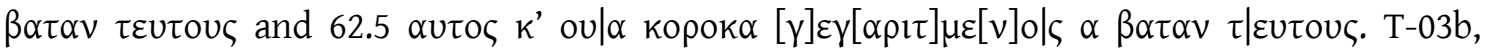
[---]oi : avtoi : eptuve[---]|[---]itan mẹ|[---]p is : [---], is too fragmentary for any conclusion to be reached. However, since avtoi follows a possible thematic sg.dat. it is perhaps used as emphatic adjective. Finally, in 37.2 it seems to occur in an imprecative apodosis, however its meaning

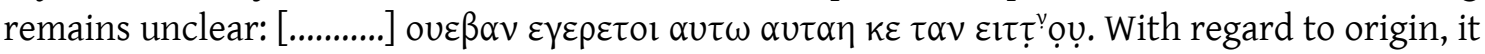

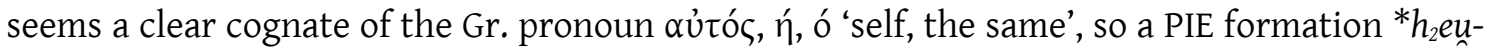
to- $\left({ }^{*} h_{2}\right.$ eu-to- in LIPP II, 344). In Phr. It is also attested in the compound reflexive pronouns

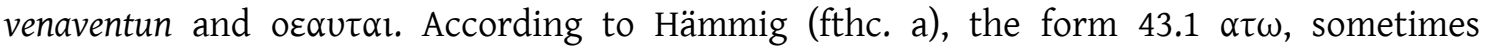
considered a variant of this pronoun, is a bad segmentation of the PN $A \delta \varepsilon \mid v<\pi>\alpha \tau \omega$.

Haas 1966, 195 and 197 (with a confusion); CIPPh I, 40-41; Orel 1997a, 418; Ligorio \& Lubotsky 2013, 184; LIPP II, 344; Hämmig fthc. a.

$\alpha v \tau \omega$ see $\alpha v \tau \circ \zeta$.

$\alpha \omega \rho \omega$ (adj.) 'untimely'

NPhr. sg.gen. $\alpha \omega \rho \omega 6.1(88)$

A clear borrowing from Gr. ớwpos, -ov 'untimely, unseasonable', which qualifies the daughter

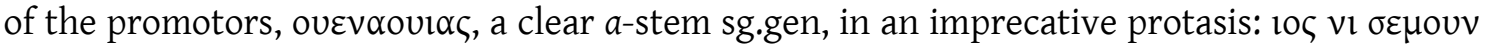

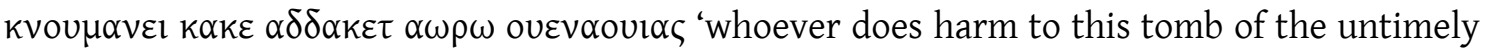
(dead) Venavias'. It is also found in the Gr. part of this epitaph, however it qualifies two people:

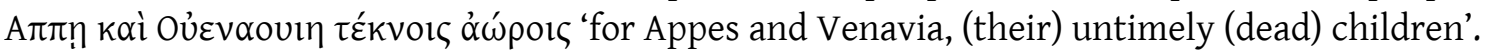
The use of this adj. is very common in Gr. epitaphs dedicated to children in Anatolia.

Brixhe 2002b, 253.

ay (conj.) 'if, or'?

OPhr. ay $\mathrm{B}-03, \mathrm{G}-01 \mathrm{a}$

ai $\mathrm{P}-06$

NPhr. $\quad \alpha 140.3(31), 56.3(64)$

Its function is not clear because all occurrences of ay are fragmentary contexts. However, in most instances it seems to precede an imprecative protasis: B-03 evtevey ay yosyos yenvra leti=t

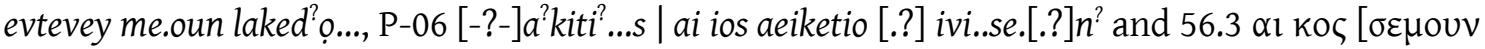

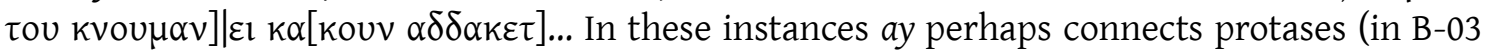
and P-06) and curses (in 56.3 the Gr. and the Phrygian one), but it may also be a conditional conj., especially in 56.3, 'if someone does harm to this tomb...'. This seems to fit in the restored

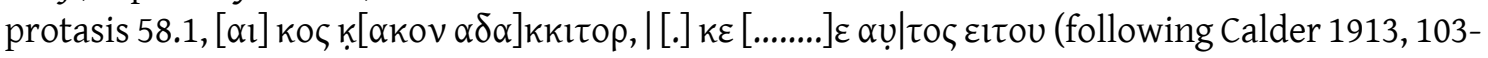
104). Either way, its function is very similar to the compound conj. ayny. The other occurrences are even more obscure: G-01a [---] ? lavi[---]isvolkay | : dumeyay : [---]deda[---], 40.3 [... $\xi] \varepsilon v v \alpha v \alpha l$

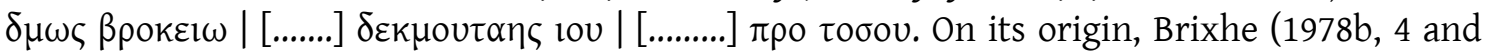
1997, 57) equated it to the Dor. and Aeol. conj. $\alpha i$ and considered both forms the old locative of the PIE demonstrative-anaphoric pronoun *e/o- (contrary to EDG 379), also LIPP (II, 348), where these forms are considered as inherited from PIE *éh $i$. Woudhuizen (2008-2009, $183 \S 4)$, by contrast, considered that ay is a variant of aey and equated them to the Gr. conj. However, the contexts suggest that aey is not related to ay.

Brixhe 1978b, 3-6; Brixhe 1997, 57-59; Woudhuizen 2008-2009, 183 § 4; Ligorio \& Lubotsky 2013, 184; LIPP II, 348. 
ayniy (conj.) 'or, if'

OPhr. aini P-101

ayniy B-05 1. 11; aynị B-01

NPhr. alv $7.3(14), 15.1(120)$

alvi 2.2 (130) bis, 3.1 (97), 8.1 (86), 9.1 (87), 10.1 (112), 11.2 (18), 14.1 (73), 19.2 (129), 18.1

(4), 21.2 (43), 25.1 (115), 31.1 (29), 35.1 (25), 36.1 (26), 40.4 (102), 52.1 (75); $\alpha<1>v 117.5$

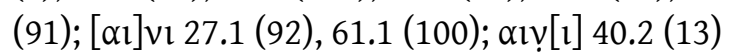

A compound conj. built by adding the particle ni(y) to ay 'if'. The form $\alpha \mathrm{lv}$ shows an apocope

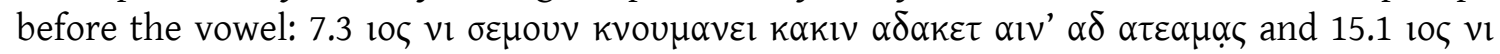

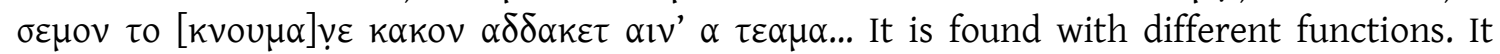
connects alternative clauses (two imprecative protases) as disjunctive conj.: B-05 iv $\dagger$ imun inmeney as enan daket torvetun 个iray ayniy oy tubnuv nevos me deritoy..., B-01 yos tivo [t] a spereta

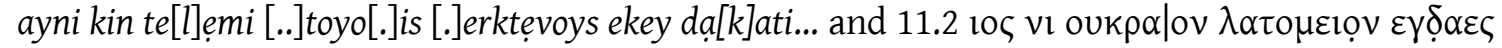

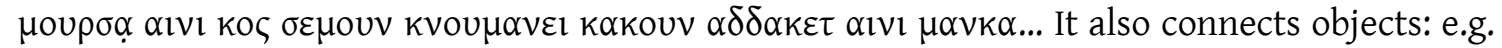

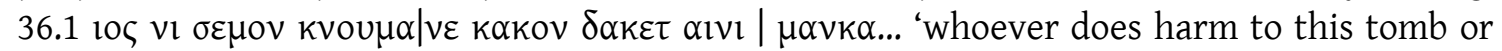
stele...'. Finally, it introduces sentences, so it does not work as disjuntive conj. in four

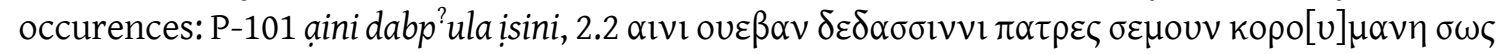

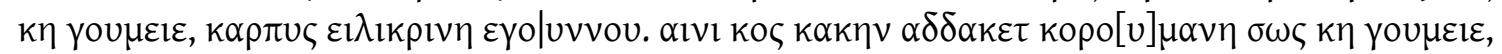

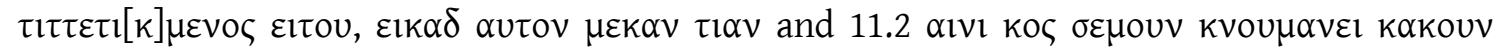

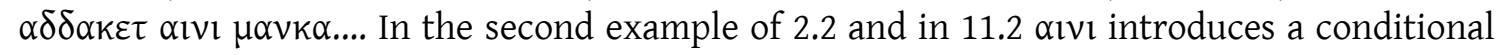
clause, 'if someone does harm to this ground...', although in P-101 it is impossible. Here, Hämmig (fthc. b) suggested a meaning similar to Lat. utinam or Gr. cỉ үó $\rho$, introducing a wish. Brixhe 1978b, 15-21; CIPPh I, 244-245; Diakonoff \& Neroznak 1985, 90; Brixhe 1997, 57-59; Ligorio \& Lubotsky 2013, 184; Hämmig 2013, 131 fn. 16; Avram 2015, 208; Hämmig fthc. b.

\section{$a \uparrow$ iiai and $a \uparrow$ ion see $a \uparrow$ ios.}

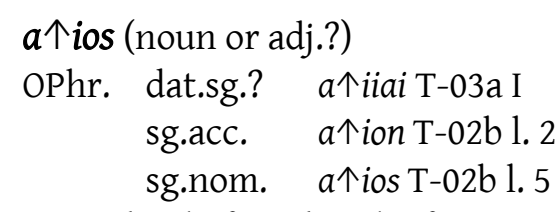

A word only found in the fragmented stelae from Tyana: T-02b [---]tumida $\vdots$ memeuis $:[---] \mid[---] a$ : tesan $: a \uparrow i o n: v[---] \mid[---]$ oitumen $\vdots$ mida $a[--]|[---] n: a \uparrow i o s: m i[--]|[---] n \vdots$ batan $\vdots e .[---]$ and T-03aI $a \uparrow$ iiai $\vdots$ polodreltes $\vdots$ poreti $\vdots$ otu|[---]. Since it appears in fem. ( $a \uparrow$ iiai) and masc. ( $a \uparrow$ ion and $a \uparrow$ ios), it is very likely an adjective, although a noun cannot be ruled oput (see vrekun / vrekan). In T03, Brixhe $(1991,38)$ considered it a word in dat.sg. followed by a sg.nom. polodretes and the verb poreti. In T-02b 1.2 it seems to agree in acc.sg. with tesan, a C-stem noun? In any case, the damaged context of all the occurrences means that no conclusive information can be gleaned. a relationship with the PN A $\zeta 10 \varsigma$ (KNP 48 §20-2, from Phrygia and Lycaonia) cannot be excluded. Brixhe 1991, 38 and 41.

\section{$a \uparrow \operatorname{ses}(\mathrm{PN})$}

OPhr. sg.nom. a个ses HP-109

A PN incised on a bronze bowl from Bayındır (East Lycia). Although it remains unparalleled, the other incised bowls bear common PN. Consequently, it may be a PN. According to Brixhe (2004a, 114-115), $\langle\uparrow s\rangle$ is a reiterative notation of $\langle\uparrow\rangle$ (considered $\langle\mathrm{ts}\rangle$ ) similar to Gr. $\langle\xi \sigma\rangle$, instead of the single $\langle\xi\rangle$ in some inscriptions. One wonders if it is a local palatalisation of the common PN ates. Varinlioğlu 1992, 12 and 14-15; Orel 1997a, 318; Brixhe 2004a, 114-115. 
$a \uparrow\left[i / e^{?} .{ }^{?}\right](?)$

OPhr. $a \uparrow\left[i / e^{?}.\right] \mathrm{NW}-139$

Fragmented graffito on the bottom of a small cup. Since $\langle\uparrow\rangle$ is always followed by the vowels /e/ or /i/ (leaving aside a个ses), Brixhe and Sivas (2009, 137-138) suggested the restoration $a \uparrow[i / e$.$] . Nevertheless, it remains unclear, as does the possible relation with a \uparrow$ ios suggested by these authors (2009, 137-138).

Brixhe \& Sivas 2009, 137-138. 



\section{$B(b)-B \beta$}

[-?-] $] b a[-?-]$ (PN?)

OPhr. [-?-]ba[-?-] G-329

Despite the bad conservation of this graffito incised on a potsherd, the two remaining letters can be considered the beginning of a PN such as baba or babas. However, a PN abas cannot be ruled out.

Brixhe 2002a, 83-84.

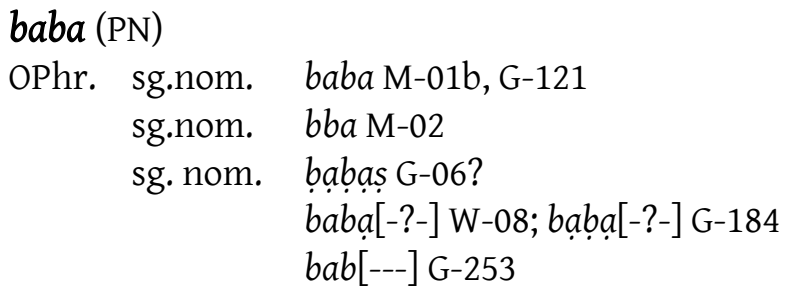

A masc. Lallname very common throughout Anatolia (see KPN 113 § 133-1, B $\alpha \beta \alpha \varsigma$ ). In Phr. this name shows a hesitation between the forms with or without the ending $-\mathrm{s}$. Since baba M-01b and $b b a \mathrm{M}-02$ bear the same patronymic and title (memevais proitavos), they probably refer to the same person and, consequently, $b b a$ is a mere "lapsus du lapicide" of baba according to Lejeune (1969a, 28 fn. 42). In both inscriptions it is the subject of the sentence: M-01b baba memevais proitavos $k$ Фiyanaveyos sikeneman edaes and M-02 bba memevais proitavo[s] $k$ 个ianaveyos akaragayun edaes. In W-08 this PN occurs after another PN, bateles, and the formula alus si $\uparrow$ eto. Note also that in this inscription the letter $b$ is 8-shaped. In the other instances of this PN, baba is the only readable word and, with the exception of G-06, the occurrences are graffiti incised on potsherds (the owners?). Only in G-121 is it known to be complete, and baba isolated. Lejeune 1969a, 28 fn. 42; CIPPh I, 10, 19, 91, 113, 157 and 197-198; Brixhe 2004a, 51.

babas and bab[---] see baba.

bagun (noun) 'idol'

OPhr. sg.acc. bagun G-136

This word written after two PNs, tadoy iman bagun., on a small alabaster eagle refers clearly to the object given to tado- by iman, probably the eagle itself. The first hypothesis on the meaning and origin of this word was given by Lejeune $(1969 b, 293)$, who translated it as 'present' by

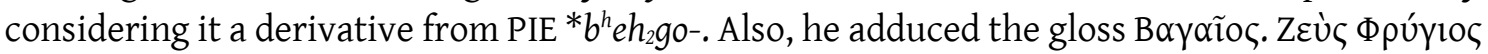

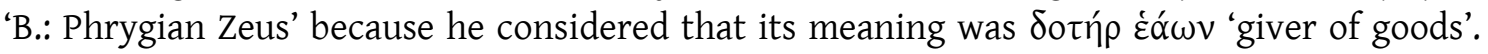
Although Sowa $(2008,28)$ also adopted this view, the proposed etymology must be rejected because the preservation of the PIE stop as voiced is not expected. This is why Lubotsky suggested two alternative etymologies. Although the second one, which takes bagun back to PIE ${ }^{*} b^{h}{ } h_{2} \dot{g}^{-} u$ - 'lower arm, elbow' (see, e.g., Gr. $\pi \tilde{\eta} \chi \theta \varsigma$ 'forearm, arm' or Skt. bāhú- 'lower arm, arm, foreleg of an animal'), fits well phonetically, its meaning is not very likely for this short text. Nevertheless, Lubotsky's first proposal, a word meaning 'idol' borrowed from OP baga- 'god', is very attractive. The chronology of this artefact fits perfectly because it was found in a building from Persian times (perhaps the $6^{\text {th }} \mathrm{c} . \mathrm{BC}$ ) and the eagle could be an early representation of the

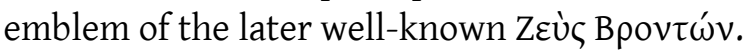

Lejeune 1969b, 293; CIPPh I, 125; Lubotsky 2004, 231; Matzinger 2006, 194-195; Sowa 2008, 28. 
babiy[---] (PN?)

OPhr. babiy.[---] G-138

Fragmented graffito on a potsherd. Perhaps it may be considered a derivative from a PN such as baba(s) through the suffix *-io-, similar to imeneia with regard to iman. However, there is no evidence to choose between a fem. form of the PN (as imeneia) or an adjectival one, although the adduced parallel favours the former hypothesis.

Brixhe 1984, 126.

B $\alpha \varsigma$ (DN) 'Bas'

OPhr. sg.acc. batan $\mathrm{T}-02 \mathrm{~b}$; bata? n? G-121?

sg.acc. bato?ạn B-04?

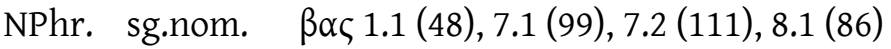

sg. acc. $\quad \beta \alpha \tau \alpha v 20.2(128), 62.2(33), 62.5$ (35)

A clear $t$-stem DN whose inflexion is the same as nevos. Both OPhr. occurrences are obscure. Indeed, the context of $\mathrm{T}-02 \mathrm{~b}$ is very fragmented, but it seems to be a stele erected by Midas: [---]n $\vdots a \uparrow i o s \vdots$ mi[---] | [---]n $\vdots$ batan $\vdots$ e.[---]. B-04 is another possible OPhr. occurrence, which presents a very dubious 0 . This unexpected letter is only shown ed out by Brixhe (2004a, 38 and $41)$, but he tended to consider it an accident of the stone. Either way, the context is far from

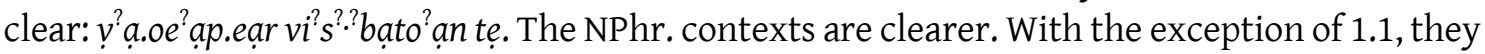
represent four different imprecative apodosis. The first one is read in 7.1 (perhaps 56.3 is to be

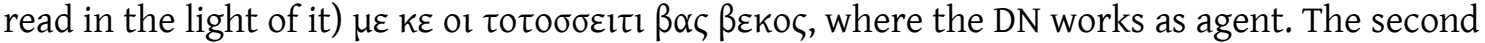
is represented by 7.2 and 8.1: $\beta \alpha \varsigma 101 \beta \varepsilon \kappa o \varsigma ~ \mu \varepsilon \beta \varepsilon \rho \varepsilon \tau$. The third apodosis appears in a more

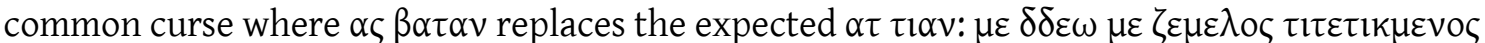

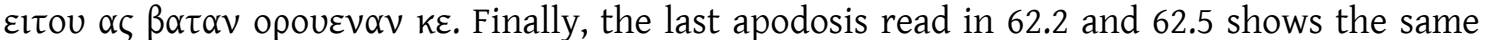

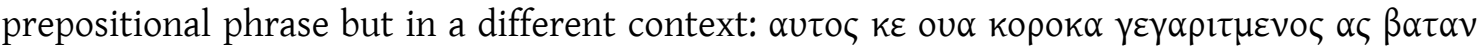

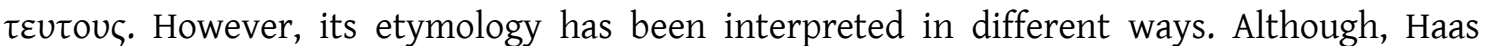
suggested the similarity with the root ${ }^{*} b^{h} e h_{2^{-}}$'to speak' (LIV ${ }^{2}$ 69-70, IEW 105-106, see Gr. $\varphi \eta \mu$ í, $\varphi \alpha ́ v \alpha$, llatí for, fari), he preferred an interpretation which must be rejected because of his segmentation of the occurrences. Nevertheless, his proposal was followed by Diakonoff and Neroznak $(1984,97)$, and Brixhe (2004a, 38 and 41) considered it a suggestive hypothesis. More recently, Lubotsky $(1997,123)$ rejected a proposal by Witczak $(1992-1993,267-268)$, who equated this word to Myc. pa-de-i and pa-de (which he read as * $\Phi \alpha \varsigma, \Phi \alpha \delta \circ \varsigma$ ), Old Polonaise Boda and, tentatively, Old Indian Bhadrāa, and reconstructed a root * $b^{h} a d-$ 'lucky, happy, proper, good' for all of them. Finally, it must be said that some old and new proposals equated this name to Gr. $\gamma \tilde{\eta}$ 'earth' (see Hämmig fthc. a). However, the Gr. word does not show a dental inflexion, the occlusive correspondences cannot be accepted, and the etymology of $\gamma \tilde{\eta}$ is not clear. Consequently, although this is a very attractive possibility in terms of meaning, it must be rejected. A new hypothesis has been suggested by Obrador-Cursach (2017), who considered it a derivative of the PIE root * $b^{h} e_{2^{-}}$'to shine' (LIV' 68-69, IEW 104-105, see Gr. pó os 'light'). If this is the case, it is a formation * $b^{h} \circ h_{2}-t-{ }^{*}{ }^{*} h^{h} e h_{2}-t$ - parallel to Gr. $\varphi \tilde{\omega} \varsigma, \varphi \omega \tau$ 'ó 'man, mortal, hero'. The vocalism of the root in the Phr. nom. must be considered a levelling from the other forms, unlike the Gr. word, where the strong vocalism was spread to the other forms. According to this theory, $\beta \alpha \varsigma$ 'the shining one' is an epiclesis of Zeus, who in Phrygia presides over the fertility of the fields, and this name could be a calque of Tarhunt's epithets pihaim $(m) i_{-}^{-}$, piham $(m) i_{-}^{-}$, and pihaššašši- 'splendorous, shining, vel.sim.'.

Haas 1966, 95; Panagl \& Kowal 1983, 192-193; Diakonoff \& Neroznak 1985, 97; Bayun \& Orel 1988b, 136-137, Brixhe 1991, 42; Witczak 1992-1993, 267-268; Brixhe 1993, 331; Brixhe 1997, 51 fn. 32; Lubotsky 1997, 123; Brixhe 2004a, 38 and 41; Drew-Bear, Lubotsky \& Üyümez 2008, 115; Hämmig 2013, 136 fn. 12; Obrador-Cursach 2017. 


\section{bastidages (PN?)}

OPhr. bastidages HP-101

Since it seems to follow the probable preposition per (note that the segmentation is not at all clear), it cannot be considered a word in nom. (see PN as ates). Brixhe (2004a, 103-106) suggested a fem. gen. in *-es, still not identified in Phrygian. In any case, this inscription, read on a clay cylinder from Lydia, remains unexplained.

Dinç \& Innocente 1999; Brixhe 2004a, 103-106.

batan, $\beta \alpha \tau \alpha v$ see $\beta \alpha \zeta$.

bateles (PN)

OPhr. sg.nom. bateles $\mathrm{W}-08$

Inscription read on a rock: [-?-] ates agomoi | sa ??ta tedaes | alus si个eto? | bateles bab.[-?-]. This hapax follows the formula alus si $\uparrow$ eto, which is the last complete sentence in the inscriptions $\mathrm{W}-09$ and W-10, both on rocks. Consequently, it seems probable that it is not syntactically related. Moreover, the first three lines are written in boustrophedon but the fourth, where this sequence is read, is not. So the relationship between this and the preceeding lines is surprusing. It must also be noted that the $b$ of bateles and the following baba[-?-] are written 8-shaped. In terms of interpretation, bateles has been taken as an $e$-stem anthroponym in the nominative. Although no parallel can be adduced, this explanation is very likely since the sequence which follows bateles is considered to be the well attested PN baba(s).

Brixhe \& Drew-Bear 1982, 78; Orel 1997a, 48 and 419; Morante Mediavilla 2000, 235-236; Ligorio \& Lubotsky 2013, 188.

bạto?ạn see $\beta \alpha \varsigma$.

$b^{?} a y$ ( $(\mathrm{PN}$ ?)

OPhr. beay or ray G-251

Its first letter is difficult to read. This graffito on a potsherd is probably the abbreviation of a PN or merely a sequence written in order to identify its owner.

CIPPh I, 196-197.

bba see baba.

be (PN?)

OPhr. be G-333

Probably an abbreviation of a PN or a complete $e$-stem Lallname in nominative without the ending $-s$.

Brixhe 2002a, 87-88; Brixhe 2004a, 51.

bevdos (noun) 'statue, image'

OPhr. neut.nom.-acc.sg. bevdos B-01, B-08

$S$-stem word inherited from PIE * $b^{h}$ eu $d^{h}$-os- 'perception', derived from the root * $b^{h} e u d^{h}$ - $\left(L I V^{2} 82\right.$ -

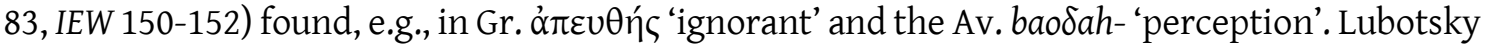
(2008) identified this Phr. word in B-01, misread by the previous editors, through a new reading and the comparison with Gr. $\beta \varepsilon \tilde{v} \delta$ os 'dress' in Sappho but also 'garland' and 'statue', according

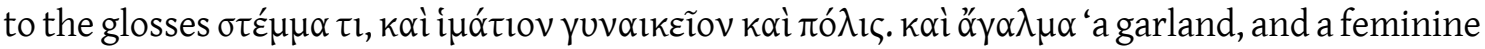

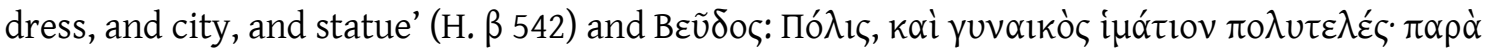

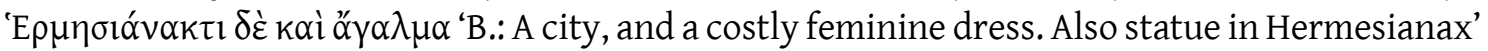
(EM 195.53). This word, previously considered an Asian borrowing (see, e.g., DELG 174), can now be identified as a Phr. loanword. In B-01 it appears in a niche where a statue of the Mother- 
Goddess was expected to be placed: si bevdos adi..[..] kavarmọyo imroy edaes etovesniyo 'Adi..[..] made this statue for this field...'. Recently, it has been also read in B-08, found near B-01, however the context is severly damaged and we only know that it is followed by key 'and' (Brixhe \& Vottéro 2016, 134-136, withough considering Lubotsky 2008). At least two cities from

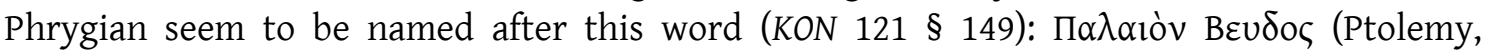
Geography 5.5.5; Beudos quod vetus appellant 'Beudos called the old' in Liv. 38.15.14; pl.gen. ethnic

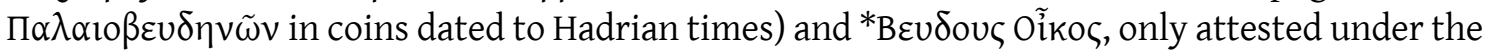

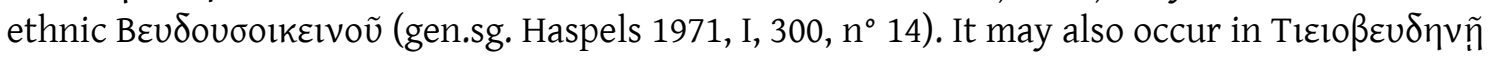
(fem.sg.dat. ethnic), of the Mother-Goddess (in Drew-Bear 1978, 43,11 = SEG 28.1188).

Orel 1997a, 139-140; Lubotsky 2008; Brixhe \& Vottéro 2016, 134-136.

bekos (noun) 'bread'

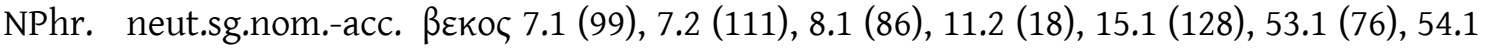
(108), $62.2(33) ; \beta \varepsilon<k>0 \mid \varsigma 11.2$ (18)

Glosses

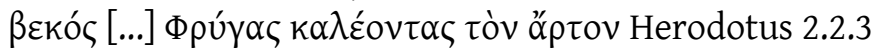

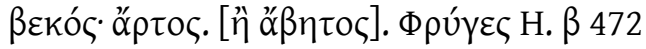

After originally being identified as a possible borrowing from an unknown language (see Lejeune 1979, 221-223), this s-stem is now thought to go back to ${ }^{*} b^{h} h_{1} g$-ós- $\left({ }^{*} b^{h} h_{1} g^{\prime}\right.$-ós- in Lubotsky 2004, 233, who improved the first identification given by Panagl \& Kowal 1983, 186-187). Its PIE root, * $b^{h} e h_{1}$ - 'to warm' (IEW 113), shows the same enlargement - $g$ - found in Gr. $\varphi \omega \omega \gamma \omega$ 'bake' (< *bhohg-, EDG 1600, DELG 1236), ON baka 'id.', OHG bahhan 'id.', Russ. bažitb, bažátb 'wish, want, whereupon starve', etc. (note that $L I V^{2}$ 67-68 reconstructs a root * $b^{h}{ }^{\circ} h_{3} g$-). On its contexts, $\beta \varepsilon \kappa o \zeta$ always occurs in different imprecative apodoses and some instances related to the god Bas: 7.1

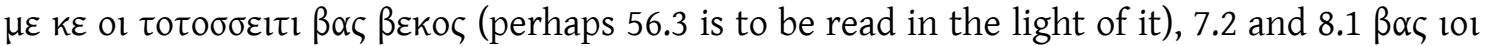

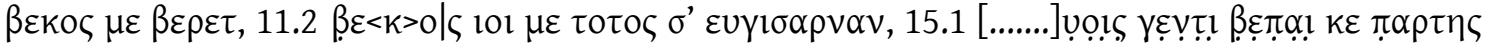

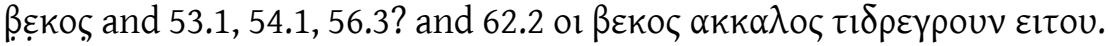

Lejeune 1979, 221-223; Panagl \& Kowal 1983, 186-187; Lubotsky 2004, 233; Matzinger 2006, 198-199.

\section{benagonos (PN)}

OPhr. sg.nom. benagonos G-116

This PN, read on a pithos from the $6^{\text {th }} \mathrm{c}$. BC, has been considered a compound but both forms are still discussed. The first element, bena-, was equated by Lejeune $(1969 b, 294)$ to the Zeus epithet Bźvvioc. However, the origin of this adduced word is not clear. The links to Gr. $\varepsilon \dot{v} \theta \varepsilon v \varepsilon \dot{\varepsilon} \omega$ 'thrive, flourish' (given by DGE s.v.) and PIE * $g^{u} e n h_{2}$ ' 'woman' (also suggested by Lejeune 1969b, 294) are phonetically indefensible. Regarding to -gonos, it has been equated with Gr. compounds in -yovos (Lejeune 1969b, 294, followed by Neumann 1988, 9), but the Phrygian voiced stop of gonos does not fit this etymology. Two alternatives are given by Lubotsky $(2004,232)$ : it could

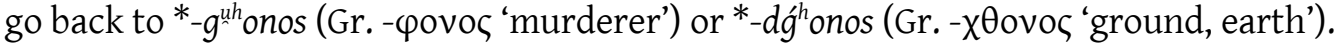

Lejeune 1969b, 294; Brixhe 1982, 239; CIPPh I, 108-109; Roller 1987a, 65; Neumann 1988, 9; Lubotsky 2004, 232; Matzinger 2005, 380; Matzinger 2006, 195-196.

ßętạ! (noun or adjective?)

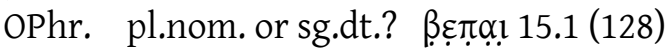

Brixhe and Drew-Bear $(1997,86-91)$ categorised it as a pl.nom. However, since it follows the

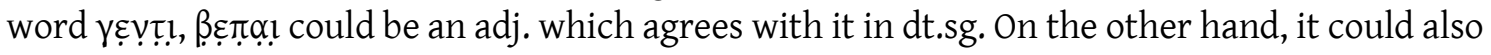

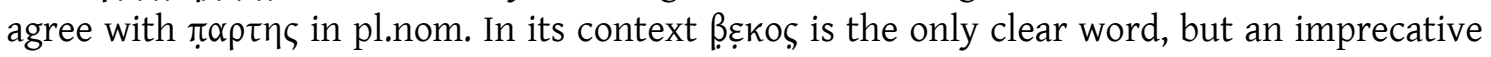

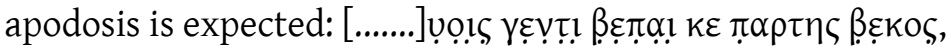

Brixhe \& Drew-Bear 1997, 86-91.

$\beta \varepsilon \rho \varepsilon \tau$ see $\alpha \beta \beta \varepsilon \rho \varepsilon \tau$. 
$\beta \imath \lambda \alpha \tau \alpha \delta \varepsilon v \alpha v$ (noun?)

OPhr. sg.acc. $\quad \beta \imath \lambda \alpha \tau \alpha \delta \varepsilon \mid v \alpha v$ MPhr-01 (W-11) l. 1

Its case could be governed by the preposition $\varepsilon v$. A segmentation $\beta \backslash \lambda \alpha \tau \alpha \delta \varepsilon v \alpha v$ is possible. In any case its meaning and segmentation are as obscure as its context in the MPhr. epitaph:

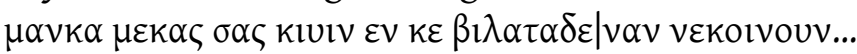

Brixhe 2004a, 15.

$\beta \lambda \alpha \sigma k o v$ (noun or verb?)

MPhr. $\beta \lambda \alpha \sigma \kappa o v$ MPhr-01 MPhr-01 (W-11) 1.3

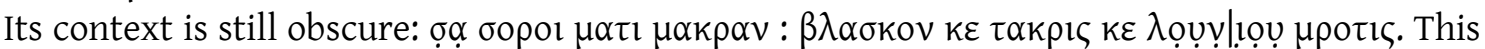
unparalleled word is therefore difficult to interpret. Brixhe (2004a, 18-19) categorised it as a verb in 1sg. or 3pl. due the presence of the possible suffix -sk-. Nevertheless, a sg.acc. (even a sg.gn) noun cannot been ruled out. This word has yet to be satisfactorily explained.

Brixhe 2004a, 18-19.

\section{bonok (PN)}

OPhr. sg.nom. bonok W-01a

This PN name agrees with the title with follows it: bonok akenanogavọs materan areyastin vrekun tedatoy... Its origin is obscure and no parallel can be adduced to it. A common old explanation (still followed by Woudhuizen 2008-2009, 184) equated this word with Aeol. ßavó or Cypr. Bovó 'wife', but these are phonetically incompatible because they go back to PIE * $g^{u}(e) n-h_{2^{-}}$, attested in Phrygian as knays.

Lubotsky 1988, 12; Diakonoff \& Neroznak 1985, 63, no A7; Janda 1997, 272; Orel 1997a, 33-36; Brixhe 2004a, 51; Wittke 2004, 203; Bernd-Ersöz 2006, 72; Sowa 2012, 50; Ligorio \& Lubotsky 2013, 192.

ḅonokaua see monokaua.

bo.[---] (?)

OPhr. bo.[---] G-130

Beginning of a damaged word read in a sequence incised on a potsherd: servas bo.[---]. The first letter was corrected after writing a $p$.

CIPPh I, 120.

braterais (noun) 'brother'

OPhr. placc. buraterạis B-04

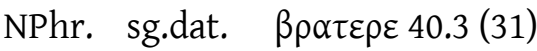

This word is clearly inherited from PIE *b'réh 2 tēr (NIL 38-41, IEW 163-164), see, e.g., Lat. fräter,

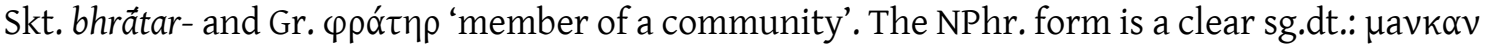
ı $\alpha v \varepsilon \sigma \tau \alpha \varepsilon \varsigma \beta \rho \alpha \tau \varepsilon \rho \varepsilon \mid \mu \alpha \iota \mu \alpha \rho \eta \alpha v$. However, braterais has been discussed. It is attested in the last line of the inscription: ? lakes ' braterais patriyio is is $k(e)$. The older interpretation, given by Orel (1997a, 56 and 420, followed by Blažek 2005, 20 and Woudhuizen 2008-2009, 184), considered it a pl.dat. However, Brixhe $(2004 a, 42)$ suggested the possibility that we are dealing with a pl.acc.: PIE ${ }^{*} b^{h}$ réh $_{2}$ terngs $>*$ braterans > braterais. The following word seems to be inflected in the same case.

Brixhe 1996, 131; Orel 1997a, 56, 420; Brixhe 2004a, 24, 42; Blažek 2005, 20; Woudhuizen 2008-2009, 184; Ligorio \& Lubotsky 2013, 190.

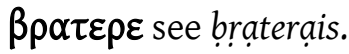




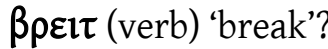

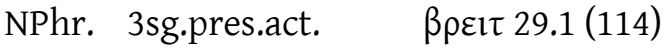

Brixhe and Drew-Bear $(1997,79)$ considered an inherited verb from a PIE root *breH- / *briH'to cut' (LIV ${ }^{2}$ breiH-, IEW 166-7), attested, e.g., through Lat. frio 'to rub, break or crumble into small pieces', Skt. bhrinantini 'to hurt' and OCS briti 'shave' There were doubts as to the segmentation, but the preceding $\kappa \varepsilon$ has finally been interpreted as the conj.: $10 \varsigma \kappa \varepsilon \beta \rho \varepsilon \tau \tau$ $\pi \varepsilon p \beta \varepsilon \delta \alpha v$... It is clearly the verb of this imprecative protasis.

Brixhe \& Drew-Bear 1997, 79.

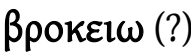

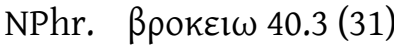

It was suggested to be the EN 'Phrygian' by Haas $(1966,104)$. However, due to the context,

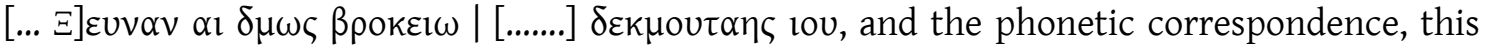
must be rejected. Orel (1997a, 334, 421) considered it an adj. in sg.nom. meaning 'weaker, more

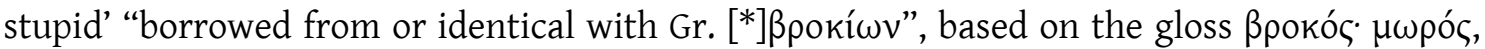
"E $\lambda \lambda \eta v \varepsilon \varsigma$ 'b.: stupid, Greeks'. Nevertheless, this explanation cannot be accepted because it is based on poorly attested documentation and the assumption that this sentence is a curse, which clearly it is not. This word, then, remains unexplained.

Haas 1966, 104; Kowal 1984b, 184; Orel 1997a, 334, 421.

\section{bugnos (PN?)}

OPhr. bugnos P-02

It is followed by a PN and its title in gen., sest bugnos vasos kanutiievanos, and sest looks like a pronominal sequence ses=t (Neumann 1988, 7), it seems to refer some element of the monument. On the basis of ses=t it has been interpreted as a noun in pl.acc. referring to the monument itself "hos lapides" (Neumann 1988, 7 fn. 12 and Neumann 1997, 119) or sg.nom. However, it has also been classed as a PN by Orel (1997a, and 421). It is unparalleled both as a noun and an anthroponym. Nevertheless, the pl.acc. is expected to be -ois, so it may be a sg.nom. In that case, it could be a PN and the whole text can be translated as 'This is Bugnos (the son) of Vasus (the grandson) of Kanutî̀.

Neumann 1988, 7; Neumann 1997, 119; Orel 1997a, and 421. 


\section{$\Gamma(g)-\Gamma \gamma$}

$g a(\mathrm{PN})$

OPhr. ga NW-131

Although this complete graffito incised on the bottom of a cup can be considered an abbreviation of a PN, Brixhe and Sivas $(2009,133-134)$ do not rule out rule out the possibility that it may be a complete PN, in the light of $\Gamma \alpha$, found in the north of Phrygia and Pisidia (KPN $131 \S 202-1$ and 202-2). In this case, ga is an $a$-stem PN in sg.nom without the ending -s.

Brixhe 2004a, 51; Brixhe \& Sivas 2009, 133-134.

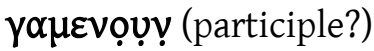

MPhr. $\gamma \alpha \mu \varepsilon v o \underline{u}$ MPhr-01 (W-11) 1.2

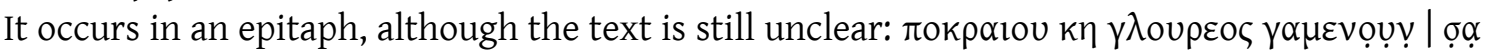

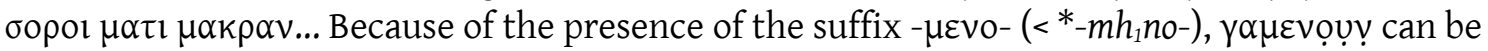
considered a past participle in sg.acc.masc. or sg.nom.-acc.neut. In any case, its meaning and etymology remain unknown.

Brixhe 2004a, 17-18.

$\operatorname{gard}[---](?)$

OPhr. gard[---] G-198

Incomplete graffito incised on the handle of a vase. Although in such a context PNs predominate, it may be equated to the Pisidian ethnics $\Gamma \alpha \rho \delta_{1} \beta 1 \alpha v o \zeta$ and $\Gamma \alpha \rho \delta v \beta 1 \alpha v o \zeta$ (attested in Gr. inscriptions from the north of Pisidia, KON 134 § 195). Moreover, it seems to share its root with Гóp $\delta 10 v$, the name of the most famous Phrygian city (where this graffito was found), and with Manegordo (located in Galatia, near Ancyra, Itinerarium Antoninum 142.5), or with Luw. gurta- 'city' (on it see Simon 2016 and 2017b). In any case, if gard[---] is related to these words, the $a$-vocalism may indicate its Pisidian origin.

CIPPh I, 165.

\section{garies (PN)}

OPhr. sg.nom. garies or paries G-224 b

Graffito incised with other PNs on a marmite: ata $\mid$ garies or paries $\mid Y u v$. Therefore, it can be considered an $e$-stem PN, although clear parallels are lacking. Despite the problematic reading of the first letter, Orel (1997a, 224 and 452), adducing a similar but not equivalent PN gathered by Gindin $(1981,56)$, worked with a reading paries. If indeed it is to be read as paries, it can be related to the first element of the Hitt. PN Pariziti (LNH 137 § 942). Nevertheless, this remains a mere possibility.

CIPPh I, 180; Orel 1997a, 224 and 452.

gata[-?-] see vata[-?-].

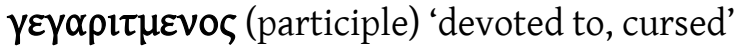

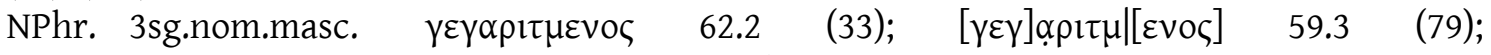
$[\gamma] \varepsilon \gamma[\alpha \rho \imath \tau] \mu \varepsilon[v] \mathrm{o} \mid \varsigma 62.5(36)$

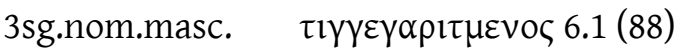

A reduplicated perfect participle read in three different imprecative apodoses. The first is

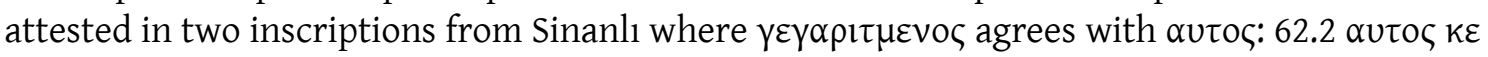

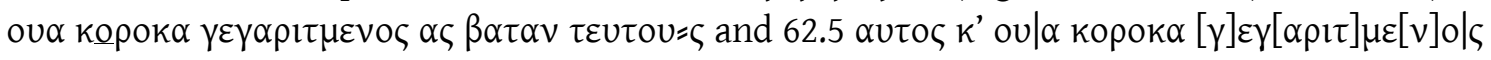
$\alpha \beta \alpha \tau \alpha v \tau \mid \varepsilon \cup \tau O v=\zeta$. The other two apodoses are unparalleled but simpler: $6.1 \tau \mathrm{\tau} \gamma \mid \gamma \varepsilon \gamma \alpha \rho ı \tau \mu \varepsilon v o \zeta$

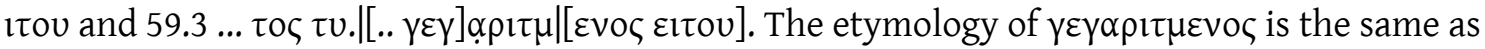


Gr. $\chi \propto \propto \rho i \zeta \omega$ 'gratify or indulge, give graciously', which goes back to the PIE root * $\dot{g}^{h}$ er $(H)$ - 'desire, enjoy' (LIV $176-177$, IEW 440-441), also attested, e.g., in Skt. háryati 'to find pleasure, enjoy, like' and Lat. horitur 'urge, exhort'. Note that the Phrygian root shows the extension -i-, also found in these examples. According to Lubotsky and Ligorio $(2013,183)$, the $a$-vocalism of the

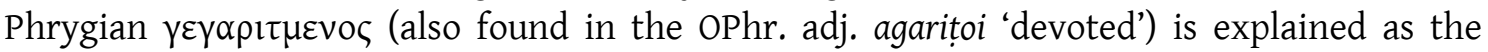
vocalisation of ${ }_{r}^{*}$ : ${ }^{*}{ }^{h} r H i t-$. However, such a vocalisation is only possible if ${ }^{*} \mathrm{H}$ is indedd ${ }^{*} h_{2}$.:

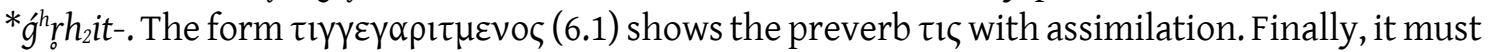
be added that in some inscriptions from Anatolia the Gr. participle $\kappa \varepsilon \chi \alpha \rho ı \mu \mu \varepsilon v \mid o \zeta$ is used as a

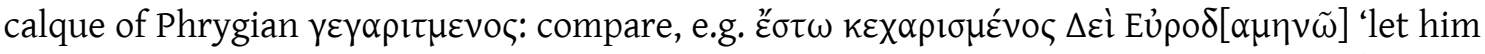

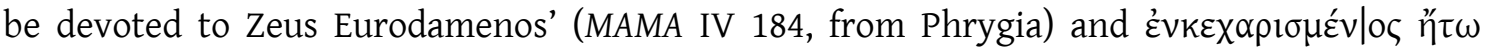

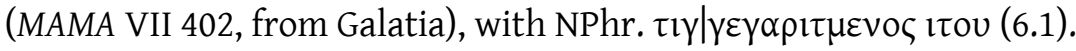

Haas 1966, 209; Brixhe 1982, 245; Lubotsky 1989b, 148; Orel 1997a, 252-253, 431; Lubotsky 2004, 230; Matzinger 2005, 380; Woodhouse 2006, 162; Sowa 2007a, 90-91; Lubotsky \& Ligorio 2013, 183.

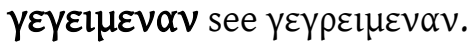

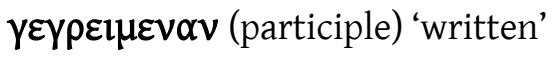

NPhr. sg.acc.fem. $\quad$ $\varepsilon \gamma \varepsilon 1 \mu \varepsilon v \alpha v 62.2(33)$

sg.acc.fem. $\quad \gamma \varepsilon \gamma \rho \varepsilon \iota \mu \varepsilon v \alpha v 53.1$ (76), 60.1 (59), 60.2 (60), 62.1 (32), $62.2(33), 62.3$ (34),

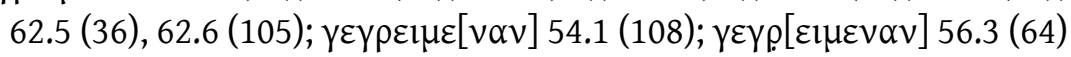

sg.acc.masc. $\quad$

sg.acc.masc. $\quad \gamma \varepsilon|\gamma \rho \imath| \mu \varepsilon|v o| v 56.2(58)$

This perfect participle is commonly found in a formulaic protasis, where it agrees with outav:

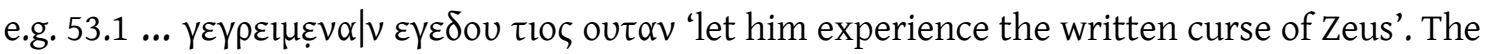

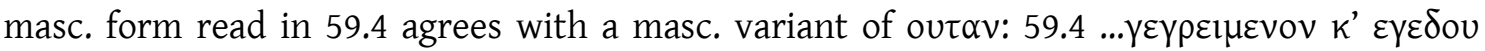

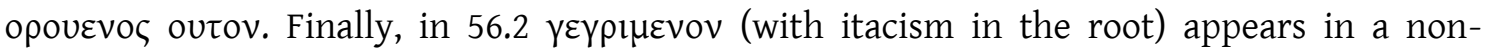

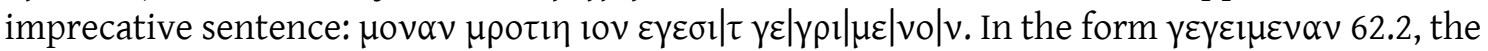
onset cluster $\gamma \rho$ - seems to be simplied in $\gamma^{-}$. Regarding its etymology, Haas $(1966,86-87)$ equated $\gamma \varepsilon \gamma \varepsilon \mu \mu \varepsilon v \alpha v$ to Gr. $\chi \chi^{\prime} \omega$ ' 'graze, spread, (be)smear, enqueue, anoint, plaster' and, consequently, suggested that the root of $\gamma^{\varepsilon-} \gamma \rho \varepsilon \mathrm{l}-\mu \varepsilon v \alpha \nu$ goes back to the PIE verbal root * $g^{h}$ rei-s-, commonly reconstructed as * $g^{h}$ rei(H)- 'strike' (LIV 203 , IEW 457).

Haas 1966, 86-87; Bayun \& Orel 1990; Orel 1997a, 377; Lubotsky 2004, 230; Sowa 2007a, 90-91; EDG 1650; Ligorio \& Lubotsky 2013, 184, 185 and 192.



geies (PN)

OPhr. nom.sg. geies or t? eies G-125

A word read after the verb eneparkes in a potsherd. Although t? eies was the common reading, CIPPh (I, 116) preferred to read geies. It is very likely a PN in nom.sg. and the agent of eneparkes, despite its unusual position after the verb: [---]rono.oy eneparkes geies.

CIPPh I, 116.

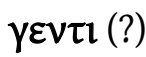

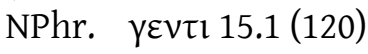

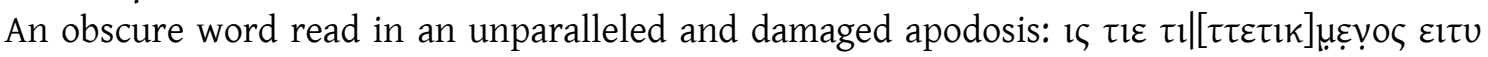

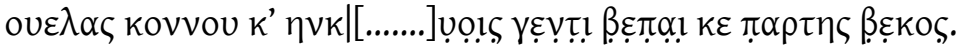

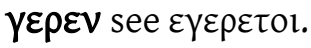


yoviov (noun) 'child'?

OPhr. sg.acc. yoviov 16.1 (116) 1.8

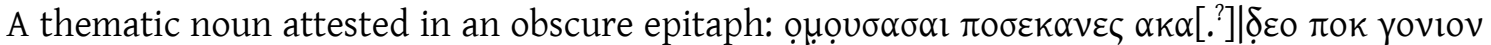

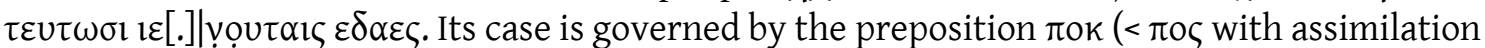
with yoviov). Its meaning remains unknown, although a borrowing from the diminutive

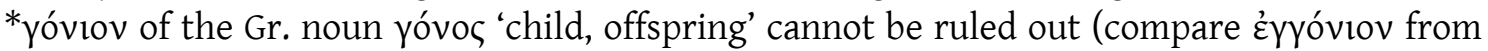
हैy $\gamma$ ovos 'grandson').

Brixhe \& Neumann 1985, 176-177; Ligorio \& Lubotsky 2013, 187.

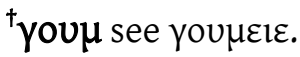

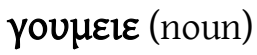

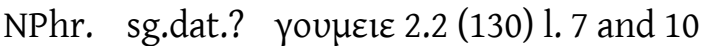

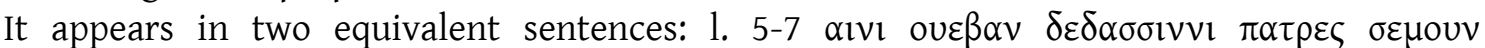

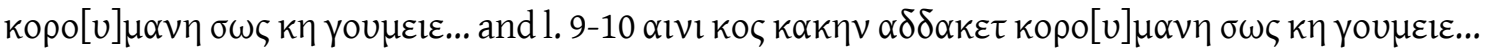

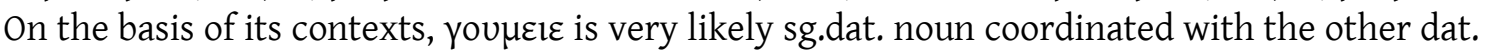

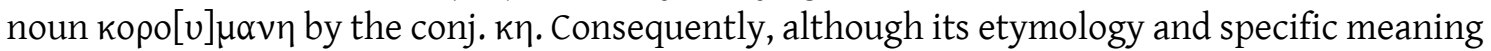

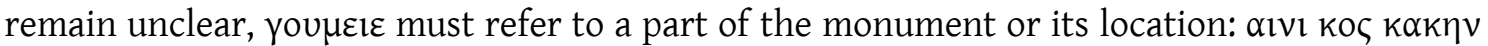

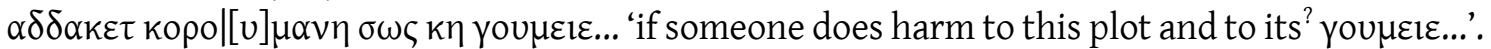

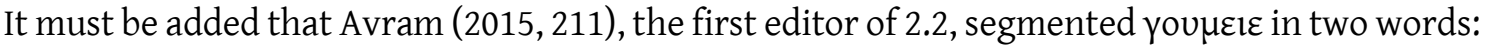

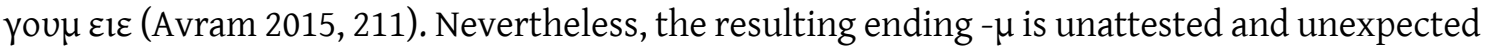
in Phrygian (PIE *-m\# yields - $n \#$ in Phrygian). Finally, Avram $(2015,211)$ also suggested that its root can be related to Eүọvvou.

Avram 2015, 211.

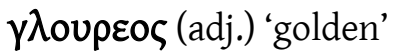

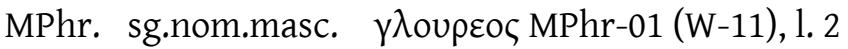

Gloss $\quad \gamma \lambda$ oú $\rho \varepsilon \alpha \cdot \chi \rho u ́ \sigma \varepsilon \alpha . \Phi \rho u ́ \gamma \varepsilon \varsigma$

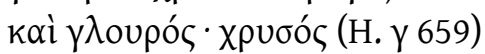

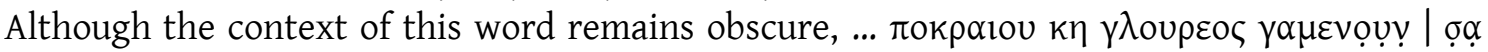

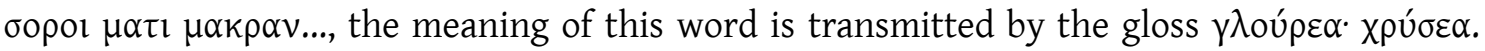

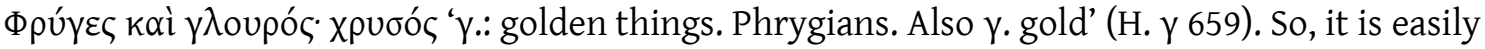
analysed as an adj. derived from the PIE root ${ }^{*} g_{0}^{h} h_{3^{-}}$'green, yellow' parallel to Gr. $\chi \lambda \omega \rho$ ó $\varsigma$ 'greenish-yellow, pale green', also attested, e.g., in Lat. helus, (h)olus 'green plants, vegetables, cabbage'. Skt. as hari- 'fallow, greenish' (used in compounds). According to Brixhe (2004a, 17), $\gamma$ ү (see, e.g., $k \uparrow$ ianaveyos and kubeleya), perhaps this spelling is a consequence of using the Gr. script. In any case, Phrygian $\gamma \lambda$ oupros must be derived from the noun * $\gamma \lambda$ oú $\rho \circ$, which occours

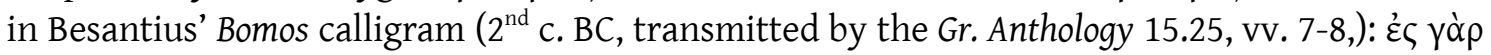

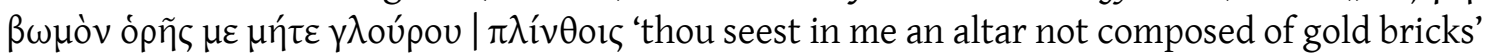
(in sg.gen., see EDG 277).

Brixhe 2004a, 17; Sowa 2007a, 159; Sowa 2008, 31, 50, 88; EDG 277; Ligorio \& Lubotsky 2013, 185, 186.

guvatis see țuvatis. 



\section{$\Delta(d)-\Delta \delta$}

$d$ (mark)

OPhr. $d \mathrm{G}-282$

Mark incised on the underside of the base of a bowl.

$d[-?-]$ see $a^{1}$.

dạ[---] (PN?)

OPhr. da[---] G-303

Potter's stamp with the beginning of a probable PN.

Brixhe 2002a, 63.

dabati (verb)

OPhr. 3sg.pres.ind.act. dabati B-08; da[b]ati B-01 1.5

A verb found in the two large incriptions from Germanos. Although we know that they are cultic texts, their contents are still unclear and the fragments in which both occurences appear are eroded: B-01 [..] toyo[.] is [.] erktevvoys ekey da [b]ati | opito [k]ey and B-08 si tadila[---] |[---] bevdos key [---]|[---] key dabati [---]. Note that B-01, previously considered a form related to daket 'he does', is restored in the light of B-08. Its meaning and origin remain unknown.

Brixhe \& Vottéro 2017, 138.

\section{daguvas (PN)}

OPhr. sg.nom. daguvas G-293

Graffito incised on the bottom of a bowl. According to (Brixhe 2002a, 53-55), daguvas is very likely a PN, although its origin is unclear. As a working hypothesis he suggested two possibilities. Perhaps daguvas is the same PN found as Takuwa in Hittite (LNH 170-171 § 1219), although de initial voiced stop is not expected. The second equates it to Gr. $\tau \alpha \chi u ́ \varsigma$ 'swift, fast' and considers daguvas a PN name derived from a PIE adj. * $d^{h} n g^{h}-u$ - 'id.'. However, the etymology of the Gr. form is still problematic (see EDG 1456-1457) and the vocalisation does not fit as Phrygian.

Brixhe 2002a, 53-55.

\section{$\delta \propto \delta ı \tau \imath$ (noun?)}

NPhr. sgd.dat.? $\delta \alpha \delta ı \imath 122.1$ (9)

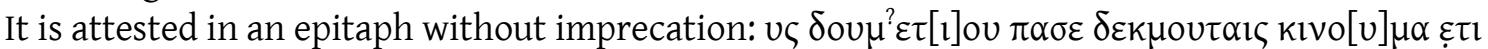

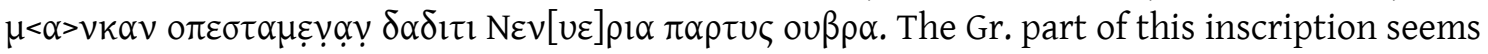

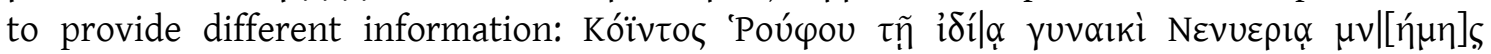

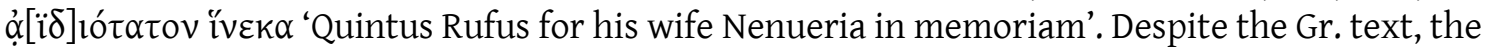
Phr. part remains obscure since the two versions do not fit word-for-word. Consequently, two different interpretations have been suggested. The first considers $\delta \alpha \delta \imath \tau 1$ a verb, which could be in 3sg.ind.pres.act. (see $\rho \propto \delta ı \tau 1)$, and was suggested by Lubotsky (1989a, 79), who translated a part of this sentence as "'made a grave and a standing monument for Nenueria' uel sim". Consequently, to this possibility, $\delta \alpha \delta i \tau l$ is somehow to * $d^{h} e_{1^{-}}\left(L I V^{2} 136-138\right.$, IEW 235-239, see $\alpha \delta \delta \alpha \kappa \varepsilon \tau)$. However, $\delta \alpha \delta \imath \tau$ seems to be in 3sg.ind.pres.act. (see $\rho \alpha \delta \imath \tau \imath)$ and the expected Phr. form in such a context is $\varepsilon \delta \alpha \varepsilon \zeta$ (3sg.ind.aor.act.). On the other hand, Orel (1997a, 75, followed by Woudhuizen $2008-2009,211$ ) considered that the root of this supposed verb is the PIE ${ }^{*} \mathrm{deh}_{3^{-}}$ 'give' (LIV 2 105-106, IEW 223-225). Nevertheless, this interpretation must be rejected in the light

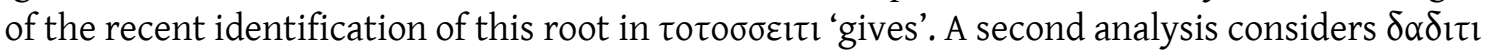

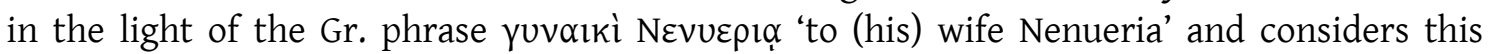


Phrygian word a noun in sg.dat. First suggested by Calder (in MAMA IV, 7), it was followed by Haas (1966, 103-104), who equated it to Gr. $\tau \eta \theta i ́ s,-i ́ \delta o s ~ ' a u n t '$, and Woodhouse $(2006,166)$, who agrees with Haas' proposal and adduces parallel semantic changes such as Alb. motër 'sister' from PIE *méh ${ }_{2} t e \bar{r}$ 'mother' (see Demiraj 1997, 279). However, 'wife' in NPhr. occurs as kvalkav (sg.acc.).

Haas 1966, 103-106; Lubotsky 1989a, 79; Orel 1997a, 75; Woudhuizen 2008-2009, 211.

\section{$\delta \alpha \delta$ ov (PN?)}

NPhr. sg.gen.? $\delta \alpha \delta$ ov $11.2(18)$

A possible o-stem PN in sg.nom. or sg.dat. attested in a non-imprecative part of an epitaph:

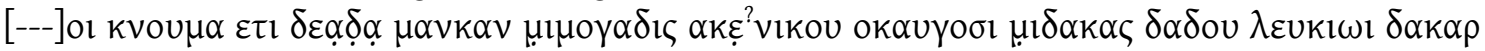

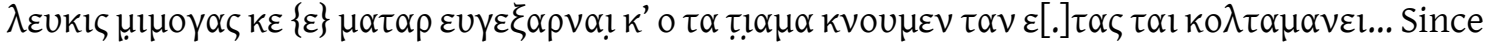
it follows the PN $\mu 1 \delta \alpha \kappa \alpha \varsigma, \delta \alpha \delta o v$ is verly likely a sg.gen. used as patronymic. Wouhouse (2006, 171) considered that $\delta \alpha \delta$ ov was a common noun 'grandfather' inherited from a PIE * $d^{h} \bar{e} d^{h} \circ$ adducing Gr. $\tau$ ' $\theta \eta$ ' 'grandmother' and Slavic * dĕd 'grandfather'. However, it is easier to consider it a variant of the Lallnamen $\Delta \alpha \delta \alpha, \Delta \alpha \delta \alpha \varsigma, \Delta \alpha \delta \eta \varsigma, \Delta \alpha \delta \omega \nu, \Delta \alpha \delta \delta$ o , etc. commonly found across all of Anatolia (KPN 139-141 § 244, see also NPhr. $\delta \alpha \delta \omega v)$.

Bayun \& Orel 1988c, 142; Orel 1997a, 82 and 421; Wouhouse 2006, 171.

\section{$\delta \alpha \delta \omega \nu(\mathrm{PN})$}

NPhr. sg.nom. $\quad \delta \alpha \delta \omega v 43.1(69) 1.12$

sg.dat. $\quad \delta \alpha \delta \omega v \varepsilon \mid \mathrm{l} 43.1(69) 1.7-8$

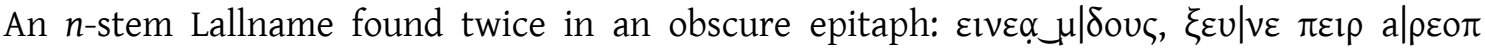

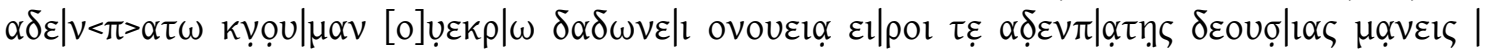

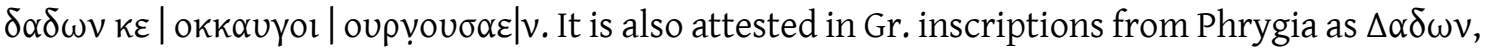
$\triangle \alpha \delta \omega v \tau \circ \varsigma$ (KPN $141 \S 244-7$ ), although in this language it follows the $n t$-inflection.

KPN 141 \& 244-7; Orel 1997a, 346 and 421.

\section{$\delta \alpha \delta \omega v \varepsilon l$ see $\delta \alpha \delta \omega v$.}

davoi (PN)

OPhr. sg.dat. davoi M-06; davoi B-05 1.2

A PN engraved on a rock-cut altar (M-06) and in the non-imprecative part of the Vezirhan stele: M-06 [v]? rekun deiatiteea.? davoi iman and B-05 iben edatoy dakeran atriyas davoi okimakiva [---] |

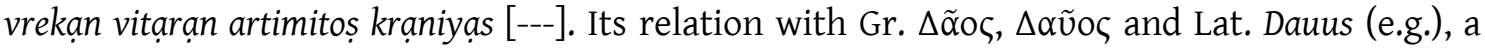
common PN for slaves, especially in drama (see, e.g., Terentius, Andria 1, 2, 24 Dauus sum, non Oedipus 'I am Davus, not Oedipus'), seems evident. The sequence -vo- can be considered an epenthetic glide also found in devun. However, if one considers that many Phrygian PNs are borrowed from Anatolian languages, it is perhaps better explained as a reflex of non-Phrygian origin. Ramsay $(1895,360)$ connected the Pisidian PN $\Gamma \delta \alpha \beta$ ○ with Gr. $\Delta \tilde{\alpha}$ ○ (the OPhr. forms had not yet been found) and considered that the Pisidian form was the reflex of the Gr. one. However, Pisidian $\Gamma \delta \alpha \beta$ o५ (N12), the gen. of $\Gamma \delta \alpha \beta \alpha(\mathrm{N} 10, \mathrm{~N} 11$ [bis], N27), is now interpreted as inherited from Proto-Luwic *hanta-wa- 'belonging to the front side', the same root is found in the Pisidian PN in gen. $Г \delta \varepsilon \beta \varepsilon \tau \iota \varsigma$, cognate of Lyc. noun xñtawat( $(i)$ - 'ruler' and Luw. handawat $(i)$ -

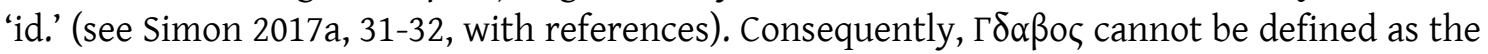
Pisidian rendering of $\Delta \tilde{\alpha}$ os.

Bayun \& Orel 1988a, 181; Vassileva 1995a, 270; Orel 1997aa, 422; Berndt-Ersöz 2006, 76-78; Brixhe 2004a, 55; Hämming 2013, 139 fn. 30.

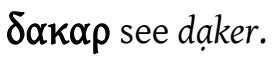


$\delta \alpha \kappa \alpha \rho \varepsilon v$ and $d a[k]$ ati see $\alpha \delta \delta \alpha \kappa \varepsilon \tau$.

\author{
dạker (noun) \\ OPhr. sg.nom.? daker B-05 1.5 \\ pl.acc. dạkerạiș B-05 1.7 \\ sg.acc. dạkeran B-05 l. 2

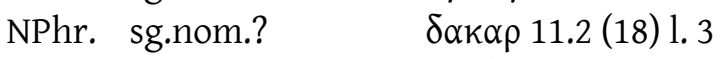 \\ pl.nom. $\quad \delta[\alpha] \mid \kappa \varepsilon \rho \eta \varsigma ~ 16.1$ (116) 1. 9-10
}

An $r$-stem noun without a clear meaning. It is found three times in the non-imprecative part of the Vezirhan stele: B-05 sin=t imenan kaliya ti tedat[...]edekm[...]meas ? d? ư mị | iben edatoy dakeran atriyạs davoi okimakivva[---] | vrekan vitaran artimitos kraniyas [---] | pantạ vebras adun p?os key estat pator. ike[...] e...] andati | vay niptiyạy dạker kạatu enpsatus meka[---]assiyạ..? | nidus ad kaliyay karatu panato ando popostois klaniv | kelmis ke umnișet evradus dạkerais key iverais [..] | atikraiu... It is also found in the non-imprecative part of two epitaphs completely written in Phrygian: 11.3 [---]or

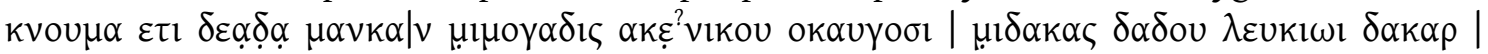

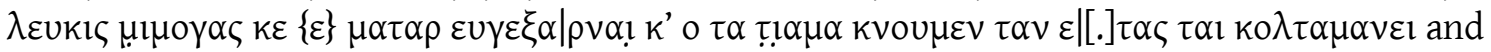

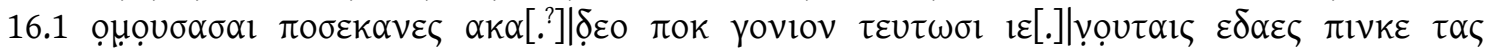

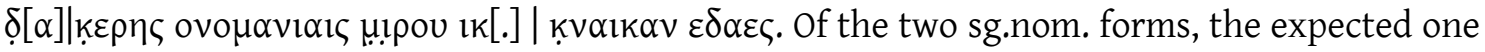
is $\delta \alpha \kappa \alpha \rho$, in the light of the inflection of matar. Then, despite its antiquity, daker can be a secondary form which levelled its last vowel from the other forms. As Brixhe (2004a, 54) suggested, this noun very likely derives from the verb $(\alpha \delta) \delta \alpha \kappa \varepsilon \tau$.

Brixhe 2004a, 54 .

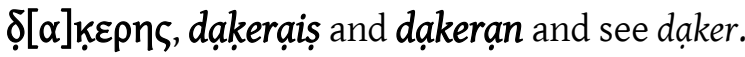

dạket, $\delta \alpha \kappa \varepsilon \tau$, dakor, ${ }^{\dagger}$ dạpitiy and daY et see $\alpha \delta \delta \alpha \kappa \varepsilon \tau$.

das (?)

OPhr. das W-10

An obscure word attested in an unclear text engraved on a sheer lone rock: alus si $\uparrow$ eto das. The

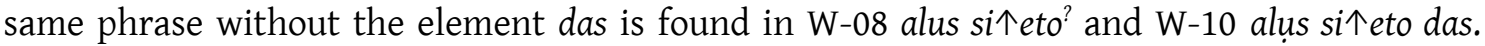
Although Orel (1997a, 51 and 421) considered it a PN in sg.nom. (also Avram fthc.), the subject of the sentence is clearly alus, if si $\uparrow$ eto is a verb. In that case, this interpretation does not fit the context. However, the status of si $i$ eto is not clear and an anthroponymic sequence cannot be ruled out.

Brixhe \& Drew-Bear 1982, 86; Orel 1997a, 51 and 421; Avram fthc.

${ }^{\dagger}$ dabpulaịsini see daspula and isini.

dabpula (noun)

OPhr. pl.nom.acc. dabpula P-101

A graffito incised on the bottom of a pot: aini dabp? ula isini. Although this obscure text has been discussed and even its segmentation was unclear, Hämmig (fthc. b) has recently equated it to

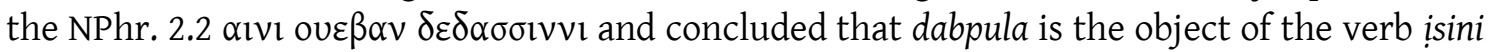

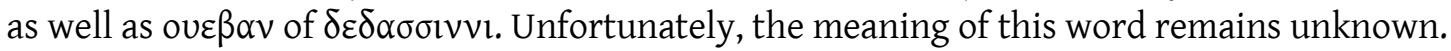
CIPPh I, 244-254; Orel 1997a, 302 and 421; Hämmig fthc. b.

$\delta \delta \varepsilon \omega$ see $\delta \varepsilon \omega \varsigma$. 
$d e^{1}(\mathrm{PN} ?)$

OPhr. de G-341

Very likely this graffito incised on a sherd is an abbreviation of a PN, as is common in such inscriptions.

Brixhe 2002a, 95.

${ }^{\dagger} \mathrm{de} \mathrm{e}^{2}$ see dedasity.

$\delta \varepsilon \alpha \underline{\alpha} \delta \underline{\alpha}(?)$

OPhr. $\quad \delta \varepsilon \alpha \underline{\delta} \underline{\alpha} \alpha 11.2(18) 1.1$

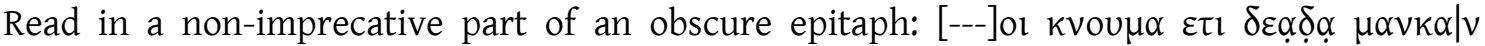

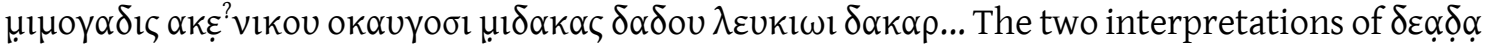
must be rejected. Orel (1997a, 81 and 422) considered that it was a chain of clitics, de=ai=de, where $\delta \varepsilon$ was an unidentified particle and $\delta \varepsilon \alpha$ the Phr. cognate of the Gr. Sió 'through'. However, this last particle occurs in Phr. as $\tau^{-}$, so this solution is phonetically impossible. On the other hand, Woodhouse $(2006,171 \mathrm{fn} .24)$ segmented $\delta \varepsilon \alpha \delta \alpha$ and equated the second element to Gr. " $\not \delta \eta$ 'already, by this time', but this can again be ruled out because a voiceless stop would be expected in the Phr. outcome. Consequently, this word remains to be explained. Orel 1997a, 81 and 422; Woodhouse 2006, 171 fn.24.

[-?-]ded?[---] (PN?)

OPhr. [-?-]ded?[---] NW-116

Although it is very likely a Lallname with a similar structure to nana or baba (see Brixhe 2002a, 21 ), the bad preservation of this pot graffito do not allow to give any conclusion.

Brixhe 2002a, 21.

${ }^{\dagger}$ dedapitiy, $\delta \varepsilon \delta \alpha \sigma \sigma \mathrm{vv} \mathbf{l}$ and dedasitiy see $\alpha \delta \delta \alpha \kappa \varepsilon \tau$.

devọs and devun see $\delta \varepsilon \omega \varsigma$.

deiatiteea[.?] (?)

OPhr. deiatiteea $\left[{ }^{?}\right] \mathrm{M}-06$

Attested in a text engraved on a little rock-cut monument: rekun deiatiteea.? davoi iman. Bayun and Orel $(1988 \mathrm{a}, 181)$ considered deiati a verb in 3 sg. derived from the PIE verbal root ${ }^{*} d^{\text {h }} e h_{1}$ - to do' (LIV ${ }^{2} 136-140$, IEW 235-239). However, the sequence -ia- is not expected. There is very likely a word boundary between the contiguous e: deiatite ea [.?], although this remains unclear. CIPPh I, 26; Bayun \& Orel 1988a, 181; Orel 1997a, 29 and 423.

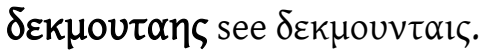

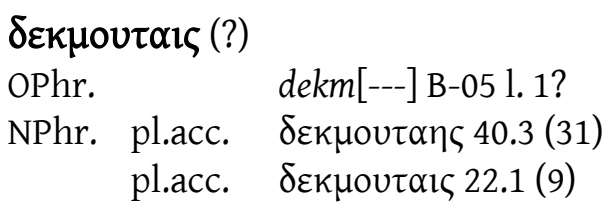

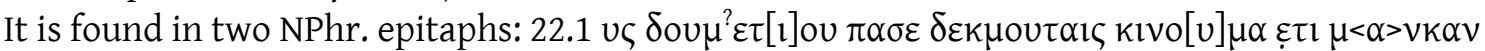

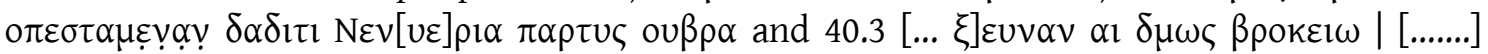

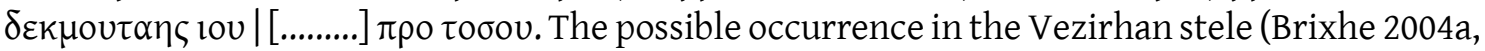
53 and Sowa 2007a, 80-81) is unclear since this part of the text is badly damaged: compare Brixhe's 2004a, 65 reading of the line sint imenan kaliya ti tedat [...] dekm[...]meas d $^{?} u^{?}$ ? mid... with Neuman's $(1997,18)$ sint imenan kaliya titedat [...] e e emọ . menana . a..., where the restoration 


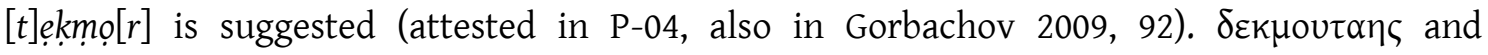

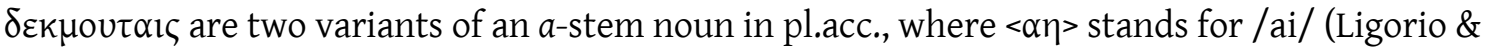
Lubotsky 2013, 183). Its meaning and etymology are unknown, since attempts to identify them must be refuted. Neumann $(1986,84)$ suggested that it was the ordinal number 'tenth' derived from PIE *dékm- 'ten' (also Orel 1997a, 74 and 422-423, Blažek 2005, 30). However, the presence of the voiced dental stop in the Phr. form is unexpected. The same can be said of Woudhuizen's

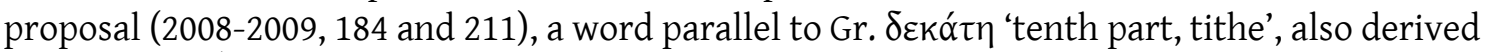
from PIE *dékm-. Finally, it also rules out the interpretation given by Haas (1966, 103-105), Calder $(1911,169)$ and Woodhouse $(2006,163)$, who equated $\delta \varepsilon \kappa \mu o v \tau \alpha 1 \varsigma$ to the Gr. formula

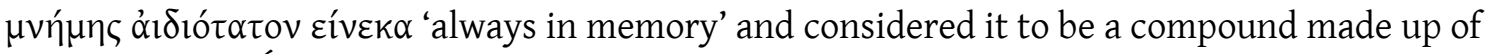
the numeral *dékm- and *uétos 'year', whose meaning is suggested to be 'decade'. On the other hand, Diakonoff and Neroznak (1985, 35 and 117) considered it a deverbative adj. which goes back to PIE * $g^{u} e m$ - 'to step' (LIV 209-210, IEW 464-465, see, e.g., Gr. $\beta \alpha i ́ v \omega$, Lat. uenio), giving it the perfective meaning 'passed away, dead': * $d^{(h)} e-g^{w} m \bar{o}-t-o->* d e k m u t o-$. Nevertheless, the first element of this formation is difficult to explain and it is an ad hoc etymology.

Haas 1966, 103-105; Neumann 1986a, 80 and 84; Diakonoff \& Neroznak 1985, 35 and 117; Orel 1997a, 74 and 422-423; Brixhe 1999, 301; Brixhe 2002a, 68; Brixhe 2004a, 53; Woodhouse 2006, 162-163; Woudhuizen 2008-2009, 184 and 211; Ligorio \& Lubotsky 2013, 183.

dekm[---] and see $\delta \varepsilon \kappa \mu o u v \tau \alpha ı$.

${ }^{\dagger} \delta \varepsilon 0 \pi$ okyoviov see $\alpha \kappa \alpha\left[{ }^{?}\right] \delta \varepsilon \circ$, pos and yoviov.

$\delta \varepsilon \circ \zeta$ see $\delta \varepsilon \omega \varsigma$.

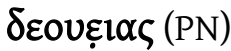

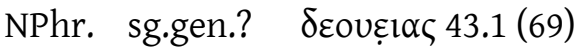

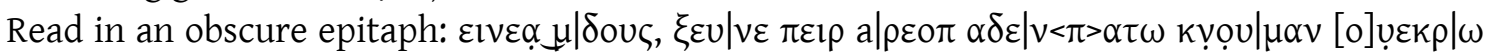

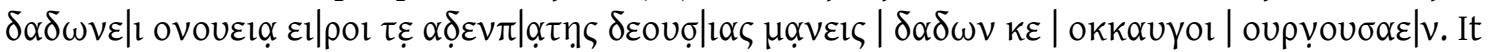

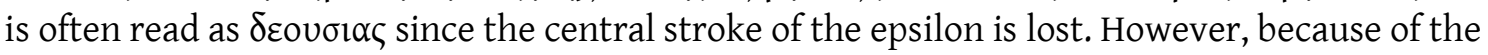

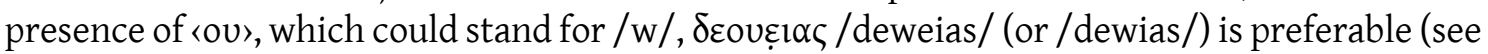

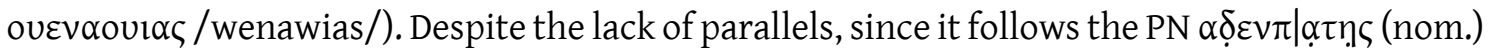
it can be considered an $a$-stem, PN in sg.gen., used as a patronymic (on the other hand, KPN 145 $\S 269$ is considered a fem. PN).

Haas 1960, 64; KPN 145 § 269.

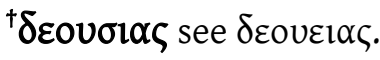

derạgiv see derạliv.

\section{derạliv (?)}

OPhr. derạliv B-05 1.9

Obscure word read in the imprecative part of the Vezirhan stele: sin=t imenan kaka oskavos kakey kan dedasitiy tubetiv oy kevos deraliv mekạs key kovis abretoy nun ibey nevotan niptiyan sirun mireyun. According to Neumann $(1997,23)$, who read it as deragiv, its unclear ending is found in the preceding tubetiv. However, tubetiv is a verb in 3sg. and deraliv remains unclear. See Hämmig's analysis (2013, 140 and 142-143) for the comparable words found in its position in the other analogous curses of this inscription.

Neumann 1997, 23; Brixhe 2004a, 61; Ligorio \& Lubotsky 2013, 184; Hämmig 2013, 140 and 142-143. 
deritoy (verb)

OPhr. 3sg.subj.pres.med. deritoy B-05

A verb read in an imprecative apodosis of the Vezirhan stele: tiv† imun inmeney asenan daket torvetun 个iray ayniy oy tubnuv nevos, me deritoy kovis ke abretoy nun oy nev<otan>. It has been considered mederitoy as a verb with preverb; however, in the apodosis only verbs in imperative

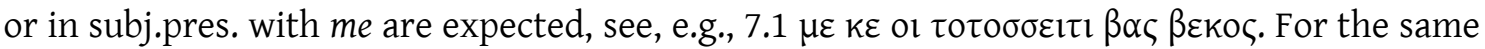
reason, the aor. m-ederitoy suggested by Gorbachov (2008, 94, fn. 4) can be ruled out. The meaning and the etymology of deritoy remain unknown.

Neumann 1997, 25; Brixhe 2004a, 63; Sowa 2007a, 74; Gorbachov 2008, 94, fn. 4; Hämmig 2013, 140 and 142-143.

deș[---] (prep.?)

OPhr. des[---] B-06

The begining of a word read on a damaged stele: stal' $a$ ke: $\uparrow$ ekm? [at]es key[---]a? $a^{2} o^{?}[---] \mid d e s[---]:$ event noktoy : emetetariyois | [---]y ... Orel (1997a, 152 and 422) equated it to the Gr. particle $\delta$ ń 'now, so, then' and Brixhe (2004a, 71) suggested the presence of the prep. $\delta \eta$ followed by the beginning of an unknown word s[---]. However, the first proposal can be ruled out because the voiced stop is unexpected, and the second cannot be corroborated, since the sequence is partially preserved.

Vassileva 1995, 27-34; Brixhe 1996, 125-136; Orel 1997a, 152 and 422; Brixhe 2004a, 71.

$\delta \varepsilon \tau$ ov (noun) '(funerary) monument'

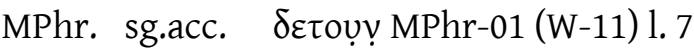

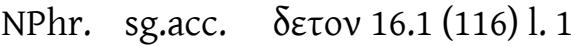

sg.acc. $\quad$ Eetouv $40.3(31)$

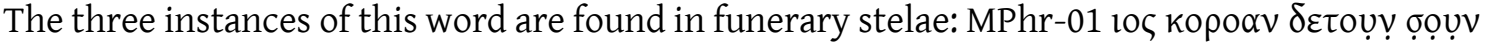

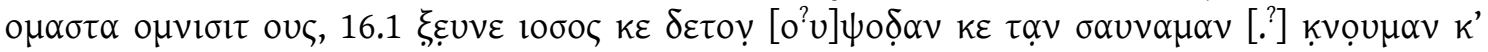

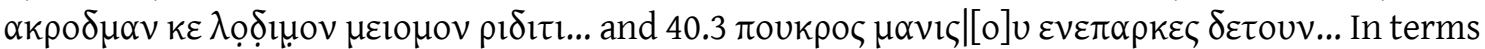

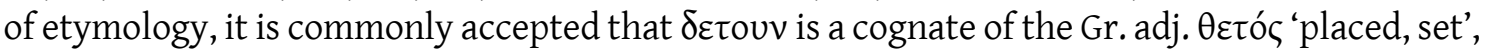
which goes back to the form ${ }^{*} d^{h} h_{1}$-to- (NIL 102-103), derived from the verbal root ${ }^{*}{ }^{h}{ }^{h} h_{1}$ ' to do, to put' (LIV $2136-140$, IEW 235-239). Consequently, it has been considered to mean 'inscription' or, preferably, '(funerary) monument'.

Brixhe \& Neumann 1985, 170; Lubotsky 1993a, 131; Orel 1997a, 152 and 423; Brixhe 2004a, 23; Sowa 2007a, 91; Woudhuizen 2008-2009, 184 § 34; Ligorio \& Lubotsky 2013, 186; Avram 2016, 128.

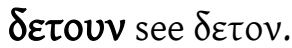

deVeti see $\alpha \delta \delta \alpha \kappa \varepsilon \tau$.

$\delta \varepsilon \omega \varsigma$ (noun) 'god'

OPhr. sg.nom. devos P-03

sg.acc. / sg.gen.? devun B-07

NPhr. pl.dat. $\quad \delta \delta \varepsilon \omega 20.2(128)$

pl.dat. $\quad \delta \varepsilon \circ \operatorname{loc}_{17.3(7), 18.3(6)}$

pl.dat. $\quad \delta \varepsilon \omega \varsigma$ S 3.1 (97), 10.1 (112), 17.6 (119), 19.1 (96), 20.1 (63), 20.3 (62), 24.1

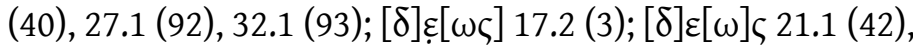

pl.dat. $\quad \delta 10$ ( $30.1(39)$

pl.dat. $\quad \delta ı \omega \varsigma 12 . .1(121), 18.1(4), 18.2(5), 22.2(118) ; \delta[\imath \varsigma \zeta] 35.1(25)$ ?

pl.dat. $\quad \delta v \omega \varsigma 10.2(113)$

All the NPhr. forms appear in the basic formula, with many variants studied by Lubotsky (1998): $\mu \varepsilon \delta \varepsilon \omega \varsigma \kappa \varepsilon \zeta \varepsilon \mu \varepsilon \lambda \omega \varsigma$ $\kappa \varepsilon$ 'in the sight of gods and men'. According to Lubotsky $(1998,419)$, this 
noun is the Phr. outcome of PIE * $d^{h} h_{1}$-s-ó- 'god' (NIL 102), a cognate of Gr. Өcó 'id.'. The previous proposal (Brixhe 1983, 115 and 117), a noun derived from PIE *deiuōs (NIL 71-72, attested in Skt. devá 'god' and Lat. deus 'id.'), was ruled out because the simplification *ei- > /e:/ is difficult to defend in Phrygian and the presence of a voiced stop is unexpected in the Phr. word. The most common form is the NPhr. pl.dat. $\delta \varepsilon \omega \varsigma\left(<*_{-}^{*} i s\right)$, with some trivial variants: $\delta 1 \omega \varsigma$ and $\delta 10 \varsigma$, which present the hesitation /e/ /i/ (see § 4.1.1), $\delta v \omega \varsigma$, where upsilon is used instead of ipsilon because of the influence of the Gr. itacism, and $\delta \varepsilon \circ \zeta$ and $\delta 10 \varsigma$, which shows the loss of vowel length differentiation between /o:/ and /o/. The form devos is clearly the sg.nom. because of its context. Indeed, in the text where it is read, engraved on a stone block, it agrees with the adj. mekas where vasous iman mekas kanutieivaị devos ke mekas. Ligorio and Lubotsky $(2013,186)$ explains its non-etymologic $-v$ - as an epenthesis parallel to tovo. OPhr. devun, which also shows this epenthesis, is less clear, since its ending can be considered a pl.gen. *-ōn (according to Brixhe 2004a, 83) or a sg.acc. ${ }^{*}$-on and its context remains obscure: yos tiv[.][[.?] ke devun $k$ umnotan ordoineten.

Brixhe 1983, 115 § 4.1; CIPPh I, 234; Diakonoff \& Neroznak 1985, 101-102; Brixhe 1990, 77; Orel 1997a, 293 and 422; Lubotsky 1998, 419; Brixhe 2004a, 83-84; Lubotsky 2013, 186.

$\delta \eta$ (preposition) 'in, among, in the sight of'?

NPhr. $\delta \eta 18.1(4)$

It is only attested once in a common imprecative apodosis: $\delta \eta \delta \iota \omega \varsigma \zeta \varepsilon \mu \varepsilon \lambda \omega[\varsigma \tau \imath \tau \varepsilon \tau] ı \kappa \mu \varepsilon v o \zeta$

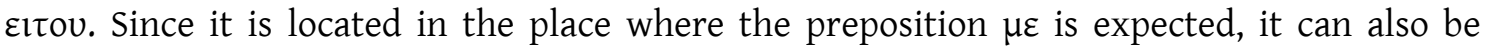
considered a preposition governing dat., with a similar meaning to $\mu \varepsilon+$ dat. On its etymology, although Brixhe $(1997,55-56)$ suggested a PIE base $* d^{h}$ - or $* d$-, only the first of these can be defended for Phr. Consequently, it is very likely a cognate of the Gr. allative $-\theta \varepsilon v$ 'towards, to', which goes back to PIE * $d^{\text {h }}$ e (LIPP II, 148-149), also found in in Skt. kúha, Av. kudā 'where?' $\left(<{ }^{*} k^{w} u+d^{h} e\right)$ and Lat. $u b i$ 'where' (with its original locative meaning, see Berenguer 2000, 25). Its possible occurrence as preverb in B-05 dedasitiy is rejected by Hämmig $(2013,131)$ and by Ligorio and Lubotsky $(2013,192)$.

Brixhe 1983, 126; Lubotsky 1989a, 83; Brixhe 1997, 55-56; Brixhe 2004a, 61; Ligorio \& Lubotsky 2013, 192; Hämmig 2013, 131; LIPP II, 149.

di (PN?)

OPhr. di or id C-103

Complete graffito incised on a lekythos. It is very likely an anthroponymic abbreviation. Although the reading direction is unknown, because of the proximity to the handle it is most likely dextroverse. Then, $d i$ is the most probable reading (CIPPh I, 222).

CIPPh I, 222.

dide (PN)

OPhr. sg.nom. dide HP-112

An $e$-stem PN incised on a bronze bowl found in Bayındır (East Lycia). Despite the lack of the ending -s, it is a sg.nom. (see, e.g., voine G-228). It is a variant of the Lallanamen $\Delta \eta \delta \eta \varsigma, \Delta \eta \delta 1 \zeta$, $\Delta 1 \delta \alpha \varsigma$, etc. (from Phrygia, Bithinia and Lydia, KPN $146 \S 278,282$ ).

Varinlioğlu 1992, 13 and 15 no. 10; Orel 1997a, 319-320 and 423; Brixhe 2004a, 116-117.

$\delta$ Iıoıv (?)

NPhr. Suolv $50.2(55)$

Found in a damaged imprecative apodosis: $10[\varsigma \vee 1 \sigma \varepsilon \mu]$ ouv $|\kappa[v o u \mu \alpha] v \varepsilon l| \kappa[\alpha \kappa o u v] \alpha \delta \delta \alpha \mid \kappa[\varepsilon \tau$,

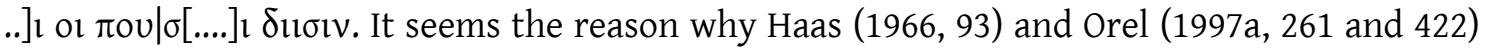
considered it a variant of $\delta \varepsilon \omega \varsigma$. Orel also explained it as "an unusual orthoraphic variant ... with 
the ending of dat. pl. in its unreduced form going back to *-oisi. Note $v \dot{\varepsilon} \varphi \varepsilon \lambda \kappa v \sigma \tau \imath \kappa o ́ v$ in the auslaut". However, it is ad hoc explanation and this word remains unclear.

Haas 1966, 93; Brixhe 1968, 318; Orel 1997a, 261 and 422.

dile? (PN)

OPhr. dile? G-246

Graffito incised on a bowl. The last sign is difficult to read, perhaps a ligature of several letters or a non-alphabetic mark. Despite the lack of parallels, it si very likely to be a PN.

Brixhe 1984, 193.

\section{Siouvolv (DN)}

NPhr. sg.acc. Siouvolv $6.1(88)$

According to Calder (1928, 217, followed by Gusmani 1958, 902 and Lubotsky 1989b, 147 and 152), this is a loanword from Gr. $\Delta$ lóvūбoৎ ‘Dionysus' (on Greek variants se García Ramón 1987). Indeed, it appears in an imprecative apodosis, where a god is expected to be the keeper of the

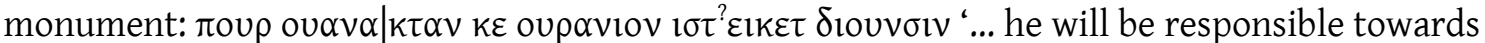
the heavenly king Dionysos' (translation suggested by Lubotsky 2004, 235). Although this identification is obvious, two details are to be explained. According to Gusmani $(1958,902)$, the

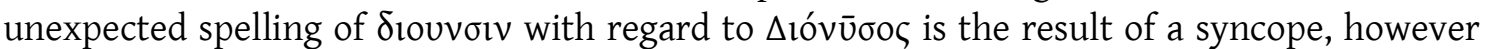
Lubotsky $(1989 b, 153)$ suggested a scribal error which corrupted the form * Jiovvolv. The second unexpected feature is its ending, where $-\imath v$ was engraved instead of the more predictable -ouv.

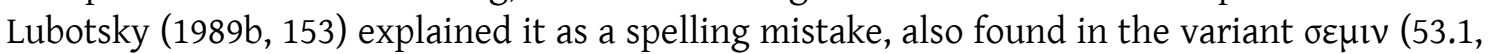
61.1) of the common pronoun $\sigma \varepsilon \mu o u v$ (pace Brixhe 1999, 308, who did not rule out a "théonyme autochtone").

Calder 1928, 217; Gusmani 1958, 902; Lubotsky 1989b, 147 and 153; Orel 1997a, 111 and 424; Brixhe 1999, 308; Brixhe $2002 b, 62$.

dis (?)

OPhr. dis G-11 b

Attested in an obscure inscription engraved on a trapezoidal block: sit kraroy veao yọy[.] dis. Brixhe (2002a, 37) equated it to Gr. dís, which goes back to PIE *duis 'twice, doubly' (Skt. dvis and Lat. bis). However, it does not fit with the Phrygian form, where a voiceless stop is

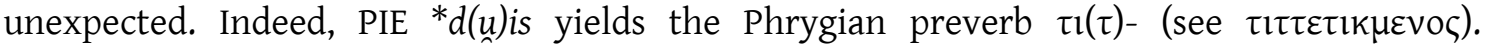
Consequently, dis remains unexplained.

Brixhe 2002a, 37.

\section{$\delta 10 \varsigma$ and $\delta 1 \omega \varsigma \delta \varepsilon \omega \varsigma$.}

$\delta \mu \omega \varsigma$ (noun?)

NPhr. $\delta \mu \omega \varsigma 40.3(31)$

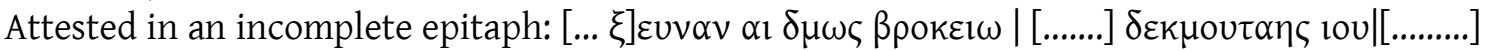

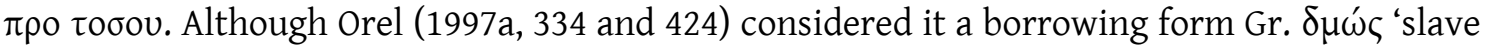
taken in war', the context is obscure and this possibility cannot be corroborated. Indeed, Gr. $\delta \mu \omega ́ \varsigma$ never occurs in Gr. inscriptions from Phrygia.

Neroznak 1978, 126; Orel 1997a, 334 and 424.

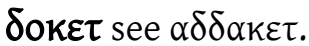




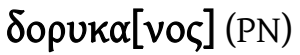

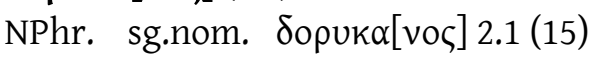

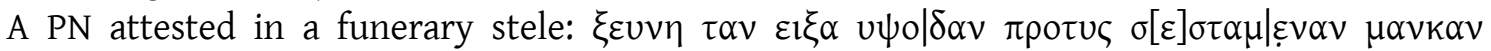
$\alpha \mu !|\alpha \sigma 1 \alpha v 101 \alpha v \alpha \rho \delta \circ \rho v \kappa \alpha|[v o \zeta---]$. It was restored by Haas in the light of other occurences of

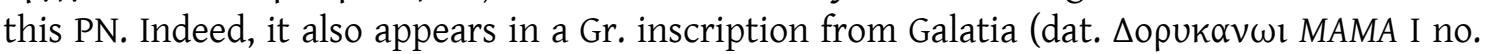
308 ) and one from Hierapolis (see KPN $152 \S 302-1$, also on a coin from the same city, RPC 2936,

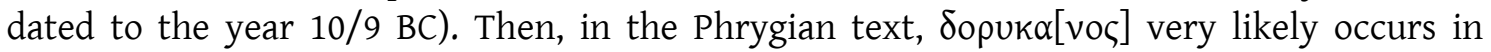
apposition to the noun $\alpha v \alpha \rho$ 'man, husband'. Because of the presence of $\delta o \rho v$ - it must be considered a Gr. PN.

Haas 1966, 106; Orel 1997a, 78 and 424; Avram fthc..

$\delta \mathrm{ov \delta} \alpha \varsigma(\mathrm{PN})$

NPhr. $\delta o u \delta \alpha \varsigma 37.2(30)$

A-stem Lallname well attested in Phrygian (KPN 156-154 § 306-1 - 306-11). It occurs in an

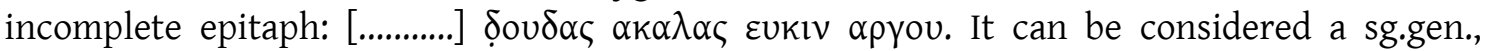
although a sg.nom. cannot be ruled out.

Orel 1997a, 329 and 425.

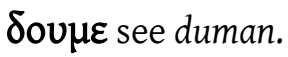

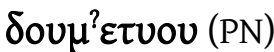

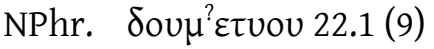

An o-stem PN borrowed from Lat. Domitius, attested in Gr. as $\Delta$ ouítı (in Phrygia it occurs in a

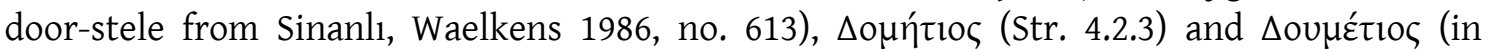
inscriptions from Epeiros and in Str. 14.1.42). This PN occurs in a bilingual epitaph, and in the

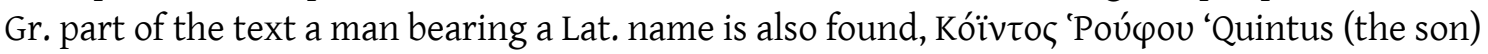
of Rufus'. However, the two texts do not contain the same information. In addition, it must be

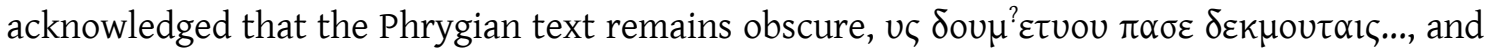

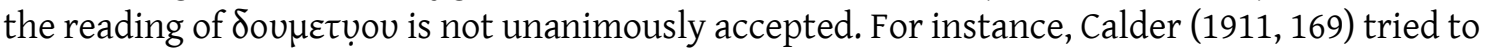

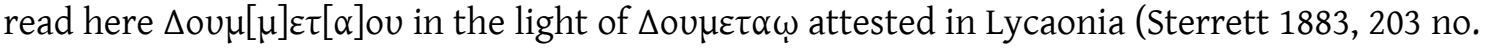

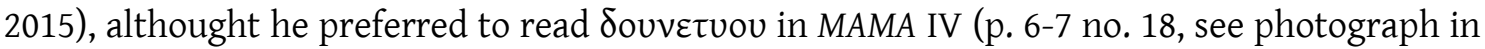
Pl. 14).

Calder 1911, 169.

duman (noun) '(religious) community, association'?

OPhr. sg.acc. duman B-01 1.3

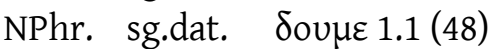

Both occurrences are found in cultic contexts: the OPhr. form in a niche engraved on a rock devoted to the Mother-Goddess, B-01 matar kubeleya ibey a duman ektetoy, and the NPhr. in an

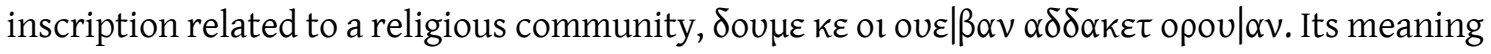
has been identified in the light of the Gr. word $\kappa \omega$ ' $\mu \eta$ 'unwalled village' read in in the Gr. part of

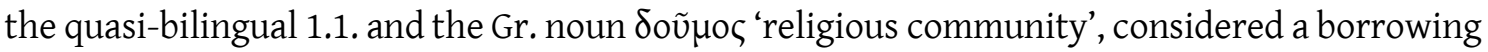
from Phr. This last word is found in Gr. inscriptions from North-East Lydia, Pisidia, one from Phrygia (Neumann 2002) and another from Thracia (IGBulg IV 1925,b), as well as in Gr. poems (e.g., Hipponax 40.2 and Philodemus AP 7.222). It also occurs in Lat. inscriptions as dumus (in Lancia, Hispania, see Aldea Celada 2013) and in the compound dumopireti 'the fire-kindlers of

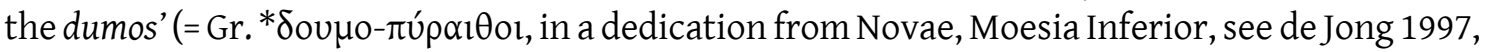

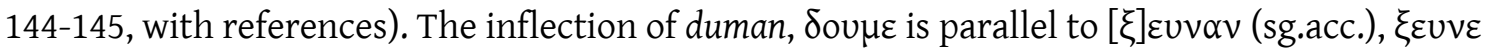
(sg.dat.). On its etymology, we can tentatively identify a relationship with Gr. $\theta \omega \mu$ ó $\varsigma$ 'heap' and 
Go. doms 'judgement', which seem to go back to a derivative from the the PIE root * $d^{\text {h }}$ eh ${ }^{-}$' $p u t$ ' (LIV 136-140, IEW 235-239).

Kretschmer 1900; Haas 1961, 80; Haas 1970, 28; Diakonoff \& Neroznak 1985, 104-105; Masson 1987b; Bayun \& Orel 1988a, 187; Bayun \& Orel 1988b, 148; Fauth 1989, 197-198; Lubotsky 1997, 124-125; Orel 1997a, 141 and 425; Neuman 2002; Lubotsky 2004, 233; Polito 2004; Polito 2005; Woodhouse 2006, 177-178; Woudhuizen 2008-2009, 183 § 42; EDG 350; Ligorio \& Lubotsky 2013, 189.

${ }^{\dagger}$ dumas see dumasta.

dumasta (title?) 'leader of a duman'?

OPhr. sg.nom. dumasta G-131; dumasta? G-245

A word only read in two sherds from Gordion: G-131 [-?-] dumasta eia[---] and G-245 dumasta? v.[-?-]. According to Bayun and Orel $(1988$ a, 198, followed Lubotsky 1997, 125) it is a religious title derived from the noun duman.

CIPPh I, 193; Bayun \& Orel 1988a, 198; Lubotsky 1997, 125; Orel 1997a, 183 and 425.

${ }^{\dagger}$ dumastaeia[---] see dumasta and eia[---].

${ }^{\dagger}$ dumasta? v.[-?-] see dumasta.

dumeyay (adj.)

NPhr. sg.dat.fem. dumeyay G-01a

It occurs in a very damaged text engraved on a slab: [---]ọ?lavi[---]isvolkay $\mid \vdots$ dumeyay : [---]deda[---]. Although the context is damaged, it is very likely an adj. derived from duman which agrees with [---]isvolkay. Orel (1997a, 157 and 425) considered it an epithet of the MotherGoddess. However, the text does not provide any information on this possibility.

Lejeune 1969b, 293; Bayun \& Orel 1988a, 198; Lubotsky 1997, 125; Orel 1997a, 157 and 425.

$\delta \nu \omega \varsigma$ see $\delta \varepsilon \omega \varsigma$.

dupratoy see pupratoy. 


\section{$\mathrm{E}(e)-\mathrm{E} \varepsilon$}

$\boldsymbol{e}$ (mark)

OPhr. e NW-125; $e^{?} \mathrm{NW}-113$

Two isolated letters incised on sherds. NW-113 can be also read as $v$ ?

Brixhe 2002a, 19-20; Brixhe \& Sivas 2009, 131-132.

ea.[---] (?)

OPhr. ea.[---] T-02c

Read on a fragment of a broken stele from Tyana: [---] $|\vdots e a .[---]|[---] . n a .$. Because it is preceded by a possible interpunction, it is a clear beginning of a word.

CIPPh I, 267.

$\varepsilon \alpha u \tau \alpha 1$ see venavtun.

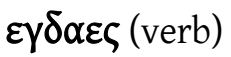

NPhr. $\varepsilon \gamma \delta \alpha \varepsilon \varsigma 11.2(18) 1.7$

Although $\varepsilon \gamma \delta \alpha \varepsilon \zeta$ looks like a verb in 3sg.ind.aor.act. like edaes, it occurs in an imprecative

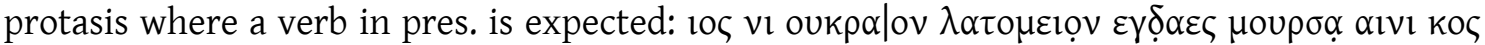

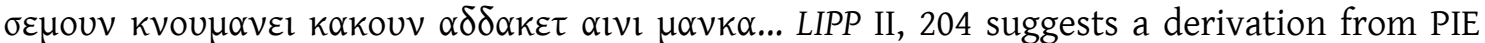
* $\left(h_{1}\right)$ ég ${ }^{h}$ - 'from, from within' (with the meaning 'hat ausgeführt'). In any case, this hapax remains unclear.

Ligorio \& Lubotksy 2013, 191; LIPP II, 204.

$\varepsilon \gamma \varepsilon \delta$ ou see egeseti.

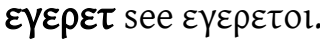

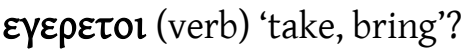

OPhr. 3sg.ind.aor.med. egertoy W-01c

NPhr. 3pl.ind.pres.act. $\quad \gamma \varepsilon \rho \varepsilon[\tau / v] 28.1(71)$

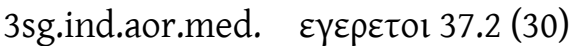

A verb attested in three different contexts: W-01c ataniyen kuryaneyon tan egertoy, $28.1 \tau 1 \zeta \mathrm{K \varepsilon}$

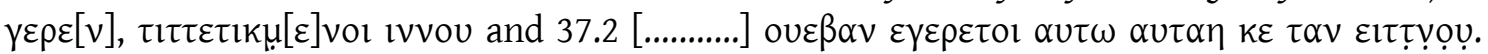
Because of the position of egertoy at the end of a sentence, and morphological traces such as a possible augment $e$ - and a middle ending -toy, it has been interpreted as a verb by Lubotsky $(1988,24)$. Since the inscription W-01c interpunction is used, the preceding sequence tan has been considered by some scholars to be part of the same word. Nevertheless, according to Lubotsky $(1988,24)$, the best segmentation is tan egertoy, in which where the first element is the fem. pronoun tan. Consequently, ataniyen kuryaneyon tan egertoy must mean something like 'Ataniyen, the commander, ...ed her (Matar)'. The form in 28.1, found in an imprecative protasis, is problematic because the last letter of the ending is lost and the analysis is ambigious. Ligorio and (Lubotsky 2013, 191) prefered the restoration $\gamma \varepsilon \rho \varepsilon[v]$, considering a 3pl., because the apodosis is clearly plural. However, the pronoun which introduces the protasis, $\tau 1 \varsigma$, seems to be in sg. So, one must assume that the problem stems from the pronoun or the congruence between protasis and apodosis. If $\gamma \varepsilon \rho \varepsilon[v]$ is preferred, $\tau 1 \zeta \kappa \varepsilon \gamma \varepsilon \rho \varepsilon[v], \tau \iota \tau \tau \varepsilon \tau 1 \kappa \mu[\varepsilon]$ vol $1 v v o v$ may be translated as 'they who $\gamma \varepsilon \rho \varepsilon[v]$, let them become accursed'. But, if $\gamma \varepsilon \rho \varepsilon[\tau]$ is preferred, $\tau 1 \zeta ~ \kappa \varepsilon$ $\gamma \varepsilon \rho \varepsilon[\tau]$, $\tau ו \tau \tau \varepsilon \tau ו k \mu[\varepsilon]$ vol $ı$ vvou may be translated as 'And whoever $\gamma \varepsilon \rho \varepsilon[\tau]$, let them become

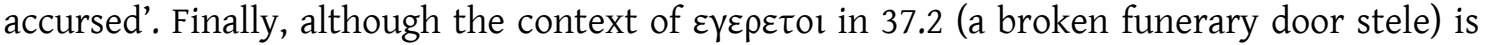

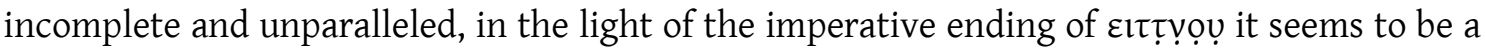


curse. On its segmentation, $\varepsilon ү \varepsilon \rho \varepsilon \tau o l$ has also been considered $\varepsilon \gamma \varepsilon \rho \varepsilon \tau$ ol, but this passive ending is attested in forms such as $\alpha \beta \beta \varepsilon \rho \varepsilon \tau o l$. If the whole sentence is considered a curse, the presence

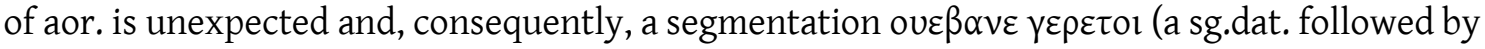
the verb in 3 pl.ind.pres.med.) cannot be ruled out. The origin of this verb remains unclear, since

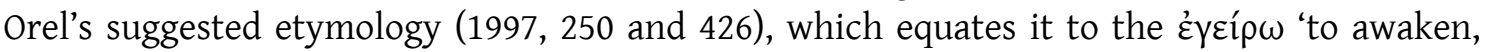
rouse, raise', is not possible because the voiced stop of the PIE verbal root * $h_{1}$ ger- 'awake' (LIV ${ }^{2}$ 245-246, IEW 390) would be expected to become voiceless in Phrygian. Also the suggestion made by Woodhouse $(2006,163)$, who considered that the initial $e$ - is a preverb instead of the augment, is impossible.

Lubotsky 1988, 24; Orel 1997a, 250, 296, 426; Woodhouse 2006, 163 n. 13; Ligorio \& Lubotsky 2013, 191.

egeseti (verb) 'hold, experience'

OPhr. 3sg.subj.pres.act.? egeseti P-04 a

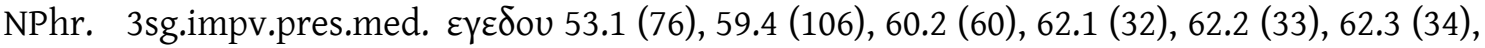

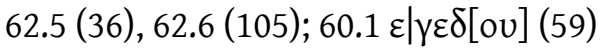

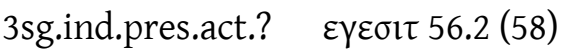

This verb is found three different contexts. The OPhr. form is the verb of an elusive imprecative protasis: P-04a ios ni akenan egeseti, o? 'kirterko[..]. tekmor ot.[....]seti vebru. The NPhr. forms are read in two different texts. The imperative $\varepsilon \gamma \varepsilon \delta$ ov (ending parallel to Gr. $-\sigma \theta \omega$ ) is the verb of an

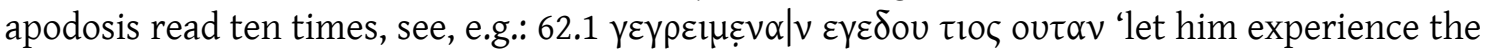

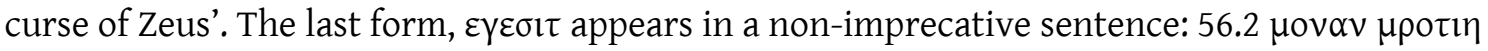
lov $\varepsilon \gamma \varepsilon \sigma i \tau ~ \gamma \varepsilon \gamma \rho ı \mu \varepsilon \vee v$. The interpretation of the ending of the forms egeseti and $\varepsilon \gamma \varepsilon \sigma ı \tau$ is not at all clear and the continuity of the intervocalic -s- is unexpected (is it a secondary restoration?). On its root, Ligorio and Lubotsky $(2013,185)$ suggest that it follows the inherited PIE * segh $^{h}$ 'to hold, to overpower' (LIV ${ }^{2}$ 515-516, IEW 888-889, Gr. Ě $\chi \omega$ 'have, hold', Skt. sáhate 'overwhelm, defeat'). Previous interpretations such as that of Orel $(1997,426)$, who considered it an inherited verb from the PIE root *h $h_{2}$ eg- 'drive' (LIV 255-256, Gr. ó $\gamma \omega$ 'lead', Lat. ago 'drive' and Skt. ájati 'drive, propel, cast'), must be rejected because a voiced stop is not expected in Phrygian and the meaning does not fit.

Brixhe 1982, 245; Lubotsky 1988, 12-13 and 21; Brixhe 1990, 91; Orel 1997a, 426; Sowa 2007a, 84-85; Ligorio \& Lubotsky 2013, 185.

$\varepsilon \gamma \varepsilon \sigma \iota \tau$ see egeseti.

Eyouvvou (noun) 'offspring'

OPhr. sg.dat. Eүouvvou 2.2 (130)

As Avram $(2015,211)$ identified, this is a clear borrowing from Gr. हैy $\gamma$ ovov > Eyouvvou

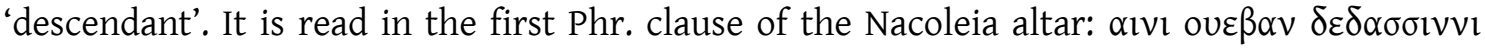

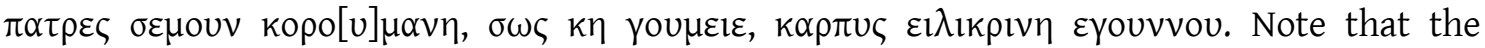

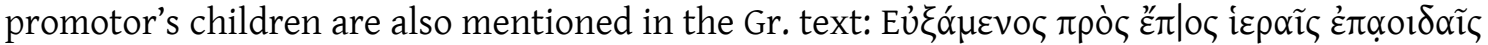

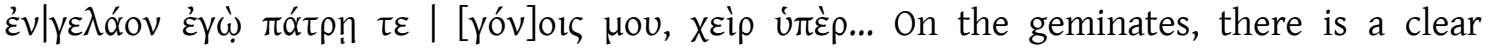
hypercorrection after their simplification in Gr. and Phr. by the Imperial age.

Avram 2015, 211.

edae and edaes see $\alpha \delta \delta \alpha \kappa \varepsilon \tau$.

edaie (verb?)

OPhr. edaie HP-02

Read on a damaged stone slab found in Kocagür (14 km far from the ancient Parion): [-?-] | tanari[---]| [---]liake | edaie [-?-]. According to the first editors, it seems to be a 3sg. of a preterite verb with augment. As a working hypothesis, they also equated it to $\delta \alpha i ́ \omega$ 'light up, kindle'. 
However, since this verb goes back to PIE * deh 2 u- 'kindle, burn' (LIV $104-105$, IEW 179-181), this possibility must be ruled out. Indeed, if it is an inherited word, the voiced dental stands for PIE $* d^{h}$ (see $\left.\alpha \delta \delta \alpha \kappa \varepsilon \tau\right)$. Unfortunately, no alternative identification can be given. It is perhaps related to edaviy. The unusual ending is also attested in etlnaie (P-04), and this parallel suggests that, despite the place where it was found (Mysia on Hellespont), the text is indeed Phr. (the alphabet is clearly Phr.).

Brixhe \& Keleş 2011, 158.

edạviy (verb?)

OPhr. edaviy B-04

An unparalleled word attested in the precariously read block from Üyücek (often considered Mysian before Brixhe 2004a, 21): $m^{?} ? p^{?} t_{0} v^{?} a \uparrow i y \cdot a^{?} e^{?}$ lavoy $\cdot$ ue | edaviy $p^{?} i s^{?} \cdot$ anernevey | $y^{?}$ a.oe ap.earvi? $s^{?} \cdot$ ? bato? ante... According to Brixhe (2004a, 21), it could be a noun in dat. or a verb. However, the latter option must be preferred, since the dat. athem. ending is expected to be written as -ey (see materey). Its root is possibly also attested in edaie. Nevertheless, its meaning and morphological details remain unclear.

Brixhe 2004a, 21.

edạtoy see $\alpha \delta \delta \alpha \kappa \varepsilon \tau$.

eia[---] see eies.

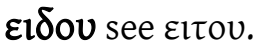

${ }^{\dagger} \varepsilon 1 \varepsilon$ see $\gamma$

eies (PN)

OPhr. ? eia[---] G-131

sg.nom. eies $\mathrm{G}-108$

Although G-131 is broken, both graffiti read on sherds seem to be PNs related to Eiaৎ (masc.) / E $1 \alpha$ (fem.) or I $\alpha \varsigma$ (masc.) I $\alpha$ (fem.), attested in Bithynia, Pontos, Phrygia and Pisidia (KPN 157 §

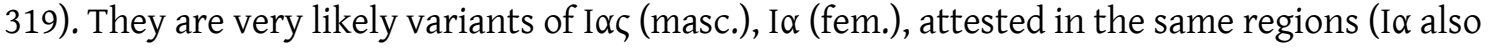
in Cylicia, see KPN 188-189 § 447). In G-108 eia[---] follows the word dumasta.

CIPPh I, 102 and 120-121.

$\varepsilon \imath \lambda \iota k \rho \imath v \eta$ (adj.) 'pure'

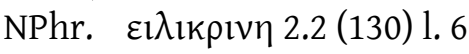

Although Avram $(2015,14-15)$ does not rule the possibility that we are dealing with a

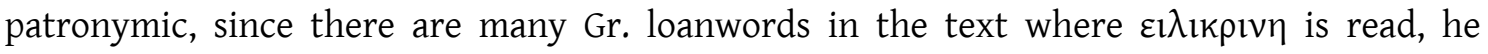

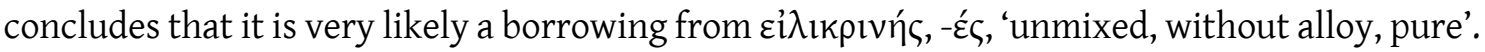

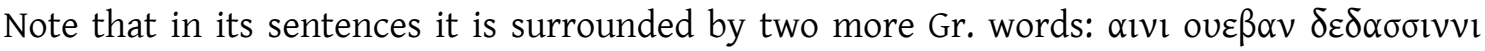

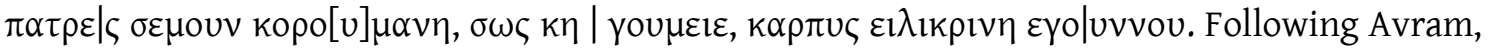

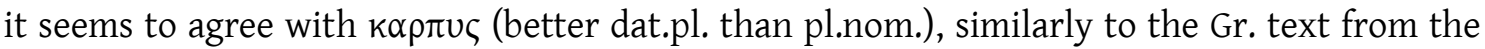

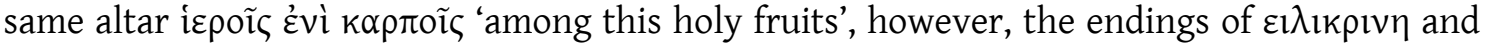
картuৎ are not clear.

Avram 2015, 14-15. 


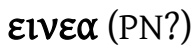

NPhr. sg.nom.? Elved 43.1 (69) 1.1

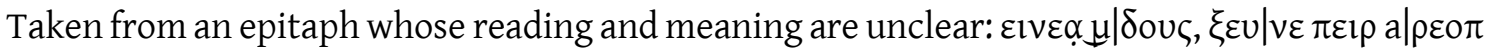

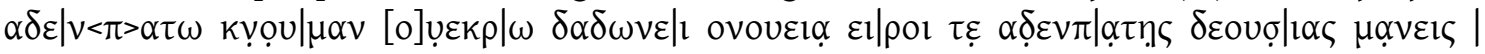

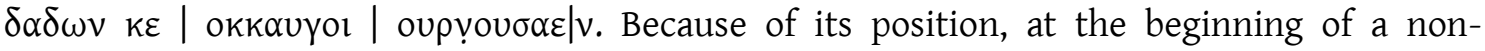
imprecative text of a funerary stele, it is very likely a PN in sg.nom. attested in Gr. as Ivveac (from Pisidia-Lycia, KPN $200 \S 471-6$ ). Recently, Hämmig suggested a reading $\Sigma^{?} \mathrm{INEM}^{?} \mathrm{~A}^{?} \mid \triangle \mathrm{OT}^{?} \mathrm{E}^{\text {E }}$, but because of the lack of parallels and interpretations the old reading is still defensible. Hämmig fthc. a.

$\varepsilon 1 \xi \alpha$ (noun?)

NPhr. sg.acc.? $\quad \varepsilon 1 \xi \alpha 2.1$ (15)

Hapax read in a sequence of nouns and adjectives in acc. describing the monument, where it follows the pronoun $\tau \alpha v$ and precede the adverb $v \psi \circ \delta \alpha v$ : $\Xi \varepsilon v v \eta \tau \alpha v \varepsilon l \xi \alpha v \psi \circ \mid \delta \alpha v \pi \rho \circ v \varsigma$

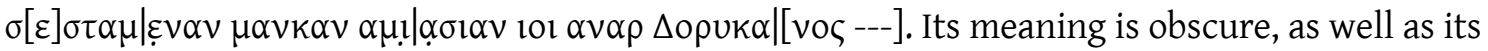
lexical category, but most likely is a noun in acusative (with the loss of the nasal).

Lubotsky 1993a, 131-132.

Elo丂 see loc.

Elpol (noun) 'hero'?

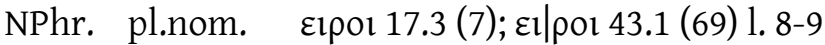

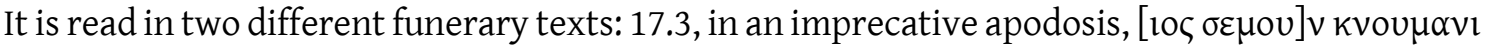

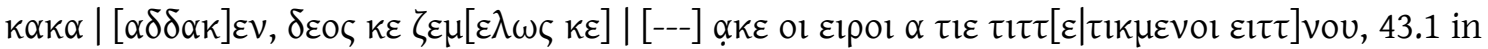

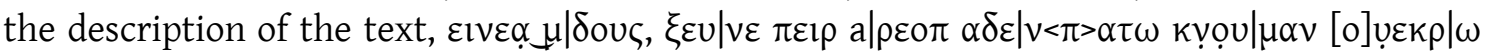

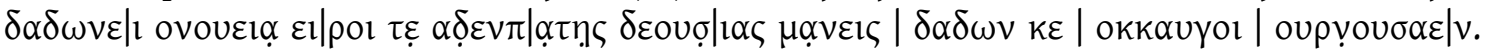
Although Orel (1997a, 71 and 429) classified it as a thematic sg.dat, in the light of 17.3, where it seems to be the subject of the sentence, it is better to consider it a pl.nom. (as Woodhouse 2007,

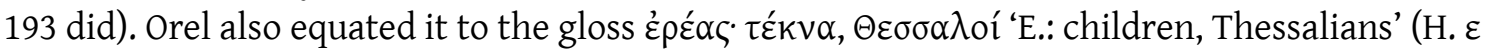
5681). Nevertheless, the gloss is not related to Phrygian. A feasible interpretation is to take it as a borrowing from Gr. ท̆ $\rho \omega \varsigma$, ñ $\rho$ o with the common funerary meaning of 'deceased'. Either way, it should be noted that the segmentation of 43.1 is unclear.

Bayun \& Orel 1988c, 161; Orel 1997a, 71 and 429; Brixhe 1999, 301; Woodhouse 2007, 193.

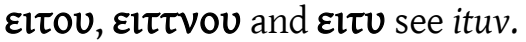

evẹemesmeneya (adj.) 'well-remembering'?

OPhr. sg.nom.fem. evẹmemesmeneya B-01 1.6

According to a suggestion by Lubotsky (1988, $15 \mathrm{n} .6$ and 1993b, 97), this word is an epithet of Matar meaning 'well-remembering', classified as a reduplicated sg.nom.fem. perfect participle

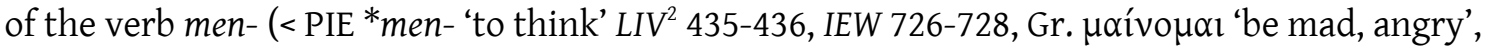
Skt. mányate 'to think, believe, imagine') with the prefix * $h_{1} s u->$ ev(e)- 'well' (LIPP II, 299-300, Gr. عu- 'id.', Skt. va- 'id.'). So the word can be separated as follows: prefix eve-+ reduplication -me-+ verbal root -mes- + middle-passive participle suffix -men- $\left(<\right.$ PIE $\left.{ }^{*}-m h_{1} n o^{-}\right)+$fem. suffix -eya. Although this is a very attractive interpretation, there are some problematic details, such as the unexpected presence of an -s after the verbal root, the presence of the vowel $e$ after $\mathrm{ev}$ (note that the reading of the letters is not clear according to CIPPh I, 64-65) or the suffix -eya instead of $-a$. Nevertheless, Lubotsky's approach is preferable to Orel's suggestion (1997, 144, 430 and 444): a segmentation evememes meneya, where the first word is considered a verb meaning 'speak favourably, declare' and the second word, also considered a Matar epithet, is 


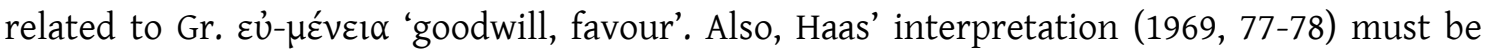
rejected: according to him it is an anthroponymic sequence, 'Minnis (the daughter) of Minneos'. Either way, the context remains obscure, although it seems to be an imprecative part of the inscription: ... opito [k]ey oy evememesmeneya anato (.?) | kavarmoyun matar otekonov (.?)| kesiti...

Haas 1969, 77-78; CIPPh I, 64-65; Lubotsky 1988, 15 n.6; Lubotsky 1993b, 97; Orel 1997a, 144, 430 and 444; Lubotsky 1997, 121; Berndt-Ersöz 2006, 85; LIPP II, 299-300.

\section{event (verb?)}

OPhr. event B-06

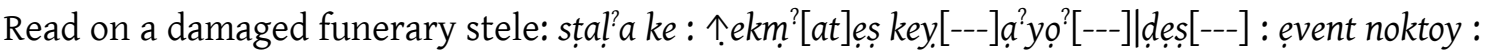
emetetariyois | [---]y ... According to Brixhe (2004a, 71-72), it could be a verb in 3pl. where the dental is preserved (in contrast to forms such as vitaran). Ligorio and Lubotsky $(2013,186)$ offer the segmentation eventnoktoy, although the NPhr. vouktov is clearly segmented in another text. In any case, the root of such a verb and its meaning remain unclear.

Brixhe 2004a, 71-72; Ligorio \& Lubotsky 2013, 186.

${ }^{\dagger}$ evventnoktoy see ẹvent and noktoy.

eveteksetẹ? (adj.?)

OPhr. sg.dat. eveteksete $e^{?} \mathrm{~W}-01 \mathrm{~b}$

The reading of the ending is not at all clear, only the higher horizontal stroke was engraved in the last (e), so Hämmig (fthc. a) has recently argued that it is indeed a mistake and it in fact stands for <i> (following the common readings published before CIPPh and Lubotsky 1988): eveteksetiy. She also considered it a verb. However, the sentence in which it is read is a protasis and da Yet is a more suitable verb: yos esai=t materey eveteksete? $y$ ovevin onoman da Yet, lakedo key venavtun avtay materey. Indeed, as it follows the DN materey in sg.dat., eveteksete? $y$ has traditionally been considered an epithet of the Goddess which agrees with materey. So, according to this interpretation, for some unclear reason the missing strokes of the the argued $<e>$ were never engraved. Although it is not a satisfactory explanation, the reading <e fits better because of the resulting ending and the position of the word. On its meaning, Lubotsky (1988, 20 and 1993b, 97) identified the beginning as the PIE prefix * $h_{1}$ su- > ev(e)- (LIPP II, 299-300, Gr. $\varepsilon v^{-}$, Skt. su-) but had nothing to add about this formation. Since its root is very likely tek-, perhaps this is a secondary $t$-stem noun built on the PIE verb *tek- 'to sire, beget' (LIV 618, Gr.

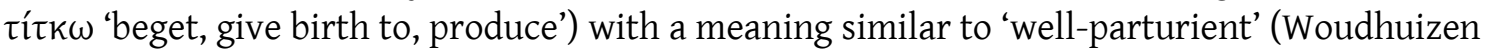
2008-2009, 185 suggested a similar interpretation before). This is only possible if we consider that the root taken is teks-, with a secondary s-aor. However, other roots (e.g.*dek'- 'to show, to point out', $L I V^{2}$ 108-109) cannot be ruled out. Consequently, the meaning remains unclear. Lubotsky 1988, 20; Bayun \& Orel 1988a, 182; Janda 1997, 273; Berndt-Ersöz 2006, 85; LIPP II, 300; Hämmig fthc. a.

\section{evkobeyan (adj.?)}

OPhr. sg.acc.fem. evkobeyan B-01 1.9

Despite the fact that Orel considered it an epithet of Matar meaning 'victorious', in the light of OIr. cob 'id.', neither the segmentation (although it is the most likely solution) nor the parallel are clear enough to defend such an interpretation: [k]ey oy evememesmeneya anato $\left(.^{?}\right)$ | kavarmoyun matar otekonov (.') | kesiti oyvos aey apaktneni | pakray evkobeyan epaktoy. The presence of the suffix *-eio- is shared with other fem. words such as kubeleya or imeneia.

Lubotsky 1993b, 97; Orel 1997aa, 430; Berndt-Ersöz 2006, 85-86. 
evradus (noun or adj.)

OPhr. sg.nom.? evradus B-05 1.7

An obscure word read in an elusive context: kelmis ke umnișet evradus dạkerạiṣ key iverais [..] | atikraiu. Perhaps a $u$-stem noun or adjective. Neumann $(1997,22)$ preferred the segmentation etevradus. However, Brixhe $(2004 a, 59)$ considered -et to be the ending of the preceding verb. Neumann 1997, 22; Brixhe 2004a, 59.

evtevey (?)

OPhr. evtevey B-03 (bis)

Read twice on astone block, the context is highly obscure, but there are very likely to be two imprecative protases (only the last word of the first protasis remains) and one apodosis: essk...a[---] a.. [...] | evtevey ay yosyos yenvra | eti=t evtevey me.oun laked?o | [-?-]. On its segmentation, Bayun and Orel (1988a, 190), Brixhe (2004a, 41) and Ligorio and Lubotsky $(2013,192)$ assume etitevtey for the second occurrence. However, eti and $=t$ are found independently. Because of its ending -ey, it can be considered a sg.dat. athematic noun or adjective, although a verb (perfect, according to Lubotsky 1988, 18 and Ligorio \& Lubotsky 2013, 192) cannot be ruled out and is expected if evtevey is the last word of the first protasis. In any case, its root remains unexplained. Its beginning perhaps is related to the prefix ${ }^{*} h_{1} s u->$ ev(e)- 'well' (Gr. $\varepsilon \dot{v}-$, Skt.

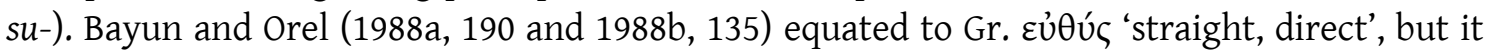
does not fit with the Phrygian development of the inherited voiced aspirate. On the other hand, Woudhuizen $(2008-2009,185)$ hypothesised a Myc. form *ew(e)-diwija 'good goddess' as the origin of the Phrygian form, however such a unattested formation is unjustified and does not fit the ending of evtevey.

Lubotsky 1988, 18; Bayun \& Orel 1988a, 190; Bayun \& Orel 1988b, 135; Lubotsky 1989a, 79 n.2; Brixhe 1996, 131; Brixhe 2004a, 41; Woudhuizen 2008-2009, 185; Ligorio \& Lubotsky 2013, 192.

†'evteveyay, see evtevey.

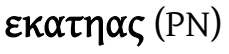

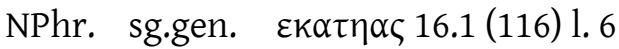

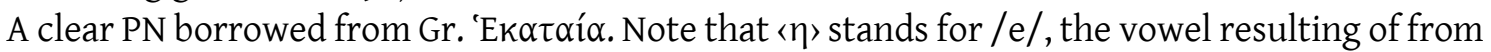
the monophthongation of /aj/ as in $k \alpha i ́$ i $>\varepsilon$. The sane result is also attested for this name in MAMA 6.16 'Ek $\alpha \tau \varepsilon \dot{\alpha}$ (= SEG 6.239, from Laodikeia, Phrygia). The Phrygian occurrence is in

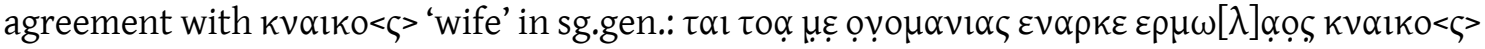
$\varepsilon \kappa \alpha \tau \eta \alpha \varsigma$ opọ $\sigma \alpha \sigma \alpha 1 \pi 0 \sigma \varepsilon \kappa \alpha v \varepsilon \varsigma . .$.

Brixhe \& Neumann 1985, 175; Orel 1997a, 427; Brixhe 1999, 301; Ligorio \& Lubotsky 2013, 183.

ekey (adverb?) 'there'?

OPhr. ekey B-01

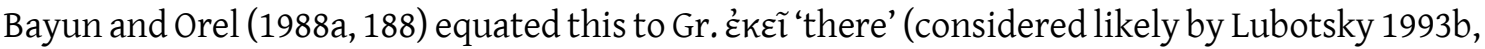
97). So, it seems to be inherited fromPIE $*\left(h_{1}\right) e-k e(i)$. Nevertheless, its context is still obscure: ayni kin te[l]emi [..] toyo[.]is [.] erktẹvoys ekey da[[k]ati. On the other hand, key could be take as the copulative conj., however, the residual $e$ - would remain unexplained.

Bayun \& Orel 1988a, 188; Lubotsky 1993b, 97.

ekọ.[---] (?)

OPhr. ekọ.[---] T-03c

A badly damaged fragment of a stele from Tyana. It is clearly the beginning of a word because of the presence of interpunction: : [---]uṣ.t[---][[---]nimoi : eko..[---].

Bayun \& Orel 1988a, 188; Lubotsky 1993, 97. 
e?lakes see lakedo.

ektetoy (verb) 'possess'?

OPhr. 3sg.ind.aor.med. ektetoy B-01 1.3

According to Ligorio and Lubotsky $(2013,191)$ it is a verb inherited from PIE *tkeh ${ }_{1}^{-}$'rule, gain,

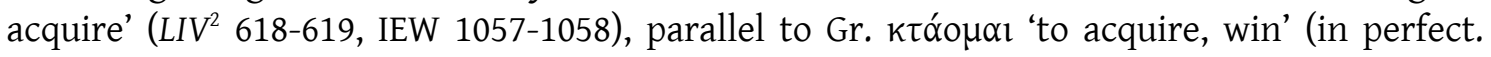
'possess'). Both the Gr. and Phr. forms show a metathesis in the root, pointing to the presence of ${ }^{*} h_{1}$ (on this point, see Beeke 2010, 789). In any case, the meaning of the sentence in whch it occurs remains unclear: matar kubeleya ibey a duman ektetoy '(The statue of the) Mother Kubeleya was adquired by the duman for themselves' (?).

Diakonoff \& Neroznak 1985, 31; Orel 1997a, 141-142 and 438-439; Lubotsky 1997, 125; Ligorio \& Lubotsky 2013, 191.

ẹmete see ẹmetẹtariyois.

ẹmetẹtariyois (noun?)

OPhr. ẹmetẹtariyois B-06

Read on a badly damaged funerary stele before the imprecative part of the epitaph in an

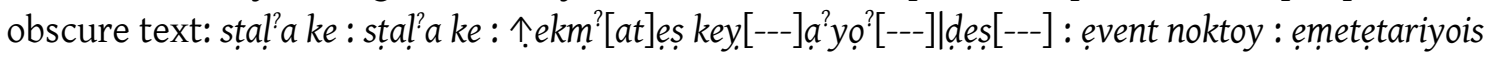
[---]y .... The ending -ois shows that it is a pl.acc. (as Brixhe 2004a, 72 suggested). Orel (1997a, 153) worked with the reading e $\uparrow$ ete tariyois and considered that the first word was a verb in 2 sg. person. However, such a verbal form is unattested in Phr. (it is only defensible as 3 sg.ind.aor.act. $-e<s>$ ) and even the ending of the supposed $e \uparrow e t e$ is unexpected (unless it is not a PN in sg.nom. but this does not seem to be the case).

Bakir \& Gusmani 1991; Vassileva 1995, 27-34; Brixhe 1996, 125-136; Orel 1997a, 153; Brixhe 2004a, 72.

em.[-?-] (PN?)

OPhr. em.[-?-] G-211

em? $[$ [-?-] or en?.[-?-] G-175

Graffiti on sherds, very likely the beginning of a PN. In G-211 the remaining strokes point to $a$ (as Orel 1997a, 218 and 427 preferred), or e. In G-175, the second letter is not clearly read and is followed by unclear strokes.

CIPPh I, 152-153 and 172; Orel 1997a, 203, 218 and 427.

$\boldsymbol{\varepsilon V}$ (preposition) 'in'

MPhr. Ev MPhr-01 (W-11) l. 1

NPhr. $\quad$ ev 16.1 (116) 1.12

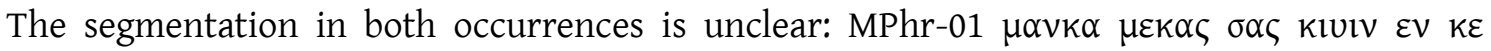

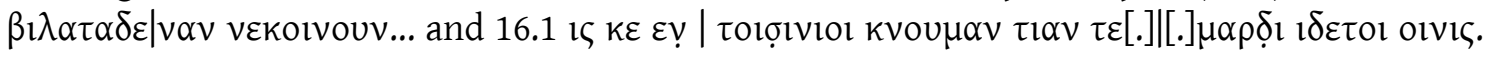
Also note that in MPhr-01 it is followed by an sg.acc. and in 16.1 by dat. or, perhaps, pl.acc. Indeed, its only certain occurrence is as a preverb in eneparkes. Regarding etymology, it seems to be inhereted from PIE * $h_{1}(e) n$ 'id.' (LIPP II, 221-222; parallel to Gr. غ̇v).

Brixhe \& Neumann 1985, 182; Brixhe 1990, 93-94; Brixhe 1997, 49; LIPP II, 222.

enạn see asenạn.

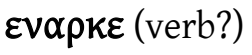

NPhr. 3sg.ind.aor.act. ع $\alpha \rho \kappa \varepsilon 16.1$ (116) 1.5

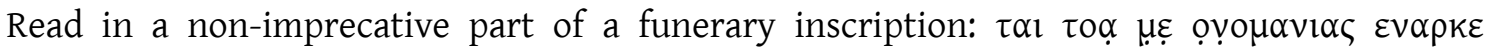
$\varepsilon \rho \mu \omega[\lambda] \alpha \varphi_{\varsigma} \kappa v \alpha 1 \kappa o<\varsigma>\varepsilon \kappa \alpha \tau \eta \alpha \varsigma . .$. According to Brixhe and Neumann $(1985,173-174)$ it is a verb in aor., where $\varepsilon$ - is the augment, - $v \alpha \rho \kappa$ - the root and $-\varepsilon$ the ending (instead of - $\varepsilon \zeta$; engraver's 
mistake?). They also considered the analysis $\varepsilon v-\alpha \rho k-\varepsilon$, however this is less probable because the augment is expected (see $\varepsilon v-\varepsilon-\pi \alpha \rho \kappa-\varepsilon \varsigma$ ). In any case, its meaning remains unclear. Orel's reading and interpretation $(1997,130)$, $\varepsilon v \alpha \rho \kappa \varepsilon$ as a variant of $\alpha \nu \alpha \rho$ 'man', must be rejected because there are no parallels for such a hesitation.

Brixhe \& Neumann 1985, 173-174.

eneparkes (verb) 'inscribe'

OPhr. 3sg.ind.aor.act. eneparkes G-125; eneparkes? M-01dI; [e]n[e]|p|arkes G-01c

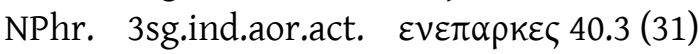

All occurrences are the same form of this verb: M-01d midas s=materan tvemes eneparkes?, $\mathrm{G}-01 \mathrm{C}$

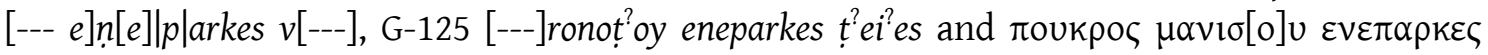

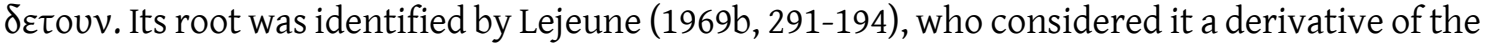
PIE *perḱ- 'engrave, rip' (LIV 275 , IEW 821, only surely attested in Lith. peřšti, peřséti 'to hurt sharply'). The vocalisation goes back to a long-grade *perrk- > $\pi \alpha \rho k-$. Finally, it bears a preverb and the augment, as happens in aor.

Lejeune 1969b, 291-294; Brixhe 1982, 236; CIPPh I, 116; Diakonoff \& Neroznak 1985, 128-129; Heubeck 1986, 78; Bayun \& Orel 1988a, 178; Lubotsky 1988, 17; Lubotsky 1989b, 152; Orel 1997a, 427; Lubotsky 1997, 123-124; Gorbachov 2005; Sowa 2005, 617; Sowa 2007a, 77-79; Sowa 2008, 100-101; Woudhuizen 2008-2009, 193; Ligorio \& Lubotsky 2013, 191; LIPP II, 222.

eniyệ[---] (?)

OPhr. eniye $[---] \mathrm{K}-01 \mathrm{IV} \mathrm{b}$

Read on a fragment of the severely damaged stele from Kerkenes dağ: ... | eniyẹ[---] | [---].pa (

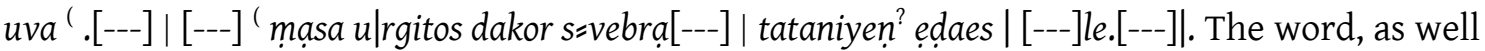
as its context, remains unclear.

Brixhe \& Summers 2006, 120-121; Draycott \& Summers 2008, 68-69.

enpsatus (noun?)

OPhr. sg.nom.? enpsatus B-05 1.5

Unparalleled word read in a obscure, non-imprecative sentence of the Vezirhan stele: vay niptiyạy dạker kạatu enpsatus mekạ[---]asiyạ... | nidus ad kaliyay karatu pana to andopopostois klạniv... Brixhe $(2004 \mathrm{a}, 58)$ suggested as a working hypothesis that it was an action noun with the suffix

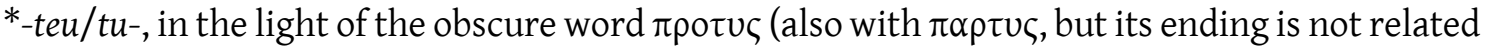
to this question).

Neumann 1997, 22; Brixhe 2004a, 58.

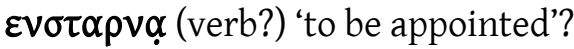

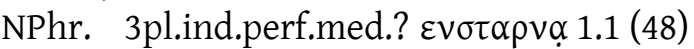

Lubotsky $(1997,123-124)$ considered this word a verb 3pl.ind.perf.med. inherited from the PIE

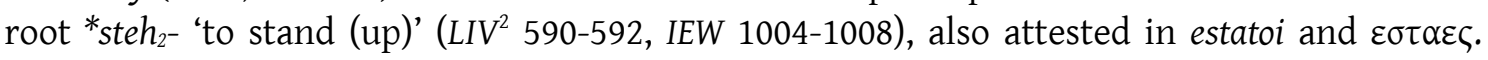
Moreover, he considered that the ending was a compound built with two different med. endings: ${ }_{-r} r-n t a i$. On $-n$ as $3 p l$, see $\delta \alpha k \alpha \rho \varepsilon v$ (similar to Lat. fecerunt). The meaning 'to be appointed' is given by Lubotsky on the basis of the contrast with the Gr. part of this text:

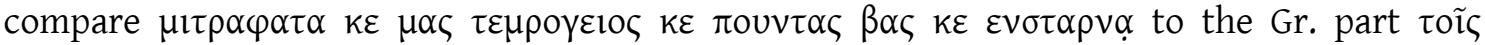
$\left.\pi \rho\right|_{\gamma \varepsilon \gamma \rho \alpha \mu \mu \varepsilon ́ v o l \varsigma} \theta \varepsilon \mid$ oĩ . This interpretation fits well with its context but the vocalisation of $*_{-r}$ - and the suffixal cluster *-r-ntai are unparalleled. Recently, LIPP (II, 238) has tentatively considered $\varepsilon v \sigma \tau \alpha \rho v \alpha$ to be derived from * $\left(h_{1}\right)$ enstr-na 'in the middle' with the meaning 'therein, there'. However, such a form, which only occurs in Anatolian (Hitt. ištarna), must be rejected because of the unexpected vocalisation of $r$ in $\alpha \rho$ instead of o(v) $\rho$. A segmentation $\varepsilon v \sigma \tau \alpha \rho v \alpha$ (prep. + noun) cannot be ruled out. In any case, this word remains unclear.

Lubotsky 1997, 123-124; Woodhouse 2007, 193; Sowa 2007, 77; Sowa 2008, 97. 


\section{enumalay [-?-] (PN)}

OPhr. enumalay,[-?-] G-321

Graffito read on a sherd. It is possibly a complete $a$-stem PN in sg.dat., although no parallel can be adduced. Brixhe (2002a, 76-789 showed the similarity of its beginning with the

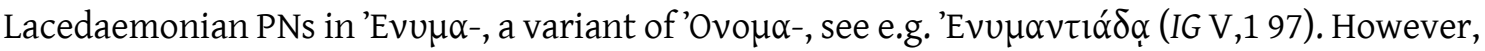
such names are never attested in Anatolia and this comparison is unlikely to be of any significance.

Brixhe 2002a, 76-78.

en.[---] see em.[---]?

epav'es (verb)

OPhr. 3sg.aor.ind.act. epaves (B-08)

Found in severely eroded inscriptions related to the cult of the Mother-Goddess: [---] kavarmoyo [---]|[---] epav' esniyoy [---]|[--- mata]r kubeley [a---]... Despite the lack of a space between epav?es and niyoy, the word boundary is confirmed through comparison with etovesniyo[y?] (B-01). Brixhe and Vottéro (2016, 136-137), who do not rule out the alternative reading epar'es, consider it a verb in aor. In any case, the context is too fragmentary to provide any information.

Vottéro 2016, 136-137.

epaktoy (verb?)

OPhr. 3sg.aor.ind.med.? epaktoy B-01

Read at the end of the Germanos inscription (in an imprecative apodosis): kavarmoyun matar otekonov (.?) | kesiti oyvos aey apaktneni | pakray evkobeyan epaktoy. It is very likely to be a verb because of the presence of the possible augment $e$ - and the middle ending -toy. The vocalism of the unidentified root (also attested in apaktneni?) is the result of a laryngeal or a strange long grade similar to eneparkes, although both may be the result of analogy.

Lubotsky 1988, 16; Orel 1997a, 146 and 428.

$\varepsilon \pi \rho 1[-?-](?)$

NPhr. $\varepsilon \pi \rho 1 \mid[-?-] 37.2(30)$

Unparalleled word read in a severly damaged part of a funerary text: [

.] \imath \varepsilon \pi \rho ! \mid[\ldots . . . . . . ..] \varepsilon \iota$

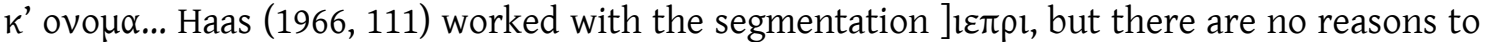
defend $\varepsilon \pi \rho 1 \mid[-?-]$ or ] $1 \varepsilon \pi \rho 1 \mid[-?-]$. It is even unknown whether the word boundary was at the end of the line or if the word continued on the following line.

Haas 1966, 111.

eptuve[---] (?)

OPhr. eptuve[---] T-03b

Read on a fragment of the 'black stele' from Tyana: [---]ọi : avtoi : eptuve[---] | [---]itan mẹ| [---]p? is: [---]. According to Brixhe (1991, 43-44 and 2004a, 102), it is a verb in 3sg.aor.ind.act., eptuve[s], where $e$ - is the augment. However, this theory is difficult to accept since in its root (etymologically unexplained) an $e$-grade is expected (see $e$-da-es $<*_{-} d^{h} e h_{1}-$ ). Then, the first proposal offered by Çınaroğlu and Varinlioğlu (1985, 10-11), 3pl.aor.ind.act. eptuve[n], could be a better fit (pace Brixhe), but the context is not clear enough to rule out a noun or a PN (see ataniyen). By contrast, Vassileva $(1992,3)$ and (Fol 1997, 262) considered it an epithet of the goddess Matar related to "I $\pi \tau \alpha$ / Eil $\tau \alpha \alpha$ (attested in Thracia and Lydia in the Roman Imerial Age). Nevertheless, there is no reason to believe that this stele is devoted or even related to Matar (the only possible DN read in the stelae from Tyana is batan). Finally, Orel (1997a, 315 and 428) suggested that we may be dealing with the preverb ep(i)-, which he equated to Gr. '̇ंí 'upon', 
even though it is not attested elsewhere. In conclusion, the sole certainty about this word is its beginning, indicated by the presence of the preceding interpunction.

Çınaroğlu \& Varinlioğlu 1985, 10-11; Heubeck 1986, 78; Varinlioğlu 1991, 30; Brixhe 1991, 43-44; Fol 1997, 262; Orel 1997a, 315 and 428; Brixhe 2004a, 102; Sowa 2007a, 79.

$\varepsilon \rho \alpha$ (adverb?) 'then'

NPhr. $\varepsilon \rho \alpha 62.5$ (36)

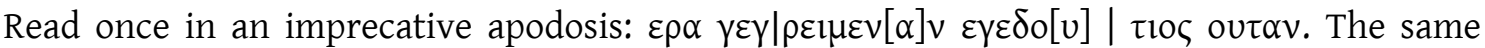

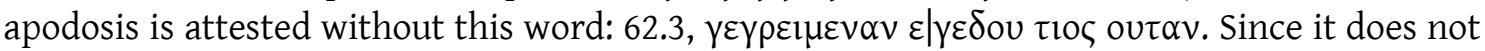
seem to agree with anything, but introduces the imprecation, Brixhe $(1997,62)$ considered it to be an adverb and equated it to Gr. óp 'then' (expressing consequence) and, in particular, to

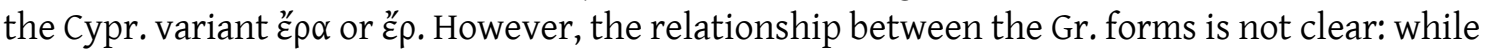
the first goes back to * $h_{2}(e) r$, the Cypr. form goes back to * $h_{1}(e) r$ (EDG 121, LIPP II, 289). So the Phrygian word, which also shows the addition of $-\alpha$, can only be related to the second of these forms. Despite the controvesyinner Gr. controversial between its forms, this meaning is very suitable for a word which introduces an apodosis ('if someone does..., then he will suffer...').

Brixhe 1997, 62; LIPP II, 289.

er? $v^{?}$ ot? $s^{?} a t i($ verb?)

OPhr. er $v^{?}{ }^{?} \mathrm{t}^{?} \mathrm{~s}^{?}$ ati P-04 b

Read on a stone block: ios er? $v^{?}$ ot ${ }^{?} s^{?}$ ati kakuioi. Although Lubotsky $(1988,13)$ equated it to verbal forms with -ti, is would be the only 3.sg. with -ati instead of -eti. However, it is followed by another verb kakuioi in an imprecative curse and it could be considered that ios er? $v^{\text {? }} \mathrm{t}^{?} \mathrm{~s}^{\text {? }}$ ati is the protasis and kakuioi the apodosis (kakoioi is attested only in the protasis of another curse, G02). In any case, its meaning remains unclear (contrary to Woudhuizen 2008-2009, 199), as does its root.

CIPPh I, 239; Lubotsky 1988, 13; Woudhuizen 2008-2009, 199.

ẹsagas (adj.?)

OPhr. sg.gen.fem.? [-?-] ẹsagas W-07

Read in a very damaged text related to a cult niche [---]t[---] : [---]ñ[---] ẹsagas $\vdots$ akenạs [---]. It seems to be a sg.gen.fem. adj. which agrees with the noun akenas. Nevertheless, it is unclear whether its beginning is preserved or not. On the other hand, Orel $(1997 \mathrm{a}, 46) \mathrm{read}$ [eda]es agas where agas is considered to be a PN in sg.nom. borrowed from Hitt. Agga, which is unlikely. CIPPh I, 51; Orel 1997a, 46.

esai and esait see $\sigma \varepsilon \mu o u v$.

eșk...a[---] (?)

OPhr. eșk...a[---] B-03

B-03 is a severely damaged text read on a stone block and no parallel can be adduced to supply it: eșk...a[---] a.. [...]. Although Orel $(1997 a, 149)$ suggested the reading [---]es kuria[---] and related the alleged second word to kuryaneyon, the remaining strokes are not clear enough to substantiate such a tentative proposal.

CIPPh I, 70-71; Orel 1997a, 149.

est[....]es (noun?)

OPhr. pl.acc.? est[.....]es B-07

Read in the non-imprecative part of a funerary stele: $s=$ manes iyungidas manitos apelev porniyoy esț[..] | [..] es va knais manuka odeketoy... Following Brixhe (2004a, 79-80), it is a fem. PN in sg.nom. which agrees with va knais: 'Est..., his wife'. Since manuka is better explained as a PN, it is 
preferable to consider est $t$ [..] | [..] es the object of its sentences and, consequently, an athematic noun in pl.acc. It very likely refers to the monument itself or the relatives. Nevertheless, a segmentation est [.....]es cannot be ruled out (see sest).

Brixhe 2004a, 79-80.

estaes (verb) 'put, erect'

OPhr. 3sg.ind.aor.act. estaeș M-11

3sg.ind.imp.act.? estat B-05 1. 4

3sg.ind.aor.med. estatoi G-144

NPhr. 3sg.ind.aor.act.? $\varepsilon \mid[.] \tau \alpha \varsigma 11.2(18) 1.5-6$ ?

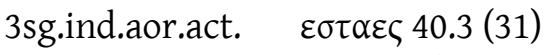

ppp.fem.sg.acc. $\sigma[\varepsilon] \sigma \tau \alpha \mu \mid \varepsilon v \alpha v 2.1$ (15)

Forms of a Phr. verb inherited from PIE *steh $2^{-}$'stand, erect' (LIV ${ }^{2}$ 590-592, IEW 1004-1008), attested in Gr. ï $\sigma \tau \eta \mu l$ 'make, stand', Latin sto 'stand, stay', skt. tissthati 'id.'. The most singular form is estat B-05 1. 4, with augment and a secondary ending -t, instead of -es attested for the aor.: B-05 panta vebrạ adun p?os key estat pator.?ike[...] [e...]andati... Because of this feature, it has been considered an imperfect by Brixhe (2004a, 57), but no other occurrence has been identified. The other forms (except $\sigma[\varepsilon] \sigma \tau \alpha \mu \mid \varepsilon v \alpha v$ ) are a common aor. However, $\mathrm{M}-11$ is difficult to read and the context is lost: M-11 [---] sestaes. Indeed, only 40.3 has a more extensive context, $\mu a v \kappa \alpha \nu \iota \alpha \nu \varepsilon \sigma \tau \alpha \varepsilon \varsigma \beta \rho \alpha \tau \varepsilon \rho \varepsilon \mid \mu \alpha \iota \mu \alpha \rho \eta \alpha \nu$, because G-144 is a short graffito: estatoi avun. The form $\varepsilon \mid[.] \tau \alpha \zeta$, is highly doubtful, since the reading and its affiliation with this verb are not clear. In its context, $\varepsilon \mid[.] \tau \alpha \zeta$ is the only word which can be considered a verb: ... $\mu \alpha \tau \alpha \rho \varepsilon v \gamma \varepsilon \xi \alpha \mid \rho v \alpha !$ ! K’ o

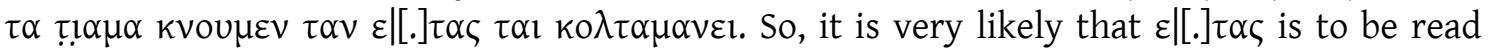
$\varepsilon \mid[\sigma] \tau \alpha<\varepsilon>\zeta$. Note that sigma and epsilon show a very similar quadratic shape, which could account for an engraver's mistake of this type, see the parallel case of $\kappa v \alpha i k 0<\zeta>$. Finally, $\sigma[\varepsilon] \sigma \tau \alpha \mu \varepsilon v \alpha v$ is read on a NPhr. funerary stele, in a sentence where the monument is described.

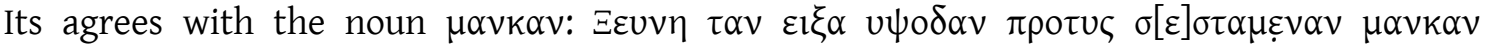
$\alpha \mu 1 \alpha \sigma l \alpha v$... Since it is clearly a ppp. in sg.acc.fem., its second letter has been supplied by comparison with other participle such as $\tau \varepsilon \tau \tau \imath k \mu \varepsilon v o \varsigma$ or $\gamma \varepsilon \gamma \alpha \rho \imath \tau \mu \varepsilon v o \varsigma$.

Lubotsky 1993a, 132; Lubotsky 1997, 123; Neumann 1997, 21; Brixhe \& Slvas 2003, 72; Brixhe 2004a, 52,57 and 82; Sowa 2007a, 77-78; Ligorio \& Lubotsky 2013, 185, 191 and 192.

\section{$\varepsilon\left[\sigma^{?}\right] \tau \alpha \varsigma$, estat and estatoi see estaes.}

${ }^{\dagger}$ estatoiavun see estaes and avun.

eti (conj.?) 'and'?

OPhr. eti B-03

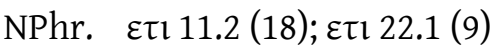

The OPhr. eti seems to be the same as NPhr. equ. Nevertheless, both segmentations and their context are not clear: B-03 evtevey ay yosyos yenvra | eti=t evtevey me.oun laked?o | [-?-] and $22.1 \mathrm{vc}$

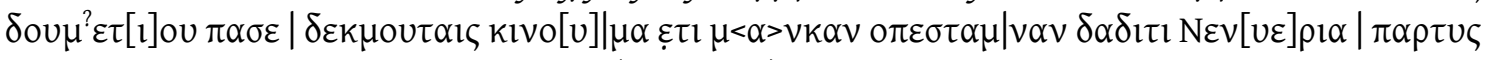
oußpa. In B-03, Ligorio and Lubotsky $(2013,192)$ preferred to read etitevtevey, but they only analysed its ending and evtevey appears without etit at the beginning of the line. If eti is considered an independent word, it can be equated to Gr. हैंน, Lat. et and Skt. áti and Go. ip and, then, inherited from PIE * $h_{1}$ eti (LIPP II, 260-261).

Orel 1997a, 150, 429; LIPP II, 261.

etit see $\varepsilon \tau \imath$.

${ }^{\dagger}$ etitevtevey see $\varepsilon \tau 1$ and tevte. 
etlnaie (verb?)

OPhr. etlnaie P-04 a

The ending of this word is only found in the also obscure edaie and both forms seem to have the augment ${ }^{*} h_{1} e^{-}$. According to Brixhe and Keleş $(2011,158)$, in the root etlnaie an apocope worked, although they do not identify the verb. Its context (non-imprecative) is still too elusive for any evidence of its meaning to be found: otuvoi vetei etlnaie.

Brixhe \& Keleş 2011, 158.

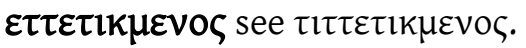

${ }^{\dagger}$ etovesniyo see $\tau 0 \tau 0 \sigma \sigma \varepsilon l \tau l$ and niyoy.

$\varepsilon \rho \mu \omega[\lambda] \alpha \operatorname{cọ}_{(\mathrm{PN})}$

NPhr. sg.nom. $\varepsilon \rho \mu \omega[\lambda] \mid \alpha \underline{\text { ọ }} 16.1$ (116) 1. 5-6

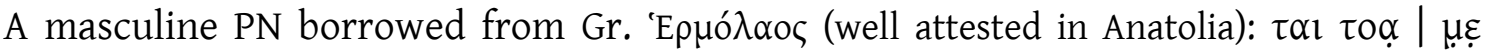

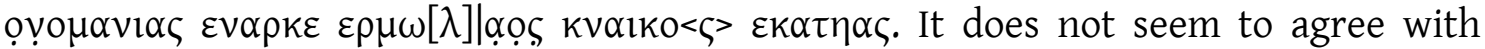
anything, since $\kappa v \alpha \imath k 0<\zeta>$ agrees in sg.gen. with $\varepsilon \kappa \alpha \tau \eta \alpha \zeta$.

Brixhe \& Neumann 1985, 174; Bayun \& Orel 1988c, 155; Orel 1997a, 130 and 428.

esuryoyoy (PN?)

OPhr. sg.dat.? esuryoyoy M-01f

Although it was considered a verb by Gusmani and Poetto $(1981,66)$, it is more likely a thematic PN in sg.dat because of its context. Compare M-01f [?]. as tuaveniy ae esuryoyoy totin edae [s] with ates arkiaevais akenanogavos midai lavagtaei vanaktei edaes.

Lejeune 1969a, 38 fn. 78; Gusmani \& Poetto 1981, 66; CIPPh I, 17; Diakonoff \& Neroznak 1985, 135; Lubotsky 1988, 19; Bayun \& Orel 1988a, 179; Orel 1997a, 22, and 429; Berndt-Ersöz 2006, 74.

$\varepsilon v \gamma \varepsilon \xi \alpha \rho v \alpha \mathbf{l}$ (?)

NPhr. sg.dat.? $\varepsilon \cup \gamma \varepsilon \xi \alpha \rho v \alpha 111.2$ (18) 1. 4-5

sg.acc.? Euүı $\sigma \alpha \rho v \alpha v 11.2(18) 1.10$ ?

An obscure word which appears twice in the same inscription. Their endings are not necessarily what they seem to be in the light of the common hesitations in the inflection of the a-stems. The contexts of both texts are very different. In 1. 4-5 it appears in a sentence which describes

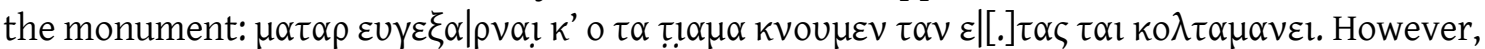

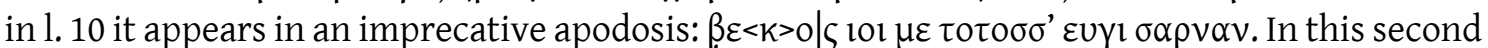

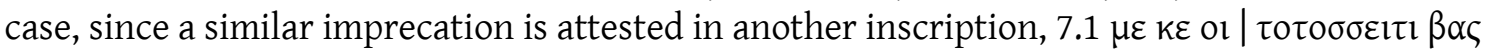

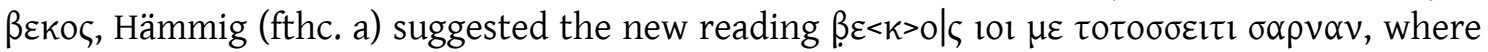
$\sigma \alpha \rho v \alpha v$ appears in the place expected for the god (see $\sigma \alpha \rho v \alpha v$ ). Consequently, the second occurrence of this word can be rejected. The first, meanwhile, is very uncertain, since - $\xi \alpha \rho \alpha \alpha$ is very similar to $\sigma \alpha \rho v \alpha v$, however the remaining $\varepsilon v \gamma \varepsilon-$ remains unclear. Commonly, it has been taken as a PN, although no parallel can be adduced. According to this interpretation, Orel (1997

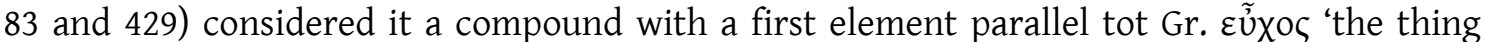
prayed for, object of prayer, prayer, vow' and عủn 'prayer or vow' (<PIE * $h_{1} e u g^{\text {uh }}$ - 'to promise,

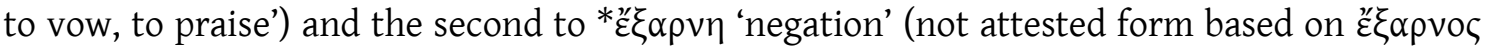
'denying'). However, this is a hypothetical interpretation.

Lubotsky 1988, 20; Orel 1997a, 83 and 429; Avram 2016b, 74-78.

$\varepsilon \cup \gamma 1 \sigma \alpha \rho v \alpha v$ see $\varepsilon \cup \gamma \varepsilon \xi \alpha \rho v \alpha l$ and $\sigma \alpha \rho v \alpha \nu$. 
EUKIV (noun) 'vow'

NPhr. sg.acc. EUkıv $1.2(98), 37.2(30)$

A loanword from Gr. عủxń 'vow', a very common word in the Gr. inscription devoted to deceased from Anatolia (see de Hoz 2017). The Phrygian word shows the simplification of the Gr. voiceless aspirated stop into aplain voiceless stop in Phrygia and the Gr. itacism. In both occurrences, it

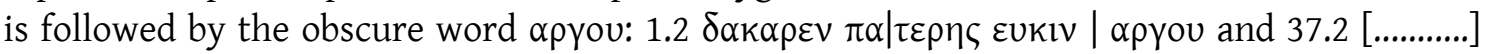

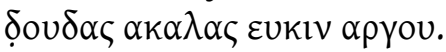

Haas 1966, 111; Brixhe 1983, 129; Orel 1997a, 329, 360 and 429; Brixhe 1999, 298; Lubotsky 2004, 231; Ligorio \& Lubotsky 2013,189 .

ey.[---] (PN?)

OPhr. ey.[---] G-230

Incomplete graffito incised on a fragment of a pithos. Despite its bad preservation, since the third dubious letter consists of a vertical stroke, it seems related somehow to the also incomplete graffito eyiy[---] (G-314). Very likely the beginning of an unidentified PN.

CIPPh I, 184; Orel 1997a, 227.

eyiy[---] (PN?)

OPhr. eyiy[---] G-314

It could be a complete word (note the glide -iy in ayniy), but the inscription is broken and its meaning unknown. It is very likely to be a PN, perhaps related to eies (G-109).

Brixhe 2002a, 72.

eymi (?)

OPhr. eymi G-178

It has been commonly interpreted as the copulative verb in 1sg.ind.act. 'I am' parallel to Att.

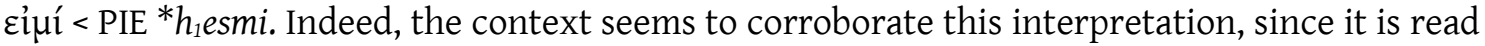
on a "petite idole, grossièrement anthropomorphe" (CIPPh I, 154) whose complete inscription, eymiva? $k$ ? ? [---], is considered to mean 'I am Bacchus'. The supposed DN cannot correspond to Bacchus, although 〈ey> is sontimes used to note /e/ in the copulative conj. ke, key $<{ }^{*} k^{w} e$. An etymological alternative is to consider eymi a form of ituv 'let become', inherited from PIE * $h_{1}$ ei'to go' (LIV 232-233, IEW 293-296), Gr. عĩul 'id.', Lat. eo 'id.', skt. eti 'id.'. In any case, the whole text remains obscure and even the segmentation is unclear. Note that even the segmentation can be reconsidered in the light of B-05, where the ending -iv is attested (tebetiv and dereliv). CIPPh I, 154; Bayun \& Orel 1992-193, 10; Orel 1997a, 398; Sowa 2007, 73; Sowa 2008, 93; Blažek 2005, 21.

†eymivakị[---] see eymi and vaki.

$e^{\Psi}+t a[---](\mathrm{PN})$

OPhr. $\quad$ Ut ta[---] G-112

Fragmented graffito incised on contigous sherds. The letter 4 only occurs in this inscription and has been considered a variant of $\Psi$. Orel (1997a, 172 and 428) read it as epta- and considered this word a DN parallel to Hitt. Hé-pit, the Lyd. Mother-Goddess "I $\pi \tau \alpha$ / Eĭ $\tau \tau \alpha$ (read in the Gr. inscriptions from Lydia) and Thracian compounds in ept-. However, this comparison is ungrounded and the form ept-is never found in Phrygia. It is more likely to be a PN, as many of the graffiti from Gordion are, perhaps a variant of iktes G-02a or iketaios W-02 (and the

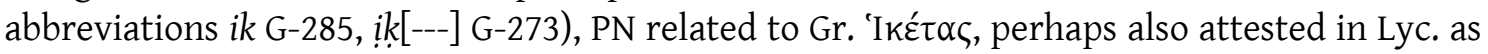

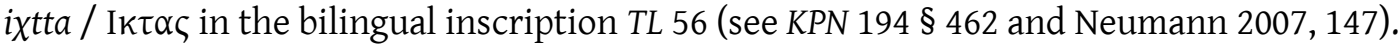
CIPPh I, 105; Orel 1997a, 172 and 428. 


\section{e.gi.va $(\mathrm{PN})$}

OPhr. e.gi.va G-331

Complete graffito incised on a sherd. The relationship with olgiavos (G-150) is not ruled out by Brixhe (Brixhe 2002a, 86) despite the hesitation between $e$ - and o-.

Brixhe 2002a, 86.

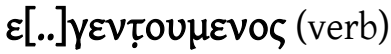

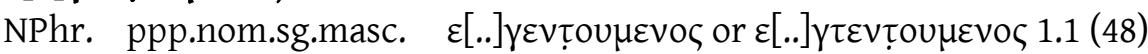

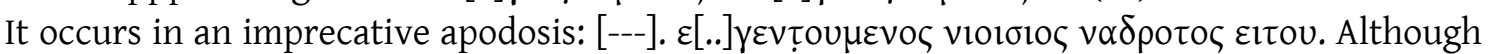
its beginning is lost and the second readable letter is dubious, it seems to be a ppp. because of the presence of the suffix -meno- < PIE ${ }^{*}{ }_{-} h_{1} n o^{-}$. However, the expected reduplications is lacking.

Orel 1997a, 98-99; Lubotsky 1997, 121.

e.[---] (?)

OPhr. e.[---] T-02b

Beginning of a unidentified word which occurs on a fragment of stele from Tyiana: [---]oitumen $\vdots$ mida[---]|[---]n $\vdots a \uparrow$ ios $\vdots$ mi[---]|[---]n $\vdots$ batan $\vdots$ e.[---].

CIPPh I, 266. 


\section{$F(v)$}

$v$ (mark)

OPhr. $\quad v$ G-257, NW-110; $v^{?} \mathrm{NW}-113$

Graffiti incised on sherds. They seem to be used as an owner's mark, and can be considered either the abbreviation of a PN or mere non-verbal marks. NW-113 can be also read as $e^{\text {? }}$.

CIPPh I, 141; Roller 1987a, 37; Brixhe 2002a, 18 and 19.

$v a$ (poss. pron.) 'her'

OPhr. sg.nom.fem. va B-07 sg.dat.fem. vay B-05 1.5

NPhr. sg.acc.fem. oav $16.1(116) 1.12$ sg.nom.fem. ov 4.1 (2), 62.2 (33); ov| 662.5 (36)

sg.acc.fem. ovav $60.1(59)$

Inherited poss. pron. derived from from PIE *su-eh $($ LIPP II, 751-752) and parallel to Gr. ö 'his, her, its'. This poss. is mostly found after the noun it agrees with: B-05 pator. ike[...] e[..] ]andati

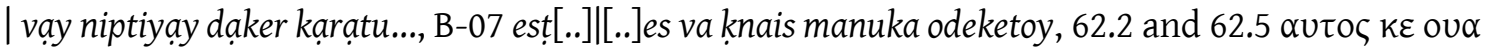

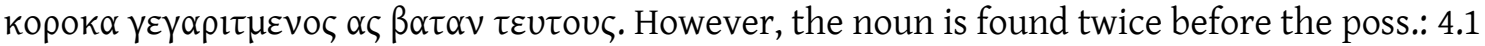

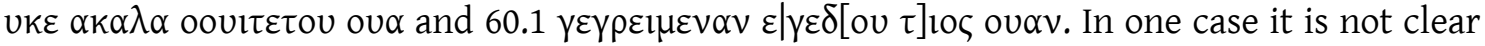

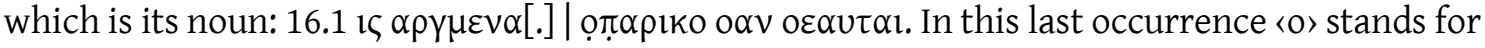
/w/.

Brixhe 2004a, 57-58; Ligorio \& Lubotsky 2013, 185 and 192; LIPP II, 751.

vaki[---] (?)

OPhr. vaki[---] G-178

Because this word was engraved on a small idol after the word eymi, it was considered by Bayun and Orel (1998a, 196, followed by Orel 1997a, 205) to be the Lyd. DN baki (well-known in Gr. as

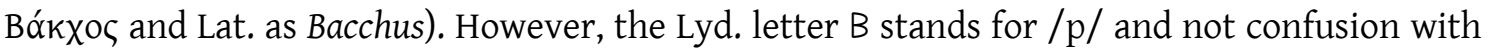
$\langle\mathrm{v}\rangle / \mathrm{w} /$ or $\langle\mathrm{f}\rangle / \mathrm{f} /$ is attested in this language. Consequently, such an interpretation must be ruled out. Even this segmentation is not at all clear: in the light of tubetiv this text can be read as eymiv aki[---], although the ending in -iv is only clearly found in Bithynia.

CIPPh I, 154; Bayun \& Orel, 1998a, 196; Orel 1997a, 205 and 466.

vana (PN)

OPhr. sg.nom.? vana B-102

Complete graffito incised on a sherd, very likely a PN. Brixhe (2004a, 86-87) suggested the possibility of a sg.nom. without an ending - s. On its root, Brixhe $(1996,138)$ considered two

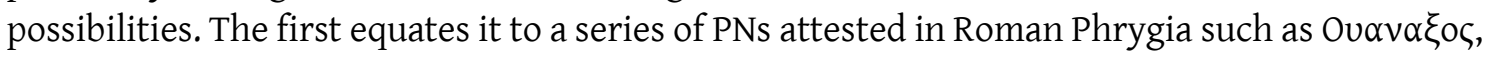

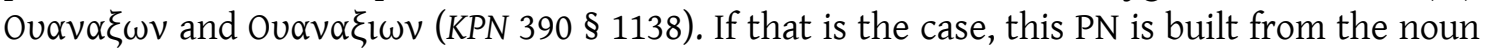
* uanak $(t)$-, attested in Phrygian as vanaktei (very likely a Gr. borrowing). The second possibility is an Anatolian PN in the light of Wana, Wanni (LNH $204 \S 1488$ and 1489), derivatives from the noun wanni 'stone', also considered the origin of the Isaurian and Lykaonian PN Ovav $\alpha \lambda_{1 \varsigma}$ (KPN 389 § 1137-1). Following this latter interpretation, vana can be considered a complete PN (the same Wana) or an abbreviation (e.g. Ovav $\alpha \lambda_{1} \varsigma$ ). As Brixhe also considers, in such a scenario where several languages coexist, the same PN can be interpreted in different ways by each bearer.

Bakır \& Gusmani 1993, 136-137; Brixhe 1996, 138; Orel 1997a, 153-154, 466; Brixhe 2004a, 86-87. 
vanaktei (noun) 'king, lord'

OPhr. sg.dat. vanaktei $\mathrm{M}-01 \mathrm{a}$

NPhr. sg.acc. ov $\alpha v \alpha \kappa \tau \alpha v 6.1$ (88)

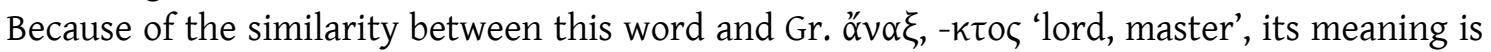
clear. However, its origin is disputed: while Brixhe (e.g. 1994, 176-177) considered the Gr. and Phrygian words to have a common heritage, Cassola (1997, 145-146) and, more recently, Petrakis $(2016,104-105$, who argued a Mynoan origin for this word) prefer to interpret it as a Gr. loanword. Indeed, since other royal titles, lavagtaei and kuryaneyon, are considered borrowings, the Phrygian vanakt- is very likely also one. On its inflection, it is a clear athematic noun. Its sg.nom. is attested in the compound modrovanak 'the lord of Modra/-oi' (M-04), where, *-ks became - $k$ (see also bonok) and, as in the Gr. nom., the dental dropped. In M-01a it is the title of the king Midas, ates arkiaevais akenanogavos midai lavagtaei vanaktei edaes, but in 6.1 it is

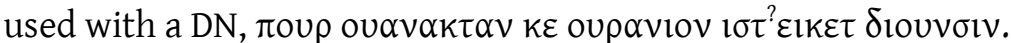

Brixhe 1990, 73-75; Brixhe 1993, 340-341; Brixhe 1994, 176-177; Orel 1997a, 11 and 466; Brixhe 2002b, 257; Sowa 2008, 40 fn. 2; EDG 98-99, Petrakis 2016, 104-105.

vasos and vasuos see vasus.

vasus (PN)

OPhr. sg.gen. vaslos P-02

sg.nom. vasous $\mathrm{P}-03$

sg.nom. vasus $\mathrm{P}-05$

A PN only found on stone blocks from Pteria which very likely refers to the same man (also qualified as kanutieivais): P-02 sest bugnos va|sos kanutii?evanoș?, P-03 vasous iman mekas | kanutieivaị | devọs ke mekas and P-05 vasus kanutiẹ[---]. The inflection very likely follows a ustem, in the light of the form vasus. Its sg.gen. lost its -u- before the vowel o, *uasu-os > vasos (parallel to *diu-os $>\tau 105$ ). The form vasous shows a hesitation between /o/ /u/ (perhaps a corrected mistake during the engraving of the text). The origin of this PN, according to Orel (1997a, 292 and 466), is the PA word *wassu- (sic) 'well' (*wósu-, according to Melchert 1994, 260), attested in Palaic and CLuw. uāšu- 'id.' and HLuw. wasu), as well as other PN from Roman

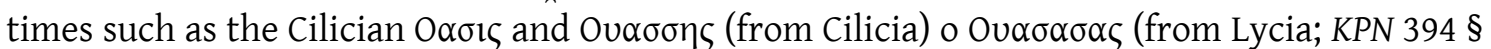
1145-1 - 1145-7). Very likely, OPhr. Vasus is the hypocoristic of a Luwian PN such as Wasurunti(ya)- (MALATYA 1) or Wasusarma- (TOPADA § 2, LNH 207 § 1514).

Brixhe 1983, 117; CIPPh I, 231; Brixhe 1990, 70-71; Lubotsky 1993b, 96 n.2; Orel 1997a, 466; Ligorio \& Lubotsky 2013, 186.

v?ata[-?-] (PN or adj.?)

OPhr. v'ata[-?-] or g?ata[-?-] G-236

Graffito incised on a late sherd. Because it is preceded by the PN nana, CIPPh (I, 187) suggested that this word is an adj. which agrees with the PN (similar to Gr. Г $\lambda \cup \kappa \dot{\omega} \kappa \alpha \lambda \eta$ ) or a compound PN nana v'ata[-?-] or nana g?ata[-?-] (Orel 1997a, 229 and 447). However, no parallel can be adduced for any interpretation and it is impossible to know whether the text is complete. Even the first letter is not clear, although $\langle\mathrm{v}\rangle$ is the more likely reading according to editors.

CIPPh I, 187; Orel 1997a, 229 and 447.

vay see $v a$.

va.[---] (PN?)

OPhr. va.[---] G-134

Damaged graffito incised on a sherd. Its third letter can be read as $u$ or $s$, although the remaining strokes of are not clear enough to support a definitive reading (CIPPh I, 123). Bayun and Orel (1988a, 199-200) read it in the light of vanak- (M-01a), however such a segmentation of vanaktaei 
is indefensible and the presence of « $\mathrm{n}\rangle$ does not fit with the strokes. On the other hand, Orel (1997a, 185 and 466) read it as vaș[---] and considered it another occurrence of vasos ("an epithet or a cultic term", as he stated). In any case, it is very likely an anthroponym, as is common in such graffiti.

CIPPh I, 123; Bayun \& Orel 1988a, 199-200; Orel 1997a, 185 and 466.

veaoyoy (verb?)

OPhr. veaolyoy $\mathrm{G}-11 \mathrm{~b}+\mathrm{G}-11 \mathrm{c}$

Read on a stone block, the whole text is vague: sit kraroy veaol yoy [.'] | dis. In the light of its ending, Brixhe $(2002,36)$ suggested that it is a 3sg.opt. verb (compare with kakoioi), although its root remains unidentified. Nevertheless, a thematic adj. or noun in agreement with kraroy. cannot be ruled out.

Brixhe 2002a, 36 .

\section{vebạn (noun) 'grave'}

OPhr. sg.acc. vebạn B-05 1.13

NPhr. ? ovย̣[---] 27.1(92)

sg.acc. oue $\beta \alpha v 1.1(48), 2.2$ (130), 37.2 (30)

Although Haas $(1966,98)$ considered the meaning 'harm', Lubotsky $(1997,127)$, in the light of the quasi-bilingual 1.1, equated it to the Gr. $\mu \nu \eta \mu \varepsilon \tilde{o}$ ' 'monument, tomb' read in the same

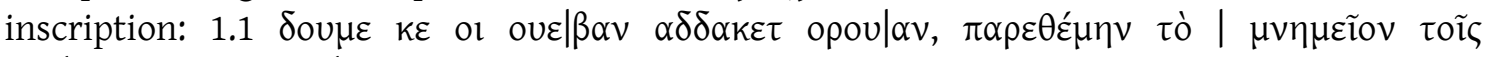

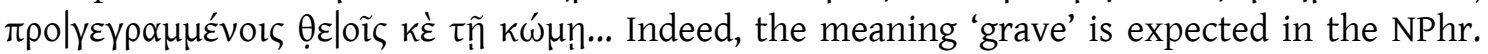

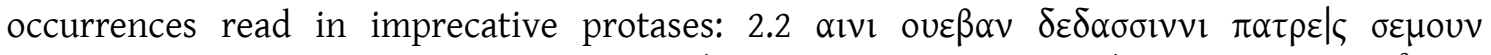

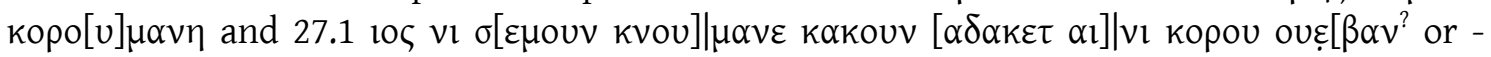
$\beta \varepsilon v o c]$. Perhaps the occurrence of 37.2 is also read in a (damaged) protatis: [............] ove $\beta \alpha v$

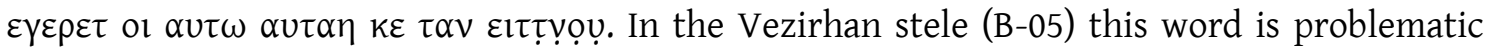
because it appears in the apodosis: B-05 yos isekosos 个emeney dupratoy, veban ituv. Dealing with this problem, Brixhe $(2004 a, 64)$ suggested that veban is a directive acc., not before identified in Phrygian. Following him, Avram $(2016,122-123)$ considers that the collation veban ituv means 'may he go in the grave' (= 'may he die') and refutes Gorbachov's interpretation 'may become

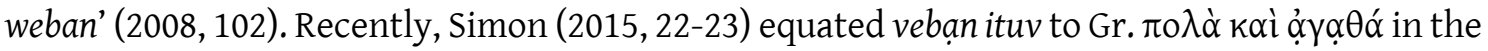
Gr. summary of this inscription and considered that it means 'good thing'. However, this meaning is not defensible in the light of the NPhr. occurrences. Its etymology remains unclear. It can be derived from the PIE root *ueb ${ }^{h}$ - 'to weave, braid' (LIV 658 , IEW 1114), attested in Hitt. uep-zi 'to weave(?)' and uepa- 'woven fabrics (?)' (see Kloekhorst 2008, 1001-1002), Gr. v́ $\varphi \alpha i ́ v \omega$ 'to

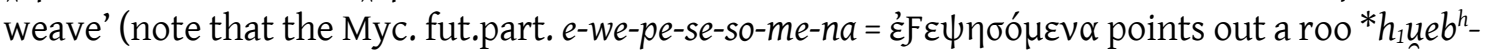
according to Beekes 1969, 67 and EDG 1540-1541), v́ $\varphi$ ' 'web', Skt. vabh- 'to bind, to fetter', OHG weban 'to weave' and ToA wäp-, ToB wāp- 'id.'. If this is the case, we are dealing with a neuter noun in *-ēn >-ān, like iman, imenos 'shrine', or an $\bar{a}$-stem fem. in sg.acc. However, the semantic development must be explained.

Haas 1961, 80; Haas 1966, 98; Neumann 1997, 26; Lubotsky 1997, 127; Orel 1997a, 329-330 and 466; Brixhe 2004a, 64; Gorbachov 2008, 102, Hämmig 2013, 151; Simon 2015, 22-23; Avram 2016a, 122-126.

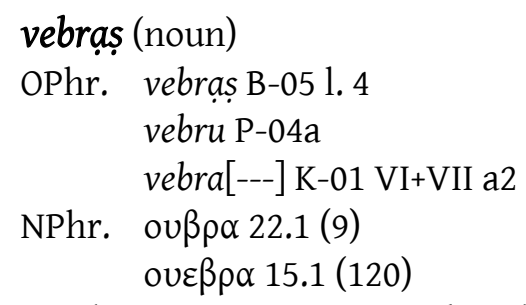

An elusive noun. Bayun and Orel (1988c, 133) equated it to Gr. üßpı 'wanton violence, outrage' but this was subsequently rejected by Orel (1997a, 467). On the other hand, Lubotsky (in Brixhe 


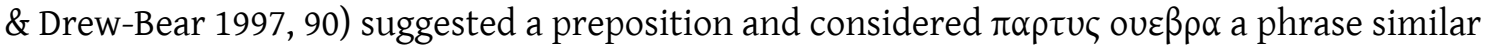

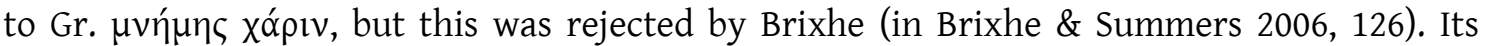
contexts are non-imprecative: B-05 panta vebras adun p? os key estat pator. ike[...]e[..] andati..., K-01 VI+VII a2 [---] ' masa u|rgitos dakor s=vebra [---] | tataniyen? e ẹdaes, $15.1[\ldots . . . . . . . . . . \pi] \alpha \rho \tau v \varsigma$ ove $\beta \rho \alpha$ and

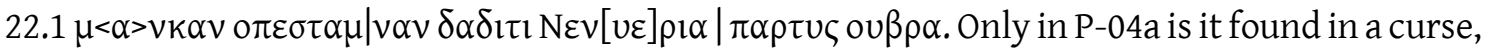

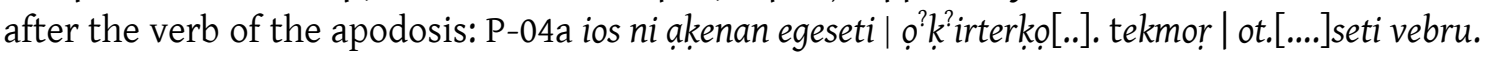
Moreover, this last form is also morphologically different to the other occurrences, which seem to follow an $a$-stem paradigm. Brixhe (in Brixhe \& Summers 2006, 126) considered that the form svebra[---] shows an etymological spelling. However, since *su- became $v$ - in Phr. (see va or venavtun) and the origin of this word has not been identified, it is more likely that we are dealing with the clitic pronoun attached to this noun: $s=v e b r a[---]$ (see, e.g. $s=$ materan M-01dI).

Bayun \& Orel 1988c, 133; Brixhe \& Drew-Bear 1997, 87-90; Orel 1997a, 296-297 and 467; Brixhe 2004a, 56; Brixhe \& Summers 2006, 126.

vebru see vebraṣ.

venavtun (reflexive pronoun) 'himself, herself, itself'

OPhr. acc.sg.masc. venavtun $\mathrm{W}-01 \mathrm{~b}$

NPhr. dat.sg.fem. oe $\quad$ o $\alpha$ v $\alpha 116.1$ (116) 1.12

Compound pronoun built by attaching the inherited PIE reflexive *sue (Lat. se, Gr. $\check{\varepsilon}$, Lesb. fє, Skt. sva-) to the reflexive avto-, a parallel formation to Gr. $\dot{\varepsilon}-\alpha u \tau o \tilde{v}, \tilde{\eta} \varsigma$, ov. The first element in the OPhr. occurrence has been recharacterised by appending the sg.acc. ending $-n$. It appears in an imprecative apodosis without parallels: yos esai=t materey eveteksete $e^{?} y$ ovevin onoman da $Y$ et lakedo key venavtun avtay materey. The NPhr. sg.dat. form occurs in an imprecative protasis

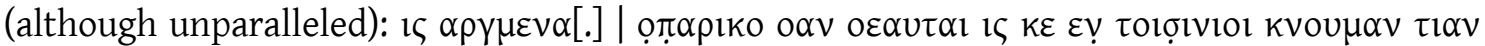
$\tau \varepsilon[] \mid.[.] \mu \alpha \rho \delta \delta_{1} 1 \delta \varepsilon \tau o l$ olvic. Although the first editors of this text, Brixhe and Neumann (1985,

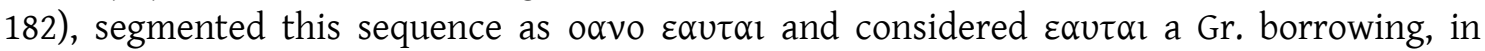

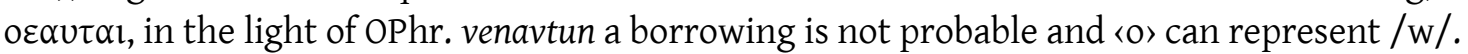
Torp 1908, 213; Meister 1911, 24; Haas 1966, 195, 197; Brixhe 1978b, 12; CIPPh I, 40-41; Brixhe \& Neumann 1985, 182; Bayun \& Orel 1988a, 183; Lubotsky 1988, 22; Janda 1997, 273; Morante Mediavilla 2006, 336; Woudhuizen (2008-2009), 191 § 161; Ligorio \& Lubotsky 2013, 185 and 190-191.

vetei (noun or adj.?)

OPhr. sg.dat. vetei $\mathrm{P}-04 \mathrm{a}$

Despite several proposals, Brixhe $(2004 a, 101)$ considered that this word remains unclear. Indeed, scholars only agree that it is a sg.acc. which agrees with otuvoi: otuvoi vetei etlnaie. In fact, the whole sentence in which it is attested remains unclear. Haas $(1966,182)$ translated it into Lat. as ipsi, however this interpretation has not been accepted. Woudhuizen $(1993,13)$, on the other hand, equated it to Myc. we-te-i /wetehi/ 'year' (alphabetic Gr. Éto ) and considered otuvoi the numeral eight. However, this last word works better as PN, so the context does not support such an interpretation. Finally, Orel (1997a, 295) equated it to Lat. uetus 'aged, old' (inherited from PIE *uet-os-) and considered that otuvoi vetei means 'For Otuvo- the elder'. However, such an anthroponymic formula is unparalleled in Phrygian.

Haas 1966, 180; CIPPh I, 237-238; Woudhuizen 1993, 13; Orel 1997a, 295 and 468; Brixhe 2004a, 101; Woudhuizen 20082009, $191 \S 163$.

$v i(\mathrm{PN})$

OPhr. vi G-243

Owner's mark read on a sherd. It is very likely an abbreviated PN. CIPPh I, 191; Roller 1987a, 41; Bayun \& Orel 1988a, 199; Orel 1997a, 232 and 486. 


\section{vitạạn (?)}

OPhr. vitaran B-05 1.3

It follows the word vrekan in the Vezirhan stele, iben edatoy dakeran atriyas davoi okimakiva[---] | vrekan vitaran artimitos kraniyas [---] and seems to agree with this noun. On this basis, Brixhe $(2004 a, 55)$ considered that the probable adj. vrekan qualifies vitaran (considered a noun). However, vrekan is more likely a noun (see vekrun). Consequently, vitaran may be an adj. in addition, Brixhe suggested that the root of this word is also attested in vitav. However, its meaning remains unclear.

Neumann 1997, 20; Brixhe 2004a, 55.

$v i \uparrow e(?)$

OPhr. vi个e W-10

The interpretation of this word is related to the letter $\uparrow$. Brixhe and Drew-Bear $(1982,86)$ considered that it may reflect a palatalisation of PIE ${ }^{*} k$ with a later depalatisation (he considered that this letter was similar to Gr. sampi), so he identified the word as inherited from the PIE root *ueik- 'bend, wind, change' (IEW 1130-1131 *weik-/4) parallel to Lat. uicis 'turn, occasion'. However, this interpretation has not been followed. Orel (1997a, 51 and 468) considered it a verb in 2sg.aor. inherited from the PIE root *ueid- 'see, know' (LIV 665-667, IEW

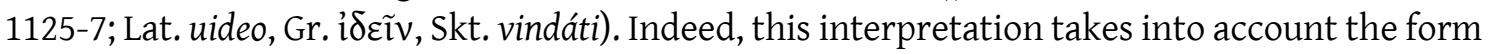

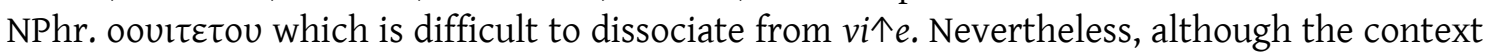
of this OPhr. word remains obscure, the presence of the verb edae can be adduced as an

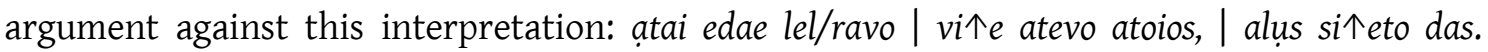
Consequently, this word remains unexplained.

Brixhe \& Drew-Bear 1982, 86; Brixhe 1982, 231; Orel 1997a, 51 and 468.

voine and voineios see voines.

voines (PN)

OPhr. sg.nom. voine G-228

sg.nom. voines $\mathrm{G}-129, \mathrm{G}-286$

sg.nom. voineios $\mathrm{G}-145$

All forms are sg.nom. but voine is a variant without the ending -s. G-145 voneios is derived through the suffix *-eio- from the simpler form voine-. Then, it is a a parallel formation to lagineios (see Innocente 1997, 39). In most instances the PN constitutes the whole graffito, and it is only in G-145 that this PN is attested in a larger text: voineios uriienois $\mathrm{ku}[---]$. Note that in this graffito the engraver first wrote $\Psi$ (or « $Y$ ?) instead of 〈s〉. Orel (1997a, 468) interpreted this word as the noun for 'wine' and equated to Gr. oivos and Lat. uinum. Although this interpretation can be considered likely because voine(s) were incised on pottery, the inflection of voine(s) is not thematic, like the adduced parallels, but shows the common $e$-stem of many PN.

Lejeune 1969b, 292; Brixhe 1983, 128; CIPPh I, 119, 132 and 183; Brixhe \& Neumann 1985, 169; Brixhe 1987, 129 fn. 107; Masson 1987a, 111; Roller 1987a, 53; Neumann 1988, 7; Lubotsky 1988, 19; Bayun \& Orel 1988a, 200; Brixhe 1991, 42; Brixhe 1993, 340; Orel 1997a, 468; Innocente 1997, 39; Brixhe 2002a, 46-47; Sowa 2008, 36 and 80.

voși[---] see vosịk?[---].

vosị? ${ }^{?}[---](?)$

OPhr. vọ̣li[---] K-01-Ia vosik? $[---] \mathrm{K}-01-\mathrm{III}$

An obscure word in a very fragmented text engraved on a stele: [---]oitio :? vosik? [---]. Even the interpunction which seems to precede this word is dubious. Brixhe (in Brixhe \& Summers 2006, 
118) also considered the segmentation vos $i k$ ? [---], where vos is taken as the 3sg.poss.pron. (masc.nom.sg.). However, no parallels are found a part from [---] vos |i[---], read in the first preserved line of this text and perhaps it is the same word (also damaged). On it, Brixhe (in Brixhe \& Summer 2006, 114) also suggested the same interpretation. So, the word remains unclear until more parallels are found.

Brixhe and Summers 2006, 114 and 118.

${ }^{\dagger}$ voy see tubetiv and oy.

$v^{?}$ o.[-?-] see [-?-]i?.

vrekan and $v^{?} r^{?}$ ekeș? see vrekun.

vrekun (noun?) 'sculpture, relief?

OPhr. sg.acc.(fem.) vrekạn B-05 1.3

pl.nom.? $\quad$ v? $^{?} r^{?}$ ekeș ${ }^{?} \mathrm{HP}-114$ ?

sg.acc. vrekun W-01a; rekun M-06

Because the differences between each word are significant, it is better to analyse them one by one. The form vrekun was the most widely considered form among prior reserachers. Because in W-01a it occurs in a description of the monument (a façade from which a statue of the goddess has been lost), the meaning 'sculpture, relief' given by Matzinger (2005, 386-390 and 2006, 358-360, followed by Ligorio and Lubotsky 2013, 192, who prefer the translation 'idol') fits very well. Indeed according to this interpretation, bonok akenanogavọ materan areyastin vrekun tedatoy means 'Bonok, the akenanogavos, made for himself as relief (this) Matar Aresyastis'. Also, the etymology suggested by Matzinger is really attractive: a noun inherited from the PIE verbal root *uerǵ- 'work' (LIV'2 686-687, IEW 1168-1169) equated to Gr. "̌pyov 'work, deed, action', with

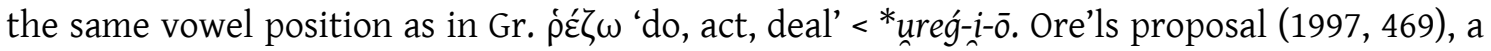
derivative from the PIE root *ureǵh- (sic.) 'break' (*ureh ǵ $_{1}-L^{2} V^{2}$ 698, IEW 1181-1182) does not fit the context and ${ }^{*} e_{1}$ is expected to yield $*_{\bar{e}}>-a$ in Phr. In M-06 the context and the word are less clear: M-06 rekun deiatiteea.? davoi iman 'Iman ... this relief for Davos'. There is no trace of a prior letter here and CIPPh (I, 26) considered it a phonetic simplification: vrekun > rekun. More difficult is the interpretation of vrekan read on the Vezirhan stele: B-05 dakeran atriyas davoi okimakivua[---] | vrekan vitaran artimitoș kraniyas [---]. Although Brixhe $(2004 \mathrm{a}, 55)$ considered it an adj. in agreement with vitaran, it seems more likely to be a secondary feminisation of vekrun. Note that here the text addresses the relief of the goddess as follows: vrekan vitaran artimitos kraniyas 'the vitaran idol of Artemis Kraniyas'. So, vrekan is a noun and vitaran its adje. The last occurrence, $v^{?} r^{2} e k e s^{?}$, is really striking because it does not fit the paradigm of vrekun or vrekan. Since it is read on the Persepolis clay tablet, it is clearly an athematic pl.nom. parallel to others in the same text: $30^{?}$...ekes $30^{?} i^{?} \mid . .30^{?} y^{?} r^{?}$ ekes ${ }^{?} \mid .30^{?}$ knays $30^{?} s^{?} \mid 4 i^{?} v^{?} r^{?} i 40^{?}$ knayke? $e^{?}[s]^{?} \mid .^{?} 40^{\text {? }}$ $m^{?}$ akeres $40^{?}$... Perhaps it is another word somehow related to vrekun. Finally, the still common interpretation that vrekun is the endo-ethnonym of the Phrygians (see, e.g., Janda 1997, 272;

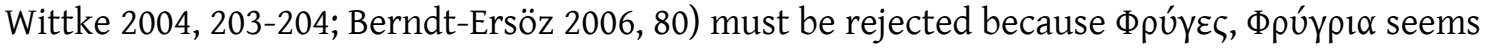
to go back to PIE ${ }^{*} b^{h} r g^{h}$-, whose stops are not expected to become voiceless, but voiced (see above the form Bpípl $\alpha$ ). Indeed, the first scholar to suggest this possibility was Lubotskty (1988, 13-14), who rejected it in later papers (see also Simon 2014b, 94 fn. 21). The source of this

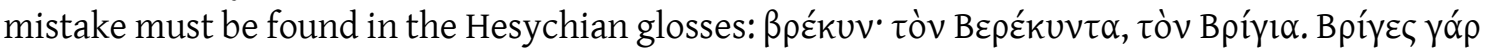

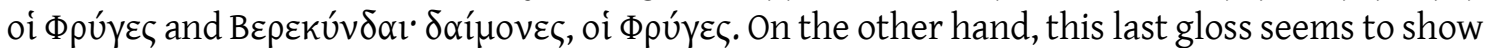

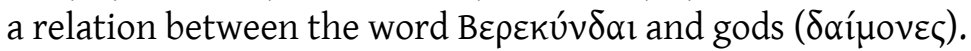

CIPPh I, 26; Bayun \& Orel 1988a, 180; Janda 1997, 272; Neumann 1997, 20; Orel 1997a, 469; Brixhe 2004a, 55; Wittke 2004, 203-204; Matzinger 2005, 386-390; Berndt-Ersöz 2006, 80; Matzinger 2006, 358-360; Woodhouse 2006, 175; Ligorio \& Lubotsky 2013, 192; Simon 2014b, 94 fn. 21. 
v.[---] (?)

OPhr. v.[---] G-315

Incomplete graffito read on a sherd. Perhaps the beginning of a PN.

Brixhe 2002a, 72-73.

$v[---](?)$

OPhr. $v[---]$ G-01c, T-02b.

Beginning of an unknown word read on a stone slab (G-01c) and a fragment of stele (T-02b). CIPPh I, 85 and 266. 

$\zeta \varepsilon\llcorner\rho \alpha$ and $\zeta \varepsilon\llcorner\rho \alpha 1$ see $\uparrow i r a y$.

\section{$\mathrm{z} \zeta$}

$\zeta \varepsilon \mu \varepsilon \lambda o \zeta$ and $\zeta \varepsilon \mu \varepsilon \lambda \omega$ see $\zeta \varepsilon \mu \varepsilon \lambda \omega \varsigma$.

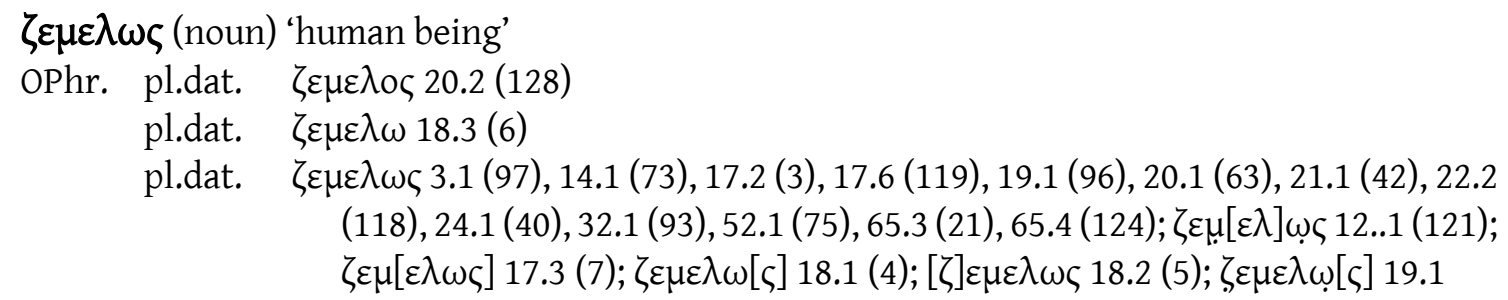

pl.dat. $\quad[\zeta \varepsilon \mu] \mid \varepsilon \lambda \omega \sigma \mathrm{Ll} 27.1$ (92)

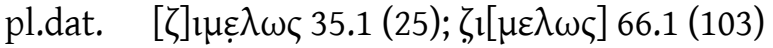

pl.dat. $\quad \sigma \zeta \varepsilon \mu \varepsilon \lambda \omega \varsigma 10.2$ (113), 30.1 (39)

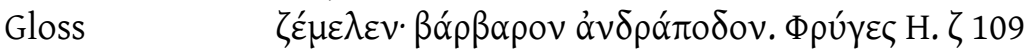

All epigraphic occurrences are variants of the same form read in a imprecative apodosis: e.g. $17.6 \mu \varepsilon \zeta \varepsilon \mu \varepsilon \lambda \omega \varsigma \kappa \varepsilon \delta \varepsilon \omega \zeta \kappa \varepsilon \mid \tau \imath \tau \varepsilon \tau 1 \kappa \mu \varepsilon v o \zeta \varepsilon i \tau o v$. It is generally accepted to be a derivative of the PIE root * $d^{(h)} \dot{g}^{h} e-m$ - 'earth' (NIL 86-99, IEW 414-416, see also Kloekhorst 2014a) with the suffix *-elo- similar to Gr. $\chi \theta \alpha \mu \alpha \lambda$ ó 'near the ground, on the ground, flat' and Lat. humilis 'low, humble', so it is a nominalised adjective. The first sound can be interpreted as a centum depalatalisation with a secondary palatalisation (perhaps with a simplification of the initial

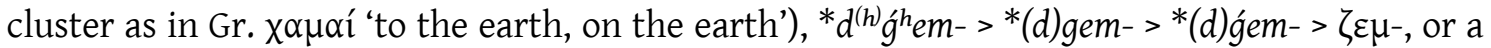
methatesis with a satzm treatment $*^{*} d^{h} \hat{g}^{h} e_{-}>*{ }^{*} d e_{-}>\zeta \varepsilon$ - However, since Phr. is a centum language, only the first interpretation is valid. Independent evidence for this secondary

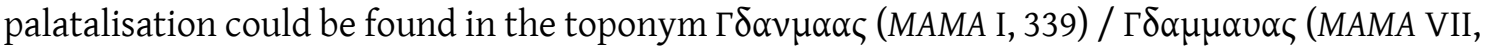
589, from Çeşmelisebil, see Robert 1980, 382). If indeed it is Phrygian and not Pisidian, its first part seems to go back to ${ }^{*} d^{(h)} g^{h} m$ (compare with Skt. -jm- in majmán-). In any case, $\zeta$ seems to

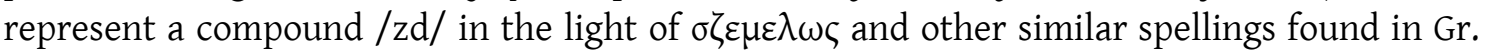
inscriptions from Phrygia (Brixhe 1978a, 7 and 1987a, 46). The form $\zeta \mu \varepsilon \lambda \omega \varsigma$ shows the pretonic hesitation /e/ /i/ (Ligorio \& Lubotsky 2013, 187). Finally, while different endings are attested, each of them reveals a thematic inflection. The hesitation between omega and omicron reveals the loss of the lengthened vowel, ${ }^{*}-\bar{o} i s>-\omega \varsigma>-o \zeta$, and $\zeta \varepsilon \mu \varepsilon \lambda \omega \sigma$ seems a recharacterised dat.. The gloss form does not fit in the paradigm; because of final ny it seems to be its acc. but the

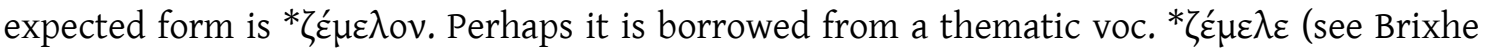
1993, 334).

Brixhe 1978a, 7; Brixhe 1982, 242; Brixhe 1990, 96; Brixhe 1993, 334; Lubotsky 1998, 416; Brixhe 1999, 297; NIL 88; Ligorio \& Lubotsky 2013, 185.

\section{$\zeta \varepsilon \mu \varepsilon \lambda \omega \sigma \mathrm{l}$ and $\zeta \mu \mu \varepsilon \lambda \omega \varsigma$ see $\zeta \varepsilon \mu \varepsilon \lambda \omega \varsigma$.}

$\zeta \omega \varsigma$ (adj.) 'alive, living'

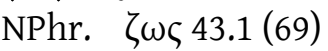

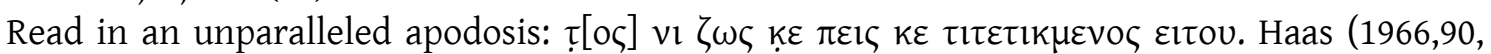
followed by Woodhouse 2007) considered it a Gr. loanword, the pres.participle of the verb $\zeta \tilde{\omega}$ 'live' (PIE < * $g^{u} e i h_{3^{-}} / g^{u} i e h_{3^{-}}$, so * $g^{u} i e h_{3^{-}}$uo-s). Indeed, the old labialised stops are not expected to appear as palatal in the light of $k^{w} e>k e(y), k \varepsilon$. On the other hand, Heubeck 1987, 83-85 and Lubotsky 1994 suggested an engraver's mistake for $\zeta<\varepsilon \mu \varepsilon \lambda>\omega \varsigma$. However, there is no $\delta \varepsilon \omega \varsigma$ but $\pi \varepsilon ı \zeta$ in the same formula, and this mistake is difficult to explain. So the Gr. borrowing remains the better (albeit tentative) explanation.

Haas 1966, 90; Heubeck 1987, 83-85; Lubotsky 1994; Woodhouse 2007. 



\section{$\mathrm{H} \eta$}

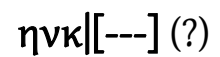

NPhr. $\eta v k \mid[---] 15.1(120)$

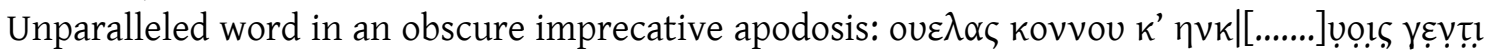

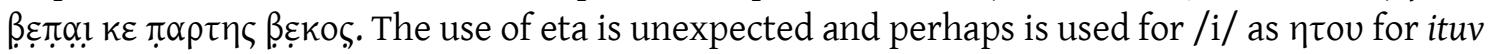

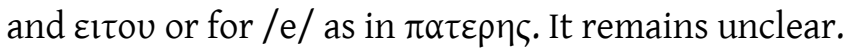

Brixhe \& Drew-Bear 1997, 90.

${ }^{\dagger} \eta \sigma 10 u$ see $\delta \varepsilon \kappa \mu o v \tau \alpha \iota \varsigma$ and $10 v$.

$\eta \tau$ 



\section{$\Theta \theta$}

$\theta \alpha \lambda \alpha \mu \varepsilon \imath$ (noun) 'funerary chamber'

OPhr. sg.dat. $\quad \theta \alpha \lambda \alpha \mu \varepsilon l 18.1(4)$

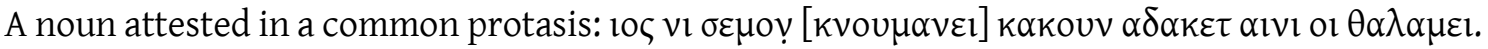
It is a clear borrowing from $G r$. $\theta \alpha \lambda \alpha$ á $\mu \eta$ 'a lurking-place, den, hole cave' used, as well as $\theta \alpha \lambda \alpha \mu o ́ \varsigma$ 'inner room or chamber', in the sense of '(funerary) chamber' > 'tomb'. See a similar use of this

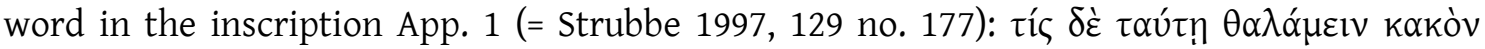

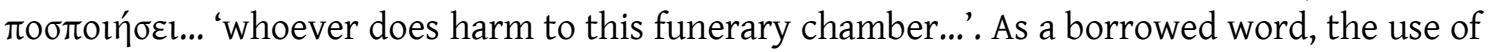
theta is also explained.

Brixhe 1978b, 5; Brixhe \& Waelkens 1981, 71; Brixhe 1983, 129; Brixhe 1993, 341; Brixhe 1994, 175; Brixhe 1999, 298; Brixhe 2002b, 258; Ligorio \& Lubotsky 2013, 194; Avram 2016, 129.

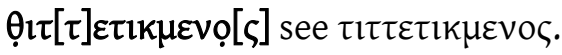





\section{I (i) $-\mathrm{I} \mathrm{l}$}

lav see yos.

iben (pronoun) '(to) himself'

OPhr. sg.acc. iben B-05 1.2

sg.dat. ibey B-01; B-05 1. 10

Third-person plural pronoun identified by Hämmig (2013, 139-140), who classifies ibey as a sg.dat. formation parallel to, e.g., Lat. sibi or Oscan sifei $<{ }^{*} s e-b^{h} e i$ and Gr. $\sigma \varphi \varepsilon i \bar{\imath}$ (in zero grade) based on PIE $*(u)$ e. The previous segmentation ibeya B-01 was suggested in the light of the preceding word kubeleya, matar kubeleya ibey a duman ekteto. However, since this word appears in B-05 1.10 koyis abretoy nun ibey nevotan niptiyan sirun mireyun, the word boundary after ibey is clear. The sg.acc. iben seems to be an analogous form created after the dat. It appears in an unclear, non-imprecative part of the Vezirhan stele: B-05 1. 1-2 sin=t imenan kaliya ti tedat [...]edekm[...]meas ${ }^{?} d^{?} u^{?}$ mid | iben edatoy dakeran atriyas davoi okimakiva[----]...

Brixhe 2004a, 54; Hämmig 2013, 139-140.

ibey see iben.

${ }^{\dagger}$ ibeya see iben and $a$.

id see di.

$1 \delta \varepsilon \tau 0 \imath$ (verb)

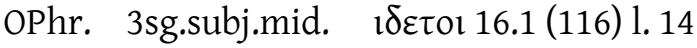

Because of the ending - $\tau$ or and the lack of augment, it seems to be a verb in 3sg.subj.mid. Indeed,

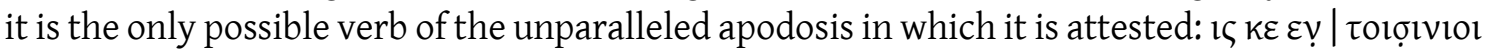

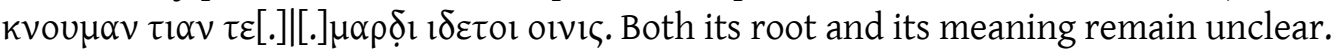

Brixhe \& Neumann 1985, 183; Brixhe 2004a, 53.

idi (PN)

OPhr. sg.nom. idi HP-113

This graffito incised on a bronze bowl found in Lycia seems to be a complete $i$-stem PN in sg.nom., despite the lack of the ending -s. This name is also found in Pisidia as I $\delta$ 1o (both in sg.gen., KPN $192 \S 452-3$ ). The Phr. form can be read as /iddi/ or /idi/.

Varinlioğlu 1992, 13 and 15-16; Orel 1997a, 320; Brixhe 2004a, 117-118.

idn[-?-] (?)

OPhr. idn[-?-] NW-136

Graffito (perhaps fragmented) incised on a sherd found in the Dorylaion höyük and dated to the Persian period. The sequence is unparelled in the whole Phrygian corpus and even the letters can be considered non-verbal marks. Nevertheless, a PN cannot be ruled out in the light of Semitic theoforics like Iddin-Bēl, which are well attested in cuneiform sources.

Brixhe \& Sivas 2009, 136.

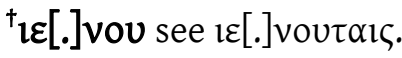




\section{$1 \varepsilon[.] \operatorname{vov\tau \alpha } 1 \zeta(?)$}

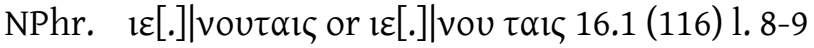

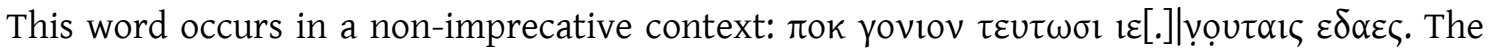

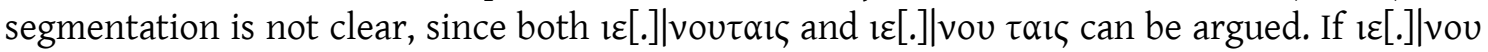

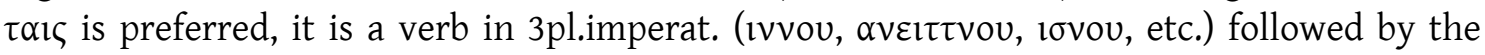
pronoun $\tau \alpha 1 \zeta$ (pl.acc. or pl.dat.fem.). However, it is possible to consider $1 \varepsilon[] \mid. v o v \tau \alpha 1 \zeta$ an $a$-stem noun (perhaps an agent noun, as Brixhe \& Neumann 1985, 178 suggested) in pl.acc. (<*-ans). In any case, its meaning remains obscure.

Brixhe \& Neumann 1985, 177-178.

${ }^{\dagger} i v$ and ${ }^{\dagger}$ ivimun see yos and ivimum.

iverais (noun?)

OPhr. pl.acc.? iverais B-05 1.7

An obscure $a$-stem noun coordinated with dakerais through the conj. key in a non-imprecative sentence: kelmis ke umnișet evradus dạkerạiș key iverais [..] | ạtikrạiu... It seems to be a pl.acc. of an a- or $c$-stem noun.

Brixhe 2004a, 59.

ivi..se.[.?] n (?)

OPhr. ivi..se.[.?]n? $\mathrm{P}-06$

Like the whole inscription, this word remains unclear. Even the reading is confusing: [-?-]a?kiti? ...s $\mid$ ai $:$ ios aeiketio [.?] ivi..se.[.?]n?

CIPPh I, 243.

$i^{?} \underline{v}^{?} r^{?} i$ (noun?)

OPhr. i? $v^{?} r^{?} i \mathrm{HP}-114$

The clay tablet on which it is read is seriously damaged and this word could be s? $\left.\left.\right|^{?}\right|^{?} v^{?} r^{?} i$. Like the other words of the text, it seems to be a noun determined by a numeral: $30^{?}$...ekes $30^{?} i^{?} \mid . .30^{\text {? }}$ $y^{?} r^{?}$ ekes ${ }^{?} \mid .30^{?}$ knays $30^{?} s^{?} \mid i^{?} y^{?} r^{?} i 40^{?}$ knayke $e^{?}[s]^{?} \mid ?^{?} 40^{?}$ m?akeres $40^{?}$... The other words appear in nom., however, $i^{?} v^{?} r^{?} i$ does not show a nominative ending. No parallel can be adduced.

Brixhe 2004a, 118-126.

$i k(\mathrm{PN}$ ?)

OPhr. $i k \mathrm{G}-285$

$$
i k[-?-] \mathrm{G}-273
$$

G-285 is a complete graffito incised on a fragment of a cup. Consequently, it is very likely an abbreviated (but unknown) PN. It may be the same abbreviation read in G-273, but it is possible that more letters were incised. Both inscriptions seem to be owner's marks.

CIPPh I, 200-211; Roller 1987a, 19; Bayun \& Orel 1988a, 199; Brixhe 2004a, 45-46.

$i k[-?-]$ see $i k$.

${ }^{\dagger} \mathbf{\imath k}[$.] see $\mu \mathrm{k}$ s and $k e$.

ike[...] (?)

OPhr. ike[...] B-05 l. 4

Badly preserved sequence from a very obscure part of the Vezirhan stele: estat pator.?ike[...]ẹ[..] andati | vạy niptiyay dạker...

Neumann 1997; Brixhe 2004a, 42-67. 
iketaios (PN)

OPhr. sg.nom. iketaios W-02

An o-stem name read in a damaged text engraved on a façade: iketaios pseika? ed $^{?}[a] e^{?}$ s. It very

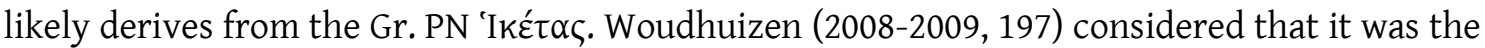

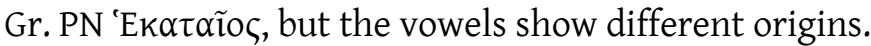

CIPPh I, 43; Bayun \& Orel 1988a, 183; Berndt-Ersöz 2006, 81; Woudhuizen 2008-2009, 197.

${ }^{\dagger} i k t e s$ see petes.

ịlay (PN)

OPhr. sg.dat. ịlay B-107

illa[-?-] or iya $[-?-]$ G-268

ila[---] G-259

The only clear form is the sg.dat. ilay incised on a fragment of Mysian plate. This a-stem PN is also attested on the Lyd. border as E $1 \lambda \alpha \varsigma$ and $I \lambda \lambda \alpha \varsigma$ (KPN 158 § 321-6 and 463-3). Leaving aside the loss of their endings, the other examples present certain some problems. Indeed, G-268 can be alternatively read as iya[-?-]. However, since no parallel can be adduced for iy a[-?-] the reading illa[-?-] is preferable. Bayun and Orel $(1988 a, 198)$ read iya[-?-] even in G-259, where there is no trace of the lower stroke of this supposed yod. G-268 is perhaps complete and shows its nom. without the ending $-s$.

CIPPh I, 201-207; Bayun \& Orel 1988a, 198; Brixhe 1996, 144; Brixhe 2004, 91-92.

illa[---] see illay.

$\operatorname{im}[---](?)$

OPhr. im[---] G-318

Incised on a sherd where the beginning and the end of the text are lost: [---]os : im[---]. In determing the sequence, only the word boundary marked by the interpunction is clear.

Brixhe 200a, 74-75.

iman $^{1}$ (noun) 'shrine'

OPhr. sg.nom.? i? mạa? $[n] \mathrm{G}-04$ ?

sg.acc. imenan B-05 l. 1

sg.dat. inmeney B-05 1.11

A common noun related to the PN iman, its meaning is established by the comparison with Gr. iepòv in B-05. Its etymology has remained unclear but Vine (2010, see also LIPP II, 234) recently provided a very suitable proposal: a derivative of the PIE verbal root *men 'stand fast, remain' $\left(L I V^{2} 437\right.$, IEW 729) with the preposition/preverb $*\left(h_{1}\right) e n$. Consequently, this word is similar to frozen Gr. adverb $\varepsilon \mu \mu \varepsilon v \varepsilon$ ' ‘unceasing' and OIr. ainmne 'patience'. Its inflection is derived from a hysterodynamic root-noun. Although its sg.nom. as a noun is precariously preserved (G-04 on a stone block [---]evi? | tatas.[---]|[---] i? ma ? [n---]|[-?-]), when used as a PN it is well preserved and may go back to *en-mèn. While its sg.acc. is very conservative, ${ }^{*}\left(h_{1}\right)$ en-mén-n $>*_{\text {immenan }}>$ imenan, its sg.dat. shows a levelling in the vocalism of the root from the sg.acc., * $\left(h_{1}\right)$ en-mn-ế $i>$ *immenei > inmeney. Regarding the contexts of the occurrences, these last two cases are found in the same text, the Vezirhan stele: the sg.acc. in the presentation of the monument (1. 1 sin=t imenan kaliya ti tedat[...] edekm[...]meas ? d? unid) and the dat. in an imprecative protasis, where it agrees with the pronoun $<$ s>imun in sg.dat.masc.-neut. pronoun, in spite of some engraver's mistakes (l. 11 †iv imun inmeney as enan daket, see Hämmig 2013, 149).

Brixhe 1974; Matzinger 2005, 377; Vine 2010; Ligorio \& Lubotsky 2013, 187; Hämmig 2013, 149; LIPP II, 234. 
$\operatorname{iman}^{2}(\mathrm{PN})$

OPhr. sg.nom. iman M-06, G-136, G-210, P-01, P-03, P-04c; iman M-03

A PN derived from the noun iman. Both words share the same inflection. While the PN appears once as a completed text on a sherd (owner's mark), it mostly occurs as the subject of different sentences: M-06 [?] rekun deiatiteea.? davoi iman, G-136 tadoy iman bagun, P-01 [-?-]e[..]u[.. t] $]$ ovo iman [-?-], P-03 vasous iman mekas kanutieivais devọs ke mekas and P-04c iman olitovo ẹdae [s] mekas. This PN is also attested in Gr. inscriptions from Phrygia and Pisidia, with a parellel $n$-stem inflection, as I $\mu \alpha v$, I $\mu \varepsilon v o \varsigma$ (KPN 195-196 § 466-1). It is very likely related to the PN imeneia. Brixhe 2013, 58 and 65.

imelan (?)

OPhr. imelan G-10

Its similarity with imenan and the lack of parallels are suspicious and, despite the lack of a third stroke to write $\langle\mathrm{n}\rangle$ instead of $\langle\mathrm{l}$, we are dealing with another occurrence of imenan (engraver's mistake?). The stone fragment on which it was engraved is severely damaged and the text is far from being clear: [---]ekeay : imelan.

Brixhe 2002, 31; Vine 2010, 344 fn.6.

imenạn see iman ${ }^{1}$.

imeneia (PN or patronymic?) 'Iman's daughter'?

OPhr. sg.nom. imeneia G-183 b

Since imeneia follows the fem. PN tiveia (in a graffito incised on the bottom of a cup), imeneia seems to agree with tiveia in sg.nom. Moreover, imeneia seems to be related to the PN iman (a derivative with the suffix -ia-) and is very likely a patronymic 'Tiveia (daughter) of Iman', if it does not refer to the husband of this woman. However, a compound PN cannot be ruled out. Brixhe 1983, 115; Neumann 1988, 6; Brixhe 2004a 83; Brixhe 2008, 76.

imroy (noun) 'field'?

OPhr. sg.dat. imroy B-01 1.2

An $o$-stem noun. It has been suggested that this word is related to $\mu \rho \circ \sigma(\sigma \alpha \varsigma) 114$, $\mu \rho \circ 58$ and

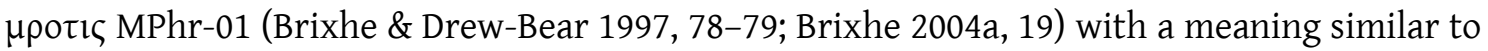
'death' or 'dead' and its beginning is simply explained as a prothetic $i-$. Nevertheless, these other forms present different patterns and the so-called prothetic $i$ - only occurs in B-01. Indeed, they actually look like different words which share only the sequence (-)mro-. The monument on which this inscription was engraved, a rock with a niche containing a statue of Matar, is not a funerary monument but a shrine. Then, even a semantic relationship can be rule out. Accordingly, there is no reason to consider the initial $i$ - epenthetic vowel. Going further and revisiting its sentence, si bevdos adi..[..] | kavarmoyo imroy edaes, it is clear that imroy is the recipient of the statue. So, it could be the niche, the rock or the place where it has been put. A very attractive etymology can be proposed. Indeed, imroy appears to be a borrowing from the Luw. word im(ma) ra(i)- 'open country', a cognate of Hitt. gimra- (c.) 'the outdoors, countryside, field, military campaign' (< PIE * '́him-ro- ‘winter, snow' NIL 162-169, Kloekhorst 2008, 476-477). In the light of this identification, we can read the first sentence of B-01 as 'this statue, Adi.....]

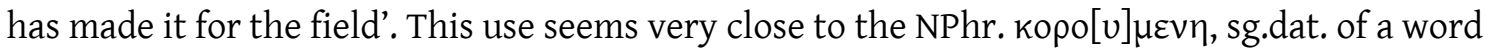

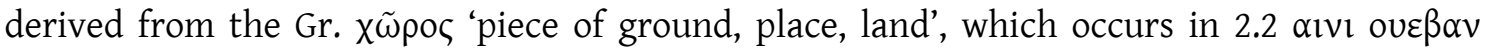

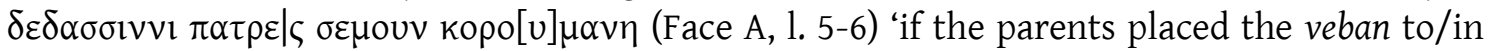

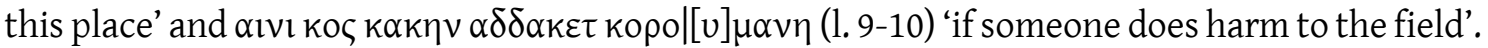

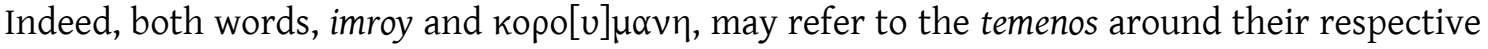
monuments. Finally, imroy is perhaps also found in the Mother-Goddess 'I $\mu \rho o v \mid \gamma \alpha \rho \eta v \tilde{n}$ (read in the Gr. inscription from Laodicea MAMA I 2b, see Schürr 1991-1993, 163). 
imun see $\sigma \varepsilon \mu o u v$.

inas (PN)

OPhr. sg.nom. inas Dd-102

A-stem noun with the ending -s. It appears incised on a silver bowl (whose origin is unknown) following the dat. surgastoy. This PN is also attested as the fem. Iv $\alpha$ c in Lycia and Ivv $\alpha$ in Mysia

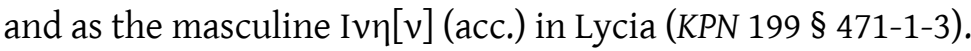

CIPPh I, 272.

inmeney see iman ${ }^{1}$.

ivvou see ituv.

101 (anaphoric pronoun) 'him, her'

OPhr. sg.dat. oy B-01 1.6, B-05 1.9, 1. 11 and 1.12

OPhr. sg.dat. $\quad$ lol $2.1(15), 7.2(111), 8.1(86), 11.2(18)$

sg.dat. ol 1.1 (48), 7.1 (99), 17.3 (7), 18.1 (4), 40.1 (12), 50.2 (55), 53.1 (76), 62.2 (33), $62.4(35)$

This pronoun is always found as oy in OPhr. texts: B-01 ... [..] toyo[.]is [.] erktevvoys ekey da [b]ati opito [k]ey oy evẹmemesmeneya anato... B-05 1. 9 yos niy art sin=t imenạn kaka oskavos kạkey kạn dedạsitiy tubetiv oy kevos derạliv mekạs key kovis abretoy..., B-05 1. 11-12 †iv† imun inmeney asenan dạket torvetun $\uparrow$ iray ayniy oy tubnuv nevos, me deritoy kovis ke abretoy nun oy nev<otan $>$... However, in NPhr. texts, where it is often used in imprecative apodoses referring to the violator, it appears

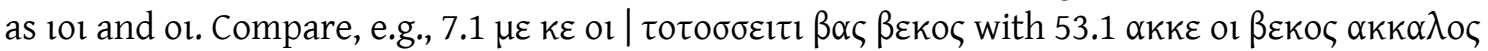
$\tau 1 \delta \rho \varepsilon \rho o u v \varepsilon v \mid \tau o u$. Brixhe $(1997,66)$ and Hämmig (fthc. a) consider that 101 is the stressed variant (similar to Homeric Gr. Éoĩ) and or the clitic (Gr. oi < *so-i, LIPP II, 734-735). On the other hand, Lubotsky (1997, 126 and Ligorio \& Lubotsky 2013, 190) considered them two phonetic contextual variants: 101 appears after a consonant (e.g. $7.2 \beta \alpha \varsigma 101 \beta \varepsilon \kappa \circ \varsigma \mu \varepsilon \beta \varepsilon \rho \varepsilon \tau)$ and ol after a vowel (18.1 $\alpha \mathrm{lvı}$ ol $\mid \theta \alpha \lambda \alpha \mu \varepsilon \mathrm{l})$. He also considered that it derived from the PIE anaphoric pronoun ${ }^{*} h_{1} e(i)-/{ }^{*} h_{1}$ - found in Lat. as is, ea, id, rather than the PIE form *seu-oi suggested by Brixhe

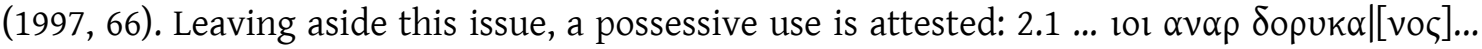
'her husband Doryka[nos]'.

Brixhe 1978a, 10-11; Brixhe 1997, 66; Lubotsky 1997, 126; Ligorio \& Lubotsky 2013, 190; Hämmig 2013, 138, fn. 29; LIPP II, 735; Hämmig fthc. a.

ios see yos.

iosais (PN)

OPhr. sg.nom. iosais G-117

A word incised on a pithos with capacity marks. Despite the lack of parallels (NPhr. 1000 is a variant), it is very likely a PN in sg.nom. ${ }^{*}-n_{0}-s>-$ ais (see arkiaevais).

CIPPh I, 110; Diakonoff \& Neroznak 1985, 112-113; Roller 1987a, 65; Lubotsky 1988, 19; Brixhe 1991, 43.

1000ৎ (PN?)

NPhr. sg.nom. 10б0ৎ 16.1 (116) 1.1

According to the first editors (Brixhe \& Neumann 1985, 169), it is an o-stem PN in sg.nom. However, the text, a description of the monument, does not seem to support this interpretation

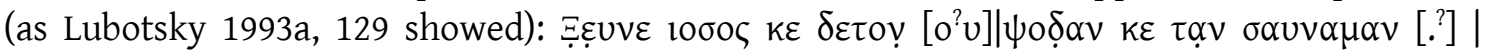

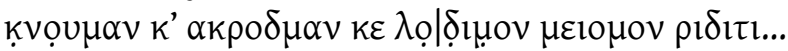

Brixhe \& Neumann 1985, 169; Lubotsky 1993a, 129. 


\section{0v[---] (?)}

NPhr. $\quad$ lou|[--- 40.3 (31)

This sequence is found in a very damaged part of a funerary stele completely written in Phr. The fragment is not imprecative but it remains obscure because of the gaps and the lack of

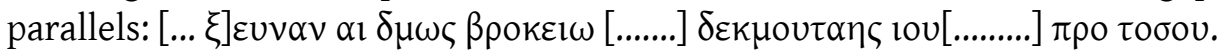
Kowal 1984b, 184.

is (verb?) 'to be'?

OPhr. 3sg.pres.? is B-07

According to Brixhe (2004a, 82) it is the 3sg.pres. of the copulative verb: PIE *hésti > *est > is,

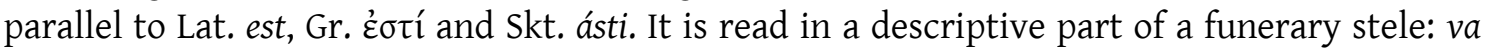
knais manuka odeketoy meros ke manes is... Brixhe also considers that this verb appears in apocopated form in the apodosis of the conclusive imprecation, me kos anivay eti (i)s manin. However, since it follows a clear verb, is easier to consider this $s$ as the clitic pronoun me kos anivayeti s=manin. Because of the final position of is in the sentence, its consideration as the preposition ${ }^{*} h_{1} e n s>$ is (LIPP II, 266), suggested in the preverb $1 \sigma \tau^{?} \varepsilon 1 \kappa \varepsilon \tau$, may be ruled out. Brixhe 2004a, 82.

เৎ see ios.

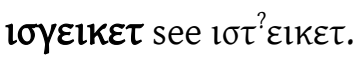

ise (PN?)

OPhr. ise G-114

Complete graffito incised on a sherd, very likely a PN. If not abbreviated, it is a sg.nom. without the ending -s. However, no parallel can be adduced. On the other hand, Orel $(1997 \mathrm{a}, 433)$ considered it a toponym in the light of the Cilician 'I $\sigma \sigma o$ c, although the same work $(1997,174)$ also considers the possibility tht it is a PN. Indeed, PN is the most common kind of word in such graffiti.

CIPPh I, 106-107; Bayun \& Orel 1988a, 198; Lubotsky 1988, 19; Orel 1997a, 174 and 433.

isekosos (perfect participle?) 'what it says, contents'?

Ophr. isekosos B-05 1. 13

The first interpretation of this word given by Neumann $(1997,25)$, who considered it a toponym, was refuted by Brixhe (2004a, 64) because it is unexpected in such a curse: yos isekosos 个emeney dupratoy, veban ituv. On the other hand, Sowa $(2015,189)$ considered it an active perfect participle in sg.masc.nom. of the PIE verb *sek" ${ }^{u}$ 'say' $\left(L I V^{2}, 526-527\right)$ attested, e.g., in Lat.

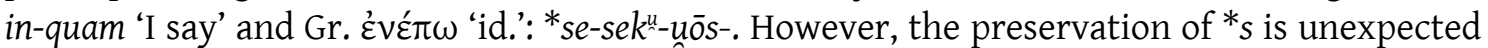
in both positions. Recently, Simon $(2015,17-18)$ equated this last Phrygian sentence of the

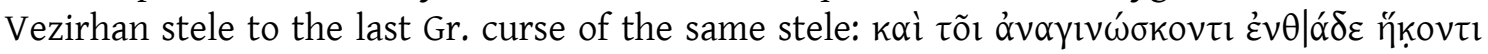

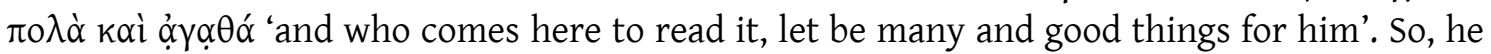

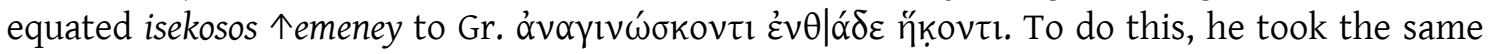
root used by Sowa and improved his interpretation by considering that the preverb *en- was added to the root without reduplication, similarly to Lat. or Gr. parallels: *en-sek $k_{-}^{u}-u_{0} \bar{s}-$. While the shift *en- $>*_{i n-}$ is attested in iman and the loss of * ${ }^{*}$ - before $*_{-o}$ - is generalised in Phrygian, on the basis of his interpretation the ${ }^{*}-s$ - of the root has a different context, which can explain why it is not lost: *-ns- >-s-. However, it does not explain why this consonant remains in the suffix *-uōs- and, more problematically, the identification between the Gr. and the Phr. text is hampered by the Phr. apodosis (see veban). The ending was classified as pl.acc.masc. ${ }^{*}$-ons $>-$ os, and Simon considered that the word refers to the contents of the inscription. It must be said 
that the ending is not altogether clear; this word can be also a sg.nom. (in agreement with yos?) or even a pl.dat. *-ois > NPhr. - $\omega$ c. Indeed, Phr. pl.acc. is expected to be as -ois.

Neuman 1997, 25; Brixhe 2004a, 64; Sowa 2015, 189; Simon 2015, 27-28.

ịsini (verb)

OPhr. 3pl.subj.pres.act. ịsini P-101 3sg.impv.act. isnou NW-101 a

NPhr. 3sg.impv.act. lovou $9.1(87)$ 3sg.impv.act. $\quad 10 \mathrm{v} 1 \mathrm{o}[\mathrm{v}] 21.1(42)$

A verb with no clear meaning. The form isini occurs in a graffito incised on the bottom of a cup: P-101 aini | dabp?ula isini. It has been identified by Hämming (fthc. b) in the light of the recently

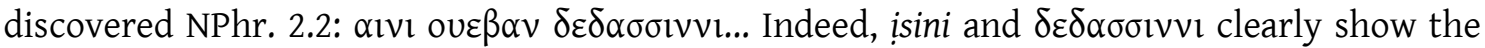
same 3pl. ending -sini / - $\sigma \sigma \mathrm{lvvl}$. However, the meaning of P-102 remains unclear. The other

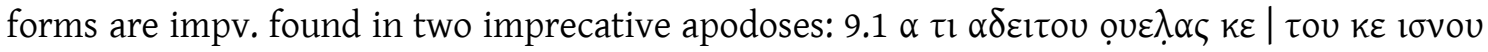
$\alpha \sigma \tau 01 \pi \alpha \rho \tau \eta \varsigma$ and $21.1[\zeta \varepsilon] \mid \mu \varepsilon \lambda \omega \varsigma \kappa \varepsilon[\delta] \varepsilon[\omega] \varsigma \mu \varepsilon$ kovvou $\kappa \varepsilon 1 \sigma v 10[v] \mid \alpha l \pi \alpha \rho \tau \eta \varsigma$. However, the variant $10 \mathrm{v} 1 \mathrm{o}[\mathrm{v}]$ remains unexplained. The OPhr. form isnou is read on a terracotta disc: NW101a deVeti | toTi a tiei | as|na isnou. Brixhe (2004a, 9-10) suggested that isnou goes back to PIE * $h_{1}$ es- 'to be' (LIV 241-242, IEW 340-341) and also considered NPhr. ıvvov 28.1 a variant of this verb. However, on the basis of its occurrences, this last form is more easily explained as a variant of $(\alpha \delta)$ Eıtvou.

Brixhe 2004a, 9-10; Hämmig fthc. b.

isnou and $10 \mathrm{vlo}[\mathrm{v}]$ see isini.

toos see yos.

ispas (PN)

OPhr. sg.nom. ispas W-12

An $a$-stem PN read after other possible PNs in a stone fragment from Kütahya: sitoros aros $\mid$ ispas. Since no parallel is attested in Phrygian, Bilgen, Brixhe and Coşkun (2011,148-149, followed by Locatelli 2015, 109-110) interpreted it in the light of the many PNs found in Anatolia which

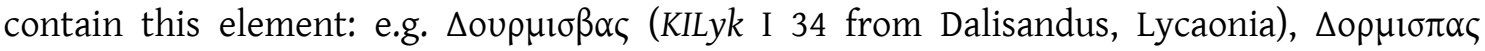

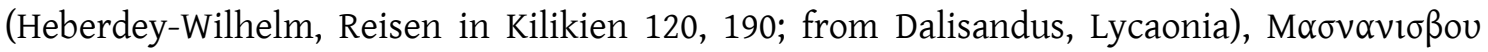

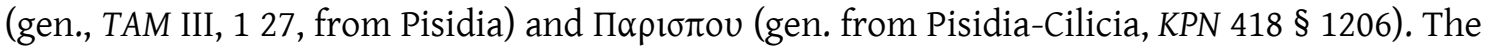
interpretation given by the first editors and Locatelli is that PNs in $-1 \pi \alpha \varsigma \sim-1 \beta \alpha \varsigma$ contain the Anatolian word for 'horse', although they consider some of the vowels to be unexpected. However, since PIE * $h_{1} e ́ k u$ - 'horse' (post-Anatolian PIE *héku-o-, NIL 230-233, IEW 301-302, see also Kloekhorst 2008, 237-239) in Lyc. is attested as esb- (where $<b$ > represents / $\beta /$ ) and in HLuw.

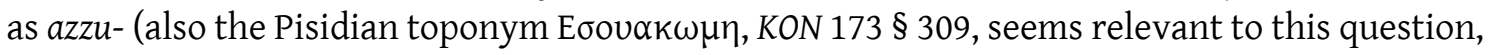
see Starke 1995, 119), this onomastic element cannot be considered the Anatolian 'horse'. Consequently, the best candidate is the Median aspa-, which even fits perfectly from a chronological point of view, since W-12 is dated to the $4^{\text {th }} \mathrm{C}$. BC. Nevertheless, it is not at all clear that all the occurrences from Anatolia are related to the same form because names such as M $\alpha \sigma v \alpha v i \sigma \beta o v$ can be analysed as $M \alpha \sigma v \alpha-v i \sigma \beta o v$ in the light of $K \lambda v-v i \sigma \beta\|\alpha \varsigma\|$ (recently found in Termessos, Adiego in p.c.). In any case, in the light of the other occurrences of PNs with -l $\pi \alpha \varsigma$ $\sim-1 \beta \alpha \varsigma$ (only found in compound names), Bilgen, Brixhe and Coşkun (2011, 148-149) also considered the possibility of two instead of three PNs in this inscription. Then, aros|ispas would be a compound PN despite the lack of parallels. However, the first element is obscure and -os can be considered the common sg.nom. thematic ending.

Bilgen, Brixhe \& Coşkun 2011, 148-149; Locatelli 2015, 109-110. 


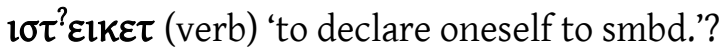

NPhr. 3sg.subj.pres.act. $1 \sigma \tau^{2} \varepsilon 1 \kappa \varepsilon \tau 6.1$ (88)

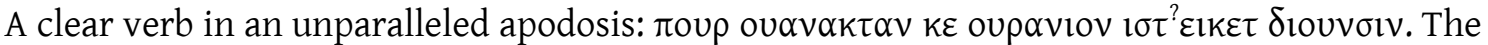
reading of its third letter conditions its etymology and meaning: $\gamma$ or $\tau^{?}$ The older reading is

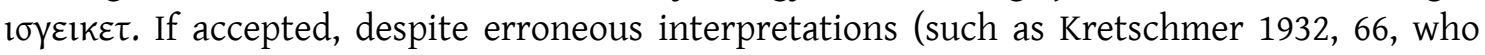

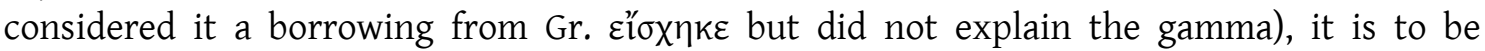
considered an inherited verb from the PIE root *seg ${ }^{h}$ - to hold, to overpower' (LIV ${ }^{2}$ 515-516, IEW 888-889, Gr. '̌ $\chi \omega$ 'have, hold') in zero-grade with a prothetic initial $t$ - (a common feature of Gr. from Phrygia). In such a scenario, the whole apodosis means: 'and he will have to do with the

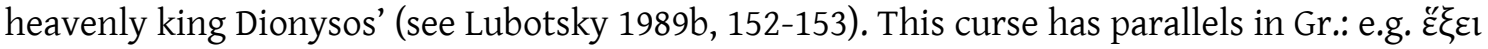

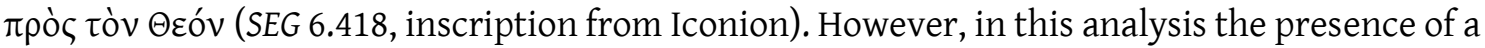
kappa before the ending remains unexplained. On the other hand, Lubotsky (2004, 235,

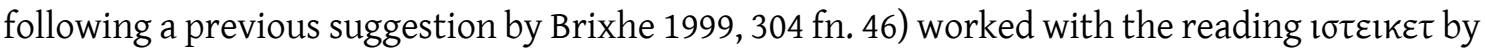

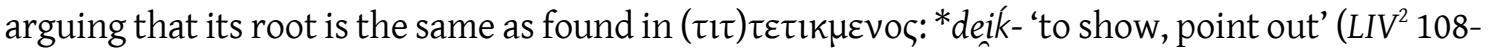
109, IEW 188-189, Gr. 'id.', Skt. diśáti 'point out, show, exhibit', Lat. dico 'say, utter, speak'). Following this explanation, the kappa is inherited from the PIE root. Regarding the beginning, $1 \sigma$ - is interpreted as a preverb ${ }^{*} h_{1} e n s>*_{e s}>$ is (LIPP II, 266) and the whole formation is equated

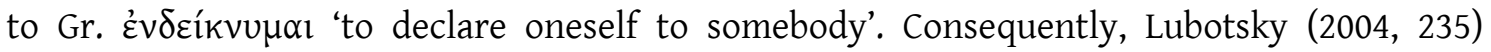
translates this apodosis as 'he will be responsible towards the heavenly king Dionysos' (perhaps 'let him be responsible' is more suitable since the verb is subj.). It must be added that $1 \sigma$-before the dental of the root is expected to undergo an assimilation, as in $\tau ı \tau-\tau \varepsilon \tau \imath k \mu \varepsilon v o \zeta$, although perhaps this is merely an etymological notation.

MAMA I, 216-217 no. 413; Kretschmer 1932, 66; Dressler 1965, 96; Lubotsky 1989b, 152-153; Brixhe 1999, 304 fn. 46; Lubotsky 2004, 235; Ligorio \& Lubotsky 2013, 193.

itovo see tovo.

\section{itoiesgloka (?)}

OPhr. itoiesgloka G-229

Obscure sequence which precedes once the PN mamutas in a graffito incised on a handle: mamutas sokposa I mamutas itoiesgloka. Since the two lines seem to rhyme, CIPPh (I, 184) considered that the meanings of sokposa and itoiesgloka are complementary. However, the lack of a parallel for both words complicates their analysis. Moreover, the segmentation itoies gloka cannot be ruled out, since -es is well attested as sg.nom. (e.g., garies G-224, eies G-108 and paries G-224).

CIPPh I, 183-184.

ltov see ituv.

ituv (verb) 'become'

OPhr. 3sg.impv.act. ituv B-05 1.13

NPhr. 3sg.impv.act. $\quad \alpha \delta \varepsilon l \tau o v ~ 9.1 ~(87), 38.1$ (44), 39.1 (11), 40.2 (13), 41.1 (45), 42.1 (101), 44.1 (61), $44.3(67), 49.3(85), 51.1(80), 53.1(76), 53.2(77), 56.1(57), 58.1$

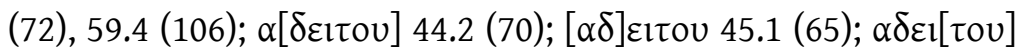

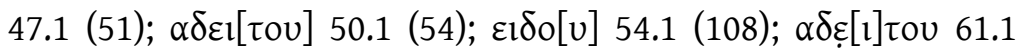
(100)

3pl.impv.act. $\quad \alpha \delta \varepsilon ı \tau \tau \vee o v ~ 40.1(12)$

3sg.impv.act. $\quad \varepsilon 1 \delta o[v] 54.1(108)$

3sg.impv.act. Eltov 1.1 (48), 2.2 (130), 4.1 (2), 7.1 (99), 8.1 (86), 10.1 (112), 11.1 (17), 11.3

(17), $13.1(122), 14.1(73), 17.2(3), 17.5$ (91), $17.6(119), 18.1(4), 18.3$

(6), 19.1 (96), 20.2 (128), 20.3 (62), 22.2 (118), 24.1 (40), 25.1 (115), 
25.2 (126), 26.1 (8), 26.2 (38), 29.1 (114), 30.1 (39), 32.1 (93), 33.1

(28), 34.1 (37), 35.1 (25), 36.1 (26), 36.3 (94), $37.1(10), 43.1(69), 46.1$

(53), 52.1 (75), 53.1 (76), 55.1 (56), 58.1 (72), 64.1 (81), 65.2 (104),

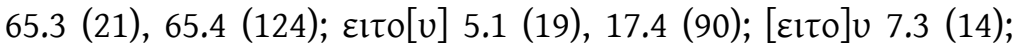

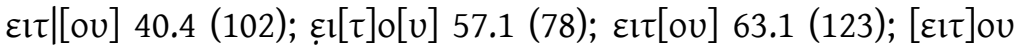

$66.1(103)$

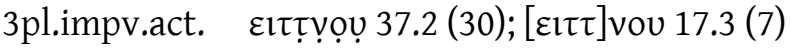

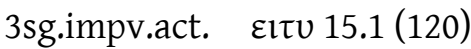

3pl.impv.act. $\quad$ пou $18.2(5)$

3pl.impv.act. Ivvou $28.1(71) ;<1>$ vvov $62.4(35)$

3sg.impv.act. itov 6.1 (8)

This verb is always found in imprecative apodoses: e.g. yos isekosos 个emeney dupratoy, veban ituv

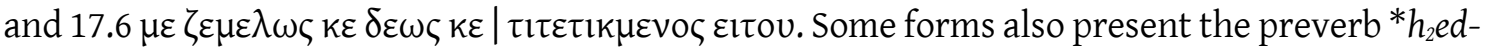

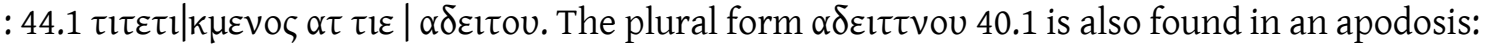
$\zeta \varepsilon ı \rho \alpha \kappa \varepsilon$ ol $\pi \varepsilon l \varepsilon \zeta \kappa \varepsilon \tau \imath \tau \mid \tau \varepsilon \tau 1 k \mu \varepsilon v \alpha \propto \tau \tau \tau l \varepsilon \alpha \delta \varepsilon ı \tau \tau v o v$. This last form is the key to identifying the

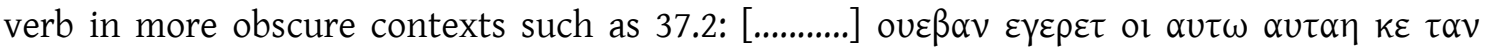

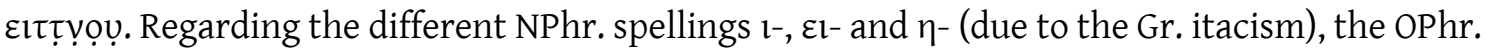
ituv reveals that the first vowel is $i$ - and not the diphthong ei-. Consequently, its etymology can

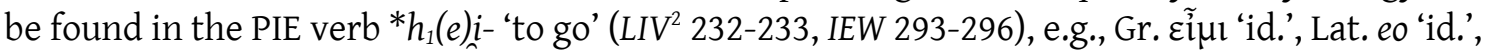

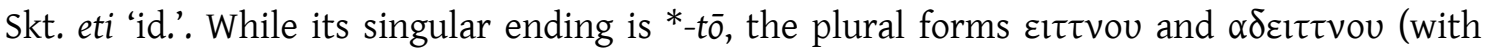
preverb) seem to be a metathesis of the inherited PIE ending: ${ }^{-} n t \bar{o}>-t n u$. The form $\varepsilon 1 \delta$ o[v] 54.1

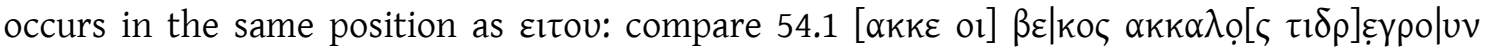

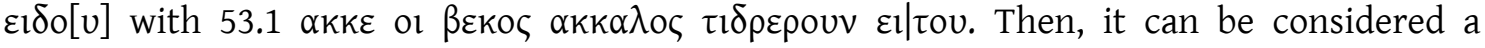
secondary intervocalic voicing of the stop: $\varepsilon 1 \mid \tau o v>\varepsilon 1 \delta o[v]$. Finally, in 28.1, ıvvou is found in the

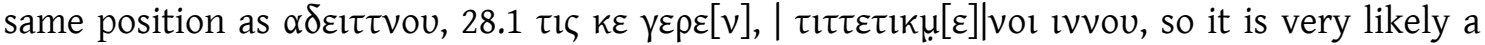
variant without a preverb. The second possible occurrence of this variant is found in an unparalleled apodosis: $62.4 \alpha \zeta \alpha v \alpha v \kappa \alpha 1$ ol $\pi \alpha v \tau \alpha \kappa \varepsilon v \alpha \mid<1>v v 0 v$.

Panagl \& Kowal 1983, 1988; Brixhe 1990, 81-84 and 90-91; Orel 1997a, 426; Brixhe 2004a, 64; Sowa 2007a, 88; Ligorio \& Lubotsky 2013, 192.

it $[---]^{1}(?)$

OPhr. it[---] T-01b

Because of the interpunction, it can be clearly identified as the beginning of a word. However, since the stele on which it is read is very fragmented no interpretation can be given: [---]sid. $[---]\left|[---] . l e n^{?}: i t[---]\right|[---]$ ponani : [---].

CIPPh I, 259-260.

$i t[--]^{2}(?)$

OPhr. it[-?-] or [-?-]ti G-274 b

Unparalleled graffito incised on a sherd. Even its reading direction is unknown. It is perhaps a PN. Another sherd from the same vase bears the incision mam? $i$.

iyga[-?-] see ịlay.

iyungidas (PN)

OPhr. sg.nom. iyungidas B-07

According to Brixhe $(2004 a, 77-78 ; 2006,401)$, this is a patronymic read in an onomastic part of a funerary stele, where it agrees with manes: $s$ manes iyungidas manitos apelev porniyoy esț[..]. It has been equated to the epic Gr. forms in $-1 \delta \eta \zeta$. However, the phonetic correspondence is not expected since the voiced stop shifted to voiceless in Phr. Consequently, either it is a borrowed suffix or, more likely, the identification is incorrectright. Note that the same Gr. patronymic 
suffix was erroneously suggested for Lyc. ipresidah (TL 29, see Adiego 2011, 329-332 and Schürr 2017, 3-5). Indeed, manes iyungidas can be considered a compound PN such as M-03 [b] abas iman. In any case, this name remains unparalleled.

Gusmani \& Polat 1999, 156; Brixhe 2004a, 77-78; Brixhe 2006, 401; Avram fthc.

$i^{?} \cdot[---](?)$

OPhr. i?:[---] G-128

Graffito incised on an undated pithos:[-?-]avsị i? ${ }^{\text {? }}$ [---]. Although the whole inscription is obscure, a word boundary is considered between both the two ¿i. However, since the letter yod is not

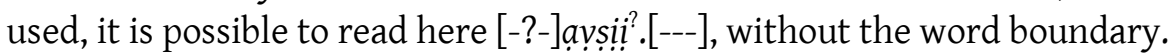

Brixhe 2002a, 44 


\section{$\mathrm{K}(k)-\mathrm{K} k$}

$k$ see $k e$.

${ }^{\dagger} k a\left[?{ }^{?}\right]$ see podaskai.

kad[---] and [-?-]kad see kadiun[---].

kadiun[---] (PN?)

OPhr. [-?-]kad G-102 a?

$\mathrm{kad}[---] \mathrm{C}-101$ ?

kadiun[---] G-103

Since all occurrences are found on sherds, it has been considered a PN. Perhaps G-102a and C101 are abbreviations of the same PN found in G-103. Since it is not attested elsewhere, its origin is very likely Phrygian. In G-102 another graffito was incised: [---]d?oi? ọ [---].

Lejeune 1969a, 21; CIPPh I, 97-98, 221.

kạvarmọyo and kạvarmọyoi see kavarmoỵun.

kavarmoyun (PN)

OPhr. sg.gen.? kavarmọyo B-01 1. 2; kavarmoyo B-08

sg.acc. kavarmoyun B-01 1. 7

Despite the lack of parallels, it has been considered an o-stem PN by Lubotsky (1989b, 152). This interpretation is better than the proposal of Orel's (1997, 140, 146 and 435), who considered it an adjective, since kavarmoyun in B-01 does not seem to agree with any noun. The case of kavarmoyo is dubious because of the still discussed o-ending, although it is often considered the thematic gen.sg < *-o-uo by Brixhe. Attempts to read it as a dat.sg. "kavarmoyoi (Bayun \& Orel 1988a, 186-187 and Orel 1997a, 140, 146 and 435) must be rejected because there is a blank used to note the word boundary between $o$ and the following $i$ (with accidental traces according to Lubotsky 1993, 93 after CIPPh I, 64 consideration of a probable letter). The two occurrences in B-01 appear in two different contexts. While kavarmoyo is read at the beginning of the inscription, where the general monument is depicted (si bevdos adi..[..] kavarmoyo imroy edaes...), the acc. form appears in a less clear part (opito [k]ey oy ev[e]m[e]mesmeneya anato $\left(.^{?}\right)$ kavarmoyun matar otekonov (.?) | kesiti oyvos a). In B-08 the text is eroded and the context lost (Brixhe \& Vottéro 2016, 136).

Bayun \& Orel 1988a, 186-187; Lubotsky 1989b, 152; Lubotsky 1993, 93; Orel 1997a, 140, 144, 146 and 435; Brixhe \& Vottéro 2016, 136.

kaka see kakouv.

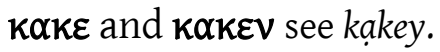

kakey (adverb) 'ill'

OPhr. kakey B-05 1.8

NPhr. KakE 6.1 (88), 7.1 (99), 65.3 (21), 65.4 (124)

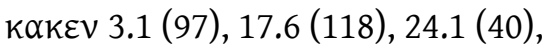

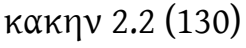

Kakıv 7.3 (14)

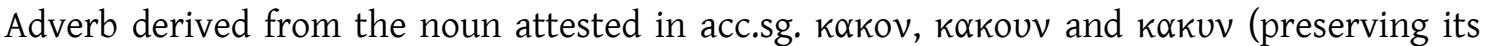
sound in unstressed position). The use of this adverb instead of the more common noun in the 


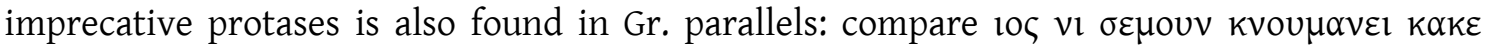

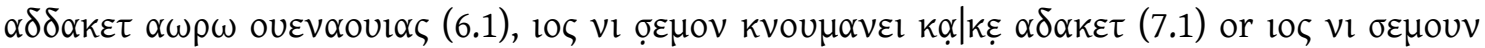

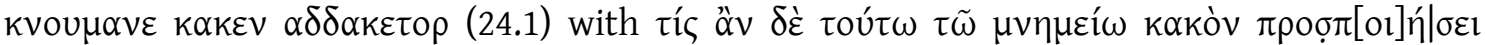

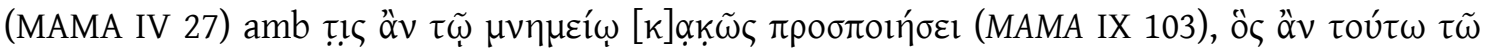

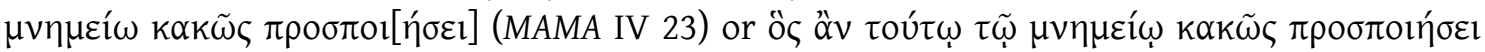

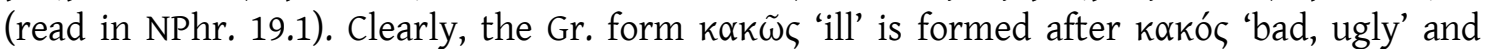

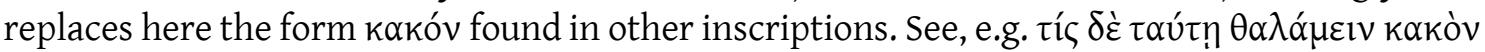

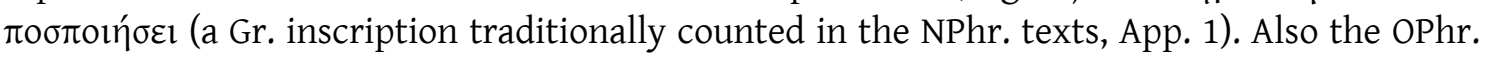
occurrence B-05, yos niy art sin=t imenan kaka oskavos kakey kạn dedasitiy..., is an imprecative protasis. On the different spellings, the final yod from kakey is merely graphical, as well as the last ny of the NPhr. forms, a common hypercorrection documented after the drop of this nasal sound in final position. The eta in most instances in the NPhr. subcorpus notes the vowel /e/,

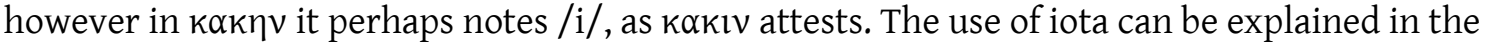
light of the neutralisation of /e/ and /i/ in unstressed position. In any case, its ending may go back to the PIE thematic ins. ${ }^{*}$-eh $($ see $\S$ 4.1.2.2.3 and $\S$ 4.2.3.2).

Brixhe 1999, 309; Hämmig 2013, 146-147.

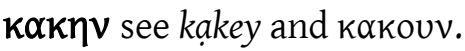

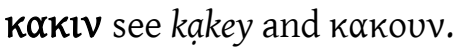

kakoioi (verb) 'damage, maltreat'

OPhr. 3sg.opt. kakoioi G-02c 3sg.opt. kakuioi P-04b

Denominative verb formed after the noun kakouv with the suffix *-oio. The verb is parallel to

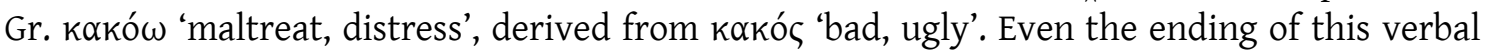
form is the same as found in the Gr. opt. -ol. Indeed, both Phrygian forms occur in two different protases (G-02 c ios oporokitis. | kakoioi tovo and P-04 b ios ervotsati kakuioi...) and are morphologically the same, but kakuioi shows the common shift /o/ into /u/.

CIPPh I, 87 and 239; Meier-Brügger 1992, 65; Brixhe 2006, 40; Sowa 2007a, 87-88; Kloekhorst 2015, 114.

kakov see kakouv.

kokouv (noun) 'harm'

OPhr. pl.nom.-acc. kaka B-05

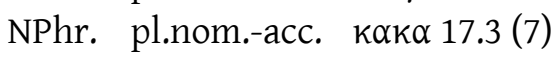

sg.nom. Kakov 10.1 (112), $14.1(73), 15.1(120), 16.1(116), 19.2$ (129), 22.2 (118), 25.1

(115), 29.1, 31.1, 32.1, 33.1, 36.1, 37.2, 40.4, 43.1, 52.1, 58.1, 62.2, 66.1

sg.nom. Kakouv 4.1 (2), 5.1(19)?, 8.1 (86), 9.1 (87), 10.2 (113), $11.2(18), 12 . .1(121)$ ?,

13.1 (122), 17.4 (90), 17.5 (91), $18.1(4), 18.3(6), 20.1(63), 20.2(128), 21.1$

(42)?, 21.2 (43), 25.2 (126), 26.2 (38), 27.1 (92), 30.1 (39), 30.2 (68), 33.1

(28), 33.2 (95), 35.1 (25), 36.3 (94), 37.1 (10), 38.1 (44)?, 40.2 (13), 41.1

(45), 42.1 (101), 44.1 (61), 44.2 (70)?, 44.3 (67), 45.1 (65), 46.1 (53), 47.1

(51)?, 49.1 (110)?, 50.1 (54), $50.2(55)$ ?, 51.1 (80), 53.1 (76), 53.2 (77), 55.1

(56), 56.1 (57), 57.1 (78), 59.2 (47), 59.3 (79), 59.4 (106), 60.1 (59), 60.2

(60), 61.1 (100), 62.1 (32), 62.3 (34), 62.4 (35), 62.5 (36), 62.6 (105), 63.1

(123), $64.1(81), 65.1(20)$

sg.nom. Kakvv $20.3(62)$

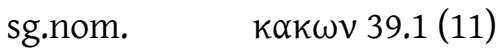


A thematic neuter noun derived from an adjective. Most occurrences are found in the common

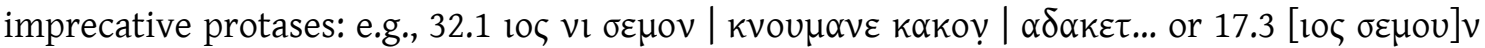
$\kappa v o u \mu \alpha v \imath \kappa \alpha \kappa \alpha \mid[\alpha \delta \delta \alpha \kappa] \varepsilon v$... Even the OPhr. form appears in this position: yos niy art sin=t imenan kaka oskavos kakey | kan dedasitiy... The main form is the sg.nom. form kakouv but the spelling variants show the common hesitation between /o/ and / $\mathrm{u} /:$ k $\alpha \kappa v v$, $\kappa \alpha \kappa o v$ and $\kappa \alpha \kappa \omega v$ (after the

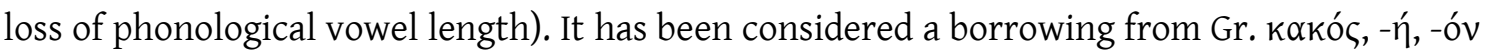
'bad' (EDG 620) but also a Greco-Phrygian isogloss (as Brixhe 2006, 40 defends). Indeed, there is not a clear argument to prefer one interpretation over another, because even the Gr. etymology remains unclear. In Phrygian its derived adverb kakey / $k \alpha k \varepsilon$ is used in the same position in the curse.

Ramsay 1905, 81; Meier-Brügger 1992, 65; EDG 620; Brixhe 2006, 40.

kakuioi see kakoioi.

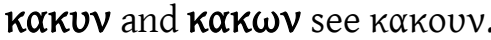

kaliya $(\mathrm{PN})$

OPhr. sg.nom. kaliyạ B-05 1.1

sg.dat. kaliyay B-05 1.6

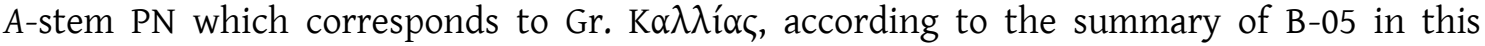
language: 1.1 sin=t imenan kaliya ti tedat [...], 1.6 nidus ad kaliyay karatu panato and Gr. $1.1 \mathrm{~K} \alpha \lambda \lambda i$ íc

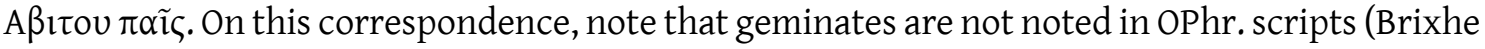
2004a, 51), so kaliy a may be read as /kallija/. However, despite the quasi-bilingual text, a Luw. origin cannot be ruled out in the light of Kwa/i-li-i(a)/Kwalija/ read in the graffito no. 5 or Suratkaya (Beşparmak Mountain, Caria, see Oreshko 2013a, 361) with a Phrygian labiovelar treatment: Kwaliya > Kaliya. A variant of this Luw. name is attested in Phrygian as kuliya, read

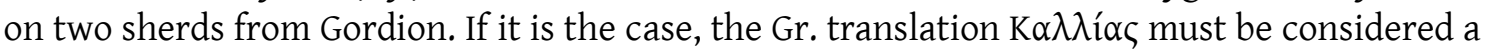
later reinterpretation of this PN.

Brixhe 2004a, 51.

kạliyay see kạliyạ.

kan (adverb?) 'somehow'

OPhr. kan B-05 1.9

NPhr. Kav $20.3(62) ; 46.1$ (53)

Since its only certain occurrence is in a protasis with many parallels, it is not likely to be a particle related to Arc. $k \alpha v$ (Aeol. $k \varepsilon$, Ion. ö́v): yos niy art sin=t imenạn kaka oskavos kakey | kạn dedasitiy... Consequently, Hämmig $(2013,148)$ has suggested that it is an adverb derived from the pronoun * $k^{u} e / o$ - (a root also attested in Phrygian as ko ) with the meaning 'somehow', parallel to Lat. quam and Arm. k'an 'id'. In that case, it shows a fossilised acc. ending -an (PIE < $\left.*_{e h} m\right)$ similar to the one found in the adverb $v \psi \circ \delta \alpha v$. Also, as Brixhe $(2004 a, 61)$ considered, it is very likely found in the NPhr. sequence $\alpha$ lk $\alpha v$ read in two apodoses: $20.310 \zeta v l \sigma \varepsilon \mu v v$

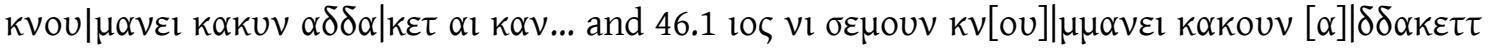
$\alpha \mathrm{l} \kappa \alpha v_{. .}$

Brixhe 2004a, 61; Hämmig 2013, 148.

kanutiẹ[---] see kanutieivais. 
kanutieivais (patronymic) 'son of kanutî’

OPhr. kanutiẹ[---] P-05

sg.nom. kanutieivaịs $\mathrm{P}-03$

sg.gen. kanutii'evanoș? $\mathrm{P}-02$

Since always it is found following the same person (a man called vasus only documented in Pteria), it is considered a patronymic: P-02 sest bugnos valsos kanutii evanoṣ?, P-03 vasous iman mekas | kanutieivais | devọs ke mekas and P-05 vasus kanutiẹ[---]. Indeed, the name Kanutî is found in Neo Assyrian (Fales \& Jakob-Rost 1991, 132-133 no. 66). Regarding its inflection, the sg.nom. has been used by Brixhe (2004a, 41-12) to prove the shift *-ans > -ais. Going one step beyond, Ligorio and Lubotsky $(2013,187)$ considered it a t-stem: sg.nom. *-unt-s $>{ }^{*}$-uans $>-(e)$ vais and

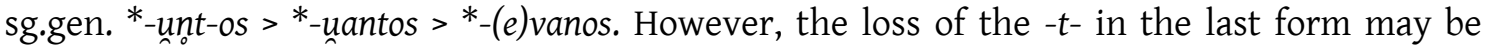
analogous to the sg.nom. (see $\S$ 4.2.1.1.5.2).

CIPPh I, 231; Brixhe 2004a, 41-12; Ligorio \& Lubotsky 2013, 187.

kanutii? evanoṣ see kanutieivạis.

karatu (verb?)

OPhr. 3sg.impv. karatu B-05 1. 5; karatu B-05 1.6

This form can be considered a verb in imperative because of its ending in - $t u$, also documented in OPhr. as -tuv and in NPhr. as - - 0 . Regarding its root, Gorbachov $(2008,106 \mathrm{fn}$. 31) suggested a loanword from HLuw. $k a+r a / i-t u$ 'to sacrifice' (in ALEPPO 6 twice). However, the contexts of both Phrygian occurrences are still obscure: ... vay niptiyạy dạker karatu enpsatus mekạ[---]asiyạ..? | nidus ad kaliyay karatu panato andopopostois klam?iv[..? ...

Gorbachov 2008, 106 n. 31.

\section{karea[-?-] (PN?)}

OPhr. karea[-?-] B-103

Perhaps this word read on a sherd is complete and is an a-stem PN without s-ending. However, because of the lack of parallels it remains unclear.

Brixhe 2004a, 88.

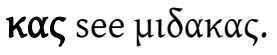

ke (conj.) 'and'

OPhr. $\quad k$ B-04 1. 7?, B-07

ke B-04, B-05 1.7 and 1. 12, B-06, B-07, P-03

key B-05 1.4?, 1.7 and 1. 9; B-08 (bis)

MPhr. $\kappa \eta$ MPh-01 1.2

NPhr. $\quad$ k 11.2 (18) 1. 5, 15.1 (120), 16.1 (116) 1. 3, 37.2 (30), 53.1 (76), 59.4, 62.5

KE 1.1 (48), 3.1 (97), 4.1 (2), 6.1 (88), 7.1 (99), 8.1 (86), 9.1 (87), 10.2 (113), 11.2 (18), 15.1

(120), 16.1 (116) 1.1 and 1. 2, 17.2 (3), 17.3 (7), 17.6 (119), 18.2 (5), 18.3 (6), 19.1 (96),

20.1 (63), 20.2 (128), 20.3 (62), 21.1 (42), 22.2 (118), 24.1 (40), 27.1 (92), 28.1 (71), 29.1

(114), 30.1 (39), 34.1 (37), 37.2 (30), 40.1 (12), 43.1 (69), 50.1 (54), 58.1 (72), 62.2 (33),

$62.3(34), 62.5(36)$

kп $2.2(130)$

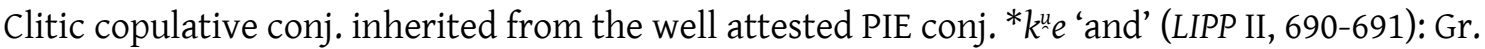
$\tau \varepsilon$ (Myc. qe), Lat. -que, Skr. ca, etc. As is common in other IE languages, it usually appears after the second word it links or after the first word of the second sentence it coordinates. Sometimes it appears twice, after the first and the second element. Compare, e.g., $\mu \varepsilon \delta \varepsilon \omega \varsigma \kappa \varepsilon \zeta \varepsilon \mu \varepsilon \lambda \omega \varsigma \kappa \varepsilon$ (3.1) with $\delta \varepsilon \omega \zeta \zeta \varepsilon \mu \varepsilon \lambda \omega \varsigma \kappa \varepsilon$ (24.1). Key, as Hämmig (2014, 132-133) identified, is a mere graphic 
variant of $k e$. The form $k \eta$ reveals the use of eta to note the short vowel /e/ also attested in other words. Finally, $k$ and $k$ are the apocopated form before vowel: see B-07 1. 2-3 meros ke manes

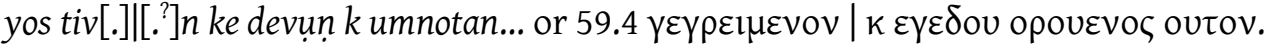
Berenguer Sánchez 2000, 445-446; Brixhe 2004a, 17; Poccetti 2012; Hämmig 2013, 132-133; LIPP II, 691.

${ }^{\dagger} \kappa \varepsilon \beta \rho \varepsilon \imath \tau$ see ke and $\beta \rho \varepsilon ı$.

kevos see nevos.

kek.[---] (?)

OPhr. kek.[---] G-128

Unparalleled sequence read after the PN atas on a sherd.

CIPPh I, 119 .

\section{kelmis (PN?)}

OPhr. sg.nom. kelmis B-05 1. 7

The only parallel of this word is the name of one of the Dactyls of Mount Ida, Ké $\lambda \mu \iota \zeta$. He appears in Ov. Met. 4.282 (as Celmis) and in Clem.Al. Strom. 1.16.75 (= Idaean Dactyls frag. 282, Melkelbach

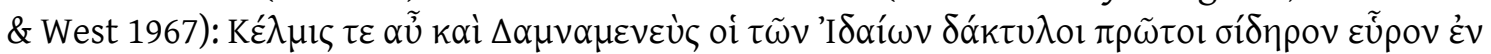

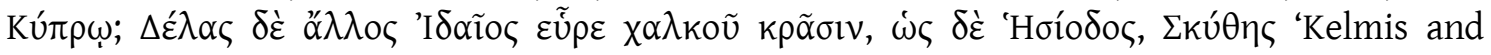
Damnameneus, the Idaean Dactyls, were the first to discover iron in Cyprus; Delas, another Idaean, discovered the mixing of bronze, but according to Hesiod it was Scythes'. The nom.

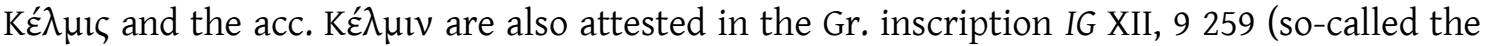
'Dactyl's Hymn', from the $4^{\text {th }}$ c. BC, see Schaaf 2014, 306-307 with a revised edition). The importance of this text is that its chronology is not far from the Phrygian B-05 and that it shows an $i$-stem. Although it is unknown whether they refer to the same person or character, it can be interpreted as a PN. However, its context in the Phrygian text B-05 remains unclear: andopopostois klam?iv[..?] | kelmis ke umnișet evradus dạkerais key iverais [..] ... Neumann 1997, 22; Brixhe 2004a, 59; Berndt-Ersöz 2006, 169.

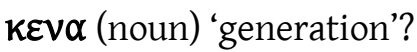

NPhr. pl.nom-acc.neut. kEv 62.4 (35)

A word read in an imprecative apodosis, where it works as the subject: $\alpha \varsigma \alpha v \alpha v \kappa \alpha$ l ol $\pi \alpha v \tau \alpha$ $\kappa \varepsilon v \alpha<1>v \vee v 0$. According to Lubotsky $(2004,233)$ it is a derivative which goes back to PIE ${ }^{*} g e n h_{1}-$ (NIL 139-153), parallel to Gr. үعveá 'race, generation, offspring' (secondary fem.) or Lat. genus, -eris 'birth, descent, origin; a race, stirps, offspring' (pl.nom.-acc.neut. genera). Thus, Lubotsky suggested a form * genh ${ }_{1} e s-h_{2}>$ keneha $>\kappa \varepsilon v \alpha$, in the light of our knowledge of Phrygian phonetics. The earlier interpretation given by Haas (1966, 119, followed by Brixhe 1993, 341 and Orel 1997a, 255), a loanword from Gr. kعvó ` 'empty', hardly fits with the context.

Lubotsky 2004, 233; Matzinger 2006, 199-200.

keneman (noun) 'niche'

OPhr. sg.nom.-acc.neut. keneman M-01b

Because of its context, baba memevais proitavos $k$ Фiyanaveyos si=keneman edaes, and its ending, keneman is clearly the object which agrees with the pronoun si. Since the monument on which it was engraved is not a tomb but a cult façade, the meaning given by Haas $(1996,76)$ in the light

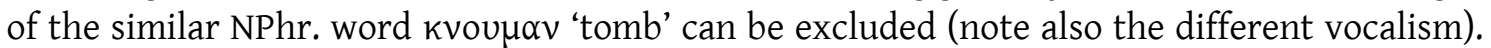
Böker-Klähn (2000b, 90, followed with more realia-arguments by Berndt-Ersöz 2005, 72-74) suggested a loanword from Akkadian sikkanum via Hitt. sikkanu, which implies that si-, attested before the object in some of this kind of sentence (see B-01 si bevdos ... edaes), is the beginning 
of the noun. More likely, it refers to the niche which is excavated in the centre of the façade where this text is engraved. Following the first tentative identification by Haas $(1966,76$, also in Beekes 1969, 21), Lubotsky $(1988,15)$ and Matzinger $(2005,378)$ classified keneman as a noun derived from the PIE verbal root * $k_{e} h_{1^{-}}$, attested in Skt. khánati 'to dig' (see also Ligorio \& Lubotsky 2013, 189 and 192-193). Then, a form *kenh ${ }_{1}-m_{0}$ is suggested. However, LIV (344) reconstructs this root as ${ }^{*} k^{(w)} e h_{2^{-}}$(IEW 634) and this laryngeal does not fit the Phrygian form. An alternative interpretation can be found by equating OPhr. kene-man to Gr. *ken(e)-wó- 'empty,

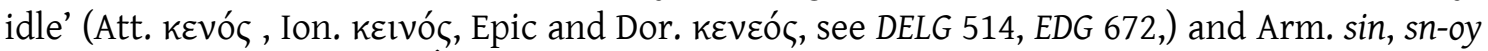
'empty', which go back to *ken-e/o- (Clackson 1994, 138-139 and Martirosyan 2010, 575 and 2013, 116). Consequently, it implies a derivation from *ken-e- 'empty' to *ken-e-mn 'cavity, niche'. Haas 1966, 76; Beekes 1969, 21; Panagl \& Kowal 1983, 187; Brixhe \& Neumann 1985, 170-171; Lubotsky 1988, 15; Neumann 1994, 347-348; Gorbachov 2005, 197; Matzinger 2005, 378; Ligorio \& Lubotsky 2013, 189 and 192-193.

\section{kenos (PN)}

OPhr. sg.nom.kenos G-297

A complete inscription incised on a sherd. Very likely a complete o-stem PN. It can be hardly interpreted as the singular of $k \varepsilon v \alpha$ because such a word would be very disconcerting in this

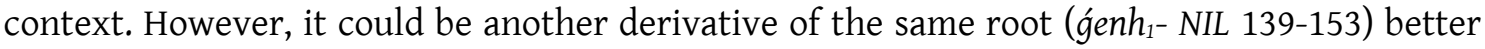

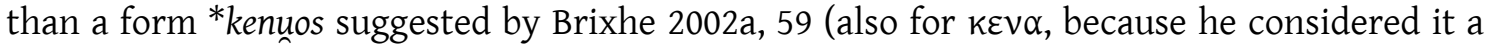
parallel or loanword from the Gr. kعvó ৎ 'empty').

Brixhe 2002a, 59.

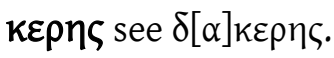

\section{kermọ̣[---] (PN?)}

OPhr. kermộ[---] or kernọ[---] G-104

It is difficult to choose between the two readings because the sherd is broken. While Bayun and

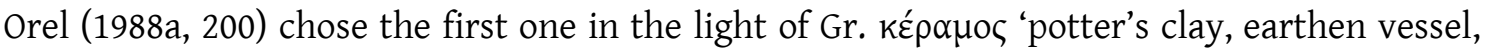
wine-jar', Woudhuizen $(2008-2009,198)$ preferred the second one and considered it a parallel

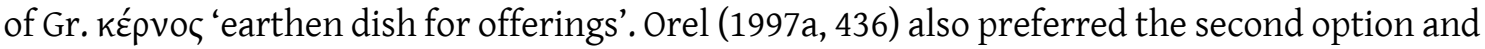

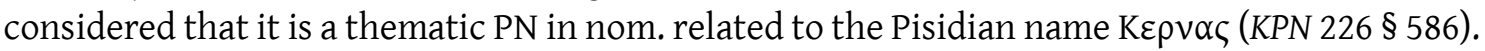
CIPPh I, 98-99; Bayun \& Orel 1988a, 200; Orel 1997a, 436; Woudhuizen 2008-2009, 198.

\section{kernộ[---] see kermọo[---].}

\section{kesiti (verb?)}

OPhr. 3sg.? kesiti B-01 1. 8

Although both the context (kavarmoyun matar otekonov ? kesiti oyvos aey apaktneni) and its meaning are unclear, the ending suggests that we may be dealing with a verb. The segmentation of this word is given by Lubotsky $(1993 b, 96)$.

Lubotsky 19936, 96.

\section{key and $\mathrm{k \eta}$ see $k e$.}

key.[---] (?)

OPhr. key.---] B-06

A damaged sequence in the first conserved line of a funerary stele. Brixhe (2004a, 71) suggested that perhaps key is found here as well as in B-05 (1. 4, 7 and 9). Now key is known to be an alternative spelling of the copulative conj. However, it occurs in the same line as ke, so this

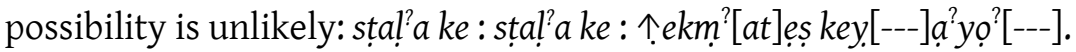

Brixhe 2004a, 71. 


\title{
kikos (PN)
}

OPhr. sg.nom. kikos G-284

Since it is a complete graffito incised on a sherd, this word is very likely a PN. Brixhe (2002a, 45)

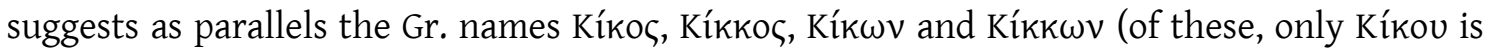
attested in Anatolia, in the inscription CIG 4367 from Ormeleis, Pisidia), assumed to be derived from the Gr. noun Kĩkvৎ 'strength, vigour' if we accept the etymology given by Meier-Brügger and Lamberterie (see EDG 697), a reduplicated form of * kueh ${ }_{1}^{-}$'to be strong' (LIV 339 , IEW 592594): *kikuos. While this form fits well with Phrygian historical phonology, the Gr. etymology has been discussed by Beekes (EDG 697, see also § 4.6.1.5. for a Phr. interpretation of this noun) and the Phr. and Gr. names are not necessarily cognates; the Phr. name could be a borrowing from Gr. names, as Brixhe admits (see muksos, in the first datable Phr. inscription), or even a mere illusory coincidence.

Brixhe 2002a, 45.

kin see kos.

$\kappa \imath v o[v] \mu \alpha$ see $\kappa v o v \mu \alpha v \varepsilon l$.

\author{
kıoulৎ (pronoun) 'any'? \\ MPhr. sg.nom. kiбuis MPhr-11 (W-11) l. 1 \\ sg.nom.-acc. kiviv MPhr-11 (W-11) 1.5
}

According to Brixhe (2004a, 14-15) this is a compound pronoun made with the interrogative pronoun * $k^{u} i s^{i}$ 'who' and the non-personal pronominal theme *ue / *uo / *ui or the verbal form *uei-si 'he wants, wishes'. In the latter scenario, a good parallel is the Lat. quiūs, however this would imply the simplification * $i>i$, often rejected by Lubotsky. Morphologically, the neuter form shows an ending $-v$ borrowed from the nominal inflection. Finally, it must be added that, with the exception of a small number of words, the whole funerary stele on which both forms

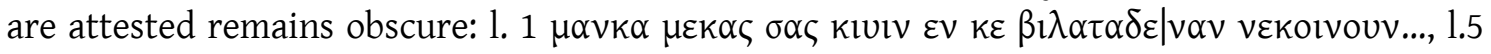

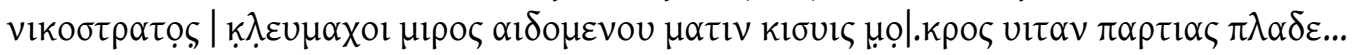
Brixhe 2002a, 14-15.

\section{klạmiv[..?] see klaniviv.}

\section{klaniv (?)}

OPhr. klaniv or klam?iv[..?] B-05 1.6

This word is read in the non-imprecative part of B-05: nidus ad kaliyay karatu panato andopopostois klạniv kelmis ke umnișet evradus dạkerạiș key iverais [..]. The reading presents certain difficulties: while Neumann $(1997,19)$ read klaniv, Brixhe $(2004 a, 58$ and 61) preferred klam?iv[..?] and suggested that perhaps two letters are lost. The first reading fits better with the shape of the discussed letter and a word boundary after waw is not surprising in this stele: see tubetiv or deraliv. The form tubetiv seems to be a verb in tubetiv (related to the imperative tubnuv), however here the ending is not -tiv. On the other hand, deralive is not clearer than klaniv. The only possible related term is found in the polionym from Galatia K入óveos, -ov (located in Bayat by Ramsay 1890, 234-235 and KON $269 \S 545-1$ but in Turgut by Drew-Bear 1996, 961). Perhaps the klaniv is a sg.gen. in the light of Gr. K $\lambda$ áveov, but this is a very tentative possibility and it remains an open question.

Neumann 1997, 19; Brixhe 2004a, 58 and 61. 


\section{k. $\lambda \varepsilon u \mu \alpha \chi 01(\mathrm{PN})$}

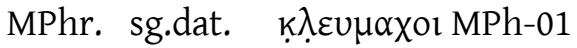

A clear thematic PN borrowed from Gr. K $\lambda \varepsilon$ ó $\mu \alpha \chi \circ \zeta$ ('famous in battle'). It explains the unusual presence of the letter chi in Phrygian. This PN is read on a funerary stele erected by a man who

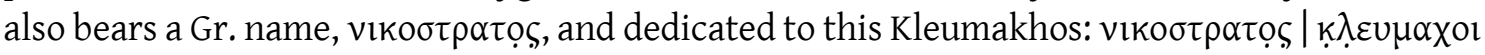

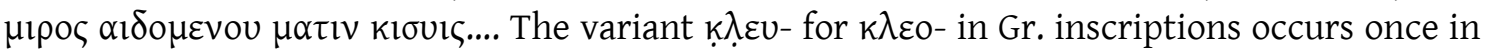
Caria (IK Rhod. Peraia 302), but it is more frequent in Central Greece and the Aegean Islands but here can be explained as a Phrygian shift.

Brixhe 1997, 327; Brixhe 2004a, 24.

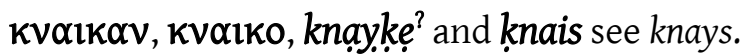

knays (noun) 'woman, wife'

OPhr. sg.nom. knais B-07

pl.nom. knayke? [s] HP-114

sg.nom. knays HP-114

NPhr. sg.acc. $\quad$ ḳvalk $\alpha v 16.1(116) 1.11$

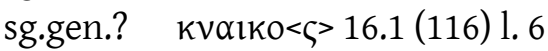

Fem. noun inherited from PIE ${ }^{*} g^{w} n e h_{2^{-}}$'woman' (NIL 178, IEW 473, see the detailed study in

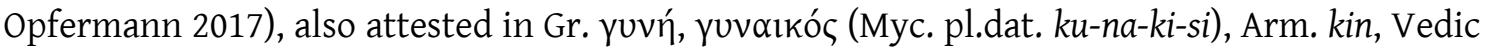
gnä 'id.' (also 'goddess'), Go. qino, ToA śäm, ToB śana, etc. The shift to voiceless of the first stop has been justified because of its position before the nasal (Brixhe \& Neumann 1985, 174-175 and even Brixhe \& Drew-Bear 2010, 165), however it is a general shift, as is the loss of labialisation. As in Gr. (and Messapian pl.dat.? gunakhai), its inflection in Phrygian takes a - $k$ - in cases other than nom. Even in the nominative kains / knays the ancient proterodynamic inflection of this PIE $h_{2}$-stem is lost, compare, e.g., in the Gr. sg.nom. $\gamma u v \eta \eta^{*} g^{u}(e) n-h_{2}$. All Phrygian forms shows the addition of the suffix * $i H$ to the whole stem (note that it is similar to the Gr. voc. yúval) and in sg.nom. the s-ending is levelled from $i$-stems (e.g. tuvatis). Recently, Opfermann (2017, 62 and 74) has considered that the sg.nom. goes back to the PIE abstract noun * $g^{u}{ }^{u} h_{2}$-éi- 'femininity' but the Phrygian form does not show the expected vocalisation of the nasal in this position $\left((C) R H_{x} V>(C) V_{x} R V\right.$, see $\S$ 4.1.2.2.3). The sg.acc. and sg.gen. are attested in the same NPhr.

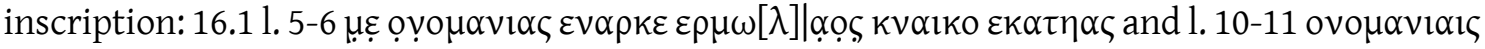
u.pov $1 \kappa[] \mid. \kappa v \alpha \iota \kappa \alpha \nu \varepsilon \delta \alpha \varepsilon \varsigma$. The sg.gen. is expected to be ${ }^{*} \kappa v \alpha \iota k-о \zeta$ in the light of other consonant stems (e.g. artimitos, $\tau 10 \varsigma$ < * diuos or opovevos). A good explanation for this unexpected form is the shape of the letters: since in these inscriptions epsilons and sigmas are quadratic and the following word, $\varepsilon \kappa \alpha \tau \eta \alpha \varsigma$, begins with epsilon where a sigma is supposed, it is very likely that the engraver erroneously reused a sigma as an epsilon by adding the central stroke (the only feature that differentiates the two letters). Consequently, $\kappa v \alpha 1 k 0<\varsigma>$ can

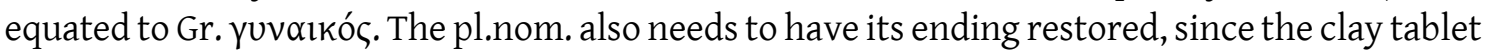
on which it is read is broken. Since there are other athematic pl.nom. this restitution is easy:

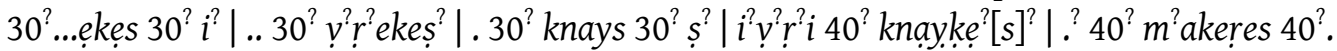

Brixhe \& Neumann 1985, 174-175; Brixhe 2004a, 79-80 and 125; Brixhe 2006, 307-308; Lubotsky 2004, 234; Brixhe 2006, 40; Matzinger 2006, 200-201; Brixhe \& Drew-Bear 2010, 165; EDG 291-292; Ligorio \& Lubotsky 2013, 184; Kloekhorst 2015, 114; LIPP II, 295; Opfermann 2017.

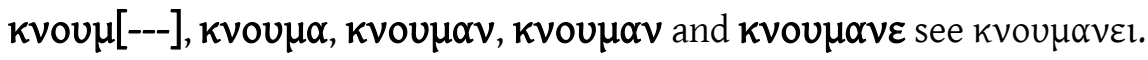




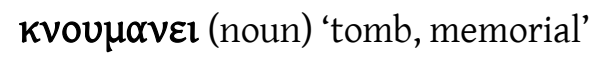

NPhr. sg.nom.-acc.

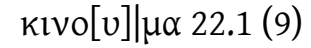

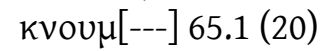

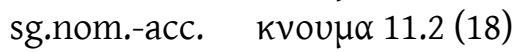

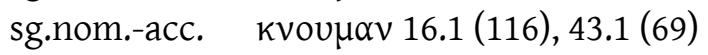

sg.dat. $\quad \quad k v o u \mu \alpha v 40.3(31)$

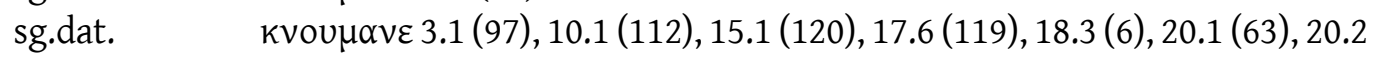

(128), 24.1 (40), 25.2 (126), 27.1 (92), 30.1 (39), 31.1 (29), 33.1 (28), 33.2

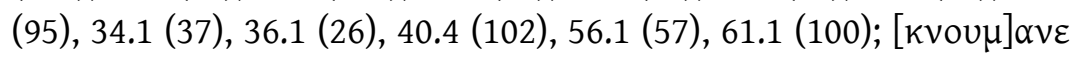

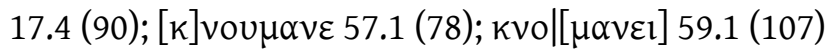

sg.dat.

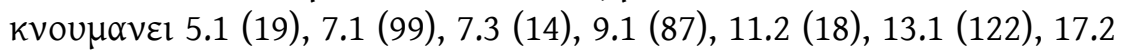

(3), 20.3 (62), 21.2 (43), 22.2 (118), 25.1 (115), 32.1 (93), 33.3 (127), 37.1

(10), 44.1 (61), 52.1 (75), 53.1 (76), 53.2 (77), 59.2 (47), 59.4 (106), 62.1

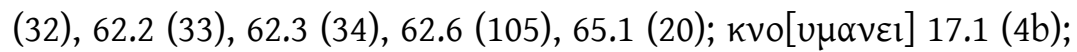

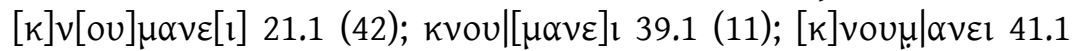

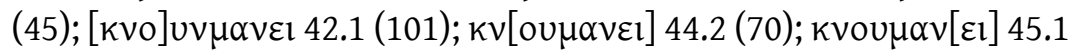

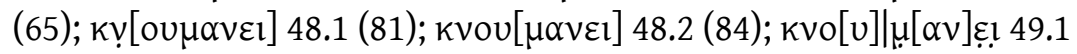

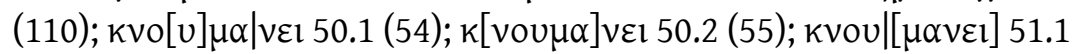

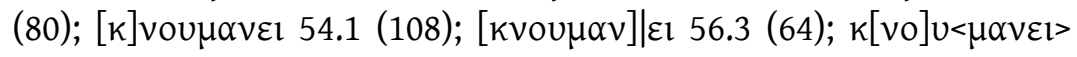

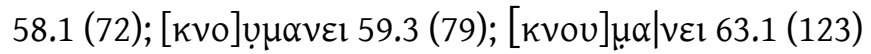

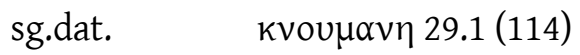

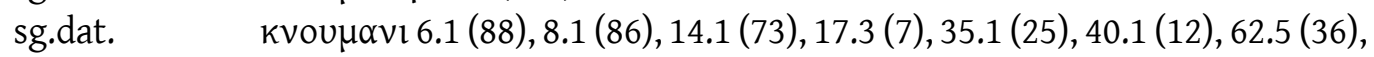
$66.1(103)$

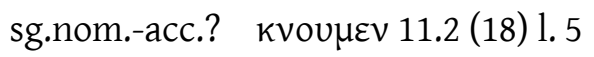

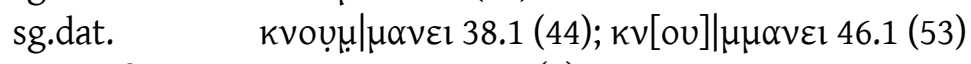

sg.gen.? $\quad k<v>$ ovplvos $18.2(5)$

A clear neuter word built by adding the suffix $-m n$ to the PIE verbal root * $k n e u H-$ ' 'scratch, dig' (LIV² 366, IEW 562, found in Greek kvúw 'id.'): *knuH-mn (see Lubotsky 1998, 414 fn. 4). This form,

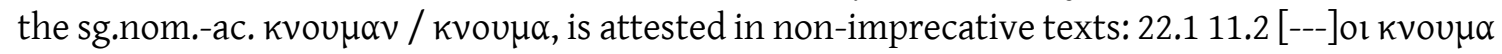

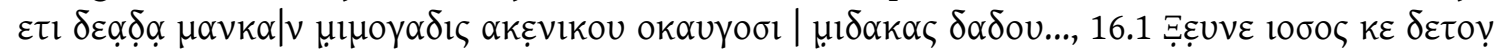

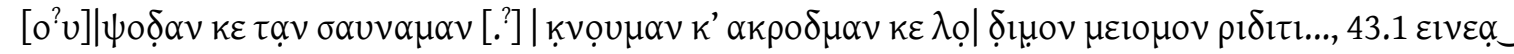

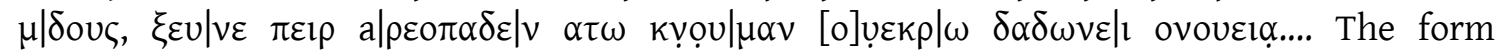
$\kappa ı v o[v] \mid \mu \alpha 40.3$ is also found in a non-imprecative text and is also a sg.nom.-acc. with epenthetic

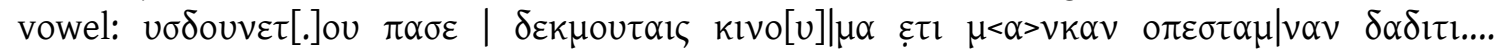
However, most instances of this word are sg.dat. variants attested in the imprecative protasis:

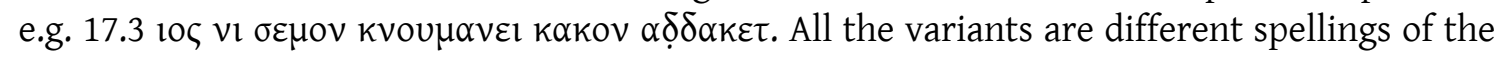
PIE ending *-ei $\langle\varepsilon l\rangle,\langle\varepsilon\rangle,\langle\eta\rangle$ and $\langle l\rangle$ that arose under the influence of Greek itacism. The form

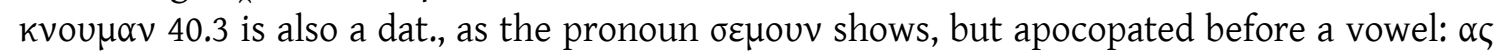

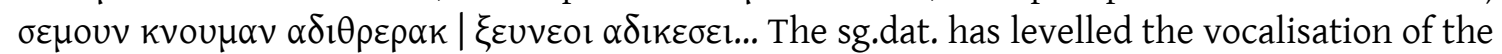
suffix from the sg.nom. The form $k<v>$ ouplvo 18.2 seems to be a conservative sg.gen. * $k n u H-$ $m n$-ós, with an epenthetic vowel in the suffix. However, because of its position after the

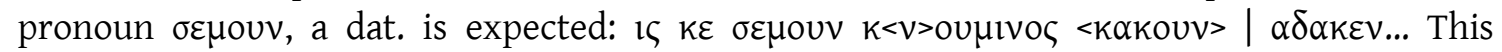
particular oddity can be explained in the light of Gr. inscriptions from Phrygia, where the use of gen. instead of dat. Is not unusual, even in the same collation (Brixhe 1987a, 97-98): see, e.g.,

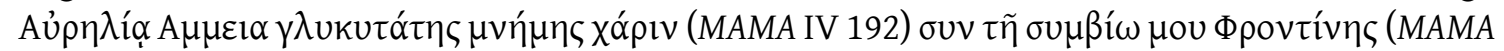

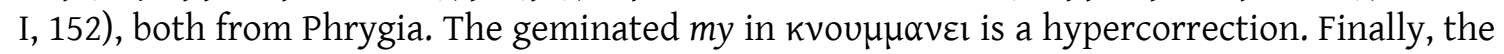

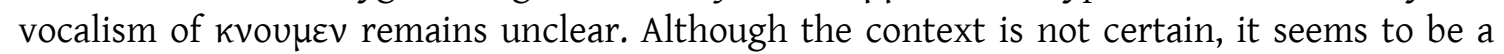

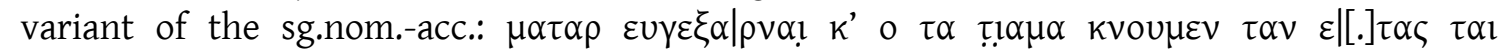
ко $\lambda \tau \alpha \mu \alpha v \varepsilon 1 . .$.

Lubotsky 1998, 414 fn.4; Avram 2016a. 


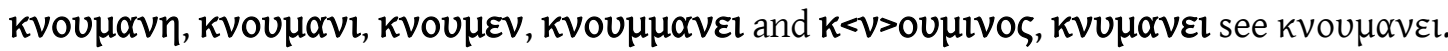

\section{kovis (noun)}

OPhr. sg.nom. kovis B-05 1. 12; kovis B-05 1.10

Although in 1.10 it was read as koris, Gorbachov $(2008,102)$ and, especially, Hämmig $(2013,132)$ showed that lines 9-10 and 12 contain two variants of the same curse and that this word, wellread in 1.12, is the same as in 1. 10. According to Hämmig, it is an $i$-stem sg.nom. noun, qualified by the adj. mekas once: 1.10 mekas key | kovis a bretoy nun ibey nevotạn niptiyan sirun mireyun. In 1 . 12 it appears without an adjective: nevos me deritoy kovis ke abretoy nun oy nev<otan>. Hämmig also suggested the meaning 'calamity', 'misfortune' or 'illness', although its etymology has not been identified.

Neumann 1997, 19 and 25; Brixhe 2004a, 62; Gorbachov 2008, 102; Hämmig 2013, 132.

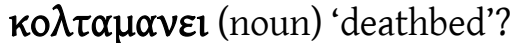

NPhr. sg.dat. $\quad$ ко $\lambda \tau \alpha \mu \alpha v \varepsilon l 11.2$ (18)

A noun found in a sentence where some parts of the tomb are mentioned: $\mu \alpha \tau \alpha \rho \varepsilon v \gamma \varepsilon \xi \alpha \mid \rho v \alpha !$. ${ }^{\prime}$

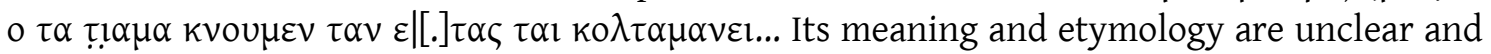
few scholars have taken a stance on this word. Orel (1997a, 84 and 438) proposed the word ко $\lambda \tau \alpha \eta$ from 37.2, however this is the result of a negligent reading, which was followed by Woodhouse 2010, 139. On the other hand, Woodhouse considered it a PIE formation * $g^{w}$ olth ${ }_{2} m n$ $\left({ }^{*} g_{2}\right.$ olth $h_{2} m$ in in Woodhouse 2006, 172 but ${ }^{*} g_{1}$ olth ${ }_{2} m n$, Woodhouse 2010, 139, where ${ }^{*} g_{1}$ - stands for the more common *'g-) related to Skt. jathára- 'belly, body, uterus, lap', Go. kilbei 'womb' and $\mathrm{MoE}$ child. He also suggested a similar meaning to the last adduced parallel: 'family, offspring, generation'. However, the presence in the same period of parts of the tomb ( rules out such a semantic interpretation. Another interpretation can be found in the comparison with Arm. katat 'den, lair', equated to Baltic forms such as Lith. guôlis 'den, lair, (coll.) bed', gùltas 'bed, lair', gulti 'to lie down, fall ill' or. Latv. guôla 'nest, den, lair, (coll.) bed' (Martirosyan 2009, 346-347) and sometimes also to the obscure Gr. $\gamma \omega \lambda$ có $\varsigma$ 'hole' (considered "not very probable" by EDG 293-294). If the root of ko $\lambda \tau \alpha \mu \alpha v \varepsilon$ is in some way related to these forms, it could mean something as suitable as 'deathbed' in the light of the uses of $\theta \alpha \lambda \alpha$ ' $\mu \eta,-\eta$ ('lurkingplace, den, lair') and its derivative $\theta \alpha$ x́ $\alpha \mu \circ \varsigma,-о \varsigma$ '(funerary) chamber' in Gr. funerary inscriptions from Anatolia. However, a formation ${ }^{*} g^{w} l H-t o / e 2_{2^{-}}$(see Kroonen 2013, 309-310 about PGerm. *kulda-) is uncertain for the Phrygian form (particularly given the lack of the expected vocalisation ${ }^{* *} k l o ̄ t a-$ in this position, see $\left.\S 4.1 .2 .2 .3\right)$. Even its gender is problematic.

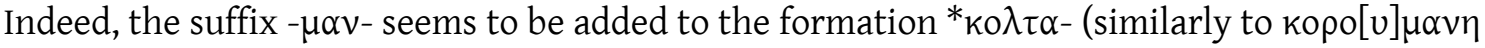
2.2). This would give a neuter noun, yet the presence of the pronoun $\tau \alpha$, if the segmentation is correct, shows that the word is fem. As can be seen, ko $\lambda \tau \alpha \mu \alpha v \varepsilon 1$ remains unclear.

Haas 1966: 98-103; Haas 1969, 84-87; Orel 1997a, 84 and 438; Woodhouse 2006, 172; Woodhouse 2010, 139.

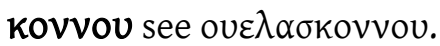

koris see koyis.

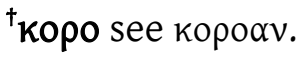

kopoav (noun) 'boy, lad, male infant'?

MPhr. sg.acc.? короov MPhr-01 (W-11) 1.7

sg.gen.? короо MPhr-01 (W-11) 1. 6

Although Brixhe (2004a, 21-22, followed by Avram 2015, 210) considered that the Gr. word xẃpos 'a definite space, piece of ground, place' occurs in MPhr, Lubotsky 2017 reconsidered the 


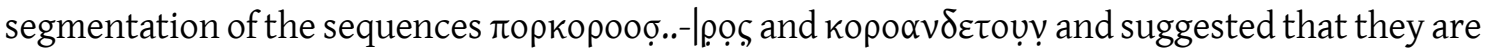

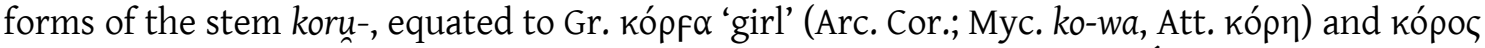

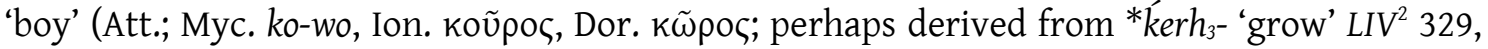
IEW 577, according to EDG 752-753). Then, kopoav /korwan/ is the sg.acc.fem. of 'girl' (instead of a form поркоро, suggested by Brixhe) and короо its masculine in an unclear case. Although this scenario is morphologically likely, no girl is identified in the inscription, which refers to

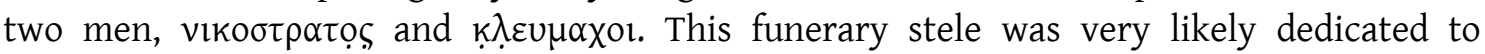
$\kappa \lambda \varepsilon \cup \mu \alpha \chi 01$, so perhaps it is he who is called koru-. Consequently, we are probably dealing with two forms of the same $u$-stem noun referring to this man: kopoov, with the athematic acc. ending, and kopoos, the athematic gen.

Brixhe 2004a, 21-22; Avram 2015, 210; Lubotsky 2017.

корока (noun) 'offspring, descendants'?

NPhr. корока $62.5(36)$

корока $62.2(33)$

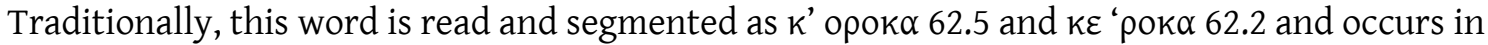

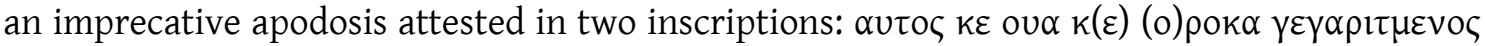

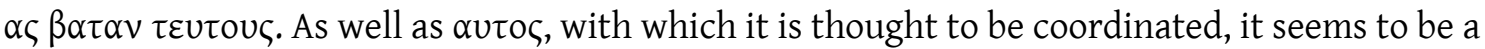
nominative (sg.fem. or pl.neuter?). However it is difficult to choose between a neut.pl. or fem.sg. because the possessive ova with which it agrees is also ambiguous. The hesitation attested at the beginning is explained as a product of sandhi with the copulative conj. $k \varepsilon$ : note

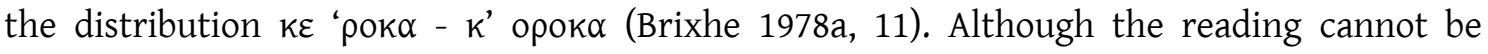
corroborated, it is perhaps another example of the common confusion between circular letters. Its meaning and etymology remain unclear, but a meaning 'offspring' or 'descendants' is very attractive in the light of the common Gr. formulae. In that case, and taking into account the context (see $\S 4$ 4.3.3., note the strange position of the assumed compulative conj. $k(\varepsilon)$ 'and'), it can be considered a noun derived from the stem koru- 'boy' (see also kopoav), as cla. Consequently, the imprecative formula can be segmented as follows: $\alpha \cup \tau o \zeta \kappa \varepsilon$ ov $\alpha$ корок $\alpha$ $\gamma \varepsilon \gamma \alpha \rho ı \tau \mu \varepsilon v \circ \varsigma \alpha \varsigma \beta \alpha \tau \alpha \nu \tau \varepsilon \cup \tau O v=\varsigma$. However, this interpretation must remain hypothetical until we have determined a satisfactory explanation for the verb $\tau \varepsilon u \tau o v$.

Brixhe 1999, 312; Woodhouse 2007, 193-194 fn. 8.

kopov (noun) 'a definite space, piece of ground, place'

NPhr. sg.dat. kopou 27.1 (92)

This word, a clear borrowing from the Gr. $\chi \omega$ ' $\rho \circ \varsigma$, , ov 'a definite space, piece of ground, place' (note Gr. $\chi>$ Phrygian $k$ ), is found in a NPhr. imprecative apodosis and may allude to the space

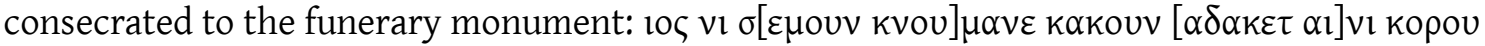

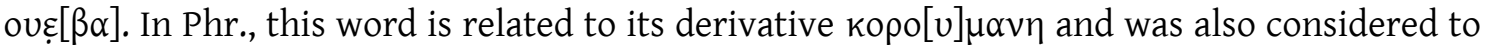

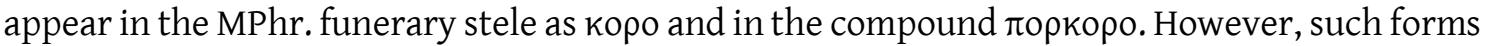
have been reanalysed (see kopo $\alpha$ ).

Brixhe 1983, 127-128; Brixhe \& Neumann 1985, 179; Brixhe 1990, 95; Brixhe 1999, 298; Brixhe 2002b, 258; Brixhe 2004a, 21-22; Lubotsky 2004, 231; Ligorio \& Lubotsky 2013, 189; Avram 2015, 12-13.

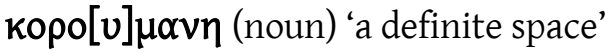

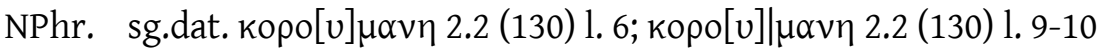

This noun, derived from kopov, has the suffix $-m n$. Despite this feature, it is found in the same

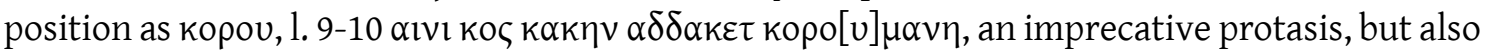

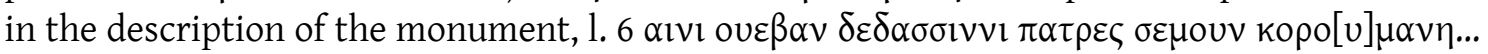
Consequently, it seems very likely that the meaning of this derivative is similar to the original word: it refers to the space consecrated to the monument.

Avram 2015, 12-13. 
kos (indefinite pronoun) 'someone, somebody, something'

OPhr. sg.nom.-acc.neut. kin B-01 1.4

sg.nom.masc. kos B-07

NPhr. sg.nom.-acc.neut. kiv $61.1(100)$

sg.nom.masc. коৎ 2.2 (130) 1. 9; 11.2 (18); 56.3 (64), 58.1 (72)

As occurs in Lat., Phrygian shows a PIE stem ${ }^{*} k^{u} 0-{ }^{*} k^{u} \cdot{ }^{u}$ - in the inflection of its indefinite pronoun (LIPP II, 452-457). The sg.nom.-acc.neut. presents the ending ${ }^{*}-m$, instead of the original *-d (Lat. quid), as Skt. kím < PIE * $k^{u} i-m$ (Ligorio \& Lubotsky 2013, 183). This form is used

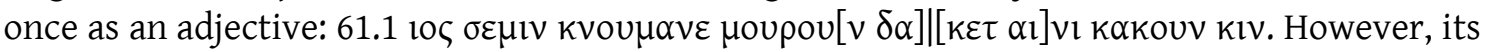
OPhr. occurrence, also found in an imprecative apodosis, seems to have a pronominal function: yos tivo [t] a spereta ayni kin te[l] emi... On the other hand, the sg.nom.masc. appears in a variant of the common protases: instead of the relative pronoun yos, los 'whoever', a conditional conj.

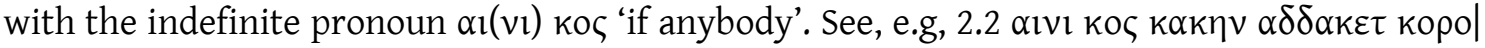

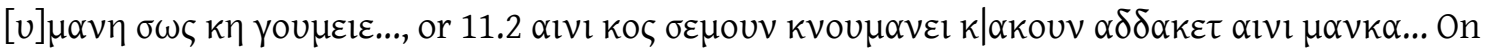
one occasion it is used in a apodosis (a prohibitive meaning introduced by me): me kos aniva $y$ eti $s=$ manin.

Brixhe 1982, 235; Brixhe 2002a, 35-36; Hämmig 2013, 148; Ligorio \& Lubotsky 2013, 191; LIPP II, 454-455.

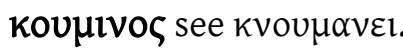

krạniyạ and krạniyạp see kraniyạs.

krạniyạs (adjective) 'of, from a spring or fountain'?

OPhr. sg.gen. kraniyas B-05 1.3

This word is found in a non-imprecative obscure part of the Vezirhan stele: vrekan vitaran artimitoṣ krạiyạs [---] | pantạ vebrạ adun... The sequence discussed here is precedeed by the theonym in sg.gen. artimitos but the stele is damaged after it. Previously, Neumann (1997, 18-19 and 21) read it as kraniya-p and Brixhe $(2004 a, 56)$ as kraniy a $p$ [---]. The basis for Brixhe's reading was the unexpected ending in $-p$, which he considered the beginning of another word even though in this inscription blanks are used as word boundaries. The solution to this problem is the reading of this supposed $\langle\mathrm{p}\rangle$, given that the shapes of $\langle\mathrm{p}\rangle$ and $\langle\mathrm{s}\rangle$ are very similar in this stele (see Neumann 1997, 15). Taking this into account, a reading kraniyas is defensible in the light of the form of $\langle\mathrm{s}\rangle$ written for the nearby words artimitos and atriyas. In this case, kraniyas is a mere sg.gen. denominative adj. created with the common suffix -yo/a-. This adj. agrees with the preceding DN artimitos in the same way as, e.g., kubileya / kubeleya with matar (W-04 and B-01,

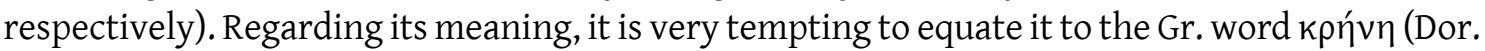

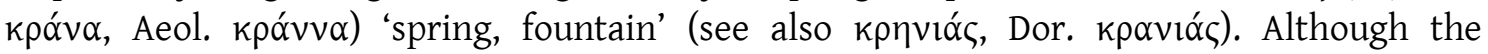
etymology of this Gr. word is unclear, its presence in Phrygian can be considered an Aeol. borrowing similar to stala B-01. Moreover, this connection between the Anatolian Artemis and water is well known, especially after the syncretism between Artemis and the Persian goddess

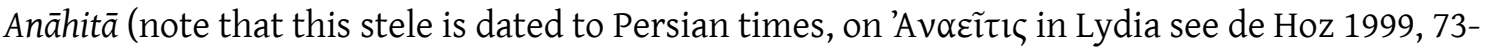

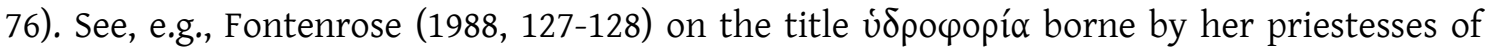
Didyma. Finally, a relationship between kraniyas and kpavós, found in the epithet of Matar,

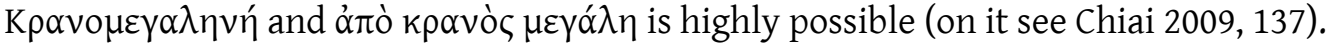

Neumann 1997, 18-19 and 21; Brixhe 2004a, 56.

\section{kraroy (?)}

OPhr. kraroy G-11 b

Unclear word in obscure text: sit kraroy veao dis. On the basis of its ending, it can be considered either a verb in 3sg.opt. or a thematic noun in sg.dat. Brixhe $(2002 \mathrm{a}, 26)$ seems to opt for the 
latter possibility, adducing Gr. $\kappa \lambda \tilde{\eta} \rho \circ \varsigma$ (Dor. $\kappa \lambda \tilde{\alpha} \rho \circ \varsigma$ ) 'lot, that which is assigned by lot, allotment' as a similar word by assuming an anticipatory assimilation. Either way, this remains an open question.

Brixhe 2002a, 36.

$k u(\mathrm{PN} ?)$

OPhr. $\quad k u$ G-241

Complete inscription incised on a sherd from Gordion. It is very likely an abbreviated anthroponym used as an owner's mark. kuliya is the sole PN with this beginning in the whole Phrygia corpus, however it could correspond to another (non-attested) name.

CIPPh I, 190; Roller 1987a, 49; Bayun \& Orel 1988a, 199.

kubeleya (adjective) 'from the Kubel- mountain'

OPhr. sg.nom. kubeleya B-01; kubeley[a] B-08

sg.nom. kubileya W-04

The three occurrences of this thematic adj. (note the suffix *-ey/o-) agree with the DN matar (the Mother-Goddess): B-01 matar kubeleya ibey a duman ektetoy, B-08 [--- mata]r kubeley[ $a$---] and W-04 matar kubileya [---]toylen. Note that this last form shows the common hesitation /e/ /i/ (see 4.1.1.). Regarding its origin, Brixhe (1979b) suggested that kubeleya derives from the Phr.

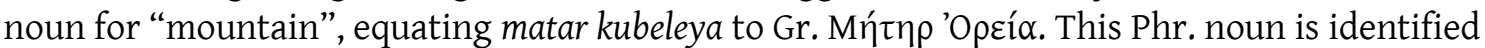

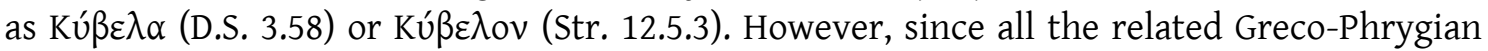
sources refer to the name of a specific mountain (even a castellum) or mountains, kubeleya should preferably be considered an epiklesis related to this mountain (or mountains), with the meaning 'Matar of the Kubel- (mountain)' (CIPPh I, 47, see also Oreshko 2013b, 82-86). See D.S.

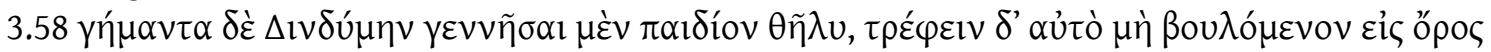

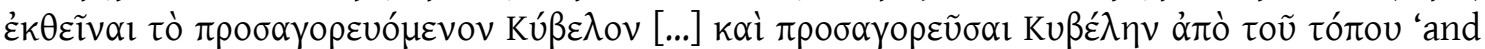
[Meion] marrying Dindymê he begat an infant daughter, but being unwilling to rear her he exposed her on the mountain which was called Cybelus [...] and called her Cybelê after the name

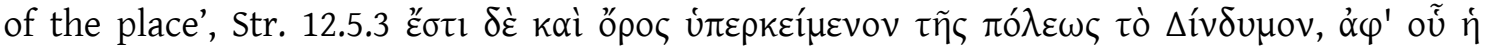

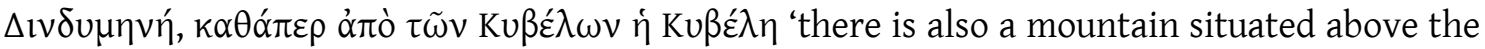
city, Dindymum, after which the country Dindymenê was named, just as Cybelê was named

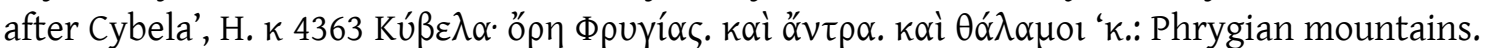
Also, caves and chambers', Ovid, Fast. 4.363-365 Inter, ait, uiridem Cybelen altasques Celaenas amnis it insana, nomine Gallus, aqua. qui bibit inde, furit '[Erato] said: "Between green (Mount) Cybele and high Celaenae, there flows a river with insane water, called 'Gallus.' Who drinks of it goes mad"' and Liv. 38.18.5 ad Cuballum, Gallograeciae castellum, castra habentibus Romanis 'while the Romans were encamped near Cuballum, a fortress of Galatia'. The identification of this mountain is unclear and the origin of the oronym kybel- remains unknown: is it Phrygian, Anatolian or even pre-IE? In any case, the equation of this name with Kubaba is impossible in linguistic terms, since it implies ad hoc shifts in the labial stop even if a Lyd. intermediary form is considered (contrary to Munn 2006, 120-125 and 2008, 161). Of course, this does not rule out a Gr. syncretism between both mother-goddesses, and its relationship with Kußź $\lambda \eta$ / Cybele seems obvious despite the convoluted history of this name. The Gr. form Kußź $\lambda \eta$ may be an early borrowing of this theonym, since the last $-\eta$ shows the general loss of intervocalic $/ j /$ and the

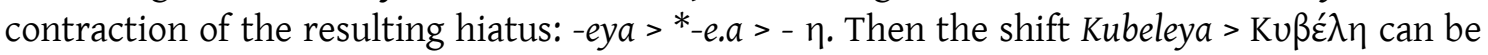

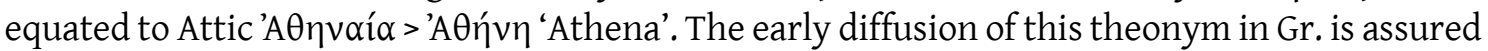
by the presence of Qußó $\lambda \alpha \varsigma$ in Locri Epizephyrii (Calabria, Italy) in the first half of the $6^{\text {th }}$

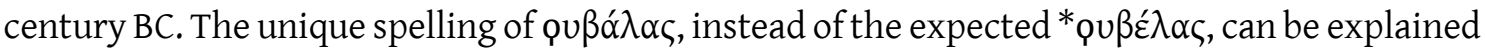
as an adaptation to the north-western dialect of Locri Epizephyrii. Although the inscriptions from the city do not provide another example of $\varepsilon \lambda>\alpha \lambda$ (or of $\varepsilon \rho>\alpha \rho$ ), it is a common feature of these group of dialects: see Delphian $\Delta \alpha \lambda \varphi$ or for $\Delta \varepsilon \lambda \varphi$ oí (Méndez Dosuna 1985, 397). The 
alternative explanation, a dissimilation from Kubaba (the North Syrian Mother-Goddess also found in Lydian as Kuwawa and in Herodotus as Kußń $\beta \eta)$, must be refuted in the light of the Phr. form, even though $Q<v>\beta \alpha ́ \beta \alpha \varsigma$ (SEG 49.1357) also occurs in Locri Epizephyrii. The original form

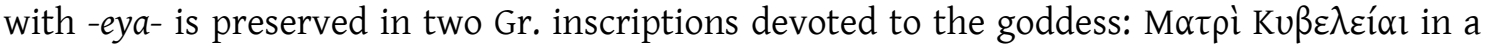
votive inscription from Bulgaria ( $4^{\text {th }}$ C. BC, Nessebar Museum, inv. no. 1354, Sharankov 2009, 48

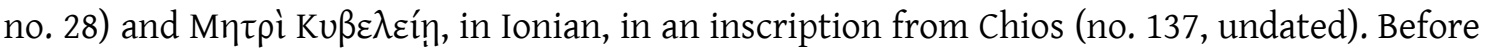
the Phrygian form Kubeleya was known, Robert (1933, 483-484) suggested that the Mother-

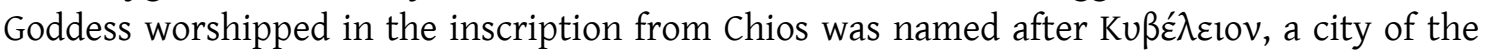
Erythraean peninsula known by Str. 14.1.33 and St.Byz. 10.245. However, there is a votive inscription from Erythrai which clearly shows that the goddess worshipped there was the

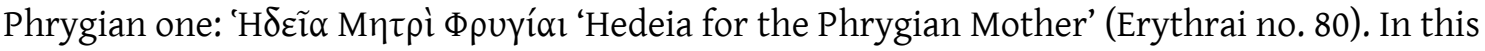

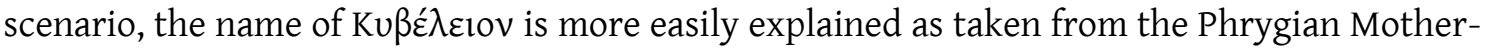
Goddess.

Brixhe 1979b; CIPPh I, 47; Brixhe 2002c, 52-53; Oreshko 2013b, 82-86.

kubileya see kubeleya.

kuliya[-?-] see kuliyas.

\section{kuliyas (PN)}

OPhr. kuliyạ[-?-] G-101

sg.nom. kuliyas $\mathrm{G}-127$

Both occurrences of the name are incised on sherds. G-101 is broken and it is impossible to know if there were more letters incised (perhaps $-s$ ), since a sg.nom. ending $-a$ is also possible. Its origin seems to be Luw. in the light of the graffito no. 5 from SURATKAYA read as ku-li-i(a) /kulija/ by Oreshko (2013a, 361), a simplification of kwa/i-li-i(a) /kwalija/. This PN also occurs in Cappadocia as Ku-li-a (LNH 97 § 612).

CIPPh I, 95-96 and 117-118; Bayun \& Orel 1988a, 198; Draycott \& Summers 2006, 73; Brixhe 2013, 58.

\section{[-?-]kupolas (PN)}

OPhr. [-?-]kupolas G-139

Although the sherd on which this graffito was incised is broken before the first letter, it is very likely to be complete. In any case, kupolas seems to be an a-stem PN without the ending -s, created with the suffix -lā-. An alternative interpretation was given by Diakonoff and Neroznak (1985, 119-120) who considered it the Phrygian word for 'pot', referring to the support iself.

CIPPh I, 127; Diakonoff \& Neroznak 1985, 119-120; Neumann 1988, 8; Bayun \& Orel 1988a, 198.

\section{kuryaneyon (noun) 'ruler'}

OPhr. sg.nom. kuryaneyon W-01c

Read after a PN in a text engraved on a cult façade: ataniyen kuryaneyon tan egertoy. Ligorio \& Lubotsky $(2013,187)$ considered it a Myc. loanword attested only in alphabetic Gr. as koıpové $\omega v$

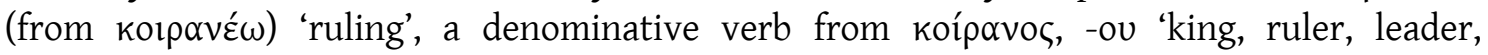
commander, lord', whose roots goes back to PIE *kor-io- 'war, army' (NIL 440-441, IEW 615-616). Since the Phrygian word does not present the metathesis *kori- > koip-, Lubotsky $(1988,23)$ suggested that the loanword must be taken from Mycenaean times, although it is not attested in this dialect. Indeed, other titles seem to be borrowed from Gr.: lavagtaei and vanaktei. However, there is no reason to rule out the possibility that it is an inherited word, although this would imply that Phrygian shared with Gr. the formation of denominative verbs in *-ey-. Phr. kuryaneyon agrees with ataniyen in sg.nom. and seems to be used as a title. Brixhe, on the other hand (in Brixhe \& Summers 2006, 128), interpreted it as a noun in sg.acc. 
CIPPh I, 41-42; Bayun \& Orel 1988a, 183; Lubotsky 1988, 23-25; Brixhe 1990, 63-64; Janda 1997, 276-277; Berndt-Ersöz 2006, 80, 86; Brixhe \& Summers 2006, 128; Ligorio \& Lubotsky 2013, 187, 188.

$k \uparrow$ ianaveyos (title or ethnic?)

OPhr. sg.nom. $\quad k \uparrow$ ianaveyos M-02

sg.nom. $\quad k$ Фiyanaveyos $\mathrm{M}-01 \mathrm{~b}$

Both occurrences (from the second quarter of the $6^{\text {th }} \mathrm{c} . \mathrm{BC}$, Midas City) qualify the same man: $\mathrm{M}-01 \mathrm{~b}$ baba memevais proitavos $k \Phi$ iyanaveyos si=keneman edaes and $\mathrm{M}-02$ bba memevais proitavo[s] $k \uparrow$ ianaveyos akaragayun edaes. They show that $\Phi$ is a variant of $\uparrow$, although the sound that this letter represents is still obscure. OPhr. $k \uparrow$ ianaveyos seems to be a DN, since it works as a common adj. with the suffix $-y o / a-$. Although the original toponym has often been identified with Tyana (see Vassileva 2008, 167), CIPPh (I, 257) rejected this interpretation because of the clear consonantal differences in their beginnings between Tuwanuwa- and kథiyanaveyos / $k \uparrow i a n a v e y o s$. Unfortunately, no clear alternative can be given. The city of Kíos (now Gemlik, a

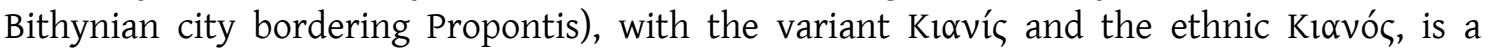
tempting possibility (KON 266-267 § 520), but it is uncertain. In any case, the unusual beginning seems to show a non-Phrygian origin, and a title cannot be ruled out.

Brixhe 1982, 230; CIPPh I, 257; Berndt-Ersöz 2006, 72.

$k \Phi$ iyanaveyos see $k \uparrow$ ianaveyos. 



\section{$\wedge(l)-\Lambda \lambda$}

la[---] see tadaila[---].

lagineios (PN)

OPhr. masg.sg.nom. lagineios G-110

fem.sg.nom. [l']agineia G-276

Two variants of the same PN documented on potsherds. The first is an o-stem masc., while [l] agineia seems to be the fem. of lagineios G-110, according to CIPPh (I, 212-213). It has been considered a genuine Phrygian PN by Brixhe $(1983,122)$ and Innocente $(1997,40)$. It can conceivably be the ethnic of the Phr. toponym $\Lambda \alpha \gamma \varepsilon$ sv $\alpha$, a city located in the modern Ilgin (or,

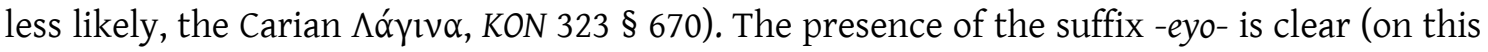
point, see Neroznak 1978, 93, Bayun \& Orel 1988a, 198 and Orel 1997a, 440).

Neroznak 1978, 93; Neumann 1981, 148; Brixhe 1983, 122; CIPPh I, 103-104; Diakonoff \& Neroznak 1985, 36 and 120; Bayun \& Orel 1988a, 198; Neumann 1988, 7; Brixhe 1993, 339; Innocente 1997, 40; Orel 1997a, 440; Wittke 2004, 202; Anderson 2012, 181; Avram fthc.

lavagtaei (noun) 'leader of the people'

OPhr. sg.dat. lavagtaei M-01a

A clear noun related to the Myc. ra-wa-ke-ta /lāwāgetās/, Dor. $\lambda \alpha \gamma \varepsilon$ ć $\alpha \varsigma$ 'id.', in agreement with midai, to whom the inscription is dedicated by ates: ates arkiaevais akenanogavos midai lavagtaei vanaktei edaes. Its ending, an athematic sg.dat. as vanaktei, is problematic, because an $a$-stem dat. * lavagetai would be expected in the light of, e.g., midai. The main question is whether this is an error (because of the proximity of vanaktei?) or not. Brixhe $(1983,1116)$ considered that a syncope worked here, and it is not not a loanword from Gr. (against Panagl \& Kowal 1983, 193, Lubotsky 1988, 18, Neumann 1988, 16 and Cassola 1997, 145) but rather a shared lexical isogloss with this language. On the other hand, in order to explain this oddity Lubotsky $(1988,18)$ suggested a borrowing from the Gr. nominative /lāwāgetās/ token as s-stem, where the -s in intervocalic position dropped: *lauagetasei > lavagtaei. However, this is not a satisfactory explanation, since $a$-stem $\mathrm{Gr}$. borrowings are commonly preserved as $a$-stems in Phrygian. Consequently, a mistake may be considered here, although in fragmentary corpora this must always be a last resort. In any case, since it is a compound of the verb * $h_{2} e g$ - 'to drive, lead' ( $L^{2} V^{2}$ 255-256, IEW 4-51, see a recent revision by Jiménez Delgado 2015), a voiceless stop would be expected in an inherited Phrygian word, so a borrowing is the most plausible explanation.

Neroznak 1978, 71-72; Brixhe 1983, 116; Panagl \& Kowal 1983, 193; CIPPh I, 8; Bayun \& Orel 1988c, 134; Bayun \& Orel 1988a, 175; Lubotsky 1988, 18; Neumann 1988, 16; Brixhe 1990, 73-76; Brixhe 1993, 340-341; Cassola 1997, 145; Brixhe 2002b, 257; Brixhe 2002c, 63; Brixhe 2004a, 41; Neumann 2005, 548; Sowa 2005, 612; Brixhe 2006, 40; Berndt-Ersöz 2006, 72 and 128-129; Gusmani 2006, 16; Woodhouse 2006, 178; Brixhe 2008, 72; Hämmig 2013, 137 fn. 27; Jiménez Delgado 2015.

lavọy (noun?)

OPhr. sg.dat. lavọy W-04

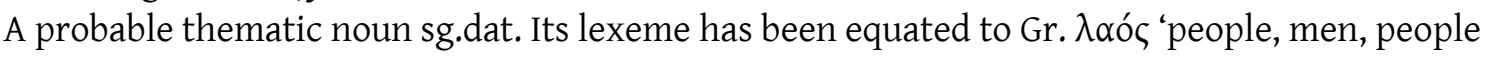
assembled' $<\lambda \alpha$ Fo (Brixhe 2004a, 41 who considered the preceding sequence ae a preposition, which is highly unlikely), a word whose origin is disputed (see EDG 832-833). Unfortunately, neither the context nor the segmentation are clear: $a^{?} m^{?}{ }^{?} p^{?}$ tov $a \uparrow i y \cdot a^{?} e^{?}$ lavoy $\cdot$ ue | edaviy. However, the alternative readings are aelavọy and aglavọy, although parallels are lacking.

Brixhe 2004a, 41.

lakeaọ see lakedo. 
lakedo (verb) 'to take'

OPhr. 3sg. impv. med. la|kedo W-01b; laker d’ọ (lapis lakeaọ) B-03?

3 sg. ind. aor. act.? e?lakes B-04?

Since lakedo $\mathrm{W}-01 \mathrm{~b}$ constitutes with key a whole imprecative apodosis, yos esai=t materey eveteksete? y ovevin onoman da Yet, lakedo key venavtun avtay materey, it is a clear verb in 3sg. impv. med. <*-(s) $d^{\text {h}} \bar{o}$. Lubotsky $(2004,234-235)$ equated its root to Gr. $\lambda \alpha \mu \beta \alpha ́ v \omega(\lambda \alpha \beta \varepsilon \tilde{\imath} v)$ 'take hold of, grasp, seize', going back to PIE * sleh $_{2} g^{u}$ - 'id.' (LIV ${ }^{2}$ 566, IEW 958). Segmentations such as la-kedokey are ungrounded and must be rejected (see, e.g., LIPP II, 133). The other two adduced occurrences are highly doubtful. Indeed, lake d do $^{\prime}(\mathrm{B}-03)$ is read as lakeao, but because this kind of vocalic sequence in Phr. is unexpected Lubotsky considered here an erroneous stroke in the supposed $\langle d\rangle$. A possible argument to support this interpretation is that B-03 could appear in another imprecative apodosis (as well as in $\mathrm{W}-01 \mathrm{~b}$ ): yosyos yenvra | etitevtevey me.oun lakeao | [-?]. Furthermore, the form e?lakes (B-04) is also problematic because of the reading difficulties (few strokes persist of the first letter) and the lack of parallels. However, this sequence strongly recalls lakedo and fits as its active aor. (note the probable augment and its ending -es $<*-e-s-t$ ). However, its context remains obscure and this possibility must be taken as a working hypothesis until a definitive explanation can be given: bato?ante | e? lakes s? braterais patriyio is? $k(e)$. Lubotsky 1988, 20-21; Brixhe 1990, 69 and 91; Janda 1997, 273-275; Brixhe 2004a, 41; Lubotsky 2004, 234-235; Matzinger 2006, 201-202; Sowa 2007a, 78.

lakedokey see lakedo.

$\lambda \alpha \pi \tau \alpha$ (adj.)

NPhr. sg.nom. $\lambda \alpha \pi \tau \alpha$ MPhr-01 (W-11) 1.4

Although this sequence is unparalleled, according to Brixhe (2004a, 19-209) it is a probable adj. with the suffix *-to in fem., similar to bilata or omasta. Its root remains unknown. In its doubtful

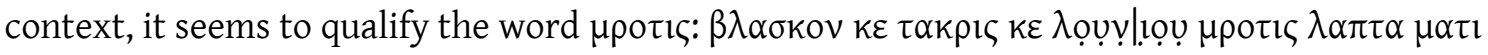
aolvouv...

Brixhe 2004a, 19-20; Sowa 2007a, 91.

$\lambda \alpha \tau o \mu \varepsilon 10 v$ (noun) 'grave'

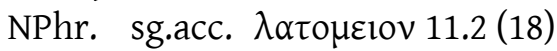

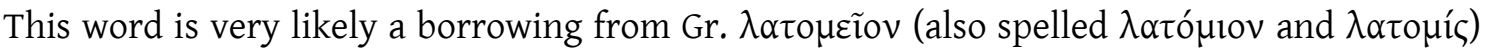
'stone-quarry' (according to Woodhouse 2006, 182). The meaning 'grave' is often used in funerary inscriptions from Perinthos (see, e.g., IG II ${ }^{2} 13218$ or CIG 2032). It is a very good fit with

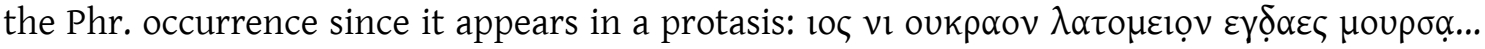
Although this term is not recorded in Anatolia by Kubińska (1968), it is very likely attested in a badly preserved Gr. imprecative protasis of the NPhr. inscription 56.3 (64 , as Calder 1911, 210-

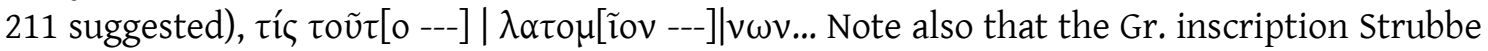
1997, no. 399 (from Perinthos), in which this word also occurs, was made by a Christian man from Phrygia.

Woodhouse 2006, 182.

lelavo see leravo.

leravo (PN?)

OPhr. sg.gen.? leravo or lelavo W-10

Although the reading and the meaning of the whole text are not at all clear, this word appears to be a PN, as do many other words in this inscription: atai edae lel/ravo / vi $\uparrow e$ atevo atoios... However, it remains unparalleled. Its ending has been adduced by Brixhe, in many papers, as 
one of the clearest occurrences of the gen. ending *-uo in Phrygian (as well as atevo in the same inscription).

CIPPh I, 54-55; Brixhe 1990, 96-97; Brixhe 2004a, 51; Brixhe 2006, 42-43; Brixhe 2008, 76.

leț?[---] (PN?)

NPhr. lett? ${ }^{?}[---] \mathrm{G}-266$

Incised on a potsherd, this fragmentary graffito is only accompanied by two nonverbal marks. Although only one of the three remaining letters can be confidently read (note that Roller 1987a, 41 read la[---]), it is very likely the beginning of a PN, as is often the case in this sort of text. Unfortunately, no parallel can be adduced.

$\lambda \varepsilon \cup \kappa ı$ (PN)

NPhr. sg.nom. $\lambda \varepsilon \cup k i \varsigma 11.2(18)$

OPhr. sg.dat. $\lambda \varepsilon v \kappa i \omega l 11.2(18)$

A Gr. PN, $\Lambda$ cúkioৎ, well attested across the Gr. world (with many instances from Phrygia). In Phr. (as well as in Gr.), this PN is an o-stem, as its dat. shows. Nevertheless, its nom. has the spelling 1 for 10, common in Gr. inscriptions from Roman Phrygia (see Brixhe 1987a, 49-50) and

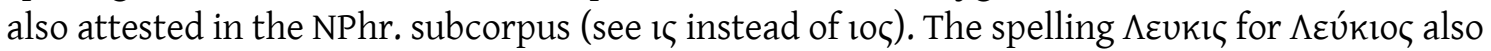
occurs in the Gr. inscription MAMA IX List 189, p. 306.

Orel 1997a, 82, 83 and 441; Woodhouse 2006, 170; Avram fthc. a.

$\lambda \varepsilon u k i \omega l$ see $\lambda \varepsilon u \kappa ı$.

$\lambda \circ \delta ı \mu v$ (noun or adj.?)

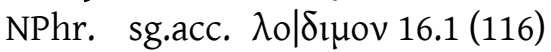

Since it agrees with $\mu \varepsilon 10 \mu \mathrm{v}$ in a sequence of several words referring to parts of the monument

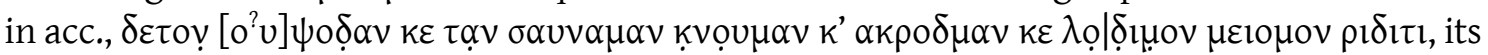
case is clear, although its specific meaning and lexical category remain obscure. Orel (1997a, 441) considered it a noun and, in the light of his reading $\lambda \circ[1] \mid \delta \imath \mu o v$, equated it to the Lithuanian láidoti 'bury' and láidymas 'grave' < *loid ${ }^{(h)}$-imos. However, his reading (and, by extension, his interpretation) is ungrounded.

Brixhe \& Neumann 1985, 172; Orel 1997a, 441.

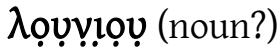

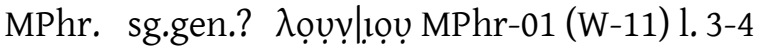

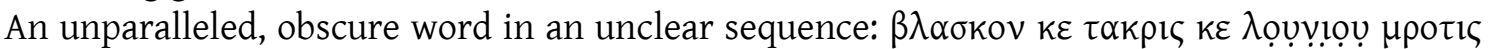
$\lambda \alpha \pi \tau \alpha \mu \alpha \tau \iota \alpha$ olvouv...

Brixhe 2004a, 19.

$\operatorname{luk}(\mathrm{PN}$ )

OPhr. luk G-290

Since it is a complete graffito incised on a potsherd, it can very likely be considered an abbreviated PN. However, no parallel can be adduced.

Brixhe 2002a, 50-51. 



\section{$M(m)-\mathrm{M} \mu$}

$m^{1}$ (mark)

OPhr. $\quad m$ G-332

Isolated letter incised on a potsherd as an owner's mark. It is perhaps the initial of a PN.

Brixhe 2002a, 86.

$m^{2}(?)$

OPhr. $m$ G-204

Incised on a potsherd between more enigmatic letters and short sequences segmented by blanks: [---] da alu $m$ s [-?-]. The whole inscription remains unexplained.

CIPPh I, 168.

mago?'[---] (title) 'magus'?

OPhr. mago? [---] B-108

Incised on two adjacent potsherds, this damaged sequence is preceded by a PN: saragis :? mago?[---]. Consequently, Gusmani (in Gusmani \& Polat 1999a) suggested that it was a patronymic. However, as Brixhe (2004a, 93) notes, it could also be the addressee in dat., since its ending is lost. Although there is no parallel in the Phrygian corpus and its fragmentation

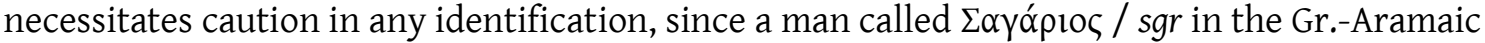
bilingual inscription from Faraşa became "magus of Mithra" (see Lipiński 1975a, 176) and the potsherd B-108 is dated to the late $6^{\text {th }}$ or early $5^{\text {th }}$ C. BC (when Phrygian was under Persian domination), mago? [s] is very likely the well-known priest title magus in sg.nom., see OPers.

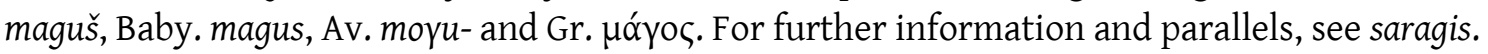
Gusmani \& Polat 1999a; Brixhe 2004a, 93.

$\mu \alpha \gamma^{?} \rho \varepsilon$ (noun) 'part of the tomb'?

NPhr. sg.dat. $\mu \alpha \gamma^{?} \mid \rho \varepsilon 19.2$ (129)

Read in a common NPhr. apodosis, this unparalleled word must be a fem. noun since it is placed

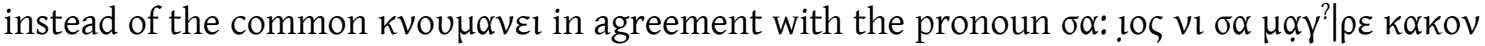
$\alpha \beta \beta \varepsilon \mid \rho \varepsilon \tau 01$ olvl $\sigma \varepsilon \rho ? \mid 0 \alpha . .$. It is true that the alternative reading $\mu \alpha \tau \mid \rho \varepsilon$ provides a known Phrygian word, but it is not a good fit in this context because it is expected to refer the funerary monument or a part of it. Also $\mu \alpha \underline{\mu} \mid \rho \varepsilon$, without parallels, was adduced by the editors. Taking into account the first reading, Brixhe and Drew-Bear (2011, 165-166) equated it to Gr. $\mu$ ókpo 'bath-tub, sarcophagus', a simplification of $\mu \alpha$ ' $\tau \tau \rho \alpha$ 'kneading-trough and bath-tub, sarcophagus', and settled on the conclusion of a borrowing from Gr. Despite their explanations and the attractiveness of this meaning, the presence of a voiced stop is problematic and, worse still, the stone block does not seem to belong to a sarcophagus. Moreover, the etymology of the

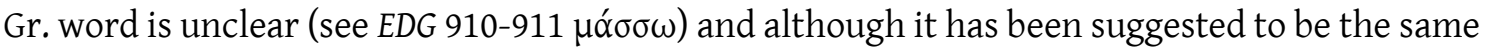
MPhr. word as $\mu \alpha \kappa \rho \alpha v$ (MPhr-01), spelled differently for unknown reasons, this divergence is unparalleled. On the other hand, Kubińska $(1968,51)$ showed that the use of this Gr. word in Anatolia is restricted to Cilicia. Consequently, this word remains unexplained.

Brixhe \& Drew-Bear 2010, 165-166.

$\mu \alpha \iota \mu \alpha \rho \eta \alpha v$ (noun) 'memorial chapel, shrine'

NPhr. sg.acc. $\mu \alpha \imath \mu \alpha \rho \eta \alpha v 40.3$ (31)

It is read in a sentence in which the details of the building of the funerary monument are recorded: $\mu \alpha \nu \kappa \alpha \nu 1 \alpha \nu \varepsilon \sigma \tau \alpha \varepsilon \varsigma \beta \rho \alpha \tau \varepsilon \rho \varepsilon \mu \alpha \iota \mu \alpha \rho \alpha \nu$. It is clearly an $a$-stem fem. word in sg.acc. The common opinion is that this is an adj. parallel to Gr. $\mu \alpha \rho \mu \alpha$ ó $\rho$ o,$\alpha$, ov 'flashing, gleaming, of marble'. In this case, the adj. agrees with the noun $\mu \alpha v \kappa \alpha v$. Although the primary meaning of 
Gr. $\mu \alpha$ óp $\mu \alpha \rho \circ$ was 'stone', with a secondary meaning 'marble, crystalline rock' through folk etymology which equated it to $\mu \alpha \rho \mu \alpha i ́ p \omega$ 'flash, sparkle, gleam', Neumann $(1986,80-81)$ rejected this interpretation because the stele is not made of marble. Instead, he considered it a borrowing from Lat. memoriam, since the sequence could be read as /memarian/ (due to itacism). The weakness of the original hypothesis, then (the Phr. word could keep the meaning 'stone'), is compounded bythe hesitation $\mu \alpha l^{-} \sim \mu \alpha \rho^{-}$, which Ramsay $(1905,89)$ considered a possible engraver's mistake, and the distance in the text between $\mu \alpha v \kappa \alpha v$ and $\mu \alpha \iota \mu \alpha \rho \eta \alpha v$. Moreover, this Lat. word also occurs as $\mu \varepsilon \mu o$ prov 'memorial chapel, shrine' in Gr. epitaphs from

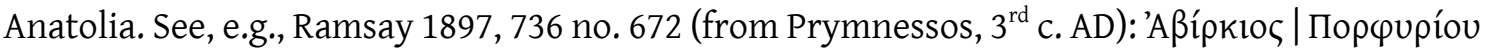

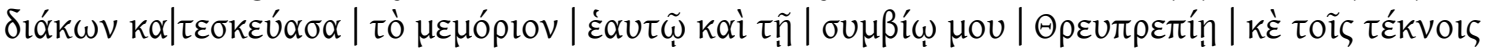
'I, Avircius son of Profirios, deacon, made this memorial chapel for myself and my wife Threuprepia and for my children'. In the light of this, Neumann's alternative is defensible (see

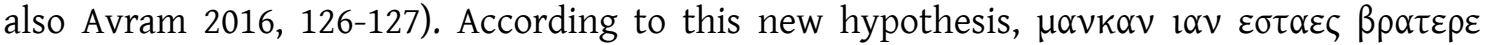
$\mu \alpha \iota \mu \alpha \rho \eta \alpha v$ means 'stele which (he) erected for (his) brother as memorial'.

Ramsay 1905, 89; Calder 1991, 180; Kowal 1984b, 183; Neumann 1986a, 80-81; Brixhe 1999, 301; Woodhouse 2006, 160 fn. 9; Ligorio \& Lubotsky 2013, 184; Avram 2016, 126-127.

\section{makiotaTibi (?)}

OPhr. makiotaTibi P-106

Very obscure sequence incised on a potsherd, segmented by interpunctions: [---].ti : makio?taTibi $\vdots$ :---]. The discussed value of the letters (the unclear $T$ and the 8-shaped $\langle b 〉$ ), as well as the lack of parallels, hinders any interpretation. It has been interpreted very tentatively as two PN by some scholars (e.g., Orel 1997a, 442 and 460): makio ta Tibi. In any case, it remains unclear. CIPPh I, 250; Orel 1997a, 305-306, 442 and 460; Morante Mediavilla 2000, 159-161, 181; Brixhe 2004a, 31.

\section{m?akeres (noun)}

OPhr. pl.nom. miakeres HP-114

Despite the lack of parallels, its presence in the administrative clay tablet from Persepolis points to a noun. As well as the other nouns on the tablet, it is accompanied by a numeral: $i^{?} y^{?} r^{?} i$ $40^{?}$ knayke $e^{?}$ ? $40^{?}$ m? akeres 40 ? Although, its meaning and etymology remain unknown, in the light of other texts from the Fortification Archive it can perhaps be interpreted as a reference to to specialised workers or to animals such as goats or sheep. The first possibility was suggested by Diakonoff \& Neroznak $(1985,121)$ and is more likely because of the presence of women (knayke? $[s]$ ) in the same text. Then, it could can be a deverbative noun derived from PIE

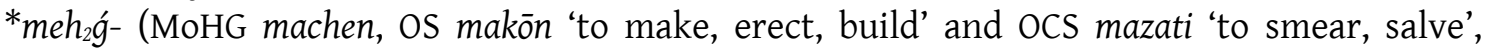
perhaps also Gr. $\mu \alpha \alpha \sigma \sigma \omega$ 'to knead', EDG 910-911). However, it remains unclear, although it seems to share an ending with dạker (B-05) / $\delta \alpha \kappa \alpha \rho$ (pl.nom. $16.1 \delta[\alpha] \mid \kappa \varepsilon \rho \eta \varsigma)$, a noun derived from the verbal root dāk-<PIE * $d^{h} h_{1}-k$ - with the suffix *-ēr- / -er-. A relationship with Gr. $\mu$ ák $\alpha \rho$ 'blessed, happy, blissful' (considered Pre-Gr. by Beekes in EDG 893, see also DELG 659) cannot be ruled out, although it is difficult to defend and the prehistory of this Greek word has yet to be determined. Brixhe 2004a, 125.

$\mu \alpha \kappa p \alpha v$ (noun or adj.?) 'long' or 'tomb'?

MPhr. sg.acc. $\mu \alpha k \rho \alpha v$ MPhr-01 (W-11) 1.3

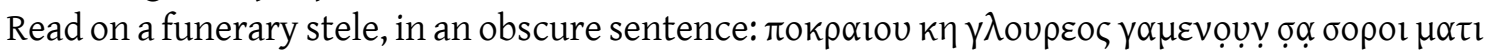

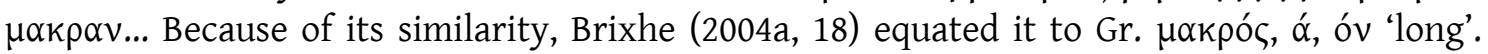
However, it does not qualify anything unless we consider $\mu \alpha \tau$ to be a noun in sg.acc. Alternatively, Brixhe also equated it to Gr. $\mu$ ók $\rho \alpha$ 'bath-tub, sarcophagus' (simplification of 'kneading-trough, bathing-tub, mortar'). If this were the case, $\mu \alpha$ k $\rho \alpha v$ could be related to $\mu \alpha \gamma^{?} \mid \rho \varepsilon(19.2=129)$, but the difference between the voiceless and the voiced stops is unsatisfactory (pace Brixhe \& Drew-Bear 2010, 165-166). 
Brixhe 2004a, 18; Brixhe \& Drew-Bear 2010, 165-166.

mama (PN)

OPhr. sg.nom. mama G-173

Incised on a potsherd, this graffito contains an a-stem PN in nom. It is a clear Lallanme, which is very common in Gr. inscriptions from the whole of Asia Minor (see M $\alpha \mu(\mu) \alpha$ KPN 281-282, § 850).

CIPPh I, 151; Bayun \& Orel 1988a, 198; Orel 1997a, 442; Brixhe 2008, 79.

mami (PN)

OPhr. sg.nom. mami G-274 a

Incised on a potsherd, this graffito is PN in nom. without the ending -s, a variant of mamas type. It has sometimes been read as iman (e.g. Orel 1997a, 244) but it does not fit with the strokes of the first (or last) letter. It is also attested in Gr. inscriptions from Isauria as M $\alpha \mu \mu \iota \varsigma$ (KPN $284 \S$ 850-13).

CIPPh I, 211; Bayun \& Orel 1988a, 198.

\section{mamutas (PN)}

OPhr. sg.nom. mamutas G-229 (bis)

Incised on the handle of a pot, this PN appears at the beginning of the two lines of the inscription (which appear to rhyme): mamutas sokposa | mamutas itoiesgloka. It is thought to be of Anatolian origin. Indeed, it can be analysed as ma-mutas, where -mutas follows a Luwic form *muwata- 'might, potency', which is very common in the Anatolian onomastics (see Melchert 2013,34 ). An exact parallel is found in M $\alpha \mu$ otn (from Lycia, Cau 2003), although there are some

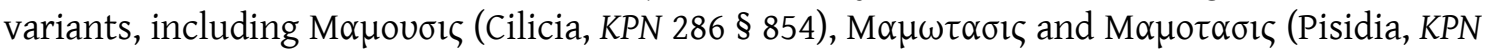
$286 \S 854-1$ and 3). Nevertheless, OPhr. mamutas can also be considered an ethnic in the light of

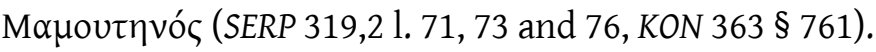

CIPPh I, 184; Bayun \& Orel 1988a, 197; Orel 1997a, 226 and 442; Lubotsky 1998, 420, fn. 23; Neumann 1988, 17; Brixhe 1993, 339; Innocente 1997, 35; Wittke 2004, 200; Brixhe 2008, 79; Ligorio \& Lubotsky 2013, 194.

mane see manes.

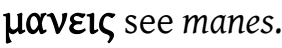

manes (PN)

OPhr. nom. manes B-07

nom. mane $\mathrm{Dd}-103$

acc. manin $\mathrm{B}-07$

gen. manitos B-07

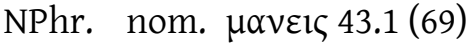

Masc. PN with different nominatives: with or without the nom. ending -s and $\varepsilon 1$ instead of $e$ (due to Gr. itacism or levelling from other forms?). With the exception of the nominative, its paradigm follows the $i$-stem inflexion, where the gen. takes a dental shape, as illustrated by artimitos and urgitos. It is well attested in Gr. inscriptions as Mavn

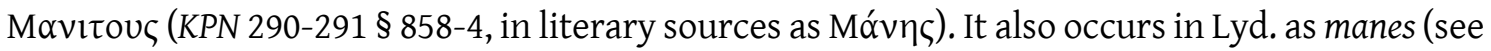
Gusmani 1964, 163), in Carian as mane (see Adiego 2007, 381) and in Aramaic as mny (in the bilingual Lydian-Aramaic inscription from Sardis, see Lipiński 1975, 159). Its origin is unknown. KPN 290-291 § 858-4; Neroznak 1978, 86; Masson 1987a, 111-112; Orel 1997a, 443; Gusmani \& Polat 1999b, 156; Brixhe 2004a, 77-78 and 127; Brixhe 2006, 40; Brixhe \& Summers 2006, 125; Brixhe 2008b, 74; Ligorio \& Lubotsky 2013, 189. 
$\mu \alpha v i \sigma o v(\mathrm{PN})$

NPhr. $\mu \alpha v i \sigma o v 41.3(31)$

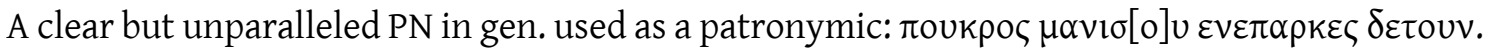
It is very likely a variant of manes.

manin see $\mu \alpha v \varepsilon 1 \zeta$.

manitos see $\mu \alpha v \varepsilon 1 \zeta$.

$\mu \alpha \boldsymbol{\alpha} \alpha$ (noun) 'stele'

MPhr. sg.nom. $\mu \alpha v \kappa \alpha$ MPhr-01 (W-11) 1.1

NPhr. sg.dat. $\quad \mu \alpha v k \alpha 3.1(97), 11.2(18), 31.1(29), 36.1(26), 64.1(81)$

sg.dat. $\quad \mu \alpha v \kappa \alpha 14.1(2), 17.2(3), 43.1(69), 60.2(60), 62.4$ (35)

sg.acc. $\quad \mu \alpha \nu \kappa \alpha v 2.1$ (15), 11.2 (18), 41.3 (31); $\mu<\alpha>v \kappa \alpha \nu 22.1$ (9)

sg.dat. $\mu[\alpha \vee k] \varepsilon 17.5(91)$ ?

sg.dat. $\mu \alpha v k \eta \varsigma 8.1$ (86)

A clear $a$-stem fem. noun. Note that the sg.dat. $\mu \alpha v \kappa \alpha$ drops the second element of the long diphthong $-\alpha \mathrm{l}>-\alpha$, preserved in $\mu \alpha \nu \kappa \alpha$ l. These two forms are well attested in the protases of

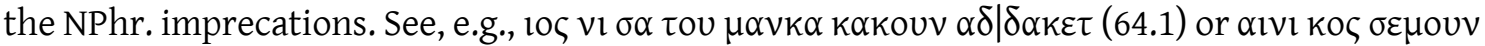

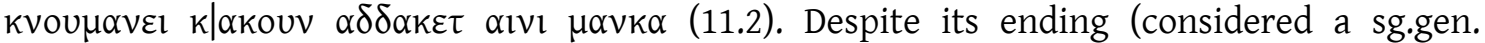
influenced by $\mathrm{Gr}$. according to Brixhe $(1983,119)$ and Ligorio and Lubotsky $(2013,189)$, the form $\mu \alpha v \kappa \eta \varsigma$, which occurs in the same position, must be understood as a sg.dat. (with confusion

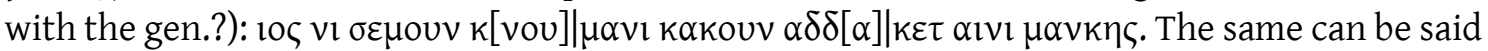
for the dubious $\mu[\alpha v k] \varepsilon$, where, if the restitution is accepted, the letter $\varepsilon$ appears as a result of the Gr. influence, since in this language $\alpha$ often appears as $\varepsilon$ (e.g. the common $\kappa \alpha i$ ' $>\varepsilon \varepsilon^{\prime}$ 'and'). The sg.nom. is clearly attested in MPhr-01, where it agrees with the adj. $\mu \varepsilon k \alpha \zeta: \mu \alpha v \kappa \alpha \mu \varepsilon \kappa \alpha \varsigma$ $\sigma \alpha \zeta$ Klvıv $\varepsilon \vee \kappa \varepsilon \beta \imath \lambda \alpha \tau \alpha \delta \varepsilon \mid v \alpha v v \varepsilon \kappa$ Kolvouv. Finally, the acc. forms occur in non-imprecatory parts

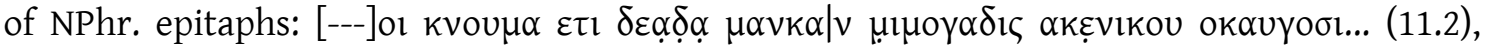

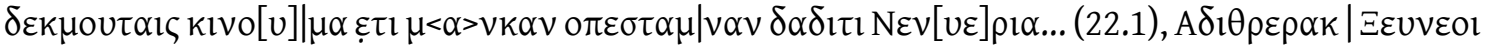

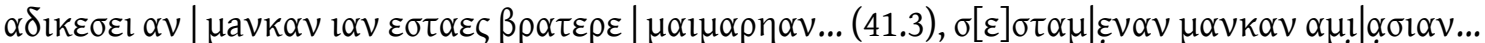
(2.1). Its root seems to be derived from the PIE root *men- 'remain' (LIV ${ }^{2} 437$, IEW 729) in lengthened grade: ${ }^{m} m \bar{e} n->\mu \alpha v-$. However, the presence of the suffix -ka has not been explained. On the other hand, the relationship with $\mu \alpha v i k \alpha$ in Plu. De Isis et Osiris 360b, suggested by Haas $(1966,67)$, a clear adj. in pl.neut.nom.-acc., must be ruled out because this adduced word is derived from the PN Móvnc. Similarly, an interpretation in the light of Lat. manus 'hand', which has been given to explain manuka (see Brixhe 2004a, 81) cannot be accepted because it goes back to a PIE vocalism *mon- $u$ - (according to de Vaan 2008,363 ) that is incompatible with Phr., and manuka is better explained as a PN.

Haas 1966, 67; Brixhe 1983, 119; Brixhe 1993, 331; Orel 1997a, 443; Gusmani \& Polat 1999b, 157-158; Brixhe 2004a, 13-14; Vine 2010, 352; Woodhouse 2006, 160 fn. 9; Ligorio \& Lubotsky 2013, 183 and 189.

$\mu \alpha v \kappa \alpha 1, \mu \alpha v \kappa \alpha v, \mu \alpha v \kappa \varepsilon$, and $\mu \alpha v k \eta \zeta$ see $\mu \alpha \nu \kappa \alpha$.

manuka (PN)

OPhr. sg.nom. manuka

The form manuka appears in a Greco-Persian funerary stele from Daskyleion (the seat of the Persian satrapy of Hellespontic Phrygia): [.]gat : s=manes iyungidas manitos apelev porniyoy esț[......]es va knais manuka odeketoy. Although it has been considered a variant of the noun manka 'stele' and the object (pl.acc.neut.) of the verb odeketoy (Brixhe 2004a, 81), this explanation cannot be substantiated because of the unexpected $-u-$. Taking into account the location of the 
inscription, it is more plausible to consider manuka an OP PN also found in the administrative clay tablets from Persepolis as Manukka (see Schmitt 1973, 17-19 and Mayrhofer 1973, 189 s.v.). Then, va knais manuka means 'his [= Manes'] wife Manukka'.

Brixhe 2004a, 81.

$\mu \propto \varsigma$ (DN)

NPhr. sg.nom. $\mu \alpha \varsigma 1.1(48)$

A DN equated to Gr. Mńv, the Moon God, by Janda (in Lubostky 1997, 122 fn. 10). It is read in a short list of three words, where it agrees with the ethnic $\tau \varepsilon \mu \rho о \gamma \varepsilon 1 о \varsigma: ~ \mu \imath \tau \rho \alpha \varphi \alpha \tau \alpha \mid \kappa \varepsilon \mu \alpha \varsigma$

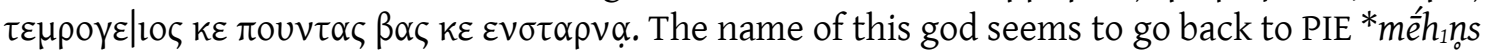

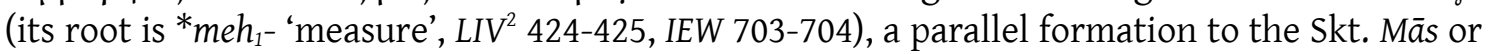
the Iranian Ma. However, Phr. $\mu \alpha \varsigma$ form cannot go back to $\mu \alpha \varsigma$, because an ending -ais is expected from ${ }^{*}$-ns (see the pl.acc. ending). Therefore, one must assume that $\mu \alpha \varsigma$ is a secondary $a$-stem extended from the sg.acc.

Lubotsky 1997, 122 fn. 10.

ṃasa (PN)

OPhr. sg.nom. mạsa K-01 VI-VIIa1

Masculine $a$-stem PN in sg.nom read on the fragmented stele from Kerkenes Dağ: ( $m a s a$ u|rgitos dakor $s=v e b r a[---]$ 'Masa the son of Urgitos makes? this vebra-...'. Its origin is clearly Anatolian: ${ }^{\mathrm{m}}$ Masa is already attested in Hitt. (LNH 115 § 770, see also *m masa-muwa LHN 115 § 771) and its etymology is perhaps to be found in the Luwic word massan- 'god', attested in CLuw. mašša(i)-, HLuw. DEUS-n(i)- (= /massan(i)-/?), Lyc. mahan(a)- and, perhaps, Carian msn- in the PN msnord(on it see Adiego 2007, 385). It also occurs in Gr. inscriptions from Roman times in Pisidia/Southern Phrygia, Lycia, Galatia and, recently, in Cicilia (see KPN 300 § 875 and Laflı 2017, 166).

Brixhe \& Summers 2006, 125.

matar (noun and DN) 'mother'

OPhr. sg.nom. matar W-04, W-06, B-01; [mata]r B-08

mate [...] W-05b

mater [---] M-01c

sg.acc. materan $\mathrm{M}-01 \mathrm{dI}, \mathrm{W}-01 \mathrm{a} ;$ matera $\left[n^{?}\right] \mathrm{M}-01 \mathrm{~d}$ II?

sg.dat. materey $\mathrm{M}-01 \mathrm{e}, \mathrm{W}-01 \mathrm{~b}$ (bis)

NPhr. sg.nom. $\quad \mu \alpha \tau \alpha \rho 11.2(18)$

A clear fem. $r$-stem noun inherited from PIE *méh $t e \bar{e}$ 'id.', attested in Gr. $\mu$ in Lat. māter, Vedic mātā (mātāras), Arm. mayr, etc. A particularity of its inflexion is that the dat. form shows levelling of the e-grade of the suffix from the acc. The occurrence of M-01dII is very fragmented, but because of the last $a$ it is very likely a sg.acc.: matera[ $n---] \mid$ avi[---]. Moreover, mater [---] M-01c is ambiguous and only a sg.nom. can be ruled out, while mate [...] W-05b is expected to be sg.acc. or sg.dat. (see Lubotsky 2017, 430). It should be noted that in most instances this word is used in reference to the Mother-Goddess and is often followed by an epithet: matar kubileya W-04, matar kubeleya B-01 (also [mata]r kubeley[a ---] in B-08), materan areyastin $\mathrm{W}-01 \mathrm{a}$ and materey eveteksetey $\mathrm{W}-01 \mathrm{~b}$. It is possible that only the NPhr. occurrence is used as the common noun for mother, where it appears in a funerary context close to PNs: $\lambda \varepsilon \cup \kappa ı \varsigma ~ \mu \iota \mu о \gamma \alpha \varsigma \kappa \varepsilon\{\varepsilon\} \mu \alpha \tau \alpha \rho \varepsilon \cup \gamma \varepsilon \xi \alpha \mid \rho v \alpha 1 . .$. Finally, according to Ligorio and Lubotsky $(2013,189)$, before the reading problems encountered with the last word of the first line in 19.2 (129), they read $\mu \alpha \tau \mid[\varepsilon] \rho \varepsilon$, a dat. of matar. However, its context is an imprecative protasis in which terms referring to parts of the tombs are expected. So, despite the lack of parallels, the reading $\mu \alpha \gamma_{\gamma}$ ? $\mid \rho \varepsilon$ (given by Brixhe \& Drew-Bear 2011, 165-166) is still defensible.

Orel 1997a, 443; Gorbachov 2005, 197; Matzinger 2005, 378; Ligorio \& Lubotsky 2013, 189; Lubotsky 2017, 430. 
mater[---], matera[---] and materan see matar.

${ }^{\dagger} \mu \alpha \underline{\underline{\alpha}}[\varepsilon] \rho \varepsilon$ see $\mu \alpha \underline{\gamma} \gamma^{?} \rho \varepsilon$ and matar.

materey see matar.

$\mu \alpha \tau \imath$ (noun or adj.?)

MPhr. ? $\quad \mu \alpha \tau 1 \mathrm{MPhr}-01$ (W-11) 1.3 and 1.4

sg.acc. $\mu \alpha \tau \iota v$ MPhr-01 (W-11) 1.5

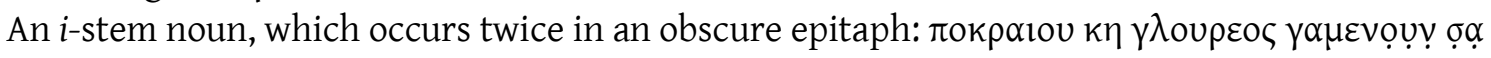

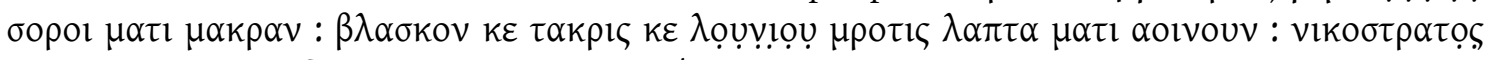

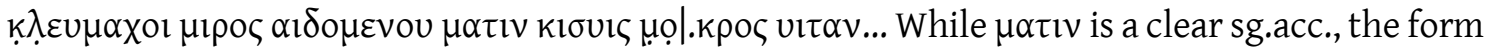
$\mu \alpha \tau l$ is problematic. While an ending is expected, in 1. 3, it seems to agree with $\mu \alpha \kappa \rho \alpha \nu$ and perhaps an acc. $-n$ is lost before the following stop by assimilation. However, a sg.nom. without -s cannot be ruled out. Its origin, as well as its meaning, remains unknown. It is possible that the same word occurs in $\uparrow$ ekmatin (B-06).

Brixhe 2004a, 18.

$\mu \alpha \tau \imath v$ see $\mu \alpha \tau \imath$.

$m a .[] a s.(\mathrm{PN})$

OPhr. sg.nom. ma.[.]as G-202

This graffito incised on a potsherd is very likely an $a$-stem personal name. The reading mavas given by Bayun and Orel $(1988 \mathrm{a}, 189)$ is ungrounded and was later replaced by mar [o]as (Orel

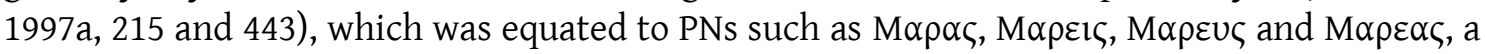
stem found elsewhere in Anatolia (KPN 297 § 873-5 - § 873-7). However, the reading cannot be corroborated.

CIPPh I, 167; Bayun \& Orel 1988a, 198; Orel 1997a, 215 and 443.

\section{ma.?[.]mas (PN)}

OPhr. sg.nom. ma.?.]mas G-202

The loss of the central letters of this graffito incised on a potsherd makes it difficult to interpret. However, it is very likely an $a$-stem PN, although no parallel can be adduced. The readings mayas (Bayun \& Orel 1988a, 198) and mar[o]as (Orel 1997a, 215) are ungrounded, especially the former. CIPPh I, 167; Bayun \& Orel 1988a, 198; Orel 1997a, 215.

\section{$m a[\ldots]$ un (noun)}

OPhr. sg.acc. $\quad m a[. .] u$.$n HP-102$

Although its central letters are lost (the proposed completions of Gusmani 1988 and Orel 1997a, 135 are not defensible) and it is a hapax, it is very likely a masc. or neuter noun in sg.acc because of its position and the clear ending. It perhaps refers to the support (a vase) offered by a man called Midas to Aiasa(s): midas aiasay ma[....]un.

Gusmani 1988; Orel 1996; Orel 1997a, 135-137; Brixhe 2004a, 106-108.

$\mu \delta$ ovৎ see $\mu \delta$ vel. 
$\mu \delta$ vel (noun) part of the monument

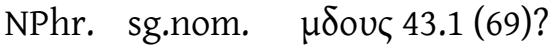

sg.dat. $\quad \mu \delta$ vel $14.1(73)$

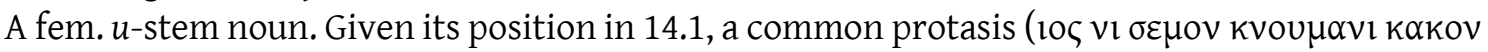
$\alpha \beta \beta \varepsilon \rho \varepsilon \tau o \rho ~ \alpha ! ̣ l ~ \sigma \alpha \zeta \mu \delta \cup \varphi \varepsilon)$, it must refer to a part of the funerary monument. However, its precise meaning remains unknown. In 43.1 the context is less clear but is totally different (an enumeration of people related to the monument), and the very presence of this word has been questioned by a new reading proposed by Hämmig (fthc. a): $\Sigma^{?} \mathrm{INEM}^{?} \mathrm{~A}^{?} \mid \Delta \mathrm{OT}^{?} \mathrm{E}^{\text {? }}$ instead of $\varepsilon i v \varepsilon \alpha \_\mu \mid \delta o u \zeta, \ldots$. In any case, regarding the origin of this word, Haas $(1966,78)$ suggested a borrowing from Lyd. mru- 'stele' (on this point, see Gusmani 1964, 168-169). This meaning is highly compatible with the context and the spelling may indicate a borrowing (from an Anatolian language?). In 43.1 (69), $\mu \alpha v \kappa \alpha \iota$ refers to the stele itself, a fact we can use to rule out the occurrence of $\mu \delta v$ - occurs in these inscriptions. This possibility would only be defensible in 14.1 (73, found in the western NPhr. area). In any case, the Lyd. mru- perhaps occurs in Phrygian as $\mu \rho \mathrm{o}(\varsigma)$ in 29.1 (114).

Brixhe \& Neumann 1985, 179; Hämmig fthc. a.

$\mu \varepsilon^{1}$ (preposition) 'before, in the sight of, among'

NPhr. $\mu \varepsilon 3.1$ (97), 10.1 (112), 10.2 (113), 16.1 (116), 17.2 (3), 17.6 (119), 18.2 (5), 18.3 (6), 19.1 (96), 20.2 (128), 21.1 (42), 27.1 (92)?, 65.3 (21), 65.4 (124), 66.1 (103)?, 19.2 (129).

A preposition inherited from PIE *me- (LIPP II, 494, documented in Gr. $\mu \varepsilon \tau \alpha ́$ and $\mu \varepsilon ́ x \rho 1)$. It governs dat. and occurs in the common formula $\mu \varepsilon \delta \varepsilon \omega \varsigma \kappa \varepsilon \zeta \varepsilon \mu \varepsilon \lambda \omega \varsigma \kappa \varepsilon$ 'in the sight of gods and men', found in imprecatory apodoses. Parallels of this formula in other languages confirm its

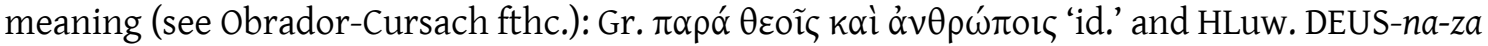
| CAPUT-tá-za-ha *366-na-na 'id.'. It must be added that in 21.1 it has been identified as postposition, although Hämmig has withdrawn this following her new reading. Finally, while this form has traditionally been identified as a preverb in positions like $\mu \varepsilon \beta \varepsilon \rho \varepsilon \tau$, it is now better explained as the prohibitive particle (see $m e^{2}$ ).

Brixhe 1979a, 184-188; Brixhe 1997, 53-55; Orel 1997a, 443; Lubotsky 1998, 420; Obrador-Cursach fthc.; LIPP II, 494.

$m e^{2}$ (prohibitive particle) 'not'

OPhr. me B-05 l. 12, B-07

NPhr. $\mu \varepsilon 7.1$ (99), 7.2 (111), 8.1 (86), 11.2 (18)

Prohibitive particle which goes back to PIE * meh (LIPP II, 511-512), documented in Gr. $\mu$ ń, Arm. $m i$, Skt. $m \vec{a}$, OP $m \bar{a}, A v . m \bar{a}$, ToAB $m \bar{a}$, and, perhaps Alb. mo. It is always found in apodoses where the verb is in subj. instead of imperative, without negative: B-05 tubnuv nevos me deritoy..., B-07

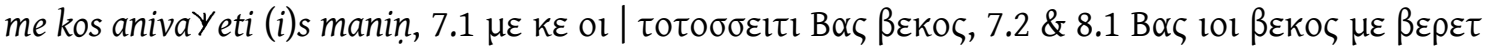

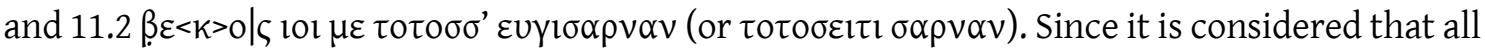
PIE ${ }^{*} \bar{e}$ and ${ }^{*} e_{1}$ become $a$ in Phrygian, this particle has been identified as a preverb, documented as the preposition $\mu \varepsilon$ (see $\mu \varepsilon^{1}$ ), which contrasts with Haas' (1966) previous identification (see Hämmig fthc. a and Obrador-Cursach fthc. on the new definition). Consequently, it must be considered that not all PIE * eh yield Phr. $\bar{a}$. The same problem is found in the ending of the adverb kake(y) / $\kappa \alpha \kappa \varepsilon$ (see $\S 4.1 .2 .2 .3$.). Finally, note that $7.2 \mu \varepsilon \kappa \varepsilon$ can be equated to Gr. $\mu \tilde{\eta} \tau \varepsilon$ 'and not'.

Haas 1960, 27; Haas 1970, 65; Brixhe 2004a, 84; Hämmig 2013, 143 fn. 36; LIPP II, 512; Hämmig fthc. a.; Obrador-Cursach fthc. a

$m e^{3}$ (PN?)

OPhr. me G-242

A complete graffito incised on a potsherd, perhaps an abbreviated PN.

CIPPh I, 191; Orel 1997a, 232 and 444. 
${ }^{\dagger} \mu \varepsilon \beta \varepsilon \rho \varepsilon \tau$ see $m e^{2}$ and $\alpha \beta \beta \varepsilon \rho \varepsilon \tau$.

${ }^{\dagger}$ mederitoy see $m e^{2}$ and deritoy.

$\mu \varepsilon 10 \mu \mathrm{ov}$ (noun or adj.?)

NPhr. sg.acc. $\mu \varepsilon 10 \mu$ ov 16.1 (116) l.

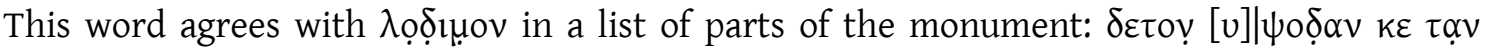

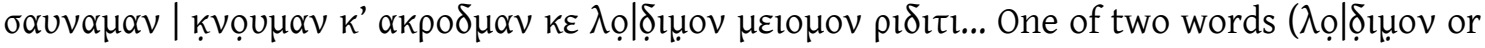
$\mu \varepsilon 10 \mu \mathrm{ov})$ must be a noun and the other its adjective, but this identification is difficult to resolve without more parallels of the words.

Brixhe \& Neumann 1985, 167.

$\mu \varepsilon \kappa \alpha$, meka[----], mekaị̦[-?-] and $\mu \varepsilon \kappa \alpha v$ see mekas.

mekas (adj.) 'big, great'

OPhr.

meka[---] B-05

pl.dat or pl. acc.? mekaị̦[-?-] G-239

sg.nom. mekas M-05, G-111, P-03, P-04c, G-147; mekạs B-05

MPhr. sg.nom. $\quad \mu \varepsilon \kappa \alpha \varsigma$ MPhr-01 (W-11) l. 1

NPhr. sg.dat. $\quad \mu \varepsilon \kappa \alpha 35.1(25)$

sg.acc. $\quad \mu \varepsilon \kappa \mid \alpha \vee 2.2(130)$

Adj. inherited from PIE *meǵ- $h_{2^{-}}$'big, great' (NIL 468-478, IEW 708-709). The sg.nom. form has developed an ending -s, as well as in Gr. $\mu \varepsilon$ c $\alpha \varsigma$ 'id.'. This case is the most attested by far and is used to qualify objects ( $\mu \alpha v \kappa \alpha \mu \varepsilon \kappa \alpha \varsigma \sigma \alpha \varsigma$ MPhr-01), gods (devos ke mekas P-03) and people (apelan mekas M-05). On the other hand, the sg.acc. $\mu \varepsilon \kappa \alpha v$ shows a levelling in $e$-grade from the sg.nom., and is attested once: $\mu \varepsilon \kappa \alpha \nu \tau \imath \alpha \nu$ 2.2. The sg.dat. is identified because of the concordance with a restored DN (according to a comparison with 2.2, see Obrador-Cursach 2016) $\mu \varepsilon \kappa \alpha \mid \tau[1 \varepsilon]$

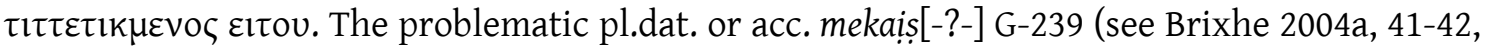
see also Ligorio \& Lubotsky 2013,187 ) incised on a potsherd has lost the probable noun which it agrees with, but it shows that the Phrygian word does not present the suffix *-lo- introduced in Gr. ( $\left.\mu \varepsilon \gamma \alpha \lambda o_{-}, \mu \varepsilon \gamma \alpha \lambda \eta ́\right)$ and, perhaps, in Go. (mikils). Finally the form meka[---] is not clear because of the loss of the final letters. It is common to find that this word refers to (a part of) the monument (see, e.g., Brixhe 2004, 14 and Avram 2015, 212 fn. 82), however, this interpretation is not longer defensible (see Obrador-Cursach 2016).

Orel 1997a, 444; Brixhe 2004a, 14; Woudhuizen 2008-2009, 187 \& 211; Brixhe 2004, 41-42; Woodhouse 2006, 161; Avram 2015, 212 fn. 82; Obrador-Cursach 2016.

${ }^{\dagger} m e k o s$ see $m e^{2}$ and kos.

${ }^{\dagger}$ mem see memevais.

memevais (patronymic) 'son of Mem-'

OPhr. sg.nom. memevais M-01b, M-02

sg.nom. memeuis $\mathrm{T}-02 \mathrm{~b}$

All occurrences follow PNs: baba memevais M-01b, bba memevais M-02 and tumida memeuis T-02b. It is therefore considered a patronymic derived from a PN (unattested, but perhaps a variant of mama) through the suffix -evan- found also in arkiaevais and kanutievais, where their nominatives are suggested to have evolved from *-evan-s $>$ *-evais. The explanation of mem- as a "hyperemphatisch" particle (LIPP II, 505) is refuted by the systematic contexts of onomastic 
formulae. Finally, note that the variant memeuis found in Tyana shows the common Luw. contraction *uwa > $\mathrm{u}$ (on it, see Rieken 2001). Note also that 〈 $\mathrm{u}\rangle$ is used here instead of 〈v〉. Neroznak 1978, 72, 73 and 85; Brixhe 1984, 266; Brixhe \& Neumann 1985, 180; Lubotsky 1988, 17; Innocente 1997, 40; Brixhe 2004a, 12; Wittke 2004, 199; Ligorio \& Lubotsky 2013, 187.

memeuis see memevais.

meros (noun)

OPhr. sg.nom.-acc. meros B-07

MPhr. sg.nom.-acc. $\mu 1$ po $\mathrm{MPhr}-01$ (W-11) 1.5

NPhr. sg.dat.? Mipov 16.1 (116) 1.10

All occurrences of this noun occur on funerary stelae: va knais manuka odeketoy meros ke manes

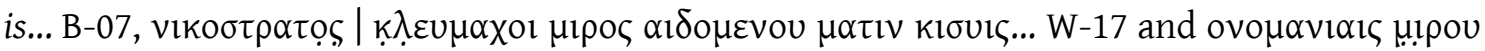
$\imath \kappa[] \mid. ~ \kappa v \alpha \iota k \alpha \nu \varepsilon \delta \alpha \varepsilon \zeta \ldots . .16 .1$ (116). However, the contexts are not clear enough to illustrate its meaning. In any case, note that the hesitation /e/ /i/ is not unusual in Phr. (see § 4.1.1). Finally, we must acknowledge a possible derivative adj. from this word: mireyun.

Brixhe \& Neumann 1985, 179; Brixhe 2004a, 81-82; Simon 2014a, 145-146 fn. 10.

mer?oun (noun?)

OPhr. sg.acc.? mer? oun B-03

The dubious letter could be read as $\langle 1\rangle$, but no parallel can be adduced to corroborate it. Its context, perhaps a curse, is not clearer: yosyos yenvra etitevtevey me.oun laked'ọ| [-?-].

CIPPh I, 71; Lubotsky 1993b, 96 fn. 2.

mey? (PN)

OPhr. mey? G-345

Complete graffito incised on a potsherd from the $4^{\text {th }}$ or $3^{\text {th }} \mathrm{C} . \mathrm{BC}$, which is very likely an abbreviated PN. The reading of its last letter is problematic: its shape $X$ can be explained in at least two ways and the sequence is unparalleled in Phrygian. According to Brixhe (2002a, 9-99), it could be a Gr. chi ( $\mathrm{X}$ ) and, consequently, this graffito would be one of the earliest occurrences of the Gr. alphabet used to write the Phrygian language. If this were the case, the use of an aspirated letter would be merely graphical and could stand for a voiceless velar stop. This is why it has been related to and derived to the adj. mekas by Brixhe. See the very suitable parallel of the Gr. PN MÉ $\alpha \varsigma,-\alpha$. Nevertheless, it is more plausibly explained as an occurrence (the last) of the Phrygian yod, with the same shape found in B-06, despite being an earlier text and found far from Gordion). If this were the case, we could be dealing with the abbreviation of a PN such

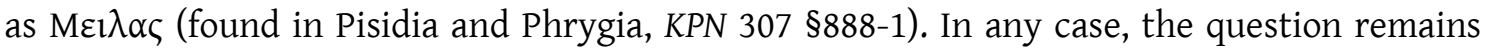
open.

Brixhe 2002a, 98-99; Avram 2015, 212 fn. 82.

$m e ̣[---]^{1}(\mathrm{PN} ?)$

OPhr. $m e e^{[---] ~ G-167}$

This fragmented graffito on a potsherd is very likely the beginning of a PN, however this is difficult to confirm.

CIPPh I, 147; Bayun \& Orel 1988a, 199; Orel 1997a, 200-201.

$m e ̂ \mid[---]^{2}(?)$

OPhr. mel[---] T-03 b

Beginning of a damaged word. No further observations can be made because of the severe fragmentation of the text: eptuve[---]|[---]itan mel|[---]p? is : [---]...

Brixhe 1991, 39; Brixhe 2004a. 
midai see midas.

$\mu 1 \delta \alpha \kappa \alpha \varsigma(\mathrm{PN})$

NPhr. sg.nom.? $\mu 1 \delta \alpha \kappa \alpha \varsigma 11.2(18)$

An unparalleled $a$-stem PN, which appears in a non-imprecative NPhr. sentence: $\mu 1 \delta \alpha \kappa \alpha \varsigma \delta \alpha \delta$ ov $\lambda \varepsilon \cup \kappa i \omega \iota \quad \delta \alpha \kappa \alpha \rho . .$. Although it could be segmented as $\mu 1 \delta \alpha$ and considered a variant of midas without the ending -s, the resultant $k \alpha \varsigma \delta \alpha \delta$ ov is not satisfactory. However, it is very likely a derivative of such a well-known PN.

Orel 1997a, 82 and 445.

midas (PN)

OPhr. mida $\quad$ m[-- ] T-02 b

sg.dat. midai M-01a

sg.nom. midas M-01d I; G-137, HP-102

This $a$-stem PN has an unclear origin, but it is unlikely to be Phrygian since a Mita of Pahhuwa is attested in the Hitt. text CTH 146 (from $16^{\text {th }}-15^{\text {th }}$ c. BC). Berndt-Ersöz $(2015,112-113$, following Burke 2001, 260-261) considers that it derives from Hitt. mit(t)a-, miti- (adj.) 'red' (on this point, see Kloekhorst 2008, 583). However, this is a mere possibility. In any case, midas is a welldocumented dynastic name, since almost three Phrygian kings bore this name according to Gr. sources (Berndt-Ersöz 2008 and 2012, 33). The Midas mentioned in the M-01 façade could be one of them. A king Midas is also documented in Neo-Assyrian texts from the reign of Sargon II (722705 BC) as Mitā šàr māt Muški 'Mita the King of the land Muški'. However, other people also borne this name, as we can see in the potsherds G-137 and HP-102 and some later Gr. inscriptions from

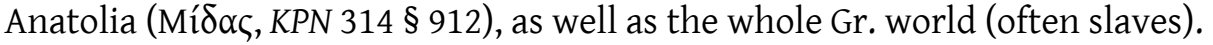

Neroznak 1978, 104; Orel 1997a, 445; Burke 2001, 260-261; Berndt-Ersöz 2012, 33; Berndt-Ersöz 2015, 112-113.

mịạ[---] see midas.

$\mu \iota \mu о \gamma \alpha \delta ı$ see $\mu \iota \mu о \gamma \alpha$.

$\mu \iota \mu \operatorname{\gamma os}^{(\mathrm{PN})}$

NPhr. sg.nom. $\mu ц \mu о \gamma \alpha \varsigma 11.2(18) 1.4$

sg.gen. $\mu \mu \mu о \gamma \alpha \delta ı 11.2(18) 1.2$

Both forms of this unparalleled dental-stem PN occur in the same inscription. Its inflexion is not at all clear. While the nom. shows the simplification $*_{-} d-s>-s$, similar to $*_{-t-s}>-s$ found in nevos or $\beta \alpha \varsigma$, regarding to the gen., Woodhouse $(2006,170)$ interpreted that this case actually is * mimogados, the form expected in the light of artimitos. However, the confusion $1 \sim 0$ is striking. On the other hand, the letter 1 could stand for 10 , see, e.g., 15 instead of $10 \varsigma$ or $\lambda \varepsilon v \kappa ı \varsigma$ for $\lambda \varepsilon v k i \circ$ in the same inscription (a phenomenon also recorded in Gr. inscriptions from Phrygia, see Brixhe 1987, 50-51). Then, we are dealing with a common consonant-stem gen. -os. Nevertheless, the presence of the $-i$ - in this ending remains incomprehensible (perhaps a levelling from another paradigm?). In any case, these examples fit with their position in the context: $\lambda \varepsilon v \kappa ı \varsigma, \mu \iota 0 \gamma \alpha \varsigma \kappa \varepsilon\{\varepsilon\} \mu \alpha \tau \alpha \rho$ (a sequence of sg.nom. words) and $\mu \alpha \nu \kappa \alpha \mid v \mu l \mu o \gamma \alpha \delta i \varsigma$

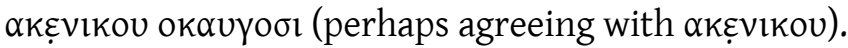

Woodhouse 2006, 170.

mireyun (adj.?)

OPhr. sg.acc.masc.-neut. mireyun B-05

An adj. which agrees with sirun in an apodosis: nun ibey neyotan niptiyan sirun mireyun... It has been considered a derivative of the noun $\mu$ ipos (perhaps the same noun found as meros), 
through the suffix -eio-. On its meaning, Simon (2014a) suggested 'all, whole', while the noun sirun is interpreted as 'offspring' on the basis of comparison with Hitt. formulae. However, it remains unclear because of the lack of internal data.

Neumann 1997, 24; Brixhe 2004a, 20, 62 and 81; Simon 2014a.

\section{$\mu 1 \rho \circ \varsigma$ and $\mu 1 \rho \circ v$ see meros.}

\section{$\mu \iota \tau \rho \alpha \varphi \alpha \tau \alpha(\mathrm{PN})$}

NPhr. sg.nom. $\mu ı \tau \rho \alpha \varphi \alpha \tau \alpha 1.1$ (48)

Because of the similarity with the Iranian PN *MiOra-päta- (theofortic 'protected by Mithra'), documented in Lyc. as miOrapata and mizrppata (Neumann 2007, 217 and 218 s.v.) and in Gr. as

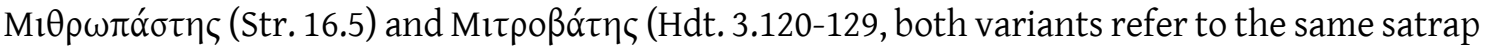
of Hellespontic Phrygia), its interpretation is obvious (the unmotivated phi of the Phrygian form may be a common hyperorrect spelling). This was first given by Kretschmer (in von Prott $1898,363)$ and followed by Schmitt $(1982,35)$, Diakonoff and Neroznak $(1985,124)$ and Orel (1997a, 446). However, since it appears in a short list with two DNs which bears an ethnic,

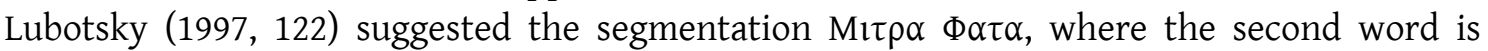
interpreted as an ethnic of a region not attested elsewhere. Older interpretations such as that of Haas, who understood the sequences as "Mitra und Phata" $(1961,77)$ or "Mitra und Ahura ( $\left.x^{u} a t \bar{a} y\right)$ ", must be rejected because of the structure given by the copulative conj. $k \varepsilon$ among the

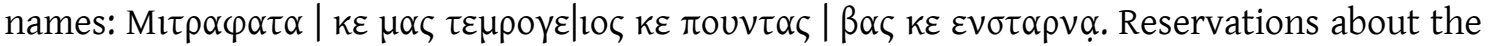
identification as a PN seem to be cultural rather than linguistic: Why does a man appear within a short list of gods? An easy explanation can be found in the Phrygian cult of the dead (see de Hoz 2017).

von Prott 1898, 363; Haas 1961, 77; Haas 1966, 98 and 1976, 61-62; Schmitt 1982, 35; Lubotsky 1997, 122; Orel 1997a, 446; Brixhe 1999, 299; Neumann 2007, 217 and 218; Drew-Bear, Lubotsky \& Üyümez 2008, 115.

\section{miye[.?]o广i (?)}

OPhr. miye[.] $]$ $4 \mathrm{H} \mathrm{NW}-135$

A very obscure sequence incised on a ceramic vase. There is a blank between the two series of preserved letters, where a letter could be incised. Consequently, the number of words remains unclear: one or two? Moreover, the presence of the obscure letter 4 and the fact that this sequence is unparalleled make this text difficult to interpret.

Brixhe \& Sivas 2009, 136.

\section{mi[---] (?)}

OPhr. mi[---] T-02 b

A certain beginning of a word delimited by the interpunction. Orel $(1997 \mathrm{a}, 310)$ suggested that it could be the name midas read above in the same inscription. Nevertheless, the shortness of the remaining fragment of this word condemns it to remain unclear. The whole sequence is really fragmented: [---]oitumen $\vdots$ mida[---]|[---]n $\vdots$ a个ios $\vdots$ mi[---]|[---]n $\vdots$ batan $\vdots$ e.[---].

CIPPh I, 266; Orel 1997a, 310.

$\mu \mu v \rho \alpha$ see $\mu$ oupovv.

$\mu \nu \kappa \alpha v$ see $\mu \alpha \nu \kappa \alpha$. 
modrovanak (title) 'sovereign of Modra/-oi'

OPhr. sg.nom. modrovanak M-04

A compound noun made up of the toponym modro- and the common noun vanak 'sovereign, king' (see vanaktei), a similar formation is found in Gr. $\alpha \sigma \tau \breve{v}-\alpha$ ' $v \alpha \xi$ 'lord of the city' (e.g. Aesch.,

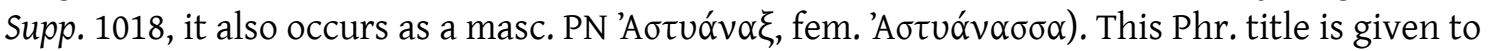

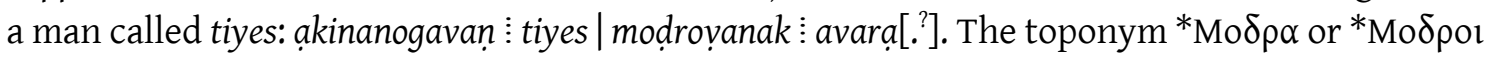

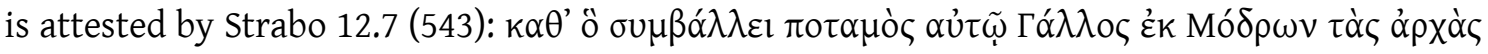

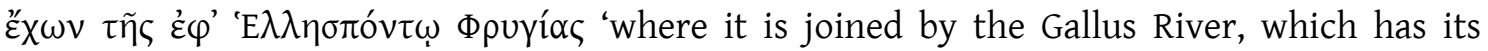
beginnings at Modro- in Phrygia on the Hellespont'. The late work De Thematibus 4.28 of

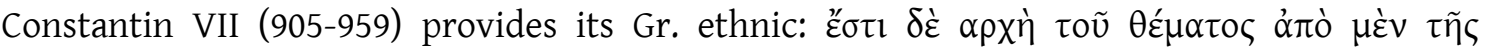

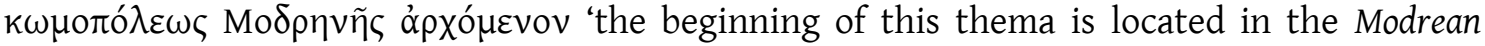
village'. On its identification with the modern Mudurnu (Bolu province, ancient Bithynia), see Şahın 1986. Note, however, that his remark on Strabo's text is a clear mistake, as Neumann (1986b) pointed out.

CIPPh I, 23; KON 391-392 § 823; Neumann 1986b; Bayun \& Orel 1988a, 180; Neumann 1988, 9; Bakır \& Gusmani 1993, 143; Brixhe 1993, 331; Brixhe 1996, 138; Brixhe 1997, 47 fn. 19; Innocente 1997, 38; Orel 1997a, 446; Brixhe 2002a, 61; Wittke 2004, 202; Berndt-Ersöz 2006, 75; Ligorio \& Lubotsky 2013, 188.

uovav (adj.) 'alone, only'

NPhr. sg.dat.fem. $\mu$ ov $\alpha$ v 56.2 (58)

Very likely an adj. which agrees with $\mu \rho \tau^{\prime \prime \eta}$ in sg.dat. (on its ending, see $\sigma \alpha v$ instead of $\sigma \alpha l$ ) related to Gr. $\mu$ óvo,$-\eta$, -ov 'alone, only'. Since the etymology of the Gr. word seems to be * monuo- (see EDG 965), the loss of $u$ before $o$ can be explained as an internal Phrygian issue and the consideration of a borrowing is not required since in the fem. it could be a levelling. Recently, Hämmig (fthc. b) interpreted it as an adverb parallel to $k \alpha v$. However, this can be ruled out

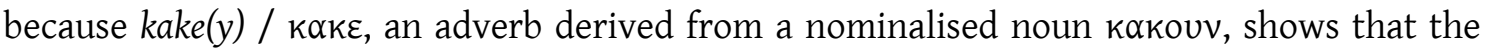
thematic nouns can derive into adverbs through the ending $-\varepsilon$ (<PIE sg.instr. ending $\left.{ }^{*}-e_{1}\right)$. The

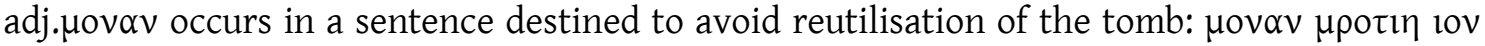
$\varepsilon \gamma \varepsilon \sigma 1|\tau \gamma \varepsilon| \gamma \rho \imath|\mu \varepsilon| v o \mid v$. Previous interpretations are highly unsatisfactory: e.g., Orel (1997a, 446) gave a sense 'harm' without any explanation, considering the sentence to be a curse. Orel 1997a, 446; Hämmig fthc. b.

ṃ?onokaua (patronymic?)

OPhr. m? onokaua M-01c

This word was often read as ḅonokaua in the light of bonok. However, this reading does not take into account the remaining strokes of this inscription and there is no reason to consider its first letter an unfinished 〈b〉 (Berndt-Ersöz 2006, 85). Since it follows a PN it could be a patronymic: mater.. atatas m? onokaua. Unfortunately, there are no parallels and this inscription may have been longer at the end.

Haspels 1971, 290; Brixhe 1983, 118; Brixhe 1984, 12; Bayun \& Orel 1988a, 178; Orel 1997a, 15 and 420; Berndt-Ersöz 2006, 85.

moro.[---] (PN?)

OPhr. moro.[---] G-214

Incised on a potsherd, the ending of this damaged graffito, very likely a PN. The last preserved stroke is vertical and could be a part of many letters. The reading moroi given by Bayun and Orel (1988a, 198, a dat. according to them) is a mere possibility. However, the inscription could be longer.

CIPPh I, 174-175; Bayun \& Orel 1988a, 198. 
Houpouv (noun) 'stupid action, mistreatment?'

NPhr. pl.nom.-acc. $\mu \mu v \rho \alpha 35.1$ (5)

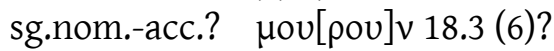

sg.nom.-acc. $\mu$ oupou[v] $61.1(100)$

All of the occurrences appear as the direct object of imprecative protases: 18.3 [10] $\mathrm{vl}^{\circ \varepsilon \mu o u v}$

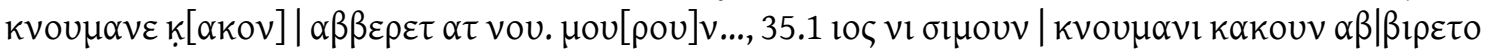

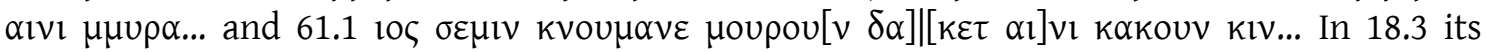
presence is very dubious since it is restored and the preceding word is unclear. Morphologically, it is an o-stem adj. substantiated equated to Gr. $\mu \omega$ pó $\varsigma$ 'dull, stupid' (see on it EDG 992). It is a parallel process to kakouv. The spelling of $\mu \mu \nu \rho \alpha 35.1$ can ben explained as hypercorrect.

Orel 1997a, 446.

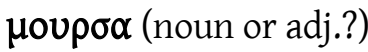

NPhr. $\mu$ oup $\sigma \alpha 11.2(18)$

Because of its ending it seems to be a pl.neut. Since it appears in an imprecative sequence (105

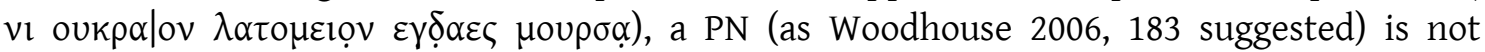
expected. On the other hand, translations such as those provided by Woudhuizen (2008-2009, 206) and Haas $(1966,102)$ are ungrounded.

Orel 1997a, 446; Woodhouse 2006, 183.

Họ.kpos (?)

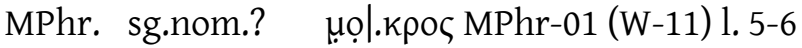

A word which has lost one central letter. It cannot be restored because of the lack of parallels

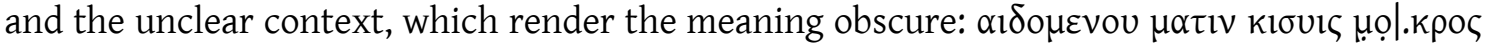
$v i \tau \alpha \nu \pi \alpha \rho \tau \imath \alpha \zeta$.

Brixhe 2004a, 21.

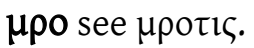

mroy see $\mu$ pos.

upos (noun) 'stele'?

NPhr. Sg.gen. $\quad \mu$ o os 29.1 (114)

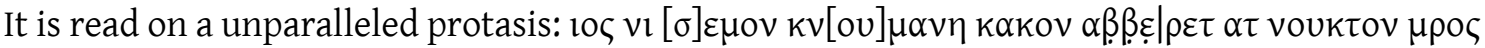
$\sigma \alpha \varsigma$ (or $\mu \rho \circ \sigma \sigma \alpha \varsigma$ )... It looks like a thematic noun of fem. gender because it agrees with the pronoun $\sigma \alpha \varsigma$. Note that the segmentation is not at all clear; it was analysed as a single noun

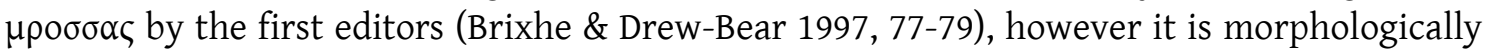
unusual and the presence of the pronoun is defensible in such a position in the light of MPhr$01 \mu \alpha \nu \kappa \alpha \mu \varepsilon \kappa \alpha \varsigma \sigma \alpha \varsigma$. Also, imroy has been argued by Brixhe and Drew-Bear $(1997,77)$ to be the same word with a prothetic $i$-. However, the context of this last word is absolutely different and this relationship can be rejected (see its entry). In the case of $\mu \rho \circ$, it can be identified as an

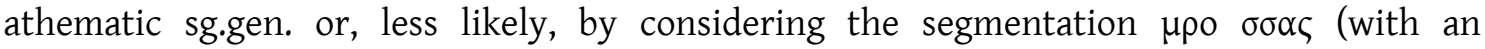
hypercorrected geminates), a thematic sg.dat. If the first possibility is accepted, it can be considerered a borrowing from Lyd. mru- 'stele' (Gusmani 1964, 168).

Brixhe \& Drew-Bear 1997, 77-79.

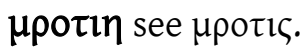




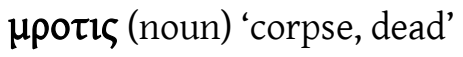

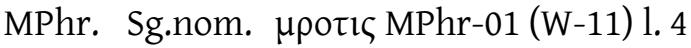

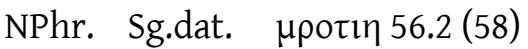

A noun inherited from PIE *mr-ti- 'death' (NIL 488-489). On the development of its meaning, compare with Lat. mors, mortis 'death' but sometimes 'corpse' through metonymy. In MPhr-01 this word was identified by Brixhe (2004a, 19), although its context remains obscure: $\beta \lambda \alpha \sigma k o v$

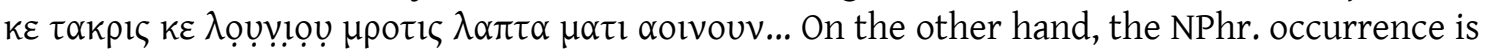

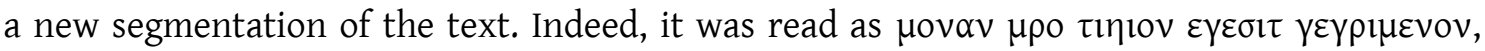

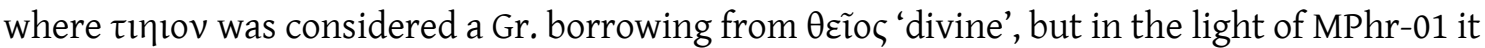

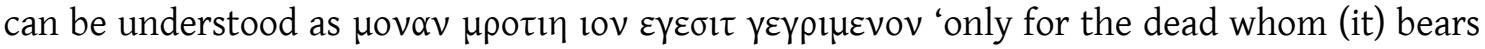
written'.

Brixhe 2004a, 19.

muksos (PN)

Ophr. Sg.nom. muksos G-346

A clear thematic PN incised on a beam of Midas Mound near three other names: nana muksos |

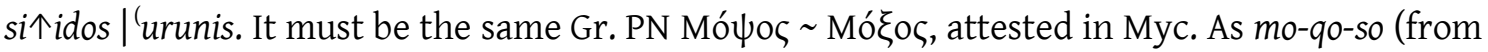
Cnossos, $15^{\text {th }} \mathrm{c} . \mathrm{BC}$ ) and mo-qo-so-jo (from Pylos, $13^{\text {th }}-12^{\text {th }} \mathrm{c}$. BC). It is also documented in ancient sources related to Anatolia: in Hitt. (in a letter of Arnuwandas I to Madduwatta, $15^{\text {th }} \mathrm{c} . \mathrm{BC}$ ), Hluw. Muksasa- (the bilingual KARATEPE I § 21) and Phoenician mpš (in the same inscription). All occurrences go back to a form *mok ${ }^{u}$ so-. Yakubovich $(2015,36-38)$, without mentioning the Phrygian occurrence, wonders why the Phoenician form is closer to Gr., with the regular evolution of the labialised $\mathrm{Gr}$. form of the I millennium $\mathrm{BC}$, while the Luw. occurrence of the same inscription shows the survival of the labialised stop, retaining the form from Mycenaean times. Either way, since the Phrygian form shows the regular evolution of this last sound and a common shift $o>u$, this testimony is not necessarily borrowed from Luw.

Liebhart \& Brixhe 2010, 147-149.

murtan (PN)

Ophr. sg.nom. murtan G-226

A late graffito on a potsherd $\left(4^{\text {th }}-5^{\text {th }}\right.$ c. BC). The letters are so similar in shape to the Gr. ones that one cannot rule out that it is written in the Gr. alphabet. However, it is considered Phrygian by the editors (CIPPh I, 183). This word is very likely a PN in nom., whose ending is parallel to iman, imenos: *-en >-an. Going one step further, Bayun and Orel (1988a, 198-199 and Orel 1997a, 446)

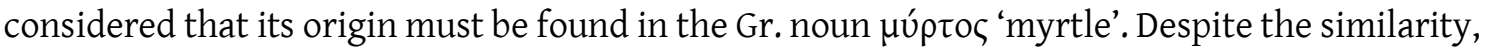
though, this is a mere possibility.

CIPPh I, 183; Bayun \& Orel 1988a, 198-199; Orel 1997a, 446. 


$$
\mathrm{N}(n)-\mathrm{N} v
$$

$n$ (mark)

Ophr. $n$ G-280, G-304

These graffiti incised on potsherd, composed only of one letter, seem to be merely an owner's mark, not necessarily derived from a PN.

Brixhe 2002a, 41-42 and 64-65.

na (?)

Ophr. nạ W-05 a

Obscure sequence following natimeyon, whose segmentation is not clear, engraved on a façade. CIPPh I, 48.

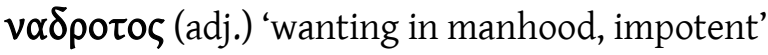

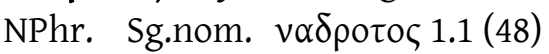

O-stem adj. in sg.nom.mas. Probably a loanword from Gr. óvóv $\delta \rho \omega \tau o \zeta$, -ov 'widowed' with a derivation in its meaning similar to ó $v \alpha v \delta \rho \circ \zeta$, -ov 'impotent, husbandless'. This interpretation is broadly consistent with the one given by Lubotsky $(1997,122)$, who suggested that could be connected with Gr. $\alpha v \alpha v \delta \rho o ́ o \mu \alpha 1$ 'to become impotent'. The context, an imprecative apodosis,

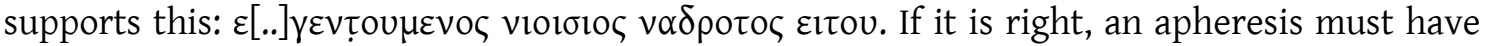
worked here. Brixhe $(1987 \mathrm{a}, 115)$ noted that in Gr. from Phrygia this phenomenon is more documented than in other places. Moreover, this word shows the weakness of the nasal in preconsonantal position, also common in Gr. inscriptions from Phrygia (see, e. g., 'A

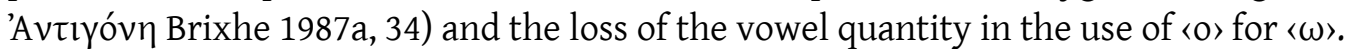

Lubotsky 1997, 122.

nạẹ[---] (?)

Ophr. naẹ[---] G-262

Fragmented graffito whose nature is unknown.

CIPPh I, 203.

nana (PN)

Ophr. Sg.nom. nana G-236?

Na?na? $a^{?}[-?-]$ G-195?

A-stem Lallname in sg.nom. without s-ending, also documented in Gr. inscriptions from the whole of Anatolia (KPN 346-349 § 1012-1013, N $\alpha v \alpha, N \alpha v \alpha \varsigma$ and variants). In G-236, the likely segmentation nana v/gata[-?-] is dubious. In G-195 there is the possibility of considering the variant ṇạa $a[\mathrm{~s}]$.

CIPPh I, 163 and 187; Bayun \& Orel 1988a, 199; Orel 1997a, 447; Liebhart \& Brixhe 2009, 146-147.

ṇạna[-?-] see nana.

${ }^{\dagger}$ nanavata[-?-] see nana \& vata[-?-].

natimeyon (?)

Ophr. natimeyon $\mathrm{W}-05 \mathrm{a}$

Isolated occurrence followed by the obscure sequence na: natimeyon na. The word boundary is assumed here because of the presence of $<\mathrm{nn}>$. This ending can stand for 0 -stem acc.-masc. or nom.-acc. neuter, if not the same sg.nom. ending as in kuryaneyon. The nature of the word is unknown. Note, however, the preservation of the vowel -on, instead of the expected -un. Orel's 
(1997, 445) segmentation meyon and comparison with Gr. $\mu \varepsilon^{\prime} \omega v$ 'smaller, less' is highly speculative.

CIPPh I, 48; Lubotsky 1988, 23-24; Brixhe 1996, 137-138; Orel's 1997, 445; Woodhouse 2006, 178; Vine 2010, 347.

${ }^{\dagger}$ natimeyonna see natimeyon \& na.

nevos (noun) 'son' or 'descendant'

Ophr. sg.nom. nevos B-05 l. 12

sg.acc. nevotan B-05 1. 10; Nev<otan> B-05 1.12

T-stem noun inherited from PIE *nepot- 'nephew, gradson, descendant' (NIL 520-524, IEW 764).

It occurs in two imprecative apodoses of the same inscription: nun ibey nevotan niptiyan sirun mireyun... and tubnuv nevos mederitoy kovis ke abretoy nun oy nev<otan>. Its meaning is supported

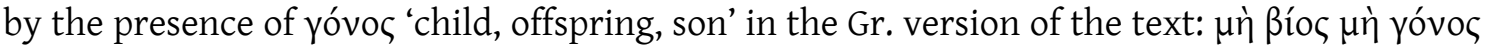
y'vorț[o] 'let him have neither life nor offspring'. Although Hämmig (2013, 134-138, who identified the word, see also Simon 2014a) considered that it means 'son' in contrast with niptiya- 'daughter', in other languages *nepot- commonly means 'descendant', 'grandson' or 'nephew': Lat. nepos 'grandson, descendant' nephew' (Catalan nebot 'nephew', Italian nipote

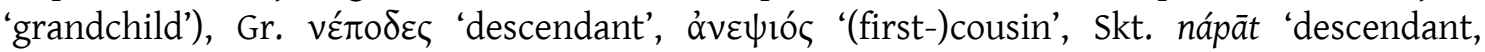
offspring, (grand)son', OP napā 'grandson', OHG neva 'nephew', OE nefa 'nephew, grandson, stepson', etc. So, the meaning 'male descendant' in contrast to niptiya- 'female-descendant' is more likely. Note that Gr. yóvo ‘ also means 'offspring, descent'. In any case, this word shows the shift *-t-s>-s (see also $\beta \alpha \varsigma, \beta \alpha \tau \alpha v$ ) and stands as the sole occurrence of * $p>v$ in Phr.

Hämmig 2013, 134-138, Simon 2014a.

nevotạn see nevos.

${ }^{\dagger} v \varepsilon 1 \xi \alpha$ see $\varepsilon 1 \xi \alpha$.

vekolvouv (noun or verb?)

MPhr. Nekolvouv MPhr-01 (W-11) 1.2

Because of the ending -ouv, although the word can considered an o-stem noun in sg.acc. ${ }^{*}$-on or pl.gen. *-on, a verb in 3pl. *-ont cannot be ruled out. Etymologically, this word is also obscure. Brixhe $(2004 a, 17)$ suggested a possible derivative from the root * $k^{u} \cdot e_{n}$ - 'take notice' ( $L^{2} V^{2} 377-$

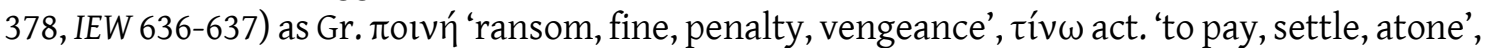
med. 'to make (oneself) pay or atone, punish, avenge' and $\tau \iota \mu$ ' 'estimate, price, value, honour, honorary office'. However, he does not explain the form $v \varepsilon^{-}$. It can be equated to Lat. $n \breve{e}-$, a variant of $n \bar{e}$ 'no, not' (< PIE *né 'id.' LIPP II, 511-512) in composition: scio 'I know', ne-sciō 'I do not know'. However, it is a mere possibility. Unfortunately, the context, an epitaph, does not provide useful information because it is still obscure: $\mu \alpha v \kappa \alpha \mu \varepsilon \kappa \alpha \varsigma \sigma \alpha \varsigma$ KIviv $\varepsilon v \kappa \varepsilon \beta \lambda \lambda \alpha \tau \alpha \delta \varepsilon v \alpha \nu$ vekolvouv.

Brixhe 2004a, 15 and 17.

\section{$v \varepsilon v[v \varepsilon] \rho i \alpha(\mathrm{PN})$}

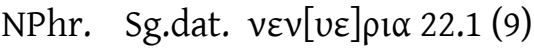

Although the sequence is damaged ( $\delta \alpha \delta \imath \imath \mathrm{N} \varepsilon v[v \varepsilon] \rho ı \alpha \mid \pi \alpha \rho \tau \cup \varsigma$ ou $\beta \rho \alpha)$, it has been restored thanks to the Gr. part of the text, where Nevvepla can be read. So, we have a fem. $a$-stem PN, probably a dat. with the loss of the second element of the original ending -ai. No exact parallels

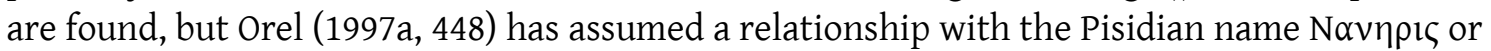
the Cilician Nev $\alpha$ pı (KPN 358 § 1028).

Haas 1966, 105; Lubotsky 1989a, 79; Orel 1997a, 75 \& 448. 


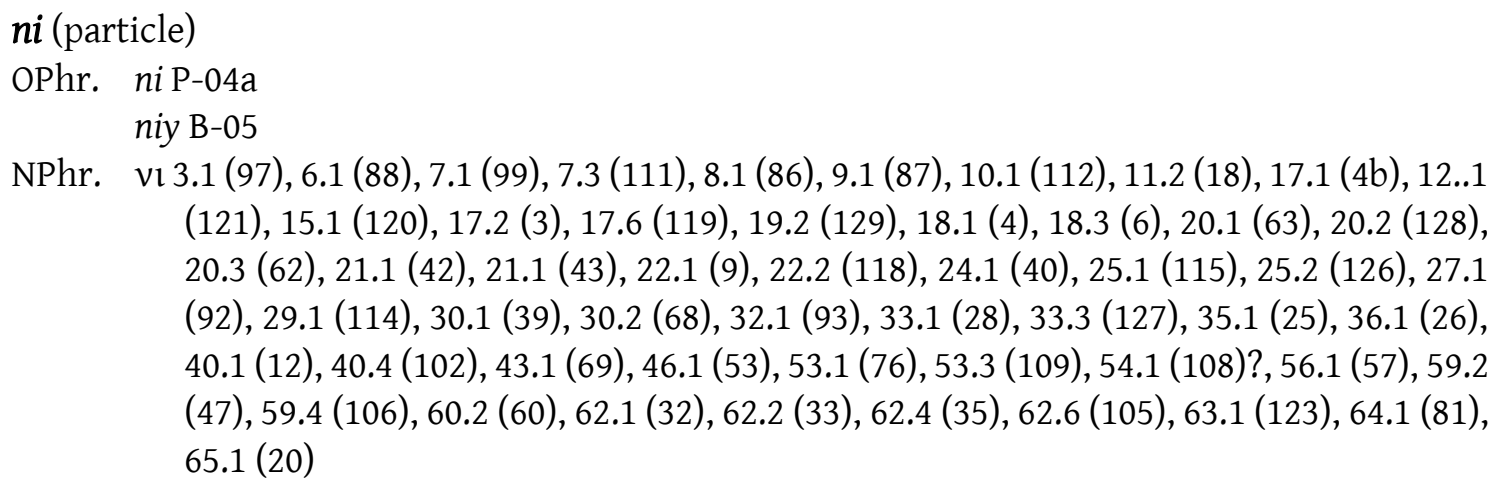

Encl. particle attached to the relative pronoun yos and the anaphoric tos in order to create an indefinite pronoun 'whoever'. It is also found with ay / $\alpha$ in order to form the disjunctive conj.

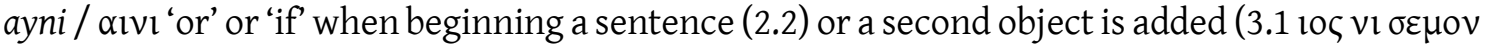

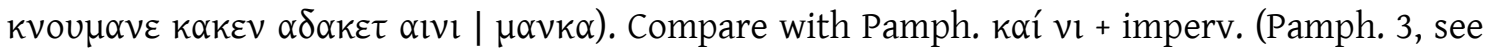
Brixhe 1976, 131-132). Although its origin is not at all clear, it seems close to Gr. - ve / -v1, which

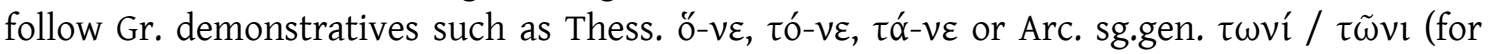
$\tau \circ \tilde{v} \delta \varepsilon$ ), instead of the $-v v$ found in other forms, and in the adverb $\pi \rho \tau_{\alpha} \alpha v i$ ' in front of'. It is supposed to be related to the PIE demonstrative *eno- 'this, that' (EDG 1001). The Gr. variant $v \mathrm{v}$, which is phonetically closer to the Phrygian one, seems to contain the deictic $*_{-i}$ and both the Phrygian niy / $n i$ / vı and the Gr. - vı could be analysed as the zero grade * $n h_{1}-i$ (Prósper 1993, 470). An alternative analysis is a form * $n_{n-i}$ 'inside, within' (LIPP II, 225 and 229-230). Nevertheless, the Phrygian ni can also represent *ne. It is clear that the Phr-form niy is a variant with a glide arising before a vowel but only visible in B-05, which uses the letter yod.

Prósper 1993, 470; Brixhe 1997, 63; Orel 1997a, 448; LIPP II, 225 and 229-230.

nidus (noun or adjective)

OPhr. sg.nom.? nidus B-05

Although its meaning is unknown, it seems to be an 0 - or $u$-stem noun or adj. in nominative singular. Its context is also obscure: mekạ[---]asiyạ.. | nidus ạd kaliyay karatu pạato.

Brixhe 2004a, 58.

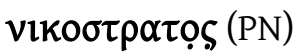

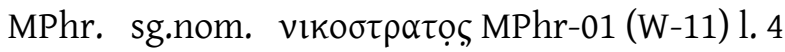

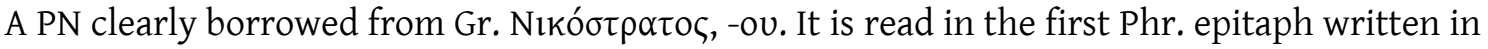

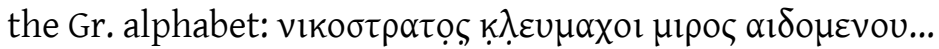

Brixhe 2004a, 25.

nina (PN)

OPhr. sg.nom. nina G-212

Written on a potsherd, this graffito contains an $a$-stem PN in nom. despite the lack of the sending. $\mathrm{Niv}(v) \alpha$ is a common Anatolian Lallname (KPN 360-361 § 1040-1 and 1040-9).

Bayun \& Orel 1988a, 199; Orel 1997a, 218-219 and 448-449.

violotos (adj.)

NPhr. sg.nom. viololos 1.1 (48)

Although the meaning of this word is unknown, the context, a clear apodosis (whose protasis

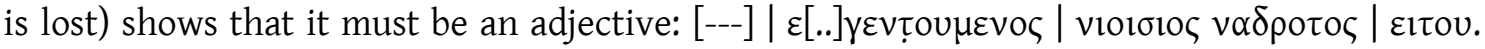
Consequently, it is an o-stem in sg.nom. On the other hand, Haas' phonetic interpretation (1961, 79 \& 1966, 97, followed by Panagl \& Kowal 1983, 188) /niwisios/ was rejected by Lubotsky (1997, 122).

Lubotsky 1997, 122. 
niptiyan (noun) 'daughter' or 'female-descendent'

OPhr. sg.acc. niptiyan B-05

sg.dat. niptiyay B-05

This $a$-stem kinship term is inherited from *nept-ih $2^{-}$, derived from the PIE *nepot- (NIL 520-524, see nevos) and means 'daughter', according to Hämmig (2013, 134-138), who identified this word. It occurs in an obscure sentence, pator.?ike[...]e[... andati / vạy niptiyay daker, and an apodosis, nun ibey nevotan niptiyan sirun mireyun. Adducing some possible parallels from Hitt. and rejecting Hämmig's analysis of $*_{-} i h_{2}>-i y a$, Simon (2014a) considered that niptiya- means 'grandson' and is a secondary fem. form derived from *nept-(i)io- 'grandson'. Indeed, he considered that nevotan niptiyan means 'son and grandson'. However, from a phonetic and morphological point of view, Hämmig's interpretation is easier and has good parallels in Lat. neptis 'granddaughter', Skt. naptit- 'daughter, granddaughter', Av. naptī- 'granddaughter', Lith. nepte 'id.'. As in the case of nevos, the meaning of OPhr. niptiya- is more likely 'femaledescendant' than 'daughter', in comparison with its cognates in other langauges. Then, although the meaning 'daughter' cannot be refuted, the pairing nevotan niptiyan 'maledescendant and female-descendant' can be considered emphatic. Note that the Gr. summary of this text only uses the term yóvoৎ 'child, offspring'.

Hämmig 2013, 134-138; Simon 2014a.

niptiyạy see niptiyan.

$\operatorname{vi\tau l}$ see $\pi \varepsilon v v \imath \imath l$.

niy see ni.

niye[---] see tataniyen.

niyoy (?)

OPhr. niyoy B-08; niyo[y?] B-01

This word follows to probable verbs: etoves niyo[y?] (B-01) and epav'es niyoy (B-08). Because of the lack of spaces (used in both inscriptions to mark word boundaries), etoves niyo[y $\left.{ }^{\text {? }}\right]$ was commonly segmented as etovesniyo[.']. However, the recent finding of B-08 provides a good parallel to defend such word boundary. The lack of space may show that it is a clitic word. Anyhow its nature and meaning remains unknown.

Brixhe \& Vottéro 2016, 136-137.

ni[---] (?)

OPhr. ni[---] or [---]in G-325

A late broken graffito, whose $n$ is similar to the Gr. Consequently, it is perhaps written in Gr. and not in the Phrygian alphabet. The text is obscure, probably a PN of the owner, but not necessarily. It is too short for any comparisons to be made. Furthermore, the writing direction is also unknown.

Brixhe 2002a, 80 .

nm (owner's mark)

OPhr. $n m$ G-215

An obscure sequence without parallels. Perhaps this graffito incised on a potsherd is a mere owner's mark without a clear acrophonic origin.

CIPPh I, 175; Roller 1987a, 40; Bayun \& Orel 1988a, 199. 
noktoy see vouktov.

noievos (PN)

OPhr. sg.nom.? noievos G-140

Written on a potsherd, it is probably an o-stem PN. Nevertheless, no parallel can be adduced.

CIPPh I, 127-128; Bayun \& Orel 1988a, 199; Brixhe 1991, 43; Orel 1997a, 449.

vouktov (noun) 'violation'?

OPhr. sg.dat. noktoy B-06

NPhr. sg. acc. vouktov 29.1 (114)

A clear thematic noun with an unclear meaning. While the NPhr. context is a clear apodosis, $10 \varsigma$

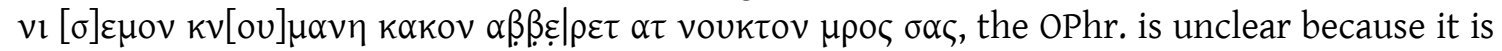
very damaged: des [---] : eventnoktoy : emetetariyois | [---]y. Orel (1997a, 449), who equated to Gr.

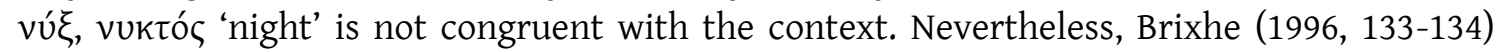

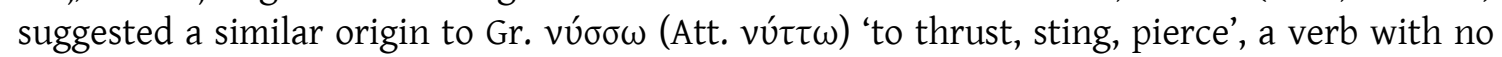
clear origin (see DELG 760 and EDG 1028) but a very pertinent meaning, 'violation, infringement' (uel sim.). Anyhow, a relation of Phr. nokto- with PIE *nek- 'to perish, disappear' (LIV² 451-452, attested in Skt. naśyati 'to be lost, perish' and in the Lat. causative noceo 'to do harm, inflict injury, do hurt to') seems more plausible.

Brixhe 1996, 133-134; Brixhe \& Drew-Bear 1997, 78; Orel 1997a, 449; Brixhe 2004a, 72-73.

vov. (?)

NPhr. vou. $18.3(6)$

This sequence is obscure due to Ramsay's problematic reading $(1887,389)$. However, since it

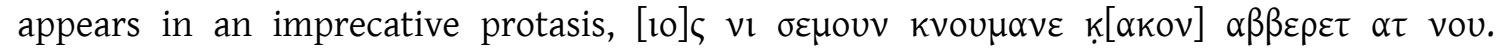

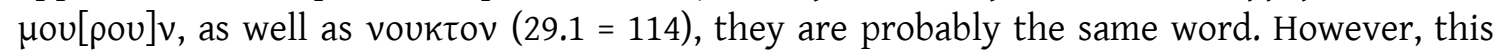
cannot be corroborated because the inscription is lost.

nun (adverb) 'now, then'

OPhr. nun B-05 (x2)

A particle inherited from PIE *nu, ${ }^{*} n u H,{ }^{*}$ num 'now', also documented in Gr. vv, vṽv, Skt. nú, nü, nūn-ám, Lat. num, nunc, OHG nūn, Lithuanian nū, nù, Hitt. nu, etc. (see LIPP II, 578-579). The Phrygian form presents the same addition as the Gr. one (EDG 1025), either *-m (Lat. num) or ${ }^{*}$-n (Skt. nūn-ám). The contexts of the two occurrences of this word are two variants of an apodosis: mekạs key koyis ạbretoy nun ibey nevotạn niptiyan sirun mireyun and kovis ke abretoy nun oy nev<otan>.

Neumann 1997, 24; Orel 1997a, 449; Brixhe 2004a, 62; Hämmig 2013, 144; LIPP II, 579.

$n[--]^{1}(?)$

OPhr. $\quad n[---]$ P-107

Because of the interpunction used in this graffito, it is surely the beginning of a word: [---].k.ui $\vdots n[---]$. However, its nature and meaning remain unknown due to its fragmentation.

CIPPh I, 250-251.

$n[---]^{2}(?)$

OPhr. $\quad n[---]$ or [---]n G-288

A broken graffito preserving an isolated letter which could be followed by others. However, its Phrygian nature is not certain, nor are its lexical category or writing direction.

Brixhe 2002a, 48-48. 



\section{$\Xi \xi$}

$[\xi] \varepsilon u v \alpha v$ see $\xi \varepsilon u v \varepsilon$.

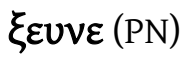

NPhr. sg.acc. [ $\xi]$ cuvav $41.3(31)$ ?

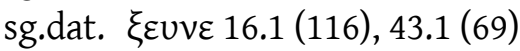

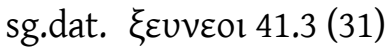

sg.dat. $\xi \varepsilon \cup v \eta 2.1(15)$

This word has been considered a PN since it is attested in Gr. inscriptions from Phrygia and Galatia (KPN 368 § 1063). However, Gr. $\Xi \varepsilon u v \alpha$ / $\Xi \varepsilon u v \eta$ does not follow the clear Phrygian $n$-stem. Hämmig (fthc. a) has recently suggested that it is in fact a funerary formula. It is true that in

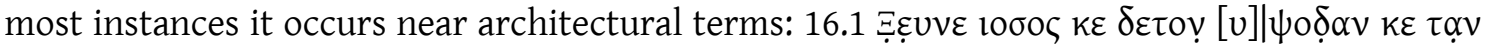

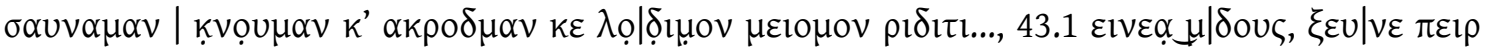

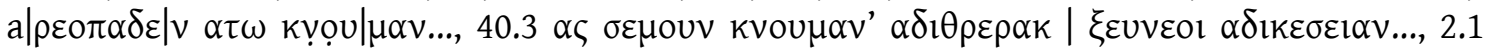

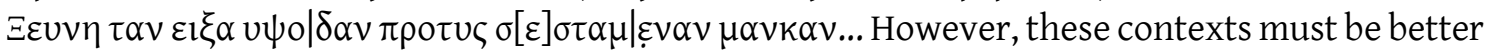
explained if we are to rule out the strong parallel in Gr. as a PN.

Sowa 2008, 36.

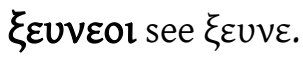

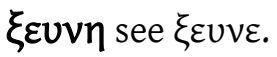





$$
O(0)-00
$$

\section{o (preposition) '?'}

NPhr. o $11.2(18)$

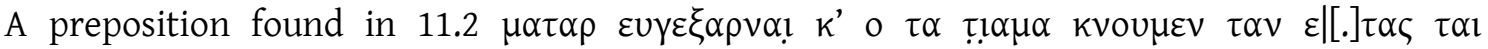
$\kappa o \lambda \tau \alpha \mu \alpha v \varepsilon 1 . .$. The case that this preposition governs remains unclear. In addition, it occurs as

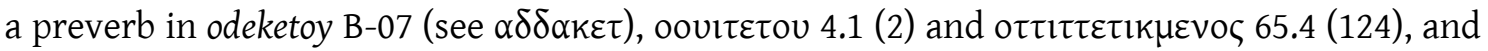

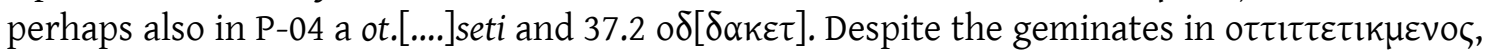
the particle goes back to PIE $* h_{2} \mathrm{O}$ (LIPP II, 323-324) and this gemination may be considered a hypercorrection.

Brixhe 1997, 57; LIPP II, 323-324.

oov see $v a$.

oavo see va \& venavtun.

\section{[-?-]obata $m^{2} . .[-?-](?)$}

OPhr. [-?-]obata? m?..[-?-] G-221

An obscure sequence in a misunderstood graffito incised on a potsherd: [-?-]aratapa[-?-] | [-?-]obatam..[-?-] | [---]. Bayun and Orel's segmentation o bata $m$ (1988a, 196, also in Orel 1997a, 223 and 419) assumes that it is the sg.nom. of the sg.acc. batan (which they considered a common noun). However, such an assumption is no longer defensible, since we know that $\beta \alpha \varsigma$ is sg.nom. of batan and not an $a$-stem.

CIPPh I, 178-179; Bayun \& Orel 1988a, 196; Orel 1997a, 222-223 and 419.

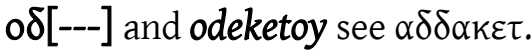

ovevin (pron.) 'his own'?

OPhr. ovevin $\mathrm{W}-01 \mathrm{~b}$

A pronominal complex which agrees with onoman in $\mathrm{W}-01 \mathrm{~b}$ in sg.acc.: yos esai=t materey eveteksete? $y$ ovevin onoman da Yet... It has therefore been understood to have a meaning related to possession. Recently, Ligorio and Lubotsky $(2013,191)$ considered it a compound, whose second part -vin goes back to a PIE form * suin (LIPP II, 751-754), the possessive pronoun also attested in fem. as va, ova. Its ending is the same as found in kin or sin. By contrast, ove- remains unclear.

Haas 1966, 195-197; Neroznak 1978, 76; Lubotsky 1988, 21; Janda 1997, 273; Ligorio \& Lubotsky 2013, 191; LIPP II, 754.

or see 101.

olvis (?)

OPhr. olvis $16.1(116)$

An obscure, unparalleled sequence. It is read in a possible but not clear imprecative apodosis:

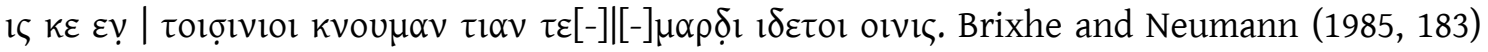
suggested that we may be dealing with two words. However, the hypothetical presence of $v \mathrm{l}$ is not expected here.

Brixhe \& Neumann 1985, 183.

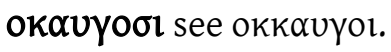


okimạkịva[---] (?)

OPhr. okimakivag[---] B-05

An obscure word with no known relationship. Unfortunately, its context is not clear: atriyas davoi okimakiva [---] | vrekạn vitarana... Its segmentation, meaning and function remain unknown. Brixhe 2004a, 55; Hämmig 2013, 142.

ọkirterkọ[..]. (?)

OPhr. okirterkọ[..]. P-04 a

An obscure word documented in an imprecative sequence without parallels: okirterkọ...]. tekmor | ot.[....]seti vebru. Its segmentation, like the other aspects of this sequence, remains unclear.

okkauyol (noun or adjective?)

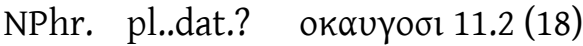

pl.nom.? оккаuүol $43.1(69)$

A clear thematic word. Both occurrences are read in obscure contexts, perhaps where the

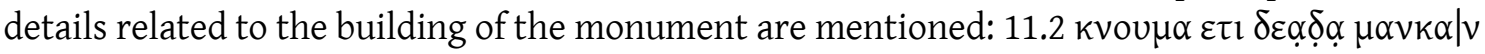

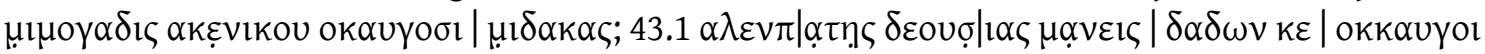

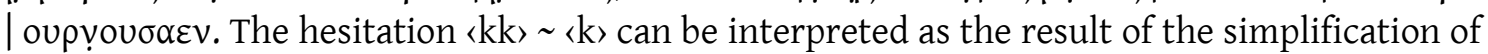
the geminates, but until the etymology has been established we cannot rule out a

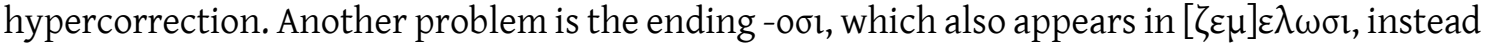
of the common - $\omega \varsigma$ (see $\delta \varepsilon \omega \varsigma, \zeta \varepsilon \mu \varepsilon \lambda \omega \varsigma$ ). Does it reflect the Gr. influence? Orel's doubtful interpretation of this word as 'eye-witness' (1997a, 449-450) is both phonetically and semantically impossible.

Brixhe \& Neumann 1985, 177; Orel 1997a, 449-450.

\section{[-?-]olgiavos (?)}

OPhr. [-?-]ol' g'iavos G-150 a

A problematic graffito on a potsherd with some different reading possibilities: [-?-]olgiavos (preferred by CIPPh I, 137), [-?-]oygiavos, [-?-]oyliavos (preferred by Bayun \& Orel 1988a, 195 and Orel 1997a, 194). The only parallel adduced in order to favour one reading is the Gr. name

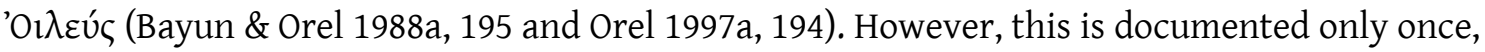
doubtfully, in the whole of Anatolia (the Gr. inscription from Halicarnassus $\operatorname{MDAI}(A)$ 1890, 252, no. 2) and the hesitation in the use of yod is very uncommon (it is only documented in the isolated spelling $k \uparrow$ ianaveyos $\mathrm{M}-02$, an inscription with other problems such as bba for baba, see Lubotsky 1993b, 95). The pithos on which the graffito is written also bears another anthroponym (asakas), an illegible sequence and its capacity mark.

CIPPh I, 135-137; Bayun \& Orel 1988a, 195; Orel 1997a, 194.

ọloitoro (noun?)

OPhr. oloitoro P-04 c

The only obscure word in a simple sentence: iman oloitoro | edae $[s]$ mekas. Since it follows the anthroponym iman, it could be interpreted as patronym or similar. However, from a morphological perspective its $-o$ ending is unusual, it has no parallels and the reading is doubtful.

CIPPh I, 239-240.

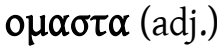

MPhr. o $\mu \alpha \sigma \tau \alpha$ MPhr-01 (W-11) 1.8

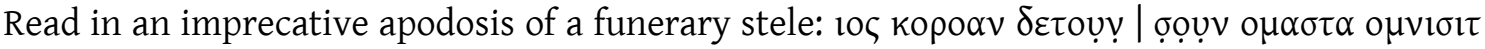
ouc. According to Brixhe $(2004 a, 24)$, it is a verbal adj. featuring the suffix *-te/o- and substantiated such as bilata or lapta. Its meaning, as well as its etymology, is unknown, but it is 
perhaps related to omnisit. It could be analysed as either * $\bar{a}_{\text {-stem }}$ dat. (<*-ai, like $\sigma \alpha$ instead of $\sigma \alpha 1$ in the same inscription) or pl.acc.neuter.

Brixhe 2004a, 24; Sowa 2007a, 91 (= 2008, 115).

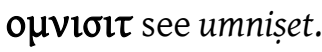

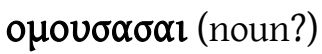

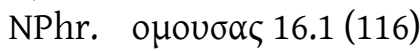

From a descriptive part of a funerary stele: $\kappa v \alpha$ k Tok yoviov... This segmentation was given by Brixhe and Neumann $(1985,175$, followed by Orel 1997a, 450 and TITUS), who considered it a possible word in agreement in dat. with the previous

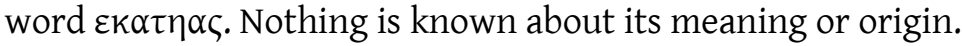

Brixhe \& Neumann 1985, 175; Orel 1997a, 450.

ovoux see onoman.

onoman (noun) 'name'

OPhr. sg.nom.-acc- onoman W-01b

NPhr. ? ovo $\mu \alpha[-?-] 37.2$ (30)

The OPhr. form is attested in a clear imprecative apodosis: yos esai=t materey eveteksetey ovevin onoman da Yet... The second context, however, engraved on a door-stele, is less clear because of

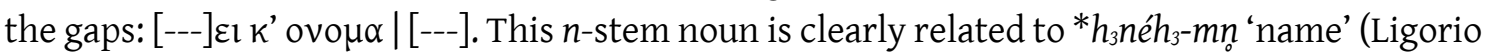
\& Lubotsky 2013, 186), as well as Gr. övoud 'id.' and Arm. anun 'id.'. The Phr. form does not provide additional information on the complicated origin of this word, since it is an exact cognate of Gr. óvo $\alpha$. Although the Gr., Arm. and Phr. forms go back to the Transponat ${ }^{*} h_{3} n{ }^{\prime} h_{3^{-}}$ $m \eta$, the PIE is reconstructed as * $h_{3}$ né $_{3}-m_{n}$ by Kloekhorst in the light of HLuw. álaman- 'name' (2008, 518-519) but as * $h_{1} n e ̂ ́ h_{3}-m \eta n$ by Neri (2005), who focuses on forms such as Dor. and Lacon.,

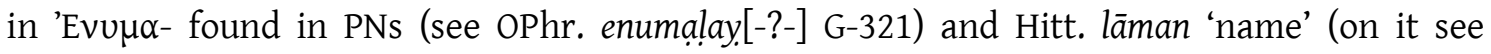

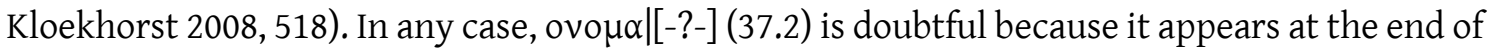
the line but the beginning of the next line is lost. The other alleged occurrences, ovouavias and ovouavials (both 16.1), seem to be derivatives of this word.

Neronak 1978, 76; CIPPh I, 40-41; Diakonoff \& Neroznak 1985, 127; Neumann 1988, 11; Janda 1997, 273; Orel 1997a, 450; Matzinger 2005, 378; Panagl 2005, 490; Sowa 2005, 613; Morante Mediavilla 2006, 332; Woodhouse 2006, $161 \mathrm{fn} .10$; Kloekhorst 2008, 518-519; Woudhuizen 2008-2009, 188 § 109; EDG 1084-1085; Ligorio \& Lubotsky 2013, 186.

ovouavias (noun)

NPhr. pl.dat. ovouavias 16.1 (116) 1.5

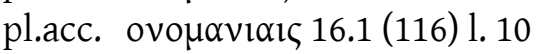

Obscure $a$-stem derivative from onoman through the suffix -io-. The form ovouavias must be the pl.dat. <*-äis because of the presence of the preposition $\mu \varepsilon$, while ovo $\mu \alpha v i \alpha 1 \zeta$ could be its pl.acc. $<*$-ans. However, the etymological form of the pl.dat. cannot be ruled out because the

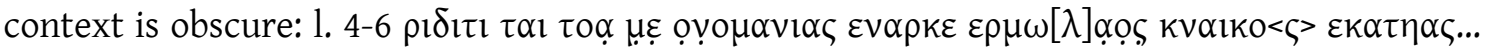

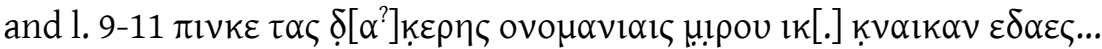

CIPPh I, 173, 178 \& 179.

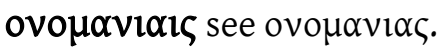


ovoukla (?)

NPhr. ovouela 43.1 (69)

Obscure sequence read on a funerary stele. Its segmentation is highly doubtful, as is its reading. Recently, Hämmig (fthc. a) suggested the reading $\Sigma$ ?'IONOY $\Sigma^{?} \mathrm{I}^{?} \mathrm{~A}$ ?

Hämmig fthc. a.

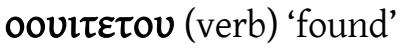

NPhr. 3sg.imp. oovitetov 4.1 (2)

A verb read in an imprecative apodosis:

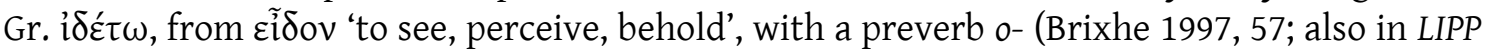
II, 324). The origin of this verb must be found in the PIE root *ueid- 'behold, see' (LIV' 665-667, IEW 1125-1127): Lat. uideō 'to see', Arm. gitem 'to know', Go. wait 'I know', Skt. véda 'I know', etc. The alternative given by Brixhe, a theme *uit-, does not fit any known Indo-European form (as he admits, 1997, 75).

Haas 1966, 209; Brixhe 1979a, 190-192; Georgiev 1981, 131; Brixhe \& Neumann 1985, 181; Diakonoff \& Neroznak 1985, 142; Brixhe 1997, 57; Orel 1997a, 60 \& 468; Brixhe 2004a, 21; Woodhouse 2006, 163-164; LIPP II, 324.

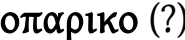

NPhr. отаріко 16.1 (116)

An obscure sequence without parallels. Its context is an imprecise imprecative protasis: ic

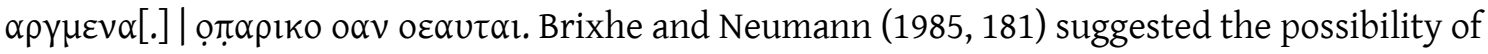

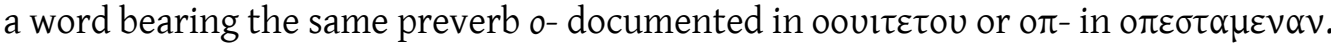

Brixhe \& Neumann 1985, 181.

o $\varepsilon \varepsilon \sigma \tau \alpha \mu \varepsilon v \alpha \nu$ (perfect participle) 'erected'

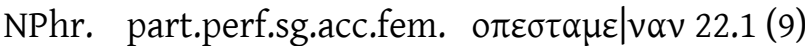

Perfect participle sg.acc.fem. (in agreement with $\mu<\alpha>v \kappa \alpha \nu$ in its sole occurrence) of a verb derived from *steh ${ }_{2}$ ' 'to stand' (LIV ${ }^{2} 590-592$, IEW 1004-1008) with reduplicated root *se-stā-, as

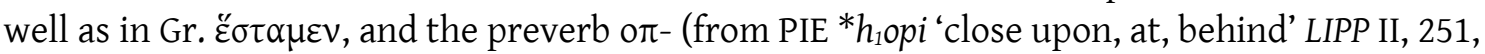
e.g., Gr. ö $\pi \_\theta \varepsilon v$ '(from) behind, at the back, after(wards)', Lat. ob-stāre 'to stand before or against any thing'). Might this preverb also occur in oporokitis. .

Ligorio \& Lubotsky 2013, 192; LIPP II, 251.

opito (verb?)

OPhr. 3sg.impv.act.? opito B-01

According to Lubotsky $(1988,22)$, a verb $3^{\text {rd }}$ singular imperative. This is very likely since it appears in a curse: ekey dạ[b]ati opito [k]ey oy ev[e]m[e]mesmeneya anato (-?)... However, this interpretation is far from certain and no meaning has been suggested.

Lubotsky 1988, 22; Lubotsky 1993b, 97.

oporokitis.? (noun or adj.?)

OPhr. oporokitis.? G-02 b

Read in an imprecative protasis: ios oporokitis. ' kakoioitov podaskai?. If kakoioi is the verb of the protasis (as it appears to be, according to Kloekhorst 2015, 116-117), oporokitis.? must be a noun.

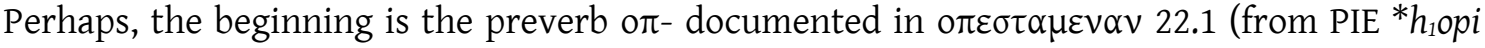
'close upon, at, behind' LIPP II, 251; see, e.g., Gr. ö $\pi 1 \sigma \theta \varepsilon v$ '(from) behind, at the back, after(wards)'). Nevertheless, nothing can be concluded about -orokitis.' for now. It is unclear whether the last unreadable stroke is accidental or part of a letter. In the first case, oporokitis could be an i-stem sg.nom. (adj.?) in agreement with ios. Orel's segmentation op oro kiti si is unfounded (Orel 1997a, 158-160).

Neroznak 1978, 96; CIPPh I, 87; Orel 1997a, 158-160; Lubotsky 2004, 232; Kloekhorst 2015, 116-117; LIPP II, 324. 
op (?)

NPhr. op $12.1(121)$

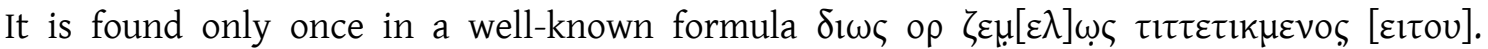
According to Brixhe and Drew-Bear $(1997,95)$, it is the result of "un lapsus du graveur" originated in the presence of the previous [ $\alpha \delta \delta] \mid \alpha \kappa \varepsilon \tau o \rho$. Lubotsky $(1998,417)$, however, neither marks this error nor offers any explanation.

Brixhe \& Drew-Bear 1997, 95; Lubotsky 1998, 417.

opßouv (noun?) 'orphan'?

NPhr. sg.acc. opßouv 59.3 (79)

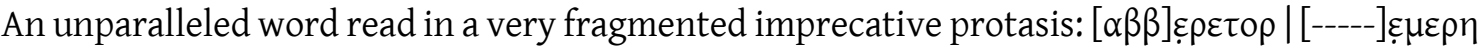

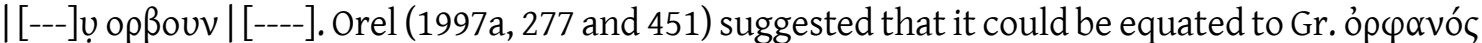
'orphan'. This is not impossible, since a basic form ${ }^{*} h_{3} \mathrm{orb}^{h}-\mathrm{o}$ - has been considered in PIE in the light, e.g., of Arm. orb, -oy 'orphan' and Lat. orbus 'orphaned, bereft' (EDG 1113-1114). However, the precariously conserved context compels us to be cautious with this identification.

Orel 1997a, 277 and 451.

ordoineten (noun)

OPhr. ordoineten B-07

According to Brixhe (2004a, 84), an e-stem noun in sg.acc. Its meaning, like its etymology, has yet to be identified. It agrees with the adj. umnotan in a relative clause: is yos tiv[.|.?]n ke devun $\mathrm{k}(e)$ umnotan ordoineten.

Brixhe 2004a, 84.

орока see корока.

opovav (noun) 'keeper, protector'

NPhr. sg.nom. opou|av $1.1(48)$

sg.acc. o oovevav $20.2(128)$

sg.gen. o oovevo 59.4 (106)

An $n$-stem hysterokinetic noun. Lubotsky (1997, 127-128) analysed this word as *soruenen, equated to Gr. oũpos 'watcher, guard(ian)', also found, e.g., in Att. ö pos 'border, boundary' and Myc. wo-wo /worwos/ '(a) guarding', 'thing being guarded' or 'place for guard(s)' (see Lane 2012). Then, Phryg. *soruēn must be a secondary inflection after the temathic from *sor-uó- (preserved in Gr.), derived from the PIE verbal root *ser- 'to bind, to tie together, thread' (LIV ${ }^{2} 534$, IEW 910). Vine's objections to his proposal are not relevant, since he is convinced that PIE *s- remains in NPhr., interpreting it as a Gr. borrowing. The meaning has been identified in the light of its

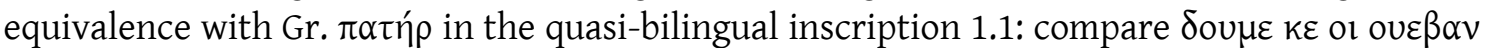

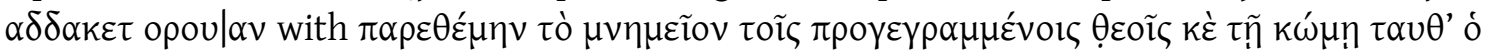

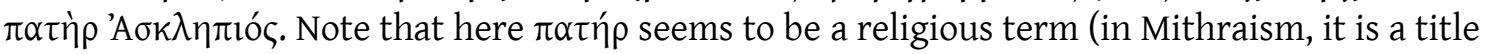
used by priests). Moreover, in the other two inscriptions it occurs as the epiklesis of Zeus, 21.6

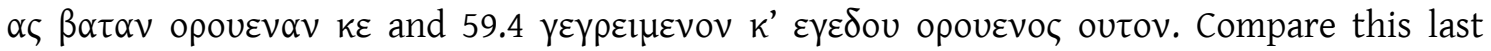

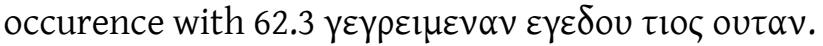

Lubotsky 1997, 127-128; Drew-Bear, Lubotsky \& Üyümez 2008, 115; Vine 2010, 344-345; Sowa 2012; Ligorio \& Lubotsky 2013, 183 and 185.

opovevav and opovevos see opovav. 
oskạvos (?)

OPhr. oskavos B-05 1.8

The context is an imprecative protasis: yos niy art sin=t imenan kaka oskavos kakey. Following Hämmig's suggestion (2013, 147-148), it could be a masc.sg.nom. perfect participle in *-uo-, which seems to agree which the pronoun yos, meaning something like 'to intend'. This would explain kaka as its object. Nevertheless, neither the origin nor the precise meaning is known and the presence of - $v 0$ - instead of a simplified -o- needs to be explained.

Neumann 1997; Brixhe 2004a, 60; Hämmig 2013, 147-148.

o? $s s[-?-](?)$

OPhr. o? ss[-?-] or [-?-]sso? G-248

An obscure graffito incised on a potsherd. Due to the separation of the letters, they could be separated monograms; nevertheless, CIPPh (I, 194-195) assumed that they are the beginning or the ending of a word. Only three letters remain, but the original inscription may have had more. Roller 1987a, 38 (who read $r$ s s) considered it an owner's mark.

CIPPh I, 194-195; Roller 1987a, 38.

o $\tau$ see $\alpha \delta$.

otekonov (?)

Ophr. otekonov B-01

The context of this unexplained word is too obscure to shed light on its meaning: kavarmoyun matar otekonov (-?)| kesiti...

Lubotsky 1993b, 94; Ligorio \& Lubotsky 2013, 184.

otu (?)

OPhr. ọtu[-?-] T-03 a I or ọtu|[v]oi T-03aI + T- 03b?

otu P-04a or otuvoi P-04a?

The beginning of this word is given by the interpunction in T-03aI, but it may be incomplete. Its nature and its meaning are unknown and the context does not offer additional information. Brixhe $(1991,38)$ suggested that this text was originally followed by T-03b, so that the word could be read as otul[ $[v]$ oi, attested in P-04a otuvoi. However, he also assumes that it could be a complete word (following Haas 1966, 180): a masc. PN in sg.nom. without the ending -s, a variant

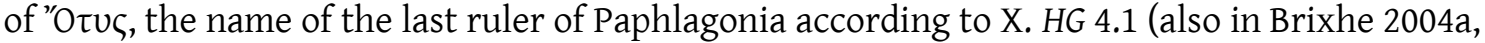
101-102). The same possibility is given to otu P-04a: otu voi vetei etlnaie. On the other hand, this last occurrence has been also segmented as otuvoi, a thematic sg.dat. Since vetei is equated to

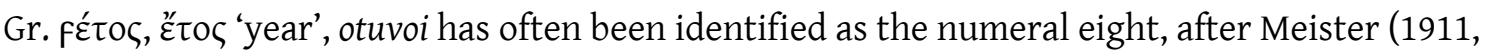
22). According to this interpretation, otuvoi vetei means 'in the $8^{\text {th }}$ year'. The presence of this suggested numeral is interpreted as its date 'in the eighth year'. However, phonetically it implies the shift PIE *-kt- > Phr. -tt-, since this number is reconstructed as ${ }^{*} h_{3} e k t o ̄$ or $* h_{3} e k t e h_{3}$, although this cluster seems to be preserved in vouktov $(29.1=114$, and in the probable borrowing vanaktei M-01a). Moreover, another possibility put forward by Haas (1938, 132, similar to Brixhe's suggestion) is the reading otu voi vetei, where otu is a PN. According to this segmentation, voi is the sg.dat.masc. of the poss. pronoun *su- (see va), which agrees with vetei. Following this interpretation, the meaning would be something like 'Otus to his Vetei'.

Meister 1911, 22; Haas 1938, 132; Neroznak 1978, 82; CIPPh I, 237-238; Brixhe 1991, 38; Orel 1997a, 451; Brixhe 2004a, 101-102.

otuvoi see otu. 


\section{ot.[....]seti (verb?)}

OPhr. 3sg.subj. ot.[....]seti P-04 a

A damaged word occurring in a curse: ios ni akenan egeseti | okirterkọ[..]. tekmor | ot.[....]seti vebru. Despite the gap, such a beginning and the ending -seti show that it is very likely a verb. If this is the case, the beginning could be the preverb o- (< PIE * $h_{2}$ o, LIPP II, 323-324), as in odeketoy. CIPPh I, 238.

ova and oudv see va.

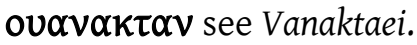

oußpa see vebrạs.

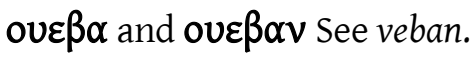

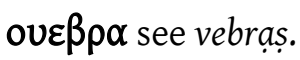

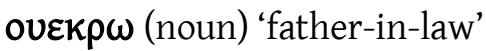

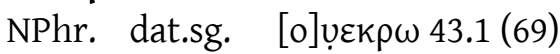

It has been interpreted as an o-stem sg.dat. meaning 'father-in-law' by Orel (1997a, 346 and 467), going back to PIE *suekrúH- 'mother-in-law' (NIL 672-675, IEW 1043-1044), as Lat. socrus 'motherin-law' (also 'father-in-law') and socer 'father-in-law', Gr. Ékvpós 'id.', sk. śváśura 'id.', etc. If this is correct, it seems to agree with the following PN $\delta \alpha \delta \omega v \varepsilon$ in sg.dat.: $\alpha \delta \varepsilon v<\pi>\alpha \tau \omega$ k [o] Orel 1997a, $346 \& 467$.

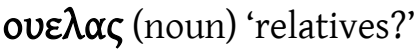

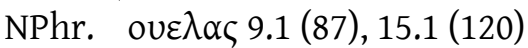

According to Ligorio and Lubotsky $(2013,189)$, this is an $a$-stem in pl.nom. inherited from PIE * suel-eh ${ }_{2}$-es and likely means 'relatives'. An alternative has recently been proposed by Hämmig

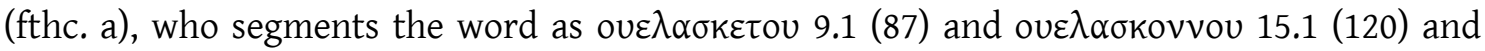
considers it a verb in $3^{\text {rd }} \mathrm{sg}$. and $3^{\text {rd }} \mathrm{pl}$. respectively. She also read in 21.1 (42) the form

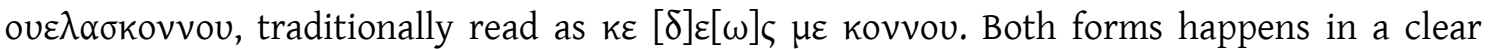

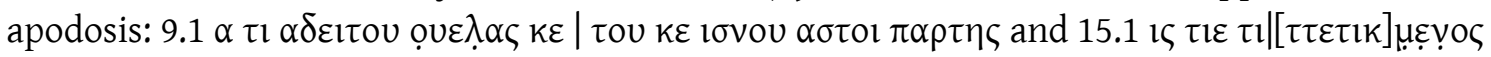

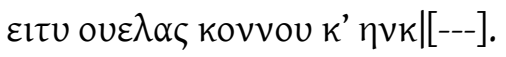

Ligorio \& Lubotsky 2013, 189; Hämmig fthc. a.

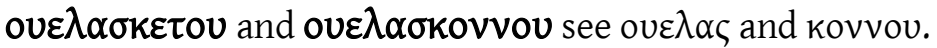

ovevaoulaৎ (PN)

NPhr. sg.gen. ovevooulac 6.1 (88)

In this $a$-stem fem. PN, the digraph 〈ou〉 denotes /w/, so we must read /wenawias/. This

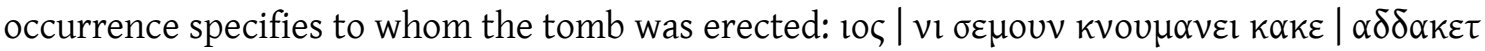
$\alpha \omega \rho \omega$ ovevaoulac. It is also attested in the Gr. text of the same inscription, where it appears as OủEvoouin (sg.dat., see KPN 396 § 1153). Dressler (1964, see also Brixhe 2013, 67-68) suggested that it is a Luwian PN in -wiya, although the first element remains unclear (see § 4.6.2.2). KPN 396 \& 1153-2 and § 1153-3; Orel 1997a, 108 \& 467; Brixhe 2013, 67-68; Ligorio \& Lubotsky 2013, 189. 
oukpaov (adj.)

NPhr. oukpa|ov 11.2 (18)

Obscure word read in an imprecative protasis. It seems to agree with $\lambda \alpha \tau$ to $\mu \varepsilon 10$ v in sg.acc.: $10 \varsigma$

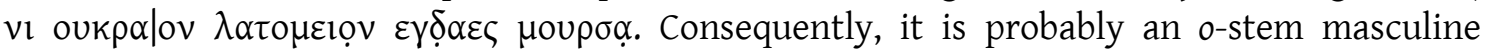
adjective. However its meaning and origin remain unknown.

oupaviov (adj.) 'heavenly'

NPhr. masc.sg.acc. oupaviov 6.1 (88)

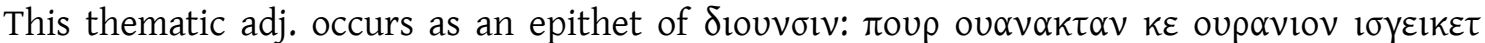
$\delta$ iouvolv. Its origin is a little ambiguous, and although it can be considered a Gr. borrowing from oúpóvio ' 'id.', one cannot rule the possibility that it is an inherited word going back to PIE *uors(EDG 1128) because the absence of the initial *u- reconstructed for the Gr. form also drops in

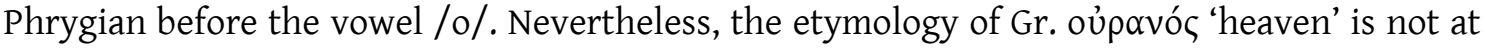
all clear (see DELG 838-839 and EDG 1128) and a compensatory lengthening *-Vrs- > - Vr-is not identified in Phr., hence it is more likely a borrowing from Gr.

Orel 1997a, 111 \& 465; Brixhe 2002a, 62; Lubotsky 2004, 234; Ligorio \& Lubotsky 2013, 193.

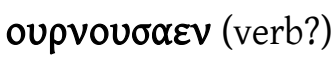

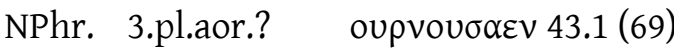

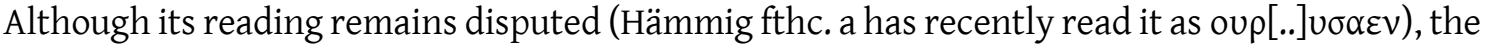
isolated ending could reveal that it is a verb in $3^{\text {rd }}$ person plural aor., parallel to singular $\varepsilon \delta \alpha \varepsilon \zeta$ :

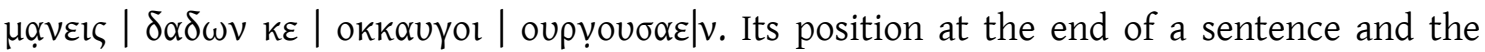
presence of several possible subjects make this suggestion more likely. However neither the meaning nor the origin are known.

Hämmig fthc. a.

ous (particle)

MPhr. ous MPhr-01 (W-11) 1.8

NPhr. \ 62.2 (33) 1. 6, 62.5 (36) 1. 9-10

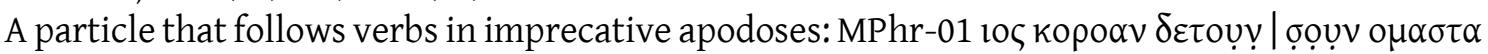

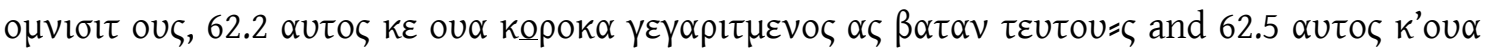

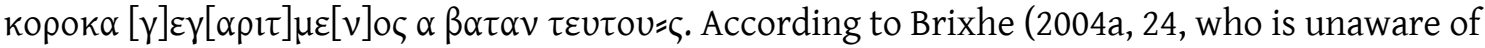
the NPhr. occurrence), it may go back to PIE *e/o in mas.pl.acc., ${ }^{*}$ os and presents the shift $*_{0}>$ $u$. However, the context of MPhr. remains obscure and in the NPhr. occurences the DO seems

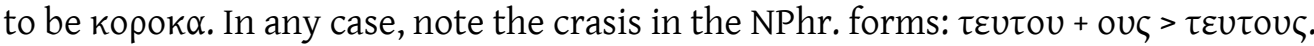

Brixhe 2004a, 24; Obrador-Cursach 2017, 309.

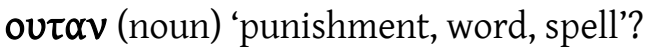

NPhr. acc. sg. outav 53.1 (76), 54.1 (108), 60.2 (60), 62.1 (32), 62.2 (33), 62.3 (34), 62.5 (36), 62.6

(105); o $<<\tau>\alpha \vee 60.1(59)$

acc. sg. outov $59.4(106)$

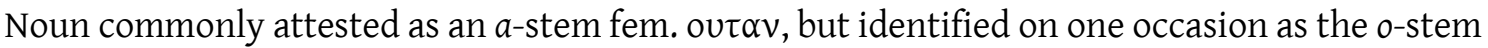
masculine outov. Its context, an imprecative apodosis, always reads as follows: $\gamma \varepsilon \gamma \varepsilon l \mu \varepsilon v \alpha v$

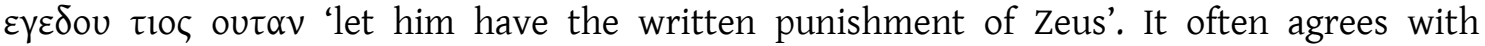

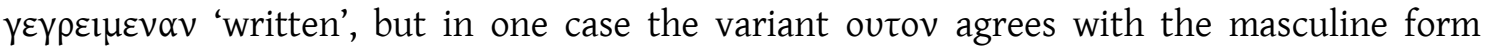

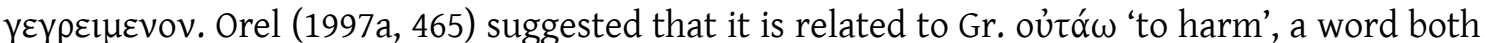
"morphologically and etymologically" unclear according to EDG (1131-1132). However, it is easier to consider the Phr. word a derivative from the verbal root *ueth ${ }^{-}$'to say' (LIV 2694-695) attested in Lat. uetō 'forbid, oppose, veto', MWe. dy-wed- 'to say”, Hitt. uttar / uddan- (n.) 'word, 
speech' and CLuw. utar / utn- (n.) 'word, spell' (an interpretation that is not assured, see Kloekhorst 2008, 932-933). Bayun and Orel $(1989,32)$ considered it an Anatolian borrowing. Nevertheless, neither the Hitt. nor the Luw. inflection of this word is a good fit as the origin of this Phr. $a$-stem noun. Consequently, it can be explained as a secondary $a$-stem inflection developed from the oblique cases of the PIE noun *uéth ${ }_{2}-r$, $u t h_{2}$-én-s (as Kloekhorst 2008, 932933 reconstructs).

Bayun \& Orel 1989, 32; Orel 1997a, 465.

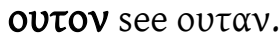

oy see 101.

†oynev see 101 \& nevos.

oyvos (?)

OPhr. oyvos B-01

An obscure word read in an unclear sequence: kesiti oyvos aey apaktneni... Since even the segmentation is disputed (Brixhe 199, 131 prefers a segmentation oy vos), interpretations such as the one proposed by Orel (1997a, 145 and 444), who equated it to Gr. oĩos 'alone', are very uncertain.

Orel 1997a, 145 and 444. 



\section{$\Gamma(p)-\Pi \pi$}

${ }^{+} p[---]$ see kraniyas.

$p a(\mathrm{PN})$

OPhr. pa G-162, G-258, G-310, [-?-]pa G-271

This sequence, which must be a PN, can be interpreted as either an abbreviation or a complete name (see KPN $419 \S 1213-1$ П $\alpha$, from Isauria). If the second case is accurate, it is a monosyllabic Lallname in the nominative without the ending $-s$, similar to $\beta \alpha$, a variant of $\beta \alpha c$. Perhaps both scenarios are represented in these occurrences. On the other hand, G-162 could be read as ap and G-271 could have more letters at the beginning.

CIPPh I, 144-145, 200, 209; Roller 1987a, 46; Brixhe 2002a, 68-69.

pakray (noun?)

OPhr. sg.dat. pakray B-01 1.9

Bayun and Orel (1988a, 189 and later Orel 1997a, 452) considered this word a borrowing from a Semitic language meaning 'religious assembly' (Akkadian puhru 'assembly, gathering of clan or family', Ugaritic phr 'assembly, cluster, group'), so an $a$-stem in the sg.dat., but this part of the inscription (apaktneni | pakray evkobeyan epaktoy) is not well understood. Consequently, this identification should be viewed sceptically, although no alternative is given. In any case, it is a probable $a$-stem noun in the sg.dat.

Neroznak 1978, 91; Bayun \& Orel 1989a, 188; Lubotsky 1993, 97; Orel 1997a, 452; Bernd-Ersöz 2006, 85-86.

\section{pạato (?)}

OPhr. panato B-05 1.6

An obscure word which Neuman $(1997,21-22)$ related to panta. However, adopting Brixhe's sceptical view (2004a, 58), this interpretation is very unlikely, since the second $a$ is difficult to account for in its paradigm. In addition, the context remains obscure: nidus ad kaliyay karatu panato andopopostois klam? iv[.. ?]. Therefore, this word is unexplained.

Neumann 1997, 21-22; Brixhe 2004a, 58.

panta (adjective) 'whole, all, every'

OPhr. ? panta B-05l.

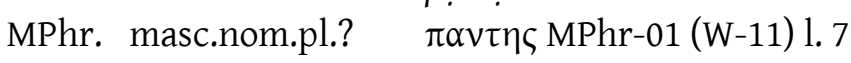

NPhr. neut.pl.nom-acc. $\pi \alpha v \tau \alpha 62.4$ (35)

Adjective inherited from from PIE ${ }^{*} p h_{2}$-ent- 'all'. It seems to be attested in masc.pl.nom.-acc. $\pi \alpha v \tau \eta \varsigma /$ pantes/ (PIE < ${ }^{*} p h_{2}$-ent-es). However, the context remains obscure: $\pi \alpha \rho \tau 1 \alpha \varsigma \pi \lambda \alpha \delta \varepsilon \pi \mathrm{s} \rho$ kopoo.. $\mid \rho \circ \varsigma$ $\pi \alpha v \tau \eta \varsigma \pi \varepsilon v v i \tau 1 . .$. It also appears in the neut.pl.nom.-acc. $\pi \alpha v \tau \alpha$ (PIE < ${ }^{*} p h_{2}-e n t-h_{2}$, Greek $\pi \tilde{\alpha} \varsigma$ 'all, every, whole', ToAB pont-), which agrees with $\kappa \varepsilon v \alpha$ in a singular apodosis: $\alpha \varsigma$ $\alpha v \alpha v \kappa \alpha 1$ ol $\pi \alpha v \tau \alpha \kappa \varepsilon v \alpha \mid<l>v v o v$. Finally, the form panta in B-05 is ambiguous because the context is still obscure: artimitos kraniyạs [---] | pantạ vebras ạdun p?os key estat pator.?ike[...]e[...] andati... It can be considered to agree with vebrạs, a sg.gen., but a form *pantas would be expected. So, either it is an irregularity or it agrees with a lost word in the line above.

Brixhe 1999, 302; Brixhe 2008, 72; Ligorio \& Lubotsky 2013, 186.

$\pi \alpha v \tau \eta \zeta$ see panta.

paries see garies. 
$\pi \alpha \rho \tau \alpha \nu$ see $\pi \alpha \rho \tau \eta \varsigma$.

$\pi \alpha \rho \tau \eta \varsigma($ adj.?)

NPhr. $\pi \alpha \rho \tau \alpha v 66.1(103)$

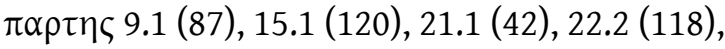

$\pi \alpha \rho \tau \cup \varsigma$ 22.1; [ $\pi] \alpha \rho \tau \cup \varsigma 15.1(120)$

An obscure word which is only attested in epitaphs. Its inflection is not at all clear: note the differences between the endings and the presence of an iota in $\pi \alpha \rho \tau 1 \alpha \varsigma$ (and $i$-stem in MPhr. despite NPhr. occurrences? See Brixhe 1999, 301-302). Perhaps this diversity of endings shows that the word is an adjective. It is especially clear in 9.1, where $\pi \alpha \rho \tau \eta \varsigma$ seems to agree with

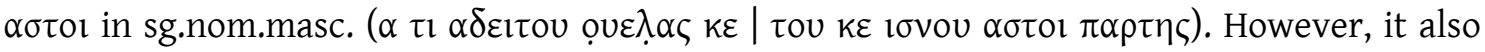
occurs in sequences where no agreement can be identified: 15.1 ove $\lambda \alpha \varsigma$ kovvou k' $\eta v \kappa \mid[\ldots . . . . .$.$] ụols$

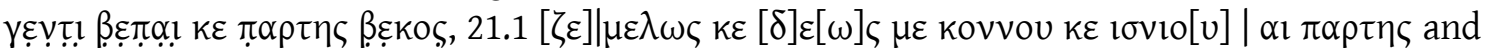

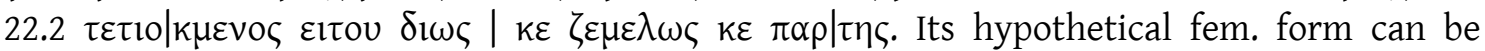

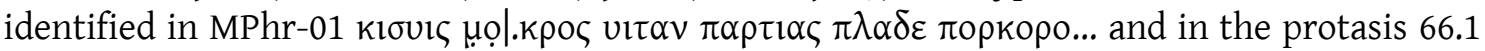

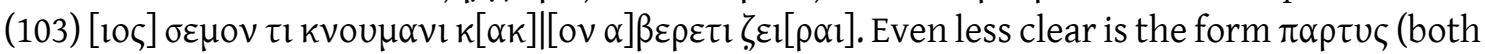

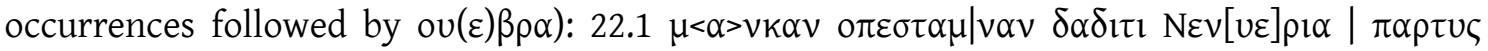

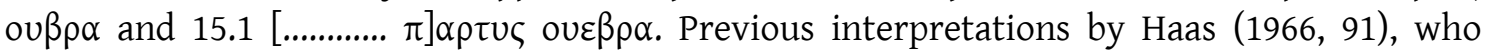
interpreted it as the Iranian word for 'judge', and Orel (1997a, 452), who gave it the meaning

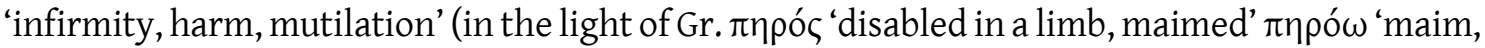
mutilate'), are simply ungrounded.

Brixhe 1999, 301-302; Brixhe 2004a, 21.

$\pi \alpha \rho \tau \iota \alpha \varsigma(?)$

MPhr. $\pi \alpha \rho \tau \imath \alpha \varsigma$ MPhr-01 (W-11) 1.6

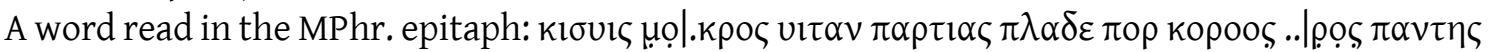
... It seems to derive from $\pi \alpha \rho \tau \eta \varsigma$, although the meaning of both terms remains unclear. Brixhe (2004a, 21) considered it an $i$-stem pl.acc. However, the expected ending is -ais.

Brixhe 1999, 301-302; Brixhe 2004a, 21.

$\pi \alpha \rho \tau \cup \varsigma$ see $\pi \alpha \rho \tau \eta \varsigma$.

$\pi \alpha \sigma \varepsilon(?)$

OPhr. $\pi \alpha \sigma \varepsilon 22.1(9)$

An unparalleled word that occurs in a sentence where the monument is described, before the

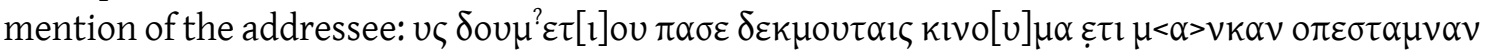
$\delta \alpha \delta \imath \tau 1 ~ v \varepsilon v[v \varepsilon] \rho \imath \alpha \pi \alpha \rho \tau \cup \varsigma$ ou $\beta \rho \alpha$. The relation with panta is highly unlikely, since it does not fit with its inflexion. The ending corresponds to an athematic sg.dat., in the light of $\tau \imath \varepsilon$ or and adverbs such as $\kappa \alpha \kappa \varepsilon$.

$\pi \alpha \tau \varepsilon \rho \eta \varsigma$ see $\pi \alpha \tau \rho \varepsilon \varsigma$.

pator. (?)

OPhr. pator. B-05

Since the reading of its some letters is unclear (Neumann 1997, 21 read patorp), as is the segmentation (pator.'ike[...] or pator. 'ike[...]?), and as the context remains obscure, the word is

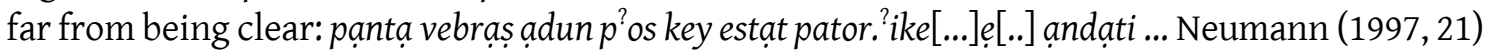
suggested a relation with the word for 'father' (see patriyio? is? and $\pi \alpha \tau \rho \varepsilon \varsigma$ ). Indeed, the vocalism recalls the Gr. noun $\pi \alpha$ $\tau \omega \rho$ 'possessor' and is perhaps the first element of a compound, as Brixhe (2004a, 57) suggested. In any case, this question remains open. 
$\pi \alpha \tau \rho \varepsilon \varsigma$ (noun) 'parents'

NPhr. pl.nom. $\pi \alpha \mid \tau \varepsilon \rho \eta \varsigma 1.2(48)$

pl.nom. $\pi \alpha \tau \rho \varepsilon \varsigma 2.2(130)$

Given their grammatical context (they are the subjects of the verbs), these forms must be the nominative plural of the inherited PIE word for 'father' * $p h_{2} t e \bar{e}$ (see, e.g., Gr. $\pi \alpha \tau \eta$ ' 'id.', Skt. pitr,

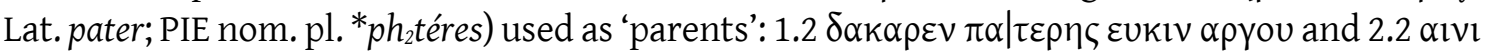

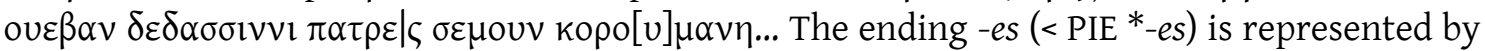

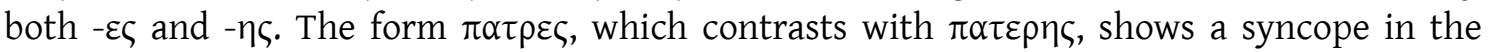
syllable where the stress would be expected. Consequently, it must have changed its position, perhaps to the last syllable as a levelling from the sg.gen. (PIE *ph trés) or the sg.dat. (PIE * ph $h_{2}$ tréi), or to the first syllable from the acrostatic paradigm for 'mother' (PIE nom. pl. *méh ${ }_{2}$ teres).

Haas 1966, 112; Orel 1997a, 452; Brixhe 1999, 301-302; Avram 2015, 208 and 209 fn. 55.

patriyiọ? is? (noun) 'relatives'

OPhr. pl.acc. patriyio? is? ${ }^{3} \mathrm{~B}-04$

Substantiated thematic adj. in the pl.acc. (< PIE ${ }^{*}$-oms). It is a derivative, through the suffix *-io-, from the word for 'father' PIE * ph This formation is parallel to Gr. $\pi \alpha$ á $\tau$ io,$\alpha$, ov 'of or belonging to one's father', so the meaning must be something similar to 'relatives of the father's side'. It is coordinated with the word for 'brothers': braterais patriyiọ? is? ke '(to the) brothers and relatives'.

Bayun \& Orel 1988c, 136; Orel 1997a, 56 \& 452; Brixhe 2004a, 41-42.

pẹi (?)

OPhr. pẹi $m[-?-]$ or pli $m[-?-]$ or pẹin or plin $\mathrm{W}-13$

The reading of this doubtful and precariously preserved inscription (read on a wall with a small niche, perhaps a façade) is far from certain. Even the editors (Brixhe \& Sivas 2003, 67-69) are unsure whether this is indeed a written sequence. If the last remaining letter is read as $m$, Brixhe considers that it could be the abbreviation of a word (perhaps matar), because it is not expected as the ending of a word. However, such a segmentation is not clear and the whole sequence could be an abbreviated word or a damaged one. Consequently, it remains obscure. Brixhe \& Sivas 2003, 67-69.

$\pi \varepsilon 1 \varepsilon \zeta$ see $\pi \varepsilon \tau \varepsilon \zeta$.

$\pi \varepsilon 1 \rho(?)$

NPhr. $\pi \varepsilon 1 \rho ~ 43.1(69)$

Doubtful segmentation in an obscure sequence. Hämmig (fthc. a.) has recently proposed the reading ח!̣IPA|PE.

Hämmig fthc. a.

$\pi \varepsilon 1 \varsigma$ (adj.?) 'dead'?

NPhr. $\pi \varepsilon 1 \zeta 43.1$ (69)

This obscure word is coordinated in the form $\pi \varepsilon 1 \zeta$ with $\zeta \omega \varsigma$, probably a borrowing from Gr. $\zeta \omega \varsigma$ 'living', so it seems to be the nominative singular and is probably the antonym, similarly to $\delta \varepsilon \omega \varsigma$ with respect to $\zeta \varepsilon \mu \varepsilon \lambda \omega \varsigma$ in an analogous construction, 'gods and men'. On the other hand, a form $\pi \varepsilon \varepsilon \varepsilon \zeta$, which has the same relationship with $\zeta \varepsilon 1 \rho \alpha$, and is probably the nominative plural,

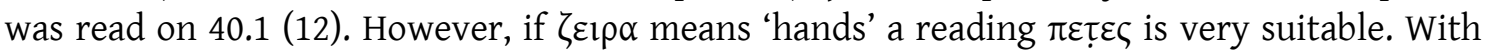
regard to $\pi \varepsilon 1 \varsigma$, the etymological proposals of Orel's (1997a, 453, PIE * pēi- 'harm, inflict pain, 
abuse') and Woodhouse (2007, 198, PIE * g'eiuis 'living') are not convincing. The context of 43.1

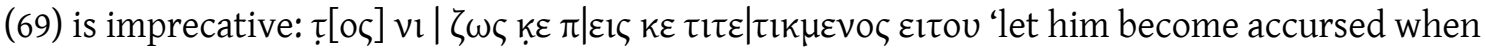
living and dead(?)'.

Orel 1997a, 453; Woodhouse 2007, 198.

$\pi \varepsilon v$ see $\pi \varepsilon v \nu \imath \tau l$.

$\pi \varepsilon \nu v i \tau \imath$ (verb?)

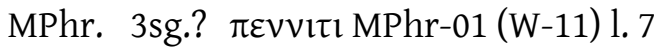

Because of its ending, it may be a verb, although its meaning and its origin are unknown. The

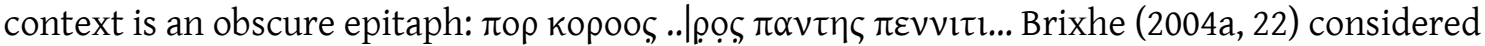
a word boundary between the occurrences of ny because he assumed that in this inscription geminates are not marked, as in OPhr. inscriptions. However, it is written in the Gr. alphabet, so there seems little justification for this segmentation. Otherwise, $\pi \varepsilon v v i \tau l$ is preferred because it provides a more common root to this this possible verb.

Brixhe 2004a, 22.

$p^{2} e r$ see p'erbastidages.

p'erbastidages (PN?)

OPhr. p'erbastidages HP-101

A complete sequence incised on a clay spindle whorl from northern Lydia. Perhaps this unparalleled word is a compound, athematic noun in pl.acc. with the same element per attested in $\pi \varepsilon \rho \beta \varepsilon \delta \alpha v$ if not $p^{?}$ er bastidages, a preposition + PN (preferred by Brixhe 2004a, 103-106). IT is also possible that we are dealing with a PN p? erbastidages of Thracian or "Persianised Thracian" origin, according to Dinç and Innocente $(1999,69-71)$ and Vassileva $(2015,94)$, in the light of the occurrences given by Detschew $(1976,45)$. If this is the case, it may be a common name with sg.nom. in -es.

Dinç \& Innocente 1999, 69-71; Brixhe 2004, 103-106; Vassileva 2015, 94.

$\pi \varepsilon \rho \beta \varepsilon \delta \alpha v$ (noun) 'grave'?

NPhr. sg.acc. $\pi \varepsilon \rho \beta \varepsilon \delta \alpha \nu 29.1$ (114)

A clear $a$-stem noun which works as the direct objet. On the other hand, since it happens in a clear imprecative protasis, $10 \varsigma \mid \kappa \varepsilon \beta \rho \varepsilon \mathfrak{i} \pi \varepsilon \rho \beta \varepsilon \delta \alpha v$, it must refer to (some part of) the monument. Indeed, $-\beta \varepsilon \delta \alpha$ - can go back to a PIE root * ${ }^{h} e d^{h} h_{2^{-}}$'pierce, dig' (LIV 66 , IEW 113-114) attested in Hitt. padda- ${ }^{i}$ / padda- 'dig (the ground), to bury(?)', Lat. fodio 'dig', Lith. bedù 'stick, dig'. It means that $\pi \varepsilon \rho$ could be inherited from PIE * per 'cross, pass', equated to Gr. $\pi \varepsilon p i$ (see also p'erbastidages).

petes (noun) 'feet'

OPhr. pl.nom. pẹtes G-02

NPhr. pl.nom. $\pi \varepsilon \tau \varepsilon \varepsilon \zeta 40.1$ (12)?

Nominative plural forms of the Phrygian word for 'feet', which goes back to PIE *ped- 'id.' (NIL

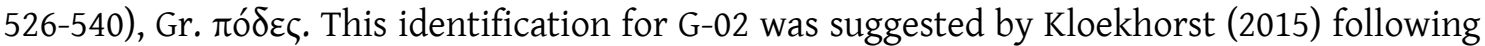
his own reading, which improved the previous interpretation, iktes. In its context it agrees with agaritoi: agaritoi petes adoikavoi... The NPhr. form was previously read as $\pi \varepsilon 1 \varepsilon \zeta$ and related to the obscure word $\pi \varepsilon i \varsigma$. However, since the word for hands is also attested in the same apodosis, $\zeta \varepsilon 1 \rho \alpha \kappa \varepsilon$ ol $\pi \varepsilon 1 \varepsilon \zeta \kappa \varepsilon \tau \imath \tau \mid \tau \varepsilon \tau 1 k \mu \varepsilon v \alpha \alpha \tau t l \varepsilon \alpha \delta \varepsilon l \tau \tau v o v$, and is not the only instance of confusion over this letter in both readers' copies, showing that the inscription was damaged at this point, these new interpretations must be taken into account. 
$\pi ı v \kappa \varepsilon$ (numeral?) 'five'?

OPhr. $\pi \mathrm{lvK \varepsilon \tau \alpha \varsigma} 16.1$ (116)

Brixhe and Neumann $(1985,178)$ suggested that a segment $\pi ı v \kappa \varepsilon \tau \alpha \varsigma$ could be an agent noun because of the presence of suffix -ta-. If this is the case, it must be a nominative singular.

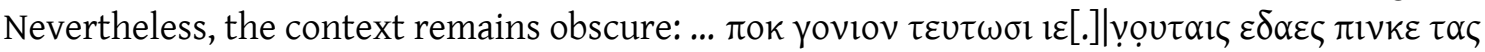

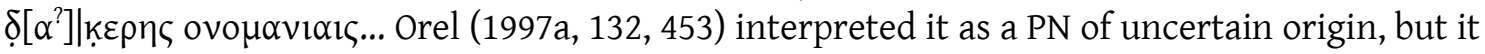
does not fit with the context, while Ligorio and Lubotsky $(2013,187)$ gave the segmentation

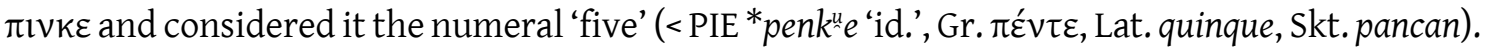
Brixhe \& Neumann 1985, 178; Ligorio and Lubotsky 2013, 187.

${ }^{(+)} \pi \mathrm{l} v \kappa \varepsilon \tau \alpha \zeta$ see $\pi \mathrm{l} \kappa \varepsilon$ and $\tau \alpha \varsigma$.

$p^{?} i s^{?}(?)$

OPhr. p?is? W-04 1.5

The isolation of this word is given by Brixhe (2004a, 40). It is preceded by edaviy and anernevey (a verb?). Its nature, function and origin are unknown.

Brixhe 2004a, 40.

pitave[---] (?)

OPhr. pitave[---] G-113

A fragmented graffito on a potsherd. According to Orel (1997a, 174 and 453) it is the word for 'pithos' borrowed from Gr. $\pi$ í $\theta$ oc. However, the presence of the sequence-ave- casts some doubt on this interpretation. Given the obscure context it is preferable to be cautious and acknowledge that the meaning is unclear.

CIPPh I, 106; Bayun \& Orel 1988a, 193; Orel 1997a, 174 \& 453.

$\pi \lambda \alpha \delta \varepsilon$ (adverb or preposition?) 'near, nearby’?

OPhr. $\pi \lambda \alpha \delta \varepsilon \mathrm{MPhr}-01(\mathrm{~W}-11) 1.6$

According to Brixhe (2004a, 21-22), it is a word featuring the zero grade of the PIE root * plh ${ }^{-}$

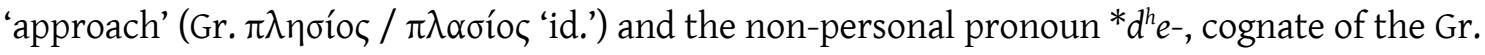
$-\theta \varepsilon$. If it works as preposition, it probably requires the case of porkoro, the following word: vitav

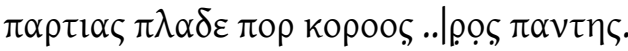

Brixhe 2004a, 21-22.

ploriatạ[---] (?)

OPhr. ploriata [---] G-132

A graffito incised on a potsherd. The only interpretation is given by Orel (1997a, 453), who considered it a loanword from Hitt. pulluriya 'vessel'. His segmentation was ploria and he explained it as a nominative singular of an $a$-stem fem. Nevertheless, the suggested Hitt. word is not attested (a misinterpretation of pul(l)- (n.) 'lot; allotment, share; destiny, fate' or the obscure pulla-, noun which appears with the determinatives DUG 'vessel' and É 'house'?). Consequently, this word remains unclear.

Neroznak 1978, 102; CIPPh I, 121-122; Orel 1997a, 184 \& 453.

†podas see podaskai. 


\section{podaskai (verb?)}

OPhr. 3sg.? podaskai? G-02c

Before Kloekhorst's reading (2015) of petes in the first part of the inscription, podas was considered the word for 'feed' (after Lejeune 1969b, 291). However, since the curse can be divided into the protasis ios oporokitis[?] kakoioi tovo and the apodosis podaskai , this word must be a verb, so the ending -ai must be third singular. The suffix -ske/o- probably appears here. Kloekhorst $(2015,117)$ also gives the hypothetical meaning "'he will be trampled upon' (namely by the protective feet?)". However, without more occurrences we remain far from establishing a convincing interpretation of this verb.

Kloekhorst 2015, 117.

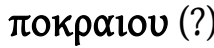

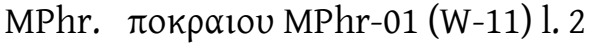

This obscure word seems to be a sg.gen. related to the personal name noukpoc. Could it also be

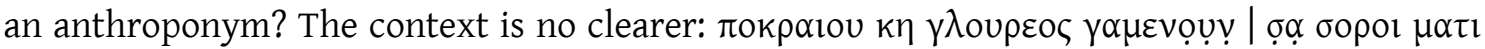

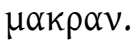

Brixhe 2004a, 17.

polodrẹtes (appellative?)

OPhr. sg.nom. polodreltes T-03aI

An e-stem anthroponym in the nominative singular. Since it agrees with the anthroponym otu it is considered an appellative by Brixhe (2004a, 101): a iiai ! polodrẹ|tes $\vdots$ poreti $\vdots$ ọtu. Orel (1997a, $313 \& 453)$ suggested that the beginning was parallel to Gr. $\pi 0 \lambda v-/ \pi 0 \lambda \lambda_{0}-$.

Orel 1997a, 313 \& 453; Brixhe 2004a, 101-102.

\section{popostois (noun?)}

OPhr. acc.pl.? popostois B-05 1.6

Read in a obscure part of this large inscription: ... nidus ad kaliyay karatu panato ando popostois klạniv kelmis ke umnișet evrạdus dạkerais key iverais [..] ... Brixhe (2004a, 58), rejecting Neumann's $(1997,22)$ segmentation andop opostois, read the single word andopopostois. Because of its ending it can be considered a thematic noun in acc.pl., ${ }^{*}$-ons $>$-ois. Either way, its meaning remains unclear.

Neumann 1997, 22; Brixhe 2004a, 58; Hämmig 2013, 137.

por (preposition) 'for'

OPhr. por W-05b

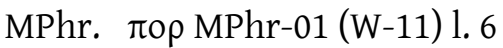

NPhr. $\pi$ oup 6.1 (88)

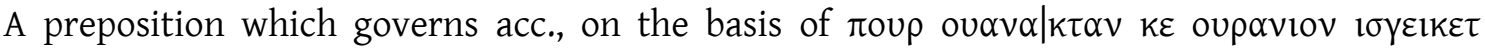
Siouvolv (6.1) 'let him be responsible before the heavenly lord Dionisos'. Nevertheless, in

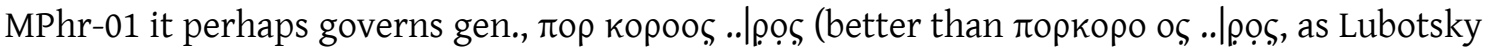

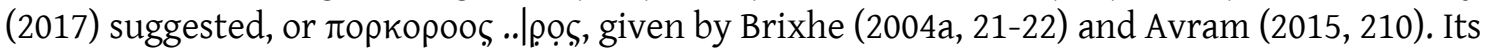
oldest occurrence, in $\mathrm{W}-05 \mathrm{~b}$, is ambiguous because of the loss of the ending of the following noun: [---]nst[--- e]daes por mate [---]. Note that, following CIPPh (I, 49), it has been interpreted as

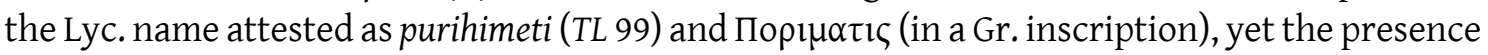
of Matar is far more likely on this kind of cult façade, as established by Lubotsky $(2017,430)$. In any case, the origin of the preposition por must be found in the zero grade of the PIE adverb *pr

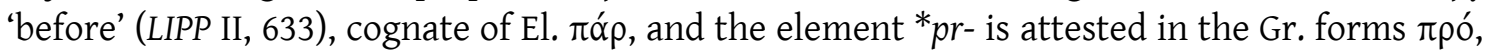

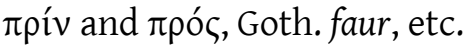


CIPPh I, 49; Bayun \& Orel 1988a, 184; Lubotsky 1989b, 151-152; Brixhe 1993, 332-333; Brixhe 1997, 55; Orel 1997a, 45 \& 454; Wittke 2004, 349; Brixhe 2004a, 21; Berndt-Ersöz 2006, 80; Neumann 2007, 293; Ligorio \& Lubotsky 2013, 186; LIPP II, 633; Lubotsky 2017, 430.

poreti (verb)

OPhr. 3sg.pres.act.? poreti T-03 a I

The ending -ti shows that it is a 3 sg. present subjunctive of an unknown verb: $a \uparrow$ iiai : polodre|tes ! poreti $\vdots$ otu.

Heubeck 1986, 77; Brixhe 1991, 43; Sowa 2007a, 73-74.

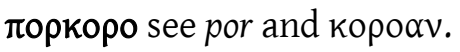

†pormatẹ[---] see por and matar.

\section{porniyoy (PN?)}

OPhr. porniyoy B-07

Read on a stele following an anthroponymic sequence: $s=$ manes iyungidas manitos apelev porniyoy esț[..][[..] es va knais. It is clearly an 0 -stem in the dat. Probably a hypocorism or patronym derived by the suffix -io- from a name that is not attested. Gusmani $(2001,165)$ suggested we may be

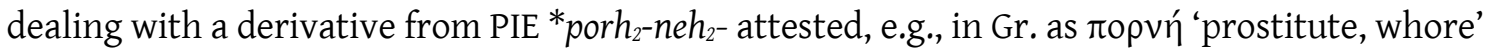
or $\pi \varepsilon \dot{\rho} \nu \eta \mu \mathrm{u}$ 'to sell'.

Gusmani \& Polat 1999b, 156-157; Gusmani 2001, 165; Brixhe 2004a, 79.

$p^{?}$ os (postposition and adverb?)

OPhr. p?os B-05 1.4

NPhr. ток 16.1 (116)

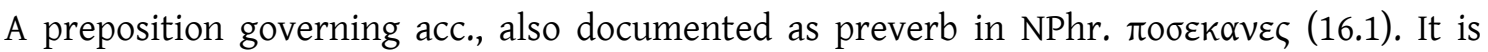
derived from the PIE adverb *pos 'after' (LIPP II, 628), Ved. pascat, OCS po 'behind, after' (<* pos),

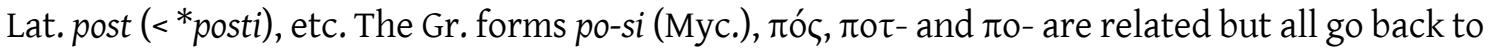

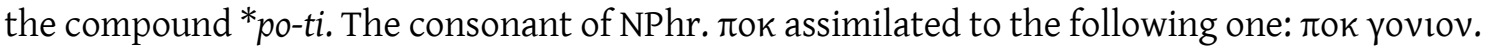
Brixhe and Neumann $(1985,176-177)$ considered this sequence a compound noun. The OPhr.

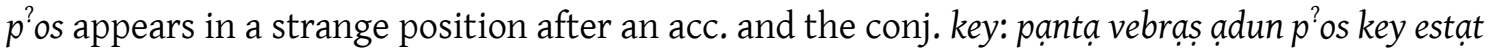
pator. ike[...]e[... a andati...

Brixhe \& Neumann 1985, 176-177; Brixhe 1997, 56; Brixhe 2004a, 56-57; LIPP II, 628.

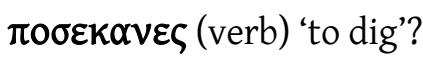

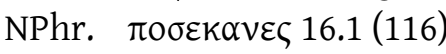

The $3 \mathrm{sg}$. aor. of an obscure verb, with the strengthened grade of the root, parallel to edaes. Its

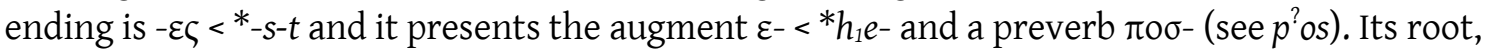
-KaV- < *kēn-, has been said to go back to PIE *ken- 'to rub, scrape, scratch off' (IEW 559-563, see Brixhe \& Neumann 1985, 176), however it never appears as a verb. It is perhaps related to PIE *ken- 'empty', Gr. kevó ` 'id.'. Ligorio and Lubotsky $(2013,191)$, suggested a meaning 'to dig'.

Brixhe \& Neumann 1985, 176; Ligorio \& Lubotsky 2013, 191.

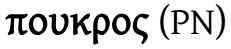

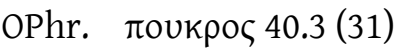

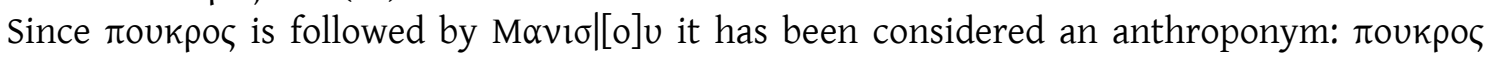

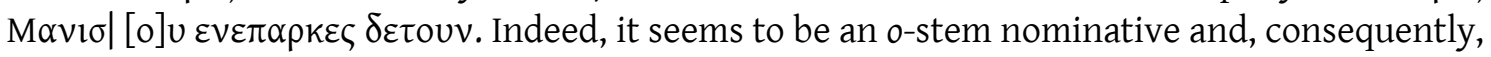

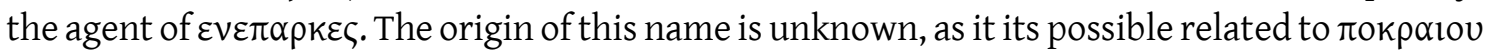
MPhr-01 (Brixhe 2004a, 17).

Orel 1997a, 333 \& 455; Brixhe 2004a, 17. 


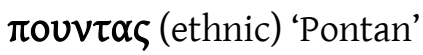

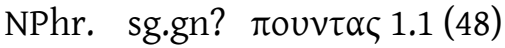

This words seems to be syntactically related to the god Bac. In the same inscription 1.1 (48), from Eskişehir, another god, $\mu \alpha \varsigma$, it is qualified with the epithet $\tau \varepsilon \mu \rho \circ$ clo ' 'of the Thymbris'. Consequently, this word has been suggested to be a borrowing from Gr. Пóv兀os, the south shore of the Black Sea. However, there is a village in the south of Eskişehir with the Gr. name *Potana

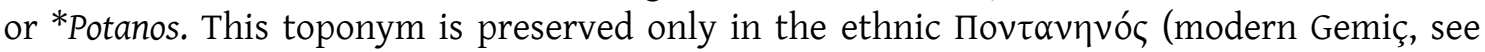
Ramsay 1890, 435 and 1905, 104, also KON $504 \S 1085$ ), applied to a man (on a funerary stele from Akoluk, Haspels 1971 I, no. 105), the Mother-Goddess (in a vow from Gemiş, MAMA V Lists Note:188,5) and the gods Hosios and Dikaios (in another vow, MAMA V Lists Note:188,5). Because of the proximity of these inscriptions and the use of this ethnic to qualify gods, the second origin is more likely. In any case, Lubotsky $(1997,132)$ also considered it a fem. adj. in the nominative singular, which would imply that $\mathrm{B} \alpha \mathrm{c}$ is a female divinity. However, this must be rejected because the sg.nom. of the $a$-stem fem. adj. is $-a-\varnothing$, as kubileya (W-04) shows. Although

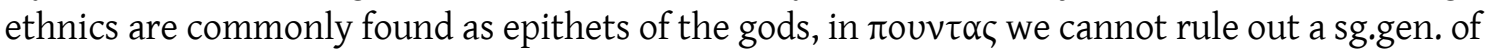

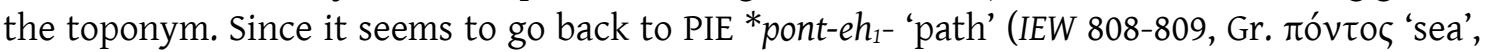

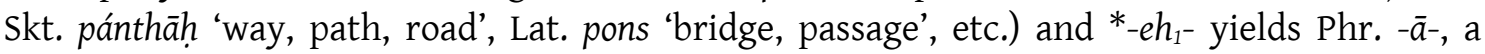

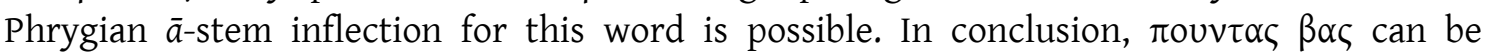
translated as 'Bas from Ponta-'. See tias for a similar formation and problems.

Ramsay 1905, 104; Bayun \& Orel 1988b, 148; Orel 1997a, 101 and 454; Lubotsky 1997, 123; Ligorio \& Lubotsky 2013, 186.

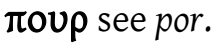

$\pi 0 v \sigma[. .].(?)$

NPhr. $\pi 00 \sigma[. .] .50.2(55)$

An obscure sequence read in a damaged protasis of a curse without parallels: $10[\varsigma \vee \imath \sigma \varepsilon \mu]$ ouv | $\kappa[\operatorname{vou} \mu \alpha] v \varepsilon 1|\kappa[\alpha \kappa o u v] \alpha \delta \delta \alpha| \kappa[\varepsilon \tau, \quad] l$ or $\pi$ ou $\mid \sigma[. ..] \mathrm{l} \delta u \sigma ı v$. The last part of the word is lost: although the reading $\pi \circ v \sigma[. ..] \mathrm{l}$ could be accepted, it may be only a stroke of a longer letter. Consequently, the reading it is too uncertain for any interpretation to be given.

$\pi \rho 0$ (noun?)

NPhr. $\pi \rho 040.3(31)$

Although this is very similar to the Gr. preposition $\pi \rho$ ó $\varsigma$, since there is not preceding text it

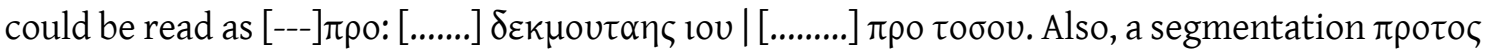
is possible, see $\pi \rho \circ \tau \varphi$. The following sequence ov can be related to ouc MPhr-01. Nevertheless, the obscure context does not offer much information.

proitavos (noun) title

OPhr. sg.nom. proitavos M-01b; proitavo[s] M-02

This noun is used in reference to the same person in both occurrences: M-01b baba memevais proitavos $k$ Фiyanaveyos si keneman edaes and bba memevais proitavo[s] $k \uparrow$ ianaveyos akaragayun edaes, read on a façade and a step-monument, respectively. Since memevais seems to be a patronymic, proitavos has been considered a title in sg.nom. Brixhe (2004a, 60), on the other

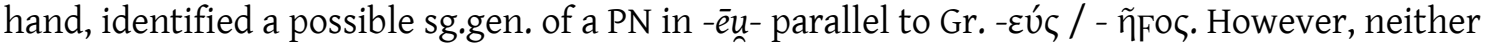
of the candidates which share this ending (akenanogavos and oskavos) are independently documented as a PN and the ending is in fact considered sg.nom. (see § 4.2.1.1.5.9.). On the origin of the word, only Orel (1997a, 13 and 454) considered it derived from PIE verbal root ${ }^{*} h_{1} e i_{-}$ 'to go' with a preverb pro- and the suffix -avo- and transLat.g it as 'leader, chief'. Although Lat. praetor is an attractive parallel, neither the Phr. verb $i-<{ }^{*} h_{1} e i-$ nor the suffix -avos explains the presence of a $-t-$, so this interpretation is unsatisfactory. 


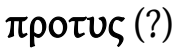

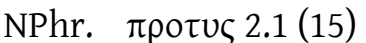

This unparalleled word is read in a funerary inscription which describes the monument: $\xi \varepsilon v v \eta$

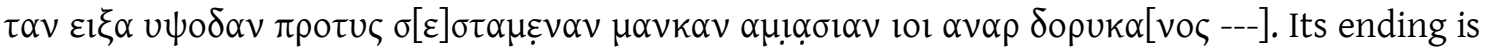
the same as $\pi \alpha \rho \tau u \varsigma$. Despite the opacity of this word, Lubotsky, after rejecting previous explanations which identified it as a verb (morphologically impossible) or an adverb (equated to Gr. $\pi \rho \circ \tau^{\prime}$ ), suggested a thematic noun in pl.acc. governed by the possible preposition $v \psi \circ \delta \alpha v$. This can be accepted if the shif*-ons > -ois considered by Brixhe is ruled out.

Lubotsky 1994, 132 fn. 5.

pseika ${ }^{\text {(noun?) }}$

OPhr. pseika? $\mathrm{W}-02$

A badly preserved word read in a dedication engraved on a small façade: iketaios pseika ed? $[a] e^{?} s$. Despite the lack of parallels and the loss of its ending, because of its position in the sentence it is very likely the patronymic of iketatios, the direct object of the sentence or the addressee in dat. In the light of the remaining strokes of the last letter, an ending $-a$ is the best option, in which case it could be a neuter noun in pl.nom.-acc. However, this remains unclear. Orel (1997a, 41 and 454), on the other hand, based on a forced reading of the inscription, considered it an ethnic attested in D-101 as pserkeyoy in the light of his adduced parallel from Pisidia $\Psi \varepsilon \rho \kappa ı$ « $\omega \mu \eta \tau \eta$. However, neither the reading nor the parallel can be accepted. In W-02 the sequence must be read as pseik, not pseir-, and the Pisidian word cannot be considered a parallel,

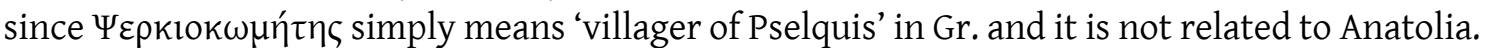
Indeed, it is an ethnic from the $2^{\text {nd }}$ and $3^{\text {rd }} c$. AD with two occurrences in Pisidia (KON $661 \S 1440$ ) but solid attestation in Egypt (also with the variant $\Psi \varepsilon \lambda \kappa \iota \tau \varepsilon \varsigma$ on papyri), since it is based on the name of an oppidum located in the Nubian west bank of the Nile (Pleiades place no. 795846): Egyptian Pr-Slk.t (Pr-Slq), Gr. $\Psi \varepsilon \lambda \kappa ı \zeta$ or $\Psi \varepsilon \lambda \chi ı ı$. So, the presence in Pisidia can be explained as a very late migration of particular people inside the Roman Empire. Because the initial ps- only has one other attestation in the whole Phrygian corpus that can also be interpreted as a PN, pseukeyoy or pseukeyoy, both occurrences may be variants of a name borrowed from an unidentified language. Nevertheless, it remains unclear.

CIPPh I, 43; Orel 1997a, 41 and 454; Obrador-Cursach fthc. b.

pserkeyoy see pseukeyoy.

pseukeyoy (PN)

OPhr. sg.dat. pseukeyoy or pserkeyoy Dd-101

Read on a stamp seal before a clear PN in sg.nom: pseu'keyoy atas. Although the reading of the fourth letter is not at all clear because of a dent (but given the shape of the end of the strokes a $u$ can be preferred), it can be considered a thematic PN in dat., perhaps related somehow to pseik. Since no parallel can be found, a very attractive possibility is to consider pserkeyoy a PN borrowed from Gr. $\Sigma \pi \varepsilon \rho \chi \varepsilon i o ́ \varsigma$, a PN found in Roman Caria (Tralles 83, the form $\Sigma \pi \varepsilon \rho \chi u ́ \lambda \varepsilon 10 \varsigma$ is attested in Ephesos and Smyrna and $\Sigma \pi \varepsilon \rho x i ́ s$ in Thessalia). On Orel's interpretation as a DN, see pseika?

CIPPh I, 43; Orel 1997a, 41 and 454; Obrador-Cursach fthc. b. 



\section{$P(r)-P \rho$}

ray. see bay.

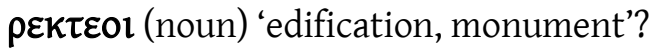

NPhr. $\rho \varepsilon \mid k \tau \varepsilon O l 47.1(51)$

Despite the fact that the text is not complete, this hapax is attested in a common protasis

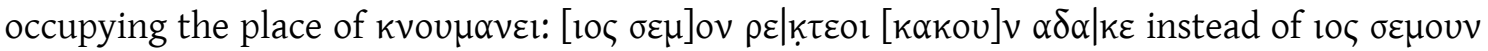

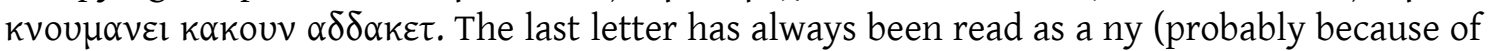
the ending of the previous word), but only an "upright stroke" remains, as Calder (1911, 195, the first editor) described; only Brixhe and Neumann $(1985,172)$ suggested the possible reading

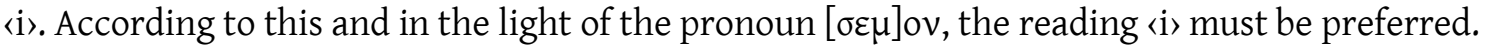
Consequently, it is an o-stem masc. or neuter dat., as is expected in this position. Defending the common reading brings totally ungrounded interpretations (see Brixhe 1978b, 19). Two possible meanings have been suggested on the basis of two respective etymological interpretations. The first was suggested by Calder $(1911,195)$ and followed by Orel $(1997 a, 339$ and 455), who considered it a borrowing from Lat. rectio 'a leading, guiding, government, direction' or erectio 'a setting up, erecting'. While rectio does not fit in this context, erectio does, and this means that certain processes must be assumed: an apheresis, the semantic evolution from 'a setting up' to 'construction', the adoption in the o-stem paradigm of this Lat. $n$-stem and the common hesitation between /e/ and /i/ (see $\delta \varepsilon \omega \varsigma \sim \delta i \omega \varsigma)$. The second interpretation, which is absolutely impossible, was given by Haas $(1996,80)$, who considered to word a derivative from a form *leg $g^{h} t o-(\mathrm{sic})$, so similar to Lat. lectus 'a couch, bed' $<{ }^{*} l e g^{h}$-to- / *leg - -tu(on the formation see Vaan 2008, 332, the root clearly goes back to PIE *leg ${ }^{h}$ - 'lie'). Despite the hesitation between / $\mathrm{r} /$ and /l/ in Phrygian (compare $\sigma \kappa \varepsilon \lambda \varepsilon \delta \rho l \alpha l$ with $\sigma \kappa \varepsilon \rho \varepsilon \delta \rho l \alpha \varsigma$ ), the voiceless velar stop is unexpected and does not explain the sequence -हo- instead of -o-. Calder 1911, 195; Haas 1996, 80; Brixhe 1978b, 19; Orel 1997a, 339 and 455.

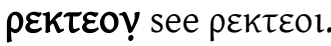

\section{[?] rekun see vrekun.}

$r i(\mathrm{PN}$ )

OPhr. ri G-305

Perhaps an abbreviated anthroponym. Although the support is broken, if more letters were written, vestiges would be expected. Only one name is attested with this beginning in the Phrygian corpus, rigaru / ritaru.

Brixhe 2002a, 65.

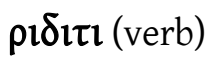

NPhr. 3sg.pres.sub. pı\&ııı 16.1 (116)

The segmentation is not at all clear. It could be read as $\rho ı \delta \imath \imath \tau \alpha 1$, but the lack of parallels of this last ending makes $\rho ı \delta \imath \imath$ preferable. This word must be the verb (transitive because of the acc.)

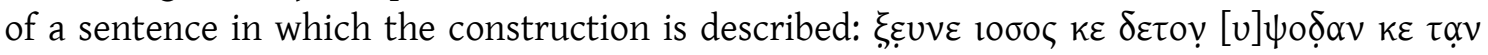

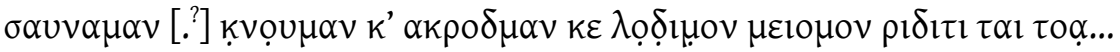

Brixhe \& Neumann 1985, 173; Orel 1997a, 129 and 455. 
rig? aru (PN)

OPhr. rig? ${ }^{\text {aru } \mathrm{G}-222}$

The letter read as $\langle g\rangle$ could be $\langle t\rangle$. However, the first option is preferred because the appendix of the horizontal stroke in the right part is very short. Morphologically, it is very likely a $u$ stem PN in the sg.nom. without the $s$ ending, as otus $\sim$ otu. However, no parallel has been found for this anthroponym.

CIPPh I, 179; Brixhe 1996, 141; Brixhe 2004a, 89.

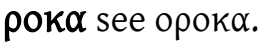




\section{$\zeta(s)-\Sigma \sigma$}

$\boldsymbol{s}^{1}$ (owner's mark)

OPhr. s G-204, NW-106, NW-117

Graffiti incised on sherds. In NW-106 and NW-117 this letter is isolated and seems to be an owner's or commercial mark. In G-204, however, it occurs in an unusual context where at least one PN (alu) has been identified: [---]da alu $m s$ [-?-].

CIPPh I, 168; Brixhe 2002a, 15-16 and 22.

$\boldsymbol{s}^{2}$ see $\sigma \varepsilon \mu o u v$.

șabas (PN)

OPhr. sg.nom. șabas M-08

This is the only sequence which has been read in this damaged inscription. It is preceded by an illegible sequence separated by a blank. Consequently, it is very likely a complete word. As CIPPh (I, 27-28) remarks, this probable PN is very similar to $\Sigma \alpha \beta 1 \varsigma$ or $\Sigma \alpha \beta \cup \varsigma$ (KPN 449 § 1349), both found in Phrygia. If this is the case, it is an $a$-stem PN in the nominative with the ending -s. Bayun and Orel (1988a, 181, also Orel 1997a, 31 and 456) identify this name in the DN $\Sigma \alpha \beta \alpha$ '́ 10 . CIPPh I, 27-28; Bayun \& Orel 1988a, 181; Fol 1997, 263; Orel 1997a, 31 and 456; Fol 1997.

$\sigma \alpha l$ see $\sigma \varepsilon \mu o u v$.

sakor see akor.

$\sigma \alpha v$ see $\sigma \varepsilon \mu o u v$.

saragis (PN)

OPhr. sg.nom. saragis B-108; șaragiș M-101 (Brixhe \& Sivas 2003-4a)

The first occurrence, B-108, is a graffito incised on a fragment of a bowl followed by a probable interpunction and the sequence mago? [---]. Here, this PN was read in the light of the other occurrence (Gusmani \& Polat 1999, 64 read it as [---]saragiś or [---]saraliś). M-10 is an isolated graffito on another damaged sherd (hard to date because it was found on the surface without a clear context). On the basis of the contexts in which it appears, it would seem to be an $i$-stem anthroponym. Because of the lack of parallels in other languages it has been considered by Brixhe (2004a, 93) a genuine Phr. PN. In addition, since a name $\Sigma \alpha \gamma \alpha \rho ı$ and variants such as $\Sigma \alpha \gamma \alpha \rho$ io are especially well attested in Gr. inscriptions from Galatia and Phrygia dated between the $2^{\text {nd }}$ and $3^{\text {rd }} \mathrm{c} . \mathrm{BC}$, a metathesis in OPhr. occurrences of saragis can be considered (see a similar

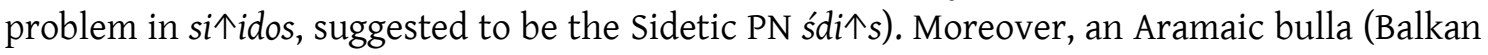
1959, pl. XXXIVb) found in Daskyleion (as well as B-108) reads LSGRY or LSGDY. If the first reading is preferred, as in Lamaire (2000 II, 4, 3), the text means 'to Sagaris' (the second reading 'to SGDY' is difficult to defend), a possibility made stronger by the Greco-Aramic inscription from Faraşa (Cappadoccia, dated later to the third c. BC according to Lipińsky 1975, 174), in

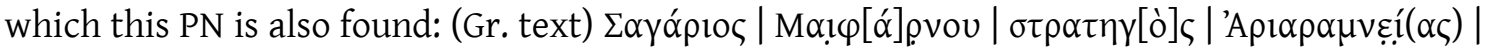

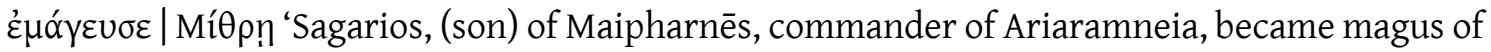
Mithra' (Aramaic text) sgr br mhyprn rb hy[l]? | mgyš [lm]trh 'Sagari, son of Mahifarna, chief of the army, became magus of Mithra'. Also, in the light of this occurrence (despite the chronological divergence), saragis ?' mago? [s] could mean 'Saragis the magus'. Finally, Saragis is perhaps related to the enigmatic word oóyopic, a weapon used by the Scythian tribes, the 
Persians, Amazons, Mossynoeci, etc., considered Iranian in origin (EDG 1300) or, more likely, to the river name $\Sigma \alpha \gamma \gamma \alpha$ ó

Brixhe 2004a, 93; Brixhe \& Sivas 2003, 70.

\section{$\sigma \alpha \rho v \alpha \nu(\mathrm{DN})$}

NPhr. sg.nom. $\sigma \alpha \rho v \alpha v 11.2(18)$

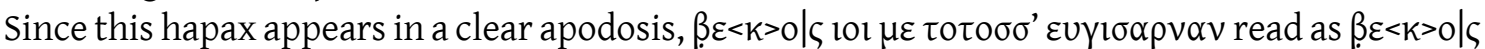

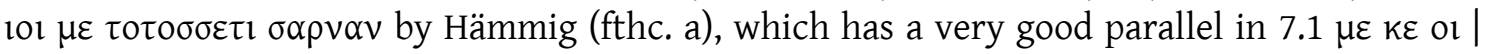

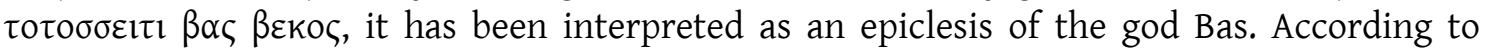
Hämmig, it is very likely a sg.nom. in *-enn. Recently, Avram (2016b, 77-78) has identified this word in the epithet of Zeus, $\Sigma \alpha \rho v \varepsilon v \delta \eta v o \zeta$, found in north-east Phrygia / north-west Galatia, Bithynia and Dacia. Unfortunately, neither the origin nor the meaning of this word has been identified.

Hämmig fthc. a; Avram 2016b, 77-78.

$\sigma \alpha \varsigma$ see $\sigma \varepsilon \mu o u v$.

$\sigma \alpha v v \propto \mu \alpha v$ (noun)

OPhr. sg.acc. $\sigma \alpha u v \alpha \mu \alpha v 16.1$ (116)

This word occurs in a sequence of several nouns in the sg.acc. that refer to different parts of

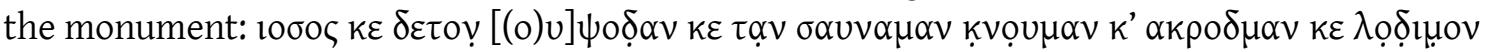

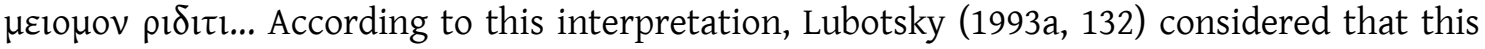
word could be "the term for the foundation, the pedestal of the monument", and in the light of the Hitt. šämăna- 'foundation(s); foundation deposit' he considered it a borrowing from an Anatolian language (followed by Gorbachov 2009, 106 fn. 32 in order to strengthen his interpretations of the borrowed words). Although this interpretation is very attractive, it brings with it problems that cannot be solved by Lubotsky's suggestion of an intermediate Anatolian language: the metathesis of the resonants ( $\sigma \alpha v v \alpha \mu \alpha v$ instead of ** $\sigma \alpha \nu \mu \alpha v \alpha v)$ and the raising of the diphthong - $a->-a u-$. A significant element is the presence of $\tau \alpha v$ before the word $\sigma \alpha v v \alpha \mu \alpha v$. This pronoun shows us that the word is undoubtedly fem. (Lubotsky 1993a, 131).

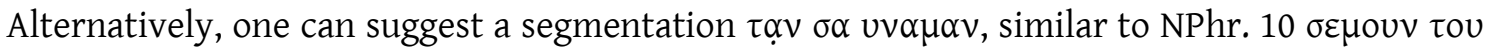
$\kappa v o u \mu \alpha v \varepsilon l$. The resultant form ${ }^{\circ} v \alpha \mu \alpha v$ could be a phonetic or graphic variant of onoman (OPhr.

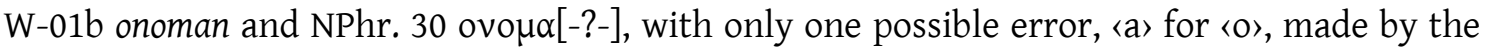
engraver in a sequence of several $\langle a\rangle$, and the constant hesitation of the letters $\langle 0\rangle,\langle 0 u\rangle$ and $\langle u\rangle$,

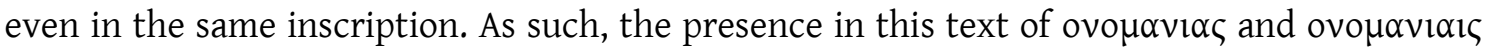
does not invalidate this interpretation, although the question remains open.

Brixhe \& Neumann 1985, 170-171; Lubotsky 1993a, 132; Gorbachov 2009, 106 fn. 32.

sa ? $^{\prime} \operatorname{ta}(?)$

OPhr. pl.nom.-acc. sa甲?ta W-08

The context of this sequence is more or less clear: ates agomoi | sag?ta tedaes, where ates is the agent, agomoi the indirect object and edaes the verb. So, the meaning is 'Ates made/put sa $\mathrm{Q}^{\text {? }} \mathrm{ta}$ for Agomos'. Consequently, sa $\mathrm{Q}^{\text {? }}$ ta must be the direct object and therefore a neuter noun in pl.nom.-acc. (contrary to Orel 1997a, 47-48 and 456, who considered a neuter singular). Whatever it means, this word presents a reading problem in the third letter, transcribed as $Q$ and similar to Gr. qoppa, which greatly complicates the interpretation because it is the only occurrence in the whole Phr. corpus.

CIPPh I, 53; Orel 1997a, 47-48 and 456.

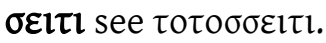


$\sigma \varepsilon \mu \mathrm{tv}$ see, $\sigma \varepsilon \mu \mathrm{ov}$ and $\sigma \varepsilon \mu \mathrm{ov}$ see $\sigma \varepsilon \mu \mathrm{ovv}$.

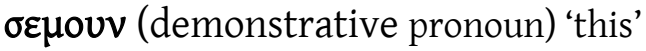

OPhr. sg.dat.fem. esai $\mathrm{W}-01 \mathrm{~b}$

sg.dat.masc.neut. <s>imun B-05 1.10

particle $\quad s$ B-07, M-01dI

pl.acc.masc.? ses $\mathrm{P}-02$ ?

sg.nom.-acc.neut. si B-01, B-08; M-01b, G-11 b

sg.acc.masc. $\quad \sin \mathrm{B}-05$

MPhr. sg.dat.fem.

sg.nom.fem.?

NPhr. sg.dat.fem.

sg.dat.fem.

sg.dat.fem.

sg.gen.fem.

sg.dat.fem.

бọ MPhr-01 (W-11) 1.3

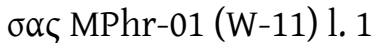

sg.dat.masc.-neut.

$\sigma \alpha 17.5$ (91), 21.1 (42), 25.1 (115), 44.3 (67), 64.1 (81), 65.3 (21), 65.4

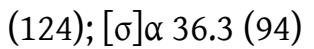

$\sigma \alpha 143.1(69), 62.4(35)$

$\sigma \alpha v 60.2(60)$

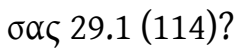

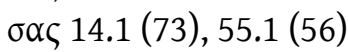

sg.dat.masc.-neut.

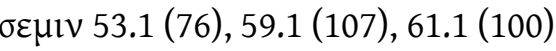

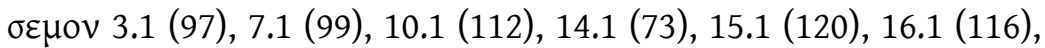

17.5 (91), 18.1 (4), 21.1 (42), 25.1 (115), 29.1 (114), 30.1 (39), 32.1

(93), 33.3 (127), 36.1 (26), 37.2 (27), 39.1 (11), 47.1 (51), 58.1 (72),

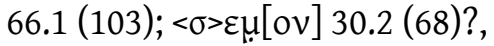

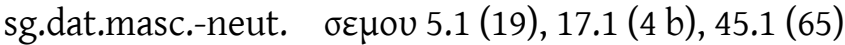

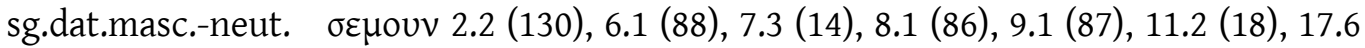

(119), 18.2 (5), 18.3 (6), 20.1 (63), 20.2 (128), 21.2 (62), 24.1 (40),

25.1 (115), 27.1 (92), 31.1 (111), 33.1 (28), 33.2 (95), 34.1 (37), 37.1

(10), 40.1 (12), 41.1 (45), 42.1 (101), 44.1 (61), 46.1 (53), 48.2 (84),

49.1 (110), 50.1 (54), 50.2 (55), 51.1 (80), 56.1 (57), 57.1 (78), 58.1

(72), 59.3 (79), 59.4 (106), 62.1 (32), 62.2 (33), 62.5 (36), 62.6 (105),

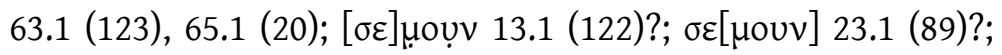

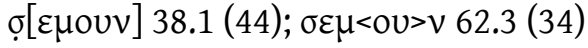

sg.acc.masc.-neut. $\quad$ $\sigma \varepsilon \mu \mathrm{ouv} 40.3$ (31)

sg.dat.masc.-neut. $\quad \sigma \varepsilon \mu \nu v 20.3(62)$

sg.dat.masc.-neut. $\sigma$ luouv 35.1 (25)

pl.dat.masc.-neut.? $\sigma \omega \varsigma 2.2$ (130)

A clear demonstrative pronoun which goes back to PIE *so- / to- or, better, *ki- (this possibility is considered by Ligorio \& Lubotsky 2013, 185; see $\S 4.2 .1 .2 .1$ ). Most occurrences appear in the

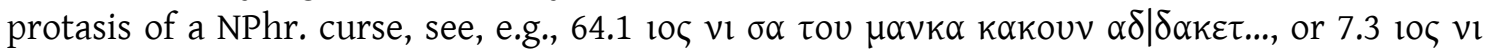

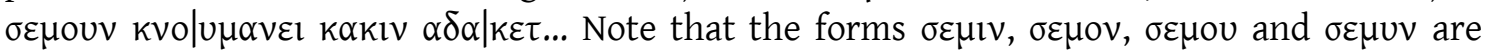
simply alternative spellings of $\sigma \varepsilon \mu o u v$. On one occasion, $\sigma \varepsilon \mu o u v$ is attested as sg.acc.: $40.3 \alpha \varsigma$

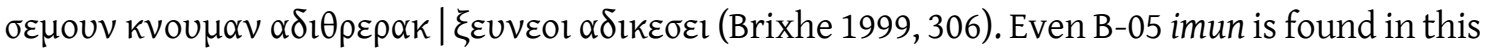
position at the beginning of the protasis after the pronoun instead of the expected *simun, however the spelling here is aberrant (see Hämmig 2013, 149): †iv $\dagger<s>i m u n$ inmeney as enạn daket... Furthermore, its fem. inflection, shared with a-stem nouns, shows some unexpected forms. Because of the loss of the final nasal and the $-i$ of the diphthongs, $\sigma \alpha v$ and $\sigma \alpha$ are variants of the etymological form $\sigma \alpha 1$. Also $\sigma \alpha \varsigma$, with gen. ending, is used instead of the dat. $\sigma \alpha(1)$ in 14.1

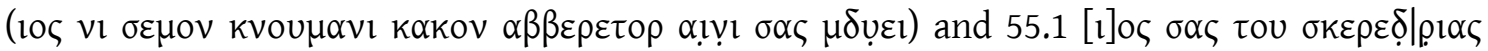

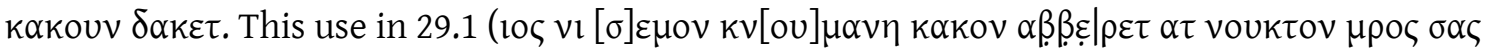
or $\mu \rho \circ \sigma \sigma \alpha \varsigma)$ and MPhr-01 ( $\mu \alpha \nu \kappa \alpha \mu \varepsilon \kappa \alpha \varsigma \sigma \alpha \varsigma)$ is still unclear. The other OPhr. forms are more complex: on three occasions it is complemented with the particle $t$ (related to the anaphoric $\tau \circ)_{)}$, esai $=t$, ses=t, $\sin =t$ and $s i=t$, and esai=t is a compound of the pronoun $e^{-}$, which goes back to 
PIE * $h_{1} e / o^{-}$, and sai. The form ses=t has been interpreted as a determinative pronoun in the sg.nom. or sg.acc. (Neumann 1988, 7 fn. 12 and Neumann 1997, 119) in concordance with bugnos: P-02 sest bugnos valsos kanutiievanos. The sequence is similar to esai=t, so it is easy here to interpret the last $-t$ as the emphatic particle. However, the vocalism of the pronoun is difficult to explain. Perhaps it is a levelling from other cases. Orel (1997a, 292 and 429), on the other hand, considered it the verb 'to be' in the third singular present (going back to PIE * $h_{1} e s-t i$, "this is Bugnos..."), but this is difficult to substantiate because of the position of this word at the beginning. The form si agrees twice with the neuter noun in sg.nom.-acc., B-01 si bevdos and M$01 \mathrm{~b}$ si keneman, but also stands alone once, $\mathrm{G}-11 \mathrm{~b}$ sit kraroy veao | dis. The form sin clearly agrees with a masculine noun in sg.acc.: B-05 sin=t imenan... Finally, the proclitic particle $s$, which must have its roots in this pronoun and be parallel to $t$ with regard to $\tau o \varsigma$, is found attached to nouns (in acc. and nom. respectively): M-01dI midas |s=materan | tvemes eneparkes ${ }^{?}$ and B-07 s=manes iyungidas manitos apelev porniyoy...

Lejeune 1969b, 296-297; Neroznak 1978, 72, 75, 80, 114, etc.; Brixhe 1978b, 12-20; Neumann 1988, 7 fn. 12; Neumann 1997, 119; Orel 1997a, 292 and 429; Brixhe 1999, 306; Ligorio \& Lubotsky 2013, 185; LIPP II, 739-740.

$\sigma \varepsilon \mu v v$ see $\sigma \varepsilon \mu o u v$.

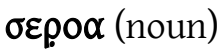

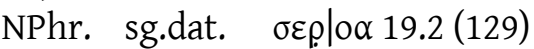

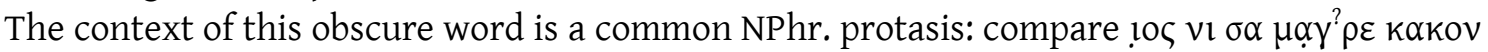

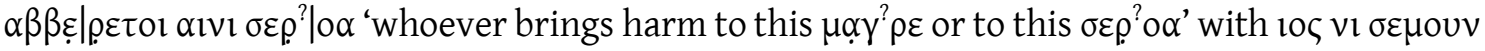

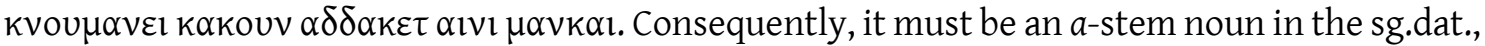
where the final $-i$ of the original ending - $a i$ has dropped. This word is expected to refer to some part of the tomb or the burial plot. According to Brixhe and Drew-Bear (2010, 165), a relationship with servas is probable. However, this occurrence is documented in a totally different context and G-130, where it can also be read, is even more obscure than this inscription.

Brixhe \& Drew-Bear 2010, 165.

servas (?)

OPhr. servas G-130

An obscure word read in a large but broken sequence incised on a potsherd: [---]es servas bo.[---]. It has been tentatively equated to Lat. seruus by Orel (1997a, 183 and 457). However, G130 may be dated to the $5^{\text {th }} \mathrm{C}$. BC, so this possibility is indefensible. Consequently, the word

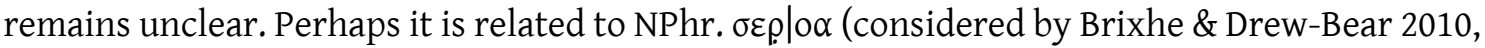
165).

Neroznak 1978, 101; CIPPh I, 120; Orel 1997a, 183 and 457; Brixhe \& Drew-Bear 2010, 165.

$\sigma[\varepsilon] \sigma \tau \alpha \mu \varepsilon v \alpha v$ see estaes.

sett:---] (PN?)

OPhr. setț[---] G-263

Damaged graffito on a potsherd. It is preceded by a mutilated triangle. Although the letters are lost at the bottom, the first 〈s〉 confirms the dextroverse reading. Orel's lecture sat [---] is impossible because this 〈a〉 does not fit there. It is perhaps, then, a PN referring the owner. However, no parallel can be adduced.

CIPPh I, 203-204; Roller 1987a, 50; Bayun \& Orel 1988a, 199; Orel 1997a, 240 and 456.

sest see $\sigma \varepsilon \mu o u v$. 
${ }^{\dagger}$ șeștạeș see [---]s and estaes.

${ }^{\dagger}$ seVeltias see $s^{?} V^{?} e^{?} l$ and tias.

seVel (noun) 'weight'

OPhr. sg.nom. seVel G-249

The seVeltlias inscription was incised on an alabaster weight and is considered one of the oldest Phrygian text according to CIPPh (I, 195-196) and Brixhe (2004b, 276-277). Since it is found on a weigh,the sequence seVel must be a borrowing from the Aramaic šqel 'weight' (also found in Gr.

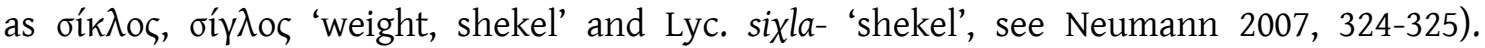
Consequently, seVel t|ias can be equated to, e.g., šql hmt 'Shekel of Hamath', šql șydn 'Shekel of Sidon', šql qrqr 'Shekel of Qarqar' (see Riis \& Buhl 1990 and Deutsch \& Millard 2014).

CIPPh I, 195-196; Bayun \& Orel 1988a, 199; Orel 1997a, 234-235 and 457.

${ }^{\dagger}$ svebrạ[---] see $\sigma \varepsilon \mu o u v$ and vebras.

$\sigma \zeta \varepsilon \mu \varepsilon \lambda \omega \varsigma$ see $\zeta \varepsilon \mu \varepsilon \lambda \omega \varsigma$.

si see $\sigma \varepsilon \mu o u v$.

$\sigma ı \beta \eta[-?-](?)$

NPhr. $\quad$ or $\beta \eta[-?-] 37.2(30)$

Since it follows the formula evkıv apyou, it probably appears at the beginning of a sentence. However, because the following words are lost and no parallel can be adduced, its meaning, nature, origin and possible completeness remain unclear.

Orel 1997a, 329 and 457.

olpouv and $\sin$ see $\sigma \varepsilon \mu o u v$.

${ }^{\dagger}$ sini see $\alpha \delta \delta \alpha \kappa \varepsilon \tau$ \& da8pulaịsini.

$\operatorname{sir}(\mathrm{PN})$

OPhr. sir G-185

This complete graffito, read on a potsherd, is very likely an abbreviation of a PN. However, CIPPh (I, 158) considered the possibility of a complete Anatolian PN in the light of the Pisidian occurrence $\Lambda \mathrm{i} \rho$ (KPN 272 § 819).

CIPPh I, 158; Bayun \& Orel 1988a, 199; Orel 1997a, 208 and 457.

sirun (noun?)

OPhr. sg. acc. sirun B-05 1. 10

The word occurs in a singular imprecative apodosis in agreement with the word mireyun: nun ibey nevotan niptiyan sirun mireyun. According to Simon sirun mireyun means 'the whole progeny', where sirun stands for 'progeny', in the light of adduced Hitt. parallels. However, this identification is not corroborated by internal or linguistic evidence.

Neumann 1997, 24; Brixhe 2004a, 20, 62 and 81; Hämmig 2013, 143-145; Simon $2014 a$.

sit see $\sigma \varepsilon \mu o u v$. 


\section{sitoros (PN)}

OPhr. sg.nom. sitoros W-12

This word is engraved on a stone with other two PNs: sitoros aros $\mid$ ispas. No parallel has been

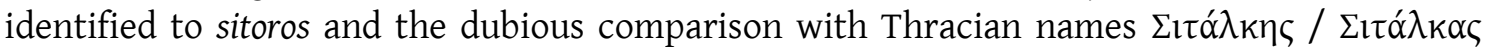
given by Brixhe (in Bilgen, Brixhe \& Coşkun 2011, 148) is not at all conclusive.

Bilgen, Brixhe \& Coşkun 2011, 157-148.

sit: $[---](?)$

OPhr. siț[---] o [---]tịs G-194

A fragmented sequence on a potsherd. Its writing direction is not clear. If it is dextroverse we can consider it the beginning of a word, otherwise it is a word ending (a sg.nom. of an $i$-stem?). In any case, perhaps it is a PN.

CIPPh I, 162-163; Bayun \& Orel 1988a, 199; Orel 1997a, 473.

si $\uparrow$ eto (verb?)

OPhr. 3sg.imp.? si个eto W-08, W-09, W-10

This word always occurs in a formula, where alus also appears, only found at the end of three inscriptions engraved on rocks: W-08 [-?-] ates agomoi $\mid$ sa $\rho^{?}$ ta tedaes $\mid$ alus si $\uparrow e t o ? \mid$ bateles

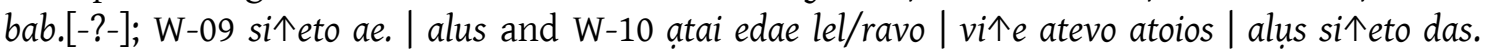
According to Brixhe (1982, 230-231), it may be a verb in 3sg.imp. in the light of its possible ending -to. However, given the initial s-and the similarity with the PN si个idos, we cannot rule out a non-Phrygian PN (a gen. used as a patronymic?).

Brixhe 1982, 230-231.

$s i \uparrow i d o s(\mathrm{PN})$

OPhr. sg.nom. si iidos G-105, HP-110, G-346

A thematic PN incised on two kind of objects: a beam of the Midas Mound at Gordion, together with more PNs (nana muksos $\mid$ si $\uparrow$ idos |'urunis), and on large bronze bowls found in this tumulus (G-105, followed by the word akor) and the Lycian tumulus Bayındır D (HP-110). Brixhe (2004a, 150) suggested that this PN perhaps shares its root with the verb si个eto and considered it a compound belonging to "the old Phrygian stock of names" (2013, 57). Schürr (2017, $4 \mathrm{fn} .13)$ suggested that si idos is the Sidetic PN śdi $\uparrow s$ (S6, following Pérez Orozco 2007, 128, the outcome

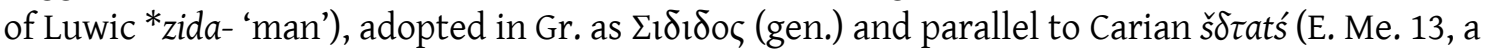
fem. form according to Adiego 2007, 271). However, this interpretation cannot be proved (see also Nikolaev 2017, fn. 23).

Brixhe 1982, 230-231; Varinlioğlu 1992, 15; Brixhe 2004a, 150; Liebhart \& Brixhe 2009, 149-151; Brixhe 2013, 57; Schürr 2017, 4 fn. 13; Nikolaev 2017, fn. 23.

\section{$\sigma \kappa \varepsilon \lambda \varepsilon \delta \rho 1 \alpha 1$ (noun)}

OPhr. sg.dat. $\sigma \kappa \varepsilon \lambda \varepsilon \delta \rho l \alpha l 44.3(67)$

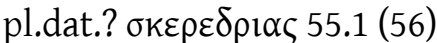

Despite the divergences in the spelling (the recurrent $-\alpha \varsigma$ for the expected dat. $-\alpha 1$ and the hesitation between liquid consonants), both forms of this a-stem fem. noun happens in the

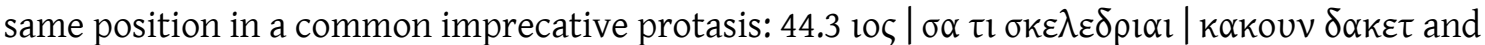

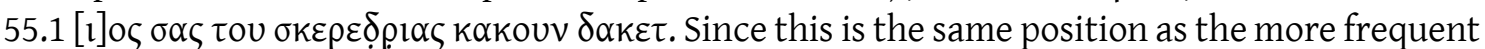

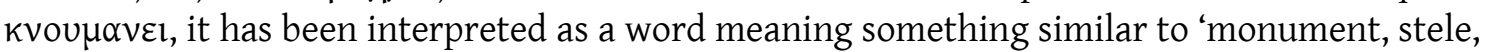
tomb' (Ligorio \& Lubotsky 2013, 194). Alternatively, a meaning 'cadaver' or 'skeleton' has been

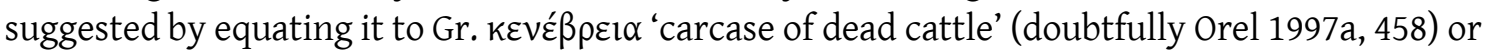

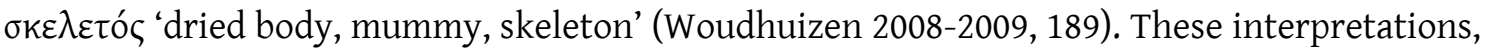


especially the second one, are attractive, see for instance Gr. parallels such as Strubbe 1997, no.

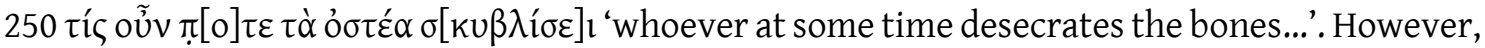
references to the monument are more common by far and the relation between $\sigma \kappa \varepsilon \lambda \varepsilon \delta \rho i \alpha \zeta$ and

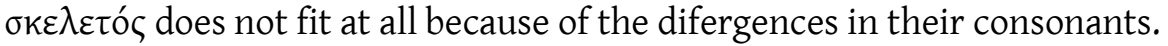

Lejeune 1969b, 295; Orel 1997a, 458; Woudhuizen 2008-2009, 189; Ligorio \& Lubotsky 2013, 194.

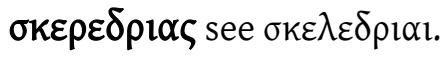

${ }^{\dagger}$ smateran see $\sigma \varepsilon \mu o u v$ \& materan.

sọ[---] (?)

OPhr. sọ[---] or [---]ọs G-191

Even the direction of writing of this fragmentary graffito on a potsherd is obscure. If [---]os is preferred, it could be a sg.nom. ending of an o-stem (a PN perhaps).

CIPPh I, 161; Orel 1997a, 210 and 472.

\section{sokposa (?)}

OPhr. sg.nom. sokposa G-229

Read on a potsherd, this word follows the PN mamutas, which is repeated in the following line: mamutas sokposa $\mid$ mamutas itoiesgloka. Perhaps the name of this mamutas was compounded: mamutas sokposa. However, it is substituted in the second line and no parallel can be adduced to this so called PN because the proposal G-189 made by Orel (1997a, 210) does not fit at all. CIPPh I, 183-184; Bayun \& Orel 1988a, 197; Orel 1997a, 210, 227 and 458.

бopor see бopov.

oopov (noun) 'cinerary urn, sarcophagus'

MPhr. sg.dat. oopol MPhr-01 (W-11) 1.3

NPhr. sg.dat. oopov 65.3 (21), 65.4 (124)

The three occurrences are read in funerary stele and preceded by the fem. pronoun $\sigma \alpha$. So, it is a clear o-stem fem. noun. On the basis of the context and the resemblance, it has been identified as a borrowing from Gr. бopó -ov 'cinerary urn' by Brixhe, used in the Gr. part of 65.3 (21):

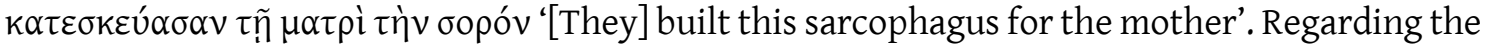
meaning, Kubińska $(1968,32-35)$ shows that in Anatolia this word is used as 'sarcophagus'. Despite the different spellings, all three forms are in the sg.dat. Indeed, oopol MPhr-01 stands for /soro:j/ in a inscription where omega is not used. The ending of the NPhr. form oopov, which appears in the common imprecative protasis instead of the more common $\sigma \varepsilon \mu o u v$

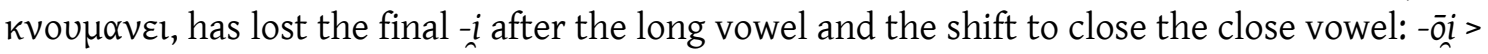
$*_{-\bar{o}}>-\bar{u}$ (according to Brixhe \& Drew-Bear 1997, 103).

Haas 1966, 248; Brixhe \& Drew-Bear 1997, 103; Orel 1997a, 248 and 458 Brixhe 2002b, 258; Brixhe 2004a, 18.

\section{speretạ (noun)}

OPhr. spereta B-01

This word appears in an imprecative sentence, in a position where we expect a direct object: yos tivo [t] a spereta ayni kin te[l]emi... That is why Lubotsky 1997, 125, fn. 19 considered it a neuter

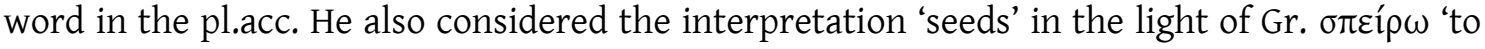
sow, to seed' and $\sigma \pi \varepsilon \dot{\varepsilon} \mu \alpha$ 'seed'. However, this latter proposal is very tentative. On the other hand, the segmentation $\alpha \sigma \pi \varepsilon \rho \varepsilon \tau$ used by Bayun and Orel (1988a, 187 and Orel 1997a, 142 and 416, who considered it a verb) is less probable, after Lubotsky's reading spereta instead of the previous speretd (1993b, 94-95).

Lubotsky 1993b, 94-95; Orel 1997a, 142 and 416; Lubotsky 1997, 125, fn. 19. 
șr[---] (?)

OPhr. $\operatorname{sr}[---] \mathrm{K}-01 \mathrm{II}$

A very short sequence which was not preceded by another word, as the fragment shows. Since the word cannot be supplied because of the lack of any parallel in Phrygian, it is doubtful whether the word actually begins with a strange $s r$ - (also poorly attested in PIE) or the $s$ is the syncopated demonstrative pronoun $s i$, which also occurs in sequences such as s=materan.

Brixhe \& Summers 2006, 115-116.

sțal' $a$ (noun) 'stele'

OPhr. sg.nom.? stal'? $\mathrm{B}$-06

This is probably a loanword from Aeol. $\sigma \tau \alpha \dot{\alpha} \lambda \lambda \alpha$ 'stele' (better than Dor. $\sigma \tau \alpha \dot{\lambda} \lambda \alpha$, as suggested by Vassileva 1995, 28-29), since the Phrygian alphabet does not represent geminates, indeed stala could represent /stalla:/. Then, the word in B-06 may refer the monument on which it is engraved. It is the first word of the remaining text but, because of the following ke, the text probably had at least one more line at the beginning. Unfortunately, however, the context is

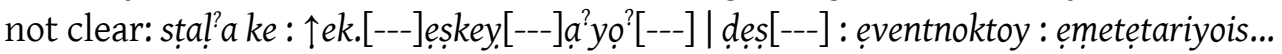
Vassileva 1995, 28-29; Brixhe 1996, 133; Brixhe 2002b, 257; Brixhe 2004a, 71.

surgastoy (DN)

OPhr. sg.dt. surgastoy Dd-102

Since the complete text Dd-102, incised on a silver bowl, is surgastoy inas, the best way to interpret it is to consider a present given by a man called inas (in the nominative) to *surgastos. Indeed, surgastoy is very likely an o-stem dat. It has also been suggested to be attested in G-164 [---].astoy and G-113[---]astoi pitave[---] (see Avram 2016b, 72-74). It was considered a DN by Orel (1997a, 459, although he debated between an anthroponym or a DN in 361) and Avram (2016b,

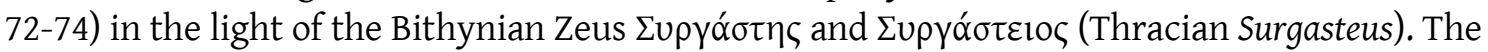

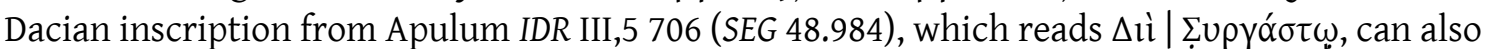
be adduced as an occurrence. However, the form śrkaśtus attested as a PN in Lyd. (Gusmani 1964, 199) is a closer parallel. Even the name Sergestus, a follower of Aeneas in Verg. Aen., has been taken into account in this issue (EDG 20). However, it is better to adduce the gloss H. $\sigma 2767$

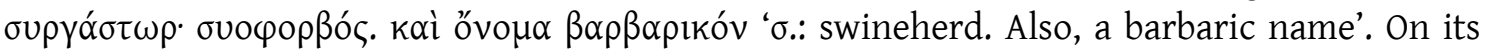
origin, the presence of the initial $s$ - points out a non Phrygian origin. A very attractive etymology for this name is given by Gusmani (1980-1981, 21-27, see also Beekes' remarks 2003, 19 fn. 21), who suggested that it is derived from the Hitt. adj. šarku- / šargau- 'eminent, illustrious, powerful' (inherited from PIE * srk-(e)u- or *sork- $(e) u$-, according to Kloekhorst 2008, 734, and related to ToB särk- 'to surpass, to be better than' and Lat. sarcio 'to patch up to med').

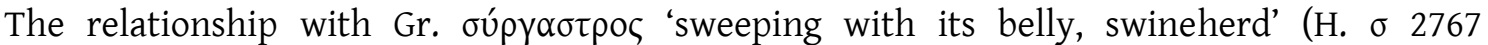

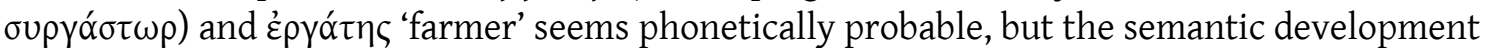
remains unclear.

CIPPh I, 272-273; Neumann 1988, 14; Orel 1997a, 361 and 459; EDG 19-20; Avram 2016b, 72-74.

$\sigma \omega \varsigma$ see $\sigma \varepsilon \mu o u v$.

$s[---](?)$

OPhr. $\quad s[---] \mathrm{G}-142$

The double $s$ in the sequence of this doubtful graffito, [---]avașs [---], suggests a word boundary after[---]avas. Nevertheless, in the absence of a more complete sequence, this beginning of a word remains unclear and no interpretation can be given. 


\section{$T(t)-T \tau$}

$t^{1}$ (mark)

OPhr. $t \mathrm{G}-337$ a

This isolated letter is incised on a cup where the sequence tu and a nonverbal mark were also inscribed. It is probably an abbreviation of the same name represented by the other abbreviated name $t u$. However, it could be a simple mark.

Brixhe 2002a, 91-92.

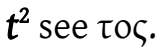

$t a^{1}(\mathrm{PN})$

OPhr. ta G-182

[-?-]ta NW-103

Both graffiti were incised on potsherds and G-182 is a complete graffito. In NW-103 it is possible that a letter has been lost at the beginning. In any case, it can be interpreted as a complete $a-$ stem monosyllabic PN in nom.sg. without the ending $-s$ or as an abbreviation of a PN such as tatas.

CIPPh I, 156; Bayun \& Orel 1988a, 199; Orel 1997a, 207 and 459; Brixhe 2002a, 13.

$[t] a^{2}, \tau \alpha$ see $\tau \circ \zeta$.

tadila[---] (noun)

OPhr. sg.nom.-acc. tadila[---]

This word occurs in an eroded cultic inscription on a rock (near B-01): [--- mata]r kubeley[a ---] | si tadila[---] | [---] bevdos key [---]. Although the segmentation is unclear and its ending is perhaps illegible, the presence of the pronoun si shows that it must be a neuter noun in sg.nom.acc. Its meaning and origin remain unknown. Brixhe and Vottéro $(2016,138)$ suggested a segmentation si tadi la[---].

Brixhe and Vottéro 2016, 138.

tadoy (PN)

OPhr. dt.sg. tadoy G-136

Although no parallel can be adduced, this is very likely a PN. In its context, an inscription engraved on a small alabaster bird of prey which reads tadoy iman bag? ${ }^{\text {un }}$, it is clearly the recipient of the object (bagun) given by a man called iman.

CIPPh I, 124-125.

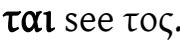

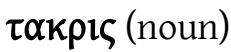

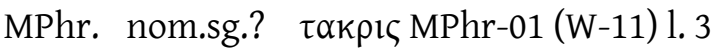

Perhaps an $i$-stem noun in the nom.sg. or, less probably, in the acc.pl. The obscure context

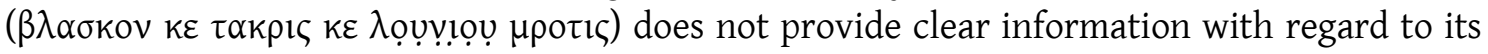
meaning.

Brixhe 2004a, 19.

$\tan , \tau \propto v$ see $\tau o \varsigma$. 
tanarị..[---] (?)

OPhr. tanari...----] HP-02

This word, like others read in the dubious inscription from Kocagür (near Parion), has no parallel. Like the rest of the text, it is incomplete and obscure. In addition, the segmentation is not clear, since the initial ta could be the pronoun attested in other inscriptions, as Brixhe and Keleş suggested (2011, 157-158).

Brixhe \& Keleș 2011, 157-158.

${ }^{\dagger}$ tanegertoy see tan \& egertoy.

tariyois (noun?)

OPhr. ac.pl? tariyois B-06

A very unclear sequence which could be also segmented as emetetariyois. The ending -ois could be interpreted as a pl.dat. (<PIE*-ois) or pl.acc. (<PIE*-ons, preferred here), according to Brixhe. Consequently, it could be a noun. The context, however, does not offer clear information. Brixhe 1996, 134; Orel 1997a, 153; Brixhe 2004a, 72.

${ }^{\dagger}$ tata see tataniyen.

\section{[-?-]tatae? $[. . ?](\mathrm{PN})$}

OPhr. [-?-]tatae? $\left[. .{ }^{?}\right] \mathrm{W}-11$

This is probably an $a$-stem PN in the nominative, a variant of atas or tates. This badly preserved inscription is read on a step monument with a possible idol: [.?]y[?]agaua | [-?-]tatae? [..?] | [-?-]e[.].

Brixhe \& Sivas 2002, 107-108.

tataniyen? $(\mathrm{PN})$

OPhr. nom.sg. tataniyen? $\mathrm{K}-01 \mathrm{VI}-\mathrm{VII} \mathrm{b}$

Although Brixhe (on tataniyen in Brixhe \& Summers 2006, 127) offered the segmentation tata niye[.] edaes, only space for one letter remains after niye[, and in the light of ataniyen in W-01c it is very likely that it must be read as tataniyen. Indeed, this ny fits very well with the remaining part of a vertical sign. Consequently, this word is a mere variant of ataniyen, as tatas is of atas. As in the case of ataniyen, it is preferable to understand this word as an anthroponym in the nominative, although its ending is expected to be -an in the light of iman, imenos. So, we have a sequence tataniyen? e daes which means 'Tataniyes made/put (it)'.

Brixhe \& Summers 2006, 126-128; Draycott \& Summers 2008, 68-69.

tatas (PN)

OPhr. nom.sg. tatas G-04

nom.sg. tates G-122; [t] ?ates G-148?

It is very likely that tatas is an $a$-stem Lallname PN in nom. with the ending -s, a mere variant of atas or tates. Nevertheless, the inscription in which it is read is badly damaged and far from clear. Ophr. tates is a variant in -e. Both graffiti in which it is read are isolated names incised on potsherds. However, in G-148 it is doubtful whether the first $t$ was present as in G-112, hence it could be the PN ates attested in M-01a. In any case, it is a very common type of PN across the whole of Anatolia (see KPN 494-498 § 1517-1 - 1517-6)

Neroznak 1978, 97, 98 and 108; CIPPh I, 90, 114 and 134; Bayun \& Orel 1988a, 199; Orel 1997a, 178 and 460.

tates see tatas. 
$\tau \varepsilon(?)$

OPhr. $\tau \varepsilon 43.1$ (69)?, $\tau \varepsilon 16.1$ (116) 1. 13 ?

Despite the similarity with Gr. $\tau \varepsilon$ 'and', it cannot represent this conj. because it is well attested in Phr. as ke, key and $k \varepsilon$. Even the existence of this segmentation is doubtful, since it only occurs in two problematic texts. Indeed, in 43.1 (69) the reading and segmentation $\varepsilon 1|\rho o 1 ~ \tau \varepsilon \alpha \lambda \varepsilon v \pi| \alpha \tau n \zeta$ is far from being clear and in 16.1 (116) it was probably followed by one or two letters (Brixhe

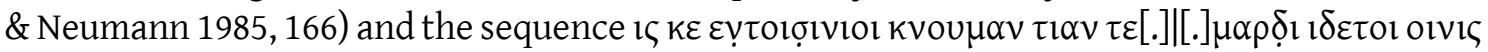
remains obscure, it could be an unknown longer word.

Brixhe \& Neumann 1985, 166.

$\tau \varepsilon \alpha \mu \alpha \varsigma$ see $\tau \imath \alpha \mu \alpha \varsigma$.

tedatoy and tedat[---] see $\tau 0 \varsigma$ and $\alpha \delta \delta \alpha \kappa \varepsilon \tau$.

$t^{?}$ eies see geies.

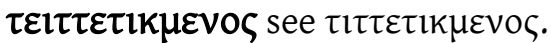

tevano....[-?-] (?)

OPhr. tevano....[-?-] M-05

This word follows an anthroponym qualified by mekas: apelan uac. mekas tevano[---]. However, its nature remains unclear, as do its segmentation and reading. Haas $(1960,28)$, in his questionable reading (Morante Mediavilla 2006, 328-329), considered it an anthroponym read as Evanos. Lubotsky $(1988,14)$, on the other hand, suggested that the first element $t$ could be the known particle, so t=evanọ̣. However, the last 〈S〉 does not fit the trace of a letter there (CIPPh I, 25). Orel (1997a, 28 and 461) understood this word to be an $a$-stem meaning 'cultic object', but since this inscription is read on a "broken" façade (Berndt-Ersöz 2006, 235), his explanation is unlikely. Another problem is that we do not know the length of the inscription after the last traces. Consequently, it remains unclear.

Haas 1960, 28; CIPPh I, 25; Bayun \& Orel 1988a, 180; Lubotsky 1988, 14; Orel 1997a, 28 and 461; Berndt-Ersöz 2006, 78; Morante Mediavilla 2006, 328-329.

tekmor (noun) 'sign, omen'

OPhr. sg.nom.-acc. tekmor P-04 a; [t]ekmọ [r] B-05, 1. 1?

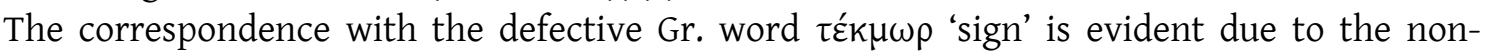
distinction between long and short vowels in the Phrygian alphabet. The etymology of the Gr.

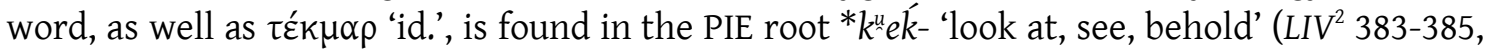
IEW 638-639; see specific morphological details and discussion in Nussbaum 2014). Consequently, because it is known that ${ }^{*} k^{u} e$ becomes $k e$ in Phr. it must be considered a Gr. borrowing. In P-04 this noun occurs in a clear curse, probably in its apodosis. However, the sequence is not clear due to the lack of parallels and the existence of several gaps: ios ni akenan egeseti okirterko[---] tekmor ot[---]seti vebru. It probably works as the direct object. In B-05, the presence of this word is debated. While Neumann $(1997,20)$ argued that the sequence ]ekmo [ fits with [t]ekmo [r] or $\delta \varepsilon \kappa \mu o u v \tau \alpha \eta \varsigma$, Brixhe $(2004 \mathrm{a}, 53)$ read dekm[---].

Lubotsky 1988, 13; Neumann 1997, 20; Orel 1997a, 296 and 460; Brixhe 2004a, 53.

tel'ẹmi (noun?)

OPhr. tel'ẹmi B-01, 1. 4

The dubious letter could be also read as $\langle y\rangle$, but $\langle 1\rangle$ is the more probable according to CIPPh (I, 65). This unclear word occurs in a imprecation and, due to its position, seems to agree with the 
neuter indefinite pronoun kin in the sg.acc. (Lubotsky 1993b, 97), despite the fact that this ending is somewhat unusual: yos tivo [t]a spereta ayni kin te[l]emi |[..]toyo[.]is [.]erktevoys ekey da[b]ati. That is why Orel (1997a, 460) suggested restoring telemi[n], but no trace can be observed. Moreover, since in this inscription the end of a line always coincides with a word boundary, according to Lubotsky $(1933 b, 94)$, the presence of an ending in the following line is not expected. Finally, its meaning and etymology remain unclear. Orel (1997a, 143 and 460) gave an alternative proposal to his previous one (Bayun \& Orel 1988a, 188, where it is considered a loanword from Gr. $\theta \alpha \lambda \alpha$ $\mu \eta$ 'cave, burial chamber'), comparing it with Gr. $\tau \varepsilon \lambda \alpha \mu \omega$ ' 'broad strap or band for bearing or supporting anything'. Nevertheless, the Phr. word, allegedly related to Gr. $\tau \alpha \lambda \alpha^{\alpha} \sigma \sigma \alpha 1$ 'to endure, tolerate', does not fit with the laryngeal of the PIE root *telh ${ }^{-}$'bear, endure' (LIV² 622-623, IEW 1060-1061).

CIPPh I, 65; Lubotsky 1993b, 97 and 143; Orel 1997a, 143 and 460.

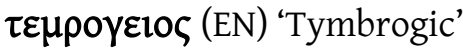

NPhr. masc.nom.sg. $\tau \varepsilon \mu \rho \circ \varepsilon \mid$ to 1.1 (48)

An o-stem masculine adj. which agrees with the DN M $\alpha$ in the nominative. In the sentence

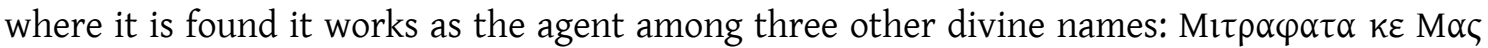

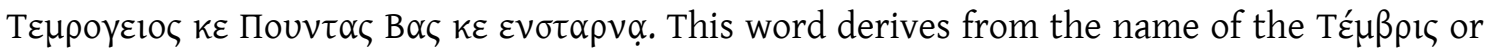

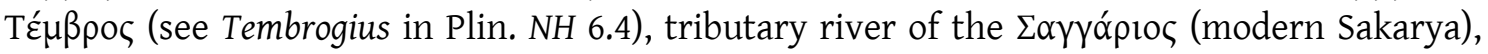
through the common suffix -eio-. Note that river cults are quite abundant in Greco-Roman Anatolia (also in Dorylaion, where this inscription was found; see Parker 2016).

von Prott 1898, 363; Lubotsky 1997, 122; Orel 1997a, 100 and 460.

tesan (noun?)

OPhr. ac.sg. tesan $\mathrm{T}-02 \mathrm{~b}$

This word, which only appears in a fragmented stele from Tyana, is bordered by the interpunction and is followed by $a \uparrow$ ion which seems to agree with it: [---]tumida : memeuis : [---]|[---]a !esan $\vdots a \uparrow i o n \vdots v[---] \mid[---]$ oitumen $\vdots$ mida $[---]$. Since this last word has been interpreted as an adjective, tesan has been considered a masculine noun in the acc. (Brixhe 1991, 42). On its meaning, Orel (1997a, 310 and 461) suggested a borrowing from the Lyd. taśẽn 'column' (40, see Payne \& Sasseville 2016, 76). On the other hand, according to Brixhe $(1991,42) a \uparrow$ ion could also be interpreted as a noun and, if this is the case, tesan should be considered an adj. or an acc. pronominal sequence $t=e s a n$, parallel to esai=t. However, in all clear occurrences of such a sequence the clitic particle follows the pronoun: esai=t, ses $=t$, sin=t and $s i=t$. Consequently, the word remains unexplained.

Brixhe 1991, 42; Orel 1997a, 310 and 461.

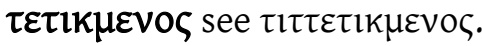

teu[-?-] (PN)

OPhr. teu[-?-] G-340

This graffito incised on a potsherd was perhaps followed by more letters, but no trace remains after the last letter. Although no parallel can be adduced here, according to Brixhe (2002a, 95) it is very likely to be a PN, perhaps an abbreviation.

Brixhe 2002a, 94-95.

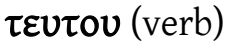

NPhr. 3sg.imp.act. $\quad \tau \varepsilon \cup \tau$ เou $62.2(33), 1.6 ; 62.5(36), 1.9-10$

? $\quad \tau \varepsilon \cup \tau \omega \sigma \mathrm{l} 16.1(116), 1.8$

The word $\tau \varepsilon \cup \tau$ - has been interpreted as a Galatian loanword. Indeed, the two occurrences of

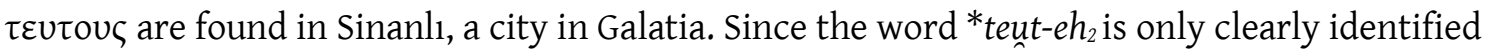


in some IE western branches (Italic, Celtic, Gm. and Baltic), it has been considered a borrowing from an unknown European language (EDG 461-465). However, it must be said that the Celtic element teuto- in Galatian shifted to touto- in the light of the tribal names Ambitoutus (near Gordion, according to Plin. HN 5.146) and Toutobodiaci (associated with Tectosages, according to Plin. HN 5.146) and consequently the Phrygian word may not have this origin. Moreover, the morphology of the word presents some problems. Firstly, both occurrences of $\tau \varepsilon \cup \tau o u \varsigma$, as its traditionally segmented, are in the same sentence, an apodosis of a curse: $\alpha v \tau \circ \varsigma \kappa \varepsilon$ ov $\alpha$ kopok $\alpha$

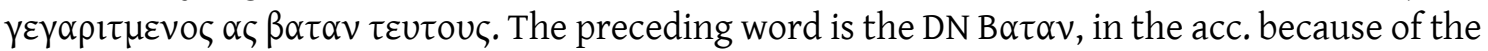
preposition $\alpha$. However, $\tau \varepsilon \cup \tau o u \varsigma$ is not an acc. and there is no verb in this apodosis. In such a scenario, the easiest explanation is to consider it a verb in 3sg.imp.act. $\tau \varepsilon v \tau o u$ (as suggested in

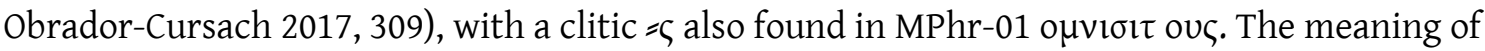
this verb and its origin are still unknown. Also unclear is the form $\tau \varepsilon \cup \tau \omega \sigma \mathrm{l}$, considered an ostem noun in pl.dat. by Brixhe and Neumann $(1985,177$, see $\zeta \varepsilon \mu \varepsilon \lambda \omega \sigma l$ instead of common $\zeta \varepsilon \mu \varepsilon \lambda \omega \varsigma)$, which seems to share the same root.

Brixhe \& Neumann 1985, 177; Bayun \& Orel 1988b, 156; Orel 1997a, 253 and 461; Ligorio \& Lubotsky 2013, 194; ObradorCursach 2017, 308-309.

$\tau \varepsilon \cup \tau \omega \sigma \mathrm{l}$ see $\tau \varepsilon \cup \tau o u \varsigma$.

ti and $\tau \imath^{1}$ see $\tau$ เo .

$\tau \imath^{2}$ see $\tau \imath \varepsilon$.

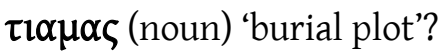

NPhr. dt.sg. $\quad \tau \varepsilon \alpha \mu \alpha 15.1(120), 1.2$

dt.sg. $\quad \tau \varepsilon \alpha \mu \alpha \varsigma$ 7.3 (14) 1. 8-9, 10.1 (112) 1. 7, 21.2 (43) 1. 3-4?, 25.1 (115) 1.2

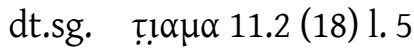

dt.sg. $\quad \tau \imath \alpha \mu \alpha \varsigma 9.1$ (87) 1. 2-3

A clear $a$-stem fem. noun. Commonly, some occurrences are quoted as $\alpha \tau \varepsilon \alpha \mu \alpha \mid \varsigma$, however the duplicity of forms beginning with or without $\alpha$ - has been well explained through the identification of $\alpha$ as the preposition $\alpha \delta$ also present as a preverb in $\alpha \delta \delta \alpha \kappa \varepsilon \tau$ (Brixhe \& DrewBear 1997, 89), the common verb of the protasis in which $\tau \varepsilon / 1 \alpha \mu \alpha-$ mainly occurs. On the other

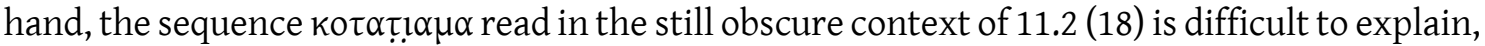

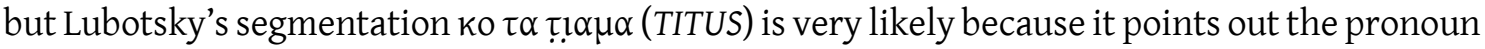

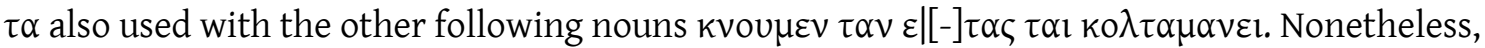
the form ko remains unclear. Perhaps it is better to analyse it as $k=0(\tau)$, where $k$ stands for $k \varepsilon$ apostrophed before a vowel and o $(\tau)$ is a phonetic variant of $\alpha \tau$, whose $-\tau$, geminated with the one in the pronoun $\tau \alpha$, has been simplified. If this were the case, $\tau \alpha \tau 1 \alpha \mu \alpha$ would stand in the dat. and would have dropped the final -1 of its ending $-\alpha 1$, as in $\mu \alpha v \kappa \alpha, 1$. 9. As with other $a-$ stems, the dative and gen. endings occur interchangeably for phonetic reasons. Finally, the hesitation $e / i$ is known in other Phrygian words (e.g. $\delta \varepsilon \omega \varsigma / \delta i \omega \varsigma)$ and has been explained as an effect of hiatic (Brixhe 2008, 75) or pretonic position (Lubotsky). Regarding its meaning, all occurrences show that it must be a component of the tombs because of its position in the

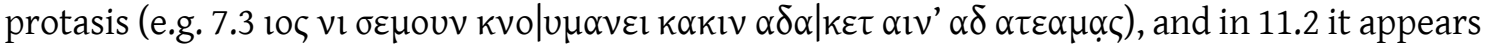

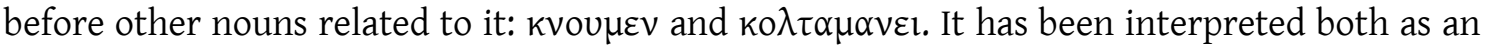
inherited word equated with Gr. $\sigma \tilde{\eta} \mu \alpha$ 'sign, mark, token' and as a borrowing from CLuw. tiiamm(i)- 'earth' by Orel 1997a, 463. Nevertheless, the first possibility is very unlikely, even more so if it is equated, despite the semantic difficulties, with Skt. dhyāman- 'thought', because the consequent PIE root ${ }^{*} d^{h}{ }^{i e h}{ }_{2}$ - does not fit with Phrygian tia-. On the other hand, the Luw. form tiiamm(i)- 'earth', which goes back to PIE *dǵh -em- (NIL 86-99, some phonetic details are 
still unclear, see Kloerkhost 2008, 860-861) is actually an attractive proposal. If this etymology is accepted, it may refer to the portion of earth sacred to the tomb, i.e. the burial plot, as is also the case of the Gr. borrowing kopo-.

Brixhe \& Drew-Bear 1997, 89; Orel 1997a, 463.

$\tau \imath \propto \nu$ see $\tau 1 \varepsilon$.

tias (ethnic?) 'from Tios'?

OPhr. sg.nom.masc. tlias (G-249)

Read on a weight, it qualifies the word seVel 'weight'. In the light of parallels such as šql hmt 'Shekel of Hamath', šql sydn 'Shekel of Sidon' or šql qrqr 'Shekel of Qarqar' (see Riis \& Buhl 1990

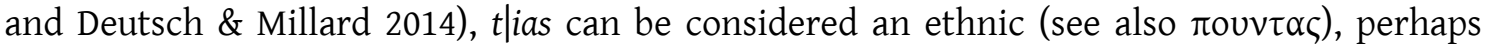
related to the Bithynian city Tíciov, Tíos, Tńlov (KON 618-619 § 1337), named after Ti- (the Phrygian Zeus) according to FGrH 699 F 9 of Demosthenes' Bithynian History (St.Byz s.u. Tíos):

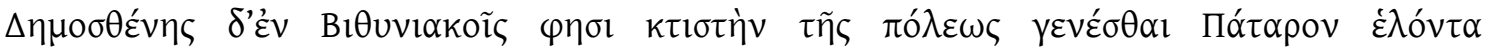

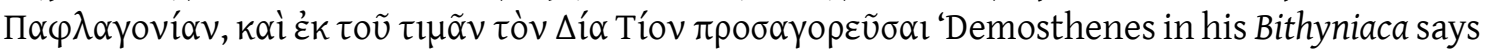
that the city's founder was Pataros, who conquered Paphlagonia, and that he called it Tios after Zeus worship'. Nevertheless, other unrecorded cities could be also named after this central Phrygian god, and the suggested identification is a mere possibility.

tib (PN)

OPhr. tib G-158

Abbreviation of a PN incised on a potsherd. The development of this abbreviation remains unknown because of the lack of parallels.

CIPPh I, 141-142; Roller 1987a, 51; Orel 1997a, 197 and 461.

$\tau \imath \gamma \gamma \varepsilon \gamma \alpha \rho \imath \tau \mu \varepsilon v o \varsigma$ see $\gamma \varepsilon \gamma \alpha \rho \imath \tau \mu \varepsilon \vee o \zeta$.

$\tau 1 \delta \rho \varepsilon \gamma \rho o u v$ (adj.) 'unenjoyable, innutribile'

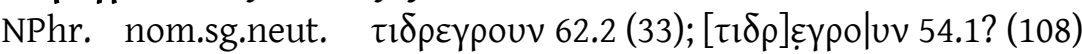

nom.sg.neut. $\tau 1 \delta \rho \varepsilon \rho o u v 53.1$ (76)

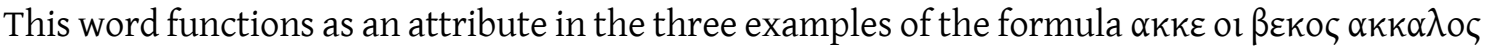
$\tau \imath \delta \rho \varepsilon \gamma \rho o u v ~ ' m a y ~ b r e a d ~ \alpha \kappa k \alpha \lambda$ os become $\tau$. for him'. Thus, it agrees with $\beta \varepsilon \kappa o \varsigma$ in the neuter sg.acc., so it is a thematic adj. and its endings go back to PIE *-on. It also presents the well-known prefix $\tau l^{-}<* d(u) i s-$. The form $\tau 1 \delta \rho \varepsilon \rho o u v$, if it is not an engraver's error for $\tau 1 \delta \rho \varepsilon \gamma \rho o u v$, perhaps reflects the difficulties of articulating consonant clusters in Phrygian. Its etymology remains

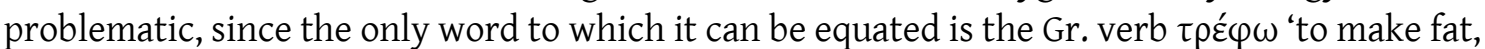
feed, bring up, care for', according to Haas (1966, 69 and 84) and Lubotsky (2004, 235-236). If we accept their hypothesis, and reject Beeke's Pre-Gr. etymology $(2010,1504-1506)$ for $\tau \rho \varepsilon ́ \varphi \omega$, both occurrences go back to a PIE form * $d^{\text {h }}$ reg $g^{\text {uh }}$-ro- whose labialised stop fits with the obscure Myc. adj. to-ro-qa (which modifies the term for 'oil'). However, these Gr. words call for a better explanation of their history and relation with other potential IE occurrences.

Haas 1966, 69 and 84; Panagl \& Kowal 1983, 187-188; Lubotsky 2004, 235-236.

$\tau \imath \delta \rho \varepsilon \rho o u v$ see $\tau \imath \delta \rho \varepsilon \gamma \rho \circ u v$. 
$\tau \boldsymbol{\tau} \boldsymbol{\varepsilon}(\mathrm{DN})$ 'Zeus'

OPhr. sg.dat. tiei NW-101 A II

NPhr. sg.dat. $\quad$ Il 9.1 (87), 38.1 (44), 39.1 (11), 42.1 (101), 44.3 (67), 47.1 (51), 49.3 (85), 50.1 (54), $51.1(80), 53.1$ (76), 53.2 (77), 54.1 (108), 56.1 (57), 58.1 (72), $59.4(106), 66.1$ (103)

sg.acc. $\quad \tau \iota \alpha \vee 2.2(130), 1.8 ; 7.1(99), 7.3(14), 16.1$ (116) l.13; 46.1 (53) 1. 9.

sg.dat. $\quad \tau i \varepsilon 3.1$ (97), 4.1 (2), 10.1 (112), 14.1 (73), 15.1 (120), 17.2 (3), 17.3 (7), 25.1 (115),

25.2 (126), 27.1 (92), 30.2 (68), 33.3 (127), 35.1 (25), 36.1 (26), 36.3 (94), 40.1 (12),

40.4 (102), 41.1 (45), $44.1(61), 44.2$ (70), 52.1 (75), 55.1 (56), $61.1(100), 63.1(123)$

sg.dat. $\quad \operatorname{\tau in} 8.1(86), 18.3(6), 20.3(62), 29.1$ (114), 30.1 (39), 45.1 (65)

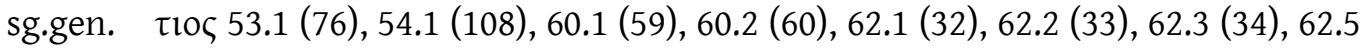

(36), $62.6(105)$

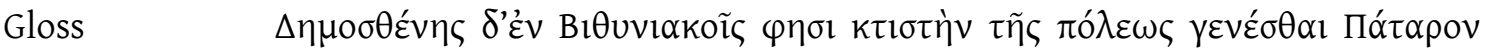

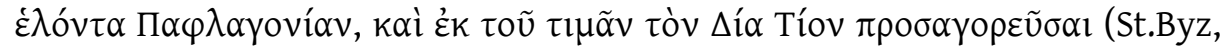
Bithyniaca).

This $i$-stem DN, equated with Gr. Zzúc and based on the PIE root *di-éu- 'sky' (NIL 70-71), was identified by Lubotsky (2004, 229-230, improving his previous proposals). Most instances occur in the common imprecative apodosis as the agent of the curse. The form $\tau \imath \alpha v$ is its acc. and goes back to PIE * diếm, parallel Gr. forms Z $\tilde{\eta} v, \Delta i ́ \alpha, \Delta$ ífo. In all instances, it is governed by the preposition $\alpha \zeta$ in 7.1, 7.3 and 46.1. In 2.2 the uses of the accusatives seem to be related to the

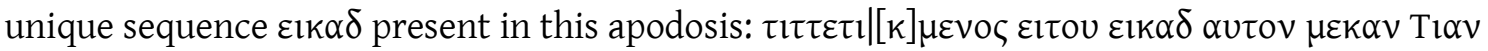
'let him become accursed by? the same great Zeus'. The last occurrence, 45.1, is in another possible imprecation but the context remains obscure and the reason for the presence of the

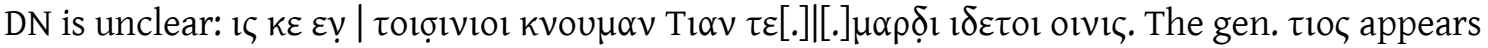

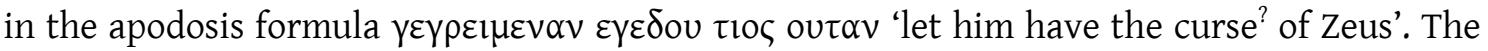

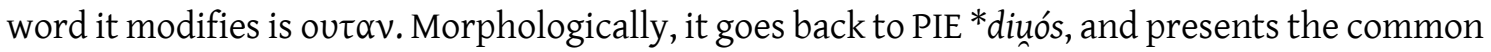
drop of *u before the vowel 0 . Compare with Gr. $\Delta$ lós, $\Delta$ lfóc. The other occurrences, tiei, $\tau 1, \tau 1 \varepsilon$ and $\tau ı \eta$, are its dat. case, equated to Gr. $\Delta \mathfrak{\imath}, \Delta \mathfrak{i}$ fí, reflecting the PIE form *diuéi. Here, the drop of * $u$ has been explained as a levelling from the other cases. With the exception of the OPhr. occurrence, it appears in the same context as the acc., i.e. in the apodosis. The difference is that it is governed by the preposition $\alpha \delta / \alpha \tau$, whose dental geminates before that of $\mathrm{DN}$ and is often simplified. On occasion this dative is used without the preposition, but the meaning is clearly the same. The different graphemes are due to phonetic and graphical reasons. According to Lubotsky $(1997,126$, fn. 23), the form $\tau 1$ only occurs before vowels while $\tau i \eta$ only occurs before consonants. By contrast, $\tau 1 \varepsilon$ occurs in both instances, although it is less attested before vowels (only five times). Regarding the only OPhr. form, the dat. tiei appears in the obscure object governed by the preposition ad: deVeti | to Ti a tiei. It is possible that this DN can be found in words such as tiveia and the unclear sequences tiv[.|.?]n and tivo, but the readings are not clear enough for this to be confrmed.

Heubeck 1987, 70-73; Lubotsky 1989a; Brixhe 1997, 42-47; Lubotsky 1997, 126, fn. 23; Lubotsky 1998; Brixhe 2002a, 7; Lubotsky 2004, 229-230; Matzinger 2006, 203.

tiei see $\tau 1 \varepsilon$.

tiveia (PN?)

OPhr. sg.nom. tiveia G-183a

This graffito, read on the bottom of a bowl, is composed of two words: tiveia imeneia. Despite its simplicity, the circular disposition of the text does not allow tiveia to be conclusively identified as the first element, although its letters are bigger than those of imeneia. Some scholars have considered that these words refer to the object itself. However, it is more likely to be an anthroponym, in the light of the common practise in this type of text. Consequently, tiveia is 
considered an $a$-stem fem. personal name in nom. Lubotsky $(2004,230)$ suggested that it is perhaps related to the DN ti- 'Zeus'. In any case, it is very likely related to PNs read in Gr.

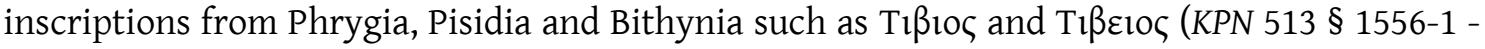
1556-2, also borne by Phr. slaves in Greece, see e.g. the slaves list Chios 62). Consequently, tiveia imeneia is a compound anthroponymic formula (personal name + patronymic? 'Tiveia (the

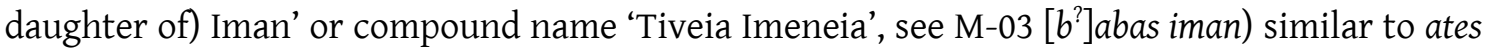
arkiaevais.

CIPPh I, 156-157; Innocente 1997, 39 and 40; Orel 1997a, 463; Brixhe 2004a, 83; Lubotsky 2004, 230; Wittke 2004, 201.

tivo (?)

OPhr. tivo B-01, 1. 4

No parallel to this sequence can be adduced. It occurs in a possible imprecative: yos tivo [t]a spereta ayni kin te[l]emi. The relation with the DN ti- is suggested by Lubotsky $(2004,230)$ and Brixhe (2004a, 83).

Brixhe 2004a, 83; Lubotsky 1993, 96-97.

tiv[.|.']n (noun?)

OPhr. sg.acc. tiv[.|.?]n B-07, 1. 2-3

Since this is the first element in a sequence of nouns in sg.acc. linked by the copulative conj. ke, it is very likely another noun in the acc.: yos tiv[.|.?]n ke devun $k(e)$ umnotan ordoineten. The gap of one or two letters complicates the identification of this hapax. Lubotsky $(2004,230)$ and Brixhe (2004a, 83) suggested that it may be related to the DN ti- 'Zeus', but this is a mere hypothesis, as in the case of tivo.

Brixhe 2004a, 83; Lubotsky 2004, 230.

$\tau i \eta$ see $\tau 1 \varepsilon$.

tinu. [---] (PN)

OPhr. tinu. [---] G-190

In this graffito incised on a potsherd the letter $\langle\mathrm{u}\rangle$ is merged with « $\mathrm{n}$, after which no more letters can be read, only traces before the broken border. Despite the lack of parallels, it seems to be an abbreviated PN. The reading tinui given by Bayun and Orel $(1988 \mathrm{a}, 199)$ is far from being corroborated.

CIPPh I, 160-161; Orel 1997a, 201.

$\tau 10 \zeta$ see $\tau 1 \varepsilon$.

$\operatorname{tir}(\mathrm{PN} ?)$

OPhr. tir or tr NW-111

According to Brixhe's reading (2002a, 18-19), it is unclear whether this graffito incised on a potsherd is composed of two or three letters. However, it is very likely an abbreviation of a PN, despite the lack of parallels.

Brixhe 2002a, 18-19.

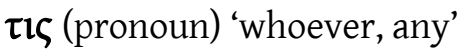

NPhr. neut.sg.nom.-acc. $\tau 130.1(39)$

masc.nom. $\quad$ tı $28.1(71)$

This sequence, read only once, presents some problems. First of all, according to the first editor (Calder 1913,101), who was the only person to see it, "there is a space, due apparently to an ancient fault in the Stone, between the first and second letters" where "no certain trace of a 
letter could be made out in this space". Secondly, it occurs at the beginning of a imprecative

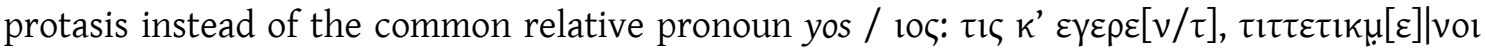
ivvou. Consequently, it is very likely used as a relative pronoun. Note, however, that $\tau 1 \zeta$ is expected to be pl. in the light of the apodosis but it is morphologically a sg. Thirdly, there appears to be a clear related to the Gr. indefinite pronoun $\tau \iota \varsigma, \tau l$, which sometimes functions as the relative. However, it goes back to PIE * $k^{u} i s$, which in Phrygian is attested in the neuter kIv, showing the Phrygian development $*^{*}{ }^{u}->k$ - consistent with other occurrences. Consequently, it must be a Gr. borrowing.

tișị̦ (PN)

OPhr. sg.nom. tișị̦ W-102

This single word incised on a potsherd is very likely an $i$-stem PN. However, no parallel can be adduced.

Brixhe \& Sivas 2003, 66.

tiyes (PN)

OPhr. sg.nom. tiyes M-04

The inscription in which this name is read bears the title modrovanak 'the King of Modro'. Some time ago Tiyes was interpreted as the nominative of the DN ti-by Lubotsky $(1988,12 \mathrm{fn}$. 3), but he later showed that this was incorrect $(2004,229$ fn. 2). However, this mistake sometimes appears in the work of other scholars. As Orel $(1997 a, 26)$ argued, the origin of this name must be Anatolian in the light of occurrences such as Hitt. Tiiia- and Gr. Tinos (also found in Phrygia) and Tios, from Pisidia (KPN 513-514 § 1558).

Neroznak 1978, 75; CIPPh I, 23; Lubotsky 1988, 12 fn. 3; Neumann 1988, 15; Inocente 1997, 38; Orel 1997a, 26 and 463; Brixhe 2002a, 61; Lubotsky 2004, 229 fn. 2; Wittke 2004, 201.

${ }^{\dagger} \tau 1 \eta 10 v$ see $\mu \rho \circ \tau 1 \varsigma$ \& yos.

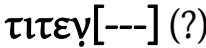

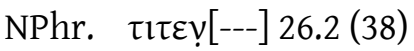

This word begins a sentence after the common NPhr. imprecative formula. However, this part of the inscription, $\tau ı \tau \varepsilon y[].[$ circa 9 ] $ı$, was badly damaged when Ramsay copied it $(1905,100)$ and no parallel has been found. Consequently, this word remains unclear, despite the fact that Orel considered it a possible $i$-stem word in sg.nom.

Orel 1997a, 92 and 463.

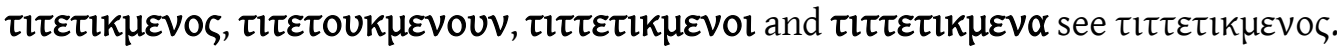

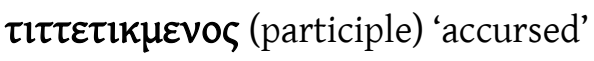

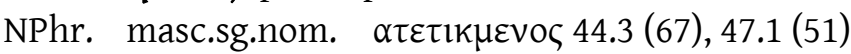

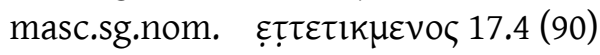

masc.sg.nom. $\quad \theta_{1} \tau[\tau] \varepsilon \tau \iota \kappa \mu \varepsilon v o ̣[\zeta] 45.1(65)$

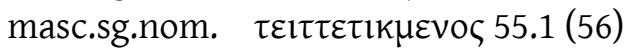

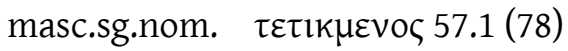

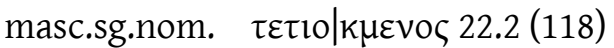

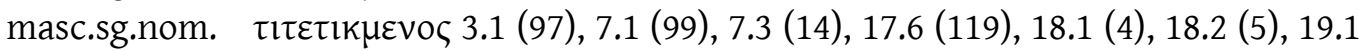

(96), 20.2 (128), 30.2 (68), 32.1 (93), 33.3 (127), $36.3(94), 40.4$ (102), 43.1

(69), 44.1 (61), 58.1 (72), 59.4 (106), 61.1 (100), 64.1 (81), 65.1 (20), 65.4

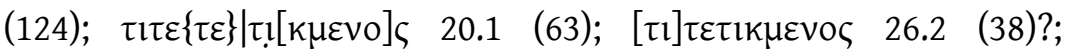




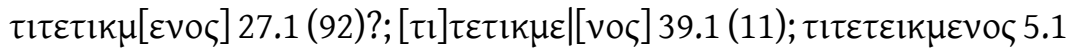

(19)

\begin{tabular}{|c|c|}
\hline pl.gen. & 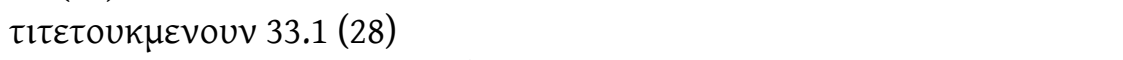 \\
\hline masc.pl.nom. & 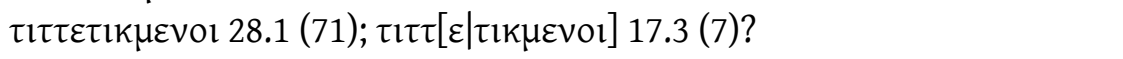 \\
\hline neut.pl.nom. & $\tau \iota \tau \tau \varepsilon \tau 1 \kappa \mu \varepsilon v \alpha 40.1(12)$ \\
\hline masc.sg.nom. & 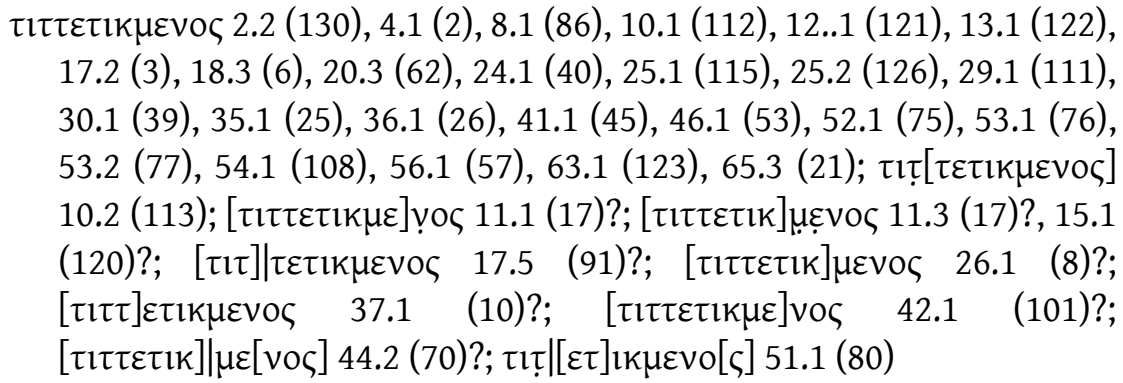 \\
\hline
\end{tabular}

All occurrences are variants of the same basic form $\tau \varepsilon \tau 1 k \mu \varepsilon v o-$, which only occurs in the

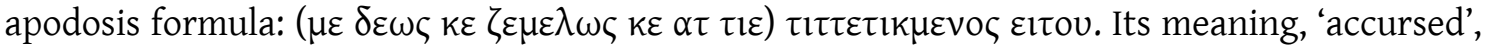
has been established since the earliest studies of Phrygian. Formally, it is the reduplicated past participle ( $\left.{ }^{*}-m h_{1} n o-\right)$ of the root - $\tau$ ik-. The origin of this root has been identified by Lubotsky $(1998,420$, fn. 22 and 2004, 235) in the PIE verbal root *deik- 'to point, indicate' (LIV 108-109,

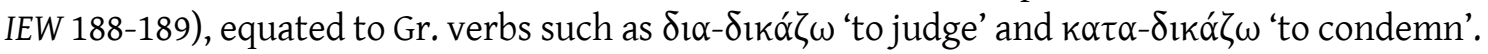
Most of the forms present the preverb $\tau_{1}(\tau)-<$ PIE $* d(u) i s-$. The last original ${ }^{*}-s$ of this preverb is the origin of the dental geminated sequence $-\tau \tau$ - through an assimilation, which often is later

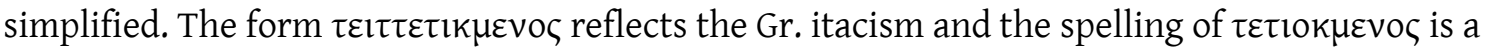

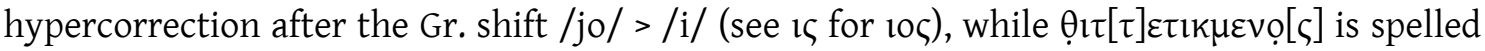
with a hypercorrected theta. Also, the preverb $\alpha \tau$ is present in two occurrences $(44.3,47.1)$ instead of $\tau 1(\tau)$-, although the last voiceless dental has been simplified after the appearance of

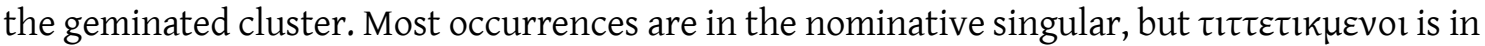

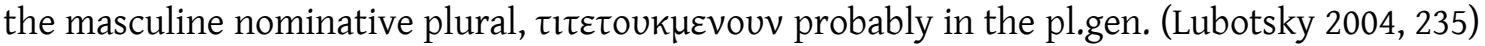
and $\tau ı \tau \tau \varepsilon \tau \iota k \mu \varepsilon v \alpha$ in the neuter nominative plural.

Lubotsky 1998, 420, fn. 22; Lubotsky 2004, 235; Sowa 2007a, 89-90.

tvemes (?)

OPhr. tvemes M-01dI

The only occurrence of this word is in the text midas $\mid s=$ materan $\mid$ tvemes eneparkes, in which only verb is the last word. Its agent must be midas and its direct object s=materan. The word tvemes could be a pl.acc. There is no connector between materan and this word. It may be an $e$-stem PI (without parallels) in the nominative but its relation with midas is strange and has led to suggestions that we are in fact dealing with two sentences. In any case, the question remains open.

CIPPh I, 14; Bayun \& Orel 1988a, 178; Orel 1997a, 17-18.

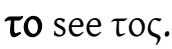

$\tau \circ \alpha(?)$

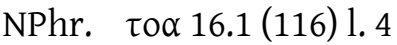

This is an unparalleled sequence which appears after a verb and before a preposition: $\rho 1 \delta \imath \tau \imath \tau \alpha l$

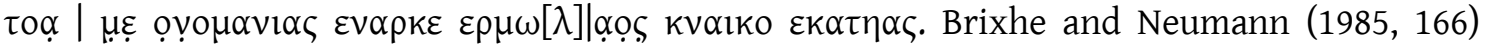

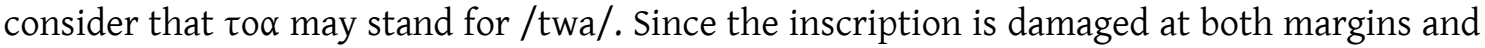
on other lines some letters are lost, it may have been followed by another letter. However, only iota fits there (Brixhe \& Neumann 1985, 173).

Brixhe \& Neumann 1985, 166 and 173. 
tovo see $\tau$

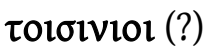

NPhr. Tololviol 16.1 (116)

This word is read in a sentence which closes the inscription and is very likely to be an

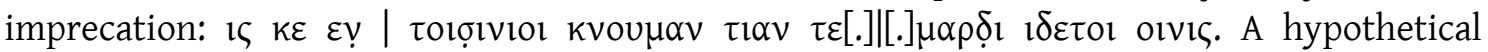

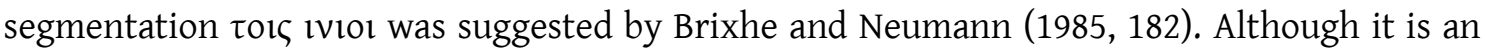
obscure sentence, $1 \mathrm{viol}$ is not expected to resemble the verbal forms $10 \mathrm{vio}[\mathrm{v}]$, 10vov or ivvov because they appears at the end of the apodosis, not at the beginning of the imprecation like iviol. Consequently, it remains unclear.

Brixhe \& Neumann 1985, 182-183.

tolos (PN?)

OPhr. sg.nom. tolos M-07

The whole remaining inscription consists of this isolated word. It looks like an o-stem anthroponym in the nominative, but no parallel can be adduced.

CIPPh I, 27; Neumann 1988, 15; Innocente 1997, 38; Orel 1997a, 30 and 464.

torvetun (verb) 'to cut wood'

OPhr. masc.sg.nom.pres.part.? torvetun B-05, l. 11

Hämmig $(2013,150$, fn. 52, see also Ligorio \& Lubotsky 2013, 185) suggested that torvetun probably derives from the PIE noun *doru- 'tree, wood', found, e.g., in Gr. Sópv 'wood, tree, spear', skt. däru 'wood', Hitt. tāru 'id.' and ToAB or 'id.'. Since the Gr. text of this inscription

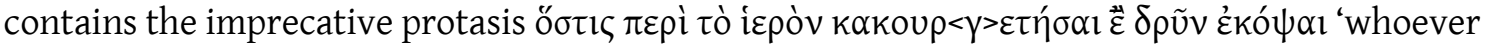
messes up towards the sanctuary or cuts a tree...' and is an excellent fit with the Phr. protasis of 1.11 tiv † ?imun inmeney asenan daket torvetun $\uparrow$ iray ayniy oy tubnuv, this proposal is very likely. Morphologically, it can be an o-stem noun in sg.acc. (Brixhe 2004a, 63) or, more likely on the basis of the syntax, a masc.sg.nom.pres.part. of a denominative verb derived from *doru-

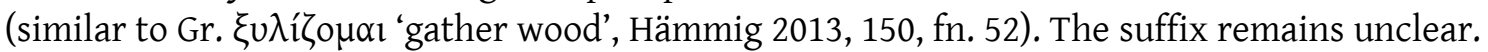
Compare its ending with kuryaneyon. On the prohibition of cutting trees in shrines, see the very interesting parallels in Epikrates' Testament 1. 74-76 $\left(2^{\text {nd }} \mathrm{c}\right.$. BC, from Yatağan, Mysia, Herrmann \& Polatkan 1969) and in the confession inscriptions from Lydia and Phrygia (such as de Hoz 1999, no. 61.23).

Brixhe 2004a, 63; Hämmig 2013, 150, fn. 52; Ligorio \& Lubotsky 2013, 185; Hämmig fthc. a.

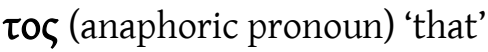

OPhr. masc.-neut.sg.gen. tovo G-02c; [t]ovo P-01?

fem.sg.acc. $\tan \mathrm{W}-01 \mathrm{c}$

neut.pl.nom.-acc. [t]a B-01

particle $\quad t$ B-05 $1.1 \& 1.2, \mathrm{~W}-01 \mathrm{~b}$

neut.sg.nom.-acc. ti B-05 1.1

NPhr. particle $\tau 53.1(76)$

masc.sg.nom. $\quad$ tos $17.2(3), 18.3(6), 19.2(129), 35.1(25), 43.1(69), 59.3(79), 66.1$ (103)

fem.sg.acc.

fem.sg.dt.

fem.sg.dat.

$\tau \alpha \vee 2.1$ (15) 1.1,11.2 (18) 1. 5, 16.1 (116) 1. 2, 37.2 (30)

neut.sg.dat.

$\tau \alpha 111.2$ (18), 16.1 (116) 1. 4; [ $\tau] \alpha 121.1$ (42)?

particle

$\tau \alpha 4.1(2), 11.2(18) 1.5$

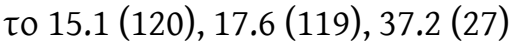

neut.sg.dat.

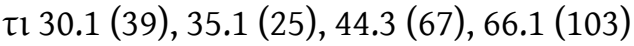

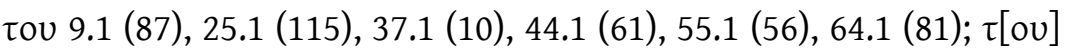
$30.1(39) ?$ 
This pronoun goes back to PIE anaphoric *to- (LIPP II, 779-799). Although most forms are morphologically clear, some need to be explained. The OPhr. tovo has been interpreted as gen. with an epenthetic - $v$-: PIE * toso > to.o. The presence of tovo in P-01 and P-04 $\mathrm{c}$ is highly doubtful. NPhr. $\tau$ ou can be explained as a developing of *tōi, whereas the forms $t, \tau$ and $t i, \tau l$ seem to fall outside the paradigm and are used as emphatic particles in a similar position to $s$, si: note that it strengthen the demonstrative pronoun in, e.g., esai=t and $\sigma \varepsilon \mu o u v=\tau$. The masc.sg.nom. $\tau$. $\zeta$ is always used as an anaphoric pronoun at the beginning of the imprecative apodosis: $10 \varsigma \mathrm{Vl}$... To vi... ('whoever..., this one...'). This usage is also possible in G-02 tovo 'of him', considered by Kloekhost to be the ending of the imprecative protasis (ios oporokitis | kakoioi tovo ! podaskai?), and $\mathrm{W}-01 \mathrm{c}$, where tan may refer to the represented matar (ataniyen $\vdots$ kuryaneyon $\vdots$ ta|n egertoy). However, this usage is not so clear in other occurrences. It often appears in agreement with

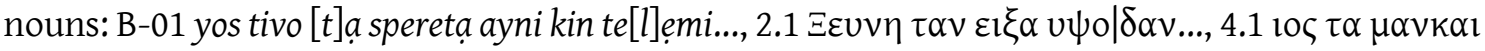

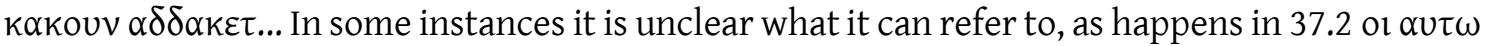

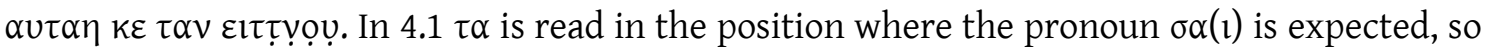

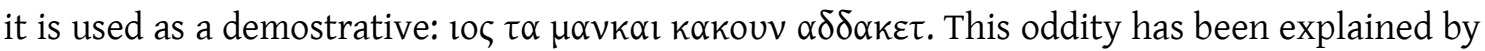
Lejeune $(1969 b, 296)$ and Brixhe $(1978 b, 7)$ as the influence of the Gr. article. The form to is a

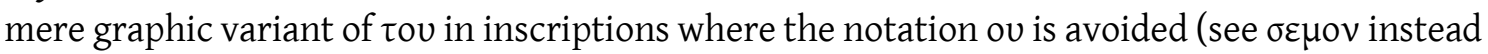
of $\sigma \varepsilon \mu o u v)$. Both forms perhaps function as a true article since they appear between a

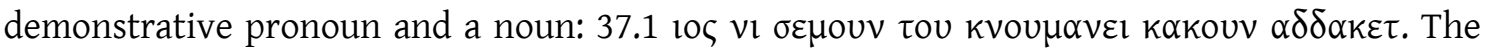

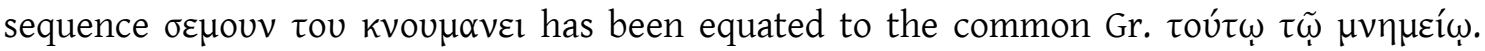

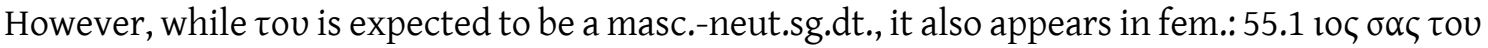

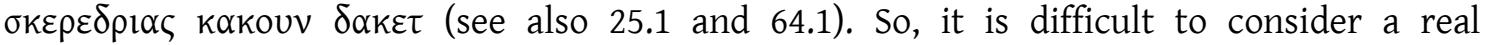
concordance. It is probably used as an indeclinable particle, like $t$ or $t i$. Indeed, in the light of this considerations, Brixhe $(1978 \mathrm{~b}, 21)$ defined $\tau \mathrm{l}$ and $\tau$ ov as two diferent particles whose purpose is to reinforce the demonstrative pronoun.

Gusmani 1958, 881; Lejeune 1969b, 296-27 and 299; Brixhe 1978a, 11-12; Brixhe 1978b, 7-8 and 21; Ligorio \& Lubotsky 2013, 190; Kloekhorst 2015, 114; LIPP II, 779-799.

\section{tosk[---] (?)}

OPhr. tosk[---] G-147

An incomplete graffito on a potsherd. This beginning of a word follows the well attested word mekas. Due to the loss of its ending and the lack of parallels, it remains unclear, although Bayun and Orel (1988a, 195 and Orel 1997a, 192) gave the segmentation mekas tos $k[---]$.

Bayun \& Orel 1988a, 195; Orel 1997a, 192.

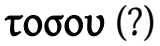

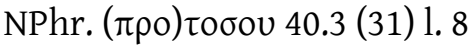

Anderson's drawing $(1898,121)$ suggests that after this text there were no more traces of letters. However, this cannot be corroborated. The word was preceded by $\pi \rho 0$. It is unclear if it was

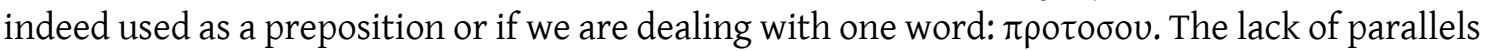
and the presence of gaps greatly complicate the interpretation of the last part of this inscription, where $\pi$ potooov is read. Kowal $(1984 b, 184)$ is right to reject Haas' identification $(1966,104)$ of a verb in this sequence. Moreover, Orel (1997a, 335 and 457) suggested a borrowing from or a word related to Gr. $\pi \rho \tilde{\omega} \tau \circ \varsigma$ 'first', but as a result of the last sequence ov is difficult to defend (it is true that an obscure ouv MPhr-01 is attested). In any case, this sequence remains unclear.

Kowal 1984b, 184; Orel 1997a, 335 and 457. 
totin (noun) 'offering'

OPhr. sg.acc. totin M-01f

The word totin is segmented by the interpunction used in this inscription. CIPPh (I, 17) suggested, with reservations, that it is perhaps a pronoun similar to Gaul. $\operatorname{sosin}(\mathrm{G}-153, \mathrm{~L}-13)<$ *so-sin, so Phrygian totin < *to-tin. On the other hand, Orel (1997a, 22 and 464) equated it to Skt.

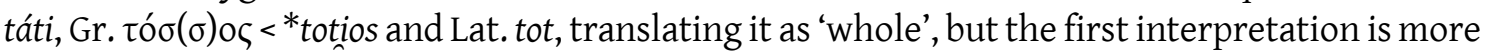
attractive. What is clear is that it is probably a word in the acc. and, consequently, the direct object of the sentence [--]as tuaveniy ae esuryoyoy totin edae [s]. It does not seem to agree with another word and, because of the presence of edaes, it perhaps refers to something related to the monument. Recently, Ligorio (2016) identified here the PIE word * $d h_{3}$-ti- 'gift' (NIL 61),

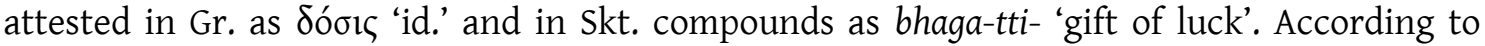
Ligorio, the sentence basically means '[---]as has put (it) as a gift'. Since the context is clearly religious, perhaps it is better translated as 'offering'.

CIPPh I, 17; Bayun \& Orel 1988a, 179; Orel 1997a, 22 and 464; Ligorio 2016.

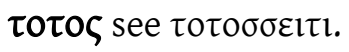

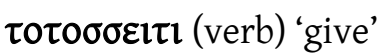

OPhr. 3sg.aor.act.ind.? etoves B-08

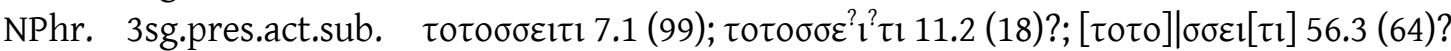
The segmentation of $\tau 0 \tau 0 \sigma \sigma \varepsilon l \tau l$ has been discussed because of the uncommon sequence - $\sigma \sigma-$. Although some scholars considered that it shows a word boundary (sometimes identifying

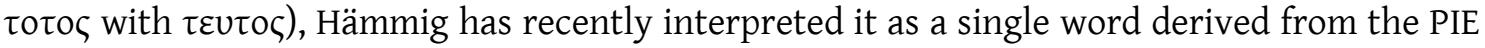
* deh $3^{-}$'to give' (LIV 105-106, IEW 223-225). Of course, this implies that it is a present reduplicated. However, a minor problem arises in the vocalisation of the reduplication, since something like PIE *dé-deh ${ }^{-}$(Vedic dádāti) $>$Phr. ${ }^{*} t e-t \overline{-}$ - would be expected in the light of $\delta \varepsilon \delta \alpha \sigma \sigma \mathrm{lvvı} 2.2$ (130). Hämmig also considered $-\sigma \sigma$ - the reflex of the PIE suffix ${ }^{*}$-sk-, although this is not at all clear (see $\S$ 4.2.2.1.1.2). In any case, it always occurs in imprecative apodosis: 7.1

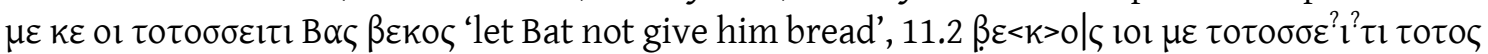

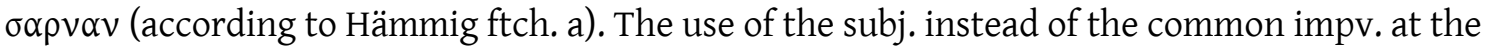
end of the imprecative apodosis is coherent with the presence of the prohibitive particle $\mu \varepsilon$. The OPhr. form is less clear. It occurs in the cultic inscription B-01: si bevdos adi..[..] kavarmoyo imroy edaes etoves niyo[y?]. Formerly, it was segmented as etovesniyo (see Lubotsky 1993b, 96; Bayun and Orel 1988a, 186-187 segmented etoves ni yo), but the comparison with epav'esniyoy in B-08 provides the word boundary, despite the lack of space here (is niyoy a clitic word?). Recently, Brixhe and Vottéro $(2016,137)$ reconsidered the possibility that we are dealing with a verb (as Haas 1969, 77 suggested before). As a working hypothesis, and in the light of NPhr.

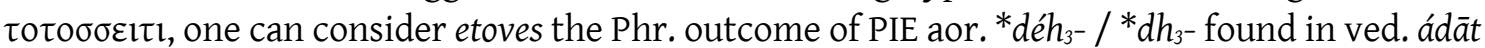
'(s)he gave', Gr. દ̌ $\delta \circ \mu \varepsilon v$ 'we gave', Lacon. ǩ $\delta o v$ 'I gave' (IG V(1) 1.B1), arm. et '(s)he gave', etc.). In that case, the glide $v$ can be explained as a mere antihiatic spelling between the root and the ending (compare with devos 'god' < *dhesós). In any case, the context is still obscure and it is difficult to corroborate this hypothesis.

Haas 1969, 77; Hämmig fthc. a; Brixhe and Vottéro 2016, 137.

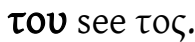

toTi (PN?)

OPhr. sg.nom. to Ti NW-101 A II

According to Brixhe, this word is perhaps an $i$-stem PN in nom. without ending $-s$. It is clearly the only word that can function as the agent of its sentence: deVeti toTi a tiei. However, no 
parallel can be adduced. The word present the strange letter T (n. $19 \mathrm{c}$ of CIPPh I, 282 catalogue), discussed in § 3.1.2.

Brixhe 2002a, 8.

tr see tir.

$\tau \rho \alpha[\ldots . . ..] \tau \eta[---]$ (noun?)

NPhr. $\tau \rho \alpha[\ldots . ..] \tau \eta[---] 21.1(42)$

Despite the fact that there are some gaps which cannot be restored due to the lack of parallels of this word and its context, it is probably a fem. noun with a meaning related to the tomb, because it occurs in an imprecative protasis after the pronoun $\sigma \alpha$. On the other hand, some scholars consider that the word is $\sigma \alpha \tau \rho \alpha[. ..] \tau \eta[---]$. Orel $(1997 a, 95)$ suggested a reconstruction in the light of Gr. $\tau \rho \alpha$ á $\varepsilon \zeta \alpha$ 'table', but it is an unfounded proposal without parallels.

Orel 1997a, 95 and 464.

tu (PN?)

OPhr. tu G-337 b

According to Brixhe (2002a, 91-92) this is a probable abbreviation of a PN. This graffito was incised on a ceramic vessel that also bears an isolated $t$ and a nonverbal mark.

Brixhe 2002a, 91-92.

tuaveniy (?)

OPhr. tuave/niy M-01f

A word delimited by interpunction. The final glide is raised because of the initial vowel of the following word: [---]as tuaveniy ae esuryoyoy totin edaẹ[s]. The nature and the function of the word remain obscure.

CIPPh I, 17.

tubetiv (verb) '?'

OPhr. 3sg.Subj.Pres tubetiv B-05 1.9

OPhr. 3pl.imperat. tubnuv B-05 1.10

Two variants of an obscure verb which are read in two different but equivalent imprecative protases (following Hämmig 2013, 132-133): tubetiv oy nevos deraliv...; ay niy oy tubnuv nevos mederitoy... Since tubetiv is spelled differently to the expected *tubetiy, Neumann $(1997,23)$ and Gorbachov (2008, 100-101) preferred the segmentation tubeti. Gorbachov considered the possibility of a borrowing from Luw. $t \bar{u} b(a) i-$ 'strike' (found both in CLuw. and HLuw.), although he also admits that the Phr. form may continue PIE ${ }^{*}(s) t u b^{h}$-, a protoform suggested by Melchert $(1994,242)$ for this Luw. verb and Lyc. tubidi, tubeiti 'strike down', also compared with Gr. $\sigma \tau \cup \varphi \varepsilon \lambda i \zeta \omega$ 'to strike hard, maltreat' (this etymon is not considered in EDG 1418-1419).

Neumann 1997, 23; Gorbachov 2008, 100-101; Hämmig 2013, 132-133.

tubnuv see tubetiv.

țuvatis (PN)

OPhr. sg. nom. țuvatis or guvatis G-133

I-stem anthroponym in nom. Both readings possibilities go back to PNs found in Anatolia. However, the form țuvatis is preferred (following Innocente 1997, 325) because of the Luw. parallel Tuwattis (contrary to Bayun \& Orel 1988a, 198).

CIPPh I, 122; Bayun \& Orel 1988a, 198; Neumann 1988, 17; Brixhe 1993, 339; Neumann 1995, 135; Innocente 1997, 35. 
tumoy (noun?) 'house'?

OPhr. sg.dat.? tumoy B-06

This word is found after the relative pronoun yos and both are written together between interpunctions because the pronoun is clitic. Although the inscription is in a precarious state of conservation (it was reused some centuries later), since yos tumoy occurs at the end of the text it is perhaps the beginning of a curse: [---]y:yostumoy: $\uparrow$ ekmatin|[---]atonkeyen. However, there are too many gaps to clearly determine what the text says. Bakır and Gusmani $(1991,163)$ and Brixhe $(2004 \mathrm{a}, 72)$ considered it a verb in the $3^{\text {rd }}$ sg.opt. However, the verb is not commonly found immediately after the relative pronoun and, if the sentence is a curse, we must remember that the optative is not used in the protasis. Vassileva $(1995,29-31)$ interpreted it as a variant

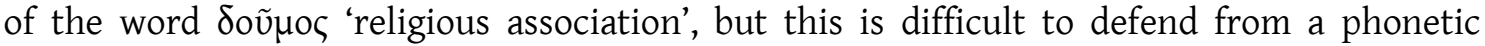
perspective because no other example of the shift OPhr. $t>\mathrm{NPhr}$. $d$ is found. It is probably an ostem noun in the sg.dat. and is perhaps based on the PIE root noun *dôm 'home, house' with a secondary o-stem as well as Gr. סóno 'house, living, room' (often used in funerary contexts) and Skt. dáma- 'house' (EDG 347). This proposal is made on the basis of the change *d $>t$ (see e.g. $\tau \imath \tau \tau \varepsilon \tau 1 k \mu \varepsilon v o \varsigma$ ), the vowel shift $*_{o}>u$ (see e.g. muksos) and the possible reference to the monument itself as a 'funerary house'. Indeed, if it is a curse, this reference is expected in such a position. Nonetheless, the word remains unclear because of the poor preservation of the text. Bakır \& Gusmani 1991, 163; Vassileva 1995,29-31; Orel 1997a, 153 and 464; Brixhe 2004a, 72.

tuo? [---] (?)

OPhr. tuo?[---] G-302

Only two complete letters survive on this pottery fragment. The third shows a circular trace that may or may not be accidental. It could be an anthroponym, but this remains to be explained.

Brixhe 2002a, 63-64.

tutut.. (?)

OPhr. tutut.. W-01a

Text appearing after a relative pronoun: yos tutut ...a-m-noy... The following letters are illegible. However, CIPPh (I, 38) considered the reading tututey : amnoy to be the most probable. If they are right, these two words could be two datives (Lubotsky 1988, 16). They have recently been

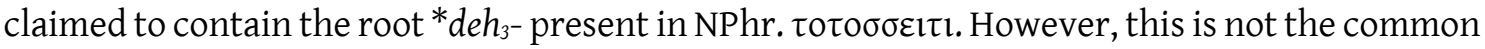
position for the verb and it does not fit the CIPPh reading. Consequently, this sequence remains obscure.

Neroznak 1978, 76; CIPPh I, 38; Bayun \& Orel 1988a, 182; Lubotsky 1988, 16; Hämmig fthc.

זU.|[...] (?)

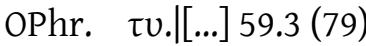

A sequence in a very damaged part of an imprecation. It is preceded by [....]TO $\Sigma$. If this last sequence is the known pronoun it could mark the beginning of the apodosis. Nevertheless, this sequence is very difficult to interpret. 



\section{$Y(u)-Y v$}

$u^{?}$ (mark)

OPhr. $u^{?} \mathrm{G}-278$ a

Although there are more letters on this cup, this one, as well as $\psi$, occurs in an isolated position with the sequence [-?-]?[---]ai?. It is very likely to be a mere commercial or owner's mark.

Brixhe 2002a, 38-39.

$v$ (adverb) 'neither, nor'

NPhr. $v 4.1(2)$

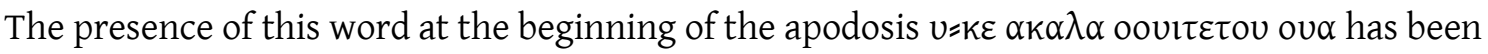
explained as a graphic variant of the dat. pronoun (1)or 'to him' by Heubeck $(1958,22-3)$ and Brixhe $(1997,49,67)$. However, some remarks can be made. First, it is an unusual spelling of /oj/ that has no parallels in the NPhr. corpus. Moreover, the presence of this suggested pronoun seems too pleonastic, since there is another reference to the accursed in the possessive ovd. Finally, if the verb means 'to find', it needs a negative particle in order to be something undesirable. LIPP (II, 338) provides another explanation: $v=k \varepsilon$ goes back to * $h_{2} u-k^{w} e$ 'but also' but such an interpretation hardly fits the context. Consequently, neither interpretation is defensible and another reading is required. Indeed, it is more easily explained as the negative adverb parallel to Gr. ov, and, if this is the case, the construction $v=k \varepsilon$ would be a parallel of $G r$.

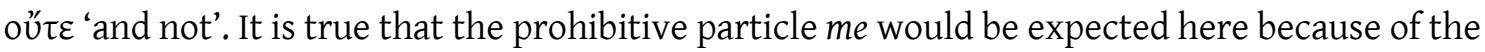
imperative verb, but it is not an unattested occurrence in the light of the Gr. funerary formula

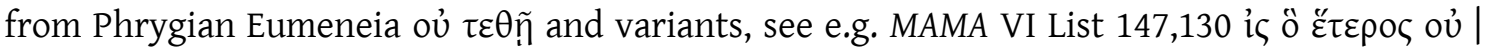
$\tau \varepsilon \theta \tilde{n}$. 'into which no-one else will be placed'. The verbs in these adduced parallels are in the subjunctive, but also the prohibitive particle $\mu$ n would be expected instead of ov. Then, this form should be compared with Gr. oủk, oủk(i), oủx(i) 'not', Arm. oč 'id.' and Alb. as 'id.', which is commonly considered the result of a PIE formation * $h_{2}$ oiu $\left(-k^{u} i d\right)$ (see EDG 1123, Martirosyan 2010, 531 and 2013, 91, with references). The NPhr. text points out a form without $*_{i}$, although a phonetic erosion - common in such grammatical words - cannot be ruled out, if not a consequence of the Gr. influence. In any case, the sentence in which it is found may mean 'and shall he not find his akala'.

Heubeck 1958, 22-3; Neumann 1971, 156; Brixhe 1997, 49,67; LIPP II, 338.

uei (PN?)

NPhr. uei G-338

Complete graffito. According to Brixhe (2002a, 92-93) it is an abbreviated anthroponym, better than a complete nominative form (without the ending $-s$ ). However, no parallel has been identified.

Brixhe 2002a, 92-93.

uva (PN)

NPhr. uva K-01 V

This PN features a nominative without the ending -s. It is characterised by the sign ' which is always followed by a PN. Since the following word presents the same sign we can assume that it is an anthroponymic sequence, despite the fragmentation of the text: [---].pa ' $u v a{ }^{(} \cdot[---]$.

Brixhe \& Summers 2006, 123. 


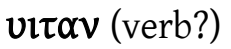

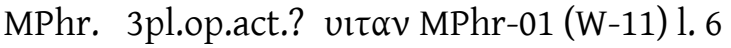

According to Brixhe $(2004 \mathrm{a}, 21)$ it can be analysed as an $a$-stem noun in the sg.acc. or as a verb in the 3pl.opt.act. He considers the latter option more likely because $\pi \alpha \rho \tau \eta \varsigma$ is assumed to be

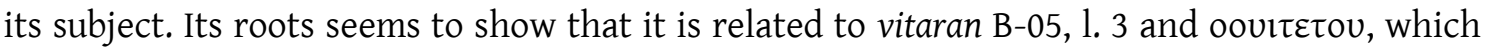
goes back to the PIE root *ueid- 'behold, see' (LIV 665-667, IEW 1125-1127). Nonetheless, the

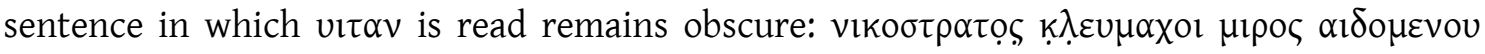

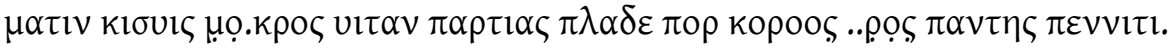

Brixhe 2004a, 21.

\section{$u^{?} l$ ekey (?)}

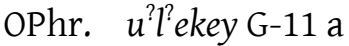

The whole text in which this sequence is read remains obscure; even the disposition of the text has yet to be established. Following Brixhe (2002a, 35), while key could be identified as the copulative conj., it is preferable to take this sequence as one word. In the light of this observation, it could be a consonantal stem noun in the sg.dat. However, the word remains unclear.

Brixhe 2002a, 35.

\section{umnișet (verb)}

OPhr. 3sg.pres.act.sub. umnișet B-05, 1. 7

MPhr. 3sg.pres.act.sub. ouvıoi MPhr-01 (W-11) 1.8

Despite the vocalic differences, these are probably different (but common) spellings of the same form. Nevertheless, the root *umn- (probably also present in the adj. umnotan) is not identified, so the meaning is unknown. Perhaps in B-05 the agent of umniset is kelmis: kelmis ke umniset evradus dạkerais key iverais [--] atikraiu. The form ouvıloı occurs in a relative clause:

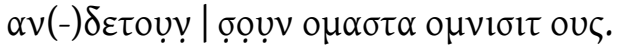

Brixhe 2004a, 24 and 59.

umnotan (adj.)

OPhr. ac.sg. umnotan B-07

It is very likely it is an $a$-stem deverbative adj. with the suffix -ta- of the same root attested in umniset and opviolt. It agrees with the noun ordoineten in a relative clasue: yos tiv[.|.?]n ke devun $k(e)$ umnotan ordoineten...

Brixhe 2004a, 84.

uposọy (PN?)

OPhr. dt.sg. uposọy G-189

This complete isolated word on a potsherd is very likely an o-stem PN in the dat., although no parallel is found. The second $o$ is barely visible and the first letter presents an accidental stroke. This led Bayun and Orel (1988a, 199 and Orel 1997a, 209-210) identified [---]kposoy as the same name that occurs in G-229 sokposa. However, their interpretation must be rejected because it is clear that G-189 did not contain any letter before the first letter of the reading.

CIPPh I, 160 .

urakạ[---] (PN?)

OPhr. uraka[---] G-292

Despite the fact that the last letters are lost and no parallels can be adduced, this isolated word on a potsherd is expected to be a PN.

Brixhe 2002a, 53. 


\section{$\operatorname{urgitos}(\mathrm{PN})$}

OPhr. sg.gen. urgitos K-01 VI-VII a2

PN in gen. used as a patronymic of the name in nom. masa (with Hitt. origin). According to Brixhe (in Brixhe \& Summers 2006, 125), *Urgis may be the nominate (for its inflection see artimitos). In any case, such a name is found only in the Hurrian PN of Mursili III, Urhi-Tešub 'Tešub is truth' (vel. sim., LNH 198 § 1443). If the equation urhi- > urgi- is right (a hypocoristic), it is a new example of the continuity of Anatolian royal onomastics in Phr. This is more plausible if we consider the location in which the stele was found: Kerkenes Dağ, in Cappadocia.

Brixhe \& Summers 2006, 125.

\section{uriienoisku[---] (?)}

OPhr. uriienoisku[---] G-145

An obscure sequence preceded by the PN voineios (with a correction in the last letter). The presence of two $i$ has been considered a possible word boundary (CIPPh I, 132) as in M-06 davoi iman, however two opposing parallels can be adduced: T-03 a I a个iiai and P-02 kanutiievanos. Another possibility is to suggest a word boundary after uriienois (a word in dat.pl?). With their arguable etymological speculation, this last segmentation appears in Orel $(1997 a, 191)$ and Bayun and Orel $(1988 a, 195)$. In any case, this sequence remains unclear. Neroznak 1978, 101; CIPPh I, 132; Bayun \& Orel 1988a, 195; Orel 1997a, 191.

$\operatorname{url}(\mathrm{PN}$ )

OPhr. url G-109

This sequence is the second and last of the G-109 ceramic graffito. It is preceded by the anthroponym aladis and a small amount of space is appreciated between the two words. Because of the unusual ending $-r l$ it must be considered an abbreviation of a possible patronymic. However, no clear parallel can be adduced. Tentatively, Orel (1997a, 171 and 465) suggested a

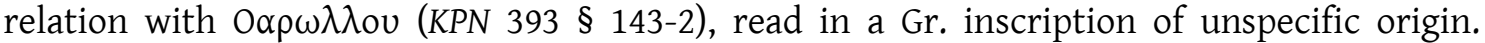
However, the difference in vowels casts doubt on his proposal. Another possibility is to read it as urg and consider it an abbreviated form of urg(itos) (K-01).

CIPPh I, 103; Bayun \& Orel 1988a, 200; Orel 1997a, 171 and 465; Liebhart \& Brixhe 2009, 150.

urunis $(\mathrm{PN})$

OPhr. nom.sg. urunis G-346

This $i$-stem PN is written on a beam of Tumulus MM at Gordion, near three other PNs: nana, muksos and si个idos (Liebhart \& Brixhe 2009). Regarding its origin, it must be the Luw. PN ${ }^{\mathrm{m}}$ Urawanni (an ethnic in origin, see Melchert 2013, 37), with the common simplification $w a>u$. In The the Phrygian inscription, urunis is preceded by the mark ', which occurs before a PN. Liebhart \& Brixhe 2009, 150.

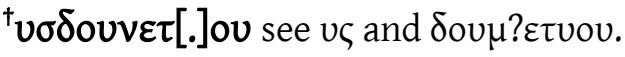

Uৎ (PN?)

NPhr. vऽ 22.1 (9)

It appears at the beginning of a epitaph followed by a Lat. name: $v \varsigma \delta$ ou $\mu^{?} \varepsilon \tau v o v \pi \alpha \sigma \varepsilon$

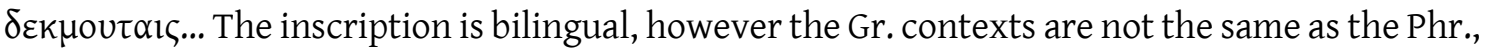
although this part is obscure. Because of its position, it is very likely a PN followed by its

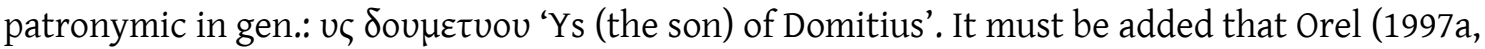
73-74) manipulated the reading in the light of the name given in the Gr. text of the same

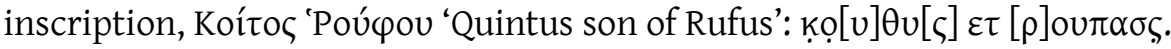


$v \psi \circ \delta \alpha v$ (adverb) 'above, on the top'

NPhr. $\quad v \psi \circ \mid \delta \alpha v 2.1$ (15); [o? $v] \mid \psi \circ \delta \alpha \sim v 16.1$ (116)

An adverb identified by Lubotsky 1993a and equated to Gr. vं $\psi o ́ \theta \varepsilon v$ 'from on high, from above'. Both forms go back to *upsod ${ }^{h}$, derived from PIE *up-s- 'above' (LIPP II, 833). The Phrygian word shows the zero-grade of the locative particle ${ }^{*}-d^{h} n$, attested in some Gr. dialects as $-\theta \alpha$ (e.g. Aeol. $\pi \rho$ ó $\sigma \alpha \alpha$ 'before'). In the light of numerous occurrences, the last $-v$ must be etymological. In both inscriptions, this adverb occurs alongside nouns referring to parts of the funerary monument. Lubotsky 1993a; Orel 1997a, 77 and 465; Ligorio \& Lubotsky 2013, 183; LIPP II, 833.

$\underline{u} 7 d(?)$

OPhr. $\quad u \neq d \mathrm{G}-106$

This unparalleled sentence occurs in isolation on a bronze bowl. Because of the ending in - $d$, it is probably an abbreviation, perhaps a PN. The second letter is difficult to read in the light of other known examples. It can only be likened to a sign written in G-244 (see § 3.1.5). According to Brixhe (2004a, 28, who follows Lejeune 1970,59-60) it could be a diacritic 7 , denoting a voiced affricate sound (see also Brixhe 1982, 240-241). Orel's (1997, 170 and 465) identification of the

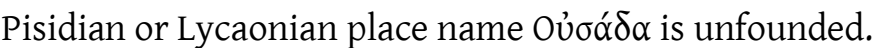

Brixhe 1982, 240-241; CIPPh I, 101; Morante Mediavilla 2000, 185-196; Brixhe 2004a, 28. 


\section{$\checkmark(y)$}

$\boldsymbol{y}$ (owner's mark)

OPhr. y G-254

Since it is an isolated letter on a potsherd, it is probably a mere commercial mark, not necessarily an abbreviated form of a PN.

CIPPh I, 198; Roller 1987a, 38; Bayun \& Orel 1988a, 200; Orel 1997a, 237 and 469.

\section{$\left[. ? \mathrm{?}\left[{ }^{?} \cdot\right] \operatorname{agaua}(?)\right.$}

OPhr. [.?]y[?] ]agaua W-11

The ending has a parallel in m?onokaua. On the basis of its ending in $-a,\left[{ }^{?}\right] y\left[{ }^{?}\right]$ agaua has been considered an epiclesis of the goddess Matar by Brixhe (Brixhe \& Sivas 2002, 108-109). However, he did not rule out a neut.pl.nom.-acc. noun as a secondary possibility. Its context, as well as the word itself, is badly damaged: [.?]y[.?]agaua |[-?-]tatae??..?]| [?]e[.].

Brixhe \& Sivas 2002, 108-109.

$y e^{?}(?)$

OPhr. $y e^{?} \mathrm{NW}-129$

This sequence is written by a ligature and below an isolated $a$. Although this kinds of short sequences are considered anthroponymic abbreviations, Brixhe (Brixhe \& Sivas 2009, 133) does not rule out the possibility that we are dealing with a complete $e$-stem Lallname in the nominative without the ending $-s$.

Brixhe \& Sivas 2009, 133.

yẹ.ḅ..[---] (?)

OPhr. yẹ...[---] K-01 Ib

The beginning of a very damaged sequence. The first letter could also be read as $i-$, which is less likely but remains defensible because the non-notation of the glide is found in the same inscription: -tio-. The last remains of letters are vertical, but illegible. This sequence remains unclear. It is preceded by [---]vos $(\mid i)$.

Brixhe \& Summers 2006, 115.

\section{[-?-]yemeyọn (?)}

OPhr. [-?-]yemeyon G-312

This graffito on a potsherd is complete at the end but unclear at the beginning. Brixhe (2002a, 70) suggested the possibility of a lost initial letter $i$, as in the case of iyungidas, because of the lack of words beginning with $y$ - except the relative pronoun. This is categorically untrue, see yenvra and yẹ...[---]. Also, the last yod has lost its bottom and, in fact, the reading is given in the light of the very suitable parallel kuryaneyon, a nominative singular of a present participle ${ }^{*}-\bar{n}$. However, the contexts are very different and in G-312 an anthroponym is expected. It could be an $n$-stem anthroponym.

Brixhe 2002a, 70 .

\section{yenvrạ (?)}

OPhr. yenvra B-03

This word occurs after the reduplicated relative pronoun yosyos in a probable imprecative protasis: yosyos yenvra | etitevtevey me - oun lakeao | [-?-]. It could be an a-stem word but its case it is unknown. It appears to be an $a$-stem nominative but that case it is not expected here. 
yos (pronoun) 'who, whoever'

OPhr. masc.sg.nom. yos B-01, B-05, B-06, B-07, W-01a, W-01b

masc.sg.nom. yosyos B-03

masc.sg.nom. ios G-02b, P-04a, P-04b, P-06

masc.sg.nom. tiv† B-05

MPhr. masc.sg.nom. 10 MPhr-01 (W-11) 1. 7

NPhr. masc.sg.nom. $\quad$ lo 3.1 (97), 4.1 (2), 5.1 (19), 6.1 (88), 7.1 (99), 7.2 (111), 7.3 (14), 8.1 (86), 9.1 (87), 10.1 (112), 11.2 (18), 13.1 (122), 14.1 (73), 15.1 (120), 17.2 (3), 17.4 (90), 17.6 (119), 18.1 (4), 18.3 (6), 19.2 (129), 20.1 (63), 20.2 (128), 20.3 (62), 21.1 (42), 21.2 (43), 22.2 (118), 23.1 (89), 24.1 (40), 25.1 (115), 25.2 (126), 27.1 (92), 29.1 (114), 30.1 (39), 30.2 (68), 31.1 (29), 32.1 (93), 33.1 (28), 33.2 (95), 33.3 (127), 35.1 (25), 36.1 (26), 37.2 (27), 37.1 (10), 41.1 (45), 43.1 (69), 44.1 (61), 44.2 (70), 44.3 (67), 45.1 (65), 46.1 (53), 48.1 (81), 48.2 (84), 49.1 (110), 50.1 (54), 50.2 (55), 51.1 (80), 52.1 (75), 53.1 (76), 53.3 (109), 54.1 (108), 55.1 (56), 56.1 (57), 58.1 (72), 59.1 (107), 59.2 (47), 59.3 (79), 59.4 (106), 60.2 (60), $61.1(100), 62.1(32), 62.2(33), 62.3(34), 62.4(35), 62.5(36)$, 62.6 (105), 63.1 (123), 64.1 (81), 65.1 (20), 65.3 (21), 65.4 (124); [1] os 39,1 (44), 40.4 (102).

masc.sg.nom. $\quad$ Elo $40.1(12)$

masc.sg.nom. $\quad 1 \varsigma 17.1(4 \mathrm{~b}), 12 . .1(121), 15.1(120), 16.1(116), 18.2(5)$

masc.sg.nom. $100 \varsigma 34.1(37)$

masc.sg.acc. lov $56.2(58)$

fem.sg.acc. $\quad l \alpha v 40.3(31)$

A relative pronoun derived from PIE * $(H)$ i-o- 'id.' (*h, $h_{2}$ ió- in LIP II, 312-315) and equated to Gr. ös,

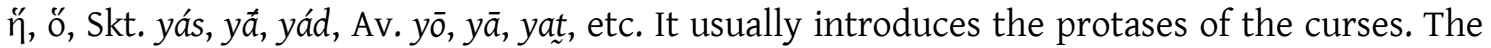
forms yos, ios and $10 \varsigma$ are the masculine nominative singular. Also, $1 \varsigma$ and $\varepsilon 10 \zeta$ must be analysed in the same way. While $1 \varsigma$ is explained by the Gr. phonetic development $10>1$ (Brixhe 1987a, 5051), عloৎ is a graphic variant arising from the Gr. itacism. yosyos is a clear reduplicated form, similar to Lat. quisquis, quaequae, quidquis 'whoever, whatever, everyone who'. In turn, $1 \sigma 0 \varsigma$ is probably a development of the same form, where 1 - stands for 10- (as i $)$ ) and -sy- (from yos + yos) has become - $\sigma$ - The form tiv † B-05 is particularly strange. Since it appears where yos is expected, Hämmig $(2013,149)$ considered it a mere error. The sg.acc.masc. lov is a possible new

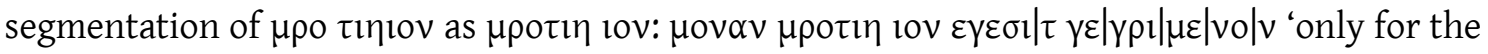
death whom it has written'. However, there is a problem in the gender because its antecedent $\mu$ potı $\eta$ is fem. Finally, there is sg.acc.fem. $\iota \alpha v$, which goes back to $*\left(h_{1}\right) i-e h_{2}-m$.

Haas 1966, 226; Brixhe 1978b, 21-22; Brixhe 2004a, 72; Hämmig 2013, 149; Ligorio \& Lubotsky 2013, 190; LIP II, 312-315.

${ }^{\dagger}$ yostumoy see yos \& tumoy.

yosyos see yos. 
$\Psi$ (mark)

OPhr. $\quad$ Y G-278b, G-294, G-298

Incised on potsherds, an isolated letter used as a mark. In G-278 it occurs near an obscure sequence: [-?-]?[.] a $^{\text {? }} u^{\text {? }}$.

Brixhe 2002a, 38-40, 55-56 and 59-60.

$\checkmark$ (mark)

OPhr. V G-322, G-324, NW-105, NW-112, NW-126 (bis), NW-128; \ NW-119, NW-122

Isolated mark incised on several potsherds. This mark has been catalogued as the sign $20 \mathrm{~b}$ by CIPPh (I, 242). However, it is not necessarily a letter (see Brixhe \& Sivas 2009, 138).

Brixhe 2002a, 14, 19, 23, 78, 79-80; Brixhe \& Sivas 2009, 130 and 132.

Yir (PN?)

OPhr. Yir G-339

An abbreviated word read on a sherd with some non-verbal marks. Because of the context it is probably an anthroponym. However, no parallel can be adduced.

Roller 1987a, 24 and 40; Brixhe 2002a, 93.

Yuv see YuvaYaros.

YuvaYaros (PN)

OPhr. sg.nom. Yuva Yaros G-115

? $\quad$ Yuv G-224

The graffito $\mathrm{G}-115$, read on a sherd dated to the $6^{\text {th }} \mathrm{c} . \mathrm{BC}$, is complete and it is a clear o-stem anthroponym. It has been equated to the OP PN ${ }^{*}$ Uvaxštra (without a clear etymology). It is also attested in Akkadian as ${ }^{\mathrm{m}} \dot{U}-a k$-sa-tar, ${ }^{\mathrm{m}} U k$-sa-tar and ${ }^{\mathrm{m}} \dot{U}-m a-k u$-iš-tar, in Elamite as Ma-ki-iš-tur-ri and Ma-ak-iš-tar-ra (note that in Elamite the sign ME/PI often represents /v/) and finally in Gr.

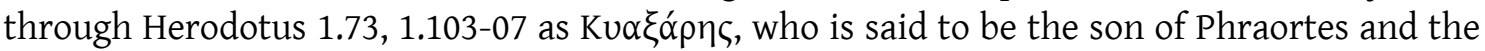
king of Media who conquered the parts of Asia Minor east of the Halys River (585 a.C.), in the same c. as the Phrygian graffito G-115. In addition to its cultural value, this name has often been used to establish the value of the letter $\Psi$. According to Lejeune 1978, 785-787, the second $Y$ in this name is the reflex of the Persian variant -xš- instead of the Median -xštra-, and therefore stands for $/ \mathrm{ks} /$. An open problem is the beginning of the name, where $\Psi$ can only represent an original /h/, so the context is very different. Lejeune suggested a hypercharacterisation grounded in a regressive assimilation of / ks/ in order not to lose the initial sound (not used in Phrygian), but this explanation is difficult to corroborate. The graffito G-224, in which Yun is read, has been considered an abbreviation of Yuva Yaro.

Haas 1966, 55-56; Schmitt 1973, 56-58; Haas 1976, 49-68; Lejeune 1978, 785-787; Schmitt 1978, 411-412; Schmitt 1982, 3435; Diakonoff 1993, 478-479; Morante Mediavilla 2000, 197-227; Tavernier 2007, 466-467. 

$\uparrow$ (owner's mark)

OPhr. $\uparrow \mathrm{G}-203 \mathrm{a}, \mathrm{G}-225$

In both of its occurrences this letter appears isolated among in potsherds and probably was used as a commercial or owner's mark. In the internal side of G-203 (from $4^{\text {th }} \mathrm{c}$. BC) a mark X is also found and in G-225 (from $4^{\text {th }}-3^{\text {rd }} \mathrm{c}$. BC) an A.

CIPPh I, 168 and 181; Roller 1987a, 31 and 48; Bayun \& Orel 1988a, 199; Orel 1997a, 215-216, 225; Morante Mediavilla 2000, 164 .

个ek see $\uparrow e k m a t i n$.

个ekmatin (noun?)

OPhr. sg.acc. 个ekmatin B-06 1.3

pl.acc.? 个ekm? [at]es B-06 l.1?

This $i$-stem nound or adj. only occurs in a very damaged funerary stele. Since $\mu \alpha \tau 1(v)$ is attested in MPhr-01, one can suggest a segmentation $\uparrow e k$ matin is possible. In any case, $\uparrow e k$ remains unexplained: it is a preposition or a prefix?. The segmentation of this $\uparrow e k m a t i-$ is unclear In 1.1,

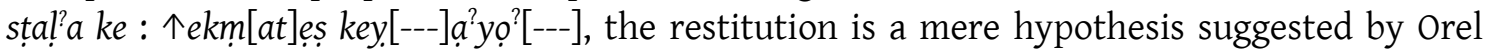
(1997a, 151), but it fits the lost space and the remaining strokes. Although the context is absolutely unclear, 1.3 may contain an imprecative protasis: yostumoy: $\uparrow$ ekmatin |[---]atonkeyen. Anyhow, its origin and meaning are unknown, contrary to Orel (1997a, 152 and 422, who considered it a PN (arbitrariously read as dekmatin).

Orel 1997a, 152 and 422; Brixhe 2004a, 72-73.

\section{个emeney (noun)}

OPh. sg.dat. 个emeney B-05

A clear $n$-stem noun (parallel inflection to iman, imenos), it is read in a protasis of a curse: yos isekosos $\uparrow e m e n e y$ dupratoy veban ituv. A recent analysis offered by Simon $(2015,25-27)$ considered it derived from a verb which goes back to PIE * $\hat{g}^{h} e h_{1-}$ 'move' (LIV 172 , IEW 418), * ${ }^{h}{ }^{h} h_{1-}$ 'leave behind, let return' (LIV 173, IEW 418-419) or * $g^{h} e^{2}{ }^{-}$'to come; to arrive' (LIV ${ }^{2} 196$, IEW 418-419),

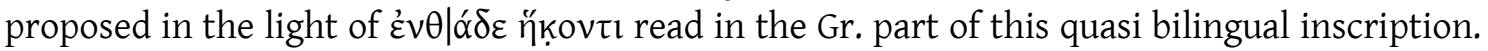
However, the identification of both texts is not clear (at least the apodosis is not the same). On the other, Sowa $(2015,189)$ tentatively suggested a borrowing from Gr. $\sigma \tilde{\eta} \mu \alpha$ 'sign, mark, gravestone'.

Neumann 1997, 52; Brixhe 2004a, 64; Gorbachov 2008, 102-105; Hämmig 2013, 151; Sowa 2015, 188-189; Simon 2015, 2527.

\section{$\mathrm{Ti}(\mathrm{PN}$ )}

OPhr. Ti G-275

A complete graffito on a potsherd which must be an abbreviated word, probably an anthroponym, used as an owner's mark. The first letter has been considered a variant of $\uparrow$ because it is a hapax but similar to $\uparrow$ in $a \uparrow$ iia T-03.

Heubeck 1986, 76; CIPPh I, 212; Roller 1987a, 41; Orel 1997a, 244 and 461; Morante Mediavilla 2000, 172; Brixhe 2004a, 96. 
个irạy (noun) 'hand'

OPhr. sg.dat. iray B-05

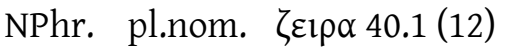

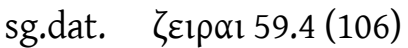

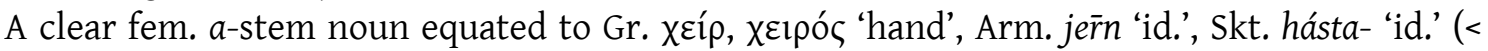
*g'hés-to-), Hitt. keššar 'id.', etc., which goes back to PIE *g'hes-r- 'id.' (NIL 170-172). The $a$-stem

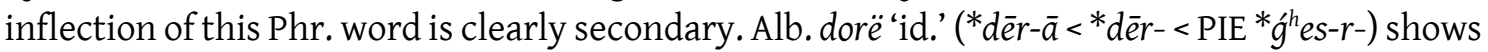
the same new inflection, although in this language almost all PIE C-stems become o- and astems (see Demiraj 1997, 140 with references). The OPhr. occurrence appears in an imprecative protasis: †iv $\dagger<s>$ imun inmeney asenan dạket torvetun $\uparrow$ irạy ạniy oy tubnuv... According to Hämmig (2013, 150-151, who took up an old theory rejected by Brixhe 1991, 84-89 and other scholars), it is used there as an ins. 'von Hand' (a similar use in NPhr. 59.4). In the NPhr. subcorpus it again

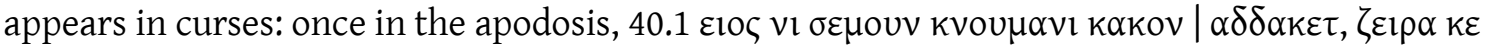

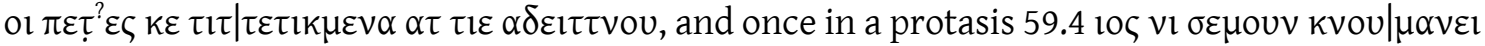

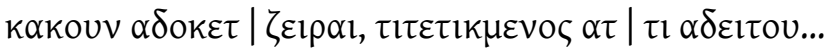

Hämmig 2013, 150-151. 


\section{Acephalous words}

$[--] a(?)$

OPhr. [---]a T-02b

Ending of a word segmented by interruption read on a stele: [---]tumida $\vdots$ memeuis : [---]|[---]a : tesan : $a$ 个ion : $v[---] .$. It does not agree with the words that follow (in sg.acc.). Orel (1997aa, 471) considered it a sg.nom. of an $a$-stem, but this cannot be corroborated.

Orel 1997aa, 471.

\section{$[---] a . .[(?)$}

OPhr. ]a..[ ] B-03

A seriously damaged part of this inscription on a stele. Its context is no clearer: esck...a[ ] ]a.. [ ] | evtevey...

\section{[-?-].a (PN?)}

OPhr. [-?-].a G-227

Graffito on a potsherd whose first letters are lost. Because the original text is only suggested to have four letters at most, CIPPh (I, 182) considered it a possible dissyllabic Lallname. However, it could also be an abbreviation. Bayun and Orel (1988a, 199), on the other hand, read it as a sinistroverse ai [---], but the central appendix of the $a$ is good evidence for the CIPPh (I, 182) reading. Finally, Orel's reading ...ita (in the light of G-223, 1997, 472 and 225) is difficult to corroborate on the basis of the remaining strokes.

Bayun \& Orel 1988a, 199; CIPPh I, 182; Orel 1997aa, 472 and 225.

[-?-]ạb see [-?-]abas.

\section{[-?-]abas (PN)}

OPhr. [-?-]ab G-217

$$
\text { [-?-] a bas P-104 }
$$

Graffiti read on sherds. Both seem to contain a PN very likely related to $A \beta(\beta) \alpha \varsigma$ (very common

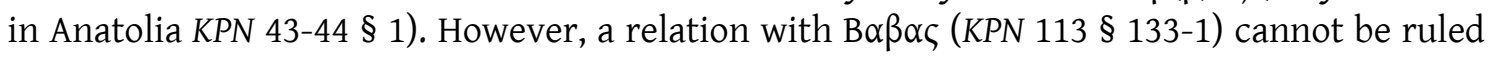
out. G-217 is very likely an abbreviation.

Neroznak 1978, 111; CIPPh I, 248.

[---]agineiạ see lagineios.

\section{[---] $a^{?} d a d[---](\mathrm{PN}$ ?)}

OPhr. [---]a? $d a d[---] \mathrm{G}-308$

A damaged graffito on a potsherd. Although no parallel can be adduced in the Phrygian corpus, Brixhe (2002a, 68) suggested that it could be a Lallname (see LNH 241 Adada).

Brixhe 2002a, 68 .

\section{[---].aesi..[---] see [---]m?aesi..[---].}

\section{$[---]$ ạes (?)}

OPhr. [---]aes G-149

Because of the evident similarity, Orel $(1997 \mathrm{a}, 471)$ considered this fragmented graffito on a potsherd to be a 3sg.aor. verb (see, e.g., edaes). However, a verb like this is only read in monumental inscriptions.

Lubotsky 1988, 18; Orel 1997a, 193 and 471. 


\section{[---]ạvas (PN?)}

OPhr. [---] avaș G-142

Read on a potsherd, the complete graffito is [---]avașs[---]. Because the Phrygian alphabet does not note the geminates, a word boundary can be inserted between the two $s$ (as suggested by CIPPh I, 129). However, no analysis can be given for [---]avas, only that it could be a sg.nom. $a-$ stem (Orel 1997a, 471) perhaps a masculine PN, see, e.g. Midas.

CIPPh I, 129; Orel 1997a, 189 and 471.

\section{[-?-].'[.]ai? (?)}

OPhr. [-?-].?[.]ai? G-278a

Two isolated letters incised on the same potsherd: $u^{?}$ and $\psi$. If the last letter is indeed an $\langle i\rangle$, it could be a sg.dat. $a$-stem (Brixhe 2002a, 39). However, the sequence remains obscure.

Brixhe 2002a, 39.

\section{$[---] a i o s[---](?)$}

OPhr. [---]aios[-?-] G-159 b

A fragment read on a pot sherd which seems to contain another fragmented inscription: G-159b [---]ser.[---]. According to CIPPh (I, 142-143), [---]aios could be an ending of a word, see iketaios. CIPPh I, 142-143; Orel 1997a, 197 and 471.

\section{[---]ạinẹ[---] (PN?)}

OPhr. [---]ạinẹ[---] G-299

A word suggested doubtfully by Brixhe $(2002 \mathrm{a}, 61)$ to be a PN. However, no parallel can be adduced.

Brixhe 2002a, 61.

\section{[---]aisạ[---] (?)}

OPhr. [---]ạișa[---] G-267

Read on a potsherd, this sequence has no parallels.

CIPPh I, 206-207; Orel 1997a, 241 and 471.

\section{$[---] a k[---](?)$}

OPhr. [---]ak[---] G-309

Two letters read on a potsherd.

Brixhe 2002a, 67.

\section{[---].akavi[---] (?)}

OPhr. [---].akavi[---] G-172

Read on a potsherd. Before the first (a), an angular remaining is observed which could be an $m$ according to CIPPh (I, 150, accepted by Orel 1997a, 202 and 472). Orel interpreted it as a 3sg.pres, but did so speculatively.

CIPPh I, 150; Orel 1997a, 300.

\section{[---]ake.ano[---] see akenanogavos.}

\section{[---]akios (PN?)}

OPhr. [---]ạkios G-272

Read on a potsherd. It is the sg.nom. o-stem word. It has been equated to akio[---] by Bayun and Orel (1988a, 196) but remains unclear.

CIPPh I, 210; Bayun \& Orel 1988a, 196; Orel 1997a, 243 and 471. 


\section{[-?-]akiti...s (?)}

OPhr. [-?-]akiti...s P-06

Written on an altar, it is not known if it was preceded by more text: [-?-]akiti...s $\mid$ ai $!$ ios aeiketio $\left[{ }^{2}\right]$ ivi..se.[ [ $]$ n. The sequence remains unclear.

CIPPh I, 242-243; Bayun \& Orel 1988a, 196; Orel 1997a, 243 and 471.

\section{[---]alabịios [---] (?)}

OPhr. [---]alabịios [---] C-01

Incised on a calcareous slab, this inscription is badly damaged: [---]e[...]alabịos [---]. Orel (1997a, 246 and 471) interpreted it as a PN (without parallels) and suggested a relation with the gloss

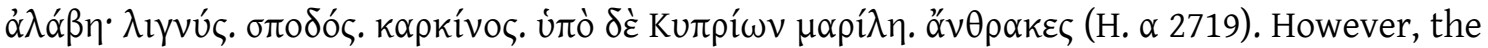
text is not clear enough for this suggestion to be seriously considered.

CIPPh I, 242-243; Orel 1997a, 246 and 471.

\section{[---].ale[---] (?)}

OPhr. [---].ale [---] G-171

This fragmented sequence on a potsherd could be read as [---]kale? [---] or [---]uale?[---]. Although Orel (1997a, 435) considered it a variant of [---]kalai[---] G-177 (specifically, a PN), the sequence is similar but not the same and the reading of the first letter of G-171 is not at all clear. CIPPh I, 150; Bayun \& Orel 1988a, 198; Orel 1997a, 202 and 435.

\section{[---]ạmai..[---] (?)}

OPhr. [---]amai..[---] G-155

A damaged graffito incised on a potsherd. The first doubtful letter could be read as $v$ or $r$ while the second is very dubious because only a vertical stroke remains. Interpretations such as the one offered by Orel (1997a, 196 and 471, who segmented [---]amai as $a$-stem sg.dat.) are very tentative.

CIPPh I, 139-140; Orel 1997a, 218 and 471.

\section{[---]ạmi.e[---] see [---]anịi.ẹ[---].}

...a.m.?noy (?)

OPhr. sg.nom? ...a.m.?noy W-01a

A damaged sequence read on a façade, possibly part of an imprecative apodosis: yos tutut ...a.m.'noy ! akenanogavos | aey... According to Orel (1997a, 35 and 423), whose reading of the beginning of the word (as well as his interpretation) is very tentative, it could be a sg.dat. noun. CIPPh I, 37-38; Orel 1997a, 35 and 423.

\section{[---].an (PN?)}

OPhr. [---].an G-291

A sequence on a potsherd followed by a non-graphical mark. Following Brixhe (2002a, 52), it could be an abbreviated PN (the most likely possibility), an ending of a PN in the light of iman, or an unknown noun.

Brixhe 2002a, 51-52.

\section{$[\ldots . ..] \alpha v(?)$}

NPhr. [....] $\alpha$ v 39.1 (11)

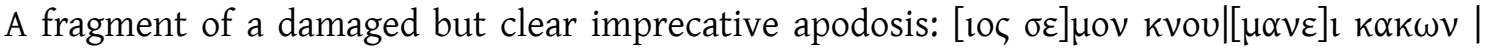
$[\ldots ..] \alpha v \alpha \beta \beta \varepsilon \mid[\rho \varepsilon \tau . .$. The curse itself is very common but this sequence is never attested as part of

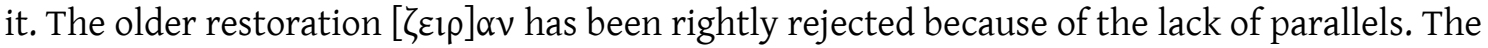
ending refers to a sg.acc. $a$-stem noun, however it could also be a dat. or an adv. 


\section{[---]ane[---] (PN?)}

OPhr. [---]ane[---] G-232

Graffito read on a potsherd. This sequence only has a parallel in the PN manes, but the identification is very tentative.

CIPPh I, 185; Orel 1997a, 228 and 471.

\section{$[---] a n i \cdot e[---](?)$}

OPhr. [---]ani.e. [---] or [---]ami.e. [---] G-209

An unparalleled sequence read on a potsherd. The reading (and its consequent interpretation) given by Orel (1997a, 196 and 471) does not fit with the remaining strokes.

CIPPh I, 171; Orel 1997a, 196 and 471.

\section{$[---] \arg (\mathrm{PN}$ )}

OPhr. [---]arg G-157 a

This fragmented graffito on a potsherd is written above an (uncertaintly read) Aramaic text. Because the ending - $r g$ is wholly unexpected, it has been considered an abbreviated PN by CIPPh (I, 141). However, no parallel can be adduced.

CIPPh I, 141; Bayun \& Orel 1988a, 199; Orel 1997a, 196 and 471; Sowa 2005, 178.

\section{[---]ares (?)}

OPhr. [---]ares G-197

The end of a word read on a potsherd. The ending -es could correspond to a PN in the nom. However, no parallel can be adduced.

CIPPh I, 164; Orel 1997a, 213 and 471.

\section{[-?-]aratapa[-?-](?)}

OPhr. [-?-]aratapa[-?-] G-221

An obscure, unparalleled sequence on a potsherd, following the PN atas: [-?-]a.iy[-?-] | [-?-]keno[-?-]|[-?-] atas [-?-]| [-?-]aratapa[-?-]|[-?-]o bata? $m$ ?..[-?-].

CIPPh I, 178-179; Bayun \& Orel 1988a, 196; Orel 1997a, 223 and 471.

\section{[---]as (PN?)}

OPhr. sg.nom. [---]as M-01f

This is very likely the subject of its sentence: [---]as tuaveniy ae esuryoyoy totin edaẹ[s]. So, a masculine $a$-stem PN.

CIPPh I, 21; Orel 1997a, 213 and 471; Ligorio 2016.

\section{[---].as (PN?)}

OPhr. sg.nom.? [---].as G-218

Fragmented graffito incised on a potsherd. Very probably an ending of an $a$-stem masculine PN in nom. The remaining stroke at the beginning could be from $\mathrm{a}\langle\mathrm{u}\rangle$ or $\langle\mathrm{n}\rangle$, for example.

CIPPh I, 177; Orel 1997a, 221 and 471

\section{[---].astoy (PN)}

OPhr. sg.dat. [---].astoy G-164

$$
\text { sg.dat. [---]astoi G-113 }
$$

Sequences incised on a potsherd. G-113 is followed by pitave[---]. The two occurrences are ery likely to be different spellings of the same PN (the dedicatee). Bayun and Orel (1988a, 199 and Orel 1997a, 199, also followed by Avram 2016b, 74) suggested that G-164 may be the ending of the surgastoy (Dd-164). However, their reading of the last part of G-113 (ios toi pitave[---]) is ungrounded. 
CIPPh I, 177; Brixhe 1996, 145; Orel 1997a, 199 and 459; Brixhe 2002a, 76; Brixhe 2004a, 92: Avram 2016b, 74.

[---]asiya ...? (?)

OPhr. [---]asiya..? B-05 1.5

An unparalleled, damaged sequence: dạker kạratu enpsạtus mekạ[---]ạsiyạ..? | nidus ạd kạliyay... It was earlier read as mek . a as- $k<e>y$ by Neumann $(1997,18)$.

Neumann 1997, 18 and 22; Brixhe 2004a, 48 and 65.

[---]astoi see [--].astoy.

[---].ata[---] (PN)

OPhr. [---..ata [---] G-120

A damaged PN on a potsherd. The unidentifiable strokes at the beginning could fit with a sequence atata[---], similar to atatas. However, this identification is very tentative.

CIPPh I, 112; Bayun \& Orel 1988a, 197; Orel 1997a, 177 and 416.

\section{[-?-]atesito.[-?-](?)}

OPhr. [-?-]atesito.[-?-] G-252

A fragmented graffito on a potsherd. We do not know whether it should be segmented into two words. Bayun and Orel (1988a, 197, also Orel 1997a, 252) considered that a first word which can be read is the PN ates, but this remains unclear.

CIPPh I, 197; Bayun \& Orel 1988a, 197; Orel 1997a, 252.

\section{[---]atonkeyen (?)}

OPhr. [---]atonkeyen B-06

Written on a marble stele, this is what survives of the last line of the text: yos tumoy: $\uparrow$ ekmatin

| [---]atonkeyen. Since it appears to be a curse, keyen has been suggested to be a 3pl.opt. by Brixhe $(1996,135)$. The segmentation [---]aton keyen was proposed earlier by Gusmani (Bakır \& Gusmani 1991, 162 fn. 23), who considered keyen an e-stem sg.acc. noun. However, the gaps and the lack of parallels render the sequence obscure, and these proposals are very tentative.

Bakır \& Gusmani 1991, 162; Brixhe 1996, 135-136.

.au.[---] (?)

OPhr. au. $[---] \mathrm{G}-169$

Graffito incised on a potsherd. Because the bottom part is broken, we do not know whether the first letter is $\langle\mathrm{l}\rangle$ or $\langle\mathrm{y}\rangle$. It is expected to be a PN, but no parallel can be adduced. Bayun and Orel (Bayun \& Orel 1988a, 199 and 1988b, 134) considered it another occurrence of lavageta-, while Orel (1997a, 201 and 440) also connected it with the verb lakedo. However, neither of these proposals fits with the remaining angular stroke of the last conserved letter.

CIPPh I, 148-149; Bayun \& Orel 1988b, 134; Bayun \& Orel 1988a, 199; Orel 1997a, 201 and 440.

\section{[---].aus (?)}

OPhr. [---].aus G-270

Graffito incised on a potsherd. It is clearly the ending of an unparalleled word. Perhaps a sg.nom. u-stem PN.

CIPPh I, 208-207; Bayun \& Orel 1988a, 197; Orel 1997a, 242 and 471.

[---]ạy! [---] (owner's mark)

OPhr. [---]ay!l[---] or [---]y!a

Graffito read on a potsherd. Because the bottom part of the text is badly damaged, both the letters and the writing direction are unclear. Orel (1997a, 229) suggested the segmentation 
[---]ay (a-stem sg.dat.) l[---], but given the difficulties of reading and the shortness of the fragment this is a very tentative interpretation. Consequently, the sequence remains obscure. CIPPh I, 186-187; Roller 1987a, 41; Orel 1997a, 229, 440 and 471.

\section{[---].ayosț'eș[---] (?)}

OPhr. [---].ayosț?eș[---] G-176

Graffito incised on a potsherd. The segmentation [---].ayos țes [---] has been doubtfully suggested by CIPPh (I, 153). Orel went one step further and interpreted [---].a yos ț eș[---], taking yos as the relative pronoun. However, these segmentations are not well grounded: the sequence -st- in a word is not unknown (see areyastin and surgastoy) but the pronoun is not expected in such a text.

CIPPh I, 153; Orel 1997a, 204, 461 and 471.

$[--] a^{2} y \varphi^{2}[---](?)$

OPhr. [---] $a^{?} y o^{?}[---]$ B-06

Read on the damaged first line of a stele: stal! $a$ ke: $\uparrow e k .[---] e s k e y[---] a^{2} y 0^{2}[---] \ldots$ The fragment is too short and the sequence too obscure to be interpreted satisfactorily.

\section{[---]a.iy[---] (?)}

OPhr. [---]a.iy[---] G-221

The first conserved line of a large graffito incised on a sherd: [---]|[-?-]a-iy[-?-]|[-?-]keno[-?-]. Orel (1997a, 222 and 414) equated it to areyastin, and while it is true that the second remaining letter could be read as $\langle r\rangle$, this is far from clear and the contexts are very different.

CIPPh I, 153; Orel 1997a, 222, and 414.

\section{[---]ḅal (PN?)}

OPhr. [---]ḅal G-193

Incised on a potsherd, this graffito is considered an abbreviation by CIPPh (I, 162). No parallel can be adduced, it is perhaps a PN.

CIPPh I, 162; Orel 1997a, 211 and 419; Sowa 2007a, 161-162.

\section{[---]ḅas[---] (?)}

OPhr. [---]ḅas[---] G-186

Graffito incised on a potsherd. It could be a complete PN, however, according to CIPPh (I, 158), it is more likely to be the ending of a longer PN such as abas or babas. It may even be a PN ending in -asis or -asos.

CIPPh I, 158; Bayun \& Orel 1988a, 197; Orel 1997a, 208.

\section{$[---] g[---](?)$}

OPhr. [---]g[---] G-05

The only remaining letter on a fragment of calcareous stone. Orel $(1997 \mathrm{a}, 164)$ suggested that it could be an abbreviated noun, as often found on potsherds. However, this is not the case here, and the text is too short to make an alternative suggestion.

\section{[.]gat (verb?)}

OPhr. 3sg.imperfet [.]gat B-07

The use of interpunction identifies this as a clear ending of a word and very likely the ending of a sentence. Unfortunately, it is the first preserved word of this funerary inscription and its beginning has been lost: [.]gat : s manes iyungidas manitos apelev porniyoy... According to Gusmani (2001, 165, who read [.]tat) and Brixhe (2004a, 76), it may be a verb, which fits well in this position, similar to estat. Gusmani also suggested that this verb could be the 3sg. imperfect of 
egeseti, $\varepsilon \gamma \varepsilon \sigma i \tau$ and $\varepsilon \gamma \varepsilon \delta \circ \mathrm{v}$ and, consequently, a form [e]gat could be considered. However, it remains unclear since the word is badly preserved and has lost its context.

Gusmani 2001, 165; Brixhe 2004a, 76.

\section{[---]gen (?)}

OPhr. [---]gen or [---]ten M-10

Because it is followed by interpunction, this sole conserved sequence of an inscription on a stone block is a clear ending. The first remaining letter is not clear. On the other hand, Lubotsky $(1988,23)$ pointed out that -en is a highly unusual ending in Phr., though by no means unattested, see, e.g., ataniyen.

CIPPh I, 29; Lubotsky 1988, 23; Orel 1997a, 32 and 473.

[-?-]go..[---] (?)

OPhr. [-?-]go..[---] G-201

Graffito incised on a potsherd. The last two traces of letters could be read as $\langle\mathrm{y}\rangle$ or $\langle\mathrm{r}\rangle$ and $\langle\mathrm{i}\rangle$ or $\langle\mathrm{k}\rangle$. However, there are no parallels to this sequence to clarify both the reading and the meaning.

CIPPh I, 167; Orel 1997a, 214 and 431.

$[---] d[---](?)$

OPhr. [---]d[---] G-300

Damaged graffito on a potsherd where only a letter remains.

Brixhe 2002a, 61.

$[-?-]]^{2}[-?-](?)$

OPhr. [-?-] d? $^{?}[-?-] \mathrm{G}-330$

Damaged graffito on a potsherd where only two fragmented strokes remain.

Brixhe 2002a, 61.

$[---] d a(?)$

OPhr. [---]da G-204

Incised on a fragment of a pithos, this sequence begins with a strange inscription: [---]da alu $m$ $s$ [-?-]. Orel $(1997 \mathrm{a}, 216)$ connected it to the obscure W-10 formula alus si $\uparrow$ eto das and, in 421, tentatively considered it a PN. However, the contexts are really different and this graffito remains still obscure.

CIPPh I, 168; Orel 1997a, 216 and 421.

[---].da.[---] (?)

OPhr. [---].da.[---] G-238

Graffito incised on a potsherd. Bayun and Orel (1988a, 198, and Orel 1997a, 230 and 445) considered it the dat. of midas: [m]idai. Although it fits well with the remaining damaged strokes, it cannot be corroborated.

CIPPh I, 188; Bayun \& Orel 1988a, 198; Orel 1997a, 230 and 445.

\section{[---]deda[---] (?)}

OPhr. [---]deda[---] G-01 a

Written on a highly fragmented calcareous slab, this sequence, as well as the rest of the text, remains unclear: [---]isvolkay ! dumey ay : [---]deda[---]. According to CIPPh (I, 183), the tempting identification with the verb edaes is imprudent (even so, Orel 1997a, 156-157 restored this verb here).

CIPPh I, 183. 
[---]dio[---] (?)

OPhr. [---]dio[---] or [---]odi[---] or [---]no[---] or [---]on[---] G-343

A graffito incised on a potsherd, its writing direction, as well as the reading itself, is ambiguous. Consequently, this sequence remains unclear.

Brixhe 2002a, 97.

\section{[---]d'oi o $^{?}[---](?)$}

OPhr. [---]d'o? o? ? $^{2}[--] \mathrm{G}-102 \mathrm{~b}$

Graffito incised on a potsherd contiguous to [-?-]kad. Orel (1997a, 168 and 424), taking the reading as certain, connected it to PNs such as $\triangle o \alpha$ (Cappadocia) and $\Delta o \mathrm{o} \alpha$ (Pisidia, see KPN 149$150 \$ 291)$. However, since the reading is highlu uncertain, this interpretation is of little value. CIPPh I, 96-97; Orel 1997a, 167-168 and 424; Kloekhorst 2015, 115.

\section{[---]doika.[---] see adoikavos.}

\section{$[-?-] e[.] u.[. .].(?)$}

OPhr. [-?-]e[..]u[...] P-01

A very obscure sequence at the beginning of the inscription on this stone block: [-?-] | [-?]e[..]u[... t]ovo iman [-?-] | [-?-]. It has been read as evvuio by Orel (1997a, 209), but it does not fit well with the remaining traces.

CIPPh I, 228; Orel 1997a, 209.

$[---] . e(?)$

OPhr. [---].e G-256

Graffito incised on a potsherd. It seems that the complete remaining letter is the last one because no more traces are found, but the text is too short to be interpreted.

CIPPh I, 199; Orel 1997a, 237-238 and 471.

\section{$[---] e[---](?)$}

OPhr. [---]e[---] C-01

The remaining letter between two gaps on a fragment of calcareous slab, which cannot be identified. Its context is not much clearer: [---]e[---]alabịos [---].

CIPPh I, 220; Orel 1997a, 246 and 471.

\section{$[---] e[---](?)$}

OPhr. [---]ẹ[---] B-05 1. 4

An unclear sequence. The context does not shed light on a possible interpretation: key estat pator. ike[...]e[... ạndạti | vạy niptiyạy...

$[\ldots . . . . ..] \varepsilon(?)$

NPhr. [.........]ह $58.1(72) 1.6$

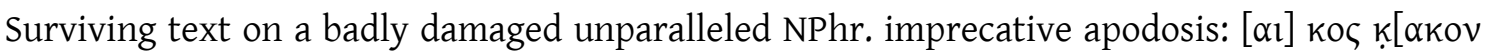

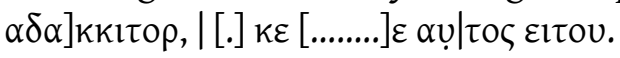

$[--] \operatorname{eg} i^{2} i \cdot[---](?)$

OPhr. [---]eg? $i^{2}$. [---] G-206

Incised on a potsherd, this unparalleled sequence has not been definitively read. As such, it remains obscure.

CIPPh I, 169; Orel 1997a, 206 and 472. 
[---]edleia[---] (?)

OPhr. [---]edleia[---] T-03a II 1. 3-4

An unparalleled sequence on a badly damaged stele: [---]sn|a[---]|[---]ed|eia[---]ọ $r \uparrow e \mid s ! \operatorname{ar}[---]$.

Brixhe 1991, 39; Orel 1997a, 472.

[---]edekm[---] see tekmor.

[---].evei $\mathbf{S}^{3}[---](?)$

OPhr. [---].evei?'s[---] G-143

Graffito incised on a potsherd. Despite the difference of the vowel, it has been equated to the ending of memevais by Orel (1997a, 189-190). While this is the only feasible parallel, the sequence is so badly preserved that it must remain tentative.

CIPPh I, 130; Orel 1997a, 186-187 and 472.

[---]evi. (?)

OPhr. [---]evi.? G-04

An obscure, damaged sequence on a fragmented calcareous block: [---]evi.? | tatas.[---]|[--].m..[--] [-?-]. The last doubtful letter could be an (0).

CIPPh I, 90; Orel 1997a, 163.

[-?-]ẹ़:

OPhr. [-?-]eiv[---] G-279

Fragmented graffito incised on a potsherd. We do not know if its beginning is lost. Brixhe (2002a, 41). This sequence is only attested in the word P-03 kanutieivais. However, as Brixhe admitted, it could be the product of chance.

Brixhe 2002a, 41.

$[--] \boldsymbol{\varepsilon l}$ (noun?)

NPhr. sg.dat.? [---]عi $37.2(30)$

Read on a Phrygian stele door, this inscription is badly damaged and has no clear parallel: [.............]

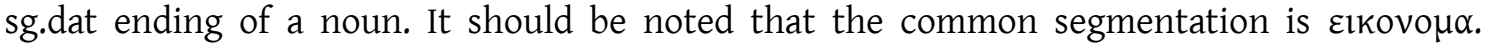
However, this has been rejected here because ovoux is a clear word. On the other hand, Orel

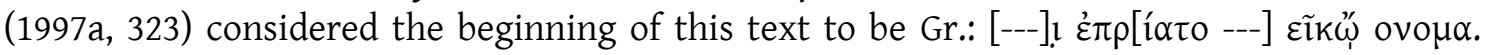

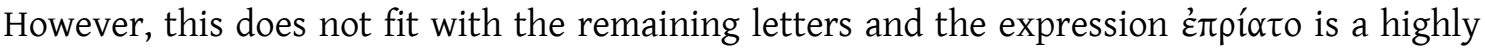
unusual finding in tombs from Phrygia.

Orel 1997a, 323.

\section{[-?-].eivanous [-?-] (adjective?)}

OPhr. sg. nom.? [-?-].eivanous[-?-] G-250

This fragmented graffito on a potsherd has been equated to kanutiievanos (sg.nom.) by Bayun and Orel (1988a, 200), despite the difference in ie ei. However, it could be an analogous adj. formation. The spelling -ous remains the ending of the PN vasous (nom.). In the light of this parallel, a word boundary can be assumed after the last remaining letter.

CIPPh I, 196; Bayun \& Orel 1988a, 200; Orel 1997a, 235 and 472.

[---]eka? $[---](?)$

OPhr. [---]eka'[---] T-01 a

One of the fragments of a stele on which only this sequence remains. Because of its brevity, this sequence remains unclear. The reading $[v r] e k u[n]$ given by Orel $(1997 a, 307)$ does not fit the last readable letter. 


\section{[---]ekeay (DN?)}

OPhr. sg.dat. [---]ekeay G-10

Read on a fragment of stone. According to Brixhe (2002a, 31), it can be an a-stem sg.dat. word, perhaps an epiclesis of matar if this is the dedicatee of the inscription. The word is only followed by imelan, a possible noun referring to the object to which it is dedicated. However the text is too short to give a clear interpretation: [---]ekeay! imelan.

Brixhe 2002a, 31.

...ẹkẹs (noun)

OPhr. pl.nom. ...ekes HP-114

Read on the clay tablet from Persepolis, it is preceded and followed by the number 30. Despite the unreadable letters, it is very likely the ending of an athematic noun in the pl.nom, similar to the other words in the text such as m?akeres.

Brixhe 2004a, 125.

\section{$[---] e^{?} ! \underline{t}[---](?)$}

OPhr. [---] $e^{?} ! \underline{y}[---]$ or [---] $e^{?} y \varphi_{0}[---] \mathrm{G}-180$

Found on a potsherd, this graffito is badly damaged and even the reading remains unclear.

CIPPh I, 155; Orel 1997a, 206 and 472.

\section{[......] $] \mu \varepsilon p \eta$ (noun?)}

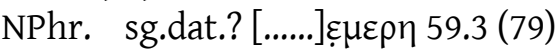

Partial word read on a large worn slab used as tombstone. It occurs in an unparalleled

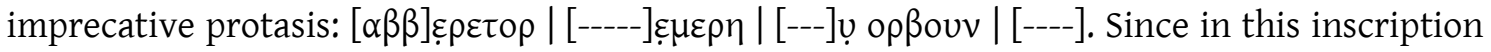
the word boundaries fit with the lines it is clearly the ending of a word and because of the ending $-\eta$ it is very likely an athematic sg.dat.

\section{[.]erktẹvoys (?)}

OPhr. sg.dat.? [.] erktẹvoys B-01

According to Bayun and Orel (1988a, 188, also Lubotsky 1993b, 97), this sequence on the Germanos inscription is likely to be an o-stem sg.dat. of an unidentified word. Orel's (1997a, 143) reading verktevoys and his consequent interpretation are difficult to defend in the light of the remaining letters and the lack of parallels.

Bayun \& Orel 1988a, 188; Lubotsky 1993b, 97; Orel 1997a, 139, 143 and 467.

\section{[---]es (PN?)}

OPhr. [---]es G-126; [---].es G-130

Graffiti on potsherds, in G-126 this ending has been identified by Orel (1997a, 183) as the ending of a verb in aor. However, it could be also the ending of a masc. PN in the sg.nom., e.g. in the light of ates or manes, as he also admits for G-130. In the latter inscription, it is followed by the unparalleled word(s) servas bo.[---].

Orel 1997a, 180, 183 and 472.

\section{$[---] e^{2} y y[---]$ see $[--] e^{?} ! v[---]$.}

[-?-]e[.] (?)

OPhr. [-?-]e[.] W-11

Severely damaged text on an undated stone altar: [?.]y[?] $]$ agaua | [-?-]tatae? [..?] [-?-]e[.]. 


\section{$[--] . v e i\left[.{ }^{2}\right] s(?)$}

OPhr. [---].vei[.] $]$ G G-247

Graffito incised on a potsherd. The first stroke could correspond to 1 or $y$. Close to this first sign are two points considered accidental by CIPPh (I, 194) but taken to be interpunction by Orel, who segmented the graffito as [---]y: vei[o]s, although this interpretation must be rejected in the light of the first considerations. The final doubt concerns a blank space where a small $o$ could be written according to the first editors. If this were the case, it would correspond to an sg. nom. o-stem ending with the suffix -eio- attested in langineios, voineios and kpiyanaveyos / $k \uparrow$ ianaveyos.

CIPPh I, 194; Orel 1997a, 234.

\section{[---]vesța (?)}

OPhr. [---]vesta G-165

Unparalleled graffito on a potsherd. Orel $(1997 a, 200)$ suggested that it could be a separate word and equated it to Gr. $\dot{\sigma} \sigma \tau$ í ' 'hearth, fireplace, altar'. However, given the size of the space, where more letters would fit, this interpretation is highly tentative.

CIPPh I, 146; Orel 1997a, 200.

\section{$[--] v 0[---](?)$}

OPhr. [---]vo[---] G-01 a

The two remaining letters of the first two lines of this stone slab.

[---]voṣli[---] see vosịk ${ }^{2}[---]$.

\section{[---]vi.is[---] (?)}

OPhr. [---]v.i.s[---] G-152

Incised on a potsherd, this graffito could be read, without a clear favourite, as [---]vaias[---], [--]vaies[---], [---]veias[---] or [---]veies[---], according to CIPPh (I, 138). Orel (1997a, 194-195 and 466) overlooked the other possibilities and read it as vaias, for which he suggested an Iranian origin. However, his interpretation is ungrounded since no parallel can be adduced.

CIPPh I, 138; Orel 1997a, 194-195 and 466.

$[--] \mathfrak{l}(?)$

NPhr. [---] $37.2(30)$

The first letter conserved in 37.2. It occurs in an unparalleled and badly damaged word: [---] $\varepsilon \pi \rho ! \mid[---]$.

\section{$[--] i a(\mathrm{PN}$ ?)}

OPhr. [---]ia P-102

On a fragment of handle, the whole sentence [---]ia aspẹ[---] has been interpreted, doubtfully, as a two-limbed PN by CIPPh (I, 245). Consequently, it is an a-stem nom. of an unknown PN. CIPPh I, 245; Orel 1997a, 303 and 472.

\section{[---]ies (?)}

OPhr. [---]ies G-265

This fragmented graffito on a potsherd is convincingly equated by CIPPh (I, 205) to the nom. ending of PNs such as eies, garies or paries and ieies.

CIPPh I, 205; Orel 1997a, 241 and 472. 


\section{[-?-]i?o. (?)}

OPhr. [-?-]i?o. or v'o.[-?-] G-287

A very doubtful grafitto read on a sherd. The writing direction is not at all clear, the key being found in a small stroke of what has been identified as a $v$, which could be accidental. Brixhe (2002a, 47-48) suggested that if it is to be read as [-?-]i'o it can be a sg.gen ending. However, an abbreviated PN (the most common text in this kind of graffito) cannot be excluded here.

Brixhe 2002a, 47-48.

[---]ime[---] (?)

OPhr. [---]ime[---] G-179

Incised on a potsherd, this graffito contains a sequence which is only attested in the name iman, imenos (only in oblique cases, perhaps a dat. ime[ney]) and its fem. imeneia. However, the reading is far from certain and should be treated with caution because we could be dealing with a word boundary like [---]i me[---].

CIPPh I, 154; Orel 1997a, 206 and 472.

[---]in see ni[---].

$[-?-] \operatorname{ir}[-?-](?)$

OPhr. [-?-]ir[-?-] or [-?-]kr[-?-] NW-114

The writing direction of this damaged graffito incised on a potsherd is unknown, so the reading of the remaining strokes is not at all clear.

CIPPh I, 20.

$[---] ı(?)$

NPhr. [---]ı $26.2(38)$

A damaged sequence found after a clear and complete imprecation. Because of the gaps, it remains obscure: $\tau ו \tau \varepsilon y[-] \mid[-$ c. 9 -]ı५.

[.] ]isdọ[---] (?)

OPhr. [?.]isdọ[---] o [---]ọsi.?[---] B-106 a

Incised on a potsherd, the writing direction of this graffito is unclear, so any interpretation must be highly tentative. If we accept the first reading, proposed by Brixhe (2004a, 91), a word boundary can be considered between the two consonants: [.?]is dọ[---]. On the other hand, if [---]ousi.'[---] is preferred, the presence of an ending -ous (see vasous) could be identified. The text, then, remains obscure.

Brixhe 2004a, 90-91.

\section{[---]isvolkay (?)}

OPhr. [---].isvolkay G-01a;

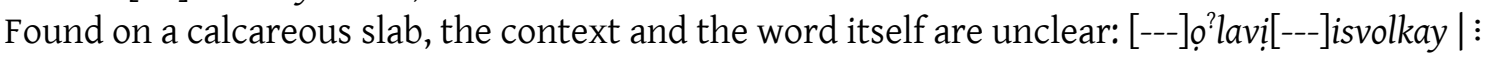
dumeyay : [---]deda[---].. The reading given by Orel [---]aisvoykay is ungrounded because the alleged first $a$ is totally incompatible with the remaining strokes and the alleged first yod is not inclined.

Lubotsky 1989b, 152.

\section{$[--]$ ita[---] $(?)$}

OPhr. [---]ita[---] G-01 a

The few legible letters of a badly damaged inscription on a slab: [ ]ita.[ ] terkeya ask|[---]. The text is too short to be interpreted. The restitution [pr]oita[vos] given by Orel $(1997 \mathrm{a}, 158)$ is based on the reading of an accidental mark on the surface of the stone and it must be rejected. 


\section{[---]itan (?)}

OPhr. [---]itan T-03 b

A clear ending of a noun read on a fragment of stele found in Tyana: $\vdots$ eptuve[---] | [---]itan $m e||[---] p$ ? is : [---]. It may correspond to a word in sg.acc.

Brixhe 1991, 39.

\section{[-?-]kad see kad.}

\section{[---]kakrayun (?)}

OPhr. sg.ac. [---]kakrayun G-03

Read on a block, this unparalleled sequence is followed by a fragmented word: [-?-]kakrayun ni[-?-]. It could be a sg.ac. noun with the same ending as akaragayun, but this is not at all clear. On the other hand, Orel (1997a, 162 and 412) read here an adj. akrayun equated to Gr. ókpaĩos 'dwelling on heights' and considered it an epithet of a masculine god. However, the context does not allow this to be corroborated.

CIPPh I, 88.

\section{[-?-]kalai[---] (?)}

OPhr. [-?-]kalai[---] G-177

A fragmented graffito incised on a potsherd. Perhaps the beginning is preserved. It is very likely a PN. Bayun and Orel (1988a, 198, also Orel 1997a, 204-205) considered it to be the anthroponym that occurs on G-171, which they read as kale instead of [---].ale [---]. However, this last graffito is not as clear as it seems in Bayun and Orel and the relation is far from certain.

CIPPh I, 153-154; Bayun \& Orel 1988a, 198; Orel 1997a, 204-205.

\section{[-?-]keno[-?-] (?)}

OPhr. [-?-]keno[-?-] G-221

This sequence, incised on a potsherd, can only be equated to kenos G-297, but the relation is unclear. Note that in G-221 it appears in an obscure text ([-?-]a.iy[-?-]|[-?-]keno[-?-]|[-?-] atas...), while in G-297 it is isolated. Orel (1997a, 222-223) gave the reading [---]kena[---] in his commentary (but not in the transliteration) and considered it another occurrence of akenanogavos. However, his adduced ‘a〉 (and his consequent interpretation) must be refuted in the light of CIPPh (I, 178).

CIPPh I, 178-179; Orel 1997a, 222-223.

\section{[---]kob[---] (?)}

OPhr. [---]koḅ[---] G-168

An obscure sequence incised on a potsherd. Bayun and Orel (1988a, 200, also Orel 1997a, 201) interpreted it in the light of B-01 evkobeyan as an epithet of a divinity. Nevertheless, the contexts and locations of the two words are completely different, so this interpretation remains unclear.

CIPPh I, 148; Bayun \& Orel 1988a, 200; Orel 1997a, 201.

$[--] k o[. . ?] a v[---](?)$

OPhr. [---]ko[..?]av[---] G-316

A highly problematic sequence incised on a potsherd, which remains obscure.

Brixhe 2002a, 73-74.

[-?-]kr[-?-] see [-?-]irr[-?-]. 
$[--] k^{2}$ tra see [---] $u^{2}$ tra.

\section{[---].k.ui (?)}

OPhr. [---].k.ui P-107

A clear ending of a word incised on a potsherd before the beginning of another word: [---].k.ui :

$n[---]$. It remains obscure.

CIPPh I, 251-252; Orel 1997a, 307.

[.] $]$ (mark?)

OPhr. [.?] or [.?]y G-344

An isolated letter incised on a potsherd. The reading is not at all clear.

Brixhe 2002a, 97-98.

\section{[---].l (PN?)}

OPhr. [---].l NW-104

A fragmented graffito on a potsherd. Only the last letter remains legible. Brixhe (2002a, 14) considered it an abbreviation of a PN.

Brixhe 2002a, 13-14.

\section{[---]lasime.[---] (PN?)}

OPhr. [---]lasime.[---] G-216

A fragmented graffito incised on a potsherd that remains obscure. Bayun and Orel (1988a, 200) suggested a segmentation [---]las imen[---], where imen[---], which they equated to the fem. PN imeneia. However, if this is true, here [---]las must be the ending of a masculine PN, thus it cannot be a compound PN in sg.nom. On the other hand, the adduced imen[---] could be a dat. imen[ey]. Nevertheless, this is far from certain and cannot be corroborated. Note that Orel (1997a, 220) equated it to PNs such as $\Lambda \alpha \sigma \alpha \mu \circ \varsigma$ and $\Lambda \alpha \sigma \sigma \alpha \mu \circ \varsigma$ (attested in Gr. inscriptions from Phrygia, see KPN 269 § 798-2). However, the Phrygian occurrence does not fit at all with the adduced Gr. parallels.

CIPPh I, 175-176; Bayun \& Orel 1988a, 196 and 200; Orel 1997a, 220.

$[---] l e .[---](?)$

OPhr. [---]le.[---] K-01 VIII

An isolated fragment of the stele from Kerkenes Dağ. It is too short to provide any useful information.

Brixhe \& Summers 2006, 129.

[---].len? (?)

OPhr. [---].len ${ }^{?} \mathrm{~T}-01 \mathrm{~b}$

A clear ending of a word in the severely damaged context of the stelae from Tyana: [---]sid.[---] $\mid$ [---].len $\vdots i t[---] \mid$ [---]ponani : [---]. Although the reading of the last letter is dubious (but $n$ is more plausible than an ending in $-l$, which is another possibility), it is perhaps a word in sg.acc.; note that this ending is recorded in the fragment $\mathrm{T}-02 \mathrm{~b}$, oitumen.

CIPPh I, 260.

\section{[---]liake (?)}

OPhr. [---]liake HP-02

Read on the stone inscription found in Parion. Brixhe and Keleş $(2011,158)$ suggested the possibility of an $a$-stem word [---]lia and the copulative conj. ke. However, it remains unclear because of the fragmentation of the text: [-?-]| tanari[---]|[---]liake | edaie [-?-].

Brixhe \& Keleş 2011, 158. 
[---]l?ie....mị[----] (?)

OPhr. [---]! i.e....mi[---] G-196

A very problematic graffito incised on a potsherd. The reading is far from clear. Bayun and Orel (1988a, 198, also Orel 1997a, 213-214 and 442) considered that there is a beginning of a PN.

CIPPh I, 164; Bayun \& Orel 1988a, 198; Orel 1997a, 213-214 and 442.

[---].m.[---] (?)

OPhr. [---].m.[---] G-04

The only certain letter of the third remaining line of this stone block: [---]evi.? $\mid$ tatas .[---] [---].m.[---] | [-?-]. Orel (1997a, 163) read the word iman here, which is a plausible fit with the remaining strokes. However, it is preferable to be cautious because of the poor state of conservation of the text.

CIPPh I, 90 .

\section{$[---] m a(\mathrm{PN} ?)$}

OPhr. [---]ma G-301

A graffito incised on a potsherd. According to Brixhe (2002a, 62), it is the ending of an $a$-stem PN in sg.nom. such as mama.

Brixhe 2002a, 62.

\section{[---]ṃ?agi.[---] (?)}

OPhr. [---]mªgi.[---] G-240

An incomplete graffito incised on a potsherd. Although the first letter is not at all clear, CIPPh (I, 190) ruled out the reading 〈l〉. Consequently previous and subsequent (such as Orel 1997a, 231 and 440) interpretations which equated it to lagineios must be rejected.

CIPPh I, 190.

.$\mu \alpha \rho \delta \boldsymbol{\imath}(?)$

NPhr. . $\mu \alpha \rho \delta 116.1(116)$

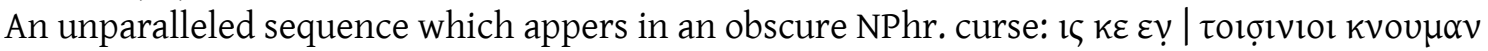
$\tau \imath \alpha \nu \tau \varepsilon . \mid$. $\mu \alpha \rho \delta \delta_{1} \imath \delta \varepsilon \tau 0 \imath$ olvı५.

[---]mª̣esi..[---] (?)

OPhr. [---]ṃacesi..[---] G-07

The sole remaining sequence of this stone inscription. It has no parallel. Orel $(1997 \mathrm{a}, 164)$ suggested a word-division and the reading [---]m? aes iya[---]. However, despite his explanation

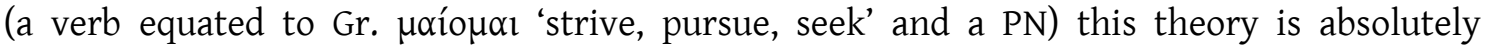
ungrounded. Consequently, the sequence remains unclear.

CIPPh I, 91; Orel 1997a, 164.

\section{[---]ṃe.[---] (?)}

OPhr. [---]me.[---] G-220

A fragmented graffito incised on a potsherd. It is too short to warrant discussion.

CIPPh I, 177-178; Orel 1997a, 221-222 and 472.

\section{[...]meass d? $d^{2} u^{2} m i \mathfrak{i} d(?)$}

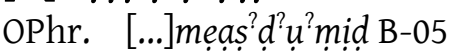

A very dubious sequence at the end of the first line, whose reading and segmentation are unclear, as is the context: sin=t imenan kaliya ti tedat[...]edekm[...]meas? d? ư? mid | iben edatoy dakeran... Perhaps there are two words: [...]mẹs ${ }^{?} d^{?} u^{?}$ ? mid 


\section{[-?-]me $\operatorname{Ii}[-?-](?)$}

oPhr. [-?-]me? Ii[-?-] G-244

One of the two possible occurrences of the rare letter I. However, a Gr. inscription cannot be ruled out. In any case, this graffiti remains unexplained.

CIPPh I, 192; Orel 1997a, 232 and 472; Morante Mediavilla 2000, 190-196.

\section{$[---] n(?)$}

OPhr. [---]n T-02 b; [---]n T-02b, G-288; [-?-]n G-260; [.?]n B-07

In all cases it is the last letter of a lost word. In T-02, a stele fragment from Tyana, both instances seem to be the sg.acc. ending, especially the second one, which could agree with batan: [---]oitumen : mida[---]|[---]n $a$ 个ios $\vdots$ mi[---] [---]n $\vdots$ batan $: e .[---] . .$. In B-07 it is a damaged word in an imprecative apodosis: yos tiv[.|.?]n ke devun $\mathrm{k}(e)$ umnotan ordoineten... The other two occurrences are graffiti on potsherds where only this letter remains and are very likely to be owners' marks. G-260 is perhaps written in Gr. and not in the Phrygian alphabet (CIPPh I, 201202).

CIPPh I, 201-202; Roller 1987a, 41; Orel 1997a, 472.

\section{$[---] . n a(?)$}

OPhr. [---].na T-02c

An unknown sequence on a badly damaged stele fragment from Tyana: [---] | $€$ ea.[---]|[---].na.

[---]ne[---] (?)

OPhr. [---]ne[---] G-156

A broken graffito incised on a potsherd.

CIPPh I, 140; Orel 1997a, 196 and 472.

\section{[---]nimoi (noun?)}

OPhr. [---]nimoi T-03c

A clear ending of a word, perhaps sg.dat. or pl.nom., read on a badly damaged fragment of a stele from Tyana: [---]us.t.[---][[---]nimoi $:$ eko..[---].

Varınhoğlu 1991, 30; Vassileva 1992, 3; Orel 1997a, 315 and 472; Brixhe 2004a, 102.

\section{[---]no (?)}

OPhr. [---]no G-320

According to Brixhe (2002a, 77), a clear abbreviation of a unclear word. It is read on a potsherd that shows an arrow incised under the word.

Brixhe 2002a, 77.

[---]no[---] see [---]dio[---].

\section{[---]nolo[----] (?)}

OPhr. [---]nolọ[---] G-255

A broken graffito incised on a potsherd. This sequence is unparalleled in Phr. and remains obscure.

CIPPh I, 198-199; Orel 1997a, 237 and 472.

\section{[---]nst[---] (?)}

OPhr. [---]nst[---] W-05b

A severely damaged sequence read on a rock under a niche: $[\quad] n s t[\quad$ e]daes por matẹ[...]. Orel 1997a, 45. 
[---]ọ[---] (?)

OPhr. [---]o[---] T-02a

The sole remaining letter of the first line of this obscure stele fragment from Tyana: [--- $o_{0}[---] \mid$

[---].tade.[---]|[---]pipi.[---]|[-?-].

$[--]$ (?)

OPhr. [---]ọ G-111

The last letter of a lost word. On the potsherd where it is read it is followed by an adjective, but the two forms do not seem to agree: [---]o mekas.

CIPPh I, 104; Orel 1997a, 172 and 472.

[---]odil[---] see [---]dio[---].

[---]or (?)

NPhr. [---]or $11.2(18)$

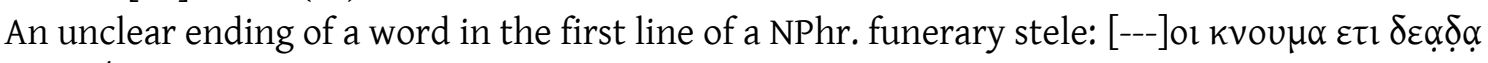
$\mu \alpha v \kappa \alpha \mid v$. Perhaps this ending corresponds to a noun or adj. in sg.dat. or a pl.nom.

[---].oiduo.[---] (?)

OPhr. [---].oiduo.[---] P-105

An unparalleled, broken sequence incised on a potsherd. Orel (1997a, 305 and 425) suggested that the sequence contains the numeral two after a sg.dat. ending. However, this must be rejected because the sequence is extremely doubtful and the conservation of the voiced stop is not expected.

CIPPh I, 248-249; Orel 1997a, 305 and 472.

[---]oitumen (?)

OPhr. [---]oitumen T-02 b

Read on the larger fragment of a stele from Tyana: [---]a $\vdots$ tesan $: a \uparrow i o n: v[---] \mid[---]$ oitumen $:$ mida $[---]$... Orel $(1997,444)$ segmented [---]oitu men and equated the last word to the men Gr. $\mu \eta \mathfrak{v}, \mu \dot{v}^{2}$.

CIPPh I, 266; Lubotsky 1988, 23.

\section{[---]ọitio (?)}

OPhr. [---]ọitio K-01 III

Read on a fragment of the Kerkenes Dağ stele: [---]oitio !? vosik? [---]. The ending of this obscure word is problematic, as are the other occurrences, see, e.g., kavarmoyo.

Brixhe \& Summers 2006, 118.

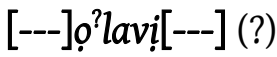

OPhr. [---]ọ?lavi[---] G-01a

One of the fragments of this badly damaged inscription on a slab: [---]vo[---]|[--- sayuve[---] $\mid$ [---]ọlavi[---]isvolkay | : dumeyay : [---]deda[---].

\section{$[---] o^{2} m o y(\mathrm{PN} ?)$}

OPhr. sg.dat.? [---]ơ moy G-323

According to Brixhe (2002a, 79), this fragment of a graffito on a potsherd is very likely to be the ending of a PN in dat.

Brixhe 2002a, 79. 


\section{[---]onn[---] see [---]dio[---].}

\section{$[---] o^{2} r \uparrow e \mid s(?)$}

OPhr. [---]ọr $r e \mid s \quad$ T-03 a II

A badly damaged sequence read on a stele fragment from Tyana: [---]sn | a[---] | [---]ed|eia[---] | [---]o? $r \uparrow e \mid s \vdots \operatorname{ar}[---]$. It is a clear ending of a word which, according to Brixhe $(1991,39)$, may correspond to an athematic pl.acc. or a verb in aor. However, a PN in sg.nom. cannot be ruled out. In any case, it remains remains unclear.

Brixhe 1991, 39.

\section{[---]os (?)}

OPhr. sg.nom.? [---]os G-318

Incised on a potsherd, this graffito shows an ending of a word and the beginning of another: [---]os : im[---]. Although the words are unclear, [---]os is very likely a thematic sg.nom. ending. The same may also be said of [---]ọs G-191, if it is not read as sọ[---].

Brixhe 2002a, 74-75.

\section{$[---] o s v e[---](?)$}

OPhr. [---]osve[---] G-08

Read on a stone fragment, according to CIPPh (I, 92-93) a word boundary can be considered between [---]os and ve[---], where the first element is a thematic sg.nom (thus Orel 1997a, 165). However, it remains unclear.

CIPPh I, 92-93; Orel 1997a, 165.

\section{[-?-]0?ss (?)}

OPhr. o?ss[-?-] or [-?-]sso? G-248

An obscure sequence incised on a potsherd. Even the writing direction is unclear. Note that the gemination is not expected in texts written in the Phr. Alphabet; when it appears, a word boundary can often be considered. However, this sequence is so short that it is difficult to apply the rule in this case. On the other hand, the possibility that we are dealing with "monogrammes indépendants" (Brixhe 2002a, 194) cannot be ruled out, in the light of G-204.

CIPPh I, 194-195; Orel 1997a, 234.

\section{[---]ọusi[---] see [---]isdọ[---].}

[-?-]p see [-?-]p̣?asakas.

\section{[-?-]p?asakas (PN?)}

OPhr. [-?-]p?asakas W-101 b

Incised on a potsherd, where [-?-]p was also written before firing. The whole sequence is unparalleled, but asakas is found on a potsherd from Gordion. Consequently, this initial $p$ is problematic. Is it a different PN from asakas or does it stands for another word? Note that the isolated $p$, which could be same element, may be an abbreviation of another PN. It is perhaps a compound noun whose first element is abbreviated, but this is a very tentative explanation and the reading remains unclear.

Bilgen, Brixhe \& Coşkun 2011, 145. 


\section{[---].pa (PN?)}

OPhr. sg.nom. [---].pa K-01 V

A sequence read on a stele fragment of Kerkenes Dağ: [---].pa ' uva '.[---]. Since it is followed by an onomastic sequence, it may be a PN in sg.nom. without the ending -s. However, it remains obscure.

Brixhe \& Summers 2006, 123.

\section{$[---] p b a s[-?-](?)$}

OPhr. [---]pbaș[-?-] G-174

Incised on a potsherd, this graffito shows an unparalleled cluster, tentatively compared with bba by CIPPh (I, 152). It is possible that the ending of the word is conserved and we can read a PN in sg.nom. However, this remains unclear. CIPPh I, 151-152; Bayun \& Orel 1988a, 199; Orel 1997a, 203.

\section{[---]pipi.[---] (?)}

OPhr. [---]pipi.[---] T-02 a

An unparalleled sequence read on a stele fragment from Tyana: [---]o[---] | [---].tade.[---] | [---]pipi.[---] | [-?-]. Orel (1997a, 308 and 453) suggested that it could be a Lallname but the sequence is not clear enough for this to be stated with any certainty.

Orel 1997a, 308 and 453.

\section{[---]ponani (?)}

OPhr. [---]ponani $\mathrm{T}-01 \mathrm{~b}$

An unparalleled sequence read on a stele fragment from Tyana: [---]|[---]sid.[---]|[---].len? $\vdots$

it[---]|[---]ponani : [---]|[-?-].

CIPPh I, 260; Orel 1997a, 308 and 473.

\section{[---]pis (?)}

OPhr. [---]p? is T-03b

Due to the interpunction, this sequence found on a stele fragment from Tyana is a clear ending of a word: [---]itan mel[---]p̣ is : [---]. However, no other conclusions can be drawn. Perhaps, as Orel (1997a, 315 and 473) suggested, it is a sg.nom. of an $i$-stem word.

Brixhe 1991, 39; Orel 1997a, 315 and 473.

$[---] r \cdot[---](?)$

OPhr. [---]r.[---] G-326

A badly damaged sequence on a potsherd. It is too short to be analysed.

Brixhe 2002a, 80-81.

$[---] . r e(?)$

OPhr. [---].re G-200

[---].re? [-?-] G-205

Fragmented graffiti on potsherds.

CIPPh I, 166 and 169; Orel 1997a, 214, 216 and 473.

[---]ríneme $e^{2}[---]$ (?)

OPhr. [---] $r^{2} e m e^{2}[---]$ G-09

An obscure sequence read on a fragment of stone. 


\section{[---]ripos (PN?)}

OPhr. [---]ripos HP-115

A graffito incised on the bottom of a bowl or vessel. It is very likely a PN, perhaps an o-stem in sg.nom. or a consonant-stem in sg.gen.

Brixhe \& Keleş 2011, 134.

$[---] r k^{2} \cdot[---](?)$

OPhr. [---]rk?.[---] G-207

A fragment of a graffito incised on potsherd. It is far from being clear.

CIPPh I, 170; Orel 1997a, 217.

\section{$[---]$ maniviv[---](?)}

OPhr. [---]rmaniv[---] G-199

An unparalleled, fragmented sequence incised on a potsherd. Orel $(1997 a, 214)$ read here a PN related to manes. However, this interpretation is very tentative and the whole sequence remains unclear.

CIPPh I, 165; Orel 1997a, 214.

\section{[---]ronoț oy (?)}

OPhr. sg.dat.? [---]ronoț?oy G-125

A graffito incised on a potsherd: [---]ronot 'oy (note that $t^{?}$ could be read as $\langle\mathrm{i}\rangle$ or $\langle\mathrm{g}\rangle$ ), it is very likely a PN in sg.dat., the addressee of the object given by t? eies. However, this fragmented PN has no parallel. Orel $(1997 \mathrm{a}, 179)$ suggested as a working hypothesis that if it is read as Jronopios, it could be interpreted in the light of Gr. $\pi \rho 0 v \omega$ mioc 'in front, before the door'. However, this is mere speculation.

CIPPh I, 116; Orel 1997a, 179.

..pọs (noun?)

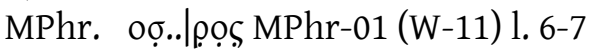

An obscure sequence of unknown nature (perhaps a noun) with epigraphic reading problems.

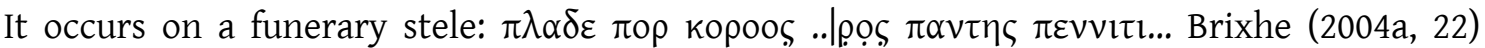

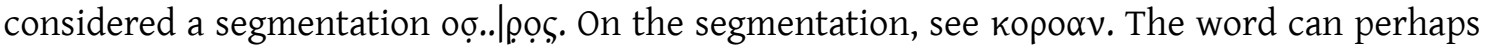

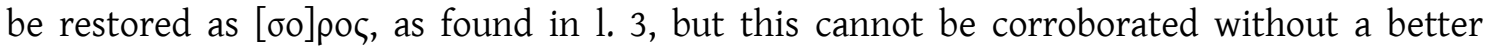
understanding of the context.

Brixhe 2004a, 22.

$[---] s(?)$

OPhr. [---]s M-11

The end of a word incised on a rock before a clear verb: [---]s estaes [---].

$[---] \operatorname{saes}[---](?)$

OPhr. $\quad[---]$ saes $[---]$ G-163

A fragmented graffito incised on a potsherd. This sequence remains unclear.

CIPPh I, 145; Orel 1997a, 199.

\section{$[-?-] \operatorname{sar} \cdot[-?-](?)$}

OPhr. [-?-]sar.[-?-] G-192

A fragmented sequence incised on a potsherd. Orel (1997a, 211) considered it the beginning of a PN of Anatolian origin. However, this cannot be corroborated.

CIPPh I, 145; Orel 1997a, 199. 


\section{$[-?-] s^{?} a u(\mathrm{PN} ?)$}

OPh. [-?-] $]^{?} \mathrm{au} \mathrm{G}-188$

A fragmented graffito incised on a potsherd. According to CIPPh (I, 159), it is an abbreviation because of the unparalleled ending -au. Perhaps a PN.

CIPPh I, 159; Orel 1997a, 209 and 471.

\section{[---]ṣayuve[---](?)}

OPhr. [---]sayuve[---] G-01 a

A fragment of the very damaged slab: [---]vo[---]|[---]ṣayuve[---]|[---]ọ?lavi[---]... This sequence, and indeed the whole inscription, remains unclear.

CIPPh I, 83.

\section{$[---] \operatorname{ser} \cdot[---](?)$}

OPhr. [---]ser.[---] G-159 a

Read on a potsherd which seems to have another non-contiguous written fragment: G-159a [---]aios[-?-]. According to CIPPh (I, 142-143), they may be parts of the same text. Orel (1997a, 197 and 457), on the other hand, considered it another occurrence of servas in G-130. However, these interpretations are very tentative.

CIPPh I, 142-143; Orel 1997a, 197 and 457.

$[---]$ seti see ot.[....]seti.

$[---] s ̦ e u \cdot[---](?)$

OPhr. [---]seu.[---] G-181

An obscure sequence incised on a potsherd. It is too short to be analysed.

CIPPh I, 155-156; Orel 1997a, 206 and 473.

\section{[-?-]si[-?-] (PN?)}

OPhr. [-?-]si[-?-] NW-102

One of three graffiti incised on this potsherd: [-?-]si[-?-]| alis|[---]. It is perhaps an abbreviation of a PN, in the light of alis.

Brixhe 2002a, 12.

[---]sid.[---] (?)

OPhr. [---]sid.[---] T-01b

One of the few damaged fragments read on a stele fragment from Tyana: [---] | [---]sid.[---] | [---].len? $\vdots i t[---]|[---] p o n a n i:[---]|[-?-]$. The text is completely fragmented and remains unclear. CIPPh I, 259-260.

\section{$[-?-] \operatorname{sit}[---](?)$}

OPhr. [---]sit[---] G-154

This graffito incised on a potsherd can also be read as [---]tis[-?-], but the first reading is preferable because of the strokes of its $s$. Either way, it remains unclear.

CIPPh I, 195 and 457.

[---]sn (?)

OPhr. [---]sn T-03 a II

A very damaged sequence read on a stele fragment from Tyana: [---]sn $|a[---]|[---] e d \mid$ eia[---] | [---]ọ? $r \uparrow e \mid s \vdots$ ar[---].

Brixhe 1991, 39. 
[-?-]sso? see o ${ }^{?} s[-?-]$.

$[--] s^{2} a t e .[---](?)$

OPhr. [---]ș ate.[---] G-307

An unparalleled, fragmented graffito incised on a potsherd. It remains obscure.

Brixhe 2002a, 66-67.

[---.tade.[---] (?)

OPhr. [---].tade.[---] T-02a

An unparalleled sequence read on a stele fragment from Tyana: [---]ọ[---] | [---].tade.[---] | [---]pipi.[---]|[-?-].

$[---]$ ten see $[---] g e n$.

[---]t? erkeya (?)

OPhr. [---]t? erkeya G-01 b

An obscure sequence on a badly damaged slab: [ ]ita.[ ] ] țerkeya ask|[---]. It is very likely to be a fem. adj. in sg.nom. due to the presence of -eya, see, e.g., kubeleya. This does not mean that it is necessarily an epithet of the Mother-Goddess, as Orel (1997a, 158) considered. However, it remains unclear.

CIPPh I, 84; Orel 1997a, 158.

\section{[---]t? $t^{2}$ itenorola[---] (?)}

OPhr. [---] t? vitenorola[---] G-141

An unparalleled graffito incised on a potsherd. Despite the segmentation suggested by Orel (1997a, 188-189), it remains unclear.

CIPPh I, 128-129; Orel 1997a, 188-189.

$[---] t i$ see $i t[---]$.

[---].ti (?)

OPhr. [---].ti P-106

A clear word end in a longer graffiti incised on a potsherd: [---].ti : makio ${ }^{2} t a T i b i:$.[---]. It is perhaps a verbal ending (3sg., as Orel 1997a, 305 and 473 suggested) but it remains unclear, as does the remainder of the text.

Orel 1997a, 305 and 473.

\section{$[--] t^{3} i^{3} a(?)$}

OPhr. [---]t $t^{2}{ }^{2} a \mathrm{G}-223$

A graffito incised on a potsherd. Its first two remaining letters can be read in the opposite direction: [---] $i^{2} t^{2} a$. It is considered an $a$-stem sg.nom. by Orel (1997a, 224 and 472), but it remains unclear because it could be a mere abbreviation.

CIPPh I, 179-180; Orel 1997a, 224 and 472.

\section{[---]țivi.[---] (?)}

OPhr. [---]țivi.[--] G-219

A fragmented graffito incised on a potsherd. Due to the lack of parallels it remains unclear. 


\section{[---]t'i isiteoy (PNs?)}

OPhr. [---]t? $i^{?}$ siteoy or [---] $g^{?} i$ 'siteoy B-104

The reading of the beginning of this broken graffito incised on a potsherd is far from clear. Moreover, the second remaining letter could also be read as $u$, although this is less probable. A very likely interpretation is given by Brixhe $(2004 a, 89)$, who suggested that two names can be read here: the sg.nom. ending of the first one [---] $t^{?} i$ ? $s$ and a complete second one in sag.dat., iteoy. However, this remains a working hypothesis.

Bakır \& Gusmani 1993, 144; Brixhe 1996, 140-141; Brixhe 2004a, 88-89.

\section{[---]toyen (PN?)}

OPhr. [---]toylen W-04

The last readable sequence of a text engraved on a rock niche: matar kubileya [---]toy|en. Its ending perhaps corresponds to a sg.acc. noun or the series of probable PN sg.nom. in -en (see Lubotsky 1988, 23). However, the loss of the previous word makes the interpretation of this text very doubtful.

Lubotsky 1988, 23.

\section{[..]toyo[.]is (?)}

OPhr. [..] toyo[.]is B-01

An damaged sequence in the obscure inscription from Germanos. However, it seems to be an imprecative context: yos tivo [t]a spereta ayni kin te[l]ẹmi | [..]toyo[.]is [.]erktẹvoys ekey dạ[b]ati... The possibility that there are two words is ruled out by Lubotsky $(1993 \mathrm{~b}, 95)$. Lubotsky 19936, 95.

\section{[---].tuti.[---] (?)}

OPhr. [---].tuti.[---] G-261

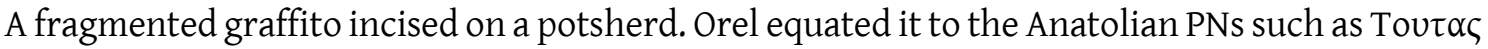
(from Pisidia and Cilicia, KPN 523 § 1596-1). However, the unidentifiable stroke before the first readable letter invalidates this theory.

CIPPh I, 202-203; Orel 1997a, 239 and 465.

\section{[---] tumida (?)}

OPhr. sg.nom. [---]țmida T-02 b

An $a$-stem PN in sg.nom. without the ending -s, perhaps complete. It is followed by a patronymic on a fragment of a stele from Tyana: [---] | [---] țumida $\vdots$ memeuis $\vdots[---] \mid[---] a \vdots$ tesan $\vdots$ a ion $\vdots$ $v[---] \ldots$

CIPPh I, 266; Brixhe 1991, 42; Innocente 1997, 40; Gusmani \& Polat 1999b, 156;

\section{$[--] v(?)$}

OPhr. [---]v 59.3

The ending of an unknown word in a damaged sequence between a clear protasis and a clear apodosis. The verb suggests that it may be another kind of protasis: $[\alpha \beta \beta] \varepsilon \rho \varepsilon \tau o \rho|[. . ..] \varepsilon \mu \varepsilon \rho \eta|$ $[\ldots]$ o o $\rho \beta o u v \mid[\ldots .$.$] .$

$[---] u \underline{a}[---](?)$

OPhr. [---]ua [---] G-328

A severely damaged graffito incised on a potsherd.

Brixhe 2002a, 82-83. 


\section{[---]uiva.[---] (?)}

OPhr. [---]uiva.[---] P-103 a

Graffiti from potsherd with inscriptions on both sides: [---]uiva.[---] in the interior face and [---]uirk[---] on the exterior (P-103 b). Both graffiti remain unclear.

CIPPh I, 246-247; Orel 1997a, 303-304 and 473.

\section{[---]uirk:---] see [---]uiva.[---].}

\section{[-?-]unik[---] (?)}

OPhr. [-?-]unik[---] G-264

Graffito incised on a potsherd. The beginning is probably conserved but it remains unclear. The lack of parallels and the loss of the ending complicate its interpretation.

CIPPh I, 204; Orel 1997a, 240.

\section{[---]vors (?)}

NPhr. [---]vois 15.1 (120)

An unparalleled sequence read on a damaged sentence located after a common NPhr. apodosis:

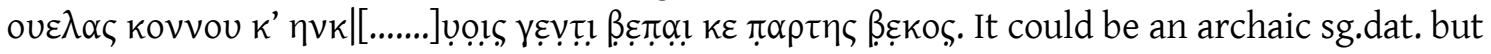
is always written - $\omega \varsigma$ or -o in NPhr. inscriptions. On the other hand, perhaps we are dealing with a noun in pl.acc.?

\section{[-?-].u.s[-?-] (?)}

OPhr. [-?-].u.s[-?-] G-151

A badly damaged sequence incised on a potsherd. It remains obscure.

CIPPh I, 137.

\section{$[---]$ ụs $[---](?)$}

OPhr. [---]ues[---] NW-122

An unparalleled and obscure sequence incised on a potsherd.

Brixhe \& Sivas 2009, 130 .

\section{$[---] u s s a$ see assụ $[---]$.}

\section{[---]ụs.t[---] (?)}

OPhr. [---]us.t. [---] T-03c

Read on a stele fragment from Tyana: [---]ụ.t[---][[---]nimoi : eko..[---]. There is too much damage to reach any conclusions.

\section{[---].uta (?)}

OPhr. sg.nom. [---].uta G-296

According to Brixhe (2002a, 57-58), a probable PN in sg.nom. without the ending -s, similar to mamutas.

Brixhe 2002a, 57-58.

\section{[---]utra (PN?)}

OPhr. [---] $u^{?}$ tra[-?-] or [---] $k^{2}$ tra[-?-] G-233

A broken graffito incised on a potsherd. Despite the two possible readings, it remains unparalleled. It is perhaps an $a$-stem PN without the ending -s. Orel (1997a, 228 and 473) equated it to the Iranian onomastic element -puvra 'son', but it cannot be corroborated. CIPPh I, 185-186; Orel 1997a, 228 and 473. 
$[---] y(?)$

OPhr. [---]y B-06

A clear ending of an unknown word which is also the ending of an obscure sentence before a relative clause: eventnoktoy : ẹmetetariyois | [---]y : yostumoy: $\uparrow$ ekmatin |[---]atonkeyen.

Orel 1997a, 473.

\section{$[---] y^{?} i b[---](?)$}

OPhr. [---]y?ib[---] G-231

A broken graffito incised on a potsherd, without parallels. Orel (1997a, 227-228) considered the segmentation [---]y? ib[---] in the light of ibeya, which he considers an epithet of Matar. However, this theory is ungrounded, and ibeya is now considered a pronoun, which is not a good fit with this kind of text.

CIPPh I, 184-185; Orel 1997a, 227-228.

\section{$[---] y ! l a[---]$ see $[---] a y ! ![--]$.}

\section{[---]yon (?)}

OPhr. [---]yon B-101

A word ending. It could be considered a thematic masc.sg.acc. or neut.sg.nom.-acc. but also a masc.sg.nom. in the light of kuryaneyon. Either way, it remains unclear.

Bakır \& Gusmani 1993, 143-144; Brixhe 1996, 137-138; Brixhe 2004a, 86.

\section{$[---] \uparrow[---](?)$}

OPhr. [---]个[---] T-02 c

An isolated letter read on a badly damaged fragment of stele from Tyana: : ea.[---] | [---].na $[---]|[---]|[---] \uparrow$. This is not an expected ending so we can assume that the text continued after it.

CIPPh I, 267.

\section{$[---] T$ Tis (?)}

OPhr. [---]Tis NW-120

The end of a graffito incised on a potsherd which fits well as a sg.nom. ending of a $i$-stem word. Note the presence of the rare letter, tentatively read as /-ts'is/ by Brixhe and Sivas $(2009,129)$. However, it remains unparalleled.

Brixhe \& Sivas 2009, 129.

\section{$[---] Y o ̣[---](?)$}

OPhr. [---]Yọ[---] or [---]ọ Y[---] G-306

An obscure sequence incised on a potsherd. Even the writing direction is unclear.

Brixhe 2002a, 66. 



\section{The indirect sources: the glosses}

The aim of this chapter is to give a relatively detailed account of the Phrygian glosses in the light of the information provided by the inscriptions. Although glosses were studied during the $19^{\text {th }}$ and $20^{\text {th }}$ centuries to establish the position of Phrygian in the Indo-European language family (see Morante Mediavilla 2007), they must be reconsidered in the light of our better knowledge of the inscriptions. However, because of the complexity of Phrygian onomastics, I decline to study here the anthroponyms, DNs (even epithets) and toponyms considered Phrygian by ancient sources (mainly Greek and Latin). Note that most of the PN borne by Phrygians were borrowed from the surrounding Anatolian languages or the ruling peoples. Glosses containing only PNs, as is the case of twenty lemata in Hesychius' lexicon, are also omitted. ${ }^{217}$ Although some of these names are found in Phrygian and Greek inscriptions from Phrygia, finding the origin is often highly laborious, if not outright impossible. Consequently, I leave this question to be addressed in a future study.

In general, the 29 glosses are not hugely valuable to the knowledge of Phrygian. In some instances they are a good complement to the inscriptions, since they provide the meaning of a word attested therein. Most of them, however, are not expected to be found in the inscriptions because of the nature of these texts. Consequently, it is impossible to corroborate their filiation and one must treat them with particular caution because of the specific problems associated with this kind of evidence.

The first point to be considered is the distinction between the true and the fictitious glosses. Indeed, their origins are often obscure and the information they give (usually very poor) lacks precision. Moreover, it is not unusual for the attribution of a word to a given community to be refuted by other scholars, who may propose a new attribution. Phrygian is particularly susceptible to such false attributions because the ethnic is used as equivalent to 'Anatolian' or even 'oriental' ${ }^{218}$ in compositions as fundamental as the Homeric poems or Virgil's Aeneid.

Even when Phrygia is used as a specific denomination it is important to consider that the territory occupied by the Phrygians changed considerably between the early Iron Age and Roman Imperial times. Most of the OPhr. territory was no longer considered Phrygian after the settlement of other peoples or was split in later provincial divisions. In such a scenario, it is easy to understand both why words which cannot be taken as Phrygian were attributed to this language and why some words identified as Phrygian were attributed to other surrounding peoples (e.g. Bythinians) in ancient sources.

Moreover, the textual transmition of the glosses is often highly complicated, and even their sources are unknown. To this problem, we must add the rarity of the words themselves. Indeed, most of them are hapax only transmitted in one or a small number of manuscripts. This implies that copyists could easily produce misspellings that would go unidentified and uncorrected. So, the the circumstances of the manuscripts and the palaeography are relevant questions.

The glosses now interpreted as having another origin are not included here. That is the case of Gr. ṕíokoৎ (borrowed in Lat. as riscus) 'coffer, chest', said to be Phrygian by Donatus (on Ter. Eun. 754). It is very likely to derive from the Proto-Celtic word *rusko- 'bark' (attested in OIr. rúsc 'id.', MBret. rusquenn 'id.', Gaul. rusc 'beehive', etc., see Matasovič 2009, 317). Beekes (in EDG 1288-1289) considers that "the word would have reached Gr. from Galatian through Phrygian because of the change $u>i$ ". Although the Galatian origin is likely, Phrygian does not explain

\footnotetext{
${ }^{217}$ I follow the criteria established by Adiego 1992 and 2007, 7-8 in his overview of Carian glosses. Adiego's method is also applied by Molina Valero 2010 to Lycian. Both Carian and Lycian, share with Phrygian the problem of being fragmentary languages.

${ }^{218}$ See Haas 1966, 9, Heubeck 1967, 581, Innocente 1995, 216-217 and Matzinger 2005, 377.
} 
such a shift (perhaps a mere itacism?). Consequently, there is no reason to relate this word to Phr.

Another gloss I omit is tiara, 'a kind of cap': tiara est pileum Phrygium quod dicunt 'tiara is a Phrygian cap, as others call it' (Schol. Iuu. Sat. 6.516). ${ }^{219}$ Fick $(1873,415)$ considered it a gloss, but the scholiast does not say that the word is Phrygian: he merely describes the tiara in order to explain what Juvenal is recounting in his verse. At this point, the cap (not the word) is said

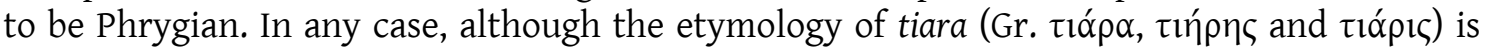
unknown, it is considered an oriental word (related to the Persian world) borrowed from a nonIE language (see EDG, 1481), so there are no grounds for claiming a Phrygian origin.

In addition, the commonly adduced platonic passage, which explains that some Phrygian words are very similar to the Gr. ones (Cra. 410, 1-7, Socrates is speaking), is also

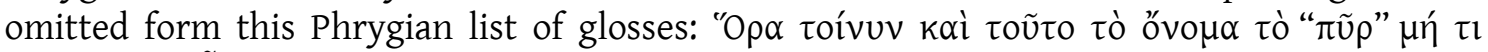

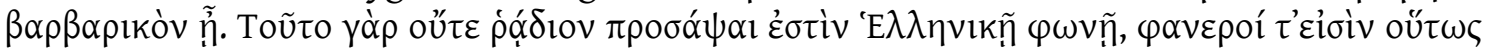

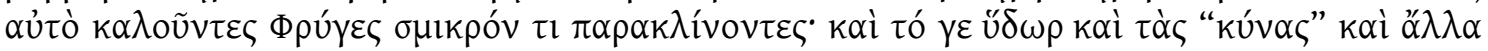
$\pi 0 \lambda \lambda \alpha^{\alpha}$ 'well, this word $\pi \tilde{u} \rho$ is probably foreign; for it is difficult to connect it with the Gr. language, and besides, the Phrygians have the same word, only slightly altered. The same is the case with $v \delta \omega \rho$ (water), kú $\omega v$ (dog), and many other words.' The reason this passage is disregarded is the absence of the Phrygian terms. Indeed, it is said that they are similar to the respective Phrygian words, but the Phrygian forms are not given.

After these considerations, only 28 glosses considered Phrygian by their sources can be analysed in the light of what we know about this languge:

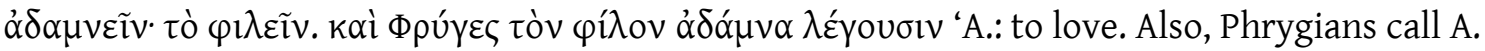

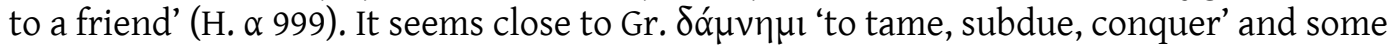

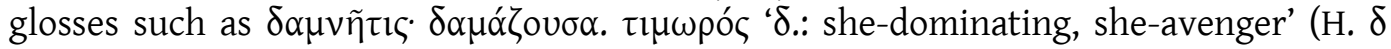

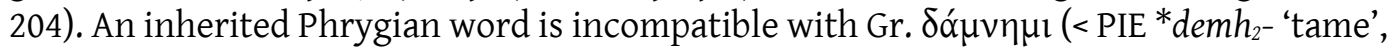
see EDG 301) because of the preservation of the voiced stop. Indeed, a Greek formation (with the so-called " $\alpha$-intensive") is the most likely explanation for $\alpha \delta \alpha \mu v \varepsilon \tilde{v} v$ if one considers the sexual connotations of Gr. Jó $\mu v \eta \mu$.

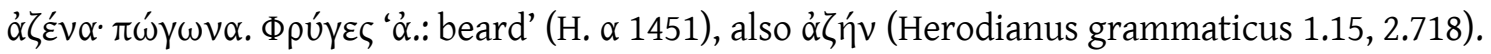
This word has been used to show the satom treatments of velars in Phrygian, since it has been considered to be derived from PIE *génu- 'chin', as well as Gr. үévuৎ 'jaw', Lat. gena 'cheek' (but dentes genuīī 'molars'), Go. kinnus 'id.', Arm. cnawt, ToA śanw-e-ṃ 'id.', skt. hánu 'jaw-bone', etc. However, ’’ $\mathcal{c}^{\prime} v \alpha$ has very significant differences with these suggested cognates: it is not a $u$-stem noun (Lat. gena is reshaped after māla) and the beginning $\dot{\alpha}-$ remains unexplained. Consequently, it is difficult to accept $\dot{\alpha} \zeta \bar{c} v \alpha$ as a Phrygian word inherited from PIE *'énu-, although this etymology is very attractive and a secondary palatalization can be assumed.

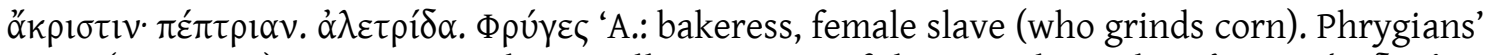

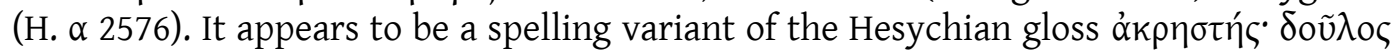
'A.: slave' ( $\alpha 2560$, as DGE 56 seems to assume). According to Kretschmer (1934, 205-206),

\footnotetext{
${ }^{219}$ plebeia et Phrygia uestitur bucca tiara 'his plebeian cheeks are covered with a Phrygian tiara'. The whole scholium reads as follows: Sacerdotis habitu. Tiara nam galea sacerdotis est, quae per malas veniens, mento subligatur. tiara est pileum Phrygium quod dicunt 'in priest dress, since tiara is a priest cap which, falling by the cheeks, is binded in the chin. Tiara is a Phrygian cap, as others call it'. Note that the explanation of this scholium is similar to Isidore's of Sevilla Etymologiae 19.31.4-5 explanation of the mitra, another kind of cap, also considered Phrygian (and counted in Fisk list of Phrygian glosses): mitra est pilleum Phrygium, caput protegens, quale est ornamentum capitis devotarum. Sed pilleum virorum est, mitrae autem feminarum 'mitra is a Phrygian cap which, protecting the head, is an ornament of the devoted women head. Although this cap is proper of men, it is also worn by women'. Although, other texts consider it Lyd. (Alcm. Fr. 1.1.67.69 or Pi. N. 8.15), nowadays its etymology is unclear (EDG, 959 considers a IIr. or Pre-Greek origin).
} 
the suffix -st- could indicate Phrygian origin. However, Beekes (EDG 26) considers the possibility of a Pre-Gr. suffix. In any case, neither Phrygian nor Pre-Gr. is the most feasible explanation for this word. Indeed, ókpı

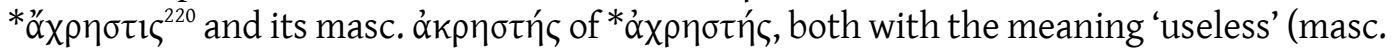

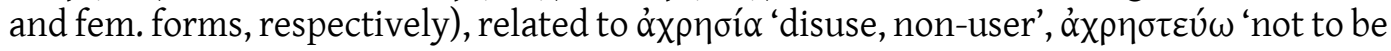

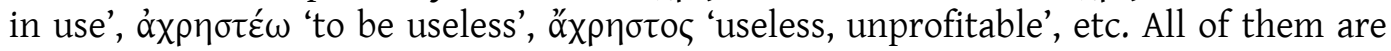
derived from $\chi \rho \alpha$ ó $\mu \alpha 1$ 'to desire, yearn after, use'. Compare the reconstructed form ${ }^{*} \alpha$ -

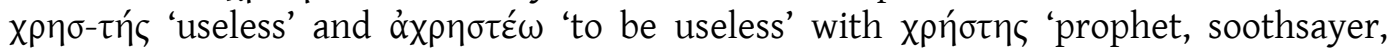
creditor, usurer, debtor' and $\chi \rho \eta \sigma \tau \varepsilon v ́ o \mu \alpha \mathrm{l}$ 'to be kind or merciful', also derived from the same root. Anyhow, the plain pronunciation of the aspirated stop, $\chi>k$ is a well-known feature of Gr. borrowings also found in Gr. inscriptions from Phrygia (see Brixhe 1987a, 110-113). This is very likely the reason why the gloss was attributed to Phrygian. It is also possible that in the source(s) of these glosses - perhaps a comedy - (Phrygian?) slaves were called 'useless' (incidentally, a common topos). One can adduce some verses of Aristophanes' Birds where Manes (a slave with a Phrygian name!) is said to be lazy and

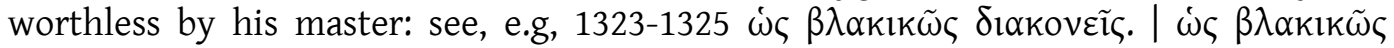

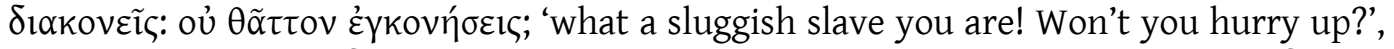

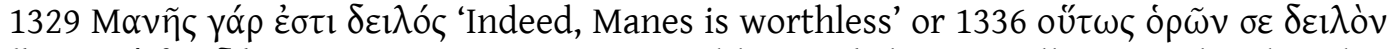

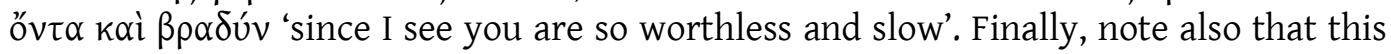

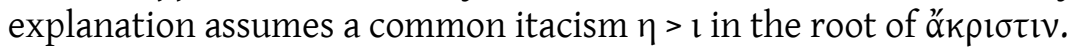

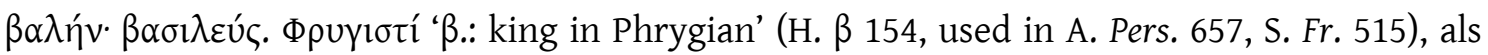

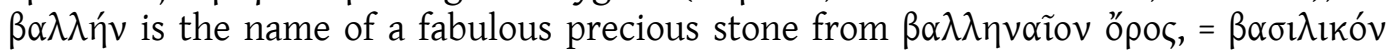
'royal mountain' in Phrygia, according to Ps.-Plu.Fluv.12.3,4. This word has been considered a borrowing from Semitic BSL 'lord' (see Sowa 2007b, 160-164, contrary to Beekes in EDG 197, who considered an Anatolian borrowing, adducing an assumed Lyc. word $\pi \alpha \lambda \eta v$, which must be the Gr. $\pi \alpha \lambda^{\lambda} \eta$ 'fight, battle'). As Sowa (2007b, 164), the attribution to Phrygian is given because in the ancient grammatical tradition this term was labelled a "geographical term designating things of Asia Minor origin in general". Consequently, it is very likely that this word is totally unrelated to the Phrygian language. Solmsen $(1909,138-139)$. This said, one can assume that it has an IE origin, as derived from PIE * $b^{h} l h_{2^{-}}$'white', with the same suffix - $\eta v$ found in kík $\lambda \eta v$ (H. $\left.\kappa 2655\right)$. It would imply a semantic development 'the white one' > 'splendorous' > 'king'.

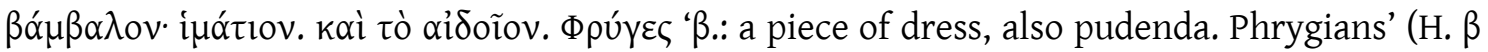
174). This gloss is said to encompass two different words (see Robert 1963, 153 and EDG 199). The second is perhaps a children's word (see Solmsen 1897b, 72).

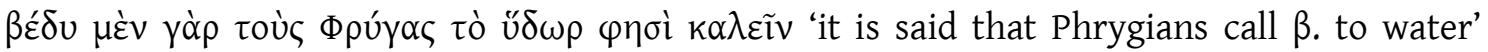
(Clement. Strom., 5.8.46-47). This word, which appears in a fragment of an Orphic ritual (Orph. Fr.219), is also found with the meaning 'air' in Philyll.19. Despite this divergence, its etymology seems to be clear, since it is similar to the PIE word for 'water' *uódr, if one considers that beta is a late spelling for /w/. In any case, the presence of the voiced dental means that a Phrygian origin cannot be claimed for this word.

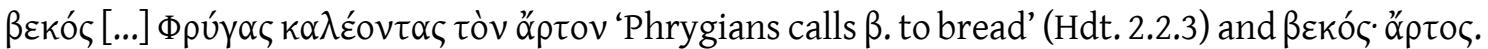

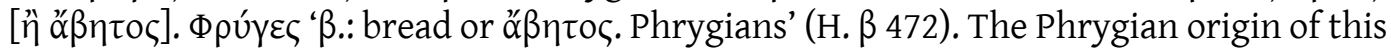
word is confirmed by the NPhr. inscriptions. It must go back to PIE * $b^{h} h_{1} g^{\prime}$-ós- (Panagl \& Kowal 1983, 186-187 and Lubotsky 2004, 233).

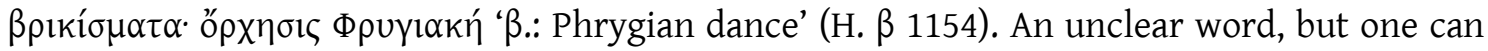

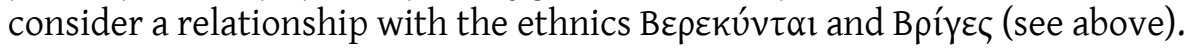

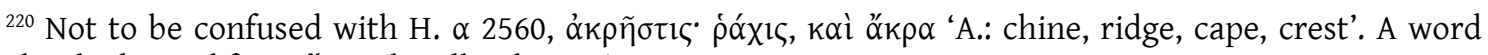
clearly derived from äk $\rho \alpha$ 'headland, cape'.
} 


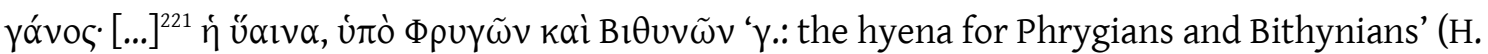
$\gamma$ 1154). According to Morante Mediavilla (2006), it may be a form parallel to oúóvouv

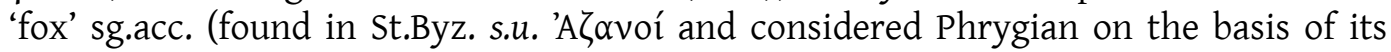
context ${ }^{222}$ with the possible shift $*^{*->} g^{-}$. Although in general her analysis is highly sound, the spelling of yóvo

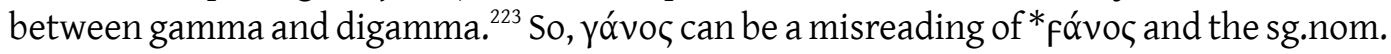
of oướvouv. In such a scenario, Phrygian * fóvo may have derived from PIE *suH- 'pig' in

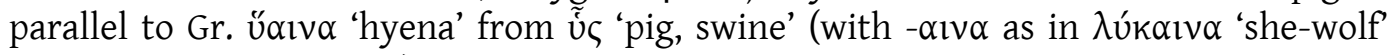
regarding to $\lambda$ úko ' 'wolf'). From a phonetic point of view, this gloss can be considered a Phrygian word.

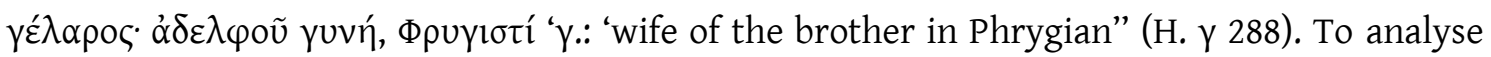
this gloss one must consider the common confusion between gamma and digamma in parallel to yóvo५. Then, a form * ${ }^{*} \varepsilon \dot{\lambda} \alpha \rho \circ \zeta$ can easily derive from the reflexive pronoun

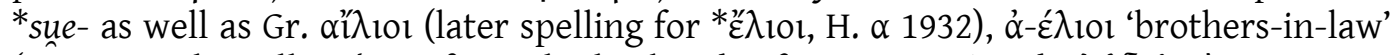

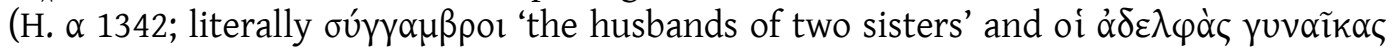

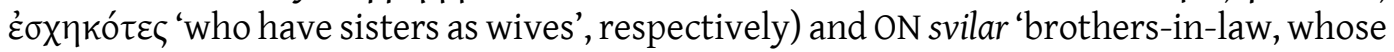
wives are sisters'. All these forms share the presence of the suffix *-lo-/-leh $2^{-}$(see EDG 2425). Finally, the Phrygian word * ${ }^{*} \varepsilon \dot{\lambda} \alpha-$ seems to have added a secondary suffix - $\rho$-. In

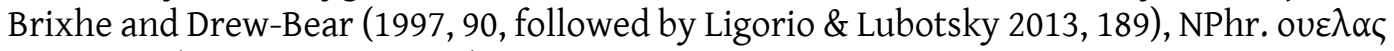
'relatives' $(9.1=87,15.1=120)$ is found to share the same origin. Consequently, there is

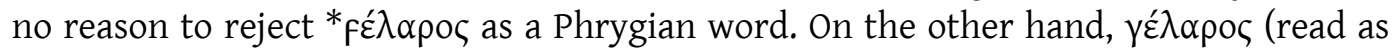
* $\gamma \varepsilon ́ \lambda \alpha f o \zeta)$ has been related to Gr. $\gamma \alpha \lambda$ ó $\omega \varsigma$ 'husband's sister' < * $\gamma \alpha \lambda$ - $\alpha$ fo-, a thematisation *of * ǵl $h_{2}$-eu-, and Arm. tal 'id.' (see EDG 259 and Martirosyan 2010, 596). Similar formations are found in Lat. glōs 'husband's sister' (derived from an unexpected form without laryngeal), oCS zъlzva 'id.' and Ru. zólva, zolóvka 'id.' (forms with *-uu-). Nevertheless, this

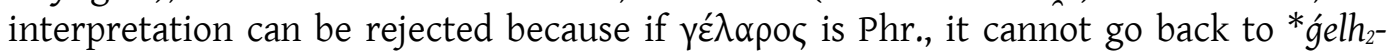
because of the Lautverschiebung of this language.

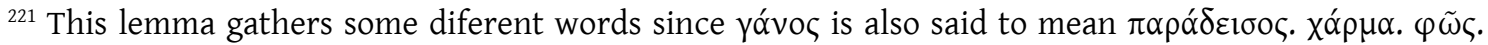

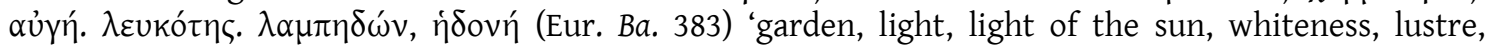
enjoyment'. With the first meaning, yóvoৎ is a borrowing from North-West Semitic gn 'garden' (in

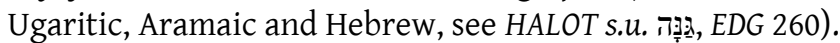

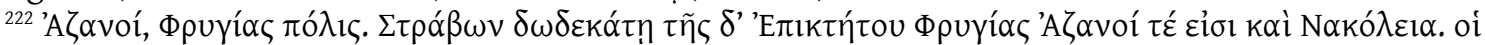

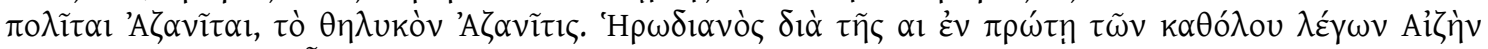

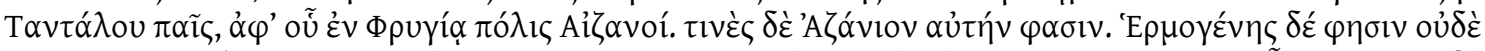

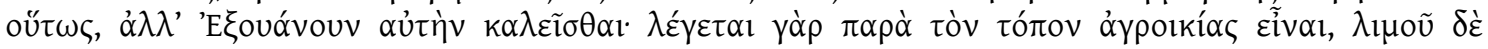

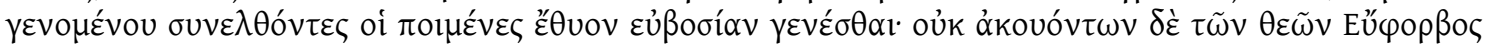

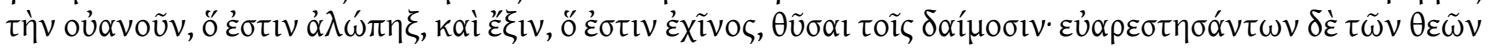

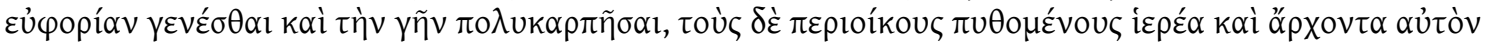

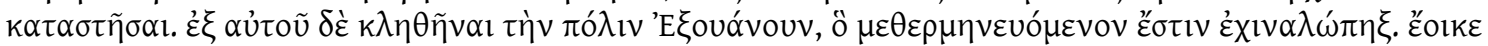

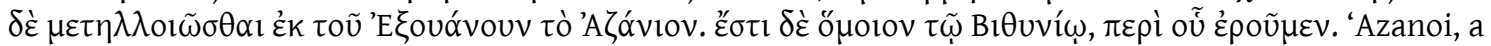
Phrygian city (in Strabo's book 12) Aizanoi and Nakoleia are cities of Phrygia Epiktetos. Its citizens are called Azanittai, fem. Azanîtis. Herodianos writes ai- in the first syllable saying that "Aizēn was the son of Talantos, after whom the city Aizanoi is called. Some people call it Aznion". However, Hermogenes says that it is not right, but it was called Exvanun. Indeed, he tells that ther are some villages around this place and, because of a hunger, sheferds, who met there, sacrificed means of subsistence. Nevertheless, since the gods did not herd them, Euporbos sacrificed a vanos, which is a fox, and an exis, which is a hedgehog, to the divinities. After this reconcilation with the gods, the earth produced many food and fruits and, when the neighbors knew it, they designated him prist and leader. After it, the city was called Exvanun, which is translated as hedgehog-fox [echinalópexx]. It seems that Exvanun become Azanion in a similar way that Bythenion, about whom we speak.' of course, despite being an etiological explanation, far from providing a good etymology for the city, this text attests the name of these animals.

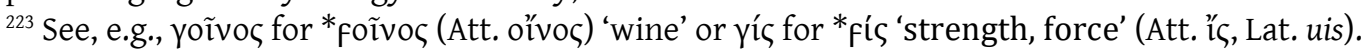




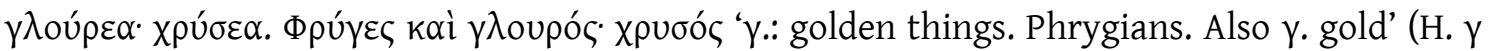
659). This gloss has a literary source, since it is found in Besantius' Bomos 7, and was

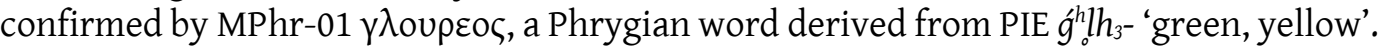

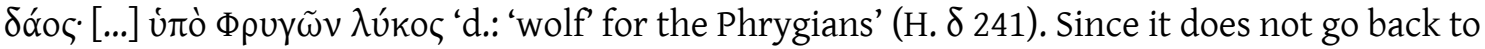
any IE word, its origin can be found in Aramaic d?b, $d ? b$ ? 'wolf' (see CAL, s.u. and, for Semitic cognates, Kogan 2011, 208). Phrygian seems to have borrowed it from the absolute $d ? b$ ['de: $\beta]$, with the Aramaic allophonic $[\beta]$ in such position, the common Phrygian shift $*_{\bar{e}}>\bar{a}$ and a thematisation in -os. Consequently, this Aramaic word may have been borrowed into Phrygian and, from this language, to Gr. Finally, note that in Aramaic it is also used as a PN (Lipiński 1975b, 225-226) and it could be the origin of the Phrygian PN *davos (OPhr. sg.dat. davoi M-06 and B-05, also borne by slaves in Gr. texts as $\Delta \tilde{\alpha} f \circ \varsigma, \Delta \tilde{\alpha}$ o and attested in Lat. as Dauus). Nevertheless, M-06, the earliest occurrence of this name, is dated to the $7^{\text {th }} \mathrm{c}$., before the Achaemenid conquest. It is therefore unlikely that Aramaic had sufficient influence to be the origin of such a characteristic Phrygian name.

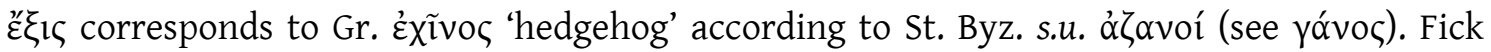
$(1873,412)^{224}$ considered it a misreading of *' $\xi \zeta \varsigma$ and related it to its equivalent words in

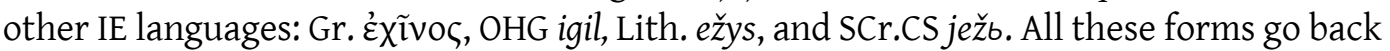
to PIE * $h_{1} e$ g $^{h}-i$ - (IEW, 292; in OHG * egilla- replaced the expected *egina-, while the Gr. word, as well as Arm. ozni, derives from $\left.{ }^{*} h_{1} \circ g^{h}-i(H)-n-\right)$. Consequently, Fick's reading and interpretation seem to be correct, since PIE ${ }^{*} h_{1} e{ }^{h} i s$ is expected to yield ${ }^{*}{ }^{\prime} \zeta_{1} \varsigma$ in Phrygian $\left(* \dot{g}^{h}>*^{*} g>\zeta\right.$ before front vowel).

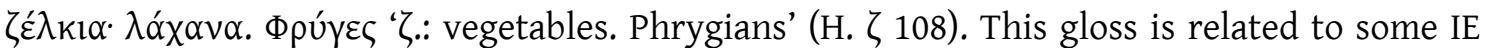
words for vegetation derived from PIE * ${ }^{h} e l h_{3}$ - 'green, yellow' (EDG 1638-1639): Lith. žélti 'to green, sprout', želmuō 'plant, shoot, growth', žole 'grass, herb, flower', Lat. helus, (h)olus, -eris 'green plants, vegetables, cabbage' and Ossetian zæeldœe 'low grass', etc. The same root

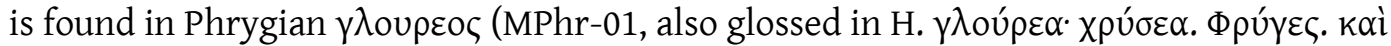

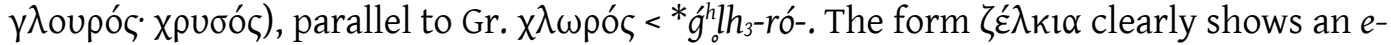
grade and shows the Phrygian secondary palatalisation of $*^{\prime}{ }^{*} *^{*} g$ before the front vowel. Although the development of its root seems to confirm that the word is Phrygian, the suffix - kl- is unapparelled. Perhaps it may be analysed as a secondary formation with *io- derived from and adj. $* \zeta \varepsilon \lambda-k o-$.

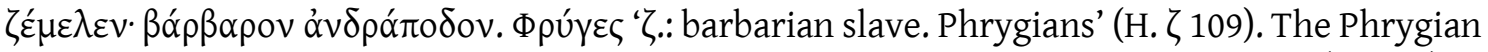
gloss is confirmed by the NPhr. inscriptions since $\zeta \varepsilon \mu \varepsilon \lambda \omega \varsigma$ 'human being' (pl.dat.) is found in the formula $\mu \varepsilon \zeta \varepsilon \mu \varepsilon \lambda \omega \varsigma$ ( $\kappa \varepsilon) \delta \varepsilon \omega \varsigma$ ( $\kappa \varepsilon$ ) 'in the sight of men and gods'. It derives from PIE * $d^{(h)} \dot{g}^{h} e-m$ - 'earth' with the suffix *-elo- (and very likely with simplification of the initial cluster): * $\left(d^{h}\right) g^{h} e-m->\zeta \varepsilon \mu-\varepsilon \lambda_{0}$.

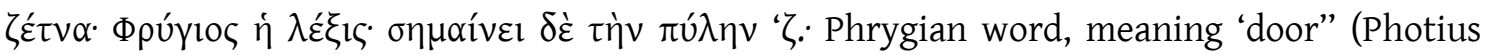
lexicographus s.u.). Although there is a textual variant, $\pi v \gamma \eta$ v instead of $\pi \dot{\lambda} \lambda \eta v$ 'rump,

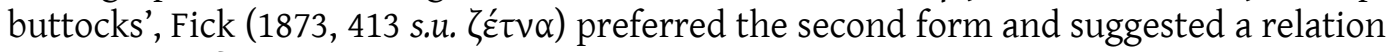
with Gr. $\chi \alpha v \delta \alpha$ v $\omega$ 'to hold, include, contain' and Lat. prae-hendō 'to grasp, seize', Go.

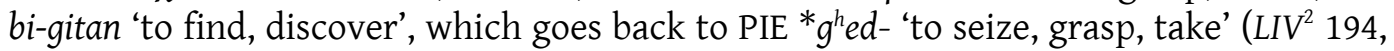

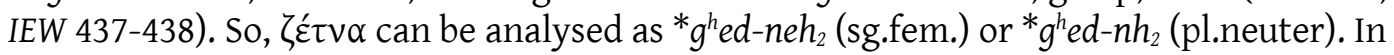
any case, since it shows the Phrygian shifts ${ }^{*} d>t$ and ${ }^{*} g^{h} e>\zeta \varepsilon$, the filiation of this gloss is very likely.

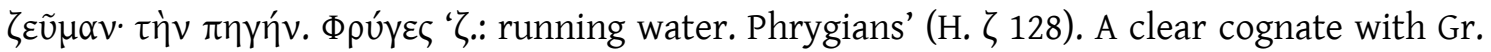
$\chi \varepsilon \tilde{u} \mu \alpha$ 'id.', which goes back to * $\dot{g}^{h} e u-m n$. As can be seen, both the root and the suffix show

${ }^{224}$ See also Morante Mediavilla 2006, 331 fn. 30 and 2007, 445 and EDG 489. 
the expected Phrygian developments $* g^{h} e^{-}>{ }^{*} g e->\zeta \varepsilon$ - and $-m_{0} n>-\mu \alpha v$. Consequently, the Phrygian origin of this word is highly probable.

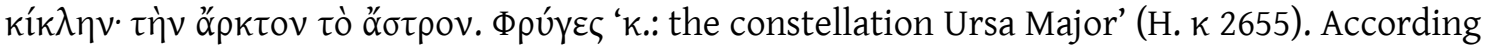

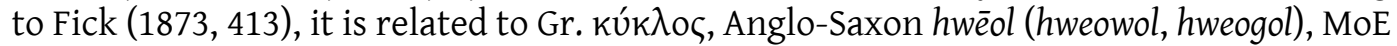
wheel and Skt. cakrá-, all them with the meaning 'wheel' and derived from a reduplicated form of the root * $k^{w} e l(H)$ - 'turn': ${ }^{*} k^{w} e-k^{w} l o-$. The form kík $\lambda \eta v$ shows the same reduplication but there is no trace of thematisation: ${ }^{*} k^{w} e-k^{w} l-$. Orel $(1997-1998,112)$ considered it to be

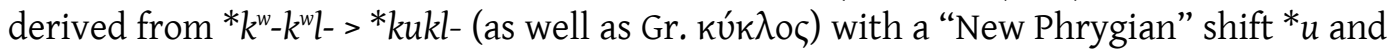
$* \bar{u}>i$. However, this must be refuted in the light of ${ }^{*} g^{w} n$ - 'women' > Phrygian knais, Gr. yuvท́. Therefore, the development of the labiovelars is as expected in Phrygian, and the rising ${ }^{*} e>i$ is a common feature, however the ending $-\eta v$ is expected to appear as $-\bar{a} n$ in

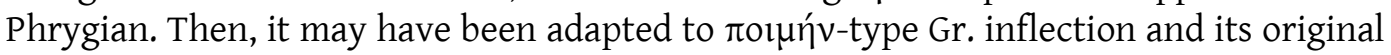
meaning may be 'wagon' (see Porzig 1954, 183, Morante Mediavilla 2007, 444 fn. 947 and EDG 799). This gloss also explains the Mother-Goddess epithet Kık $\lambda \dot{\varepsilon} \alpha$, which occurs in two votive inscriptions from Roman Phrygia (one from Altintaş and one from Appia / Pinarbaş1-Abya, see MAMA X 226). The interpretation of such adj. as 'she of the chariot' fits the iconography of this goddess in Roman times, since she is referred to and represented as driving a chariot drawn by lions. ${ }^{225}$

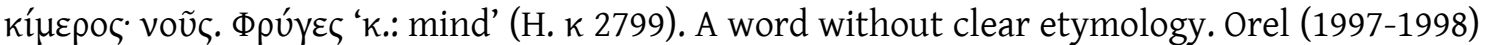

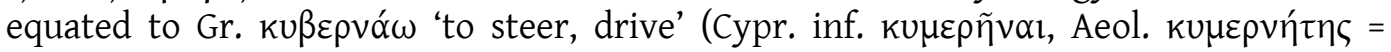

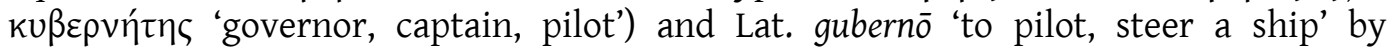
considering these verbs derived from a non-IE borrowing “* $\kappa u ́ \mu \varepsilon \rho o v$ or (less reliable)

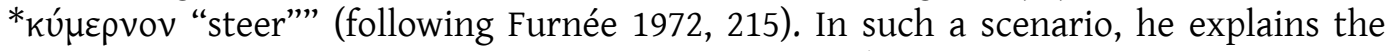
divergent vocalisation between Phrygian kí $\mu \varepsilon \rho \varsigma$ and * ${ }^{*} \mu \varepsilon \rho o v$ as a "the New Phrygian shift of * $u, *_{\bar{u}}$ to -l-" (Orel 1997-1998, 112). However, this shift can be also considered a mere Gr. itacism */y/ > /i/ and there is no specific feature which connects this word to the Phrygian language. Consequently, this gloss remains unclear.

$\mu \tilde{\alpha} \cdot \pi \rho o ́ \beta \alpha \tau \alpha . ~ \Phi \rho u ́ \gamma \varepsilon \varsigma$ ‘ $\mu .:$ cattle. Phrygians' (H. $\mu$ 40). This is very likely to be an onomatopoeic word which may be related to "the sound-imitation $\mu \eta\left({ }^{*} m \bar{e}\right)$ " (EDG 942), also found in Gr.

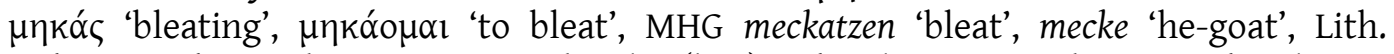
mekčióti, mekénti 'id.', Lat. micciō, 'id.', Skt. (lex.) meka- 'he-goat' and Arm. mak'i 'sheep'. Perhaps $\mu \tilde{\alpha}$ is derived from *mē with the common Phrygian shift of this long vowel and was secondarily considered pl.neuter, but it may also be a new creation in Phrygian.

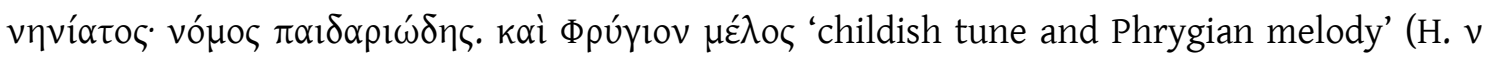
581). According to Hippon. fr. 129 Bgk. (= fr. 163 Masson, Poll. 4, 79), it is a tune for the flute. Following EDG (1016), it is derived from vnvía "a public eulogy, sometimes accompanied by the flute (Cic. Leg. 2, 24, 62)", and it may also be the origin of Lat. nēnia. Its origin can be found in a Lallwort because of the reduplication of the consonant (see

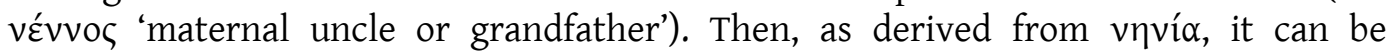
considered a Gr. word. Note also that the presence of eta in the first syllabe is problematic from a Phrygian point of view.

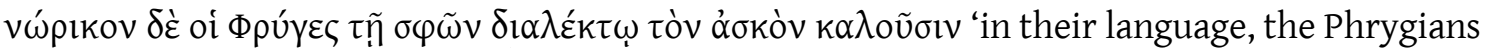

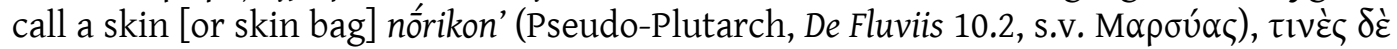

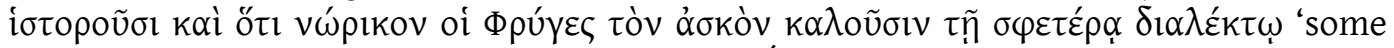
people report that the Phrygians call a skin nốrikon in their language' (Eustathius of Thesalonica, Comm. Ad Dionis. Perieget. 121 = Geogr. Graec. Min. II 724) and, without

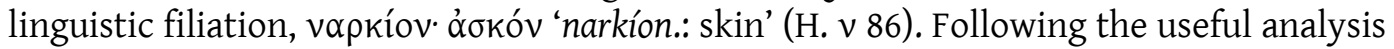
given by Kaczyńska (2011, 57-59), Hesychian vapkíov must be a variant of vópıkov,

${ }^{225}$ Another word for 'chariot' sometimes claimed to be Phrygian is the poetic word $\sigma \alpha \tau$ íval 'carriage (for women)'. However, the beginning makes difficult to connect it with Phrygian. Then, a Thracian or Anatolian origin cannot be excluded, although it is far for being clear. 
despite the differences in the root vocalism and the sound cluster because of "both the close form and the identical meaning". After Haas tentatively established a relationship with the Slavic *nora (referring to "animal's underground hiding place, burrow, hole", 1966, 154-155, however it can be considered a Ugro-Finnish borrowing), Crevatin (1972) considered it a borrowing from a Semitic language in the light of Assyrian naruqqu $(\mathrm{m})$, Babylonian nuruqqum 'skin, skin vessel to contain water or wine; bag, sack'. Indeed, the Assyrian and Babylonian word explains where the meaning 'skin' comes from, however it does not mean that the Phrygian town Nópıkov (whose name is glossed by PseudoPlutarch and Eustathius) was in fact named after the Semitic word. A folk-etymology cannot be ruled out, even when it is accepted that Phrygian borrowed this word. By comparing vẃpıkov with naruqqu $(m)$ / nuruqqum, a third, unclear, language must be identified to explain the vocalic divergences $(a / u>c$ ond $u>i)$.

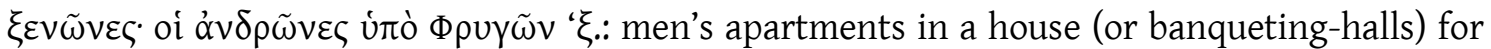
the Phrygians' (H. $\xi 54)$. It is the Gr. word $\xi \varepsilon v \omega \omega v, \tilde{\omega} v o \varsigma^{\prime}$ 'guest-chamber', as is explained

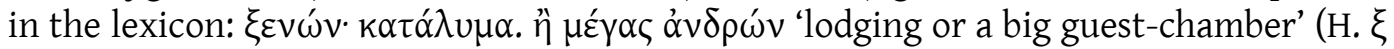
53). Then, the attribution to the Phrygian language must be rejected.

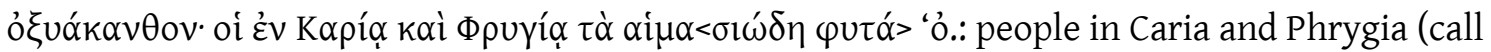
it to) garden plants' (H. o 42). It is indeed the masculinisation of the Gr. word ó 'vó́k $\alpha v \theta \alpha$ 'fiery thorn, Cotoneaster Pyracantha'. So, it is not related to the Phrygian language or to Carian.

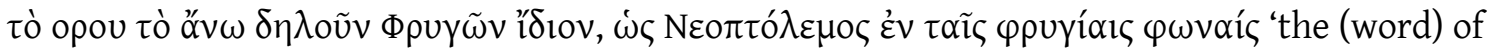
the Phrygians orou clearly (corresponds to Greek) anō [='above'], as Neoptolemos (of Parion says) in his Phrygian Phrases' (Achilles Tatius, Ad Arato, Phaenom. 85; see Mette 1980, 15). Gusmani (1959b, 14) equated opou to Hitt. šarā 'up(wards), aloft' and Lyc. hri 'up; on (top)' and considered it an isogloss between Phrygian and the Anatolian languages. However, it is not so easy. If šarā goes back to PIE *ser-, ${ }^{*}$ sr- (see Kloekhorst 2008, 730), the first vowel of orou is unexpected (even more so if it is equated to Greek píov 'mountainridge'). A relation with Hitt. aru- 'high' and CLuw. aru- 'id.' is attractive. According to Kloekhorst $(2008,212)$, both Anatolian forms may go back to PIE * $h_{3}(0) r-u-$. Consequently, opou can be explained both as a Phrygian cognate or a borrowing (despite the vocalism). Sowa (2012, 45 fn. 5) considered this gloss in his study of opovav 'keeper, protector'.

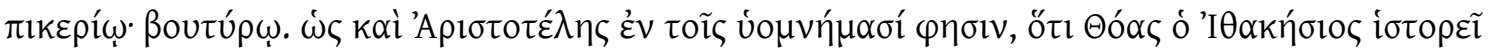

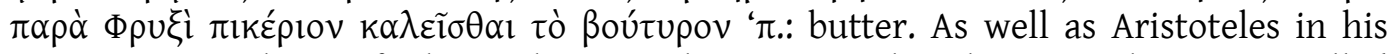
Commentaries, Thoas of Ithaca observes that among the Phrygians 'butter' is called $\pi ı k \varepsilon$ í $^{\prime}$ (Erot. 73, 13 = Ar. Byz. F. 101 and Arist. Fr. 636 = Beeker - Gigon 773). The etymology of this word is unknown (EDG 1190) and this gloss cannot be corroborated.

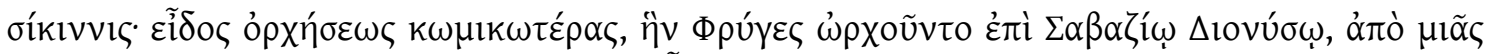

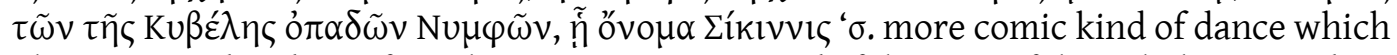
Phrygian used to dance for Sabazios Dionisos instead of that one of the Cybele's attendant Nymphs' (Eust. Ad Il. 20, 1077). Although oíkıvvıৎ was classed as Phrygian in Fick's (1873) list of Phrygian glosses, no explanation has been given as to the origin of this word. If its origin is Phrygian (which is far from clear), it must go back to *ki- (as the pronoun *ki > si). As such, perhaps kikinnis > бíkıvvıৎ was an onomatopoeic word in origin. Nevertheless, it cannot be considered more than a working hypothesis.

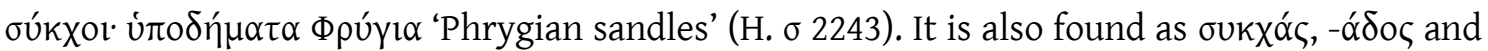
was borrowed into Lat. as soccus (see EDG 1421). It is considered by Knobloch $(1958,198$ 200) to be a loan from the Caucasus, perhaps also borrowed into Av. haxa- 'sole of the foot'. In any case, the presence of chi means that the word cannot be Phrygian in origin.

Finally, one can add to this list another Hesychian gloss, although it is not explicitly considered Phrygian: 


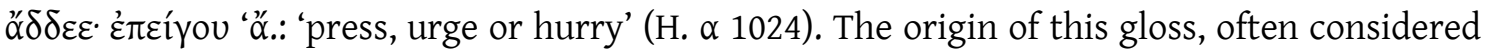
Pre-Gr., is not given. Nevertheless, this verb in impv., which "corresponds exactly to the Gr. imperative $\theta \varepsilon ́ \varepsilon$ from $\theta \varepsilon ́ \omega$ 'to run"' (Mihaylova 2016, 309, based on Georgiev 1941, 79; the root of the verb goes back to PIE * $d^{h} e$ u- 'to run, flow' IEW 259-260- LIV ${ }^{2} 147-148$ ), is a clear borrowing in this language. The word also transmitted as gloss $\delta u ́ \alpha v \cdot \kappa p \eta ́ v \eta v ~ ' \delta .:$ 'well, spring' is also derived from the same root ${ }^{*} d^{h} u(u) e h_{2^{-}}$(compare with Skt. dhávate 'runs, flows', dhautí- 'spring, stream' or OHG tau, Germ. Tau, OE deaw 'dew'). Because ö $\delta \delta \varepsilon \varepsilon$ has the preverb o $\alpha$ - and the the shift $* d^{h}$ - > $\delta$-, Mihaylova $(2016,310 \mathrm{fn} .6)$ does not rule out a Phrygian origin. Indeed, both features are typically Phrygian and this possibility is very strong. The loss of * u- in * $d^{h}$ eue $\left.>(\alpha) \delta\right) \delta \varepsilon \varepsilon$, which is unexpected from a Phrygian point of view, can be considered the result of the Gr. adaptation (compare with davos > $\Delta \tilde{\alpha} \circ \zeta)$.

After this detailed analysis, the glosses can be gathered into groups according to their relationship with Phrygian. Only three glosses from this extensive list can be confirmed as

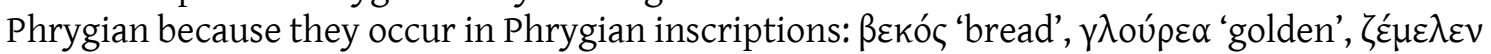

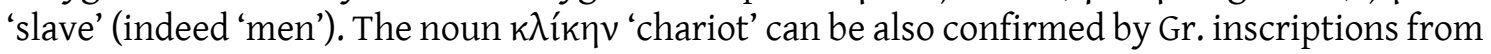
Phrygia that corroborate its Phrygian origin. There are seven glosses that are very likely to be Phrygian on the basis of phonetic analysis, although they are never found in any inscription:

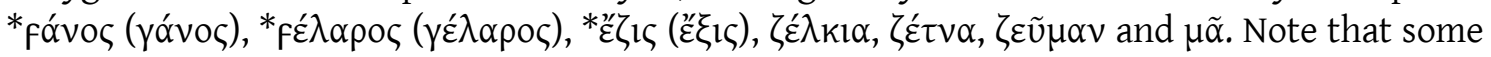
of them encountered obstacles to their transmition.

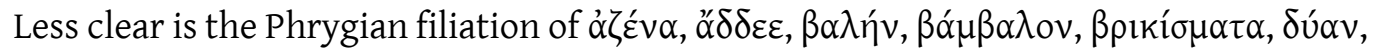

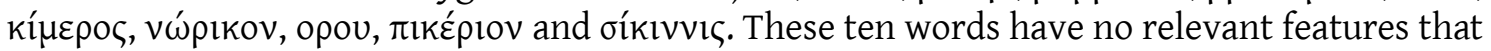
confirm or contradict their Phrygian status. Finally, seven glosses cannot be considered

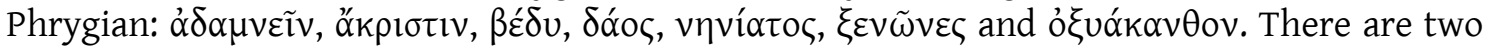
reasons for their omission. The first is simply that these words are attributed to another

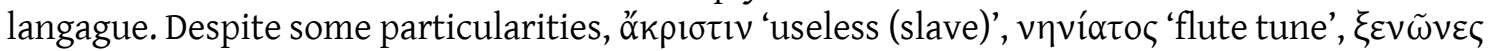

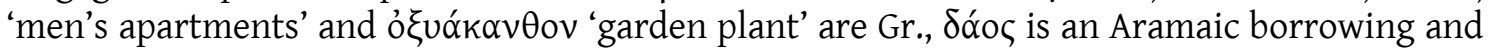
$v \omega$ pıkov is an Assyrian word. The second reason is the presence of features incompatible with Phrygian. This is the case of ó $\delta \alpha \mu v \varepsilon \tilde{v} v$ 'to love' and $\beta \varepsilon \varepsilon^{\delta} v$ 'water', where the continuity of the PIE voiced stop is unexpected.

According to the information given above, the following table summarises the degree of Phrygian filiation of each of the glosses, where 'Confirmed' means that the word appears in Phrygian or Gr. inscriptions fom Phrygia, 'Very probable' means that it has features which point to the Phrygian language, 'Unclear' means that there are no relevant features, and 'Excluded' means that the words cannot be considered Phrygian.

Table 36 Classification of the glosses regarding their relationship with Phrygian

\begin{tabular}{|c|c|c|c|}
\hline Confirmed & Very probable & Unclear & Excluded \\
\hline 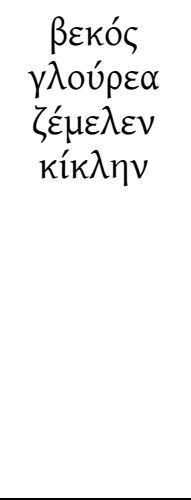 & 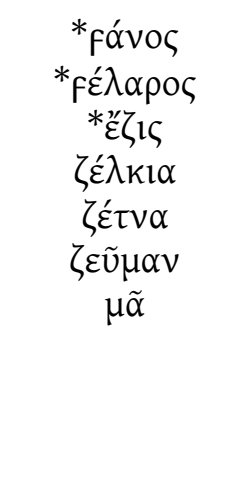 & 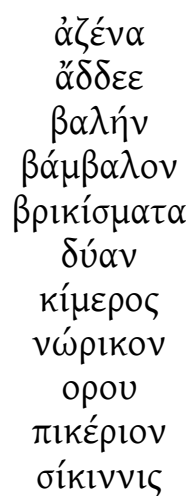 & 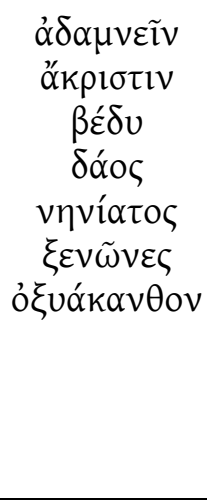 \\
\hline
\end{tabular}




\section{Conclusions}

After analysing 783 lemmata gathered ( $\$ 5$ ) from the 513 inscriptions considered in this dissertation, the main conclusion is obvious: most of the Phrygian words remain unexplained. Indeed, we do not know the grammatical category of at least 143 words, and 148 are only tentatively classified, as a result of the fragmentation of the inscriptions, difficulties with segmentation of the words and the abundance of hapax legomenon (especially in the old Phrygian subcorpus and the MPhr-01 epitaph). In addition, the graffiti from Gordion contain many isolated personal names which in most instances provide scant information about the language, since most of them seem to be borrowed from the Anatolian repertories. Nevertheless, there are many personal names without clear parallels, whose origin is unknown.

It is no less true that many words can be more clearly analysed. On the basis of these words, it can be assumed that most of the identified lexicon is inherited from Proto-IndoEuropean, although loanwords (mostly from Greek and the Anatolian languages) are also found ( $\$ 4.4$ and 4.6). Formulae are particularly productive for the identification of word meanings because they can be compared with similar texts found in other epigraphic corpora from Anatolia. Certainly, our better knowledge of the archaeology and history of Anatolia from the Iron Age to the Roman period is a useful source for interpreting the texts, and the in-depth study of Greek, Lydian, Lycian, Carian, Aramaic and Phoenician inscriptions found in Anatolia has provided suitable parallels for the contents of the Phrygian inscriptions. As such, a purely etymological approach to the Phrygian lexicon (still found in some papers) must be ruled out.

In parallel with the analysis of the lemmata, the basic elements of the Phrygian grammar - as far as they can be established - are given in $\S 4$. Note, however, that the Phrygian verb is still problematic (§ 4.2.2) because of the lack of forms and the specific features of some

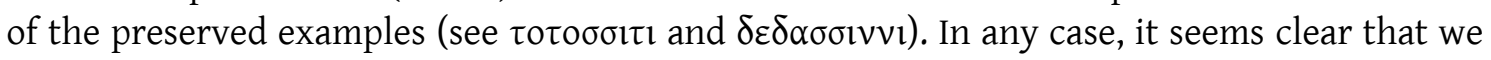
are dealing with an Indo-European language very closely related to Greek (§ 4.5). Perhaps the most relevant feature corroborated here is the Lautverschiebung theory as proposed by Lubotsky (2004). Indeed, the extended implementation of his proposal has been highly productive in refining the etymology of some words, not only in this dissertation but also in papers by other scholars (see, for example, Hämmig 2013, Kloekhorst 2015 and Ligorio 2016). In addition, the shift -Vns > -Vis, first proposed by Brixhe (1990, 65-67), and the treatment of the PIE laryngeals closely related to the Greek equivalents is confirmed, among other Phrygian features. The loss of the PIE laryngeal ${ }^{*} h_{1}$ in ${ }^{*}-e h_{1} \#\left({ }^{*} m e h_{1}>m e, \mu \varepsilon\right.$ and kake(y), $\left.\kappa \alpha \kappa \varepsilon\right)$ is one of the most relevant novelties identified here.

With regard to morphology, two features stand out. The patronymic suffix -evais /evanos is corroborated as an inheritance from PIE poss. suffix *-uent-. Also, -avos is accepted as

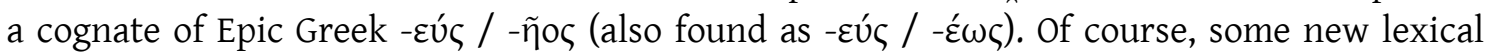

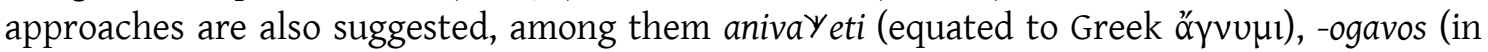

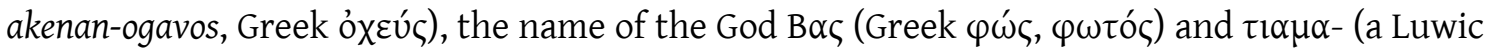
borrowing).

Other conclusions have a bearing on our knowledge of the Phrygian alphabet. This is the case of the letters CIPPh no. 20 ( $\Psi, V)$, considered to be a mere graphic variant of $\langle\mathrm{k}\rangle(\mathrm{K})$, and CIPPh no. 18, which is excluded from the repertory of letters. Finally, it is shown that analysis of the Phrygian language through the inscriptions must form the basis of any approach to the "Phrygian" words found in indirect sources (mainly glosses), since some of them are incompatible with a Phrygian origin. Some of these words also provide priceless information

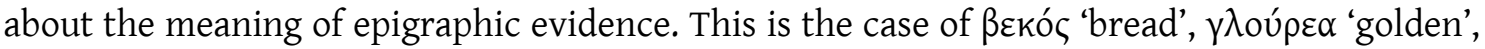

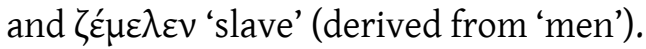


Despite the efforts of this dissertation, there are many aspects to be analysed in greater depth in future research, leaving aside the amount of unexplained words and the edition of new inscriptions. Perhaps the most important area for further study is the Phrygian verbal morphology, where new results could clearly modify our view of the language. A complete study of formulae (imprecative or otherwise) used in Anatolia would be also desirable, covering aspects such as their survival from the Iron Age to the Roman Imperial period, the typology of the different variants, regional innovations, and so on.

Onomastics are also an important field to be fully studied, as we do not know the origins of many personal names found in Phrygian (sometimes shared with other corpora). Finally, a holistic approach to the Old Phrygian alphabet is essential for the future of this field and could shed light on complex questions such as the origin of the alphabet, its relation with Greek and the Anatolian scripts, the Phrygian alphabetic reform, the evolution of the letters, local variations, and so on.

As can be seen, the study of Phrygian is an open field that calls for an interdisciplinary approach (with contributions from archaeology, Indo-European, Greek, Anatolian, Aramaic, Iranian, etc.). I hope that this lexicon proves to be a useful tool for those interested in Phrygian and helps attract more scholarly attention which can improve our knowledge of to this fragmentary language. 
Catalogue of the Phrygian inscriptions 



\section{Old Phrygian Inscriptions \\ M - Midas City (Midas Kenti, Yazılıkaya) \\ Stone inscriptions}

\section{M-01}

Rock-cut façade dated to the second quarter of the $6^{\text {th }} \mathrm{c}$. BC (earlier than $550 \mathrm{BC}$ ).

\section{M-01a}

Horizontal inscription under the pediment of the façade.

Mordtmann 1862, 21-23 no. 5 (Tafel A-B, no. 5); Gosche 1864, 225 no. 1; Ramsay 1883, 128-129 no. 1; Perrot \& Chipiez 1890, 88-89; Pauli 1894, 58 no. 1; Körte 1898, 65; von Reber 1898, 566; Schwyzer 1923, Appendix IV, 8, 1; Sayce 1926, 32, no. 1; Friedrich 1932, 125 no. A 1; Haas 1951, 24 no. I; Haas 1966, 187-188 no. I; Haas 1970a, 52 no. M-01a; Haas 1970b, 24 no. I; Haspels 1971 I, 289, no. 1; Neroznak 1978, 71 no. A1; CIPPh I, 6-9 no. M-01 a (II, pl. I-1, I-2 and I-3); Diakonoff \& Neroznak 1985, 61 no. A 1; Woudhuizen 1993, 1-5 no. M-01; TITUS, no. M-1a; Orel 1997a, 9-12 no. M-01a; Berndt 2002, 9 no. 1 = M-01a (Abb. 10); Berndt-Ersöz 2006, 232-234 no. 30 (Figs. 4, 50-53 and 134).

ates $\vdots$ arkiaevais $\vdots$ akenanogavos $\vdots$ midai $\vdots$ lavagtaei $\vdots$ vanaktei $\vdots$ edaes

'Attes the son of Archias, the akenanogavos, made (it) for Midas the leader (and) the king.'

\section{M-01b}

Vertical inscription on the right pilaster of the façade.

Mordtmann 1862, 21-22 no. 6 (Tafel A-B, no. 6); Gosche 1864, 225 no. 2; Schmidt 1869, 137; Ramsay 1883, 129-130 no. 2; Pauli 1894, 58 no.2; Solmsen 1897a, 60-62; Körte 1898, 85; von Reber 1898, 566; Schwyzer 1923, Appendix IV 8,2; Sayce, 1926, 32 no.2; Friedrich 1932, 125 no. 2; Haas 1966, 190 no. II; Haspels 1971 I, 289-290, no. 2; Neroznak 1978, 72-73 no. A 2; CIPPh I, 9-10 no. M-01 b (II, pl. II-1); Diakonoff \& Neroznak 1985, 61-62 no. A 2; TITUS, no. M-1b; Orel 1997a, 12-14 no. M-01b; Berndt 2002, 9 no. 1 = M-02b (Abb. 11); Berndt-Ersöz 2006, 232-234 no. 30 (Figs. 4, 50-53 and 134).

\section{baba $\vdots$ memevais $\vdots$ proitavos $\vdots k$ Фiyanaveyos $\vdots$ si keneman $\vdots$ edaes}

'Baba the son of Meme(s), the proitavos, the kФiyanaveyos, made this niche.'

\section{M-01c}

Inside the central niche, to the left, there are two adjacent inscriptions. Text II, to the right of I, was first incised.

Mordtmann 1862, 26-2 no. 8 (Tafel A-B, no. 8); Gosche 1864, 225 no. 5; Haspels 1971 I, 290 no. 4 (II fig. 599/4); Neroznak 1978, 108-109 no. A 78; CIPPh I, 11-12 no. M-01 c (II, pl. II-2 and 
II-3); Diakonoff \& Neroznak 1985, 74 no. A 78; TITUS, no. M-1c; Orel 1997a, 14-16 no. M-01c; Berndt-Ersöz 2006, 232-234 no. 30 (Figs. 4, 50-53 and 134).

$$
\text { I II }
$$

matẹ... atatas m? onokaua

1 bonokaua Haspels et Orel.

\section{M-01d}

Inside the central niche, to the right. Two inscriptions are readable, but more traces and some letters are visible at the lowest part. Also, two circles were drawn.

Mordtmann 1862, $26-27$ no. 7 (Tafel A-B, no.7); Brandenburg 1906, 645; Haspels 1971 I, 290-291 no. 5 (II, fig. 298/5 and 599/5); Neroznak 1978, 109, no. A 79; CIPPh I, 12-14 no. M-01 d (II, pl. IV and pl. V); Diakonoff \& Neroznak 1985, 74 no. A 79; TITUS, no. M-1a; Orel 1997a, 16-19 no. M-01d; Berndt-Ersöz 2006, 232-234 no. 30 (Figs. 4, 50-53 and 134).

$\begin{array}{cc} & \text { I } \\ \leftarrow & \text { midas } \\ \leftarrow & \text { s=materan } \\ \leftarrow & \text { tvemes eneparkes? }\end{array}$

II

$\begin{array}{cc}\leftarrow & \text { matera[--- }] \\ \leftarrow & \text { avi[---] }\end{array}$

(III)

$\leftarrow \quad a \quad b$ ?[---].[.]nm.[---
$[---] . . .[---]$

(I) 'Midas engraved this Mother-Goddess tvemes.'

\section{M-01 e}

On the socle to the right of the central niche.

CIPPh I, 15 no. M-01 e (II, pl. VI-1, 2 and VII-1,2); TITUS, no. M-1e; Orel 1997a, 19-20 no. M-01 e; Berndt-Ersöz 2006, 232-234 no. 30 (Figs. 4, 50-53 and 134).

1 .ag?a uel .ap?a,

.. a o.. materey. $a g^{?} a$... 


\title{
$M-01 f$
}

Inside a niche in the rock wall to the left of the façade.

Mordtmann 1862, 27 no. 9 (Tafel A-B, no. 9); Gosche 1864, 225 no. 3; Ramsay 1883, 130131 no.3; Pauli 1894, 58 no. 3; Kretschmer 1901, 115-116; Sayce 1926, 32 no. 3; Friedrich 1932, 125 no. A 4; Haas 1951, 25 no. IV; Haas 1966, 190-191 no. IV; Haas 1970, 25 no. IV; Haspels 1971 I, 290 no. 3 (II fig. 599/3); Neroznak 1978, 71 no. 4 A 4; CIPPh I, 15-16 no. M-01 f (II, pl. III-1, 2, 3, 4); Diakonoff \& Neroznak 1985, 63 no. A 4; TITUS, no. M-1f; Orel 1997a, 20-22 no. M-01 f; BerndtErsöz 2006, 232-234 no. 30 (Figs. 4, 50-53 and 134); Ligorio 2016, 34.

\section{[.].as $\vdots$ tuave|niy $\vdots$ ae $\vdots$ esuryoyoy $\vdots$ totin $\vdots$ ẹdaẹ $[s]$ \\ 'X-as ... made this present/offering.'}

\begin{abstract}
M-02
On a vertical side of an outcrop of rock ("altar"), almost contemporaneous with M-01b (575-550 BC).

Mordtmann 1862, 21 no. 11 (Tafel A-B, no. 11); Gosche 1864, 225 no. 7; Schmidt 1869, 136-137; Ramsay 1883, 129 and 132 no. 5; Ramsay 1889a, 185; Pauli 1894, 58 no. 5; Kretschmer 1899, 352-353; Sayce 1926, 32 no. 5; Friedrich 1932, 125 no. A 3; Haas 1966, 191 no. III; Haspels 1971 I, 291 no. 8 (II fig. 600/8); Neroznak 1978, 73 no. A 3; CIPPh I, 18-19 no. M-02 (II, pl. VIII-1); Diakonoff \& Neroznak 1985, 62 no. A 3; TITUS, no. M-2; Orel 1997a, 22-24 M-01 f; Berndt 2002, 49-50 no. 71 (Abb. 88-90).
\end{abstract}

\section{bba : memevais $\vdots$ proitavo[s] \\ $k \uparrow$ ianaveyos : akaragayun \\ edaes}

'Baba the son of Meme(s), the proitavos, the $k$ 个ianaveyos, made the akaragayun.'

\section{M-03}

Undated step monument ("altar"), perhaps dated to the Middle Phrygian period I or II.

Mordtmann 1862, 30 no. 10 (Tafel A-B, no. 10); Gosche 1864, 225 no. 6; Ramsay 1883, 131 no. 4; Pauli 1894, 58 no. 4; Kretschmer 1899, 354; Sayce 1926, 32 no. 4; Friedrich 1932, 125 no. 5; Haas 1966, 191 no. V; Haspels 1971 I, 292 no. 9 (II fig. 30 and 600/8); Neroznak 1978, 75 no. A 5; CIPPh I, 19-21 no. M-03 (II, pl. VIII-2); Diakonoff \& Neroznak 1985, 62 no. A 5; TITUS, no. M-1f; Orel 1997a, 24-25 no. M-03; Berndt 2002, 50 no. 72 (Abb. 91); Berndt-Ersöz 2006, 250-251 no. 69 (Figs. 4, 79 and 137).

\section{[---] abas imanạ akio[---]}

[b]abas Pauli, Syce, Haas et Neroznak : abas CIPPh et Orel. 


\section{M-04}

On a step monument ("altar") dated to the $6^{\text {th }}$ c. BC.

Mordtmann 1862, 22 no. 12 (Tafel A-B, no. 12); Gosche 1864, 225 no. 8; Ramsay 1883, 132 no. 6; Ramsay 1889b, 310; Pauli 1894, 58 no. 6; von Reber 1898, 584-585; Sayce 1926, 32 no. 6; Friedrich 1932, 125 no. A 6; Haas 1951, 24-25 no. VI; Haas 1966, 192 no. VI; Haas 1970b, 24-25 no. VI; Haspels 1971 I, 291 no. 7 (II fig. 28 and 599/7); Neroznak 1978, 75 no. A 6; CIPPh I, 21-23 no. M-04 (II, pl. X-1, 2 and XI-1, 2); Diakonoff \& Neroznak 1985, 62 no. A 6; TITUS, no. M-1f; Orel 1997a, 25-27 M-04; Berndt 2002, 39-40 no. 58 (Abb. 62 and 63); Berndt-Ersöz 2006, 251-252 no. 70 (Figs. 4, 80 and 136).

$$
\begin{aligned}
& \text { akinanogavan } \vdots \text { tiyes } \\
& \leftarrow \quad \text { modrovanak } \vdots \text { avara[.? }]
\end{aligned}
$$

\section{M-05}

On the remains of a rock-cut pediment. Dated to the first half of the $6^{\text {th }} \mathrm{c} . \mathrm{BC}$.

Ramsay 1883, 133 no. 10 (pl. 3, no. 10); Pauli 1894, 58 no. 10; Kretschmer 1899, 357; Sayce, 1926, 33 no. 10; Friedrich 1932, 126 no. A 8; Haas 1951, 25 no. VIII; Haas 1966, 192 no. VIII; Haas 1970b, 25 no. M-05; Haspels 1978 I, 292 no. 10 (II, fig. 33 and 600/10); Neroznak 1978, 79-80 no. A 8; CIPPh I, 24-25 no. M-05 (II, pl. IX-2); Diakonoff \& Neroznak 1985, 64 no. A 8; TITUS, no. M-5; Orel 1997a, 27-28 no. M-05; Berndt 2002, 54 no. 80 (Abb. 97-98); Berndt-Ersöz 2006, 235-236 no. 33 (Figs. 4 and 42 ).

$$
\text { apelan (uac.) mekas tevanọ[---] }
$$

\section{M-06}

On a little rock-cut altar dated to the $7^{\text {th }} \mathrm{c} . \mathrm{BC}$.

Haspels 1971 I, 291 no. 6 (II, fig. 31 and 603/6); Neroznak 1978, 109 no. A80; CIPPh I, 2526 no. M-06 (II, pl. XII-1, 2); Diakonoff \& Neroznak 1985, 74 no. A 80; TITUS, no. M-6; Orel 1997a, 28-30 no. M-06; Berndt 2002, 34 no. 46 (Abb. 52); Berndt-Ersöz 2006, 261-262 no. 94 (Fig. 4).

$$
\begin{gathered}
\text { rekun : deiatiteea } \\
\text { davoi iman }
\end{gathered}
$$

1 Lapis ṛekun : fрعкuv Haspels : [v]'ṛekun CIPPh.

$$
\text { 'Iman (made?) this work' ... for Davos.' }
$$




\section{M-07}

On the wall of a cave. Undated.

Haspels 1971 I, 294 no. 19; CIPPh I, 27 no. 27 (II, pl. XIII-1); TITUS, no. M-7; Orel 1997a, 3031 no. M-07.

$$
\text { tolos }
$$

\section{M-08}

On a rock. Undated.

CIPPh I, 27-28 no. M-08 (II, pl. XIV-2, 3 and XV-1, 2); TITUS, no. M-8; Orel 1997a, 31 no. M-08; Berndt 2002, 21 no. 14 (Abb. 27).

... $\quad$... sabas

\section{M-09}

On an undetermined architectural element. Undated.

Calder 1926, 26 (fig. 1); Friedrich 1932, 127 no. 18; Haas 1966, 188-189 no. XVIII; Haspels 1971 I, 294 no. 18; Neroznak 1978, 84 no. A18; CIPPh I, 28 no. M-09 (II, pl. XIII-2); Diakonoff \& Neroznak 1985, 66 no. A 18; TITUS, no. M-9; Orel 1997a, 31-32 no. M-09.

$$
\text { [---] ạken?ano[---] }
$$

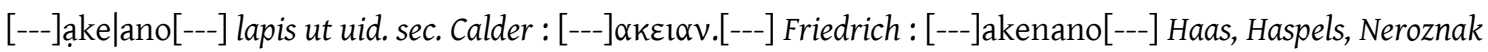
et Orel, cfr. akenanogavos M-01 a : [---]ạkeiano[---] aut [---]ạketano[---] aut [---]ạkegano[---] mal. CIPPh.

\section{M-10}

On a stone block. Undated.

CIPPh I, 29 no. M-10 (II, pl. XIII-3); TITUS, no. M-10; Orel 1997a, 32 no. M-10.

$$
\text { [---]gen : [---] or [---]ten : [---] }
$$

\section{M-11}

Incised on a rock, the text is very eroded.

Brixhe \& Sivas 2003, 70-72 no. 4-b (75-76 fig. 6 and 7).

$$
\text { [---] eștạ ș }
$$

'... erected.' 
Instrumenta

\section{M-101}

Incised on an undated sherd.

Brixhe \& Sivas 2003, 69-70 no. 4a.

șaragis 


\section{W - West-Phrygia (excluding Midas City)}

\section{Stone inscriptions}

\section{W-01}

On a rock-cut façade dated to ca. $550 \mathrm{BC}$, known as 'Areyastin monument'. Situated 1.6 $\mathrm{km}$ north of Midas City among the rocks west of the road from Midas City to Çukurca. Three inscriptions surround its pediment.

\section{W-01a}

Mordtmann 1862, 23-24 no. 13 (Tafel A-B, no. 13); Gosche 1864, 225 no. 9; Ramsay 1883, 133 no. 8; Ramsay 1888, 380-381; Ramsay 1889b, 309; Pauli 1894, 58 no. 7; Torp 1896, 10; Körte 1898, 117 (and 85 no. 0); von Reber 1898, 571-572; Meister 1911, 22-25; Schwyzer 1923, 404 (Appendix IV 8,3 a); Sayce 1926, 33 no. 8; Friedrich 1932, 125-126 no. 7 a; Haas 1951, 22-23 (and 17-18) no. VIIa; Haas 1966, 193-197 no. VII a; Haspels 1971 I, 292 no. 11 a; Neroznak 1978, 76-77 no. A7 a; CIPPh I, 36-38 no. W-01 a (II, pl. XVI-2. XVII-1, 2, 3, 4 and XVIII-1, 2); Diakonoff \& Neroznak 1985, 63 no. A 7 a; Lubotksy 1988, no. W-01a (p. 10, Fig. 1); Woudhuizen 1993, 5-9 no. W-01; TITUS, no. W-1a; Orel 1997a, 33-36 W-01 a; Berndt-Ersöz 2006, 237-238 no. 37 (Figs. 47 and 49).

$$
\begin{array}{lcc}
\mathrm{II} & \leftarrow & \text { materan } \vdots \text { areyastin } \\
\mathrm{III} & \rightarrow & \text { bonok } \vdots \text { akenanogavọs } \\
\mathrm{I} & \leftarrow & \text { vrekun } \vdots \text { tedatoy } \vdots \text { yos tutut ...a.m.noy } \vdots \text { akenanogavos } \mid \text { aey }
\end{array}
$$

'Bonok, the akenanogavos, made this Mother-Goddess as his idol'. Whoever...'

\section{$W-01 b$}

Mordtmann 1862, 24-25 no. 14 (Tafel A-B, no. 14); Gosche 1864, 225 no. 9; Ramsay 1883, 132-133, no.7; Ramsay 1889b, 311; Pauli 1894, 58 no. 8; Torp 1896, 10; Körte 1898, 117; von Reber 1898, 571; Meister 1911, 22-25; Schwyzer 1923 (Appendix IV 8, 3 b); Sayce 1926, 32 no. 7; Friedrich 1932, 126 no. 7 b; Haas 1951, 20-22 no. VIIb; Haas 1966, 195-197 no. VII b; Haas 1970b, 20-23 no. VIIb; Haspels 1971 I, 292-293 no. 11 a (II, fig. 83, 84, 601 and 602); Neroznak 1978, 76-77 no. A 7 b; CIPPh I, 39-41 no. W-01 b (II, pl. XVI-2, 3, 4 and XX-1, 2); Diakonoff \& Neroznak 1985, 63 no. A 7 b; Lubotksy 1988, no. W-01b (p. 10, Fig. 1); TITUS, no. W-1b; Neroznak 1997, $36-39$ no. W-01 b; Berndt-Ersöz 2006, 237-238 no. 37 (Figs. 47 and 49).

$$
\begin{gathered}
\rightarrow \quad \text { yos esait } \text { : materey } \vdots \text { eveteksete } e^{?} y \text { ovevin } \vdots \text { onoman } \vdots \text { da Yet } \vdots \text { la- } \\
\leftarrow \quad \text { kedo key } \vdots \text { venavtun } \vdots \text { avtay } \text { materey }
\end{gathered}
$$

1 eveteksetẹy leg. CIPPh. : eveteksetiy ceteri : FFFTFKSETTS legitur.

'Whoever puts his own name in this Mother eveteksetẹ? $y$, let him be took by the MotherGoddess herself.' 


\section{W-01c}

Mordtmann 1862, 24-25 no. 14 no. 8 (Tafel A-B, no. 14); Gosche 1864, 225 no. 9; Ramsay 1883, 133 no. 9; Ramsay 1889b, 310; Pauli 1894, 58 no. 9; Torp 1896, 10; Körte 1898, 118; von Reber 1898, 572; Meister 1911, 319; Schwyzer 1923, Appendix IV 8, 3 c; Sayce 1926, 33 no. 9; Friedrich 1932, 126, no. 7 c; Haas 1951, 23, no. VIIc; Haas 1966, 197 no. VII c; Haspels 1971 I, 292-293 no. 11 b; Neroznak 1978, 76-77 no. A 7 c; CIPPh I, 41-42 no. W-01 c (II, pl. XVI-1 and XIX-3, 4); Diakonoff \& Neroznak 1985, 63 no. A 7 c; Lubotksy 1988, no. W-01c (p. 10, Fig. 1); TITUS, no. W-1c; Orel 1997a, 39-40 W-01 c; Berndt-Ersöz 2006, 237-238 no. 37 (Figs. 47 and 49).

$$
\begin{gathered}
\leftarrow \quad \text { ataniyen } \vdots \text { kuryaneyon }: \text { taln egertoy } \\
\text { 'Ataniyen the ruler X-ed it.' }
\end{gathered}
$$

\section{W-02}

"Façade Situated at Kümbet Asar Kale, c. $1.5 \mathrm{~km}$ north-east of the village of Kümbet" (Berndt-Ersöz 2006, 232). Dated to the middle $6^{\text {th }} \mathrm{c} . \mathrm{BC}$.

Haspels 1971 I, 293 no. 12 (II fig. 98, 99 and 604); Neroznak 1978, 110 no. A 81; CIPPh I, 4243 no. W-02 (II, pl. XX-1, 2 and XXI-1, 2, 3); Diakonoff \& Neroznak 1985, 75 no. A 81; TITUS, no. W-2; Orel 1997a, 41-12 no. W-02; Berndt-Ersöz 2006, 231-232 no. 29 (Fig. 31); Obrador-Cursach fthc. b.

\section{iketaios : pseika? ed? $[a] e^{?}$ s}

'Iketaios ... made.'

\section{W-03}

On a rock-cut façade in Arslankaya "situated c. 4 km south-east of Döğer and c. $1.3 \mathrm{~km}$ south of Küçük Kapı Kaya [...]. Arslankaya stands among other rocks at the border of the plain west of Emre Gölü" (Berndt-Ersöz 2006, 222). Dated to the middle $6^{\text {th }}$ c. BC.

Kretschmer 1896, 218; Körte 1898, 93; Friedrich 1932, 126 no. 11; Haas 1966, 197 no. XI; Haspels 1971 I, 294 no. 20 (II, fig. 186-188); Neroznak 1978, 81 no. A 11; CIPPh I, $43-45$ no. W-03 (II, pl. XXII-1, 2 and XXIII-1, 2); Diakonoff \& Neroznak 1985, 64 no. A 11; TITUS, no. W-3; Orel 1997a, 42 no. W-03; Berndt-Ersöz 2006, 222-223 no. 16 (Fig. 27 and 122).

$$
\text { [---]m[...?].t....m[..?]m.[..].[---] }
$$




\section{W-04}

On undated step monument with a niche in Ayazini, "situated c. $600 \mathrm{~m}$ north of the road junction by the 'Pointed Rock', the Sivri Taş in the south of the Köhnüş valley" (BerndtErsöz 2006, 245).

Ramsay 1883, 134 no. 11 (pl. 3 no. 11); Ramsay 1888, 371-372; Pauli 1894, 58 no. 11; Körte 1898, 120 (and fn. 3) and 121 no. 0; Sayce 1926, 33 no. 11; Friedrich 1932, 126 no. 9; Haas 1966, 197 no. IX; Haspels 1971 I, 293 no. 13 (I, 293 and II fig. 604 no. 13); Neroznak, 1978, 80 no. A 9; CIPPh I, 45-47 no. W-04 (II, XXIV-1, 2, 3); Diakonoff \& Neroznak 1985, 64 no. A 9; TITUS, no. W-4; Orel 1997a, 42-43 no. W-04; Berndt-Ersöz 2006, 245-246 no. 56 (Figs. 5 and 73).

$$
\begin{array}{ll}
\leftarrow \text { matar kubileya }[\quad & \text { toy- } \\
& \text { en }
\end{array}
$$

\section{W-05}

Rock-cut façade at Mal Taş, "situated among the rocks bordering the Köhnüş valley on the east side, c. $700 \mathrm{~m}$ south of the tall rock called Sivri Taş" (Berndt-Ersöz 2006, 227). Dated to first half of the $6^{\text {th }} \mathrm{c}$. BC.

\section{$W-05 a$}

Kretschmer 1896, 218 (219); Körte 1898, 108-109; von Reber, 1898, 564 (pl. IV); Sayce 1926, 34; Friedrich 1932, 126 no. 12; Haas 1966, 198 no. XII; Haspels 1971 I, 293 no. 14 (II fig. 157, 158 and 603 no. 14); Neroznak 1978, 81 no. A 12; CIPPh I, 47-78 no. W-05 a (II, XXV-3); Diakonoff \& Neroznak 1985, 64 no. A 12; TITUS, no. W-5a; Orel 1997a, 43-44 no. W-05 a; Berndt-Ersöz 2006, 227-228 no. 24 (Figs. 5 and 33-36)

\section{natimeyon nạ}

\section{$W-05 b$}

Haspels 1971 I, 293-294 no. 15 (II, fig. 603 no. 15); Neroznak 1978, 110 no. A 82; CIPPh I, 48-49 no. W-05 b (II, XXVI); Diakonoff \& Neroznak 1985, 75 no. A 82; TITUS, no. W-5b; Orel 1997a, 44-45 no. W-05 b; Berndt-Ersöz 2006, 227-228 no. 24 (Figs. 5 and 33-36); Lubotsky 2017.

$$
\text { [ ]nst [ e]daes por matẹ[...] }
$$

por mạtẹ[ran] siue por mạtẹ[rey] prop. Lubotsky : pormatẹ[..] dub. CIPPh.

'... made (it) for the Mother-Goddess...' 


\section{W-06}

Rock-cut façade situated at Findık site (c. $40 \mathrm{~km}$ south-west of Eskişehir) and dated to the MP II or LP.

Haspels 1971 I, 294 no. 16 (II, fig. 218 and fig. 604); Neroznak 1978, 110 no. A 83; CIPPh I, 50 no. W-06 (II, XXVII-2 and XXVIII-1, 2); Diakonoff \& Neroznak 1985, 76 no. A 83; TITUS, no. W6; Orel 1997a, 45 no. W-06; Berndt-Ersöz 2006, 217-218 no. 5 (Fig. 6 and 16).

$$
\begin{gathered}
\text { [-?-] matạ [-?-] } \\
\text { '... the Mother-Goddess...' }
\end{gathered}
$$

\section{W-07}

On a niche at Fındık site (c. $40 \mathrm{~km}$ south-west of Eskişehir), dated to the MP II or later.

Haspels 1971 I, 294 no. 17 (II, fig. 604); Neroznak 1978, 110 no. A 84; CIPPh I, 50-51 no. W07 (II, XXVII-2, 3 and XXIX); Diakonoff \& Neroznak 1985, 75 no. A 84; TITUS, no. W-7; Orel 1997a, 45-46 no. W-07; Berndt-Ersöz 2006, 216-217 no. 3 (Figs. 6 and 10).

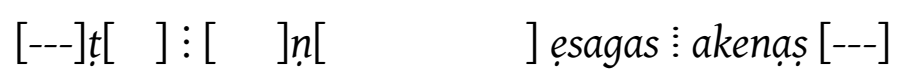

\section{W-08}

Undated inscription engraved on a lone rock at Çepni. Its $<b>$ appears as 8-shaped.

Brixhe \& Drew Bear 1982, 68-79 no. I; CIPPh I, 52-53 no. W-08 (II, pl. XXXII, XXX-2 and XXXI-1, 2); Diakonoff \& Neroznak 1985, 76 no. A 92; TITUS, no. W-8; Orel 1997a, 46-49 no. W-08.

$$
\begin{aligned}
& \rightarrow \quad \text { [-?-] ates agomoi } \\
& \leftarrow \quad \text { sa९?ta tedaes } \\
& \rightarrow \quad \text { alussi } \uparrow e t 0^{?} \text { ? } \\
& 4 \quad \rightarrow \quad \text { bateles bab.[-?-] }
\end{aligned}
$$

'Attes made the sa $\varphi^{?}$ ta for Agomos...'

\section{W-09}

Undated inscription engraved on a lone rock at Çepni.

Brixhe \& Drew Bear 1982, 79-81 no. II; CIPPh I, 54 no. W-09 (II, XXXIII-1, 2); Diakonoff \& Neroznak 1985, 76 no. A 93; TITUS, no. W-9; Orel 1997a, 49-50 no. W-09.

si个eto ae

alus 
$\mathrm{W}-10$

Engraved on an undated sheer lone rock at Çepni.

Brixhe \& Drew Bear 1982, 81-86 no. III; CIPPh I, 54-55 no. W-10 (II, pl. XXXVI, XXXIV and XXXV); Diakonoff \& Neroznak 1985, 76 no. A 94; TITUS, no. W-10; Orel 1997a, 50-52 no. W-10.

$$
\begin{array}{ll}
\leftarrow \quad & \text { atai edae lel/ravo } \\
\rightarrow & \text { vi } \uparrow \text { e atevo atoios } \\
\leftarrow \quad & \text { alus si } \uparrow \text { eto das }
\end{array}
$$

\section{$\mathrm{W}-11$}

On an undated altar "situated $500 \mathrm{~m}$ south of Demirli Köy among some rocks called Menekşe Kayaları” (Berndt-Ersöz 2006, 269).

Brixhe \& Sivas 2002; Berndt-Ersöz 2006, 269-270 no. 112 (Fig. 75).

$$
\begin{aligned}
& {[.] y[. ?] \text { agaua }} \\
& {[-?-] \text { tatae? }[. . ?} \\
& {[-?-] e[.]}
\end{aligned}
$$

\section{$\mathrm{W}-12$}

On a fragment of stone from Seyitömer (25 km far from Kütahya, formerly Kotiaeion). dated to $4^{\text {th }}$ C. BC as earlier.

Bilgen, Brixhe \& Coşkun 2011, 145-148 no. 2.

$$
\begin{array}{ll}
\leftarrow & \text { sitoros aros } \\
\leftarrow \quad \text { ispas }
\end{array}
$$

\section{$\mathrm{W}-13$}

On a vertical face of a massif in the surrounding area of Demirli Köy among some rocks called Menekşe Kayaları.

Brixhe \& Sivas 2003, 66-69 no. 3.

$$
\begin{gathered}
\text { pẹlli m?[-?-] } \\
\text { or } \\
\text { pẹllin? }
\end{gathered}
$$




\section{Instrumenta}

\section{$\mathrm{W}-101$}

On a fragment of a pot dated to the $5^{\text {th }} \mathrm{c} . \mathrm{BC}$ found at Seyitömer $(25 \mathrm{~km}$ far from Kütahya, formerly Kotiaeion). Inscription A was incised before firing.

Bilgen, Brixhe \& Coşkun 2011, 142-145 no. 1.

$$
\begin{aligned}
& \mathrm{A} \leftarrow[-?-] p \\
& \mathrm{~B} \leftarrow[-?-] p ? \text { ?asakas }
\end{aligned}
$$

\section{$\mathrm{W}-102$}

Undated sherd found in Yaslanbayır, a höyük near Emircik.

Brixhe \& Sivas 2003, 65-66 no. 1.

$$
\leftarrow \quad \text { tișịs }
$$




\section{B - Bithynia}

\section{Stone inscriptions}

\section{B-01}

Inscription under a niche located near Germanos - Soğukçam dated to the Phrygian Late Period (550-330 BC). All lines are sinistroverse. This text must be compared with B-08, also found in the same site (Brixhe et Vottéro 2016).

Tuğrul \& Firatlı 1966, 230-235 and 236-241; Haas 1969, 70-75 no. XXVIII; Neroznak 1978, 89 no. A 28; CIPPh I, 62-68 no. B-01 (II, pl. XXXVII-1, 2, 3, 4, XXXVIII-1, 2, 3, 4, XXXIX-1, 2, 3, 4, XL-1, 2, 3, 4 and XLI-1, 2, 3, 4); Lubotsky 1993b; Diakonoff \& Neroznak 1985, 68 no. A 28; TITUS, no. B-1; Orel 1997a, 138-147 no. B-01; Berndt-Ersöz 2006, 239-240 no. 40 (Figs. 48).

si bevdos adi..[..]

kavarmoyo imroy edaes etoves niyo[y?]

matar kubeleya ibey a duman ektetoy

$4 \quad$ yos tivo [t] a spereta ayni kin tel? emi

[..] toyo[.]is [.] erktevoys ekey da [b]ati

opito [k]ey oy evememesmeneya anato [.]

kavarmoyun matar otekonov [?]

$8 \quad$ kesiti oyvos aey apaktneni

pakray evkobeyan epaktoy

1 si bevdos adi..[..] Lubotksy, s[.]bev[.]osadi[---] CIPPh $\| 2$ niyo[i'] Brixhe et Vottéro 2016, cf. B-08 : etovesniyo[.] CIPPh : etovesniyo Lubotsky : etovesniyoi cett. || 3 evẹmẹmesmeneya Lubotsky, ev[.]m[.]mesmeneya CIPPh || 5 dạ[b]ati Brixhe et Vottéro 2016, cf. B-08: da[k]ati cett.

'Adi... (the son) of Kavarmoyos? made/put this statue for/in this field...'

\section{B-02}

Big Greco-Persian funerary stele found near Afşartarakçı Köyü (Afşarıvvel in CIPPh) and dated to the Phrygian Late Period (550-330 BC). Preserved in the Istanbul Archaeology Museums (inv. no. 5412).

CIPPh I, 68-71 no. B-02 (II, pl. XLII-1, 2); TITUS, no. B-2 (without transcription); Orel 1997a, 147-148.

.u?teanom?tṣ.. p?op? 


\section{B-03}

On two contiguous sides of a large parallelepiped stone found in Firanlar. Undated.

CIPPh I, 69-71 no. B-03 (II, pl. XLIII-2, 3 and XLIV-1, 2); Woudhuizen 1993, 15-16 no. B-03; TITUS, no. B-3; Orel 1997a, 148-150 no. B-03.

eșk...a[ ]a.. [...]

evtevey ay yosyos yenvra | eti=t evtevey me.oun laked?o | [-?-]

\section{B-04}

On a lost marble block found in a wall of a house in Üyücek. It was considered Mysian in some old publications.

Cox \& Cameron 1932; Friedrich 1932, 140-141, no. XI (as Mysian); Neroznak 1978, 36-37, no. B-01 (as Mysian); Bayun \& Orel 1988c (as Phrygian); Orel 1997a, 52-56, W-11; TITUS, no. Mys. BO-1 - BO-7; Brixhe 2004a, 32-42 no. B-04.

$$
\begin{aligned}
& \text { [--- } \\
& \text { [.]a/di } \left.i^{?} k n[. . . ?] a / d[\text { [.] }] \text { [...] }\right] \text { / } / \underline{d}[---] \\
& \text { lami? } b \text { ? av ? aymokves • amp? } i \\
& 4 \quad a^{?} m^{?} \text { ? } p^{?} \text { tov? a个iy } a^{?} e^{?} \text { lavoy } \text { ue } \\
& \text { edaviy } p^{?} \text { is? } \cdot \text { anerneuey } \\
& \text { y?a.oe? ap.earvi? s? ? bato? ante } \\
& \text { ? lakes s braterais patriyiọ? is } k(e)
\end{aligned}
$$

\section{B-05}

Great Greco-Persian stele found in Vezirhan (Archaeological Museum of Istanbul inv. no. $6219 / 71.27$ ) dated to the $5^{\text {th }}$ c. BC. The whole Phrygian text is sinistroverse while the Greek one is dextroverse.

Neumann 1997; Brixhe 2004a, 42-67 no. B-05; Gorbachov 2008, 92-93; Hämmig 2013 (lines 8-13); Sowa 2015, 184-190; Simon 2015 (only 1. 13).

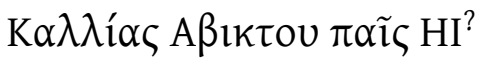

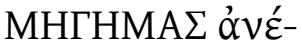

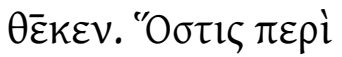

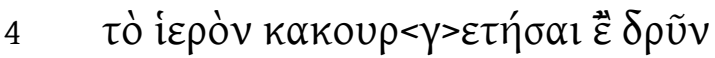

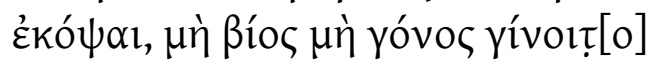


1 sin=t imenan kaliya ti tedat [oy .]edekm[...]meass? d? ư? mị iben edatoy dạkeran atriyạs dạvoi okima akịva[---] vrekạn vitarạn artimitos krạiyạs [---]

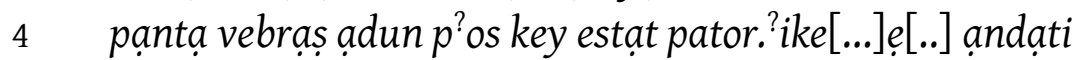
vay niptiyạy daker karatu enpsạtus mekạ[---] asiyạ..? nidus ad kaliyay karatu panato ando popostois klaniv kelmis ke umnișet evraduṣ dạkerạiṣ key iverais [..] atikraiu yos niy art sin=t imenạn kạkạ oskạvos kakey kạn dedạsitiy tubetiv oy nẹvos derạliv mekas key kovis ạbretoy nun ibey nevotạn niptiyan sirun mireyun †iv $\dagger<$ s>imun inmeney asenan daket torvetun $\uparrow$ iray ayniy oy tubnuv nevos, me deritoy kovis ke abretoy nun oy nev<otan> yos isekosos 个emeney dupratoy, veban ituv

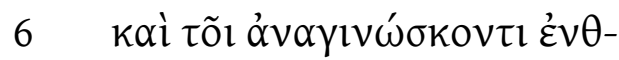

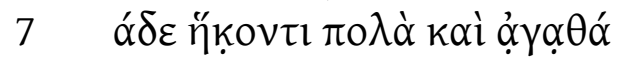

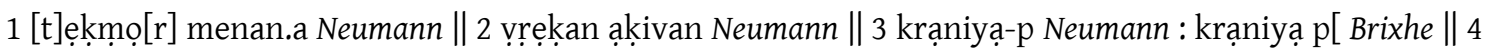
pator-p ike[......] an dati Neumann $\| 5$ meka as-k<e>y Neumann $\| 6$ [.]ạ(:)kaliyay karatu panato ando-p oposțoịs klạniv Neumann : nidus ạd kạliyay kạratu pạnạto ạndopopostois klạm?iv[..?] Brixhe $\|$ 7 kelmis-ke umniṣ etevrạadus dakeraiṣ-key iveraiṣ Neumann \| 8 art sin-t imenenan Neumann \| 9 : dedapitiy țubeti voyṇeṿos deragiv mekạs-key Neumann : de dapitiy tubeti voy kevos derạliv mekạs key Brixhe $\| 10$ kovis

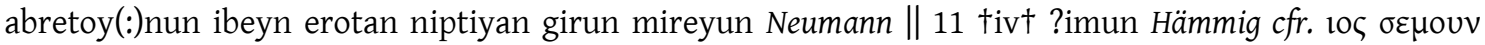
passim : ivimum Brixhe : asenạn Neumann et Hämmig : as enan Brixhe : șirayay(:)niyọy Neumann : ^irạy ạyni yoy Brixhe : 个iray ayniy oy Hämmig $\| 12$ koris ke abretoy nun oynev Neumann et Brixhe : abretoy nun oy nev<otan> Hämmig $\| 13$ pupratoy Neumann : dupratoy Brixhe.

'[Greek] Kallias the son of Abiktos put this ... Whoever does harm around this shrine or cuts a tree, he shall not have neither life nor offspring and who comes here and reads it, let him have many and good things. [Phrygian] Kallias put this shrine ... [1. 8-13] whoever does harm around this shrine ... his son, his daughter and ... Whoever puts an asenan in this shrine, cutting a tree by his hand or ... his son, let him not ... his son. Whoever...'

\section{B-06}

Damaged marble funerary stele found in a ground of a later tumulus of Daskyleion (dated to the $4^{\text {th }} \mathrm{c} . \mathrm{BC}$ ). Perhaps the stele dates to the first half of the $6^{\text {th }} \mathrm{c} . \mathrm{BC}$.

Bakır \& Gusmani 1991; TITUS, no. Dask-1 - Dask-4 ; Orel 1997a, 151-153 no. B-04; Brixhe 2004a, 68-73 B-06.

$$
\begin{aligned}
& \text { stal'a ke : 个ekm?[at]es key[---]a? yọ?[---] } \\
& \text { des [---] : event noktoy : ẹmetẹtariyois } \\
& \text { [---]y: yos tumoy: } \uparrow e k m a t i n \\
& 4 \quad[---] a t o n k e y e n
\end{aligned}
$$

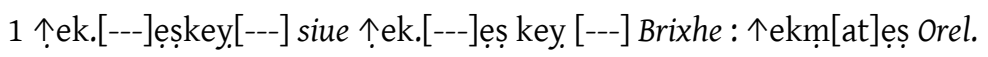




\section{B-07}

Great marble stele found in Daskyleion and dated to the first quarter of the $5^{\text {th }} \mathrm{c} . \mathrm{BC}$.

Gusmani \& Polat 1999a; Gusmani 2001, 164-166; Brixhe 2004a, 73-85 no. B-07.

[.]gat: s=manes iyungidas manitos apelev porniyoy est [...]

[..] es va knais manuka odeketoy meros ke manes is yos tiv[.]

[?]n ke devụn k umnotan ordoineten, me kos anivayeti s=manin

'This (is) Manes (the son) of Iyungida, the grandson of Manes... his wife Manukka ... and Manes... Whoever ... of ... and the gods?... Let nobody do harm to Manes.'

\section{B-08}

A great inscription engraved on a rock near B-01 in Germanos - Soğukçam and dated to the Phrygian Late Period (550-330 BC). Blanks are used to separate the words. The sinistroverse inscription is very eroded and only few letters are legible.

Brixhe \& Vottéro 2016.

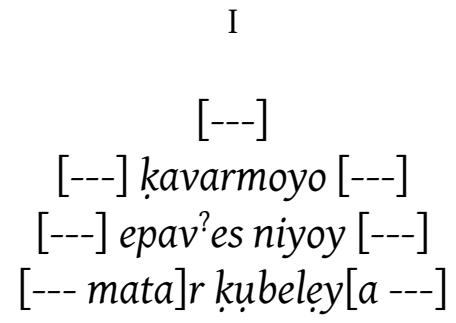

II

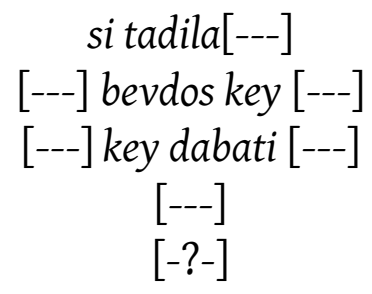

I 3 epav?esniyoy fort. epar?esniyoy.

\section{Instrumenta}

\section{B-101}

Fragment of an Attic cup found in Daskyleion (digging deposit inv. no. 2013 = DASK 91: BUH). Dated to between 525 and 500 BC.

Bakır \& Gusmani 1993, 136 no. 1 and 143-144; Brixhe 1996, 137-138 § 3.1.1; Brixhe 2004a, 85-86 no. B-101.

$$
\leftarrow \quad \text {---]yon }
$$




\section{B-102}

Fragment of an Attic cup found in Daskyleion (digging deposit inv. no. $542=$ DASK 90/91: BBG/BNY/BBS) and dated to between 480 and $470 \mathrm{BC}$.

Bakır \& Gusmani 1993, 136-137 no. 2 and 143-144; Brixhe 1996, 138-139 § 3.1.2.; Orel 1997a, 153-154 no. B-101; Brixhe 2004a, 86-87 no. B-102.

\section{$\leftarrow$ vana}

\section{B-103}

Fragment of an Attic kantharos found in Daskyleion (digging deposit inv. no. $2014=$ DASK 91: BTK). Dated to between 350 and 340 BC.

Bakır \& Gusmani 1993, 137 no. 3 and 143; Brixhe 1996, 139-140 § 3.1.3.; Orel 1997a, 154 no. B-102; Brixhe 2004a, 87-88 no. B-103.

$$
\leftarrow \text { karea[-?-] }
$$

\section{B-104}

Fragment of a northwestern Anatolian amphora (digging deposit inv. no. 935 = DASK 91: BPR) found in the satrapal palace in Daskyleion. First half of the $5^{\text {th }} \mathrm{c} . \mathrm{BC}$.

Bakır \& Gusmani 1933, 138-139 no. 5 and 144; Brixhe 1996, 140-141 § 3.1.4.; Orel 1997a, 154 no. B-103; Brixhe 2004a, 88-89 no. B-104.

\section{[---]t/g? $i / u^{?}$ siteoy.}

\section{B-105}

Fragment of northwestern Anatolian amphora (digging deposit inv. no. 298 = DASK 89: AKT) found in Daskyleion. Dated to the $4^{\text {th }}$ C. BC.

Bakır \& Gusmani 1933, 139 no. 6 and 143; Brixhe 1996, 141-142 § 3.1.5.; Orel 1997a, 154155 no. B-104; Brixhe 2004a, 89-90 no. B-105.

$$
a k
$$

\section{B-106}

Fragment of northwestern Anatolian amphora (digging deposit inv. no. 860 = DASK 91: BTS) found in Daskyleion. Dated to the $4^{\text {th }}$ C. BC.

Bakır \& Gusmani 1933, 140 no. 7 and 144; Brixhe 1996, 142-144 § 3.1.6.; Orel 1997a, 155 no. B-105; Brixhe 2004a, 90-91 no. B-106.

$$
\text { [-?-]isdọ[---] or [---]ọusi[-?-] }
$$




\section{B-107}

Fragment of Mysian plate (digging deposit inv. no. 723 = DASK 91: BVB) found in Daskyleion. Dated to the second half of the $6^{\text {th }} \mathrm{c}$. BC.

Bakır \& Gusmani 1933, 140 no. 8 and 144; Brixhe 1996, 144-145 § 3.1.7.; Orel 1997a, 155 no. B-106; Brixhe 2004a, 91-92 no. B-107.

$$
\leftarrow \text { ilay }
$$

\section{B-108}

Graffito incised on some contiguous fragments of a bowl dated to the $6^{\text {th }}$ or the beginning of the $5^{\text {th }}$ c. BC. Found in Daskyleion (digging deposit inv. no. 1225 = DASK 93: CUICUO).

Gusmani \& Polat 1999b, 61-64; Brixhe 2004a, 92-93.

$$
\leftarrow \text { saragis :? mago? }\left[s^{?}---\right]
$$

1 saragis Brixhe : ]saragiś siue ]saraliś Gusmani et Polat.

'Saragis the magos?...' 


\section{G - Gordion (Yassihüyük)}

\section{Stone inscriptions}

\section{G-01}

Seven fragments of a calcareous slab found in Building NTC, dated to the $6^{\text {th }} \mathrm{c}$. BC (Ankara Museum inv. no. 12494).

Young 1951, 10 (pl. IV fig. 2); Young 1953, 21; Haas 1966, 198-199 no. XXIV (translitered in 179); Young 1969, 276 no. 24; Lejeune 1969b, 289; Lejeune 1970, 70; Neroznak 1978, 84 no. A 24; CIPPh I, 81-85 (II, pl. XLIV-3, 4, XLV-1, 2, 3, 4); Diakonoff \& Neroznak 1985, 81-85 no. A 24; TITUS, no. G1; Orel 1997a, 156-158 no. G-01.

A

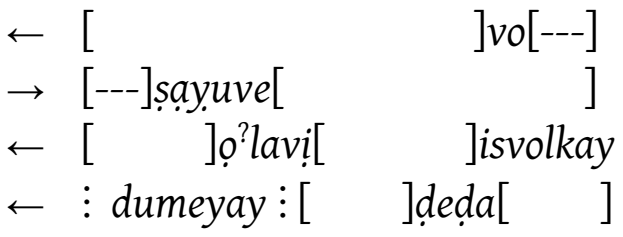

B

$\rightarrow\left[\begin{array}{cr}{[\quad] \text { ita. }[\quad} & \text { ]terkeya ask } \\ \mathrm{C} & \end{array}\right.$

$\leftarrow \quad[--e] n[e]|p| a r k e s v[---]$

\section{G-02}

Undated calcareous slab reused in a canal to the west of the Gate, uncertain date, although no later than the $6^{\text {th }} \mathrm{c} . \mathrm{BC}$ (Gordion Museum inv. no. I 118). Two feet were engraved to the right of the slab.

Young 1955, 10-11 (pl. 5 fig. 22); Masson 1954, 441 no. 27; Brixhe 1968, 308; Haas 1969, 78-79 no. XXIX; Young 1969, 279-280 no. 43 (p. 277 fig. 7 and pl. 71); Lejeune 1969b, 289 no. 43; Lejeune 1970, 70 no. 43;
Neroznak 1978, 96 no. A 43; CIPPh I, 85-87 no. G-02 (II, pl. XLVI-2 and XLVII-1, 2); Diakonoff \& Neroznak 1985, 70 no. A 43; Woudhuizen 1993, 9-12 no. G-02; TITUS, no. G-2; Orel 1997a, 158-161; Kloekhorst 2015.

A agaritoi ! pẹtes : adoikavoi

B ios oporokitis.?

C kakoioi tovo: podaskai?

А АГАРIIOI : IKTE $\Sigma$ Young : agarțioi : iktes CIPPh et Orel : agaritoi : petes Kloekhorst \| C podaska? CIPPh et Orel : podaskai? Young and Kloekhorst.

'Devoted foot of/for Adoikavos. Whoever ... harms it, ...'

\section{G-03}

Calcareous block which found reused in rubble packing for the bed of the north wall of MP Building C (Gordion Museum inv. no. I 127).

Young 1969, 271 no. 39 (p. 268 fig. 4 and pl. 69); Lejeune 1969b, 289 no. 39; Lejeune 1970, 70 no. 39; Neroznak; 1978, 95 no. A 39; CIPPh I, 88 no. G-03 (II, pl. XLVI-1); Diakonoff \& Neroznak 1985, 70 no. A 39; TITUS, no. G3; Orel 1997a, 162.

\section{[-?-]kakrayun ni[-?-]}

\section{G-04}

Calcareous block found re-used as a building stone in the wall of a Hellenistic house (Gordion Museum inv. no. I 420), uncertain date.

Young 1968, 235-236 (pl. 76 and 18); Haas 1969, 81 no. XXXI; Young 1969, 280 no. 44 (p. 277 fig. 7 and pl. 69); Lejeune 1969b, 289 no. 44; Lejeune 1970, 71 no. 44; Neroznak; 1978, 97 no. A 44; CIPPh I, 89 no. G-04 (II, pl. 
XLVIII-1); Diakonoff \& Neroznak 1985, 70 no. A 44; TITUS, no. G-4; Orel 1997a, 162-163.

$$
\begin{gathered}
\text { [--- }] \text { evi. } \\
\text { tatas .[--- }] \\
{[---] i^{?} m a^{?}\left[n^{---}\right]} \\
{[-?-]}
\end{gathered}
$$

\section{G-05}

Undated fragment of calcareous stone reused in the $3^{\text {rd }} \mathrm{c}$. BC in the early east gate (Gordion Museum inv. no. I 47), uncertain date.

CIPPh I, 90-91 no. G-05 (II, pl. XLVIII-2); TITUS, no. G-5; Orel 1997a, 163-164.

$$
\text { [---]g[---] }
$$

\section{G-06}

Undated fragment of calcareous stone found in the surface near Tumulus $\mathrm{J}$ (Gordion Museum inv. no. I 77).

CIPPh I, 91 no. G-06 (II, pl. XLIX-1); TITUS, no. G-6; Orel 1997a, 164.

\section{[---] babạas? ${ }^{[---]}$}

\section{G-07}

Fragment of calcareous stone reused in the repair of the east gate, dated to the end of the $5^{\text {th }}$ or beginning $4^{\text {th }}$ c. BC (Gordion Museum inv. no. I 114).

CIPPh I, 91 no. G-07 (II, pl. XLIX-2); TITUS, no. G-7; Orel 1997a, 164.

$$
\text { [---]m?ạesi.[---] }
$$

\section{G-08}

Undated fragment of calcareous stone found in the surface close to Tumulus $\mathrm{H}$ (Inv. no. I 115).

CIPPh I, 92-93 no. G-08 (II, pl. XLIX-3); TITUS, no. G-8; Orel 1997a, 165-166.

$$
\text { [---]osve[---] }
$$

\section{G-09}

Undated fragment of calcareous stone found in the surface close to Tumulus $\mathrm{H}$ (Inv. no. I 116).

CIPPh I, 93 no. G-09 (II, pl. L-1, 2); TITUS, no. G-9; Orel 1997a, 166.

$$
\text { [---]r?eme? [---] }
$$

\section{G-10}

Undated fragment of calcareous stone without clear origin (Gordion Museum inv. no. I 655).

Brixhe 2002a, 29-31 no. G-10.

$$
\begin{aligned}
& \text { [-?-] } \\
& \leftarrow \quad \text { [---]ekeay. } \\
& \rightarrow \quad \text { : imelan }
\end{aligned}
$$

\section{G-11}

Undated trapezoidal calcareous block found on the surface of a field $5 \mathrm{~km}$ far from Yassihöyük (Gordion Museum inv. no. I 655).

Brixhe 2002a, 29-31 no. G-11.

$$
\begin{aligned}
\mathrm{A} & \leftarrow u^{?} l^{?} \text { ekey } \\
\mathrm{B}+\mathrm{C} & \leftarrow \text { sit kraroy veaol yoy [.? }] \\
& \leftarrow \text { dis }
\end{aligned}
$$




\section{Instrumenta}

\section{G-101}

Two undated, contiguous fragments of a pot (Istanbul Archaeology Museum inv. no. 4002).

Körte \& Körte 1904, 172 no. 2 (fig. 152); Friedrich 1932, 127, no. 16; Haas 1966, 198 no. XVI (as Greek); Lejeune 1969a, 20 no. XVI; Lejeune 1969b, 289 no. 16; Lejeune 1970, 71 no. 16; Neroznak 1978, 83 no. A 16; CIPPh I 95-95 G-101 (II, pl. LI-1); Diakonoff \& Neroznak 1985, 66 no. A 16; TITUS, no. G101; Orel 1997a, 166-167 G-101.

$$
\text { kuliyạ[---] }
$$

\section{G-102}

Two undated, contiguous fragments of a Cyprian cup (Istanbul Archaeology Museum inv. no. 4000).

Körte \& Körte 1904, 172 no. 3 (fig. 152); Friedrich 1932, 127, no. 17; Haas 1966, 198 no. XVII; Lejeune 1969a, 20-21 no. XVII; Lejeune 1969b, 289 no. 17; Lejeune 1970, 71 no. 17; Neroznak 1978, 71 no. A 17; CIPPh I, 96-97 no. G-102 (II, pl. LI-2); Diakonoff \& Neroznak 1985, 66 no. A 17; Orel 1997a, 167168 no. G-102.

$$
\begin{array}{ll}
\text { А } & {[-?-] \mathrm{kad}} \\
\text { в } & {[---] \mathrm{d}^{?} \cdot \mathrm{oi} \cdot \mathrm{o}^{?} \cdot[---]}
\end{array}
$$

\section{G-103}

Undated broken handle of a Phrygian pot (Staatliche Museen $\mathrm{zu}$ Berlin, Antikensammlung inv. no. 4609).

Körte \& Körte 1904, 172 no. 4 (fig. 154); Lejeune 1969a, 21 no. XVI bisI; Lejeune 1969b, 289 no. 17 bis; Lejeune 1970, 71 no. 17 bis; Neroznak 1978, 84 no. A 17 bis; CIPPh 9697 no. G-103 (II, pl. LI-3); Diakonoff \&
Neroznak 1985, 66 no. A 17 bis; TITUS, no. G101; Orel 1997a, 168 no. G-103.

$$
\text { kadiun[---] }
$$

\section{G-104}

Fragment of a deep bowl dated to the (early) $8^{\text {th }} \mathrm{c}$. BC, found below the final floor of Megaron 10 (Gordion Museum inv. no. I 366).

Young 1966, 276 (pl. LXXIII); Lejeune 1969a, 23; Young 1969 257-259 no. 29 fig. 1 (pl. 67); Lejeune 1969b, 289 no. 29; Lejeune 1970, 71 no. 29; Neroznak 1978, 91 no. A 29; CIPPh I, 98-99 no. G-104 (II, pl. LI-4); Diakonoff \& Neroznak 1985, 68 no. A 29; Orel 1997a, 168 no. G-104; Brixhe 2004b, 276-277 no. G-104; Sams 2011, 65 and 67 (Fig. 4.16).

$$
\text { kernọ[---] or kermọ!---] }
$$

\section{G-105}

Bronze bowl dated to late $740 \mathrm{~s} \mathrm{BC}$ and found inside Tumulus MM (Museum of Anatolian Civilizations, inv. no. 18441).

Young 1958, 153 (pl. XXV, 21); Young 1963, 362; Haas 1966, 198 no. XXV; Lejeune 1969a, 22 no. XXXV; Young 1969, 260 and 262 no. 25 (p. 258, fig. 1 and pl. 68); Lejeune 1969b, 289 no. 25; Lejeune 1970, 71 no. 25; Neroznak 1978, 87-88, no. A 25; Young 1981, 130 fig. 84; Brixhe 1981, 273 no. MM 68 (p. 274, fig. $134 \mathrm{~A}$ and pl. $97 \mathrm{~A}$ ); CIPPh I, 99-100 no. G-105 (II, LII-1, 2); Diakonoff \& Neroznak 1985, 67 no. A 25; TITUS, no. G-105; Orel 1997a, 169 no. G-105.

si个idos akor 


\section{G-106}

Bronze bowl dated to late 740s BC and found inside Tumulus MM (Museum of Anatolian Civilizations, without inv. no., find no. B 1040).

Young 1969, 262 no. 32 (p. 263 fig. 3 and pl. 68); Lejeune 1969b, 289 no. 32; Lejeune 1970, 71 no. 32; Neroznak 1978, 92, no. A 32; Brixhe 1981, 273 no. MM 67 (p. 274 fig. 134 B and pl. 97 B); Brixhe 1982, 240-241; CIPPh I, 100-101 no. G-106 (II, pl. LII-3); Diakonoff \& Neroznak 1985, 69 no. A 32; Orel 1997a, no. $169-170$.

$$
\text { ụtd }
$$

\section{G-107}

Bronze bowl dated to late $740 \mathrm{~s} \mathrm{BC}$ and found inside Tumulus MM (Museum of Anatolian Civilizations, inv. no. 13067).

Young 1969, 262 no. 33 (p. 258 fig. 1); Lejeune 1969b, 289 no. 33 and 291; Lejeune 1970, 71 no. 33; Neroznak 1978, 92 no. A 33; Brixhe 1981, 273-275 no. MM 69 (p. 274 fig. $134 \mathrm{C}$ and pl. 97 C); CIPPh I, 101-102 no. G107 (II, pl. LII-4); Diakonoff \& Neroznak 1985, 69 no. A 33; TITUS, no. G-107; Orel 1997a, no. 170.

$$
\text { ata }
$$

\section{G-108}

Bronze omphalos bowl dated to late 740s $\mathrm{BC}$ and found inside Tumulus MM (Museum of Anatolian Civilizations, without inv. no., find. no. B 855).

Young 1969, 260 no. 30 (p. 261 fig. 2); Lejeune 1969b, 289 no. 30 (p. 291); Lejuene 1970, 71 no. 30; Neroznak 1978, 91-92 no. A 30; Brixhe 1981, 275-276 no. MM 119 (p. 274 fig. $134 \mathrm{D}$ and pl. 98 A; p. 276); CIPPh I, 102 no. G-108 (II, pl. LIII-1); Diakonoff \& Neroznak 1985, 69 no. A 30; TITUS, no. G108; Orel 1997a, 170-171 no. G-108.

$$
\text { eies }
$$

\section{G-109}

Contiguous sherds of a spherical jar dated to late $740 \mathrm{~s} \mathrm{BC}$ and found inside Tumulus MM (Museum of Anatolian Civilizations, find. inv. no. P 1825). A space separates the words.

Young 1969, 260 no. 31 (p. 258 fig. 1); Lejeune 1969b, 289 no. 31 (p. 258 fig. 1 and 67; p. 291 and 292); Lejuene 1970, 71 no. 31; Neroznak 1978, 92 no. A 31; Brixhe 1981, 275-277 no. MM 362 (p. 274 fig. $134 \mathrm{D}$ and pl. 98 A; p. 276); CIPPh I, 102-103 no. G-109 (II, pl. LIII-3); Diakonoff \& Neroznak 1985, 69 no. A 31; TITUS, no. G-109; Orel 1997a, 171 no. 109 .

\section{aladis url}

agadis urg dub. Young : agadis url Neroznak et CIPPh.

\section{G-110}

Sherd of a large spherical-bodied jug found in a house below Tumulus $\mathrm{H}$ and dated to the late $8^{\text {th }}$ or $7^{\text {th }} \mathrm{C}$. BC (Gordion Museum inv. no. I 40).

Young 1969, 267 no. 34 (p. 268 fig. 1); Lejeune 1969b, 289 no. 34 (p. 292); Lejune 1970, 71 no. 34 (p. 57); Neroznak 1978, 93 no. A 34; CIPPh I, 103-104 no. G-110 (II, pl. LIII2); Diakonoff \& Neroznak 1985, 69 no. A 34; TITUS, no. G-110; Orel 1997a, 171-172 no. G110.

\section{lagineios}

\section{G-111}

Fragment of a tall pithos or amphora in a house below Tumulus $\mathrm{H}$ and dated to the late $8^{\text {th }}$ or $7^{\text {th }}$ c. BC (Gordion Museum inv. no. I 41).

Young 1969, 267 no. 35 (p. 269 fig. 5); Lejeune 1969b, 289 no. 35 (p. 291); Lejune 1970, 71 no. 35 (p. 54); Neroznak 1978, 93 no. 
A 35; CIPPh I, 104 no. G-111 (II, pl. LIV-1); Diakonoff \& Neroznak 1985, 69 no. A 35; TITUS, no. G-111; Orel 1997a, 172 no. G-111.

$$
\text { [---]ọ mekas }
$$

\section{G-112}

Two contiguous sherds of a large coarse vessel found in a house under Tumulus E, dated to the $6^{\text {th }} \mathrm{c}$. BC (Museum of Anatolian Civilizations, without inv. no., find no. I 1).

Young 1969, 270-271 no. 37 (p. 258 fig. 1); Lejeune 1969b, 289 no. 37 (p. 291); Lejune 1970, 71 no. 37 (p. 63-64); Neroznak 1978, 94 no. A 37; CIPPh I, 105 no. G-112 (II, pl. LV-1); Diakonoff \& Neroznak 1985, 69 no. A 37; TITUS, no. G-112; Orel 1997a, 172-173 no. G112.

$$
e^{4}+a[---]
$$

\section{G-113}

Sherd found in Tumulus E, dated to the $6^{\text {th }} \mathrm{C}$. BC (Museum of Anatolian Civilizations, without inv. no., Find No. I 66).

Young 1969, 271 no. 38 (p. 71 fig. 38); Lejeune 1969b, 289 no. 38 (p. 293); Lejune 1970, 71 no. 38 (p. 58); Neroznak 1978, 94 no. A 38; CIPPh I, 105-106 no. G-113 (II, pl. LV-2); Diakonoff \& Neroznak 1985, 69 no. A 38; TITUS, no. 113; Orel 1997a, 173-174 no. G113.

$$
\text { [---]astoi pitave[---] }
$$

\section{G-114}

Sherd found in a house under Tumulus $E$, perhaps to be dated to the second quarter of the $6^{\text {th }}$ c. BC (Gordion Museum inv. no. I 163).

Young 1969, 270 no. 36 (p. 263 fig. 3 and pl. 70); Lejeune 1969b, 289, no. 36; Lejeune 1970, 71 no. 36; Neronak 1978, 93 no. A 36;
CIPPh I, 106-107 no. G-114 (II, pl. LVI-1); Diakonoff \& Neroznak 1985, 69 no. A 36; TITUS, no. G-114; Orel 1997a, 174 no. G-114.

ise

\section{G-115}

Fragment of a bowl found in a rubble filling near the Persian Gate Building and dated to the $6^{\text {th }} \mathrm{C}$. BC (Gordion Museum inv. no. I 107).

Young 1969, 271 no. 40 (p. 263 fig. 3 and pl. 67); Lejeune 1969b, 289 no. 40; Lejeune 1970, 71 no. 40; Neroznak 1978, 95 no. A 40; CIPPh I, 107 no. G-115 (II, pl. LVI-2); Diakonoff \& Neroznak 1985, 70 no. A 40; TITUS, no. G-115; Orel 1997a, 174 no. G-115.

YuvaYaros

\section{G-116}

Pithos found beneath the floor of Building M, dated to the MP period (Gordion Museum inv. no. P 2082).

Edwards 1959, 265; Lejeune 1969a, 22 no. 41; Young 1969, 271-272 no. 41; Lejeune 1970, 72 no. 41; Neroznak 1978, 95 no. A 41; CIPPh I, 108-109 no. G-116 (II, pl. LVII-1, 2); Roller 1987a, 65, 3B-5; Diakonoff \& Neroznak 1985, 71 no. A 41; TITUS, no. G116; Orel 1997a, 175 no. G-116.

(Metr. mark) 4

\section{benagonos}

\section{G-117}

Pithos found just over the surface of the clay stratum of the Phrygian Terrace, dated to the MP period (Gordion Museum inv. no. P 2279).

Young 1969, 272 no. 42 (p. 268 fig. 4 and pl. 70), Lejeune 1969b, 289 no. 42; Lejeune 
1970, 72 no. 42; Neroznak 1978, 96 no. A 42; CIPPh I, 109-110 no. G-117 (II, pl. LVIII--1); Roller 1987a, 65 3B-7 (pl. 7); Diakonoff \& Neroznak 1985, 70 no. A 42; TITUS, no. G117; Orel 1997a, 175-176 no. G-117.

[Metr. mark] 51/21

iosais

\section{G-118}

Undated bottom of a bowl found in a clay filling inside Building $\mathrm{N}$, dated to the MP period (Gordion inv. no. I 228).

Young 1969, 280-281, no. 45 (p. 263 fig. 3 and pl. 69); Lejeune 1969b, 289 no. 45; Lejeune 1970, 72 no. 45; Neroznak 1978, 97 no. A 45; CIPPh I, 110-111 no. G-118 (II, pl. LVIII-2); Diakonoff \& Neroznak 1985, 70 no. A 45; TITUS, no. G-118; Orel 1997a, 176 no. G118.

$$
\text { ata }
$$

\section{G-119}

Bottom of a bowl found in the west area of the north court of the MP-Persian Gate Building and tentatively dated to the $5^{\text {th }} \mathrm{c}$. BC (Gordion inv. no. I 62).

Young 1969, 281, no. 46 (p. 263 fig. 3 and pl. 72); Lejeune 1969b, 289 no. 46; Lejeune 1970, 72 no. 46; Neroznak 1978, 97 no. A 46; CIPPh I, 111 no. G-119 (II, pl. LIX-1); Diakonoff \& Neroznak 1985, 70 no. A 46; TITUS, no. G- 119; Orel 1997a, 176-177 no. G119.

\section{[-?-]atas}

\section{G-120}

Sherd found in the fill of the wall between Building $\mathrm{M}$ and $\mathrm{N}$, belonging to the MP period (Gordion Museum inv. no. I 227).
Young 1969, 281, no. 47 (p. 263 fig. 3 and pl. 72); Lejeune 1969b, 289 no. 47; Lejeune 1970, 72 no. 47; Neroznak 1978, 97-98 no. A 47; CIPPh I, 112 no. G-120 (II, pl. LIX-1); Diakonoff \& Neroznak 1985, 70 no. A 47; Orel 1997a, 177 no. G-120.

$$
\text { [---]..atạ[---] }
$$

\section{G-121}

Undated fragment of a bowl found in a discard pile to the west of Megaron 3 (Gordion Museum inv. no. I 189).

Young 1969, 281, no. 48 (p. 263 fig. 3 and pl. 69); Lejeune 1969b, 289 no. 48; Lejeune 1970, 72 no. 48; Neroznak 1978, 98 no. A 48; CIPPh I, 113 no. G-121 (II, LX-1); Diakonoff \& Neroznak 1985, 71 no. A 48; TITUS, no. G121; Orel 1997a, 177 no. G-121.

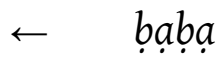

\section{G-122}

Fragment of a pithos found in a burned filling over the floor of a building (remodelled in Persian times) and dated to the middle $5^{\text {th }}$ c. BC (Gordion Museum inv. no. I 384).

Young 1969, 282, no. 49 (p. 268 fig. 4 and pl. 73); Lejeune 1969b, 289 no. 49; Lejeune 1970, 72 no. 49; Neroznak 1978, 98 no. A 49; CIPPh I, 113-114 no. G-122 (II, pl. LX-2); Diakonoff \& Neroznak 1985, 71 no. A 49; TITUS, no. G-122; Orel 1997a, 178 no. G-122.

$$
\leftarrow \quad \text { tates }
$$

\section{G-123}

Fragment of a pot found dug into the clay of the South Cellar above Megaron 6, MP or LP? (Gordion Museum inv. no. I 436).

Young 1969, 282, no. 50 (p. 268 fig. 4 and pl. 73); Lejeune 1969b, 289 no. 50; Lejeune 1970, 72 no. 50; Neroznak 1978, 98 no. A 50; 
CIPPh I, 114 no. G-123 (II, pl. LXI-1); Diakonoff \& Neroznak 1985, 71 no. A 50; TITUS, no. G-123; Orel 1997a, 178 no. G-123.

\section{[-?-]ates}

\section{G-124}

Fragment of a (Lydian?) vessel found over the rubble beddings for the foundation walls of Building B (Persian period), perhaps it dates to the $6^{\text {th }} \mathrm{c}$. BC (Gordion Museum inv. no. I 110).

Young 1969, 282, no. 51 (p. 283 fig. 8 and pl. 73); Lejeune 1969b, 289 no. 51; Lejeune 1970, 72 no. 51; Neroznak 1978, 99 no. A 51; CIPPh I, 115 no. G-124 (II, pl. LXI-2); Diakonoff \& Neroznak 1985, 71 no. A 50; Orel 1997a, 178 no. G-124.

\section{[-?-]ates? $[---]$}

\section{G-125}

Fragment of a pot found in a filling which contained fragments ranging from pre-burning times into the fourth $\mathrm{c}$. BC. Perhaps it dates to the $6^{\text {th }}$ c. BC (Gordion Museum inv. no. I 377).

Young 1969, 235, no. 52 (pl. 76-16); Haas 1969, 79-81 no. XXX; Young 1969, 282 and 284 no. 52; Lejeune 1969b, 290 no. 52; Lejeune 1970, 72 no. 52; Neroznak 1978, 99 no. A 52; CIPPh I, 115-116 no. G-125 (II, pl. LXII-1); Diakonoff \& Neroznak 1985, 71 no. A 52; TITUS, no. G-125; Orel 1997a, 179-180 no. G-125.

\section{$\leftarrow \quad$ [---]ronot? ${ }^{?}$ oy $\vdots$ eneparkes $t^{?} \cdot e^{?} \cdot e s$}

'Teyes engraved it for [---]ronotos.'

\section{G-126}

Fragment of the shoulder of a pithos found in a filling outside the palace area. Perhaps it dates to the $5^{\text {th }} \mathrm{C}$. BC (Gordion Museum inv. no. I 377).
Young 1969, 284, no. 53 (p. 268, fig. 5); Lejeune 1969b, 290 no. 53; Lejeune 1970, 72 no. 53; Neroznak 1978, 99-100 no. A 53; CIPPh I, 117 no. G-126 (II, pl. LXII-2); Diakonoff \& Neroznak 1985, 71 no. A 53; Orel 1997a, 180 no. G-126.

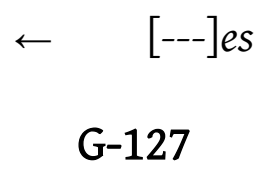

Incised on two contiguous sherds of a vessel in the South Trench and date to the $5^{\text {th }}$ or $4^{\text {th }}$ C. BC (Ankara Archaeological Museum without inv. no., Founding No. I $31)$.

Young 1969, 284 no. 54 (p. 268, fig. 5); Lejeune 1969b, 290 no. 54; Lejeune 1970, 72 no. 54; Neroznak 1978, 100 no. A 54; CIPPh I, 117-118 no. G-127 (II, pl. LXIII-1); Diakonoff \& Neroznak 1985, 71 no. A 54; TITUS, no. G127; Orel 1997a, 180 no. G-127.

\section{kuliyas}

\section{G-128}

On an undated sherd of a pot found in a mixed fill (layer 4) over the area of Terrace Building Rooms 1-2 (Gordion Museum I 246).

Young 1969, 284 no. 55 (p. 268, fig. 5 and pl. 72); Lejeune 1969b, 290 no. 55; Lejeune 1970, 72 no. 55; Neroznak 1978, 100 no. A 55; CIPPh I, 118-119 no. G-128 (II, pl. LXIII-2); Diakonoff \& Neroznak 1985, 71 no. A 55; TITUS, no. G-128; Orel 1997a, 181 no. G-128.

$$
\text { atas kek.[---] }
$$

\section{G-129}

On a fragment of a jug found above the clay on the area of Megaron 4 and dated to the $6^{\text {th }}$ or $5^{\text {th }}$ c. BC (Museum of Anatolian Civilizations without inv. no., finding no. I 31). 
Edwards 1963, 46-47 no. 25; Lejeune 1969a, 22; Young 1969, 284 and 286, no. 56 (p. 285, fig. 9 and pl. 73); Lejeune 1969b, 290 no. 56; Lejeune 1970, 72 no. 56; Neroznak 1978, 100-101 no. A 56; CIPPh I, 119 no. G-129 (II, LXIV-1); Diakonoff \& Neroznak 1985, 71 no. A 56; TITUS, no. G-129; Orel 1997a, 182 G129.

\section{voines}

\section{G-130}

Two contiguous fragments of a vessel found in the filling of a deep cellar dug into the clay just to the west of Megaron 5. Perhaps it dates to the $5^{\text {th }}$ C. BC (Gordion Museum inv. no. I 363).

Young 1969, 286 no. 57 (p. 285, fig. 9 and pl. 73); Lejeune 1969b, 290 no. 57; Lejeune 1970, 72 no. 57; Neroznak 1978, 101 no. A 57; CIPPh I, 120 no. G-130 (II, pl. LXIV-2); Diakonoff \& Neroznak 1985, 71 no. A 57; TITUS, no. G-130; Orel 1997a, 182-183 no. G.130.

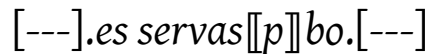

$1 \mathrm{~b}$ supra $\mathrm{p} s c r$.

\section{G-131}

On a handle of a jug found just below the surface of the mound in the area of Persian Building $\mathrm{E}$, in mixed Hellenistic filling. Perhaps it dates to the $5^{\text {th }} \mathrm{C}$. BC (Museum of Anatolian Civilizations without inv. no. 18380).

Young 1969, 286 no. 58 (p. 285 fig. 9 and pl. 74); Lejeune 1969b, 290 no. 58; Lejeune 1970, 73 no. 58; Neroznak 1978, 102 no. A 58; CIPPh I, 120-121 no. G-131 (II, pl. LXII-3); Diakonoff \& Neroznak 1985, 72 no. A 58; TITUS, no. G-131; Orel 1997a, 183-184 no. G131.

$$
\text { [-?-] dumasta eia[---] }
$$

\section{G-132}

On a fragment of an undated pot found in a pit over the area of Megaron 4 (Gordion Museum inv. no. I 234).

Young 1969, 286 no. 59 (p. 269 fig. 5 and pl. 74); Lejeune 1969b, 290 no. 59; Lejeune 1970, 73 no. 59; Neroznak 1978, 102, no. A 59; CIPPh I, 121-122 no. G-132 (II, pl. LXV-1); Diakonoff \& Neroznak 1985, 72 no. A 59; TITUS, no. G-132; Orel 1997a, 184 no. G-132.

$$
\text { ploriatạ[---] }
$$

\section{G-133}

On a fragment of a bowl found in a filling of the second half of the $5^{\text {th }} \mathrm{c} . \mathrm{BC}$, to the west of the Persian Gate Building (Layer 5b) (Museum of Anatolian Civilizations without inv. no. 18379).

Young 1969, 286 no. 60 (p. 269 fig. 5 and pl. 74); Lejeune 1969b, 290 no. 60; Lejeune 1970, 73 no. 60; Neroznak 1978, 102-103 no. A 60; CIPPh I, 122 no. G-133 (II, pl. LXV-2); Diakonoff \& Neroznak 1985, 72 no. A 60; TITUS, no. G-133; Orel 1997a, 184-185 no. G133.

\section{țuvatis or guvatis}

\section{G-134}

On a handle of a jug found in the refill in the trench of a plundered wall bed of a building in the Persian city (above the Phrygian CC Building). Very likely it dates to the $5^{\text {th }}$ C. BC (Gordion Museum I 150).

Young 1969, 286 no. 61 (p. 269 fig. 5 and pl. 71); Lejeune 1969b, 290 no. 61; Lejeune 1970, 73 no. 61; Neroznak 1978, 103 no. A 61; CIPPh I, 123 no. G-134 (II, pl. LXVI-1); Diakonoff \& Neroznak 1985, 72 no. A 61; Orel 1997a, 185 no. G-134. 


\section{G-135}

Fragment of a handle of a cup found in the (disturbed) surface of the clay layer, to the north of Building I. Perhaps, it dates to the MP period (Gordion Museum I 225).

Young 1969, 287 no. 62 (p. 285 fig. 9 and pl. 74); Lejeune 1969b, 290 no. 62; Lejeune 1970, 73 no. 62; Neroznak 1978, 103 no. A 62; CIPPh I, 123-124 no. G-135 (II, pl. LXVI-2); Diakonoff \& Neroznak 1985, 72 no. A 62; TITUS, no. G-135; Orel 1997a, 185 no. G-135.

\section{[-?-]agipeia}

[-?-]agineia Orel 1997.

\section{G-136}

On a little alabaster figure of a falcon found in the plundered wall-trench of a bed for Building W (Persian Level). Tentatively dated to the $6^{\text {th }} \mathrm{c}$. BC (Museum of Anatolian Civilizations without inv. no.).

Young 1964, 280-281 (pl. 83, 6, as Greek); Lejeune 1969a, 22 and 23; Haas 1969, 82-83 (as Greek); Young 1969, 287-288 no. 63 (p. 285 fig. 9 and pl. 72); Lejeune 1969b, 290 no. 63; Lejeune 1970, 73 no. 63; Neroznak 1978, 103-104, no. A 63; CIPPh I, 124-125 no. G-136 (II, pl. LXVII-1, 2); Diakonoff \& Neroznak 1985, 72 no. A 63; TITUS, no. G-136; Orel 1997a, 185-186 no. G-136.

$$
\text { tadoy: iman | bagun }
$$

'Iman (gave) this idol to Tados.'

\section{G-137}

On a fragment of a vessel found just above the plundered west wall of the Phrygian city. Perhaps it dates to the $5^{\text {th }} \mathrm{c}$. BC (Gordion Museum inv. no. I 407).

Young 1969, 288 no. 64 (p. 269, fig. 5 and pl. 73); Lejeune 1969b, 290 no. 64; Lejeune 1970, 73 no. 64; Neroznak 1978, 104 no. A 64; CIPPh I, 125-126 no. G-137 (II, pl. LXVII-3);
Diakonoff \& Neroznak 1985, 72 no. A 64; TITUS, no. G-137; Orel 1997a, 187 no. G-137.

$$
\text { midas [-?-] }
$$

\section{G-138}

On a fragment of a dinos found in a fourth c. filling (Layer 5) in the area above Room 8 of the Phrygian Terrace Building, a context dated to the $4^{\text {th }} \mathrm{c}$. BC (Gordion Museum inv. no. I 249).

Young 1969, 288 no. 65 (p. 283 fig. 8 and pl. 74); Lejeune 1969b, 290 no. 65; Lejeune 1970, 73 no. 65; Neroznak 1978, 104 no. A 65; CIPPh I, 126 no. G-138 (II, pl. LXVIII-1); Diakonoff \& Neroznak 1985, 72 no. A 65; TITUS, no. G-138; Orel 1997a, 187 no. G-138.

$$
\text { babiy:[---] }
$$

\section{G-139}

On a handle of a jug found in a mixed filling outside the Phrygian palace area. Perhaps it dates to the $5^{\text {th }} \mathrm{c}$. BC (Gordion Museum inv. no. I 374).

Young 1969, 288 no. 66 (p. 283 fig. 8 and pl. 74); Lejeune 1969b, 290 no. 66; Lejeune 1970, 73 no. 66; Neroznak 1978, 105 no. A 66; CIPPh I, 127 no. G-139 (II, pl. LXVIII-2); Diakonoff \& Neroznak 1985, 73 no. A 66; TITUS, no. G-139; Orel 1997a, 187 no. G-139.

$$
\text { [-?-]kupolas }
$$

\section{G-140}

On a handle of an undated pot found in mixed disturbed filling at the west side of the mound (Gordion Museum inv. no. I 372).

Young 1969, 288 no. 67 (p. 285 fig. 9 and pl. 71); Lejeune 1969b, 290 no. 67; Lejeune 1970, 73 no. 67; Neroznak 1978, 105 no. A 67; CIPPh I, 127-128 no. G-140 (II, pl. LXVIII-3); 
Diakonoff \& Neroznak 1985, 73 no. A 67; TITUS, no. G-140; Orel 1997a, 188 no. G-140.

\section{$\leftarrow \quad$ noievos}

\section{G-141}

Fragment of a handle of a cup found in a mixed filling of a building at the west side of the mound and dated to the $5^{\text {th }} \mathrm{c} . \mathrm{BC}$ (Gordion Museum inv. no. I 410).

Young 1969, 288-289 no. 68 (p. 285 fig. 9 and pl. 69); Lejeune 1969b, 290 no. 68; Lejeune 1970, 73 no. 68; Neroznak 1978, 105 no. A 68; CIPPh I, 128-129 no. G-141 (II, pl. LXIX-1); Diakonoff \& Neroznak 1985, 73 no. A 68; TITUS, no. G-141; Orel 1997a, 188-189 no. G-141.

$$
\text { [---]țitenorola[---] }
$$

\section{G-142}

On a fragment of a bowl found in a cellar intruded into the clay layer and filled up around the middle of the $5^{\text {th }} \mathrm{c}$. BC (Gordion Museum inv. no. I 296).

Young 1969, 289 no. 69 (p. 283 fig. 8); Lejeune 1969b, 290 no. 69; Lejeune 1970, 73 no. 69; Neroznak 1978, 106 no. A 69; CIPPh I, 129 no. G-142 (II, pl. LXIX-2); Diakonoff \& Neroznak 1985, 73 no. A 69; TITUS, no. G142; Orel 1997a, 189 no. G-142.

$$
\text { [---]avaș ș̣[---] }
$$

\section{G-143}

Fragment of a pithos found in a fill of a building which contained a mixture of diverse materials. Tentatively dated to the $6^{\text {th }}$ c. BC (Museum of Anatolian Civilizations with digging number I 18).

Young 1969, 289 no. 70 (p. 269 fig. 5 and pl. 73); Lejeune 1969b, 290 no. 70; Lejeune 1970, 73 no. 70; Neroznak 1978, 106 no. A 70;
CIPPh I, 129-130 no. G-143 (II, pl. LXX-1); Diakonoff \& Neroznak 1985, 73 no. A 70; TITUS, no. G-143; Orel 1997a, 189-190 no. G143.

$$
\leftarrow \quad \text { [---].evei? } s[---]
$$

\section{G-144}

On the bottom of a bowl or cup found in a building to the north of the Persian Gate. Perhaps it dates to the $5^{\text {th }} \mathrm{C}$. BC (Museum of Anatolian Civilizations with the digging number I 111).

Young 1969, 289 no. 71 (p. 290 fig. 10 and pl. 72); Lejeune 1969b, 290 no. 71; Lejeune 1970, 73 no. 71; Neroznak 1978, 106 no. A 71; CIPPh I, 130-131 no. G-144 (II, pl. LXX-2); Diakonoff \& Neroznak 1985, 73 no. A 71; TITUS, no. G-144; Orel 1997a, 190 no. G-144.

\section{estatoi avun}

\section{G-145}

On a handle of a jug found in a Hellenistic layer above the area of the street between the Phrygian Terrace and $\mathrm{CC}$ Buildings and dated to the $5^{\text {th }} \mathrm{C}$. BC (Museum of Anatolian Civilizations digging no. I 264).

Young 1969, 289 no. 72 (p. 290 fig. 10 and pl. 70); Lejeune 1969b, 290 no. 72; Lejeune 1970, 73 no. 72; Neroznak 1978, 100-101 no. A 72; CIPPh I, 131-132 no. G-145 (II, pl. LXIX3); Diakonoff \& Neroznak 1985, 73 no. A 72; TITUS, no. G-145; Orel 1997a, 190-191 no. G145.

$$
\begin{aligned}
& \text { voineio【Y】 uriienois } k u[---] \\
& S
\end{aligned}
$$

$\Psi$ corrigitur et S scrip. infra. 


\section{G-146}

Two non-contiguous fragments of a pot found in a building to the north of the Persian Gate and dated to between the ending of the $6^{\text {th }}$ and the beginning of the $4^{\text {th }}$ C. BC.

Young 1969, 291 no. 73 (p. 290 fig. 10 and pl. 73); Lejeune 1969b, 290 no. 73; Lejeune 1970, 73 no. 73; Neroznak 1978, 107 no. A 73; CIPPh I, 132-133 no. G-146 (II, pl. LXXI-1, 2); Diakonoff \& Neroznak 1985, 74 no. A 73; TITUS, no. G- 146; Orel 1997a, 191-192 no. G146.

\section{[---].....[--- a]doikavos}

\section{G-147}

Two sherds of a pithos found in the South Trench and dated to between the $6^{\text {th }}$ and $5^{\text {th }}$ c. BC.

Young 1969, 291 no. 74 (p. 283 fig. 8 and pl. 73); Lejeune 1969b, 290 no. 74; Lejeune 1970, 74 no. 74; Neroznak 1978, 107 no. A 74; CIPPh I, 133-134 no. G-147 (II, pl. LXXII-1); Diakonoff \& Neroznak 1985, 74 no. A 74; TITUS, no. G-147; Orel 1997a, 192 no. G-147.

\section{[--- mekas tosk[---]}

\section{G-148}

Fragment of a pot found in a disturbed pocket in the clay near the north end of the Gate Building and dated to between the ending of the $6^{\text {th }}$ and the $4^{\text {th }} \mathrm{c}$. BC.

Young 1969, 292 no. 75 (p. 269 fig. 5 and pl. 73); Lejeune 1969b, 290 no. 75; Lejeune 1970, 73 no. 75; Neroznak 1978, 107 no. A 75; CIPPh I, 134 no. G-148 (II, pl. LXXII-2); Diakonoff \& Neroznak 1985, 74 no. A 75; TITUS, no. G-148; Orel 1997a, 192-193 no. G148.

\section{G-149}

Fragment of a pot found to the west of the palace area in the refill of a trench cut to plunder a wall of a Building and dated to $5^{\text {th }}$ C. BC (Gordion Museum inv. no. I 364).

Young 1969, 292 no. 76 (p. 290 fig. 10 and pl. 73); Lejeune 1969b, 290 no. 76; Lejeune 1970, 74 no. 76; Neroznak 1978, 107 no. A 76; CIPPh I, 134-135 no. G-149 (II, pl. LXXI-3); Diakonoff \& Neroznak 1985, 74 no. A 76; Orel 1997a, 193 no. G-149.

\section{[---]aes}

\section{G-150}

Fragments of a pithos found in a deposit of a pottery over the floor of a house and dated to the ending of the $4^{\text {th }}$ or the beginning of the $3^{\text {rd }}$ c. BC (Museum of Anatolian Civilizations digging no. P 3541).

Young 1969, 292 no. 77 (p. 293 fig. 11); Lejeune 1969b, 290 no. 77; Lejeune 1970, 74 no. 77; Neroznak 1978, 108 no. A 77; CIPPh I, 135-137 no. G-150 (II, pl. LXXIII-1); Roller 1987a, 67 3B-30; Diakonoff \& Neroznak 1985, 74 no. A 77; TITUS, no. G-150; Orel 1997a, 193-194 no. G-150.

[Metr. mark] 3

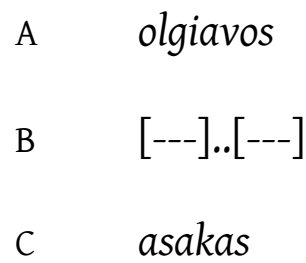

\section{G-151}

Fragment of a pithos found in a filling dated to the $3^{\text {rd }} \mathrm{c}$. BC (Gordion Museum inv. no. I 48).

CIPPh I, 137 no. G-151 (II, pl. LXXIII-2); Orel 1997a, 194 no. G-151.

$$
\text { [-?-].u.s[-?-] }
$$




\section{G-152}

Fragment of a pithos found in a filling dated to the $4^{\text {th }} \mathrm{c}$. BC (Gordion Museum inv. no. I 69).

CIPPh I, 138 no. G-152 (II, pl. LXXIV-1); Orel 1997a, 194-195 no. G-152.

$$
\text { [---]v.i.s[---] }
$$

\section{G-153}

Fragment of a bowl found in a filling of Building A dated to the $3^{\text {rd }}$ c. BC (Gordion Museum inv. no. I 75).

CIPPh I, 138 no. G-153 (II, pl. LXXIV-2); TITUS, no. G-153; Orel 1997a, 195 no. G-153.

$$
\text { [--- a]doikaṿ?[---] }
$$

\section{G-154}

Undated sherd without known context provenience (Gordion Museum inv. no. I 76).

CIPPh I, 139 no. G-154 (II, pl. LXXV-1); Orel 1997a, 195 no. G-154.

$$
\begin{gathered}
\leftarrow[-?-] \operatorname{sit}[---] \\
\text { or } \\
\rightarrow[---] \text { tis[-?-] }
\end{gathered}
$$

\section{G-155}

Undated sherd without known context provenience (Gordion Museum inv. no. I 86).

CIPPh I, 139-140 no. G-155 (II, pl. LXXV3); TITUS, no. G-155; Orel 1997a, 195-196 no. G-155.

$$
\text { [---]amai...[---] }
$$

\section{G-156}

On a fragment of a cup found in the Gate Building and dated to the $5^{\text {th }}$ or $4^{\text {th }} \mathrm{C}$. BC (Gordion Museum inv. no. I 98).

CIPPh I, 140 no. G-156 (II, pl. LXXIV-4); Orel 1997a, 196 no. G-156.

$$
\text { [---]ne[---] }
$$

\section{G-157}

Undated sherd found in the surface near Building NCT (Gordion Museum inv. no. I 103). Under the Phrygian inscription an Aramaic one was incised.

CIPPh I, 141 no. G-157 (II, pl. LXXIV-1); Orel 1997a, 196 no. G-157.

$$
\begin{aligned}
& \text { Phrygian: } \rightarrow[---] \arg \\
& \text { Aramaic: } \leftarrow l \text {...[--- }]
\end{aligned}
$$

\section{G-158}

Fragment of the bottom of a cup found in a Hellenistic filling in the area of Building $C$ and dated ca. 200 BC (Gordion Museum inv. no. I 106).

CIPPh I, 141-142 no. G-158 (II, pl. LXXVI2); Roller 1987a, 51 2B-193 (Fig. 72); TITUS, no. G-158; Orel 1997a, 197 no. G-158.

tib

\section{G-159}

Two non-contiguous sherds found in a building to the north of the Persian Gate and dated to between the ending of the $6^{\text {th }}$ and the $4^{\text {th }} \mathrm{c}$. BC. (Gordion Museum inv. no. I $122 \mathrm{a}$ and $\mathrm{b}$ ).

CIPPh I, 142-143 no. G-159 (II, pl. LXXVI3 and LXXVII-1); TITUS, no. G-159; Orel 1997a, 197 no. G-159. 


$$
\underset{[---] \text { ser.[---] }}{\text { Bios }}
$$

\section{G-160}

On a fragment of a cup found in the cellar cut in Building $\mathrm{E}$ and dated to the $4^{\text {th }}$ c. BC (Gordion Museum inv. no. I 124).

CIPPh I, 143 no. G-160 (II, pl. LXXVII-2, 3); TITUS, no. G-160; Orel 1997a, 197-198 no. G-160.

$$
a k a \cdot[---]
$$

\section{G-161}

Bottom of a cup perhaps found in the area of Building NCT and dated to the $3^{\text {rd }} \mathrm{c}$. BC (Gordion Museum I 128).

CIPPh I, 143-144 no. G-161 (II, pl. LXXVIII1); TITUS, no. G-161; Orel 1997a, 198 no. G161.

\section{asuiadoṣ or askịadoș}

\section{G-162}

Bottom of a cup found in a filling in the area of Building A and dated to the $4^{\text {th }} \mathrm{C} . \mathrm{BC}$ (Gordion Museum inv. no. I 129).

CIPPh I, 144-145 no. G-162 (II, pl. LXXVIII2); Roller 1987a, 46 2B-123 (Fig. 37); TITUS, no. G-162; Orel 1997a, 198-199 no. G-162.

$$
\rightarrow \quad p a \text { or } \leftarrow \quad a p
$$

\section{G-163}

sherd found in a filling in the area of Building $G$ and dated to the $4^{\text {th }}$ c. BC (Gordion Museum inv. no. I 140).

CIPPh I, 145 no. G-163 (II, pl. LXXIX-1); TITUS, no. G-163; Orel 1997a, 199 no. G-163.

$$
[---] s a ? e s[---]
$$

\section{G-164}

Undated sherd found in a filling in the area of Building E (Gordion Museum inv. no. I 146).

CIPPh I, 145 no. G-164 (II, pl. LXXIX-2); TITUS, no. G-164; Orel 1997a, 199 no. G-164.

$$
\text { [---].astoy }
$$

Dub. [sur]gastoy

\section{G-164 bis}

On a mortar found in the same confusing context of G-164 (Gordion Museum inv. no. St 238). Strokes without reading.

CIPPh I, 146 no. G-164 bis (II, pl. LXXIX3).

\section{G-165}

Fragment of the bottom of a bowl found in Building $\mathrm{E}$ and dated to the $4^{\text {th }} \mathrm{C} . \mathrm{BC}$ (Gordion Museum inv. no. I 147).

CIPPh I, 146 no. G-165 (II, pl. LXXX-1); TITUS, no. G-165; Orel 1997a, 200 no. G-165.

$$
\text { [---]ỵesța }
$$

\section{G-166}

On the neck of a vessel found in Building $\mathrm{R}$ and dated to the ending of the $5^{\text {th }}$ or beginning of the $4^{\text {th }}$ c. BC (Gordion Museum inv. no. I 149).

CIPPh I, 146-147 no. G-166 (II, pl. LXXX2); TITUS, no. G-166; Orel 1997a, 200 no. G166.

$$
a b s
$$

\section{G-167}

Fragment of cup found in the area of Building A and dated to the $4^{\text {th }}$ or $3^{\text {rd }} \mathrm{C} . \mathrm{BC}$ (Gordion Museum I 152). 
CIPPh I, 147 no. G-167 (II, pl. LXXX-4); Orel 1997a, 200-201 no. G-167.

$$
m e ̣[---]
$$

\section{G-168}

Sherd found in a filling dated to the $4^{\text {th }}$ or $3^{\text {rd }}$ c. BC (Gordion Museum I 153).

CIPPh I, 147-148 no. G-168 (II, pl. LXXX3); Orel 1997a, 201 no. G-168.

$$
\text { [---]koḅ[---] }
$$

\section{G-169}

Fragment of the bottom of an undated cup found in the area of Building B (Gordion Museum inv. no. I 164).

CIPPh I, 148-149 no. G-169 (II, pl. LXXXI1, 2); Orel 1997a, 201 no. G-169.

$$
. a u^{?} \cdot[---]
$$

\section{G-170}

Fragment of a vessel found between Buildings $C$ and $G$ and dated to between the $6^{\text {th }}$ and the beginning of the $4^{\text {th }}$ c. BC (Gordion Museum inv. no. I 167).

CIPPh I, 149 no. G-170 (II, pl. LXXXI-3); TITUS, no. G-170; Orel 1997a, 201-202 no. G170.

$$
\leftarrow \operatorname{are} e^{?} \cdot[---]
$$

\section{G-171}

Fragment of a pithos found in the area of Building NCT and dated to the $5^{\text {th }}$ or $4^{\text {th }} \mathrm{C}$. BC (Gordion Museum I 170).

CIPPh I, 149-150 no. G-171 (II, pl. LXXXII1, 2); Orel 1997a, 202 no. G-171.

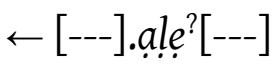

\section{G-172}

Fragment of the bottom of a little cup found in Küçük Höyük sector and dated to the first half of the $6^{\text {th }} \mathrm{C}$. BC (Grodion Museum inv. no. I 190).

CIPPh I, 150 no. G-172 (II, pl. LXXXII-3, 4); Orel 1997a, 202 no. G-172.

$$
\text { [---].akavi?[---] }
$$

\section{G-173}

Fragment of the bottom of a cup found in the façade of Building $\mathrm{M}$ and dated to the $5^{\text {th }}$ or the $6^{\text {th }}$ c. BC (Gordion Museum inv. no. I 201).

CIPPh I, 151 no. G-173 (II, pl. LXXXIII-3); TITUS, no. G-173; Orel 1997a, 202-203 no. G173.

mama

\section{G-174}

Fragment of a pithos found in the Küçük Höyük area and dated to a little after 547 BC (Gordion Museum inv. no. I 207).

CIPPh I, 151-152 no. G-174 (II, pl. LXXXII5); TITUS, no. G-174; Orel 1997a, 203 no. G174.

$$
\text { [---]pbaṣ[-?-] }
$$

\section{G-175}

Fragment of the bottom of a pot found in a filling over Building $\mathrm{M}$ and dated to the $5^{\text {th }}$ C. BC (Gordion Museum inv. no. I 214).

CIPPh I, 152-153 no. G-175 (II, pl. LXXXIII1); Orel 1997a, 203 no. G-175.

$$
\text { en.[--- }
$$

or

$$
\text { emp.[---] }
$$




\section{G-176}

Fragment of a vessel found near Building $\mathrm{M}$ and dated to the $4^{\text {th }}$ or $3^{\text {rd }}$ century BC (Gordion Museum inv. no. I 222).

CIPPh I, 153 no. G-176 (II, pl. LXXXIII-2); TITUS, no. G-176; Orel 1997a, 204 no. G-176.

$$
\leftarrow \text { [--- } . \text { ayosțtes } e \underline{[---}]
$$

\section{G-177}

Fragment of a cup found in Building $M$ and dated to the $6^{\text {th }}$ or the $5^{\text {th }}$ c. BC (Gordion Museum inv. no. I 226).

CIPPh I, 153-154 no. G-177 (II, pl. LXXXIII4); TITUS, no. G-177; Orel 1997a, 204 no. G177.

$$
\text { [-?-]kalai[---] }
$$

\section{G-178}

On a little idol of calcareous stone found in the Terrace Building and dated to the first half of the $6^{\text {th }} \mathrm{c}$. BC (Gordion Museum inv. no. I 230).

CIPPh I, 154 no. G-178 (II, pl. LXXXIV-1 and LXXXIV-2); TITUS, no. G-178; Orel 1997a, 204-205 no. G-178.

$$
\text { eymiva } a^{?} k^{?} i^{?}[---]
$$

\section{G-179}

On a sherd found in a filling near Building $N$ and dated to the ending of the $4^{\text {th }}$ or beginning of the $3^{\text {rd }}$ c. BC (Gordion Museum inv. no. I 236).

CIPPh I, 154 no. G-179 (II, pl. LXXXIV-3); TITUS, no. G-179; Orel 1997a, 206 no. G-179.

$$
\text { [---]ime[---] }
$$

\section{G-180}

Sherd, perhaps found in a filling near Building $\mathrm{N}$ and tentatively dated to the $3^{\text {rd }}$ c. BC (Gordion Museum inv. no. I 239).

CIPPh I, 155 no. G-180 (II, pl. LXXXV-1 and LXXXV-2); Orel 1997a, 206 no. G-180.

$$
\left.[---] e^{?} ! \varphi !---\right]
$$

or

$$
[---] e^{?} y \underline{y}[---]
$$

\section{G-181}

Fragment of a cup found in a filling of Building $\mathrm{P}$ and dated to the $6^{\text {th }}$ or $5^{\text {th }} \mathrm{C}$. BC (Gordion Museum inv. no. I 243).

CIPPh I, 155-156 no. G-181 (II, pl. LXXXV4); Orel 1997a, 206 no. G-181.

$$
\text { [---]șeu.[---] }
$$

\section{G-182}

On a sherd found in the area of Building $\mathrm{N}$ and dated to the first half of the $4^{\text {th }} \mathrm{C} . \mathrm{BC}$ (Gordion Museum inv. no. I 253).

CIPPh I, 156 no. G-182 (II, pl. LXXXVI-1); TITUS, no. G-182; Orel 1997a, 207 no. G-182.

$$
\text { ta }
$$

\section{G-183}

Bottom of a cup found in a filling in the area of Building R and dated ca. $4^{\text {th }} \mathrm{C} . \mathrm{BC}$ (Gordion Museum inv. no. I 253).

CIPPh I, 156-157 no. G-183 (II, pl. LXXXV3); TITUS, no. G-183; Orel 1997a, 207 no. G183. 


\section{G-184}

Sherd found in a filling near Building $R$ and dated to the $3^{\text {rd }}$ c. BC (Gordion Museum inv. no. I 256).

CIPPh I, 157 no. G-184 (II, pl. LXXXV-4); TITUS, no. G-184; Orel 1997a, 208 no. G-184.

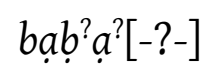

\section{G-185}

Sherd found in a filling near Building $\mathrm{R}$ and dated to the $3^{\text {rd }}$ c. BC (Gordion Museum inv. no. I 257).

CIPPh I, 158 no. G-185 (II, pl. LXXXVI-2); TITUS, no. G-185; Orel 1997a, 208 no. G-185.

$$
\leftarrow \operatorname{sir}
$$

\section{G-186}

Sherd found in a filling near Building $T$ and dated to the $3^{\text {rd }}$ c. BC (Gordion Museum inv. no. I 261).

CIPPh I, 158 no. G-186 (II, pl. LXXXVI-3); Orel 1997a, 208 no. G-186.

\section{[-?-]ḅas[-?-]}

\section{G-187}

Sherd found in a filling near Building $Q$ and dated to the $3^{\text {th }}$ c. BC (Gordion Museum I 271).

CIPPh I, 159 no. G-187 (II, pl. LXXXVI-4); Orel 1997a, 209 no. G-187.

$$
a s[---]
$$

\section{G-188}

Fragment of a cup found in a filling near Building $\mathrm{T}$ and dated to the $5^{\text {th }}$ or $6^{\text {th }} \mathrm{C}$. BC (Gordion Museum inv. no. I 274).

CIPPh I, 159 no. G-188 (II, pl. LXXXVII-4); Orel 1997a, 209 no. G-188.

$$
\text { [-?-]ṣ? } a u
$$

\section{G-189}

Handle of a pot found in a filling near Building $\mathrm{O}$ and dated to the $4^{\text {th }}$ c. BC (Gordion Museum inv. no. I 277).

CIPPh I, 160 no. G-189 (II, pl. LXXXVII-1, 2); TITUS, no. G-189; Orel 1997a, 209-210 no. G-189.

$$
\text { uposo? } ? y
$$

\section{G-189 bis}

Undated sherd found dug into the clay of the South Cellar above Megaron 6, MP or LP? (Gordion Museum inv. no. I 282). Not a sure Phrygian inscription, since only some strokes remain.

CIPPh I, 160 no. G-189 bis (II, pl. LXXXVII3).

$$
a \text {. }
$$

\section{G-190}

A fragment of a handle of a vessel found in Building $\mathrm{W}$ and dated to the $4^{\text {th }} \mathrm{C} . \mathrm{BC}$ (Gordion Museum inv. no. I 287).

CIPPh I, 160-161 no. G-190 (II, pl. LXXXVIII-1); Orel 1997a, 210 no. G-190.

$$
\leftarrow \text { tinu.[---] }
$$




\section{G-191}

Fragment of an undated pithos found dug into the clay of the South Cellar above Megaron 6, MP or LP? (Gordion Museum inv. no. I 288).

CIPPh I, 161 no. G-191 (II, pl. LXXXVIII-2); Orel 1997a, 210 no. G-191.

$$
\begin{gathered}
{[---] o ̣ s} \\
\text { or } \\
\text { sọ[---] }
\end{gathered}
$$

\section{G-192}

Sherd found in the area of Building $P$ and dated to the $4^{\text {th }} \mathrm{C}$. BC (Gordion Museum inv. no. I 290).

CIPPh I, 161-162 no. G-192 (II, pl. LXXXVIII-3); Orel 1997a, 211 no. G-192.

$$
\text { [-?-]sar.[-?-] }
$$

\section{G-193}

Fragment of an undated pithos found dug into the clay of the South Cellar above Megaron 6, MP or LP? (Gordion Museum inv. no. I 293).

CIPPh I, 162 no. G-193 (II, pl. LXXXIX-1); Orel 1997a, 211 no. G-193.

$$
\leftarrow[-?-] \text { bal }
$$

\section{G-194}

Fragment of an undated bowl found dug into the clay of the South Cellar above Megaron 6, MP or LP? (Gordion Museum inv. no. I 302).

CIPPh I, 162-163 no. G-194 (II, pl. LXXXIX2); Orel 1997a, 211-212 no. G-194.

$$
\rightarrow \operatorname{sit}[---]
$$

$$
\begin{gathered}
\text { or } \\
\leftarrow s i t[---]
\end{gathered}
$$

\section{G-195}

Fragment of an undated bowl found dug into the clay of the South Cellar above Megaron 6, MP or LP? (Gordion Museum inv. no. I 304).

CIPPh I, 163 no. G-195 (II, pl. LXXXIX-3); Orel 1997a, 212 no. G-195.

$$
\text { nạ? nִạ?[-?-] }
$$

Fort. $n a^{2} n a^{?}[s]$

\section{G-196}

Sherd found in a filling in the area of Building $\mathrm{W}$ and dated to the $4^{\text {th }}$ c. BC (Gordion Museum inv. no. I 316).

CIPPh I, 164 no. G-196 (II, pl. LXXXVIII-4); TITUS, no. G-196; Orel 1997a, 212-213 no. G196.

$$
\text { [---]l?i.e...mị[---] }
$$

\section{G-197}

Sherd found in a filling in the area of Building W and dated to the $5^{\text {th }}$ or $4^{\text {th }} \mathrm{c}$. BC (Gordion Museum inv. no. I 332).

CIPPh I, 164 no. G-197 (II, pl. XC-1); TITUS, no. G-197; Orel 1997a, 213 no. G-197.

$$
\text { [--- }] a^{?} r e s
$$

\section{G-198}

Undated fragment of a vessel handle found dug into the clay of the South Cellar above Megaron 6 (Gordion Museum inv. no. I 337). 
CIPPh I, 165 no. G-198 (II, pl. XC-2); TITUS, no. G-198; Orel 1997a, 213 no. G-198.

$$
\leftarrow \operatorname{gard}[---]
$$

\section{G-199}

Fragment of an undated jug found dug into the clay of the South Cellar above Megaron 6 (Gordion Museum inv. no. I 344).

CIPPh I, 165 no. G-199 (II, pl. XC-3); TITUS, no. G-199; Orel 1997a, 213-214 no. G-199.

$$
\text { [---] rmaniv[---] }
$$

\section{G-200}

Fragment of an undated pithos found dug into the clay of the South Cellar above Megaron 6 (Gordion Museum inv. no. I 345).

CIPPh I, 166 no. G-200 (II, pl. XC-4); Orel 1997a, 214 no. G-200.

$$
\text { [---..re }
$$

\section{G-201}

Undated sherd found dug into the clay of the South Cellar above Megaron 6 (Gordion Museum inv. no. I 347).

CIPPh I, 166-167 no. G-201 (II, pl. XCI-1); Orel 1997a, 214 no. G-201.

$$
\text { [-?-]go..[---] }
$$

\section{G-202}

Fragment of an undated bowl found dug into the clay of the South Cellar above Megaron 6 (Gordion Museum inv. no. I 355).

CIPPh I, 167 no. G-202 (II, pl. XCI-2); TITUS, no. G-202; Orel 1997a, 215 no. G-202.

$$
\leftarrow \text { ma.[.]as }
$$

\section{G-203}

Fragment of the bottom of a bowl found in a filling near the walls and dated to the $4^{\text {th }}$ C. BC (Gordion Museum inv. no. I 369).

CIPPh I, 167-168 no. G-203 (II, pl. XCI-3 and 4); Roller 1987a, 31 2A-206 (Fig. 25) and 48 2B-141 (Fig. 38); Orel 1997a, 215-216 no. G-203.

$$
\begin{array}{ll}
\text { A } & \uparrow \\
\text { B } & . X
\end{array}
$$

\section{G-204}

Fragment of a pithos found in the Terrace Building and dated to the $4^{\text {th }} \mathrm{C} . \mathrm{BC}$ (Gordion Museum inv. no. I 378).

CIPPh I, 168 no. G-204 (II, pl. XCII-1); TITUS, no. G-204; Orel 1997a, 216 no. G-204.

$$
\text { [---]da alu } m s \text { [-?-] }
$$

\section{G-205}

Fragment of a bowl found in a filling near the walls and dated to the $5^{\text {th }}$ and $4^{\text {th }} \mathrm{c}$. BC (Gordion Museum inv. no. I 387).

CIPPh I, 168-169 no. G-205 (II, pl. XCII-3 and XCII-4); Orel 1997a, 216 no. G-205.

$$
\text { [---].re[-?-] }
$$

\section{G-206}

Sherd found in a mixed filling of a building at the west side of the mound and dated to the $5^{\text {th }} \mathrm{c}$. BC (Gordion Museum inv. no. I 388).

CIPPh I, 169 no. G-206 (II, pl. XCII-2); Orel 1997a, 216-217 no. G-206.

$$
\leftarrow[---] \operatorname{eg} ? \cdot i^{?} \cdot[---]
$$

Fort. mam $[a] s$. 


\section{G-207}

Sherd found in a mixed filling of a building at the west side of the mound and dated to the $5^{\text {th }} \mathrm{c}$. BC (Gordion Museum inv. no. I 390).

CIPPh I, 170 no. G-207 (II, pl. XCIII-1); Orel 1997a, 217 no. G-207.

$$
[---] r k^{?} \cdot[---]
$$

\section{G-208}

Fragment of a bowl found in a mixed filling of a building at the west side of the mound and dated to the $5^{\text {th }} \mathrm{C}$. BC (Gordion Museum inv. no. I 395). A non-verbal mark (contrary to Orel 1997a, 217).

CIPPh I, 170-171 no. G-208 (II, pl. XCIII-2); Roller 1987a, 25 2A-130 (Fig.18); Orel 1997a, 217 no. G- 208.

\section{G-209}

Two contiguous sherds cup found in a mixed filling of a building at the west side of the mound and dated to $5^{\text {th }} \mathrm{c}$. BC (Gordion Museum inv. no. I 402).

CIPPh I, 171 no. G-209 (II, pl. XCIII-3); Orel 1997a, 217-218 no. G- 209.

$$
\begin{gathered}
{[---] a n i ? \cdot e^{?}[---]} \\
\text { or } \\
{[---] a m i ? \cdot e^{?} \cdot[---]}
\end{gathered}
$$

\section{G-210}

Bottom of a cup found in a mixed filling of a building at the west side of the mound and dated to the $5^{\text {th }}$ c. BC (Gordion Museum inv. no. I 404).

CIPPh I, 171-172 no. G-210 (II, pl. XCIII-4); TITUS, no. G-210; Orel 1997a, 218 no. G- 210. iman

\section{G-211}

Fragment of the bottom of a vessel cup found in a mixed filling of a building at the west side of the mound and dated to the $5^{\text {th }}$ c. (Gordion Museum inv. no. I 405).

CIPPh I, 172 no. G-211 (II, pl. XCIV-1); Orel 1997a, 218 no. G- 211.

$$
\text { em.[?] }
$$

\section{G-212}

Fragment of the bottom of a cup found just above the plundered west wall of the Phrygian city, perhaps dated to the $5^{\text {th }} \mathrm{C} . \mathrm{BC}$ (Gordion Museum inv. no. I 408).

CIPPh I, 173 no. G-212 (II, pl. XCIV-2); TITUS, no. G-212; Orel 1997a, 218-219 no. G212.

$$
\begin{aligned}
& \leftarrow \text { nina } \\
& \text { G-213 }
\end{aligned}
$$

Fragment of a saucer found in a mixed filling of a building at the west side of the mound and dated to the $5^{\text {th }} \mathrm{c}$. BC (Gordion Museum inv. no. I 416). Two nonverbal marks also incised.

CIPPh I, 173-174 no. G-213 (II, pl. XCIV-3); Orel 1997a, 219 no. G- 213.

$$
\begin{aligned}
& \text { A Mark } \\
& \text { B Mark } \\
& \text { c } \rightarrow[---] u^{?} s s a \\
& \text { or } \\
& \leftarrow \operatorname{assụ?[---]~}
\end{aligned}
$$




\section{G-214}

Fragment of the bottom of a pot found in a mixed filling of a building at the west side of the mound and dated to the $5^{\text {th }} \mathrm{C} . \mathrm{BC}$ (Gordion Museum inv. no. I 429).

CIPPh I, 174-175 no. G-214 (II, pl. XCIV-4); TITUS, no. G-214; Orel 1997a, 219-220 no. G214.

$$
\text { mor? o.[--- ] }
$$

\section{G-215}

Bottom of a cup or sauce found in a mixed filling of a building at the west side of the mound and dated to the $5^{\text {th }} \mathrm{C} . \mathrm{BC}$ (Gordion Museum inv. no. I 430).

CIPPh I, 175 no. G-215 (II, pl. XCV-1); Roller 1987a, 40 2B-35 (Fig. 31 and Plate 4); TITUS, no. G-215; Orel 1997a, 220 G-215.

$$
n m
$$

\section{G-216}

Fragment of a cup found in a mixed filling of a building at the west side of the mound and dated to the $5^{\text {th }} \mathrm{c}$. BC (Gordion Museum inv. no. I 441).

CIPPh I, 175-176 no. G-216 (II, pl. XCV-2); TITUS, no. G-216; Orel 1997a, 220 no. G-216.

$$
\text { [---]lasime.[---] }
$$

\section{G-217}

Sherd found in Building $\mathrm{P}$ and dated to the $4^{\text {th }}$ c. BC (Gordion Museum inv. no. I 443).

CIPPh I, 176 no. G-217 (II, pl. XCV-4); Orel 1997a, 220-221 no. G-217.

$$
[-?-] a b
$$

\section{G-218}

Handle of a vessel found in the PersianPhrygian Building (PPB) and dated to the $5^{\text {th }}$ or $4^{\text {th }}$ C. BC (Gordion Museum inv. no. I 444).

CIPPh I, 176-177 no. G-218 (II, pl. XCV-3); Orel 1997a, 221 no. G-218.

$$
\text { [---].as }
$$

\section{G-219}

Fragment of a pithos found near the wall and dated to the $5^{\text {th }}$ or $4^{\text {th }} \mathrm{c} . \mathrm{BC}$ (Gordion Museum inv. no. I 447).

CIPPh I, 177 no. G-219 (II, pl. XCVI-1, 2); TITUS, no. G-219; Orel 1997a, 221 no. G-219.

$$
\text { [---]tivi.[---] }
$$

\section{G-220}

Sherd found to the west of Terrace Building and dated to the $4^{\text {th }}$ or $3^{\text {rd }} \mathrm{c}$. (Gordion Museum inv. no. I 449).

CIPPh I, 177-178 no. G-220 (II, pl. XCVI-3, 4); Orel 1997a, 221-222 no. G-220.

$$
\text { [---]me.[---] }
$$

\section{G-221}

sherd found near the west wall and dated to the $4^{\text {th }}$ C. BC (Gordion Museum inv. no. I 450).

CIPPh I, 178-179 no. G-221 (II, pl. XCVII1); TITUS, no. G-221; Orel 1997a, 222-223 no. G-221.

$$
[-?-]
$$

$$
\begin{array}{cc}
\leftarrow & {[-?-] a . i y[-?-]} \\
\leftarrow & {[-?-] k e^{\prime} \text { no? }^{?}[-?-]} \\
\leftarrow & {[-?-] \text { atas }} \\
\leftarrow & {[-?-] \operatorname{aratap}^{?} a[-?-]} \\
\leftarrow & {[-?-] \text { obata } m^{2} . .[-?-]} \\
& {[-?-]}
\end{array}
$$




\section{G-222}

Fragment of a vessel found in the Persian-Phrygian Building (PPB) and dated to the $5^{\text {th }}$ or $4^{\text {th }}$ c. BC (Gordion Museum inv. no. I 451).

CIPPh I, 179 no. G-222 (II, pl. XCVII-2); TITUS, no. G-222; Orel 1997a, 223 no. G-222.

\section{rig?aru}

\section{G-223}

Sherd found in the Persian-Phrygian Building (PPB) and dated to the $5^{\text {th }}$ or $4^{\text {th }} \mathrm{C}$. BC (Gordion Museum inv. no. I 452).

CIPPh I, 179-180 no. G-223 (II, pl. XCVII4); Orel 1997a, 223-224 no. G-223.

$$
[---] t^{?} \cdot ? \cdot a
$$

\section{G-224}

Marmite found in Building $\mathrm{X}$ and dated to the $4^{\text {th }}$ c. BC (Gordion Museum inv. no. I 455).

CIPPh I, 180-181 no. G-224 (II, pl. XCVIII1, 2 and XCI-1); TITUS, no. G-224; Orel 1997a, 224 no. G-224.
A ata
B garies or paries
C Yuv

\section{G-225}

Bottom of a saucer found in Building PPB and dated to the $4^{\text {th }}$ or $3^{\text {rd }} \mathrm{C} . \mathrm{BC}$ (Gordion Museum inv. no. I 457).

CIPPh I, 181 no. G-225 (II, pl. XCI-2); Roller 1987a, 48 2B-152 (Fig. 39 and Plate 4); Orel 1997a, 225 no. G-225.

$$
\begin{array}{ll}
\text { A } & a \\
\text { B } & \uparrow
\end{array}
$$

\section{G-226}

A jar ("amphorette" according to CIPPh) found in a layer dated to the $4^{\text {th }}$ or $3^{\text {rd }} \mathrm{c}$. BC (Gordion Museum in. no. I 463). The shape of the letters are very similar to Greek ones and perhaps it is not Phrygian.

CIPPh I, 181-182 no. G-226 (II, pl. XCIX-3); TITUS, no. G-226; Orel 1997a, 225 no. G-226.

\section{murtan}

\section{G-227}

Fragment of the bottom of a vessel found in a layer dated to the $4^{\text {th }} \mathrm{c}$. (Gordion Museum inv. no. I 466).

CIPPh I, 182 no. G-227 (II, pl. C-1); Orel 1997a, 225 no. G-227.

$$
\leftarrow \text { ? [..].a }
$$

\section{G-228}

Fragment of a handle of a vessel found in Building PPB and dated to the $5^{\text {th }}$ or $4^{\text {th }}$ C. BC (Gordion Museum inv. no. I 468). A bird is drawn before the inscription.

CIPPh I, 183 no. G-228 (II, pl. C-2, 4); Roller 1987a, 53 no. 2C-3 (Fig. 43 and Plate 4); TITUS, no. G-228; Orel 1997a, 226 no. G228.

$$
\text { voine }
$$

\section{G-229}

Handle of a vessel found in Building PPB and dated to the $5^{\text {th }}$ or $4^{\text {th }} \mathrm{C}$. BC (Gordion Museum inv. no. I 470). 
CIPPh I, 183-184 no. G-229 (II, pl. C-3); TITUS, no. G-229; Orel 1977, 226-227 no. G229.

mamutas sokposa

mamutas itoiesgloka

\section{G-230}

Fragment of a pithos found in the area of Megaron 8 and dated to the $4^{\text {th }}$ C. BC (Gordion Museum inv. no. I 472).

CIPPh I, 184 no. G-230 (II, pl. CI-1); TITUS, no. G-230; Orel 1977, 227 no. G-230.

$$
\text { ey. }[---]
$$

\section{G-231}

Fragment of a pithos found in the area of Megaron 8 and dated to the $4^{\text {th }}$ c. BC (Gordion Museum inv. no. I 473).

CIPPh I, 184-185 no. G-231 (II, pl. CI-2); Orel 1977, 227-228 no. G-231.

$$
\text { [---]y? } i b ̣[---]
$$

\section{G-232}

Sherd found in the area of the Megaron 8 and dated to the $5^{\text {th }}$ or $4^{\text {th }} \mathrm{C}$. BC (Gordion Museum inv. no. I 474).

CIPPh I, 185 no. G-232 (II, pl. CII-1); Orel 1977, 228 no. G-232.

$$
\leftarrow \text { [---]ane[---] }
$$

\section{G-233}

Sherd found in the SE of Building PPB and dated to the $4^{\text {th }} \mathrm{c}$. BC (Gordion Museum inv. no. I 475).

CIPPh I, 185-186 no. G-233 (II, pl. CI-4); Orel 1977, 228 no. G-233.

\section{[---]utra}

or

[---]ktra

\section{G-234}

Fragment of the bottom of a little cup found in a layer near the north wall and dated the $5^{\text {th }}$ and $4^{\text {th }}$ c. BC (Gordion Museum inv. no. I 484).

CIPPh I, 186 no. G-234 (II, pl. CII-2); TITUS, no. G-234; Orel 1977, 228-229 no. G-234.

$$
\leftarrow^{?} \quad \text { ata }
$$

\section{G-235}

Sherd found in a layer near the west wall and dated to the $5^{\text {th }}$ c. BC (Gordion Museum inv. no. I 487).

CIPPh I, 186-187 no. G-235 (II, pl. CI-3); Roller 1987a, 41 no. 2B-51 (Fig. 32); Orel 1997a, 229 no. G-235.

$$
\begin{gathered}
\rightarrow ?[---] a y ![---] \\
\text { or } \\
\leftarrow \text { ?---]y!ạ[---] }
\end{gathered}
$$

\section{G-236}

Sherd found in a layer near the west wall and dated to the $4^{\text {th }}$ or $3^{\text {rd }}$ c. BC (Gordion Museum inv. no. I 490).

CIPPh I, 187 no. G-236 (II, pl. CII-3); TITUS, no. G-236; Orel 1997a, 229 no. G-236.

$$
\text { nanav?ata[-?-] }
$$

Fort. manag? ata[-?-]. 


\section{G-237}

Fragment of a pithos found in a layer of Building $X$ with materials dated to between the $8^{\text {th }}$ and $6^{\text {th }} \mathrm{C}$. BC (Gordion Museum inv. no. I 497).

CIPPh I, 188 no. G-237 (II, pl. CII-4); TITUS, no. G-237; Orel 1997a, 230 no. G-237.

ako

\section{G-238}

Fragment of a pithos found above the Megaron 7 and dated to between the $4^{\text {th }}$ and the $3^{\text {rd }}$ c. BC (Gordion Museum inv. no. I 500).

CIPPh I, 188 no. G-238 (II, pl. CIII-1); Orel 1997a, 230 no. G-238.

$$
[---] \cdot d a \cdot[---]
$$

\section{G-239}

Fragment of a pithos found above the Megaron 7 and dated to the $4^{\text {th }}$ c. BC (Gordion Museum inv. no. I 501).

CIPPh I, 189 no. G-239 (II, pl. CIII-3); TITUS, no. G-239; Orel 1997a, 230-231 no. G239.

mekaị̦ [-?-]

\section{G-240}

Sherd found above Megaron 7 and dated to the $5^{\text {th }}$ or $4^{\text {th }}$ c. BC (Gordion Museum inv. no, I 508).

CIPPh I, 189-190 no. G-240 (II, pl. CIII-2); Orel 1997a, 231 no. G-240.

$$
\text { [---] } m^{?} a g i .[---]
$$

G-241

Fragment of a bowl found in a filling in the area of the west wall dated to the $4^{\text {th }}$ or $3^{\text {rd }}$ c. BC (Gordion Museum inv. no. I 509).

CIPPh I, 190 no. G-241 (II, pl. CIII-4); Roller 1987a, 49 no. 2B-167 (Fig. 40); Orel 1997a, 231 no. G-241.<smiles>[Mg][Mg]</smiles>

\section{G-242}

Fragment of a bowl found in a filling above the Megaron 7 and dated to the $4^{\text {th }} \mathrm{c}$. BC (Gordion Museum inv. no. I 511).

CIPPh I, 190-191 no. G-242; Orel 1997a, 231-232 no. G-242.

$$
\leftarrow \quad m e
$$

\section{G-243}

Fragment of a bowl found in a filling above the Megaron 7 and dated to the $4^{\text {th }} \mathrm{c}$. BC (Gordion Museum inv. no. I 512).

CIPPh I, 191 no. G-243; Roller 1987a, 41 no. 2B-52 (Fig. 32); Orel 1977, 232 no. G-243.

$$
v i
$$

\section{G-244}

Fragment of a cup found in a filling near the west wall dated to the $3^{\text {rd }} \mathrm{c}$. BC (Gordion Museum inv. no. I 520). Perhaps not Phrygian but Greek.

CIPPh I, 192 no. G-244 (II, pl. CIV-3); Orel 1977, 232 no. G-244.

\section{[-?-]me? Ii[-?-] or [-?-]ME? ZI[-?-]}

\section{G-245}

Two fragments of a mortar found in a filling near the west wall dated to the $4^{\text {th }} \mathrm{c}$. BC (Gordion Museum inv. no. I 521). 
CIPPh I, 192-193 no. G-245 (II, pl. CV-1 and CV-3); TITUS, no. G-245; Orel 1977, 232233 no. G-245.

$$
\leftarrow \text { ḍumast.v.[-?-] }
$$

\section{G-246}

Two contiguous fragments of a bowl found in a filling in the area of Building $U$ dated to the $5^{\text {th }}$ or the $4^{\text {th }}$ c. BC (Gordion Museum inv. no. I 533).

CIPPh I, 193 no. G-246 (II, pl. CV-2); Orel 1977, 233 no. G-246.

$$
\leftarrow \text { dile? }
$$

\section{G-247}

Sherd found in a filling in the area of the north wall and dated to the $4^{\text {th }} \mathrm{C}$. BC (Gordion Museum I 536).

CIPPh I, 194 no. G-247 (II, pl. CVI-1 and CVI-2); Orel 1977, 233-234 no. G-247.

$$
\leftarrow[---] . v e i\left[{ }^{?}\right] \mathrm{s}
$$

\section{G-248}

Fragment of a cup found in the area of Building $\mathrm{U}$ and dated to the $5^{\text {th }} \mathrm{c} . \mathrm{BC}$ (Gordion Museum inv. no. I 537).

CIPPh I, 194-195 no. G-248 (II, pl. CV-4); Roller 1987a, 38 no. 2B-9 (Fig. 28); Orel 1997a, 234 no. 248.

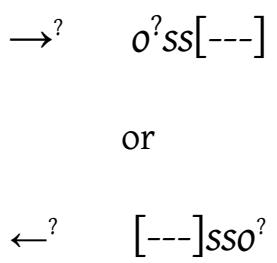

Roller $r s$.
Unfinished alabaster weight found in a layer of Building CC3 and dated to the $8^{\text {th }} \mathrm{c}$. BC (Gordion Museum inv. no. I 539).

CIPPh I, 195-196 no. G-249 (II, pl. CVI-3, 4); TITUS, no. G-249; Orel 1997a, 234-235 no. 249.

$$
\begin{gathered}
\leftarrow \text { seVelt- } \\
\text { ias }
\end{gathered}
$$

$$
\text { 'Shekel of Ti-' }
$$

\section{G-250}

Fragment of a jug found in a filling in the area of the north wall dated to the $4^{\text {th }} \mathrm{c}$. BC (Gordion Museum inv. no. I 543).

CIPPh I, 196 no. G-250 (II, pl. CVII-2); Orel 1997a, 235 no. 250.

\section{[-?-].eivanouș[-?-]}

\section{G-251}

Sherd found above the terrace wall of archaic circuit at west and dated to the $4^{\text {th }}$ c. BC (Gordion Museum inv. no. I 544).

CIPPh I, 196-197 no. G-251 (II, pl. CVII-1); Orel 1997a, 235-236 no. 251.

$$
\leftarrow \text { ray or bay. }
$$

\section{G-252}

Sherd found in a filling in the west wall dated to the $3^{\text {rd }} \mathrm{c}$. BC (Gordion Museum inv. no. I 545).

CIPPh I, 197 no. G-252 (II, pl. CVII-3, 4); TITUS, no. G-252; Orel 1997a, 236 no. 252.

$$
\text { [-?-]atesito.[-?-] }
$$

Fort. [-?-] ates ito.[-?-] 


\section{G-253}

Sherd found in a filling or in the wall and dated to the end of the $4^{\text {th }}$ or beginning of the $3^{\text {rd }}$ c. BC (Gordion Museum inv. no. I 547).

CIPPh I, 197-198 no. G-253 (II, pl. CVIII-1); TITUS, no. G-253; Orel 1997a, 236-237 no. 253.

$$
\leftarrow b a b[---]
$$

\section{G-254}

Fragment of a cup found in a filling in the area of Building $U$ and dated to the $4^{\text {th }}$ or $3^{\text {rd }}$ c. BC (Gordion Museum I 548).

CIPPh I, 198 no. G-254 (II, pl. CVIII-2); Roller 1987a, 38 no. 2B-13 (Fig. 29); Orel 1997a, 237 no. G-254.$$
y
$$

\section{G-255}

Undated sherd (Gordion Museum inv. no. I 549).

CIPPh I, 198-199 no. G-255 (II, pl. CVIII-3); TITUS, no. G-255; Orel 1997a, 237 no. G-255.

$$
\text { [---]nolọ[---] }
$$

\section{G-256}

Sherd found in the Küçük Höyük dated before the Persian conquest (Gordion Museum inv. no. I 551).

CIPPh I, 199 no. G-256 (II, pl. CVIII-4); Orel 1997a, 237-238 no. G-256.

$$
\leftarrow[---] . e
$$

Bottom of a cup found in the Küçük Höyük and dated to before the Persian conquest (Gordion Museum inv. no. I 552).

CIPPh I, 200 no. G-257 (II, pl. CIX-1); Roller 1987a, 37 no. 2B-4 (Fig. 28); Orel 1997a, 238 no. G-257.

$v$

\section{G-258}

Sherd found in the Küçük Höyük and dated to before the Persian conquest (Gordion Museum inv. no. I 554).

CIPPh I, 200 no. G-258 (II, pl. CIX-2); TITUS, no. G-258; Orel 1997a, 238 no. G-258.

$$
p a
$$

\section{G-259}

Fragment of the bottom of a vessel found inside the South Cellar and dated to the beginning of the $4^{\text {th }}$ c. BC (Gordion Museum inv. no. I 556).

CIPPh I, 201 no. G-259 (II, pl. CIX-4); TITUS, no. G-259; Orel 1997a, 238-239 no. G259.

$$
i l^{?} a[---]
$$

\section{G-260}

Fragment of a vessel found in a layer dated to the first half of the $6^{\text {th }} \mathrm{c}$. BC (Gordion Museum inv. no. I 557).

CIPPh I, 201-202 no. G-260 (II, pl. CIX-3); Roller 1987a, 41 no. 2B-54 (Fig. 32); Orel 1997a, 239 no. G-260.

$$
[-?-] n
$$




\section{G-261}

Fragment of the bottom of a saucer found in a layer dated to the end of the $5^{\text {th }}$ or beginning of the $4^{\text {th }}$ C. BC (Gordion Museum inv. no. I 558).

CIPPh I, 202-203 no. G-260 (II, pl. CIX-6); TITUS, no. G-261; Orel 1997a, 239 no. G-261.

$$
\leftarrow \text { [---].tuti.[---] }
$$

\section{G-262}

Fragment of a vessel found in a filling above Building $\mathrm{E}$ and dated to the $3^{\text {rd }} \mathrm{C} . \mathrm{BC}$ (Gordion Museum inv. no. I 559).

CIPPh I, 203 no. G-262 (II, pl. CIX-5); TITUS, no. G-262; Orel 1997a, 239-240 no. G262.

$$
\text { nạẹ[---] }
$$

\section{G-263}

Sherd found above Building NCT and dated to the $4^{\text {th }} \mathrm{c}$. BC (Gordion Museum inv. no. I 560).

CIPPh I, 203-204 no. G-263 (II, pl. CX-1); Roller 1987a, 50 no. 2B-172 (Fig. 40); Orel 1997a, 240 no. G-263.

$$
\text { șeț[--- ] }
$$

\section{G-264}

Undated sherd (Gordion Museum inv. no. I 579).

CIPPh I, 204 no. G-264 (II, pl. CX-2); TITUS, no. G-264; Orel 1997a, 240 no. G-264.

$$
\text { [-?-]unik[---] }
$$

Fragment of the bottom of a little cup found in a house below Tumulus $\mathrm{H}$ and dated to before the $650 \mathrm{BC}$ (Gordion Museum inv. no. I 582).

CIPPh I, 205 no. G-265 (II, pl. CXI-1); Orel 1997a, 240-241 no. G-265.

$$
\text { [---]ies }
$$

\section{G-266}

Three contiguous fragments of a little plate found in a filling dated to the beginning of the $4^{\text {th }} \mathrm{c}$. BC (Gordion Museum inv. no. I 587). There are two nonverbal marks also incised.

CIPPh I, 205-206 no. G-266 (II, pl. CX-3); Roller 1987a, 41 2B-56 (Fig. 33); Orel 1997a, 241 no. G-266.

$$
\text { lẹt? [--- ] }
$$

\section{G-267}

Sherd found in the mound of the Tumulus $E$ and dated to the last quarter of the $6^{\text {th }}$ c. BC (Gordion Museum inv. no. I 593).

CIPPh I, 206-207 no. G-267 (II, pl. CXI-2); Orel 1997a, 241 no. G-267.

$$
\text { [---]aị̦ạ }{ }^{?}[---]
$$

Fort. $\leftarrow[---] a^{?} \operatorname{sina}[---]$

\section{G-268}

Sherd found in the mound of the Tumulus $E$ and dated to the last quarter of the $6^{\text {th }}$ c. BC (Gordion Museum inv. no. I 594). 
CIPPh I, 207 no. G-268 (II, pl. CXI-3); TITUS, no. G-268; Orel 1997a, 241-242 no. G268.

$$
\text { illa[-?-] or iỵa[-?-] }
$$

\section{G-269}

Fragment of a little cup found in the mound of the Tumulus $\mathrm{E}$ and dated to the last quarter of the $6^{\text {th }}$ c. BC (Gordion Museum inv. no. I 595). The writing direction is unclear.

CIPPh I, 208 no. G-269 (II, pl. CXIII-1); TITUS, no. G-269; Orel 1997a, 242 no. G-269.

aoa

\section{G-270}

Sherd found in the mound of the Tumulus $E$ and dated to the last quarter of the $6^{\text {th }} \mathrm{C}$. BC (Gordion Museum inv. no. I 596).

CIPPh I, 208-209 no. G-270 (II, pl. CXI-4); Orel 1997a, 242 no. G-270.

$$
\text { [---].ạus }
$$

\section{G-271}

Three contiguous fragments of a pithos found in the mound of the Tumulus $\mathrm{E}$ and dated to the last quarter of the $6^{\text {th }} \mathrm{C} . \mathrm{BC}$ (Gordion Museum inv. no. I 603).

CIPPh I, 209 no. G-271 (II, pl. CXII-1); Orel 1997a, 243 no. G-271.

$$
\leftarrow \quad[-?-] p a
$$

\section{G-272}

Fragment of a little cup found below the habitation floor in the Tumulus $\mathrm{E}$ and dated to before 520-500 BC (Gordion Museum inv. no. I 604).
CIPPh I, 210 no. G-272 (II, pl. CXII-2); TITUS, no. G-272; Orel 1997a, 243 no. G-272.

$$
\leftarrow \quad \text { [---] ạkios }
$$

\section{G-273}

Sherd found in the mound of the Tumulus $\mathrm{E}$ and dated to the last quarter of the $6^{\text {th }}$ c. BC (Gordion Museum inv. no. I 610). Found in Tumulus E. Writing direction unknown.

CIPPh I, 210-211 no. G-273 (II, pl. CXIII-2); Roller 1987a, 19 no. 2A-44 (fig. 9); Orel 1997a, 243 no. G-273.

$$
\leftarrow ? i k[-?-]
$$

\section{G-274}

Three contiguous fragments of a vessel found in a filling tentatively dated to the $4^{\text {th }}$ c. BC (Gordion Museum inv. no. St 658).

CIPPh I, 211 no. G-274 (II, pl. CXII-3, 4); TITUS, no. G-274; Orel 1997a, 244 no. G-274.

$$
\begin{aligned}
& \mathrm{A} \leftarrow \mathrm{mam}^{?} i \\
& \mathrm{~B} \rightarrow i t[-?-] \text { or } \quad[-?-] t i
\end{aligned}
$$

\section{G-275}

Sherd found in a filling dated to the $4^{\text {th }}$ or the beginning of the $3^{\text {rd }} \mathrm{c}$. BC (Gordion Museum inv. no. I 574).

CIPPh I, 212 no. G-275 (II, pl. CXIII-3); Roller 1987a, 41 no. 2B-55 (Fig. 32 and Plate 4); TITUS, no. G-275; Orel 1997a, 244 no. G275. 


\section{G-276}

Fragment of a bowl found in a filling dated to the $4^{\text {th }}$ or the beginning of the $3^{\text {rd }} \mathrm{c}$. BC (Gordion Museum inv. no. I 626).

CIPPh I, 212-213 no. G-276 (II, pl. CXIII-4); TITUS, no. G-276; Orel 1997a, 245 no. G-276.

\section{[---]agineia}

1 fort. [l]agineia.

\section{G-277}

Fragment of a cup found in the South Cellar and dated to the end of the $8^{\text {th }}$ or $7^{\text {th }}$ c. BC (Gordion Museum inv. no. I 300).

Roller 1987a, 21 no. 2A-67 (fig. 11); Brixhe 2002a, 37-38 no. G-277.

armam

or

arma.a

\section{G-278}

Two contiguous fragments of a cup found in the South Cellar dated to the end of the $8^{\text {th }}$ or $7^{\text {th }}$ C. BC (Gordion Museum inv. no. I 301 and I 315).

Roller 1987a, 21 no. 2A-66 (fig. 11) and 39 no. 2B-25 (fig. 30); Brixhe 2002a, 38-40 no. G-278.

$$
\begin{aligned}
& \text { А }[-?-] . ?[.] a i^{?} u^{?} \\
& \text { В } \Psi
\end{aligned}
$$

\section{G-279}

Fragment of a vessel found in the South Cellar dated to the end of the $8^{\text {th }}$ or $7^{\text {th }} \mathrm{c}$. BC (Gordion Museum inv. no. I 318).

Brixhe 2002a, 41 no. G-279.

\section{[-?-] eiv}

\section{G-280}

Sherd found in the South Cellar and dated to the end of the $8^{\text {th }}$ or $7^{\text {th }}$ c. BC (Gordion Museum inv. no. I 319).

Brixhe 2002a, 41-42 no. G-280.

$n$

\section{G-281}

Sherd perhaps found in the Tumulus $\mathrm{E}$ and dated to before the second half of the $6^{\text {th }}$ c. BC (Gordion Museum inv. no. I 597).

Brixhe 2002a, 42 no. G-281.

$$
\begin{aligned}
& \text { A } a \text { or lor } d \\
& \text { B Mark }
\end{aligned}
$$

\section{G-282}

Fragment of a cup found in the South Cellar and dated to the $7^{\text {th }}$ and the $4^{\text {th }} \mathrm{c}$. BC (Gordion Museum inv. no. I 563).

Roller 1987a, 39 n²B-23 (fig. 30); Brixhe 2002a, 43 no. G-282.

\section{d}

\section{G-283}

Fragment of a pithos found in Tumulus E (Gordion Museum inv. no. I 613). Undated.

Brixhe 2002a, 44-45.

$$
\leftarrow \text { [-?-]avssị i ??[---] }
$$

\section{G-284}

On a fragment of a handle of a jug found in an undated filling (Gordion Museum inv. no. I 637). 
Roller 1987a, 23 no. 2A-92 (fig. 13); Brixhe 2002a, 44-45.

mark

kikos

\section{G-285}

Fragment of an undated cup found in Megaron 4 (Gordion Museum inv. no. I 651).

Brixhe 2002a, 45-46.

$$
i k
$$

\section{G-286}

Fragment of a handle of an undated vessel found in the north wall (Gordion Museum inv. no. I 653).

Brixhe 2002a, 46-47 no. G-286.

\section{voines}

\section{G-287}

Undated sherd (Gordion Museum inv. no. I 654).

Brixhe 2002a, 47-48 no. G-287.

$$
\begin{gathered}
\rightarrow[-?-] i ? \cdot 0 . \\
\text { or } \\
\leftarrow v^{?} \cdot \text { o.[-?-] }
\end{gathered}
$$

\section{G-288}

Undated sherd (Gordion Museum inv. no. SF 89-23).

Brixhe 2002a, 48-49 no. G-288.

$$
\begin{gathered}
\rightarrow \underline{n[---]} \\
\text { or } \\
\rightarrow[---] \eta !
\end{gathered}
$$

Fragment of a cup found in a pit and dated to the $4^{\text {th }}$ or $3^{\text {rd }}$ c. BC (Gordion Museum inv. no. SF 89-144).

Brixhe 2002a, 49-50 no. G-289.

$$
\operatorname{ain}[---]
$$

\section{G-290}

Fragment of a vessel tentatively dated to the $4^{\text {th }}$ c. BC (Gordion Museum inv. no. SF 89-232).

Brixhe 2002a, 50-51 no. G-290.

$$
\text { luk }
$$

\section{G-291}

Sherd found in a pit in the ground of Building I:1 and dated to the $2^{\text {nd }}$ quarter of the $5^{\text {th }}$ C. BC (Gordion Museum inv. no. SF 89-319). Also, a non-verbal mark was incised.

Brixhe 2002a, 51-52 no. G-291.

$$
\text { [---].ạn }
$$

\section{G-292}

Sherd found in a pit in the middle of Building I:2 and dated to the $8^{\text {th }}$ or the $7^{\text {th }} \mathrm{c}$. BC. (Gordion Museum inv. no. SF 89-337).

Brixhe 2002a, 52-53 no. G-292.

$$
\text { urakạ[--- }
$$

\section{G-293}

Bottom of a bowl found above Buildings $\mathrm{I}$ and tentatively dated to the $5^{\text {th }} \mathrm{C} . \mathrm{BC}$ (Gordion Museum inv. no. SF 89-364).

Brixhe 2002a, 53-55 no. G-293.

$$
\text { daguvạs }
$$




\section{G-294}

Sherd found in a context and dated to the $4^{\text {th }}$ C. BC (Gordion Museum inv. no. SF 89-397).

Brixhe 2002a, 55-56 no. G-294.

$\psi$

G-295

Fragment of the bottom of a cup found in a pit in Building I:2 and dated to the end of the $6^{\text {th }} \mathrm{C}$. BC (Gordion Museum inv. no. SF 89-475).

Brixhe 2002a, 56-57 no. 295.

$$
\leftarrow[-?-] a \underline{b} a \underline{a}
$$

\section{G-296}

Fragment of a jar dated to the $5^{\text {th }}$ or $4^{\text {th }} \mathrm{c}$. BC (Gordion Museum inv. no. SF 89-476).

Brixhe 2002a, 57-58 no. 296.

$$
\leftarrow[---] . u t a
$$

\section{G-297}

Cup found in the Secondary Citadel and dated to the Midel Phrygian period, $8^{\text {th }}$ or $7^{\text {th }}$ c. BC (Gordion Museum inv. no. SF 89-484).

Brixhe 2002a, 58-59 no. 297.

\section{kenos}

\section{G-298}

Fragment of a vessel found in a filling in Building I:2 and dated to before the end of the $6^{\text {th }}$ C. BC (Gordion Museum inv. no. SF 89-643).

Brixhe 2002a, 59-60 no. 298. sherd found in a layer of Building I:2 and dated to the $8^{\text {th }}$ or the $7^{\text {th }}$ C. BC (Gordion Museum inv. no. SF 89-652).

Brixhe 2002a, 60-61 no. 299.

$$
\text { [---]ạinẹ[---] }
$$

\section{G-300}

Sherd found in pit and dated to the $4^{\text {th }} \mathrm{C}$. BC (Gordion Museum inv. no. SF 89-675).

Brixhe 2002a, 61 no. 300.

$$
[---] d[---]
$$

\section{G-301}

Fragment of a pithos found in a pit in Building I:2 and dated to the $8^{\text {th }}$ or $7^{\text {th }}$ C. BC (Gordion Museum inv. no. SF 89-362).

Brixhe 2002a, 62 no. G-301.

$$
[---] m a
$$

\section{G-302}

Fragment of a pithos found above Building I:1 and dated to the $8^{\text {th }}$ or $7^{\text {th }} \mathrm{C} . \mathrm{BC}$ (Gordion Museum inv. no. SF 89-477).

Brixhe 2002a, 62-63 no. G-302.

$$
\text { tuo?[--- }
$$

\section{G-303}

Sherd dated to between 500 and $300 \mathrm{BC}$ (Gordion Museum inv. no. SF 89-682).

Brixhe 2002a, 63-64 no. G-303.

$$
\leftarrow d a[---]
$$




\section{G-304}

Fragment of the bottom of a little cup dated to between 500 and 300 BC (Gordion Museum inv. no. SF 89-687).

Brixhe 2002a, 64-65 no. G-304.

$n$

\section{G-305}

Sherd found in a filling of Building I:2 and dated to between the $8^{\text {th }}$ or $7^{\text {th }}$ C. BC (Gordion Museum inv. no. SF 89-692).

Brixhe 2002a, 65 no. G-305.

ri

\section{G-306}

Sherd dated to the $5^{\text {th }}$ C. BC (Gordion Museum inv. no. SF 89-693).

Brixhe 2002a, 66 no. G-306.

$$
\begin{gathered}
\rightarrow[---] \Psi o[---] \\
\text { or } \\
\leftarrow[---] \varphi \varphi[---]
\end{gathered}
$$

\section{G-307}

sherd found in a pit in Building I:2 and dated to the end of the $6^{\text {th }} \mathrm{C}$. BC (Gordion Museum inv. no. SF 89-700).

Brixhe 2002a, 66-67 no. G-307.

$$
\text { [---] ș?ate.[---] }
$$

\section{G-308}

Sherd dated to the end of the $4^{\text {th }} \mathrm{C} . \mathrm{BC}$ (Gordion Museum inv. no. SF 89-705 $=$ YH 34716).
Brixhe 2002a, 67-68 no. G-308.

$$
\text { [--- }] a ? d a d[---]
$$

\section{G-309}

Sherd found in the Lower Town between the Citadel Mound and the Küçük Höyük and dated to the end of the $5^{\text {th }}$ or the $4^{\text {th }} \mathrm{c}$. BC (Gordion Museum inv. no. SF 89-125).

Brixhe 2002a, 68 no. G-309.

$$
\text { [--- }] \text { ak[---] }
$$

\section{G-310}

Fragment of a handle of an undated pot found in the Lower Town (Gordion Museum inv. no. SF 94-41).

Brixhe 2002a, 68-69 no. 310.

$$
\leftarrow p a
$$

\section{G-311}

Sherd perhaps found in the NW sector of the city in a Hellenistic layer and dated to the $4^{\text {th }}$ c. BC (Gordion Museum inv. no. SF 94-76). Phrygian?

Brixhe 2002a, 69 no. 311.

$$
a
$$

\section{G-312}

sherd found in the Lower Town and dated to the $5^{\text {th }}-4^{\text {th }}$ C. BC (Gordion Museum inv. no. SF 94-255).

Brixhe 2002a, 70-71 no. G-312.

[-?-]yemeyọn 


\section{G-313}

Sherd found in the Lower Town and dated to the $5^{\text {th }}-4^{\text {th }}$ C. BC (Gordion Museum inv. no. SF 94-267).

Brixhe 2002a, 71 no. G-313.

$$
\leftarrow \text { amoṣ }
$$

\section{G-314}

Fragment of a handle found to the west of the city and dated to the $5^{\text {th }}-4^{\text {th }}$ C. BC (Gordion Museum inv. no. SF 94-267).

Brixhe 2002a, 72 no. G-314.

$$
\text { eyiy[---] }
$$

\section{G-315}

Sherd dated to between the $5^{\text {th }}-3^{\text {rd }}$ c. BC and found in the Secondary Citadel Mound (Gordion Museum inv. no. SF 95-61 = YH 43750).

Brixhe 2002a, 72-73 no. G-315.

$$
\text { V.[---] }
$$

\section{G-316}

Undated sherd (Gordion Museum inv. no. SF 95-239.02).

Brixhe 2002a, 73-74 no. G-316.

$$
\text { [-?-]ko[??]ạv[---] }
$$

\section{G-317}

Sherd found in the Secondary Citadel Mound and dated to the $5^{\text {th }}$ or $3^{\text {rd }}$ c. BC found in the Western Mound (Gordion Museum inv. no. SF 95-262).

Brixhe 2002a, 74 no. G-317.

$$
a[---]
$$

G-318

Undated sherd found in the Lower Town (Gordion Museum inv. no. SF 95-269).

Brixhe 2002a, 74-75 no. G-318.

$$
\text { [---]os : im[---] }
$$

\section{G-319}

Bottom of a cup found in the NW sector of the citadel and dated to Hellenistic times (Gordion Museum inv. no. SF 95-327 = YH 43944).

Brixhe 2002a, 75-76 no. G-319.

$$
\text { aiay }
$$

\section{G-320}

Hellenistic sherd found in the Mosaic Building (Gordion Museum inv. no. SF 95$328=\mathrm{YH}$ 43592). An arrow was incised under the letters.

Brixhe 2002a, 76 no. G-320.

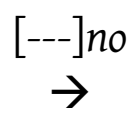

\section{G-321}

Fragment of a tile found in a Hellenistic wall and dated to the $4^{\text {th }}$ or $3^{\text {rd }} \mathrm{c}$. BC found in a wall (Gordion Museum inv. no. SF 96-73).

Brixhe 2002a, 76-78 no. G-321.

$$
\text { enumạlay.[-?-] }
$$

\section{G-322}

Sherd dated to between 560 and $550 \mathrm{BC}$ found in the west sector of the city (Gordion Museum inv. no. SF 97-247 = YH 56127). 
Brixhe 2002a, 78 no. G-322.

$$
\text { V }
$$

\section{G-323}

Fragment of a pithos found in Building I and dated to between the $7^{\text {th }}$ and the $6^{\text {th }} \mathrm{c}$. BC (Gordion Museum inv. no. SF 89-671).

Brixhe 2002a, 78-79 no. G-323.

$$
\text { [---] ’ moy }
$$

\section{G-324}

Fragment of the handle of a vessel found in the Lower City (Gordion Museum inv. no. SF 97-141 = YH 35580). Tentatively dated to the Hellenistic or Roman period.

Brixhe 2002a, 79-80 no. G-324.

$$
\text { V }
$$

\section{G-325}

Sherd found in the west sector of the city (Gordion Museum inv. no. SF 93-142 = YH 37944). Tentatively dated to the Hellenistic or Roman period.

Brixhe 2002a, 79-80 no. G-324.

$$
\begin{gathered}
\text { ni[--- } \\
\text { or } \\
{[---] \text { in }}
\end{gathered}
$$

\section{G-326}

Undated fragment of a pithos (Gordion Museum inv. no. SF 95-339 = YH 44144).

Brixhe 2002a, 80-81 no. G-326.

$$
\text { [---]r.[---] }
$$

\section{G-327}

Sherd found in the Secondary Citadel Mound and dated to the middle of the $6^{\text {th }} \mathrm{c}$. BC (Gordion Museum inv. no. SF 97-252= YH 57632).

Brixhe 2002a, 81-82 no. G-327.

$$
\rightarrow a[-?-]
$$

or

$$
\leftarrow[-?-] a
$$

\section{G-328}

Sherd found in the Secondary Citadel Mound and dated to the middle of the $6^{\text {th }} \mathrm{c}$. BC (Gordion Museum inv. no. SF 97-251 = YH 57633).

Brixhe 2002a, 82-83 no. G-328.

$$
\text { [---]ụa[---] }
$$

\section{G-329}

Sherd found in the Secondary Citadel Mound and dated to the middle of the $6^{\text {th }} \mathrm{c}$. BC (Gordion Museum inv. no. SF 97-249 = YH 57635).

Brixhe 2002a, 83-84 no. G-329.

$$
\text { [-?-]ḅa[-?-] }
$$

\section{G-330}

Sherd found in the Secondary Citadel Mound and dated to the middle of the $6^{\text {th }} \mathrm{c}$. BC (Gordion Museum inv. no. SF 97-254 = YH 57636).

Brixhe 2002a, 84 no. G-330. 


\section{G-331}

Fragment of an oenochoe found in the Secondary Citadel Mound and dated to the middle of the $6^{\text {th }} \mathrm{C}$. BC (Gordion Museum inv. no. SF 97-250 = YH 57637).

Brixhe 2002a, 84-86 no. G-331.

\section{e.gi.va}

\section{G-332}

Two contiguous sherds found in the Secondary Citadel Mound and dated to the middle of the $6^{\text {th }}$ c. BC (Gordion Museum inv. no. YH 57638).

Brixhe 2002a, 86 no. G-332.

$m$

\section{G-333}

Two contiguous fragments of a vessel found in the Secondary Citadel Mound dated to the middle of the $6^{\text {th }}$ c. BC (Gordion Museum inv. no. YH 57639).

Brixhe 2002a, 87-88 no. G-333.

be

\section{G-334}

Sherd found in the Secondary Citadel Mound and dated to the middle of the $6^{\text {th }} \mathrm{c}$. BC (Gordion Museum inv. no. YH 57640).

Brixhe 2002a, 88 no. G-334.

$$
\rightarrow ? a[-?-]
$$

\section{G-335}

Two contiguous fragments of a vessel found to the south of the City and dated to between $6^{\text {th }}$ and the first half of the $4^{\text {th }} \mathrm{c}$. BC (Gordion Museum inv. no. I $33 \mathrm{a} / \mathrm{b}$ ).
Roller 1987a, 23 no. 2A-102 (fig. 14); Brixhe 2002a, 88-89 no. G-335.

$$
\begin{aligned}
& \text { A.. } \\
& \text { B . }
\end{aligned}
$$

\section{G-336}

Cup found in the South Cellar and dated to the end of the $8^{\text {th }} \mathrm{C}$ or the beginning the $7^{\text {th }}$ C. BC (Gordion Museum inv. no. P 3400).

Roller 1987a, 21 no. 2A-73 (fig. 11) and 39 no. 2B-27 (fig. 30); Brixhe 2002a, 89-90 no. G-336.

ape

\section{G-337}

Cup found in the South Cellar and dated to the end of the $8^{\text {th }} \mathrm{C}$ or the beginning the $7^{\text {th }}$ C. BC (Gordion Museum inv. no. I 349).

Roller 1987a, 20 no. 2A-29 (fig. 10) and 39 no. 2B-22 (fig. 30); Brixhe 2002a, 91 no. G337.

\section{A $\quad t$ \\ B $\quad t u$ \\ C mark \\ G-338}

Jug found in the South Cellar and dated to the end of the $8^{\text {th }}$ or the beginning the $7^{\text {th }}$ c. BC (Gordion Museum inv. no. P 3215).

Roller 1987a, 20 no. 2A-51 (fig. 9) and 39 no. 2B-19 (fig. 29); Brixhe 2002a, 92-93 no. G-338.

uei 


\section{G-339}

Cup dated to between the $6^{\text {th }}$ and $4^{\text {th }} \mathrm{C} . \mathrm{BC}$ (Gordion Museum inv. no. P 1886). Several nonverbal graffiti were also incised.

Roller 1987a, 24 no. 2A-111 (fig. 16) and 40 no. 2B-44 (fig. 31 and photo pl. 3); Brixhe 2002a, 93-94 no. G-339.

$$
\leftarrow Y_{i r}
$$

\section{G-340}

Fragment of an Attic cup found in the NW of the city and dated to the third quarter of the $4^{\text {th }} \mathrm{C}$. BC (Gordion Museum inv. no. SF 97-276 = YH 58004).

Brixhe 2002a, 94-95 no. G-340.

$$
\text { teu[-?-] }
$$

\section{G-341}

Fragment of a probable Attic plate dated to the first quarter of the $4^{\text {th }} \mathrm{C}$. BC (Gordion Museum inv. no. SF 93-15 = YH 35694).

Brixhe 2002a, 95 no. G-341.

$$
\leftarrow \text { de }
$$

\section{G-342}

Fragments of the bottom of a jug found in the Middle Phrygian Building E and dated to the end of the $8^{\text {th }}$ and the beginning of $7^{\text {th }}$ c. BC (Gordion Museum inv. no. P 1144).

Brixhe 2002a, 96 no. G-342.

$$
\text { apel }
$$

\section{G-343}

Sherd found in the South Cellar and dated to the end of the $8^{\text {th }}$ or the beginning of $7^{\text {th }}$ c. BC (Gordion Museum inv. no. I 641).
Brixhe 2002a, 97 no. G-343.

$$
\text { [---]ṇo[---] or [---] dio[---] }
$$

or

$$
\text { [---]oṇ[---] or [---]oḍi[---] }
$$

\section{G-344}

Sherd tentatively dated to the beginning of $4^{\text {th }}$ c. BC (Gordion Museum inv. no. YH 33908).

Brixhe 2002a, 97-98 no. G-344.

$$
\leftarrow[-?-] !
$$

\section{G-345}

Fragment of a cup tentatively dated to the end of $4^{\text {th }} \mathrm{c}$. BC or the beginning of the $3^{\text {rd }}$ C. BC (Gordion Museum inv. no. SF 95183).

Brixhe 2002a, 98-99 no. G-345.

$$
\text { mey? }
$$

Fort. $\mu \varepsilon \chi$ ut Brixhe pro.

\section{G-346}

Graffiti incised on a roof beam of the tomb chamber in Tumulus MM and dated ca. 740 BC.

Sams 2009; Liebhart \& Brixhe 2009.

nana muksos

si idos

'urunis 


\section{G-347}

Pyramidal stamp seal made of rock following the Achaemenid type. A direct reading is needed.

Körte \& Körte 1904, 170-171 no. 1 (Abb. 151). 


\section{C- Central Phrygia (excluding Gordion)}

\section{Stone inscriptions}

\section{C-01}

A calcareous slab found at Karahüyük ( $35 \mathrm{~km}$ far from Ankara, between Hacıtuğrul and Yenidoğan) and preserved (without Inv. No.) in the site deposit.

CIPPh I, 220-221 no. C-01 (II, pl. CXIV); TITUS, no. C-1; Orel 1997a, 246 no. C-01.

$$
\text { [---]e[...]alabịioș[---] }
$$

\section{Instrumenta}

\section{C-101}

An undated fragment of a plate found at Karahüyük (same context of C-102 and C-103) and preserved in the site deposit (temporary no. Y.H. 23. 72).

CIPPh I, 221 no. C-101 (II, pl. CXV-1); TITUS, no. C-101; Orel 1997a, 288 C-101.

$$
\leftarrow \operatorname{kad}[---]
$$

\section{C-102}

An undated fragment of a pot with fragment of a handle found at Karahüyük (same context of C-101 an C-103) and preserved in the site deposit (temporary no. Y.H. 75/10).

CIPPh I, 221-222 no. C-102 (II, pl. CXV-2); TITUS, no. C-102; Orel 1997a, 288-289 C-102.

$$
\text { amos }
$$

\section{C-103}

Upper part of an undated kind of lekythos found at Karahüyük (same context of C-101 and C-102) with a graffito incised on the handle. Preserved in the site deposit (temporary no. Y.H. 75/9).

CIPPh I, 222 no. C-103; Orel 1997a, 289 C-103.

$$
\begin{aligned}
& \rightarrow d i \\
& \text { or } \\
& \leftarrow i d
\end{aligned}
$$




\section{P - "Pteria" (Alacahöyük, Pazarlı and Boğazkale)}

\section{Stone inscriptions}

\section{P-01}

Undated stone block documented by Hamilton in a house of Alacahöyük (before 1842) but now lost.

Hamilton 1842 I, 383; Sayce 1885, 910; de Saussure 1898, 167 (fig. 166) [= 1922, 544]; Körte \& Körte 1904, 19 no. 1; Sayce 1926, 34; Friedrich 1932, 126 no. 13; Haas 1966, 183 no. XIII; Neroznak 1978, 81 no. A 13; CIPPh I, 228-229 no. P-01 (CXV-3); Diakonoff \& Neroznak 1985, 64 no. A 13; TITUS, no. P-1; Orel 1997a, 290-291 no. P-01.

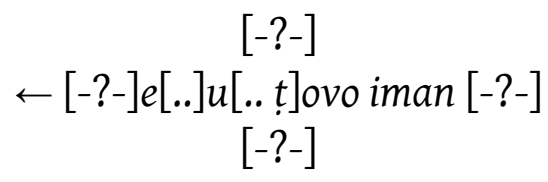

\section{P-02}

Undated stone block found in a house of Alacahöyük, now preserved in the Ankara Archaeological Museum (inv. no. 10110).

Mordtmann 1861, 191 (wrongly considered P-01); Ramsay 1883, 123 no. 13 (pl. III); de Saussure, 1898, 171 (fig. 168) [= 1922, 550]; Körte \& Körte 1904, 19; Sayce 1926, 33 no. 13; Friedrich 1932, 126 no. 10; Haas 1966, 182-183, no. X; Neroznak 1978, 80 no. 10; CIPPh I, 229-231 no. P-02 (II, CXVI-1, 2, 3, 4); Diakonoff \& Neroznak 1985, 64 no. A 10; TITUS, no. P-2; Orel 1997a, 291-292 no. P-02.

$$
\begin{array}{ll}
\leftarrow & \text { sest bugnos va- } \\
\leftarrow & \text { sos kanutii? evanoș? }
\end{array}
$$

2 fort. kanutie?evanoṣ?

$$
\text { '... of Vasos (the grandson) of Kanutî.' }
$$

\section{P-03}

Slab found in Alacahöyük by Chantre in 1893 (in the same house of P-04), preserved in the Ankara Archaeological Museum (inv. no. 7820). Tentatively dated to the $7^{\text {th }} \mathrm{C}$. BC by Bossert 1942, 289.

De Saussure 1898, 174-165 no. I (Fig. 167) [= 1922, 546-547 (pl. II)]; Kretschmer 1899, 355357; Sayce 1926, 34; Friedrich 1932, 126 no. 14; Bossert 1942, 284 no. 1102; Haas 1951, 23-24 no. XIV; Haas 1966, 182 no. XIV; Haas 1970b, 23-24 no. XIV (Tafel III); Neroznak 1978, 82 no. A. 14; CIPPh I, 231-234 no. P-03 (II, pl. CXVII-2 and pl. CXVIII-1,2); Diakonoff \& Neroznak 1985, 64 no. A 14; TITUS, no. P-3; Orel 1997a, 292-294 no. P-03. 
$\leftarrow \quad$ vasous iman mekas

$\rightarrow \quad$ kanutieivaịs

$\leftarrow$ devọs ke mekạs

'Vasos Iman the great (the son) of Kanutî and the great god.'

\section{P-04}

Stone block found in Alacahöyük by Chantre (in the same house of P-03) with inscriptions in three faces dated not after the $6^{\text {th }}$ C. BC (CIPPh I, 235). Preserved in Ankara Archaeological Museum (inv. no. 10756).

De Saussure 1898, 174-177 no. II [= 1922, 553-556 no. II (p. 563, fig. 169 and pl. I)]; Calder 1913, 102-103 (only P-04 a); Sayce 1926, 34; Friedrich 1932, 127 no. 15; Haas 1951, 18-19 no. XV; Haas 1966, 179-181 no. XV; Haas 1970a, 44 no. XV (Tafel II); Haas 1970b, 18-20 no. XV; Neroznak 1978, 82-83 no. A 15; CIPPh I, 234-240 no. P-04 (II, pl. CXIX-1, 2, 3, 4); Diakonoff \& Neroznak 1985, 65 no. A 15; Woudhuizen 1993, 13-15 no. P-04; TITUS, no. P-4; Orel 1997a, 294-299 no. P-04.

\begin{tabular}{|c|c|c|c|}
\hline \multirow[t]{4}{*}{ A } & \multirow[b]{4}{*}{4} & $\leftarrow$ & otuvoi vetei etlnaie \\
\hline & & $\rightarrow$ & ios ni ạkenan egeseti \\
\hline & & $\leftarrow$ & 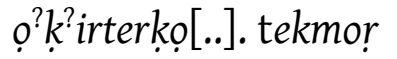 \\
\hline & & $\rightarrow$ & ot.[....]seti vebru \\
\hline B & & $\leftarrow$ & ios er? $v^{?}$ ot ${ }^{?} s^{?}$ ati kakuioi \\
\hline C & & $\leftarrow$ & iman olitovo \\
\hline & & $\leftarrow$ & ẹdạe [s] mekas \\
\hline
\end{tabular}

1 otuvoi fort. otu voi.

\section{P-05}

Unfinished statue of a lion found in 1937 in the south of Alcahöyük. Perhaps the statue is older than the inscription, but both remain undated (another lion found near to this one was dated by Bossert 1942, 83 no. 1057 to the $8^{\text {th }}$ or $7^{\text {th }}$ C. BC, see also Summers \& Özen 2012, 516518).

CIPPh I, 240-241 no. P-05 (II, pl. CXXII-2 and CXXIII-1, 2); TITUS, no. P-5; Orel 1997a, 299300 no. P-05.

vasus kanutiẹ[---]

Fort. kanutiẹ[(i)vanos]. 


\section{P-06}

Altar found in the west summit of a mountain called Kalehisar, near Mahmudiye village and $4 \mathrm{~km}$ from Alacahöyük. The altar is incised in the rock and oriented to South-East, also the feet of a statue of the Mother-Goddess remain.

CIPPh I, 242-243 no. P-06 (CXXIV-1, 2, 3, 4 and CXXV-1, 2, 3); TITUS, no. P-6; Orel 1997a, 300-301 no. P-06; Berndt-Ersöz 2006, 266-267 no. 108 (Fig. 95).

$$
\begin{aligned}
& \rightarrow \quad[-?-] a^{?} k i t i{ }^{?} . . . s \\
& \leftarrow \quad \text { ai : ios aeiketio [.?] ivi..se.[.?]n? }
\end{aligned}
$$

\section{Instrumenta}

\section{P-101}

Bottom of a pot dated to the 7th c. BC (according to Bossert 1942, 289), broken in two fragments. Was found in Pazarlı in a preliminary prospection (inv. no. 6236) but now it is lost. Its letter $b$ is 8 -shaped.

Koşay 1937, 33 (fig. 16); Koşay 1939, 9 and 20 (pl. XVI fig. 19); Koşay 1941, 16 (pl. XVII); Bossert 1942, 289 fig. 1106; Akurgal 1943, 43 no. 116; Masson 1954, 442 no. 25; Haas 1966, 183 no. XXVI; Neroznak 1978, 88 no. A 26; CIPPh I, 244-245 no. P-101 (II, pl. CXXVI-1); Diakonoff \& Neroznak 1985, 67 no. A 26; TITUS no. P-101; Orel 1997a, 301-302 no. P101.

$$
\text { ạini|dabp?ula ịsini }
$$

1 dabp'ulaịsini CIPPh post multas lectiones.

\section{P-102}

Graffito on a fragment of a handle dated to the $7^{\text {th }}$ c. BC found in Boğazkale (excavation no. $102 \mathrm{~d}$ ) and preserved in the Ankara Archaeological Museum (inv. no. 3547).

Bittle \& Güterbock 1935, 57 and 84-85 (pl. 31-13); Bossert 1942, 289 no. 1105; Haas 1966, 184 no. XX; Neroznak 1978, 85 no. A 50; CIPPh I, 245 no. P-102 (II, pl. CXXVI-2);
Diakonoff \& Neroznak 1985, 66 no. A 20; Orel 1997a, 302-303 no. P-102.

$$
\text { [---]ia aspẹ[---] }
$$

\section{P-103}

Fragment of a ceramic vessel dated to the $8^{\text {th }}$ or $7^{\text {th }}$ C. BC found in Boğazkale in 1955 (excavation no. Bo 155/n) with one graffito in each face.

Neumann 1975, 76-77 no. 1; Neroznak 1978, 77 no. A 85; CIPPh I, 246-247 no. P-103 a and P-103 b (II, pl. CXXVII-1, 2); Diakonoff \& Neroznak 1985, 75 no. A 85; Orel 1997a, 303-304 no. P-103a and P-103b.

$$
\begin{array}{ll}
\text { А } & [---] \text { ụiva.[--- }] \\
\text { в } & {[---] u^{?} \cdot i r k ?[---]}
\end{array}
$$

\section{P-104}

On a fragment of a cup dated to the $7^{\text {th }}$ or $6^{\text {th }}$ c. BC found in Boğazkale in 1958 (excavation no. Bo 377/q).

Neumann 1975, 77-78 no. 2; Neroznak 1978, 111 no. A 86; CIPPh I, 248 no. P-104 (II, pl. CXXVII-3); Diakonoff \& Neroznak 1985, 75 no. A 86; Orel 1997a, 304 no. P-104.

\section{[-?-]ạạas[-?-]}




\section{P-105}

On a sherd dated to the $7^{\text {th }}$ or $6^{\text {th }}$ c. BC, found in Boğazkale in 1958 (excavation no. Bo $377 / q)$.

Neumann 1975, 79-80 no. 4; Neroznak 1978, 111 no. A 87; CIPPh I, 248-249 no. P-105 (II, pl. CXXVIII-1); Diakonoff \& Neroznak 1985, 75 no. A 87; Orel 1997a, 304 no. P-105.

$$
\leftarrow \text { [---].oiduo.[---] }
$$

\section{P-106}

On a sherd dated to the $7^{\text {th }}$ or $6^{\text {th }} \mathrm{c}$. BC found in Boğazköy in 1961 (excavation no. Bo 790/t). Perhaps this is a fragment of the same vessel of $\mathrm{P}-107$ (found in the same context). Its letter $b$ is 8 -shaped.

Neumann 1975, 81-82 no. 5; Neroznak 1978, 111 no. A 88; CIPPh I, 249-250 no. P-106 (II, pl. CXXVIII-2); Diakonoff \& Neroznak 1985, 75 no. A 88; TITUS no. P-106; Orel 1997a, 305-306 no. P-106.

\section{[---].ti : makio?taTibi :.[---]}

\section{P-107}

On a sherd dated to the $7^{\text {th }}$ or $6^{\text {th }} \mathrm{c}$. BC found in Boğazkale in 1961 (excavation no. Bo 791/t). Perhaps it was the same vessel than P-106 (found in the same context).

Neumann 1975, 82 no. 6; Neroznak 1978, 112 no. A 89; CIPPh I, 250-251 no. P-107 (II, pl. CXXVII-4); Diakonoff \& Neroznak 1985, 75 no. A 89; Orel 1997a, 306 no. P-107.

$$
\text { [---].k.ui } \vdots n[---]
$$

\section{P-108}

Stamp seal made of stone and found in Boğazköy following the Neo-Assyrian style, very similar to HP-116. A direct reading is needed.

Bittle \& Güterbock 1935, 79-80 (Taf. 29, no. 16); Haas 1966, 184 no. XXVII; Boehmer \& Güterbock 1987, 88 no. 277 (Taf. XXXIV no. 277). 


\section{T- Tyana (Tuwanuwa, Kemerhisar)}

\section{$\mathrm{T}-01$}

Two lost fragments of a basalt stele dated to the last quarter of the $8^{\text {th }} \mathrm{c} . \mathrm{BC}$ found in a house of Kemerhisar in 1895.

Pridik 1900, 26 no. 29; Myres 1908, 13-16 (Pl. XIII); Friedrich 1941, col. 869 no. 21; Ruge 1948, col. 1630 no. 7; Masson 1954, 441; Haas 1966, 200 no. XXI; Neroznak 1978, 8586 no. A 21; CIPPh I, $258-260$ no. T-01 (II, pl. CXXIX-1, 2); Diakonoff \& Neroznak 1985, 66 no. A 21; Orel 1997a, 307-308 no. T-01a and $\mathrm{T}-01 \mathrm{~b}$.

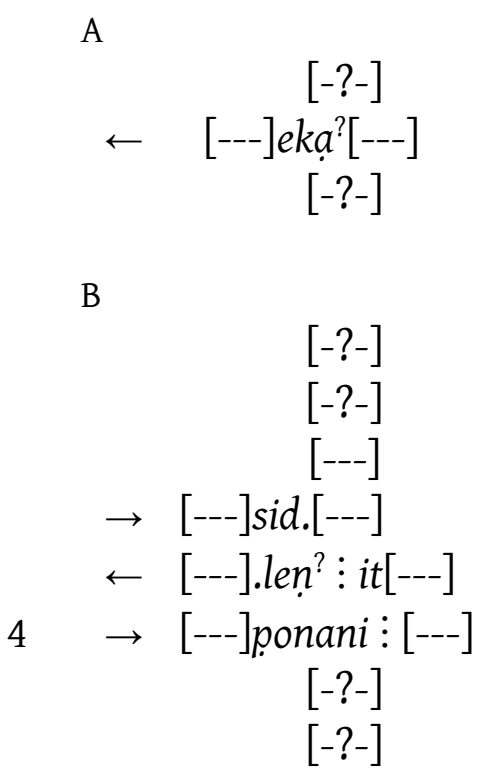

\section{$\mathrm{T}-02$}

Fragments of a basalt stele dated to the last quarter of the $8^{\text {th }} \mathrm{c}$. BC and found in 1906 and 1907. Now they are lost.

Weber 1908, 370 no. 77 (current frag. B); Garstang 1908, 10 (pl. XIII-1; current frag. B); Myres 1908, 13-16 (ordered B + C + A); Sayce 1926, 34-35 (current frag. B); Friedrich 1932, $127-128$ no. 19 (where $\mathrm{a}=$ current B, b = C, c = A); Ruge 1948, col. 1635 no. 8; Haas 1966, 199-200 no. XIX; Lejeune 1969a, 26 no. 33 and 42; Lejeune 1970, 85; Neroznak 1978, 84-85 no. A 19; Mellink 1979, 249-280 (fig. 1 a, b, c and d); CIPPh I,
262-267 no. T-02 (II, pl. CXXX-1 - CXXX-3); Diakonoff \& Neroznak 1985, 66 no. A 19; TITUS, T-02 (only b); Orel 1997a, 308-311 no. $\mathrm{T}-02$.

A

$$
\begin{array}{cc} 
& [---] \text { o[ [--- }] \\
& \rightarrow \quad[---] . t a d e .[---] \\
& {[---] p i p i .[---]} \\
& {[-?-]} \\
& {[-?-]}
\end{array}
$$

B

$$
\text { [---] }
$$

$\rightarrow[---]$ țumida $\vdots$ memeuis $:[---]$

$\leftarrow[---] a \vdots$ tesan $\vdots a \uparrow$ ion $\vdots v[---]$

$4 \rightarrow$ [---]oitumen $\vdots$ mida[---]

$\leftarrow[---] n \vdots a \uparrow$ ios $\vdots$ mi $[---]$

$\rightarrow[---] n \vdots$ batan $\vdots e .[---]$

$$
\text { C }
$$

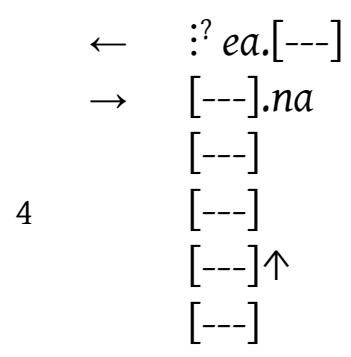

\section{T-03}

Fragments of a basalt stele dated to the last quarter of the $8^{\text {th }} \mathrm{c}$. BC and found in Kemerhisar in 1982.

CIPPh I, 268 no. T-03 (only mentioned; II CXXXI-1 - CXXXI-4); Çınaroğlu \& Varinlioğlu 1985; Brixhe 1991; Varinlioğlu 1991; TITUS, no. T-03; Orel 1997a, 311-315 no. T-03; CIPPh Sup. II, 94-103 no. T-03.

A I

$$
\begin{gathered}
\rightarrow \quad \text { a个iiai } \vdots \text { polodrẹ- } \\
\leftarrow \quad \text { tes } \vdots \text { poreti } \vdots \text { otu-? } \\
{[---]}
\end{gathered}
$$



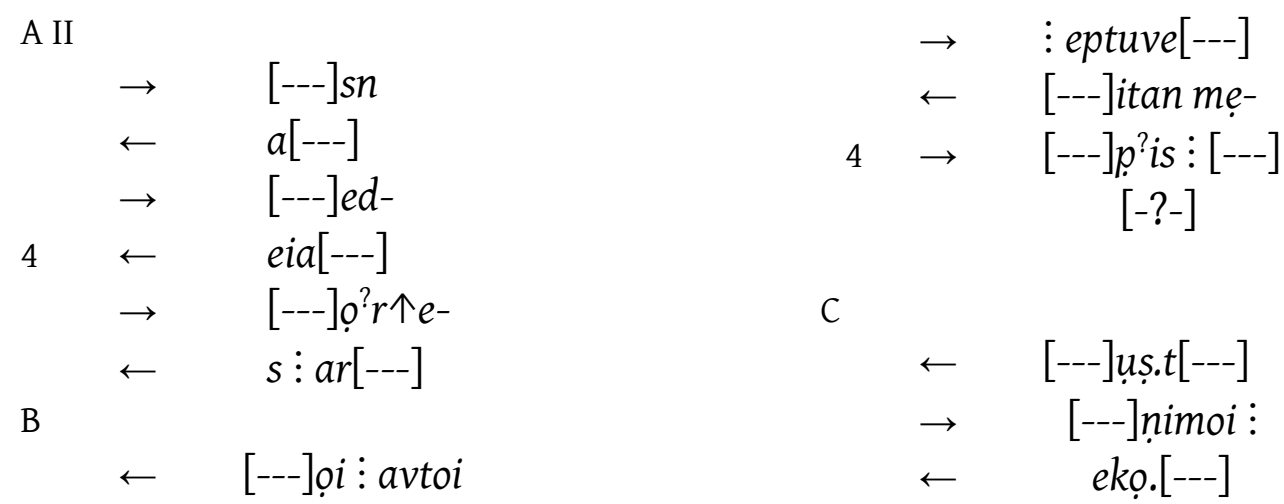

C
$\leftarrow \quad$ [---]uṣ.t[---]
$\rightarrow \quad$ [---]nimoi :
$\leftarrow \quad$ ekọ.[---] 


\section{K - Kerkenes Dağ}

\section{Stone inscriptions}

\section{$\mathrm{K}-01$}

Several fragments of a white stone stele dated to the first half of the $6^{\text {th }} \mathrm{c} . \mathrm{BC}$ and found at the Cappadocia gate.

Brixhe \& Summers 2006.

\begin{tabular}{|c|c|c|}
\hline I a & $\rightarrow$ & [---] vọs $\mid i[---]$ \\
\hline$I b$ & $\rightarrow$ & iẹḅ..[---] or yẹb..[---] \\
\hline II & $\rightarrow$ & $s \underline{s}[---]$ \\
\hline III & $\rightarrow$ & [---]ọitio !’? vosịk?[---] \\
\hline \multicolumn{3}{|l|}{ IV - X } \\
\hline IV a & & $\ldots$ \\
\hline IV b & $\rightarrow$ & eniyẹ[---] \\
\hline V & $\leftarrow$ & [---].pa $u v a^{(} \cdot[---]$ \\
\hline VI+VII a1 & $\leftarrow$ & [---] ' masa u- \\
\hline VI+VII a2 & $\rightarrow$ & rgitos dakor s=vebrạ[---] \\
\hline VI+VII b & $\rightarrow$ & tataniyen? ẹdaes \\
\hline VIII & $\rightarrow$ & {$[---] l e .[---]$} \\
\hline IX & & . \\
\hline
\end{tabular}

VI+VII b tata niye[---] ẹdaes Brixhe \& Summers 2006, 127.

'... Uva ... Masa (the son) of Urgi(s) ... Tataniyen made this vebras...'

\section{Instrumenta}

\section{$\mathrm{K}-101$}

Graffiti incised on the bottom of a clay bowl (identification no. 04TR11U22pot01) found in the Palatial complex

Brixhe and Summers 2006, 133, fig. 35.
a $\leftarrow n^{?}$
$\mathrm{b} \leftarrow s^{?}$
$\mathrm{c} \leftarrow s i^{?}$ 


\section{$\mathrm{K}-102$}

Jug with incised mark, perhaps a letter. Found in the Palace Complex.

Kerkenes News 4 2001, 11-12 (fig. 16).

$$
\leftarrow \quad n^{?}
$$

\section{$\mathrm{K}-103$}

Sherd from the shoulder of a closed vessel with a letter incised after firing. Cappadocia Gate (Kerkenes inv. no. K11.275).

http://www.kerkenes.metu.edu.tr/kerk1/07finds/InPottery/SherdwithGraffito.html\#11TR24U25 pot01

$$
\leftarrow \quad y
$$

\section{$\mathrm{K}-104$}

Flat base of a pot with a letter incised mark before firing, perhaps a letter. Cappadocia Gate (Kerkenes inv. no. K00.092).

http://www.kerkenes.metu.edu.tr/kerk1/07finds/InPottery/SherdwithGraffito.html\#11TR24U17 pot01

$$
\leftarrow \quad n^{?}
$$




\section{NW - Dorylaion (near Eskişehir)}

\section{Stone inscriptions}

\section{NW-01}

On the upper face of a stone block with a relief of a horseman. It is preserved in the Eskişehir ETI Archaeology Museum. The text is very eroded and only few letters and strokes remain.

Unpublished.

\section{Instrumenta}

\section{NW-101}

Terracotta disc found in zone R 6-9 of Dorylaion höyük surface and preserved in the Eskişehir ETI Archaeology Museum (find no. ŞH 90-1). Both faces are written, however their reading in some instances are not clear. Another incised similar disc also incised was found there but without text (see. CIPPh Supp. I, 10-11 no. *NW101a).

Darga 1993, 488 and 497 (fig. 9d-e); Brixhe 2002a, 4-10 no. NW-101.

$$
\begin{array}{lll}
\text { Face A I } & \text { deVeti } \\
\text { A II } & \text { toTiatiei } \\
\text { Face B } & \text { as- } \\
& & \leftarrow \text { naisnou }
\end{array}
$$

\section{NW-102}

Fragment of the bottom of a bowl found in the zone $\mathrm{G} 14$ of the Dorylaion höyük and preserved in the Eskişehir ETI Archaeology Museum. Dated to between 550 and 330 BC.

Brixhe 2002a, 12 no. NW-102.

$$
\begin{array}{ll}
\text { a } & {[-?-] \text { si[-?-] }} \\
\text { b } & \text { alis } \\
\text { c } & \text {.[--- }]
\end{array}
$$

\section{NW-103}

Sherd found in the G 14 zone of the Dorylaion höyük and preserved in the Eskişehir ETI Archaeology Museum. Dated to between 550 and $330 \mathrm{BC}$.

Brixhe 2002a, 13 no. NW-103.

$$
[-?-] \text { ta }
$$

\section{NW-104}

Sherd found in the G 14 zone of the Dorylaion höyük and preserved in the Eskişehir ETI Archaeology Museum. Dated to between 550 and $330 \mathrm{BC}$.

CIPPh Supp. I, 13-14 no. NW-104.

$$
\text { [--- }] . l
$$

\section{NW-105}

Sherd found in the G 14 zone of the Dorylaion höyük and preserved in the Eskişehir ETI Archaeology Museum. Dated to between 550 and $330 \mathrm{BC}$.

Brixhe 2002a, 14 no. NW-105.

V 


\section{NW-106}

Bottom of a cup found in the sector I 13 (ABIB level) of the Dorylaion höyük and preserved in the Eskişehir ETI Archaeology Museum. Dated to between 550 and 330 BC.

Brixhe 2002a, 14-15 no. NW-106.

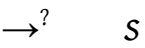

NW-108

Fragment of the bottom of a cup found in the sector S 24 (AARH level) of the Dorylaion höyük and preserved in the Eskişehir ETI Archaeology Museum. Dated to between 550 and $330 \mathrm{BC}$.

Brixhe 2002a, 16-17 no. NW-108.

$$
d[-?-] \text { or } a[-?-]
$$

\section{NW-109}

Fragment of the bottom of a cup with non-verbal marks found in the sector S 24 (AAVG level) of the Dorylaion höyük and preserved in the Eskişehir ETI Archaeology Museum. Dated to between 550 and 330 BC.

Brixhe 2002a, 17 no. NW-109.

\section{NW-110}

Fragment of the bottom of a cup found in the sector $\mathrm{H} 14 / \mathrm{b}$ (BBBO level) of the Dorylaion höyük and preserved in the Eskişehir ETI Archaeology Museum. Dated to between 550 and $330 \mathrm{BC}$.

Brixhe 2002a, 18 no. NW-110.

\section{NW-111}

Sherd found in the sector $\mathrm{H} 13 / \mathrm{d}$ (ABCY level) of the Dorylaion höyük and preserved in the Eskişehir ETI Archaeology Museum. Dated to between 550 and 330 BC.

Brixhe 2002a, 18-19 no. NW-111.

tir or tr

\section{NW-112}

Fragment of the bottom of a cup found in the level AACE of the Dorylaion höyük and preserved in the Eskişehir ETI Archaeology Museum. Dated to between 550 and $330 \mathrm{BC}$.

Brixhe 2002a, 19 no. NW-112.

V

\section{NW-113}

Fragment of the bottom of a cup found in the level AAYY of the Dorylaion höyük and preserved in the Eskişehir ETI Archaeology Museum. Dated to between 550 and $330 \mathrm{BC}$.

Brixhe 2002a, 19-20 no. NW-113.

$$
\text { yor } e
$$

\section{NW-114}

Fragment of the bottom of a cup found in the level AAKP of the Dorylaion höyük and preserved in the Eskişehir ETI Archaeology Museum. Dated to between 550 and $330 \mathrm{BC}$.

Brixhe 2002a, 20 no. NW-114.

$$
\text { [-?-] }] \text { ir[-?-] or [-?-]kr[-?-] }
$$




\section{NW-116}

sherd found in the sector I 13/d (AALP level) of the Dorylaion höyük and preserved in the Eskişehir ETİ Archaeology Museum. Dated to between 550 and 330 BC.

Brixhe 2002a, 21 no. NW-116.

$$
\text { [-?-]ded?[---] }
$$

\section{NW-117}

Fragment of the bottom of a cup found in the sector I 14 (AAHO level) of the Dorylaion höyük and preserved in Eskişehir the ETI Archaeology Museum. Dated to between 550 and $330 \mathrm{BC}$.

Brixhe 2002a, 22 no. NW-117.

$$
\rightarrow ? \quad s^{?}
$$

\section{NW-118}

Fragment of a cup found in the surface of the Dorylaion höyük and preserved in the Eskişehir ETI Archaeology Museum. Only an upper angle of a letter remains. Dated to between 550 and 330 BC.

Brixhe 2002a, 22-23 no. NW-118.

\section{NW-119}

Sherd found in the surface of the Dorylaion höyük and preserved in Eskişehir the ETI Archaeology Museum. Only an upper angle of a letter remains. Dated to between 550 and $330 \mathrm{BC}$.

Brixhe 2002a, 23 no. NW-119.

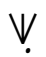

\section{NW-120}

Sherd found in the surface of the Dorylaion höyük and preserved in the Eskişehir ETI Archaeology Museum (inv. no. ŞH 05, M 20 a+b ACCU). Dated to between 550 and $330 \mathrm{BC}$.

Brixhe \& Sivas 2009, 129 no. NW-120.

$$
[---] T i s
$$

\section{NW-121}

Sherd found in the surface of the Dorylaion höyük and preserved in the Eskişehir ETI Archaeology Museum (inv. no. ŞH 05, T24 c+d ACCU). Dated to between 550 and $330 \mathrm{BC}$.

Brixhe \& Sivas 2009, 129-130 no. NW121.

\section{V}

\section{NW-122}

Sherd found in the surface of the Dorylaion höyük and preserved in the Eskişehir ETI Archaeology Museum (inv. no. ŞH 00 H13 ABHK). Dated to between 550 and $330 \mathrm{BC}$.

Brixhe \& Sivas 2009, 130 no. NW-122.

$$
\leftarrow \quad \text { [---]ụes[--- }
$$

\section{NW-123}

Sherd found in the Dorylaion höyük and preserved in the Eskişehir ETI Archaeology Museum (inv. no. \$̧H 07, V13 a, ACYC). Dated to between 550 and 330 BC.

Brixhe \& Sivas 2009, 130-131 no. NW123.

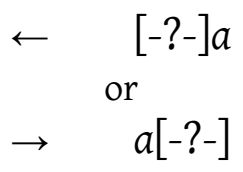




\section{NW-124}

Sherd found in the surface of the Dorylaion höyük and preserved in the Eskişehir ETİ Archaeology Museum (inv. no. ŞH 96, surface, AANM). Dated to between 550 and $330 \mathrm{BC}$.

Brixhe \& Sivas 2009, 131 no. NW-124.

$a$

\section{NW-125}

Sherd found in the Dorylaion höyük and preserved in the Eskişehir ETİ Archaeology Museum (inv. no. ŞH 06 U13 a+-c, ACNA). Dated to between 550 and $330 \mathrm{BC}$.

Brixhe \& Sivas 2009, 131-132 no. NW125.

e

\section{NW-126}

Sherd found in the Dorylaion höyük and preserved in the Eskișehir ETI Archaeology Museum (inv. no. ŞH 06, J16 a+b, ACMO). Dated to between 550 and $330 \mathrm{BC}$.

Brixhe \& Sivas 2009, 132 no. NW-126.

$$
\text { V V }
$$

\section{NW-127}

Bottom of a pot found in the Dorylaion höyük and preserved in the Eskişehir ETI Archaeology Museum (inv. no. ŞH 06 U13 b, ACLZ). Dated to between 550 and 330 BC.

Brixhe \& Sivas 2009, 132 no. NW-127.

$a$

\section{NW-128}

Fragment of the bottom of a pot found in the Dorylaion höyük and preserved in the Eskişehir ETI Archaeology Museum (inv. no. ŞH 06, U13 a+c, ACNA). Dated to between 550 and $330 \mathrm{BC}$.

Brixhe \& Sivas 2009, 132 no. NW-128.

V

NW-129

Sherd found in the Dorylaion höyük and preserved in the Eskișehir ETİ Archaeology Museum (inv. no. ŞH 06, U13b, ACKS). Dated to between 550 and $330 \mathrm{BC}$.

Brixhe \& Sivas 2009, 133 no. NW-129.

$$
\begin{aligned}
& \rightarrow^{?} \quad a \\
& \leftarrow \quad y e ? ?
\end{aligned}
$$

\section{NW-130}

Bottom of a cup found in the Dorylaion höyük and preserved in the Eskişehir ETI Archaeology Museum (inv. no. ŞH 06, U13 a+c ACNA). Dated to between 550 and 330 $\mathrm{BC}$.

Brixhe \& Sivas 2009, 133 no. NW-130.

$a$

\section{NW-131}

Bottom of a cup found in the Dorylaion höyük and preserved in the Eskişehir ETI Archaeology Museum (inv. no. ŞH J14 d, ACJD). Dated to between 550 and $330 \mathrm{BC}$.

Brixhe \& Sivas 2009, 133-134 no. NW131.

ga 


\section{NW-132}

Bottom of a cup found in the Dorylaion höyük and preserved in the Eskişehir ETI Archaeology Museum (inv. no. ŞH U13 a+c, ACNA). Dated to between 550 and 330 BC.

Brixhe \& Sivas 2009, 134 no. NW-132.

$a$

\section{NW-133}

Bottom of a cup found in the Dorylaion höyük and preserved in the Eskişehir ETI Archaeology Museum (inv. no. ŞH 06, U13 $a+c, A C N A$ ). Dated to between 550 and 330 $B C$. Perhaps it is a non-verbal graffito.

Brixhe \& Sivas 2009, 134-135 no. NW133.

$$
e^{?}
$$

\section{NW-134}

Fragment of the bottom of a cup with a non-verbal mark found in the Dorylaion höyük and preserved in the Eskişehir ETI Archaeology Museum (inv. no. ŞH 07, V13 a, ACYB). Dated to between 550 and 330 BC. Perhaps it is a non-verbal graffito.

Brixhe \& Sivas 2009, 135 no. NW-134.

\section{V}

\section{NW-135}

Fragment of the bottom of a cup found in the Dorylaion höyük and preserved in the Eskişehir ETI Archaeology Museum (inv. no. ŞH 07, U13 a+c, ACNA). Dated to between 550 and $330 \mathrm{BC}$. Perhaps it is a nonverbal graffito.

Brixhe \& Sivas 2009, 135-136 no. NW135.

$$
\text { miye[-?-]o广 } i
$$

NW-136

Sherd found in the Dorylaion höyük and preserved in the Eskişehir ETI Archaeology Museum (inv. no. ŞH 01, H13-I13, ABOJ). Dated to between 550 and 330 BC. Perhaps it is a non-verbal graffito.

Brixhe \& Sivas 2009, 136 no. NW-136.

$$
\leftarrow \quad i d n[-?-]
$$

\section{NW-137}

Sherd with a non-verbal mark found in the Dorylaion höyük and preserved in the Eskişehir ETI Archaeology Museum (inv. no. ŞH 07, V13 b, ACTK). Dated to between 550 and 330 BC. Perhaps it is a non-verbal graffito.

Brixhe \& Sivas 2009, 136-137 no. NW137.

\section{V}

\section{NW-138}

Bottom of a cup found in the Dorylaion höyük and preserved in the Eskişehir ETI Archaeology Museum (inv. no. ŞH 07, J16 b, ACSG). Dated to between 550 and 330 BC. Perhaps it is a non-verbal graffito.

Brixhe \& Sivas 2009, 137 no. NW-138.

\section{$a$}

\section{NW-139}

Fragment of the bottom of a pot found in the Dorylaion höyük and preserved in the Eskişehir ETI Archaeology Museum (inv. no. ŞH 07, U13 a+b, ACNA). Dated to between 550 and $330 \mathrm{BC}$. Perhaps it is a nonverbal graffito.

Brixhe \& Sivas 2009, 137-138 no. NW139.

$$
a \uparrow\left[i / e^{?} ?\right]
$$




\section{Dd - Diverse documents}

\section{Dd-101}

Pyramidal seal stamp made of chalcedony with a silver handle. Ther is a under the inscription. Its provenance is unknown. It is preserved in the private collection of Jonathan Rosen, New York (formerly belonged to Dr. Borowski). Dated to between 550 and 330 BC (Genz 2009,310 fn. 20 i 21).

Gusmani \& Poetto 1981; CIPPh I, 271 no. Dd-101 (II, pl. CXXXII-1, 2, 3); Diakonoff \& Neroznak 1985, 75 no. A 90; TITUS, no. Dd-101; Orel 1997a, 360 no. Dd-101; Obrador-Cursach fthc. b.

$$
\begin{gathered}
\leftarrow \quad \text { pser?keyoy atas } \\
\text { or } \\
\leftarrow \quad \text { pseu?keyoy atas } \\
\text { 'Atas for Pser/ukeyos'. }
\end{gathered}
$$

\section{Dd-102}

Undated silver bowl preserved in the Musée d'art et d'histoire de Genève (inv. no. 23469, formerly AD 2386). There are obvious signs that a previous inscription had been removed.

Lazović, Dürr, Durand, Houriet \& Schweizer 1977, 7 and 18 no. 2 (p. 40-41, fig. 11; as Greek); CIPPh I, 27-271 no. Dd-102 (II, pl. CXXXIII-1, 2); TITUS, no. Dd-102; Orel 1997a, 361 no. Dd102.

$$
\begin{aligned}
& \leftarrow \quad \text { surgastoy inas } \\
& \text { 'Inas for Surgastos' }
\end{aligned}
$$

\section{Dd-103}

Agate cylindric seal made of agate dated to the $6^{\text {th }}$ or $5^{\text {th }} \mathrm{c} . \mathrm{BC}$ and preserved in the Buffalo Museum of Science (inv. no. C 15046). Its origin is unknown. With the inscription a man dressed in Persian styles is depicted with two lions.

Friedrich 1965, 154-156; Haas 1966, 176-177 no. c; Neroznak 1978, 86 no. A 22; Diakonoff \& Neroznak 1985, 67 no. A 22; Masson 1987a; Orel 1997a, 361-362 no. Dd-103; Brixhe 2004a, 126127 no. Dd-103.

$$
\begin{aligned}
& \rightarrow \quad \text { mane } \\
& \leftarrow \quad \text { on:en }
\end{aligned}
$$




\section{HP - Dispersed inscriptions found outside Phrygia}

\section{Stone inscriptions}

\section{HP-01}

A Phrygian graffito incised on a Hieroglyphic Luwian orthostat found in Karkemiš and dated to $850 \mathrm{BC}$. Because of historical reasons, the Phrygian inscription is to be dated to the last quarter of the $8^{\text {th }} \mathrm{c}$. $\mathrm{BC}$.

Börker-Klähn 1994.

$$
\rightarrow \quad \text { atatas }
$$

\section{HP-02}

Big stone slab found in the downtown of Kocagür (perhaps the ancient Pitya Pityeia, $14 \mathrm{~km}$ from Parion, Mysia on the Hellespont). The alphabet is clearly Phrygian, but the language not so sure according to editors.

Brixhe \& Keleş 2011.

$$
\begin{aligned}
& {[-?-] } \\
\leftarrow & \text { tanarị[--- }] \\
\rightarrow & {[---] \text { liake } } \\
\leftarrow \quad & \text { edaie }[-?-]
\end{aligned}
$$

\section{Instrumenta}

\section{HP-101}

Undated clay spindle whorl found in a höyük from Çamönü (formerly Karasonya, northern Lydia) and preserved in the Manisa Museum (without inv. no.?).

Dinç \& Innocente 1999; Brixhe 2004a, 103-106 no. HP-101.

$$
\begin{gathered}
\leftarrow \quad p^{?} \text { erbastidages } \\
\text { or } \\
\leftarrow \quad p^{?} \text { er bastidages } \\
\text { HP-102 }
\end{gathered}
$$

Silver cup found in the main tumulus of Ikiztepe (Lydia) by clandestine diggers, now preserved in the Ankara Museum of Anatolian Civilizations (inv. no. 75-5-66).

Gusmani 1988; Brixhe 1989-1990; TITUS, no. W-11; Orel 1996; Özgen \& Öztürk 1996, 106 no. 60; Orel 1997a, 135-137 no. W-101; Brixhe 2004a, 106-108 no. HP-102.

$$
\begin{gathered}
\leftarrow \text { midas aiasay mạ..un } \\
\text { 'Midas (gave) ma..un to Ayasa(s).' }
\end{gathered}
$$

\section{HP-103}

Silver cauldron found in Tumulus D from Bayındır (East Lycia) and preserved in the Antalya Museum (inv. no. 11-21-87). Dated to the middle of the 8th c. BC.

Varinlioğlu 1992, 11-12 no. 1; TITUS, no. Bay-1; Orel 1997a, 316 no. L-101; 2004a, 109110 no. HP-103.

\section{ates}

\section{HP-104}

Silver cauldron found in Tumulus D from Bayındır (East Lycia) and preserved in the Antalya Museum (inv. no. 12-21-87). Dated to the middle of the $8^{\text {th }} \mathrm{c} . \mathrm{BC}$.

Varinlioğlu 1992, 11-12 no. 2; TITUS, no. Bay-2; Orel 1997a, 316 no. L-102; 2004a, 110111 no. HP-104. 


\section{HP-105}

Silver ladle found in Tumulus D from Bayındir (East Lycia) and preserved in the Antalya Museum (inv. no. 43-21-87). Dated to the middle of the $8^{\text {th }} \mathrm{c}$. BC.

Varinlioğlu 1992, 11 no. 3 (pl. I); TITUS, no. Bay-3; Orel 1997a, 316-317 no. L-103; 2004a, 111-112 no. HP-105.

\section{ates}

\section{HP-106}

Silver plain omphalos bowl found in Tumulus D from Bayındır (East Lycia) and preserved in the Antalya Museum (inv. no. 6-21-87). Dated to the middle of the $8^{\text {th }} \mathrm{c}$. BC.

Varinlioğlu 1992, 14 no. 4 (pl. II); TITUS, no. Bay-4; Orel 1997a, 317 no. L-104; 2004a, 112 no. HP-106.

ates

\section{HP-107}

Bronze plain omphalos bowl found in Tumulus D from Bayındır (East Lycia) and preserved in theAntalya Museum (inv. no. 19-21-87). Dated to the middle of the $8^{\text {th }} \mathrm{c}$. BC.

Varinlioğlu 1992, 12 and 14 no. 5; TITUS, no. Bay-5; Orel 1997a, 317 no. L-105; 2004a, 113 no. HP-107.

ates

\section{HP-108}

Bronze plain omphalos bowl found in Tumulus D from Bayındır (East Lycia) and preserved in the Antalya Museum (inv. no. 14-21-87). Dated to the middle of the $8^{\text {th }} \mathrm{c}$. BC.
Varinlioğlu 1992, 12 and 14 no. 6; TITUS, no. Bay-6; Orel 1997a, 317-318 no. L-106; 2004a, 113 no. HP-108.

ates

\section{HP-109}

Bronze plain omphalos bowl found in tumulus D from Bayındır (East Lycia) and preserved in the Antalya Museum (inv. no. 15-21-87). Dated to the middle of the $8^{\text {th }} \mathrm{c}$. $\mathrm{BC}$.

Varinlioğlu 1992, 12 and 14-15 no. 7; Orel 1997a, 318 no. L-107; 2004a, 114-115 no. HP109.

$$
a \uparrow s e s
$$

\section{HP-110}

Bronze plain omphalos bowl found in Tumulus D from Bayındır (East Lycia) and preserved in the Antalya Museum (inv. no. D-16). Dated to the middle of the $8^{\text {th }} \mathrm{c} . \mathrm{BC}$.

Varinlioğlu 1992, 13 and 15 no. 8; TITUS, no. Bay-8; Orel 1997a, 318-319 no. L-108; 2004a, 115-116 no. HP-110.

$$
\text { si个idos }
$$

\section{HP-111}

Bronze plain omphalos bowl found in Tumulus D from Bayındır (East Lycia) and preserved in the Antalya Museum (inv. no. 17-21-87). Dated to the middle of the $8^{\text {th }} \mathrm{c}$. $\mathrm{BC}$.

Varinlioğlu 1992, 13 and 15 no. 9; TITUS, no. Bay-9; Orel 1997a, 319 no. L-109; 2004a, 116 no. HP-111.

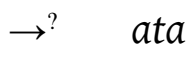




\section{HP-112}

Bronze petaled omphalos bowl found in Tumulus D from Bayındır (East Lycia) and preserved in the Antalya Museum (inv. no. $\mathrm{D}-18)$. Dated to the middle of the $8^{\text {th }} \mathrm{c} . \mathrm{BC}$.

Varinlioğlu 1992, 13 and 15 no. 10; TITUS, no. Bay-10; Orel 1997a, 319-320 no. L-110; 2004a, 116-117 no. HP-112.

\section{$\leftarrow \quad$ dide \\ HP-113}

Bronze plain omphalos bowl found in Tumulus D from Bayındır (East Lycia) and preserved in the Antalya Museum (inv. no. D-26). Dated to the middle of the $8^{\text {th }} \mathrm{c} . \mathrm{BC}$.

Varinlioğlu 1992, 13 and 15-16 no. 11; Orel 1997a, 319 no. L-111; 2004a, 117-118 no. HP-113.

$$
\rightarrow \quad \text { idi }
$$

\section{HP-114}

Clay tablet dated to the ending of the $6^{\text {th }}$ or the first half of the $5^{\text {th }} \mathrm{c}$. BC found in the Fortification Archive of Persepolis among many tablets written in Elamite and Aramaic. Preserved in the University of Chicago's Oriental Institute Museum (inv. no. A 29797).

Friedrich 1965, 154-156; Haas 1966, 176 no. b; Neroznak 1978, 86-87, no. A 23; Diakonoff \& Neroznak 1985, 67 no. A 23; Orel 1995, 128-132; Orel 1997a, 363-364 no. Dd-104; Brixhe 2004a, 118-126 no. HP-114.

$$
\begin{aligned}
& \text { 30?...ẹkes 30? } i \text { ? } \\
& \text {.. 30? y? r? ekes? } \\
& \text {. 30? knays 30? s? } \\
& 4 \quad i^{?} y^{?} r^{?} i \mathrm{i} 40^{?} \text { knayke? }[s] \text { ? } \\
& \text { ? } 40 ? \mathrm{~m} \text { ?akeres } 40 \text { ? } \\
& \text { [---] } \\
& \text { [-?-] } \\
& \text {.. aṇamaka }
\end{aligned}
$$

' 30 ...ekes, $30 i$..., 30 vrekes, 30 women, 30 (s)ivri, 40 women, 40 makeres, $40 \ldots$ (in the month of) Anamaka.'

\section{HP-115}

Fragment of the bottom of a threelegged bowl or vessel made of soft greenish gray stone with an inscription suggested to be Phrygian by Brixhe \& Summers 2006, 134. Found in Alişar Höyük (Cappadocia, not far from Kerkenes Dağ).

Schmidt \& Krogman 1933, 133, 109-110 fig. 172 (as Byzantine); Gelb 1935, 77 no. 94 (as Greek); Brixhe \& Summers 2006, 134 (as Phrygian).

$$
\leftarrow \quad[---] \text { ripos }
$$

\section{HP-116}

Stamp seal made of rock following the Neo-Assyrian style found in Nemrut Dağ. Its style is very similar to P-108. A direct reading is needed.

Mellink 1960, 64 (Pl. 12, fig. 9a-9b); Boehmer 1977, 81 (80, Abb. 6); Boehmer \& Güterbock 1987, 86 (Abb. 56). 


\section{Middle Phrygian Inscriptions}

\section{MPhr-01}

Great funerary stele dated to the end of the $4^{\text {th }}$ c. BC or the beginning of the $3^{\text {rd }} \mathrm{C} . \mathrm{BC}$ and found in Alanyurt (olim Bavurdu, not far from the ancient city of Dokimeion). Preserved in the Afyon Museum (without inv. no.). A colon occurs after each verse of this metric epitaph.

Brixhe 2004a, 7-26 no. W-11; Lubotsky 2017.

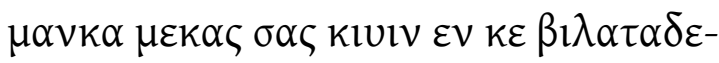

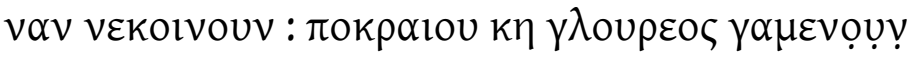

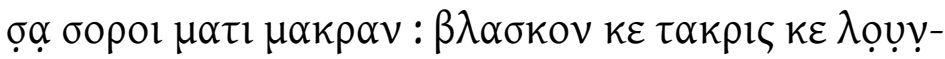

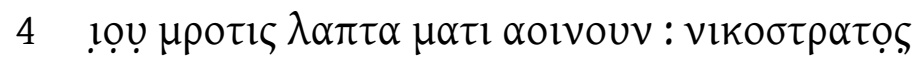

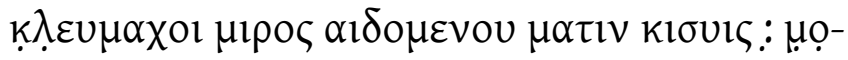

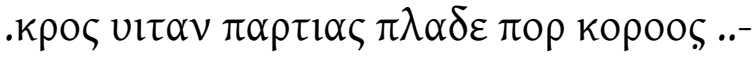

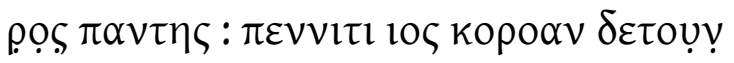

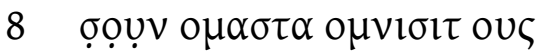

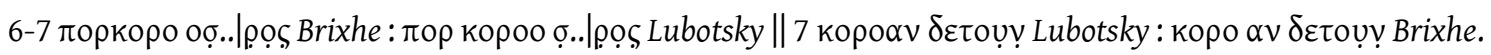

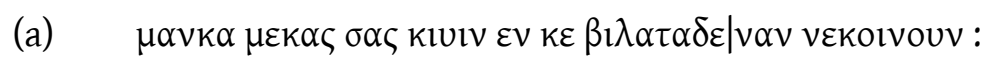

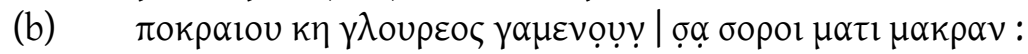

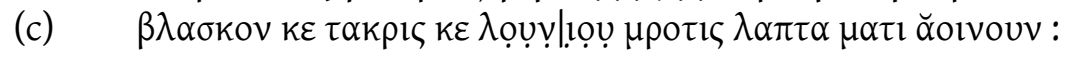

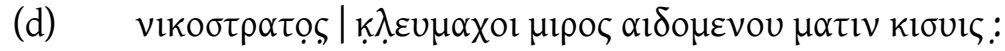

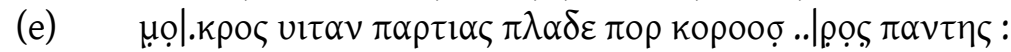

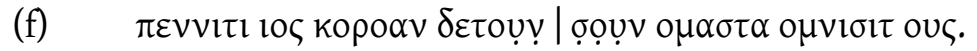





\section{New Phrygian Inscriptions}

\section{Eskişehir (Dorylaion)}

\section{1}

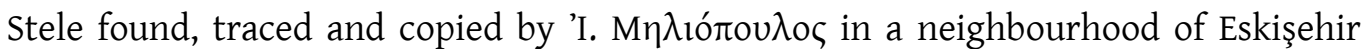
("0,95 ${ }^{\mathrm{m}}$ langen, $0,55^{\mathrm{m}}$ breiten", letters " $5 \mathrm{~cm}$ hohe", "Funde" 1898,362 ). The inscription is lost, but an impression and a drawing are preserved in the Kleinasiatische Kommission of the Wiener Akademie der Wissenschaften (Lubotsky 1997, 115 fn. 1).

“Funde" 1898, 362-363; Ramsay 1905, col. 103-14 no. XLVIII; Calder 1911, 188-189 no. XLVIII; Friedrich 1932, 135 no. 48; MAMA V Lists I no. 182.89; Haas 1951, 7-9 no. 48; Haas 1966, 120, no. 48; Haas 1970a, 38-39 no. 48; Haas 1970b, 7-9 no. 48; Diakonoff \& Neroznak 1985, 86, no. C 48; TITUS, no. 48 (only the Phrygian text); Lubosky 1997, 115-130; Orel 1997a, 97-102 no. W-34.

$$
\begin{aligned}
& 0 \text { [ ]. } \\
& 1 \varepsilon[. .] \gamma \varepsilon v \tau+o u \mu \varepsilon v o \zeta
\end{aligned}
$$

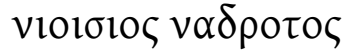

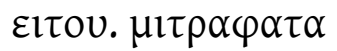

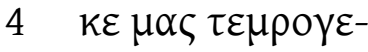

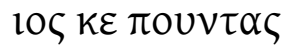

$$
\begin{aligned}
& \beta \alpha \varsigma \kappa \varepsilon \varepsilon \vee \sigma \tau \alpha \rho \vee \alpha \text {. }
\end{aligned}
$$

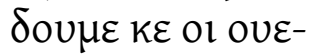

$$
\begin{aligned}
& 8 \quad \beta \alpha v \alpha \delta \delta \alpha \kappa \varepsilon \tau \text { o } \rho \text { o - }
\end{aligned}
$$

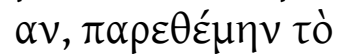

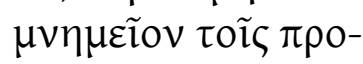

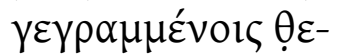

$$
\begin{aligned}
& 12 \text { oĩ } \kappa \dot{\varepsilon} \tau \tilde{\eta} \kappa \omega ́ \mu \tilde{\eta} \text {. }
\end{aligned}
$$

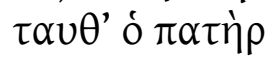

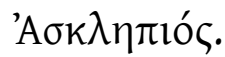

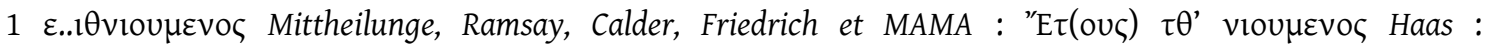

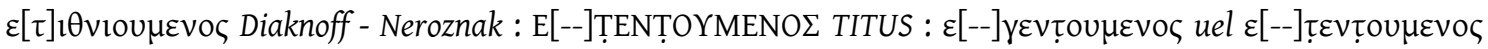
TITUS 1997 : عıт

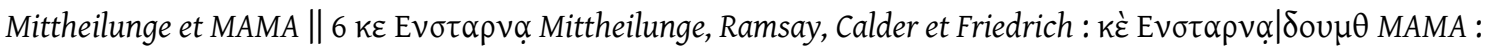

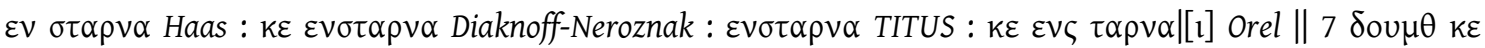

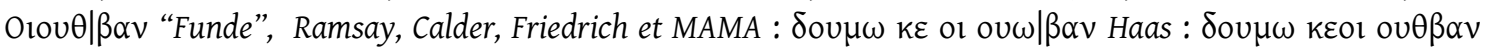

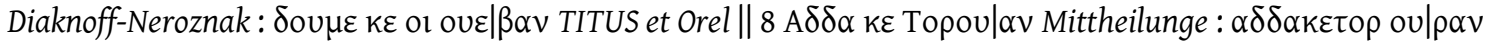

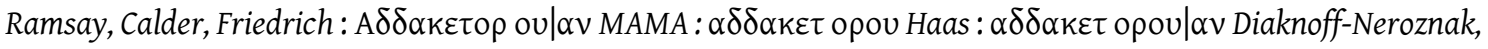

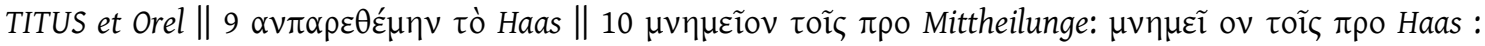

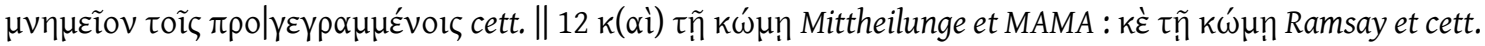

'[Phrygian] ... let him become X-ed and viololos and impotent. Mithrapata and Mas Tembrogios and the Pontic Bas... and for the community the father does this tomb. [Greek] I, the father Asklepios, erected this memorial for the above-mentioned gods and the town'. 


\section{2}

"Grey marble stele with acroteria; in pediment, rosette; in field, defaced ox-head [...] H. $1.38 \mathrm{~m}$;; W. (base) 0.45 m., (shaft) 0.37 m.; Th. 0.185 m. Letters (slight apices) 0.016 m. to 0.02 m." (Macpherson 1954, 13). Lunate sigma and epsilon. It is is preserved in the Eskişehir Museum (inv. no. 57).

Macpherson 1954, 13-15 (with photograph) (= SEG 14.783); Haas 1966, 127 no. 98; Diakonoff \& Neroznak 1985, 87 no. C 98; TITUS no. 98 (only Phrygian text); Orel 1997a, 359-360 no. Dd*-01.

$$
\begin{aligned}
& \mathrm{K} \lambda \omega \delta i ́ \alpha
\end{aligned}
$$

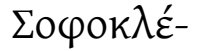

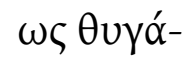

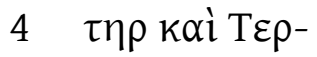

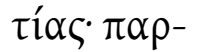

$$
\begin{aligned}
& \theta \varepsilon ́ v \varepsilon, \chi \alpha \tilde{\imath} \rho \varepsilon . \\
& \delta \alpha \kappa \alpha \rho \varepsilon v \pi \alpha-
\end{aligned}
$$

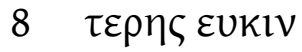

$$
\begin{aligned}
& \text { apjou. }
\end{aligned}
$$

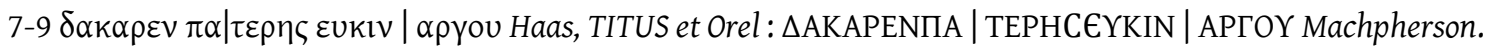

'[Greek] Clodia the daughter of Sofocles and Tertias: hail maiden. [Phrygian] Her parents made (it) as a vow'.

\section{Seyitgazi (Nakoleia)}

\section{1}

Monolingual inscription on a stele. Copied twice by Ramsay (June of 1881 and August of 1883), also by J. R. S. Sterrett in 1883 (Ramsay 1887, 394). Rectangular sigma and epsilon.

Ramsay 1887, 394 no. XV (without edition); Ramsay 1905, col. 114-116 no. XV; Calder 1911, 172-174 no. XV; Friedrich 1932, 131 no. 15; Haas 1966, 116 no. 15; Kowal 1984a, 6-9; Diakonoff \& Neroznak 1985, 84, no. C 15; TITUS, no. 15; Orel 1997a, 76-79 no. W*-21.

$$
\begin{aligned}
& \xi \varepsilon \cup \vee \eta \tau \alpha \nu \varepsilon 1 \xi \alpha \cup \psi \circ- \\
& \delta \alpha \nu \pi \rho \circ \cup \varsigma \sigma[\varepsilon] \sigma \tau \alpha \mu- \\
& \text { हv } \alpha \nu \mu \alpha \nu \kappa \alpha \nu \alpha \mu l^{-}
\end{aligned}
$$

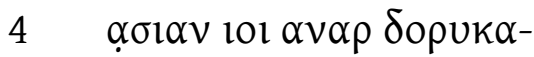

$$
\begin{aligned}
& \text { [vos ---] }
\end{aligned}
$$

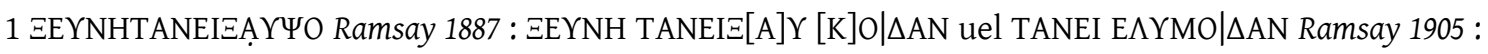

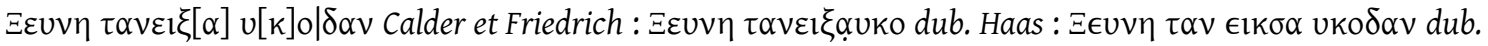

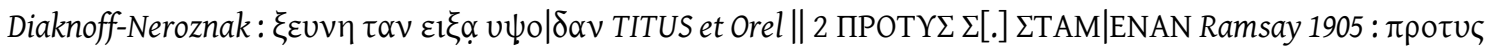
$\sigma[\varepsilon] \sigma \tau \alpha \mu \mid[\varepsilon] v \alpha v$ Calder et Friedrich : $\pi \rho \circ \tau \sigma \sigma \sigma[\varepsilon] \sigma \tau \alpha \mu$ Haas : $\pi \rho \sigma \nu \varsigma, \sigma[\epsilon] \sigma \tau \alpha \mu[\epsilon] v \alpha v$ Diaknoff-Neroznak et Orel 


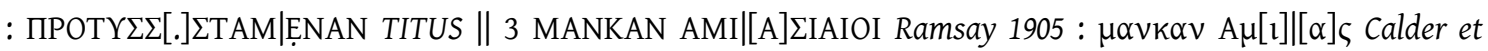

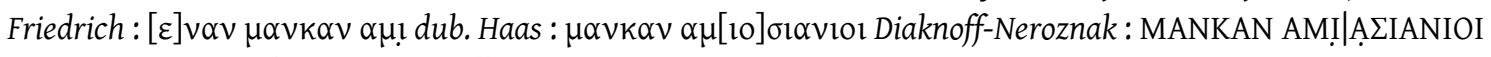

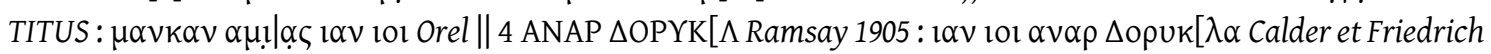

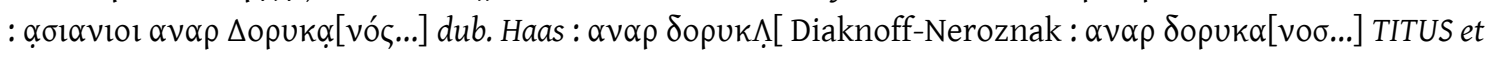
Orel.

'For Xeune this... this stele ... her husband Dorykanos'

\section{2}

Big altar $(188 \times 27 \times 35 \mathrm{~cm})$ dated to the $3^{\text {rd }} \mathrm{c}$. AD found in Nakolia and now preserved in the garden of the Eskişehir Museum (inv. no. A - 434 - 08). Its four faces are decorated with reliefs which represent one person in each of its four faces (very likely the promoter of the altar, Brogimaros, and his family) and hexametric inscriptions preserved can be read. The Phrygian text is in the Face A (under the Greek inscription) and it was incised after Brogimaros' death, as well as the other Greek inscription (sponsored by Brogimaros' son). Indeed, two different lapicides worked on it in two different times. Rectangular sigma and epsilon, cursive omega.

Hämmig 2013, 131 fn. 16 (only l. 1); Avram 2015; Obrador-Cursach 2016; de Hoz 2017, $141(1.1-4)$.

A

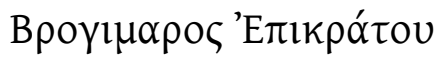

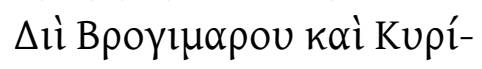

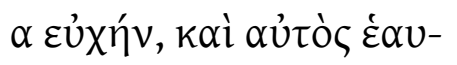
$4 \tau \tilde{\omega} \mu \nu \eta \mu o ́ \sigma u v o v$. uac.

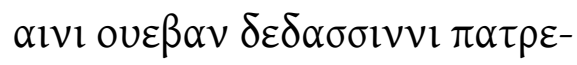

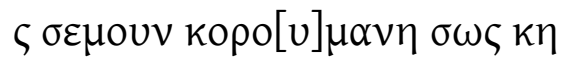

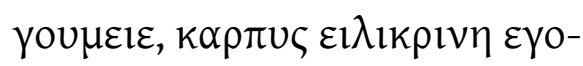
8 uvvou uac.
Relief

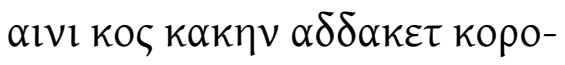

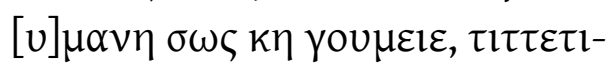

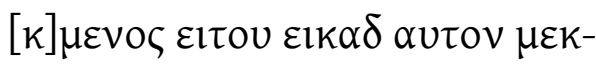
12

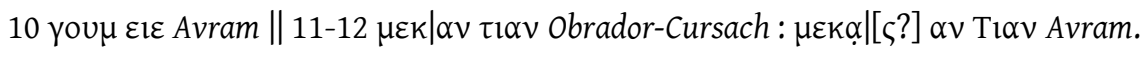

B

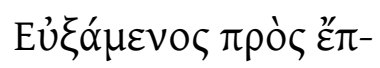

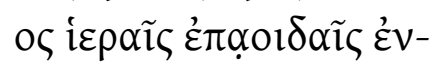

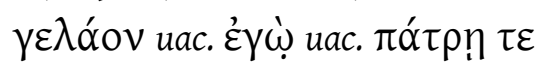

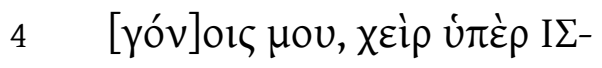

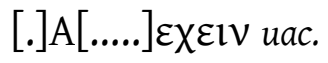

relief

$[---] \lambda \underline{\alpha} \alpha \varepsilon \delta o \eta<v>\omega \nu \mu \eta \underline{\eta} \varepsilon-$

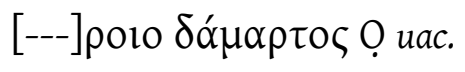




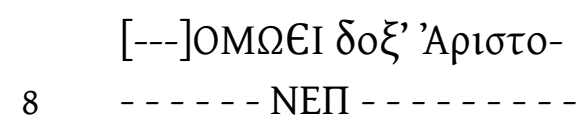

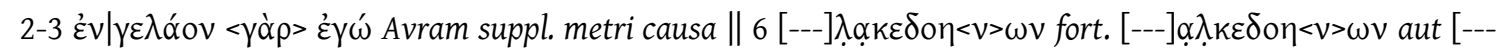

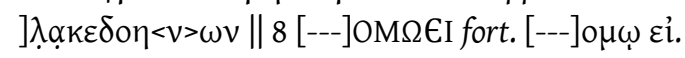

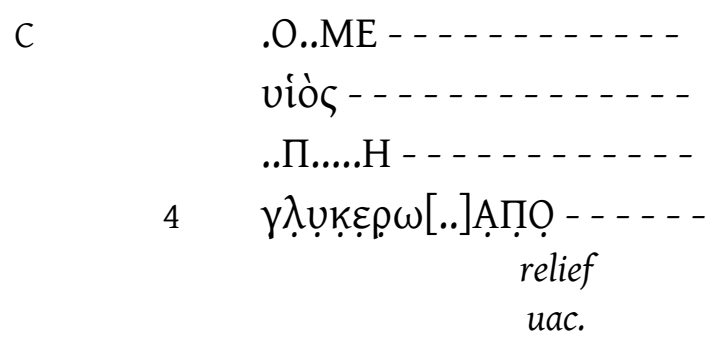

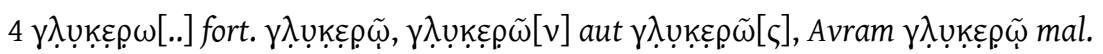

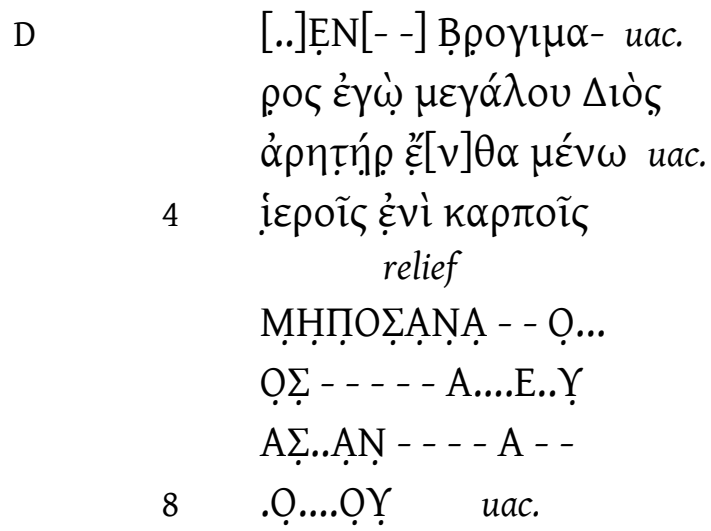

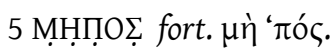

'[Greek A] Brogimaros (son) of Epikrates (dedicates) to Zeus of Brogimaros and to Kyria (his wife) a prayer; and he (dedicates) also the tomb for himself'. [Phrygian] If ' the parents put this tomb in this place, ... If anybody does harm to this place and ..., let him become accursed by the great Zeus. [Greek B] Praying for this purpose with sacred incantations I enjoyed my tribe and my children... [Greek D] I Brogimaros the priest of the great Zeus stay here among my sacred offspring...'

\section{3. Çavdarhisar (Aizanoi)}

3.1

White marble door-stele $(1.25 \times 0.60 \times 0.15 \mathrm{~m})$ with the relief of a couple. Preserved in the Çavdarhisar Museum (without inv. no.). The letters are rough. Rectangular sigma and epsilon.

Miltner 1937, col.51-52 no. 55 (photograph no. 29 and copy of the text); MAMA VII, xxviii (a); Haas 1966, 127 no. 97; Diakonoff \& Neroznak 1985, 81-82 no. B 97 (as variant of B 6); Waelkens 
1986, 96 no. 226 (Tafel 33, no. 226 and Tafel 103); TITUS, no. 97 (only Phrygian text); Orel 1997a, 118-119 no. W*-50.

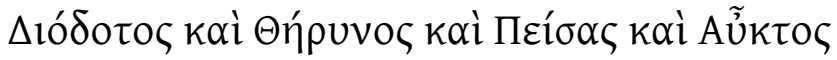

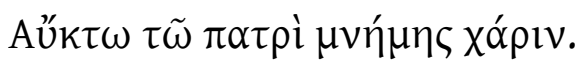

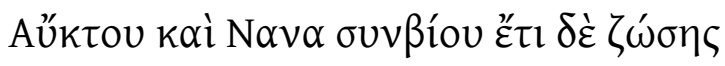

4

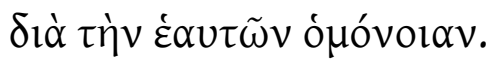

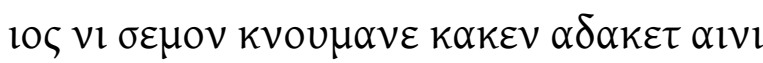

$\mu \alpha \nu \kappa \alpha, \mu \varepsilon \zeta \varepsilon<\mu \varepsilon>\lambda \omega \varsigma \kappa \varepsilon \delta \varepsilon \omega \varsigma \kappa \varepsilon \tau 1 \varepsilon \tau \imath \tau \varepsilon-$

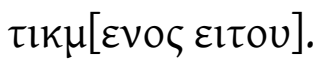

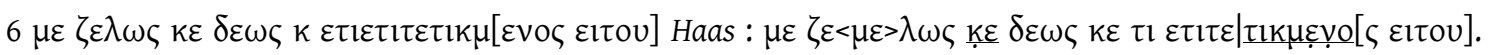

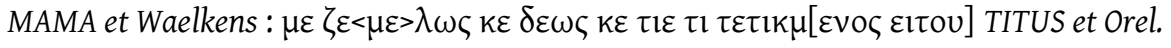

'[Greek] Diodotos and Therynos and Pisas and Auktos for their father Auktos in memory. Of Auktos and Nana, his wife, whilst she is alive, for their concord. [Phrygian] Whoever does harm to this tomb or the stele, let him [become] accurse[d] by Zeus among men and gods.'

\section{4. Üçüyük}

\section{1}

A lost funerary stele dated to the $2^{\text {nd }} \mathrm{c}$. AD and copied by Ramsay in August 1884. Lunate sigma and epsilon.

Ramsay 1887, 386-387 no. II (with copy); Ramsay 1905, col. 105-106 no. II (only the Phrygian text); Calder 1911, 165 no. II; Friedrich 1932, 128 no. B-2; Haas 1951, 4-5 no. 2; Haas 1966, 43 and 114 no. 2; Haas 1970b, 4-6 no. 2; Diakonoff \& Neroznak 1985, 78 no. B 2 (only the Phrygian text); TITUS, no. 2 (only the Phrygian text); Orel 1997a, 57- 60 no. W*-12; Brixhe 1999, 300,301 and 311 (only l. 8).

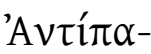

$\tau \rho \circ \varsigma \kappa \alpha i \mathrm{~B} \alpha-$

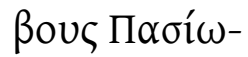

$4 \operatorname{vos} \Lambda \varepsilon \circ v \tau[i \omega]$

$\dot{\alpha} \delta \varepsilon \lambda \varphi \tilde{\omega} i \delta i ́-$

V.

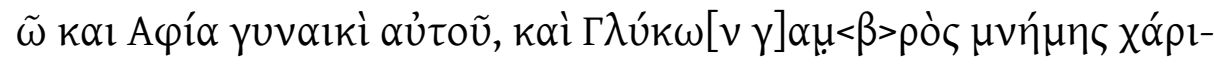

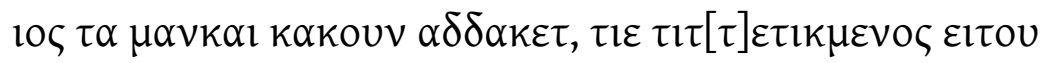

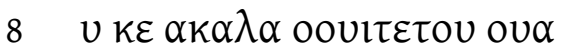




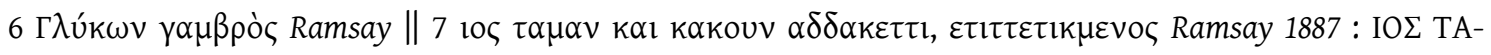

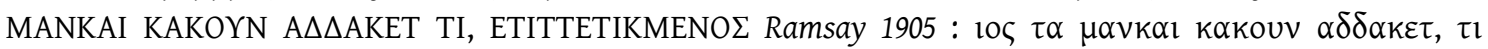

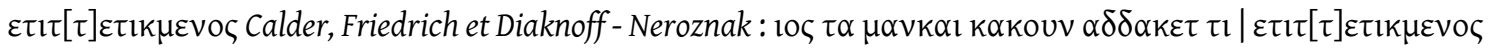

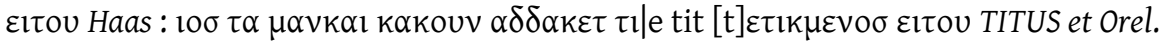

'[Greek] Antipatros and Babus (sons of) Pasion for his own brother Leontios and for Aphia, his daughter. Also, Glykon his son-in-law in memory. [Phrygian] Whoever does harm to this stele, let him become accursed by Zeus and let him not find $\alpha \kappa \alpha \lambda \alpha$.

\section{Ortaköy (formerly Alikel Yaila, Orkistos)}

\section{1}

First New Phrygian inscription published by Pococke, who only commented that it was found among broken stones $(1752,9)$.

Pococke 1752, 9 no. 3 (a copy); CIG III no. 3822e (with Pocockes's copy); Gosche 1864, 225 no. 14; Ramsay 1887, 395-396 no. XIX (with Pococke's copy); Ramsay 1905, col. 116-117 no. XIX (only the Phrygian text); Calder 1911, 174 no. XIX; Friedrich 1932, 131 no. B-19; Haas 1966, 117 no. 19; Diakonoff \& Neroznak 1985, 77 no. B 19 (only the Phrygian text as variant of B 10); TITUS 19 (only the Phrygian text); Orel 1997a, 86-87 no. W*-24.

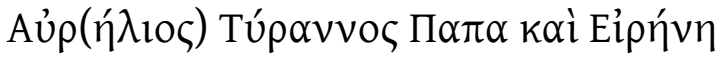

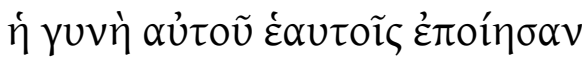

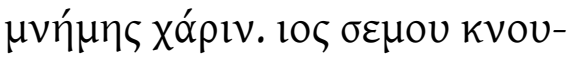

$$
\begin{aligned}
& 4 \mu \alpha v \varepsilon l k \alpha[k O V]<\alpha \delta \delta \alpha K>\varepsilon<\tau>, \tau l \tau \varepsilon \tau \varepsilon l k \mu \varepsilon v o \zeta \varepsilon l \tau o[v] \text {. }
\end{aligned}
$$

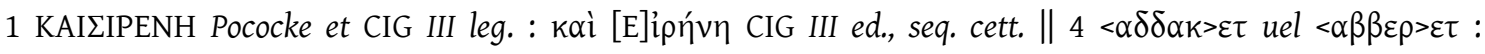

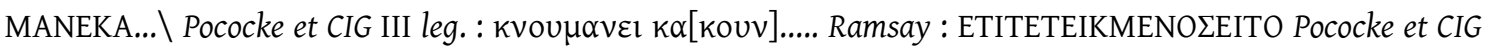

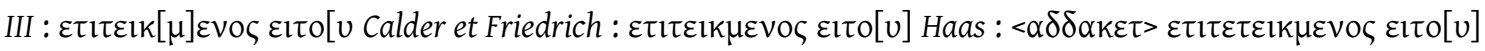

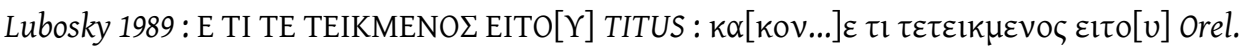

'[Greek] Aur(elios) Tyrannos Papa and Irene, his wife, made it for themselves in memory. [Phrygian] Whoever <mak>es ha[rm] to this tomb, let him become accursed.'

\section{Bağlıca}

\section{1}

"Baghlija, in the wall of the cemetery behind the tekke. Limestone stele. H., 1.82; w., $0 \cdot 84$; letters, 11. 1-7, 0.025, 11. 8,9, 0.0175. Of the inscription, 11. 1-7 are carved in a tabula ansata, 1. 8 on the border of the tabula, and 1.9 on the shaft immediately below the receding surface" (MAMA I, 216-217). Preserved in the Konya Museum. A last Greek line was added ignoring the Phrygian text, since it is related to the first Greek text. Lunate sigma and epsilon, minuscule omega. Ivy leaves delimiting the code-switching. 
MAMA I, 216-217 no. 413 (with photographs); Friedrich, 1932140 no. 88 (SEG 6.96); Gusmani 1958, 903; Haas 1966, 108-110 and 126 no. 88; Haas 1970a, 47 and 51 no. 88; Diakonoff \& Neroznak 1985, 81 no. B 88; Lubotsky 1989 b no. 88; TITUS, no. 88 (only the Phrygian text); RECAM IV, no. 96 (SEG 52.1458, only the Greek text); Orel 1997a, 109-112 no. W*-42.

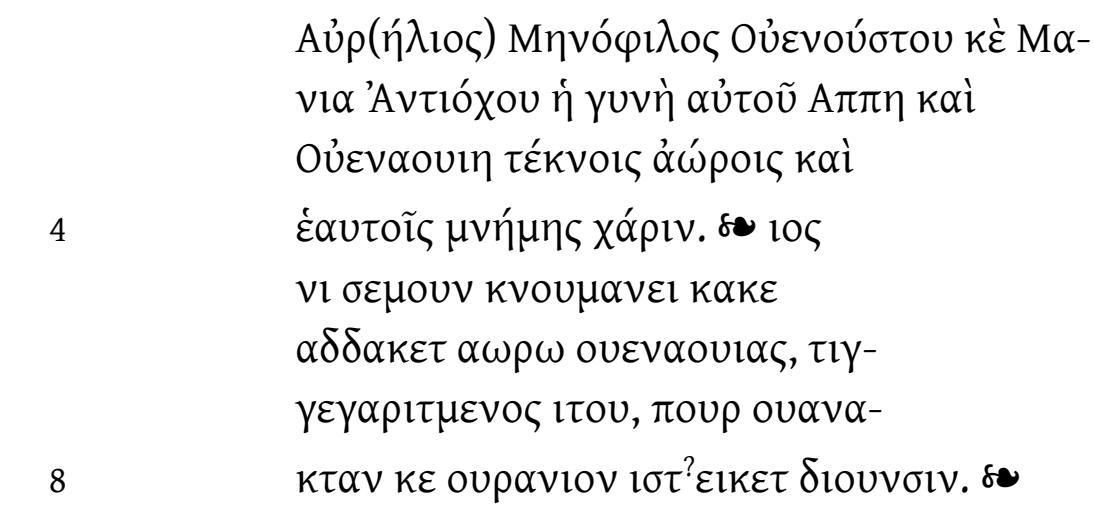

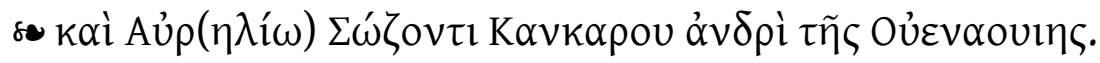

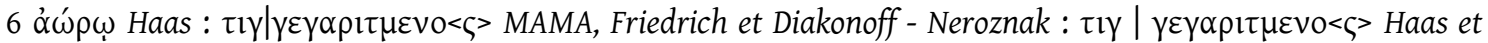

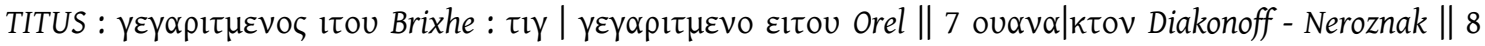

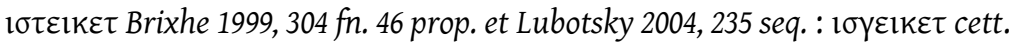

'[Greek] Aur(elios) Menophilos (the son) of Venustos and Mania (the daughter) of Antiochos, his wife, for Appe and Venavia, their untimely (dead) children in memory. [Phrygian] Whoever does harm to this tomb of the untimely (dead) Venavia, let him be at the mercy of and reckon with the heavenly king Dionysos. [Greek] Also for Aur(elios) Sozon (the son) of Kankaros, Venavia's husband.'

\title{
7. Erten
}

\section{1}

"Copied in or before 1934 by Süleyman Gökçe at Erten Yayla, in front of the Kale. Erten Yayla is between Kümbet and Hoşref Paşa Han; the stone has since disappeared" (MAMA VII 1956, xxviii).

MAMA VII, xxviii no. (c); Haas 1966, 128, no. 99; Haas 1970a, 45 no. 99; Diakonoff \& Neroznak 1985, 81 no. B 99; TITUS, no. 99; Orel 1997a, 119-120 no. W*-51.

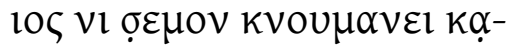 \\ k६ $\alpha \delta \alpha \kappa \varepsilon \tau, \tau l \tau \varepsilon \tau \imath k \mu \varepsilon v o \zeta$ \\ $\alpha \zeta \tau l \alpha \nu$ हุı $\tau O U, \mu \varepsilon \kappa \varepsilon$ ol

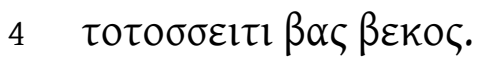

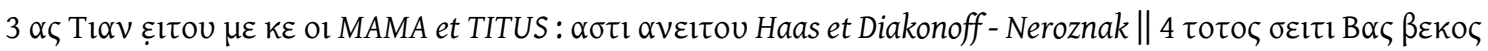

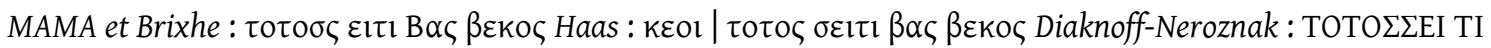

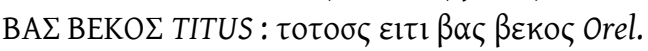


'Whoever does harms to this tomb, let him become accursed by Zeus and let Bas not give bread to him'.

\title{
7.2
}

"Erten. On a hilly ridge NW of the village, in the ancient necropolis. Inscription on slab forming part of a tomb construction of considerable size, in dark gray hard stone. The slab was originally decorated with a relief showing two doors, consisting of four panels each. Two panels only preserved, decorated each with a frontal figure, the one male, the other female. Inscription carved on flat band running along upper part. Band h. 0.235 (chipped of above, along a first line, now disappeared, spoiling top of first surviving line). Inscription broken at both ends. The two lines together h. 0.08 to 0.09; line 2 w. I.02 (extant). Letters h. 0.02 to 0.05." (Haspels 1971: 316). Lunate sigma and epsilon, minuscule omega.

Haspels 1971 I, 316 no. 45 (II, fig. 617 or 614 no. 45 photograph of a squeeze); Brixhe 1978a, 5 no. 111 (only the Phrygian text); Waelkens 1986, 128-129 no. 319 (Tafel 47 no. 319, with Haspel's Photograph); TITUS, no. 111 (only the Phrygian text); Orel 1997a, 120-121 no. W*-54.

$$
\begin{aligned}
& \text { [---] }
\end{aligned}
$$

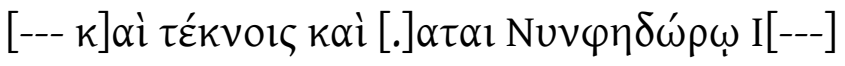

$$
\begin{aligned}
& \text { [---] 10ऽ } \alpha \delta \alpha \kappa \varepsilon \tau, \beta \alpha \varsigma \text { 101 } \beta \varepsilon \kappa o \varsigma ~ \mu \varepsilon \beta \varepsilon \rho \varepsilon \tau \text { [---] }
\end{aligned}
$$

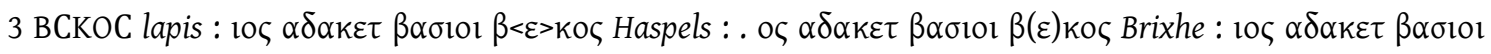

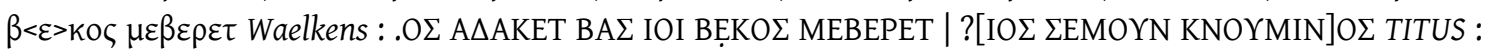

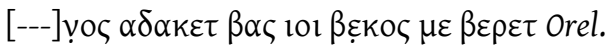

'[Greek] ... and for the children and [.]atas Nymphedoros ... [Phrygian] Whoever does (harm to this tomb), let Bas not produce bread to him'.

\section{3}

Copied by Ramsay in Hürsevpaşa in May 1881 and August 1883, also by J. R. S. Sterrett in 1883 (Ramsay 1887, 393). Lunate sigma and epsilon.

Ramsay 1887, 393-394 no. XIV (with copy); Ramsay 1905, colum. 114 no. XIV (only the Phrygian text); Calder 1911, 172 no. XIV; Friedrich 1932, 130 no. 14; Haas 1966, 116 no. 14; Diakonoff \& Neroznak 1985, 79 no. B 14 (only the Phrygian text); TITUS, no. 14 (only the Phrygian text); Orel 1997a, 325-326 no. S*-05.

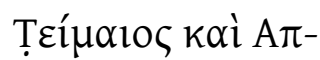

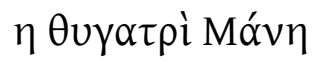

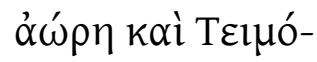

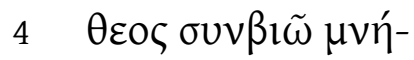

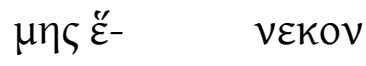




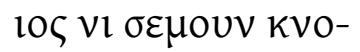

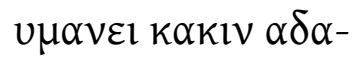

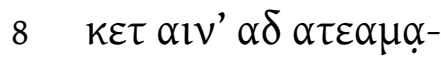 \\ $\zeta, \tau \iota \tau \varepsilon \tau \iota k \mu \varepsilon \vee O \zeta ~ \alpha-$ \\ $\sigma \tau \iota \alpha \nu[\varepsilon ı \tau o] v$.}

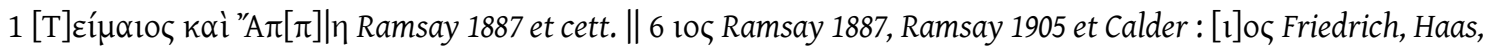

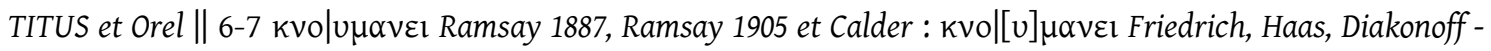
Neroznak, TITUS et Orel || 7-8 $\alpha \delta \alpha \mid \kappa \varepsilon \tau$ Ramsay 1905 et cett. : $\alpha \delta[\alpha] \mid \kappa \varepsilon \tau$ Ramsay $1887 \||| 8 \alpha \mathrm{lvl}$ fort. : $\alpha \mathrm{lv} \alpha \delta \alpha \tau \varepsilon \varepsilon \alpha \mu \alpha$

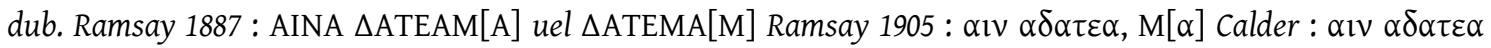

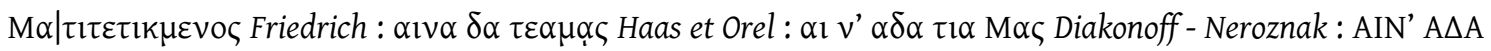

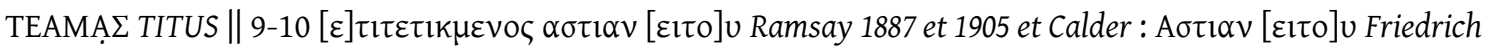

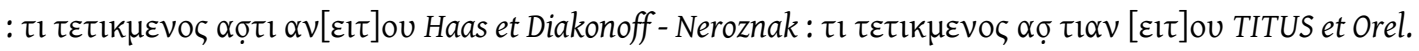

'[Greek] Timaios and Ape for (their) untimely (dead) daughter Manes and Timotheos for (his) wife in memory. [Phrygian] Whoever does harm to this tomb or to this plot, let him be accursed by Zeus.'

\section{Güney}

\section{1}

"Geinik, in a heap of building material. Bomos of white marble, broken above, worn at the edges. H., 0.34; base, 0.40; th., 0.37; letters, 0.025; h. of inscription, 0.21" (MAMA I, 212). Lunate sigma and epsilon.

MAMA I, 212 no. 405 (with photograph); Friedrich 1932, 140 no. 86; Haas 1966, 126 no. 86; Haas 1970a, 45 no. 86; Diakonoff \& Neroznak 1985, 83 no. B 86; TITUS, no. 86; Orel 1997a, 106107 no. W*-40.

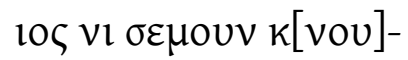

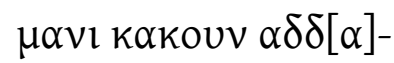

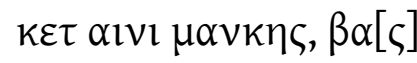

$$
\begin{aligned}
& 4101 \beta \varepsilon \kappa о \varsigma \mu \varepsilon \beta \varepsilon \rho \varepsilon[\tau] \\
& \alpha \tau \tau ı \eta ~ \kappa \varepsilon \tau \imath \tau \tau \varepsilon \tau \imath k \mu[\varepsilon]- \\
& \text { VOS ElTOU. }
\end{aligned}
$$

$3 \beta \alpha[-]$ MAMA, Friedrich et Diakonoff-Neroznak : $\beta \alpha[-] \mid \mathrm{l}$ Haas : $\beta \alpha[\varsigma]$ TITUS et Orel $\| 4$ 1ol $\beta \varepsilon \kappa \circ \varsigma \mu \varepsilon \varepsilon \varepsilon \rho \varepsilon[-]$ MAMA

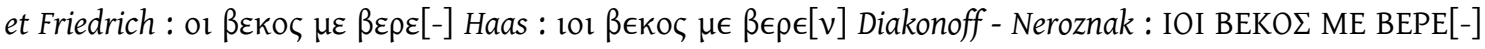

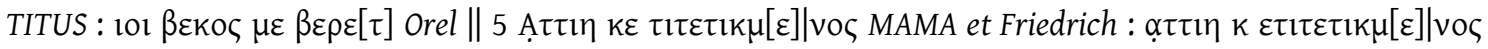

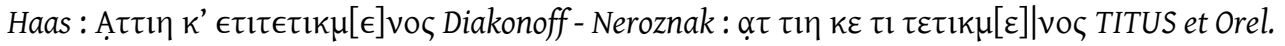

'Whoever does harm to this tomb or to this stele, let Bas not produce bread to him and let him become accursed by Zeus'. 


\section{Beyköyü}

\section{1}

"Bey Köi, in the cemetery. Block of bluish limestone, cut flat in front, sides rough-hewn, back unworked. H. 1.10; w. 0.54; th., 0.61; letters, 0.015 to 0.0225 . The inscription begins $\mathrm{m} .0 .035$ from the top of the stone, a nits h. is 0.12" (MAMA I 1928, 212). Lunate sigma and epsilon.

MAMA I, 212 no. 406 (with photograph); Friedrich 1932, 140 no. 87; Haas 1966, 126 no. 87; Diakonoff \& Neroznak 1985, 79-80, no. B 87; TITUS, no. 87 (only the Phrygian text); Orel 1997a, 107-108 no. W*-41.

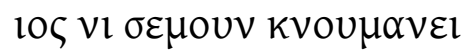

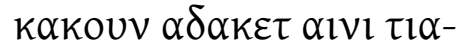

$$
\begin{aligned}
& \mu \alpha \varsigma, \alpha \tau l \propto \delta \varepsilon\llcorner\tau O v \text { ọv } \lambda \alpha \varsigma \varsigma \varepsilon
\end{aligned}
$$

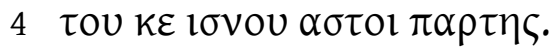

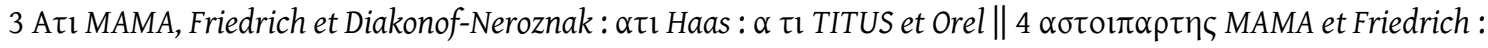

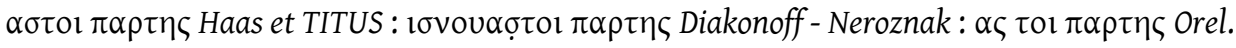

'Whoever does harm to this tomb or the plot, let him become accurse by Zeus and ...'

\section{Gökçeyayla (formerly Orhaniye and Kilise, near Malos)}

\section{1}

Found by Haspels: "Kilise-Orhaniye, in the village. Rectangular block of gray marble, built into corner of house, base buried in ground. Inscription (a) in tabula ansata. Inscription (b) above a small four- panelled "door", sculptured lower down on the stone, a little left of centre; on the two upper panels, a knocker and a key-plate. Right upper part of inscription (a) rather damaged. Stone h. from "door" to top 0.72, w. 0.54, th. 0.39. "Door" h. 0.20, w. 0.17, d. 0.015. Inscription (a) h. 0.245, w. 0.47. Letters h. 0.012 to 0.02." (Haspels 1971, 321). Lunate sigma and epsilon. The last Greek text seems to be a later addition.

Haspels 1971 I, 321, no. 56 (II, fig. 619, no. 56 photograph); Brixhe 1978, 5-6 no. 112; Waelkens 1986, 122 no. 292 (Tafel 44, no. 292 with Haspels' photograph); TITUS, no. 112 (only the Phrygian text); Orel 1997a, 121-122 no. W*-53.

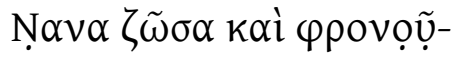

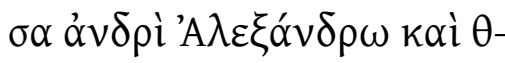

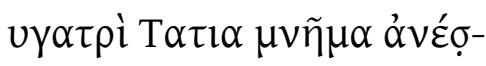

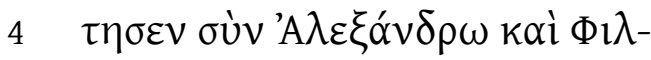

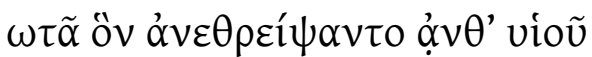

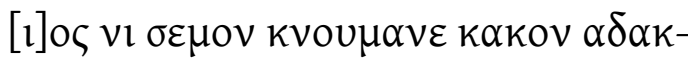

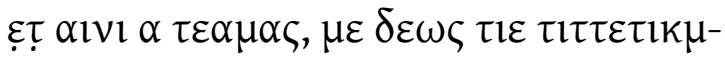

8 EVoৎ ElTOU. 


\section{'Avтíoxe,

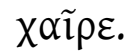

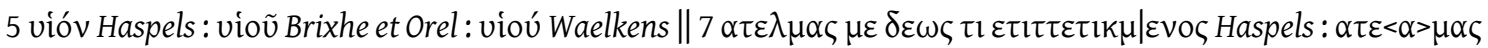

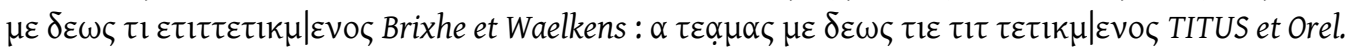

'[Greek] Nana, whilst she is alive and of sound mind, for her husband Alexandros and his daughter Tatia built this tomb with Alexandros and Philotas, whom she grew up like a son. [Phrygian] Whoever does ham to this tomb or the plot, let him become accursed by Zeus among gods. [Greek] Hail Antiochos!'.

\section{2}

"Kilise-Orhaniye. In the village, in front of a house SW of mosque. Fragmentary dark marble "door-stone", partly covered by earth. The right side seems to have been sawn off straight at some time or other, probably for re-use; more than half remains. The left side of the pediment survives, with traces of a side-akroterion. In the door-panels, knocker in left lower panel, and remains of key-plate in what is left of right upper panel. Inscription begins above "door", but here is entirely illegible as the surface is damaged; it is then carried on the upper part of the door-frame (see the transcription). "Door-stone" h. 0.68, w. below 0.46 (extant). Door panels h. 0.145, w. 0.145. Inscription w. 0.42 (extant). Letters h. 0.0I to 0.015" (Haspels 1971, 321322). Lunate sigma and epsilon.

Haspels 1971 I, 321-322, no. 57 (II, fig. 619 no. 57 with photograph of the squeeze); Brixhe 1978a, 6-7 no. 113; Waelkens 1986, 122 no. 293; TITUS, no. 113 (only the Phrygian text); Orel 1997a, 122-123 no. W*-54.

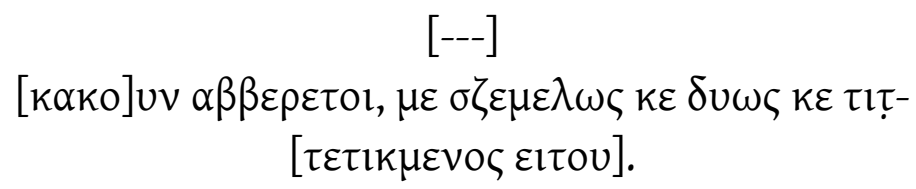

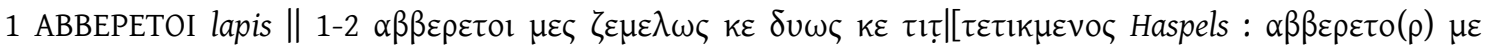

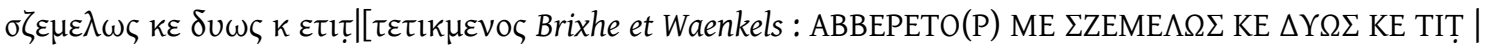

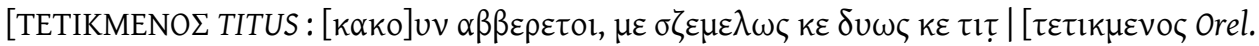

'[Whoever] brings [har]m [to this tomb], [let him be] ac[cursed] among men and gods.'

\section{Bayat (*Etsyena)}

\section{1}

Last words of a curse: a participle and the imperative verb. Copied by Ramsay in August 1884 (Ramsay 1887, 395). According to Haas (perhaps based on Friedrich 1932, 138 fn. 74), it is the same inscription of 11.3 , but Brixhe $(1999,286)$ considered that very likely they are two different inscriptions.

Ramsay 1887, 395 no. XVII (only copy); Friedrich 1932, 131 no. 17; Haas 1966, 116 no. 17 (confused with 11.3); Waelkens 1986, 214 no. 544 (confused with 11.3); TITUS, no. 17. 


\title{
$[---. . \mu \varepsilon]$ yos $\varepsilon ı \tau o v$.
}

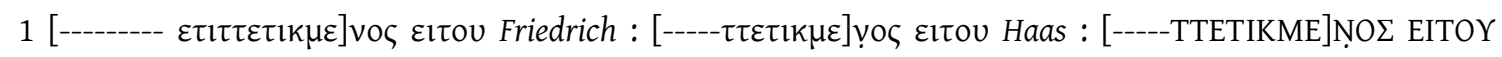
TITUS : -] yos EITov Brixhe.

$$
\text { ‘... let him be [---]ed' }
$$

\section{2}

Found in a fountain, "the following inscription was clearly cut in small well-formed letters, but some zealous Kizilbash (Bayat is a village of heretics) has taken the trouble to deface every line with a chisel. I made an impression in the hope that some elucidative text might hereafter be discovered. There were originally several more lines at the top: 10 is complete and ends the inscription" (Ramsay 1887, 395). Rectangular sigma and epsilon.

Ramsay 1887, 395 no. XVIII (with copy); Ramsay 1905, col. 110 no. XVIII (the three last lines); Calder 1911, 174 no. XVIII (the three last lines); Calder 1926, 26-27 no. XVIII (revision of some lectures); Friedrich 1932, 131, no. 18 (without lines 1-3, 5 and 6); Haas 1951, 9-10 no. 18; Haas 1966, 85-87 (with copy) and 116-117 no. 18 (p. 99 copy); Haas 1970b, 9-10 no. 18; Diakonoff \& Neroznak 1985, 84-85 no. C 18; TITUS, no. 18; Orel 1997a, 79-86 no. W*-23; Hämmig fthc. a. No. 18.

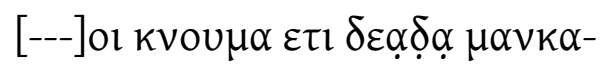

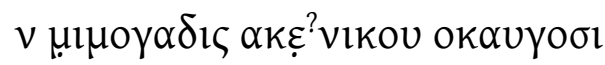 \\ $\mu 1 \delta \alpha \kappa \alpha \zeta \delta \alpha \delta \circ v \lambda \varepsilon v \kappa ı \omega \iota \delta \alpha \kappa \alpha \rho$

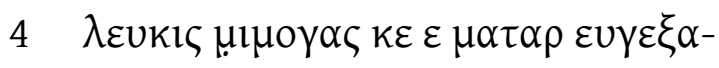

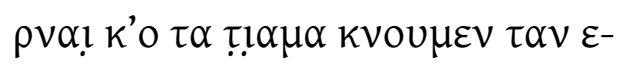

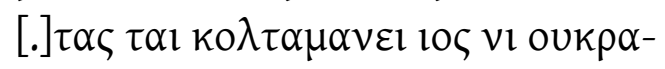

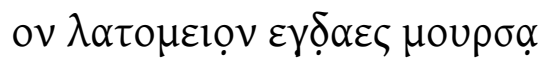

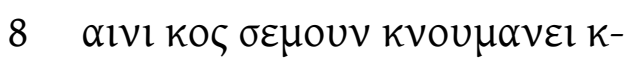

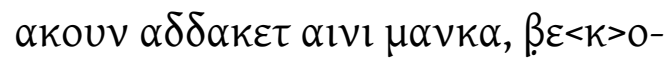

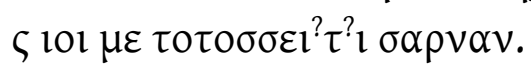

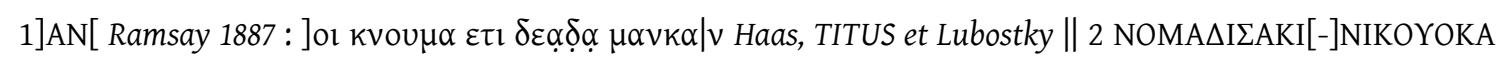

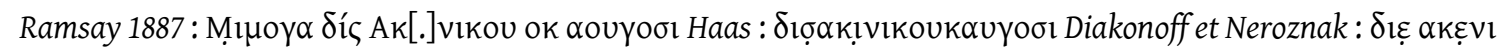

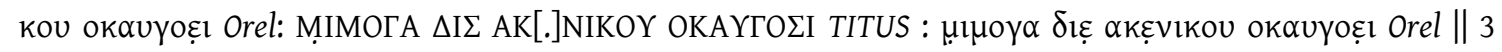

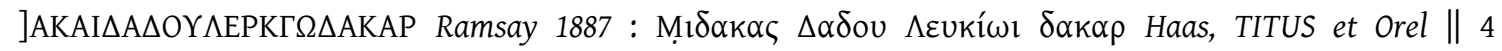

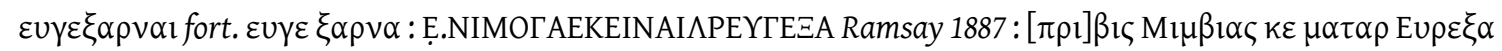

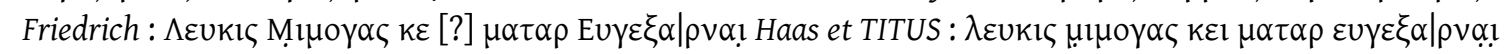

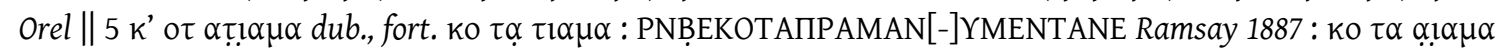

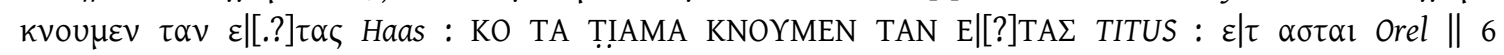

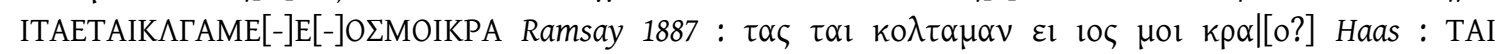

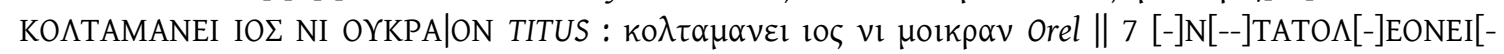

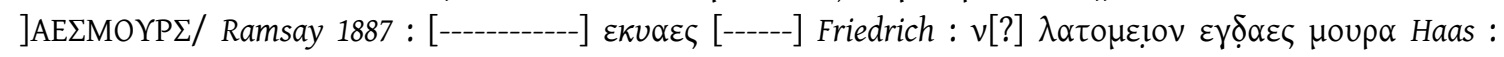

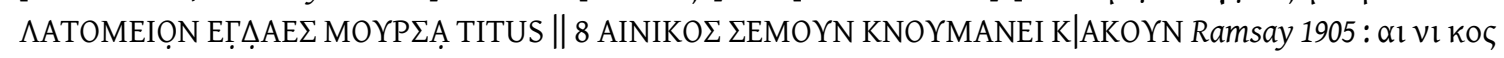

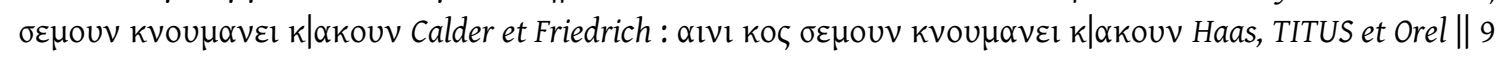


A $\triangle$ AKET AINI MANK(A) AKEO Ramsay $1905: \alpha \delta \delta \alpha \kappa \varepsilon \tau$ alvı $\mu \alpha v \kappa \alpha$ ḄEO Calder et Friedrich : $\alpha \delta \delta \alpha \kappa \varepsilon \tau$ alvı

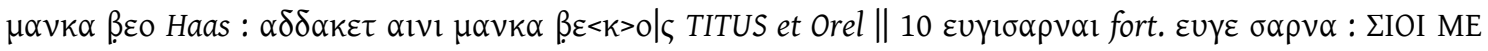

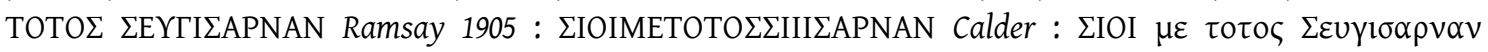

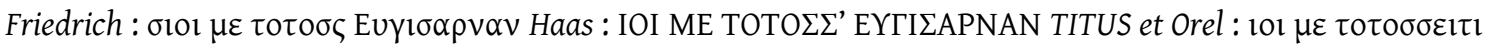

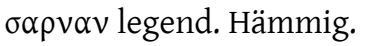

'[L. 8-10] If someone does harm to this tomb or to the stele, let Sarnan not give him bread'

\section{3}

Copied by Calder in 1912, "above the triangular pediment of a doorstone" (Calder 1926, 23). Lunate sigma and epsilon. This inscription was confused with 11.1 by Haas (1966, 116 no. 17 and 124, no. 74$)$. However, Brixhe $(1999,286$.$) argued that 11.1(17)$ and $11.3(74)$ are two different inscriptions.

Calder 1926, 23 no. LXXIV; Friedrich 1932, 138 no. 74; Haas 1966, 116 no. 17 and 124, no. 74 (redirecting to his no. 17 = 11.1); Diakonoff \& Neroznak 1985, 77 B 17 (as variant of B 10); Waelkens 1986, 214 no. 544 (also confused with 11.1); TITUS, no. 17 (following Haas); Orel 1997a, 79 no. W*-22; Brixhe 1999, 286.

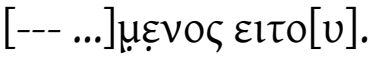

1 ]

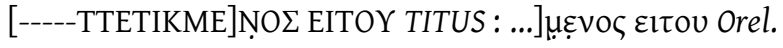

$$
\text { '... let him be [---]ed.' }
$$

\section{Akpinar}

\section{1}

Fragment of a door-stele $(0,135$ x 0,51 x 0,24 m, letters 0,015, Brixhe \& Drew-Bear 1997, 92). Now preserved in the Afyon Museum (inv. no. E 9991). Lunate sigma and epsilon.

Brixhe \& Drew-Bear 1997, 91-95 no. IV (with photograph); Ligorio \& Lubotsky 2013, 182 no. 121 (only the number is given to it).

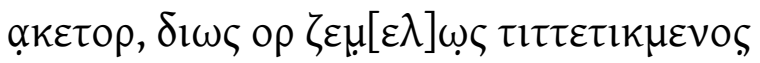

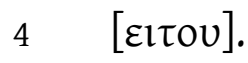

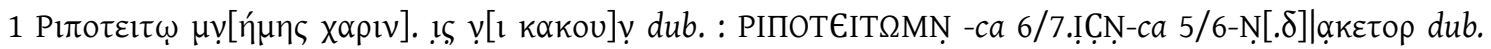

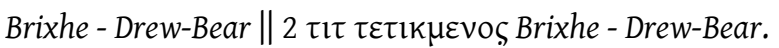

'[Greek] ... for Rhipotitos in memory in memory. [Phrygian] Whoever [ma]kes har[m], let him be accursed (in the sight of) gods and men.' 


\section{3. Özburun}

\section{1}

Gray basalt stele-door $(1,25 \times 1,48 \times 0,50 \mathrm{~m}$; letters 0,03$)$ dated to $190 \mathrm{BC}$ because of its typology (Drew-Bear \& Lochman 1996, 123). It was found in a fountain from Kaklık Mevkii. Some reliefs of tools were engraved on the panels of the door. Lunate sigma and epsilon.

Drew-Bear \& Lochman 1996, 123 (Levha / Pl. XXII with photograph); Brixhe \& DrewBear 1997, 95-98 no. V (with photographs); Ligorio \& Lubotsky 2013, 182 no. 122 (only enumerated).

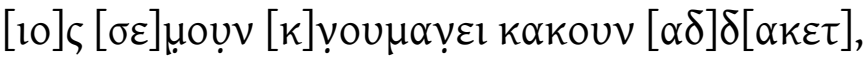

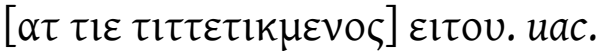

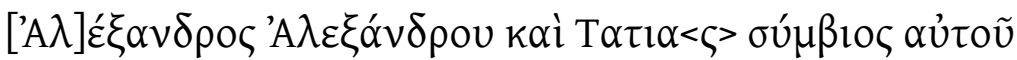

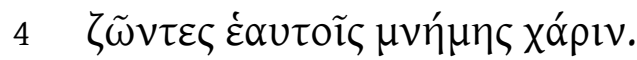

$1[\alpha \delta] \delta[\alpha \kappa \varepsilon \tau] d u b .:--\kappa v] \operatorname{ou} \mu \alpha v[\varepsilon \kappa \alpha \kappa]$ ouv [ ] Drew-Bear-Lochman: [ ][---] [----] Brixhe

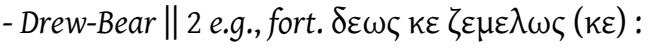

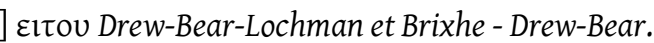

'[Phrygian] [Wh]oever [ma]k[es] harm to this tomb, let him be [accursed by Zeus]. [Greek] [Al]exandros (the son) of Alexandros and Tatias, his wife, whilst they are alive, made it for themselves in memory.'

\section{Göynük}

\section{1}

Fragment of an inscription engraved on a door-stele found in a wall of the oda by Calder $(1926,22)$.

Calder 1926, 22-23 no. LXXIII; Friedrich 1932, 138 no. 73; Haas 1966, 124 no. 73; Diakonoff \& Neroznak 1985, 82 no. B 73 (only the Phrygian text); Waelkens 1986, 203 no. 505; TITUS, no. 73; Orel 1997a, 105-106 no. W*-39.

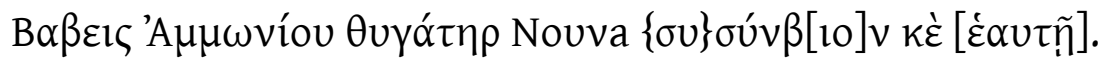

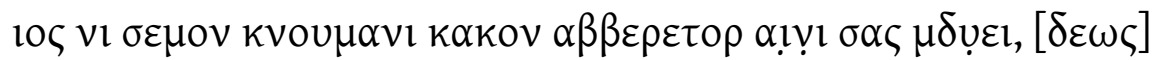

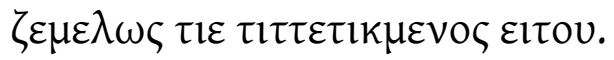

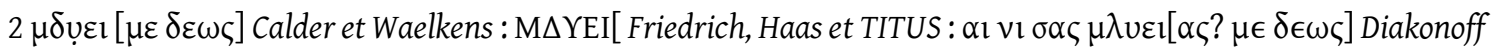

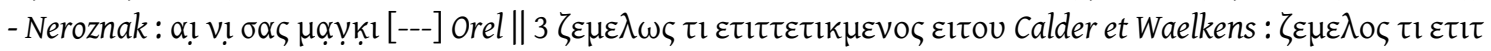

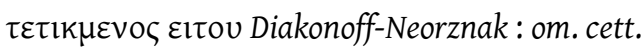

'[Greek] Babis the daughter of Ammonios for Nunas, her husband, and [for herself]. [Phrygian] Whoever does harm to this tomb and to this $\mu \delta$ vel, let him be made accursed (by) Zeus (in the sight of) [gods] and men'. 


\title{
15. Sopalının köprü
}

\section{1}

Door-stele $(0,81 \times 0,55 \mathrm{~m}$; letters 0,015$)$ found in Sopalının köprü, in the south of the Seyitler Gölü (not far from Gezler Köyü, Brixhe \& Drew-Bear 1997, 86-87). Some relieves were engraved on the panels. Lunate sigma and epsilon.

Brixhe \& Drew-Bear 1997, 86-91 no. III (with photographs); Ligorio \& Lubotsky 2013, 182 no. 120 (only enumerated).

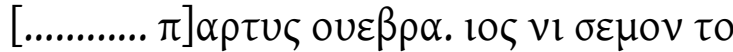 \\ $[\kappa v o v \mu \alpha]$ e $\varepsilon \alpha \kappa o v \alpha \delta \delta \alpha \kappa \varepsilon \tau \alpha l v^{\prime} \alpha \tau \varepsilon \alpha \mu \alpha, 1 \zeta \tau 1 \varepsilon \tau l^{-}$

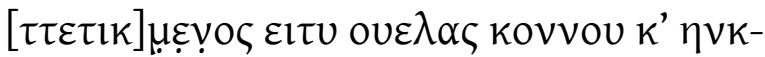 \\ $4 \quad[\ldots . . .$.$] ]$
}

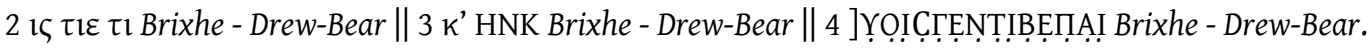

'... Whoever does harm to this [tom]b or to this plot, let him be [accur]sed by Zeus...'

\section{Gezler Köyü}

\section{1}

White marble stele with a pediment in the top ( $93 \times 36 \times 12,5 \mathrm{~cm}$ ) identified by Brixhe in Afyon Museum (without inv. no.). The 14 lines of this inscriptions are eroded in both margins. It is dated to the $1^{\text {st }}$ or beginning of the $2^{\text {nd }} \mathrm{C}$. $\mathrm{BC}$ because of palaeographic reasons (considered one of the oldest NPhr. texts by Brixhe \& Neumann 1985, 161). Classic letters without apices but rectangular sigma.

Brixhe \& Neumann 1985, 161-184 (pl. I-III with photographs and copy); Lubotsky 1993a, 128 (only 1. 1-4); TITUS, no. 116; Orel 1997a, 125-135 no. W*-57.

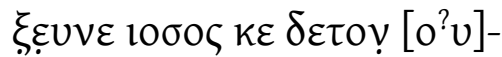
$\psi \circ \delta \propto \alpha v \kappa \varepsilon \tau \alpha \underline{\alpha} \sigma \alpha u v \alpha \mu \alpha \nu[?]$

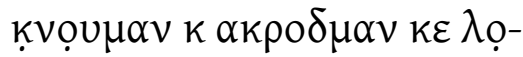

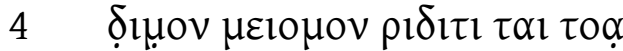
$\mu \varepsilon$ o

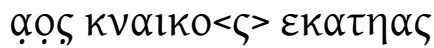

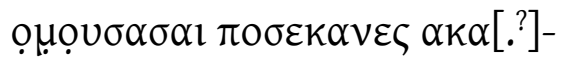

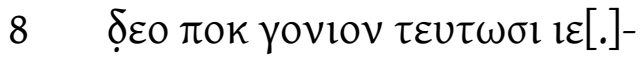
you

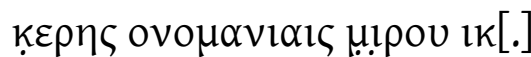
$\kappa v \alpha i \kappa \alpha \nu \varepsilon \delta \alpha \varepsilon \varsigma, 1 \zeta \alpha \rho \gamma \mu \varepsilon v \alpha[. ?]$

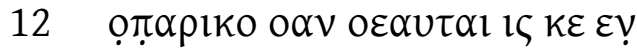

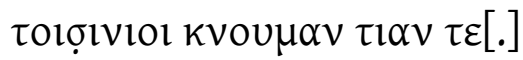

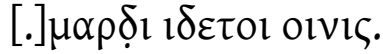




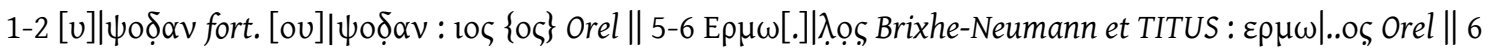

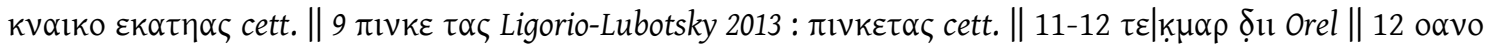
$\varepsilon \alpha u \tau \alpha 1$ Brixhe-Neumann.

\title{
17. Afyonkarahisar (Akroenos)
}

\section{1}

Copied by Seetzen (according to CIG III, 10). It is said to be engraved in a little altar. Only the beginning of the imprecative protasis remains of the Phrygian text.

CIG III, 10 no. 3880 (with copy but only edition of the Greek text); Ramsay 1887, 388 no. IV bis; Calder 1911, 167, IV (bis); Friedrich 1932, 129 no. 4 bis; Haas 1966, 114 no. 4bis; Diakonoff \& Neroznak 1985, 77 no. B 4 bis (only the Phrygian text as variant of B 10); TITUS, no. 4 b (only the Phrygian text); Orel 1997a, 65-66 no. W*-15.

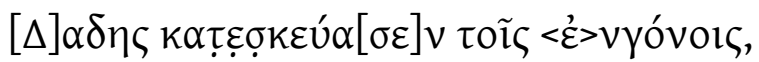 Móv<smiles>C1[AlH][AlH]1</smiles>

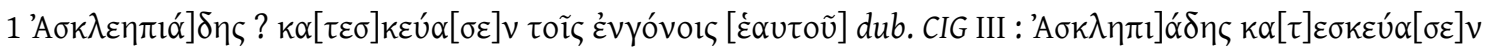

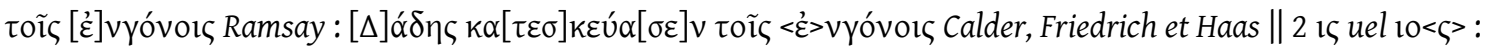
10 Ramsay : $10<\varsigma>$ Calder et Friedrich : 10 Haas et TITUS : 1५ uel to Diakonoff-Neroznak: $10 \mathrm{v1}[\sigma] \varepsilon \mu o v$ Orel.

'[Greek] Dades built (it) for her children, Manes and Zotikos. [Phrygian] Whoever [does] ha[rm] to this tom...'

\section{2}

Inscription dated to the $2^{\text {nd }}$ c. BC. Copied by Ramsay in November $1881(1887,387)$.

Ramsay 1887, 387 no. III (with copy); Ramsay 1905, col. 106 no. III; Meister 1909, 317318; Calder 1911, 166 no. III; Friedrich 1932, 129 no. 3; Haas 1966, 114 no. 3; TITUS, no. 3; Diakonoff \& Neroznak 1985, 81-82 no. B 3 (as variant of B 6); Waelkens 1986, 198 no. 490; Lubotsky 1998, 418 no. 3; Orel 1997a, 60-61 no. W*-13.

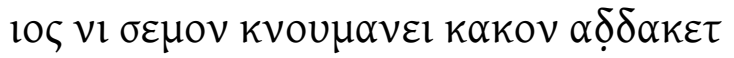

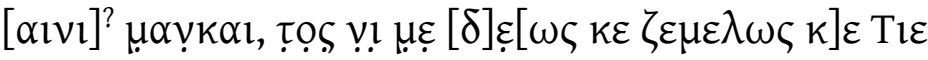 \\ $\tau ı \tau \tau \varepsilon \tau ı k \mu-$ \\ $4 \quad$ EVOৎ EITOU.
}

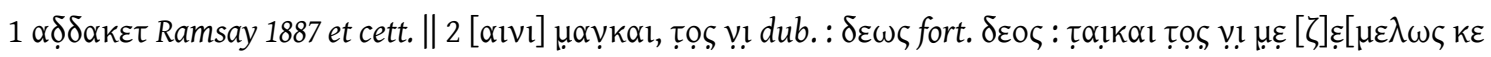

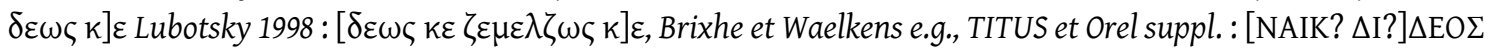
- ZIME $\Lambda \Omega \Sigma$ [12 letters] ETI Ramsay 1905 coni. : $\mu] \alpha[v] \kappa \alpha[v, \tau] \circ \varsigma[v 1 \mu \varepsilon \delta 10 \varsigma \kappa \varepsilon \zeta \varepsilon \mu \varepsilon \lambda \omega \varsigma] \varepsilon \tau \imath$ Calder coni. et

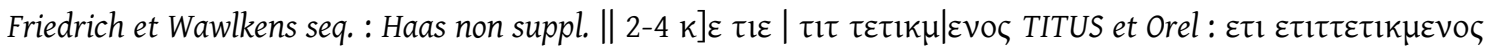




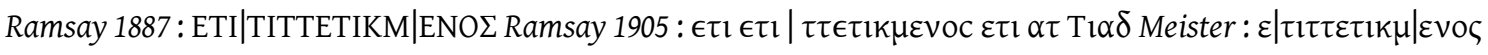

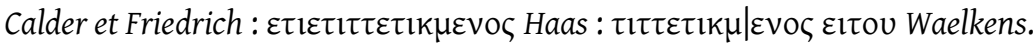

'Whoever does harm to this tomb [or] stele, let him be accursed by Zeus in the sight of [g]o[ds and men].'

\section{3}

Copied by Hamilton in 1836 and, later by Ramsay in November 1881. It was found "in the Armenian burial-ground" of Ayfon (according to Hamilton 1842, 432).

Hamilton 1842, 432 Appendix V no. 165 (with copy); CIG III 3882c (only a drawing based on Hamilton); Mordtmann 1862, 15 no. 1 (pl. A); Gosche 1864, 225 no. 11; Ramsay 1887, 389-391, VII; Ramsay 1905, col. 10 no. VII; Calder 1911, 168 no. VII; Friedrich 1932, 130 no. 7; Haas 1966, 115 no. 7; TITUS, no. 7; Orel 1997a, 70-71 no. W*-18.

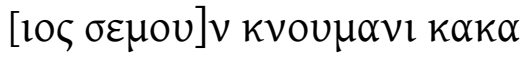 $[\alpha \delta \delta \alpha \kappa] \varepsilon v, \delta \varepsilon \circ \varsigma \kappa \varepsilon \zeta \varepsilon \mu[\varepsilon \lambda \omega \varsigma \kappa \varepsilon]$

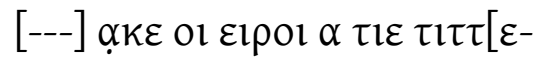

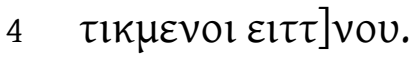

$1 \sigma \varepsilon \mu \mathrm{o}] v$ fort. : $\kappa \alpha \kappa \alpha[v$ Ramsay et Calder: $\kappa \alpha \kappa \alpha[$.$] Haas et TITUS : \kappa \alpha \kappa \alpha[v]$ Orel $\| 2$ ZEMI.. Hamilton, CIG III,

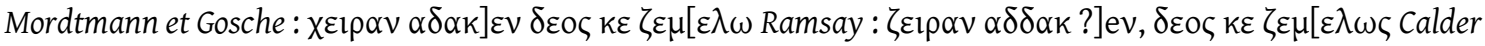
$: \alpha] \varepsilon v \delta \varepsilon \circ \zeta \kappa \varepsilon \zeta \varepsilon \mu[\varepsilon \lambda \omega]$ Haas et TITUS : $\alpha \beta \beta \varepsilon] \rho \varepsilon v \delta \varepsilon \circ \zeta \kappa \varepsilon \zeta \varepsilon \mu[\varepsilon \lambda \omega \varsigma]$ Orel $\| 3$ AKEOIEIPOIATIETII. Mordtmann

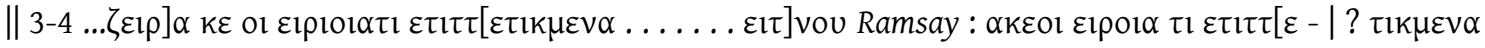

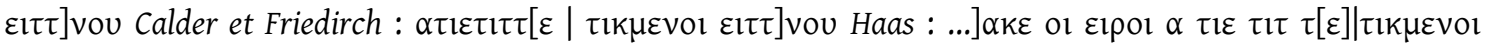

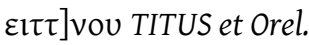

'[Whoever] does harms [to thi]s tom, (in the sight of) gods and $\mathrm{m}[\mathrm{en}]$... and let his eipor b[e accursed] by Zeus.'

\section{4}

"Afion Karahisar, in the garden of the Primary School. Limestone stele with a male and a female figure standing above and uninscribed panel. Beside the male figure, a stylus-case; beside the female figure, a keyplate with keyhole (symbolising a doorstone). On either border, a rope festoon with tassels. H. 1.18; w. 0.84; th. (top) 0.32, (shaft) 0.26; letters, 0.015 to 0.02 . The inscription is carved on the upper moulding" (MAMA IV 1933: 6). Lunate sigma and epsilon.

MAMA IV, 6 no. 16 (Pl. 13); Haas 1966, 126 no. 90; Diakonoff \& Neroznak 1985, 77 no. B90 (only the Phrygian text as variant of B 10); Waelkens 1986, 195 no. 484 no. 484 (Tafel 74); TITUS, no. 90; Orel 1997a, 112-113 no. W*-44.

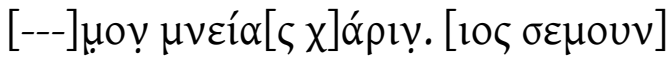

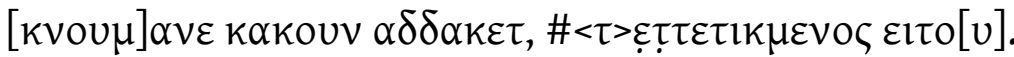

$2 \alpha \delta \delta \alpha \kappa \varepsilon \tau\{\varepsilon \tau\} \tau \varepsilon \tau 1 \kappa \mu \varepsilon v o \varsigma$ Orel.

'[Greek] ... in memory. [Phrygian] [Whoever] does harm [to this tom]b, let him b[e] accursed.' 


\title{
17.5
}

White marble door-stele ( $45 \times 78 \times 26,5 \mathrm{~cm}$ ) preserved in the Afyon Museum (without inv. no.), found "in the yard of the Secondary School" (MAMA IV, 6). Rectangular sigma and epsilon.

MAMA IV, 6 no. 17; Haas 1966, 126 no. 91; Diakonoff \& Neroznak 1985, 83 no. B 91 (only the Phrygian text); Waelkens 1986, 191 no. 469 (Tafel 70 no. 469); TITUS, no. 91 (only the Phrygian text); Orel 1997a, 113-114 no. W*-45.

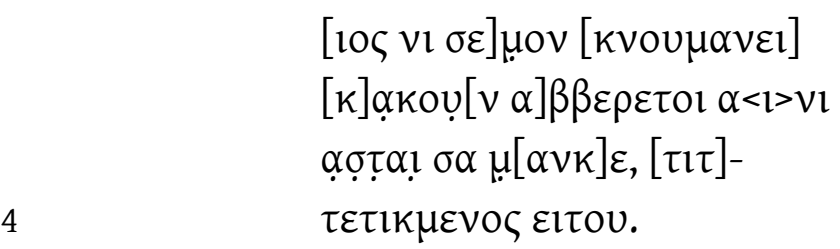

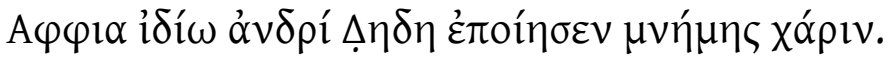

2 ABBEPETOIANI lapis : $\alpha] \beta \beta \varepsilon \rho \varepsilon \tau$ เ $\alpha<1>v 1$ MAMA : $\alpha] \beta \beta \varepsilon \rho \varepsilon \tau$ ol $\alpha[1]$ vi Haas et TITUS : $\alpha] \beta \beta \varepsilon \rho \varepsilon \tau 0<\rho>\alpha<1>v 1$

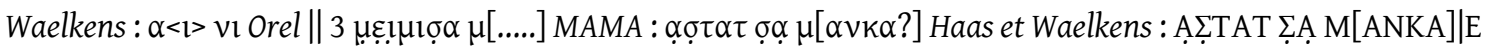

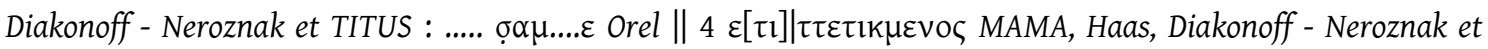

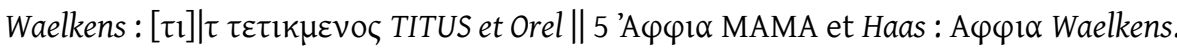

'[Phrygian] [Whoever] brings [h]ar[m to th]is [tomb] or $\alpha \sigma \tau$ Ț $\alpha$ this s[tel]e, let him be accursed. [Greek] Appia made (it) for her own husband Dedes in memory.

\section{6}

Broken door-stele $(0,97 \times 0,75 \times 0,25 \mathrm{~m})$ found in 1987 in the north of Afyon, during the scoring of the industrial area called Çapak Çayırı. In the light of its iconography, it has been considered to come from İscehisar (Dokimeion). It was later reused and now it is preserved in the Afyon Museum (inv. no. 10102). Relieves of a couple and some objects engraved on the doors. Lunate sigma and epsilon.

Brixhe \& Drew-Bear 1997, 80-86 no. II (with photograph); Ligorio \& Lubotsky 2013, 182 no. 119 (only enumerated).

\author{
$[---]$

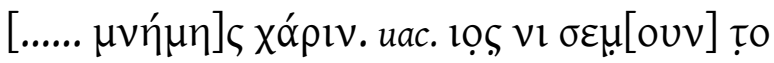

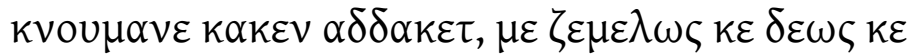

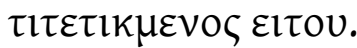

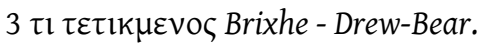


'[Greek] ... in [menor]y. [Phrygian] Whoever does harm to th[is] tomb, let him be accursed in the sight of men and gods.'

\title{
18. Sülümenli (Augustopolis)
}

\section{1}

Inscription copied by Ramsay in 1881 and in 1884. Lunate sigma and epsilon, cursive omega.

Ramsay 1882, 143; Ramsay 1887, 387-388 no. IV (with copy); Ramsay 1905, col. 106 no. IV; Calder 1911, 166 no. IV; Friedrich 1932, 128 no. 4; Haas 1966, 114 no. 4; Diakonoff \& Neroznak 1985, 81-82 no. B 6; TITUS, no. 4 (only the Phrygian text); Orel 1997a, 62-65 no. W*-14.

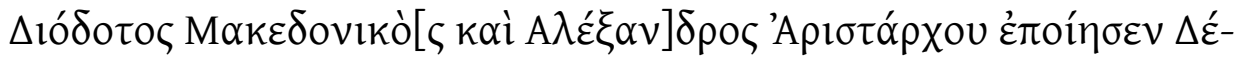

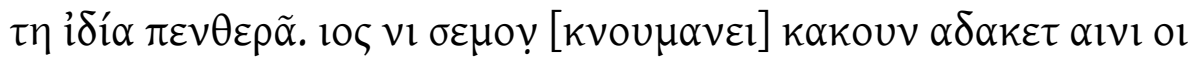

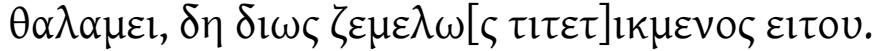

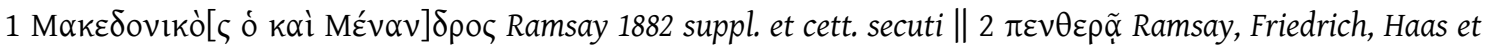

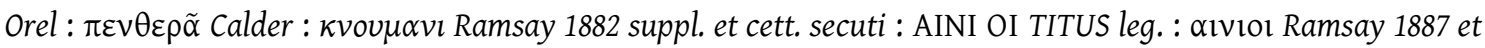
1905 et Haas : $\alpha \mathrm{lv}$ ol Calder et Friedrich : $\alpha \mathrm{l}$ vi or Orel $\| 3 \zeta \varepsilon \mu \varepsilon \lambda \omega[\sigma \tau \imath \tau \tau \varepsilon \tau] \iota \kappa \mu \varepsilon v o \sigma$ Lubostsky et Orel suppl. :

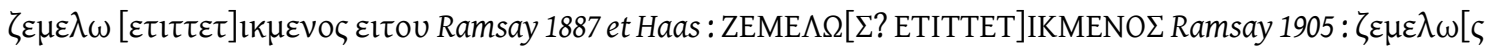

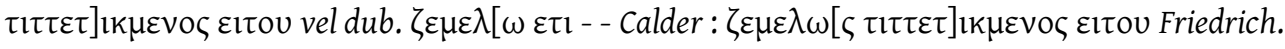

'[Greek] Diodotos Macedonia[n and Alexan]dros (the sons) of Aristarkhos made it for Dete, their own mother-in-law. [Phrygian] Whoever does harm to this [tomb] or its (funerary) chamber, let him be [accu]rsed among gods (and) men.'

\section{2}

Inscription found and read by Hamilton. Cursive omega, lunate sigma and epsilon.

Hamilton 1842 II, 477 no. 376 (only copy); CIG III, Add., no. 3883c; Mordtmann 1862, 15 no. 2 (pl. A, no. 122, copy based on Hamilton); Gosche 1864, 225 no. 15; Ramsay 1887, 388-389 no. V (with copy); Ramsay 1905, col. 108-109 no. V (with copy); Calder 1911, 167 no. V; Friedrich 1932, 129 no. 5; Haas 1966, 115 no. 5; Haas 1970a, 48 and 60 no. 5; Diakonoff \& Neroznak 1985, 82 no. B 75 (only the Phrygian text); Strubbe 1997, 178 no. 257 (only the Greek text); TITUS, no. 5 (only the Phrygian text); Orel 1997a, 66-68 no. W*-16.

\author{
$\Lambda \alpha \operatorname{I\mu \varepsilon vo\varsigma ~\alpha ̉v\delta \rho í~} \gamma \lambda v \kappa v \tau \alpha ́ \tau \omega \mathrm{Z} \omega \tau \tau[\kappa] \tilde{\omega} \mu-$

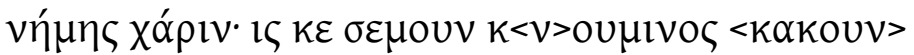

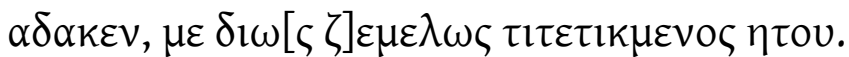

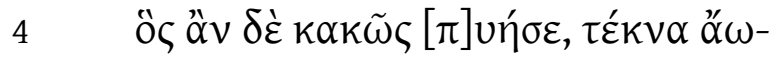

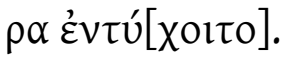

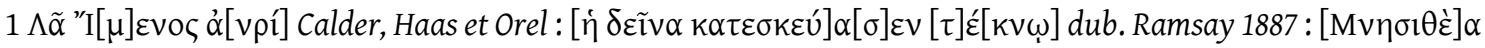

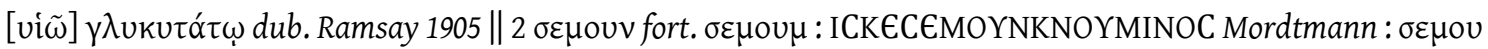




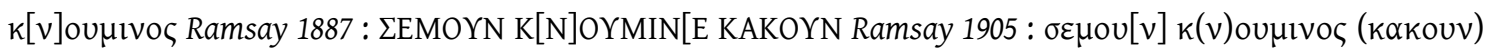

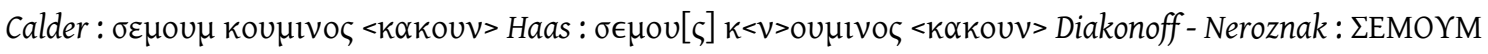

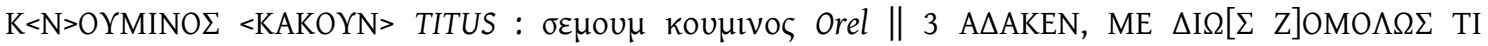

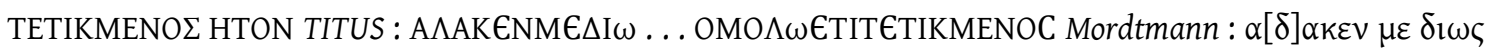

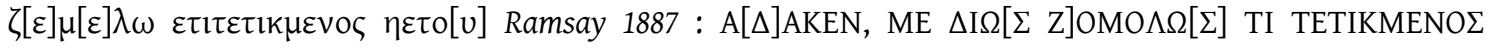

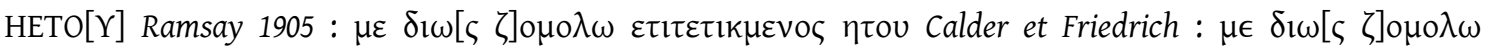

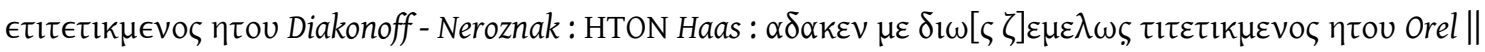

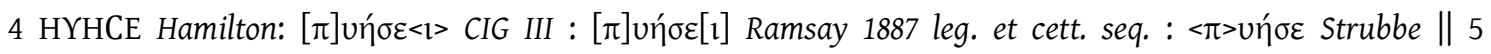

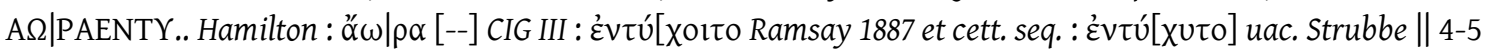
Orel om.

'[Greek] La (the daughter) of Iman for her dearest husband Zoti[k]os in memory. [Phrygian] And whoever does <harm> to this tomb, let him be accursed in the sight of god[s (and) m]en. [Greek] Whoever does harm (to it), let him have children untimely (dead).'

\section{3}

Inscription copied by Ramsay in August 1884, found "beside Surmeneh, on one of the circle of stones ( $\chi \rho \eta \pi i ́)$ which surrounded a small tumulus. There seem to have been in this neighbourhood many small tumuli, built all in the same way with a low circular wall enclosing and holding together a mound of earth" (Ramsay 1887, 389). The letters were eroded when copied. Lunate sigma and epsilon.

Ramsay 1887, 389 (with copy), VI; Ramsay 1905, col. 109-110 no. VI; Calder 1911, 167167 no. VI; Friedrich 1932, 129 no. 6; Haas 1951, 6-7 no. 6; Haas 1966, 115 no. 6; Haas 1970b, 6-7 no. 6; Diakonoff \& Neroznak 1985, 81-82 no. B 6; TITUS, no. 6; Orel 1997a, 68-69 no. W*-17.

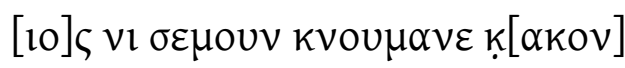 $\alpha \beta \beta \varepsilon \rho \varepsilon \tau \alpha \tau$ vov. $\mu$ ov [pov]v, $\tau \circ \zeta \vee \imath \mu \varepsilon \zeta \varepsilon \mu \varepsilon \lambda \omega \kappa \varepsilon \delta \varepsilon \circ \zeta$

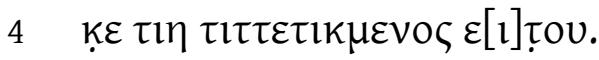

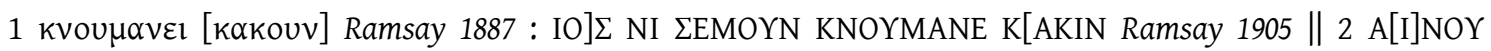
[M.]MONK[KA]N TITUS : $\alpha[1] v o v[v] \mu o[v \rho \alpha]$ tos Ramsay $1887:$ A[I]NOY[N] M[A]NK[A]N.[AY Ramsay 1905 : $\alpha[1] \operatorname{vov}[\mu] \mu[\alpha] v[\kappa \alpha] v$ Calder et Friedrich : $\alpha[1] \operatorname{vov}[\mu] \mu \circ v[\kappa \alpha] v$ Haas $1966: \alpha \tau v o v[\mu] \mu \circ v[\kappa \alpha] v$ Haas $1970 b: \alpha$.

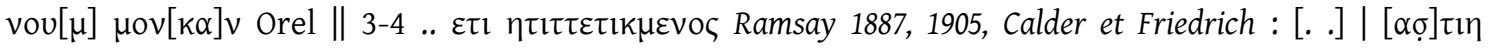

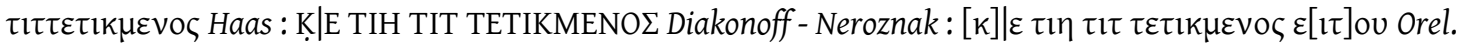

'[Wh]oever brings $\mathrm{h}[\mathrm{arm}]$ to this tomb ..., let him be made accursed by Zeus in the sight of men and gods.' 


\section{Sülün (formerly Süğlün, Prymnessos)}

\section{1}

Withe marble Door-stele (85,5 x 71 x 13,5 bottom - 20,5 above) preserved in the Afyon Musem (inv. no. E 1550/80, ). Dated to between 138-161 AD (Waelkens 1986, 199). Rectangular sigma and epsilon. Greek protasis followed by a Phrygian apodosis.

MAMA VI 1939, 133 no. 382 (pl. 67 no. 382); Haas 1966, 127 no. 96; Diakonoff \& Neroznak 1985, 81 no. B 96; Waelkens 1986, 199 no. 493 (Tafel 71, no. 493); TITUS, no. 96; Orel 1997a, 118 no. W*-49; Brixhe 2002a, 252-253.

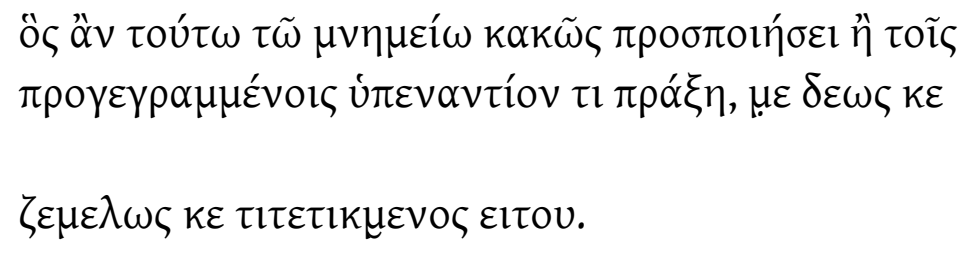

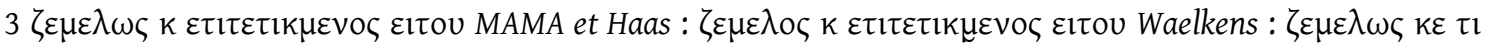

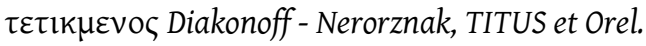

'[Greek] Who damages this monument or contravenes the foregoing injunctions, [Phrygian] let him be accursed in the sight of gods and men.'

\section{2}

Upper fragment of a calcareous stele found in höyük located in the Ahmet Karahisarı campus of the Kocatepe Univesity at Afyon-karahisar and preserved in the museum of this city. It was dated to the $2^{\text {nd }} \mathrm{C}$. BC by the first editos (Brixe \& Drew-Bear 2010, 162), but recently Ligorio \& Lubotsky 2013, 182 considered it as a NPhr. inscription, so dated to the $1^{\text {st }}$ or $2^{\text {nd }} \mathrm{C}$. AD. The shape of the sigma is classic but, it is not a so conclusive feature to consider it an Hellenistic inscription.

Brixe \& Drew-Bear 2010; Ligorio \& Lubotsky 2013, 182 no. 129 (only enumerated).

$$
\begin{aligned}
& \text { los } v 1 \sigma \alpha \mu \alpha \gamma^{?}-
\end{aligned}
$$

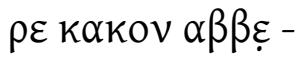

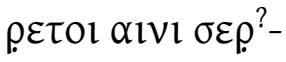

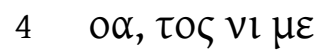

$$
\begin{aligned}
& \zeta \varepsilon \mu \varepsilon \lambda \omega[\varsigma \text {....] } \\
& \text { [---] }
\end{aligned}
$$

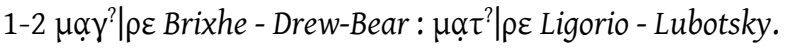

'Whoever brings harm to this mother or to this serva, [let] him ... in the sight of me[n...]'. 


\section{Bolvadin (Polybotos)}

\section{1}

Inscription copied by Calder in 1908 and 1910 (with a better reading). Although he was able to see it again in 1912, now it is lost. Lunate sigma and epsilon.

Calder 1911, 208-210 no. LXIII (with copy); Calder 1926, 28 no. LXIII (revised reading); MAMA I, 201 no. 385 (with photograph); Friedrich 1932, 137 no. 63; Haas 1966, 123 no. 63; Diakonoff \& Neroznak 1985, 81-82 no. B 63 (as variant of B 6); Waelkens 1986, 204-205 no. 509 (with photograph from MAMA I); TITUS, no. 63 (only the Phrygian text); Orel 1997a, 102-103 no. $\mathrm{W}^{*}-36$.

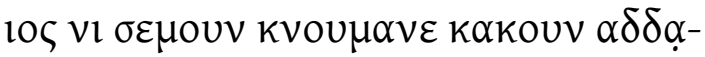

$$
\begin{aligned}
& \kappa \varepsilon \tau \tau o ̣ \rho, \delta \varepsilon \omega \varsigma \zeta \varepsilon \mu \varepsilon \lambda \omega \varsigma \kappa \varepsilon \tau \tau \imath \tau \varepsilon\{\tau \varepsilon\}- \\
& \tau ![\kappa \mu \varepsilon v o] \varsigma[\varepsilon ı \tau O u] \text {. }
\end{aligned}
$$

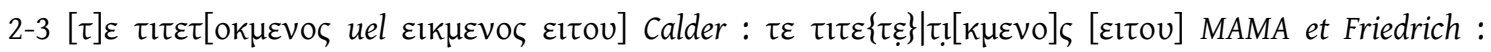

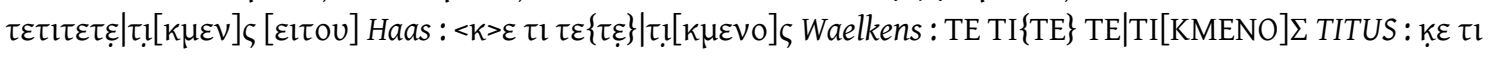

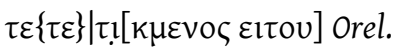

'Whoever does harm to this tomb, [let him] be accursed (in the sight of) gods and men.'

\section{2}

Stele ("H. 1.82; w. (top) 0.515, (shaft) 0.46, (bottom) 0.54; th. max. 0.175; 1. h. 0.02") found in Dura Yeri, now preserved in the Bolvadin Museum. It has three acroteria decorated with palmetes, "triangular pediment with raised boss centre, below which is a shell motif between mouldings of stylized eggs and darts above a Lesbian leaf motif surmounting pilaster capitals (that on right damaged) with double volutes and stylized floral decoration. On the shaft, between fluted pilasters above bases with mouldings in relief, is a male child between two standing figures [...] on a broken base" (Drew-Bear, Lubotsky \& Üyümez 2008, 113). Lunate sigma and epsilon.

Drew-Bear, Lubotsky \& Üyümez 2008, 113-115, no. 3 (with photograph and the translation); Ligorio \& Lubotsky 2013, 182 no. 128 (only enumerated).

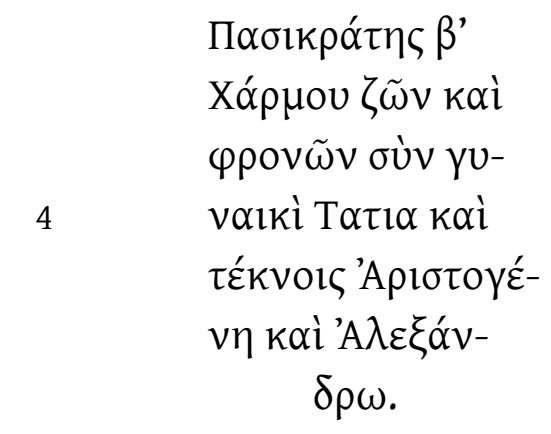




\title{
$\alpha \varsigma \beta \alpha \tau \alpha \nu$ opovev $\alpha \nu$ ke.
}

'[Greek] Pasikrates, son of Pasikrates grandson of Charmos, whilst he is alive and of sound mind, with his wife Tatia and their children Aristogenes and Alexandros. [Phrygian] Whoever afflicts harm to this grave, let him be cursed among gods and men by Bat and the Father.'

\section{3}

Complet Phrygian inscription engraved in a block stone found in 1910 in the east of the Bolovadin road to Çay. Lunate sigma and epsilon, cursive omega.

Calder 1911, 203-208 no. LXII (with copy); MAMA I, 200 no. 384 (with photograph); Friedrich 1932, 137 no. 62; Haas 1966, 123 no. 62; Diakonoff \& Neroznak 1985, 79 no. 62; TITUS, no. 62 (only the Phrygian text); Orel 1997a, 102 no. W*-35.

\author{
$10 \varsigma \nu 1 \sigma \varepsilon \mu v \nu \kappa v^{0} v-$

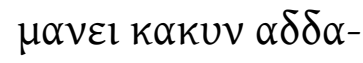 \\ $\kappa \varepsilon \tau \alpha l k \alpha \nu, \alpha \tau \tau \imath \eta \kappa \varepsilon$ \\ $4 \delta \varepsilon \omega \varsigma \kappa \varepsilon \tau \iota \tau \tau \varepsilon \tau \iota k \mu \varepsilon-$

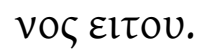

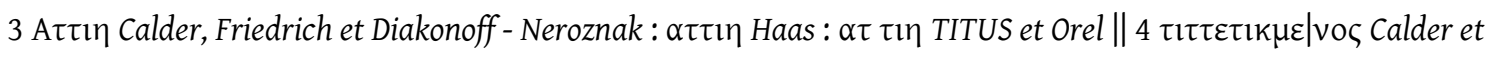

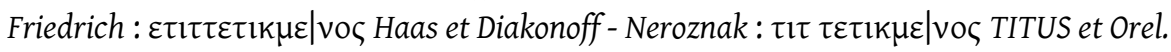

'Whoever does harm to this tomb or whatever, let him be accursed by Zeus and the gods.'

\section{Kocaöz (formerly Feleli)}

\section{1}

Copied by Hogarth: "Fellelü: on a door-tomb of which three panels remain; in the upper two are female figures, and in the lower one a wheatsheaf. The stone is half buried in packed earth, upside down, and thus the first lines and much of the right-hand portion cannot be seen. The Phrygian part of the lettering is smaller and more crowded" (1890, 158-159). Ramsay added that it was recopied by Hogarth in 1890, “when a few letters were added" (1905, col. 102). Lunate sigma and epsilon, cursive omega. 
Hogarth 1890, 158-159 no. 2 (with copy); Ramsay 1905, col. 102 no. XLII (with copy); Calder 1911, 184-185 no. XLII; Friedrich 1932, 134 no. 42; Haas 1966, 120 no. 42; Diakonoff \& Neroznak 1985, 80 no. B 42 (only the Phrygian text); Waelkens 1986, 204 no. 507; TITUS, no. 42; Orel 1997a, $94-96$ no. W*-32.

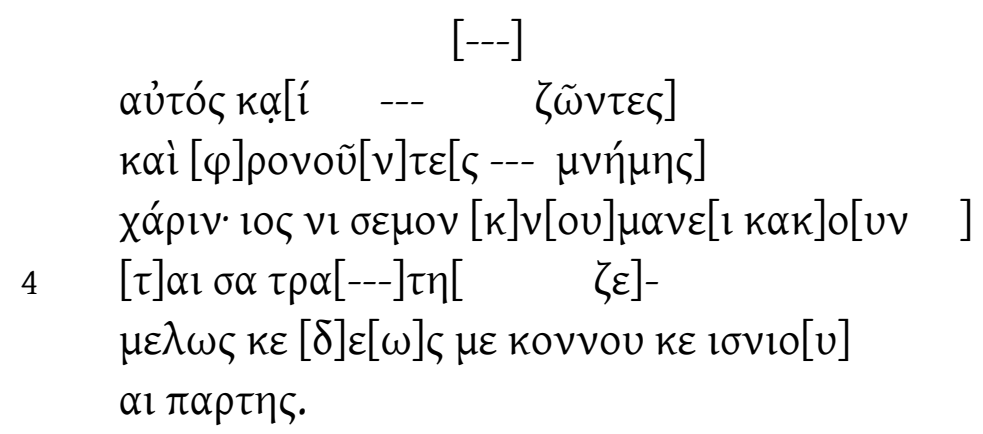

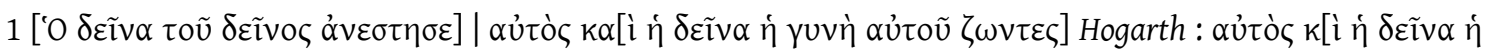

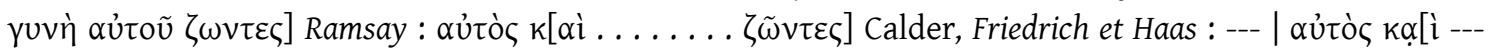

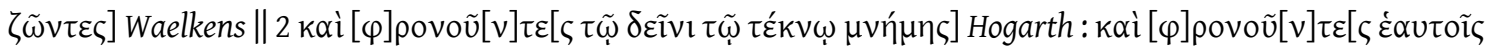

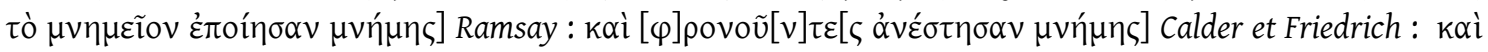

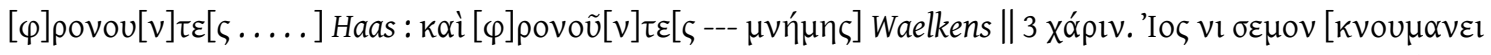

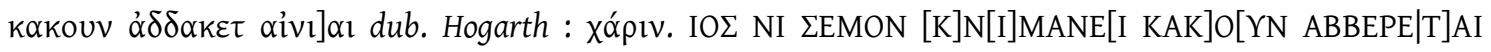

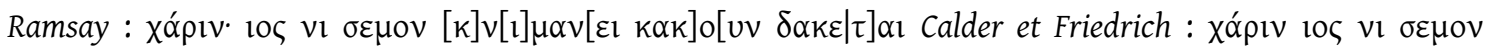

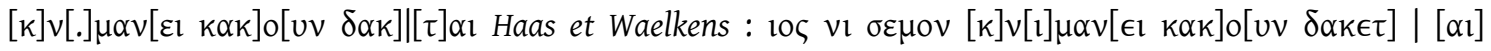

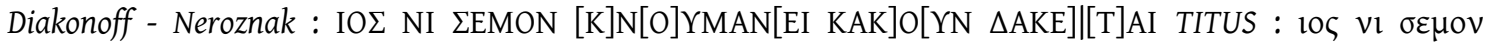
$[\kappa] v[.] \mu \alpha v[\varepsilon l k \alpha \kappa] \mathrm{o}[v v \delta \alpha \kappa] \mid[\tau] \alpha_{l}$ Orel $\| 4 \sigma \alpha \ldots . . .[\ldots . . . \zeta \varepsilon \mid \mu \varepsilon \lambda \omega \zeta$ sic Hogarth : $[\mu \varepsilon \zeta \varepsilon \mid \mu \varepsilon \lambda \omega \varsigma$ sic Ramsay $: \sigma \alpha \tau \rho \alpha[\ldots] \tau \eta[\ldots . . . . \mu \varepsilon \zeta \varepsilon \mu \varepsilon \lambda \omega \varsigma]$ Calder et Friedrich : $\sigma \alpha \tau \rho \alpha[\ldots] \tau \eta[\ldots . . \zeta \varepsilon] \mid \mu \varepsilon \lambda \omega \varsigma$ Haas : $\sigma \alpha \tau \rho \alpha \alpha[\pi \epsilon] \zeta \eta$ $[. . \xi \epsilon] \mu \in \lambda \omega \varsigma$ Diakonoff - Neroznak : $\sigma \alpha \tau \rho \alpha[. ..] \tau \eta[---\zeta \varepsilon] \mid \mu \varepsilon \lambda \omega \varsigma$ Waelkens : $\Sigma$ ATPA[...]TH[..... [ZE|ME $\Lambda \Omega \Sigma$

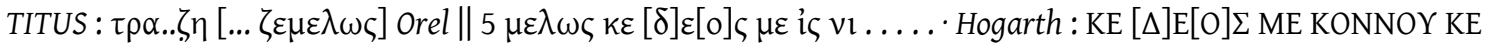
I INIO[Y] Ramsay : $\kappa \varepsilon[\delta] \varepsilon[\omega \varsigma]$ MEKONNOYKEILNIO/// Calder et Friedrich : $\kappa \varepsilon[\delta] \varepsilon[\omega] \zeta \mu \varepsilon$ kovvov $\kappa \varepsilon ~ l \sigma v i o[v]$ Haas, Diakonoff - Neroznak et TITUS : $[\delta] \varepsilon[\omega] \varsigma<\kappa>\varepsilon$ kovvou $\kappa \varepsilon$ lovio[v] Waelkens : $\kappa \varepsilon[\delta] \varepsilon[\omega] \varsigma, \mu \varepsilon \kappa o v$ vov $\kappa \varepsilon$

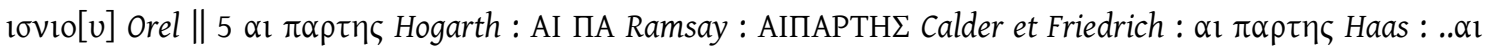

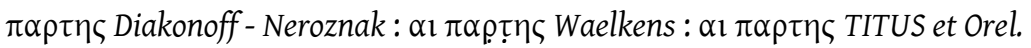

'[Greek] ... himself and [---, whilst they are alive] and of sound $\min [\mathrm{d}$, --- in] memory. [Greek] Whoever [--- ha]rm to this $\mathrm{t}[\mathrm{o}] \mathrm{m}[\mathrm{b}]$..., let him ... (in the sight of) men and gods ...'

\section{2}

Inscription engraved "on a door-tomb, broken top and right, and no built into a courtyard wall” (1890, 158). Lunate sigma and epsilon.

Hogarth 1890, 158 no. 1 (copy); Ramsay 1905, col. 103 (with Hogarth's copy); Calder 1911, 185 no. XLIII; Friedrich 1932, 134 no. 43; Haas 1966, 120 no. 43; Diakonoff \& Neroznak 1985, 79 no. B 43 (only the Phrygian text as variant of B 14); Waelkens 1986, 203-204 no. 506; TITUS, no. 43; Orel 1997a, 96-97 no. W*-33.

[--- $\mu \nu \eta ́ \mu \eta \varsigma]$

1 xóp]iv. 


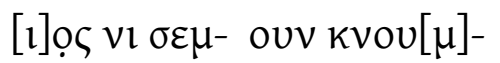

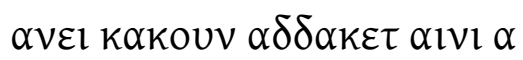 \\ $4 \quad\left[\tau \varepsilon \alpha \mu \alpha \varsigma^{?}\right.$}

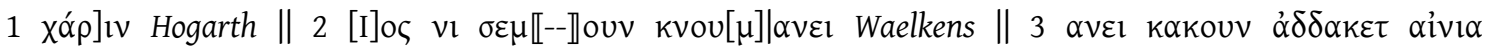

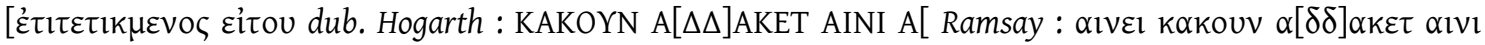

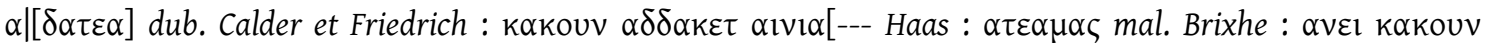

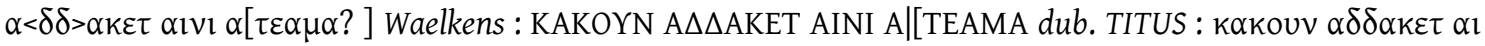
$v i \alpha \mid[---]$ Orel.

'[Greek] [... in] memory. [Phrygian] Whoever does harm to this to[m]b or to [this plot? ---]'

\section{Işıklar}

\section{1}

"White marble stele. H. 076; w. 0.46; th. 020; letters, 0.02. Pediment with foliate sidepieces and acroterion, containing boss" (MAMA IV, 6). Inscription copied by Ramsay in August 1884, who found it "among the hills south of Tchobanlar [...] in a fountain" (Ramsay 1887, 390). Dated to the $3^{\text {rd }} \mathrm{c}$. AD. Lunate sigma and epsilon.

Ramsay 1887, 390-391 no. IX (with copy); Ramsay 1905, col. 110-112 no. IX (only the Phrygian text); Calder 1911, 169 no. IX; Friedrich 1932, 129-130 no. 9; MAMA IV, 6-7 no. 18 (Pl. 14); Haas 1966, 115 no. 9; Diakonoff \& Neroznak 1985, 84 no. C 9; TITUS, no. 9; Orel 1997a, 72-76 no. $\mathrm{W}^{*}-20$.

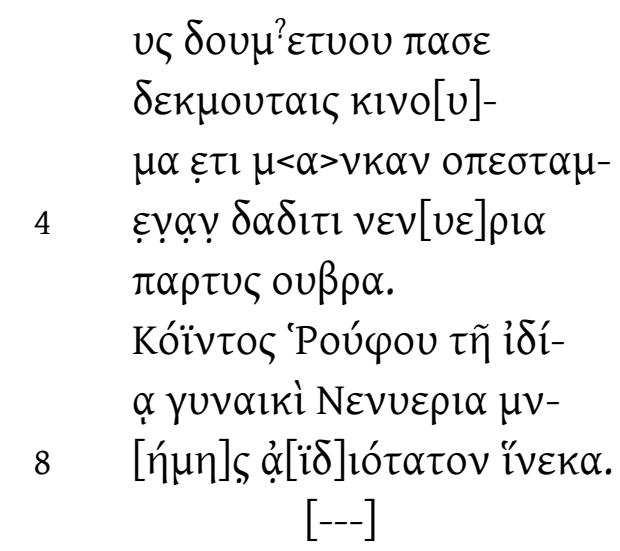

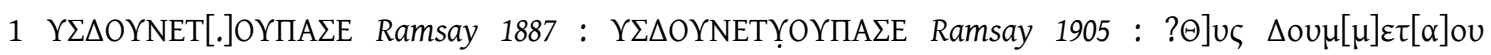

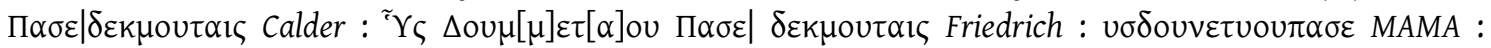

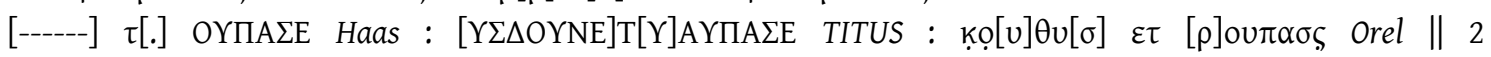

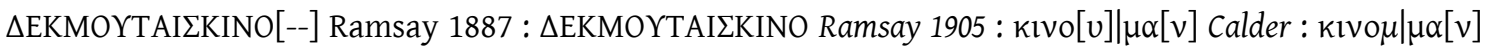

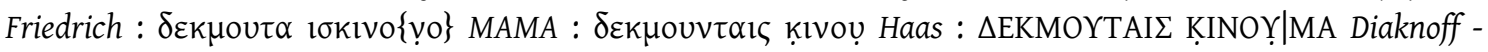

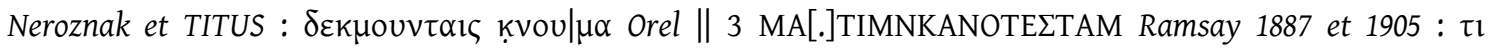

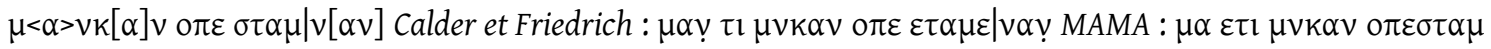

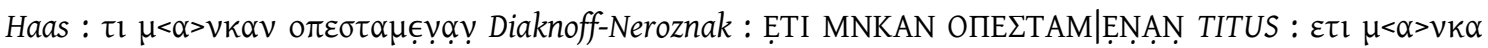

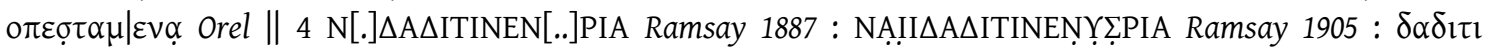

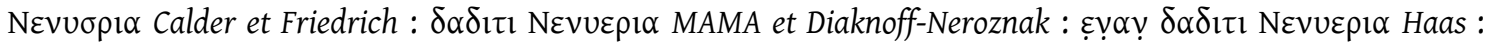

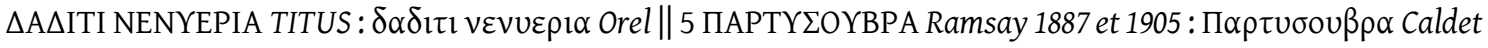

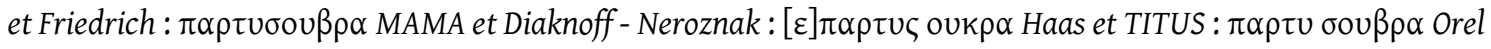

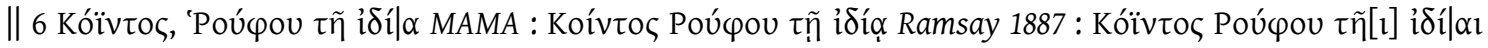
Calder et Friedrich : Koııoৎ Poú 


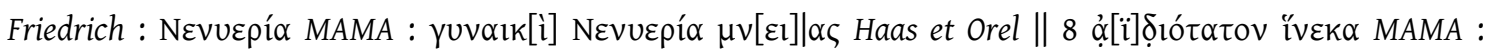

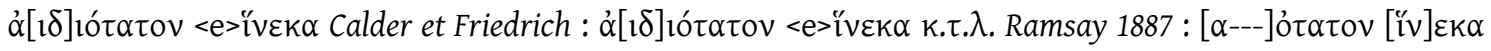
Haas : $\alpha$ [....]ỏ $\alpha \alpha \tau o v[\varepsilon ̌ v] \varepsilon \kappa \alpha$ Orel.

‘[Phrygian] ... [Greek] Quintus Rufus (made it) for his own daughter Nenueria in eternal memory.'

\section{2}

Lower part of a broken stele preserved in the Afyon Museum (inv. E. 1978). Under the figures of a man and a woman a complete Phrygian curse was engraved. Lunate sigma and epsilon, cursive omega.

Mitchell 1993, 186 fig. 33 (Photograph only); Ligorio \& Lubotsky 2013, 182 no. 118 (only enumerated).

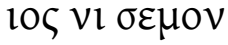

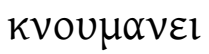

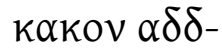

$$
\begin{aligned}
& 4 \\
& \alpha K \varepsilon \tau, \tau \varepsilon \tau 10-
\end{aligned}
$$

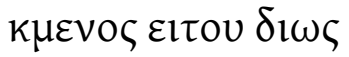

$$
\begin{aligned}
& \kappa \varepsilon \zeta \varepsilon \mu \varepsilon \lambda \omega \varsigma \text { } \kappa \varepsilon \pi \alpha \rho-
\end{aligned}
$$

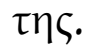

'Whoever does harm to this tomb, let him be accursed (in the sight of) gods and men partes.'

\section{Kuzören (Selmea)}

\section{1}

Fragment of an inscription found by Anderson (no more information available). Now lost. Only a Greek anthroponym and the beginning of a common Phrygian protasis was read. Lunate sigma and epsilon.

Anderson 1899 II, 300 no. 224; Haas 1966, 126 no. 89; TITUS, no. 89; Orel 1997a, 112 no. $\mathrm{W}^{*}-43$.

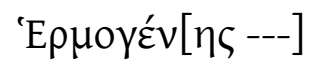

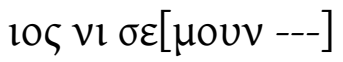

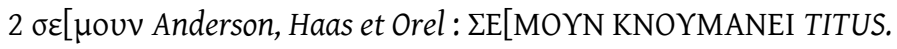

'[Greek] Hermogenes [---] [Phrygian] Whoever to th[is ---]' 


\section{Efesultan}

\section{1}

"Plain limestone block. H. 0.97; w. 0.89; letters, 0.04. The inscription begins 0.085 from the top of the Stone" (MAMA IV, 24). It was found by Legrand and Chamonard in a wall of a mosque on the road side. Lunate sigma and epsilon.

Legrand \& Chamonard 1893, 289 no. 94 (only copy); Radet \& Ouvré 1896, 111-114 no. 7 (with copy); Ramsay 1905, col. 101 no. XL (where it is said to be following Anderson's copy 1898, 122, although actually it is the inscription no. 41.1); Calder 1911, 184 no. XL; MAMA IV, 24 no. 76 (pl. 22); Friedrich 1932, 134 no. 40; Haas 1966, 119 no. 40; Diakonoff \& Neroznak 1985, 81-82 no. B 40 (as variant of B 6); TITUS, no. 40; Orel 1997a, 94 no. $W^{*}-31$.

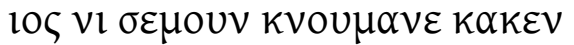

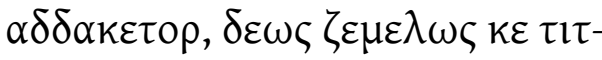 \\ $\tau \varepsilon \tau 1 K \mu \varepsilon^{-} \cdot \operatorname{vos} \varepsilon l \tau O U$.}

$1 \Sigma[$ E]MOYN Ramsay : $\sigma \varepsilon \mu$ ouv cett. $\| 2$ A $\triangle \triangle$ AKET OP $\triangle \mathrm{E} \Omega \Sigma$ ZEME $\Lambda \Omega \Sigma$ K(E) ETIT|TETIKME[N]O $\Sigma$ Ramsay :

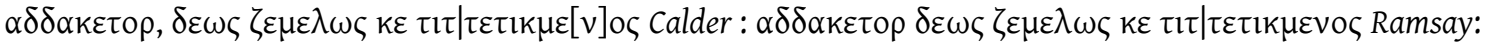

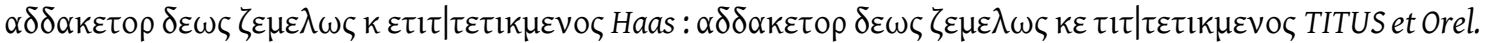

'Whoever does harm to this tomb, let him be accursed (in the sight o) gods and men.'

\section{5. Şuhut (Synnada)}

\section{1}

Door-stele ( 1 x 0,75 x 0,16-0,20 m) identified in 1973 by Marc Waelkens in Afyon Museum (without inv. no.), it is said to be found in Çai, but because its typology is considered to come from Synnada. "Il s'agit d'un monument rectangulaire, taillé dans un bloc de marbre blanc veiné de rouge des carrières de Dokimeion. Son dos a été travaillé à la pinte, tandis que les côtés et la face sont dressés à la gradine. Ce traitement indique que le monument - comme le groupe de pierres tombales à fausse porte qu'il imite et don il sera question plus loin - fut à l'origine encastré dans un ensemble funéraire plus grand" (Brixhe \& Waelkens 1981, 68). Dated ca. 150$200 \mathrm{AD}$. The inscription is engraved in the pediment. Cursive letters $(0,9 \mathrm{~cm})$ with ligatures.

Brixhe \& Waelkens 1981, 68-75 (with photograph); SEG 31.1126; Waelkens 1986, 191 no. 470 (Tafel 70, no. 470); TITUS, no. 115 (onlty the Phrygian text); Orel 1997a, 124-125 no. W*-56.

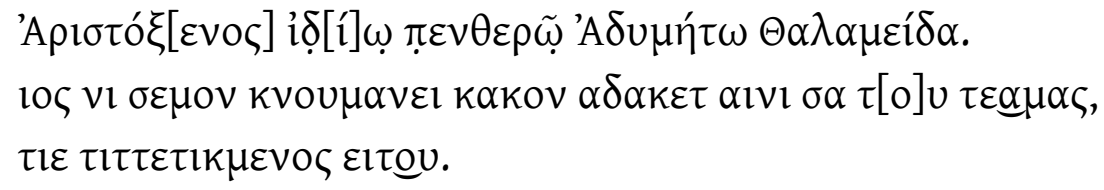

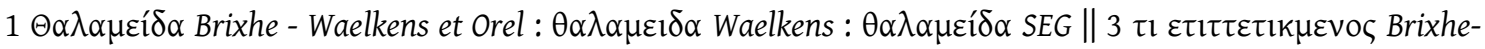

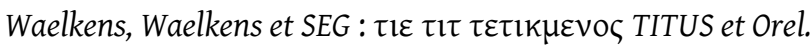


'[Greek] Aristox[enos] for his own father-in-law Adymetos Thalamidas. [Phrygian] Whoever does harm to this tomb or to this plot, let him be accursed.'

\title{
25.2
}

Complete inscription on a broken stele ("H. 0.53, w. 0.40, th. 0.12, 1. h. 0.03" Drew-Bear, Lubotsky \& Üyümez 2008, 109), preserved in Afyon Museum. The stele preserves the settings lines above and below the letters. Interpunction is used only in the syllables of the common theonym and participle of the Phrygian imprecation. Rectangular sigma and epsilon. Hedera separates the Greek text from the Phrygian one.

Drew-Bear, Lubotsky \& Üyümez 2008, 109-111 no. 1; Ligorio \& Lubotsky 2013, 182 no. 126 (only enumerated).

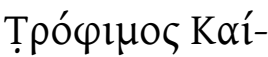

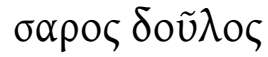

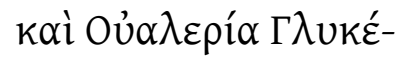

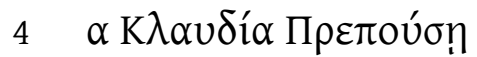

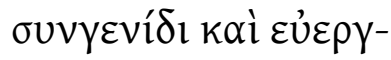

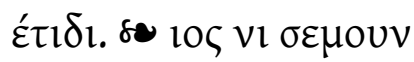

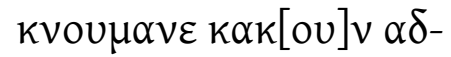 \\ $8 \delta \alpha \kappa \varepsilon \tau, T 1 \bullet \varepsilon \tau 1 \tau \cdot \tau \varepsilon[\cdot] \tau l \bullet-$

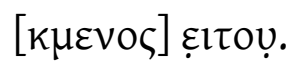

'[Greek] Trophimos slave of Caesar and Valeria Glykea (made it) for Claudia Preopusa their relative and benefactor. [Phrygian] Whoever does ha[r]m to this tomb, let him be acc[ursed] by Zeus.'

\section{Inl1}

\section{1}

Inscription copied by Ramsay in August 1884. Lunate sigma and epsilon.

Ramsay 1887, 390 no. VIII (with copy); Calder 1911, 168 no. VIII; Friedrich 1932, 129 no. 8; Haas 1966, 115 no. 8; TITUS, no. 8; Orel 1997a, 71-72 no. W*-19.

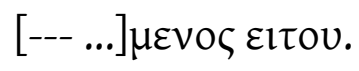

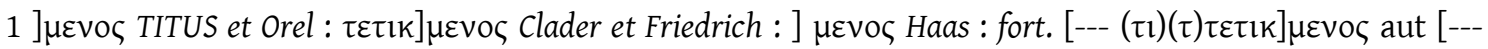

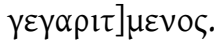


Inscription "engraved above a tombstone of the usual Phrygian "door" type" (Ramsay 1905, col. 101), found by Ramsay in 1884. Lunate sigma and epsilon.

Ramsay 1905, col. 100-101 no. XXXVIII (without copy); Calder 1911, no. XXXVIII; Friedrich 1932, 134 no. 38; Haas 1966, 119 no. 38; Diakonoff \& Neroznak 1985, 77 no. B 38 (as variant of B 10); Waelkens 1986, 201 no. 499; TITUS, no. 38; Orel 1997a, 92 no. W*-29.

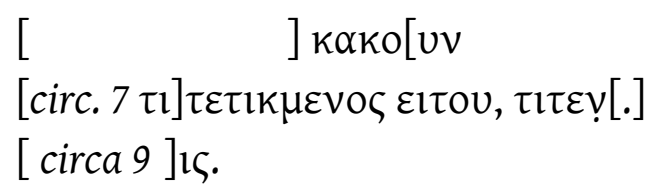

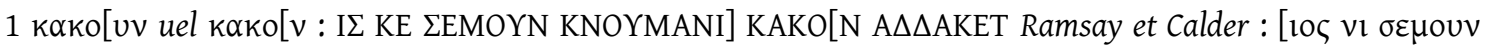

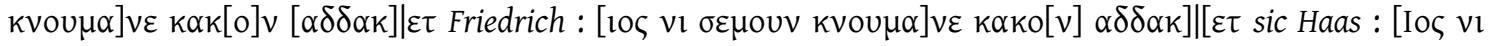

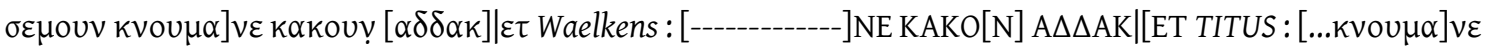

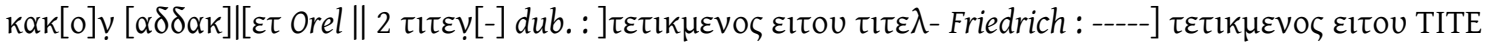

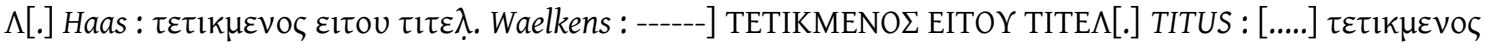

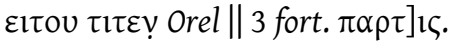

$$
\text { '... har }[\mathrm{m}] \text {..., let him be [ac]cursed ...' }
$$

\section{7. İcikli}

\section{1}

"Ijikli, in the fountain. Limestone block with incised panel, broken on l. upper corner and on r. side, complete above and below. H. 0.72; w. 0.47; letters, 0.02" (MAMA IV, 37). Dated to the late $3^{\text {rd }} \mathrm{c}$. AD.

MAMA IV, 37 no. 116 (pl. 30); Haas 1966, 127 no. 92 (excluding the third first letters); Diakonoff \& Neroznak 1985, 83 no. B 92 (only the Phrygian text); TITUS, no. 92 (only the Phrygian text); Orel 1997a, 114-116 no. $\mathrm{W}^{*}-46$. .

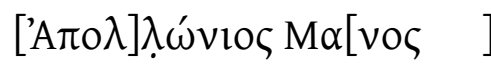

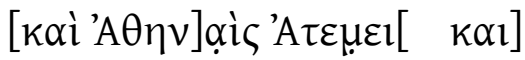

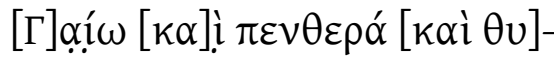

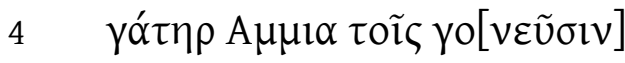

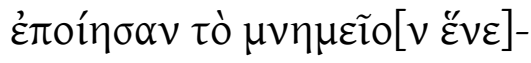

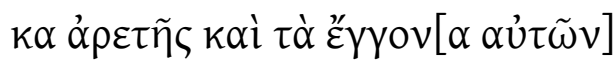

$\sigma v v \varepsilon \pi \varepsilon<\sigma>k \varepsilon v ́ \alpha \sigma \alpha v^{\prime} A[\mu \mu \iota \alpha]$

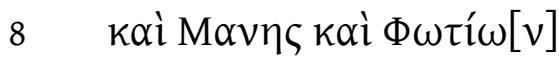

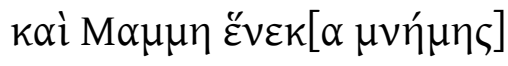

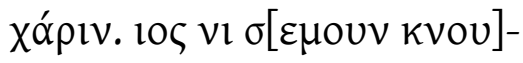

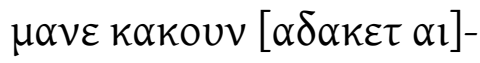

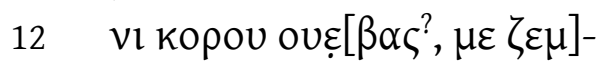

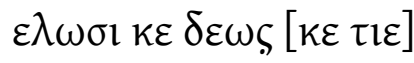

$\kappa \varepsilon \tau \imath \tau \varepsilon \tau ו \kappa \mu[\varepsilon \vee O \zeta ~ \varepsilon I \tau O U]$

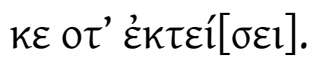




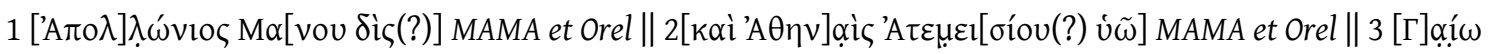

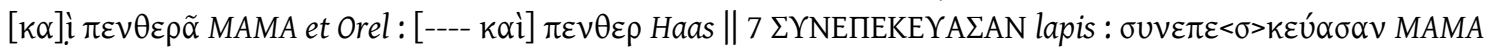

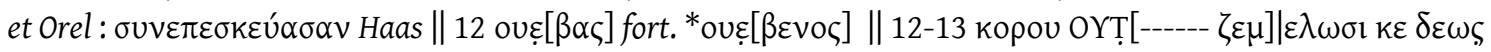

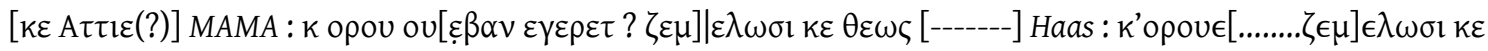
$\theta \varepsilon \omega[\sigma \mathrm{l}$ Diakonoff - Neroznak KOPOY OY[E.BAN EГEPET? ZEM] [E $\Lambda \Omega \Sigma I$ KE $\Delta$ E $\Omega \Sigma$ [KE ATTIE] TITUS : vı $\kappa$ opov

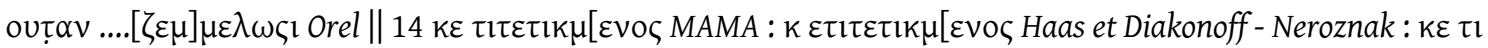

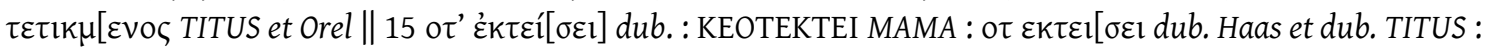

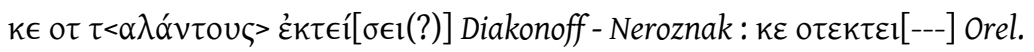

'[Greek] [Apol]onios (and) Man[os ...] Athenians, Atemi[... and G]aius and (their) mother-in-law [and dau]ghter Ammia made this memorial for (their) parents for the sake of their goodness and [their] children A[mmia] and Manes and Photion and Mamme built (it) in memory. [Phrygian] Whoever [does] harm to th[is to]mb [o]r the plot of this mem[orial], [let him be] accurs[ed by Zeus in the sight of m]en and gods] [Greek] and he shall pa[y] 370 (drachmae).'

\title{
28. Sağir
}

\section{1}

Inscription read on a bomos found "on an Imperial Estate near Antiochia ad Pisidiam" (Calder 1913, 101) by Ramsay and Calder in 1911.

Calder 1913, 101-103 no. LXXI; Friedrich 1932, 138 no. 71; Haas 1966, 124 no. 71; Haas 1970, 49 no. 71; Diakonoff \& Neroznak 1985, 79 no. B 71; TITUS, no. 71; Orel 1997a, 104-105 no. $\mathrm{W}^{*}-38$.

\author{
$\tau \iota \varsigma \kappa \varepsilon \gamma \varepsilon \rho \varepsilon[v / \tau]$, \\ $\tau \iota \tau \tau \varepsilon \tau \iota k \mu[\varepsilon]-$ \\ vol ivVou.
}

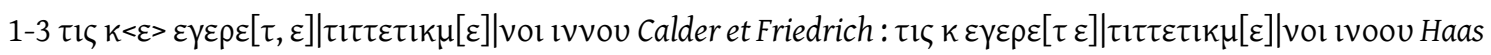

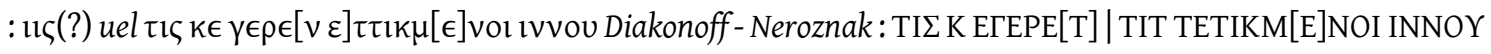

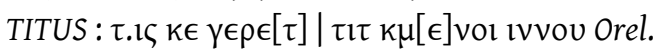

'Whoever ..., let them be accurs[e]d.'

\section{Yukarıkaşıkara}

\section{1}

Calcareous pediment-stele (0,52 x 0,73 x 0,36; letters 0.025) found by Drew-Bear in the wall of a house. In 1997 Brixhe and Drew-Bear were able to see it again and complete the reading.

Brixhe 1978a, 7 no. 114 (fragment); Brixhe \& Drew-Bear 1978, 50-54 (fragment); Diakonoff \& Neroznak 1985, 83-84 no. B 111 (fragment); TITUS, no. 114 (fragment); Brixhe \& Drew-Bear 1997, 71-80 no. I (fig. 4, complete); Orel 1997a, 123-124 no. W*-55 (fragment). 


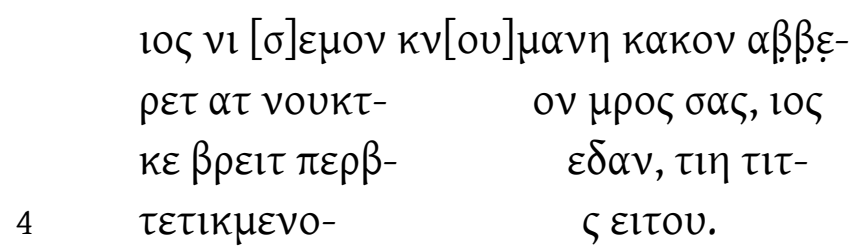

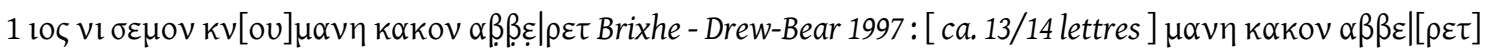

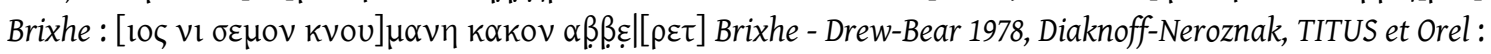

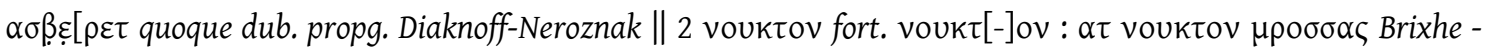

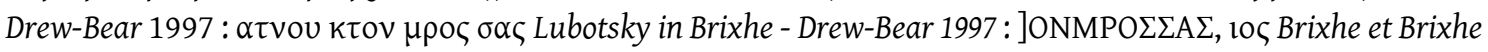

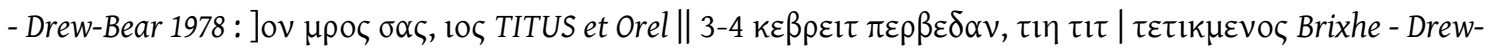

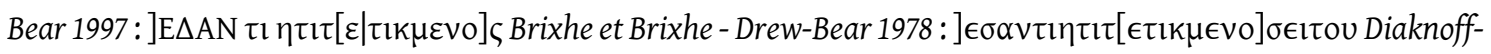

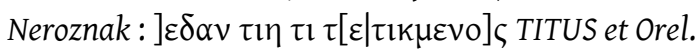

'Whoever brings harm to [t]his tomb by beating to this $\mu \rho \circ$ and who breaks' the monument?, let him be accursed (by) Zeus.'

\section{Karadilli}

\section{1}

Inscription found by Ramsay "on the top of a fountain in the plain below Kara-dil-li", who also added that "the stone has been carefully defaced by the mason; and only a few letters are legible" (Ramsay 1905, 101). According to Calder, "the stone bearing this inscription had been deliberately hacked all over, and it was difficult in many places to distinguish the modern chisel-marks from the original letters" $(1913,98)$. Lunate sigma and epsilon.

Ramsay 1905, col. 101 no. XXXIX; Calder 1911, 182-183 no. XXIX; Calder 1913, 97 no. XXXIX; Friedrich 1932, 134 no. 39; Haas 1966, 119 no. 39; Haas 1970a, 47 no. 39; Diakonoff \& Neroznak 1985, 81-82 no. B 39 (only the Phrygian text as variant of B 6); TITUS, no. 39 (only the Phrygian text); Orel 1997a, 92-93 no. W*-30.

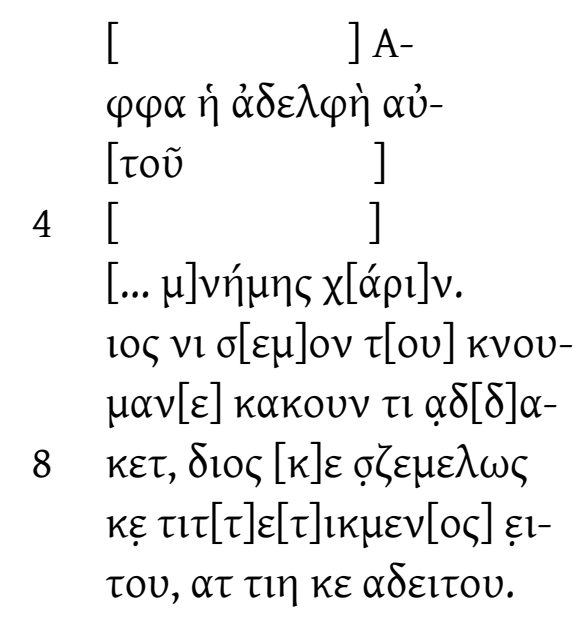

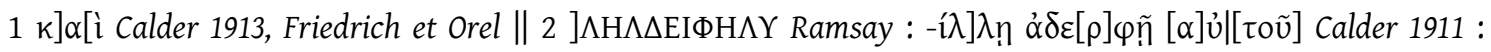

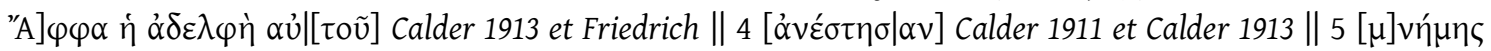

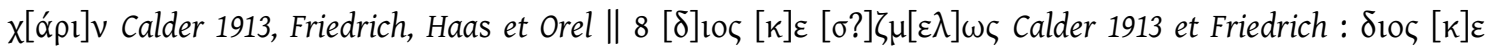

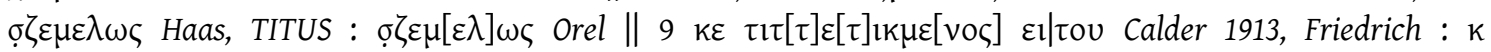




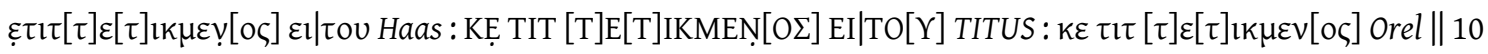

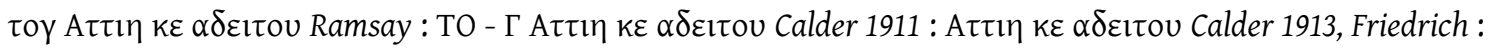

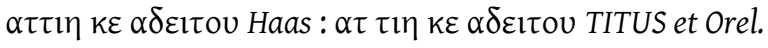

‘[Greek] [---] Appa, his sister [--- i]n memory. [Phrygian] Whoever d[o]es some harm to $t[h]$ is tom[b], let him be $a[c] c u[r] s e[d]$ (in the sight of) gods [a]nd men and let him become (accursed) by Zeus.'

\section{2}

Copied by Calder in 1911, "the stone on which this inscription was engraved had just been broken into fragments to build into the wall of a new mosque. I was able to find only [...] two pieces. It is uncertain how many lines are lost after the first line; the edges did not fit exactly, and a thin piece had been lost" (Calder 1913, 98). Lunate sigma and epsilon.

Calder 1913, 98 no. LXVIII; Friedrich 1932, 138 no. 68; Haas 1966, 124 no. 68; Diakonoff \& Neroznak 1985, 77 no. B 68 (only the Phrygian text as variant of B 10); TITUS, no. 68 (only the Phrygian text); Orel 1997a, 103-104 no. W*-37.

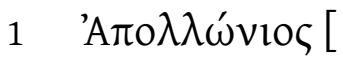

2

\section{$\zeta \tilde{\omega} v]-$}

$3 \tau \varepsilon \varsigma \kappa \alpha l \varphi \rho o v o \tilde{u}[\tau \varepsilon \zeta \alpha v \varepsilon \dot{\sigma} \sigma \eta ́]-$

$4 \sigma \alpha v \cdot \operatorname{lo\zeta } v 1<\sigma>\varepsilon \mu\left[\right.$ ouv $\left.k v o u \mu \alpha v \varepsilon^{?} \kappa \alpha\right]-$

Kouv $\alpha \delta \alpha \kappa \varepsilon[\tau---\alpha \tau \tau l]-$

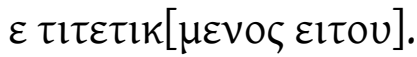

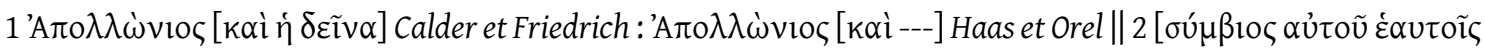

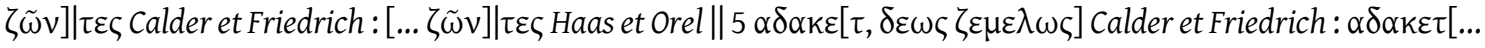

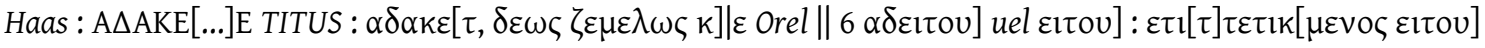

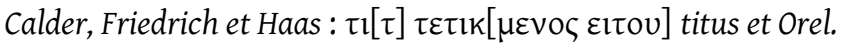

'[Greek] Apolonios [---], whilst they are alive and of sound mi[nd, erect]ed (it). [Phrygian] Whoever doe[s ha]rm to <t>hi[is tomb ---, let him be] accur[sed by Zeu]s.'

\section{Büyükkabaca}

\section{1}

"Stele with gable in the wall of a large water-trough in the village fountain. The inscription is partly submerged" (Sterrett 1888b, 402). "Limestone pediment, with circular ornament in tympanum and acroteria on each side; much worn by water, and lower edge (now forming the upper front of the trough) broken and chipped. H. 0.70; w. 1.40; th. at edge, 0.14; letters, 0.02 to 0.032 ". Nowadays it can be seen in the façade of the mosque of Dere Mahallesi, according to Brixhe \& Drew-Bear (1997, 100). Lunate sigma and epsilon.

Ramsay 1887, 400 no. XXIX (only Sterrett's copy of the Phrygian text); Sterrett 1888b, 402 no. 590; Ramsay 1905, col. 119-120 no. XXIX; Calder 1911, 177-178 no. XXIX; Friedrich 1932, 
132 no. 29; MAMA IV, 88-89 no. 240 (fig. 21); Haas 1966, 120 no. 29; Diakonoff \& Neroznak 1985, 78 no. B 29 (onlty the Phrygian text as variant of B 26); TITUS, no. 29; Brixhe \& Drew-Bear 1997, 110-113 no. VIII; Orel 1997a, 90-91 no. W*-27; Ligorio \& Lubotsky 2013, 182 no. 125 (only enumerated); Bru 2017, 409 Fig. 39 (only photo).

\author{
(Pediment:)

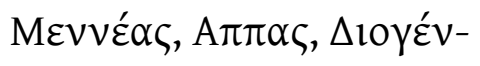

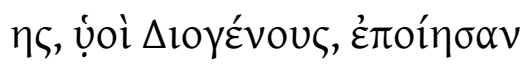

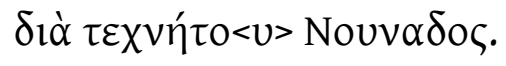
(Molding:)

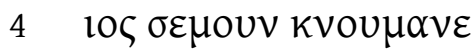

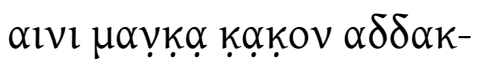
$[\varepsilon \tau,---]$

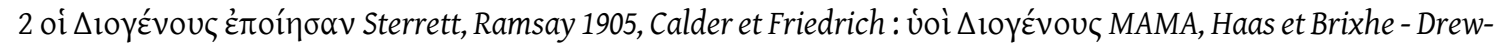

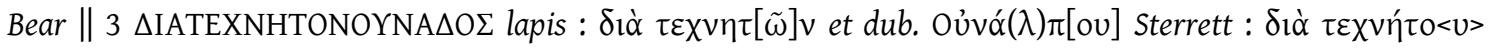

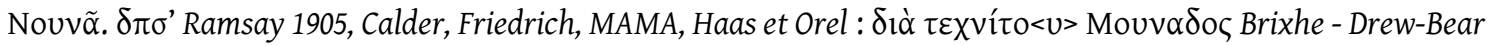

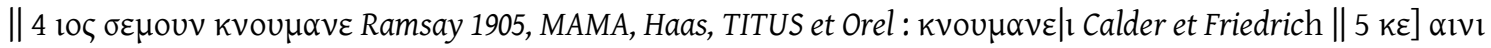

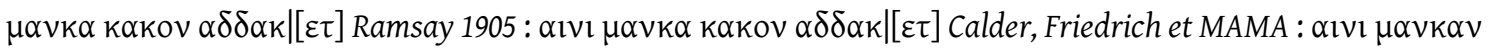

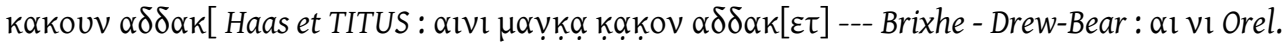

'[Greek] Menneas, Appas (and) Diogenes, children of Digones, made it through the craft Nunas. [Phrygian] Whoever do[es] harm to this tomb or stele, [---].'

\title{
32. Alcibar - Senirkent
}

\section{1}

"Aljibar, in a courtyard. Plain limestone slab. H. 0.74; w. 0.92; th. 0.23; letters, 0.02 to 0.035 , clear but not deep cut. The inscription is aligned 0.09 from the l. edge and begins 0.09 from the top; the slab is otherwise uninscribed" (MAMA IV, 88). Dated to the late $3^{\text {rd }} \mathrm{c}$. AD.

MAMA IV, 88 no. 239 (pl. 51); Haas 1966, 127 no. 93; Diakonoff \& Neroznak 1985, 82 no. B 47 (as variant of B 75); TITUS, no. 93; Orel 1997a, 116-117 no. W*-47.

\author{
lo丂 $\mathrm{vl} \sigma \varepsilon \mu \mathrm{O}$

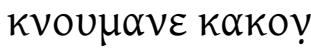 \\ $\alpha \delta \alpha \kappa \varepsilon \tau, \delta \varepsilon \omega \varsigma$ \\ $4 \zeta \varepsilon \mu \varepsilon \lambda \omega \varsigma \tau \imath \tau \varepsilon \tau \imath \kappa-$

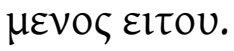

'Whoever does harm to this tomb, let thim be accursed (in the sight of) gods and men.' 


\section{Yassiören}

\section{1}

Found and copied by Sterret: "Yaztü Verau. In the wall of the Djami" (Sterrett 1888b, 393). "Limestone bomos, with defaced bust in relief on the front; the text runs above, below, and on each side of the bust. H. 0.55; w. 0.36; th. 0.22; letters, 0.015 to 0.03" (MAMA IV 1933: 89). Lunate sigma and epsilon.

Ramsay 1887, 400 no. XXVIII (with Sterrett's copy of the Phrygian text); Sterrett 1888b, 393 no. 571; Ramsay 1905, col. 118-119 no. XXVIII (only the Phrygian text); Calder 1911, 177 no. XXVIII (only the Phrygian text); Friedrich 1932, 133 no. 28 (only the Phrygian text); Calder, MAMA IV, 89 no. 241 (pl. 52); Haas 1966, 118 no. 28; Diakonoff \& Neroznak 1985, 77 no. B 28 (only the Phrygian text); TITUS, no. 28 (only the Phrygian text); Orel 1997a, 89-90 no. W*-26.

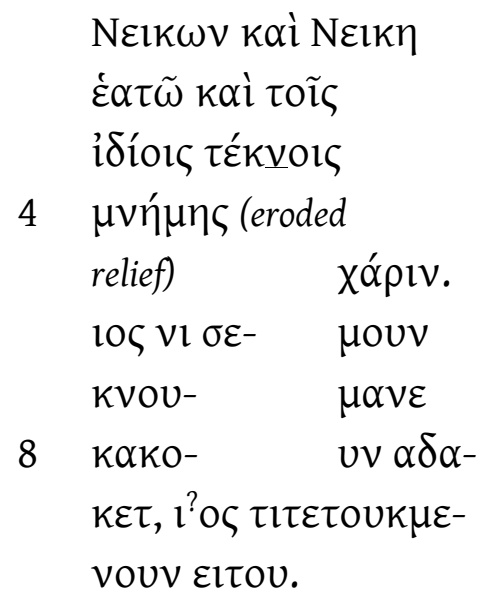

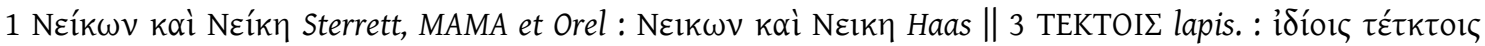

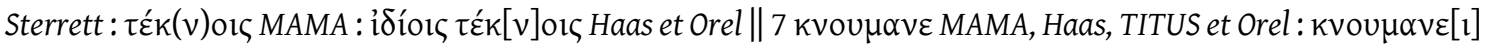

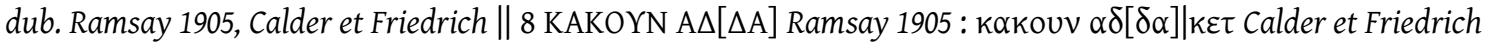

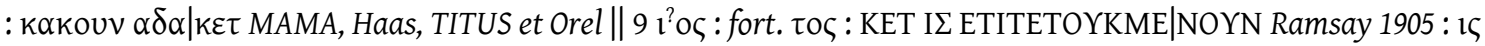

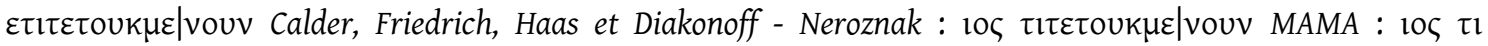

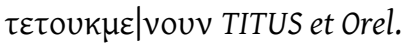

'[Greek] Nikon and Nike for himself and their own children in memory. [Phrygian] Whoever does harm to this tomb, let them be accursed.'

\section{2}

"Yaztu Veran, in the gate beside a foundation known locally as the Hamam. Limestone architrave, with projecting moulding, formerly bearing two lines of script, the upper one of which is now erased; broken at both ends. H. 0.40; w. 1.15; th. 0.70; letters, 0.025" (MAMA IV, 89).

MAMA IV, 89 no. 243 (pl. 52); Haas 1966, pg. 127, no. 95; TITUS, no. 95; Orel 1997a, 117 no. $\mathrm{W}^{*}-48$. 


\author{
$[---]$

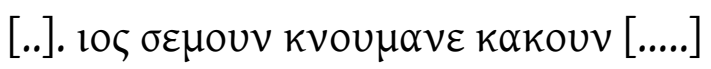 \\ $[---]$ \\ '[---]. Whoever does harm [---]'
}

\title{
33.3
}

Broken gravestone with pediment where an eagle is depicted ("H. 0.65, w. 1.14, th. 0.37, 1. h. line 10.02 , line 20.025 , line 30.015 " Drew-Bear, Lubotsky \& Üyümez 2008, 111) found in 2002 in the school of the village (said to be taken from the Gani Baba street) and preserved in the Isparta Museum. Rectangular sigma and epsilon.

Drew-Bear, Lubotsky \& Üyümez 2008, 111-112 no. 2; Ligorio \& Lubotsky 2013, 182 no. 127 (only enumerated).

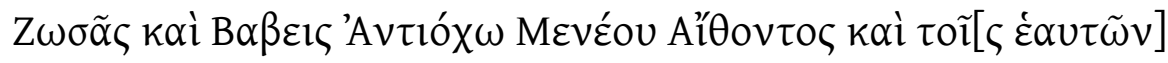

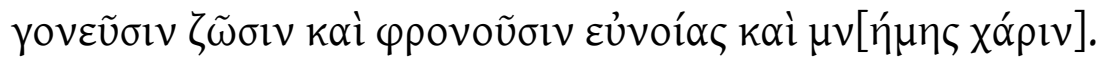

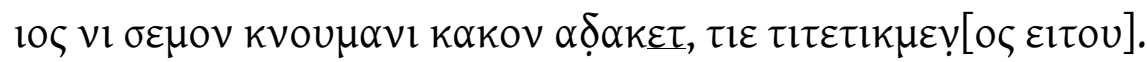

\section{A $\triangle$ AKTE lapis.}

‘[Greek] Zosas and Babeis, for Antiochos (son) of Meneas (grandson) of Aithon, and for [their] parents who are alive and of sound mind, because of their good will and in their memory. [Phrygian] Whoever does harm on this grave, [let him be] accurse[d] by Zeus.'

\section{Senirkent}

\section{1}

Inscription read "on a fragment of architrave of a large heroon: the inscription was engraved in two long lines, most of which is lost. Complete on right" (Ramsay 1905, colum. 100). The block (H. 0.42; w. 1.08; letters, 0.025) was used in the wall of the Büyük mosque (MAMA IV, 89). Lunate sigma and epsilon.

Ramsay 1905, col. 100 no. XXXVII; Calder 1911, 184 no. XXXVII; Friedrich 1932, 134 no. 37; MAMA IV, 89 no. 242 (pl. 52); Haas 1966, 119 no. 37; Diakonoff \& Neroznak 1985, 77 no. B 37 (only the Phrygian text as variant of B 10); TITUS, no. 37 (only the Phrygian text).

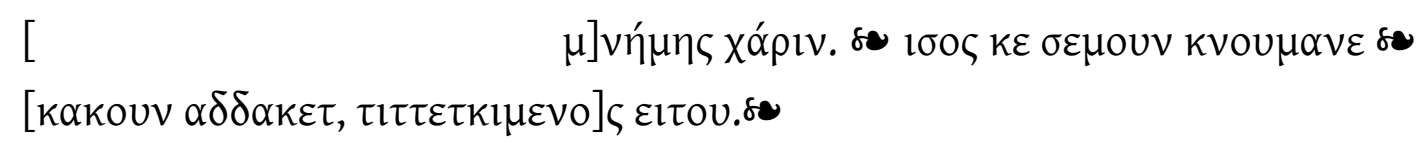

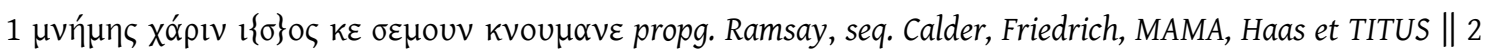

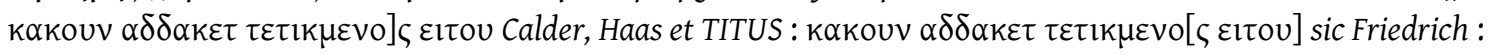

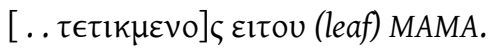


'[Greek] [--- i]n memory. [Phrygian] Whoever [does harm] to this tomb, let him be [accurse]d.'

\section{Uluborlu (Apollonia)}

\section{1}

Inscription copied by Hamilton.

Hamilton 1842, 490 Appendix V no. 449; CIG III, 58 no. 3974; Mordtmann 1862, 15 no. 4 (pl. A); Gosche 1864, 225 no. 12; Ramsay 1887, 339 no. XXV; Ramsay 1905, col. 118 no. XXV; Calder 1911, 176-177 no. XXV; Friedrich 1932, 132 no. 25; Haas 1966, 117 no. 25; Diakonoff \& Neroznak 1985, 81-82 no. B 25 (as variant of B 6); TITUS, no. 25; Orel 1997a, 87-89 no. W*-25; ObradorCursach 2016, 182.

$$
\begin{aligned}
& \text { los vi oluouv }
\end{aligned}
$$

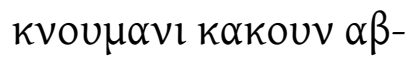

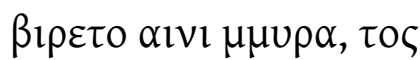

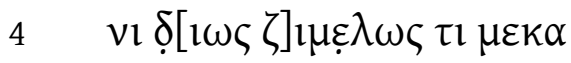

$$
\begin{aligned}
& \tau[\imath \varepsilon] \tau ı \tau \tau \varepsilon \tau \iota k \mu \varepsilon v o \zeta ~ \varepsilon l \tau o v .
\end{aligned}
$$

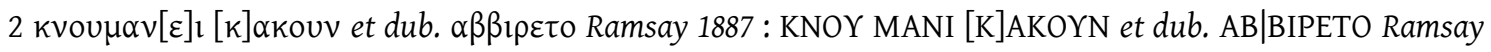

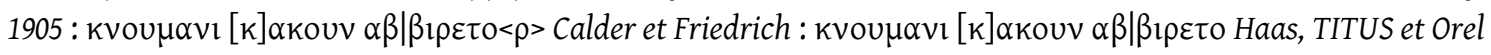

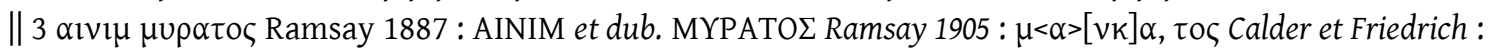

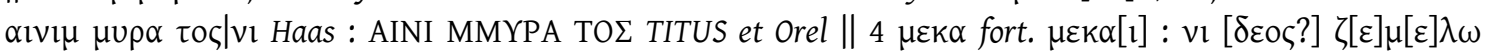

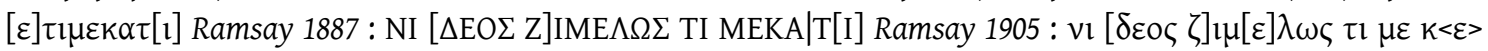

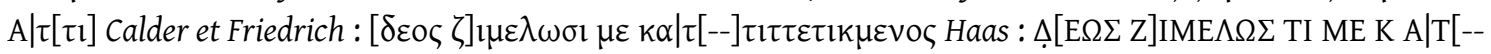

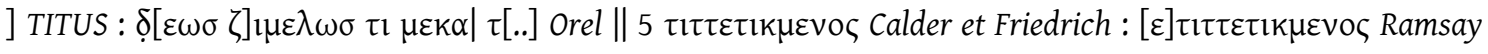

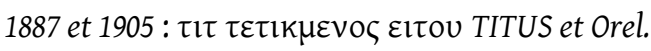

'Whoever brings harm or mistreatments to this tomb, let thim be accursed by the great $Z$ [eus] (in the sight of) g[ods and m]en.'

\section{6. Şarkıkaraağaç (Tetrapolis)}

\section{1}

Copied by Sterrett.

Sterrett 1885, 11 no. 6; Sterrett 1888a, 176 no. 175; Ramsay 1887, 399-400 no. XXVI; Ramsay 1905, col. 118 no. XXVI; Calder 1911, 177 no. XXVI; Friedrich 1932, 133 no. 26; Haas 1966, 117 no. 26; Diakonoff \& Neroznak 1985, 78 no. B 26; TITUS, no. 26; Orel 1997a, 327 no. S*-06. 


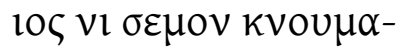

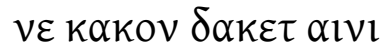 \\ $\mu \alpha \nu \kappa \alpha, \tau l \varepsilon \tau 1 \tau \tau \varepsilon \tau l-$

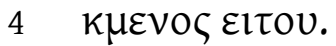

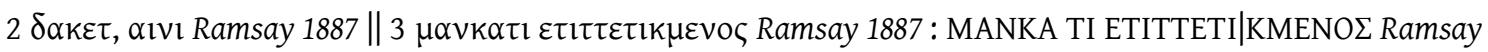

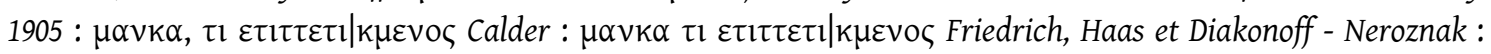
$\mu \alpha v \kappa \alpha \tau \imath \varepsilon \tau \imath \tau \tau \varepsilon \tau \imath \mid \kappa \mu \varepsilon v o \zeta$ TITUS et Orel.

'Whoever does harm to this tomb or stele, let him be accursed (by) Zeus.'

\section{2}

Copied by Sterret. Beginning of a Phrygian imprecative protasis.

Sterrett 1885, 11 no. 7; Ramsay 1887, 400 no. XXVII; Ramsay 1905, col. 118 no. XXVII; Calder 1911, 177 no. XXVII; Friedrich 1932, 133 no. 27; Haas 1966, 117 no. 27; Diakonoff \& Neroznak 1985, 77 no. B 27 (as variant of B 10); TITUS, no. 27; Orel 1997a, 327-328 no. S*-07.

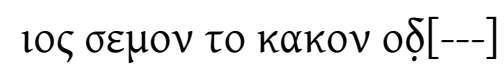

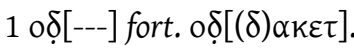

'Whoever d[oes] harm to this tomb [---].'

\section{3}

Read on a "block with plain moulding in front. H. 0.44; w. 0.76; th. 0.46; letters 0.03 to 0.04" (MAMA VIII, 62).

MAMA VIII, 62 no. 347 (pl. 171); Haas 1966, 127 no. 94; Diakonoff \& Neroznak 1985, 82 no. B 94 (as variant of B 75); TITUS, no. 94; Orel 1997a, 349-350 no. S*-19

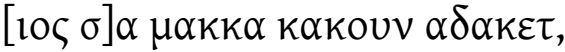

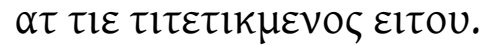

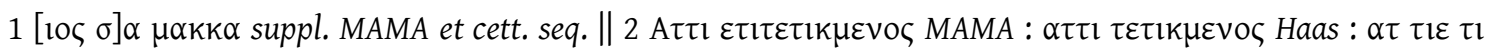

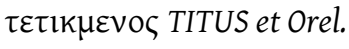

'[Whoever] does harm to [th]is tomb, let him be accursed by Zeus.' 


\title{
37. Akşehir (Philomelion)
}

\section{1}

Found and copied by Sterrett and Ramsay "high in the wall of the Mekteb Djami" (Ramsay 1887, 391). Lunate sigma and epsilon. A later Byzantine inscriptions with a cross was added.

Ramsay 1887, 391 no. X; Ramsay 1905, col. 112-113 no. X; Calder 1911, 169-170 no. X; Friedrich 1932, 130 no. 10; Haas 1966, 115-116 no. 10; Diakonoff \& Neroznak 1985, 77 no. B 10; TITUS, no. 10 (only the Phrygian text); Orel 1997a, 321- 322 no. S*-01.

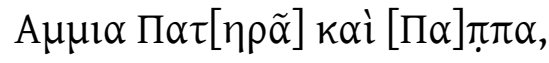 \\ $[\pi \alpha] 1 \delta i ́ o l \varsigma[\alpha \dot{v} \tau] \tilde{\eta} \varsigma \mu \nu \eta^{-}$ \\ $\mu \eta[\varsigma$ Хó $\rho] \mathrm{iv.}$ \\ 4

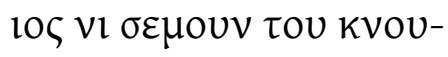

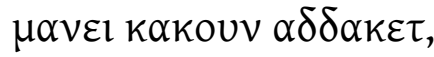

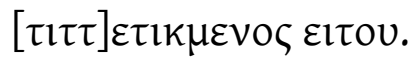

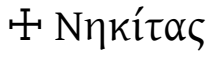

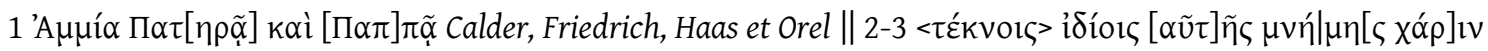

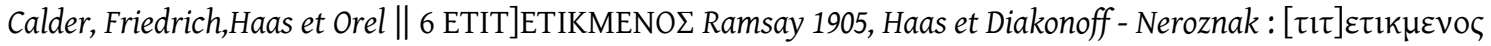

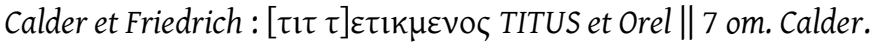

'[Greek] Ammia for Pat[era] and [Pa]pa, [h]er [ch]ildren, in memory. [Phrygian] Whoever does harm to this tomb, let him be [ac]cursed. [Greek] Niketas.'

\section{2}

On the top of a door-stone ("H. 0.98; w. 0.65; letters 0.02" MAMA VII, 39). Seen for the last time by Calder in 1910. Classic sigma but lunate epsilon.

Heberdey \& Wilhelm 1896, 163 no. 271; Ramsay 1905, col. 86-88 no. XXX; Calder 1911, 178-179 no. XXX; Friedrich 1932, 132 no. 30; MAMA VII, 39 no. 195 (pl. 10-11 no. 195); Haas 1951, 14-15 no. 30; Haas 1966, 118 no. 30; Haas 1970a, 49 and 60 no. 30; Haas 1970b, 14-15 no. 30; Diakonoff \& Neroznak 1985, 85 no C 30; Waelkens 1986, 263-264 no. 6780 (Tafel 86 no. 678); TITUS, no. 30; Orel 1997a, 328-329 no. S*-08 (lines 1-2 as Greek).

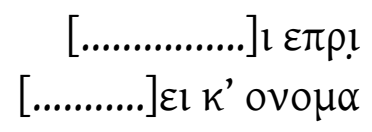

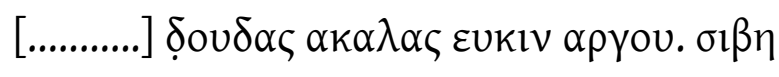

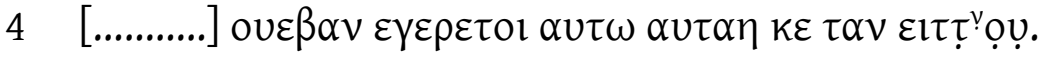




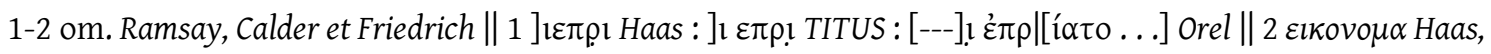

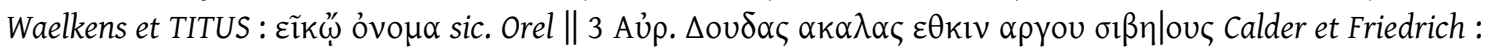

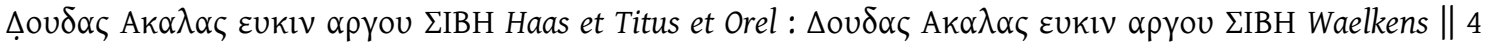

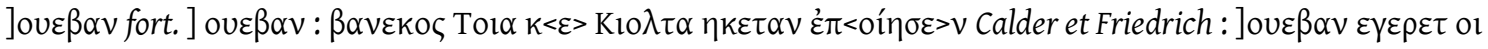

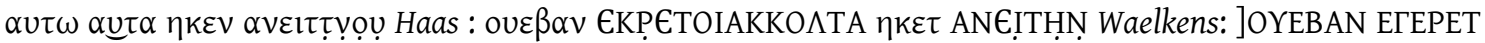

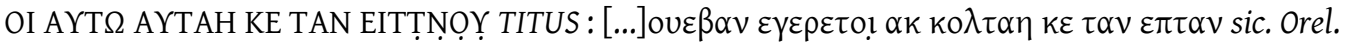

\title{
38. Doğanhisar (near Hadrianoupolis)
}

\section{1}

Inscription found by Sterrett: "Daghan Hissar. On a sarcophagus used as a water-trough in a fountain near a Djami" (1888a, 176). Ander and Calder (in 1908) were able to copy it again, but now it is lost. Lunate sigma and epsilon.

Sterrett 1888a, 176 no. 174; Ramsay 1905, col. 103 no. XLIV; Calder 1911, 185 no. XLIV; Friedrich 1932, 134 no. 44; MAMA VII, 27 no. 137, (pl. 8); Haas 1966, 120, no. 44; TITUS, no. 44; Orel 1997a, 336-337 no. S*-11.

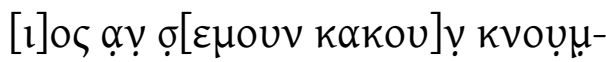

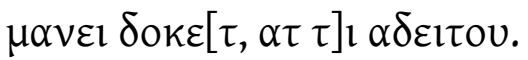

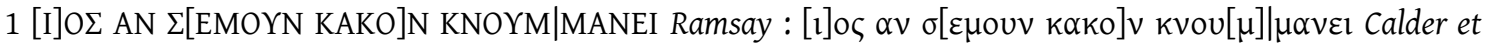

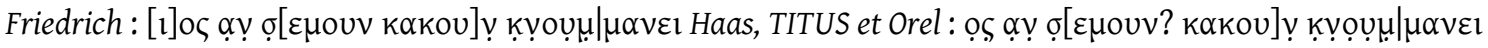

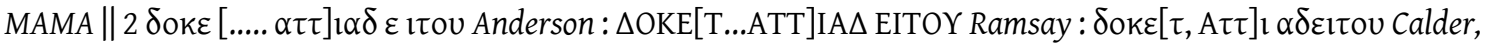

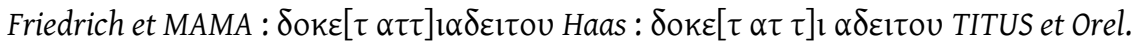

'[Wh]oever doe[s harm to this tomb], let him become (accursed) [by Ze]us.'

\section{Argitan1}

\section{1}

Copied by Sterrett and Ramsay in 1883 (Ramsay 1887, 391). Lunate sigma and epsilon, cursive omega.

Ramsay 1887, 391-392 no. XI; Ramsay 1905, col. 113 no. XI; Calder 1911, 70 no. XI; Friedrich 1932, 130 no. 11; Haas 1966, 116 no. 11; Diakonoff \& Neroznak 1985, 79 no. B 11; TITUS,

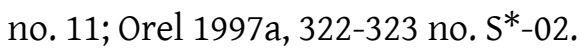

\author{
$[10 \zeta \sigma \varepsilon] \mu O V$ KVOU- \\ $[\mu \alpha v \varepsilon] \mathrm{l} \kappa \alpha \kappa \omega \nu$ \\ $[\ldots ..] \alpha \vee \alpha \beta \beta \varepsilon-$ \\ $4 \quad[\rho \varepsilon \tau, \tau]] \tau \varepsilon \tau ו \kappa \mu \varepsilon-$ \\ $[\operatorname{voc} \alpha] \tau \tau l \propto \delta \varepsilon-$ \\ [1] זov.
}




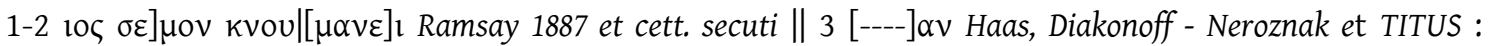

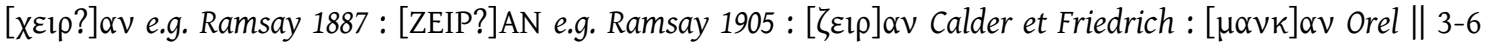

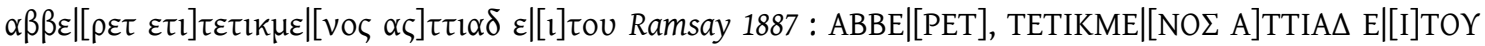

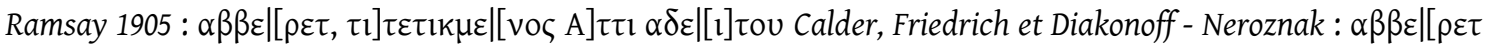

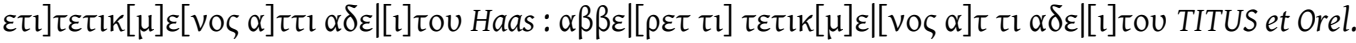

'[Who]ever brin[gs] harm to this t[om]b, let him become [a]ccursed [b]y Zeus.'

\title{
40. $\operatorname{Ilgin}\left({ }^{*}\right.$ Lageina $)$
}

\section{1}

On a white marble stone reused in the wall of a bath (CIG, 62). Copied by Seetzen in October 1803 according to CIG, and by Hamilton. Lunate sigma and epsilon, cursive omega.

Hamilton 1842 II, 478 Appendix no. 383; CIG III, 62 pars XVII no. 3986; Mordtmann 1862, 15 no. 3 (pl. A); Gosche 1864, 225 no. 13; Schmidt 1869, 132-136; Ramsay 1887, 391-393 no. XII; Ramsay 1905, col. 113-114, XII; Calder 1911, 170-172 no. XII; Friedrich 1932, 130 no. 12; Haas 1966, 116 no. 12; Haas 1970a, 60 no. 12; TITUS, no. 12; Orel 1997a, 323-324 no. S*-03.

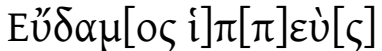 \\ П!

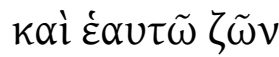 \\ 4

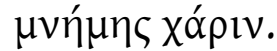

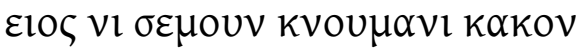

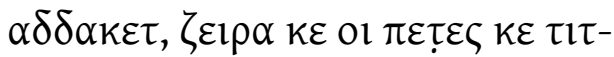 \\ $\tau \varepsilon \tau \iota k \mu \varepsilon \vee \alpha \alpha \tau \tau l \varepsilon \alpha \delta \varepsilon \imath \tau \tau \vee O v$.
}

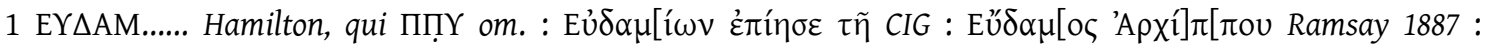

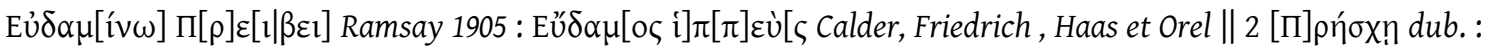

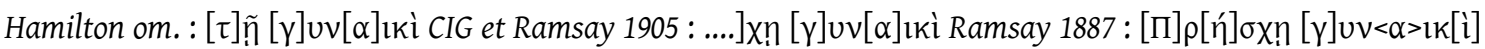

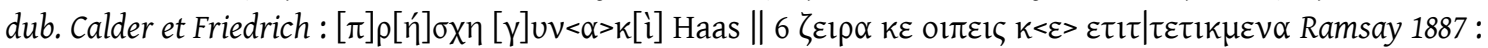

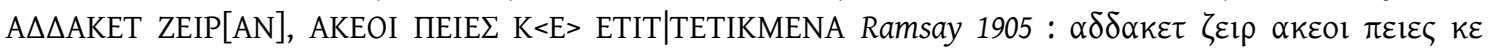

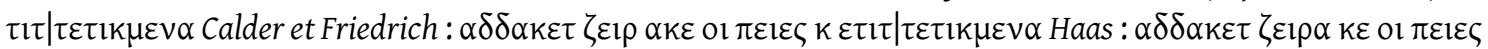

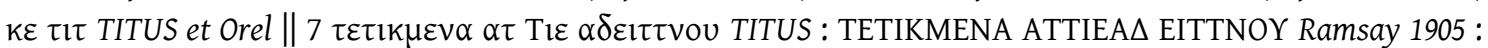

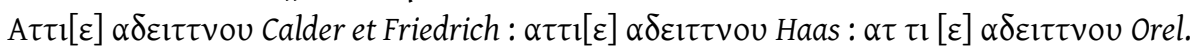

'[Greek] Eudam[os e]q[u]ite[s] for his wife Presche and for himself, whilst he is alive, in memory. [Phrygian] Whoever does harm to this tomb, let his hands and feet become accursed by Zeus.' 


\title{
40.2
}

Inscription copied by Ramsay in 1883 (Ramsay 1887, 393). Lunate sigma and epsilon.

Ramsay 1887, 393 no. XIII; Calder 1911, 172 no. XIII; Friedrich 1932, 130 no. 13; Haas 1966, 116 no. 13; TITUS, no. 13; Orel 1997a, 325 no. S*-04

\section{[--- k] $\alpha$ Kouv $\alpha \beta \beta \varepsilon \rho \varepsilon \tau \alpha \imath \underline{\varphi}[\mathrm{l}---]$ \\ $[---] \alpha \delta \varepsilon ı \tau o u$.}

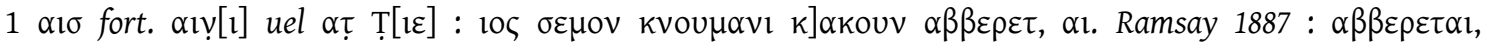

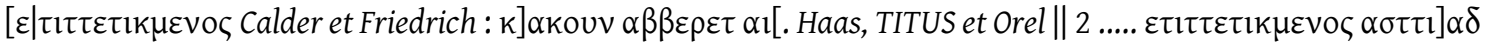

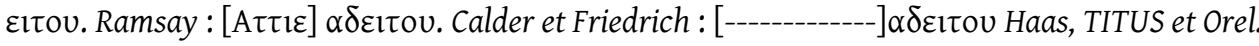

'[---] brings [h]arm o[r ---], let him become [---].'

\section{3}

Copied in Ilghin by Anderson (1898 II, 121). According to Ramsay (1905, col. 88), it is "the oldest of the whole series, and stands midway between the archaic inscriptions and those of the Roman times."

Anderson 1898 II, 121 no. 67; Ramsay, 1905, col. 88-94 no. XXXI; Calder 1911, 179-180 no. XXXI; Friedrich 1932, 132-133 no. 31; Haas 1951, 12-14 no. 31; Haas 1966, 103-104 II §16/3 and 118 no. 31; Haas 1969, 80-81 no. 31; Haas 1970b, 12-14 no. 31; Kowal 1984b, 180-185; Neumann 1986a; Diakonoff \& Neroznak 1985, 85-86 no. C 31; TITUS, no. 31; Orel 1997a, 330-331 no. S*-09.

\author{
$\alpha \varsigma \sigma \varepsilon \mu o u v \kappa v o u \mu \alpha v \alpha \delta i \theta \rho \varepsilon \rho \alpha \kappa$

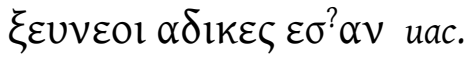

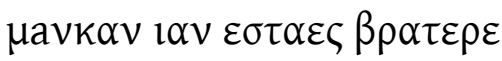 \\ $4 \mu \alpha \iota \mu \alpha \rho \alpha v, \pi$,

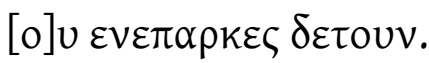 \\ $[\ldots . . \xi] \varepsilon v v \alpha v \alpha l \delta \mu \omega \varsigma \beta \rho \circ \varepsilon_{1} 1 \omega$

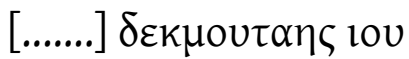

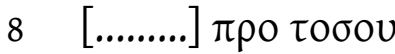

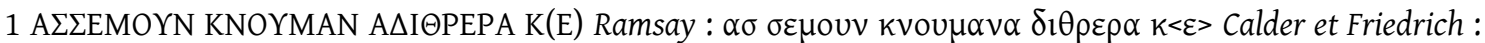

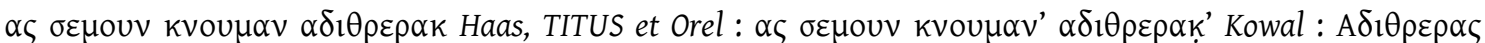

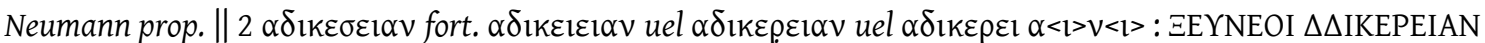

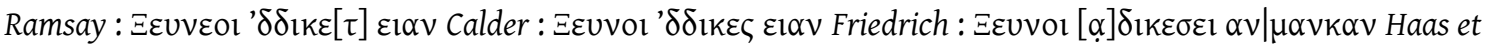

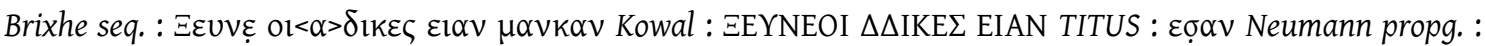

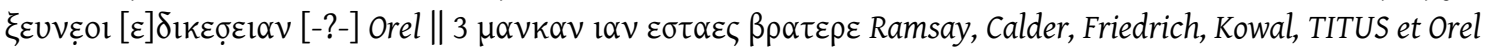

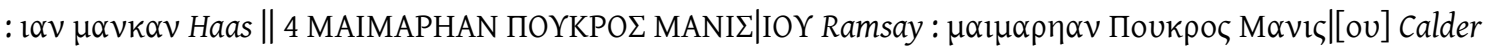

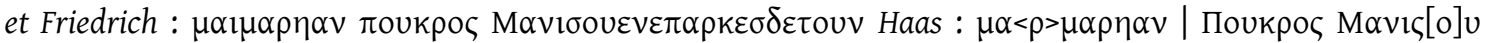

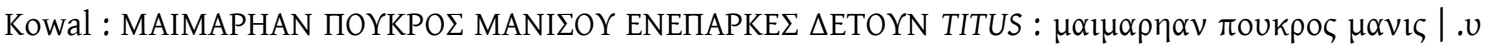

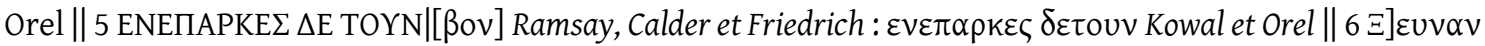




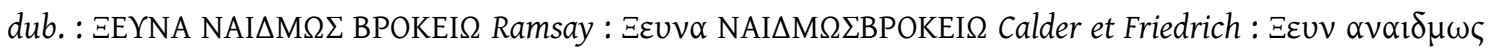

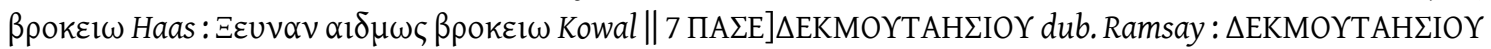

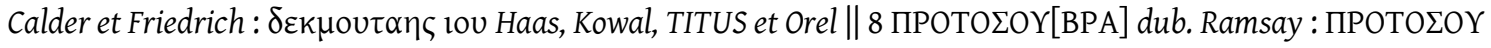

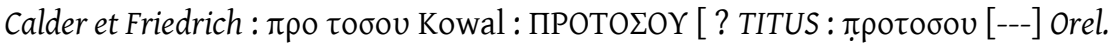

\title{
40.4
}

Stone block "with moulding on the left side, rough below. H. 0·83; w. 0.61; th. 0.19: letters 0.02 to 0.03 " (MAMA VII, 21).

MAMA VII, 21-22 no. 108 (pl. 128); Haas 1966, 128 no. 102; TITUS, no. 102; Orel 1997a, 350351 no. $S^{*}-21$.

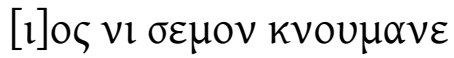 \\ $[\kappa \alpha] \kappa o v \alpha \delta \alpha \kappa \varepsilon \tau \alpha l v \imath \alpha \tau \varepsilon \alpha \mu-$

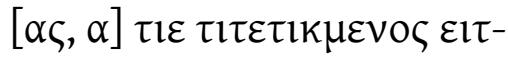 \\ 4 [ov].
}

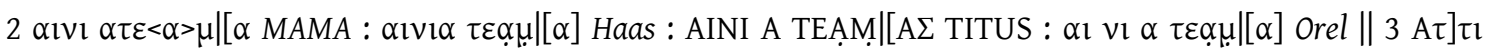

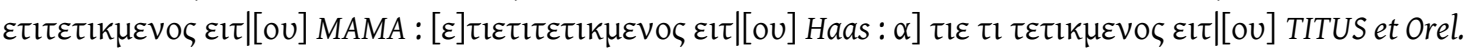

'[Wh]oever does [ha]rm to this tomb or this plo[t], let him b[e] accursed [b]y Zeus.'

\section{Mahmuthisar}

\section{1}

"Pedestal with circular column-rest above. Planed in front and on half the sides, otherwise left, otherwise left rough. Pedestal: h. 0.69; w. 0.50 to 0.40; th. 0.60; letters 0.02 to 0.035. Column-res (not rounded behind); h. 0·15; diam. 0.50" (MAMA VII, 27). Lunate sigma and epsilon.

Anderson 1989 II, 122 no. 68; Ramsay 1905, col. 103 no. XLV; Calder 1911, 185 no. XLV; MAMA VII, 27 no. 136 (pl. 123); Friedrich 1932, 135 no. 45; Haas 1966, 120 no. 45; TITUS, no. 45;

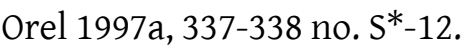

\author{
los $\sigma \varepsilon \mu \mathrm{ov}[\mathrm{v} k]$ voup-

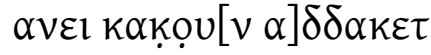 \\ $\tau ı \tau \tau \varepsilon \tau l k \mu \varepsilon \vee \circ \varsigma \alpha \tau \mathrm{Tl}-$ \\ $4 \varepsilon \alpha \delta \varepsilon l \tau o v$.
}

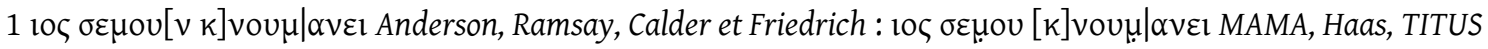

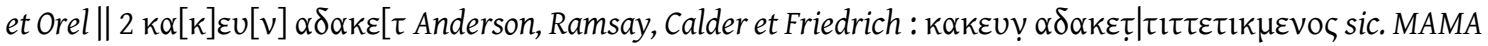

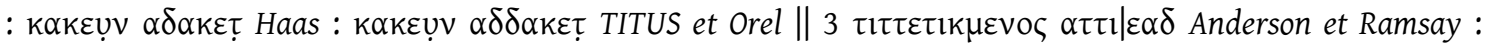

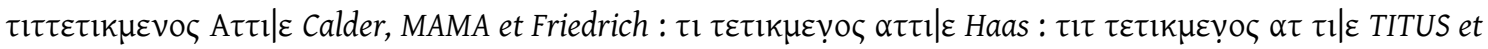

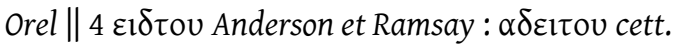

'Whoever does har[m] to th[is t]omb, let him become accursed by Zeus.' 


\section{Söğütözü}

\section{1}

Broken calcareous stele ("h. 0-77; w. 0.50; th. 0.41; letters 0.0175 to 0.0225” MAMA VII, 2).

MAMA VII, 2 no. 10 (pl. 1); Haas 1966, 128 no. 101; TITUS, no. 101; Orel 1997a, 350 no. S*_ 20.

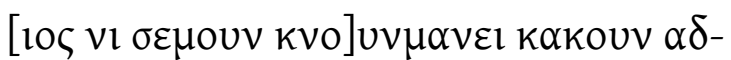 \\ $\left[\delta \alpha \kappa \varepsilon \tau, \tau \imath \tau^{2} \tau \varepsilon \tau 1 \kappa \mu \varepsilon\right] \operatorname{vo\zeta } \alpha \tau \tau l \alpha \delta \varepsilon l \tau o v$.}

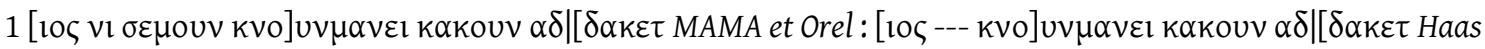

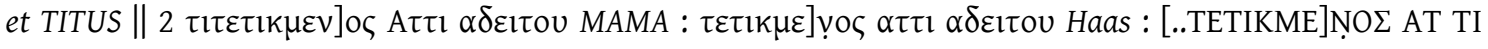

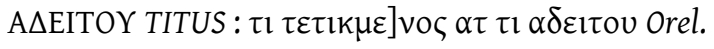

'[Whoever] d[oes] harm [to this to]mb, let him become [accurs]ed by Zeus.'

\section{Kadınhanı}

\section{1}

Engraved on the panels of a stele-door found by Ramsay "in the front wall of the ruined Khan" (Calder 1913, 99). Its "upper panels are broken across the middle, but there is no Greek inscription on the part which remains, and the above is very probably the complete epitaph" (Calder 1913, 99). Lunate sigma and epsilon, cursive omegas.

Calder 1913, 98-101 no. LXIX; MAMA I, 23 no. 33; Friedrich 1932, 138 no. 69; Haas 1951, 10-12 no. 69; Haas 1966, 124 no. 69; Haas 1970a, 53-54 no. 69; Haas 1970b, 10-12 no. 69; Diakonoff \& Neroznak 1985, 86-87 no. C 69; Waelkens 1986, 256-257 no. 664 (SEG 36.1191); LamingerPascher 1989, 51-53 (lines 1-13 as Greek!) (SEG 39.1416); TITUS, no. 69; Orel 1997a, 343-348 no. S*-17; Hämmig fthc. a. no. 69.

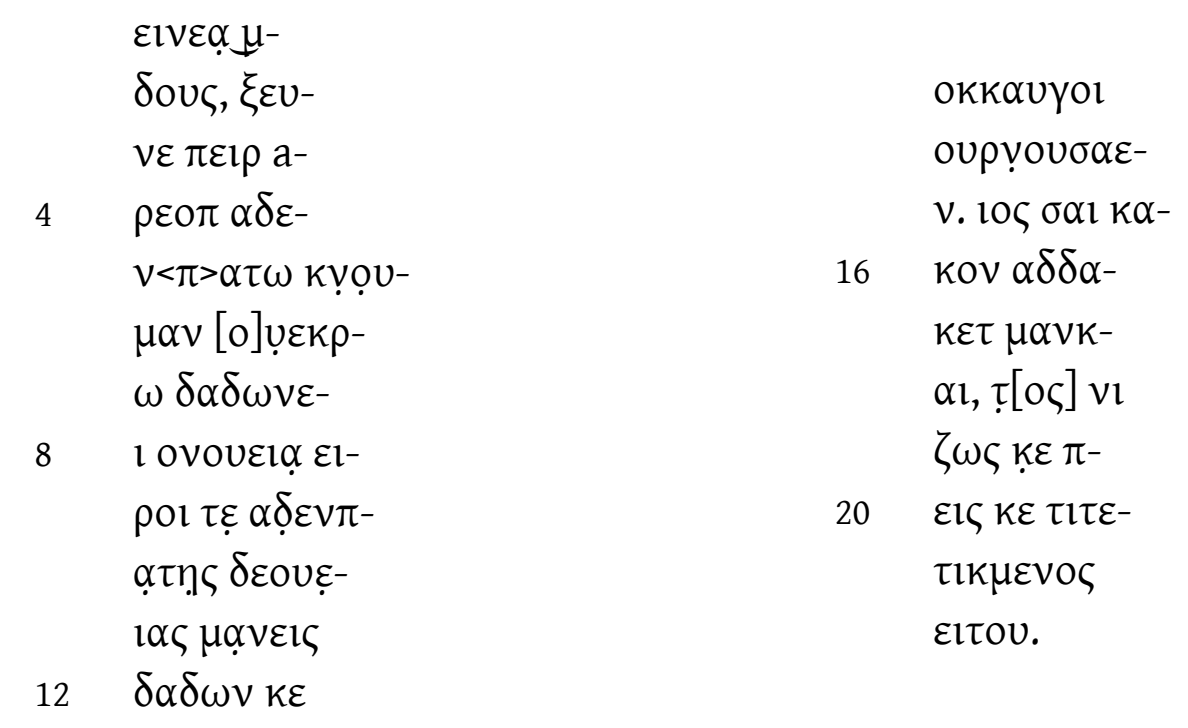




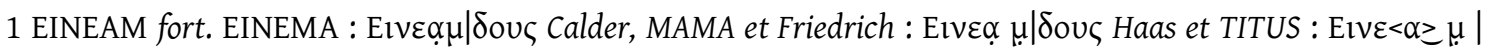

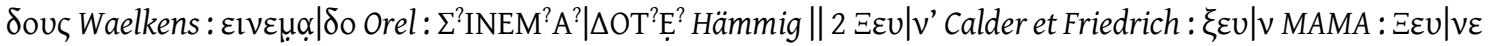

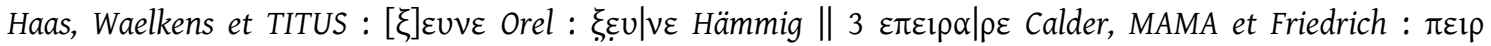

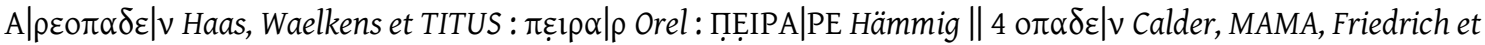

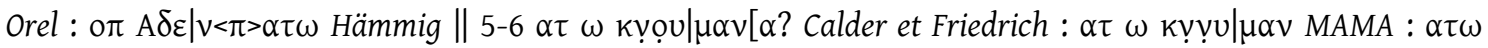

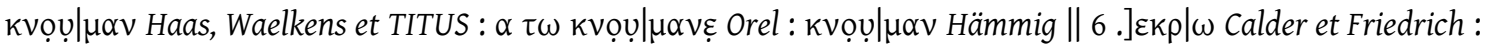

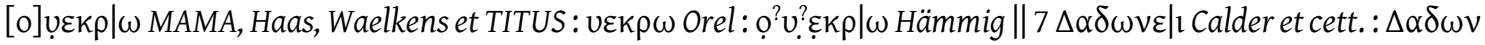

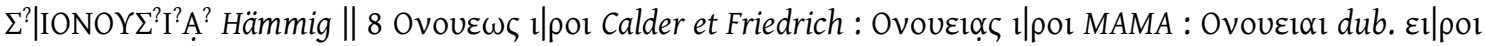

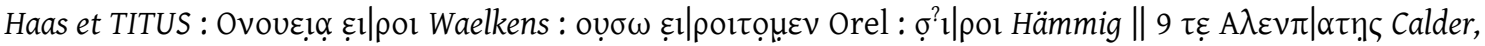

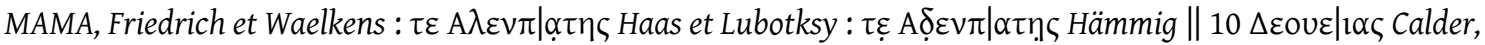

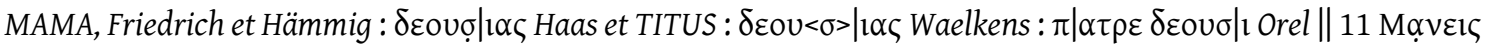

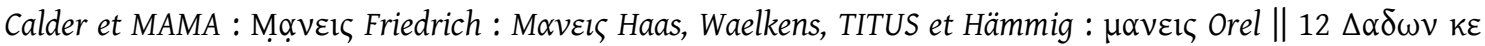

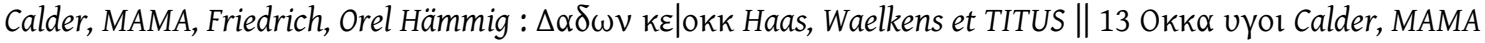

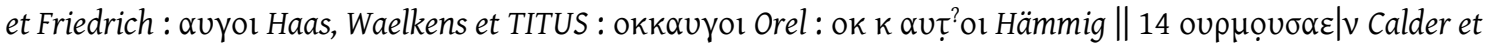
Friedrich : oup

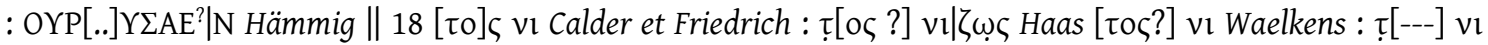
MAMA et TITUS : $\tau[10 \zeta] v \mathrm{v}$ Orel $\| 19 \zeta \omega \zeta \mathrm{k} \varepsilon \pi \mid \varepsilon \mathrm{c} \zeta$ Calder, MAMA, Friedrich et Waelkens : $\zeta<\varepsilon \mu \varepsilon \lambda>\omega \varsigma$ prop. Heubeck

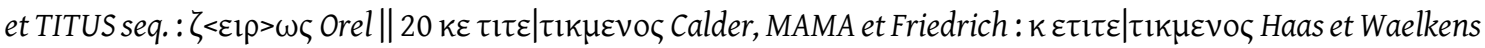

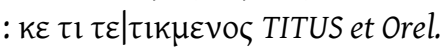

'[1. 15] ... Whoever does harm to this stele, let him be accursed whilts he is alive and dead?'

\section{Ladik}

\section{1}

Inscription copied by Calder in 1908 and 1910 and engraved "on a rough shapeless stone" (Calder 1911, 203). One column is devoted to the Greek text and the other one to the Phrygian imprecation (with a smaller letter).

Calder 1911, 203 no. LXI; Friedrich 1932, 137 no. 61; Haas 1966, 122-123 no. 59; Haas 1970a, 47 no. 61; Diakonoff \& Neroznak 1985, 77 no. B 61 (only the Phrygian text); TITUS, no. 61 (only the Phrygian text); Orel 341-342 no. S*-15.

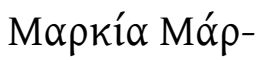

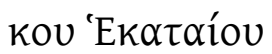

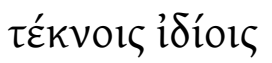

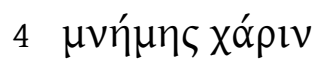

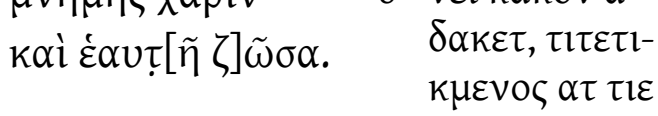

$$
\begin{aligned}
& \text { lo } \sigma \varepsilon \mu o u v
\end{aligned}
$$

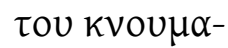

$$
\begin{aligned}
& 8 \text { VEl KaKOV } \alpha- \\
& \alpha \delta \varepsilon i \tau o u .
\end{aligned}
$$

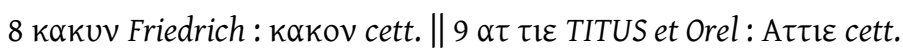

'[Greek] Markia (the daughter) of Markos (the granddaughter) of Hekateos for her own children in memory and for herself, whilst she is alive. [Phrygian] Whoever does harm to this tomb, let him be accursed by Zeus.' 


\section{2}

Copied by Calder in 1911, "was engraved on a round pillar; there was no Greek inscription accompanying it. The erasure of most of the letters appeared ancient, and was carefully executed" (Calder 1913, 101).

Calder 1913, 101 no. LXX; Friedrich 1932, 138 no. 70; Haas 1966, 124 no. 68; Diakonoff \& Neroznak 1985, 79 no. B 7 (confused with 42.1); TITUS, no. 70; Orel 1997a, S*-18.

$$
\begin{aligned}
& \operatorname{los}[\mathrm{vl} \sigma \varepsilon \mu \mathrm{ov}] \\
& \kappa v[\text { ou } \mu \alpha \varepsilon l k]- \\
& \alpha \kappa o[u v \alpha \delta \delta \alpha]- \\
& 4 \quad k \varepsilon \tau,[\tau \iota \tau \tau \varepsilon \tau \iota k]- \\
& \mu \varepsilon[\operatorname{vos} \alpha \tau \tau l]- \\
& \varepsilon \alpha[\delta \varepsilon ı \tau O u] .
\end{aligned}
$$

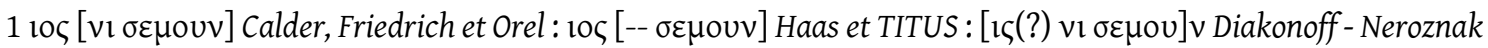

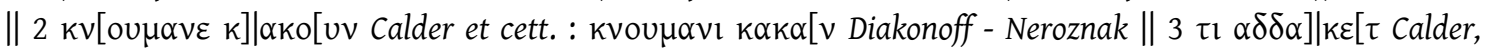

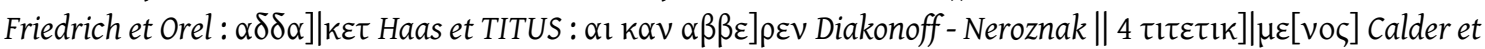

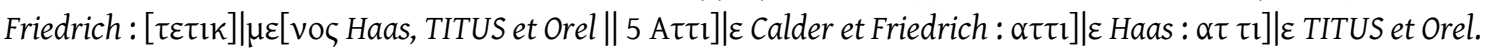

'Who[ever do]es [h]arm to [this] to[mb], [let him become accurs]e[d by Ze]us.'

\section{3}

Copied by Hogarth, who found it in a "Road-side cemetery, a mile beyond Kunderaz: on

\begin{tabular}{|c|c|}
\hline & 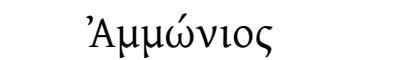 \\
\hline & 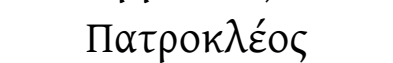 \\
\hline & $\alpha \dot{\pi} \pi \lambda \varepsilon v ́ \theta \varepsilon \rho \circ \varsigma$ \\
\hline 4 & 'A $\lambda \varepsilon \xi \xi^{\alpha} \nu \delta \rho \omega$ \\
\hline & 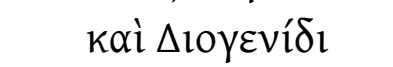 \\
\hline & 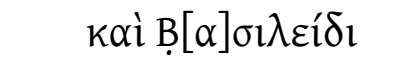 \\
\hline & $\tau \varepsilon ́ \kappa \nu 01 \varsigma \mu \nu \eta^{\prime}-$ \\
\hline 8 & 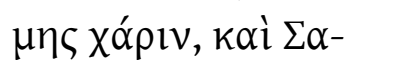 \\
\hline & $\tau \varepsilon i ́ \rho \eta ~ \gamma u v \alpha l^{-}$ \\
\hline & 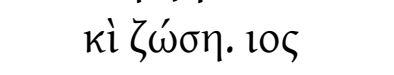 \\
\hline & 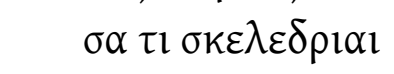 \\
\hline 12 & k $\alpha$ Kouv $\delta \alpha \kappa \varepsilon \tau, \alpha-$ \\
\hline & $\tau \varepsilon \tau 1 \kappa \mu \varepsilon v \circ \varsigma \alpha \tau$ \\
\hline
\end{tabular}
a stele which has been much worn by exposure" $(1890,159)$. Lunate sigma and epsilon.

Hogarth 1890, 159-160 no. 3; Ramsay 1905, col. 101-102 no. XLI; Calder 1911, 213-214 no. XLVII (only the Phrygian text); Friedrich 1932, 137 no. 67; Haas 1966, 123 no. 67; Diakonoff \& Neroznak 1985, 78 no. B 67 (only the Phrygian text); TITUS, no. 67 (only the Phrygian text); Orel

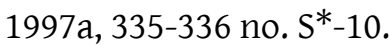




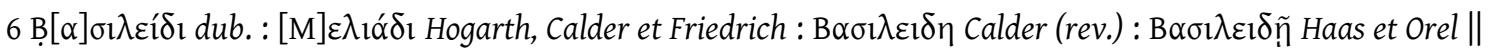

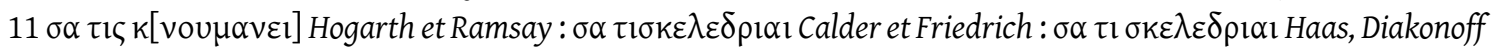

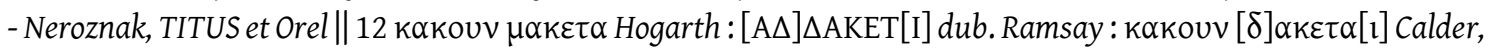

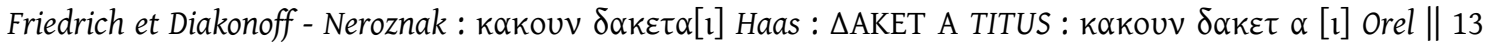

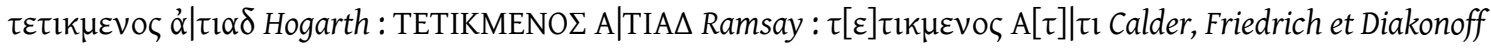

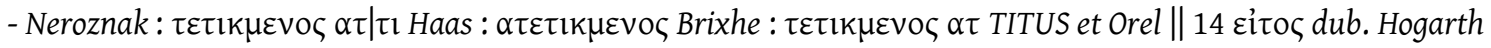

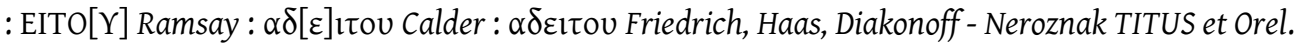

'[Greek] Ammonios the son of Patrocles, libertus, for his children Alexandros and Basilis in memory. Also for Satire his wife, whilst she is alive. [Phrygian] Whoever does harm to this skeledria, let him become accursed by Zeus.'

\section{Kurşunlu}

\section{1}

Copied by Calder in 1910 in the cemetery of Kurşunlu. "The inscription is engraved immediately under the pediment (broken) of a buried doorstone (?). I thought there had been a line (doubtless of Greek) above the inscription, but $\mathrm{T}$ was the only surviving trace of it. (Probably ớv́์ $] \tau[\eta \sigma \varepsilon v$.$) " (Calder 1911, 211). "H. 1.00; w. 0.90; th. 0.18; letters 0.025 to 0.04" (MAMA$ VII, 45). Lunate sigma and epsilon.

Calder 1911, 211 no. LXV; Friedrich 1932, 137 no. 65; MAMA VII, 45 no. 215 (pl. 12 no. 215); Haas 1966, 123 no. 65; Waelkens 1986, 223 no. 573 (Tafel 80, no. 573); Diakonoff \& Neroznak 1985, 77 no. B 65 (as variant of B 61); TITUS, no. 65; Orel 1997a, 342-343 no. S*-16.

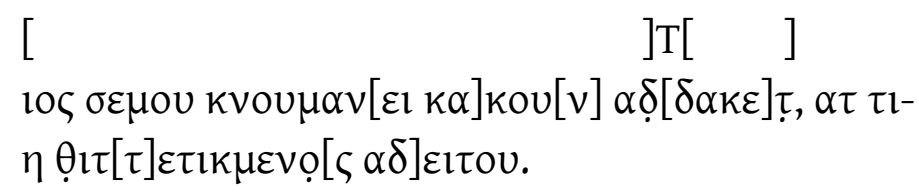

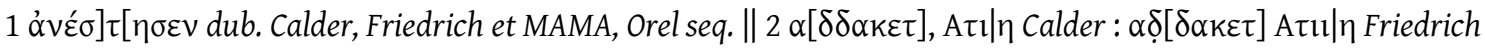

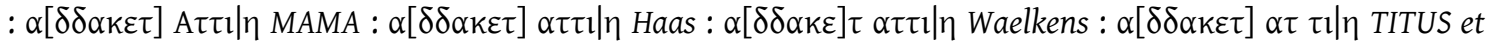

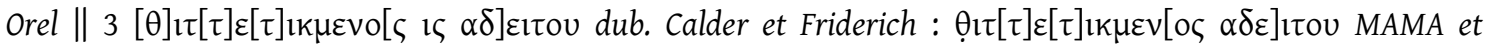

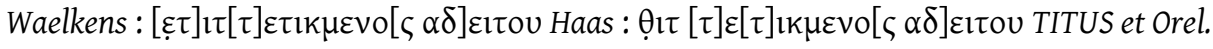

'... Whoever $\mathrm{d}[$ oes ha]rm to this tom[b], let him be accursed by Zeus.'

\section{Sarayönü}

\section{1}

"Stele of bluish limestone, broken down right side. H., 1.14; w., 0.46; th., 0.39. In the pediment, flanked by palmettes, and broken above, a lion, seated, facing r. Between the two parts of the inscription, a pick, satchel, and stylus?" (MAMA I, 22). Found in the eastern cemetery and copied by Ramsay and Calder in 1910. Lunate sigma and epsilon. 
Calder 1911, 197 no. LIII; MAMA I, 22 no. 32; Friedrich 1932, 136 no. 53; Haas 1966, 121 no. 53; Diakonoff \& Neroznak 1985, 80 no. B 53; TITUS, no. 53 (only the Phrygian text); Orel 1997a, 339-341 no. $S^{*}-14$.

$$
\begin{aligned}
& {[\ldots . . . .] \circ \varsigma \Gamma \alpha \lambda-} \\
& \lambda_{\imath \kappa}[\tilde{\omega}] \tau \tilde{\omega} i \delta i ́ \omega \\
& \tau \varepsilon \dot{\kappa} \kappa \nu \omega \mu \nu \eta \dot{\mu}-
\end{aligned}
$$

4 ฤ५ Xópiv.

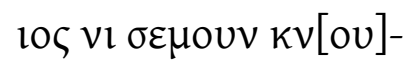

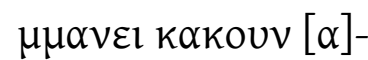

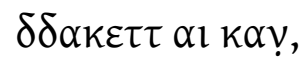

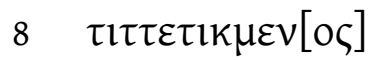

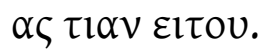

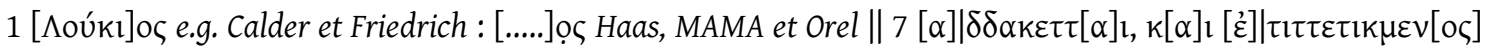

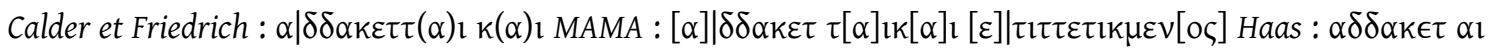

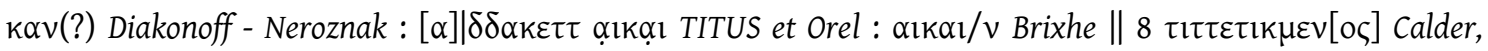

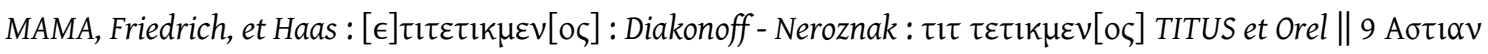

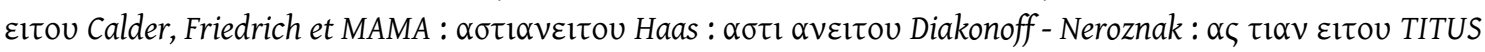
et Orel.

'[Greek] [---] for his/her own son Gallicos in memory. [Phrygian] Whoever does harm to this tomb or whatever, let him be accurse[d] by Zeus.'

\section{Zivarıkhan - Altınekin}

\section{1}

Copied by Ramsay and Calder in 1910, "the stone had been hollowed out to make a water-spout; lines 2 and 4, where the restorations are certain, confirm or estimate of the number of letters lost in the Phrygian portion" $(1911,194)$. Lunate sigma and epsilon, cursive omega.

Calder 1911, 194-195 no. LI; Friedrich 1932, 135 no. 51; Haas 1966, 121 no. 51; Diakonoff \& Neroznak 1985, 78 no. B 51; TITUS, no. 51 (only the Phrygian text); Orel 1997a, 338-339 no. S*13.

$$
\begin{aligned}
& \operatorname{A\sigma \kappa } \lambda[\tilde{\alpha} \varsigma \ldots . . .] \nu 1 \tau \varepsilon-
\end{aligned}
$$

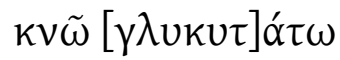

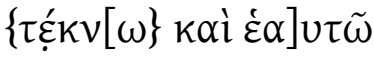

$$
\begin{aligned}
& 4\{\tau \omega\} \zeta \tilde{\omega}[v \tau \imath \mu \nu] \underline{n} \mu \eta[\varsigma] \\
& \text { Xópiv. [1oৎ } \sigma \varepsilon \mu] \text { ]ov } \rho \varepsilon- \\
& \kappa \tau \varepsilon \circ \mathrm{v}[\kappa \alpha \kappa o v] v \propto \delta \alpha- \\
& \kappa \varepsilon, \alpha \tau \varepsilon[\tau \iota k \mu \varepsilon v o] \zeta \alpha \tau \tau[\imath] \\
& 8 \alpha \delta \varepsilon 1[\tau o v . . . .] \alpha \sigma \gamma
\end{aligned}
$$




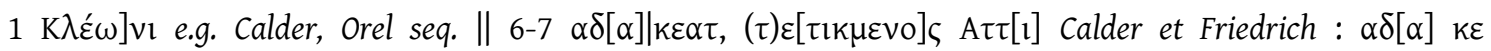

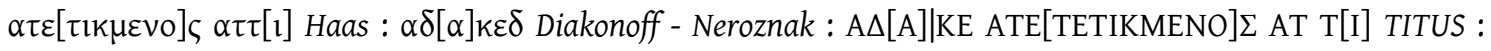
$\alpha \delta[\alpha] \mid \kappa \varepsilon\{\alpha\} \tau \varepsilon[\tau \varepsilon \tau 1 \kappa \mu \varepsilon v o] \sigma$ AT T[I] Orel $\| 8 \alpha \sigma \gamma$ dub. Calder, Friedrich et Haas : ] $\alpha \varsigma, \pi[---]$ Orel : om. TITUS.

'[Greek] Ascl[as ---] his [dea]rest son and for [her]self, whilst she is alive, in memory. [Phrygian] [Whoever] does [har]m to [thi]s rekteon, [let him] become ac[curse]d by Ze[us].'

\section{8. Çeşmelisebi}

\section{1}

Found by Calder in 1913: "[o]n a stele representing a distyle temple in front view, with a round arched pediment. In the pediment two female busts, two sets of spindle and distaff, wool-basket, and crescent. Broken below; the bait of a large reward failed to produce the lower part of the stone" (Calder 1926, 25). Only the very beginning of a Phrygian imprecative protasis remains.

Calder 1926, 25 no. LXXXI; Friedrich 1932, 139 no. 81; Haas 1966, 125, no. 81; Diakonoff \& Neroznak 1985, 77 no. B 81 (only the Phrygian text as variant of B 10); TITUS, no. 81 (only the Phrygian text); Orel 1997a, 278-279 no. C*-26.

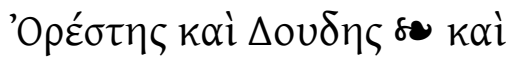

$$
\begin{aligned}
& \Delta \alpha \delta \alpha \text { se } \Delta \alpha \delta \alpha \tau \tilde{\eta} \dot{\varepsilon} \alpha v_{-}
\end{aligned}
$$

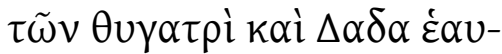

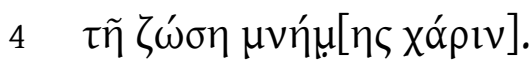

$$
\begin{aligned}
& \text { lo丂 } \kappa v[\text { ou } \mu \alpha v \varepsilon l---]
\end{aligned}
$$

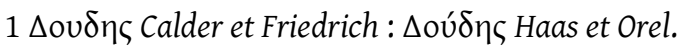

'[Greek] Orestes and Dudes and Dudas for Dada their daughter and Dada for herself, whilst she is alive, [in m]emory. [Phrygian] Whoever to the $\mathrm{t}$ [omb ---].'

\section{2}

"Stele of bluish limestone, defaced above and at the sides, broken below. H., 1.45; w., 0.63; th., 0.28; letters 11. 1-3, 0.04 to 0.05; 1l. 4, 5, 0.03; 11. 6- 7, 0.025 to 0.03." (MAMA I, 178). Found lying near the mosque. Lunate sigma and epsilon, cursive omega.

MAMA I, 178 no. 340; Friedrich 1932, 140 no. 84; Haas 1966, 126 no. 84; Diakonoff \& Neroznak 1985, 77 no. B 84 (only the Phrygian text as variant of B 10); TITUS, no. 84 (only the Phrygian text); Orel 1997a, 280-281 no. C*-28.

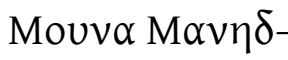

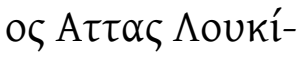

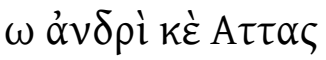


$4 \quad i \delta i[\omega \pi \alpha] \tau[\rho i]$

$\mu v[\eta ́ n \eta\rceil$ xóplv].

$10 \varsigma \sigma \varepsilon \mu[\mathrm{ouv} \tau \mathrm{\tau ov}]$

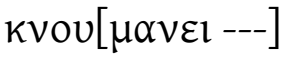

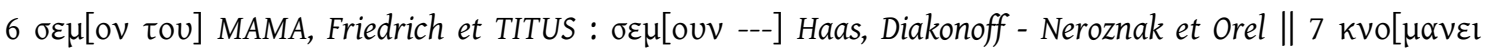

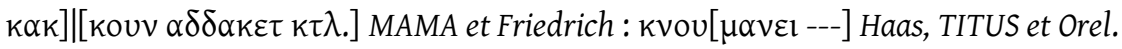

'[Greek] Muna Manedos Attas for Lucius her Husband and Attas for his ow[n fa]th[er] in memory. [Phrygian] Whoever to th[is] tom[b ---].'

\section{3}

"Cheshmeli Zebir, near the fountain below the mound. Block of grey limestone with plain moulding above. H., 0.77; w., 0.83; th., 0.28 (the moulding protrudes $\mathrm{m} .0 .07$ in front); letters, 0.04 to 0.045 . The block has been cut away on the 1., or the inscription and decoration was carried over from an adjoining block in a built tomb. Part of a table, and a basket and spindle and distaff survive" (MAMA I 1928, 179). Lunate sigma and epsilon.

MAMA I, 179 no. 341; Friedrich 1932, 140 no. 85; Haas 1966, 126 no. 85; Diakonoff \& Neroznak 1985, pg. 77 no. B 85 (as variant of B 61); TITUS, no. 85; Orel 1997a, 281-282 no. C*-29.

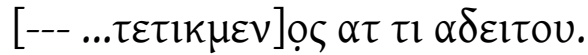

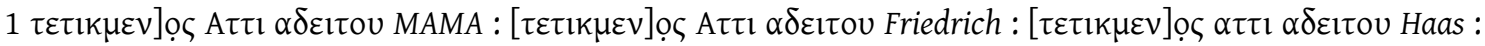

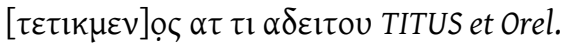

$$
\text { '[---] let him become [accurs]ed by Zeus.' }
$$

\section{9. İnsuyu}

\section{1}

"Insuyu, near Katirli Mesarlik. Round pillar. H. 1·60; diam., top 0.37, base 0.47. On the top, nine round holes round the edge and one in centre. The inscription, broken away below, is at the base" (MAMA VII 1956, 110).

MAMA VII, 110 no. 522 (pl. 143); Haas 1966, 129 no. 110; TITUS, no. 110; Orel 1997a, 287288 no. $C^{*}-37$

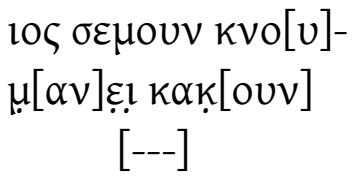

'Whoever to this to[m]b har[m ---].' 


\section{Böğrüdelik}

\section{1}

Inscription on a stele copied by Calder in 1908, his reading was revised and improved with Ramsay in 1910. Lunate sigma and epsilon, cursive omegas.

Calder 1911, 197-198 no. LIV; Friedrich 1932, 136 no. 54; Haas 1966, 121 no. 54; Haas 1970a, 48 no. 57; Diakonoff \& Neroznak 1985, 77 no. B 54 (only the Phrygian text as variant of B 61); TITUS, no. 54 (only the Phrygian text); Orel 1997a, 259-260 no. C*-11.

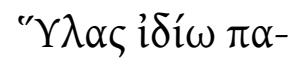

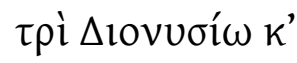

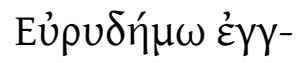

$$
\begin{aligned}
& 4 \text { ó } v \omega \kappa \dot{\varepsilon} \mu \eta \tau[\rho i] \Delta-
\end{aligned}
$$

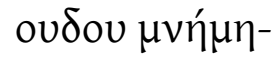

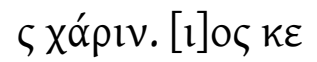

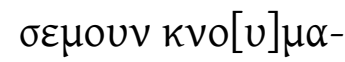

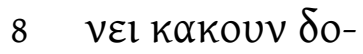

$$
\begin{aligned}
& \kappa \varepsilon \tau, \alpha \tau \tau \imath \propto \delta \varepsilon \imath[\tau o v] .
\end{aligned}
$$

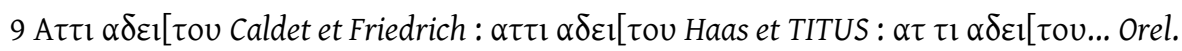

'[Greek] Hylas for this own father Dionisios and his son Eurydemos and his mother Dudu in memory. [Phrygian] [Wh]oever does harm to this to[m]b, let him become (accursed) by Zeus.'

\section{2}

Inscription engraved on a stele copied by Calder in 1908 (in 1910 he was still able to see it again, but it was broken). Lunate sigma and epsilon, cursive omega.

Calder 1911, 198-198 no. LV; Friedrich 1932, 136 no. 55; Haas 1966, 121 no. 55; Diakonoff \& Neroznak 1985, 77 no. B 55 (as variant of B 10); TITUS, no. 55; Orel 1997a, 260-261 no. C*-12.

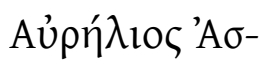

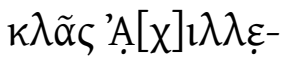

$$
\begin{aligned}
& \omega \varsigma \mathrm{K} \lambda \alpha \cup \delta 10-
\end{aligned}
$$

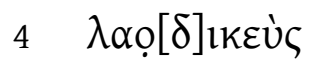

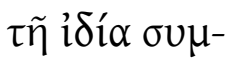

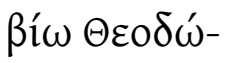

$$
\begin{aligned}
& \text { } \alpha \mu \nu \eta ́ \mu \eta \varsigma \\
& 8 \text { xópıv. }
\end{aligned}
$$




$$
\begin{aligned}
& 10[\varsigma \nu 1 \sigma \varepsilon \mu] \mathrm{ouv} \\
& \kappa[\operatorname{vov\mu \alpha }] v \varepsilon l \\
& \kappa[\alpha \kappa o u v] \alpha \delta \delta \alpha- \\
& 12 \kappa[\varepsilon \tau, . .] l \text { ol rou- }
\end{aligned}
$$

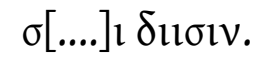

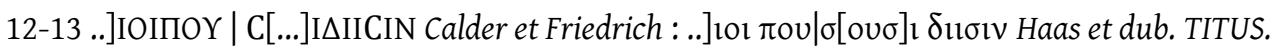

'[Greek] Aurelius Asklas the son of Achilleus, Claudioladikeian for his own wife Theodora in memory. [Phrygian] Wh[oever] do[es] h[arm] to [thi]s t[om]b, ...'

\title{
51. Çarbaşlı Yayla
}

\section{1}

Inscription read by Ramsay and Calder in 1912 and 1913 "on the two top panels of a doorstone, the top of which is lost. Very rude engraving" (Calder 1926, 24). "In the panels, knocker, keyplate, spindle and distaff, defaced object. H. 0.66; w. 0.66; w. 0.64; th. 0.34; letters 0.02 to 0.025 " (MAMA VII, 77).

Calder 1926, 24-25 no. LXXX; Friedrich 1932, 139 no. 80; MAMA VII, 77 no. 317; Haas 1966, 125 no. 80; Diakonoff \& Neroznak 1985, 77 no. B 80 (as variant of B 61); Waelkens 1986, 233 no. 595; TITUS, no. 80; Orel 1997a, 277-278 no. C*-25.

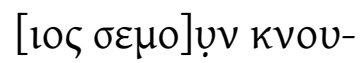 \\ $[\mu \alpha v \varepsilon 1]$ kakouv \\ $[\alpha] \delta \delta \alpha \kappa \varepsilon \tau, \tau \imath \tau-$ \\ $4 \quad[\varepsilon \tau] \iota \kappa \mu \varepsilon v o[\varsigma] \alpha \tau \tau l \propto \delta-$

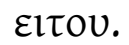

$3[\alpha] \delta \delta \alpha \kappa \varepsilon \tau \tau \imath \imath||[\varepsilon \tau] \iota \kappa \mu[\varepsilon v o \zeta$ Calder et Friedrich : $[--\alpha] \delta \delta \alpha \kappa \varepsilon \tau \tau \imath \tau||[\tau \varepsilon \tau] \tau ı \kappa \mu \varepsilon v o[\varsigma]$ Haas et TITUS : $[\alpha] \delta \delta \alpha \kappa \varepsilon \tau \tau l$

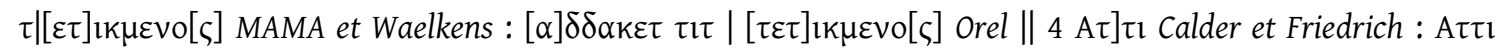

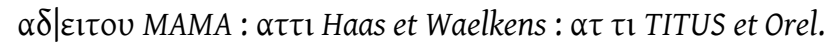

'[Whoever m]akes harm [to thi]s to[mb], let him become ac[cu]rse[d] by Zeus.'

\section{Sarıkaya}

\section{1}

Inscription read by Ramsay and Calder in 1912 "on the base of a bomos, broken at the top and on the right. A Greek inscription may have been carved on the lost portion of the bomos. It is impossible to say how many letters were lost on the r[ight] of l. 1" (Calder 1926, 23). 
Calder 1926, 23 no. LXXV; Friedrich 1932, 138 no. 75; MAMA VII, 86 no. 364(pl. 23); Haas 1966, 124 no. 75; Diakonoff \& Neroznak 1985, 82 no. B 75; TITUS, no. 75; Orel 1997a, 271-272 no. $C^{*}-20$.

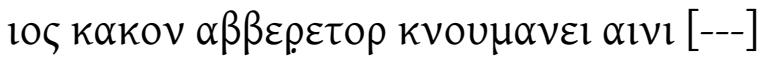

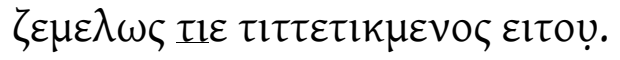

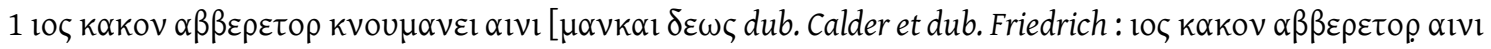

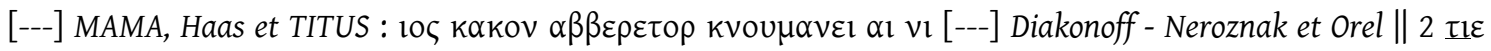

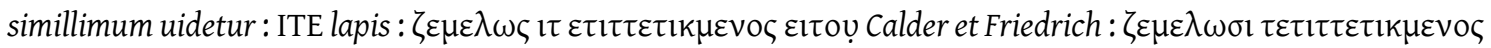

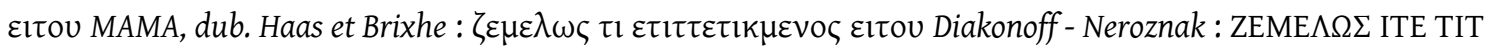
TETIKMENOs EITOY TITUS et Orel.

'Whoever brings harm to this tomb or [---], let him become accursed by Zeus (in the sight of) men.'

\section{Kelhasan}

\section{1}

Inscription read by Ramsay and Calder in 1912 "on a doorstone. Above, in an arched pediment, woman, child and man, standing. The panels of the door are decorated with (1) comb and keyhole-plate; (2) table; (3) tripod supporting two-handled basin, under it a pitcher with one handle; (4) spindle and distaff, boss, and crescent" (Calder 1926, 23). "H. 1.25; w. 0.50; th. 0.58 ; letters 0.01 to 0.0175 " (MAMA VII, 106).

Calder 1926, 23 no. LXXVI; Friedrich 1932, 139 no. 76; MAMA VII, 106 no. 495 (pl. 25 no. 495); Haas 1966, 124-125 no. 76; Diakonoff \& Neroznak 1985, 80 no. B 76 (only the Phrygian text as variant of B 33); Waelkens 1986, 247 no. 638 (Tafel 84 no. 638); TITUS, no. 76; Orel 1997a, 272273 no. $C^{*}-21$.

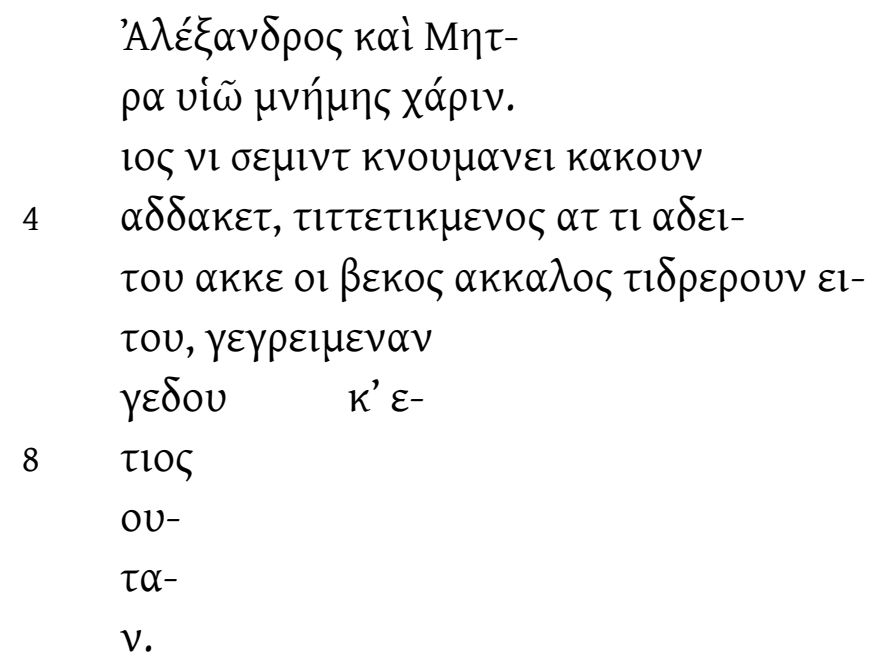

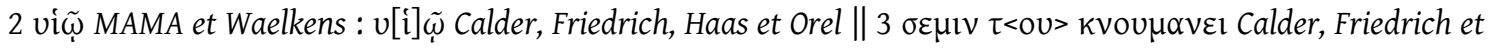

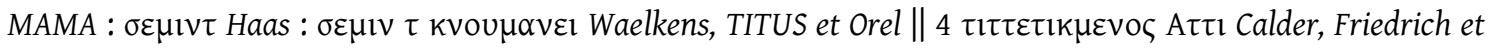

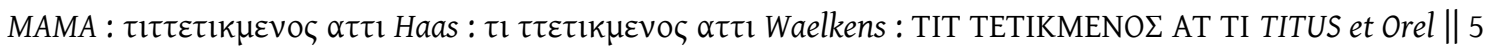

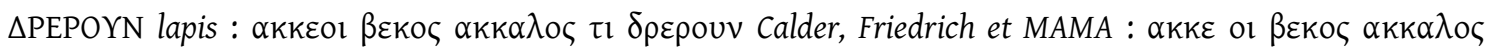




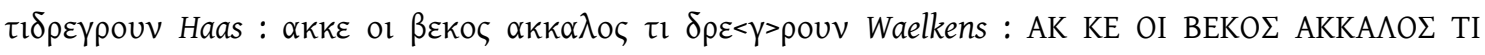

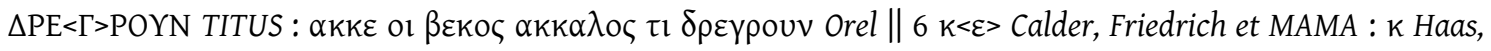

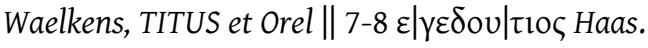

'[Greek] Alexandros and Metra for (their) son in memory. [Phrygian] Whoever does harm to this tomb, let him become accursed by Zeus and let his bread be innutrible and let him have the written curse of Zeus.'

\section{2}

Inscription read by Ramsay and Calder in 1912 "on a stele (over 6 feet high) broken at the top. Below the inscription, a tripod supporting a cooking-pot, a spindle and distaff, and a wool-basket on a table. The cross carved at the end of this inscription is a later addition" (Calder 1926, 23).

Calder 1926, 23 no. LXXVII; Friedrich 1932, 139 no. 77; Haas 1966, 125 no. 77; Diakonoff \& Neroznak 1985, 77 no. 77 (as variant of B 61); TITUS, no. 77; Orel 1997a, 273-274 no. C*-22.

\section{$0 \quad[\operatorname{lo\zeta } v 1 \mathrm{kou} \mu \alpha]-$ \\ $1 \quad[\mathrm{v}] \varepsilon \mathrm{l} \kappa \alpha \kappa[\mathrm{ou}] \mathrm{v} \alpha \delta-$ \\ $\delta \alpha K \varepsilon \tau, \tau \iota \tau \tau \varepsilon \tau l^{-}$

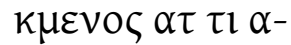

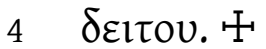

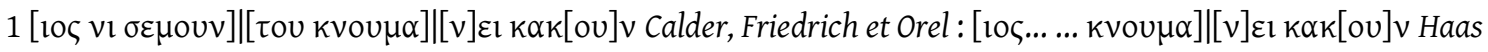

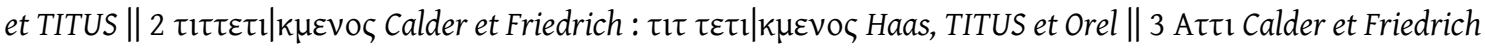
: $\alpha \tau \tau \imath$ Haas : $\alpha \tau \tau$ 1 TITUS et Orel.

'[Whoever] does ha[rm to the tom]b, let him become accursed by Zeus.'

\section{3}

"Stele, top concealed, base broken away. H. (visible) 0.40; w. 0.52; th. 0.12; letters 0.02 to 0.025” (MAMA VII, 107).

MAMA VII, 107 no. 496; Haas 1966, 129 no. 109; TITUS, 109; Orel 1997a, 287 no. C*-36.

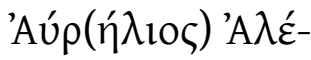

$$
\begin{aligned}
& \xi \alpha v \delta \rho \circ \varsigma \mathrm{M \varepsilon v} \text { - } \\
& \text { عov } \Sigma \varepsilon \kappa o u ́ \mu \delta \omega
\end{aligned}
$$

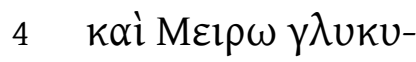

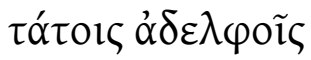

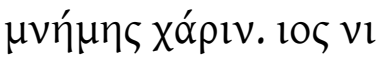

$$
\begin{aligned}
& \text { [---] }
\end{aligned}
$$


'[Greek] Aur(elios) Alexandros (the son) of Menneos for Secundus and Miros his dearest brothers in memory. [Phrygian] Whoever [---].'

\title{
54. Bulduk
}

\section{1}

Inscription engraved on a damaged bomos, "H. 0.98; w. 0.56; th. 0.42; letters 0.0275 to 0.03" (MAMA VII, 100).

MAMA VII, 100 no. 454 (pl. 140); Haas 1966, pg. 129, no. 108; Diakonoff \& Neroznak 1985, 80 no. 108 (as variant of B 33); TITUS, 108; Orel 1997a, 386 no. C*-35.

\author{
$10 \varsigma v[l \sigma \varepsilon \mu o u v k] v o u \mu \alpha v \varepsilon l$ \\ $\kappa \alpha \kappa o[u v \alpha \delta \delta \alpha \kappa] \varepsilon \tau, \tau, \tau \tau \varepsilon \tau-$

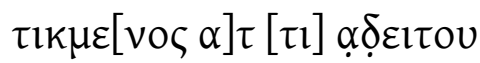

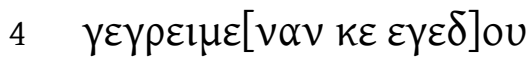 \\ $\tau 10 \zeta$ ou $[\alpha \nu \alpha K k \varepsilon$ ol $] \beta \varepsilon-$

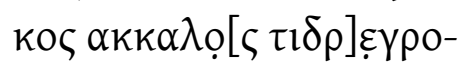 \\ $u v \varepsilon 1 \delta o[v]$.
}

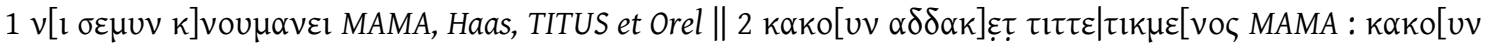

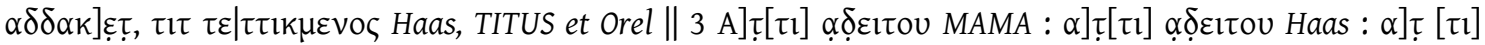

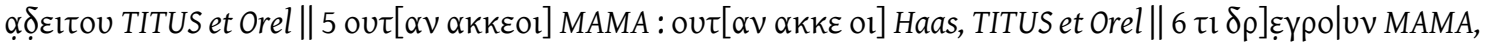
TITUS et Orel : $\tau \imath \delta \rho] \varepsilon \gamma \rho o u v \varepsilon \varepsilon \delta o[v]$ Haas.

'Whoever [mak]es [h]arm [to this t]omb, let him become accurs[ed b]y [Zeus] and let him [ha]ve the writt[en] cur[se] of Zeus [and] let [his] bread akkalo[s] be [innu]trible.'

\section{Küçükbeşkavak}

\section{1}

Broken stele ("H. 1.04; w., top 0.50, shaft 0.46, base 0.51; th. 0.28; letters 0.02 to 0.03" MAMA VII, 106) with a pediment (containing man, woman and some objects) copied by Calder in 1908 and later by Ramsay in 1910. Lunate sigma and epsilon, cursive omega.

Calder 1911, 199-200 no. LVI; MAMA VII, 106 no. 492; Friedrich 1932, 136 no. 56; Haas 1966, 121-122 no. 56; Diakonoff \& Neroznak 1985, 78 no. B 56 (only the Phrygian text); TITUS, no. 56 (only the Phrygian text); Orel 1997a, 261-262 no. C*-13. 


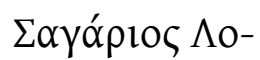 \\ ukíou $\Delta$ ou $\delta \alpha$ \\ $\tau \tilde{\eta} i \delta i ́ \alpha \sigma[v] v-$

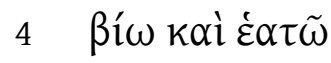 \\ $\zeta \tilde{\omega} \vee \tau \imath \mu \vee \eta ́ \mu-$ \\ $\eta \varsigma$ Xópiv.

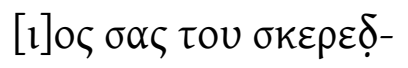

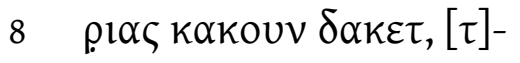

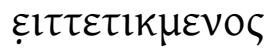

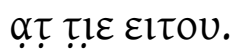

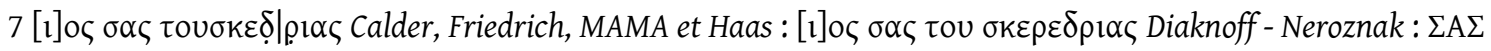

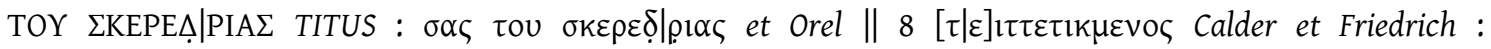

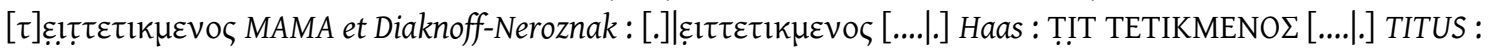

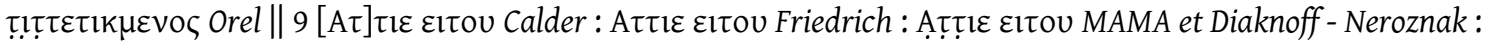

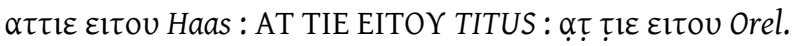

'[Greek] Sagarios (the son) of Lucius for his own wife Duda and for himself, whilst he is alive, in memory. [Phrygian] [Wh]oever does harm to this skeredrias, let him become [a]ccursed by Zeus.'

\section{Büyük Beşkavak}

\section{1}

Broken door-stele ("H. 1.25; w. 0.75; th. 0.39; letters 0.025 to 0.03 " MAMA VII, 105) with a pediment with a relief (perhaps a horse). The Greek text was very eroded, only few letters were legible, while the Phrygian curse is complete. Lunate sigma and epsilon.

Calder 1911, 200-201 no. LVII; MAMA VII, 105 no. 487 (pl. 27 no. 487); Friedrich 1932, 136 no. 57; Haas 1966, 122 no. 57; Waelkens 1986, 244 no. 629 (Tafel 84 no. 629); Diakonoff \& Neroznak 1985, 77 no. B 57 (only the Phrygian text as variant of B 61); TITUS, no. 57 (only the Phrygian text); Orel 1997a, 263-264 no. C*-14.

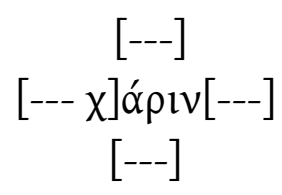

4

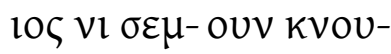

$\mu \alpha v \varepsilon \kappa \alpha-\quad k o u v \alpha \delta-$

$\delta \alpha \kappa \varepsilon \tau, \tau-\tau \imath \tau \tau \varepsilon \tau ו k \mu-$

$\varepsilon \vee O S \alpha-\quad \tau \tau l \alpha \delta \varepsilon l^{-}$

8 โov. 


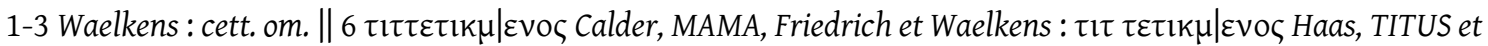

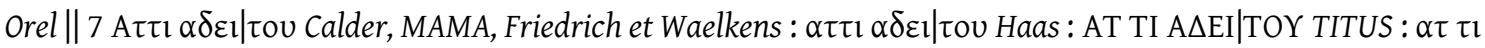
$\alpha \delta \varepsilon \mathrm{I} \mid$ tov Orel.

'[Greek] [---] in [memory ---]. [Phrygian] Whoever does harm to this tomb, let him become accursed by Zeus.'

\section{2}

Door-stele with an inscription copied by Calder in 1908 and by Ramsay and Calder in 1910. Lunate sigma and epsilon, cursive omega.

Calder 1911, 201-202 no. LVII[I]; Friedrich 1932, 136 no. 58; MAMA VII, 105 no. 488 (only the Greek text); Haas 1966, 122 no. 58; Diakonoff \& Neroznak 1985, 86 no. C 58 (only the Phrygian text); Waelkens 1986, 244 no. 630; TITUS, no. 58 (only the Phrygian text); Orel 1997a, 264-266 no. $C^{*}-15$.

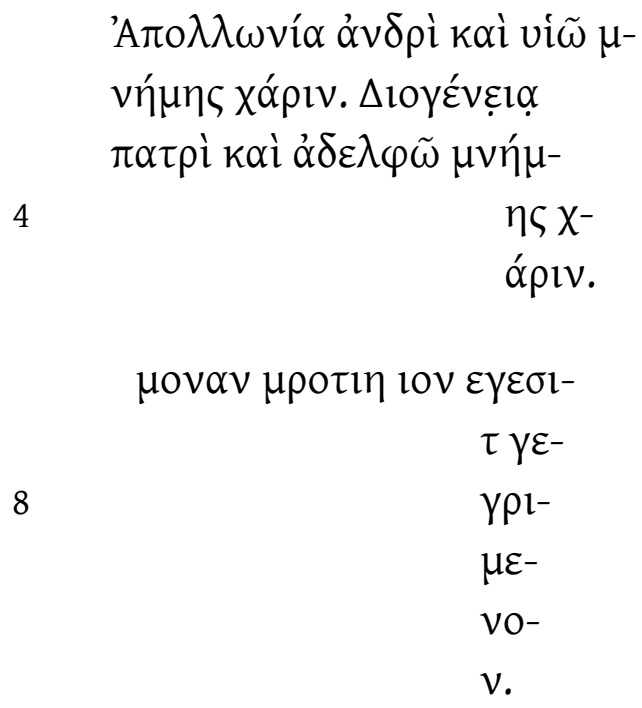

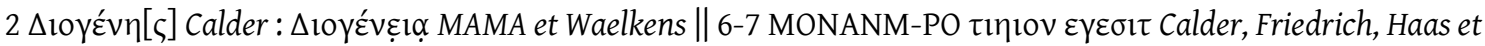

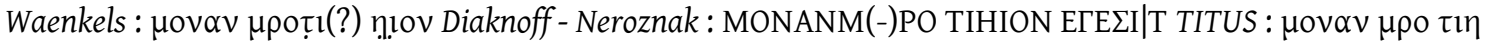

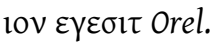

'[Greek] Apollonia for her Husband and her son in memory. Diogeneia for his father and his brother in memory. [Phrygian] Only for the dead whom it has written.'

\section{3}

Damaged stele found by Calder and Ramsay in the north of Beşkavak, beside a wall. Rectangular sigma and epsilon, cursive omega.

Calder 1911, 210-211 no. LXIV; Friedrich 1932, 137 no. 64; Haas 1966, 123 no. 64; Diakonoff \& Neroznak 1985, 79 no. B 64 (only the Phrygian text); TITUS, no. 64 (only the Phrygian text); Orel 1997a, 268-269 no. C*-18. 


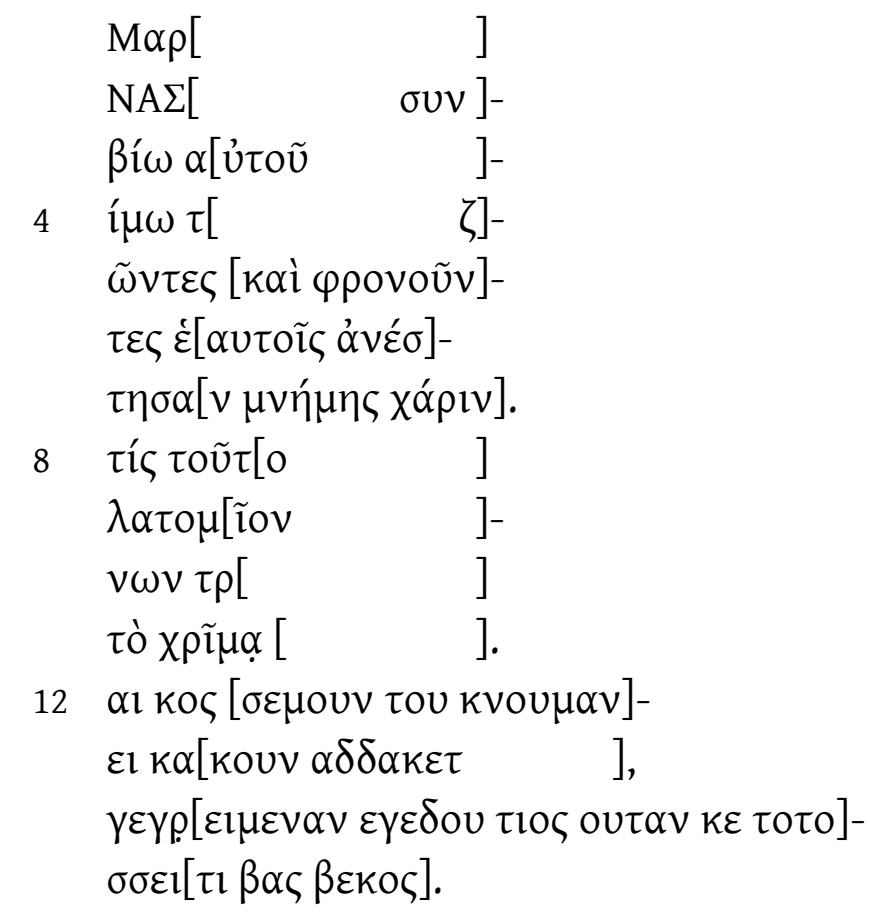

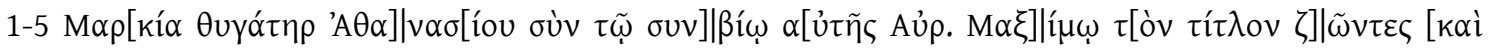

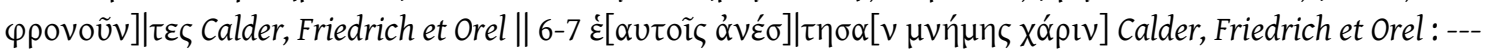

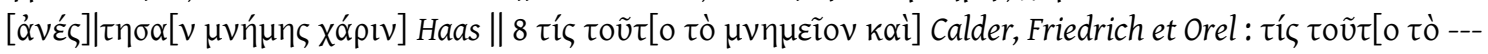

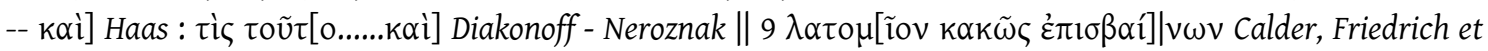

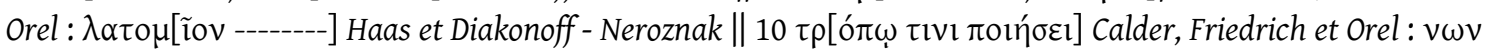

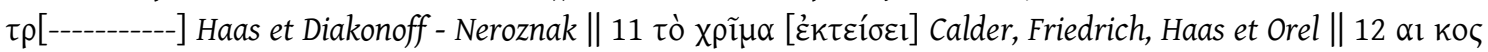

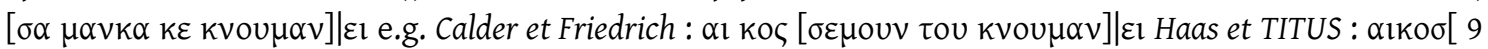

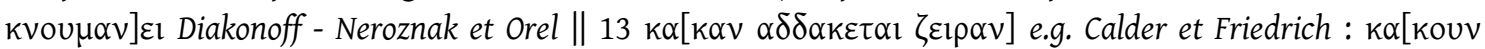
$\alpha \delta \delta \alpha \kappa \varepsilon \tau]$ Haas et TITUS : $\kappa \alpha \kappa\left[\right.$ ouv 11-12] Diakonoff - Neroznak et Orel \|| $\left.14 \gamma \varepsilon \gamma[\rho \varepsilon l \mu \varepsilon v \alpha v \varepsilon \gamma \varepsilon \delta o u \tau ~ 10]\right|_{\zeta}$ e.g.

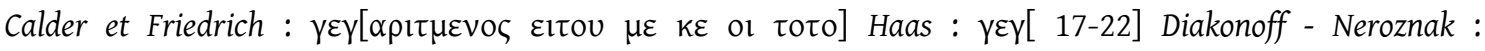

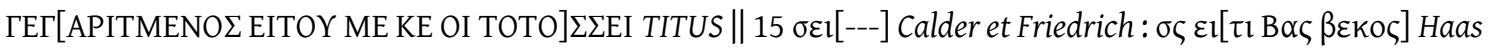

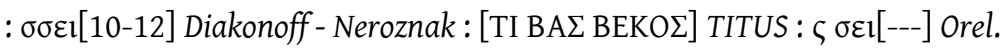

\section{Kandil}

\section{1}

Inscription read by Calder in 1913 on a broken door-stele. "Above the inscription a wool-basket and spindle and distaff. Below the inscription a lock and knocker" (Calder 1926, 24).

Calder 1926, 24 no. LXXVIII; Friedrich 1932, 139 no. 78; Haas 1966, 125 no. 78; Diakonoff \& Neroznak, 1985, 77 no. 78 (as variant of B 10); Waelkens 1986, 249 no. 650; TITUS, no. 78; Orel 1997a, 274-275 no. C*-23.

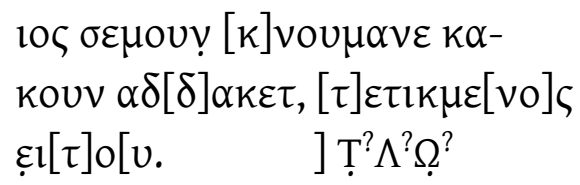

$3 T^{?} \Lambda^{?} \Omega^{?} ?$ uel $T^{?} \Lambda^{?}{ }^{?}{ }^{?}$ : ọo uel $\lambda$ o Orel. 
'Whoever d[o]es harm to this [t]omb, let him b[e] [a]ccurs[e]d. [---]'

\section{Hatırlı}

\section{1}

Badly defaced inscription engraved on a round pillar found by Callander, Ramsay and Calder, who copied it in 1912. Lunate sigma and epsilon, cursive omega.

Calder 1913, 103-104 no. LXXII; Friedrich 1932, 138 no. 72; Haas 1966, 124 no. 72; Diakonoff \& Neroznak 1985, 80 no. B 72 (only the Phrygian text); TITUS, no. 72 (only the Phrygian text); Orel 1997a, 262-271 no. C*-19.

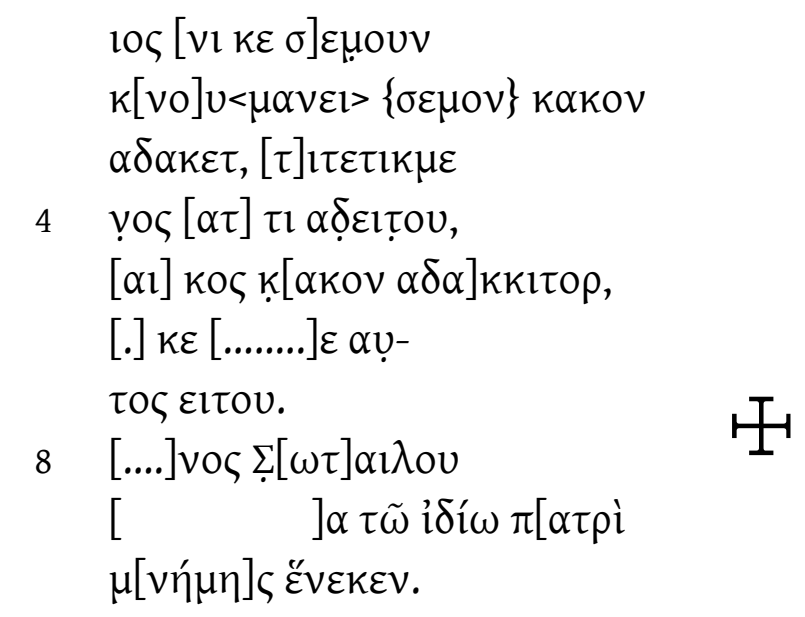

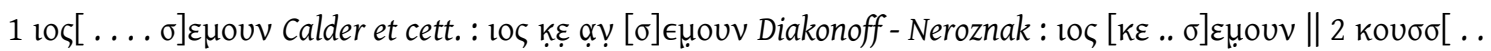

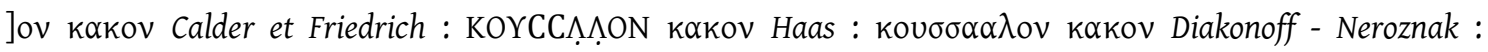

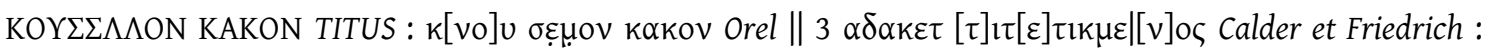

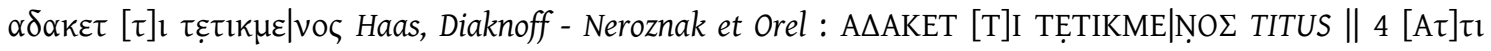

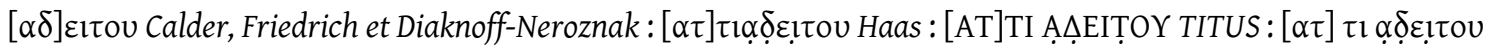

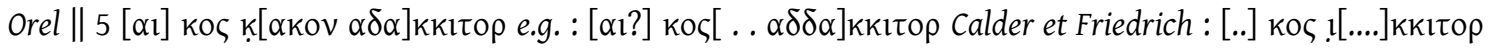

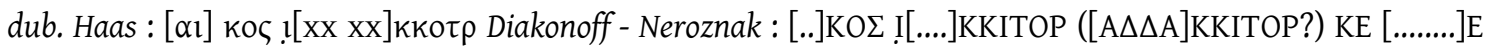

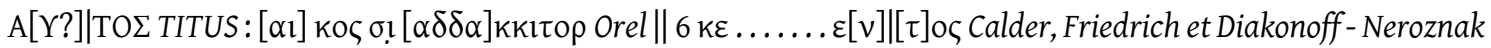

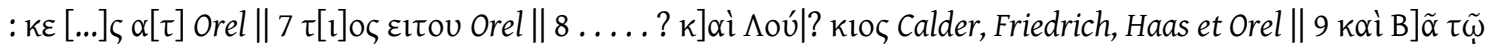

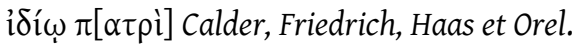

'[Phrygian] And whoever does harm to [t]his $t[o] m b$, let him be [a]ccursed [by] Zeus. [If] anybody [m]akes h[arm] [---], let him be [---] [Greek] [---]nos the son of Sotelos [---] for his own father in memory.'

\section{Kozanl1}

\section{1}

Stele first published by Anderson in 1899 and read by Calder in 1910. It is decorated "with rounded pilasters and arched pediment containing woman, spindle and distaff. H. 1.57; w. 0.57; th. 0.50; letters 0.02 to 0.03" (MAMA VII, 97). Lunate sigma and epsilon, cursive omega. 
Anderson 1899, 119 no. 117; Ramsay 1905, col. 103 no. XLVI; Calder 1991, 185 no. XLVI; MAMA VII, 97 no. 437; Friedrich 1932, 135 no. 46; Haas 1966, 129 no. 107; Diakonoff \& Neroznak 1985, 77 no. B 107 (only the Phrygian text as variant of 10); TITUS, no. 107 (only the Phrygian text); Orel 1997a, 257-258 no. $C^{*}-09$.

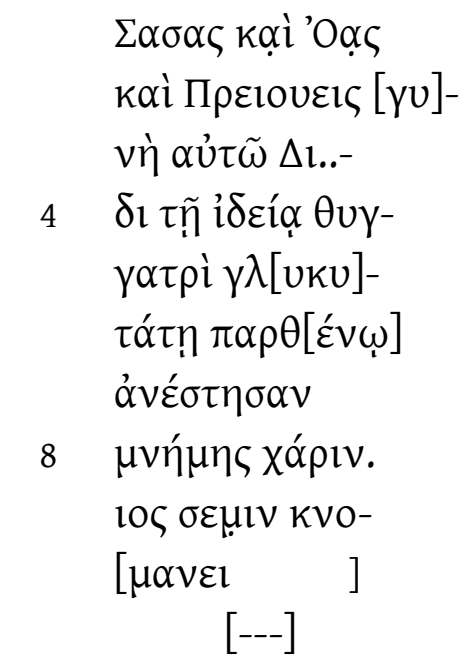

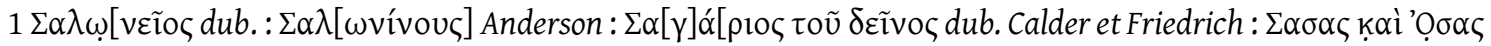

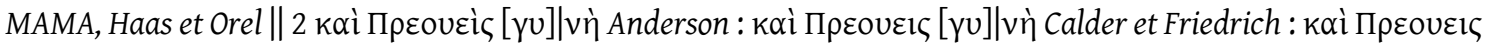

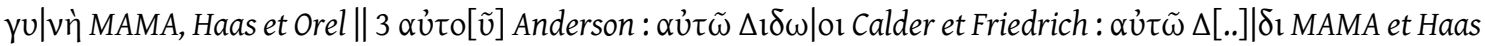

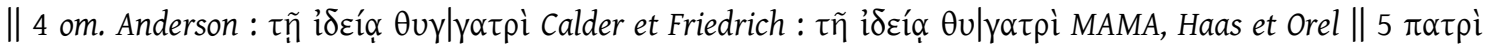

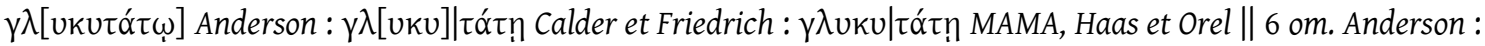

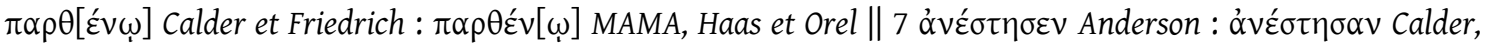

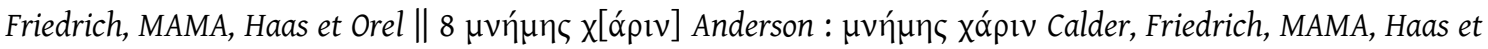

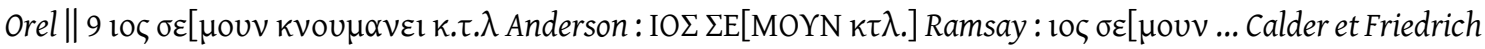

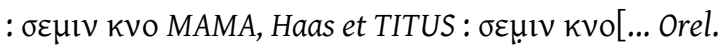

'[Greek] Sasas and Was and Preivis, his wife, for Di..di, their own dearest daughter, still a girl, dedicated (it) in memory. [Phrygian] Whoever to this to[mb ---].'

\section{2}

Inscription read by Anderson in "Sultân Mezarlik (1 h. 20 m. towards the south of Kozanli)" $(1899,122)$. The lower part was lost. Lunate sigma and epsilon.

Anderson, 1899, 122, no. 127; Ramsay 1905, col. 103 no. XLVII (only the Phrygian text); Calder 1991, 186 no. XLVII; Friedrich 1932, 135 no. 47; Haas 1966, 129 no. 47; Diakonoff \& Neroznak 1985, 77 no. B 47 (only the Phrygian text as variant of 10); TITUS, no. 47 (only the Phrygian text); Orel 1997a, 258-259 no. C*-10.

\section{$\Delta$ lovúolos \\ Avva $\theta v[\gamma] \alpha-$ \\ $\tau \rho i ̀ \mu \eta ́[\mu \eta] \varsigma$

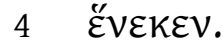




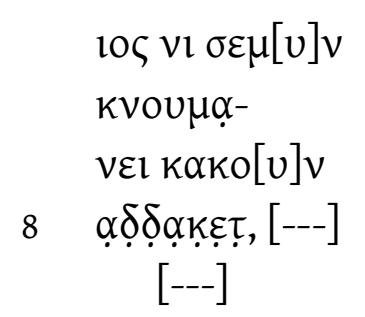

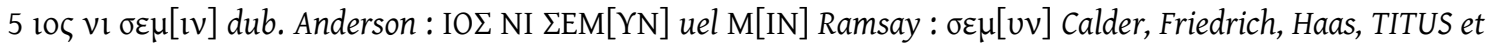
Orel.

'[Greek] Dionysios (made it) for his daughter Anna in memory. [Phrygian] Whoever does harm to th[i]s tomb, [---].'

\section{3}

Inscription first published by Crowfoot in 1899 (only the Greek text). In 1912 Ramsay and Calder were able to read it again and recover a Phrygian fragment. A man and a woman are represented in the pediment of the broken stele ("H. 1.79; th. 0.45; letters 0.03 to 0.035" MAMA VII, 97). Lunate sigma and epsilon, cursive omega.

Crowfoot 1899, 121 no. 123 (only the Greek text); Calder, 1926, 24 no. LXXIX (only the Phrygian text); Friedrich 1932, 139 no. 79 (only the Phrygian text); MAMA VII, 97 no. 435; Haas 1966, 125, no. 79; Diakonoff \& Neroznak 1985, 80 no. B 79 (only the Phrygian text as variant of 33); TITUS, no. 79 (only the Phrygian text); Orel 1997a, 275-276 no. C*-24.

\section{$\Sigma \omega \sigma i ́ \beta 10 \varsigma$ Avva}

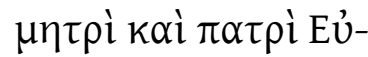

$\tau u x i ́ \omega v 1 \zeta \tilde{\omega} \vee \tau \imath$

4

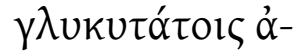

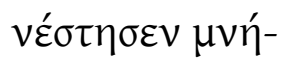

uns Xóplv.

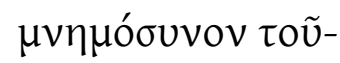

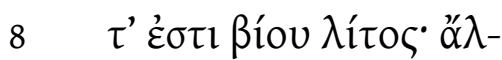

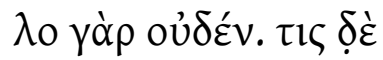

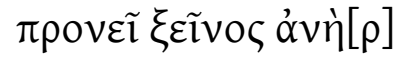

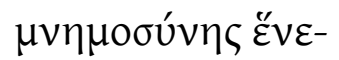

12

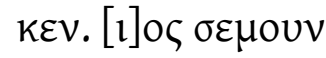

$[\kappa v o] \cup \mu \alpha v \varepsilon l \kappa \alpha-$

[Kov] $\alpha \delta \delta \alpha \kappa \varepsilon \tau$,

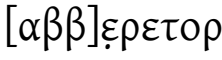

16

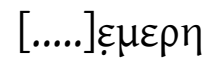

[...] o o $\beta$ ouv

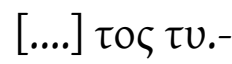

[.. $\gamma \varepsilon \gamma] \alpha \rho ı \mu \mu-$

20

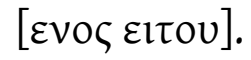




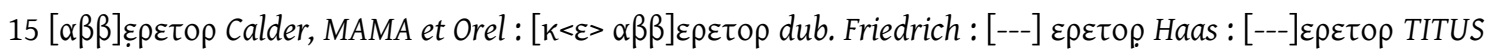

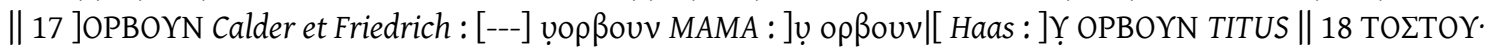

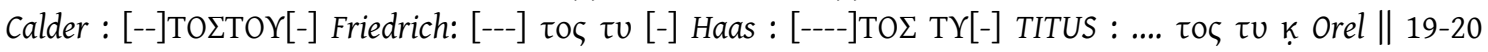

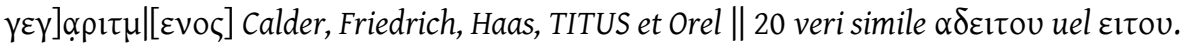

'[Greek] Sosibios for his dearest mother Anna and father Eutychion, whilst he is alive, erected (it) in memory. This stone is the memorial of life: there is nothing else (after death). A foreigner meditates (on it) on account of this remembrance. [Phrygian] [Wh]oever does ha[r]m to this $[\mathrm{t}] \mathrm{omb}, . .$.

\section{4}

Phrygian curse engraved on a stone block with panel, "H. 0.51; w. 0.72; letters 0.0125 to 0.02" (MAMA VII, 97).

MAMA VII, 97 no. 436 (pl. 25); Haas 1966, 106; Haas 1970a, 60 no. 106; Diakonoff \& Neroznak 1985, 80 no. B 106; TITUS, no. 106; Orel 1997a, 285-286 no. C*-34.

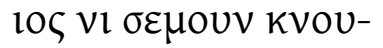

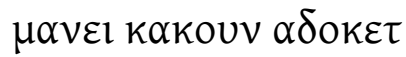

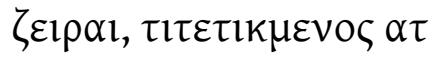

$$
\begin{aligned}
& 4 \quad \tau l \propto \delta \varepsilon l \tau o v, ~ \gamma \varepsilon \gamma \rho \varepsilon ı \mu \varepsilon \nu o v
\end{aligned}
$$

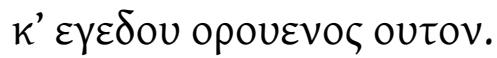

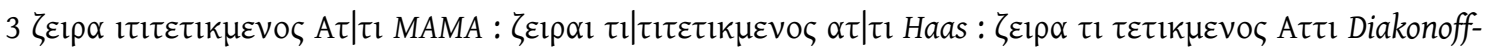

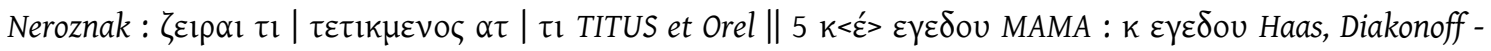
Neroznak, TITUS et Orel.

'Whoever does harm to this tomb with (his) hand, let him become accursed by Zeus and let him suffer the written curse of the Keeper.'

\section{Kerpiç}

\section{1}

Stele with a fragmented inscription copied by Ramsay and Calder in 1910.

Calder 1911, 202 no. LIX; Calder 1926, 27 no. LIX (correction of his previous copy); Friedrich 1932, 136 no. 59; Haas 1966, 122 no. 59; RECAM II, no. 369; Diakonoff \& Neroznak 1985, 80 no. B 59 (as variant of B 33); TITUS, no. 59 (sols text frigi); Orel 1997a, 266-268 no. C*-16.

$$
[---] \quad \tau,
$$

$\kappa \alpha \kappa[\mathrm{ou}] \underline{\mathrm{p}} \alpha \delta \delta \alpha \kappa \varepsilon-$

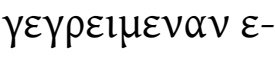

$\gamma \varepsilon \delta[\mathrm{ou} \tau]$ los ovav. 


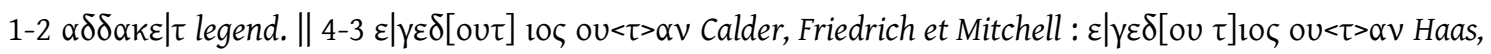
TITUS et Orel.

'[Whoever] do[e]s harm, let him suffer the written curse of Zeus.'

\section{2}

Inscription engraved on a broken stele ("h. (visible) 1.32; w. 0.52; th. 0.40; letters 0.0175 to 0.02" MAMA VII, 92) with pediment (with reliefs of two man and a woman between them and some objects) and read by Ramsay and Calder in 1910. Lunate sigma and epsilon, cursive omega.

Calder 1911, 202-203 no. LX; Calder 1926, 27-28 no. LX (improved copy); Friedrich 1932, 136 no. 60; MAMA VII, 92 no. 406; Diakonoff \& Neroznak 1985, 80 no. B 60 (only the Phrygian part as variant of B 33); Haas 1966, 122-123 no. 59; RECAM II, no. 370; Waelkens 1986, 241-242 no. 620; TITUS, no. 60 (only the Phrygian text); Orel 1997a, 266-267 no. $C^{*}-17$.

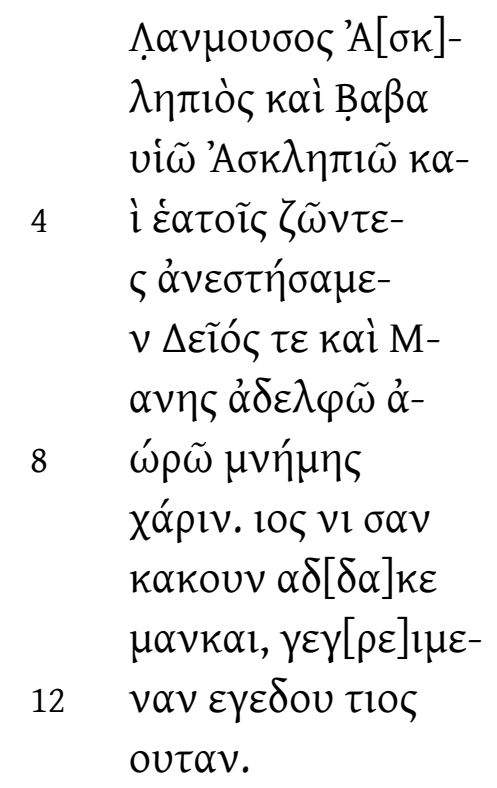

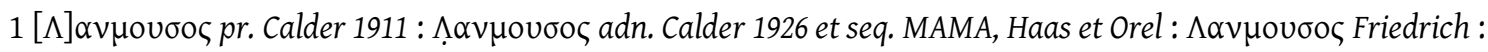

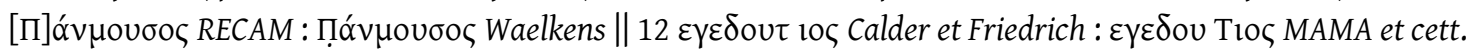

'[Greek] Lanmusos Asklepios and Baba erected (it) for his son Asklepios and for themselves, whilst they are alive, in memory and Deios and Manes for (their) brother untimely (dead) in memory. [Phrygian] Whoever does harm to this stele, let him suffer the written curse of Zeus.' 


\section{Saatl1 - Modanl1}

\section{1}

Inscription "recorded (photograph and impression) by Ian W. Macpherson near Modanli in 1953" (MAMA 1956, xxviii).

MAMA VII, xxviii-xxix no. (d); Haas 1966, 128 no. 100; Haas 1970a, 48 no. 100; RECAM II, 366; Diakonoff \& Neroznak 1985, 83 no. B 100; TITUS, no. 100 (only the Phrygian text); Orel 1997a, 281-282.

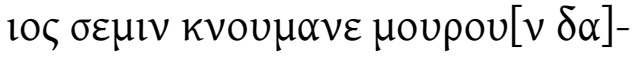

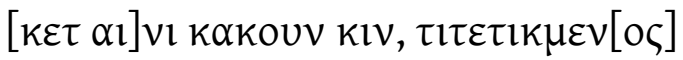

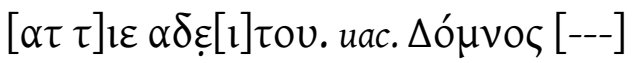

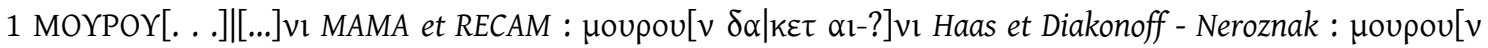

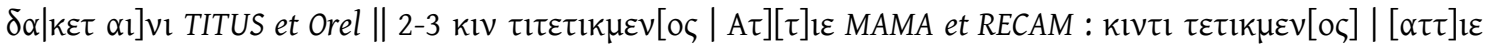

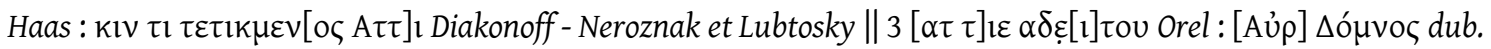
MAMA et Orel.

'[Phrygian] Whoever [does] any silliness to this tomb [or] to any harm, let him become accurse[d by Z]eus. [Greek] Domnos [---]'

\section{Sinanl1}

\section{1}

Broken door-stele ("H. 1.64; w. 0·47; th. 0.25; letters 0.01 to 0.02" MAMA VII, 76) with some reliefs (a man, a woman and several objects) published by Ramsay in 1905 (also seen by Calder in 1910).

Ramsay 1905, col. 93-94 no. XXXII; Calder 1911, 180-181 no. XXXII; MAMA VII, 76 no. 312, (pl. 19 no. 312); Friedrich 1932, 133 no. 32; Haas 1966, 119; Haas 1970a, 48 no. 32; Diakonoff \& Neroznak 1985, 80 no. B 32 (only the Phrygian text as variant of B 33); Waelkens 1986, 236 no. 605 (Tafel 82 no. 605); TITUS, no. 32 (only the Phrygian text); Orel 1997a, 249-250 no. C*-04.

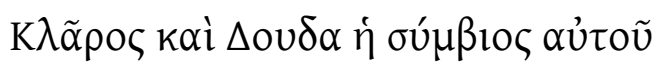

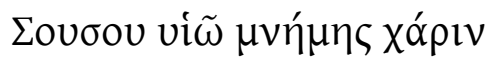

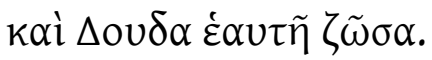

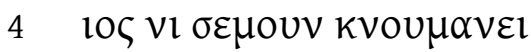

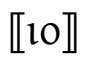

Ḳִkouv $\alpha \delta \delta \alpha \kappa \varepsilon \kappa, \gamma \varepsilon \gamma \rho \varepsilon \iota \mu \varepsilon v \alpha-$

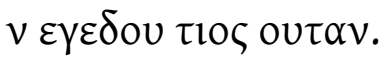




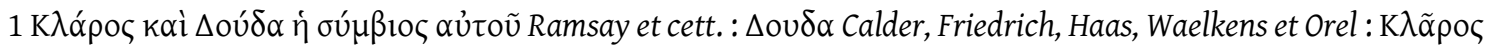

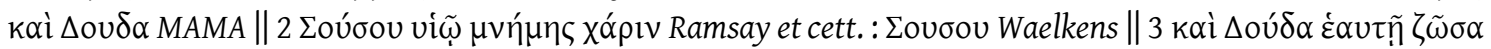

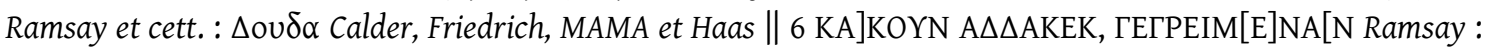

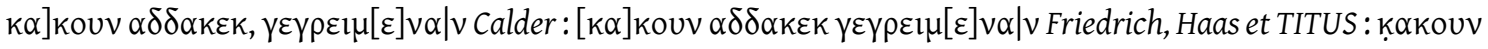

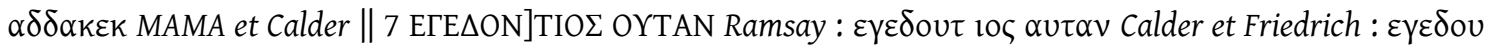
Tios outav MAMA, Haas, Waelkens, TITUS et Orel.

'[Greek] Klaros and Duda, his wife, for his son Susos in memory and Duda for herself, whilst she is alive. [Phrygian] Whoever does harm to this tomb, let him suffer the written curse of Zeus.'

\section{2}

"Doorstone with arched pediment containing two men and a woman. Panels empty. H. 1.99; w. 0.78; th. 0.40; letters 0.02 to 0.025" (MAMA VII, 76). Lunate sigma and epsilon, cursive omegas.

Ramsay 1905, col. 95-98 no. XXXIII; Calder 1911, 181-182 no. XXXIII; MAMA VII, 76 no. 313 (pl. 19 no. 313); Friedrich 1932, 133 no. 33; Haas 1966, 118 no. 33; Diakonoff \& Neroznak 1985, 80 no. B 33; Waelkens 1986, 234-235 no. 602 (Tafel 82 no. 602); TITUS, no. 33 (only the Phrygian text); Orel 1997a, 251-253 no. $C^{*}-05$.

3

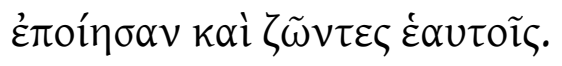

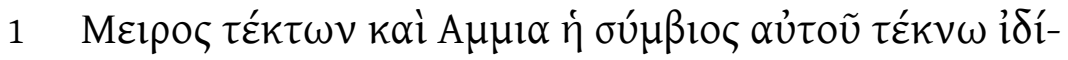

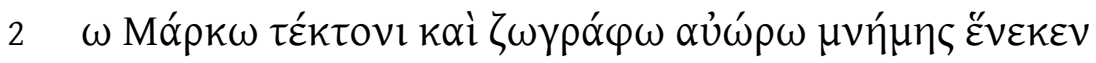

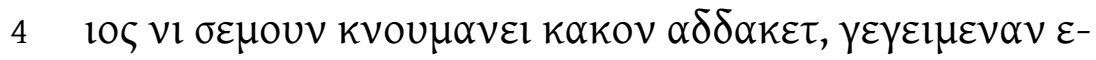

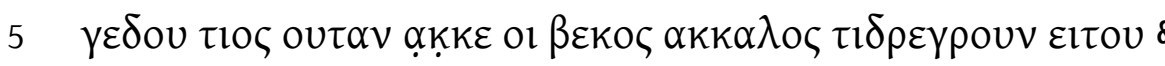

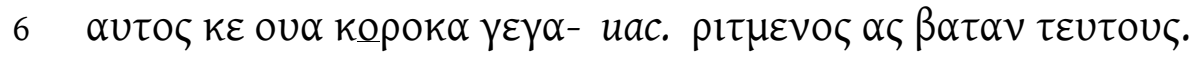

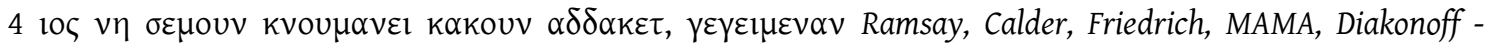

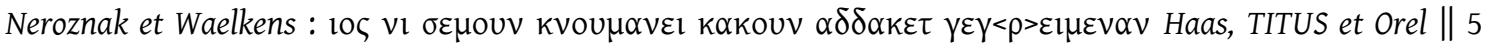

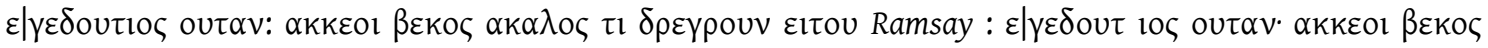

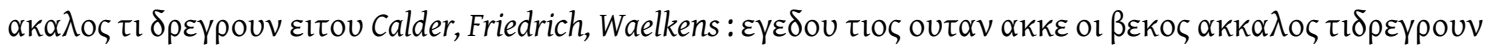

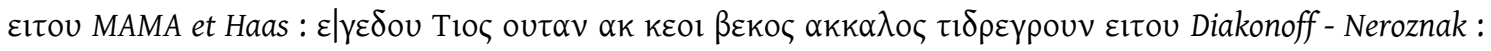

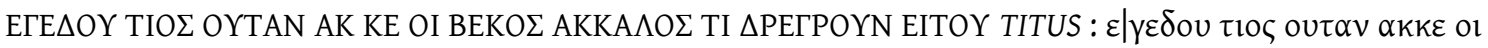

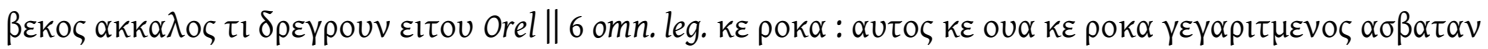

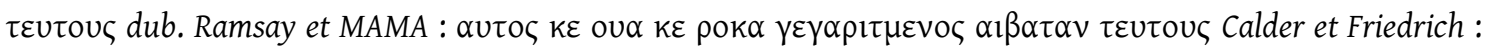

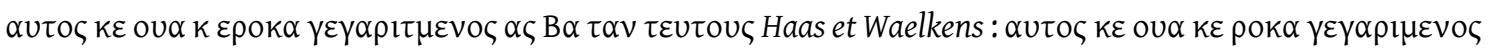

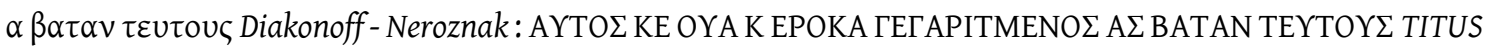

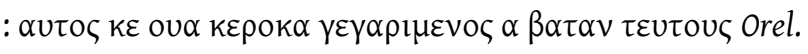

'[Greek] Miros, the carpenter, and Ammia, his wife, for their own son Markos, the carpenter and painter, untimely (dead) in memory. [Phrygian] Whoever does harm to this 
tomb, let him suffer the written curse of Zeus and let the bread be innutrible to him and let him

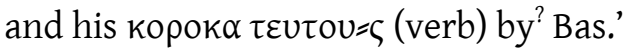

\section{3}

"Doorstone with arched pediment containing boy, man, woman, girl, the man and woman holding hands. In the panels: (1) knocker, (2) keyplate, (3) tripod (with jar beneath supporting pot, (4) spindle and distaff and basket. H. 2:11; w. 0.87; th. 0.05 to 0.05; letter 0.015 to 0.02" (MAMA VII, 76). Classic letters but rectangular sigma and epsilons.

Ramsay 1905, col. 98-99 no. XXXIV; Calder 1911, 182 no. XXXIV; MAMA VII, 76 no. 314, (pl. 19 no. 314); Friedrich 1932, 133 no. 34; Haas 1966, 119 no. 34; Diakonoff \& Neroznak 1985, 80 B 34 (only the Phrygian text as variant of B 33); Waelkens 1986, 235 no. 603 (Tafel 82 no. 604); TITUS, no. 34 (only the Phrygian text); Orel 1997a, 253-254 no. C*-06.

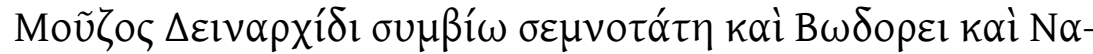

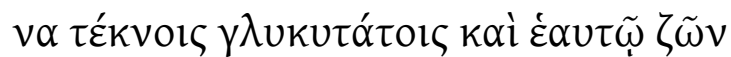 $\mu v \eta \dot{\mu \eta} \varsigma$ хópiv.

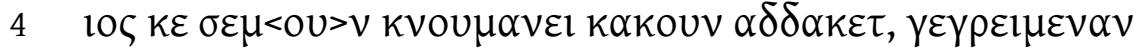

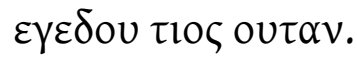

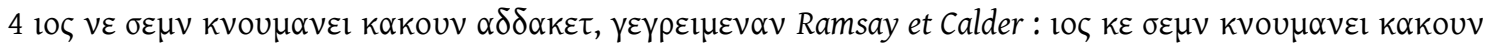

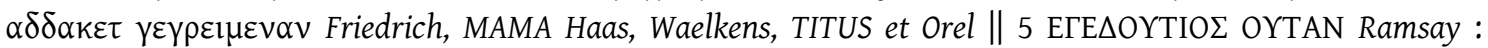

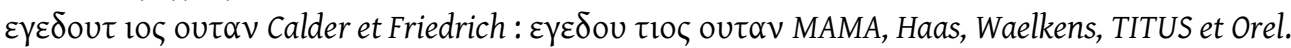

'[Greek] Mouzos (made it) for his honourable wife Deinarchis and for (their) dearest children Bodoris and Nana and for himself, whilst he is alive, in memory. [Phrygian] Whoever does harm to th[i]s tomb, let him suffer the written curse of Zeus.'

\section{4}

"Doorstone, broken above and below, with pediment containing woman, spindle and distaff, basket. H. 0.51; w. 0.68; th. 0.31; letters 0.0225 to 0.025" (MAMA VII, 77). Lunate sigma and epsilon.

Ramsay 1905, col. 99 no. XXXV; Calder 1911, 182 no. XXXV; MAMA VII, 77 no. 315 (pl. 21 no. 315); Friedrich 1932, 133 no. 35; Haas 1966, 119 no. 35; Diakonoff \& Neroznak 1985, 78-79 no. B 35; Waelkens 1986, 235 no. 604 (Tafel 82 no. 694); TITUS, no. 35 (only the Phrygian text); Orel 1997a, 254-256 no. C*-07.

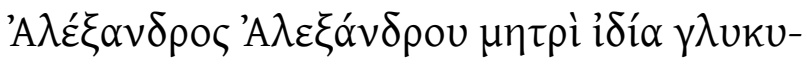

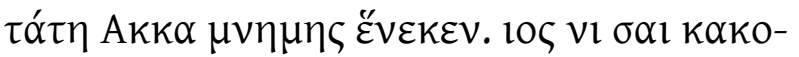
$v v \alpha \delta \delta \alpha \kappa \varepsilon \mu \mu \alpha \nu \kappa \alpha \mathrm{l}, \alpha \varsigma \alpha v \alpha v \kappa \alpha l$ ol $\pi \alpha \nu \tau \alpha \kappa \varepsilon v \alpha$ 


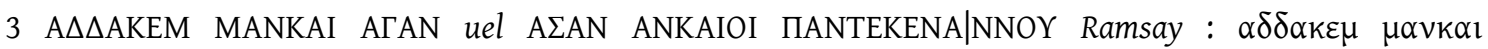

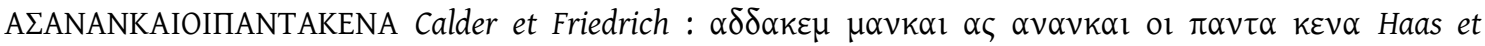

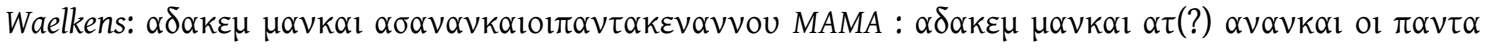

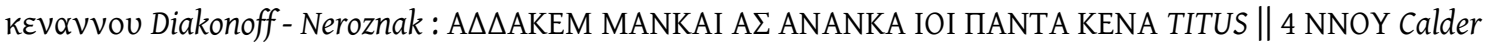
et Friedrich :[1]v vou Haas : $<>>\mid v$ vou Waelkens : [1] vvou TITUS :[1] v-vou Orel.

'[Greek] Alexandros the son of Alexandros (made it) for his dear mother Akka in memory. [Phrygian] Whoever does harm to this stele, let his whole offspring be under the necessity.'

\section{5}

Broken door-stone ("H. 1.05; w.0.59; th. 0.20; letters 0.0125 to 0.03" MAMA VI, 77) with reliefs (a woman, a man and some objects) and copied by Ramsay and Calder in 1910. Lunate sigma and epsilon.

Ramsay 1905, col. 99-100 no. XXXVI; Calder 1911, 182-183 no. XXXVI (with copy); MAMA VII, 77 no. 316 (pl. 21); Friedrich 1932, 133 no. 36; Haas 1966, 119 no. 36; Waelkens 1986, 237-238 no. 610; TITUS, no. 36 (only the Phrygian text); Orel 1997a, 256-257 no. $C^{*}-08$.

$$
\begin{aligned}
& \Lambda \alpha \lambda<\alpha>E \hat{v} \delta \eta \mu \omega ́ v[o \varsigma]
\end{aligned}
$$

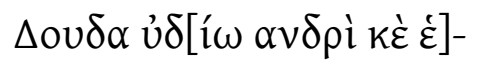

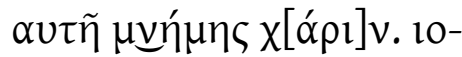

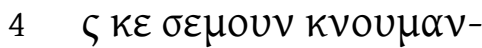

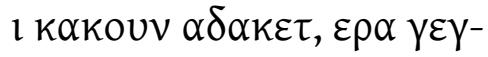

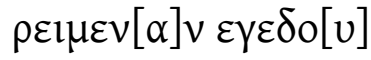

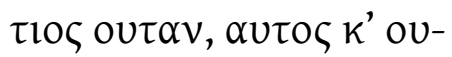

$$
\begin{aligned}
& 8 \alpha \kappa о \rho о \kappa \alpha[\gamma] \varepsilon \gamma[\alpha \rho \tau] \mu \varepsilon[v] \mathrm{o-}^{-} \\
& \varsigma \alpha \beta \alpha \tau \alpha \nu \tau-
\end{aligned}
$$

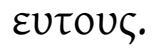

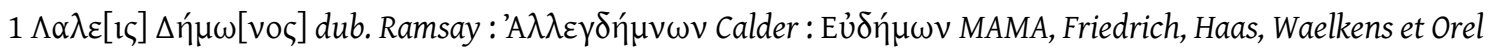

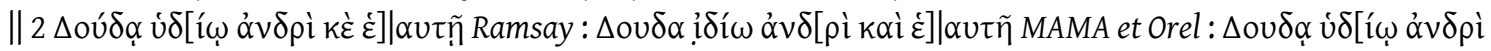

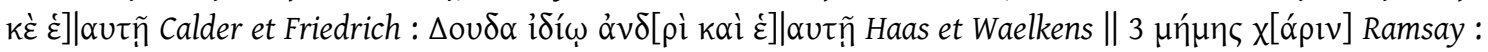

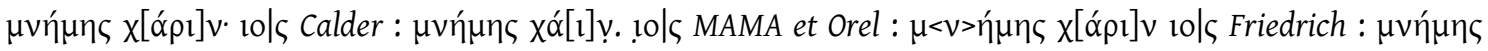

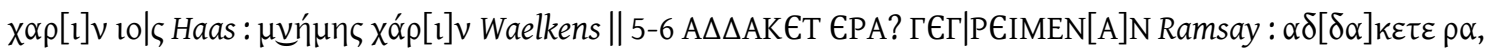

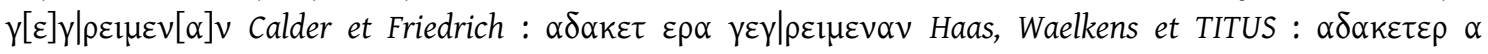

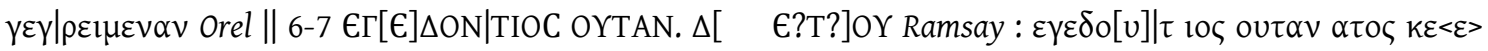

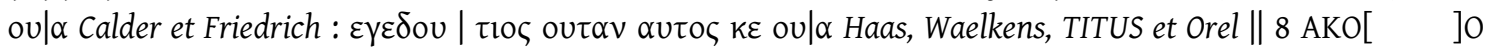

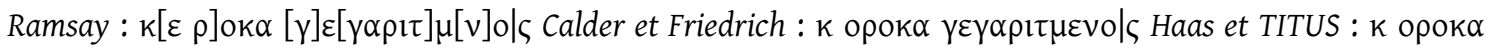

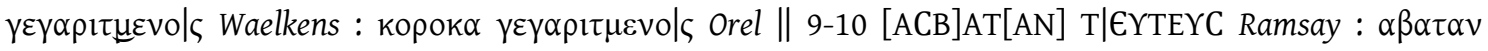

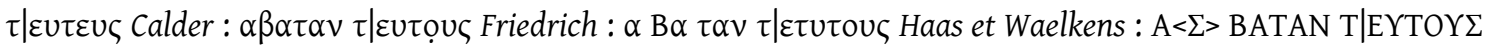
TITUS : $\alpha \beta \alpha \tau \alpha v \tau \mid \varepsilon \tau u \tau$ ouৎ Orel. 
'[Greek] Lala, (the daughter) of Eudemon, for h[er own husband] Doudas [and] for herself in memory. [Phrygian] Whoever does harm to this tomb, let him suffer the written curse

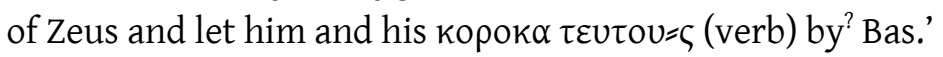

\section{6}

"Stele with pediment containing girl, woman, man. Field weathered out but lower parts of bureau and of tripod survive at bottom. The inscription is on the base. H. 1.27; w. 0*49; th. 0.30; letters 0.025 to 0.03 " (MAMA VII, 77).

MAMA VII, 77 no. 318 (pl. 21); Haas 1966, 128 no. 105; TITUS, no. 105; Orel 1997a, 284-285 no. $C^{*}-33$.

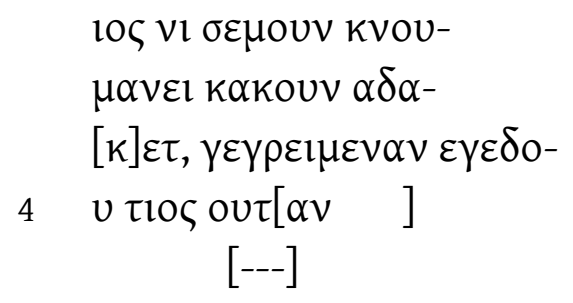

'Whoever does harm to this tomb, let him suffer the written curs[e] of Zeus [---]'

\section{Davulga (near Amorion)}

\section{1}

White marble block ("h. 0,43; 1. 1,32; épg. max. 0,26; h. 1. 0,02" Brixhe \& Drew-Bear 1997, 98) reused as a bank. A Greek hexametric epigram is engraved in a corner, with a hemistique in each side. The Phrygian imprecation can be read in the second face. Rectangular sigma and epsilon.

Brixhe \& Drew-Bear 1997, 98-102 no. VI (SEG 47.1725); Merkelbach \& Stauber 1998, 354 no. 16 / 43 / 02 (only the Greek epigram); Ligorio \& Lubotsky 2013, 182 no. 123 (only enumerated)-

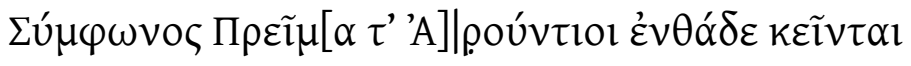

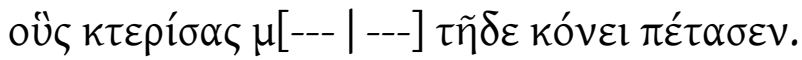

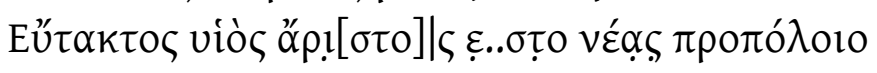

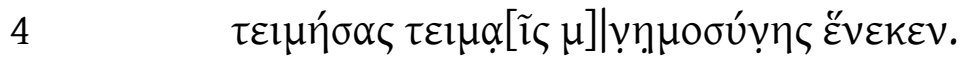

\begin{tabular}{|c|c|}
\hline & 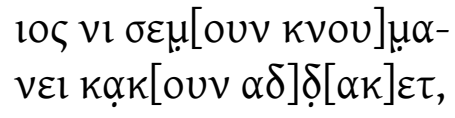 \\
\hline & 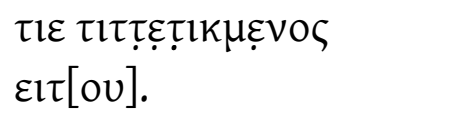 \\
\hline
\end{tabular}

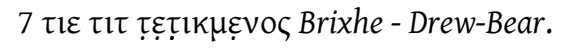


'[Greek] The Aruntians Symphonos and Prima lie here, whom after been buried [---] spread in the dust. Eutaktos, excellent son of the young servant having honoured them with honours in remembrance. [Phrygian] Whoever [m]a[k]es ha[rm] to th[is tom]b, let him be accursed by Zeus.'

\section{Peribeyli}

\section{1}

Round pillar found by Calder in 1913 with a Greek hexametric epigram (each line contains one hemistich) and a Phrygian imprecation. Its higher part, where almost one initial verse is expected to contain the name of the dead girl, is lost.

Calder 1922, 123-124 no. 7 (SEG 1.454); Calder 1926, 25 no. LXXXII (only the Phrygian text); Friedrich 1932, 139 no. 82; MAMA VII, 56 no. 258, (pl. 15); Haas 1966, 125 no. 82 (only the Phrygian text); Wilhelm 1980, 86, no. 112 (SEG 30.1488); Diakonoff \& Neroznak 1985, 78 no. B 82 (only the Phrygian text as variant of B 2); TITUS, no. 82 (only the Phrygian text); Orel 1997a, 279280 no. C*-27; Merkelback \& Stauber 1998, 356 no. 16 / 43 / 04.

\section{$[---]$}

1 [É]

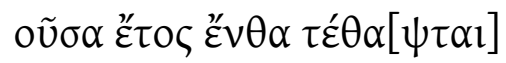

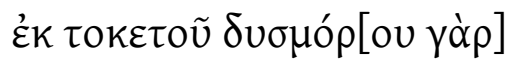

4

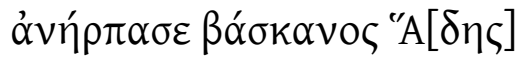

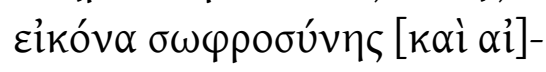

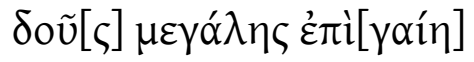

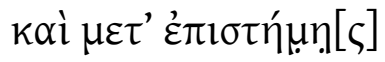

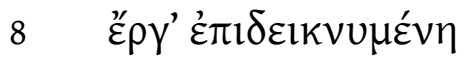

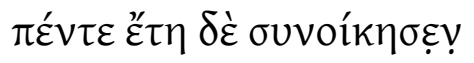

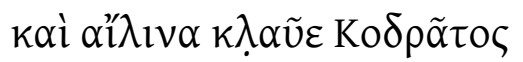
$\gamma \tilde{\eta} \kappa \rho u ́ \pi \tau \omega v\left[\sigma^{\prime}\right]$ oln $v$

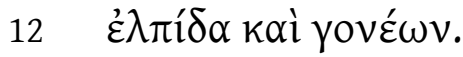

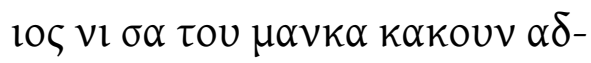

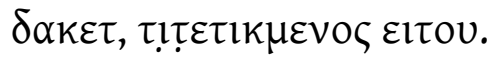

$2 \tau \varepsilon^{\prime} \theta \alpha\left[\pi \tau \alpha_{1}\right]$ Calder 1922, Friedrich, MAMA et Orel : $\tau \dot{\varepsilon} \theta \alpha[\mu \mu \alpha 1]$ Wilhelm : $\tau \dot{\varepsilon} \theta \alpha\left[\psi \alpha_{1}\right]$ emend. Wilhelm \| 3

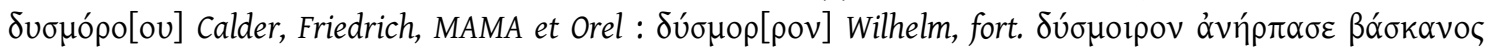

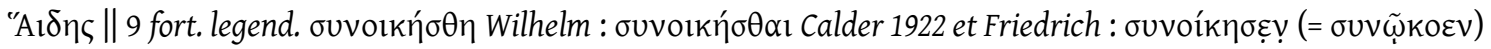

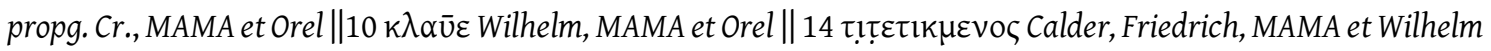

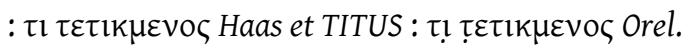




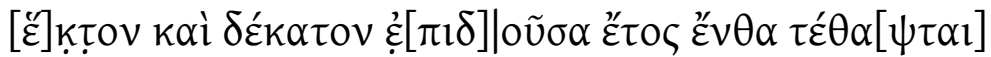

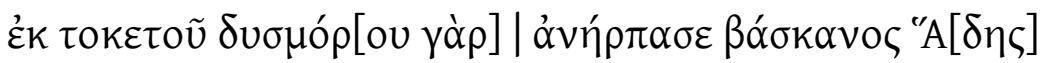

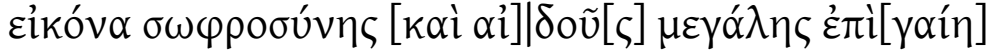

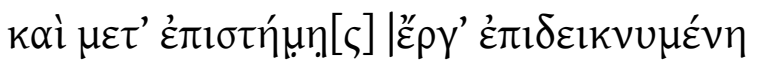

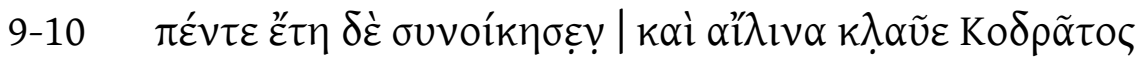

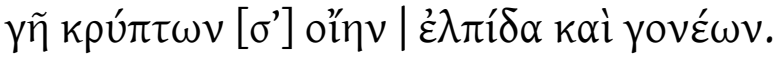

'[Greek] You who have lived sixteen years are buried here. Hades the envy took away after an unhappy childbirth an earthly picture of chastity and great reverence, that accomplished every work with prudence. In the funeral chant, Quadratus cried when he hid you in the earth, after having been living with you for five years, you who also were the only hope of the parents. [Phrygian] Whoever does harm to this stele, let him be accursed.'

\section{Aşağıpiribeyli (Petinessos)}

\section{1}

Double door-stone (". h. 1.29; w. 1.62; th., top 0.17, base 0.39; letters 0.021 to 0.026" MAMA VII, 57) broken on right and above with some reliefs (two people and several objects in the pediment) and an inscription on the upper moulding. Rectangular sigma and epsilon, cursive omega.

Ramsay 1887, 396 no. XX; Ramsay 1905, col. 117 no. XX; Calder 1911, 176 no. XX; Friedrich 1932, 131 no. 20; MAMA VII, 56-57 no. 259 (pl. 15); Haas 1966, 117 no. 20; Waelkens 1986, 218 no. 554 (Tafel 80 no. 554); TITUS, no. 20; Orel 1997a, 246-247 no. C*-02.

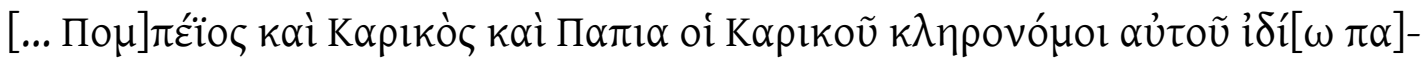

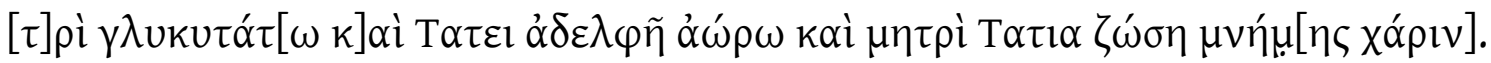

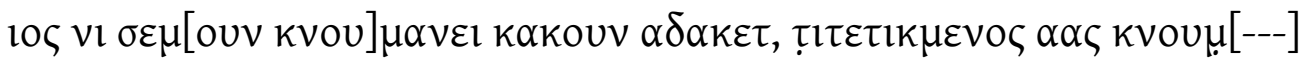

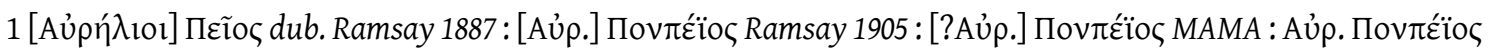

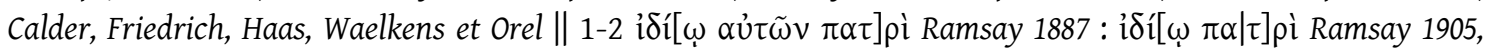

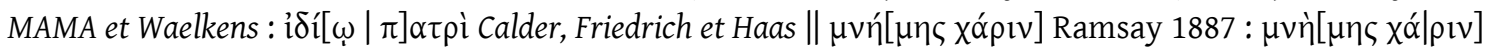

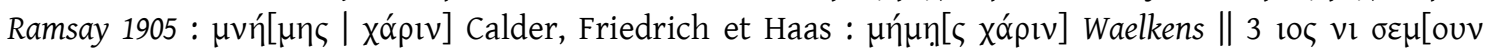

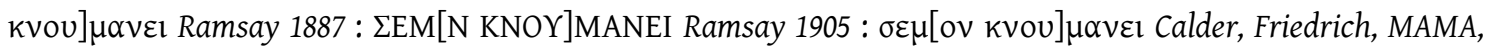

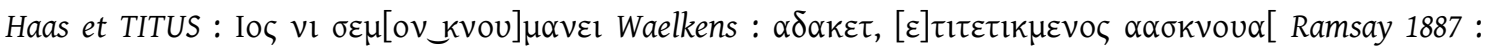

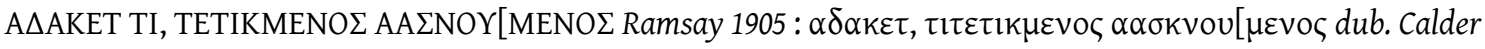

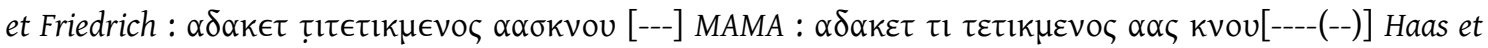

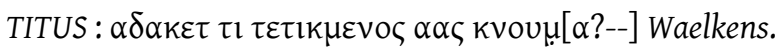

'[Greek] [Aur(elius)] Pompeius and Karikos and Papia, Karikos' heirs, for their own deares $[t$ fa]ther [a]nd for Tatis (their) untimely (dead) sister and for (their) mother Tatia, whilst she is alive, in me[mory]. [Phrygian] Whoever does harm to th[is to]mb, accursed ... [---].' 


\title{
65.2
}

A fragment of an inscription "on a smoothed surface on a rough block, lying near no. 259 [= 63.1], and possibly a detached part of the same memorial" (MAMA VII, 57).

MAMA VII, 57 no. 259a; Haas 1966, 128 no. 104; Diakonoff \& Neroznak 1985, 77 no. B 104 (as variant of B 10); TITUS, no. 104; Orel 1997a, 283-284 no. C*-32.

\author{
[ $\tau 1 \tau \tau \varepsilon \tau 1]-$

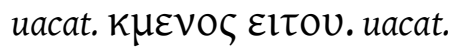 \\ '[---] let him be [accur]sed.'
}

\section{3}

Inscription copied by Ramsay in 1883, who read it "in a panel on the side of a large sarcophagus, in distinct letters of late style" (Ramsay 1887, 396). Dated to the $3^{\text {rd }}$ or $4^{\text {th }}$ C. BC by Ramsay.

Ramsay 1887, 396-397 no. XXI; Ramsay 1905, col. 117 no. XXI (only the Phrygian text); Calder 1911, 176 no. XXI; Friedrich 1932, 131-132 no. 21; Haas 1966, 117 no. 21; Diakonoff \& Neroznak 1985, 83 no. B 21; TITUS, no. 21; Orel 1997a, 247-249 no. C*-03.

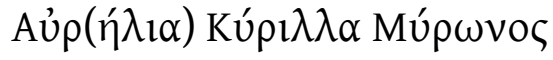

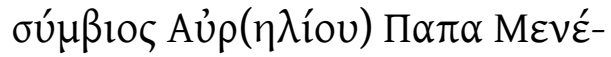

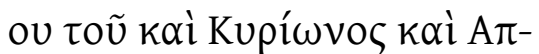

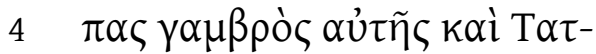 \\ $\alpha \dot{\eta} \sigma u ́ \mu \beta 10 \varsigma \alpha u ̛ \tau o \tilde{u} \zeta \tilde{\omega} v \tau \varepsilon \zeta$

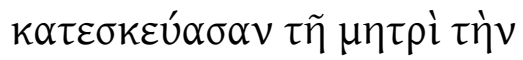

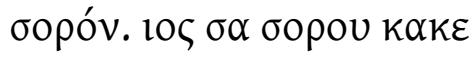 \\ $8 \alpha \delta \alpha \kappa \varepsilon \tau, \mu \varepsilon \zeta \varepsilon \mu \varepsilon \lambda \omega \varsigma \tau \imath \tau \tau \varepsilon \tau 1-$

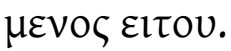

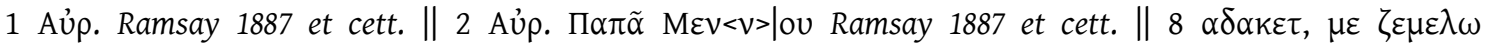

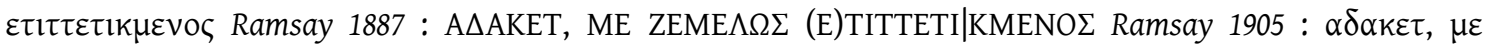
$\zeta \varepsilon \mu \varepsilon \lambda \omega \varsigma \tau \iota \tau \tau \varepsilon \tau \imath \mid \kappa \mu \varepsilon v o \varsigma$ Calder : $\alpha \delta \alpha \kappa \varepsilon \tau \mu \varepsilon \zeta \varepsilon \mu \varepsilon \lambda \omega \varsigma \tau \iota \tau \tau \varepsilon \tau \imath \mid \kappa \mu \varepsilon v o \zeta$ Friedrich et Haas : A $\triangle$ AKET ME ZEME $\Lambda \Omega \Sigma$ TIT TETIKMENO $\Sigma$ Diakonoff - Neroznak, TITUS et Orel.

'[Greek] Aur(elia) Kyrilla (the daughter) of Myron the wife of Aur(elius) Papas Meneos the son of Kyrion and Appas her brother-in-law and Tata his wife, whilst they are living, built this coffin for (their) mother. [Phrygian] Whoever does harm to this coffin, let him be accursed in the sight of men.' 


\title{
65.4
}

Inscription engraved on a withe marble block ("h. 1,10;1.1,72; épg. 0,50; h. 1. 0,04" Brixhe \& Drew-Bear 1997, 102) found in the courtyard of a mosque, which is said to come from the old mosque recently demolished. Lunate sigma and epsilon.

Brixhe \& Drew-Bear 1997, 102-110 no. VII; Ligorio \& Lubotsky 2013, 182 no. 124 (only enumerated).

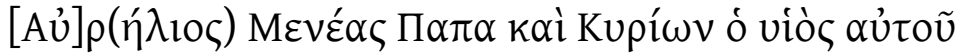

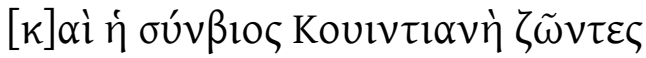

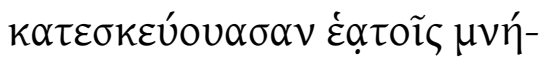

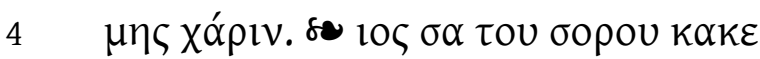

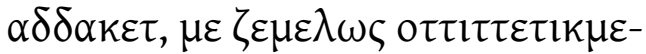 \\ se vOS ElTOU.
}

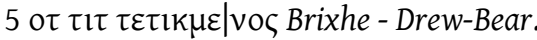

'[Greek] [Au]r(elius) Meneas Papa and Kyrion, his son, and his wife Quintiane build in life for themselves in memory. [Phrygian] Whoever does harm to this coffin, let him be accursed in the sight of men.'

\section{Turgut}

\section{1}

"Stele with a male and a female figure above. H. 230; w. 0.60; th. 0.23; letters 0.02 to 0.035" (MAMA VII, 44). Lunate sigma and epsilon.

MAMA VII, 44 no. 214 (pl. 13); Haas 1966, 128 no. 103; Haas 1970a, 60-61 no. 130; TITUS, no. 103 (only the Phrygian text); Orel 1997a, 282-283 no. C*-31; Strubbe 1997, 188 no. 274 (only the Greek text and a comentary of the Phrygian text following Haas).

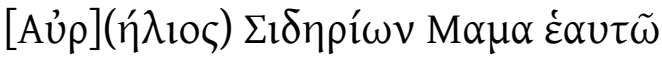

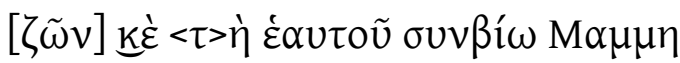

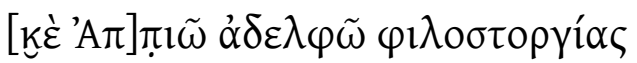

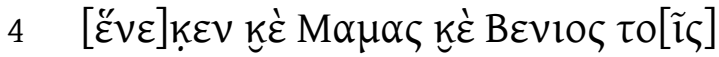

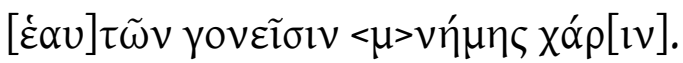

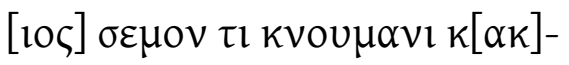

$[o v \alpha] \beta \varepsilon \rho \varepsilon \tau 1 ~ \zeta \varepsilon 1[\rho \alpha 1] \pi \alpha \rho \tau \alpha \nu, \tau o[\varsigma]$

$8\left[{ }^{\prime} \iota \mu \varepsilon\right] \zeta[[\mu \varepsilon \lambda \omega \varsigma] \alpha \tau \iota \alpha \tau \iota \tau \iota \kappa \mu \varepsilon \vee ० \varsigma$

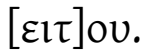

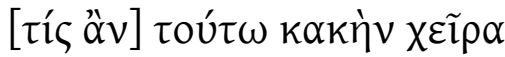

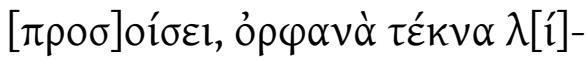

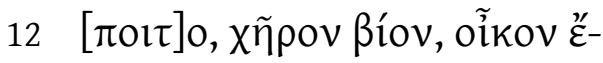

$[\rho \eta \mu]$ ov. 


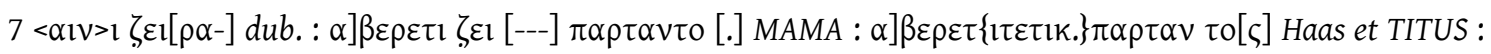

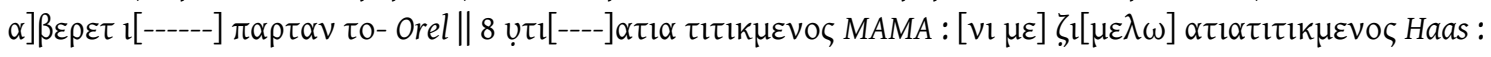

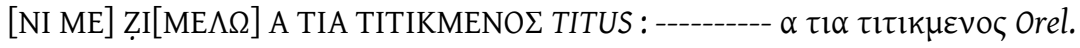

'[Greek] [Aur(elius)] Siderion Mama for himself, [whilst he is alive], and for his wife Mamme [and for his brother Ap]pios [for the]sake of affection and Mamas and Benios for their parents in memory. [Phrygian] [Whoever] brings h[arm] to this tomb with his hand partan, let him [be] accursed by Zeus [among] $\mathrm{m}$ [en]. [Greek] [Whoever br]ings a bad hand to this tomb, may he $1[$ eav]e behind his children orphaned, an empty life, his house d[ese]rted.' 


\section{Appendix: Greek inscriptions enumerated in the traditional list of New Phrygian inscriptions}

Although they are Greek, the following inscriptions were transmitted within the New Phrygian corpus, for reasons including the following: they are a calque of a Phrygian curse inscription (App. 1), they contain a word considered to be Phrygian (ПРІЕІ $\Sigma$ in App. 8), they are completely misunderstood (App. 11). After Brixhe (1999, 287-292), they can no longer be included in the Phrygian corpus.

\section{Greek inscription from Çayırbaşı (no. 1)}

Greek inscription found in Çayırbaşı and copied by Ramsay in 1884.

Ramsay 1887, 386 no. I; Calder 1911, 165 no. I; Friedrich 1932, 128 no. B 1; Haas 1966, 114 no. 1; Strubbe 1997, 129 no. 177 (1. 3-4).

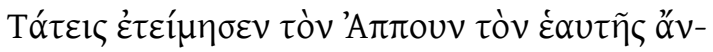

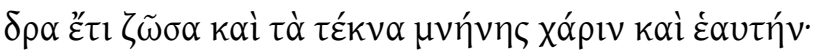

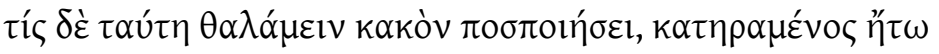

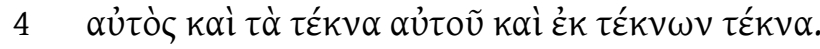

'Tatis honoured her husband Appos and their children in memory and herself, whilst she is alive. Whoever does harm to this (funerary) chamber, let him be accursed, himself and his children and the children of his children.'

\section{Greek inscription from Kuyucak (no. 16)}

Greek inscription found in Kuyucak and copied by Sterrett in 1883.

Ramsay 1887, 394-395 no. XVI (copy); MAMA V, 150 no. R 7; Haas 1966, 115 no. 16; DrewBear 1978, 29 no. 2 (MAMA V 208; SEG 29.1174).

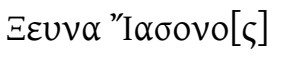

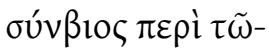

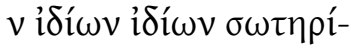

$$
\begin{aligned}
& 4 \quad \alpha \varsigma \text { Mnvì Oủ } \rho \alpha v i ́- \\
& \omega \text { kुع 'A }{ }^{\prime}{ }^{\prime} \lambda \lambda \omega v \mathrm{v} \\
& \text { हủxท́v. }
\end{aligned}
$$

'Xeuna the wife of Iaso (made) a vow to the heavenly Men and Apollo on the sake of his own safety.'

\section{Greek inscription from Yukarı Piribeyli (no. 22)}

Inscription found in Yukar1 Piribeyli by Ramsay and Sterrett in 1883. Dated to the $3^{\text {rd }}$ or $4^{\text {th }}$ century BC.

Ramsay 1887, 397 no. XXII (as Greek); Haas 1966, 117, no. 22. Cf. Calder 1911, 176 no. XXII; Brixhe 1999, 287 no. 22. 


$$
\begin{aligned}
& A \cup ̉ \rho\left(\eta \lambda_{l} \alpha\right){ }^{\prime} A v \tau \omega v i \lambda^{\prime} \alpha K \alpha-
\end{aligned}
$$

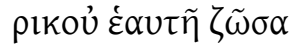

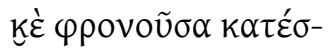

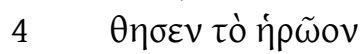

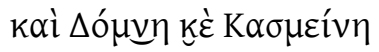

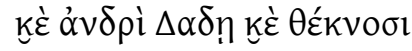

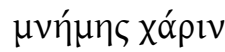

'Aurelia Antonila the daughter of Karikos built this tomb for herself, whilst she is alive and of sound mind, and for Domne and Kasmine and for her husband Dades and their children in memory.'

\section{Greek inscription from Yukar1 Piribeyli (no. 23)}

Inscription found in Yukarı Piribeyli by Ramsay and Sterrett in 1883. Dated to the $3^{\text {rd }}$ or $4^{\text {th }}$ century BC.

Ramsay 1887, 397-398 no. XXIII; Strubbe 1997, 185-186 no. 268 (1. 9-14).

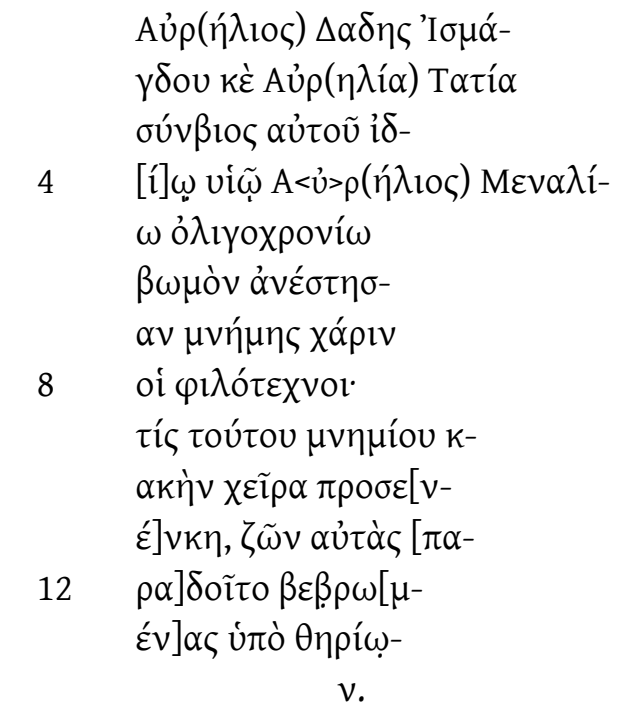

'Aurelios Dades the son of Ismagdos and Aurelia Tatia, his wife, erected, fond of art, this altar for their short-lived son Aurelios Menalios in memory. Whoever lays a wicked hand to this monument, let him, whilst he is alive, have his hands devoured by beasts.'

\section{Greek inscription from Aşağıpiribeyli (no. 24a)}

Greek inscription found in Aşağıpiribeyli and copied by Ramsay in 1883. Dated to the 3rd century BC.

Ramsay 1887, 398 no. XXIVa (as Greek).

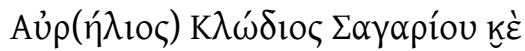

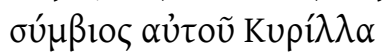

$$
\begin{aligned}
& \tau 01 \zeta \dot{\varepsilon} \alpha \tau \tilde{\omega} \nu \tau \varepsilon \kappa \nu 01 \zeta
\end{aligned}
$$

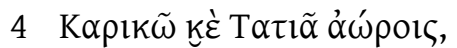

$$
\begin{aligned}
& \mu \nu-\mu-1 \varsigma \chi \alpha \rho \rho v . \Upsilon--. \Sigma Y E O I \Delta-
\end{aligned}
$$

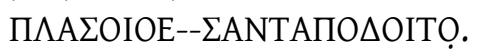


'Aurelius Klodios Sagarios and his wife Kyrilla for their untimely (dead) children Karikos and Tatias in memory...'

\section{Greek inscription from Aşağıpiribeyli (no. 24b)}

Greek inscription found in Aşağıpiribeyli and copied by Ramsay in 1883. Dated to the 3rd century BC.

Ramsay 1887, 398 no. XXIVb (as Greek); MAMA VII 276; Waelkens, 1986 no. 556.

$$
\begin{aligned}
& A \hat{v} \rho\left(\eta \lambda_{1} \circ \varsigma\right) A \lambda \varepsilon \xi \alpha v \delta \rho \circ \varsigma \text { [---] } \\
& \text { [---] } \\
& \text { [---] } \\
& \text { ö } \alpha v \\
& \kappa \alpha \kappa \tilde{\omega} \zeta
\end{aligned}
$$

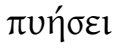

$$
\begin{aligned}
& \tau \tilde{\omega} \mu \nu \eta^{-} \\
& \mu \alpha-
\end{aligned}
$$

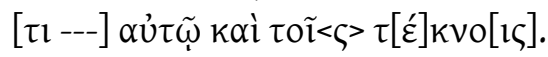

'Aurelios Alexandros [---] Whoever does harm [to] this monument [---], let him and his childrend [---].'

\section{Greek inscription from Aşağıpiribeyli (no. 24c)}

Greek inscription in a small panel from Aşağıpiribeyli and copied by Ramsay in 1883. Dated to the 3rd century BC.

Ramsay 1887, 398 no. XXIV (copy, as Greek).

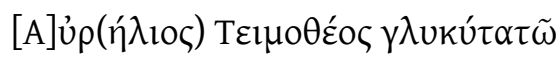

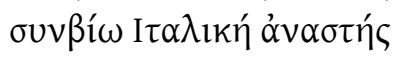

$$
\begin{aligned}
& \mu \nu \eta \mu \varsigma \chi \alpha- \\
& 4 \text { piv. }
\end{aligned}
$$

'[A]urelios the son of Timotheos erected (it) for his dearest wife Italike in memory.'

\section{Greek inscription from Iconion (NPhr. 49)}

Greek inscription found in Konya (Iconion) and copied by Ramsay and Calder in 1910. Although it was considered Phrygian, it is clearly Greek. Only l. 9 ПРІЕІ $\Sigma$ remains unclear.

Calder 1911, 188-192 no. XLIX (copy); SEG 6.434; Friedrich 1932, 135 no. 49; Haas 1966, 120-121 no.49; Laminger-Pascher 1984, 46-49 no. 62 (213 and Calder's copy); Diakonoff \& Neroznak 1985, 86 no. C 49; Brixhe 1999, 287-291 no. 49.cc

"H $\lambda$ 1о Г Гóïos åyo-

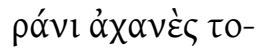

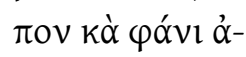

$4 \pi \rho \gamma \mu \alpha \tau \imath k-$ òv $\alpha \tilde{\tau} \tilde{\omega} k \dot{\alpha}$

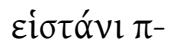




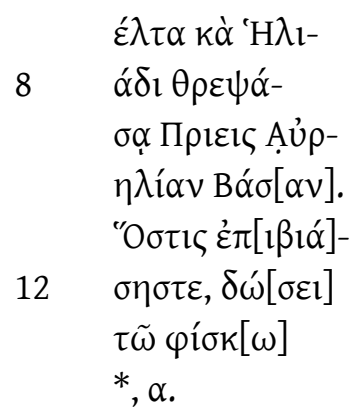

'Helios Gaios bought this plot free of constructions and declared it inalienable from him. He also raised the base (of a sarcophagus) for Helia, the nurse of (his) ПPIEII Aurelias Bas(s)a. Whoever violates (it), will pay 1000 denarii to the imperial treasury.'

\section{Greek inscription from Iconion (no. 50)}

Greek inscripcion found in Konya (Iconion) and copied by Ramsay and Calder in 1910.

Calder 1911, 192-194 no. L (copy, as Phrygian); Friedrich 1932, 135 no. 50 (as Phrygian); Haas 1966, 121 no. 50 (as Phrygian); Brixhe 1999, 291-292 no. 50 (as Greek).

$$
\begin{aligned}
& \text { Тทฺ̃ Па́ } \rho \theta \varepsilon-
\end{aligned}
$$

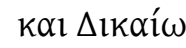

$$
\begin{aligned}
& <\varepsilon \dot{v}>x \eta ́ v \text {. }
\end{aligned}
$$

\section{Greek inscription from Sarayönü (no. 52)}

Greek inscription found in the wall of the main Djami of Sarayönü and copied by Ramsay in 1905 (again together with Calder in 1910).

Calder 1911, 195-197, LII (copy); MAMA I, no. 11 (SEG 34.1375); Friedrich 1932, 135 no. 52; Haas 1966, 121, no. 52.

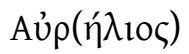

$$
\begin{aligned}
& \text { Фрoúүl- }
\end{aligned}
$$

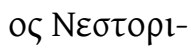

$$
\begin{aligned}
& 4 \text { avoũ Пок- } \\
& \omega \mu \eta ́ \tau \eta \varsigma \\
& \pi \alpha \rho \varepsilon \theta \theta o v \\
& \text { von 'Opovdí- } \\
& 8 \omega
\end{aligned}
$$

ยủxท́v.

'Aurelios Phrugios the son of Nestorianos villager of Poa put this vow for (his) son Orondios.' 


\section{Greek inscription from Sultan Mezarlığı Inscripció (NPhr. 66)}

Greek inscription on an altar, with serpent in relief on one side. Copied by Anderson in 1989.

Anderson 1899, 123 no. 132 (copy); Calder 1911, 212 no. LXVI (copy); Friedrich 1932, 137 no. 66; Haas 1966, 123 no. 66.

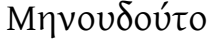

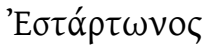

$$
\begin{aligned}
& \mu \eta \dot{\tau \varepsilon \rho ~ \varepsilon ้ \sigma \tau \eta \sigma-~} \\
& 4 \quad \varepsilon \vee
\end{aligned}
$$

'For Menodotos the son of Starton, his mother erected (it).'

\section{Hexametric inscription from Gözlü (no. 83)}

A Christian, hexametric inscription on a rough stele, found in Gözlü by Calder in 1913. Dated not earlier than the $5^{\text {th }}$ century AD.

Calder 1926, 25 after no. LXXXII (l. 1-2 as Phrygian); Friedrich 1932, 139, no. 83 (1. 1-2 as Phrygian) (SEG 6.291); Haas 1966, 125 no. 83 (l. 1-2 as Phrygian); Brixhe 1999, 287 no. 83 (l. 1 as Phrygian).

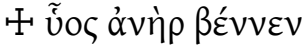

$$
\begin{aligned}
& \alpha \mu 1 \delta \varepsilon ́ \alpha \delta \omega \mu \alpha \tau \alpha, N- \\
& \text { ivv Eủyévios } \Sigma u ́ p o v \\
& 4 \mu \varepsilon \gamma \alpha \lambda \eta \dot{\tau} \tau о \rho \circ \varsigma \alpha \dot{\gamma} \gamma \lambda \alpha-
\end{aligned}
$$

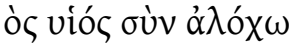

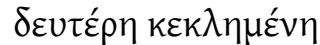

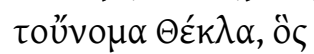

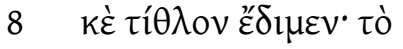

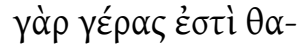

$$
\begin{aligned}
& \text { vóv } \tau \omega v \text {. }
\end{aligned}
$$

$$
\mathrm{A} \dagger \omega
$$

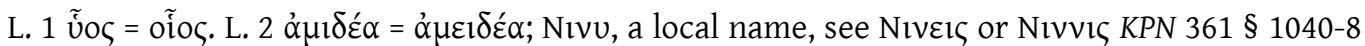

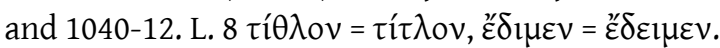

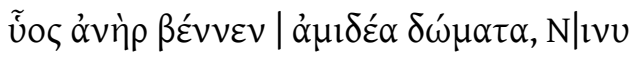

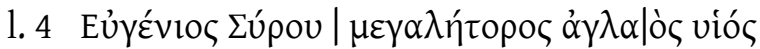

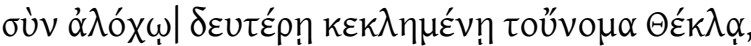

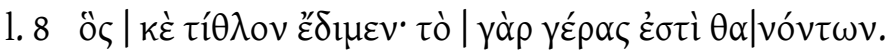

'What man bennes? the gloomy houses! Nini Eugenios the noble son of the great-hearted Syros, together with his second wife called Thekla, he who also prepared this inscription: "that is the privilege of the dead" [= Il. 23.9; Od. 24.190].' 



\section{Abbreviations and Bibliography}

\section{Abbreviations}

AnnÉp = L'Année épigraphique.

$\mathrm{BCH}=$ Bulletin de correspondance hellénique.

$C A L=$ Comprehensive Aramaic Lexicon, available at: http://cal.huc.edu/

CIG = Corpus inscriptionum Graecarum.

CIL = Corpus inscriptionum Latinarum .

CIPPhr = Brixhe, C., and Lejeune, M., 1984, Corpus des inscriptions paléo-phrygiennes. I Texte, II Planches, Paris, Editions Recherche sur les Civilisations.

CLL = Melchert, H. C., 1993, Cuneiform Luvian Lexicon, Chapel Hill.

CTH = Laroche, E., 1971, Catalogue des textes hittites, Paris, Klincksieck.

$D E L G=$ Chantraine, P., 1968-1980, Dictionnaire étymologique de la langue grecque $:$ histoire des mots, Paris,P Klincksieck.

$E D G=$ Beekes, R. S. P., 2010, Etymological Dictionary of Greek, Leiden-Boston, Brill.

eDIANA = Digital Philological-Etymological Dictionary of the Minor Ancient Anatolian Corpus Languages, available at: http://titus.uni-frankfurt.de/texte/etcs/phrygian/phryg.html

IDR III,5 = Piso, I., 2001, Inscriptions d'Apulum (Inscriptions de la Dacie Romaine - III 5), Paris, Académie des inscriptions et belles-lettres.

HALOT = Koehler, L., and Baumgartner, W., 1994, The Hebrew and Aramaic lexicon of the Old Testament, Leiden - New York, Brill.

IEW = Pokorny, J., 1959, Indogermanisches etymologisches Wörterbuch, Bern, Francke.

IGBulg III = Mihailov, G., 1961, Inscriptiones graecae in Bulgaria repertae III, 1. Inscriptiones inter Haemum et Rhodopem repertae. Fasciculus prior: Territorium Philippopolis, Sofia, Academia Litterarum Bulgarica.

IGBulg IV = Mihailov, G., 1966, Inscriptiones graecae in Bulgaria repertae Vol. 4. Inscriptiones in territorio Serdicensi et in vallibus Strymonis Nestique repertae (1966). Sofia, Academia Litterarum Bulgarica.

IGBulg V = Mihailov, G., 1997, Inscriptiones graecae in Bulgaria repertae V. Inscriptiones novae, addenda et corrigenda, Sofia, Academia Litterarum Bulgarica.

$I G R=$ Cagnat, R., Toutain, J. and Jouguet, P., 1901-1927, Inscriptiones graecae ad res romanas pertinentes, Paris, Ernest Leroux.

IK Iznik = Şahin, S., 1979-1982, Katalog der antiken Inschriften des Museums von Iznik (Nikaia), Bonn, R. Habelt.

IK Rhod Peraia = Blümel, W., 1991, Die Inschriften der Rhodischen Peraia, Bonn, Habelt.

KILyk = Laminger-Pascher, G., 1992, Die kaiserzeitlichen Inschriften Lykaoniens, fasc. 1, Wien, Österreichische Akademie der Wissenschaften. 
KON = Zgusta, L., 1984, Kleinasiatische Orstnamen, Heidelberg, Carl Winter.

KPN = Zgusta, L., 1964, Kleinasiatische Personennamen, Prag, Verlag der Tschechoslowakischen Akademie der Wissenchaften.

LIPP = Dunkel, G. E., 2014, Lexikon der indogermanischen Partikeln und Pronominalstämme, Heidelberg, Winter.

$L I V^{2}=$ Rix, H., 2001, Lexikon der indogermanischen Verben, Wiesbaden, Ludwig Reichert.

LNH = Laroche, E., 1966, Les noms des hittites, Paris, C. Klincksieck.

MAMA I = Calder, W. M., 1928, Monumenta Asiae Minoris Antiqua I. Eastern Phrygia, Manchester, The Manchester University Press.

MAMA IV = Buckler, W. H., Calder, W. M., and Guthrie, W. K. C., 1933, Monumenta Asiae Minoris Antiqua IV. Monuments and Documents from Eastern Asia and Western Galatia, Manchester, The Manchester University Press.

MAMA V = Cox, C. W. M., and Cameron, A., 1937, Monumenta Asiae Minoris Antiqua V. Monuments from Dorylaeum et Nacolea, Manchester, The Manchester University Press.

MAMA VI = Buckler, W. H., and Calder, W. M., 1939, Monumenta Asiae Minoris Antiqua VI. Monuments and Documents from Phrygia and Caria, Manchester, The Manchester University Press.

MAMA VII = Calder, W. M., Monumenta Asiae Minoris Antiqua VII. Monuments from Eastern Phrygia, Manchester, The Manchester University Press.

MAMA VIII = Calder, W. M., and Cormack, J. M. R., 1962, Monumenta Asiae Minoris Antiqua VIII. Monuments from Lycaonia, the Pisido-Phrygian Borderland, Aphrodisias, Manchester, The Manchester University Press.

NIL = Wodtko, D. S., Irslinger, B., and Schneider, C., 2008, Nomina im indogermanischen Lexicon, Heidelberg, Winter.

RECAM II = Mitchell, S., 1982, Regional Epigraphic Catalogues of Asia Minor, II: The Ankara District. The Inscriptions of North Galatia, Oxford, British Archaeological Reports.

RECAM IV = McLean, B. H., 2002, Regional Epigraphic Catalogues of Asia Minor, IV: Greek and Latin Inscriptions in the Konya Archeological Museum, London, British Institute of Archaeology at Ankara.

RPC = Burnett, A., Amandry, M., and Ripollès, P. P., 1992, Roman Provincial Coinage. Vol. I (1992): From the death of Caesar to the death of Vitellius (44 BC-AD 69), London - Paris, British Museum Press - Bibliothèque Nationale.

SB 3 = Bilabel, F. (ed.), 1926-127, Sammelbuch griechischer Urkunden aus Ägypten 3, Strassburg, K. J. Trübner.

SEB = Sammelbuch griechischer Urkunden aus Ägypten .

SEG = Supplementum Epigraphicum Graecum.

SERP = Ramsay, W. M. (ed.), 1906, Studies in the History and Art of the Eastern Provinces of the Roman Empire, Aberdeen, Aberdeen University Press. 
TAM V,1 = Herrmann, P., 1981, Tituli Asiae Minoris, V. Tituli Lydiae linguis Graeca et Latina conscripti Vol. 1, Regio septentrionalis, ad orientem vergens, Vienna.

TITUS = Lubotsky, A., 1994, "Corpus of Phrygian Inscriptions", Thesaurus Indogermanischer Textund Sprachmaterialien, available at:

http://titus.uni-frankfurt.de/texte/etcs/phrygian/phryg.html

$T L=$ Kalinka, E., 1901, Tituli Asiae Minoris 1, Tituli Lyciae, lingua Lycia conscripti, Vienna, A. Hoelder.

TLE = Pallottino, M., and Angeletti, M. P., 1978, Thesaurus linguae Etruscae, I. Indice lessicale, Roma, Consiglio Nazionale delle Ricerche.

\section{Bibliography}

Adiego, I.-X., 1992, "Glosses i pseudoglosses càries en fonts gregues", in Zaragoza, J., and González Senmartí, A. (eds.), Homenatge a Josep Alsina. Actes del Xè Simposi d’Estudis Clàssics, Tarragona 28-30 de noviembre del 1990 I, Tarragona, Diputació de Tarragona, 51-54.

Adiego, I.-X., 2004, “Los alfabetos epicóricos anhelénicos de Asia Menor", in Bádenas de la Peña, P., Torallas Tovar, S., Luján, E. R., and Gallego, M. A. (eds.), Lenguas en contacto: el testimonio escrito, Madrid, Consejo Superior de Investigaciones Científicas, 219-320.

Adiego, I.-X., 2007, The Carian Language, Leiden-Boston, Brill.

Adiego, I.-X., 2011, “Avatares licios de luvita im(ma)ra/i- 'campiña”, in Luján, E. R., and García Alonso, J. L., A Greek man in the Iberian street. Papers in Linguistics and Epigraphy in Honour of Javier de Hoz, Innsbruck, Institut für Sprachen und Literaturen der Universität Innsbruck, 327-335.

Adiego, I.-X., forthcoming a, "Local Adaptations of the Alphabet among the Non-Greek Peoples of Anatolia”, in Ferrara, S., and Valério, M. (eds.), Paths into Script Formation, Roma, Consiglio Nazionale delle Ricerche.

Adiego, I.-X, forthcoming b, "Lycian Wexssere, Waxssepddimi and related forms", in Simon, Z., Current Research on Lycian, porceedings of the International Workshop of the Digital PhilologicalEtymological Dictionary of the Minor Ancient Anatolian Corpus Languages, Institut für Assyriologie und Hethitologie, Ludwig-Maximilians-Universität München, 16-17 February 2017, Hamburg, Baar Verlag.

Agostiniani, L., 1982, Le “iscrizioni parlanti” dell'Italia antica, Firenze, Leo S. Olschki.

Åkerström, ̊̊, 1966, Die Architektonischen Terrakotten Kleinasiens, Lund, Gleerup.

Akurgal, E., 1943, “Pazarlı'da çıkan eserler üzerinde yeni araştırmalar”, Belleten 7, 1-22 and 2343.

Aldea Celada, J. M., 2013, "Apolo en el Valle del Duero. El dumus sacratus de Lancia (Villasabariego, León)", Sastre Blanco, J. C., Catalán Ramos, R., y Fuentes Melgar, P. (coords.), Arqueología en el Valle del Duero. Del Neolítico a la Antigüedad tardía: nuevas perspectivas, Madrid, Ediciones de la Ergastula, 165-173.

Anderson, G. E., 2012, "In the Shadow of Tumulus MM: the Common Cementery and Middle Phrygian Houses at Gordion", in Rose, C. B. (ed.), The Archaeology of Phrygian Gordion, Royal City of Midas, Philadelphia, The University Museum (University of Pennsylvania), 171-188.

Anderson, J. G. C., 1897, “A Summer in Phrygia: I”, The Journal of Hellenic Studies 17, 396-424. 
Anderson, J. G. C., 1898, “A Summer in Phrygia: II”, The Journal of Hellenic Studies 18, 81-128 and 340-344.

Anderson, J. G. C., 1899, "Exploration in Galatia cis Halym. Part II. Topography, Epigraphy, Galatian Civilisation", The Journal of Hellenic Studies 19, 53-134 and 280-318.

Altheim-Stiehl, R., and Cremer, M., 1985, "Eine gräko-persische Türstele mit aramäischer Inschrift aus Daskyleion", Epigraphica Anatolica 6, 1-16.

Avram, A., 2015, "Ein Altar aus Nakoleia und seine griechisch-phrygischen Inschriften", Gephyra $12,199-229$.

Avram, A., 2016a, "Zur Bezeichnung des Grabes und der Grabanlagen im Phrygischen", Takmer, B., Arca, E. N. A., and Özdil, N. G. (eds.), Vir Doctus Anatolicus. Studies in memory of Sencer Şahin / Sencer Şahin Anısına Yazılar, İstanbul, Kuzgun Yayınevi, 122-133.

Avram, A., 2016b, "Two Phrygian gods between Phrygia and Dacia", Colloquium Anatolicum 15, 70-83.

Avram, A., forthcoming, "Phrygian Personal Names in Phrygian Inscriptions", in Tsetskhladze, G. R. (ed.), Phrygian Lands Over Time, Leuven, Peeters.

Bakır, T., and Gusmani, R., 1991, "Eine neue phrygische inschrift aus Daskyleion”, Epigraphica Anatolica 18, 157-164.

Bakır, T., and Gusmani, R., 1993, “Graffiti aus Daskyleion”, Kadmos 32, 135-144.

Balkan, K., 1959, “Inscribed bullae from Daskyleion-Ergili”, Anatolia 4, 123-129.

Barnett, R. D., 1967, Phrygia and the Peoples of Anatolia in the Iron Age, Cambridge, Cambridge University Press.

Baughan, E. P., 2013, Couched in death: klinai and identity in Anatolia and beyond, Madison, The University of Wisconsin Press.

[Bayun \& Orel 1988a =] Баюн Л. С., and Oрел, В. Э., 1988а, “Язык фригийских надписей как исторический источник. I”, Вестник древней истории 1, 173-200.

[Bayun \& Orel 1988b =] Баюн Л. С., and Орел, В. Э., 1988b, “Язык фригийских надписей как исторический источник. II”, Вестник древней истории 4, 132-168.

Bayun, L. S., and Orel, V. E., 1988c, “The 'Moesian' inscription from Uyučik”, Kadmos 27, 2, 131138.

[Bayun \& Orel 1989 =] Баюн Л. С., and Орел В. Э., 1989, “Фригийско-анатолийские языковые отношения", in Нерознак, В.П. (еd.), Палеобалканистика и античность, Москва, Academia, Наука, 180-195.

Bayun, L. S., and Orel, V. E., 1990, "Die neuphrygischen Inschriften mit dem Partizip

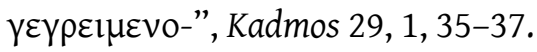

Bayun, L. S., and Orel., V. E., 1992-1993, "Palaeo-Balkanic epigraphic monuments: new discoveries and interpretations", Folia Orientalia 29, 5-17.

Beekes, R. S. P., 1969, The Development of the Proto-Indo-European Laryngeals in Greek, The Hague Paris, Mouton. 
Beekes, R. S. P., 1995, Comparative Indo-European linguistics: an introduction, AmsterdamPhiladelphia, John Benjamins.

Beekes, R. S. P., 1998, “The origin of Lat. aqua, and of *teutā 'people”, The Journal of Indo-European Studies 26, 3-4, 459-466.

Beekes, R. 2003 "The prehistory of the Lydians, the origin of the Etruscans, Troy and Aeneas", Bibliotheca Orientalis 59, 3-4, 205-241.

Beekes, R. S. P., 2003, The Origin of the Etruscans, Amsterdam, Koninklijke Nederlandes Akademie van Wetenschappen.

Berenguer Sánchez, J. A., 2000, Estudio sobre las partículas indoeuropeas con base consonántica y laringal, Madrid, Consejo Superior de Investigaciones Científicas.

Berenguer Sánchez, J. A., and Luján Martínez, E. R., 2005, "Falisco faced y el perfecto de *dhe $H_{1}-k$ - 'hacer' en las lenguas itálicas”, Emerita 73, 2, 197-216.

Berndt, D., 2002, Midasstadt in Phrygien. Eine sagenumwobene Stätte im anatolischen Hochland, Mainz, Philipp von Zabern.

Berndt-Ersöz, S., 2006, Phrygian Rock-Cut Shrines. Structure, Function, and Cult Practice, LeidenBoston, Brill.

Berndt-Ersöz, S., 2008, "The Chronology and Historical Context of Midas", Historia 57, 1, 1-37.

Berndt-Ersöz, S., 2012, "Frig Krallığı: Kökenleri, Tarihi ve Politik Gelişimi / The Phrygian Kingdom: Origins, History and Political Development", in Sivas, T. T., and Sivas, H. (eds.), Frigler. Midas'in Ülkesinde, Anttların Gölgesinde / Phrygians. In he Land of Midas, In the Shadow of Monuments, İstanbul, Tüpraş - Yapı Kredi Yayınları işbirliği ile hazırlanmıştır, 16-41.

Berndt-Ersöz, S., 2015, "Cutting the Gordian knot. The iconography of Megaron 2 at Gordion", Opuscula 8, 99-122.

Bilgen, A. N., Brixhe, C., and Coşkun, G., 2011, "Un Nouveau site épigraphique paléo-phrygien: Seyı̈ömer Höyük", Kadmos 50, 141-150.

Bittle, K., and Güterbock, H. G., 1935, Boğazköy I: neue Untersuchungen in der hethitischen Hauptstadt, Berlin, Akademie der Wissenschaften.

Blanco-Pérez, A., 2016, "Mên Askaenos and the native cults of Antioch by Pisidia", in de Hoz, M‥ P., Sánchez, J. P., i Molina, C. (eds.), Between Tarhuntas and Zeus Polieus: Cultural Crossroads in the Temples and Cults of Graeco-Roman Anatolia, Leuven, Peeters, 119-150.

Blažek,V., 2005, "Paleo-Balkanian languages I: Hellenic Languages”, Studia Minora Facultatis Philosophicae Universitatis Brunensis 10, 15-33.

Boehmer, R. M., 1977, “Siegel phrygischer Zeit”, Zeitschrift für Assyriologie und vorderasiatische Archäologie 67, 1, 78-84.

Boehmer, R. M., and Güterbock, H. G., 1987, Glyptik aus dem Stadtgebiet von Boğazköy, Berlin, Mann.

Börker-Klähn, J. 1994, “Ein Phryger in Kargamiš”, Altorientalische Forschungen 21, 1, 198.

Böker-Klähn, J., 2000, “Nachlese an phrygischen Fundplätzen” Reallexikon der Assyriologie und Vorderasiatischen Archäologie 24, 35-69. 
Bossert, E., 1942, Altanatolien. Kunst und Handwerk in Kleinasien. Von den Anfängen bis zum völligen Aufgehen in der griechischen Kultur, Berlin, Wasmuth.

Brandenburg, E., 1906, "Neue Untersuchungen im Gebiet der Phrygischen Felsenfassaden", Abhandlungen der Historischen Klasse der Königlich-Bayerischen Akademie der Wissenschaften 23, 637-716.

Brixhe, C., 1968, “Un ouvrage sur la langue phrygienne”, Revue de Philologie 42, 306-319.

Brixhe, C., 1976, Le dialecte grec de Pamphylie. Documents et grammaire, Paris, Lib. d'Amérique et d'Orient Adrien Maisonneuve.

Brixhe, C., 1978a, “Études néo-phrygiennes”, Verbum I, 1, 3-21.

Brixhe, C., 1978b, “Études néo-phrygiennes II", Verbum I, 2, 1-22.

Brixhe, C., 1979a, "Études néo-phrygiennes I", Verbum II, 2, 177-192.

Brixhe, C., 1979b, “Le nom de Cybèle. L'antiquité avait-elle raison?”, Die Sprache 25, 40-45.

Brixhe, C., 1981, "Inscriptions: les graffites du grand tumulus [appendix I]", in Young, R. S., 1981, The Great Early Tumuli, Philadelphia, The University Museum - University of Pennsylvania, 273-277.

Brixhe, C., 1982, "Palatalisations en grec et en phrygien: problèmes phonétiques et graphiques", Bulletin de la Société de linguistique de Paris 77, 209-249.

Brixhe, C., 1983, "Epigraphie et grammaire du prhygien: état présent et perspectives", in Vineis, E., (ed.), Le lingue indoeuropee di frammentaria atestazione - Die indogermanische Retsprachen. Atti del Convegno della Società di Glottologia e della Indogermanische Gesellschaft, Udine, 22-24 settembre 1981, Pisa, Giardini, 101-133.

Brixhe, C., 1987a, Essai sur le grec anatolien au debut de nostre ère, Nancy, Presses universitaires de Nancy.

Brixhe, C., 1987b, "La Langue comme critère d'aculturation: l'exemple du grec d'un district phrygien", Hethitica 8, 45-80 [= Lebrun, R. (ed.), Acta Anatolica E. Laroche Oblata. Colloque anatolien, Paris, 1-5 juillet 1985, Paris, Louvain, Peeters.

Brixhe, C., 1989-1990, "La plus occidentale des inscriptions phrygiennes", Incontri linguistici 13, 61-67.

Brixhe, C., 1990, “Comparaison et langues faiblement documentées : l'exemple du phrygien et de se voyelles longues", in Dor, J., and Kellens, J. (eds.), La reconstruction des laryngales, Liège, Université de Liège, 59-99.

Brixhe, C., 1991, "Les inscriptions paléo-phrygiennes de Tyane: leur intérêt linguistique et historique", in le Guen-Pollet, B., and Pelon, O. (eds.), La Cappadoce méridionale jusqu'à la fin de l'époque romaine. État des recherches. Actes du Colloque d'Istanbul (Institut Français d'Études Anatoliennes 13-14 avril 1987), Paris, Éditions Recherche sur les Civilisations, 37-46.

Brixhe, C., 1993, "Du paléo- au néo-phrygien”, Académie des Inscriptions \& Belles-Lettres. Comptes rendus des séances de l'année 1993. Avril-Juin, París, Diffusion de Boccard, 323-344.

Brixhe, C., 1994, “Le phrygien”, Bader, F. (ed.), Langues indo-européennes, Paris, C.N.R.S., 165-178.

Brixhe, C., 1996, "Les documents phrygiens de Daskyleion et leur éventuelle signification historique", Kadmos 35, 125-148. 
Brixhe, C., 1997, "Les clitiques du néo-phrygien", in Gusmani, R., Salvini, M., and Vannicelli, P. (eds.), Frigi e frigio. Atti del 1ํ Simposio Internazionale, Roma, 16-17 ottobre 1995, Roma, Consiglio Nazionale delle Ricerche, 41-70.

Brixhe, C., 1999, "Prolégomènes au corpus néo-phrygien", Bulletin de la Société de linguistique de Paris $94,285-315$.

Brixhe, C., 2002a, "Corpus des inscriptions paléo-phrygiennes : Supplément II”, Kadmos 41, 1102.

Brixhe, C., 2002b, "Interactions between Greek and Phrygian under the Roman Empire", in Adams, J. N., Janse, M., Swain, S. (eds.), Bilingualism in Ancient Society. Language Contact and the Written Word, Oxford, Oxford University Press, 246-266.

Brixhe, C., 2004a, "Corpus des inscriptions paléo-phrygiennes : Supplément II", Kadmos 43, 1130.

Brixhe, C., 2004b, "Nouvelle chronologie anatolienne et date d'élaboration des alphabets grec et phrygien", Comptes rendus des séances de l'Académie des Inscriptions et Belles-Lettres 148, 1, 271-289.

Brixhe, C., 2006, “Préhistoire et debut de l'histoire des dialectes grecs", Incontri linguistici 29, 3959.

Brixhe, C., 2008, "Phrygian", in Woodard, R. D., The Ancient Languages of Asia Minor, Cambridge, Cambridge University Press, 69-80.

Brixhe, C., 2013, “The personal onomastics of Roman Phrygia", in Thonemann, P. (ed.), Roman Phrygia. Culture and Society, Cambridge, Cambridge University Press, 55-69.

Brixhe, C., and Drew-Bear, T., 1978, “Un nouveau document néo-phrygien”, Kadmos 17, 1, 50-54.

Brixhe, C., and Drew-Bear, T., 1982, "Trois nouvelles inscriptions paléo-phrygiennes de Çepni", Kadmos 21, 64-87.

Brixhe, C., and Drew-Bear, T., 1997, "Huit inscriptions néo-phrygiennes", in Gusmani, R., Salvini,

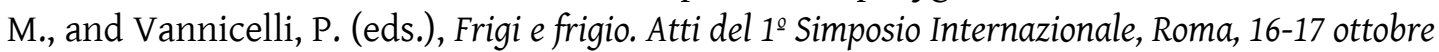
1995, Roma, Consiglio Nazionale delle Ricerche, 71-114.

Brixhe, C., and Drew-Bear, T., 2010, "Inscription phrygienne hellénistique de Prymnessos", Kadmos 49, 161-168.

Brixhe, C., and Keleş, V., 2011, “Une inscription paléo-phrygienne dans la région de Parion?", Kadmos 50, 151-160.

Brixhe, C., and Neumann, 1985, "Découverte du plus long texte néo-phrygien; l'inscription de Gezler Köyü”, Kadmos 24, 161-184.

Brixhe, C., and Sıvas, T. T., 2002, "Dédicace paléo-phrygienne inédite (Menekşekaya/Demirli)", Kadmos 41, 103-116.

Brixhe, C., and Sivas, T. T., 2003, "Exploration de l'ouest de la Phrygie, nouveaux documents Paléo-Phrygiens", Kadmos 42, 65-76.

Brixhe, C., and Sivas, T. T., 2009, Nouveaux graffites paléo-phrygiens de Şarhöyük-Dorylaion", Kadmos 48, 125-140. 
Brixhe, C., and Summers, G. D., 2006, "Les inscriptions phrygiennes de Kerkenes Dağ (Anatolie Centrale)", Kadmos 45, 93-135.

Brixhe, C., and Vottéro, G., 2016, "Germanos Sogukçam, nouvelle inscription paléo-phrygienne dans une aire cultuelle remarquable”, Kadmos 55, 1, 131-146.

Brixhe, C., and Waelkens, M., 1981, "Un nouveau document néo-phrygien au Musée d'Afyon", Kadmos 20, 66-75.

Bru, H., 2017, La Phrygie Parorée et la Pisidie septentrionale aux époques hellénistique et romaine: Géographie historique et sociologie culturelle, Leiden, Brill.

Brugmann, K., and Delbrück, B., 1906, Grundriss Vergleichenden Grammatik der Indogermanischen Sprachen 2.1, Berlin, Walter de Gruyter.

Bryce, T., 2012, The World of the Neo-Hittite Kingdoms: A Political and Military History, Oxford - York, Oxford University Press.

Bubenik, V., 1989, Hellenistic and Roman Greece as a sociolinguistic area, Amsterdam, John Benjamins.

Burke, B., 2001, "Anatolian origins of the Gordion knot legend", Greek, Roman and Byzantine Studies 42, 3, 255-261.

Burke, B., 2005, "Textile production at Gordion and the Phrygian economy", in Kealkhofer, L. (ed.), The Archaeology of Midas and the Phrygians: Recent Work at Gordion, Philadelphia, University of Pennsylvania Museum, 69-81.

Calder, W. M., 1911, “Corpus Inscriptionum Neo-Phrygiarum”, The Journal of Hellenic Studies 31, 161-215.

Calder, W. M., 1913, “Corpus Inscriptionum Neo-Phrygiarum II”, The Journal of Hellenic Studies 33, 97-104.

Calder, W. M., 1926, “Corpus inscriptionum Neo-Phrygiarum III”, The Journal of Hellenic Studies $46,22-28$.

Calder, W., M., 1922, “Inscriptions grecques métriques inédites d'Asie Mineure (Phrygie, Galatie, Lycaonie, Isaurie)”, Revue de philologie, de littérature et d'histoire anciennes 46, 2, 114-131.

Carruba, O., 1978, "La scrittura licia", Annali della scuola normale superiore di Pisa, classe di lettere e filosofia, Serie III, 8, 3, 849-867.

Cassola, F., 1997, "Rapporti tra Greci e Frigi al tempo di Mida", in Gusmani, R., Salvini, M., and Vannicelli, P. (eds.), Frigi e frigio. Atti del 1ํo Simposio Internazionale, Roma, 16-17 ottobre 1995, Roma, Consiglio Nazionale delle Ricerche, 131-152.

Cau, N., 2003, "Nuovi antroponimi indigeni nelle iscrizioni greche della Licia di età ellenisticoromana, II", Studi Ellenistici 15, 297-340.

Chantraine, P., 1984, Morphologie historique du grec, Paris, Éditions Klincksieck.

Chiai, G. F., 2009, "Die Ortsgebundenheit des Religiösen: das Paradigma der ländlichen Heiligtümer Phrygiens in der Kaiserzeit", in Auffarth, C., Hannemann, T., and Züchner, O. (eds.), Religion auf dem Lande: Entstehung und Veränderung von Sakrallandschaften unter römischer Herrschaft, Stuttgart, Franz Steiner Verlag, 133-160. 
Çınaroğlu, A., and Varinlioğlu, E., 1985, "Ein neuer schwarzer Stein aus Tyana. Eine neue altphrygische Inschrift aus Tyana”, Epigraphica Anatolica 5, 5-11.

Cox, C. W. M., and Cameron, A., 1932, "A native inscription from the Myso-Phrygian Borderland", Klio 25, 34-49.

Clackson, J., 1994, The linguistic relationship between Armenian and Greek, Oxford - Cambridge, Blackwell.

Clackson, J. P. T., 2008, “Classical Armenian”, in Woodard, R. D., The Ancient Languages of Asia Minor, Cambridge, Cambridge University Press, 124-143.

Crevatin, F., 1972. "Mote frigi, I. norikon 'otre”, Zeitschrift für vergleichende Sprachforschung 86, 2, 178-189.

Cross, F. M., 1966, “An Aramaic inscription from Daskyleion”, Bulletin of the American Schools of Oriental Research 184, 7-10.

Crowfoot, J. W., 1899, "Exploration in Galatia cis Halym", The Journal of Hellenic Studies 19, 34-14 and 318.

Cuntz, O., 1990, Itineraria Romana 1. Itineraria Antonini Augusti et Burdigalense, Leipzig, Teubner.

Darga, A. M., 1993, “Şarhöyük Dorylaion Kazıları”, Kazı Sonuçları Toplantısı 15, 1, 481-501.

de Lamberterie, C., 1991, "Le verbe ßıveĩv et le nom de la femme", Revue de philologie, de littérature et d'histoire anciennes 65, 149-160.

de Hoz, M. P., 1999, Die lydischen Kulte im Lichte der griechischen Inschriften, Bonn, Dr. Rudolf Habelt.

de Hoz, M. P., 2006, "Literacy in rural Anatolia: the testimony of the Confession Inscriptions", Zeitschrift für Papyrologie und Epigraphik 155, 139-144.

de Hoz, M. P., 2017, "Prayer to the deceased? Relations between gods, dead and the living in Phrygia Epictetus", Ancient West \& East 16, 139-154.

De Jong, 1997, Traditions of the Magi: Zoroastrianism in Greek and Latin Literature, Leiden, Brill.

Demiraj, B., 1997, Albanische Etymologien. Untersuchugen zum albanischen Erbwortschatz, Amsterdam-Atlanta, Rodopi.

de Saussure, F., 1898, "Inscriptions Phrygiennes. Description des textes" in Chantre, E., Recherches archéologiques dans l'Asie occidentale: mission en Cappadoce 1893-1894, Paris, Ernest Leroux, 165-191. [=de Saussure, F., 1922, Recueil des publications scientifiques de F. de Saussure, Gèneve, Société anonyme des éditions Sonor, 542-575]

Detschew, D., 1976, Die Thrakischen Sprachreste, Wien, Österreichische Akademie der Wissenschaften,

Deutsch, R., and Millard, A., 2014, "Ten unpublished West Semitic bronze weights", Israel Numismatic Journal 18, 15-26.

de Vaan, M., 2008, Etymological Dictionary of Latin and the other Italic Languages, Leiden - Boston, Brill.

DeVries, K., 1990, “The Gordion Excavation Seasons of 1969-1973 and Subsequent Research", American Journal of Archaeology 94, 3, 371-406. 
DeVries, K., 1997, “The Attic Pottery from Gordion”, in Oakley, J. H., Coulson, W. D. E., and Palagia, O. (eds.), Athenian Potters and Painters: The Conference Proceedings, Oxford, Oxbow, 43745.

DeVries, K., 2005, “Greek Pottery and Gordion Chronology", in Kealkhofer, L. (ed.), The Archaeology of Midas and the Phrygians: Recent Work at Gordion, Philadelphia, University of Pennsylvania Museum, 36-55.

Diakonoff, I. M., 1993, “Cyaxares”, Encyclopaedia Iranica VI, 478-479.

Diakonoff, I. M., and Neroznak, V. P., 1985, Phrygian, Delmar, New York, Caravan Books.

Dinç, R., and Innocente, L., 1999, “Ein Spinnwirtel mit phrygischer Inschrift”, Kadmos 38, 65-72.

Draycott, G. D., and Summers, G. D., 2008, Sculpture and inscriptions from the monumental entrance to the palatial complex at Kerkenes Dağ, Chicago, Oriental Institute Publications.

Dressler, W., 1964, “Altkleinasiatische Miszellen”, Die Sprache 10, 110-115.

Dressler, W., 1965, "i-Prothese vor s impurum in Kleinasien (und im Vulgärlatein)”, Balkansko Ezikoznanie 9, 2, 93-100.

Drew-Bear, T., and Lochman, T., 1996, "Grabreliefs aus Amorion, Orkistos und der antiken Siedlung von Bağlıca, Zeugen verlorengegangener Grabbauten”, Arkeoloji Dergisi 4, 109-134.

Drew-Bear, T., Lubotsky, A., and Üyümez, M., 2008, “Three New Phrygian Inscriptions”, Kadmos $47,109-116$.

Drew-Bear, T., and Naour, C., 1990, "Divinités de Phrygie", Aufstieg und Niedergang der Römischen Welt 18, 3, 1907-2044.

Duhoux, Y., 2000, Le verbe grec ancien. Éléments de morphologie et de syntaxe historiques, Louvain-laNeuve, Peeters.

Duhoux, Y., Palaima, T. G., and Bennet, J. (eds.), 1989, Problems in Decipherment, Louvain-laNeuve, Peeters.

Dupont-Sommer, A., 1966, "Une inscription araméenne inédite d'epoque perse trouvée à Daskyleion (Turquie)”, Comptes rendus des séances de l'Académie des Inscriptions et Belles-Lettres $110,1,44-58$.

Eckhardt, B., 2016, "Romanization and Isomorphic Change in Phrygia: the Case of Private Associations" The Journal of Roman Studies 106, 147-171.

Edwards, G. R., 1959, “The Gordion Campaign of 1958: Preliminary Report”, American Journal of Archaeology 63, 3, 263-268.

Edwards, R., 1963, “Gordion: 1962”, Expedition 5(3), 42-48.

Fales, F. M., and Jakob-Rost, L., 1991, "Neo-Assyrian texts from Assur. Private archives in the vorderasiatisches Museum of Berlin, Part I", State Archives of Assyria Bulletin 5, 1, 3-157.

Fauth, W., 1989, "Mykenisch du-ma, phrygisch dum-", Historische Sprachforschung 102, 187-206.

Fick, F. C. A., 1873, Die ehemalige Spracheinheit der indogermanen Europas: eine sprachgeschichtliche Untersuchung, Göttingen, Vandenhoeck \& Ruprecht's Verlag. 
Fol, A., 1997, "The paredroi between "Midas' City" and "Midas' Gardens", in Gusmani, R., Salvini, M., and Vannicelli, P. (eds.), Frigi e frigio. Atti del 1ํ Simposio Internazionale, Roma, 16-17 ottobre 1995, Roma, Consiglio Nazionale delle Ricerche, 261-266.

Fontenrose, J., 1988, Didyma : Apollo's Oracle, cult, and companions, Berkeley, University of California Press.

Furnée, E. J., 1972, Die wichtigsten konsonantischen Erscheinungen des Vorgriechischen. The Hague Paris, Mouton.

Freeman, P., 2001, The Galatian language. A comprehensive survey of the language of the ancient Celts in Greco-Roman Asia Minor, Lewiston, The Edwin Mellen Press.

Friedrich, J., and Röllig, W., 1970, Phönizisch-Punische Grammatik, Roma, Pontificium Institutum Biblicum.

Friedrich, J., 1932, Kleinasiatische Sprachdenkmäler, Berlin, de Gruyter.

Friedrich, J., 1941, "Phrygia (Sprache); Phrygia (Geschichte)", Pauly-Wissowa Real-encyclopädie der classischen Altertumswissenschaft 20,1,868-891.

Friedrich, J., 1965, “Ein phrygisches Siegel und ein phrygisches Tontafel”, Kadmos 4, 154-156.

“Funde", 1898, Mittheilungen des Kaiserlich Deutschen Archäeologischen Instituts 23, 359-367.

García Ramón, J. L., 1987, "Sobre las variantes $\Delta \mathfrak{\imath v v v v \sigma o \varsigma , ~} \Delta \mathrm{l} v v \sigma o \varsigma$ y $\Delta \mathrm{t} v v v \sigma o \varsigma$ del nombre de Dioniso: Hechos e hipótesis”, Minos 20-22, 183-200.

Garstang, J., 1908, "Notes on a journey through Asia Minor", Annals of Archaeology and Antropology 1, 1-12.

Gelb, I. J., 1935, Inscriptions from Alishar and Vicinity, Chicago, The University of Chicago Press.

Genz, H., 2009, "Thoughts on the use of seals in Iron Age central Anatolia", Saglamtimur, H., Abay, E., Derin, Z., Erdem, A. Ü., Batmaz, A., Dedeoğlu, F., Erdalkıran, M., Baştürk, M. B. i Konakşı, E. (eds.), Altan Çiligiroğlu'na armağan yukari denızın kiyisinda Uratu kralliği'na Adanmiş bir hayat - A life dedicated to Urartu on the shores of the upper sea. Studies in Honour of Altan Cilingiroglu, İtanbul, Arkeolojı ve Sanat Yayinlari, 309-317.

Genz, H., 2011, “The Iron Age in central Anatolia”, in Tsetskhladze, G. R. (ed.), The Black Sea, Greece, Anatolia and Europe in the First Millennium BC, Leuven, Peeters, 331-368.

Georgiev, V. I., 1941, Vorgriechische Sprachwissenschaf, Sofa, Imprimerie de l'Université.

Georgiev, V. I., 1981, Introduction to the history of the Indo-European languages, Sofia, Publishing House of the Bulgarian Academy of Sciences.

Gérard, R., 2005, Phonétique et morphologie de la langue lydienne, Peeters, Louvain-la-Neuve.

[Gindin 1981 =] Гиндин, Л. А.,1981, Древнейшая ономастика Восточных Балкан: фракохетто-лувийские и фрако-малоазийские изоглоссы, София, Болгарской Академии нау.

Gorbachov, Y., 2005, "The origin of the Phrygian aorist of the type edaes", in Jones-Bley, K., Huld, M., Della Volpe, A., and Dexter, M. R., (eds.), Proceedings of the sixteenth Annual UCLA IndoEuropean Conference. Los Angeles. November 2-3, 2006, Washington DC, Institute for the Study of Man, 191-217. 
Gorbachov, Y., 2008, "Nine observations on the Old Phrygian inscription from Vezirhan", Kadmos 47, 91-108.

Gosche, R., 1864, "Über phrygische Inschriften", Verhandlungen deutscher Philologen und Schulmänner in Meissen 22, 84-103.

Guarducci, M., 1978, Epigrafia greca IV: epigrafi sacre pagane e cristiane, Roma, Istituto poligráfico e Zecca dello Stato.

Gusmani, R., 1958, “Le iscrizioni dell'antico frigio", Rendiconti dell'Istituto Lombardo, Classe di Lettere 92, 870-903.

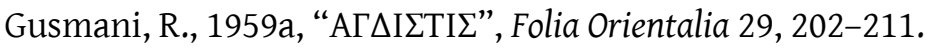

Gusmani, R., 1959b, "Relazioni linguistiche tra Frigia e Licia”, Archivio glottologico italiano 49, 916.

Gusmani, R., 1964, Lydisches Wörterbuch, Heidelberg, Carl Winter.

Gusmani, R., 1980, Lydisches Wörterbuch, Heidelberg, Carl Winter.

Gusmani, R., 1980-1981, “Note d'antroponomastica lidia”, Incontri linguistici 6, 21-27

Gusmani, R., 1988, "An epichoric inscription from the Lydio-Phrygian borderland", in Imparati, F. (ed.), Studi di storia e di filologia anatolica dedicati a G. Pugliese Carratelli, Florence, Elite, 6773.

Gusmani, R., 2001, “Altphrygisches”, in Wilhelm, G. (ed.), Akten des IV. Internationalen Kongresses für Hethitologie. Würzburg, 4.-8. Oktober 1999, Wiesbaden, Harrassowitz Verlag, 161-166.

Gusmani, R., and Poetto, M., 1981, “Un nouvo sigillo frigio iscritto”, Kadmos 20, 64-67.

Gusmani, R., and Polat, Y., 1999a, "Ein neues phrygisches Graffito aus Daskyleion”, Kadmos 38, 59-64.

Gusmani, R., and Polat, G., 1999b, "Manes in Daskyleion. Die Stele und das Relief”, Kadmos 38, 137-162.

Haas, O., 1951, “Zur Deutung der phrygischen Inschriften”, Revue hittite et asianique 11, 1-30.

Haas, O., 1961, "Phrygische Inschriften. Berichtigte Lesungen - verbesserte Deutungen", Die Sprache 7, 77-92.

Haas, O., 1966, Die phrygischen Sprachdenkmäler, Sofia, Academie Bulgare des Sciences.

Haas, O., 1969, "Neue phrygische Sprachdenkmäler", Zeitschrift für vergleichende Sprachforschung $83,70-87$.

Haas, O., 1970a, "Das problem der Herkunft der Phryger und ihrer Beziehungen zu den Balkanvölkern", Acta Antiqua Academiae Hungaricae 18, 31-69.

Haas, O., 1970b, “Zur Deutung der phrygischen Inschriften”, Revue hittite et asianique XI, 53, 130.

Hajnal, I., 2005, “Das Frühgriechische zwischen Balkan und Ägäis. Einheit over Vielheit?”, in Meiser, G., and Hackstein, O. (eds.), 2005, Sprachkontakt und Sprachwandel. Akten der XI. Fachtagung der indogermanischen Gesellschaft, 17-23. September 2000, Halle an der Saale. Wiesbaden, Reichert, 185-214. 
Hamilton, W., 1842, Researches in Asia Minor, Pontus, and Armenia; with some account of their antiquities and geology, London, J. Murray.

Hämmig, A. E., 2013, “Nevotan niptiyan, die Fluchformel der Stele von Vezirhan”, Indogermanische Forschungen, 118, 125-154.

Hämmig, A. E., fothcoming a " "The Language of the Phrygians and its Ongoing Decipherment", in Tsetskhladze, G. R. (ed.), Phrygian Lands Over Time, Leuven, Peeters.

Hämmig, A. E., fothcoming b, “The Phrygian 'set(i) forms' and the Armenian subjunctive in $-i c$-"

Haspels, C. H. E., 1971, The Highlands of Phrygia: sites and monuments, Princeton, Princeton University Press.

Heberdey, R., and Wilhelm, A., 1896, Cilicia Reisen in Kilikien, Wien, Carl Gerold's Sohn.

Herrmann, P., and Polatkan, K. Z., 1969, Das Testament des Epikrates und andere neue Inschriften aus dem Museum von Manisa, Wien, Österreichische Akademie der Wissenschaften.

Heubeck, A., 1958, "Bemerkungen zu den neuphrygischen Fluchformeln”, Indogermanische Forschungen 64, 13-25.

Heubeck, A., 1986, “Bemerkungen zur altphrygischen Inschrift T-03”, Kadmos 25, 1, 75-79.

Heubeck, A., 1987, “Phrygiaka I-III", Zeitschrift für vergleichende Sprachforschung, 100, 1, 70-85.

Hogarth, D. G., 1890, "Notes in Phrygia Paroreus and Lycaonia", The Journal of Hellenic Studies 11, 151-166.

Holzman, S., 2016, “Tortoise-Shell Lyres from Phrygian Gordion”, American Journal of Archaeology $120,4,537-564$.

Innocente, L., 1997, "Questioni di onomástica 'frigia”, in Gusmani, R., Salvini, M., and Vannicelli, P. (eds.), Frigi e frigio. Atti del 1ํ Simposio Internazionale, Roma, 16-17 ottobre 1995, Roma, Consiglio Nazionale delle Ricerche, 33-40.

Janda, M., 1997, "Zur altphrygischen Areyastis-Inschrift", in Gusmani, R., Salvini, M., and Vannicelli, P. (eds.), Frigi e frigio. Atti del 1ํ Simposio Internazionale, Roma, 16-17 ottobre 1995, Roma, Consiglio Nazionale delle Ricerche, 271-277.

Janko, R., 2015, "From Gabii and Gordion to Eretria and Methone: the rise of the Greek alphabet", Bulletin of the Institute of Classical Studies 58, 1, 1-32.

Jasanoff, J. H., 2003, Hittite and the Indo-European Verb, Oxford, Oxford Univeristy Press.

Jeffery, L. H., 1961, The local scripts of archaic Greece, Oxford, Clarendon Press.

Jiménez Delgado, J. M., 2013, "A note on the Mycenaean thematic genitive ending in month names", Indogermanische Forschungen 118, 111-124.

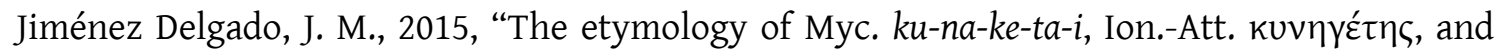
Myc. ra-wa-ke-ta, Dor. $\lambda \bar{\alpha} \gamma \bar{\varepsilon} \tau \bar{\alpha} \varsigma^{\prime}$, Glotta 91, 116-128.

Jokl, N., 1927, "Phryger", in Ebert, M. (ed.), Reallexikon der Vorgeschichte 10, Berlin, De Gruyter, 143.

Kaczyńska, E., 2011, "Phrygian glosses in Pseudo-Plutarch's Works de Fluviis", Lingua Posnaniensis $53,1,58-63$. 
Kaptan, D., 2002, The Daskyleion bullae: seal images from the western Achaemenid empire, Part 1, Leiden, Nederlands Instituut voor het Nabije Oosten.

Kaptan, D., 2013, "Déjà vu? Visual culture in Western Asia Minor at the beginning of Hellenistic Rule", in Stavrianopoulou, E. (ed.), Shifting social imaginaries in the Hellenistic Period. Narrations, Practices, and Images, Leiden - Boston, Brill, 25-50.

Kelp, U., 2013, "Grave monuments and local identities in Roman Phrygia" in Thonemann, P. (ed.), Roman Phrygia. Culture and Society, Cambridge, Cambridge University Press, 70-94.

Kelp, U., 2015, Grabdenkmal un lokale Identität. Ein Bild der Landschaft Phrygien in der römischen Kaiserzeit, Bonn, Habelt.

Kloekhorst, A., 2008, Etymological Dictionary of the Hittite Inherited Lexicon, Leiden-Boston, Brill.

Kloekhorst, A., 2014, "Proto-Indo-European "thorn"-clusters", Historische Sprachforschung 127, 43-67.

Kloekhorst, A., 2015, “The Old Phrygian word for 'feet': new readings in the 'podas'-inscription (G-02)", Kadmos, 54, 1, 107-118.

Klingenschmitt, G., 1994, "Das Albanische als Glied der indogermanischen Sprachfamilie", in Rasmussen, J. E. (ed.), In honorem Holger Pedersen, Kolloquium der Indogermanischen Gesellschaft vom 25. bis 28. März 1993, in Kopenhagen, Wiesbaden, Reichert, 221-233.

Knobloch, J., 1958, "Ein kaukasisches Lehnwort in den Klassischen Sprachen”, Die Sprache 4, 198200.

Kogan, L., 2011, Proto-Semitic lexicon, en Weninger (ed.) The Semitic languages, Berlin - Boston, Walter de Gruyter, 179-258.

Körte, A., 1898, "Die phrygischen Felsdenkmäler", Mitteilungen des deutschen archäologischen Instituts 23, 80-153.

Körte, G., and Körte, A., 1904, Gordion: Erbegnisse der Ausgrabung im Jahre 1900, Berlin, Georg Reimer.

Koşay, H., 1937, “Les sondages de Pazarli”, La Turquie kémaliste 21-22, 25-35.

Koşay, H., 1939, "Türk Tarih Kurumu Tarafından Yapılan Pazarlı Hafriyatı / Les fouilles de Pazarlı. Exécutées par les soins de la Société d'Histoire Turque”, Belleten 3, 9, 15-25.

Koşay, H., 1941, Türk Tarih Kurumu tarafindan yapilan Pazarli hafriyati raporu / Les fouilles de Pazarli entreprises par la Société d'histoire turque, Ankara, Türk Tarih Kurumu.

Kowal, B., 1984a, "Zur spätphrygischen Inschrift 15”, Klagenfurter Beiträge zur Sprachwissenschaft $10,1,6-9$.

Kowal, B., 1984b, Zur spätphrygischen Inschrift 31", Kadmos 23, 2, 180-185.

Kretschmer, P., 1899, "Neue phrygische Inschriften", Wiener Zeitschrift für die Kunde des Morgenlandes 13, 352-362.

Kretschmer, P., 1900, "Bilinguis aus Dorylaion", Mittheilungen des Kaiserlich Deutschen Archaeologischen Instituts. Athenische Abtheilung 25, 445-446.

Kretschmer, P., 1901, “Zu der phrygischen Inschrift Bd. XIII, S. 352”, Wiener Zeitschrift für die Kunde des Morgenlandes 15, 115-116. 


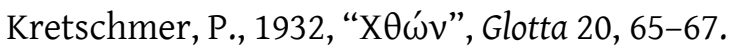

Kroonen, G., 2013, Etymological Dictionary of Proto-Germanic, Leiden - Boston, Brill.

Kubińska, J., 1968, Les monuments funéraires dans les inscriptions grecques de l'Asie Mineure, Warszawa, PWN - Editions Scientifiques de Pologne.

Kuniholm, P. I., and Newton, M. W., 2011, "Dendrochronology at Gordion”, in Rose, C. B., and Darbyshire, G. (eds.), 2011, The New Chronology of Iron Age Gordion, Philadelphia, The University Museum (University of Pennsylvania), 79-122.

Lafl1, E., 2017, "Select Funerary and votive monuments in Graeco-Roman Cilicia: Hellenistic, Roman and early Byzantine examples in the museums of Mersin and Alanya", Anatolian Studies $67,145-180$.

Laminger-Pascher, G., 1984, Beiträge zu den griechischen Inschriften Lykaoniens, Wien, Verlag der Österreichischen Akademie der Wissenschaften.

Laminger-Pascher, G., 1989, Lykaonien und die Phryger, Wien, Verlag der Österreichischen Akademie der Wissenschaften.

Lancellotti, M. G., 2002, Attis, between myth and history: king, priest, and god, Leiden, Brill.

Lane, M. F., 2012, “Linear B wo-wo / wo-wi-ja”, Pasiphae 6, 117-183.

Lazović, M., Dürr, N., Durand, H., Houriet, C., and Schweizer, F., 1977, "Objets byzantins de la collection du Musée d'Art et d'Histoire", Genava 25, 5-62.

Legrand, P. E., and Chamonard, J., 1893, "Inscriptions de Phrygie", Bulletin de correspondance hellénique 17, 241-293.

Lejeune, M., 1939, Les adverbes grecs en - $\theta \varepsilon v$, Delmas, Publications de l'Úniversité de Bordeaux.

Lejeune, M., 1969a, “Dicussions sur l'alphabet phrygien”, Studi micenei ed egeo-anatolici 10, 1947.

Lejeune, M., 1969b, “Notes paléo-phrygiennes”, Revue des études anciennes 71, 287-300.

Lejeune, M., 1970, “Les inscriptions de Gordion et l'alphabet phrygien”, Kadmos 9, 51-74.

Lejeune, M., 1978, "Sur l'alphabet paleophrygien", Annali della Scuola Normale Superiore di Pisa, Classe di lettere e filosofía, Serie III 8, 3, 783-790.

Lejeune, M., 1979, "Regards sur les sonores I.E. en vieux phrygien”, in Florilegium anatolicum. Mélanges offerts à Emmanuel Laroche, Paris, de Boccard, 219-224.

Lemaire, A., 1994, "Deux nouvelles stèles funéraires araméennes de Cilicie orientale", Epigraphica anatolica 22, 91-98.

Lemaire, A., 2000, Textes araméens d'Anatolie d'époque perse, available at: http://www.achemenet.com/en/tree/?/textual-sources/texts-by-languages-andscripts/aramaic

Liebhart, R. F., and Brixhe, C., 2009, "The recently discovered inscriptions from Tumulus MM at Gordion. A preliminary report”, Kadmos 48, 141-156.

Ligorio, O., 2016, "Old Phrygian totin", Lucida intervalla 45, 33-39. 
[Ligorio \& Lubotsky =] Лигорио, O., and Лубоцкий, А., 2013, “Фригийский язык”, in Коряков, Ю. Б., and Кибрик, А. А. (eds.), Языки мира, Реликтовые индоевропейские языки Передней и Центральной Азии, Москва, Academia, 180-195.

Lipiński, E., 1975a, Studies in Aramaic inscriptions and onomastics I, Leuven, Leuven University Press.

Lipiński, E., 1975b, Studies in Aramaic inscriptions and onomastics II, Leuven, Leuven University Press.

Locatelli, L., 2015, “Le cheval dans l'onomastique du Sud-Ouest de l'Anatolie”, BABELAO 4, 101110.

Lochman, T., 2003, Studien zu kaiserzeitlichen Grab- und Votivreliefs aus Phrygien, Basel, Skulpturhalle.

Lubotsky, A., 1988, “The Old Phrygian Areyastis-inscription”, Kadmos 27, 1, 9-26.

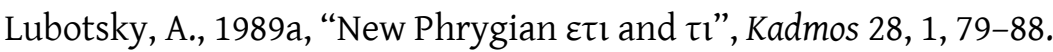

Lubotsky, A., 1989b, “The syntax of the New Phrygian inscription No. 88”, Kadmos 28, 1, 146155.

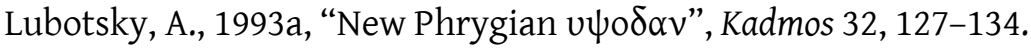

Lubotsky, A., 1993b, "Word boundaries in the Old Phrygian Germanos inscription", Epigraphica Anatolica 21, 93-98.

Lubotsky, A., 1997, "New Phrygian Inscription No. 48: Paleographic and Linguistic Comments", in Gusmani, R., Salvini, M., and Vannicelli, P. (eds.), Frigi e frigio. Atti del $1^{\circ}$ Simposio Internazionale, Roma, 16-17 ottobre 1995, Roma, Consiglio Nazionale delle Ricerche, 115-130.

Lubotsky, A., 1998, "New Phrygian metrics and the $\delta \varepsilon \omega \varsigma \zeta \varepsilon \mu \varepsilon \lambda \omega \varsigma$ formula", in Jasanoff, J., Melchert, H. C., and Olivier, L. (eds.), Mír Curad. Studies in Honor of Calvert Watkings. Innsbruck, Institut für Sprachwissenchaft, 413-421.

Lubotsky, A., 2004, "The Phrygian Zeus and the Problem of the 'Lautverschiebung”, Historische Sprachforschung 117, 2, 229-237.

Lubotsky, A., 2008, “Old Phrygian bevdos ‘statue, image', Greek $\beta \varepsilon \tilde{v} \delta$ o ‘ ‘woman’s dress”, The Journal of Indo-European Studies 36, 96-97.

Lubotsky, A., 2017, "The Phrygian inscription from Dokimeion and its meter", in Hajnal, I., Kölligan, D., and Zipser, K. (eds.), Miscellanea Indogermanica. Festschrift für José Luis García Ramón zum 65. Geburtstag. Innsbruck, Innsbrucker Beiträge zur Sprachwissenschaft, 427-431.

Luján, E. R., 2009, "On the grammaticalization of ${ }^{*} k^{w} i-/ k^{w} 0$ - relative clauses in Proto-IndoEuropean", in Bubenik, V., Hewson, J., and Rose, S. (eds.), Grammatical change in Indo-European languages. Papers presented at the workshop on Indo-European linguistics at the XVIIIth international conference on historical linguistics, Montreal, 2007, Amsterdam-Philadelphia, John Benjamins Publishing, 221-234.

Macpherson, I. W., 1954, "Inscriptions from Eskisehir and District", Annual of the British School at Athens 49, 11-16.

Mallory, J. P., and Adams, D. Q., 2006, The Oxford Introduction to Proto-Indo-European and the ProtoIndo-European World, Oxford, Oxford University Press. 
Manning, S. W., and Kromer, B., 2011, "Radiocarbon Dating Iron Age Gordion and the Early Phrygian Destruction in Particular", in Rose, C. B., and Darbyshire, G. (eds.), 2011, The New Chronology of Iron Age Gordion, Philadelphia, The University Museum (University of Pennsylvania), 123-154.

Martirosyan, H., 2010, Etymological Dictionary of the Armenian Inherited Lexicon, Leiden, Brill.

Martirosyan, H., 2013, "The place of Armenian in the Indo-European language family: the relationship with Greek and Indo-Iranian", Journal of Language Relationship 10, 85-13.

Masson, O., 1954, "Épigraphie asianique: Bibliographie relative aux inscriptions lyciennes, cariennes, lydiennes et phrygiennes", Orientalia 23, 4, 439-442.

Masson, O., 1987a, “Le sceau paléo-phrygien de Mane”, Kadmos 26, 2, 109-113.

Masson, O., 1987b, "Le mot $\triangle \mathrm{OYMO \Sigma}$ 'confrérie' dans les textes et les inscriptions", Cahiers Ferdinand de Saussure, 41, 145-152.

Matasovič, R., 2009, Etymological Dictionary of Proto-Celtic, Leiden-Boston, Brill.

Matzinger, J., 2005, "Phrygisch und Armenisch", in Meiser, G., and Hackstein, O. (eds.), Sprachkontakt und Sprachwandel: Akten der XI. Fachtagung der Indogermanischen Gesellschaft, 17.23. September 2000, Halle an der Saale / Akten der XI. Fachtagung der Indogermanischen Gesellschaft, 17.-23. September 2000, Halle an der Saale, Wiesbaden, Dr. Ludwig, Reichert, 375-394.

Matzinger, J., 2006, "Interpretation sprachlicher Daten aus Rest- und Trümmersprachen. Das Fallbeispiel der Streitfrage um eine phrygische Lautverschiebung”, Historische Sprachforschung 119, 190-210.

Mayrhofer, M., 1973, Onomastica Persepolitana: Das Altiranische Namengut der Persepolis-Tafelchen, Wien, Verlag der Osterreichischen Akademie der Wissenschaften.

McLean, B. H., 2014, An Introduction to Greek Epigraphy of the Hellenistic and Roman Periods from Alexander the Great down to the Reign of Constantine (323 B.C. - A.D. 337), Ann Arbor, The University of Michigan Press.

Meier-Brügger, M., 1992, Griechische Sprachwissenschaft, Berlin, de Gruyter.

Meier-Brügger, M., 2003, Indo-European Linguistics, Berlin-New York, Walter de Gruyter.

Meissner, T., 2016, "Archaeology and the Archaeology of the Greek language: on the origin of

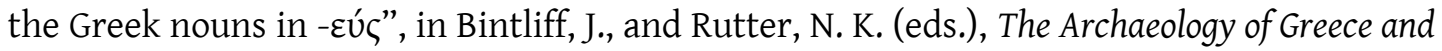
Rome, Studies In Honour of Anthony Snodgrass, Edinburgh, Edinburgh University Press, 22-30.

Meister, R., 1909, "Die äolischen Demostrativa öve, övı, ǒvv und die Partikel vı ( $v \varepsilon$ ) im Phrygischen", Indogermanische Forschungen 25, 312-325.

Meister, R., 1911, "Beiträge zur griechischen Epigraphik und Dialektologie X: Kyprische Inschriften (mit einem Exkurs über die altphrygische Arezastis-Inschrift)", Berichte über die Verhandlungen der Königlich-Sächsischen Gesellschaft der Wissenschaften, Philologisch-Historische Klasse 63, 17-38.

Melchert, H. C., 1994, Anatolian Historical Phonology, Amsterdam - Atlanta, Rodopi.

Melchert, H.C., 2004, "Second Thoughts on *y and * $h_{2}$ in Lydian" in Mazoyer, M., and Casabonne, O., Studia Anatolica et Varia. Mélanges offerts à Professeur René Lebrun, Volume II, Paris, L'Harmattan, 139-50. 
Melchert, H. C., 2005, "The problema of Luvian influence on Hittite", in Meiser, G., and Hackstein, O. (eds.), Sprachkontakt und Sprachwandel. Akten der XI. Fachtagung der Indogermanischen Gesellschaft, 17.-23. September 2000, Halle an der Saale, Wiesbaden, Reichert, $445-460$.

Melchert, H. C., 2008, "Lycian", in Woodard, R. D., The Ancient Languages of Asia Minor, Cambridge, Cambridge University Press, 46-55.

Melchert, H. C., 2013, "Naming practices in Second- and First-Millennium Western Anatolia", in Parker, R., Personal Names in Ancient Anatolia, Oxford, Oxford University Press for the British Academy, 31-49.

Mellink, M. J., 1960, “Archaeology in Asia Minor”, American Journal of Archaeology 64, 1, 57-69.

Mendel, G., 1909, "Catalogue des monuments grecs, romains et byzantins du Musée Impérial Ottoman de Brousse", Bulletin de Correspondance Hellénique 33, 245-435.

Méndez Dosuna, J., 1985, Los Dialectos dorios del noroeste: gramática y estudio dialectal, Salamanca, Ediciones Universidad de Salamanca.

Méndez Dosuna, J., 2012, in Giannakis, G. K. (ed.), “Ancient Macedonian as a Greek dialect: a critical survey on recent work", Ancient Macedonia: Language, History, Culture, Thessaloniki, Centre for the Greek Language, 133-145.

Merkelbach, R., and Stauber, J., 1998, Steinepigramme aus dem griechischen Osten, Bd. 1. Die Westküste Kleinasiens von Knidos bis Ilion, Leipzig, Teubner.

Mette, H. J., 1980, “Neoptolemos von Parion”, Rheinisches Museum für Philologie, Neue Folge, 123, $1,1-24$.

Mihaylova, B., 2016, “The Pre-Greek substratum revisited”, in Hansen, B. S. S., Whitehead, B. N., Olander, T., and Olsen, B. A. (eds.), Etymology and the European Lexicon. Proceedings of the 14th Fachtagung der Indogermanischen Gesellschaft, 17-22 September 2012, Copenhagen, Wiesbaden, Reichert Verlag, 307-317.

Miltner, F., 1937, "Epigraphische Nachlese in Anakar", Jahreshefte des Österreichischen Archäologischen Institutes 30, 9-66.

Mitchell, S., 1993, Anatolia: Land, Men and Gods in Asia Minor. Vol. I: The Celts in Anatolia and the Impact of Roman Rule, Oxford, Clarendon Press.

Molina Valero, C., 2010, "Las glosas licias en fuentes grieges", en Cortés Gabaudan, F., and Méndez Dosuna, J. V. (Eds.), DIC MIHI, MVSA, VIRVM, Homenaje al profesor Antonio López Eire, Salamanca, Ediciones Universidad de Salamanca, 459-464.

Moncunill Martí, N., 2007, Lèxic d'inscripcions ibèriques (1991-2006), Barcelona, Universitat de Barcelona (PhD dissertation).

Morante Mediavilla, B., 2000, El alfabeto epicórico frigio. Problemas epigráficos, paleográficos y de interpretación y su incidencia en nuestro conocimiento de la lengua frigia, Barcelona, Universitat de Barcelona (master dissertation).

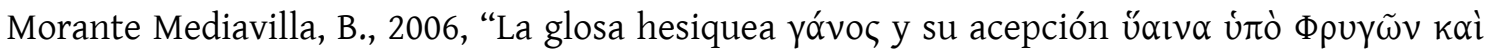

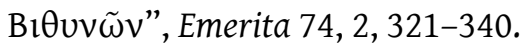

Morante Mediavilla, B., 2007, Studia Phrygia: la incidencia del testimonio de la literatura griega y romana en la descripción y las tentativas de determinar la posición lingüística de la lengua frigia desde 
la Antigüedad hasta el auge de la Lingüística Indoeuropea, Barcelona, Universitat de Barcelona (PhD dissertation).

Mordtmann, A. D., 1862, "Ueber die altphrygische Sprache", Sitzungsberichte der Königlichen Bayerischen Akademie der Wissenschaften zu München, philosophische-philologische Classe vom 4. Januar 1862, 12-35.

Müller, S., 2007, Zum Germanischen aus laryngaltheoretischer Sicht: Mit einer Einführung in die Grundlagen der Laryngaltheorie, Berlin - New York, Walter de Gruyter.

Munn, M., 2006, The Mother of the Gods, Athens, and the Tyranny of Asia: A Study of Sovereignty in Ancient Religion. Berkeley, University of California Press.

Munn, M., 2008, “Kybele as Kubaba in a Lydo-Phrygian context”, in Collins, B. J., Bachvarova, M. R., Rutherford, I. C. (eds.), Anatolian Interfaces. Hittites, Greeks and their Neighbours, Oxford, Oxbow Books, 159-164.

Muraoka, T., 2016, A Syntax of Septuagint Greek, Leuven, Peeters.

Myres, J. L., 1908, "Midas beyond the Halys: a further note on the Black Stone from Tyana", Annals of Archaeology and Antropology 1, 13-16.

Naveh, J., 1979, “The Aramaic Ostraka from Tell Beer-Sheba (Seasons 1971-76)”, Tel-Aviv 6, 18295.

Neri, S., 2005, "Riflessioni sull' apofonia radicale del proto-germanico *namōn "nome"', Historische Sprachforschung 118, 201-250.

[Neroznak =] Нерознак, В. П., 1978, Палеобалканские языки, Москва, Наука.

Neumann, G., 1961, Untersuchungen zum Weiterleben hethitischen und luwischen Sprachgutes in hellenistischer und römischer Zeit, Wiesbaden, O. Harrassowitz.

Neumann, G., 1975, "Bruchstücke alphabetischer Schriftdenkmäler aus Boğazköy”, in Bittel, K. (ed.), Boğazköy 5, Berlin, Mann, 76-84.

Neumann, G., 1979, “Phryger, 2. Sprache”, in Der kleine Pauly, München, 824-825.

Neumann, G., 1986a, “Zur Syntax der neuphrygischen Inschrift Nr. 31”, Kadmos 241, 79-84.

Neumann, G., 1986b, “Modrovanak”, Epigraphica Anatolica, 8, 52.

Neumann, G., 1988, Phrygisch und Griechisch, Wien, Verlag der Österreichischen Akademie der Wissenschaften.

Neumann, G., 1997, “Die zwei Inschriften auf der Stele von Vezirhan”, in Gusmani, R., Salvini,

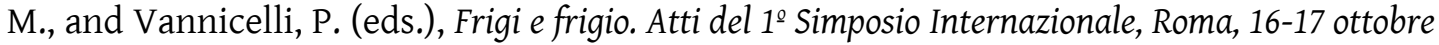
1995, Roma, Consiglio Nazionale delle Ricerche, 13-32.

Neumann, G., 2007, Glossar des Lykischen, Wiesbaden, Harrassowitz.

Nikolaev, A., 2017, “Sidetic masara ^ue[”, Indogermanische Forschungen 122, 219-226.

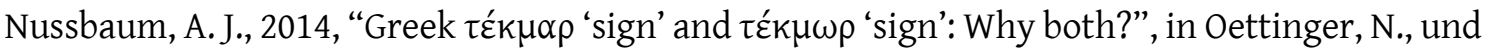
Steer, Th. (eds.), Das Nomen im Indogermanischen. Morphologie, Substantiv versus Adjektiv, Kollektivum. Akten der Arbeitstagung der Indogermanischen Gesellschaft vom 14. bis 16. September 2011 in Erlangen, Wiesbaden, Reichert Verlag, 215-260. 
Obrador-Cursach, B., 2016, "Phrygian mekas and the recently discovered New Phrygian inscription from Nacoleia", Indogermanische Forschungen 121, 177-186.

Obrador-Cursach, B., 2017, “The Phrygian god Bas”, 76, 2, Journal of Near Eastern Studies 307-317.

Obrador-Cursach, B., forthcoming a, "The Luwian origin of the Phrygian imprecations", in Tsetskhladze, G. R. (ed.), Phrygian Lands Over Time, Leuven, Peeters.

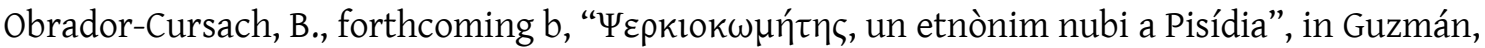
A., and Velaza, J., Miscellanea philologica et epigraphica Marco Mayer oblata, Barcelona, Edicions Universitat Barcelona.

Obrador-Cursach, B., forthcoming c, "Phrygian in contact with Greek: an overview", in de Hoz, M. P., García Alonso, J. L., and Guichard, L. A. (eds.), Local cultures and Greek paideia, Leuven, Peeters.

Opfermann, A., 2017, "Griechische, Armenische und Albanische ,Frauen“ und die Wurzel *Guen-", in Bichlmeier, H. and Opfermann, A. (eds.), Das Menschenbild bei den Indogermanen, Hamburg, Baar-Verlag, 55-80.

Orel, V., 1996, “The west Phrygian inscription from İkıztepe”, Kadmos 35, 53-54.

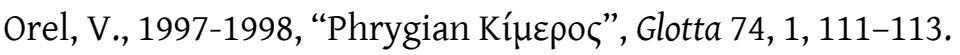

Orel, V., 1997a, The Language of Phrygians, Delmar, New York, Caravan Books.

Orel, V., 1997b, "The vocabulary of Phrygian", Orpheus 7, 37-77.

Oreshko, R., 2013a, "Hieroglyphic inscriptions of Western Anatolia: long arm of the Empire or vernacular tradition(s)?", in Mouton, A., Rutherford, I., and Yakubovich, I. (eds.), Luwian Identities. Culture, Language and Religion Between Anatolia and the Aegean, Leiden - Boston, Brill, 346-420.

Oreshko, R., 2013b, "Hipponax and linguistic, ethnic and religious milieu of western Anatolia. Some further notes on: Shane Hawkins The language of Hipponax, 2013", Hephaistos 30, 79104.

Özgen, I., and Öztürk, J., 1996, The Lydian Treasure, Ankara.

Panagl, O., 2005, “Graeco-phrygische Kontaktzonen”, in Meiser, G., und Hackstein, O. (eds.), Sprachkontakt und Sprachwandel. Akten der XI. Fachtagung der Indogermanischen Gesellschaft, 17.23. September 2000, Halle an der Saale, Wiesbaden, Dr. Ludwig Reichert Verlag, 483-494.

Panagl, O., and Kowal, B., 1983, “Zur etymologischen Darstellung von Restsprachen : am Beispiel des Phrygischen", Bammesberger, A., Das etymologische Wörterbuch. Fragen der Konzeption und Gestaltung, Verlag Friedrich Pustet Regensburg, 185-199.

Papadopoulos, J. K., 2016, "The early history of the Greek alphabet: new evidence from Eretria and Methone", Antiquity 90, 353, 1238-1254.

Parker, R., 2016, “'For Potamos, a vow': river cults in Graeco-Roman Anatolia”, in Hoz, M.-P., Sánchez Hernández, J. P., and Molina Valero, C. (eds.), Between Tarhuntas and Zeus Polieus : cultural crossroads in the temples and cults of Graeco-Roman Anatolia, Leuven, Peeters, 1-13.

Pat-El, N., 2012, Studies in the historical syntax of Aramaic, Piscataway, Gorgias Press.

Pauli, K., 1894, Altitalische Forschungen II, Leipzig, Johan Ambrosius. 
Payne, A., 2010, Hieroglyphic Luwian. An Introduction with Original Texts. $2^{\text {nd }}$ Revised Edition, Wiesbaden, Harrassowitz Verlag.

Payne, A., 2017, "Determination in the Anatolian Hieroglyphic Script of the Empire and Transitional Period", Altorientalische Forschungen 44, 2, 221-234.

Payne, A., and Sasseville, D., 2016, “Die lydische Athene: eine neue Edition von LW 40", Historical Linguistics, 129, 1, 66-82.

Payne, A., and Wintjes, J., 2016, Lords of Asia Minor. An Introduction to the Lydians, Wiesbaden, Harrassowitz.

Pérez Orozco, S., 2007, “La lengua sidética. Ensayo de síntesis”, Kadmos 46, 125-42.

Perrot, G., and Chipiez, Ch., 1890, Histoire de l'art dans l'antiquité V, Paris, Hachette.

Peters, M., 1993, "Beiträge zur Griechischen Etymologie," in Isebaert, L. (ed.), Miscellanea Linguistica Graeco-Latina, Namur, Société des études classiques, 101-108

Petrakis, V., 2016, "Writing the wanax: Spelling peculiarities of Linear B wa-na-ka and their possible implications", Minos 39, 61-158.

Pinault, G. J., 2008, Chrestomathie tokharienne: textes et grammaire, Leuven, Peeters.

[Pridik =] Придик, Е. М., 1900, Журнал Министерства народного просвещения Часть 328, $18-26$.

Poccetti, P., 2012, "La particella ke del frigio tra eredità indoeuropea ed interferenza", in Orioles, V. (ed.), Per Roberto Gusmani. Linguistica storica e teorica. Studi in ricordi II, Udine, Forum, 321333.

Pococke, R., 1752, Inscriptionum Antiquarum Graecarum et Ltinarum Liber. Acc. Numismatum Ptolemaeorum, Imperatorum, Augustorum et Caesarum, in Aegypto cursorum e scriniis Britannicis, catalogus a Rich. Pococke typis mandati, London - Oxford, Milles.

Polito, M., 2004, Il Soũuos. Un'associazione sacra in zone di contatto, Napoli, Università degli studi di Salerno, Dipartimento di Scienze dell'Antichità.

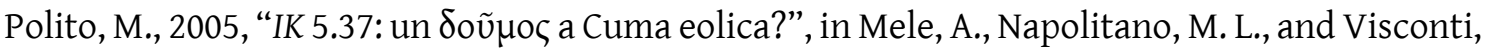
A. (eds.), Eoli ed Eolide tra madrepatria e colonie, Napoli, Luciano Editore, 525-532.

Pope, M., 1999, The Story of Decipherment: From Egyptian hieroglyphs to Maya script, London, Thames and Hudson.

Porzig, W, 1954, Die Gliederung des indogermanischen Sprachgebiets, Heidelberg, Winter.

Probert, P., 2015, Early Greek Relative Clauses, Oxford, Oxford University Press.

Prósper, B. M., 1993, La Reconstrucción del adverbio indoeuropeo, Madrid, Editorial de la Universidad Complutense.

Radet, G., and Ouvré, H., 1896, “Inscriptions de Phrygie”, Bulletin de correspondance hellénique 20, 107-118.

Ramsay, W. M., 1882 "Prymessos and Metropolis", Mitteilungen des Deutschen archäologischen Instituts, athenische Abteilung 7, 126-145.

Ramsay, W. M., 1883, "On the early historical relations between Phrygia and Cappadocia", Journal of the Royal Asiatic Society of Great Britain and Ireland 15, 100-135. 
Ramsay, W. M., 1887, "Phrygian Inscriptions of the Roman Period", Zeitschrift für vergleichende Sprachforschung 28, 381-400.

Ramsay, W. M., 1888, “A Study of Phrygian Art (Part I)", The Journal of Hellenic Studies 9, 350-382.

Ramsay, W. M., 1889a, “A Study of Phrygian Art (Continued)", The Journal of Hellenic Studies 10, 147-189.

Ramsay, W. M., 1889b, "Phrygian notes”, Beiträge zur Kunde der indogermanischen Sprachen 14, 308-312.

Ramsay, W. M., 1890, The historical geography of Asia Minor, London, John Murray.

Ramsay, W. M., 1905, "Neo-Phrygian Inscriptions", Jahreshefte des Österreichischen Archäologischen Instituts 8, 79-120.

Ricl, M., forthcoming, "Cults of Phrygia Epiktetos in the Roman Imperial Period", in Tsetskhladze, G. R. (ed.), Phrygian Lands Over Time, Leuven, Peeters.

Rieken, E., 2001, "Einige Beobachtungen zum Wechsel u/(u)ua in ther hethitischen Texten", in Carruba, O., and Meid, W. (eds.), Anatolisch und Indogermanisch / Anatolico e Indoeuropeo. Akten des Kolloquiums der Indogermanischen Gesellschaft. Pavia, 22.-25. September 1998, Innsbruck, Institut für Sprachen und Literaturen der Universität Innsbruck, 369-379.

Riis, P. J., and Buhl M-L., 1990, Hama. Fouilles et recherches 1931-1938 II 2: Les Objets de la Periode dite Syro-Hittite (Age du Fer), Copenhagen, Fondation Carlsberg.

Robert, L., 1933, “Inscriptions d'Érythrai”, Bulletin de Correspondance Hellénique 57, 467-484.

Robert, L., 1963, Noms indigènes dans l'Asie Mineure gréco-romaine I, Paris, A. Maisonneuve.

Robert, L., 1974, "Des Carpathes a la Propontide. VIII. De Pèrinthe à Apamèe, Cyzique et Claros." Studii Clasice 16: 61-80.

Roller, L. E., 1987a, Gordion special studies I: Nonverbal graffiti, dipinti, and stamps, Philadelphia, The University Museum (University of Pennsylvania).

Roller, L. E., 1987b, “Hellenistic epigraphic texts from Gordion”, Anatolian Studies 37, 103-133.

Rooselvelt, C. H., 2006, "Symbolic Door Stelae and Graveside Monuments in Western Anatolia”, American Journal of Archaeology 110, 1, 65-91.

Rose, C. B., 2012, "Introduction: the Archaeology of Phrygian Gordion", in Rose, C. B. (ed.), The Archaeology of Phrygian Gordion, Royal City of Midas, Philadelphia, The University Museum (University of Pennsylvania), 1-19.

Rose, C. B., and Darbyshire, G. (eds.), 2011, The New Chronology of Iron Age Gordion, Philadelphia, The University Museum (University of Pennsylvania).

Ruge, W., 1948, “Tyana”, Pauly-Wissowa Real-encyclopädie der Classischen Altertumswissenschaft 7, A-2, 1630-1642.

Şahın, S., 1978, "Zeus Bennios”, in Şahın, S., Schwertheim, E., and Wagner, J.(eds.), Studien zur Religion und Kultur Kleinasiens. Festschrift für Friedrich Karl Dörner zum 65. Geburtstag am 28. Februar 1976. Zweiter Band, Leiden, Brill, 771-790.

Şahın, S., 1986, "Studien über die Probleme der historischen Geographie des nordwestlichen Kleinasiens. I. Strabon XII 3,7 p-543. Der Fluss Gallos, die Stadt Modr<en>e in Phrygia Epiktetos und die Schiffbarkeit des Sangarios", Epigraphica Anatolica 7, 125-152. 
Sams, G. K, and Voigt, M. M., 2011, "In Conclusion" in Rose, B., and Darbyshire, G. (eds.), The New Chronology of Iron Age Gordion, Philadelphia, The University Museum (University of Pennsylvania), 155-168.

Sams, G. K., 1979, “Imports at Gordion. Lydian and Persian Period”, Expedition 21, 6-17.

Sams, G. K., 2009, “Gordion, 2007”, Kazı Sonuçları Toplantısı 30, 3, 139-150.

Sams, G. K., 2011, “Artifacts”, in Rose, B., and Darbyshire, G. (eds.), The New Chronology of Iron Age Gordion, Philadelphia, The University Museum (University of Pennsylvania), 59-78.

Sass, B., 2005, The alphabet at the turn of the millennium. The west Semitic alphabet ca. 1150-850 BCE. The antiquity of the Arabian, Greek and Phrygian alphabets, Tel Aviv, Emery and Claire Yass publications in archaeology.

Sayce A. H., 1885, “Appendice II: les inscriptions trouvées a Hissarlik”, in Schliemann, H., Ilios, ville et pays des troyens. Résultat des fouilles sur l'emplacement de Troie et des explorations faites en Troade de 1871 a 1882, Paris, Librairie Firmin-Didot et $C^{\text {ie }}$, 901-917.

Sayce, A. H., 1926, “The New. Neo-Phrygian Inscriptions”, The Journal of Hellenic Studies 46, 2935.

Sharankov, N., 2009, "Notes on Ancient and Mediaeval Latin and Greek Inscriptions from Bulgaria", Archaeologia Bulgarica, 13, 3, 47-61.

Schaaf, I., 2014, "Trick and Trade? : The Eretrian 'Hymn to the Idaean Dactyls' (IG XII, 9. 259)", in Harder, M. A., Regtuit, R. F., Wakker, G. C. (eds.), Hellenistic poetry in context, Leuven, Peeters, 303-322.

Schmidt, W. C. M., 1869 Neue lykische Studien, Jena, Mauke's Verlag.

Schmidt, F., and Krogman, W. M., 1933, The Alishar Hüyük Season of 1928 and 1929, Chicago, The University of Chicago Press.

Schmitt, R., 1972, “Die achäimenidische Satrapie “tayaiy drayahyā"”, Historia 21, 4, 522-527.

Schmitt, R., 1973, “Deiokes”, Anzeiger der Österreichischen Akademie der Wissenschaften 110, 137147.

Schmitt, R., 1982, Iranisches Personennamenbuch Band V. Iranische Namen in Nebenüberlieferungen indogermanischer Sprachen Faszikel 4: Iranische Namen in den indogermanischen Sprachen Kleinasiens (Lykisch, Lydisch, Phrygisch), Wien, Verlag der Österreichischen Akademie der Wissenschaften.

Schmitt, R., 2003, Meno-logium bagistano-persepolitanum. Studien zu den altpersischen Monatsnamen und ihren elamischen Wiedergaben, Wien, Österreichischen Akademie der Wissenschaften.

Schürr, D., 1991-1993, “Imbr- in lykischer und karischer Schrift”, Die Sprache 35, 163-174.

Schürr, D., 2017, "Vom Aussterben der luwischen ziti-Namen, lykisch Ipresida und dem kaunischen Imbros", Gephyra 14, 1-13.

Schwabl, H., 1999, "Zum Kult des Zeus in Kleinasien (II). Der phrygische Zeus Bennios und Verwandtes", Acta Antiqua Academiae Scientiarum Hungaricae 39, 345-354.

Schwyzer, R. (ed.), 1923, Dialectorum Graecarum exempla epigraphica potiora, Leipzig, Hirzel.

Simon, Z., 2014a, "Phrygisch niptiyan und eine gemeinanatolische Formel", Münchener Studien zur Sprachwissenschaft 68, 1, 141-148. 
Simon, Z., 2014b, “Awarikus und Warikas: zwei Könige von Hiyawa”, Zeitschrift für Assyriologie 104, 1, 91-103.

Simon, Z., 2015, "Die letzte zeile der phrygischen Inschrift von Vezirhan", Acta Classica Universitatis Scientiarum Debreceniensis 51, 17-30.

Simon, Z., 2016, “The etymology of Hittite-Luwian Gurta-", AISN n.s. 5, 189-203.

Simon, Z., 2017a, "Selected Pisidian problems and the position of Pisidian within the Anatolian languages”, Journal of Language Relationship 15, 1, 31-42.

Simon, Z., 2017b, "Kurtis: A Phrygian Name in the Neo-Hittite World", News from the Lands of the Hittites 1, 113-118.

Smyth, H. W., 1920, A Greek Grammar for Colleges, Cambridge, Harvard University Press

Solmsen, F., 1897a, “Zum Phrygischen”, Zeitschrift für vergleichende Sprachforschung, 34, 1, 36-68.

Solmsen, F., 1897b, “Thrakisch-Phrygisches”, Zeitschrift für vergleichende Sprachforschung, 34, 1, 68-80.

Solmsen, F., 1909, Beiträge zur griechischen Wortforschung, Strassburg, Trübner.

Sowa, W., 2005, "Anmerkungen zum Balkanindogermanischen”, in Schweiger, G. (ed.), Indogermanica. Festschrift für Gert Klingenschmitt. Indische, iranische und indogermanische Studien dem verehrten jubilar Dargebracht zu seinem fünfundsechzigsten Geburstag, Taimering, Schweiger VWT-Verlag, 611-628.

Sowa, W., 2007a, "Anmerkungen zum Verbalsystem des Phrygischen”, Indogermanische Forschungen 112, 69-95.

Sowa, W., 2007b, "A note to "Phrygian" words in Greek", Studia Eymologica Cracoviensia 12, 153170.

Sowa, W., 2008, Studien zum Phrygischen, Göttingen, Cuvillier Verlag.

Sowa, W., 2015, “Griechisch-phrygische bilinguale Inschriften und die Stele von Vezirhan", in Dupraz, E., and Sowa, W. (eds.), Genres épigraphiques et langues d'attestation fragmentaire dans l'espace méditerranéen, Presses universitaires de Rouen et du Havre.

Sterrett, J. R. S., 1885, Preliminary Report of an Archaeological Joruney Made in Asia Minor During the Summer of 1884, Boston, Cupples, Upham and Co.

Sterrett, J. R. S., 1888a, An Epigaphical Journey in Asia Minor, Boston, Damrell and Upham.

Sterrett, J. R. S., 1888b, The Wolfe Expeition to Asia Minor, Boston, Damrell and Upham.

Strubbe, J. Н. M., 1997, АРАI ЕПITYMВIOI. Imprecations against Desecrators of the Grave in the Greek Epitaphs of Asia Minor. A Catalogue. Bonn, Dr. Rudolf Habelt GMBH.

Summers, G. D., 1997, “The Identification of the Iron Age City on the Kerkenes Dağ in Central Anatolia", Journal of Near Eastern Studies 56, 2, 81-94.

Summers, G. D., and Özen, E., 2012, "The Hittite Stone and Sculpture Quarry at Karakız Kasabas1 and Hapis Boğazı in the District of Sorgun, Yozgat, Central Anatolia", American Journal of Archaeology 116, 507-19.

Tabbernee, W., 1997, Montanist Inscriptions and Testimonia: epigraphic sources illustrating the history of montanism, Macon, Mercer University Press. 
Tavernier, J., 2007, Iranica in the Achaemenid Period (ca. 550-330 B.C.): Lexicon of Old Iranian Proper Names and Loanwords, Attested in Non-Iranian Texts, Leuven, Peeters.

Thonemann, P., 2013, "Phrygia: an anarchist history, 950 BC-AD 100", in Thonemann, P. (ed.), Roman Phrygia. Culture and Society, Cambridge, Cambridge University Press, 1-40.

Thumb, A., 1901, Die griechische Sprache im Zeitalter des Hellenismus, Strassburg, Trübner.

Torp, A., 1896, "Zu den phrygischen Inschriften aus römischer Zeit", Skrifter udgivne af Videnskabsselkabet i Christiana (Hist.-fil. Klasse), 3-19.

Torp, A., 1908, "Eine altphrygische Inschrift aus Kappadokien”, in Sproglige og Historiske Afhandlinger Viede Sophus Bugges Minde, Med Tilloeg to Ungdomsbreve Fra Sophus Bugge, Kristiana, H. Aschehough \& Co., 210-215.

Tsetskhladze, G. R., 2007, "Thracians versus Phrygians: about the origin of the Phrygians once again”, in Çilingiroglu, A., and Sagona, A. (eds.), Anatolian Iron Ages 6, Leuven, Peeters, 283310.

Tucker, E., 2001, “Greek and Iranian”, in Christidis, A. F. (ed.), A History of Ancient Greek: From the Beginnings to Late Antiquity, Cambridge, Cambridge University Press, 773-785.

Tuğrul, L. and Firatl, N., 1967, "Germonaos Phryg Kitabesi"/ "The Phrygian Inscription of Germanos", Istanbul Arkeoloji Müzeleri Yilligi - Annual of the Archaeological Museums of Istanbul 13-14, 230-235 (Turkish), 236-241 (English).

Untermann, J., 2000, Wörterbuch des Oskisch-Umbrischen, Heidelberg, Carl Winter.

Valério, M., 2016, Investigating the Signs and Sounds of Cypro-Minoan, Barcelona, Universitat de Barcelona ( $\mathrm{PhD}$ dissertation).

van den Hout, Th. P. J., 2006, "Administration in the Reign of Tuthaliya IV and the Later Years of the Hittite Empire", in, van den Hout, Th. P. J. (ed.), The Life and Times of Hattušili III and Tuthaliya IV - Proceedings of a Symposium held in Honour of J. De Roos, 12-13 December 2003, Leiden, Nederlands Instituut voor het Nabije Oosten, 77-106.

van Dongen, E., 2014, "The extent and interactions of the Phrygian Kingdom", in Gaspa, S., Greco, A., Bonacossi, D. M., Ponchia, S., Rollinger, R. (ed.), From Source to History. Studies on Ancient Near Eastern. Dedicated to Giovanni Battista Lanfranchi on the Occasion of His $65^{\text {th }}$ Birthday on June 23, 2014, Münster, Ugarit-Verlag, 698-711.

Varinlioğlu, E., 1991, "Deciphering a Phrygian inscription from Tyana”, in le Guen-Pollet, B., and Pelon, O. (eds.), La Cappadoce méridionale jusqu'à la fin de l'époque romaine. État des recherches. Actes du Colloque d'Istanbul (Institut Français d'Études Anatoliennes 13-14 avril 1987), Paris, Éditions Recherche sur les Civilisations, 29-36.

Varinlioğlu, E., 1991, “The Phrygian Inscriptions from Bayındır” Kadmos 31, 10-20.

Vassileva, M., 1995, "Thracian-Phrygian cultural zone: the Daskyleion evidence”, Orpheus 5, 2734.

Vassileva, M., 1997, "A few notes on the recent Phrygian epigraphic data", in Gusmani, R., Salvini, M., and Vannicelli, P. (eds.), Frigi e frigio. Atti del 1ํ Simposio Internazionale, Roma, 16-17 ottobre 1995, Roma, Consiglio Nazionale delle Ricerche, 267-270. 
Vassileva, M., 2008, "King Midas in Southeastern Anatolia", in Collins, B. J., Bachvarova, M. R., Rutherford, I. C. (eds.), Anatolian Interfaces. Hittites, Greeks and their Neighbours, Oxford, Oxbow Books, 165-171.

Vassileva, M., 2015, "Phrygia and the southern Black Sea littoral", in Tsetskhladze, G. R., Avram, A., and Hargrave, J. (eds.), The Danubian Lands between the Black, Aegean and Adriatic Seas (7th Century BC - 10th Century AD). Proceedings of the Fifth International Congress on Black Sea Antiquities (Belgrade - 17-21 September 2013), Oxford, Archaeopress Archaeology, 91-96.

Velaza, J., 1991, Léxico de inscripciones ibéricas: 1976-1989, Barcelona, Publicacions Universitat de Barcelona.

Vijūnas, A., 2009, The Indo-European primary t-stems, Innsbruck, Institut für Sprachen und Literaturen der Universität Innsbruck Bereich Sprachwissenschaft.

Vine, B., 2010, “Old Phrygian iman”, in Kim, R., Oettinger, N., Rieken, E., Weiss, M. (eds.), Ex Anatolia Lux. Anatolian and Indo-European studies in honor of. H. Craig Melchert on the occasion on his sixty-fifth birthday, Ann Arbor, Beech Stave Press.

Voigt, M. M., DeVries, K., Henrickson, R. C., Lawall, M., Marsch, B., Gürsan-Salzmann, A., and Young, T. C. jr, 1997, “Fieldwork at Gordion, 1993-1995”, Anatolica 23, 1-59.

von Prott, H., 1898, "Funde", Mitteilungen des Deutschen Archäologischen Instituts, Athenische Abteilung, 23, 359-368.

von Reber, F., 1898, "Die phrygischen Felsendenkmäler" Abhandlungen der Historischen Klasse der Königlich Bayerischen Akademie der Wissenschaften 21, 529-598.

Waelkens, M. 1986, Die Kleinasiatischen Türsteine. Typologische und epigraphische Untersuchungen der kleinasiatischen Grabreliefs mit Scheintür. Mainz am Rhein, Deusches Archäologisches Institut - Verlag Philipp von Zabern.

Weber, W., 1908, "Inschriften", in Rott, H., Kleinasiatischer Sprachdenkmäler aus Pisidien, Pamphylien, Kappadokien und Lykien, Leipzig, Theodor Weicher, 347-382.

Weeden, M., 2010, "Tuwati and Wasusarma: imitating the behaviour of Assyria", Iraq 72, 39-61.

West, M. L., 2001, “Atreus and Attarissiyas”, Glotta 77, 262-266.

West, M. L., 2003, “Phrygian metre”, Kadmos 42, 77-86.

Wilhelm, A., 1980, Griechische Epigramme, Bonn, Habelt.

Willi, A., 2013, “Epicharmus, Simonides, and the 'invention' of the Greek alphabet”, Museum Helveticum 70, 2, 129-140.

Witczak, K. T., 1991-1992, "Some remarks on the New Phrygian inscription no. 88", Lingua Posnaniensis 34, 157-162.

Witczak, K. T., 1992-1993, "Two Bithynian deities in the Old and New Phrygian inscriptional texts”, Folia Orientalia 29, 265-271.

Wittke, A. M., 2004, Mušker und Phryger. Ein Beitrag zur Geshichte Anatoliens vom 12. bis zum 7.Jh. v. Chr., Wiesbaden, Dr. Ludwig Reichert Verlag.

Wittke, A. M., 2014, “Überlegungen zur Lage von Pteria”, in Gaspa, S., Greco, A., Bonacossi, D. M., Ponchia, S., Rollinger, R. (ed.), From Source to History. Studies on Ancient Near Eastern. 
Dedicated to Giovanni Battista Lanfranchi on the Occasion of His $65^{\text {th }}$ Birthday on June 23, 2014, Münster, Ugarit-Verlag, 745-765.

Woodard, R. D., 1997, Greek writing from Knossos to Homer, Oxford, Oxford University Press.

Woodard, R. D., 2014, The textualization of the Greek alphabet, Cambridge, Cambridge University Press.

Woodhouse, R., 2006, "Conditioned devoicing of mediae in Phrygian", Studia Etymologica Cracoviensia 11, 157-191.

Woodhouse, R., 2007, "New Phrygian $\zeta \varepsilon 1 \rho \alpha(1), \zeta \omega \varsigma, \pi \varepsilon 1 \varsigma$ and $\pi \varepsilon 1 \varepsilon \varsigma ", ~ S t u d i a$ Etymologica Cracoviensia 12, 189-201.

Woodhouse, R., 2009, “An overview of reserach on Phrygian from the nineteenth century to the present day", Studia Linguistica Universitatis Iagellonicae Cracoviensis 126, 167-188.

Woudhuizen, F. C., 1993, "Old Phrygian: some texts and relations", Journal ofIndo-European Studies 21, 1-25.

Woudhuizen, R., 2008-2009, “Phrygian \& Greek”, Talanta 40-41, 181-217.

Yakubovich, I., 2007, rec. "The Luwians. Edited by H. Craig Melchert. Handbook of Oriental Studies, Section One. The Near East and Middle East, vol. 68. Leiden and Boston: Brill, 2003", Journal of Near Eastern Studies 66, 2, 140-144.

Yakubovich, I., 2008, "The Origin of the Luwian Possessive Adjective", in Jones-Bley, K., Huld, M., Della Volpe, A., and Dexter, M. R., (eds.), Proceedings of the sixteenth Annual UCLA IndoEuropean Conference. Los Angeles. November 2-3, 2006, Washington DC, Institute for the Study of Man, 193-217.

Yakubovich, I., 2013, "Anatolian names in -wiya and the structure of Empire Luwian onomastics", in Mouton, A., Rutherford, I., and Yakubovich, I. (eds.), Luwian Identities. Culture, Language and Religion Between Anatolia and the Aegean, Leiden - Boston, Brill, 87-123.

Yakubovich, I., 2015, "Phoenician and Luwian in Early Iron Age Cilicia”, Anatolian Studies 65, 3553.

Young, R. S., 1951, “Gordion - 1950”, University Museum Bulletin 16, 1, 3-20.

Young, R. S., 1953, "Where Alexander the Great cut the Gordian knot: excavations which throw new light on the Phrygians and Hittites of ancient Gordion", Illustrated London News $3^{\text {rd }}$ January, 20-23.

Young, R. S., 1955, “Gordion: preliminary report, 1953”, American Journal of Archaeology, 59, 1, 118.

Young, R. S., 1958, “The Gordion Campaign of 1957: Preliminary Report”, American Journal of Archaeology, 62, 2, 139-154.

Young, R. S., 1964, “The 1963 Campaign at Gordion”, American Journal of Archaeology 68, 3, 279292.

Young, R. S., 1966, “The Gordion Campaign of 1965”, American Journal of Archaeology 70, 3, 267278.

Young, R. S., 1968, “The Gordion Campaign of 1967”, American Journal of Archaeology, 72, 3, 231241. 
Young, R. S., 1969, "Old Phrygian inscriptions from Gordion: towards a history of the Phrygian alphabet”, Hesperia 38, 2, 252-296.

Young, R. S., 1981, The Great Early Tumuli, Philadelphia, The University Museum (University of Pennsylvania). 


\section{Concordances}

Akurgal 1943

P-101

Berndt-Ersöz 2006

Anderson 1898

3

W-07

5

67

40.3

16

24

Anderson 1899

41.1

W-06

W-03

W-05a, $\mathrm{W}-05 \mathrm{~b}$

29

W-02

30

M-01a,

$\mathrm{M}-01 \mathrm{~b}$,

59.1

59.2

$\mathrm{M}-01 \mathrm{c}$,

App. 11

$\mathrm{M}-01 \mathrm{~d}$,

23.1

M-01e,

M-01f

33

$\mathrm{M}-05$

37

W-01a, W-01b, W-01c

$\begin{array}{lll}\text { passim } & 130 \quad 2.2\end{array}$

Bakır \& Gusmani 1991

40

B-01

56 W-04

passim $\quad$ B-06

69

$\mathrm{M}-03$

$70 \quad \mathrm{M}-04$

Bakır \& Gusmani 1993

95

M-06

108

P-06

112

W-11

Bittle \& Güterbock 1935

B-103

B-104

B-105

p. $57 \& 84-85$

P-102

p. $79-80$

P-108

Bilgen, Brixhe \& Coşkun 2011

Bayun \& Orel 1988c

B-107

passim B-04

1

W-101

2

W-12

Berndt 2002

Boehmer 1977

Abb. 6

HP-116

$\mathrm{M}-01 \mathrm{~b}$

$\mathrm{M}-08$

Boehmer \& Güterbock 1987

p. 86

HP-116

$\mathrm{M}-03$

M-05 
Bossert 1942

$\begin{array}{ll}1102 & \text { P-03 } \\ 1105 & \text { P-102 } \\ 1106 & \text { P-101 }\end{array}$

Börker-Klähn 1994

Passim

HP-01

Brandenburg 1906

p. 645

M-01d

Brixhe 1968

p. 308

Brixhe 1978a

$\begin{array}{ll}111 & 7.2 \\ 112 & 10.1 \\ 113 & 10.2 \\ 114 & 29.1\end{array}$

Brixhe 1981

MM 67

MM 68

MM 69

MM 119

MM 362

Brixhe 1982

p. $240-241$

Brixhe 1989-1990

passim

HP-102

Brixhe 1996
p. $137-138$ § 3.1.1.
B-101
p. 138-139 § 3.1.2.
B-102
p. $139-140$ § 3.1.3.
B-103
p. $140-141 \S 3.1 .4$.
B-104
p. $141-142 \S 3.1 .5$.
B-105
p. 142-144 § 3.1.6.
B-106
p. $144-145 \S 3.1 .7$.
B-107

Brixhe 1999

$\begin{array}{ll}49 & \text { App. } 8 \\ 50 & \text { App. } 9\end{array}$

Brixhe 2004a

W-12

MPhr-01

Brixhe \& Drew-Bear 1982

$\begin{array}{ll}\text { I } & \text { W-08 } \\ \text { II } & \text { W-09 } \\ \text { II } & \text { W-10 }\end{array}$

Brixhe \& Drew-Bear 1987

passim $\quad 29.1$

Brixhe \& Drew-Bear 1997

$\begin{array}{ll}\text { I } & 29.1 \\ \text { II } & 17.6 \\ \text { III } & 15.1 \\ \text { IV } & 12 . .1 \\ \text { V } & 18.2 \\ \text { VI } & 19.6 \\ \text { VII } & 65.4 \\ \text { VIII } & 31.1\end{array}$

Brixe \& Drew-Bear 2010

passim

Brixhe \& Keleş 2011

passim HP-115

Brixhe \& Neumann 1985

pgs. 161-184

16.1

Brixhe \& Sivas 2002

passim W-11

Brixhe \& Sivas 2003

1 W-102

2 W-103 


\begin{tabular}{|c|c|c|c|}
\hline 3 & W-13 & XL & 24.1 \\
\hline $4-\mathrm{a}$ & M-101 & XLII & 21.1 \\
\hline \multirow[t]{2}{*}{$4-b$} & M-11 & XLIV & 38.1 \\
\hline & & XLV & 41.1 \\
\hline \multirow{2}{*}{\multicolumn{2}{|c|}{ Brixhe \& Summers 2006}} & XLVI & 59.1 \\
\hline & & XLVII & 59.2 \\
\hline passim & $\mathrm{K}-01$ & XLVIII & 1.1 \\
\hline fig. 35 & $\mathrm{~K}-101$ & XLIX & App. 8 \\
\hline \multirow[t]{2}{*}{ p. 134} & HP-116 & $\mathrm{L}$ & App. 9 \\
\hline & & LI & 47.1 \\
\hline \multirow{2}{*}{\multicolumn{2}{|c|}{ Brixhe \& Waelkens 1981}} & LII & App. 10 \\
\hline & & LIII & 46.1 \\
\hline \multirow[t]{2}{*}{ pgs. 68-75 } & 26 & LIV & 50.1 \\
\hline & & LV & 50.2 \\
\hline \multirow[t]{2}{*}{ Calder 1911} & & LVI & 55.1 \\
\hline & & LVII & 56.1 \\
\hline I & App. 1 & LVII[I] & 56.2 \\
\hline II & 4.1 & LIX & 60.1 \\
\hline III & 17.2 & LX & 60.2 \\
\hline IV & 18.1 & LXI & 44.1 \\
\hline IV (bis) & 17.1 & LXII & 20.3 \\
\hline $\mathrm{V}$ & 18.2 & LXIII & 20.1 \\
\hline VI & 18.3 & LXIV & 56.3 \\
\hline VII & 17.3 & LXV & 45.1 \\
\hline VIII & 26.1 & LXVI & App. 11 \\
\hline IX & 22.1 & LXVII & 44.3 \\
\hline $\mathrm{X}$ & 37.1 & & \\
\hline XI & 39.1 & \multicolumn{2}{|l|}{ Calder 1913} \\
\hline XII & 40.1 & & \\
\hline XIII & 40.2 & LXVIII & 30.2 \\
\hline XIV & 7.3 & LXIX & 43.1 \\
\hline XV & 2.1 & LXX & 44.2 \\
\hline XVIII & 11.2 & LXXI & 28.1 \\
\hline XIX & 5.1 & LXXII & 58.1 \\
\hline $\mathrm{XX}$ & 65.1 & \multirow[t]{2}{*}{ p. $102-103$} & P-04a \\
\hline XXI & 65.3 & & \\
\hline XXV & 35.1 & \multicolumn{2}{|l|}{ Calder 1922} \\
\hline XXVI & 36.1 & & \\
\hline XXVII & 36.2 & \multirow[t]{2}{*}{7} & \multirow[t]{2}{*}{64.1} \\
\hline XXVIII & 33.1 & & \\
\hline XXIX & 31.1 & \multicolumn{2}{|l|}{ Calder 1926} \\
\hline XXX & 37.2 & & \\
\hline XXXI & 40.3 & p. 26 & M-09 \\
\hline XXXII & 62.1 & LXXIII & 14.1 \\
\hline XXXIII & 62.2 & LXXIV & 11.3 \\
\hline XXXIV & 62.3 & LXXV & 52.1 \\
\hline XXXV & 62.4 & LXXVI & 53.1 \\
\hline XXXVI & 62.5 & LXXVII & 53.2 \\
\hline XXXVII & 34.1 & LXXVIII & 57.1 \\
\hline XXXVIII & 26.2 & LXXIX & 59.3 \\
\hline XXXIX & 30.1 & LXXX & 51.1 \\
\hline
\end{tabular}




\begin{tabular}{|c|c|c|c|}
\hline LXXXI & 48.1 & A 7 a & W-01a \\
\hline LXXXII & 64.1 & A 7 b & $\mathrm{W}-01 \mathrm{~b}$ \\
\hline \multirow{2}{*}{ LXXXIII } & App. 11 & A $7 \mathrm{c}$ & $\mathrm{W}-01 \mathrm{c}$ \\
\hline & & A 8 & M-05 \\
\hline \multirow[t]{2}{*}{ CIG III } & & A 9 & W-04 \\
\hline & & A 10 & $\mathrm{P}-02$ \\
\hline $3822 \mathrm{e}$ & 5.1 & A 11 & W-03 \\
\hline $3880 e$ & 17.1 & A 12 & $\mathrm{~W}-05 \mathrm{a}$ \\
\hline $3882 c$ & 17.3 & A 13 & P-01 \\
\hline $3883 c$ & 18.2 & A 14 & P-03 \\
\hline 3974 & 35.1 & A 15 & P-04 \\
\hline \multirow[t]{2}{*}{3986} & 40.1 & A 16 & G-101 \\
\hline & & A 17 & G-102 \\
\hline \multirow{2}{*}{\multicolumn{2}{|c|}{ Cox \& Cameron 1932}} & A 17 bis & G-103 \\
\hline & & A 18 & M-09 \\
\hline \multirow[t]{2}{*}{ passim } & B-04 & A 19 & $\mathrm{~T}-02$ \\
\hline & & A 20 & P-102 \\
\hline \multicolumn{2}{|c|}{ Crowfoot 1899} & A 21 & $\mathrm{~T}-01$ \\
\hline & & A 22 & Dd-103 \\
\hline \multirow[t]{2}{*}{123} & 59.3 & A 23 & HP-114 \\
\hline & & A 24 & G-01 \\
\hline \multirow{2}{*}{\multicolumn{2}{|c|}{ Çınaroğlu \& Varinlioğlu 1985}} & A 25 & G-105 \\
\hline & & A 26 & P-101 \\
\hline \multirow[t]{2}{*}{ passim } & $\mathrm{T}-03$ & A 28 & B-01 \\
\hline & & A 29 & G-104 \\
\hline \multirow[t]{2}{*}{ Darga 1993} & & A 30 & G-108 \\
\hline & & A 31 & G-109 \\
\hline \multirow[t]{2}{*}{ p. $488 \& 497$} & NW-101 & A 32 & G-106 \\
\hline & & A 33 & G-107 \\
\hline \multicolumn{2}{|c|}{ de Saussure 1898} & A 34 & G-110 \\
\hline & & A 35 & G-111 \\
\hline p. 167 & P-01 & A 36 & G-114 \\
\hline p. 171 & $\mathrm{P}-02$ & A 37 & G-112 \\
\hline p. $174-175$ & P-03 & A 38 & G-113 \\
\hline \multirow[t]{2}{*}{ p. $174-187$} & $\mathrm{P}-04$ & A 39 & G-03 \\
\hline & & A 40 & G-115 \\
\hline \multicolumn{2}{|c|}{ de Saussure 1922} & A 41 & G-116 \\
\hline & & A 42 & G-117 \\
\hline p. 544 & P-01 & A 43 & G-02 \\
\hline p. 550 & P-02 & A 44 & G-04 \\
\hline p. $546-547$ & $\mathrm{P}-03$ & A 45 & G-118 \\
\hline \multirow[t]{2}{*}{ p. 553-556 } & P-04 & A 46 & G-119 \\
\hline & & A 47 & G-120 \\
\hline \multirow{2}{*}{\multicolumn{2}{|c|}{ Diakonoff \& Neroznak 1985}} & A 48 & G-121 \\
\hline & & A 49 & G-122 \\
\hline A 1 & M-01a & A 50 & G-123 \\
\hline A 2 & $M-01 b$ & A 51 & G-124 \\
\hline A 3 & M-02 & A 52 & G-125 \\
\hline A 4 & M-01f & A 53 & G-126 \\
\hline A 5 & M-03 & A 54 & G-127 \\
\hline A 6 & M-04 & A 55 & G-128 \\
\hline 532 & & & \\
\hline
\end{tabular}




\begin{tabular}{|c|c|c|c|}
\hline A 56 & G-129 & B 53 & 46.1 \\
\hline A 57 & G-130 & B 56 & 55.1 \\
\hline A 58 & G-131 & B 61 & 44.1 \\
\hline A 59 & G-132 & B 62 & 20.3 \\
\hline A 60 & G-133 & B 64 & 56.3 \\
\hline A 61 & G-134 & B 67 & 44.3 \\
\hline A 62 & G-135 & B 71 & 28.1 \\
\hline A 63 & G-136 & B 73 & 14.1 \\
\hline A 64 & G-137 & B 72 & $59-1$ \\
\hline A 65 & G-138 & B 75 & 18.2 \\
\hline A 66 & G-139 & B 75 & 52.1 \\
\hline A 67 & G-140 & B 86 & 8.1 \\
\hline A 68 & G-141 & B 87 & 9.1 \\
\hline A 69 & G-142 & B 88 & 6.1 \\
\hline A 70 & $G-143$ & B 91 & 8.4 \\
\hline A 71 & G-144 & B 92 & 27.1 \\
\hline A 72 & G-145 & B 96 & 19.1 \\
\hline A 73 & G-146 & B 99 & 7.1 \\
\hline A 74 & G-147 & B 100 & 61.1 \\
\hline A 75 & G-148 & B 106 & 59.4 \\
\hline A 76 & G-149 & B 111 & 29.1 \\
\hline A 77 & G-150 & C 9 & 22.1 \\
\hline A 78 & $\mathrm{M}-01 \mathrm{c}$ & C 15 & 2.1 \\
\hline A 79 & $\mathrm{M}-01 \mathrm{~d}$ & C 48 & 1.1 \\
\hline A 80 & M-06 & C 49 & App. 8 \\
\hline A 81 & W-02 & C 58 & 56.2 \\
\hline A 82 & W-05b & C 69 & 43.1 \\
\hline A 83 & W-06 & & \\
\hline A 84 & W-07 & \multicolumn{2}{|c|}{ Dinç \& Innocente 1999} \\
\hline A 85 & P-103 & & \multirow{3}{*}{ HP-101 } \\
\hline A 86 & P-104 & \multirow[t]{2}{*}{ passim } & \\
\hline A 87 & P-105 & & \\
\hline A 88 & P-106 & \multicolumn{2}{|c|}{ Drew-Bear 1978} \\
\hline A 89 & P-107 & & \\
\hline A 90 & Dd-101 & 2 & App. 2 \\
\hline A 92 & W-08 & \multicolumn{2}{|c|}{ Drew-Bear \& Lochman 1996} \\
\hline A 93 & W-09 & & \\
\hline A 94 & $\mathrm{~W}-10$ & \multirow[t]{2}{*}{ pg. 123} & \multirow[t]{2}{*}{13.1} \\
\hline B 2 & 4.1 & & \\
\hline B 6 & 18.3 & \multicolumn{2}{|c|}{ Drew-Bear, Lubotsky \& Üyümez 2008} \\
\hline B 7 & 44.2 & & \\
\hline B 10 & 37.1 & 1 & 25.2 \\
\hline B 11 & 39.1 & 2 & 33.3 \\
\hline B 14 & 7.3 & 3 & 20.2 \\
\hline B 21 & 65.3 & & \\
\hline B 26 & 36.1 & \multicolumn{2}{|c|}{ Edwards 1959} \\
\hline B 28 & 33.1 & & \multirow{3}{*}{ G-116 } \\
\hline B 33 & 62.2 & p. 265 & \\
\hline B 35 & 62.4 & \multirow{2}{*}{\multicolumn{2}{|c|}{ Edwards 1963}} \\
\hline B 42 & 21.1 & & \\
\hline B 51 & 47.1 & 25 & G-129 \\
\hline
\end{tabular}


Friedrich 1932

OPhr.

M-01a

B 30

NPhr. 


$\begin{array}{ll}\text { B 79 } & 59.3 \\ \text { B } 80 & 51.1 \\ \text { B 81 } & 48.1 \\ \text { B 82 } & 64.1 \\ \text { B 83 } & \text { App. } 12 \\ \text { B 84 } & 48.2 \\ \text { B 85 } & 48.3 \\ \text { B } 86 & 8.1 \\ \text { B 87 } & 9.1 \\ \text { B 88 } & 6.1 \\ \text { XI } & \text { B-04 }\end{array}$

Friedrich 1965

p. 154-156 Dd-103

p. 154-156 HP-114

"Funde" 1898

pgs. $362-363$

Garstang 1908

p. $10 \quad$ T- $02 b$

Gelb 1935

94

Gosche 1864

HP-116

M-01a

$\mathrm{M}-01 \mathrm{~b}$

M-01f

$\mathrm{M}-01 \mathrm{c}$

$\mathrm{M}-03$

$\mathrm{M}-02$

$\mathrm{M}-04$

W-01

17.3

35.1

40.1

5.1

18.2

Gusmani 1988

passim
Gusmani 2001

$\begin{array}{ll}\text { p. } 164-166 & \text { B-07 }\end{array}$

\section{Gusmani \& Poetto 1981}

passim

Dd-101

Gusmani \& Polat 1999a

passim

B-07

Gusmani \& Polat 1999b

passim

B-108

\section{Haas 1951}

OPhr.

$\begin{array}{ll}\text { I } & \text { M-01a } \\ \text { IV } & \text { M-01f } \\ \text { VI } & \text { M-04 } \\ \text { VIIa } & \text { W-01a } \\ \text { VIIb } & \text { W-01b } \\ \text { VIIc } & \text { W-01c } \\ \text { VIII } & \text { M-05 } \\ \text { XIV } & \text { P-03 } \\ \text { XV } & \text { P-04 } \\ \text { XXVII } & \text { P-108 }\end{array}$

NPhr.

4.1

18.3

11.2

37.2

40.3

1.1

43.1

Haas 1966

OPhr.

M-01a

M-01b

M-02

M-01f

M-03

M-04

W-01a

W-01b

W-01c

M-05 


\begin{tabular}{|c|c|c|c|}
\hline IX & W-04 & 35 & 62.4 \\
\hline $\mathrm{X}$ & P-02 & 36 & 62.5 \\
\hline XI & $\mathrm{W}-03$ & 37 & 34.1 \\
\hline XII & $W-05 a$ & 38 & 26.2 \\
\hline XIII & P-01 & 39 & 30.1 \\
\hline XIV & P-03 & 40 & 24.1 \\
\hline XV & P-04 & 42 & 21.1 \\
\hline XVI & G-101 & 43 & 21.2 \\
\hline XVII & G-102 & 44 & 38.1 \\
\hline XVIII & M-09 & 45 & 41.1 \\
\hline XIX & $\mathrm{T}-02$ & $46=107$ & 59.1 \\
\hline $\mathrm{XX}$ & P-102 & 47 & 59.2 \\
\hline XXI & $\mathrm{T}-01$ & 48 & 1.1 \\
\hline XXIV & G-01 & 59 & App. 8 \\
\hline XXV & G-105 & 50 & App. 9 \\
\hline XXVI & P-101 & 51 & 47.1 \\
\hline p. $176-177$ no. c & Dd-103 & 52 & App. 10 \\
\hline p. 176 no. b & HP-114 & 53 & 46.1 \\
\hline \multicolumn{2}{|l|}{ NPhr. } & 54 & 50.1 \\
\hline 1 & App. 1 & 55 & 50.2 \\
\hline 2 & 4.1 & 56 & 55.1 \\
\hline 3 & 17.2 & 57 & 56.1 \\
\hline 4 & 18.1 & 58 & 56.2 \\
\hline 4bis & 17.1 & 59 & 60.1 \\
\hline 5 & 18.2 & 60 & 60.2 \\
\hline 7 & 17.3 & 61 & 44.1 \\
\hline 8 & 26.1 & 62 & 20.3 \\
\hline 9 & 22.1 & 63 & 20.1 \\
\hline 10 & 37.1 & 64 & 56.3 \\
\hline 11 & 39.1 & 65 & 45.1 \\
\hline 12 & 40.1 & 66 & App. 11 \\
\hline 13 & 40.2 & 67 & 44.3 \\
\hline 15 & 2.1 & 68 & 30.2 \\
\hline 16 & App. 2 & 69 & 43.1 \\
\hline \multirow[t]{2}{*}{17} & 11.1, & 71 & 28.1 \\
\hline & 11.3 & 72 & 58.1 \\
\hline 18 & 11.2 & 73 & 14.1 \\
\hline 19 & 5.1 & 74 & 11.3, \\
\hline 20 & 65.1 & & 11.1 \\
\hline 21 & 65.3 & 75 & 52.1 \\
\hline 22 & App. 3 & 76 & 53.1 \\
\hline 25 & 35.1 & 77 & 53.2 \\
\hline 26 & 36.1 & 78 & 57.1 \\
\hline 27 & 36.2 & 79 & 59.3 \\
\hline 28 & 33.1 & 80 & 51.1 \\
\hline 29 & 31.1 & 81 & 48.1 \\
\hline 30 & 37.1 & 82 & 64.1 \\
\hline 31 & 40.3 & 83 & App. 12 \\
\hline 32 & 62.1 & 84 & 48.2 \\
\hline 33 & 62.2 & 85 & 48.3 \\
\hline 34 & 62.3 & 86 & 8.1 \\
\hline
\end{tabular}




\begin{tabular}{|c|c|c|c|}
\hline 87 & 9.1 & 71 & 28.1 \\
\hline 88 & 6.1 & 86 & 8.1 \\
\hline 89 & 23.1 & 88 & 6.1 \\
\hline 90 & 17.2 & 99 & 7.1 \\
\hline 91 & 17.5 & 100 & 61.1 \\
\hline 92 & 27.1 & 103 & 66.1 \\
\hline 93 & 32.1 & 106 & 59.4 \\
\hline 94 & 36.3 & & \\
\hline 95 & 33.2 & \multicolumn{2}{|l|}{ Haas $1970 \mathrm{~b}$} \\
\hline 96 & 19.1 & & \\
\hline 97 & 3.1 & \multicolumn{2}{|l|}{ OPhr. } \\
\hline 98 & 1.2 & I & M-01a \\
\hline 99 & 7.1 & IV & M-01f \\
\hline 100 & 61.1 & VI & M-04 \\
\hline 101 & 42.1 & VIIb & $\mathrm{W}-01 \mathrm{~b}$ \\
\hline 102 & 40.4 & VIII & M-05 \\
\hline 103 & 66.1 & XIV & P-03 \\
\hline 104 & 65.2 & $\mathrm{XV}$ & P-04 \\
\hline 105 & 62.6 & \multicolumn{2}{|l|}{ NPhr. } \\
\hline 106 & 59.4 & 2 & 4.1 \\
\hline 107 & 59.1 & 6 & 18.3 \\
\hline 108 & 54.1 & 18 & 11.2 \\
\hline 109 & 53.3 & 30 & 37.2 \\
\hline \multirow{2}{*}{110} & 49.1 & 31 & 40.3 \\
\hline & & 48 & 1.1 \\
\hline Haas 1969 & & 69 & 43.1 \\
\hline \multicolumn{2}{|c|}{ OPhr. } & \multicolumn{2}{|l|}{ Hamilton 1842} \\
\hline XXVIII & B-01 & & \\
\hline XXIX & G-02 & I, p. 383 & P-01 \\
\hline XXX & G-125 & II Appendix V, no. 165 & 17.3 \\
\hline XXXI & G-04 & II Appendix V, no. 383 & 40.1 \\
\hline p. $82-83$ & G-136 & II Appendix V, no. 449 & 35.1 \\
\hline \multicolumn{2}{|c|}{ NPhr. } & \multirow[t]{2}{*}{ II Appendix V, no. 376} & 18.1 \\
\hline \multirow[t]{2}{*}{18} & 11.2 & & \\
\hline & & \multicolumn{2}{|l|}{ Haspels 1971} \\
\hline \multicolumn{4}{|c|}{ Haas 1970a } \\
\hline & & 1 & M-01a \\
\hline \multicolumn{2}{|c|}{ OPhr. } & 2 & $M-01 b$ \\
\hline I & M-01a & 3 & M-01f \\
\hline XV & P-04 & 4 & M-01c \\
\hline \multicolumn{2}{|c|}{ NPhr. } & 5 & M-01d \\
\hline 5 & 18.2 & 6 & M-06 \\
\hline 12 & 40.1 & 7 & M-04 \\
\hline 30 & 37.2 & 8 & M-02 \\
\hline 32 & 62.1 & 9 & $\mathrm{M}-03$ \\
\hline 39 & 30.1 & 10 & M-05 \\
\hline 48 & 1.1 & $11 a$ & W-01a, \\
\hline 57 & 50.1 & & W-01b \\
\hline 61 & 44.1 & $11 b$ & W-01c \\
\hline 69 & 43.1 & 12 & W-02 \\
\hline
\end{tabular}




$\begin{array}{ll}13 & \mathrm{~W}-04 \\ 14 & \mathrm{~W}-05 \mathrm{a} \\ 15 & \mathrm{~W}-05 \mathrm{~b} \\ 16 & \mathrm{~W}-06 \\ 17 & \mathrm{~W}-07 \\ 18 & \mathrm{M}-09 \\ 19 & \mathrm{M}-07 \\ 20 & \mathrm{~W}-03 \\ 45 & 7.2 \\ 56 & 10.1 \\ 57 & 10.2\end{array}$

Heberdey \& Wilhelm 1896

43

37.2

\section{Hogarth 1890}

1

2

3

\section{Kerkenes News}

4 (2001) p. $11-12$

Kowal 1984a

15

Kowal 1984b

31

Körte 1898

p.19 no. 1

p. 19

p. 64

p. 85

p. 93

p. 108-109

p. 117

p. 117

p. 118

p. 120
P-01

21.2

21.1

44.3

K-102

2.1

40.3

P-02

$\mathrm{M}-01 \mathrm{a}$

$\mathrm{M}-01 \mathrm{~b}$

W-03

W-05a

W-01a

W-01b

W-01c

W-04
Körte \& Körte 1904

$\begin{array}{ll}1 & \text { G-347 } \\ 2 & \text { G-101 } \\ 3 & \text { G-102 } \\ 4 & \text { G-103 }\end{array}$

Koşay 1937
p. 33
P-101

Koşay 1939

p. $9 \& 20$

P-101

\section{Koşay 1941}

p. 16 P-101

Kretschmer 1896

p. $218 \quad$ W-05

Kretschmer 1899

$\begin{array}{ll}\text { p. 352-353 } & \text { M-02 } \\ \text { p. } 354 & \text { M-03 } \\ \text { p. } 355-357 & \text { P-03 } \\ \text { p.357 } & \text { M-05 }\end{array}$

Kretschmer 1901

p. 115-116 M-01f

Laminger-Pascher 1984

$62 \quad$ App. 8

Laminger-Pascher 1989

p. $51-53 \quad 43.1$

Lazović, Dürr, Durand, Houriet \& Schweizer 1997

2 Dd-102

Legrand \& Chamonard 1893

94

24.1 


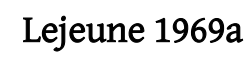

$\begin{array}{ll}62 & \mathrm{G}-135 \\ 63 & \mathrm{G}-136 \\ 64 & \mathrm{G}-137 \\ 65 & \mathrm{G}-138 \\ 66 & \mathrm{G}-139 \\ 67 & \mathrm{G}-140 \\ 68 & \mathrm{G}-141 \\ 69 & \mathrm{G}-142 \\ 70 & \mathrm{G}-143 \\ 71 & \mathrm{G}-144 \\ 72 & \mathrm{G}-145 \\ 73 & \mathrm{G}-146 \\ 74 & \mathrm{G}-147 \\ 75 & \mathrm{G}-148 \\ 76 & \mathrm{G}-149 \\ 77 & \mathrm{G}-150\end{array}$

\section{Lejeune 1970}

$\begin{array}{ll}16 & \text { G-101 } \\ 17 & \mathrm{G}-102 \\ 17 \text { bis } & \mathrm{G}-103 \\ 24 & \mathrm{G}-01 \\ 25 & \mathrm{G}-105 \\ 29 & \mathrm{G}-104 \\ 30 & \mathrm{G}-108 \\ 31 & \mathrm{G}-109 \\ 32 & \mathrm{G}-106 \\ 33 & \mathrm{G}-107 \\ 34 & \mathrm{G}-110 \\ 35 & \mathrm{G}-111 \\ 36 & \mathrm{G}-114 \\ 37 & \mathrm{G}-112 \\ 38 & \mathrm{G}-113 \\ 39 & \mathrm{G}-03 \\ 40 & \mathrm{G}-115 \\ 41 & \mathrm{G}-116 \\ 42 & \mathrm{G}-117 \\ 43 & \mathrm{G}-02 \\ 44 & \mathrm{G}-04 \\ 45 & \mathrm{G}-118 \\ 46 & \mathrm{G}-119 \\ 47 & \mathrm{G}-120 \\ 48 & \mathrm{G}-121 \\ 49 & \mathrm{G}-122 \\ 50 & \mathrm{G}-123 \\ 51 & \mathrm{G}-124 \\ 52 & \mathrm{G}-125 \\ 53 & \mathrm{G}-126 \\ 54 & \mathrm{G}-127 \\ 55 & \mathrm{G}-128 \\ & \end{array}$




$\begin{array}{ll}56 & \mathrm{G}-129 \\ 57 & \mathrm{G}-130 \\ 58 & \mathrm{G}-131 \\ 59 & \mathrm{G}-132 \\ 60 & \mathrm{G}-133 \\ 61 & \mathrm{G}-134 \\ 62 & \mathrm{G}-135 \\ 63 & \mathrm{G}-136 \\ 64 & \mathrm{G}-137 \\ 65 & \mathrm{G}-138 \\ 66 & \mathrm{G}-139 \\ 67 & \mathrm{G}-140 \\ 68 & \mathrm{G}-141 \\ 69 & \mathrm{G}-142 \\ 70 & \mathrm{G}-143 \\ 71 & \mathrm{G}-144 \\ 72 & \mathrm{G}-145 \\ 73 & \mathrm{G}-146 \\ 74 & \mathrm{G}-147 \\ 75 & \mathrm{G}-148 \\ 76 & \mathrm{G}-149 \\ 77 & \mathrm{G}-150\end{array}$

\section{Liebhart \& Brixhe 2009}

passim G-346

\section{Lubotsky 1989b}

no. 88

\section{Lubotsky 1993}

pg. 128

16.1

Lubotsky 1997

48

1.1

\section{Lubotsky 1998}

pg. 418 , no. 3

17.2

\section{Macpherson 1954}

pgs. $13-15$

1.2

\section{MAMA}

I, no. 11

I, no. 32

common

here

52

App. 10

$53 \quad 46.1$

I, no. 33

I, no. 340

I, no. 341

I, no. 384

I, no. 385

I, no. 405

I, no. 406

I, no. 413

IV, no. 16

IV, no. 17

IV, no. 18

IV, no. 76

IV, no. 108

IV, no. 116

IV, no. 239

IV, no. 240

IV, no. 242

IV, no. 243

V, Lists I 182.89

$\mathrm{V}$, no. R 7

VI, no. 382

VII, pg. xxviii, (a)

VII, pg. xxviii, (c)

VII, pgs. Xxviii-xxix, (d) 100

VII, no. 10

VII, no. 79

VII, no. 136

VII, no. 137

VII, no. 195

VII, no. 214

VII, no. 215

VII, no. 258

VII, no. 259

VII, no. 259a

VII, no. 276

VII, no. 312

VII, no. 313

VII, no. 314

VII, no. 315

VII, no. 316

VII, no. 317

VII, no. 318

VII, no. 364

VII, no. 370

VII, no. 436

VII, no. 437

VII, no. 492

VII, no. 495

VII, no. 496

VII, no. 522

VII, no. 545
$69 \quad 43.1$

$84 \quad 48.2$

$85 \quad 48.3$

$62 \quad 20.3$

$63 \quad 20.1$

$86 \quad 8.1$

$87 \quad 9.1$

$88 \quad 6.1$

$90 \quad 17.4$

$91 \quad 17.5$

$9 \quad 22.1$

$40 \quad 24.1$

$102 \quad 40.4$

$92 \quad 27.1$

$93 \quad 32.1$

$29 \quad 31.1$

$37 \quad 34.1$

$95 \quad 33.2$

$48 \quad 1.1$

16 App. 2

$96 \quad 19.1$

$97 \quad 3.1$

$99 \quad 7.1$

$100 \quad 61.1$

$101 \quad 42.1$

$79 \quad 59.3$

$45 \quad 41.1$

$44 \quad 38.1$

$30 \quad 37.2$

$103 \quad 66.1$

$65 \quad 45.1$

$82 \quad 64.1$

$20 \quad 65.1$

$104 \quad 65.2$

$24 \mathrm{~b}$ App. 6

$32 \quad 62.1$

$33 \quad 62.2$

$34 \quad 62.3$

$35 \quad 62.4$

$36 \quad 62.5$

$80 \quad 51.1$

$105 \quad 62.6$

$75 \quad 52.1$

$60 \quad 60.2$

$106 \quad 59.4$

$107 \quad 59.1$

$56 \quad 55.1$

$76 \quad 53.1$

$109 \quad 53.3$

$110 \quad 49.1$

$108 \quad 54.1$ 


\begin{tabular}{|c|c|c|c|c|}
\hline \multirow[t]{2}{*}{ VIII, no. 347} & 94 & 36.3 & 9 & $M-01 f$ \\
\hline & & & 10 & M-03 \\
\hline \multirow[t]{2}{*}{ Masson 1954} & & & 11 & M-02 \\
\hline & & & 12 & M-04 \\
\hline 25 & P-101 & & 13 & W-01 \\
\hline 27 & G-02 & & 14 & W-01 \\
\hline p. 441 & $\mathrm{~T}-01$ & & & $\mathrm{~W}-0$ \\
\hline \multirow[t]{2}{*}{ Masson 1987a } & & & & \\
\hline & & & 1 & 17.3 \\
\hline \multirow[t]{2}{*}{ passim } & Dd-103 & & 2 & 18.2 \\
\hline & & & 3 & 40.1 \\
\hline Meister 1909 & & & 4 & 35.1 \\
\hline
\end{tabular}

pgs. $317-318 \quad 17.2$

Myres 1908

Meister 1911

addendum T-01

p. 13-16 T-02

p. $22-25 \quad$ W-01

Neroznak 1978

Mellink 1960

p. 64 HP-116

A $1 \quad$ M-01a

A $2 \quad \mathrm{M}-01 \mathrm{~b}$

A $3 \quad \mathrm{M}-02$

A $4 \quad$ M-01f

A $5 \quad$ M-03

A $6 \quad M-04$

A 7 a W-01a

A 7 b W-01b

A 7 c W-01c

$16 / 43 / 04 \quad 82 \quad 64.1$

A $8 \quad \mathrm{M}-05$

A $9 \quad$ W-04

A $10 \quad \mathrm{P}-02$

A $11 \quad$ W-03

A $12 \quad$ W-05a

A $13 \quad$ P-01

A $14 \quad \mathrm{P}-03$

A 15 a P-04a

A 15 b P-04b

A 15 C P-04c

A $16 \quad \mathrm{G}-101$

A $17 \quad$ G-102

A 17 bis G-103

A $18 \quad$ M-09

A 19 a T-02b

A 19 b T-02c

A 19 c T-02a

A $20 \quad \mathrm{P}-102$

A $21 \quad \mathrm{~T}-01$

A $22 \quad$ Dd-103

A $23 \quad$ HP-114 


\begin{tabular}{|c|c|c|c|}
\hline A 24 & G-01 & A 76 & G-149 \\
\hline A 25 & G-105 & A 77 & G-150 \\
\hline A 26 & P-101 & A 78 & M-01c \\
\hline A 28 & B-01 & A 79 & M-01d \\
\hline A 29 & G-104 & A 80 & M-06 \\
\hline A 30 & G-108 & A 81 & $\mathrm{~W}-02$ \\
\hline A 31 & G-109 & A 82 & $\mathrm{~W}-05 \mathrm{~b}$ \\
\hline A 32 & G-106 & A 83 & W-06 \\
\hline A 33 & G-107 & A 84 & $\mathrm{~W}-07$ \\
\hline A 34 & G-110 & A 85 & P-103 \\
\hline A 35 & G-111 & A 86 & P-104 \\
\hline A 36 & G-114 & A 87 & P-105 \\
\hline A 37 & G-112 & A 88 & P-106 \\
\hline A 38 & G-113 & A 89 & P-107 \\
\hline A 39 & G-03 & & \\
\hline A 40 & G-115 & Neumann 1975 & \\
\hline A 41 & G-116 & & \\
\hline A 42 & G-117 & 1 & P-103 \\
\hline A 43 & G-02 & 2 & P-104 \\
\hline A 44 & G-04 & 4 & P-105 \\
\hline A 45 & G-118 & 5 & P-106 \\
\hline A 46 & G-119 & 6 & P-107 \\
\hline A 47 & G-120 & & \\
\hline A 48 & G-121 & Neumann 1997 & \\
\hline A 49 & G-122 & & \\
\hline A 50 & G-123 & passim & B-05 \\
\hline A 51 & G-124 & & \\
\hline A 52 & G-125 & Orel 1995 & \\
\hline A 53 & G-126 & & \\
\hline A 54 & G-127 & p. $128-132$ & HP-114 \\
\hline A 55 & G-128 & & \\
\hline A 56 & G-129 & Orel 1996 & \\
\hline A 57 & G-130 & & \\
\hline A 58 & G-131 & passim & HP-102 \\
\hline A 59 & G-132 & & \\
\hline A 60 & G-133 & Orel 1997 & \\
\hline A 61 & G-134 & & \\
\hline A 62 & G-135 & OPhr. & \\
\hline A 63 & G-136 & $\mathrm{W}-11$ & B-04 \\
\hline A 64 & G-137 & W-101 & HP-102 \\
\hline A 65 & G-138 & B-04 & B-06 \\
\hline A 66 & G-139 & B-101 & B-102 \\
\hline A 67 & G-140 & B-102 & B-103 \\
\hline A 68 & G-141 & B-103 & B-104 \\
\hline A 69 & G-142 & B-104 & B-105 \\
\hline A 70 & G-143 & B-105 & B-106 \\
\hline A 71 & G-144 & B-106 & B-107 \\
\hline A 72 & G-145 & L-101 & HP-103 \\
\hline A 73 & G-146 & L-102 & HP-104 \\
\hline A 74 & G-147 & L-103 & HP-105 \\
\hline A 75 & G-148 & L-104 & HP-106 \\
\hline
\end{tabular}




\begin{tabular}{|c|c|c|c|c|c|}
\hline L-105 & \multicolumn{2}{|r|}{ HP-107 } & $\mathrm{S}^{*}-05$ & 14 & 7.3 \\
\hline L-106 & \multicolumn{2}{|r|}{ HP-108 } & $\mathrm{S}^{*}-06$ & 26 & 36.1 \\
\hline L-107 & \multicolumn{2}{|r|}{ HP-109 } & $\mathrm{S}^{*}-07$ & 27 & 36.2 \\
\hline L-108 & \multicolumn{2}{|r|}{ HP-110 } & $\mathrm{S}^{*}-08$ & 30 & 37.2 \\
\hline L-109 & \multicolumn{2}{|r|}{ HP-111 } & $S^{*}-09$ & 31 & 40.3 \\
\hline L-110 & \multicolumn{2}{|r|}{ HP-112 } & $\mathrm{S}^{*}-10$ & 41,67 & 44.3 \\
\hline $\mathrm{L}-111$ & \multicolumn{2}{|r|}{ HP-113 } & $\mathrm{S}^{*}-11$ & 44 & 38.1 \\
\hline \multirow[t]{2}{*}{ Dd-104 } & \multicolumn{2}{|r|}{ HP-114 } & $\mathrm{S}^{*}-12$ & 45 & 41.1 \\
\hline & & & $\mathrm{S}^{*}-13$ & 51 & 47.1 \\
\hline NPhr. & common & here & $\mathrm{S}^{*}-14$ & 53 & 46.1 \\
\hline$C^{*}-02(20)$ & 20 & 65.1 & $\mathrm{~S}^{*}-15$ & 61 & 44.1 \\
\hline$C^{*}-03$ & 21 & 65.3 & $\mathrm{~S}^{*}-16$ & 65 & 45.1 \\
\hline$C^{*}-04$ & 32 & 62.1 & $\mathrm{~S}^{*}-17$ & 69 & 43.1 \\
\hline$C^{*}-05$ & 33 & 62.2 & $\mathrm{~S}^{*}-18$ & 70 & 44.2 \\
\hline$C^{*}-06$ & 34 & 62.3 & $\mathrm{~S}^{*}-19$ & 94 & 36.3 \\
\hline$C^{*}-07$ & 35 & 62.4 & $\mathrm{~S}^{*}-20$ & 101 & 42.1 \\
\hline$C^{*}-08$ & 36 & 62.5 & $S^{*}-21$ & 102 & 40.4 \\
\hline$C^{*}-09$ & 46,107 & 59.1 & $W^{*}-12$ & 2 & 4.1 \\
\hline$C^{*}-10$ & 47 & 59.2 & $W^{*}-13$ & 3 & 17.2 \\
\hline$C^{*}-11$ & 54 & 50.1 & $W^{*}-14$ & 4 & 18.1 \\
\hline$C^{*}-12$ & 55 & 50.2 & $W^{*}-15$ & 4bis & 17.1 \\
\hline$C^{*}-13$ & 56 & 55.1 & $W^{*}-16$ & 5 & 18.2 \\
\hline$C^{*}-14$ & 57 & 56.1 & $W^{*}-17$ & 6 & 18.3 \\
\hline$C^{*}-15$ & 58 & 56.2 & $W^{*}-18$ & 7 & 17.3 \\
\hline$C^{*}-16$ & 59 & 60.1 & $W^{*}-19$ & 8 & 26.1 \\
\hline$C^{*}-17$ & 60 & 60.2 & $W^{*}-20$ & 9 & 22.1 \\
\hline$C^{*}-18$ & 64 & 56.3 & $W^{*}-21$ & 15 & 2.1 \\
\hline$C^{*}-19$ & 72 & 58.1 & $W^{*}-22$ & 17,74 & 11.1 and 11.3 \\
\hline$C^{*}-20$ & 75 & 52.1 & $W^{*}-23$ & 18 & 11.2 \\
\hline$C^{*}-21$ & 76 & 53.1 & $W^{*}-24$ & 19 & 5.1 \\
\hline$C^{*}-22$ & 77 & 53.2 & $W^{*}-25$ & 25 & 35.1 \\
\hline$C^{*}-23$ & 78 & 57.1 & $W^{*}-26$ & 28 & 33.1 \\
\hline$C^{*}-24$ & 79 & 59.3 & $W^{*}-27$ & 29 & 31.1 \\
\hline$C^{*}-25$ & 80 & 51.1 & $W^{*}-29$ & 38 & 26.2 \\
\hline$C^{*}-26$ & 81 & 48.1 & $W^{*}-30$ & 39 & 30.1 \\
\hline$C^{*}-27$ & 82 & 64.1 & $W^{*}-31$ & 40 & 24.1 \\
\hline$C^{*}-28$ & 84 & 48.2 & $W^{*}-32$ & 42 & 21.1 \\
\hline$C^{*}-29$ & 85 & 48.3 & $W^{*}-33$ & 43 & 21.2 \\
\hline$C^{*}-30$ & 100 & 61.1 & $W^{*}-34$ & 48 & 1.1 \\
\hline$C^{*}-31$ & 103 & 66.1 & $W^{*}-35$ & 62 & 20.3 \\
\hline$C^{*}-32$ & 104 & 65.2 & $W^{*}-36$ & 63 & 20.1 \\
\hline$C^{*}-33$ & 105 & 62.6 & $W^{*}-37$ & 68 & 30.2 \\
\hline$C^{*}-34$ & 106 & 59.4 & $W^{*}-38$ & 71 & 28.1 \\
\hline$C^{*}-35$ & 108 & 54.1 & $W^{*}-39$ & 73 & 14.1 \\
\hline$C^{*}-36$ & 109 & 53.3 & $\mathrm{~W}^{*}{ }_{-40}$ & 86 & 8.1 \\
\hline$C^{*}-37$ & 110 & 49.1 & $W^{*}-41$ & 87 & 9.1 \\
\hline $\mathrm{Dd}^{*}-01$ & 98 & 1.2 & $W^{*}-42$ & 88 & 6.1 \\
\hline$S^{*}-01$ & 10 & 37.1 & $W^{*}-43$ & 89 & 23.1 \\
\hline$S^{*}-02$ & 11 & 39.1 & $W^{*}-44$ & 90 & 17.4 \\
\hline$S^{*}-03$ & 12 & 40.1 & $W^{*}-45$ & 91 & 17.5 \\
\hline$S^{*}-04$ & 13 & 40.2 & $W^{*}-46$ & 92 & 27.1 \\
\hline
\end{tabular}




$\begin{array}{lll}\mathrm{W}^{*}-47 & 93 & 32.1 \\ \mathrm{~W}^{*}-48 & 95 & 33.2 \\ \mathrm{~W}^{*}-49 & 96 & 19.1 \\ \mathrm{~W}^{*}-50 & 97 & 3.1 \\ \mathrm{~W}^{*}-51 & 99 & 7.1 \\ \mathrm{~W}^{*}-52 & 111 & 7.2 \\ \mathrm{~W}^{*}-53 & 112 & 10.1 \\ \mathrm{~W}^{*}-54 & 113 & 10.2 \\ \mathrm{~W}^{*}-55 & 114 & 29.1 \\ \mathrm{~W}^{*}-56 & 115 & 25.1 \\ \mathrm{~W}^{*}-57 & 116 & 16.1\end{array}$

pg. 143

18.1

Özgen \& Öztürk 1996

$60 \quad$ HP-102

Pauli 1894

Ramsay 1883

$\begin{array}{ll}1 & \mathrm{M}-01 \mathrm{a} \\ 2 & \mathrm{M}-01 \mathrm{~b} \\ 3 & \mathrm{M}-01 \mathrm{f} \\ 4 & \mathrm{M}-03 \\ 5 & \mathrm{M}-02 \\ 6 & \mathrm{M}-04 \\ 7 & \mathrm{~W}-04 \mathrm{~b} \\ 8 & \mathrm{~W}-01 \mathrm{a} \\ 9 & \mathrm{~W}-01 \mathrm{c} \\ 10 & \mathrm{M}-05 \\ 11 & \mathrm{~W}-04 \\ 13 & \mathrm{P}-01\end{array}$

$\begin{array}{ll}1 & \text { M-01a } \\ 2 & \text { M-01b } \\ 3 & \text { M-01f } \\ 4 & \text { M-03 } \\ 5 & \text { M-02 } \\ 6 & \text { M-04 } \\ 7 & \text { W-01a } \\ 8 & \text { W-01b } \\ 9 & \text { W-01c } \\ 10 & \text { M-05 } \\ 11 & \text { W-04 }\end{array}$

\section{Ramsay 1887}

Perrot \& Chipiez 1890

pp. $88-89$

M-01 a

Pococke 1752

I

App. 1

II

4.1

III

17.2

IV

18.1

$\mathrm{V}$

18.2

VI

18.3

VII

17.3

VIII

26.1

IX

22.1

$\mathrm{X}$

37.1

XI

39.1

XII

40.1

XIII

40.2

XIV

7.3

XV

2.1

XVI

XVII

App. 2

caput I, sectio III pag. 9, no. 35.1

XVIII

11.1

XIX

11.2

Pridik 1900

$\mathrm{XX}$

5.1

XXI

65.1

29

T-01

XXII

65.3

XXIII

App. 3

App. 4

XXIV

App. 5

XXIV

App. 6

XXIV

App. 7

no. 7

52.1

XXV

35.1

XXVI

XXVII 
XXX

\section{Ramsay 1888}

p. $371-372$

p. 380-381

Ramsay 1889a

185

Ramsay 1889 b

$\begin{array}{ll}309 & \text { W-01a } \\ 310 & \text { M-04 } \\ 310 & \text { W-01c } \\ 311 & \text { W-01b }\end{array}$

\section{Ramsay 1905}

II

III

IV

IV bis

V

VI

IX

X

XI

XII

XIII

XIV

XV

XVII

XVIII

XIX

XX

XXI

XXV

XXVI

XXVII

XXVIII

XXIX

XXX

XXXI

XXXII

XXXIII

XXXIV

XXXV

XXXVI

XXXVII
M-02

37.2

W-04

W-01a

W-01b

4.1

17.2

18.1

17.1

18.2

18.3

22.1

37.1

39.1

40.1

40.2

7.3

2.1

17.3

11.2

5.1

65.1

65.3

35.1

36.1

36.2

33.1

31.1

37.2

40.3

62.1

62.2

62.3

62.4

62.5

34.1
XXXVIII

XXXIX

XL

XLI

XLII

XLIII

XLIV

XLV

XLVI

XLVII

XLVIII

26.2

30.1

24.1

44.3

21.1

21.2

38.1

41.1

59.1

59.2

1.1

\section{RECAM}

II, no. 366

61.1

II, no. 369

60.1

II, no. 370

60.2

IV, no. 96

6.1

\section{Roller 1987a}

\begin{tabular}{|c|c|}
\hline $2 A-29$ & G-337 \\
\hline $2 \mathrm{~A}-44$ & G-273 \\
\hline $2 A-51$ & G-338 \\
\hline $2 A-66$ & G-278 \\
\hline $2 A-67$ & G-277 \\
\hline $2 \mathrm{~A}-73$ & G-336 \\
\hline $2 A-102$ & G-335 \\
\hline $2 \mathrm{~A}-111$ & G-339 \\
\hline $2 \mathrm{~A}-130$ & G-208 \\
\hline $2 A-206$ & G-203 \\
\hline $2 B-4$ & G-257 \\
\hline $2 B-9$ & G-248 \\
\hline $2 B-13$ & G-254 \\
\hline 2B-19 & G-338 \\
\hline $2 B-22$ & G-337 \\
\hline $2 B-23$ & G-282 \\
\hline $2 B-25$ & G-278 \\
\hline $2 B-27$ & $g-336$ \\
\hline $2 B-35$ & G-215 \\
\hline $2 B-44$ & G-339 \\
\hline $2 B-51$ & G-235 \\
\hline $2 B-52$ & G-243 \\
\hline $2 B-54$ & G-260 \\
\hline $2 B-55$ & G-275 \\
\hline $2 B-56$ & G-266 \\
\hline $2 B-123$ & G-162 \\
\hline 2B-152 & G-225 \\
\hline $2 B-167$ & G-241 \\
\hline $2 B-172$ & G-263 \\
\hline 2B-193 & G-158 \\
\hline
\end{tabular}




$\begin{array}{ll}2 C-3 & \text { G-228 } \\ \text { 3B-5 } & \text { G-116 } \\ \text { 3B-7 } & \text { G-117 } \\ \text { 3B-30 } & \text { G-150 }\end{array}$

Ruge 1948

7

8

Sams 2009

p. $141-143$

Sayce 1885

p. 910

Sayce 1926

$\begin{array}{ll}1 & \text { M-01a } \\ 2 & \text { M-01b } \\ 3 & \text { M-01f } \\ 4 & \text { M-03 } \\ 5 & \text { M-02 } \\ 6 & \text { M-04 } \\ 7 & \text { W-01b } \\ 8 & \text { W-01a } \\ 9 & \text { W-01c } \\ 10 & \text { M-05 } \\ 11 & \text { W-04 } \\ 13 & \text { P-02 } \\ \text { p. 34 } & \text { W-05a } \\ \text { p. 34 } & \text { P-01 } \\ \text { p. 34 } 34-35 & \text { P-04 } \\ \text { p. 34-35 } & \text { T-02b }\end{array}$

Schmidt 1869

p. $132-136$

p. $136-137$

p. 137

Schmidt \& Krogman 1933

p. $133,109-110$

HP-115

Schwyzer 1923

App. IV, 8, 1

M-01a

M-02

$\mathrm{M}-01 \mathrm{~b}$
App. IV, 8, 2

App. IV, 8, 3 a

App. IV , 8, 3 b

App. IV, 8, 3 C

SEG

1.454

6.96

6.291

6.434

14.783

29.1174

30.1126

30.1488

36.1191

39.1416

47.1725

52.1458 .96

Solmsen 1897a

p. $60-62$

M-01b

Sterrett 1885

6

36.1

7

Sterret 1888a

174

175

38.1

36.1

Sterrett $1888 \mathrm{~b}$

571

33.1

590

31.1

Strubbe 1997

177

257

App. 1

257

18.2

66.1

6.1

App. 12

App. 8

1.2

App. 2

25.1

64.1

43.1

43.1

63.1

6.1

36.2

\section{1}




\begin{tabular}{|c|c|c|c|}
\hline & & 44 & 38.1 \\
\hline & & 45 & 41.1 \\
\hline W-11 & HP-102 & 47 & 59.2 \\
\hline Dask-1-4 & B-06 & 48 & 1.1 \\
\hline Bay-1 & HP-103 & 51 & 47.1 \\
\hline Bay-2 & HP-104 & 53 & 46.1 \\
\hline Bay-3 & HP-105 & 54 & 50.1 \\
\hline Bay-4 & HP-106 & 55 & 50.2 \\
\hline Bay-5 & HP-107 & 56 & 55.1 \\
\hline Bay-6 & HP-108 & 57 & 56.1 \\
\hline Bay-8 & HP-110 & 58 & 56.2 \\
\hline Bay-9 & HP-111 & 59 & 60.1 \\
\hline Bay-10 & HP-112 & 60 & 60.2 \\
\hline & & 61 & 44.1 \\
\hline 2 & 4.1 & 62 & 20.3 \\
\hline 3 & 17.2 & 63 & 20.1 \\
\hline 4 & 18.1 & 64 & 56.3 \\
\hline 4 bis & 17.1 & 65 & 45.1 \\
\hline 5 & 18.2 & 67 & 44.3 \\
\hline 6 & 18.3 & 68 & 30.2 \\
\hline 7 & 17.3 & 69 & 43.1 \\
\hline 9 & 22.1 & 70 & 44.2 \\
\hline 10 & 37.1 & 71 & 28.1 \\
\hline 11 & 39.1 & 72 & 58.1 \\
\hline 12 & 40.1 & 73 & 14.1 \\
\hline 13 & 40.2 & 75 & 52.1 \\
\hline 14 & 7.3 & 76 & 53.1 \\
\hline 15 & 2.1 & 77 & 53.2 \\
\hline 17 & $11.1,11.3$ & 78 & 57.1 \\
\hline 18 & 11.2 & 79 & 59.3 \\
\hline 19 & 5.1 & 80 & 51.1 \\
\hline 20 & 65.1 & 81 & 48.1 \\
\hline 21 & 65.3 & 82 & 64.1 \\
\hline 25 & 35.1 & 84 & 48.2 \\
\hline 26 & 36.1 & 85 & 48.3 \\
\hline 27 & 36.2 & 86 & 8.1 \\
\hline 28 & 33.1 & 87 & 9.1 \\
\hline 29 & 31.1 & 88 & 6.1 \\
\hline 30 & 37.2 & 89 & 23.1 \\
\hline 31 & 40.3 & 90 & 17.4 \\
\hline 32 & 62.1 & 91 & 17.5 \\
\hline 33 & 62.2 & 92 & 27.1 \\
\hline 34 & 62.3 & 93 & 32.1 \\
\hline 35 & 62.4 & 94 & 36.3 \\
\hline 36 & 62.5 & 95 & 33.2 \\
\hline 37 & 34.1 & 97 & 3.1 \\
\hline 38 & 26.2 & 98 & 1.1 \\
\hline 39 & 30.1 & 99 & 7.1 \\
\hline 40 & 24.1 & 100 & 61.1 \\
\hline 42 & 21.1 & 101 & 42.1 \\
\hline 43 & 21.2 & 102 & 40.4 \\
\hline
\end{tabular}




\begin{tabular}{|c|c|c|c|}
\hline 103 & 66.1 & 293 & 10.2 \\
\hline 104 & 65.2 & 319 & 7.2 \\
\hline 105 & 62.6 & 469 & 17.5 \\
\hline 106 & 59.4 & 470 & 25.1 \\
\hline 107 & 59.1 & 484 & 17.4 \\
\hline 108 & 54.1 & 490 & 17.2 \\
\hline 109 & 53.3 & 493 & 19.1 \\
\hline 110 & 49.1 & 499 & 26.2 \\
\hline 111 & 7.2 & 505 & 14.1 \\
\hline 112 & 10.1 & 506 & 21.2 \\
\hline 113 & 10.2 & 507 & 21.1 \\
\hline 114 & 29.1 & 509 & 20.1 \\
\hline 115 & 25.1 & 544 & 11.1 and 11.3 \\
\hline \multirow[t]{2}{*}{116} & 16.1 & 554 & 65.1 \\
\hline & & 556 & 246 \\
\hline \multirow{2}{*}{\multicolumn{2}{|c|}{ Torp 1896}} & 573 & 45.1 \\
\hline & & 595 & 51.1 \\
\hline \multirow[t]{2}{*}{10} & W-01 & 602 & 62.2 \\
\hline & & 603 & 62.3 \\
\hline \multirow[t]{2}{*}{ Tuğrul-Firatli 1966} & & 604 & 62.4 \\
\hline & & 605 & 62.1 \\
\hline \multirow[t]{2}{*}{ p.230-235 and $236-241$} & B-01 & 610 & 62.5 \\
\hline & & 620 & 60.2 \\
\hline \multirow[t]{2}{*}{ Varinlioğlu 1992} & & 629 & 56.1 \\
\hline & & 630 & 56.2 \\
\hline 1 & HP-103 & 638 & 53.1 \\
\hline 2 & HP-104 & 650 & 57.1 \\
\hline 3 & HP-105 & 664 & 43.1 \\
\hline 4 & HP-106 & 678 & 37.2 \\
\hline 5 & HP-107 & & \\
\hline 6 & HP-108 & & \\
\hline 7 & HP-109 & Weber 1908 & \\
\hline 8 & HP-110 & & \\
\hline 9 & HP-111 & 77 & $\mathrm{~T}-02 \mathrm{~b}$ \\
\hline 10 & HP-112 & & \\
\hline 11 & HP-113 & Wilhelm 1980 & \\
\hline \multicolumn{2}{|l|}{ von Reber 1898} & 112 & 6 \\
\hline p. 564 & $W-05 a$ & Young 1951 & \\
\hline p. 566 & M-01a & & \\
\hline p. 566 & $\mathrm{M}-01 \mathrm{~b}$ & p. 10 & G-01 \\
\hline p. 571 & $\mathrm{~W}-01 \mathrm{~b}$ & & \\
\hline p. 571-572 & W-01a & Young 1953 & \\
\hline p. 572 & W-01c & & \\
\hline p. $584-585$ & M-04 & p. 21 & G-01 \\
\hline \multicolumn{2}{|l|}{ Waelkens 1986} & Young 1955 & \\
\hline 226 & 3.1 & p. $10-11$ & G-02 \\
\hline 292 & 10.1 & & \\
\hline 548 & & & \\
\hline
\end{tabular}




\begin{tabular}{|c|c|c|c|}
\hline \multirow[t]{2}{*}{ Young 1958} & & 44 & G-04 \\
\hline & & 45 & G-118 \\
\hline \multirow[t]{2}{*}{ p. 153} & G-105 & 46 & G-119 \\
\hline & & 47 & G-120 \\
\hline \multirow[t]{2}{*}{ Young 1963} & & 48 & G-121 \\
\hline & & 49 & G-122 \\
\hline \multirow[t]{2}{*}{ p. 362} & G-105 & 50 & G-123 \\
\hline & & 51 & G-124 \\
\hline \multirow[t]{2}{*}{ Young 1964} & & 52 & G-125 \\
\hline & & 53 & G-126 \\
\hline \multirow[t]{2}{*}{ p. $280-281$} & G-136 & 54 & G-127 \\
\hline & & 55 & G-128 \\
\hline \multirow[t]{2}{*}{ Young 1966} & & 56 & G-129 \\
\hline & & 57 & G-130 \\
\hline \multirow[t]{2}{*}{ p. 276} & G-104 & 58 & G-131 \\
\hline & & 59 & G-132 \\
\hline \multirow[t]{2}{*}{ Young 1968} & & 60 & G-133 \\
\hline & & 61 & G-134 \\
\hline \multirow[t]{2}{*}{ p. $235-236$} & G-04 & 62 & G-135 \\
\hline & & 63 & G-136 \\
\hline \multirow[t]{2}{*}{ Young 1969} & & 64 & G-137 \\
\hline & & 65 & G-138 \\
\hline 24 & G-01 & 66 & G-139 \\
\hline 25 & G-105 & 67 & G-140 \\
\hline 29 & G-104 & 68 & G-141 \\
\hline 30 & G-108 & 69 & G-142 \\
\hline 31 & G-109 & 70 & G-143 \\
\hline 32 & G-106 & 71 & G-144 \\
\hline 33 & G-107 & 72 & G-145 \\
\hline 34 & G-110 & 73 & G-146 \\
\hline 35 & G-111 & 74 & G-147 \\
\hline 36 & G-114 & 75 & G-148 \\
\hline 37 & G-112 & 76 & G-149 \\
\hline 38 & G-113 & 77 & G-150 \\
\hline 39 & G-03 & & \\
\hline 40 & G-115 & Young 1981 & \\
\hline 41 & G-116 & & \\
\hline 42 & G-117 & p. 130 fig. 84 & G-105 \\
\hline 43 & G-02 & & \\
\hline
\end{tabular}





\section{Indices}

Numbers refer to pages. Hittite and Cuneiform Luwian are given in the order used by Kloekhorst $(2008,159)$. Lycian by Neumann (2007, XIII). Sanskrit, Avestan, Greek and Tocharian A and B are given in the order of their own alphabet. The other languages are given in the order of the Latin alphabet.

\section{Common words}

\section{ANATOLIAN}

HITTITE

\begin{tabular}{|c|c|}
\hline anda & 141 \\
\hline $\operatorname{ara} \bar{a}^{i}$, ari- & 118,144 \\
\hline aru- & 343 \\
\hline ištarna & 182 \\
\hline$k \bar{a}-$ & 77 \\
\hline keššar & 70,370 \\
\hline gimra- & 206 \\
\hline kuiš, kuit & 82 \\
\hline gurta- & 116,117 \\
\hline lāman & 257 \\
\hline $\operatorname{mit}(t) a^{-}$, miti- & 115,242 \\
\hline$n u$ & 251 \\
\hline padda- ${ }^{i}$ / padda- & 268 \\
\hline pihaim(m)i- & 156 \\
\hline $\operatorname{piham}(m) i-$ & 156 \\
\hline pihaš̌šašši- & 156 \\
\hline puhru & 265 \\
\hline pulluriya & 115,269 \\
\hline š̄āmăna- & 115,278 \\
\hline šarā & 343 \\
\hline šarku- / šargaú- & $116,119,284$ \\
\hline šìna(na)- & 118 fn. 206 \\
\hline tāru & 295 \\
\hline uttar / uddan- & 117,262 \\
\hline$u_{\lambda} \bar{a} k^{-i} / u_{\alpha} \bar{a} k k-$ & 44,142 \\
\hline$u_{\text {uep }}{ }^{z i}$ & 191 \\
\hline & 191 \\
\hline
\end{tabular}

\section{CUNEIFORM LUWIAN}

$\operatorname{ari(ia)-}$

118,144

aru-

343

$\mathrm{im}(\mathrm{ma}) \mathrm{ra} / \mathrm{i} \quad \mathrm{117}, 206$

mašša(i)- $\quad 118,237$

tiiamm(i)- $\quad 117,289$

$\operatorname{tu} b(a) i-$

utar / utn-

unāšu-

298

117,263

$z \bar{a}-$ anta

atri(ya)-

azzu-

handawat(i)-

tūb(a)i-

immar(i)-

massan(i)-

wani-

wasu

$z a-$

\section{HIEROGLYPHIC LUWIAN}

141

118

209

166

298

117

117,237

118

190

77

LYCIAN

armina-

145

erije-

esb-

118,144

209

hri 343

xñtawat(i)- $\quad 166$

$\operatorname{mahan}(a)-\quad 118,237$

ñte 141

sixla-

tubeiti

tubidi

45 fn. $72,120,218$

298

298

LYDIAN

$\operatorname{arm\tau a-}$

145

artimus

98

asinas

118,147

ciw-

118 fn. 206

mru-

$119,239,245$

taśẽv

119,288

\section{Indo-Iranian}

SANSKRIT

$\begin{array}{ll}\text { ájati } & 143 \\ \text { áti } & 185 \\ \text { aśani } & 136 \\ \text { ásti } & 208\end{array}$




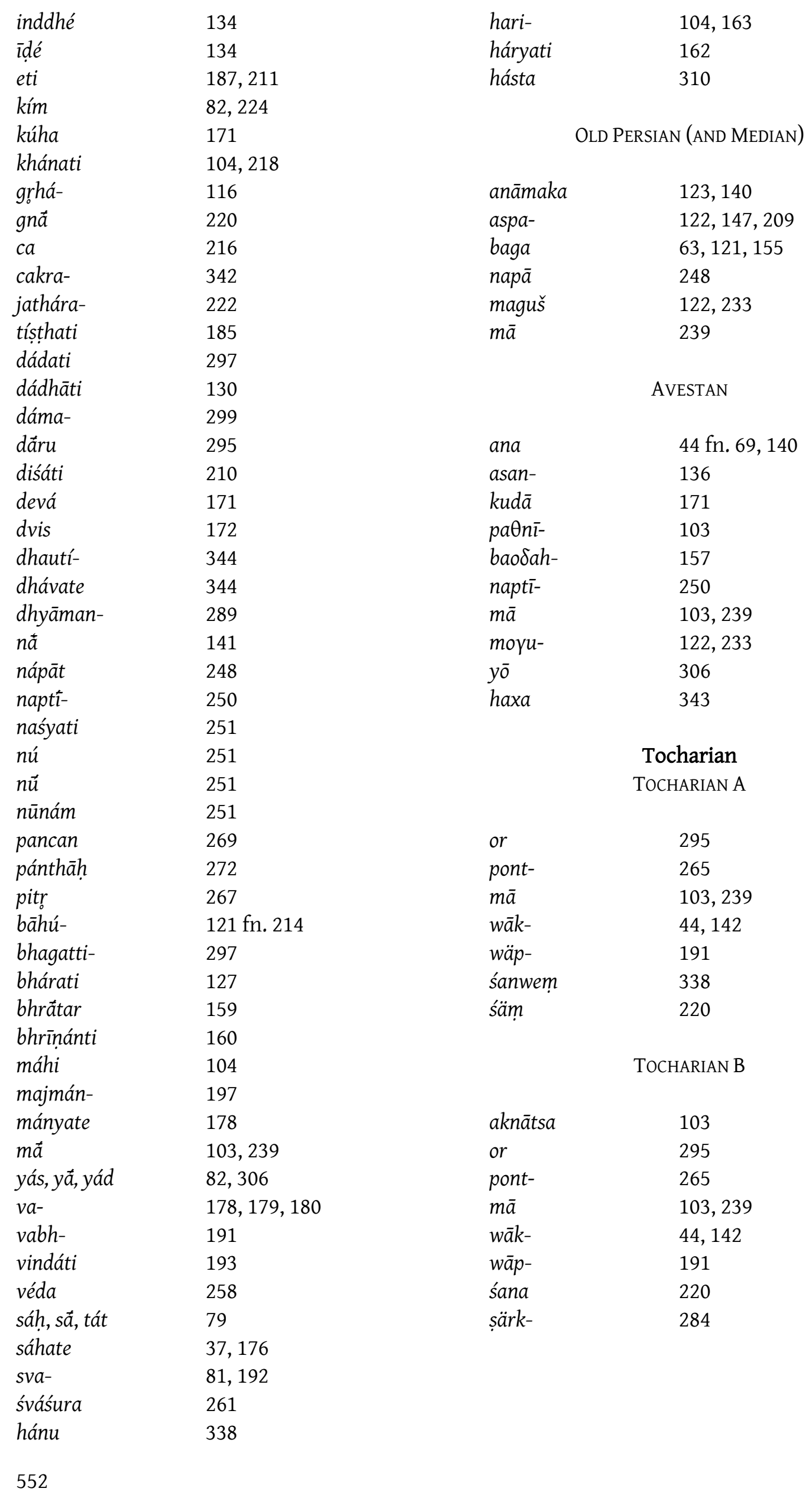




\begin{tabular}{|c|c|c|c|}
\hline \multicolumn{2}{|c|}{ Greek } & ỏpxós & 144 \\
\hline \multirow{2}{*}{\multicolumn{2}{|c|}{ MYCENAEAN }} & óp $\rho \omega$ & 144 \\
\hline & & 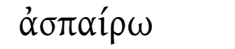 & 147 \\
\hline$e-w e-p e-s e-s o-m$ & 191 & 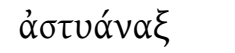 & 244 \\
\hline ko-wa & 223 & ó $\sigma \varphi 1$ & 93 \\
\hline ko-wo & 223 & $\tilde{\alpha} \tau \rho o v$ & 150 \\
\hline$k u-n a-k i-s i$ & 220 & 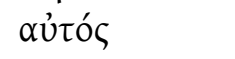 & 81,151 \\
\hline po-si & 271 & $\alpha u ̋ \omega \varsigma$ & 103 \\
\hline po-ti-ni-ja & 103 & 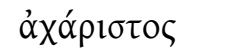 & 127 \\
\hline$r a-w a-k e-t a$ & 229 & 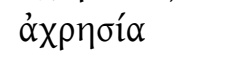 & 339 \\
\hline to-ro-qa & 290 & 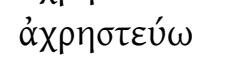 & 339 \\
\hline$w a-n a-k a$ & 109 & 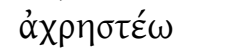 & 339 \\
\hline$w e-t e-i$ & 192 & 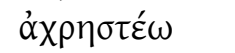 & 339 \\
\hline \multirow[t]{4}{*}{ wo-wo } & \multirow{2}{*}{$\begin{array}{l}192 \\
259\end{array}$} & 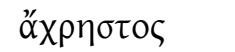 & 339 \\
\hline & & ówpos & 110,151 \\
\hline & \multirow[t]{2}{*}{ ALPHABETIC GREEK } & $\beta \alpha \lambda \eta \dot{v} v$ & 339 \\
\hline & & $\beta \alpha v \alpha ́$ & 159 \\
\hline ảyó日oıı & 62 fn. 106 & 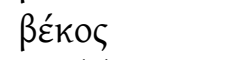 & 59,158 \\
\hline àj $\alpha \theta$ oús & 62 fn. 106 & $\beta \varepsilon ́ v(v) 10 \zeta$ & $112-114$ \\
\hline$\alpha^{\prime \prime} \gamma v \cup \mu \imath$ & 44,142 & $\beta \varepsilon ́ v(v) o \zeta$ & $112-114$ \\
\hline$\alpha ̋ \gamma \omega$ & 143 & 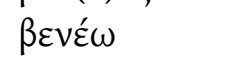 & 113 \\
\hline 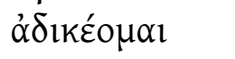 & 132 & $\beta \varepsilon v \vee \alpha ́ \alpha \rho>x \eta \nu$ & 113 \\
\hline 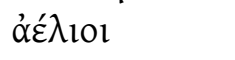 & 340 & $\beta \varepsilon \vee v \varepsilon \cup \varepsilon$ & 113 \\
\hline$\alpha \hat{i}$ & 95,151 & $\beta \varepsilon \tilde{v} \delta \circ \varsigma$ & $59,112,157$ \\
\hline 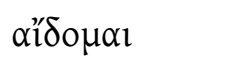 & 134 & $\beta \bar{\imath} v \varepsilon \varepsilon^{\prime} \omega$ & 113 \\
\hline$\alpha i ́ \theta \omega$ & 134 & ßovó & 159 \\
\hline 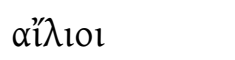 & 340 & ßроко́ & 160 \\
\hline ö́kıKUৎ & 112 & yóiöos & 135 \\
\hline 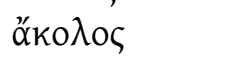 & 112 & 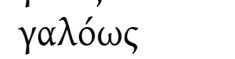 & 340 \\
\hline 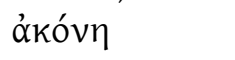 & 136 & yóvos & 340 fn. 221 \\
\hline ö́ $\rho \alpha$ & 339 fn. 220 & үóp & 152 \\
\hline 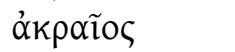 & 323 & 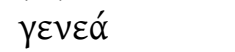 & 217 \\
\hline 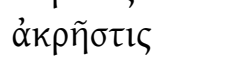 & 339 fn. 220 & үÉvטৎ & 338 \\
\hline ókpos & $110,135,139$ & $\gamma \tilde{\eta}$ & 156 \\
\hline$\alpha \dot{\alpha} \alpha \dot{\beta} \eta$ & 313 & ү入oupós & $59,112,163$ \\
\hline$\dot{\alpha} \lambda \varphi n^{\prime}$ & 144 & үóvos & $163,248,250$ \\
\hline$\alpha^{\prime} v$ & 140,215 & 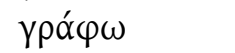 & 102 \\
\hline ơvó́ & 44 fn. $69,93,140$ & yuví & 220,342 \\
\hline 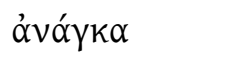 & 114 & $\Gamma \omega \lambda \varepsilon \varepsilon^{\prime} \varsigma$ & 22 \\
\hline óvóp & 110,141 & $-\delta \alpha$ & 93 \\
\hline 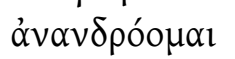 & 247 & $\delta \alpha i ́ \omega$ & 176 \\
\hline 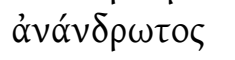 & 61,247 & $\delta \alpha ́ \mu \nu \eta \mu \imath$ & 338 \\
\hline óv $\alpha \xi$ & $64,109,190$ & $-\delta \varepsilon$ & 92,93 \\
\hline$\ddot{\alpha}^{\prime} \vee \bar{\alpha} \tau O \varsigma$ & 141 & $\delta \varepsilon ́ \kappa o \mu \alpha l$ & 44 fn. 70,130 \\
\hline 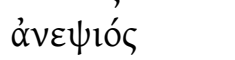 & 248 & $\delta \varepsilon \dot{\varepsilon} \mu \omega$ & 110,139 \\
\hline ơvíp & 141 & 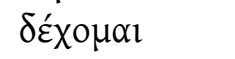 & 44 fn. 70,130 \\
\hline óv $v \omega \gamma \alpha$ & 77 & $\delta \eta ́$ & 170 \\
\hline 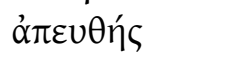 & 157 & $\delta i \alpha ́$ & 93,168 \\
\hline ä $\rho \alpha$ & $94,145,184$ & $\delta 1 \alpha \delta ı \kappa^{\prime} \alpha ́ \zeta \omega$ & 92,294 \\
\hline óp & 93,145 & $\delta i \delta \omega \mu \imath$ & 297 \\
\hline àpxń & 144 & 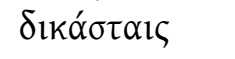 & 62 fn. 106 \\
\hline
\end{tabular}




\begin{tabular}{|c|c|c|c|}
\hline 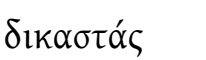 & 62 fn. 106 & $\varepsilon^{\prime \prime} \chi \omega$ & $37,176,210$ \\
\hline dís & 93,172 & $f \varepsilon$ & 81,192 \\
\hline$\delta \mu \omega \omega_{\varsigma}$ & 172 & $\zeta \tilde{\omega}$ & 197 \\
\hline 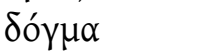 & 144 & $\zeta \omega ́ \varsigma$ & $90,110,197,267$ \\
\hline ઈópos & 299 & $\eta$ & 151 \\
\hline ઈópv & 295 & 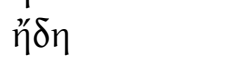 & 168 \\
\hline 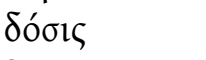 & 297 & $\grave{\eta} \dot{\varepsilon}$ & 151 \\
\hline 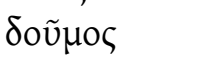 & $112,173,299$ & ท̆рwos & 178 \\
\hline$\varepsilon$ & 81,192 & 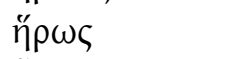 & 178 \\
\hline 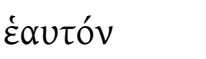 & 81,192 & $\tilde{\eta} \tau \rho \circ v$ & 150 \\
\hline Ėyүóviov & 163 & $-\theta \alpha$ & $93,104,304$ \\
\hline Épyovov & 110,176 & $\theta \alpha \lambda \alpha ́ \mu \eta$ & $55,110,111,114,201$ \\
\hline है'үyovos & 163 & & 222,288 \\
\hline 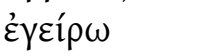 & 176 & $\theta \alpha ́ \lambda \alpha \mu \circ \varsigma$ & 222 \\
\hline हì & 95,152 & $\theta \varepsilon \tilde{\imath} о \varsigma$ & 82,246 \\
\hline 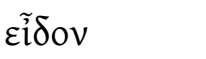 & 258 & $-\theta \varepsilon v$ & 93,170 \\
\hline 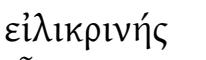 & $110,111,177$ & $\theta \varepsilon o ́ \varsigma$ & 171 \\
\hline$\varepsilon \tilde{\imath} \mu \mathrm{l}$ & 187,211 & $\theta \varepsilon \rho \mu o ́ \varsigma$ & $67 \mathrm{fn} .113$ \\
\hline cỉuí & 208 & 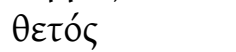 & 170 \\
\hline Eis & $91 \mathrm{fn} .151,92,93$ & 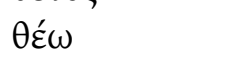 & 344 \\
\hline 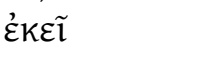 & $77,93,180$ & $\theta \rho \varepsilon ́ \psi ı$ & 131 \\
\hline غ̇kupós & 261 & $\theta \omega \mu$ ós & 173 \\
\hline 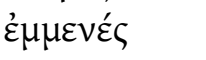 & 104,205 & $\mathfrak{i} \delta \varepsilon \tilde{\imath} v$ & 193 \\
\hline$\dot{\varepsilon} \nu$ & 93,181 & 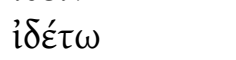 & 258 \\
\hline 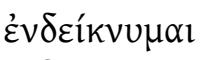 & 210 & iepóv & 99 \\
\hline$\tilde{\varepsilon} v \delta$ ov & 92,141 & ǐ $\sigma \tau \eta \mu \iota$ & 99,185 \\
\hline$\varepsilon \dot{\varepsilon} \vee \varepsilon ́ \pi \omega$ & 208 & kokós & $93,214,215$ \\
\hline$\tilde{\varepsilon}^{\prime} \vee \theta \alpha$ & 93 & kaków & 214 \\
\hline$\tilde{\varepsilon} v \theta \varepsilon v$ & 93 & $\kappa \alpha \kappa \tilde{\omega} \varsigma$ & 93,214 \\
\hline$\dot{\varepsilon} \vee \varsigma_{\zeta}$ & 92,93 & 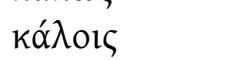 & 62 fn. 106 \\
\hline 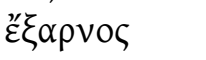 & 186 & 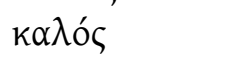 & 138 \\
\hline غ̇õ & 80,207 & 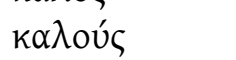 & 62 fn. 106 \\
\hline$\dot{\varepsilon} \pi i ́$ & 183 & kov & 215 \\
\hline$\ddot{\varepsilon} \rho$ & 94,184 & $\kappa \alpha \tau \alpha \delta ı \kappa^{\prime}\langle\omega$ & 294 \\
\hline$\tilde{\varepsilon} \rho \alpha$ & 94,184 & $\kappa \varepsilon$ & 215 \\
\hline 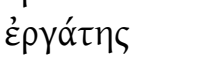 & 284 & KElVós & 104,218 \\
\hline हैpүov & 194 & 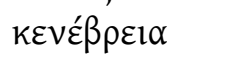 & 282 \\
\hline$\varepsilon \rho \varepsilon ́ \alpha \varsigma$ & 178 & КEVEó & 104,218 \\
\hline$\dot{\varepsilon} \zeta$ & 91.93 & KEVós & $104,217,218,271$ \\
\hline$\dot{\varepsilon} \sigma \tau i ́ \alpha$ & 321 & 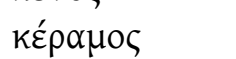 & 218 \\
\hline 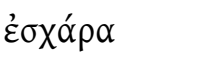 & 136 & 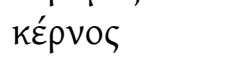 & 218 \\
\hline हैं & 185 & 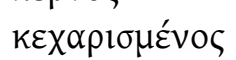 & 162 \\
\hline हैंน०ৎ & 192,260 & 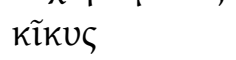 & $112,114,219$ \\
\hline$\varepsilon \dot{U}-$ & $178,179,180$ & Kıkúw & 112 \\
\hline 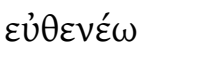 & 158 & $\kappa \lambda \tilde{\alpha} \rho \circ \zeta$ & 225 \\
\hline 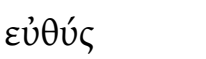 & 180 & $\kappa \lambda \tilde{\eta} \rho \circ \zeta$ & 225 \\
\hline$\varepsilon \dot{ }$ & 179 & kvúw & 68,221 \\
\hline عỦxท́ & 186,187 & Kolpavéw & $90,110,226$ \\
\hline 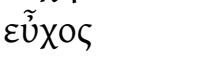 & 186 & koípavos & 104,226 \\
\hline$\dot{\varepsilon} \chi \dot{\varepsilon} \sigma \theta \omega$ & 87 & 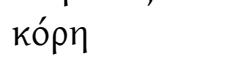 & 104,223 \\
\hline ẺX̃̃voৎ & 341 & кópos & 104,223 \\
\hline
\end{tabular}




\begin{tabular}{|c|c|c|c|}
\hline кои̃pos & 104 & 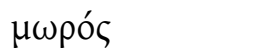 & 245 \\
\hline кои̃pos & 223 & velós & 149 \\
\hline крóv $\alpha$ & $110,114,224$ & veós & 149 \\
\hline 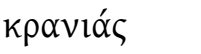 & 224 & 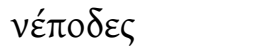 & 248 \\
\hline крávv $\alpha$ & $75,110,114,224$ & 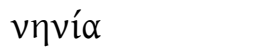 & 342 \\
\hline 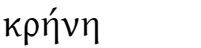 & $75,110,114,224$ & $v \mathrm{l}$ & 103,249 \\
\hline 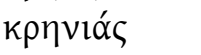 & 224 & $v i$ & 103,249 \\
\hline 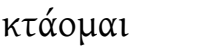 & 181 & vo & 251 \\
\hline$\kappa \cup \beta \varepsilon \rho \vee \alpha ́ \omega$ & 342 & $v \tilde{v} v$ & 251 \\
\hline 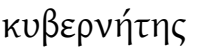 & 342 & $v u ́ \xi$ & 251 \\
\hline 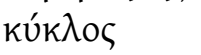 & 342 & $v u ́ \sigma \sigma \omega$ & 251 \\
\hline 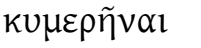 & 342 & $v u ́ \tau \tau \omega$ & 251 \\
\hline 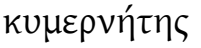 & 342 & 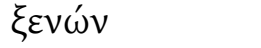 & 342 \\
\hline$\kappa \omega ́ \mu \eta$ & 173 & $\Xi \varepsilon \cup \vee \alpha$ & 253 \\
\hline 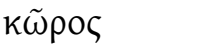 & 223 & $\Xi \varepsilon v \vee \eta$ & 253 \\
\hline$\lambda \alpha \gamma \varepsilon ́ \tau \alpha \varsigma$ & 229 & 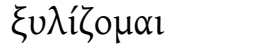 & 90,295 \\
\hline$\lambda \alpha \mu \beta \alpha ́ v \omega$ & $64,104,230$ & 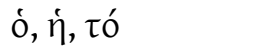 & 79 \\
\hline 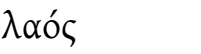 & 229 & oi & 80,207 \\
\hline$\lambda \alpha \tau o ́ \mu 10 v$ & 110,230 & oĩvos & 193 \\
\hline 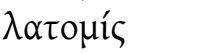 & 110,230 & 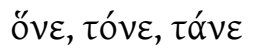 & 249 \\
\hline$\lambda$ úkos & 340 & 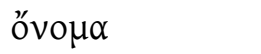 & 257 \\
\hline 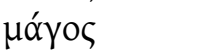 & 122,233 & ö $\pi 1 \sigma \theta \alpha$ & 93 \\
\hline 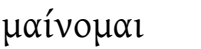 & 178 & ő $\pi 1 \sigma \theta \varepsilon$ & 93 \\
\hline$\mu \alpha \alpha_{\kappa} \alpha \rho$ & 234 & ő $\pi l \sigma \theta \varepsilon v$ & 92,258 \\
\hline$\mu \alpha \alpha_{\kappa} \rho \alpha$ & 233,234 & öpos & 259 \\
\hline 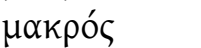 & 234 & ỏ $\rho \varphi \alpha v o ́ \varsigma$ & 259 \\
\hline$\mu \alpha \alpha_{\kappa} \tau \rho \alpha$ & 233 & ö, ท̆, ǒ (poss.) & 83,189 \\
\hline$\mu \alpha v i k \alpha$ & 236 & ǒs, ท̆, ǒ (rel.) & 82,306 \\
\hline$\mu \alpha \rho \mu \alpha i ́ \rho \omega$ & 234 & 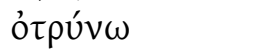 & 92 \\
\hline$\mu \alpha \rho \mu \alpha ́ \alpha \varepsilon о \varsigma$ & 124,234 & $o u ́(k)$ & 94,301 \\
\hline$\mu \alpha ́ \alpha \sigma \sigma \omega$ & 233 & oủóvouv & 340 \\
\hline$\mu \alpha ́ \alpha \sigma \sigma \omega$ & 234 & oủpávios & 262 \\
\hline 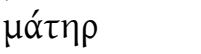 & 237 & oủpavós & 262 \\
\hline$\mu \varepsilon ́ \gamma \alpha \varsigma$ & $44,104,240$ & oũpos & 259 \\
\hline$\mu \varepsilon i ́ \omega \nu$ & 248 & 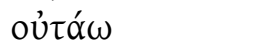 & 262 \\
\hline 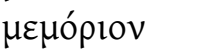 & 124,234 & oü $\tau \varepsilon$ & 94,301 \\
\hline$\mu \varepsilon \sigma o ́ \delta \mu \eta$ & 110,139 & ỏxev́s & $77,103,137$ \\
\hline$\mu \varepsilon \tau \alpha ́$ & 93,239 & $\pi \alpha ́ \lambda \eta$ & 339 \\
\hline$\mu \varepsilon ́ \chi \chi \rho l$ & 239 & $\pi \alpha ́ \rho$ & $91,93,270$ \\
\hline$\mu \eta ́$ & $44,103,239$ & $\pi \alpha \rho \alpha ́ \delta \varepsilon 1 \gamma \mu \alpha$ & 144 \\
\hline 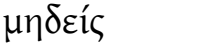 & 82 & $\pi \tilde{\alpha} \varsigma$ & 265 \\
\hline 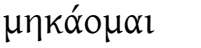 & 342 & $\pi \alpha \tau \eta ́ p$ & 259,267 \\
\hline 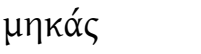 & 342 & $\pi \alpha ́ \tau \rho 10 \varsigma$ & 267 \\
\hline$\mu \tilde{\eta} \tau \varepsilon$ & 94,239 & 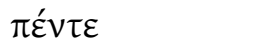 & 269 \\
\hline$\mu \eta ́ \tau \eta \rho$ & 237 & $\pi \varepsilon \rho i ́$ & 268 \\
\hline 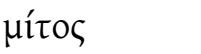 & 115 & $\pi \varepsilon ́ \rho \vee \eta \mu \iota$ & 271 \\
\hline$\mu \nu \eta \mu \varepsilon \tilde{\mathrm{l}} \mathrm{\nu}$ & 191 & тпро́ & 266 \\
\hline$\mu о \tilde{\imath} \sigma \alpha$ & 62 fn. 106 & $\pi \tilde{\eta} \times \cup \varsigma$ & 121 fn. 214,155 \\
\hline нóvos & 244 & $\pi 01 v \eta ́$ & 248 \\
\hline$\mu о \tilde{v} \sigma \alpha$ & 62 fn. 106 & 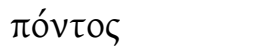 & 272 \\
\hline 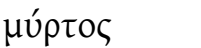 & 246 & $\pi о \rho \vee \eta ́$ & 271 \\
\hline
\end{tabular}




\begin{tabular}{|c|c|c|c|}
\hline$\pi \circ \zeta$ & 93,271 & $\tau \rho \alpha ́ \pi \varepsilon \zeta \alpha$ & 298 \\
\hline$\pi o ́ \tau v ı \alpha$ & 103 & 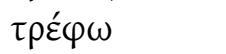 & 75 fn. 122,290 \\
\hline тoús, & 268 & $\tau \omega v i ́$ / $\tau \tilde{\omega} v \imath$ & 249 \\
\hline$\pi \rho i ́ v$ & 270 & 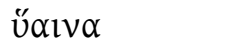 & 340 \\
\hline$\pi \rho o ́ \varsigma$ & 270 & üßpis & 191 \\
\hline$\pi \rho o ́ \sigma \theta \alpha$ & $93,104,304$ & 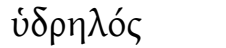 & 138 \\
\hline$\pi \rho o ́ \sigma \theta \varepsilon v$ & 93 & 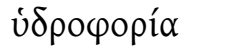 & 224 \\
\hline$\pi \rho o \tau \alpha \imath v i ́$ & 249 & $\tilde{U} \varsigma$ & 340 \\
\hline$\pi \rho \circ \tau i ́$ & 273 & 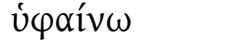 & 191 \\
\hline$\pi \rho \tilde{\omega} \tau \circ \zeta$ & 296 & 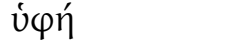 & 191 \\
\hline$\pi v^{\prime} \lambda \eta v$ & 341 & 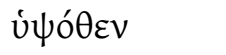 & 93,304 \\
\hline$\dot{\rho} \varepsilon ́ \zeta \omega$ & 194 & $\varphi \alpha \tilde{i} \sigma l$ & 62 fn. 106 \\
\hline ṕíбKos & 337 & $\varphi \alpha \sigma i(v)$ & 62 fn. 106 \\
\hline$\sigma a ́ \alpha$ & 77 & $\varphi \varepsilon ́ \rho \omega$ & 127 \\
\hline 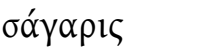 & 277 & $\varphi \eta \mu i ́$ & 156 \\
\hline$\sigma \alpha ́ \alpha \mu \rho \rho \nu$ & 77 & $\varphi \theta i ́(v) \omega$ & 88 \\
\hline$\sigma \tilde{\eta} \mu \alpha$ & 289,309 & $\varphi \rho \alpha ́ \tau \eta \rho$ & 159 \\
\hline 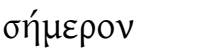 & 77 & $\varphi \omega ́ \gamma \omega$ & 158 \\
\hline 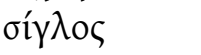 & 43,46 fn. $75,120,281$ & $\varphi \tilde{\omega} \varsigma$ & 104,156 \\
\hline oíkıvVıৎ & 343 & 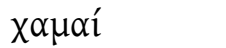 & 37,197 \\
\hline 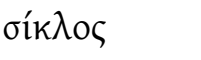 & 43,45 fn. 72,46 fn. 75 & 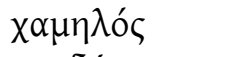 & 37 \\
\hline & 120,181 & $x \alpha v \delta \alpha ́ v \omega$ & 341 \\
\hline 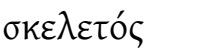 & $282-283$ & 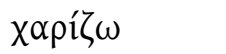 & 68,162 \\
\hline борós & 110,283 & xópls & 68 \\
\hline 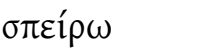 & 283 & xeíp & $37,70,310$ \\
\hline 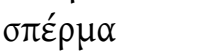 & 283 & $\chi \varepsilon \tilde{u} \mu \alpha$ & 37,341 \\
\hline$\sigma \tau \alpha ́ \alpha \alpha$ & 110 & $\chi \theta \alpha \mu \alpha \lambda o ́ s$ & 197 \\
\hline$\sigma \tau \alpha^{\prime} \lambda \lambda \alpha$ & $110,114,384$ & $\chi \lambda$ $\lambda$ مós & $63,104,163,341$ \\
\hline$\sigma \tau \eta ́ \lambda \eta$ & 110 & 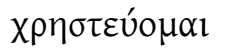 & 339 \\
\hline$\sigma \tau \cup \varphi \varepsilon \lambda \hat{i} \zeta \omega$ & 298 & 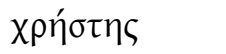 & $338-339$ \\
\hline 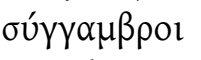 & 340 & xpíw & 162 \\
\hline 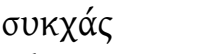 & 343 & 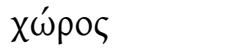 & $46,74,110,206,222$, \\
\hline$\sigma u ́ k X O 1$ & 343 & & 223 \\
\hline$\sigma u ́ \rho \gamma \alpha \sigma \tau \rho \circ \varsigma$ & 284 & & \\
\hline$\sigma u \rho \gamma \alpha ́ \sigma \tau \omega \rho$ & 284 & & Armenian \\
\hline$\sigma \varphi \varepsilon \tilde{i} \varsigma$ & 203 & & \\
\hline$\tau \alpha \lambda \alpha ́ \sigma \sigma \alpha \iota$ & 288 & anun & 257 \\
\hline$\tau \alpha \times u ́ s$ & 166 & ard & 145 \\
\hline$\tau \varepsilon$ & $95,216,287$ & cnawt & 338 \\
\hline$\tau \varepsilon ́ \kappa \mu \alpha \rho$ & 287 & ed & 103 \\
\hline$\tau \varepsilon ́ \kappa \mu \omega \rho$ & 287 & et & 297 \\
\hline$\tau \varepsilon \lambda \alpha \mu \omega ́ v$ & 288 & gitem & 258 \\
\hline$\tau \eta \dot{\theta} \theta \eta$ & 166 & jerm & 67 fn. 113 \\
\hline$\tau \eta \theta i ́ \varsigma$ & 165 & jern $n$ & 70,310 \\
\hline$\tau \eta ́ \mu \varepsilon \rho o v$ & 77 & k'an & 94,215 \\
\hline$\tau \imath \alpha ́ \alpha \rho$ & 338 & kałał & 22 \\
\hline$\tau i ́ \theta \eta \mu \imath$ & $99,103,130$ & $\operatorname{mak}^{\prime} I$ & 342 \\
\hline$\tau \iota \mu \eta ́$ & 248 & mayr & 237 \\
\hline 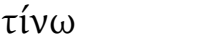 & 248 & $m i$ & 103,239 \\
\hline$\tau \iota \varsigma, \tau l$ & $82,110,293$ & $o \check{c}$ & 94,301 \\
\hline$\tau \hat{\imath} \tau \kappa \omega$ & 179 & orb & 259 \\
\hline
\end{tabular}


Albanian

as

aý

dorë

gardh

mo

motër

zjarm

zjarr

arti

bedù

ežys

gar̃das

gùltas

gulti

guõlis

láidoti

láidymas

mekčióti

nepté

nù

$n \bar{u}$

peršét

per̃šti

si

šis

viešpatni

želmuō

žélti

žolē

guõla

112

222

\section{Slavic}

Old CHURCH SLAVONIC

briti

gradb

mazati

$s$

94, 301

103

103, 239

166

67 fn. 113

67 fn. 113

Baltic

LITHUANIAN

92,145

268

341

116

222

222

222

231

231

342

250

251

251

182

182

77

77

103

341

341

341

LATVIAN

112
222
Slavic
OLD CHURCH SLAVONIC

160

116

234

77 bažát

bažít

158

158

Italic

LATIN

$a b s$

ad

91 fn. 150

93, 129

342

134

343

342

342

103

138

145

340

94, 138

172

337

77

77

171

210

173

173

187, 211

251

185

$41,89,130,182$

103

338

248

127

268

159

160

217

$104,163,341$

248

248

248

77

104, 163, 341

(h)olus

162

horitur

197

humilis

37 


\begin{tabular}{|c|c|c|c|}
\hline ignotus & 103 & & OSCAN \\
\hline tot & 297 & & \\
\hline rectio & 275 & adpúd & 129 \\
\hline erectio & 275 & niir & 141 \\
\hline lectus & 275 & sifei & 203 \\
\hline inde & 92 & & \\
\hline inquam & 208 & & Celtic \\
\hline tiara & 338 & & OLD IRISH \\
\hline is, ea, id & 207 & & \\
\hline pons & 272 & ainmne & 104,205 \\
\hline is, ea, id & 80 & ad & 129 \\
\hline maxime & 93 & and & 141 \\
\hline neptis & 250 & bé & 114 fn. 197 \\
\hline manus & 236 & $c o b$ & 179 \\
\hline orbus & 259 & rúsc & 337 \\
\hline pater & 267 & & \\
\hline mater & 237 & & GAULISH \\
\hline num & 251 & & \\
\hline nunc & 251 & bnanom & 114 fn. 197 \\
\hline mors & 246 & brogi- & 123 \\
\hline nepos & 248 & maros- & 123 \\
\hline quiuis & 219 & rusc & 337 \\
\hline praehendo & 341 & sosin & 297 \\
\hline maximus & 93 & & \\
\hline memoria & 124,234 & & Germanic \\
\hline nequis & 82 & & GoTHIC \\
\hline quam & 94,215 & & \\
\hline quinque & 269 & ahoa & 138 \\
\hline -que & 216 & aistan & 134 \\
\hline quis & 82,224 & at & 129 \\
\hline quisquis & 82,306 & bigitan & 341 \\
\hline se & 81 & doms & 174 \\
\hline sibi & 203 & faur & 270 \\
\hline socrus & 261 & gards & 116 \\
\hline soccer & 261 & hina & 77 \\
\hline sperno & 147 & $i p$ & 185 \\
\hline sto & 185 & kilpei & 22 \\
\hline sum & 208 & kinnus & 338 \\
\hline praetor & 272 & mikils & 240 \\
\hline ubi & 171 & qino & 220 \\
\hline uetus & 192 & qius & 112 \\
\hline ueto & 262 & sa, sō, pata & 79 \\
\hline uicis & 193 & wait & 258 \\
\hline uideo & 193,258 & & \\
\hline uigeo & 112 & & OLD NORSE \\
\hline uinum & 193 & & \\
\hline uiuo & 112 & baka & 158 \\
\hline uiuus & 60 & svilar & 340 \\
\hline utinam & 152 & & \\
\hline
\end{tabular}




\section{OLD ICELANDIC}

$\begin{array}{ll}\text { kvikr } & 112 \\ \text { kykr } & 112\end{array}$

OLD HIGH GERMANIC

aha 138

bahhan $\quad 158$

neva 248

weban 191

nūn 251

igil 341

tau 344

Semitic Languages

AKKADIAN

(including Assyrian and Babylonian)

$\begin{array}{ll}\text { naruqqum } & 342 \\ \text { nuruqqum } & 342 \\ \text { sikkanum } & 115,217\end{array}$

UGARITIC

340 fn. 221

phr $\quad 265$

ARAMAIC

bSl 339

mgšy $\quad 122$

šql $43,45,46$ fn. 74,120 ,

281

121

w

Elamite

Hanāmakaš

140

\section{Personal names}

\section{In cuneiform sources}

$\begin{array}{ll}\text { Agga- } & 184 \\ \text { Akiya- } & 137 \\ \text { Al(l)uwa- } & 118,139 \\ \text { Ali- } & 116,139 \\ \text { Armapiya } & 145 \\ \text { Armawiya } & 145 \\ \text { Ar-ma-zi-ti- } & 145 \\ \text { Aya- } & 116,134 \\ \text { Gurdîs } & 116 \\ \text { Immaraziti } & 117 \\ \text { Kanutî } & 62,74,123,216 \\ \text { Ku-li-a } & 117 \\ \text { Masa } & 116 \mathrm{fn} .201,117,237 \\ \text { Mitā } & 115,242 \\ \text { Muwatti- } & 117 \\ \text { Pariziti } & 161 \\ \text { Tiia- } & 293 \\ \text { Ú-ak-sa-tar } & 40,122,307 \\ \text { Uk-sa-tar } & 40,122,307 \\ \text { Ú-ma-kiš-tar } & 40 \\ \text { Ú-ma-ku-iš-tar } & 40,122,307 \\ \text { Urawanni } & 98,117,303 \\ \text { Urhitešub } & 116,303 \\ \text { Wana } & 189\end{array}$

Wanni

118,189

\section{In Hieroglyphic Luwian}

Ku-li-i(a)

$98,117,226$

Kurtis

116,118

Kwa/i-li-i(a)

$98,117,215,226$

Muksasa-

111,246

Takuwa

165

Tuwattis

117,298

Wana-

118

Wasurunti(ya)- $\quad 117,190$

Wasusarma- $\quad 117,190$

(DEUS)LUNA+MI-sa 145

\section{In Lycian}

\begin{tabular}{|c|c|}
\hline ixtta & 187 \\
\hline ipresidah & 323 \\
\hline miӨrapata & 122,243 \\
\hline mizrppata & 122,243 \\
\hline purihimeti & 270 \\
\hline waxssepddimi & 40 fn. 65 \\
\hline xssere & 40 fn. 65 \\
\hline
\end{tabular}




\section{In Lydian}

$\begin{array}{lc}\text { ate- } & 119,149 \\ \text { alus } & 118,119,139 \\ \text { manes } & 119,235 \\ \text { śrkaśtus } & 116,284 \\ & \text { In Carian }\end{array}$

$\begin{array}{lc}\text { mane } & 235 \\ \text { mute- } & 117 \\ \text { šd catś } & 282 \\ \text { msnord- } & 118 \\ & \text { In Sidetic }\end{array}$

śdi个s

$118,277,282$

\section{In Pisidian}

$\begin{array}{lc}\Gamma \delta \alpha \beta \alpha & 166 \\ \Gamma \delta \varepsilon \beta \varepsilon \tau \iota \varsigma & 166 \\ & \text { In Old Persian }\end{array}$

$\begin{array}{lc}\begin{array}{lc}\text { Anāhitā } \\ \text { Bagāna- } \\ \text { Manukka }\end{array} & 224 \\ & 122,237 \\ & \text { In Greek } \\ & \text { In Mycenaean }\end{array}$
mo-qo-so
mo-qo-so-jo
$98,111,246$
111, 246

\section{In alphabetic Greek}

\begin{tabular}{|c|c|}
\hline$A \beta \alpha \varsigma$ & 311 \\
\hline$A \beta \beta \alpha \varsigma$ & 311 \\
\hline 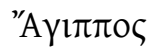 & 128 \\
\hline $\mathrm{A} \zeta \mathrm{10}$ & 152 \\
\hline Alvas & 135 \\
\hline 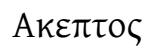 & 135 \\
\hline 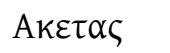 & 135 \\
\hline Aknৎ & 137,138 \\
\hline 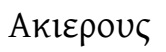 & 135 \\
\hline 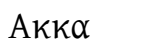 & 135 \\
\hline Аккाৎ & 137 \\
\hline $\mathrm{A} \lambda \cup \varsigma$ & 118,139 \\
\hline A $\mu \iota \alpha \varsigma$ & 140 \\
\hline$A \mu \mu \iota \alpha$ & 140 \\
\hline
\end{tabular}

\begin{tabular}{|c|c|}
\hline$A \mu \mu \omega \varsigma$ & 140 \\
\hline 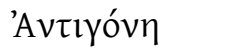 & 131,247 \\
\hline Aova & 142 \\
\hline $\mathrm{A} \pi(\pi) \propto \varsigma$ & 143 \\
\hline $\mathrm{A} \pi(\pi) \eta \varsigma$ & 143 \\
\hline 'A $\pi \varepsilon \lambda \lambda \alpha(\varsigma)$ & 143 \\
\hline 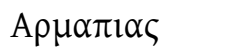 & 145 \\
\hline 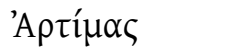 & 22 fn. 32 \\
\hline ’Apxías & $74,111,145$ \\
\hline 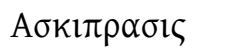 & 147 \\
\hline 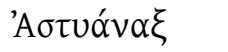 & 244 \\
\hline 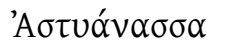 & 244 \\
\hline 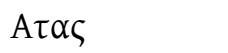 & 148 \\
\hline 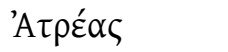 & 150 \\
\hline 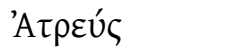 & 137,150 \\
\hline$A \tau \tau \alpha \varsigma$ & 148,149 \\
\hline A $\tau \tau \eta \varsigma$ & $33,73,149$ \\
\hline 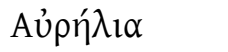 & 29 \\
\hline Aủpń入ios & 29,124 \\
\hline $\mathrm{B} \alpha \beta \alpha \varsigma$ & 155,311 \\
\hline 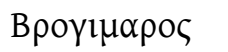 & 123 \\
\hline 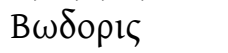 & 123 \\
\hline$\Gamma \alpha$ & 161 \\
\hline Горбі́as & 116,118 \\
\hline Гopdíns & 116,118 \\
\hline Гópঠios & 116,118 \\
\hline$\Delta \alpha \delta \alpha$ & 166 \\
\hline$\Delta \alpha \delta \alpha \varsigma$ & 166 \\
\hline$\Delta \alpha \delta \delta \circ \varsigma$ & 166 \\
\hline$\Delta \alpha \delta \eta \varsigma$ & 166 \\
\hline$\Delta \alpha \delta \omega v$ & 166 \\
\hline$\Delta \tilde{\alpha} \circ \varsigma$ & $41,124,166$ \\
\hline$\Delta \alpha \tilde{v} \circ \zeta$ & 124,166 \\
\hline$\Delta \tilde{\alpha} F \circ$ & 341 \\
\hline$\Delta \eta \delta \eta \varsigma$ & 171 \\
\hline$\Delta \eta \delta i \varsigma$ & 171 \\
\hline$\Delta \mathrm{i} \delta \propto \varsigma$ & 171 \\
\hline$\Delta o \alpha$ & 318 \\
\hline$\Delta o l \alpha$ & 318 \\
\hline$\Delta о \rho \mu \imath \sigma \pi \alpha \varsigma$ & 209 \\
\hline sopukavos & 111,173 \\
\hline 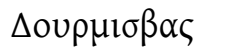 & 209 \\
\hline $\mathrm{E} 1 \alpha$ & 177 \\
\hline Elas & 177 \\
\hline Eı $\lambda \alpha \varsigma$ & 205 \\
\hline 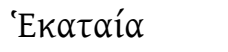 & $111,180,205$ \\
\hline 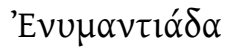 & 182 \\
\hline Е $\rho \varepsilon \mu \alpha \sigma \tau о v$ & 120 \\
\hline E $\rho \mu \alpha \pi \imath \alpha \varsigma$ & 145 \\
\hline 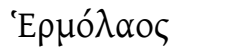 & 111,186 \\
\hline $\mathrm{I} \alpha$ & 177 \\
\hline
\end{tabular}




\begin{tabular}{|c|c|c|c|}
\hline $\mathrm{I} \alpha \varsigma$ & 177 & $N \alpha v \alpha$ & 247 \\
\hline $\mathrm{I} \delta \delta 10 \varsigma$ & 203 & $\mathrm{~N} \alpha v \alpha \varsigma$ & 247 \\
\hline $\mathrm{I} \delta 10 \varsigma$ & 203 & Navnpis & 248 \\
\hline 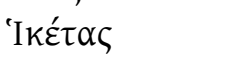 & $111,187,205$ & $N \varepsilon v(v) \alpha \varsigma$ & 120 \\
\hline $\mathrm{I} \kappa \tau \alpha \varsigma$ & 187 & Nev $\alpha \rho ı$ & 248 \\
\hline $\mathrm{I} \lambda \lambda \alpha \varsigma$ & 205 & 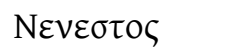 & 120 \\
\hline $\mathrm{I} \mu \alpha \nu$ & 206 & 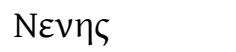 & 120 \\
\hline Ivas & 207 & 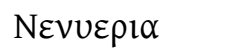 & 248 \\
\hline Ivve & 178 & 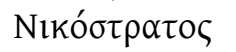 & $53,111,249$ \\
\hline \multirow[t]{2}{*}{ K $\alpha \lambda \lambda i ́ \alpha \varsigma$} & 63,75 fn. $121,106,111$ & $\operatorname{Niv} \alpha$ & 249 \\
\hline & $362,150,215$ & Nivva & 249 \\
\hline 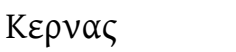 & 218 & O$\alpha \rho \omega \lambda \lambda \circ v$ & 303 \\
\hline Kíkкоৎ & 112,219 & 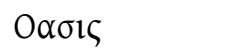 & 190 \\
\hline 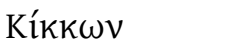 & 219 & 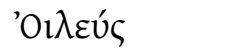 & 256 \\
\hline Kíkoৎ & 112,219 & "Otus & 260 \\
\hline Kíkwv & 219 & Ovava $\alpha \lambda_{1 \varsigma}$ & 189 \\
\hline 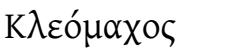 & $53,111,220$ & 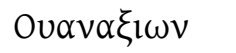 & 189 \\
\hline$K \lambda \nu v i \sigma \beta\|\alpha \varsigma\|$ & 209 & 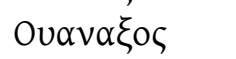 & 189 \\
\hline \multirow[t]{2}{*}{ 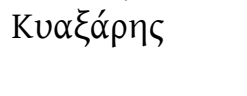 } & 40,46 fn. $73,98,122$ & 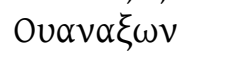 & 189 \\
\hline & 123,307 & 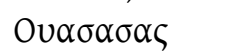 & 190 \\
\hline$\Lambda \alpha \sigma \alpha \mu \circ \varsigma$ & 325 & 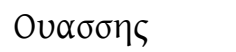 & 190 \\
\hline$\Lambda \alpha \sigma \sigma \alpha \mu \circ \varsigma$ & 325 & Ouevauia & 118 \\
\hline 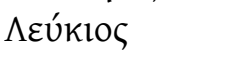 & 111,231 & Ouevauin & 118 \\
\hline$\Lambda i \rho$ & 281 & П $\alpha$ & 265 \\
\hline $\operatorname{M} \alpha \mu \alpha$ & 120 & 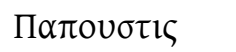 & 120 \\
\hline$M \alpha \mu \alpha$ & 235 & 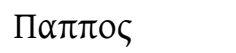 & 120 \\
\hline$M \alpha \mu \alpha \sigma \tau \alpha$ & 120 & 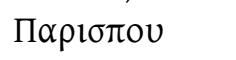 & 209 \\
\hline$M \alpha \mu \alpha \sigma \tau \iota \varsigma$ & 120 & $\Pi \alpha \varsigma$ & 142 \\
\hline$M \alpha \mu \mu \alpha$ & 235 & Порџцачıৎ & 270 \\
\hline M $\alpha \mu о \tau \alpha \sigma \iota \varsigma$ & 117 & $\Sigma \alpha \beta ı \varsigma$ & 277 \\
\hline 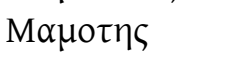 & 117,235 & $\Sigma \alpha \beta \cup \varsigma$ & 277 \\
\hline 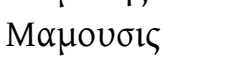 & 117,235 & 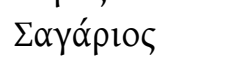 & 233 \\
\hline$M \alpha \mu \omega \tau \alpha \sigma ı \varsigma$ & 117,235 & $\Sigma \alpha \gamma \alpha \alpha \operatorname{\rho io\zeta }$ & 277 \\
\hline Maveıৎ & 73,235 & $\Sigma \alpha \rho 1 \delta \eta \rho \alpha \varsigma$ & 131 \\
\hline 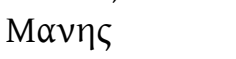 & $73,235,236$ & $\Sigma 1 \delta_{1} \delta \circ \varsigma$ (gen.) & 282 \\
\hline Mavis & 73,235 & $\Sigma \mathfrak{i} \alpha \alpha^{\prime} \lambda \alpha \varsigma$ & 282 \\
\hline Mavitous & 73 & $\Sigma \mathfrak{i} \alpha^{\prime} \lambda \kappa \eta \varsigma$ & 282 \\
\hline M $\alpha \rho \alpha \varsigma$ & 238 & $\Sigma \pi \varepsilon \rho \chi \varepsilon 1 o ́ \varsigma$ & 111,273 \\
\hline М $\alpha \rho \varepsilon \alpha \varsigma$ & 238 & $\Sigma \pi \varepsilon \rho x i ́ \varsigma$ & 111,273 \\
\hline 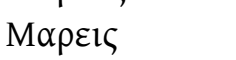 & 238 & $\Sigma \pi \varepsilon \rho \chi u ́ \lambda \varepsilon 10 \varsigma$ & 111,273 \\
\hline 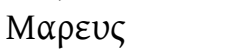 & 238 & Tinos & 293 \\
\hline 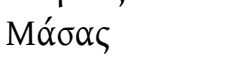 & 117 & Tios & 293 \\
\hline$M \alpha \sigma v \alpha v i \sigma \beta o v$ & 209 & & \\
\hline Méү $\alpha \varsigma$ & 241 & & In Latin \\
\hline 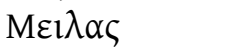 & 241 & & \\
\hline $\mathrm{M \varepsilon \mu \mu \alpha \varsigma}$ & 74 & Dauus & $124,166,341$ \\
\hline 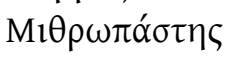 & $122,123,243$ & Domitius & 124,172 \\
\hline 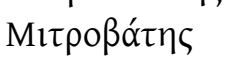 & $122,123,243$ & Nero & 141 \\
\hline Móḱs & $98,111,246$ & Sergestus & 120,284 \\
\hline 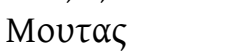 & 117 & & \\
\hline Мóభоs & $98,111,246$ & & \\
\hline
\end{tabular}


In Gaulish

Borodix

Brogimaros

$\begin{array}{lc} & \text { In Aramaic } \\ \text { bgn } & 62 \\ \text { mny } & 235 \\ \text { d?b } & 341 \\ \text { sgr } & 233,277\end{array}$

In Phoenician

$m p \check{s}$

111,246

In Elamite

\author{
Áš-šá- $k a_{4}$ \\ Ma-ki-iš-tur-ri \\ Ma-ak-iš-tar-ra \\ 122,146 \\ $40,122,307$ \\ $40,122,307$

\section{In Etruscan}

sekśtalus

120 fn. 210

III. Divine names

In Hittite

Hé-pit

187

\section{In Hieroglyphic Luwian}

Kubaba-

226

In Greek

In Mycenaean

pa-de

$p a-d e-i$

In alphabetic Greek

"Aү $\delta 1 \sigma \tau 1 \zeta$

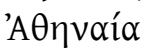

56 fn. $94,120,144$

225

225

224

143

98,145

155

114

113

111,171

183,187

191

206

183,187

217

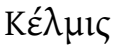

224

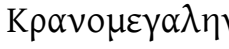

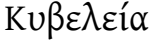

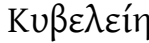

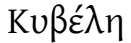

Kußń $\beta \eta$

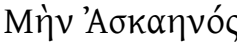

Mńv

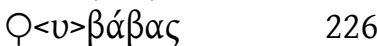

Qußádas 225

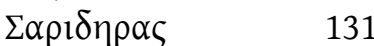

$\Sigma \alpha \rho v \varepsilon v \delta \eta v o \varsigma$

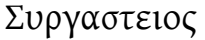

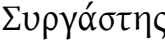

इupyóotos

119 fn. 208, 278

119,284

$119,120,284$

$119,120,284$

\section{In Latin}

Cybele

Surgasteo

124,225

120

\section{In Lydian}

artimus

145

kuwawa

226

In Lycian

ertẽmi

145

In Sanskrit

Bhadrā $\quad 156$

Mās

237 


\section{Maps}

Map 1. The Phrygian Inscriptions ${ }^{226}$

Map 2. The Old Phrygian Inscriptions

Map 3. Plan of the eastern side of the Citadel Mound of Gordion during the Middle Phrygian period (Gordion Project, Penn Museum)

Map 4. The New Phrygian inscriptions (numbers)

Map 5. The New Phrygian Inscriptions (cities)

${ }^{226}$ Excluding HP-114, from Persepolis. 


\section{The Phrygian Inscriptions}

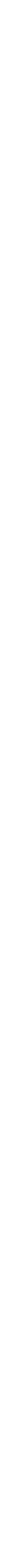




\section{The Old Phrygian Inscriptions}

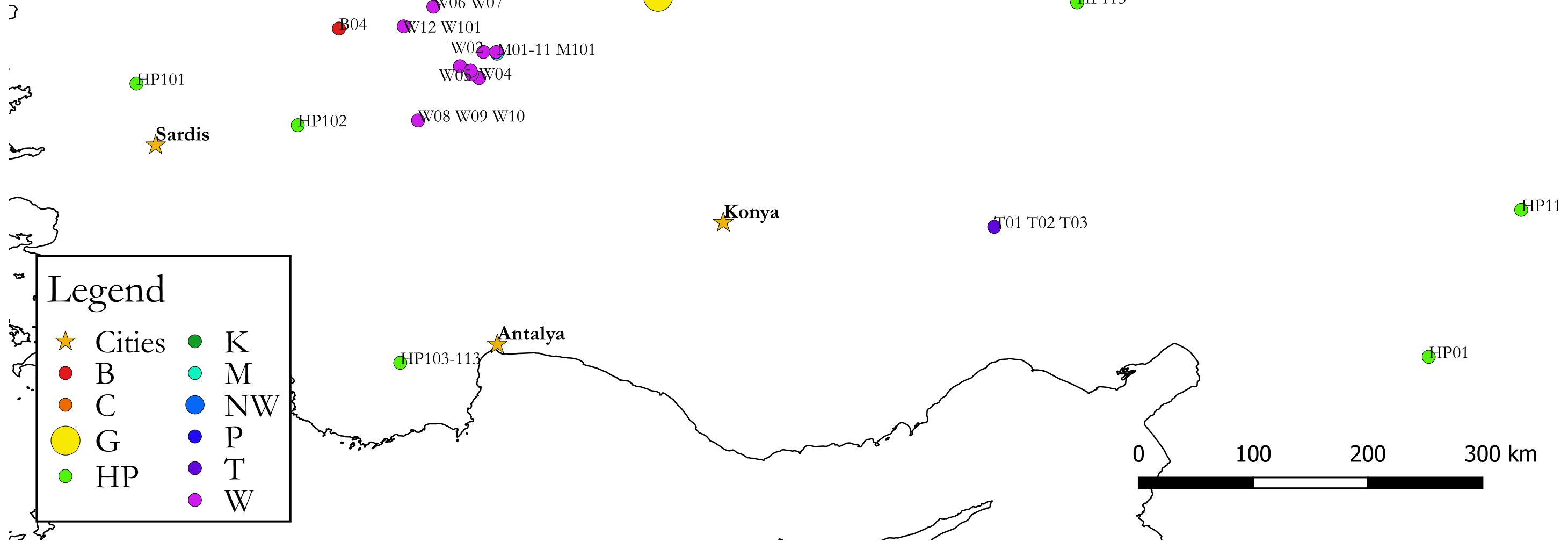




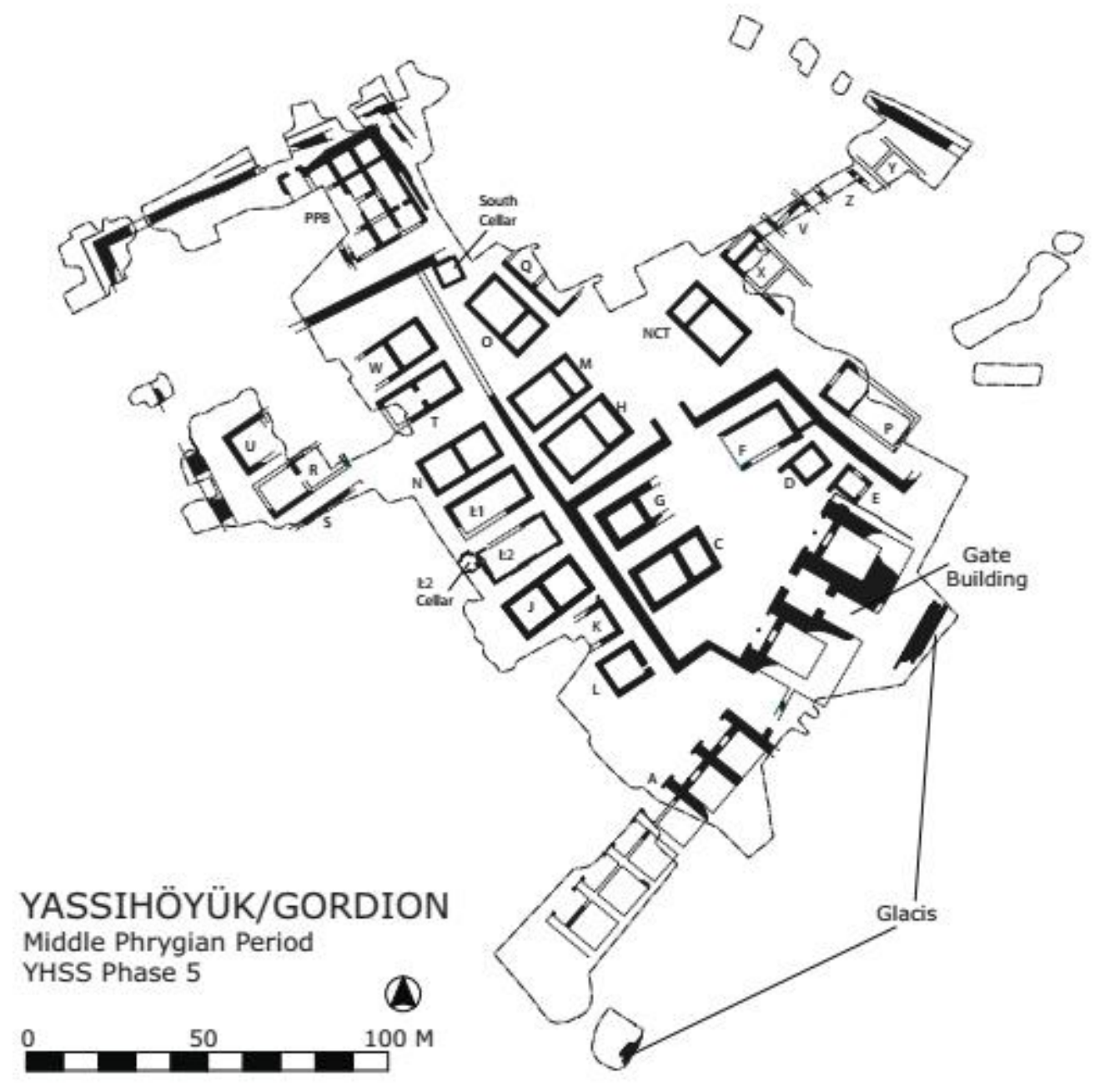




\section{The New Phrygian Inscriptions}

\section{$\triangle^{1.1} 1.2$}

$\Delta^{2.12 .2}$

$$
\begin{aligned}
& 5.1 \\
& 4.17 .27 .3 \underbrace{6.1} \\
& \mathbb{2}^{62.16} \\
& \Delta^{63.1} \quad \mathbf{6 5 . 1 - 4} \triangle \mathbf{S}^{64.1}
\end{aligned}
$$

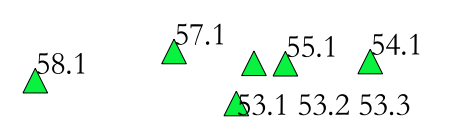

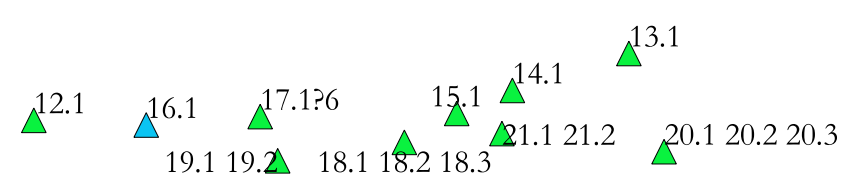

$$
\begin{aligned}
& 11.111 .211 .38^{8.1} \\
& \begin{array}{ccc}
5^{51.1} & \Sigma^{52.1} & \Sigma^{50.150 .2} \\
\mathbb{2}^{66.1} & & \mathbb{4}^{48.148 .248 .3}
\end{array} \\
& 184.12 .122 .2 \\
& 225.125 .2 \quad 26.126 .2 \\
& \mathbb{2}^{27.1} \quad \mathbb{2}^{29.1} \mathbb{2}^{28.1} \\
& \mathbb{\Delta}^{37.137 .2}
\end{aligned}
$$

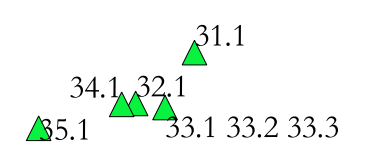

Legend

$\star$ Cities

New Phrygian

$\triangle$ Only curses

$\triangle$ Not only curses 


\section{The New Phrygian Inscriptions}

Eskisehir

Seyitgazi

Cavdarhisar

凹cuyuk

Legend

is Cities

New Phrygian

$\Delta$ Only curses

$\triangle$ Not only curses

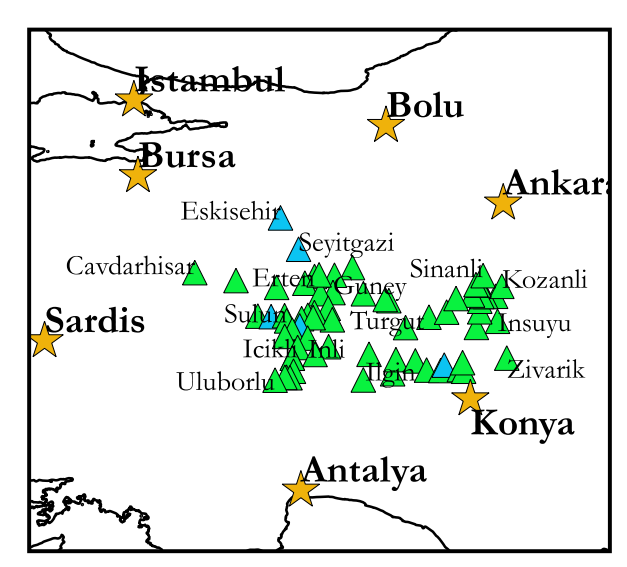

$\triangle^{\text {rtakoy }}$

Erten GGozsuszlu ßBaglica

Gokceyayla

$$
\text { Bayat } \quad \text { Guney }
$$

Beykoyu

$\triangle$ Pzburun

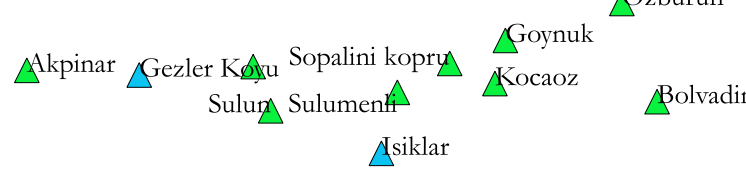

$$
\begin{aligned}
& \text { Efesultan Asiklar } \\
& \text { Suhut ¿ Inli } \\
& \text { ¿cikli \$agir }
\end{aligned}
$$

Karadill11

Buyukkabaca

Senirkent\ $\triangle^{\text {Yassiorem }}$

Elluborlu
Sinanli

Mondali Kerpic

Ǩozanli

Davulga

Asagipiribeyli \eribeyli

Hatirli

Kandi^

¿Beskavak_Bulduk
Kelhasan

Bogrudelik

¿nsuyu

Ærurgut

Cesmelisebi

Zivarik

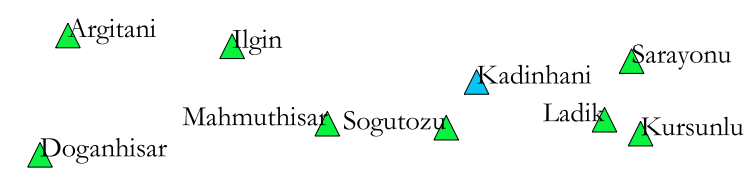

Sarkikaraagac 